Emmanouil Billis

Die Rolle des Richters im adversatorischen und im inquisitorischen Beweisverfahren 
Schriftenreihe des Max-Planck-Instituts für ausländisches und internationales Strafrecht

\section{Strafrechtliche Forschungsberichte}

Herausgegeben von Ulrich Sieber

Band S 151

Max-Planck-Institut für ausländisches und internationales Strafrecht 


\title{
Die Rolle des Richters im adversatorischen und im inquisitorischen Beweisverfahren
}

\author{
Modelltheoretische Ansätze, \\ englisches und deutsches Beweisführungssystem, \\ internationalrechtliche Dimensionen
}

Emmanouil Billis

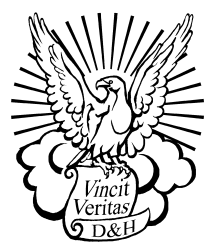

Duncker \& Humblot • Berlin 
Bibliografische Information der Deutschen Nationalbibliothek

Die Deutsche Nationalbibliothek verzeichnet diese Publikation in der Deutschen Nationalbibliografie; detaillierte bibliografische

Daten sind im Internet über $<$ http://dnb.ddb.de $>$ abrufbar.

DOI https://doi.org/10.30709/978-3-86113-804-4

Alle Rechte vorbehalten

(C) 2015 Max-Planck-Gesellschaft zur Förderung der Wissenschaften e.V.

c/o Max-Planck-Institut für ausländisches und internationales Strafrecht

Günterstalstraße 73, 79100 Freiburg i.Br.

http://www.mpicc.de

Vertrieb in Gemeinschaft mit Duncker \& Humblot GmbH, Berlin

http://www.duncker-humblot.de

Umschlagbild: Geschworenengerichtssitzung zu Freiburg i.Br. 1849, Generallandesarchiv Karlsruhe J-G F 16 C Landesarchiv Baden-Württemberg

Foto des Autors: Baschi Bender

Druck: Stückle Druck und Verlag, Stückle-Straße 1, 77955 Ettenheim

$$
\text { Printed in Germany }
$$

ISSN 1860-0093

ISBN 978-3-86113-804-4 (Max-Planck-Institut)

ISBN 978-3-428-14757-1 (Duncker \& Humblot)

Gedruckt auf alterungsbeständigem (säurefreiem) Papier entsprechend ISO 9706 ○ 


\section{Vorwort}

Die vorliegende Arbeit entstand im Rahmen der International Max Planck Research School for Comparative Law (IMPRS-CC). Sie wurde im Wintersemester 2014/2015 von der Rechtswissenschaftlichen Fakultät der Albert-Ludwigs-Universität Freiburg als Dissertation angenommen. Gesetzgebung, Literatur und Rechtsprechung konnten bis Oktober 2014 berücksichtigt werden.

Danken möchte ich an dieser Stelle besonders meinem Doktorvater Prof. Dr. Dr. h.c. mult. Ulrich Sieber. Er hat mir nicht nur große wissenschaftliche Freiheit während der Anfertigung der Arbeit gewährt, sondern mit seinen tiefgehenden, vor allem methodologischen Anregungen auch die systematische und kohärente Umsetzung des Forschungsvorhabens gefördert. Herrn Prof. Dr. Walter Perron sage ich Dank für die zügige Erstellung des Zweitgutachtens und für die wertvollen Hinweise zum Inhalt der Landesberichte.

Für die ständige day-to-day-Betreuung und ihre Geduld danke ich ganz besonders meiner Kollegin am Max-Planck-Institut für ausländisches und internationales Strafrecht, Frau Dr. Konstanze Jarvers. Mein Dank für die kritischen fachlichen Diskussionen geht auch an meine Kollegen Herrn Dr. Nandor Knust, Frau Dr. Els De Busser, Herrn Dr. Stefan Drackert, Herrn Dr. Harald Weiß, Frau Vasiliki Chalkiadaki, LL.M. und Herrn Nicolas von zur Mühlen. Den Mitarbeiterinnen und Mitarbeitern der Bibliothek des Max-Planck-Instituts bin ich dankbar für die Unterstützung bei der Literaturrecherche. Für die umsichtige redaktionelle Betreuung danke ich dem Lektorat des Instituts und insbesondere Frau Birgit Jacob und Frau Ines Hofmann.

Bedanken möchte ich mich ferner bei meinen ehemaligen Professoren in Deutschland und in Griechenland, Prof. Dr. Hans-Ullrich Paeffgen (Bonn), Prof. Dr. Ioannis Giannidis (Athen) und Prof. Dr. Theoharis Dalakouras (Thrazien), die mich früh dazu ermuntert haben, mich mit der theoretischen Seite des Strafprozessrechts auseinanderzusetzen. Ein herzlicher Dank für die motivierenden Debatten geht an die Professoren der Universität Athen, Prof. Dr. Nestor Courakis, Prof. Dr. Christos Mylonopoulos und Prof. Dr. Nikolaos Livos. Für die Förderung der Arbeit dankbar bin ich auch der Alexander S. Onassis Public Benefit Foundation. Mein größter Dank gilt schließlich meiner Familie und Eleni Eftaxia: Ohne ihre Unterstützung wäre das Gelingen dieser Arbeit nicht möglich gewesen. 


\section{Inhaltsübersicht}

\section{Einleitung}

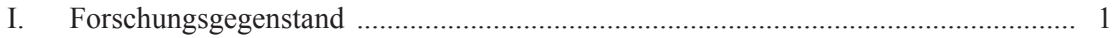

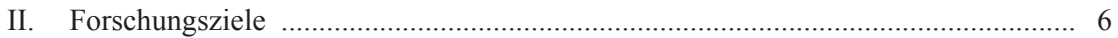

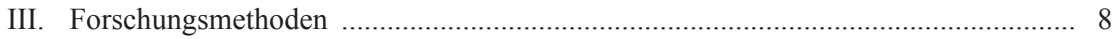

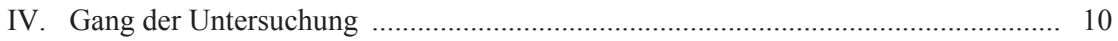

\section{Teil 1}

\section{Strafprozesssysteme und Modelle des Beweisverfahrens}

I. Die westlichen Strafverfahrenssysteme: Einführende vergleichende und rechtshistorische Betrachtungen

II. „Adversatorische“ und ,inquisitorische“ Typen des Strafund Beweisverfahrens

\section{Teil 2}

\section{Rollenverteilung bei der Beweisführung im englischen und im deutschen Strafprozess}

I. Darstellungs- und Vergleichsrahmen

II. Das englische Beweisführungssystem ......................................................... 144

III. Das deutsche Beweisführungssystem ........................................................... 222

IV. Vergleich und Klassifizierung ….................................................................. 305

V. Bewertung und rechtspolitische Schlussfolgerungen ...................................... 363

\section{Teil 3}

\section{Internationalrechtliche Dimensionen}

I. Einleitende Bemerkungen zum Analyserahmen ............................................. 389

II. EMRK: Verfahrensfairness und Prinzip der „adversarial proceedings“ ............... 391

III. Die Beweisführung im IStGH-System ............................................................. 417 


\section{Inhaltsverzeichnis}

Vorwort

Abkürzungsverzeichnis

XIV

\section{Einleitung}

I. Forschungsgegenstand 1

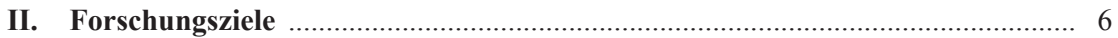

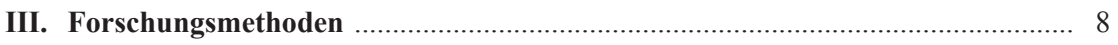

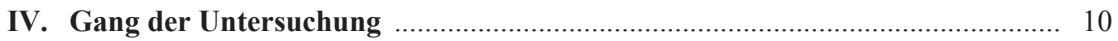

\section{Teil 1}

Strafprozesssysteme und Modelle des Beweisverfahrens

I. Die westlichen Strafverfahrenssysteme: Einführende vergleichende und rechtshistorische Betrachtungen

A. Rechtskreise, Rechtstraditionen und ihre Bedeutung für die Rechtsvergleichung

1. Einteilung der Rechtsordnungen in Rechtskreise und Rechtsfamilien .... 14

a) Einteilungskriterien ................................................................. 15

b) Einordnung der Rechte ............................................................. 17

2. Einteilung in Rechtstraditionen ........................................................ 19

B. Angloamerikanische und kontinentaleuropäische Rechtstradition ................. 21

1. Rechtstraditionen in der ,westlichen Rechtswelt“ ............................... 23

a) Zur Vergleichbarkeit unterschiedlicher Rechtswelten ................... 23

b) Herrschende „westliche“ Rechtstraditionen ................................. 25

2. Einführung in die Tradition des angloamerikanischen Strafverfahrens .... 27

a) Zur historischen Entwicklung zentraler angloamerikanischer Prozessformen

aa) Das jury-Strafverfahren und die Ursprünge des englischen Beweisrechts

bb) Die Entwicklung des jury-Strafverfahrens in den USA

b) Die Rechtsquellen und die Entwicklung des case law in der angloamerikanischen Rechtstradition

aa) Die Quellen des englischen Rechts ...................................... 37

bb) Zum Rechtsquellensystem in den USA ................................ 41 
3. Einführung in die Tradition des kontinentaleuropäischen Strafverfahrens

a) Vorbemerkungen …............................................................... 42

b) Wesentliche historische Stationen in der civil law-Tradition .......... 44

aa) Römisch-kanonisches Recht und europäisches jus commune 45

bb) Die Revolutionen und Kodifikationen der Neuzeit ................ 47

c) Die Entwicklung der kontinentaleuropäischen Gerichtsbarkeiten und Beweisverfahrensarten .................................................... 51

aa) Inquisitionsprozesse im Mittelalter und in der frühen Neuzeit 51

bb) Die Strafprozessreformen im modernen Nationalstaat .......... 54

4. Zwischenbetrachtung .................................................................... 57

\section{II. „Adversatorische“ und ,inquisitorische" Typen des Straf- und Beweis-} verfahrens

A. Einführung in die klassische Dichotomie der (Beweis-)Verfahrensmodelle ... 63

B. Grundlagen der herrschenden Unterscheidung zwischen (Beweis-)

Verfahrenstypen

1. Zur Bildung von Modellen in der Strafverfahrenstheorie ..................... 66

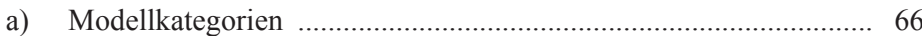

b) Der historische Ansatz für die Modellbildung ............................... 68

c) Der idealtypische Ansatz für die Modellbildung .......................... 71

aa) Historische Folklore versus prozessuales Ideal ..................... 71

bb) Die modernen Idealtypen des (Beweis-)Verfahrens .............. 73

2. Ursprungs- und Bezeichnungsfragen ................................................ 75

a) Wurzeln der modernen Modellbetrachtungen ................................ 75

b) Terminologische Streitpunkte und Begriffsauswahl ...................... 78

C. Die Bestandteile des ,adversatorischen“ und des ,inquisitorischen“

Beweisverfahrensmodells

1. Kernelemente: Strukturelle Komponente und Rollenverteilung ............ 82

a) Die zentrale Idee hinter der Dichotomie der Modelle ..................... 82

b) Blick in das Modellinnere ......................................................... 83

2. Zielsetzungskomponente ................................................................... 86

a) Einführung: Traditionelle und, ,ideologische“ Betrachtungen ........ 86

aa) Modelle zu Organisation und Zielsetzung der Strafjustiz ....... 86

bb) Das klassische Problem des Gerechtigkeitszieles: Zwischen Wahrheit und fairer Konflikterledigung ................ 90

b) Der Wahrheitsbegriff .................................................................. 93

aa) Zu den Wahrheitstheorien .................................................... 93

bb) Materielle und formelle Wahrheit: Unterscheidung zwischen Wahrheitsbegriffen? ........................................................... 94

c) Jenseits des Wahrheitsbegriffs ..................................................... 99

d) Zum Spannungsverhältnis zwischen den Verfahrenszielen ........... 101 
aa) Materielle Gerechtigkeit und Verfahrensgerechtigkeit ........ 101

bb) Wahrheit, Fairness und Absprachen .................................. 106

e) Modellbezogene Auswertung der Prozessziele .............................. 110

aa) Eine Wahrheit, zwei Erforschungsmethoden ...................... 110

bb) Vor- und Nachteile der diversen Wahrheitserforschungsmethoden

cc) Cross-examination als diagnostische Methode .................... 114

dd) Die Bedeutung der Anwälte im Wahrheitserforschungsprozess

ee) Aktenkenntnis und Beweisführung .................................... 117

f) Ausblick: Zum Bewertungsmaßstab für die konkrete

Rechtsvergleichung ................................................................ 118

3. Bestimmung der ergänzenden Elemente der Beweisverfahrensmodelle 120

a) Die Beweisvorgänge im Vorfeld des Hauptverfahrens ................. 121

aa) Vor der Klageerhebung …................................................ 121

bb) Nach der Klageerhebung ….............................................. 123

b) Vorgerichtliche Kenntnisnahme der Beweise ............................. 125

aa) Richterliche Aktenkenntnis ............................................... 125

bb) Die Beweisoffenlegung inter partes .................................. 126

c) Öffentlichkeit und Mündlichkeit im idealtypischen

Beweisverfahren ............................................................... 129

d) Laiengerichtsbarkeit und Geschworenengerichte ....................... 130

aa) Laienrichter und Berufsrichter .......................................... 130

bb) „Jury trial“ und „bench trial“ ............................................. 131

e) Das Problem der Verfahrensabsprachen ..................................... 134

4. Zusammenfassung der Modellelemente und Zwischenausblick .......... 137

Teil 2

Rollenverteilung bei der Beweisführung im englischen und im deutschen Strafprozess

I. Darstellungs- und Vergleichsrahmen

II. Das englische Beweisführungssystem ......................................................... 144

A. Überblick über den Strafprozess ................................................................. 144

1. Die Ziele und Grundprinzipien des Strafverfahrens und die EMRK ... 144

2. Der Ablauf des herkömmlichen Strafverfahrens ................................ 147

3. Die Grundsätze des Beweisrechts und -verfahrens ............................ 153

B. Die vorbereitenden Beweisführungsvorgänge ................................................ 156

1. Die „Aufbereitung“ des Beweismaterials .......................................... 157

a) Allgemeine Grundsätze: Strukturen, Waffengleichheit und Objektivitätspflichten ................................................... 157

b) Speziell zum aussagenbasierten Beweis .................................... 161 
aa) Die Beweismittel und der zeugenbasierte Beweis ............... 161

bb) Die „Zusammenstellung“ des zeugenbasierten Beweises ..... 163

cc) Die „Vorbereitung“ des zeugenbasierten Beweises .............. 166

dd) Zum Expertenbeweis ................................................... 167

2. Die Bestimmung des Umfangs der Beweiserhebungen ..................... 170

a) Beweisführung und Offenkundigkeit ....................................... 170

b) Das Vorbringen von Beweisen: Zeugenladungen
und Beweisanträge ............................................................. 171

c) Einverständliche Bestimmung der Beweiserhebungen ................. 174

d) Case Management ..................................................................... 175

C. Kenntnisnahme und Offenlegung von Beweisen ........................................ 178

1. Die Kenntnis der Beweisergebnisse des Vorverfahrens seitens

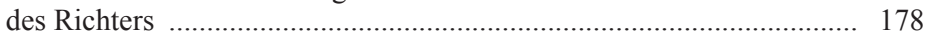

2. Akteneinsicht und Offenlegung des Vorverfahrensmaterials .............. 180

D. Die Beweisführung im Hauptverfahren .................................................... 184

1. Zulässigkeit und Ausschluss von Beweisen ..................................... 184

2. Erhebung, Präsentation und Prüfung der Stichhaltigkeit der Beweise 188

a) Grundlagen .................................................................... 188

b) Der Ablauf der Beweisvorgänge im Gerichtsverfahren ............... 193

c) Die Methoden der Beweisprüfung ............................................ 205

aa) Allgemeine Bemerkungen ................................................ 205

bb) Die Art und Weise der Vernehmungen .............................. 205

E. Zusammenfassung: Besonderheiten des Beweisführungssystems ................ 214

1. Die vorbereitenden Beweisführungsvorgänge .................................. 214

2. Kenntnisnahme und Offenlegung von Beweisen ............................... 216

3. Die Beweisführung im Hauptverfahren ........................................... 217

III. Das deutsche Beweisführungssystem ....................................................... 222

A. Überblick über den Strafprozess ............................................................ 222

1. Die Ziele und Grundprinzipien des Strafverfahrens und die EMRK ... 222

2. Der Ablauf des herkömmlichen Strafverfahrens ............................... 225

3. Die Grundsätze des Beweisrechts und -verfahrens ............................ 232

B. Die vorbereitenden Beweisführungsvorgänge .......................................... 237

1. Die „Aufbereitung“ des Beweismaterials ........................................ 238

a) Allgemeine Grundsätze: Strukturen, Waffengleichheit und Objektivitätspflichten ........................................................ 238

b) Speziell zum aussagenbasierten Beweis .................................... 242

aa) Die Beweismittel und der zeugenbasierte Beweis .............. 242

bb) Die „Zusammenstellung“ des zeugenbasierten Beweises ..... 245

cc) Die „Vorbereitung“ des zeugenbasierten Beweises ............. 248

dd) Zum Expertenbeweis ......................................................... 250 
2. Die Bestimmung des Umfangs der Beweiserhebungen

a) Beweisführung und Offenkundigkeit

b) Das Vorbringen von Beweisen: Zeugenladungen und Beweisanträge

c) Einverständliche Bestimmung der Beweiserhebungen .............. 259

d) Case Management ................................................................. 260

C. Kenntnisnahme und Offenlegung von Beweisen ....................................... 261

1. Die Kenntnis der Beweisergebnisse des Vorverfahrens seitens des Richters

2. Akteneinsicht und Offenlegung des Vorverfahrensmaterials ............... 263

D. Die Beweisführung im Hauptverfahren .................................................... 268

1. Zulässigkeit und Ausschluss von Beweisen ....................................... 268

2. Erhebung, Präsentation und Prüfung der Stichhaltigkeit der Beweise 273

a) Grundlagen ....................................................................... 273

b) Der Ablauf der Beweisvorgänge im Gerichtsverfahren ............... 278

c) Die Methoden der Beweisprüfung ........................................... 285

aa) Allgemeine Bemerkungen ................................................ 285

bb) Die Art und Weise der Vernehmungen .............................. 286

E. Zusammenfassung: Besonderheiten des Beweisführungssystems ................ 296

1. Die vorbereitenden Beweisführungsvorgänge ................................... 296

2. Kenntnisnahme und Offenlegung von Beweisen ................................ 299

3. Die Beweisführung im Hauptverfahren ............................................. 300

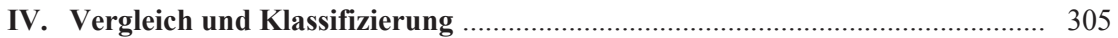

A. Überblick und Vorbemerkungen ........................................................... 305

B. Die vorbereitenden Beweisführungsvorgänge ............................................... 306

1. Die „Aufbereitung“ des Beweismaterials .......................................... 306

a) Allgemeine Grundsätze: Strukturen, Waffengleichheit und Objektivitätspflichten ......................................................... 306

b) Speziell zum aussagenbasierten Beweis .................................... 308

aa) Die Beweismittel und der zeugenbasierte Beweis ............... 308

bb) Die „Zusammenstellung“ des zeugenbasierten Beweises ..... 310

cc) Die „Vorbereitung“ des zeugenbasierten Beweises ............. 311

dd) Zum Expertenbeweis .................................................... 312

2. Die Bestimmung des Umfangs der Beweiserhebungen ..................... 314

a) Beweisführung und Offenkundigkeit ........................................ 314

b) Das Vorbringen von Beweisen: Zeugenladungen und Beweisanträge ........................................................................ 315

c) Einverständliche Bestimmung der Beweiserhebungen ................ 317

d) Case Management .................................................................. 317 
C. Kenntnisnahme und Offenlegung von Beweisen

1. Die Kenntnis der Beweisergebnisse des Vorverfahrens seitens des Richters

2. Akteneinsicht und Offenlegung des Vorverfahrensmaterials .............. 321

D. Die Beweisführung im Hauptverfahren ...................................................... 324

1. Zulässigkeit und Ausschluss von Beweisen ...................................... 324

2. Erhebung, Präsentation und Prüfung der Stichhaltigkeit der Beweise 327

a) Grundlagen .......................................................................... 327

b) Der Ablauf der Beweisvorgänge im Gerichtsverfahren ............... 330

c) Die Methoden der Beweisprüfung .............................................. 335

aa) Allgemeine Bemerkungen ................................................. 335

bb) Die Art und Weise der Vernehmungen ............................. 336

E. Zusammenfassung und Klassifizierung der nationalen Beweisführungssysteme anhand des ,adversatorischen“ und des ,inquisitorischen“ Idealtypus 341

1. Die vorbereitenden Beweisführungsvorgänge ................................... 342

a) Das englische Verfahrenssystem ................................................ 343

b) Das deutsche Verfahrenssystem ............................................. 345

2. Kenntnisnahme und Offenlegung von Beweisen ............................... 348

a) Das englische Verfahrenssystem ................................................. 348

b) Das deutsche Verfahrenssystem .............................................. 349

3. Die Beweisführung im Hauptverfahren ............................................ 350

a) Das englische Verfahrenssystem .............................................. 350

b) Das deutsche Verfahrenssystem ............................................. 353

4. Klassifizierung …...................................................................... 356

a) Vorbemerkungen ................................................................ 356

b) Das englische Verfahrenssystem ........................................... 357

c) Das deutsche Verfahrenssystem .............................................. 360

V. Bewertung und rechtspolitische Schlussfolgerungen ..................................... 363

A. Zum Wert der Bewertung und zum Bewertungsmaßstab ............................ 363

B. Wertende Betrachtung der Vergleichserkenntnisse und Überlegungen zur Annäherung der Verfahrenssysteme

1. Die vorbereitenden Beweisführungsvorgänge und die Bestimmung der Beweiserhebungen ...................................................................... 366

2. Kenntnisnahme und Offenlegung von Beweisen ............................ 370

3. Die Beweisführung im Hauptverfahren ............................................ 373

a) Allgemeine Erwägungen ........................................................... 373

b) Zu den Vernehmungsstrukturen ................................................. 377

c) $\mathrm{Zu}$ den Schlussvorträgen und den richterlichen

Schlussdarstellungen 
C. Rechtspolitische Schlussbetrachtungen: Leitsätze zur „Rebalancierung“ der Beweisführungssysteme

1. Vorbemerkungen ................................................................. 382

2. Leitsätze für Reformstrategien ....................................................... 384

\section{Teil 3}

\section{Internationalrechtliche Dimensionen}

I. Einleitende Bemerkungen zum Analyserahmen

II. EMRK: Verfahrensfairness und Prinzip der ,adversarial proceedings“

A. Eckpfeiler eines fairen Strafverfahrens: Waffengleichheit und kontradiktorische Beweiserhebung

1. Einführung: Die Auslegung der EMRK durch den EGMR

2. Allgemeine Grundsätze mit Bezug auf das Beweisverfahren 394

3. Teilgarantien 398

a) Anspruch auf wirksame Verteidigung, Beweisoffenlegung und Zeugenladung 398

b) Das Konfrontationsrecht 403

c) Die Gesamtbetrachtung der Verfahrensfairness 409

B. Schlussfolgerungen: EMRK und Beweisführungsmodelle 413

III. Die Beweisführung im IStGH-System 417

A. Der Ablauf des Verfahrens vor dem IStGH ............................................. 418

B. Grundaspekte des Beweisführungssystems ............................................. 423

1. Einführung: Internationale Zielsetzung und Beweisschwierigkeiten ... 423

2. Die Vorbereitung des Hauptverfahrens ............................................... 425

a) Die Beweissammlung ............................................................... 425

b) Beweisoffenlegung und Aktenkenntnis .................................... 426

c) Das Vorbringen von Beweisen ................................................... 429

aa) Allgemeines ................................................................... 429

bb) Die Bestimmung des Umfangs der Beweiserhebungen ........ 431

3. Die Beweisführung im Hauptverfahren ........................................... 435

a) Zulässigkeit und Ausschluss von Beweisen ................................. 435

b) Die Erhebung und Prüfung der Beweise ..................................... 438

aa) Allgemeine Grundsätze .................................................. 438

bb) Praktische Anweisungen des IStGH .................................. 440

C. Klassifizierende und wertende Schlussfolgerungen ................................... 445 


\section{Abkürzungsverzeichnis}

A.B.A.J.

Abs.

AJLH

ALJ

All ER

Am. J. Comp. L.

Am. J. Crim. Law

Am. J. Juris.

a.o.

$\mathrm{AO}$

Art.

Aufl.

BayObLG

Bd.

Begr.

BGH

BGHSt

BRAO

Buff. L. Rev.

BVerfG

BVerfGE

BZRG

bzw.

Cal. L. Rev.

Cambrian L. Rev.

Cardozo J. of Int'l \& Comp. L.

Cardozo L. Rev.

CCB 2004

CCP 2013

Chi-Kent J. Int'l \& Comp. L.

Chi.-Kent L. Rev.
American Bar Association Journal

Absatz

The American Journal of Legal History

The Australian Law Journal

All England Law Reports

The American Journal of Comparative Law

American Journal of Criminal Law

American Journal of Jurisprudence

and others

Abgabenordnung

Artikel

Auflage

Bayerisches Oberstes Landesgericht

Band

Begründer(in)

Bundesgerichtshof

Entscheidungen des Bundesgerichtshofs in Strafsachen

Bundesrechtsanwaltsordnung

Buffalo Law Review

Bundesverfassungsgericht

Entscheidungen des Bundesverfassungsgerichts

Gesetz über das Zentralregister und das Erziehungsregister

beziehungsweise

California Law Review

The Cambrian Law Review

Cardozo Journal of International and Comparative Law

Cardozo Law Review

The old Code of Conduct of the Bar of England \& Wales (8. Aufl. 2004)

The Code for Crown Prosecutors (7. Aufl. 2013)

Chicago-Kent Journal of International and Comparative Law

Chicago-Kent Law Review 
CILSA

CJA

CJPOA 1994

CLF

CLP

Colum. L. Rev.

CPIA

CPR

CPS

Cr App R

Crim.L.R.

ders.

d.h.

dies.

Diss.

DPP

Duke J. Comp. \& Int'l L.

Duke L.J.

EGGVG

EGMR

Einf.

Einl.

EJCCC

EKMR

EMRK

En.

Ent.

EU

EuGRZ

EuropStrafRecht

EWCA Crim

EWHC

FG

Fn.

FS
The Comparative and International Law Journal of Southern Africa

Criminal Justice Act

Criminal Justice and Public Order Act 1994

Criminal Law Forum

Current Legal Problems

Columbia Law Review

Criminal Procedure and Investigations Act

Criminal Procedure Rules

Crown Prosecution Service

Criminal Appeal Reports

The Criminal Law Review

derselbe

das heißt

dieselbe(n)

Dissertation

Director of Public Prosecutions

Duke Journal of Comparative \& International Law

Duke Law Journal

Einführungsgesetz zum Gerichtsverfassungsgesetz

Europäischer Gerichtshof für Menschenrechte

Einführung

Einleitung

European Journal of Crime, Criminal Law and Criminal Justice

Europäische Kommission für Menschenrechte

Europäische Konvention zum Schutz der Menschenrechte und Grundfreiheiten

Endnote

Entscheidung (in der EGMR-Rechtsprechung = Decision, Zulässigkeitsentscheidung)

Europäische Union

Europäische GRUNDRECHTE-Zeitschrift

Europäisches Strafrecht

England and Wales Court of Appeal Criminal Division

England and Wales High Court

Festgabe

Fußnote

Festschrift 
GA

Geo. L. J.

GG

ggf.

GK

GS

GVG

Harv. Int'l. L. J.

Harv. L. Rev.

Harvard JLPP

Hastings L.J.

HRA

HRRS

Hrsg.

ICJR

ICLQ

IEP

i.e.S.

i.G.z.

Ind. L.J.

insb.

IntKomm

Int'l \& Comp. L.Q.

Int'l Crim. L. Rev.

Int'l Legal Persp.

Iowa L. Rev.

Is.L.R.

IStGH

IStGHJ

IStGH-Statut

i.V.m.

i.w.S.

i.Z.m.

JA

J. Crim. L. \& Criminology
Goltdammer's Archiv für Strafrecht

The Georgetown Law Journal

Grundgesetz

gegebenenfalls

Große Kammer

Gedächtnisschrift/Gedenkschrift

Gerichtsverfassungsgesetz

Harvard International Law Journal

Harvard Law Review

Harvard Journal of Law \& Public Policy

Hastings Law Journal

Human Rights Act 1998

Online-Zeitschrift für Höchstrichterliche Rechtsprechung im Strafrecht (http://www.hrr-strafrecht.de)

Herausgeber(in)

International Criminal Justice Review

International and Comparative Law Quarterly

Internet Encyclopedia of Philosophy

im engeren Sinne

im Gegensatz zu

Indiana Law Journal

insbesondere

Internationaler Kommentar zur Europäischen Menschenrechtskonvention

International and Comparative Law Quarterly

International Criminal Law Review

International Legal Perspectives

Iowa Law Review

Israel Law Review

Internationaler Strafgerichtshof

Internationaler Strafgerichtshof für das ehemalige Jugoslawien

Statut des Internationalen Strafgerichtshofs

(Römisches Statut)

in Verbindung mit

im weiteren Sinne

im/in Zusammenhang mit

Juristische Arbeitsblätter

The Journal of Criminal Law \& Criminology 
JICJ

JP

JR

JURA

JuS

$\mathrm{JZ}$

KG

KK-StPO

Law \& Soc'y Rev.

LJIL

L.Q.Rev.

LR-StPO

L.S.

MCA

Md. L. Rev.

Melb. U. L. Rev.

Mich. J. Int'l L.

Mich. L. Rev.

Minn. L. Rev.

MLR

MschrKrim

m.w.N.

n. Chr.

NJECL

NJW

Notre Dame L. Rev.

Nr., no.

$\mathrm{NStZ}$

NStZ-RR

O.J.L.S.

OLG

PACE

Q.B.

Queen's L.J.

R.

$\mathrm{R}$

Reg.
Journal of International Criminal Justice

Justice of the Peace

Juristische Rundschau

Juristische Ausbildung

Juristische Schulung

Juristenzeitung

Kammergericht

Karlsruher Kommentar zur Strafprozessordnung

Law and Society Review

Leiden Journal of International Law

The Law Quarterly Review

Löwe-Rosenberg. Die Strafprozeßordnung und das

Gerichtsverfassungsgesetz Großkommentar

Legal Studies

Magistrates' Courts Act 1980

Maryland Law Review

Melbourne University Law Review

Michigan Journal of International Law

Michigan Law Review

Minnesota Law Review

The Modern Law Review

Monatsschrift für Kriminologie und Strafrechtsreform

mit weiteren Nachweisen

nach Christus

New Journal of European Criminal Law

Neue Juristische Wochenschrift

Notre Dame Law Review

Nummer

Neue Zeitschrift für Strafrecht

Neue Zeitschrift für Strafrecht - Rechtsprechungsreport

Oxford Journal of Legal Studies

Oberlandesgericht

Police and Criminal Evidence Act 1984

Queen's Bench Division (High Court, Law Reports)

Queen's Law Journal

Rule(s)

Rex/Regina

Regulation(s) 
Rep.

repr.

rev.

RGSt

RIDP

RiStBV

Rn.

RPE

RW

S.

SACC

S.C.

S. Cal. L. Rev.

S.C.L.R.

S.C.R.

sect.

SK-StPO

StA

Stan. L. Rev.

StGB

StPO

StraFo

$\mathrm{StV}$

u.a.

U. Chi. L. Rev.

UCLA J. INT'L L. \& FOREIGN AFF.

UK

UKHL

UKSC

UN

U. Pa. L. Rev.

U. Pitt. L. Rev.

Urt.

U.S.

US/USA
Report of the European Commission

of Human Rights

reprint(ed)

revised by

Entscheidungen des Reichsgerichts in Strafsachen

Revue internationale de droit pénal

Richtlinien für das Strafverfahren und das Bußgeldverfahren

Randnummer(n)

Rules of Procedure and Evidence (IStGH)

Rechtswissenschaft

Seite(n)

South African Journal of Criminal Law and Criminology Session Cases (Scotland)

Southern California Law Review

Supreme Court Law Review (Canada)

Supreme Court Reports (Canada)

section(s)

Systematischer Kommentar zur Strafprozessordnung

Staatsanwalt/Staatsanwaltschaft

Stanford Law Review

Strafgesetzbuch

Strafprozessordnung

Strafverteidiger Forum

Strafverteidiger

und andere(s), unter anderem

The University of Chicago Law Review

UCLA Journal of International Law and Foreign Affairs

United Kingdom

United Kingdom House of Lords

United Kingdom Supreme Court

United Nations

University of Pennsylvania Law Review

University of Pittsburgh Law Review

Urteil (in der EGMR-Rechtsprechung = Judgment)

United States Reports (of the Supreme Court)

United States of America 
usw.

v.

Va. L. Rev.

v. Chr.

Verf.

vgl.

Wash. U. L. Q.

WLR

Yale L.J.

z.B.

Zbornik PFZ

ZfRV

ZIS

zit.

ZRG KA

ZRP

ZStrR

ZStW

ZVglRWiss und so weiter

versus, von/vom

Virginia Law Review

vor Christus

Verfasser(in)

vergleiche

Washington University Law Quarterly

Weekly Law Reports

The Yale Law Journal

zum Beispiel

Zbornik Pravnog Fakulteta u Zagrebu

Zeitschrift für Rechtsvergleichung

Zeitschrift für Internationale Strafrechtsdogmatik

zitiert

Zeitschrift der Savigny-Stiftung für Rechtsgeschichte Kanonistische Abteilung

Zeitschrift für Rechtspolitik

Schweizerische Zeitschrift für Strafrecht

Zeitschrift für die gesamte Strafrechtswissenschaft

Zeitschrift für Vergleichende Rechtswissenschaft 

Thinking without comparisons is unthinkable.

And, in the absence of comparisons, so is all scientific thought and all scientific research. - Guy Swanson*

\section{Einleitung}

\section{Forschungsgegenstand}

In der ,westlichen Rechtswelt“ sind in den letzten Jahrzehnten, nicht zuletzt wegen rasanter Veränderungen des Kriminalitätsbilds aufgrund von gesellschaftlichen, technologischen und geopolitischen Entwicklungen, die Notwendigkeit und der rechtspolitische Wille zur Überwindung der nationalen Grenzen des Strafrechts evident geworden. ${ }^{1}$ Die sinnvolle Implementierung von Elementen fremder Rechtssysteme auf nationaler Ebene sowie die reibungslose Verwirklichung der Ziele der internationalen Strafjustiz, der transnationalen Verbrechensverfolgung und des universellen Menschenrechtsschutzes setzen mit Blick auf das Normensystem ein wechselseitiges Grundverständnis zwischen den Rechtsordnungen unterschiedlicher Rechtstraditionen voraus. Demgemäß befasst sich auch die rechtsvergleichende Grundlagenforschung häufig mit diversen Dynamiken in der Beziehung zwischen westlichen Strafrechtssystemen sowie mit Fragen zur Internationalisierung, Transnationalisierung und Supranationalisierung des Strafrechts. ${ }^{2}$

Dabei wird unter anderem die Frage aufgeworfen, ob die jüngeren Entwicklungen in den Rechtssystemen angloamerikanischer und kontinentaleuropäischer Prägung sowie im Rahmen der internationalen Gerichtsbarkeiten auf die Konvergenz, die Durchmischung oder eher die Divergenz der unterschiedlichen Strafverfahrensformen und Justizinstitutionen hindeuten. Lehre, Justizpraxis und Rechtspolitik müssen weiterhin sowohl auf nationaler als auch auf internationaler Ebene kontinuierlich für die Bereitstellung von funktionsfähigen strafprozessualen Mechanismen zur Konfliktlösung Sorge tragen. Sie orientieren sich dabei nach wie vor hauptsächlich an den innerstaatlichen herkömmlichen Verfahrenssystemen von traditionell

* In: Vallier (Hrsg.), Comparative Methods, S. 145.

1 Vgl. Perron, ZStW 109 (1997), 281 (281).

2 Vgl. u.a. Bárd, in: Aromaa/Viljanen (Hrsg.), International Key Issues, S. 34-38; Chase/Walker, in: Walker/Chase (Hrsg.), Categories, S. li-liv; Grande, in: Bussani/Mattei (Hrsg.), Comparative, S. 192-194, 199-203 m.w.N.; Jackson/Summers, Internationalisation, S. 3-6; Nijboer, in: Doran/Jackson (Hrsg.), Judicial Role, S. 19-20; Sieber, in: Sieber/ Albrecht (Hrsg.), Strafrecht und Kriminologie, S. 80-111; Sieber, Rechtstheorie 41 (2010), 151 (152-157, 193-198). Zum Forschungsprogramm des Max-Planck-Instituts für ausländisches und internationales Strafrecht als Forum für die Durchführung von grundlegenden rechtsvergleichenden Projekten zu den Grenzen des Strafrechts Sieber, ZStW 119 (2007), $1(1-68)$. 
hoch angesehenen Rechtsordnungen, wie der englischen, ${ }^{3}$ der/den US-amerikanischen, der französischen und der deutschen. In diesem Kontext und mit Blick auf die Schaffung der Grundlagen für die Entwicklung neuer (alternativer) Prozessformen - sofern erforderlich - ist die rechtsvergleichende Forschung von besonderem analytischem Wert. Die Optimierung der Methoden der Rechtsvergleichung und die Verbreiterung ihrer systemanalytischen Funktionen sind daher von grundlegendem Interesse für die Strafrechtswissenschaft.

Die vorliegende Forschungsarbeit beschäftigt sich mit den unterschiedlichen Prozessformen und insbesondere mit den Beweisstrukturen und Rollenverteilungen, die in nationalen und internationalen Rechtssystemen westlicher Prägung im Rahmen eines gerichtlichen Strafverfahrens zur Aufklärung eines streitigen Sachverhalts Anwendung finden bzw. gefördert werden. Die Darstellungen und Analysen erfolgen zunächst unter historischen und abstrakt-theoretischen Gesichtspunkten und anschließend in konkret-rechtsvergleichender und wertender Absicht. Im Vordergrund stehen dabei vor allem die maßgebenden Beweisführungen ${ }^{4}$ im Vorfeld und im Rahmen der herkömmlichen erstinstanzlichen Erkenntnisverfahren und insbesondere die Vorgänge, welche das Vorbringen, die Präsentation bzw. Erhebung und die Prüfung von Beweisen zum Gegenstand haben. Solche Verfahren finden aufgrund einer Strafklage weiterhin überall insbesondere in Bezug auf schwere und meistens diagnostisch komplexe Delikte zur Feststellung der materiell-rechtlich relevanten kriminellen Schuld statt.

In sachlicher Hinsicht geht die Untersuchung von der üblichen Unterscheidung zwischen angloamerikanischen (common law) und kontinentaleuropäischen (civil law) Verfahrenstraditionen sowie von der in Praxis und Lehre weitverbreiteten Gegenüberstellung der Bezeichnungen ,adversatorisches“ (adversarial) und ,inquisitorisches“ (inquisitorial) Straf- bzw. Beweisverfahren aus. Das renommierte USamerikanische Black's Law Dictionary liefert eine Beschreibung der unterschiedlichen (Beweis-)Verfahrenssysteme in der common law- und der civil law-Welt, die an dieser Stelle als simple Einführung in die herrschenden Ideen hinter den ent-

3 Als englisches Rechtssystem wird heute in der Regel das Rechtssystem von England und Wales bezeichnet, siehe dazu Darbyshire, Legal System, S. 10-11.

${ }^{4}$ In dieser Arbeit wird der allgemeine Begriff „Beweisführung“ nicht zur streng technischen Bezeichnung bestimmter Verfahrensphasen verwendet. Für eine technischere Unterscheidung zwischen den Teilaspekten bzw. Phasen des Beweisprozesses vgl. die möglichst neutralen/eigenständigen und rechtsordnungsübergreifenden Definitionen von Gle $\beta$, Beweisrechtsgrundsätze, S. 32-38, die freilich ,,den Termini des deutschen Strafprozessrechts nachgebildet" sind, siehe insb. S. 36-37: „Die Begriffe ,Beweiserhebung " und ,Beweisaufnahme" bezeichnen die förmliche Präsentation von Beweismitteln vor dem erkennenden Gericht. Dieser Akt der sinnlichen Wahrnehmung für die richterliche Überzeugungsbildung ist zu trennen von den vorhergehenden Vorgängen der Sammlung der Wahrnehmungsobjekte (Beweisgewinnung) sowie von ihrer Zulassung als Beweismittel (Beweiszulassung) und von der anschließenden Beurteilung der Glaubhaftigkeit eines Beweismittels sowie der Schlussfolgerung aus den wahrgenommenen Informationen (Beweisverwertung im Wege der Beweiswürdigung).“ 
sprechenden Prozesstypen dienen soll. Das adversary system wird dabei als ein prozessuales System definiert, an dem, wie im angloamerikanischen Rechtssystem, aktive und ungehinderte Parteien beteiligt sind, die miteinander wetteifern, um ihren „Fall“ (case) vor einem unparteiischen Entscheidungsträger vorzubringen. Mit der Bezeichnung inquisitorial system ist dagegen ein in der civil law-Welt verwendetes Beweisaufnahmesystem gemeint, in dem der Richter die Gerichtsverhandlung führt, über die Fragen entscheidet, die gestellt werden sollen, und den Rahmen und Umfang der Ermittlung bestimmt. ${ }^{5}$

Diese Terminologie wird des Öfteren im rechtsvergleichenden Kontext im Rahmen einleitender Betrachtungen verwendet, wie noch ausführlich belegt werden soll. Sie soll hauptsächlich die konzeptionelle Einführung in die Hauptfragen der jeweiligen strafprozessualen Forschung, gerichtlichen Entscheidung oder Reformdiskussion in anschaulicher Weise ermöglichen - ungeachtet dessen, ob es dabei um die Untersuchung von Problemen beispielsweise des polizeilichen Vorverfahrens, der diversen Systeme der Anklageerhebung, der Laiengerichtsbarkeiten, der Menschen-, Fairness- und Verteidigungsrechte, des materiellen nationalen und internationalen Beweisrechts, ${ }^{6}$ der Beweisaufnahme in der Hauptverhandlung, der richterlichen Beweiswürdigung oder der Absprachemechanismen geht. Meistens wird insofern die Beziehung zwischen dem ,,adversatorischen“ und dem ,inquisitorischen“ Oberbegriff quasi als Axiom behandelt: Unter der Bezeichnung „,adversatorisch“ werden hauptsächlich parteienbeherrschte Verfahrens- und Konfliktlösungssysteme abgebildet; als ,inquisitorisch“ werden dagegen die richterzentrierten Wahrheitsfindungssysteme bezeichnet.

Weiterhin werden nicht selten die ,adversatorischen“ Systeme von vornherein implizit oder explizit, meistens auf der Basis von rechtshistorischen Feststellungen, mit den common law- und die ,inquisitorischen“ Systeme mit den civil law-Verfahrenssystemen gleichgesetzt. Dabei bleibt jedoch die Tatsache unbeachtet, dass die einzelnen Bestandteile des ,adversatorischen“ und des ,inquisitorischen“ Verfahrens bisher nicht in klarer und allgemein anerkannter Weise bestimmt worden sind und dass sich in der modernen common law- wie auch in der civil law-Welt

5 Black's Law Dictionary, S. 64, 913: Adversary system: „A procedural system, such as the Anglo-American legal system, involving active and unhindered parties contesting with each other to put forth a case before an independent decision-maker. - Also termed adversary procedure; (in criminal cases) accusatorial system, accusatory procedure." Inquisitorial system: „A system of proof-taking used in civil law, whereby the judge conducts the trial, determines what questions to ask, and defines the scope and the extent of the inquiry. This system prevails in most of continental Europe, in Japan, and in Central and South America."

6 Allgemein zum Begriff des Beweisrechts vgl. an dieser Stelle Posner, Stan. L. Rev. 51 (1998-1999), 1477 (1477): ,The law of evidence is the body of rules that determines what, and how, information may be provided to a legal tribunal that must resolve a factual dispute." 
kaum exakt gleiche Rechtssysteme finden lassen. ${ }^{7}$ Insbesondere auf die Frage nach der Natur der Dichotomie adversatorisch v. inquisitorisch - konkreter: ob es sich hierbei um reale Verfahrenssysteme, rechtshistorische Abbildungen, rechtspolitische Prozessmodelle oder theoretisch konstruierte (extreme) Erscheinungsformen des Strafverfahrens handelt - wird in den meisten Fällen nicht gründlich oder eindeutig genug eingegangen. Auch die einzelnen (Struktur- und Zielsetzungs-) Komponenten der strittigen Verfahrenskategorien und die genauen Aspekte des Strafprozesses, die diese umfassen, werden in der Mehrheit der Forschungen und praktischen Erwägungen, die in der Regel jeweils bestimmte Einzelbereiche des Strafverfahrensrechts betreffen, nicht umfassend behandelt bzw. nur gezielt angesprochen.

Die Gefahren liegen dabei auf der Hand: Historische Ereignisse und terminologische Präferenzen können ohne systematische Aufarbeitung der modernen Systemrealitäten willkürlich zu allgemeingültigen „Axiomen“ umgewandelt werden. Es können sich Vorurteile hinsichtlich der Frage, welche heutigen Rechtssysteme ,gut" und „liberal" und welche ,schlecht" und ,,autoritär" sind, herausbilden und die konstruktive Bewertung der einzelnen Verfahrensformen und Tendenzen auf der Grundlage von klar ausgearbeiteten Maßstäben verdrängen. Letztendlich sind auch in der heutigen Zeit verschiedenste politisch-ideologisch wertende, folkloristische und provokant simplifizierende oder polarisierende Verwendungen der Dichotomien common law / civil law und ,adversatorisches“/, ,inquisitorisches“"Verfahren an der Tagesordnung, die rein anachronistischen rechtspolitischen Zwecken dienen.

Im Rahmen solcher übersimplifizierenden Betrachtungen werden unter anderem die modernen vertikalen und horizontalen Systemmischungen und Rechtstransplantationen $^{8}$ nicht genügend wahrgenommen, die sogar in zentralen westlichen und sich rechtstraditionell gegenüberstehenden Rechtsordnungen wie der englischen und der deutschen vorhanden sind bzw. gefordert werden. Diese „Annäherung“ der nationalen Verfahrenssysteme findet hauptsächlich aufgrund von völkerrechtlichen und supranationalen Rechtsakten sowie von internationalen Menschenrechtsinstrumenten wie der Europäischen Konvention zum Schutz der Menschenrechte und Grundfreiheiten (EMRK) und der Rechtsprechung des Europäischen Gerichtshofs für Menschenrechte (EGMR) statt; sie wird auch aus pragmatischen Gründen im Rahmen der Prozessökonomie und der transnationalen Kriminalitätsverfolgung „diktiert". 9 Darüber hinaus werden bei veralteten dichotomisierenden Klassifizierungen und pauschalen absoluten Einteilungen der Rechtssysteme meistens auch

7 Vgl. F. Allen, in: The Institute of Comparative Law in Japan (Hrsg.), Toward, S. 769: „All national systems of criminal justice are in many particulars unique, and gaining adequate appreciation of such features is one of the important objectives of serious comparative study."

8 Siehe zu diesem Begriff im strafrechtlichen Kontext u.a. Jung, ZStW 121 (2009), 467 (insb. 470-473); Langer, Harv. Int'l L. J. 45 (2004), 1 (5-6, 29-35) m.w.N.

9 Vgl. ferner Sieber, in: Sieber/Albrecht (Hrsg.), Strafrecht und Kriminologie, S. 80-94. 
die systemübergreifenden strafprozessualen Entwicklungen nicht in vollem Umfang berücksichtigt, die in Zusammenhang mit der internationalen Strafjustiz stehen und heute am besten anhand der ständigen Gerichtsbarkeit des Internationalen Strafgerichtshofs (IStGH) identifiziert werden können.

Anstatt nun an herkömmlichen - und fruchtlosen - Betrachtungen des ,,adversatorischen“ bzw. common law- und des, inquisitorischen“ bzw. civil law-Verfahrens festzuhalten, muss der Versuch unternommen werden, die generellen Ideen hinter solchen schematischen Gegenüberstellungen in einer abstrakt-theoretischen Art und Weise aufzuarbeiten, die für die (funktionale) ${ }^{10}$ Rechtsvergleichung als Forschungsmethode ${ }^{11}$ nützlich ist. Analytisch wertvolle und aussagekräftige Ergebnisse können sich insbesondere aus einer gründlichen und klar abgrenzenden Bestimmung der Natur und der einzelnen Elemente der prozeduralen Dichotomien und Taxonomien ergeben, die als allgemeine Referenzpunkte und thematische Extremgrenzen für die jeweiligen rechtsvergleichenden Untersuchungen gelten.

Dies setzt freilich eine sorgfältige logisch-systematische Definitionsarbeit voraus. Die Ausarbeitung eines rein theoretischen und kohärenten Hypothesenerstellungs-, Analyse-, Vergleichs- und Bewertungsrahmens kann der wirksamen Durchführung von komplexen konkret-rechtsvergleichenden Forschungen erheblich dienen. Sie erlaubt beispielsweise, wie vorliegend, die einfachere Untersuchung der Unterschiede, der Gemeinsamkeiten und der Effektivität der diagnostischen Strukturen des Beweisverfahrens in unterschiedlichen Strafprozesssystemen. Weitere theoretische, empirische oder rechtspolitische Untersuchungen können sich nachfolgend ebenso auf eine stabilere Grundlage stützen. Die gedankliche (heuristische)

$10 \mathrm{Vgl}$. zum Begriff der funktionalen Rechtsvergleichung Engelhart, Sanktionierung, S. 19-20 m.w.N.: ,Gemeinsamer Kernpunkt jeglicher funktionaler Rechtsvergleichung ist [...], dass von einem Lebenssachverhalt (einem Sachproblem) und nicht von einer (nationalen) Rechtsnorm oder einem (nationalen) Rechtsproblem ausgegangen wird. Anstelle von Normen werden Lösungen für ein bestimmtes Sachproblem verglichen, die Rechtsvergleichung ist also ein Problemlösungsvergleich. Sie folgt einer problembezogen-funktionalen Betrachtung und ist nicht allein normbezogen deskriptiv. Rechtsvergleichung lässt sich in diesem Sinne als der planmäßige Vergleich von Lösungen für bestimmte soziale Lebenssachverhalte in zwei oder mehreren Rechtssystemen mit dem Ziel der Erlangung neuer Erkenntnisse definieren" (Fußnoten wurden ausgelassen). Siehe auch Jescheck, ZStW 86 (1974), 761 (772-773), der u.a. die Methode der Wahrheitsfindung im Beweisverfahren als ein soziales Problem identifiziert hat, das Ausgangspunkt von rechtsvergleichenden Forschungen im Bereich des Strafverfahrensrechts sein kann; Jung, JuS 1998, 1 (2-3), und Jung, FS für Baratta, S. 366-369. Vgl. auch Husa, in: Adams/Heirbaut (Hrsg.), Method, S. 60-64; Zweigert/Kötz, Einführung, S. 33-35. Eingehend zur funktionalen Rechtsvergleichung als grundlegender Methode der Strafrechtsvergleichung (sowie zur „Strukturvergleichung“ und zur „universalen“, zur „systematischen“, zur „fallbasierten“, zur ,wertvergleichenden und wertenden“ und zur ,computergestützten“ Strafrechtsvergleichung) Sieber, in: Sieber/Albrecht (Hrsg.), Strafrecht und Kriminologie, S. 111-125.

11 Über die Rechtsvergleichung als juristische Methode siehe Jescheck, Strafrechtsvergleichung, S. 36-37. Siehe auch Engelhart, Sanktionierung, S. 12-13 m.w.N.; Hage, in: Adams/Heirbaut (Hrsg.), Method, S. 44-49. 
Zusammenstellung von abstrakt-theoretischen extremen Prozesstypen sowie ihre rechtsvergleichende und rechtspolitische Anwendung mit Blick auf das nationale und das internationale Straf- und Beweisverfahrensrecht bilden dementsprechend den Kern dieser Forschungsarbeit.

\section{Forschungsziele}

Die vorliegende Arbeit bezweckt den Gewinn grundlegender rechtsvergleichender Erkenntnisse in Bezug auf die Rollenverteilungen und die Strukturen der Beweisführung in unterschiedlichen Verfahrenssystemen westlicher Prägung sowie in Bezug auf ihre Tauglichkeit und Effektivität bei der Aufklärung von strafrechtlich relevanten Sachverhalten. Dies soll auf einer abstrakt-theoretischen und auf einer konkret-vergleichenden Ebene geschehen.

Auf der ersten Ebene richtet sich der Fokus auf die Dichotomien zwischen den angloamerikanischen und den kontinentaleuropäischen sowie zwischen den ,,adversatorischen“ und den ,inquisitorischen“ Strafverfahren, die systemübergreifend in vielerlei Hinsicht berücksichtigt werden, und insbesondere auf ihren jeweiligen historischen, theoretischen und terminologischen Hintergrund. Dabei geht es hauptsächlich um die Frage, inwieweit solche Kategorisierungen nicht nur einen rechtshistorischen und rein taxonomischen Wert haben. Genauer soll dabei untersucht werden, ob und inwieweit die phänomenologische ${ }^{12}$ Gegenüberstellung der ,,adversatorischen" und der ,inquisitorischen“ Verfahrensgruppe durch ihre gedankliche Verwandlung in zwei Extreme oder Idealtypen des Straf- und Beweisverfahrens dem analytischen Vergleich von realen komplexen Prozesssystemen dienen kann. In diesem Fall müssen in logisch-systematischer Weise die einzelnen Prozessmerkmale und Elemente identifiziert werden, welche die Bestandteile der gegensätzlichen Idealtypen darstellen sollen; hierbei sind die generellen rechtstraditionellen Beobachtungen hinsichtlich der zentralen Ideen hinter der Organisation der westlichen Beweisverfahrenssysteme zu berücksichtigen. ${ }^{13}$

12 Vgl. Perron, ZStW 109 (1997), 281 (287).

13 Wie ausführlich gezeigt werden soll, können - unter Berücksichtigung der diversen, keinesfalls einheitlichen wissenschaftlichen Diskussionen und Praxiserwägungen hinsichtlich der Unterscheidung zwischen ,adversatorischen“ bzw. common law- und ,inquisitorischen" bzw. civil law- Systemen - u.a. folgende Teilaspekte bei der Bestimmung der Bestandteile der Idealtypen als „Kandidaten“ in Betracht kommen: die Konturen des Vorverfahrens und der Anklageerhebung; die Absprachemechanismen; die Instrumente zur Gewährleistung der Verteidigungsrechte; die Prinzipien der Mündlichkeit und Öffentlichkeit; die Funktionstrennung zwischen Laien- und Berufsrichtern; die Art und Weise der vorgerichtlichen Offenlegung der Beweise; sowie die Rolle der Verfahrensbeteiligten bei der Bestimmung des Umfangs der Beweiserhebungen, bei der Durchführung der Beweisaufnahme und bei der Beweiswürdigung. 
Ziel soll die Erstellung eines kohärenten und neutralen Analyserahmens für die Darstellung und den Vergleich tatsächlicher moderner Erscheinungsformen des (Beweis-)Verfahrens in unterschiedlichen Rechtssystemen sein. Darüber hinaus müssen nicht nur die strukturellen Merkmale, sondern auch die Zielsetzungskomponenten der Idealtypen - insbesondere in Bezug auf die oft vorgebrachte Unterscheidung zwischen materieller und formeller Wahrheit und auf das Spannungsverhältnis zwischen Wahrheit, Verfahrensfairness und Menschenrechtsschutz untersucht werden. Es ist somit zunächst auf abstrakt-theoretischer Ebene und anhand von klassischen Prozesstheorien, rechtstraditionellen Ansätzen und jüngeren systemübergreifenden Tendenzen festzustellen, ob die verschiedenen Typen des westlichen Strafverfahrens dieselben Ziele verfolgen können bzw. müssen - durch diese Erkenntnis wird nämlich die Rechtsvergleichung auch in rechtspolitischer Hinsicht sinnvoll.

Auf der zweiten, konkret-vergleichenden Ebene sollen die Bestimmungen und Definitionen, die im Ergebnis der abstrakt-theoretischen Untersuchungen stehen, auf die Planung des genauen Darstellungsrahmens (einschließlich der im Einzelnen zu untersuchenden Strafprozessphasen und -merkmale) der Rechtsvergleichung von tatsächlichen modernen Beweisverfahrensordnungen Anwendung finden. In der vorliegenden Arbeit werden die Strukturen des Beweisverfahrens und insbesondere die Rolle des Richters und der zentralen Verfahrensbeteiligten bei der Beweisführung im englischen und im deutschen Strafprozesssystem einander gegenübergestellt. Dabei werden die Ziele des Straf- und Beweisverfahrens sowie vor allem die strukturellen Unterschiede und Gemeinsamkeiten der erstinstanzlichen Beweisführungen untersucht. Die Letzteren finden gegenwärtig in diesen beiden nationalen Rechtsordnungen unterschiedlichen rechtstraditionellen Ursprungs zur Aufklärung eines streitigen Sachverhalts und gerichtlichen Feststellung der kriminellen Schuld statt. Nur nebenbei soll anschließend unter Berücksichtigung der Vergleichsergebnisse versucht werden, das englische und das deutsche Beweisverfahrenssystem auf der Basis der vorhergehenden abstrakt-theoretischen Definitionen der Prozessmodelle ,phänotypisch“ einzuordnen; eine solche Klassifizierung soll der Veranschaulichung oder als Anknüpfungspunkt für weitere Forschungen dienen.

Mit eigentlichen, normativ geforderten und konkret anwendbaren Beweisverfahrensformen beschäftigt sich die Forschungsarbeit des Weiteren im Rahmen der Betrachtung der internationalrechtlichen Dimensionen der Dichotomie zwischen „adversatorischem“ und ,inquisitorischem“ Straf- und Beweisverfahren. Dies geschieht vorliegend unter zwei verschiedenen Blickwinkeln. Hinsichtlich erstens der durch die internationalen Justizinstitutionen einheitlich geforderten Beweisverfahrenstypen wird insbesondere folgende Frage untersucht: $\mathrm{Ob}$ und inwieweit sind erga omnes verbindliche Prinzipien im Rechtssystem der EMRK und in der EGMR-Rechtsprechung zu finden, die systemübergreifend Einfluss auf die Ausgestaltung der innerstaatlichen strafprozessualen Beweisführung und somit auf die 
Entwicklung von gemeinsamen beweisprozessualen Dynamiken zwischen den nationalen Strafjustizsystemen ausüben können? Hinsichtlich zweitens der Problematik der Beweisverfahrensstrukturen, wie sie in den internationalen - gegenüber einer gemischten Vielfalt von rechtstraditionellen Einflüssen offenen - Strafgerichtsbarkeiten zur Aufklärung von völkerstrafrechtlich relevanten Sachverhalten konkret verwendet werden, sollen die Beweisführungen vor dem ständigen IStGH untersucht werden. Die Untersuchung erfolgt hierbei grundsätzlich unter den gleichen Gesichtspunkten, die bei der Gegenüberstellung der englischen und der deutschen Verfahrensordnung angesprochen werden.

Die vorliegende Forschungsarbeit zielt schließlich nicht nur darauf ab, tiefgehende theoretische und rein vergleichende Erkenntnisse zu den Grundstrukturen des Beweisverfahrens zu gewinnen, sondern will auch rechtspolitisch wertvolle Schlussfolgerungen ziehen. Die wertende Betrachtung der abstrakt-theoretischen Definitionen und der konkreten Ergebnisse der Rechtsvergleichung soll der Feststellung von ,positiven“ und ,negativen“ Aspekten der westlichen Sachaufklärungsstrukturen dienen. Voraussetzung ist freilich die Heranziehung eines eindeutig bestimmten Bewertungsmaßstabs in Übereinstimmung mit den unmittelbaren Zielen und Funktionen des rechtsstaatlichen Strafprozesses und vor allem mit dem immanenten Ziel des Beweisverfahrens. Anschließend ist die Frage zu untersuchen, inwieweit es möglich und sinnvoll ist, in absoluter Weise festzustellen, welches Strafprozesssystem bzw. welches Beweisverfahrensmodell auf nationaler und auf internationaler Ebene im Allgemeinen das „,beste“ oder das „effektivste“ ist. Weiterhin soll ermittelt werden, ob es möglich ist, systemneutrale Vorschläge und einheitliche Leitsätze auszuarbeiten, die mit Blick insbesondere auf die im Rahmen der Vergleichungen festgestellten „Exzesse“ der diversen Beweisführungssysteme eine ausbalancierende und eventuell rechtsangleichende Wirkung haben können. Dadurch sollen auch die Grundlagen für weitere theoretische, rechtsvergleichende und empirische Untersuchungen und relevante rechtspolitische Reformplanungen geschaffen werden.

\section{Forschungsmethoden}

Für die Beantwortung der Forschungsfragen ist die Arbeit in einen Grundlagenteil (Teil 1), einen rechtsvergleichenden Teil (Teil 2) und einen Teil über die internationalrechtlichen Aspekte des Forschungsgegenstands (Teil 3) gegliedert. Der Grundlagenteil enthält zunächst die gezielt abstrakte Betrachtung der historischen und theoretischen Hintergründe von zentralen, weltweit einflussreichen westlichen Rechtstraditionen und Strafverfahrenssystemen. Im Zentrum der daran anschließenden Analysen steht die definitorische Auseinandersetzung mit dem Wesen und den theoretischen Dynamiken der Modellbildung im Strafprozess und in der analy- 
tischen Rechtsvergleichung. Für die Planung und Anfertigung des Grundlagenteils wurden rechtshistorische und systemtheoretische Ansätze sowie Erkenntnisse aus der Rechtskreistheorie der klassischen Rechtsvergleichungslehre und aus den soziologischen Methoden der Konstruktion von Idealtypen berücksichtigt. Diese wurden mit den klassischen juristischen Argumentationsweisen kombiniert, die sich primär auf die logisch-systematische (deduktive und induktive) Auslegung von Gesetzeslage, Literatur und Justizpraxis konzentrieren.

Die Struktur und der Umfang des rechtsvergleichenden Teils gründen sich auf die im Grundlagenteil enthaltene definitorische Bestimmung der essenziellen Elemente der gegensätzlichen Beweisführungsstile. Für die funktionale Rechtsvergleichung und für die daran anschließenden klassifizierenden und wertenden Analysen der Prozessstrukturen und Methoden zur Vorbereitung und Durchführung einer gerichtlichen Sachaufklärung wurden vorliegend zwei zentrale Strafverfahrensordnungen der common law- und der civil law-Welt, namentlich die englische und die deutsche, ausgewählt. Ihre Gegenüberstellung erfolgt im Wege der Analyse der geltenden Rechtslage (Auslegung von Gesetzen bzw. case law) sowie der interpretatorischen Bestimmungen der jeweils herrschenden Rechtsprechung und der Ansichten in der einschlägigen Literatur. Eine eigenständige umfassende empirische Untersuchung der täglichen beweisprozessualen Anwalts- und Gerichtspraxis in beiden Ländern, wie sie nur in einem zeitlich und sachlich weiten Umfang sinnvoll wäre, war vorliegend nicht möglich. Bereits existierende statistische Betrachtungen, die sich mit Blick auf die prozessualen Probleme der gerichtlichen Schuldfeststellung mit großen diagnostischen Schwierigkeiten konfrontiert sehen und daher nur begrenzt anzutreffen sind, wurden ebenso nur gezielt und nicht in ausführlicher Weise in die Forschung einbezogen.

Was die Auswahl der betreffenden nationalen Rechtsordnungen anbelangt, so ist unbestritten, dass die common law-Strafverfahrenstradition ihre Wurzeln im Rechtssystem von England hat. Trotz einer sehr langen und im Allgemeinen besonders stabilen Rechtstradition wird oft behauptet, dass die heutige prozessuale Rollenverteilung zwischen englischen Berufs- und Laienrichtern und Verfahrensbeteiligten keine große Ähnlichkeit mehr mit ihren geschichtlichen, extrem parteienzentrierten Vorgängern aufweist - auch wenn die Letzteren von anderen modernen Rechtssystemen angloamerikanischer Prägung in ihrer quasi puren Form übernommen worden sind. Gleichwohl ist das einheitliche englische Strafprozesssystem im Vergleich vor allem zu der bzw. den US-amerikanischen Verfahrensordnung(en) seltener Gegenstand umfassender, rein rechtsvergleichender Grundlagenuntersuchungen. Der deutsche Strafprozess ist seinerseits ohne Zweifel ein wesentlicher und weltweit immer noch einflussreicher Pfeiler der civil law-Verfahrenstradition. Er musste jedoch in den letzten Jahrzehnten, wie auch die Mehrheit der westlichen Strafjustizsysteme, großen rechtspolitischen und faktischen Herausforderungen begegnen. Dementsprechend sehen sich heute die deutsche Justizpraxis, die Wissenschaft und die Rechtspolitik nicht selten mit den Problemen und 
den Perspektiven eines Abschieds von den traditionellen und größtenteils immer noch hochangesehenen Prinzipien der amtlichen Sachaufklärung und des richterzentrierten Strafverfahrens konfrontiert. Sowohl die englische als auch die deutsche Rechtsordnung werden jedenfalls heute noch - neben Frankreich und den USA als die typischsten Vertreter der zwei großen westlichen Rechtstraditionen anerkannt. Darüber hinaus sind beide Staaten Mitglieder des Europarats und des IStGH-Statuts; dies erleichtert zugleich die Durchführung der internationalrechtlichen Untersuchungen im dritten Teil der Forschungsarbeit und das Ziehen von auch nationalrechtlich wertvollen Schlussfolgerungen.

Der abschließende ,internationalrechtliche“ Teil beschäftigt sich zunächst mit den strafverfahrensbezogenen Vorschriften der EMRK und insbesondere mit der systematischen und zielorientierten Auslegung der themarelevanten Rechtsprechung des EGMR. Die umfangreiche und durch nationalrechtliche Grundprinzipien geprägte Rechtsprechung des Menschenrechtsgerichtshofs hat für die Strafjustiz in sämtlichen europäischen Rechtsordnungen, wie in zahlreichen Forschungen und unter diversen Blickwinkeln bereits festgestellt worden ist, eine beträchtliche Bedeutung. Die Frage, ob und inwieweit diese komplexe und nicht immer widerspruchsfreie Rechtsprechung direkte beweisrechtliche Kernbestimmungen und Mindeststandards aufweist und welches, wenn überhaupt, ihr eigentliches Potenzial zur Entwicklung einheitlicher Beweisführungssysteme auf nationaler Ebene ist, lässt sich allerdings nicht einfach beantworten.

Auch bei der darauf folgenden Auseinandersetzung mit den Verfahrensregeln und den bisherigen Rechtsprechungsbestimmungen im IStGH-System ergeben sich Schwierigkeiten hinsichtlich der klaren Identifizierung der genauen prozessstrukturellen Richtung, welche die internationale Strafgerichtsbarkeit gerade verfolgt bzw. in Zukunft verfolgen wird. Der IStGH ist gegenwärtig der einzige ständige, auf der Basis eines breiten internationalen Konsenses eingerichtete und „multikulturell“ zusammengesetzte Gerichtshof, der für die Aufklärung von gravierenden völkerstrafrechtlichen Sachverhalten zuständig ist. Das Normensystem des IStGH und seine Rechtsprechung scheinen in allen Fällen in der Lage zu sein, die strafverfahrensrechtlichen Entwicklungen (nicht nur) in Bezug auf die internationalen Justizsysteme zu prägen.

\section{Gang der Untersuchung}

Die Untersuchung gliedert sich in drei Hauptteile. In Teil $1 \mathrm{zu}$ den Strafprozesssystemen und den Modellen des Beweisverfahrens wird zunächst (unter I.) auf die Probleme der Unterscheidung zwischen Rechtskreisen sowie zwischen westlichen Strafverfahrenstraditionen in der klassischen Rechtsvergleichungslehre und in der Rechtsgeschichte eingegangen. Anschließend (unter II.) erfolgt die Auseinander- 
setzung mit den Problemen der Bildung von Idealtypen in der modernen Strafprozesstheorie sowie die Definition des ,adversatorischen“ und des ,inquisitorischen“ Straf- und Beweisverfahrenstypus.

In Teil 2 zu der Rollenverteilung und den Beweisverfahrensstrukturen im englischen und im deutschen Strafprozess werden nach einer kurzen Einführung in den Darstellungs- und Vergleichsrahmen (unter I.), der im Einklang mit der definitorischen Bestimmung der Idealtypen in Teil 1 abgesteckt wurde, das englische (unter II.) und sodann das deutsche (unter III.) Beweisführungssystem dargelegt. In beiden Landesberichten werden die Ziele des Strafverfahrens und die Grundsätze des Beweisrechts und -verfahrens, die Phase der Vorbereitung und Bestimmung des Umfangs des maßgebenden Beweisverfahrens, Fragen der vorgerichtlichen Kenntnisnahme und Offenlegung von Beweisen sowie die Beweisführungsstrukturen im Hauptverfahren untersucht. Im Anschluss daran (unter IV.) folgen der Rechtsvergleich und darauf aufbauend die Überlegungen zur theoretischen Klassifizierung der nationalen Verfahrenssysteme anhand der im ersten Teil definierten Prozesstypen. Der wertende Abschluss des zweiten Teils (unter V.) enthält die Bestimmung des Bewertungsmaßstabs und die Bewertung der Vergleichsergebnisse sowie einige rechtspolitische Schlussbetrachtungen, die insbesondere auf die Problematik der Ausarbeitung von systemneutralen und einheitlichen Leitsätzen zur „Rebalancierung“ der Schwächen der Beweisführungssysteme eingehen.

In Teil 3 zu den internationalrechtlichen Dimensionen der Beweisführungstypen werden schließlich nach der erforderlichen Einführung in den diesbezüglichen Analyserahmen (unter I.) die „Rechtsordnung“ der EMRK und insbesondere die Grundbestimmungen der Rechtsprechung des EGMR in Bezug auf Verfahrensfairness, beweisbezogene Verteidigungsgarantien und das Prinzip der ,adversarial proceedings“ untersucht (unter II.). Die daraus gewonnenen Erkenntnisse werden weiterhin mit Blick auf die Möglichkeit der Entwicklung von systemübergreifenden normativen beweisprozessualen und prozessstrukturellen Dynamiken bewertet. Der letzte Abschnitt (unter III.) des dritten Teils und somit der ganzen Forschungsarbeit beschäftigt sich mit den Grundaspekten des Beweisführungssystems des IStGH. Im Fokus stehen insbesondere die Problematik der Zielsetzung im Völkerstrafrecht und -verfahren, die beweisbezogene Vorbereitung des Hauptverfahrens sowie die maßgebenden Beweisführungsstrukturen und die in der Hauptverhandlung anzuwendenden Beweisprüfungsmethoden. Abgerundet wird auch dieser Abschnitt durch klassifizierende und wertende Betrachtungen, die sich vor allem auf die Möglichkeiten der internationalen Strafgerichtsbarkeit zur Auswahl zwischen unterschiedlichen Verfahrensmodellen sowie auf die Perspektive einer progressiven Entwicklung neuer Beweisprozesstypen beziehen. 



\section{Strafprozesssysteme und Modelle des Beweisverfahrens}

\section{Die westlichen Strafverfahrenssysteme: Einführende vergleichende und rechtshistorische Betrachtungen}

Die folgenden Analysen konzentrieren sich auf die Strukturen des streitigen Strafverfahrens und dabei besonders auf die Rolle des Richters und der zentralen Prozessbeteiligten bei den Beweisführungen, die in verschiedenen Strafrechtssystemen westlicher Prägung und unter Berücksichtigung unterschiedlicher Verfahrensmodelle für die gerichtliche Feststellung der kriminellen Schuld stattfinden. Mit dem mehrdeutigen ${ }^{1}$ Begriff „Rechtssystem“ ist hier eine klar abgegrenzte und dynamische Gesamtheit von aufeinander bezogenen wechselwirkenden normativen Vorstellungen zum sozialen Wesen sowie von entsprechenden Interpretations- und Durchsetzungsmechanismen, Justizinstitutionen und Prozessstrukturen/-weisen gemeint. ${ }^{2}$ In diesem Sinne werden in Teil 1 der vorliegenden Studie zunächst allgemein die nach der klassischen rechtsvergleichenden Lehre voneinander abgegrenzten Strafrechtssysteme angloamerikanischer und kontinentaleuropäischer Prägung (unter I.) und die in diesen Systemen bzw. für diese Systeme entwickelten (Beweis-)Verfahrensmodelle ${ }^{3}$ (unter II.) vorgestellt. Der Vergleich anhand konkreter Rechtsordnungen folgt in Teil 2 und die Untersuchung relevanter internationalrechtlicher Aspekte in Teil 3 der Studie.

1 So können z.B. nach David/Grasmann, Einführung, S. 47, unter „Rechtssystem“ eine bestimmte Einzelrechtsordnung oder auch ,bestimmte, sich gegenseitig ergänzende Normengruppen wie equity und common law, ius civile und ius gentium" verstanden werden.

2 Vgl. u.a. Barton, Am. J. Juris. 37 (1992), 291 (291-293); David/Brierley, Major Legal Systems, S. 19; Merryman/Pérez-Perdomo, Civil Law Tradition, S. 1, und Merryman, in: Cappelletti (Hrsg.), New Perspectives, S. 223-224; Raz, The Concept, S. 1-3, 168-171, 209-210. Zur „konventionellen“ (historisch-evolutionären) Einstellung i.G.z. der ,,modernen“ Betrachtung des Rechtssystems als tatsächlichen „Prozesses“ (mit interaktiven strukturellen, materiellen und kulturellen Elementen) L. Friedman, Law \& Soc'y Rev. 4 (1969), 29 (31-38). Zur Herkunft und allgemeinen sprachlichen Bedeutung des Wortes „System““ wird in Duden Herkunftswörterbuch, S. 833, Folgendes bestimmt: „Gliederung, Aufbau, Ordnungsprinzip; einheitlich geordnetes Ganzes; [...]: Das in dieser Form seit dem 18. [Jahrhundert] bezeugte Fremdwort [...] geht auf [griechisch(-lateinisch)] sýstēma, das aus mehreren Teilen zusammengesetzte und gegliederte Ganze` zurück. Dies gehört zu [griechisch] synistánai ,zusammenstellen, -fügen, vereinigen, verknüpfen“ [...]." Siehe auch Dieckmann, Einführung, S. 190-191.

${ }^{3}$ Mehr zum Begriff und zur Anwendung von Modellen im Strafverfahren unter Teil 1, II.B. 
Die rechtsvergleichende und wertende Auseinandersetzung mit solchen nationalen und internationalen Rechtssystemen(-einheiten) und die Ermittlung der Konvergenzen und Divergenzen zwischen diversen Straf- und Beweisverfahrenstypen, der Rolle deren Hauptakteuren und der entsprechenden Prozesseinrichtungen bedürfen logischerweise zuerst einer Betrachtung der jeweiligen Systemhintergründe. Insbesondere sind dabei die historischen ${ }^{4}$ und theoretischen Grundlagen des Strafprozesses im Westen zu beachten. ${ }^{5}$ Ausgangspunkt einer derartigen Analyse kann nun eine erste „Bekanntschaft“ mit den theoretischen Konzeptionen sein, die sämtliche Rechte der Welt einem allgemeineren Vergleichsrahmen einzuordnen versuchen. In diesem Rahmen sollen die einzelnen Rechtsordnungen größere Gruppenkonstruktionen repräsentieren und auf der Makroebene schematisch gegenübergestellt werden. ${ }^{6}$

\section{A. Rechtskreise, Rechtstraditionen und ihre Bedeutung für die Rechtsvergleichung}

\section{Einteilung der Rechtsordnungen in Rechtskreise und Rechtsfamilien}

Der Versuch einer Einordnung der einzelnen verschiedenen Rechte in größere Rechtsordnungsgruppen, die oft als Rechtskreise oder Rechtsfamilien bezeichnet ${ }^{7}$ werden und sich wesentlich voneinander unterscheiden, sowie die Frage nach

4 Vgl. Koch, FS für Frisch, S. 1498-1499: „Ohne Kenntnis ihrer Entstehungsgeschichte und ihrer geisteshistorischen Wurzeln lassen sich weder ausländische Normenkomplexe noch die ihnen zu Grunde liegenden kulturgeschichtlichen Hintergründe begreifen.“

5 Vgl. Chloros, Cambrian L. Rev. 9 (1978), 11 (11).

${ }^{6}$ Nach Zweigert/Kötz, Einführung, S. 62, geht es hier um eine theoretische „Ordnungsaufgabe".

7 Nach David/Grasmann, Einführung, S. 47, handelt es sich hierbei um Ordnungsbegriffe, unter denen Prototypen darzustellen sind, auf die sich die verschiedenen Rechte zurückführen lassen. Es ist umstritten, ob beide Begriffe (Rechtskreis und Rechtsfamilie) überhaupt denselben Inhalt haben oder ob doch eine Rangordnung der Gruppierungen existiert, mehr hierzu Constantinesco, Rechtsvergleichung III, S. 74-79. So scheinen z.B. Zweigert/Kötz, Einführung, S. 62, in ihrem auf das Gebiet des Privatrechts begrenzten Werk Rechtsfamilien und Rechtskreise als ,wenige große Gruppen“ von Rechtsordnungen gleichzusetzen. Ausdrücklich unterscheidet Constantinesco, Rechtsvergleichung III, S. 129, 74-79, zwischen Rechtskreisen (von Rechtsordnungen mit grundlegenden Ähnlichkeiten) und Rechtsfamilien (als untergeordnete Zwischenkategorie), die sich anhand von sekundären Merkmalen innerhalb dieser Rechtskreise bilden lassen (z.B. romanische, germanische und nordische Rechtsfamilie innerhalb des kontinentaleuropäischen Rechtskreises i.G.z. der Einteilung von Zweigert/Kötz, siehe oben, S. 73, in den romanischen, deutschen und nordischen Rechtskreis). In diesem Sinne auch Höffe, FS für Hassemer, S. 58. Schließlich zeigen die Ausführungen von de Cruz, Comparative Law, S. 32-37, dass in der angloamerikanischen Literatur die Hauptgruppen von Rechtsordnungen meist legal families, manchmal auch legal traditions oder sogar legal systems genannt werden (aber dann mit verwirrenden Komplikationen, vgl. dazu David/Grasmann, Einführung, S. 47). 
Gruppierungs- und Einordnungskriterien (Verwandtschaftsfaktoren) stellen gemeinhin einen wichtigen Gegenstand der rechtsvergleichenden Lehre dar. ${ }^{8}$ Solche allgemeinen Fragen können zwar in der vorliegenden Forschungsarbeit nicht selbstständig analysiert werden. Die Grundgedanken und Schematisierungsvorschläge von hervorragenden, schon wegen ihrer Ausrichtungsvielfalt aber nicht unumstrittenen, ${ }^{9}$ theoretischen Forschungen an dieser Stelle aufzugreifen, dient jedoch nicht allein der besseren Veranschaulichung. Diese einführende Beschreibung der (modernen) Gruppierungsversuche und ihrer Schwierigkeiten lässt nämlich bereits manche der konkreteren Probleme der Untersuchung erkennen, wie sie die Beziehung zwischen Rechtstraditionen, entsprechenden Strafverfahrenssystemen und Beweismodellen betreffen. ${ }^{10}$

\section{a) Einteilungskriterien}

Es wurden, meist in der modernen auf das Privatrecht bezogenen Rechtsvergleichungslehre, ${ }^{11}$ verschiedene Kriterien für die theoretische Klassifizierung der

8 Dazu Zweigert/Kötz, Einführung, S. 62.

9 Vgl. Constantinesco, Rechtsvergleichung III, S. 465, und Zweigert/Kötz, Einführung, S. 72-73. Jung, JuS 1998, 1 (3) bemerkt, dass die Aussagekraft der verschiedenen Versuche zur Einteilung der Rechtsordnungen in Rechtskreise ,im Hinblick darauf, daß die zugrunde liegende schematisierende Betrachtungsweise Trennendes überbetont, nicht überbewertet werden [sollte]. Auch sind die Kriterien der Aufteilung nicht konsistent."

${ }^{10} \mathrm{Vgl}$. zu den Eigenschaften und Funktionen der Rechtskreise Constantinesco, Rechtsvergleichung III, S. 461-465. Nach David/Brierley, Major Legal Systems, S. 21: „The idea of a 'legal family' does not correspond to a biological reality: it is no more than a didactic device. We are attempting no more than to underscore the similarities and differences of the various legal systems - and, in that light, almost any systematic classification would serve the purpose. The matter turns upon the context in which one is placed and the aim in mind. The suitability of any classification will depend upon whether the perspective is world-wide or regional, or whether attention is given to public, private or criminal law. Each approach can undoubtedly be justified from the point of view of the person proposing it and none can, in the end, be recognised as exclusive." Vgl. auch van Hoecke/Warrington, ICLQ 47 (1998), 495 (536).

11 Von David/Grasmann, Einführung, S. 48, wird zunächst eine Einteilung der Rechtsordnungen in Rechtsfamilien aus privatrechtlicher Sicht empfohlen, denn das Privatrecht hat „mehr als jede andere Rechtsdisziplin mit stilbildenden Elementen die sämtlichen Zweige der einzelnen Rechtsordnungen durchdrungen und geprägt [...]. Aus der Sicht des Strafrechts allerdings wird sich wohl die nach den Institutionen des Privatrechts getroffene Einteilung eher bestätigen lassen, was wohl aus der engeren historischen und wissenschaftsmethodologischen Verwandtschaft der beiden dogmatischen Disziplinen zu erklären sein mag." Constantinesco, Rechtsvergleichung III, S. 160-166, warnt vor der Gefahr der Relativität und Unvollständigkeit bei Klassifizierungen, die auf der Grundlage eines einzigen Rechtsgebietes (wie z.B. des Privatrechts) und ohne Berücksichtigung der Rechtsordnungen als ganze erfasst sind. Diesbezüglich sprechen Zweigert/Kötz, Einführung, S. 6466, von dem „Grundsatz der materiebezogenen Relativität“ sowie dem „Grundsatz der zeitlichen Relativität“ (d.h. Einteilung in Rechtskreise und Zuordnung dazu sind von der historischen Entwicklung abhängig) in der Lehre der Rechtskreise. Siehe auch die Ausführungen von Bell, CLP 48 (1995), $63(64,66)$. 
Rechtskreise und Rechtsfamilien sowie für die entsprechende Einteilung der Rechtsordnungen vorgeschlagen. Diese Kriterien sind insbesondere historischer, geografischer, ethnischer und neuerdings typologischer, also rechtstechnischer und -struktureller (z.B. mit Blick auf die herrschenden Rechtsauffassungen, Rechtsquellen, Begriffe und Justizeinrichtungen) oder auch ideologischer (politischer, kultureller, religiöser, ökonomischer, sozial-ethischer) Natur. ${ }^{12}$ So sind beispielsweise Arminjon, Nolde und Wolff in Bezug auf das Gebiet des Privatrechts der Ansicht, dass die Klassifizierung der Rechtsordnungen in ähnlicher Weise wie die genealogische Klassifizierung seitens der Sprachwissenschaftler und unter Berücksichtigung der Originalität, der Abstammung und der Ähnlichkeiten der Rechte stattfinden soll. ${ }^{13}$ Für David sollte sich die Rechtskreiseinteilung hauptsächlich an ideologischen (weltanschaulichen, politischen und wirtschaftlichen) sowie rechtstechnischen Faktoren, insbesondere unter Berücksichtigung der juristischen Denkweise und der vorhandenen Rechtsquellen, orientieren. ${ }^{14}$ Nach Meinung von Constantinesco sind „determinierte und dadurch charakteristische Elemente“ für die Einteilung der Rechtsordnungen in Rechtskreise u.a. die Auffassung vom Recht, die Ideologie, die Rechtsquellen und die Wirtschaftsverfassung. ${ }^{15}$

Ferner befürworten Zweigert und Kötz im Rahmen der Rechtsstiltheorie folgende „stilprägende Faktoren“ zur Rechtskreiseinteilung: die historische Herkunft und Entwicklung einer Rechtsordnung; die juristische Denkweise (z.B. abstrakte Normierung versus Fallrecht), die besonders kennzeichnenden Rechtsinstitute (z.B. die Eigenheiten des Beweisrechts), die Art der Rechtsquellen und ihre Auslegung (,precedent-Lehre“ versus „statutory construction“) sowie ideologische Faktoren (,,also die von einer Religion oder einer politischen Idee geprägten Vorstellungen über die richtige Ordnung des sozialen und politischen Lebens" $).{ }^{16}$ Darüber hinaus ist als abschließendes Beispiel die von van Hoecke und Warrington vertretene Theorie des ,Rechts als Kultur“ zu erwähnen. Dabei sind für die Unterscheidung zwischen Rechtsfamilien innerhalb der - von den Autoren als Ausgangspunkt jeder Rechtsvergleichung vorgeschlagenen - vier großen (afrikanischen, asiatischen,

12 Für mehr Details und Verweise Zweigert/Kötz, Einführung, S. 63-64. Analytisch zu der Unterscheidung zwischen älteren und modernen Klassifizierungsversuchen und zu den jeweils vorgeschlagenen Kriterien Constantinesco, Rechtsvergleichung III, S. 88-157, 167. Früher schon Arminjon/Nolde/Wolff, Traité de droit comparé, S. 42-47. Zusammenfassend auch Husa, in: Smits (Hrsg.), Elgar Encyclopedia, S. 491-494. Mehr zur „Ideologie“ als typologisches Kriterium der Gruppierungsversuche schon Constantinesco, ZfRV 19 (1978), 161 (161-172).

13 Arminjon/Nolde/Wolff, Traité de droit comparé, S. 47-48; kritisch Constantinesco, Rechtsvergleichung III, S. 104-109.

14 David/Grasmann, Einführung, S. 50-55, und David/Brierley, Major Legal Systems, S. 20-21. Detaillierter zu den verschiedenen Ausprägungen von Davids Klassifizierungstheorie, Constantinesco, Rechtsvergleichung III, S. 115-122.

15 Constantinesco, Rechtsvergleichung III, S. 162 und ausführlich S. 269-431.

16 Zweigert/Kötz, Einführung, S. 67-73. Vgl. auch die Analyse von de Cruz, Comparative Law, S. 37-43. 
islamischen und westlichen) Kulturfamiliengruppen folgende ,paradigmatischen Elemente“ zu nennen: die allgemeinen Rechtsvorstellungen, die Theorie der geltenden Rechtsquellen, die Rechtsmethodologie, die Theorie der Argumentation, die Theorie der Legitimation des Rechtes, und vor allem die allgemein akzeptierten, grundlegenden ideologischen Werte und Prinzipien. ${ }^{17}$

\section{b) Einordnung der Rechte}

Anhand derartiger Kriterien und Theorien lassen sich auch die konkreten Gruppierungsvorschläge schematisieren. Die Befürworter der für die jeweilige historische ${ }^{18}$ Periode typischen Klassifizierungen haben in diesem Sinne auf verschiedene Weise versucht, die Rechtsordnungen in wenige oder mehrere Gruppen einzuteilen. Weite Verbreitung erlangt hat die Einteilung von Zweigert und Kötz: Diese unterscheidet zwischen dem romanischen (Frankreich und die Rechte des französischen Code civil), dem deutschen (Deutschland, Österreich, die Schweiz und Tochterrechte), dem nordischen, dem angloamerikanischen, dem fernöstlichen (China, Japan) und dem religiös geprägten (Islam, Hindu-Recht) Rechtskreis. ${ }^{19}$ David spricht dagegen von einer Einteilung in den kontinentaleuropäischen (römisch-germanischen) Rechtskreis (oder Romano-Germanic family), den angloamerikanischen Rechtskreis (oder Common law family), die sozialistische Rechtsfamilie (oder family of Socialist laws) und die Rechte des Fernen Ostens, Indiens, des Islam, Afrikas und Madagaskars (other systems). ${ }^{20}$ Weitere Ansichten teilen schließlich die Rechtsordnungen und -systeme in Hauptrechtsfamilien (main/parent legal families) ein, etwa nach civil law (z.B. Frankreich, Deutschland, Schweiz, Österreich, Italien), common law (z.B. England und Wales, USA, Australien, Kanada), socialist law und mixed/hybrid jurisdictions (z.B. Südafrika, Philippinen). ${ }^{21}$

17 Van Hoecke/Warrington, ICLQ 47 (1998), 495 (insb. 498, 502, 513-516, 519-522, 532-536). Nach dieser Ansicht besteht eine „Rechtsfamilie“ aus Rechtssystemen, die im Grunde die gleichen (oder ähnliche) Vorstellungen bezüglich jedes der sechs paradigmatischen Punkte teilen (S. 520).

18 Zur historischen Relativität der Klassifizierung der Rechtsordnungen Constantinesco, Rechtsvergleichung III, S. 521-522.

19 Zweigert/Kötz, Einführung, S. 68-73 (und ausführlich S. 73-313), unter Berücksichtigung auch der sogenannten ,hybriden Rechtssysteme“ (S. 72), die nicht einem einzigen Rechtskreis zugeordnet werden können. Darüber hinaus wird die sozialistische Rechtsfamilie in dieser dritten Auflage des Werkes von Zweigert/Kötz infolge der historischen Entwicklungen nicht mehr anerkannt. Ähnlich auch die schon vorher bestehende Klassifizierung von Arminjon/Nolde/Wolff, Traité de droit comparé, S. 49-53, in die französische, germanische, skandinavische, englische, russische, islamische und hinduistische Familiengruppe (familles de systèmes juridiques).

20 David/Grasmann, Einführung, S. 55-78 (und ausführlich S. 81-658); David/Brierley, Major Legal Systems, S. 22-31; siehe auch Ehrmann, Comparative Legal Cultures, S. 13-19.

21 Z.B. de Cruz, Comparative Law, S. 32-37. Zur mixed-jurisdiction family als selbstständige ,dritte Rechtsfamilie“, in der sich Elemente vor allem des common law (anglo- 
Darüber hinaus werden auch im strafrechtlichen Bereich moderne Klassifizierungsversuche wie diejenigen von Zweigert und Kötz oder von David zunächst als vertrauenswürdig angesehen und meistens als ein allgemeiner, aber keinesfalls absoluter erster Ansatz für die konkreteren Rechtsvergleichungsvorgänge betrachtet. Solche Betrachtungen, die häufig die weltweit unterschiedlichen (Verfahrens-)Strukturen in das Zentrum der Strafrechtsvergleichung stellen, berücksichtigen normalerweise primär die Unterscheidung zwischen westlichen Rechtsordnungen und insbesondere zwischen angloamerikanischen und kontinentaleuropäischen Rechten. ${ }^{22}$

So unterscheidet etwa auch Jescheck bei der Abgrenzung von größeren Territorien, die für die Vorbereitung und Durchführung von strafrechtsvergleichenden Arbeiten in Betracht kommen, zwischen folgenden Rechtskreisen: dem deutschen (einschließlich Österreich und der Schweiz), dem romanischen (vor allem Frankreich, Italien, Spanien, Belgien, den Niederlanden), dem angelsächsischen (jedenfalls England und den USA), dem skandinavischen (insbesondere Schweden und Finnland), dem sozialistischen und dem ostasiatischen (grundsätzlich Japan). Jeschecks historische Beschreibung des Verhältnisses zwischen Strafrechtsvergleichung und liberalen Strafprozessreformen seit dem 19. Jahrhundert richtet den Blick grundsätzlich auf die enge Verwandtschaft des reformierten deutschen Strafverfahrens mit dem französischen Strafprozess der post-revolutionären Zeit sowie auf den (bis dahin) begrenzten Einfluss des angloamerikanischen Rechts auf dem europäischen Kontinent. ${ }^{23}$

amerikanisches System) und des civil law (römisch-germanisches System) kombinieren lassen, Palmer, in: ders. (Hrsg.), Mixed Jurisdictions, S. 7-15; ferner zur Theorie der mixed legal systems Palmer, in: Bussani/Mattei (Hrsg.), Comparative, S. 368-383. Nach Meinung von van Hoecke/Warrington, ICLQ 47 (1998), 495 (498, 502), ist die Theorie der Rechtsfamilien nun durch die geschichtlichen Entwicklungen überholt worden, und der neue Ansatz für die Feststellung des allgemeinen Rahmens der Rechtsvergleichung muss der anthropologische oder soziologische sein: Dieser orientiert sich nicht mehr an der Unterscheidung zwischen Rechtsfamilien, sondern zwischen Rechtskulturen (legal cultures) bzw. Kulturfamilien (cultural families) wie der afrikanischen, der asiatischen, der islamischen und der westlichen (Europe, America, Oceania). Zu den „Kulturkreisen“ schon Schnitzer, Vergleichende Rechtslehre, S. 138-142 (der auch die Einteilung in Rechtskreise der primitiven Völker, der antiken Kulturvölker, der euro-amerikanischen Rechte, der religiösen Rechte und der afro-asiatischen Völker behandelt), und kritisch dazu Schroeder, ZStW 86 (1974), 783 (799-800). Für weitere Ausführungen zu den (alten und modernen) Klassifizierungsversuchen auch Husa, in: Smits (Hrsg.), Elgar Encyclopedia, S. 494-498, und Sacco, Einführung, S. 173-181.

22 So Jung, JuS 1998, 1 (3); auch Nijboer, Comparative Criminal Law, S. 33-36, und Nijboer, in: Nijboer/Sprangers (Hrsg.), Harmonisation, S. 406-407; außerdem Schultz, in: Jescheck/Kaiser (Hrsg.), Vergleichung als Methode, S. 16, und Weigend, in: Smits (Hrsg.), Elgar Encyclopedia, S. 267, 271-272. Vgl. schon Jescheck, Strafrechtsvergleichung, S. 37. Siehe auch Cole/Frankowski/Gertz, in: dies. (Hrsg.), Criminal Justice Systems, S. 23-26, und Courakis, GA 1981, 533 (534-536). Kritisch zur Übernahme solcher Klassifizierungen im Rahmen strafrechtlicher Studien Vogler, A World View, S. 3-5.

23 Jescheck, ZStW 86 (1974), 761 (771-772, 765-771); siehe auch dazu Jung, in: ders. (Hrsg.), Der Strafprozeß, S. 2-3; vgl. auch Nijboer, in: Nijboer/Sprangers (Hrsg.), Harmonisation, S. 7-8. 
Schließlich setzen sich auch die strafrechtsvergleichenden Sortierungstheorien angelsächsischer Herkunft mit der Trennung zwischen übergeordneten Rechtsordnungsgruppen auseinander. Solche Trennungen beziehen sich meistens auf die Unterscheidung zwischen westlichen und nicht-westlichen Justizsystemen sowie sehr oft im Hinblick auf die herrschenden Strafverfahrensformen - zwischen den angloamerikanischen und kontinentaleuropäischen Rechten. Häufig ist dabei die Rede von civil law (Romano-Germanic), common law, Islamic law, socialist law und mixed Rechtsfamilien, -modellen oder -kulturen. ${ }^{24}$

\section{Einteilung in Rechtstraditionen}

Ungeachtet der terminologischen Differenzierungen bei der vorgeschlagenen Einteilung der Rechtsordnungen in „Familien“-, „Kreis“- oder „Kulturgruppen“ wird durch die bisherigen Ausführungen vor allem Folgendes deutlich: Der offensichtlich relative Charakter der Klassifizierungstheorien knüpft grundsätzlich an die tatsächliche Schwierigkeit der rechtsvergleichenden Lehre an, zu einem einheitlichen Ergebnis bezüglich der Anzahl der wenigen großen Rechtsordnungsgruppen, die überhaupt erfassbar sind, zu kommen sowie die (charakteristischen) Rechtsordnungen auszuwählen, die in diese Gruppen einzuordnen sind. Gründe dafür, und zugleich Ansätze für die Vermeidung einer eventuellen „Rechtsfamilien-Falle“25, sind hauptsächlich die Vielfalt der vorgeschlagenen Einordnungskriterien, die sich nach Sicht und Stand des jeweiligen Betrachters immer wieder unterscheiden, sowie die Durchführung der Klassifizierungsarbeiten meistens nur auf der Grundlage von bestimmten Rechtsgebieten. ${ }^{26}$

Außerdem müssen zusätzlich folgende Punkte berücksichtigt werden: die Relevanz von zeitlichen und historischen Faktoren bei der Betrachtung der Rechtsordnungen i.V.m. der dynamischen kontinuierlichen Entwicklung der Rechte, der primär westliche bzw. eurozentrische Blickwinkel der kategorisierenden Lehre, die verbreitete Ansicht über die Existenz von sui generis-, gemischten und hybriden Rechtsordnungen sowie die empirische Annahme, dass es ,in der modernen Welt keine reinen Justizsysteme gibt, die ohne äußeren Einfluss gebildet und entwickelt wurden. “27 Solche Feststellungen sprechen nun dagegen, den vorerwähnten Klassifizierungen absolute Aussagekraft bei der Gesamtbetrachtung der Rechtsordnungen

${ }^{24}$ U.a. Dammer/Albanese, Comparative, S. 44-63; Deflem/Swygart, in: DuPontMorales u.a. (Hrsg.), Handbook, S. 53-54; Reichel, Comparative Criminal Justice, S. 80113; Roberson/Das, Comparative Legal Models, S. 8-19; vgl. außerdem Spencer, in: Delmas-Marty/Spencer (Hrsg.), European Criminal Procedures, S. 3-5.

25 A. Harding, ICLQ 51 (2002), 35 (49).

26 Ausführlich i.Z.m. weiteren „Gründen des Mißlingens“ Constantinesco, Rechtsvergleichung III, S. 157-169.

27 Arminjon/Nolde/Wolff, Traité de droit comparé, S. 49; vgl. auch Örücü, in: Örücü/ Nelken (Hrsg.), Comparative Law, S. 177. 
und bei der Darstellung des vorexegetischen Rahmens für weitere rechtsvergleichende Forschungen zuzubilligen. ${ }^{28}$

Diese einleitenden Ausführungen zur Theorie der Rechtskreise und Rechtsfamilien sind dennoch von gewissem Wert. Denn in der Tat bieten solche schematischen prima facie-Sortierungen und insbesondere die kombinierte Wahrnehmung der vorgeschlagenen Gruppierungskriterien für die Erforschung konkreter (Straf-) Rechtssysteme den Ansatz für die ersten Schritte detaillierterer rechtsvergleichender Analysen. ${ }^{29}$ So wird auch die Ansicht vertreten, dass ,,die tatsächlichen, ideologischen und historischen Besonderheiten alle so zusammengefasst werden [können], um eine Blaupause für den Vergleich zu formulieren“. ${ }^{30}$ Vor allem besteht aber dadurch die Möglichkeit, aus einer Vielfalt von vorgebrachten Differenzierungsfaktoren auszuwählen. In die (einleitenden) Untersuchungen sind dann diejenigen Faktoren einzubeziehen, die je nach Zielsetzung und Betrachtungsweise des Forschers für seinen Beitrag zur Überprüfung von Hypothesen, Vorurteilen und Verallgemeinerungen bezüglich konkret ausgewählter Fragen zur Beziehung zwischen Rechtsordnungen bzw. Rechtssystemen besonders dienlich sind. ${ }^{31}$

In der vorliegenden Studie bieten dementsprechend die Ursprünge, die anerkannten Hauptmerkmale sowie die grundsätzlichen Rechtskonzeptionen und Justizstrukturen verschiedener (Straf-)Rechtstraditionen den erforderlichen Hintergrundansatz für die konkrete vergleichende Auseinandersetzung mit heutigen übergreifenden Strafprozessarten und Beweisverfahrensmodellen. ${ }^{32}$ Unter dem Begriff ,Rechtstradition ${ }^{\text {"33 }}$ ist dabei nicht unbedingt eine ,eingefrorene und statische Vergangenheit", sondern vielmehr ,ein vitales, dynamisches, laufendes System “34 zu verstehen. Genauer geht es hier um ein gemeinsames, tief verwurzeltes Verständnis des Normen- und Justizsystems, das in seinen Grundzügen beibehalten und weitergegeben

${ }^{28}$ Mehr dazu de Cruz, Comparative Law, S. 33-37; Jung, JuS 1998, 1 (3-4); Örücü, in: Örücü/Nelken (Hrsg.), Comparative Law, S. 170; Schlesinger/Baade/Herzog/Wise, Comparative Law, S. 283-284; Vogler, A World View, S. 4; Zweigert/Kötz, Einführung, S. 6467, 71-73. Nijboer, Comparative Criminal Law, S. 36, bemerkt: „It is my belief that one should be careful when referring to legal families. One should see them as concepts that show the development and structure of codification etcetera, rather than be an all inclusive explanation and description of an entire legal system. It is perhaps preferable that one sees the categorisation into legal families as being explanatory in a retrospective context: it says something about the origins of rules, doctrines and legal concepts."

${ }^{29}$ Husa, in: Smits (Hrsg.), Elgar Encyclopedia, S. 493-494; siehe auch Schlesinger/ Baade/Herzog/Wise, Comparative Law, S. 284-285.

30 De Cruz, Comparative Law, S. 37.

31 Vgl. van Hoecke/Warrington, ICLQ 47 (1998), 495 (497).

32 Vgl. Jung, JuS 1998, 1 (3).

33 Zur Herkunft und allgemeinen sprachlichen Bedeutung des Wortes „Tradition“ schreibt Duden Herkunftswörterbuch, S. 858: „Überlieferung, Herkommen; Brauch, Gepflogenheit: Das Fremdwort wurde im 16. [Jahrhundert] aus [lateinisch] traditio ,Übergabe; UUberlieferung' entlehnt. Dies gehört zu [lateinisch] tradere [...].“

34 Glendon/Carozza/Picker, Comparative Legal Traditions, S. 14. 
wird; dies betrifft unter anderem die juristische Denkweise sowie die vorhandenen primären Rechtsquellen und Justizinstitutionen i.V.m. rechtspolitischen, -soziologischen und -kulturellen Vorstellungen. Eine gemeinsame Grundhaltung zum Recht erlaubt es, verschiedene Rechtsordnungen, trotz deutlicher Unterschiede und partieller Fortentwicklungen, insgesamt als eine homogene Kategorie von Rechten (i.G.z. anderen Kategorien mit wesentlich unterschiedlichen Rechtsvorstellungen) zu betrachten. ${ }^{35}$

Ein solches, in Rechtslehre und Praxis weitgehend anerkanntes Paar von unterschiedlichen bzw. gegensätzlichen Rechtstraditionen, die auch heute noch einen erheblichen Einfluss auf (nicht nur) westliche Rechtssysteme haben, bilden die angloamerikanische (oft als common law bezeichnete) und die kontinentaleuropäische (auch als civil law bekannte) Rechtstradition. ${ }^{36}$ Insbesondere die strafprozessualen Charakteristika dieses Paares stellen einen Anknüpfungspunkt für die vorliegende Arbeit dar und sollen im Weiteren ausführlicher untersucht werden.

\section{B. Angloamerikanische und kontinentaleuropäische Rechtstradition}

Die insbesondere in der strafprozessualen Lehre ${ }^{37}$ weitverbreitete Gegenüberstellung von angloamerikanischen und kontinentaleuropäischen Rechten spiegelt sich auch im Kern der vorliegenden Arbeit wider. Die bisherigen Ausführungen haben allerdings bereits gezeigt, dass jeder theoretische Versuch der Unterteilung in übergeordnete Gruppen und die Zuordnung der Rechtsordnungen in diese Gruppen lediglich von relativer Natur sein können. Derartige Kategorisierungen sind nämlich nicht viel mehr als die (mit unterschiedlichen Kriterien und unter verschiedenen Gesichtspunkten begründete) Ansicht des jeweiligen Betrachters bezüg-

35 Vgl. Merryman/Pérez-Perdomo, Civil Law Tradition, S. 2: „A legal tradition [...] is a set of deeply rooted, historically conditioned attitudes about the nature of law, about the role of law in the society and the polity, about the proper organization and operation of a legal system, and about the way law is or should be made, applied, studied, perfected, and taught. The legal tradition relates the legal system to the culture of which it is a partial expression. It puts the legal system into cultural perspective." Vgl. auch Krygier, Law and Philosophy 5 (1986), 237 (240, 251-254). Bell, CLP 48 (1995), 63 (69), versteht eine solche Tradition als: ,[...] a complex of rules, concepts, institutions and practices which characterise the way the law works in a particular area. These features build together into a process. In short, a tradition is a way of doing things, which is handed down and shapes the way in which the law operates.“ Glenn, S.C.L.R. 49 (2010), 601 (619, 609), meint: „These traditions should not be seen as reified categories within which national structures must be taxonomically classified, but as ongoing normative statements [...]"; siehe auch Glenn, Queen's L.J. 34 (2008-2009), 427 (insb. 427, 430-433, 435-438).

${ }^{36}$ Mehr dazu Merryman/Pérez-Perdomo, Civil Law Tradition, S. 2-5; vgl. auch Merryman, in: Cappelletti (Hrsg.), New Perspectives, S. 195-197; Rheinstein, Einführung, S. 77-82; Schlesinger/Baade/Herzog/Wise, Comparative Law, S. 285-287.

37 Vgl. auch Weigend, FS für Rissing-van Saan, S. 755. 
lich der „Topografie“ der Rechtswelt. Charakteristisch ist dabei die privatrechtsbezogene Betrachtung von Zweigert und Kötz, die - im Gegensatz zu vielen anderen Klassifizierungen - nicht alle Rechte der Länder Kontinentaleuropas in dieselbe Gruppe einordnet; sie unterscheidet vielmehr zwischen deutschem und romanischem Rechtskreis und stellt diese Rechtskreise dann dem angloamerikanischen Rechtskreis gegenüber. ${ }^{38}$

Darüber hinaus verschwimmen in der Gegenwart die Grenzen zwischen früher allgemein anerkannten Rechtsfamilien, und verschiedene Rechtsordnungsgruppen zeigen im historischen Verlauf ähnliche Merkmale und wechselseitige Einflüsse. Durch kontinuierliche Rechts- und Strukturtransplantationen haben sich teilweise große Ähnlichkeiten zwischen einzelnen Rechtsordnungen verschiedener anerkannter Gruppen entwickelt. Dies heißt aber nicht, dass die einzelnen Rechtsordnungen sich in ihren „Rechtsmotiven“ nicht mehr voneinander unterscheiden; sogar innerhalb derselben Gruppe oder Familie finden sich Differenzierungen. ${ }^{39}$

Dementsprechend sollten die Trennungen und Hintergrunderklärungen auf der Basis einer (oft eindimensional angewandten) Theorie der Rechtstraditionen oder einer Rechtskulturtheorie ${ }^{40}$ nicht überbewertet werden. ${ }^{41}$ Dennoch dominieren in

38 Zweigert/Kötz, Einführung, S. 68-69, 73. Skeptisch z.B. Schnitzer, Vergleichende Rechtslehre, S. 139-140. Schroeder, ZStW 86 (1974), 783 (802), bemerkt: „Im Strafrecht rücken der romanische und der deutsche Rechtskreis viel eher zu einem kontinentaleuropäischen Rechtskreis zusammen als im Privatrecht."

$39 \mathrm{Vgl}$. z.B. für die verschiedenen Rechtsquellen als ,determinierte“ Elemente der Rechtskreise Constantinesco, Rechtsvergleichung III, S. 411-417; auch dazu Ehrmann, Comparative Legal Cultures, S. 21-32.

40 Bell, CLP 48 (1995), 63 (64, 70), versteht eine solche Kultur als: „,configuration of values, concepts, practices and institutions through which individuals interpret and apply legal norms. [...] The practice of the tradition in the contemporary world is what defines a legal culture. [...] A legal culture involves a specific way in which values, practices, and concepts are integrated into the operation of legal institutions and the interpretation of legal texts." Vgl. auch Merryman/Pérez-Perdomo, Civil Law Tradition, S. 2; Merryman, in: Cappelletti (Hrsg.), New Perspectives, S. 225. Mehrmals dazu der Rechtssoziologe $L$. Friedman, Law \& Soc'y Rev. 4 (1969), 29 (34); ergänzend L. Friedman, Republic of Choice, S. 213; L. Friedman, in: Clark (Hrsg.), Comparative, S. 53; L. Friedman, in: Nelken (Hrsg.), Comparing Legal Cultures, S. 34-35. I.G.z. „legal culture“ schlägt Cotterrell, in: Nelken (Hrsg.), Comparing Legal Cultures, S. 21-30, das Konzept der „legal ideology““ vor. Ebenfalls zur Idee der Rechtskultur Ehrmann, Comparative Legal Cultures, S. 6-13, und Hörnle, ZStW 117 (2005), 801 (802), die meint, dass „kulturelle Faktoren“ lediglich als Oberbegriff anzuführen sind, ,der in historische, politische, geistesgeschichtliche und sozialpsychologische Faktoren aufzulösen ist". Vgl. außerdem die Definitionen und Verweise bei Legrand, MLR 58 (1995), 262 (263-264) (,Although groups and identities are necessarily fluid, the legal culture remains the cement that binds normality and normativity“); Nelken, in: Örücü/Nelken (Hrsg.), Comparative Law, S. 109-128. Siehe auch Brants, in: Nelken (Hrsg.), Comparative, S. 51-53; Jung, FS für Frisch, S. 1472-1473. Eingehend mit weiteren Verweisen zur Problematik der Rechtskulturen und zum Verständnis des Rechts als Kultur van Hoecke/Warrington, ICLQ 47 (1998), 495 (insb. 498-516, 532536). Zu den „Strafrechtskulturen“, zur „Transkulturalität“ und zu den „Rechtstransplanta- 
der rechtsvergleichenden Literatur und der rechtspolitischen Debatte immer noch deutlich die traditionellen Gegenpaare der großen Rechtsordnungsgruppen. Bezugspunkt sind hier nicht vereinzelte Regulierungsentwicklungen zweitrangiger Bedeutung, sondern fundamentale ,stilprägende“ Elemente, etwa das allgemeine prozessuale Rechtsdenken ${ }^{42}$ i.V.m. rechtssoziologischen und rechtskulturellen Wertungen, die über lange Zeit innerhalb eines weiten Kreises von Rechtsordnungseinheiten präsent sind. Es geht hierbei im Grundsatz um die Antithese von „westlichen“" und „nicht westlichen“ (vor allem sittlich-traditionellen und religiös geprägten) Rechten und, innerhalb der ,westlichen Welt“, von Rechten angloamerikanischer und kontinentaleuropäischer Prägung. ${ }^{43}$

\section{Rechtstraditionen in der,, westlichen Rechtswelt"6}

\section{a) Zur Vergleichbarkeit unterschiedlicher Rechtswelten}

Ungeachtet der zunehmenden Konvergenz und Interaktion der Rechtssysteme existieren weiterhin erhebliche Unterschiede zwischen den „westlichen“ und etwa den islamischen oder traditionellen afrikanischen Rechtswelten. Sie betreffen vor allem den Bereich der elementaren Sozialvorstellungen und Rechtsgrundlagen und lassen sich beispielsweise anhand von Fragen zum Familienrecht, zu den menschenrechtlichen Religions- oder Meinungsfreiheiten und den Gleichbehandlungsrechten, zur (Un-)Wandelbarkeit ,göttlicher“ und säkularer Normen oder zur allgemeinen Bedeutung von individuellen Rechten und Rechtsstreitigkeiten für die gesellschaftliche Ordnung erläutern. ${ }^{44}$ Die Existenz solcher Divergenzen erschwert

ten“ i.V.m. den internationalen und europäischen Vorgaben des heutigen Strafrechts Vogel, GA 2010, 1 (2-13).

41 Vgl. die kurzen Ausführungen von Weigend, FS für Rissing-van Saan, S. 754-755, zur Entwicklung der Beweisverwertungsverbote im Rahmen der strafprozessualen Wahrheitssuche in Deutschland und England. Vgl. noch zur „Entwicklung der Rechtskulturen“ am Beispiel der jury trial bei Ehrmann, Comparative Legal Cultures, S. 5-6, 95-104.

42 Dazu Zweigert/Kötz, Einführung, S. 68-70. Vgl. auch Constantinesco, Rechtsvergleichung III, S. 129-130; David/Brierley, Major Legal Systems, S. 20.

${ }^{43}$ Kritisch gegen die eigentliche Tauglichkeit solcher Dichotomien in der rechtsvergleichenden Forschung u.a. Frankenberg, Harv. Int'l. L. J. 26 (1985), 411 (422).

${ }_{44} \mathrm{Zu}$ den religiösen Rechtsquellen und der Unwandelbarkeit der islamischen (Privat-) Rechte allgemein Zweigert/Kötz, Einführung, S. 296-305. Ferner zur islamischen Rechtstradition Glenn, Legal Traditions, S. 180-235; Abou El Fadl, in: Bussani/Mattei (Hrsg.), Comparative, S. 295-312; zur Rechtsgeschichte und Rechtsentwicklung Krawietz, Rechtsquellen, S. 12-86. Zur muslimischen Rechtskonzeption früher auch Afchar, in: David (Hrsg.), International Encyclopedia, S. 84-106; noch früher (grundlegend, insb. zur geschichtlichen Entwicklung) Schacht, Introduction, S. 1-111. Zum islamischen Menschenrechtsverständnis Bielefeldt, in: Elliesie (Hrsg.), Islam und Menschenrechte, S. 110-115; Kalisch, in: Elliesie (Hrsg.), Islam und Menschenrechte, S. 59-65; Naeem, in: Krawietz/ Reifeld (Hrsg.), Islam, S. 75-77. Darüber hinaus, für eine Einführung in die (traditionellen) afrikanischen Rechtssysteme M'Baye, in: David (Hrsg.), International Encyclopedia, S. 138-156. Aktueller zum Rechtspluralismus und zur Art und Weise der Rechtsent- 
es, fruchtbare Schlussfolgerungen bei der Vergleichung von Rechtsordnungen zu ziehen, die ihre Konfliktlösungssysteme und Prozessordnungen auf der Basis von substantiell unterschiedlichen ethischen und ideologischen (politischen, kulturellen, religiösen) Werten gestalten - auch wenn die Konfliktlösungssysteme selbst aus rein formeller Sicht eventuell nicht mehr verschieden sind. ${ }^{45}$

Was darüber hinaus abstrakt-theoretisch als „westliche Rechtswelt“ bezeichnet werden könnte, ist eine mehr oder weniger homogene große Gruppe von Systemen, die ihre (historischen) Wurzeln hauptsächlich im römischen oder dem teilweise davon beeinflussten englischen Recht nach der normannischen Eroberung haben: Meist sind damit die europäischen und die amerikanischen Rechtssysteme gemeint. ${ }^{46}$ Diese Systeme teilen gegenwärtig grundsätzlich ähnliche, aber sicher nicht identische ${ }^{47}$ Vorstellungen bezüglich der zugrunde liegenden Werte (demokratische Machtverteilung und Kontrolle, Herrschaft des rationalisierten Rechts, anthropozentrische und menschenrechtsorientierte Betrachtungsweise der Justiz); sie entwickeln sich in einer similären, tendenziell liberalen bzw. neoliberalen Umwelt weiter. ${ }^{48}$ Zwischen westlichen Rechtssystemen kann dann auch die wertende Ver-

wicklung am konkreten Beispiel des westafrikanischen Landes Côte d'Ivoire Kouassi, in: Sieber u.a. (Hrsg.), National Criminal Law, S. 139-141. Ferner zur Rechtstradition von Subsahara-Afrika Sacco, in: Bussani/Mattei (Hrsg.), Comparative, S. 313-343.

45 Zur Verschiedenheit der ,westlichen“ und ,nicht westlichen“ Rechtskulturen bezüglich der allgemeinen Ideen zum Recht, der Rolle des Rechts in der Gesellschaft und der Auswahl der zutreffenden Konfliktlösungen, die eine transkulturelle Vergleichung ab initio lahm legen können, van Hoecke/Warrington, ICLQ 47 (1998), 495 (502-513); auch Zweigert/Kötz, Einführung, S. 69-70. Siehe auch Schlesinger/Baade/Herzog/Wise, Comparative Law, S. 319-322. Zur wertbasierten Strafrechtsvergleichung siehe Sieber, in: Sieber/ Albrecht (Hrsg.), Strafrecht und Kriminologie, S. 112, 119-123.

46 Erläuternd dazu die kritischen Ausführungen von Monateri, Hastings L.J. 51 (19992000), 479 (484-490). Auf die verbreitete Ansicht, dass die „westliche Rechtswelt“ in geografischer Hinsicht vor allem die europäischen, amerikanischen, ozeanischen und sogar die südafrikanischen Rechtsordnungen und allgemein jedes Land einschließt, in dem die „westliche Idee“ ihren (römisch-germanischen und englischen) Ursprung hatte oder im Wege z.B. der Kolonialisierung durchgesetzt bzw. willentlich und ohne Widerstand angenommen wurde, deuteten schon die Ausführungen (auch zur Gefahr des ,kulturellen Imperialismus" solcher Betrachtungen) von Sawer, in: David (Hrsg.), International Encyclopedia, S. 14 (und noch S. 16-17, 21-28 zum Einfluss des Römischen Rechts auf das moderne "westliche Recht") hin. Vgl. noch Berman, Recht und Revolution, S. 16-17; van Hoeckel Warrington, ICLQ 47 (1998), 495 (502-503).

47 Siehe etwa Safferling, in: Streng/Kett-Straub (Hrsg.), Strafrechtsvergleichung, S. 189.

48 Vgl. dazu (mit weiteren Verweisen) u.a. Clark, in: ders. (Hrsg.), Comparative, S. 2123; David, in: ders. (Hrsg.), International Encyclopedia, S. 3-5; L. Friedman, in: Clark (Hrsg.), Comparative, S. 52; Glenn, Legal Traditions, S. 147-151; Höffe, FS für Hassemer, S. 65; Merryman, in: Cappelletti (Hrsg.), New Perspectives, S. 233; Sawer, in: David (Hrsg.), International Encyclopedia, S. 16, 45-48; van Hoecke/Warrington, ICLQ 47 (1998), 495 (503-505). In kritisch-historischer Hinsicht Berman, Recht und Revolution, S. 24-30, 65-76. Vgl. außerdem die Erklärungen in den Präambeln der Satzung des Europarates, der EMRK, der Charta der Grundrechte der EU, in der Präambel und den Art. 2, 3 des Vertrags über die EU sowie in den Präambeln des Vertrags über die Arbeitsweise der EU, der Satzung der Organisation Amerikanischer Staaten und der Amerikanischen Men- 
gleichung konsequenter und kohärenter erfolgen und im Rahmen der neuen Rechtsarchitektur der ,globalen Welt“49 ${ }^{\star 4 i n n v o l l e r ~ s e i n . ~ D i e ~ A u s w a h l ~ v o n ~ s o z i a l r e c h t-~}$ lichen Organisationsformen, von nationalen, internationalen und supranationalen Rechtsstrukturen und Einrichtungen sowie von rechtspolitischen Richtungen wird nämlich im Westen auf einen gemeinsamen Nenner gebracht: Dieser umfasst insbesondere die seit den Aufklärungsrevolutionen zentrale Stellung des aktiven Individuums in der Gesellschaft als Träger subjektiver Rechte und die weithin verkündeten individuellen Freiheiten der Neuzeit. ${ }^{50}$

\section{b) Herrschende „westliche“ Rechtstraditionen}

Innerhalb der (in vielen Aspekten nicht unbestrittenen, jedenfalls aber weitgehend anerkannten) ${ }^{51}$ großen Kategorie der ,westlichen“ Rechte korrelieren die einzelnen Rechtsordnungen mit bestimmten Rechtstraditionen, die teilweise älter als der moderne Nationalstaat sind. ${ }^{52}$ Die meisten Rechtssysteme des Westens präsentieren heute gemischte Charakteristika, sodass sich sogar auf idealtypischer ${ }^{53}$ Ebene getrennte Rechtsordnungsgruppen nicht einfach erfassen lassen. Dessen ungeachtet ist der Unterschied zwischen common law- und civil law-Tradition nicht zu übersehen. Die Differenzierung erfolgt üblicherweise in Übereinstimmung mit allgemeinen Beobachtungen und Kategorisierungen der Rechtsgesellschaft in Bezug auf die diversen historischen Wurzeln, Quellen und weiteren Hauptmerkmale des angewandten Rechtsdenkens. ${ }^{54}$ Eine undifferenzierte Gesamtbetrachtung aller

schenrechtskonvention. Kurz zur Frage einer einheitlichen Betrachtung der Menschenrechte im Westen Bielefeldt, in: Elliesie (Hrsg.), Islam und Menschenrechte, S. 99.

$49 \mathrm{Zu}$ den Herausforderungen der „rechtlichen Ordnung in einer globalen Welt“ Sieber, Rechtstheorie 41 (2010), 151 (insb. 180-198).

50 Vgl. ferner van Hoecke/Warrington, ICLQ 47 (1998), 509-510, 532-536. Zur Bindung an Jherings Idee über den „Kampf ums Recht“ als einheitliches stilprägendes Element der westlichen Prozessordnungen Zweigert/Kötz, Einführung, S. 69-70. Zum Einfluss der großen Revolutionen auf die rechtlichen Werte in den westlichen Nationalstaaten der Neuzeit Berman, Recht und Revolution, S. 57-64.

51 Neben dem Aufsatz von Monateri, Hastings L.J. 51 (1999-2000), 479 (481-555), auch zur Einheitlichkeit einer ,westlichen Rechtstradition“ Glenn, S.C.L.R. 49 (2010), 601 (601-619).

52 Glenn, S.C.L.R. 49 (2010), 601 (615-616); vgl. noch Glenn, Queen’s L.J. 34 (20082009), 427 (439-440).

53 Einführend hier zum Gebrauch des Begriffs ,ideal types“ Cotterrell, in: Nelken (Hrsg.), Comparing Legal Cultures, S. 24-25; mehr dazu unter Teil 1, II.B.1.a).

${ }_{54}$ Noch einmal dazu z.B. David/Grasmann, Einführung, S. 51-55; de Cruz, Comparative Law, S. 38-43; Zweigert/Kötz, Einführung, S. 68-71. Vgl. auch Pocar, in: Walker/ Chase (Hrsg.), Categories, S. 438: ,[...] although most of the modern legal systems have attributes of both the civil law and the common law traditions, they are usually based predominantly on one or the other". Skeptisch (aber nur zum Teil mit Nachweis), ob heute „paradigmatische Unterschiede“ zwischen common law und civil law überhaupt noch existieren, van Hoecke/Warrington, ICLQ 47 (1998), 495 (500-502). 
westlichen Rechte sowie auch Betrachtungen, die für die Eigenständigkeit jeder einzelnen Rechtsordnung sprechen und gemeinsame Einflüsse von tief verwurzelten Einstellungen vorexistierender Traditionen verneinen, können ihrerseits so kurzsichtig wie die trivialsten Unterteilungen sein. ${ }^{55}$

Nun lässt sich auch im strafprozessualen Bereich eine historisch-dynamische Kontinuität ${ }^{56}$ in Bezug auf die Rechtsgrundlagen erkennen, die sich in weiten Kreisen der westlichen Gesellschaft parallel entwickelt und selbstständig ausdifferenziert haben. Eine solche Kontinuität kann - neben den jeweils herrschenden sozialpolitischen Faktoren - eine erhebliche Rolle bei der permanenten Schaffung der strukturellen und funktionalen Rahmenbedingungen der einzelnen Rechtsordnungen spielen. So ist schon empirisch unschwer festzustellen, dass beispielsweise die Juristen in England oder den USA (als typische Vertreter der ,angloamerikanischen Rechtstradition“) die als ,kontinentaleuropäisch“ eingestufte strafprozessuale Praxis und Lehre in Deutschland, Frankreich, den Niederlanden, Griechenland, Österreich oder Spanien als eine befremdliche oder nur beschränkt adaptierbare Realität verstehen (und umgekehrt). ${ }^{57}$ Auch in Zeiten der kontinuierlichen Rechtstransplantationen und der Inter- und Transnationalisierung des Rechts ist die Bedeutung solcher (mentaler) Trennungen nicht zu unterschätzen; sie dienen meist der Erhaltung „eigener“ Errungenschaften beim Instituieren der justiziellen Steuerungsmechanismen zur Lösung von sozialen Konflikten. ${ }^{58}$

55 Dazu auch Glenn, S.C.L.R. 49 (2010), 601 (604-605, 608-609, 615-616).

56 Vgl. David/Brierley, Major Legal Systems, S. 18-20. Vgl. auch Brants/Ringnalda, Issues, S. 13-14.

57 Erläuternd hierzu die (in der Gegenwart nur teilweise überholten) Beispiele von Damaška, Faces, S. 2, 4, und auch Jung, FS für Fiedler, S. 909 (zum Verfahren vor dem IStGHJ). Siehe auch Eser, FS für Jung, S. 167; Nijboer, Am. J. Comp. L. 41 (1993), 299 (299-305, 311-312). Vgl. noch Forster, in: Sieber u.a. (Hrsg.), National Criminal Law, S. 16-17; Glendon/Carozza/Picker, Comparative Legal Traditions, S. 15; Glenn, S.C.L.R. 49 (2010), 601 (607) mit Verweis auf Legrands mentalités-Theorie; Kahn-Freund, in: Cappelletti (Hrsg.), New Perspectives, S. 138-139, 144-155; Rheinstein, Einführung, S. 96; Sawer, in: David (Hrsg.), International Encyclopedia, S. 14; van Caenegem, Birth, S. 85; Zweigert/Kötz, Einführung, S. 177. Von einem ,weltweiten Wettbewerb der Rechtsordnungen" spricht Höffe, FS für Hassemer, S. 57. Zum verschiedenen Rechtsverständnis der Juristen sogar als (ein) Kriterium für die Unterscheidung der Rechtsfamilien David/ Brierley, Major Legal Systems, S. 21. Allgemeiner zur Geografie der Rechte angloamerikanischer und kontinentaleuropäischer Prägung Schlesinger/Baade/Herzog/Wise, Comparative Law, S. 290-313 mit weiteren Verweisen; auch noch Rheinstein, Einführung, S. 77-82.

58 Hier ist im Voraus die strittige Frage der Durchsetzung des Verfahrensmodells angloamerikanischer statt kontinentaleuropäischer Prägung vor internationalen Strafgerichtshöfen zu erwähnen, dazu u.a. Eser, FS für Jung, S. 167-168, und Pocar, in: Walker/Chase (Hrsg.), Categories, S. 437-444 (so auch der charakteristische Untertitel des Aufsatzes: „Does Oil Blend with Water?"). Im nationalen Rahmen charakteristisch ist seitens der Arbeitsgruppe 7 des 35. Strafverteidigertages in Berlin (2011) die Ablehnung einer grundsätzlichen ,Umwandlung des deutschen reformierten Inquisitionsprozesses in einen Parteiprozess", siehe Strafverteidigervereinigungen (Hrsg.), Abschied, S. 342. 
Von besonderem Interesse ist freilich die Diskussion über die tatsächliche Verschiedenheit der Lösungen und insbesondere der strafjustiziellen Verfahrensweisen, welche die westlichen Länder(-gruppen) jeweils bei der Auseinandersetzung mit grundsätzlich ähnlichen sozialen Problemen und Zielen entwickelt haben - oft anhand unterschiedlicher dogmatischer oder institutioneller Rechtskonzeptionen sowie Einstellungen zur Justizverwaltung. ${ }^{59}$ Im Rahmen solcher kriminalpolitischen und rechtsdogmatischen Erwägungen lässt sich unter anderem das Problem der Bestimmung und Anwendung von Verfahrenstypen und strafprozessualen Beweismodellen identifizieren, die den Fundamenten der jeweils ,eigenen“ Rechtstradition am ehesten entsprechen.

In diesem Kontext sind in der vorliegenden Arbeit die in Lehre und Praxis ,dominierende ${ }^{\text {60 }}$ Dichotomie zwischen dem angloamerikanischen und dem kontinentaleuropäischen Strafverfahrenstypus sowie die determinierenden Elemente des „adversatorischen“ und des ,inquisitorischen“ Beweisverfahrensmodells genauer zu untersuchen. Dazu und zu einer umfassenderen Erklärung der Hintergründe der betreffenden Beweismodelle werden zuerst die historischen Wurzeln und differenzierten allgemeinen Hauptmerkmale der angloamerikanischen und kontinentaleuropäischen Strafrechtstraditionen näher betrachtet. Dies geschieht jedenfalls gezielt und selektiv (mit besonderem Bezug zu Fragen des Forschungsgegenstands) und ohne Anspruch auf Vollständigkeit.

\section{Einführung in die Tradition des angloamerikanischen Strafverfahrens}

In der rechtsvergleichenden Literatur sind des Öfteren folgende Differenzierungselemente für die allgemeine Unterscheidung zwischen common law- und civil law-Tradition eingebracht worden: ${ }^{61}$

- die parallele historische Entwicklung der Rechtssysteme anglonormannischer und römisch-kanonischer Prägung durch Einrichtung von getrennten (den verschiedenartigen ideologischen, geo- und rechtspolitischen Bedingungen entsprechenden) justiziellen Institutionen und Prozessformen;

- das unterschiedlich entwickelte Rechtsverständnis grundsätzlich im Hinblick auf die Vielfalt von Rechtsquellen, Auslegungsmethoden und grundlegenden Rechtsstrukturen;

59 Vgl. Ingraham, Structure, S. 3, 17, 20; Kahn-Freund, in: Cappelletti (Hrsg.), New Perspectives, S. 148.

${ }^{60}$ C. Harding, in: Eser/Rabenstein (Hrsg.), Strafjustiz, S. 11. Vgl. Damaška, Zbornik PFZ 51 (2001), 477 (497).

61 Siehe u.a. Chloros, Cambrian L. Rev. 9 (1978), 11 (12-19); Courakis, GA 1981, 533 (552-557); de Cruz, Comparative Law, S. 45-48, 97-98, 100-108, 137-138; Merryman, in: Cappelletti (Hrsg.), New Perspectives, S. 222-229; Rheinstein, Einführung, S. 96-103; Schnitzer, Vergleichende Rechtslehre, S. 140; van Caenegem, Judges, S. 1-65; Zweigert/ Kötz, Einführung, S. 68-71. 
- die Divergenzen bei der juristischen Ausbildung und bei der Rolle der Hauptakteure in der Rechtspflege sowie

- die ursprüngliche Entstehung und entsprechende Entwicklung von unterschiedlichen, sui generis und gegenwärtig noch stilprägenden Rechtsinstituten, vor allem auf dem Gebiet des Privatrechts.

Für die konkreten Zwecke dieser strafprozessualen Abhandlung ist es nötig, sich vorerst auf die historischen Wurzeln und die Entwicklung von kennzeichnenden Strukturen und Einrichtungen des Beweisverfahrens und der gerichtlichen Verhandlung zu konzentrieren. Als tragende rechtstechnische Merkmale der Traditionen nicht außer Acht zu lassen sind im Rahmen der Rechtsquellenproblematik auch die Schaffung und die systematische Ausarbeitung von Rechtsnormen. Weitere speziellere, in den rechtsvergleichenden Studien oft diskutierte Prinzipien und Ausgestaltungsformen des Strafverfahrens, die ebenfalls für die Kontinuität der angloamerikanischen und der kontinentaleuropäischen Verfahrenstradition sprechen können, betreffen etwa: die nichtöffentliche bzw. öffentliche und die schriftliche bzw. mündliche Form des Vor- und Hauptverfahrens, die Mitwirkungsmöglichkeiten sämtlicher Verfahrensbeteiligterdie engen Ziele des Strafverfahrens, die Verfolgungspraxis der Staatsorgane oder den richterlichen Gebrauch von Vorverfahrensakten. ${ }^{62}$ Soweit jedoch solche Teilfragen in unmittelbarer Verbindung mit der zentralen Dichotomie zwischen ,adversatorischen“ und „inquisitorischen“ Ausstrahlungen des Strafverfahrens stehen, sind sie in der Folge selbstständig zu untersuchen. ${ }^{63}$

An dieser Stelle ist zunächst, im Vorfeld der konkreteren Auseinandersetzung mit den modernen (Beweis-)Verfahrensmodellen und der jeweiligen Rolle der zentralen Verfahrensbeteiligten darin, mit der notwendigen Betrachtung von grundlegenden Konturen des angloamerikanischen Strafprozesses fortzufahren. Insbesondere ist dabei die Entstehung und Weiterentwicklung der sogenannten jury trial-Institution, des Beweisrechts sowie des „Richterrechts“ zu beachten. Gleich anschließend sind entsprechende rechtshistorische Entwicklungen in den Strafverfahren auf dem Kontinent zu diskutieren.

\section{a) Zur historischen Entwicklung zentraler angloamerikanischer Prozessformen}

Es ist in rechtsgeschichtlichen Studien üblich, die Wurzeln der angloamerikanischen, meist als common law bezeichneten Rechtstradition mit der Praxis der Gerichte des Königs von England in den Jahrhunderten nach der Normannischen Eroberung (1066 n. Chr.) in Zusammenhang zu bringen. Unter dem Begriff

${ }^{62}$ Hier nur als Beispiel pauschaler Betrachtungen Bradley, in: ders. (Hrsg.), Criminal Procedure, S. xvii.

${ }^{63}$ Siehe Teil 1, II.C. und Teil 2 der Arbeit. 
„Common Law“ (,gemeines Recht") war ursprünglich ,the law common to the king's courts“ zu verstehen. ${ }^{64}$ Die neue sozialpolitische Ordnung nach der Eroberung hat in England anfangs zur Mischung von alten verstreuten und lokalen Gewohnheitsrechten, römisch-kanonischen Einflüssen und institutionellen Reformen geführt, die von den Normannen gefordert wurden und der neuen feudalistischen und stark monarchistischen Umwelt entsprachen. Ab dem 12. Jahrhundert entwickelte sich dann durch die Einsetzung von Königlichen Gerichten (royal courts), die Praxis von Wanderrichtern des Königs in straf-, land- sowie zivilrechtlichen Fällen und die Verbreitung von verschiedenen prozessualen writs und actions ein für das ganze englische Territorium geltendes gemeines Rechtssystem. ${ }^{65}$ Dieses hat in seinen Grundzügen und Rechtsmechanismen bis heute bemerkenswerte Kontinuität bewiesen. Außerdem diente es, zumindest ursprünglich, als Basis für die Schöpfung des Rechts anderer Länder, die nun als Rechtsordnungen des common law anerkannt werden, darunter vor allem der englischen Kolonien, denen schließlich die Vereinigten Staaten von Amerika (USA) entstammen. ${ }^{66}$

aa) Das jury-Strafverfahren und die Ursprünge des englischen Beweisrechts

\section{- Aufgabe der alten Beweismodi und Entstehung des reinen jury-Verfahrens (13.-17. Jahrhundert)}

Mit Blick auf das Strafverfahren nimmt die frühe Entstehung eines (quasi amtlichen) Akkusationsverfahrens mit juries of accusation (Vorläufer der moderneren grand juries) in England sicherlich eine zentrale Stellung in der Entwicklung der

${ }^{64}$ Langbein/Lerner/Smith, History, S. 4 (auch mit Verweis auf Michael Clanchy, En.1: common law „meant the royal law that was common to the whole country“). Siehe auch Baker, Introduction, S. 12-36 (und zur englischen Rechtslage vor der Normannischen Eroberung S. 1-11); Glendon/Carozza/Picker, Comparative Legal Traditions, S. 153-157; Glenn, Legal Traditions, S. 237; Höffe, FS für Hassemer, S. 57-58. Noch dazu Forster, in: Sieber u.a. (Hrsg.), National Criminal Law, S. 16; Servidio-Delabre, Common Law, S. 911. $\mathrm{Zu}$ weiteren möglichen Bedeutungen des Begriffs „common law“ de Cruz, Comparative Law, S. 102-103; Rheinstein, Einführung, S. 88-89. Zur Geschichte der Strafjustiz in England vor der Eroberung Hostettler, History, S. 11-39.

65 Ausführlich, auch zur historischen Entwicklung der royal courts und zum writSystem (d.h. den königlichen Anleitungen bezüglich z.B. des Zugangs zum Gericht und des zuständigen Verfahrens), van Caenegem, Birth, S. 1-28, 29-61. Kürzer gefasst m.w.N. Glendon/Carozza/Picker, Comparative Legal Traditions, S. 157-171; Glenn, Legal Traditions, S. 236-249; Samuel, in: Smits (Hrsg.), Elgar Encyclopedia, S. 170-174; ServidioDelabre, Common Law, S. 9-20, 25-27; Zweigert/Kötz, Einführung, S. 178-184. Vgl. noch Martínez-Torrón, Anglo-American Law, S. 5-17. Nach Grünhut, in: Mezger u.a. (Hrsg.), Strafrecht, S. 142: „Die Geschichte des englischen Strafrechts ist weithin eine Geschichte des Strafprozesses".

${ }^{66}$ Langbein/Lerner/Smith, History, S. 731-741, 874-880. Siehe auch Berman, in: ders. (Hrsg.), Talks, S. 4-5, 8; Darbyshire, in: Vogler/Huber (Hrsg.), Criminal Procedure, S. 46; Schmid, Strafverfahren, S. 6, 17-19. Allgemein zur Ausbreitung des common law in der Welt und in Nordamerika Zweigert/Kötz, Einführung, S. 214-238. 
angloamerikanischen Rechtstradition ein. Diese juries wurden grundsätzlich zur Fortsetzung und später zur gerichtlichen Zwischenüberprüfung der Stichhaltigkeit der für lange Zeit üblichen privaten Verfolgung von Delikten eingesetzt. ${ }^{67}$ Noch wichtiger für die Gestaltung des Strafprozesses war aber die seit dem 13. Jahrhundert voranschreitende Aufgabe alter Beweismodi wie des Gottesurteils (ordeal) und des Duells (trial by battle). Gleichzeitig wurde in das nun rationalisierte (strafsowie zivilrechtliche) Beweissystem die Institution der jury trials eingeführt und verbreitet. $^{68}$ Das reine jury-Verfahren zur Verhandlung gravierender Verbrechen wird noch bis heute - wenn auch erheblich verändert und in der tatsächlichen Justizpraxis größtenteils verdrängt - als differenzierendes Kerncharakteristikum der common law-Rechtsordnungen und insbesondere des herkömmlichen Strafprozesses betrachtet. ${ }^{69}$ Als Justizeinrichtung ist die jury trial schon für die Untersuchung der Verhältnisse zwischen Berufsrichtern, Verfahrensparteien und Laienrichtern in angloamerikanischen Beweisverfahrenssystemen von Bedeutung.

Die jurors (Geschworenen) wurden in England ursprünglich als selbst informierte ,Zeugen“ der jeweiligen Streitigkeit geladen und mussten als Gremium (jury) eine für die Richter verbindliche wahre Aussage (verdict) zu Tatsachenfragen machen. Erst seit dem 14. und 15. Jahrhundert begannen die juries ihre heutigen reinen Entscheidungsbefugnisse im Rahmen eines nun „instruktiven“, auf externen Kenntnisquellen basierenden Beweisverfahrens zu gewinnen. Die Tatsachenfeststellung durch Laien wurde dann von der richterlichen Verfahrensleitung und der unmittelbaren Auseinandersetzung mit Rechtsfragen getrennt. ${ }^{70}$ Für die Ent-

67 Zur komplexen Entwicklung der Ermittlungs-, Verfolgungs- und Anklageeinrichtungen (private prosecutors, Attorney-Generals, justices of the peace, constables, thieftakers, crown witnesses, police, magistrates, prosecuting solicitors, juries of presentment und später juries of indictment und grand juries) bis hin zur Herausbildung einer erst in der modernen Zeit selbstständigen public prosecution service und der endgültigen Abschaffung des grand jury-Verfahrens und letztlich auch anderer Zwischenverfahrensformen wie die committal proceedings vor dem magistrates' court in England siehe Langbein/Lerner/ Smith, History, S. 210-238, 572-573, 578-589, 665-689, 706-708, 712-713. Siehe auch Langbein, AJLH 1973, 313 (314-324, 334-335); Langbein, in: Schioppa (Hrsg.), Trial Jury, S. 19-24.

68 Zusammengefasst Milsom, Foundations, S. 406-413. Siehe auch Hostettler, Criminal Jury, S. 16-32.

${ }^{69}$ Langbein/Lerner/Smith, History, S. 269, 561. Außerdem u.a. Blake, in: Findlay/Duff (Hrsg.), Jury, S. 140; Hörnle, in: Duff u.a. (Hrsg.), Trial on Trial 2, S. 135; Redmayne, in: Duff u.a. (Hrsg.), Trial on Trial 2, S. 99-100. Polemisch Darbyshire, [1991] Crim.L.R., 740 (741): „The symbolic function of the jury far outweighs its practical significance“.

70 Insgesamt Lloyd-Bostock/Thomas, in: Vidmar (Hrsg.), Jury, S. 54-56; ServidioDelabre, Common Law, S. 18. Für mehr Details van Caenegem, Birth, S. 62-84, auch mit Ausführung der archaistischen, irrationalen ordeal- und judicial combat-Systeme als Beweismodus. Mit konkretem Bezug auf die strafprozessualen Entwicklungen und die verschiedenen Arten von juries (jury of accusation und trial jury) Langbein/Lerner/Smith, History, S. 29-53, 54-78, 208-227, 238-248. Siehe auch Grube, Richter, S. 109-131. Zur funktionalen Unterscheidung zwischen Rechts- und Tatsachenfragen bemerkt Langbein, in: Schioppa (Hrsg.), Trial Jury, S. 34: ,[...] the judge / jury relationship was ordinarily 
scheidung der jury wurden (und werden noch bis heute) förmlich keine Gründe angegeben. Überdies fand im Kontext der rechtspolitisch angestrebten „Kontrolle“ und Überprüfung der jury-Entscheidungen die graduelle Einführung eines effektiven Rechtsmittelverfahrens i.V.m. der Zunahme der richterlichen Anweisungen (instructions) an die jurors und der Entwicklung eines formalen Beweisrechts erst ab dem 17. Jahrhundert statt; das Beweisrecht wurde dabei grundsätzlich im Sinne des Ausschlusses von „unerwünschten“ Beweisen durch die Richter verstanden. ${ }^{71}$

\section{- Entstehung der ,, adversary criminal procedure“ und des formalen Beweisrechts (18.-19. Jahrhundert)}

Den Geschworenen wurde also ab einem gewissen Zeitpunkt - auch wegen sich häufender Justizirrtümer - die selbstständige Würdigung des ,ungefilterten“ Beweismaterials nicht mehr ohne Weiteres zugetraut. Hinsichtlich insbesondere der späten Entstehung eines formalen Beweisrechts in England als Kontrollmechanismus des „Informationsflusses“ und des damit verbundenen Entscheidungsspielraums der juries ist unter anderem auf den langsamen Übergang des Verfahrens mit selbst-informierten Landsleuten als jurors zu einer echt instruktiven jury trial zu verweisen. Nach einer stark vertretenen Meinung sind aber vor allem die ab Ende des 18. Jahrhunderts zunehmenden Elemente der ,adversary criminal procedure“ mit der Formierung des modernen „law of evidence“" $\mathrm{zu}$ verbinden. ${ }^{72}$

Die Zunahme der Elemente der „,adversary criminal procedure“ bedeutete vor allem die aktivere Mitwirkung von Anwälten in der Hauptverhandlung. Folgende historischen Gründe für diese (ziemlich langsame und somit eher reibungslose) Entwicklung der richterlichen Praxis werden oft vorgebracht:

- die zunehmende Aversion gegen die Todesstrafe und die Notwendigkeit der

Kontrolle und Beschränkung ihrer unproportionalen Verhängung;

harmonious and effective, and the law / fact distinction operated smoothly. The hidden truth that the jury's verdict was a mixed determination of law and fact did not have to be faced."

71 Ausführlich Langbein/Lerner/Smith, History, S. 415-464 (auch zur „law nullifying power of the Anglo-American jury“: „Although the jury is said to have a duty to obey the law, and hence to follow the trial judge's instruction on the law, that duty is unenforceable against jurors who resolve to disobey it.“, S. 426-427) und S. 443-444, 702-705 zur allmählichen (bis ins 20. Jahrhundert) Schaffung von appeal-Verfahren für Strafsachen und von entsprechenden Gerichten; siehe auch Langbein, in: Schioppa (Hrsg.), Trial Jury, S. 34-38.

72 Langbein/Lerner/Smith, History, S. 451-453. Auch Langbein, U. Chi. L. Rev. 45 (1978), 263 (306, und 272-306 bezüglich der Kerncharakteristika der jury trial während der vorherigen „lawyer-free phase"). Siehe auch Feeley, Is.L.R. 31 (1997), 183 (207, 219); Hostettler, History, S. 225-226; Lieber, Schöffengericht, S. 84-85. Vgl. auch Langbein, Colum. L. Rev. 96 (1996), 1168 (1169-1172, 1194-1202). Detaillierter zu den ersten historischen Spuren der modernen Verfahrensarten Langbein, U. Chi. L. Rev. 50 (1983), 1 (2, 123-134). 
- die Notwendigkeit einer Ausbalancierung der schwachen Position der angeklagten Personen durch die Einbeziehung von Verteidigern, die vor allem als Folge der immer stärkeren Beteiligung von Anklageanwälten im (Vor-)Verfahren angesehen wird; sowie

- die Gefahren und Beweisschwierigkeiten in Fällen von Meineid (in den vielen „reward-driven and crown witness prosecutions" $).{ }^{73}$

Die seit dem 19. Jahrhundert immer aktivere Mitwirkung von Anwälten in der Hauptverhandlung hat jedenfalls im Rahmen der Stärkung der Wahrheitsfindungsfunktion des jury-Verfahrens zur Durchsetzung des Kreuzverhörs (cross-examination) als Hauptinstrument für die Prüfung des mündlichen Beweises geführt. ${ }^{74}$ Für die Förderung des Kreuzverhörinstruments ${ }^{75}$ und auch als Schutzmechanismus gegen mögliche „Desinformation“ der jury wegen irreführender oder sonst problematischer Beweise wurde im 18. und 19. Jahrhundert ein System von Beweisausschlussregeln (exclusionary rules) seitens der Richter entwickelt. Dieses System basierte zunächst auf einer strikteren Annahme der alten hearsay-Regel (konkreter: Regel gegen hearsay-Beweis) sowie auf den nur im Strafverfahren relevanten character-, corroboration- und confession-Regeln. ${ }^{76}$

73 Siehe ausführlich mit mehreren historischen Verweisen Langbein, Origins, S. 2-7, 106-177, 253-343. Im Vergleich zu den parallelen historischen Entwicklungen auf dem Kontinent bemerkt Langbein, Origins, S. 338-339, 341: „The Roman-canon procedure used in all the European states placed upon the court the responsibility to seek the truth, and gave it the investigative authority and resources to do so. European procedure thus avoided the privatization of criminal investigation that was the central failing of English procedure. The Europeans had made criminal investigation a public function from the Middle Ages. [...] Court-conducted criminal investigation requires an investigative magistracy for the work of gathering and evaluating evidence. The problems of organizing, recruiting, training, controlling, and compensating such a corps would have been particularly unsettling to English patterns of governance, which relied upon skeletal officialdom and delegated so much authority to local gentlemen. Indeed, opposition to police forces and to public prosecution, arising from just such concerns, remained vigorous deep into the nineteenth century."

74 Klassisch ist dabei der Spruch von Wigmore, Evidence 5 (§ 1367), S. 32 (Chadbourn rev. 1974), dass cross-examination ,the greatest legal engine ever invented for the discovery of truth" sei. Trotzdem wurde das Kreuzverhör schon früh bezüglich seiner Wahrheitsfindungsfunktion mit Skepsis betrachtet. Mehr dazu und zum truth deficit des lawyerdominated Hauptverfahrens Langbein, Origins, S. 245-247, 331-343; Langbein/Lerner/ Smith, History, S. 453-454.

75 Für die Umwandlung der Hintergründe der hearsay-Regel am Ende des 18. Jahrhunderts (von: ,hearsay lacked credibility because the original statement was not made under oath" zu: ,the more modern concern - the absence of cross-examination") Gallanis, Iowa L. Rev. 84 (1999), 499 (533); vgl. auch Langbein, Colum. L. Rev. 96 (1996), 1168 (1175, 1200). Siehe auch McEwan, Evidence, S. 26-27.

76 Die hearsay-Regel erlaubte die Aussage eines Zeugen nicht, soweit er lediglich über eine andere außergerichtliche Aussage und zur Bestätigung der Wahrheit dieser Aussage berichtete. Die character-Regel betraf den Ausschluss von Beweisen zum Charakter des Angeklagten (z.B. Vorstrafen), es sei denn diese waren als Gegenbeweis angeführt. Die corroboration-Regel setzte für die Verurteilung voraus, dass die Aussage eines Komplizen 
Als ein Fundament des im 19. Jahrhundert noch im Aufbau befindlichen angloamerikanischen Beweisausschlussverfahrens gilt zunächst die typische Trennung der Befugnisse von Richter und jury. ${ }^{77}$ Die englischen Berufsrichter sollten im Voraus über die Zulässigkeit oder den Ausschluss von Beweisen entscheiden; die jury war dagegen für die Tatsachenfragen, die Bewertung der zugelassenen Beweise und somit die Entscheidung über die Schuldfrage zuständig. Eigentlich waren aber in den ersten Entwicklungsstadien des englischen Beweisrechts und -verfahrens solche Mechanismen wie Voruntersuchungen in Abwesenheit der jury oder richterliche Anweisungen an die jurors in Bezug auf die Zulässigkeit der Beweise nicht vorhanden; eine sorgfältige Unterscheidung zwischen einem Ausschluss a priori und einer vorsichtigen Bewertung ex post von „verbotenen“ Beweisen war zunächst nicht möglich. ${ }^{78}$

\section{- Heutige Lage}

Wie sich gegenwärtig die Rechtslage und Praxis hinsichtlich der Zulässigkeit und des Ausschlusses von Beweisen in England im Zusammenhang mit den Problemen der Teilnahme im Hauptverfahren und der Rollenverteilung der Verfahrensbeteiligten (Richter, Geschworene, Anwälte) entwickelt haben, stellt eine im Weiteren noch zu untersuchende Frage dar. ${ }^{79}$ An dieser Stelle ist in Bezug auf das reine englische jury-Verfahren noch zu erwähnen, dass es trotz seiner Anerkennung als tragendes Differenzierungselement bei der Gegenüberstellung mit den kontinentaleuropäischen Rechten auf nationaler Ebene seine praktische Relevanz heute zum großen Teil verloren hat.

Schon ab dem 19. Jahrhundert fanden die sogenannten summary proceedings ohne Geschworenenbank vor dem magistrates' court zur Verhandlung kleinerer Delikte immer regelmäßiger statt - bis hin zu ihrer gegenwärtigen Durchsetzung für die Mehrheit der Straffälle aus prozessökonomischen Gründen. Für die zusätzliche Verdrängung der adversarial jury-Verhandlung durch guilty pleas und für die auch in schweren Verbrechensfällen weitverbreitete plea bargaining-Praxis werden zudem als Gründe teilweise vorgebracht: der Zeitaufwand der anwaltsgeführten jury-Verfahren, die Komplexität der felony trials; die zunehmende Arbeitsbelastung der Richter, oder die nun effektivere Aufklärung von Delikten schon im

durch weitere Beweise bestätigt wurde. Die confession-Regel betraf den Ausschluss von außergerichtlichen und unwillentlichen Geständnissen. Für Einzelheiten Langbein, Origins, S. 178-180, 190-247. Allgemeiner zu diesen ersten Entwicklungen eines systematisierten angloamerikanischen Beweisrechts Langbein/Lerner/Smith, History, S. 450-458.

77 Damaška, Minn. L. Rev. 76 (1992), 425 (427) unterscheidet dabei zwischen ,unitary continental court" und „bifurcated Anglo-American court"; vgl. Geppert, Unmittelbarkeit, S. 31-32.

78 Langbein, Origins, S. 250-251.

79 Siehe unter Teil 2, II. 
Vorverfahrensstadium. ${ }^{80}$ Im Allgemeinen lassen die modernen Tendenzen im englischen Strafverfahren sehr wenig Spielraum für die kontradiktorische Verhandlung der Straffälle vor einer jury.

bb) Die Entwicklung des jury-Strafverfahrens in den USA

Die Vereinigten Staaten von Amerika bilden den zweiten großen, ab einem gewissen Zeitpunkt von seinen englischen Ursprüngen emanzipierten Pfeiler der common law-Tradition. ${ }^{81}$ Die historische Entwicklung ihrer zentralen Justizeinrichtungen ist daher von substantieller Bedeutung für die Einführung in die angloamerikanischen Rechtssysteme. Von Interesse für das Strafverfahren ist hierbei wieder das jury-Hauptverfahren. ${ }^{82}$ Die konstitutionelle Durchsetzung des jury-Verfahrens als ein Hauptkennzeichen ${ }^{83}$ der US-Rechtsordnung(en) lässt sich bis in die vorföderalistischen Kolonialzeiten zurückverfolgen. Ursprünglich war die umfangreiche Beteiligung von jurors an Zivil- sowie Strafsachen Bestandteil der Bewegungen für repräsentative Selbstregierung der Kolonisten gegen die britische Herrschaft. Doch bereits während des ersten Jahrhunderts der Amerikanischen Republik gewannen die professionellen, mehr oder weniger im englischen Common Law i.e.S. (im Folgenden: Common Law) ausgebildeten Richter mehr Autorität hinsichtlich der Auseinandersetzung mit Rechts- und Verfahrensfragen. ${ }^{84}$

Zunächst wurde im 18. und 19. Jahrhundert das System der zweit- bzw. höchstinstanzlichen professionellen Gerichtsbarkeit reformiert und in Bezug auf die Auseinandersetzung mit Rechtsfragen verstärkt. So entstand langsam ein für den ganzen Staat einheitliches Recht durch die Rechtsprechung von supreme und appellate

80 Langbein/Lerner/Smith, History, S. 706-713. Siehe auch Ashworth/Redmayne, Criminal Process, S. 291-295, 308-310, 321-339; Darbyshire, [1997] Crim.L.R., 627 (628643); Darbyshire, [2000] Crim.L.R., 895 (896-901); Forster, in: Sieber u.a. (Hrsg.), National Criminal Law, S. 17-18; Lieber, Schöffengericht, S. 103-104; Lloyd-Bostock/ Thomas, in: Vidmar (Hrsg.), Jury, S. 61-68, 89-91; Rauxloh, Plea Bargaining, S. 25-60; Redmayne, in: Duff u.a. (Hrsg.), Trial on Trial 2, S. 99-100; Vogler, ZStW 116 (2004), 129 (133).

$81 \mathrm{Zu}$ den Wurzeln des frühen nordamerikanischen Rechtssystems und seiner Emanzipierung insb. nach der amerikanischen Revolution (1776), der Durchsetzung des föderalistischen Regierungssystems und der Annahme der US-Verfassung und des „Bill of Rights“ u.a. Servidio-Delabre, Common Law, S. 117-121.

$82 \mathrm{Zu}$ den historischen Entwicklungen bezüglich der Anklagefunktion der grand jury im Vorverfahren und allgemein hinsichtlich der Ermittlungs-, Verfolgungs- und Anklageeinrichtungen im nordamerikanischen Recht Langbein/Lerner/Smith, History, S. 733-737, $741-750$.

83 „The jury is one of the hallmarks of the American system known to everyone who sees contemporary films or reads John Grisham's novels", so Fletcher/Sheppard, American Law, S. 243.

${ }^{84}$ Langbein/Lerner/Smith, History, S. 474-492, 495-503, 841-843. Vgl. auch Berman, in: ders. (Hrsg.), Talks, S. 11-17. Noch zur historischen Entwicklung des jury-Verfahrens kurz Grube, Richter, S. 163-172. 
courts. Zugleich verbreitete sich auch die Praxis der Wiederaufnahme von erstinstanzlichen Verfahren (ordering a new trial), um ,problematische“, grundsätzlich rechtswidrige jury-Entscheidungen oder auch Entscheidungen wider besseren Beweises aufzuheben. Außerdem wurde die Praxis der richterlichen Bemerkungen zu den Beweisen (judicial comment on the evidence), die sich aber letztendlich nicht durchsetzte, sowie der richterlichen Anweisungen an die jurors mit Blick auf strittige Rechtsfragen eingeführt. In diesem Zusammenhang bildeten sich auch weitere bekannte Charakteristika der US-Verfahrensrechtsordnung heraus: die Hauptverfahrensleitung durch einen einzigen Vorsitzenden Richter, die Ausfertigung von written legal opinions seitens der Höchstrichter, und die Veröffentlichung von sogenannten law reports für die selbstständige, systematische Registrierung und Förderung des amerikanischen Präzedenzfallrechts, was auch zur Ausformulierung von präziseren Regeln bezüglich der erstinstanzlichen Richter- und Jurykontrolle geführt hat. ${ }^{85}$

In der modernen Zeit sind, vor allem durch die Rechtsprechung des US-Supreme Court und die interpretatorische Mischung von alten englischen Rechtsinstituten und amerikanischen Verfassungsgarantien, umfassende und komplexe Beweisnormen in Strafsachen erwachsen. Typisch sind etwa die hearsay-Regeln des Common Law i.V.m. der Konfrontationsklausel des 6th Amendment zur US-Verfassung. ${ }^{86}$ Solche Regeln wirken zusätzlich, wenn auch nicht unbedingt explizit, auf die Bestimmung des Verhältnisses und der Rollenverteilung zwischen den am juryVerfahren Beteiligten.

Alldem ungeachtet und trotz der frühen doppelten verfassungsrechtlichen Verankerung des Rechts auf criminal jury trial ${ }^{87}$ wird heute, ähnlich wie in der englischen und anderen common law-Rechtsordnungen (u.a. Neuseeland, Australien und Kanada), ${ }^{88}$ nur noch ein kleiner Teil aller Straffälle vor einer jury verhandelt. Insbesondere hat dabei die Verbreitung von konsensualen Prozessformen und Abspracheverfahren eine Rolle gespielt. Diese haben sich in erheblichem Maße aus prozessökonomischen Gründen, nicht zuletzt wegen der zunehmenden Komplexität des anwaltsbeherrschten und zeitaufwendigen kontradiktorischen Hauptverfahrens, durchgesetzt. Die verstärkte Anwendung eines in der common law-Tradition der

85 Ausführlich zu diesen historischen Entwicklungen in der nordamerikanischen Rechtsordnung und Rechtslehre und ihren Hintergründen Langbein/Lerner/Smith, History, S. 500-532, 824-838.

${ }^{86}$ Charakteristisch hierfür ist der Fall US Supreme Court Crawford v. Washington, 541 U.S. 36 (2004).

87 Zur Entstehung von Art. III sect. 2 US-Verfassung und 6th Amendment zur USVerfassung als Antwort auf Phänomene willkürlicher Justizverwaltung, Langbein/Lerner/ Smith, History, S. 485. Auch LaFave/Israel/King/Kerr, Criminal Procedure, S. 1068-1070. Ebenso Langbein, Harvard JLPP 15 (1992), 119 (119-125).

88 Dazu u.a. Cameron/Potter/Young, in: Vidmar (Hrsg.), Jury, S. 168-172, 179-185, 209-210; Chesterman, in: Vidmar (Hrsg.), Jury, S. 129-135, 165; Vidmar, in: ders. (Hrsg.), Jury, S. 217-219, 248. Siehe auch Boll, Plea Bargaining, S. 1-17, 55-65. 
letzten 200 Jahren weithin geschätzten Verfahrenselements, namentlich der sogenannten adversary trial, hat somit zur übermäßigen Verbreitung einer in der Gegenwart ebenfalls typischen, aber nicht gleichermaßen populären alternativen Prozessart (plea bargaining) beigetragen. ${ }^{89}$ Diese Entwicklung hat zur fast vollständigen Verdrängung, jedoch nicht zum Aussterben, eines der historisch tief verwurzelten Hauptmerkmale des angloamerikanischen Strafprozesses, der jury trial, geführt. ${ }^{90}$

\section{b) Die Rechtsquellen und die Entwicklung des case law in der angloamerikanischen Rechtstradition}

Die historische Entwicklung der reinen jury trial (d.h. ohne Mitwirkung des Berufsrichters bei der Urteilsfindung) zur zentralen Prozessfigur der common lawTradition ist, wie bereits festgestellt, für die Entstehung der heutigen strafprozessualen Beweissysteme und somit für die Fragen der vorliegenden Abhandlung relevant. Die beweisverfahrensbezogene Betrachtung der angloamerikanischen Rechte wäre jedoch nicht klar genug, wenn die Problematik der Rechtsquellen und der Wege, durch die letzten Endes das nationale Beweisrecht selbst entsteht, nicht kurz angesprochen würde. Dabei offenbart sich gleichzeitig ein weiteres wichtiges Merkmal der angloamerikanischen Rechtstradition, das im Laufe der Zeit ebenfalls Veränderungen erfahren hat: die aktive Rolle des Richters nicht nur bei der Rechtsanwendung und -auslegung, sondern auch bei der Rechtsschöpfung selbst (sogenanntes Richterrecht, judge-made law). Schon im Voraus ist für das moderne englische Strafverfahren und sogar für das Verfassungssystem zu bemerken, dass die Rechtsnormen und grundlegenden Rechtsprinzipien nicht - wie in den kontinentaleuropäischen Ländern des 19. und 20. Jahrhunderts üblich - sorgfältig und möglichst vollständig kodifiziert bzw. in einem einzigen Verfassungstext zusammengestellt worden sind. Vielmehr finden sich die Quellen des englischen Rechts verstreut und über mehrere Jahrhunderte verteilt in verschiedenen (heute teilweise konsolidierten) Gesetzestexten und Gerichtsentscheidungen. ${ }^{91}$

89 Vgl. Langbein, Harvard JLPP 15 (1992), 119 (121-123, 125-127). Siehe auch Langbein, U. Chi. L. Rev. 46 (1978), 3 (19-22); Langbein, Mich. L. Rev. 78 (1979), 204 (204206). Vgl. auch Weinreb, Denial, S. 71-72.

90 Insgesamt dazu Bradley, in: ders. (Hrsg.), Criminal Procedure, S. xix; Dielmann, GA 1981, 558 (559); Feeley, Is.L.R. 31 (1997), 183 (insb. 183, 186-187, 191-192, 219-221); N. King, in: Vidmar (Hrsg.), Jury, S. 114-117; LaFave/Israel/King/Kerr, Criminal Procedure, S. 15-16; Langbein/Lerner/Smith, History, S. 755-758; Rosenau, FS für Puppe, S. 1602, 1611-1614; Trüg, ZStW 120 (2008), 331 (342-346); Turner, Plea Bargaining, S. 7-10; Vogler, ZStW 116 (2004), 129 (133, 140-141). Siehe auch Ma, ICJR 8 (1998), 74 (75-77, 91-92).

91 Dazu Spencer, in: Delmas-Marty/Spencer (Hrsg.), European Criminal Procedures, S. 142. Kurz zum englischen Verfassungsrecht Bernstorff, Einführung, S. 32-37; ServidioDelabre, Common Law, S. 55-57. Siehe auch Forster, in: Sieber u.a. (Hrsg.), National Criminal Law, S. 25-27. 
aa) Die Quellen des englischen Rechts

\section{- Entstehung und Prinzipien des case law}

Von besonderer rechtsgeschichtlicher Bedeutung für die Entstehung des heutigen Rechts von England und hiernach des Rechts seiner ehemaligen Kolonien ist, wie schon angedeutet, die Praxis der Königsrichter in den Jahrhunderten nach der Normannischen Eroberung. Vor allem ist dabei der Zusammenhang zwischen lokalen, von Wanderrichtern angewandten Gewohnheitsrechten (custom) ${ }^{92}$ und der systematischen Herausbildung, insbesondere seit dem Spätmittelalter, von Rechtsprinzipien durch Fallrecht (case law) und folglich durch die ab dem 19. Jahrhundert zunehmende Bindung der Gerichtsentscheidungen an Präzedenzfälle (Prinzip der stare decisis) zu beachten. Dieser Zusammenhang und die Verpflichtung der Richter, neue Fälle aufgrund der Regeln und Prinzipien von precedents zu entscheiden, bildeten in England letztendlich nicht nur die Grundlagen des Common Law. ${ }^{93}$ Mehr noch wurde dadurch die Autorität sowie das Außenbild der Richter als Garanten der Rechtssicherheit und der Bürgerinteressen gegen willkürliche Machtausübung seitens des Königs gestärkt. ${ }^{94}$

Die heutige Existenz einer umfassenden case law-Materie ist der Dokumentation der Gerichtsurteile durch verschiedene literature- und law report-Mechanismen zu verdanken. Diese gehen auf die mittelalterlichen year-books zurück und wurden in England (wie auch in Amerika) insbesondere ab dem 19. Jahrhundert systematischer eingesetzt. ${ }^{95}$ Zum verbindlichen Inhalt des case law wird grundsätzlich der-

92 Zur historischen Rolle der customs und zu ihrer begrenzten heutigen Rolle als Rechtsquellen Servidio-Delabre, Common Law, S. 108-110. Siehe auch Glendon/ Carozza/Picker, Comparative Legal Traditions, S. 284-286.

93 Neben dem durch die Praxis der Gerichte entstehenden Common Law sind zusätzlich im Rahmen der Rechtsquellen in common law-Rechtssystemen die primär zivilrechtlichen Rechtsinstitute der „equity“ zu erwähnen. Das jury-freie „Court of Chancery“ hat, kurz zusammengefasst, schon ab dem 14. Jahrhundert versucht, Ungerechtigkeits- bzw. Ungleichheitsphänomene in der strikten Rechtsprechung der übrigen Königsgerichte durch seine (zumindest anfangs) flexiblere und weniger technische Praxis zu korrigieren. Durch die equity-Rechtsprechung wurden dann wichtige Bereiche des angloamerikanischen materiellen und prozessualen Rechts entwickelt (z.B. ,pretrial written evidence gathering" und „law of trust" ). Heute gibt es sowohl in England als auch grundsätzlich in den USA keine selbstständigen equity-Gerichte mehr, sodass Common Law und „,equity“ nun eine einheitliche Rechtslage darstellen. $\mathrm{Zu}$ diesen Entwicklungen und den Zuständigkeitserwägungen zwischen law und equity: Servidio-Delabre, Common Law, S. 20-22, 102-108, 204. Zusammengefasst Ehrmann, Comparative Legal Cultures, S. 29-31. Nach Meinung von Langbein/Lerner/Smith, History, S. 269 (auch mit Einzelheiten zur equity S. 267-344, 345-412): „Historically, the law / equity distinction has been second only to the jury system as a defining element in the Anglo-American legal tradition."

94 Ehrmann, Comparative Legal Cultures, S. 22-23; siehe auch Elliott/Quinn, English Legal System, S. 7, 10, und Reichel, Comparative Criminal Justice, S. 85-87. Analytischer zur Geschichte des Fallrechts Baker, Introduction, S. 195-202.

95 Dazu Langbein/Lerner/Smith, History, S. 177-190, 253-257, 353-354, 443, 448$450,816-865$. 
jenige Teil von richterlichen Entscheidungen der höheren Gerichte, der sich mit Rechtsanwendungsfragen auseinandersetzt und die ratio decidendi, also die eigentlichen Entscheidungsgründe darstellt; die sogenannten obiter dicta, d.h. die Rahmenbemerkungen der Richter, haben keinen verbindlichen Wirkungsanspruch, können aber gegebenenfalls als persuasive precedent verwendet werden.

Die rechtlichen Entscheidungsgründe, die auf eine bestimmte Art und Weise der Anwendung des Rechts in einem konkreten Fall hindeuten, sind nach dem stare decisis-Prinzip vom Gericht auch in einem späteren Fall, dessen Sachverhalt ähnlich genug ist, wahrzunehmen; diese ratio bekommt eventuell Rechtswirkung für zukünftige Urteile. Ein Richter soll in diesem Rahmen grundsätzlich nur der früheren Entscheidung eines höheren Gerichts folgen. Manche Gerichte sind aber an ihre früheren Entscheidungen selbst gebunden - nicht jedoch die Strafgerichte und jedenfalls nicht mehr das englische Höchstgericht. Einzelfälle können eigentliche Präzedenzkraft für das betreffende Rechtsgebiet, wie das Beweisrecht, haben, etwa aufgrund des Alters und der Einstimmigkeit der Entscheidung oder der Zusammensetzung und Autorität des Gerichts. Historisch betrachtet sprach die Bindung an precedents immer gegen eine willkürliche Machtausübung seitens der Richter und für Rechtssicherheit und Vorhersehbarkeit. Gegner der stare decisis-Idee weisen dagegen etwa auf die Komplexität und Undurchschaubarkeit von starren und unsystematischen Präzedenzfällen hin. ${ }^{96}$

\section{- Gesetzgebung und Kodifikation}

Das Richterrecht kann jedenfalls nicht als die einzige Quelle des englischen Rechts in seiner historischen Entwicklung gelten. Fast parallel zu den ersten Entwicklungsstadien des Common Law sind auch ab initio schriftlich niedergelegte Normen zu finden, die teilweise immer noch Wirkungsanspruch haben, wie beispielsweise in der Magna Carta (1215), dem Justices of the Peace Act (1361) und den späteren Habeas Corpus Act (1679) und Bill of Rights (1689). Schon seit der (früh-)modernen Zeit der Gewaltenteilung griff aber die Legislative immer regelmäßiger zur Durchsetzung von rechtspolitischen Entscheidungen ein, vor allem mit dem Ziel, neue Normen für die notwendige Anpassung an die sich kontinuierlich weiterentwickelnden Formen der Technologie und der menschlichen Beziehungen zu schaffen. ${ }^{97}$

96 Ausführlicher dazu und allgemein zu den case law-Regeln m.w.N. Elliott/Quinn, English Legal System, S. 7-35; Forster, in: Sieber u.a. (Hrsg.), National Criminal Law, S. 52-55; Glendon/Carozza/Picker, Comparative Legal Traditions, S. 275-284; Partington, Introduction, S. 58-68; Servidio-Delabre, Common Law, S. 77-93; Slapper/Kelly, English Legal System, S. 115-147. Auch Courakis, GA 1981, 533 (536-552).

97 Ehrmann, Comparative Legal Cultures, S. 24-25; Servidio-Delabre, Common Law, S. 57; Spencer, in: Delmas-Marty/Spencer (Hrsg.), European Criminal Procedures, S. 143144. Außerdem Glendon/Carozza/Picker, Comparative Legal Traditions, S. 167-171. Ausführlicher zur Geschichte von legislation in England Baker, Introduction, S. 204-220. 
Gegenwärtig wird ein großer Teil der englischen Rechtsnormen erst durch Gesetze (vor allem statutes oder Acts of Parliament und statutory instruments) geschaffen bzw. neu bestimmt. ${ }^{98}$ Trotzdem wurden bis in die heutige Zeit kaum umfassende, in systematischer und vereinheitlichender Weise ,neues“ Recht schaffende Kodifikationen durchgeführt. Konsolidierungswerke wie die Criminal Procedure Rules (CPR) fassen meist nur grundsätzlich schon vorexistierende Gesetze oder Regeln des Common Law zusammen. ${ }^{99}$ Darüber hinaus schließt das Prinzip der Souveränität des Parlaments (parliamentary sovereignty), ${ }^{100}$ das sich selbst durch die Rechtsprechung entwickelt hat, die Gesetzesinterpretation ${ }^{101}$ und somit gegebenenfalls (z.B. bei echten Gesetzeslücken) die weitere Rechtsschöpfung durch die Gerichte nicht aus. Im Ganzen behalten daher die Regeln und Prinzipien des richterlichen Common Law weiterhin ihre zentrale Stellung in der englischen Rechtsordnung. ${ }^{102}$

Der englische Strafprozess wird jedenfalls gegenwärtig in erheblichem Maße durch eine Reihe von Parlamentsgesetzen sowie eine sekundäre Gesetzgebung und weniger unmittelbar durch Prinzipien des Common Law geregelt. Die Letzteren sind beispielsweise in Teilen des Beweisrechts oder in Bereichen wie der law on abuse of process zu finden. Selbst die gesetzlichen Regelungen haben aber oft eine Common Law-Herkunft. ${ }^{103}$ Als wichtige, zu großen Teilen selbstständige Rechtsquellen, die zugleich den modernen strafprozessualen Entwicklungen in England entsprechen, sind beispielsweise die folgenden zu erwähnen:

$98 \mathrm{Zu}$ legislativen Organen und Verfahren (legislation und delegated legislation) Elliott/ Quinn, English Legal System, S. 41-50, 77-88, 106-109; Partington, Introduction, S. 3651; Servidio-Delabre, Common Law, S. 57-63; Slapper/Kelly, English Legal System, S. 79-91, 109-115.

99 Sprack, Criminal Procedure, Rn. 2.01-2.07; http://www.justice.gov.uk/courts/proce dure-rules/criminal [Stand: Oktober 2014]. Allgemein zum Scheitern von englischen Kodifikationsarbeiten, vor allem von Benthams Kodifikationsversuchen, und zu den Gründen für das Scheitern (u.a. konservative Gegenbewegung aufgrund der tief verwurzelten Tradition des common law, dezentrale Struktur der englischen Strafjustiz, Misstrauen gegenüber strafrechtlichem „social engineering“) siehe Sieber/Engelhart, RW 2012, 364 (378); ausführlicher Teubner, Kodifikation, insb. S. 132-207.

100 Ungeachtet seiner Verpflichtungen innerhalb der EU verabschiedet das englische Parlament nach diesem Prinzip beliebig Gesetze, welche die oberste nationale Rechtsquelle darstellen, grundsätzlich nicht an vorheriges Gesetzes- oder Richterrecht gebunden sind und ihrerseits die Richter, nicht aber die nachfolgenden Parlamente binden, so Forster, in: Sieber u.a. (Hrsg.), National Criminal Law, S. 25-27; Servidio-Delabre, Common Law, S. 55-56, 77.

$101 \mathrm{Zu}$ den allgemeinen Methoden der Gesetzesauslegung Elliott/Quinn, English Legal System, S. 51-75; Servidio-Delabre, Common Law, S. 63-69; Slapper/Kelly, English Legal System, S. 91-109.

102 Servidio-Delabre, Common Law, S. 77. Vgl. noch Bohlander, LJIL 24 (2011), 393 (400); Forster, in: Sieber u.a. (Hrsg.), National Criminal Law, S. 17-18.

103 Vgl. Dennis, Evidence, Rn. 1.018. 
- der Criminal Evidence Act 1898 sowie die moderneren Konsolidierungswerke Criminal Appeal Act 1968, Juries Act 1974, Magistrates' Courts Act 1980 (MCA) und Supreme Court Act 1981 (Senior Courts Act 1981);

- der Police and Criminal Evidence Act 1984 (PACE), der zusammen mit zahlreichen Codes of Practice für das polizeiliche Vorverfahren von zentraler Bedeutung ist;

- der Prosecution of Offences Act 1985, der die Deliktverfolgungsmechanismen allgemein und (seit 2003) die Klageerhebung für konkrete Delikte (statutory charging) grundsätzlich in die Hände der Crown Prosecution Service (CPS) legte;

- der Criminal Justice Act 1987 sowie der Criminal Justice and Public Order Act 1994 (CJPOA 1994), der unter anderem Vorschriften zur Einschränkung des Schweigerechts des Beschuldigten enthielt;

- der Criminal Procedure and Investigations Act 1996 (CPIA 1996), der unter anderem disclosure-Fragen regulierte;

- der Human Rights Act 1998 (HRA), der die Rechte der EMRK in das englische Recht ,inkorporierte“ (genauer: re-enacted oder restated);

- der Youth Justice and Criminal Evidence Act 1999;

- der Anti-Terrorism, Crime and Security Act 2001 als Antwort auf die Terroranschläge vom 11.9.2001;

- der Criminal Justice Act 2003 (CJA 2003) und der Courts Act 2003, die erhebliche Änderungen in vielen der vorgenannten Gesetze, u.a. in Bezug auf die Gerichtszuständigkeit und das Beweisrecht, mit sich gebracht haben;

- die Criminal Procedure Rules 2005 (und ihre Neufassung in 2010, 2011, 2012, 2013 und 2014), die vorliegend von erheblichem Interesse sind;

- der Serious Organised Crime and Police Act 2005 mit der Errichtung der Serious and Organised Crime Agency;

- der Constitutional Reform Act 2005, durch den das vom Parlament nun getrennte Supreme Court des Vereinigten Königreichs konstituiert wurde (aktiv seit 1.10.2009); sowie

- die neueren Serious Crime Act 2007, Criminal Justice and Immigration Act 2008, Counter-Terrorism Act 2008, Criminal Evidence (Witness Anonymity) Act 2008, Coroners and Justice Act 2009, Terrorism Prevention and Investigation Measures Act 2011, Legal Aid, Sentencing and Punishment of Offenders Act 2012 und Crime and Courts Act 2013. ${ }^{104}$

104 Für mehr Details Ashworth/Redmayne, Criminal Process, S. 9-16; Forster, in: Sieber u.a. (Hrsg.), National Criminal Law, S. 48-56, 59-68; Schulte-Nover, Strafrichter, S. 190193; Spencer, in: Delmas-Marty/Spencer (Hrsg.), European Criminal Procedures, S. 143147. Siehe auch Darbyshire, Legal System, S. 300-315. Das Gesetzesrecht des Vereinigten Königreichs ist unter http://www.legislation.gov.uk/ [Stand: Oktober 2014] abrufbar. 
Diese Verstreuung der Rechtsquellen auf verbindliches Richterrecht und mehrere Einzelgesetze und insbesondere das Fehlen einer zentralen Kodifikation des Strafrechts und -verfahrens gelten für die civil law-Juristen auch weiterhin als fundamentale Unterschiede zwischen dem englischen common law-Mutterrecht und den kontinentaleuropäischen Rechtsordnungen. ${ }^{105}$ Zum Teil unterscheidet sich zusätzlich das Rechtsquellensystem in England von seinen Tochtersystemen, wie vor allem im Fall des US-amerikanischen Rechts zu sehen ist.

\section{bb) Zum Rechtsquellensystem in den USA}

Auch in den USA sind mehrere Rechtsquellen in Form von Gesetzesrecht sowie Richterrecht $\mathrm{zu}$ finden. $\mathrm{Zu}$ den politisch und historisch bedingten Besonderheiten Nordamerikas gehört die der föderalistischen Staatsstruktur entsprechende Verstreuung der komplexen (Straf-)Regeln über das Recht der einzelnen Staaten (state law) und außerdem über das Recht des Bundes (federal law). Neben der parallelen Existenz mehrerer „Rechtsordnungen“ innerhalb desselben Landes besteht ein weiterer Unterschied zum staatlich einheitlichen Recht Englands in den homogeneren Gesetzesbüchern und Kodifikationswerken, die im 20. Jahrhundert auf Bundessowie vor allem auf Staatenebene angefertigt wurden.

Im strafrechtlichen Bereich sind, neben den Vorschriften mehrerer Verfassungen und Nebengesetze, auch Strafgesetzbücher und Kodifikationen des Strafprozesses anzutreffen, die entweder neues Recht schaffen oder - wie es oft der Fall ist frühere Gesetzesregelungen und Prinzipien des Common Law systematisch organisieren bzw. neu aufnehmen. Zu erwähnen sind etwa der Model Penal Code 1962 und alle Strafgesetzbücher der Staaten (wie z.B. New York und Pennsylvania), die auf ihm basieren. Für das Strafverfahren von besonderer Bedeutung sind die verschiedenen codes of criminal procedure der Staaten, die Federal Rules of Criminal Procedure oder die Federal Rules of Evidence und die entsprechenden staatlichen court rules und evidence codes. ${ }^{106}$

Auch wenn Recht schon seit der Kolonialzeit schriftlich niedergelegt wird und Gesetze seit Ende des 19. Jahrhunderts die primäre Rechtsquelle darstellen, ist das judge-made law rechtsgeschichtlich und bis in die heutige Zeit von zentralem Wert für die Rechtsentwicklungen in den USA. Das englische Common Law war von den ersten Juristen des unabhängigen Bundes nicht ohne Bedenken aufgenommen

Eine umfangreiche case law-Sammlung ist unter http://www.bailii.org/ [Stand: Oktober 2014] abrufbar.

105 Dazu einführend van Caenegem, Judges, S. 39-53.

106 Zum Verfassungs- und Gesetzesrecht, Strafrecht und Strafprozessrecht auch Dubber, Einführung, S. 2-7, 16-17; LaFave/Israel/King/Kerr, Criminal Procedure, S. 33-35; Reinbacher, Strafrechtssystem der USA, S. 17-19; Schmid, Strafverfahren, S. 22-24; allgemein Servidio-Delabre, Common Law, S. 189-196. 
worden und wurde schließlich an die neue politische und ökonomische Wirklichkeit sowie die praktischen Erfordernisse der Vereinigten Staaten angepasst. Teilweise originäres amerikanisches Recht begann dann durch die Gerichte und ihren case law zu entstehen. Aufgrund der Komplexität und Vielfalt der Rechtsordnungen und Gerichtsbarkeiten ergab sich nach und nach eine Fassung des stare decisisPrinzips, die lockerer war als in England. Heute werden durch lang bestehende Prinzipien des Common Law, durch amerikanisches verfeinertes Fallrecht der Staatengerichte oder durch supervisory authority rulings auf Bundesebene weiterhin diejenigen Teilbereiche des Strafprozesses reguliert, die nicht von den Verfassungen und detaillierten Gesetzesregelungen erfasst werden: z.B. der Inhalt der closing statements und außerdem manche due process- und evidence law-Teilfragen und Fragen zur fairen Handhabung der Strafjustiz. Die Gesetze selbst verkörpern nicht selten frühere Regeln des Common Law. Zudem werden die Common LawPrinzipien stets bei der Interpretation der Gesetzestexte beachtet. ${ }^{107}$

Die Gesetzesauslegung durch die supreme courts und die sich eventuell dadurch ergebende richterliche Rechtsschöpfung sind von erheblicher Bedeutung für das US-Rechtssystem allgemein sowie, insbesondere in Strafsachen, für die Fortentwicklung der relevanten, auch für die juristische Ausbildung wichtigen case lawLehre. Insgesamt haben die amerikanischen Richter heute noch, in ähnlicher Weise wie ihre Kollegen in anderen common law-Ländern, ${ }^{108}$ eine zentrale Stellung bei der Produktion von Rechtsnormen inne. Den Ausführungen zu dieser für Rechtsquellensysteme angloamerikanischer Prägung typischen Struktur sowie den vorangegangenen Ausführungen zu den eigenständigen historischen beweisprozessualen Entwicklungen und zur institutionellen Funktion des reinen jury-Strafverfahrens in der common law-Tradition sind nun die parallelen rechtsgeschichtlichen Verläufe auf dem europäischen Kontinent und in der civil law-Tradition gegenüberzustellen.

\section{Einführung in die Tradition des kontinentaleuropäischen Strafverfahrens}

\section{a) Vorbemerkungen}

Der Rechtshistoriker Raoul Charles van Caenegem hat die seit dem 12. Jahrhundert getrennt verlaufenden Entwicklungen der zwei zentralen Rechtstraditionen des

107 Ausführlicher zum Common Law und case law in den USA Dubber, Einführung, S. 7-13; LaFave/Israel/King/Kerr, Criminal Procedure, S. 35-38; Reinbacher, Strafrechtssystem der USA, S. 19-21; Schmid, Strafverfahren, S. 24-31; Servidio-Delabre, Common Law, S. 196-204. Siehe auch Dawson, in: Berman (Hrsg.), Talks, S. 21-32, und Ehrmann, Comparative Legal Cultures, S. 23-24, 115.

108 Exemplarisch zu den Strafrechtsquellen in Kanada Coughlan, Criminal Procedure, S. 8-32 und zu den Quellen des Beweisrechts in Australien Hunter/Cameron/Henning, Evidence, S. 777-779. 
Westens, die beide europäische Wurzeln haben, vor allem in folgenden Punkten zusammengefasst: ${ }^{109}$

- Grundlegend sei erstens für die Entwicklungen in der common law-Tradition die sehr frühe Entstehung eines einheitlichen ,nationalen“ Rechtssystems in England und die weite Verbreitung der jury- und writ-Verfahren. Im Gegensatz dazu kam es in den kontinentalen Ländern viel später zur „Modernisierung“ des Rechts und zur nationalen Rechtsvereinheitlichung. Verantwortlich dafür waren die lokale Zersplitterung des Rechts, die unterschiedlichen Aufnahmephasen in den lokalen Regionen und den ersten kontinentalen nation-states, was das gemeine Recht (jus commune, eine gelehrte Neubearbeitung des Römischen und Kanonischen Rechts) anbelangte, und die Vermischung des Letzteren mit unzähligen Gewohnheitsrechten.

- Von zentraler Bedeutung sei zweitens die bis ins 19. Jahrhundert währende Vielfalt von bereichsspezifischen, eigenständigen prozessualen Rechtsbehelfen und Rechtswegen im englischen Common Law im Gegensatz zu den allgemeinen, auf weite Rechtsgebiete einheitlich anwendbaren Prozessregeln der kontinentaleuropäischen Rechte.

- Charakteristisch sei drittens die Präferenz in der common law-Welt für Präzedenzrecht und für empirische (from case to case) Rechtsschöpfung sowie das Fehlen echter Kodifikationswerke. Im Gegensatz dazu hat sich Kontinentaleuropa auf abstrakt-theoretische Rechtskonzepte und Definitionen, auf die allgemeinen Prinzipien und die deduktiven Begründungsweisen des an den mittelalterlichen Universitäten und in exegetischen Kommentaren und Lehrbüchern neu eingeführten Römischen Rechtssystems sowie folglich auf die großen systematischen Kodifizierungen der modernen Zeit konzentriert.

- Viertens sei die ab initio praktische Ausbildung der englischen lawyers (vor allem in den berühmten „Inns of Court“) nicht außer Acht zu lassen. Die juristische Ausbildung auf dem Kontinent fand dagegen grundsätzlich bei Gelehrten und an Universitäten statt.

Dementsprechend ergeben sich im Rahmen einer einführenden Kurzbetrachtung der historischen Wurzeln und Hauptcharakteristika der civil law-Prozesswelt größere Schwierigkeiten als bei der Untersuchung des im Zeitwandel stabileren common law. Diese beziehen sich insbesondere auf die fragmentarische und uneinheitliche Entwicklung der verschiedenen Territorial- und Länderrechte sowie auf die letztendliche Durchsetzung auf dem Kontinent von zumindest zwei zentralen Arten des Rechtsdenkens (der französischen und der deutschen) und mehreren Tochterrechten. Schließlich haben alle verschiedenen Teilrechtssysteme ihrerseits auch zur

109 Van Caenegem, Birth, S. 88-89; siehe auch van Caenegem, Judges, S. 114-126. Insb. zum deduktiven und induktiven Rechtsdenken und zur unterschiedlichen Rolle der Strafrechtsdogmatik in Deutschland und England auch Bohlander, LJIL 24 (2011), 393 (399-406). 
Weiterentwicklung von kennzeichnenden Rechtsmerkmalen innerhalb der kontinentaleuropäischen Rechtstradition mehr oder weniger stark beigetragen. ${ }^{110}$ In den folgenden Ausführungen soll nun, soweit möglich, auf Bezüge zu einzelnen Rechtsfragen in konkreten Rechtsordnungen und auf unmittelbare Vergleichungen verzichtet werden. Eine umfassende Gegenüberstellung aller Rechtssysteme kontinentaleuropäischer Prägung auf historischer, rechtspolitischer, struktureller und normativer Ebene ist hier in der Tat ausgeschlossen. Aber auch die strikte Beschränkung auf spezifische Rechtsordnungen würde an dieser Stelle nur in begrenztem Maße zu brauchbaren Ergebnissen bezüglich des generellen Identitätsbilds der prominenten Rechtstradition führen.

Aus diesem Grund ist für die vorliegende schematische Einführung eine zum Teil abstrakte, die Gemeinsamkeiten innerhalb der Rechtsordnungen stärker gewichtende Betrachtungsweise auszuwählen. Die Basis der kommenden Ausführungen bilden die Hauptentwicklungen und gemeinsamen ,prevailing attitudes ${ }^{\text {“111 }}$ in (West- und Mittel-)Europa, die von der Mehrheit der westlichen Juristen als vorrangig charakteristisch oder einflussreich für sämtliche heutigen civil law-Systeme anerkannt werden. So können diese zugleich bzw. gerade deswegen auch für das Verständnis des jeweiligen Hintergrunds der Entstehung der gegenwärtigen Strafund Beweisverfahrenssysteme von Bedeutung sein. Zunächst sind in diesem Sinne vor allem die gemeinsamen Wurzeln der Teilrechte und die prägenden Ereignisse in der europäischen civil law-Geschichte i.V.m. der Rechtsquellenproblematik zu beleuchten. Weiterhin werden die strafprozessualen Entwicklungen anhand von einführenden Fragen zur Gerichtsbarkeit und zum Beweisverfahren auf dem Kontinent angesprochen.

\section{b) Wesentliche historische Stationen in der civil law-Tradition}

Zentrale Schritte in der Entwicklung des civil law waren das jus commune und die Revolutionen und Kodifikationen der modernen Zeit. Die Suche nach den römischen Wurzeln der Tradition der kontinentaleuropäischen (römisch-germanischen) Rechte - für die englischsprachige Literatur: des civil law - führt möglicherweise bis in das Jahr 450 v. Chr. und bis zur Veröffentlichung der Zwölftafelgesetze zurück. ${ }^{112}$ Endgültig haben aber die Nachbearbeitung des antiken

110 Vgl. auch Bohlander, JICJ 12 (2014), 491 (493).

111 Merryman/Pérez-Perdomo, Civil Law Tradition, S. x (vgl. ebenso S. 143-151).

112 Der Begriff ,jus civile“ deutete ursprünglich auf das Recht der römischen Bürger hin, vgl. Hattenhauer, Europäische Rechtsgeschichte, S. 85-92 und S. 92-127, zur jus civile-Entwicklung und zu den anderen römischen Rechtsinstitutionen bis in die JustinianZeit. $\mathrm{Zu}$ den verschiedenen Bedeutungen des Begriffs „,civil law“ Clark, in: ders. (Hrsg.), Comparative, S. 12-16; David/Brierley, Major Legal Systems, S. 23 (Fn. 19); de Cruz, Comparative Law, S. 45-48; Glendon/Carozza/Picker, Comparative Legal Traditions, S. 51-52; Reichel, Comparative Criminal Justice, S. 88-89. 
Römischen Rechts durch die Kodifikationen von Kaiser Justinian in der Mitte des 6. Jahrhunderts n. Chr. und mehr noch die substantielle Neubearbeitung der Rechtswerke des Letzteren durch Gelehrte an den europäischen Universitäten im Hochmittelalter den Grundstein für den heute üblicherweise als kontinentaleuropäische Rechtstradition bezeichneten Ansatz gelegt. Neben dem solcherart neu entdeckten Römischen Recht sind weitere wichtige Bestandteile der Geschichte bzw. der Identität dieser Tradition die folgenden: das mittelalterliche Kanonische Recht, die normative Umsetzung der Revolutionsideen der (früh-)modernen Zeit sowie die inzwischen erreichten und bis heute fortdauernden Errungenschaften der Gesetzgebung (Kodifikationen) und der Rechtswissenschaft. ${ }^{113}$

aa) Römisch-kanonisches Recht und europäisches jus commune

\section{- Römisches Recht und jus commune (6.-17. Jahrhundert)}

Die Kodifikationswerke und Rechtssammlungen von Justinian im 6. Jahrhundert haben, neben mehreren öffentlich-rechtlichen Regelungen, vor allem durch die Wiederherstellung und Systematisierung des Römischen Privatrechts die gemeinsamen Grundlagen für die weitere Entwicklung der civil law-Rechtssysteme geschaffen. ${ }^{114}$ Parallel dazu führte der Untergang des weströmischen Reichs aber zumindest in Zentral- und Westeuropa für lange Zeit zu politischen Unruhen und territorialer Zersplitterung, zur Vermischung von römischen und lokalen Rechtsinstituten und Gewohnheitsrechten, die primär von den germanischen Invasoren mitgebracht worden waren, und letztendlich zu den sogenannten barbarized Roman laws. Die eigentliche „Wiederbelebung“ des Römischen Rechts auf dem Kontinent fand dann erst fünf Jahrhunderte nach der Justinian-Zeit statt. Im Zentrum dieser Entwicklung standen anfangs die byzantinische Gesetzessammlung Basilika im 9. Jahrhundert und ab Ende des 11. Jahrhunderts die auf dem Corpus Juris Civilis basierende rechtswissenschaftliche Lehre an der Universität von Bologna, Italien.

Die Arbeitsmethoden und die schriftlichen Werke der Rechtsgelehrten (Glossatoren und später Kommentatoren) in Italien wurden anschließend auch an anderen neu gegründeten Universitäten verbreitet, bis nach und nach ein grenzübergreifendes, einheitlicheres Rechtsdenken und sogar ein gelehrtes gemeines Recht in Europa entstanden. Dieses sogenannte jus commune wurde in der Folge in weiten Regionen und in den sich allmählich herausbildenden Nationalstaaten Kontinentaleuropas mehr oder weniger direkt (wenn auch auf subsidiärer Ebene) übernommen oder hatte zumindest einen erheblichen inhaltlichen Einfluss auf die vielen schon

113 Merryman/Pérez-Perdomo, Civil Law Tradition, S. 2-4, 6. Zusammengefasst zu diesen Entwicklungsstadien des civil law (mit Schwerpunkt auf dem Privatrecht) Glendon/ Carozza/Picker, Comparative Legal Traditions, S. 17-58; auch Reichel, Comparative Criminal Justice, S. 88-91.

${ }_{114} \mathrm{Zu}$ Geschichte und Inhalt des Corpus Juris Civilis siehe Hattenhauer, Europäische Rechtsgeschichte, S. 127-134. 
existierenden lokalen Rechte. Insbesondere die privatrechtlichen Konturen des Römischen Rechts und des gemeinen Rechts haben sogar zum Teil die nationalistischen Reformen des 16. und 17. Jahrhunderts überlebt und manifestieren sich in den zivilrechtlichen Kodifikationen der Napoleonischen Zeit. ${ }^{115}$

\section{- Mittelalterliches Kanonisches Recht}

Im Strafrechtsbereich ist für die Entstehung der grundlegenden Rechts- und Justizinstitutionen der kontinentaleuropäischen Rechtstradition außer dem Römischen Recht spätestens seit dem Frühmittelalter auch das ,universale“ Recht der Kirche essenziell gewesen. Anhand des Kanonischen Rechts, das selbst von römischen Rechtskonturen beeinflusst war, wurden grundsätzlich Angelegenheiten mit unmittelbarem Bezug zur Kirche reguliert. Die Kirchengerichte haben sich aber oft in säkularen, familienrechtlichen oder sogar auch strafrechtlichen Sachen eingeschaltet. Daraufhin wurde auch das Kanonische Recht der römisch-katholischen Kirche an den Universitäten des Hochmittelalters überarbeitet und gelehrt, sodass es letztendlich ebenfalls eine Rolle bei der Formierung des gemeinen Rechts (jus commune) spielte. Diese Entwicklung trat, wie noch zu zeigen ist, vor allem im Bereich des Strafrechts und Strafverfahrens auf, wobei ansonsten weiterhin die jeweiligen lokalen weltlichen Rechte und Gewohnheiten Anwendung fanden. ${ }^{116}$

\section{- „Einheitliche“ Gesetzeswerke der frühen Neuzeit}

Darüber hinaus galt seit dem Spätmittelalter vor allem im Heiligen Römischen Reich Deutscher Nation und damit in weiten Bereichen Mitteleuropas die Constitutio Criminalis Carolina von 1532. Diese ist grundsätzlich ein „Produkt“ der Rezeption in den deutschen Territorien und wurde in der Folge selbst ein Teil des gemeinen westeuropäischen Rechts. Sie war jedenfalls das damals wichtigste einheitliche Gesetzeswerk für das sonst in mehrere Rechtsquellen zersplitterte kontinentaleuropäische Strafrecht; innerhalb des zu ihrer Zeit bestehenden rechtlichen „Mehrebenensystems“"117 galt die Carolina nur subsidiär. Ihr Text beinhaltete Vorschriften

115 Insgesamt zu diesen Entwicklungen Merryman/Pérez-Perdomo, Civil Law Tradition, S. 6-11, 12-13. Siehe auch Coing, in: Cappelletti (Hrsg.), New Perspectives, S. 3234; Wesel, Geschichte, S. 232-236, 337-340. Ausführlich zum Recht des europäischen Frühmittelalters und zur nachfolgenden Entstehung und Verbreitung des gemeinen Rechts (jus commune) siehe Bellomo, Europäische Rechtseinheit, S. 35-86, 117-165. Zu den verschiedenen Konnotationen des jus commune-Begriffs Wijffels, in: Adams/Heirbaut (Hrsg.), Method, S. 147-151.

116 Merryman/Pérez-Perdomo, Civil Law Tradition, S. 11-12. Siehe auch zum Kanonischen Recht Bellomo, Europäische Rechtseinheit, S. 49-50, 68-79; Wesel, Geschichte, S. 236-242. Zum kirchlichen Strafrecht und zur Strafgewalt in rechtsgeschichtlicher Hinsicht Rees, Strafgewalt, S. 116-171. Allgemein zur historischen Entwicklung des Kanonischen Rechts Coriden, Canon Law, S. 10-27.

117 Sieber, in: EuropStrafRecht, Einf. Rn. 19. 
und Leitsätze zum Strafrecht und vor allem zum Strafverfahrensrecht, die zur Durchsetzung bzw. Reform des mittelalterlichen Inquisitionsprozesses beigetragen haben, und hat zumindest in Mitteleuropa die Entwicklungen in Strafsachen bis in das 19. Jahrhundert erheblich beeinflusst. ${ }^{118}$ Andere ,nationale“ Gesamtwerke, die daneben für das Strafrecht und insbesondere für das Strafverfahren (einschließlich der harten Straf- und Folterregelungen) des kontinentaleuropäischen Spätmittelalters und der frühen Neuzeit von Bedeutung waren, sind in erster Linie die Ordonnance de Villers-Cotterêts von 1539 und die darauf gründende Ordonnance Criminelle von 1670 für Frankreich sowie die Nueva Recopilación von 1567 für Spanien.

\section{bb) Die Revolutionen und Kodifikationen der Neuzeit}

\section{- Nationale Reformen und erste Kodifikationen der Neuzeit}

Die späteren Entwicklungen innerhalb der civil law-Tradition sind durch die intellektuellen Bewegungen der europäischen Aufklärung und die nachfolgenden westlichen (geistlichen, politischen, sozialen und wirtschaftlichen) Revolutionen im 18. und 19. Jahrhundert gekennzeichnet. Das jus commune konnte dabei, im Gegensatz zur zentralen Stellung des common law für England, seine autoritative Rolle als gemeines Recht Kontinentaleuropas nicht beibehalten, blieb aber inhaltlich auch für die neuen nationalen Staaten von Bedeutung. Die ersten Reformen in den kontinentalen Regionen der frühmodernen Zeit bezogen sich vor allem auf folgende Punkte: das öffentliche Recht und Verfahren, die neuen Ansätze des zunächst naturalistischen und säkularen, humanitären, anti-feudalistischen, rationalistischen und später nationalistischen und positivistischen Rechtsdenkens und somit die gewaltenteilende Staatsorganisation und die nationalstaatliche Justizverwaltung. 119

Die ethisch-rechtlichen Prinzipien der Revolutionszeit, die Gewaltenteilung und die Durchsetzung des Rechtspositivismus innerhalb von souveränen Nationalstaaten in Kontinentaleuropa führten somit unter anderem zur Ablehnung des Richterrechts bzw. eines Rechtssystems, das auf Präzedenzfällen oder richterlichen Gesetzesauslegungen beruht. Angenommen wurden stattdessen die ersten umfassenden Kodifikationswerke der modernen Rechtsgeschichte; durch diese wurden große „einheitliche“ Gesetzeswerke der frühen Neuzeit wie die Constitutio Criminalis Carolina schließlich verdrängt. Diese Kodifikationen ${ }^{120}$ hatten als Hauptziel die

118 Ausführlicher Sieber, in: EuropStrafRecht, Einf. Rn. 17-22. Siehe auch Ignor, Geschichte, S. 41-44; Rüping/Jerouschek, Strafrechtsgeschichte, S. 40-48. Allgemeiner in Bezug auf die deutschen Strafrechtsentwicklungen Jescheck/Weigend, AT, S. 91-97; K. Peters, Strafprozeß, S. 57-70.

119 Für Einzelheiten Merryman/Pérez-Perdomo, Civil Law Tradition, S. 15-26. Vgl. auch Sieber, in: EuropStrafRecht, Einf. Rn. 23-28.

120 Zum Kodifikationsbegriff, den Kodifikationsvoraussetzungen und den -zielen eingehend Sieber/Engelhart, RW 2012, 364 (366-381). 
zusammenstellende, systematische, einheitliche, klare und lückenlose Einsetzung von grundsätzlich neuem Recht und/oder die grundlegende wissenschaftliche Neuerschaffung von älteren Prinzipien und Rechtsinstituten. Sie haben ihren Ursprung zum großen Teil in der Napoleonischen Gesetzgebung (wie vor allem der Code civil von 1804, der Code pénal von 1810 und der Code d'instruction criminelle von 1808) bzw. in der deutschen Rechtswissenschaft und den daran anknüpfenden Rechtswerken des 19. Jahrhunderts (wie das Bayerische Strafgesetzbuch von 1813 und das spätere Bürgerliche Gesetzbuch von 1896). ${ }^{121}$

\section{- Moderne Kodifikationen des Strafrechts und -verfahrens, Rechtsprechung und Wissenschaft}

Diese grundlegenden Werke haben im Nachhinein - und mehr oder weniger in kontinuierlicher Verbindung mit dem gemeinen Recht (jus commune) und dem Römischen Recht des Mittelalters, wie es etwa durch die Pandektenlehre abermals neu bearbeitet wurde - das Recht mehrerer (nicht nur) kontinentaleuropäischer Länder geprägt. So werden gegenwärtig auch das Strafrecht und das Strafverfahren in Rechtsordnungen, die üblicherweise der kontinentaleuropäischen Rechtswelt zugeordnet werden, primär durch zentrale Gesetzeswerke geregelt, die ihre historischen Wurzeln bzw. Grundlagen in den Kodifikationen des 19. Jahrhunderts und den nachfolgenden Reformprozessen haben, zum Beispiel:

- In Frankreich selbst galt der Code pénal von 1810, ungeachtet mehrerer Reformund Nebengesetze, bis zum endgültigen Inkrafttreten des neuen Strafgesetzbuches im Jahr 1994 als Grundlage des materiellen Strafrechts. Entsprechend ist der Code d'instruction criminelle von 1808 erst durch den Code de procédure pénale aus dem Jahr 1959 ersetzt worden. ${ }^{122}$

- In Deutschland ist das ursprüngliche, für das ganze Land einheitliche Strafgesetzbuch der modernen Zeit, das Reichsstrafgesetzbuch von 1871 (das grundsätzlich auf das Preußische Strafgesetzbuch von 1851 und seine französischen und bayerischen Einflüsse zurückging), trotz mehrerer Teilanpassungen in seinen wesentlichen Konturen zumindest bis zu den Reformgesetzen von 1969 bis 1974 und der grundlegenden Neufassung des Strafgesetzbuches (StGB) von 1975

121 Zum ideologischen Hintergrund der Kodifikationen Merryman/Pérez-Perdomo, Civil Law Tradition, S. 27-33. Siehe auch Jescheck/Weigend, AT, S. 95-97; Sieber, in: EuropStrafRecht, Einf. Rn. 23-28, 38. Vgl. noch K. Peters, Strafprozeß, S. 67-70. Insb. zu den Hintergründen sowie zur Bedeutung (auch für das deutsche Strafverfahren) des Code d'instruction criminelle kurz Jung/Weigend, in: Jung u.a. (Hrsg.), 200 Jahre, S. 17-21. Zur historischen Bedeutung der französischen und deutschen Gesetzgebung des 19. Jahrhunderts für das materielle Strafrecht Europas Wesel, Geschichte, S. 459-463. Zum „Zeitalter der Kodifikationen“ Bellomo, Europäische Rechtseinheit, S. 1-33.

$122 \mathrm{Zu}$ den Strafrechtsquellen und den diesbezüglichen Entwicklungen in Frankreich Pfützner/Adams/Neumann, in: Sieber/Cornils (Hrsg.), Nationales Strafrecht, S. 245-249, 250-273. Siehe auch Sieber, in: EuropStrafRecht, Einf. Rn. 23, 36-38 m.w.N. 
weitgehend gültig geblieben. Die Strafprozessordnung (StPO) von 1877 (in der Fassung von 1987) und das Gerichtsverfassungsgesetz (GVG) von 1877 (in der Fassung von 1975) gelten, wenn auch mehrmals einer Reform unterzogen, noch als Kern des deutschen Strafprozesses. ${ }^{123}$

- In österreichischen Territorien wurden die Partikularrechte des Alten Reichs und die Constitutio Criminalis Carolina Ende des 18. Jahrhunderts durch die ersten einheitlichen Strafgesetze Constitutio Criminalis Theresiana und Josephina und nachfolgend durch das Strafgesetz von 1803 ersetzt; das Letztere bildete nun auch im modernen österreichischen Bundesstaat bis zum Inkrafttreten des neuen Strafgesetzbuches von 1974 die Basis für das materielle Strafrecht. Die Strafprozessordnung von 1873 ist ihrerseits, trotz erheblicher Reformen, heute noch gültig. ${ }^{124}$

- Auch in den Niederlanden galten im Mittelalter sowie in der Zeit nach der Unabhängigkeit (1648) vom Heiligen Reich grundsätzlich die verstreuten lokalen Rechte und Gewohnheitsrechte i.V.m. dem gemeinen Recht Mitteleuropas, bis einheitliche Rechtswerke wie das Crimineel Wetboek voor het Koningrijk Holland von 1809, kurz danach im Jahr 1811 der französische Code pénal und schließlich 1886 das Wetboek van Strafrecht in Kraft traten; das Letztere bildet bis heute die Grundlage für das niederländische Strafrecht. Für das Strafverfahren orientierte sich die Strafprozessordnung von 1838 wesentlich am Code d'instruction criminelle, wobei ihre Fortsetzung in Form der noch geltenden Strafprozessordnung von 1926 auch manche englischen Einflüsse zeigt. ${ }^{125}$

- In Strafsachen in Italien galten nach der Aufklärung als Nachfolger des gemeinen Rechts zunächst mehrere, insbesondere vom Code pénal und der österreichischen Gesetzgebung beeinflusste Strafgesetzbücher der einzelnen Territorien;

123 Siehe Fischer, StGB, Einl. Rn. 3-10; Jescheck/Weigend, AT, S. 96-107; K. Peters, Strafprozeß, S. 68-74 (auch zu gewissen Prozessordnungen im Anfang des 19. Jahrhunderts, wie der Preußischen Kriminalordnung von 1805 und der Bayerischen Prozeßordnung von 1803, die den Inquisitionsprozess enthielten). Siehe auch Sieber, in: EuropStrafRecht, Einf. Rn. 29-30 m.w.N.; Sieber/Engelhart, RW 2012, 364 (381-388). Zur Einführung der Reichsstrafprozessordnung bemerkt Rieß, Beiträge, S. 25: „Die StPO begründete bei ihrem Inkrafttreten einheitlich für das deutsche Rechtsgebiet den modernen reformierten Strafprozess, der den gemeinrechtlichen Inquisitionsprozess überwand und ablöste. Sie stellt den Schlussstein einer seit der Wende vom 18. zum 19. Jahrhundert ablaufenden Entwicklung dar, die sich zunächst in verschiedenen, aber auf einer gemeinsamen geistesgeschichtlichen Grundlage beruhenden partikularrechtlichen Verfahrensordnungen verwirklichte. Mit ihr beginnt eine neue Epoche des Strafverfahrens. Sie steht nicht isoliert, sondern in geistesgeschichtlichem Zusammenhang mit einer mindestens kontinentaleuropäischen Gesamtentwicklung und als deren Teilstück. In ihrer konkreten Ausgestaltung bildet sie deren spezifisch deutsche Variante." Zu den Rechtsquellen des gegenwärtigen deutschen Strafverfahrens u.a. Roxin/Schünemann, Strafverfahrensrecht, § 3 Rn. 1-29.

124 Sieber, in: EuropStrafRecht, Einf. Rn. 31-34; ausführlich Zerbes, in: Sieber/Cornils (Hrsg.), Nationales Strafrecht, S. 432-433, 459-461, 466-477 m.w.N.

125 Für Einzelheiten Chorus/Coppens, in: Chorus u.a. (Hrsg.), Introduction, S. 3-8; Mincke, Einführung, S. 1-6, 252-253; Nijboer, in: Chorus u.a. (Hrsg.), Introduction, S. 402-405; Sieber, in: EuropStrafRecht, Einf. Rn. 42-45 m.w.N. 
nach der nationalen Einigung (1861) traten das erste einheitliche Strafgesetzbuch 1890 und das gegenwärtige Strafgesetzbuch 1931 in Kraft. Die erste im eigentlichen Sinne einheitliche Kodifikation des grundsätzlich von französischen Einflüssen geprägten Strafprozessrechts stammt aus dem Jahr 1913 und ihr Nachfolger (Codice Rocco) aus dem Jahr 1930. Die heutige, stark an angloamerikanische Elemente anknüpfende Strafprozessordnung (Codice di procedura penale) trat 1989 in Kraft. ${ }^{126}$

- In Spanien, wo es schon seit Ende des 15. Jahrhunderts erste Anzeichen für eine nationalstaatliche Rechtsorganisation gab, ist im strafrechtlichen Bereich als wichtiger moderner Nachfolger des gemeinen Rechts (jus commune), der königlichen und verstreuten lokalen Rechte und des mittelalterlichen Rechtsbuches Las Siete Partidas der Código Penal von 1848 zu erwähnen; dieser wurde mehrmals durch neue, darauf aufbauende Strafgesetze bis hin zur Schaffung des heutigen Strafgesetzbuches von 1995 ersetzt. Die Strafprozessordnung (Ley de Enjuiciamiento Criminal) von 1882 gilt dagegen, wenn auch durch Einzelgesetze erheblich verändert, noch bis heute als Basis des spanischen Strafprozesses. ${ }^{127}$

- Schließlich haben die nach-revolutionären europäischen Kodifikationswerke des 19. Jahrhunderts in der (durch das römische Zivilrecht durchweg geprägten) Rechtsordnung Griechenlands nach der Befreiung von der 400-jährigen Unterwerfung durch das Osmanische Reich im Jahr 1830 eine erhebliche Rolle bei der Gestaltung des modernen nationalen Strafrechts gespielt. Das erste Strafgesetzbuch von 1834 hatte das Bayerische Strafgesetzbuch (1813) und den Code pénal (1810) zur Grundlage, während sein Nachfolger, das heutige Strafgesetzbuch von 1951, stärker von den jüngeren deutschen, italienischen und schweizerischen Strafgesetzen beeinflusst ist. Die erste Strafprozessordnung des unabhängigen Griechenland von 1834 basierte auf dem Code d'instruction criminelle (1808), wobei die heutige Strafprozessordnung von 1951 sich zusätzlich an der deutschen Strafprozessordnung (1877) und der italienischen Strafprozessordnung von 1930 orientiert. $^{128}$

Grundsätzlich gelten die Gerichtsentscheidungen in kontinentaleuropäischen Ländern nicht als unmittelbare Rechtsquellen, sodass sich dadurch kein allgemein verbindlicher case law ergibt. Der Richter ist primär ans Gesetz gebunden und für die ,richtige“ Interpretation und Anwendung der Rechtsnormen, nicht aber für die Schaffung neuen Rechts zuständig. Gegenwärtig spielt jedoch in den meisten

126 Ausführlich Jarvers, in: Sieber/Cornils (Hrsg.), Nationales Strafrecht, S. 281-282, 291-292, 318-321, 325-335; auch Sieber, in: EuropStrafRecht, Einf. Rn. 51-55 m.w.N.

127 Analytisch zu den diesbezüglichen Entwicklungen Bachmaier/Moral García, Spain, S. 35-43; Manso Porto, in: Sieber/Cornils (Hrsg.), Nationales Strafrecht, S. 679-681, 707709, 713-727; Merino-Blanco, Spanish Law, S. 1-24, 139-140; siehe auch Sieber, in: EuropStrafRecht, Einf. Rn. 56-62.

128 Mehr dazu bei Billis, in: Sieber u.a. (Hrsg.), National Criminal Law, S. 213-215, 257, 267-278 m.w.N.; siehe auch Sieber, in: EuropStrafRecht, Einf. Rn. 79-82. 
Rechtsordnungen insbesondere die höchstrichterliche Rechtsprechung eine zentrale und sehr einflussreiche Rolle bei der allgemeinen Rechtsfortbildung, vor allem durch die autoritative Auslegung von unklaren und abstrakten Normen und gegebenenfalls durch die Überprüfung der Verfassungsmäßigkeit der Gesetze. Darüber hinaus waren die Arbeiten von Gelehrten und die Durchbrüche der Rechtswissenschaft immer von zentraler Bedeutung für die Entwicklung, Interpretation und Reform der Rechtsinstitute innerhalb der kontinentaleuropäischen Tradition; die Rechtsdogmatik dieser Lehrbücher und Kommentare und ihre Analysemethoden produzieren jedoch keine verbindlichen Normen. ${ }^{129}$

Als ein Kernelement bei der Differenzierung zwischen den Rechtstraditionen wird weiterhin das Phänomen anerkannt, dass in der kontinentaleuropäischen Rechtspraxis und Lehre die nationalstaatliche Regulierung der sich voneinander unterscheidenden Rechtsgebiete anhand umfassender, systematischer und grundlegender Gesetzeswerke andauernd im Vordergrund steht; diese Kodifikationswerke haben ihre Wurzeln in den römisch-kanonischen und/oder nach-aufklärerischen Rechten Europas. Es wird sich zeigen, ob vor allem die zunehmende unsystematische $^{130}$ Normenproduktion auf internationalrechtlicher Ebene $\mathrm{zu}$ entsprechenden Traditionsveränderungen, genauer: zur (weiteren) Zersplitterung der nationalen (Straf-)Rechtsquellen durch diverse Nebengesetze und Rechtsakte supranationaler Herkunft führen wird.

\section{c) Die Entwicklung der kontinentaleuropäischen Gerichtsbarkeiten und Beweisverfahrensarten}

aa) Inquisitionsprozesse im Mittelalter und in der frühen Neuzeit

\section{- Weltliche und kirchliche Gerichtsbarkeiten und die Entstehung des Inquisitions- prozesses}

Während sich das römisch-kanonische jus commune verbreitete und gleichzeitig die verschiedenen lokalen und königlichen Rechte kontinuierlich ausgebaut wurden, entwickelte sich im mittelalterlichen (West- und Mittel-)Europa eine Vielfalt

129 Zur Rolle von Richter, Rechtsprechung und Wissenschaft bei der Rechtsfortbildung in der civil law-Tradition insgesamt Merryman/Pérez-Perdomo, Civil Law Tradition, S. 34-67, 80-85. Vgl. noch Glendon/Carozza/Picker, Comparative Legal Traditions, S. 127-150. Am Beispiel einzelner gegenwärtiger (Straf-)Rechtsordnungen m.w.N.: für Frankreich Hübner/Constantinesco, Einführung, S. 9-12, und Pfützner/Adams/Neumann, in: Sieber/Cornils (Hrsg.), Nationales Strafrecht, S. 247-249; für Deutschland Arzt, Einführung, S. 32-38, 94-99, und Haase/Keller, Grundlagen, S. 18-27; für Österreich Zerbes, in: Sieber/Cornils (Hrsg.), Nationales Strafrecht, S. 463-465; für Italien Jarvers, in: Sieber/ Cornils (Hrsg.), Nationales Strafrecht, S. 321-322; für Spanien Manso Porto, in: Sieber/ Cornils (Hrsg.), Nationales Strafrecht, S. 710-711; für Griechenland Billis, in: Sieber u.a. (Hrsg.), National Criminal Law, S. 260-262.

130 Vgl. Sieber/Engelhart, RW 2012, 364 (403). 
von Justizverfahren und Gerichtsbarkeitssystemen. Diese präsentierten trotz der jeweiligen territorialen Unterschiede auch erste Anzeichen für ein gemeinsames kontinentaleuropäisches Verfahrensrechtsverständnis. Im Frühmittelalter gab es etwa in den Territorien Spaniens und des Frankenreichs Königsgerichte sowie verschiedene Königs- und Militärbeamte, die auch als (grundsätzlich verfahrensleitende) Richter innerhalb z.B. mehrerer Grafen-, Volks- und Hundertschaftsgerichte tätig waren; die unterschiedlichen Territorialgerichte wurden im Grunde ebenso durch mitwirkende Laien und Schöffen besetzt. In dieser Zeit herrschten fast überall in Strafsachen noch die Privatklage - hauptsächlich vom Geschädigten erhoben - und als „Beweismodi“ der Reinigungseid und das Gottesurteil vor. ${ }^{131}$

Im für das Strafverfahren richtungweisenden Hoch- und Spätmittelalter gewannen neben den vielen verschiedenen weltlichen (Hoch- und Unter-)Gerichten auch die Gerichte der katholischen Kirche enorm an Bedeutung. Diese entschieden in sämtlichen europäischen Territorien und als Höchstinstanz in Rom nach dem römisch-kanonischen Recht über inner- oder außerkirchliche Angelegenheiten mit zunächst religiösem Bezug, wie z.B. in strafrechtlichen Ketzereifällen. Vorwiegend im Rahmen dieser Gerichtsbarkeit entstanden etwa in deutschen und französischen Regionen der berüchtigte mittelalterliche „Inquisitionsprozess“ und ab Ende des 15. Jahrhunderts die spanische, portugiesische und römische „Inquisition“ der Kirche. ${ }^{132}$ Auf dieser rechtlichen Basis fanden später die grausamen (kirchlichen und weltlichen), Hexenprozesse“ der frühen Neuzeit statt.

\section{- Charakteristika des Inquisitionsprozesses und formales Beweisrecht}

Die inquisitorische Prozessart hat seit dem Hochmittelalter durchweg die Verbrechensverfolgung von Amts wegen (Offizialmaxime) und das Streben nach

131 Ausführlich Wesel, Geschichte, S. 158-163, 169-172. Auch Ploscowe, Harv. L. Rev. 48 (1935), 433 (437-441). Zu den primitiven Akkusationsverfahren zusammenfassend Garraud, in: Esmein (Verf.), History, S. 3-7. Für Einzelheiten insbesondere zur fränkischen Gerichtsverfassung und zum Verfahren E. Schmidt, Einführung, S. 37-45. Kürzer Rüping/Jerouschek, Strafrechtsgeschichte, S. 9-11. Siehe auch Lieber, Schöffengericht, S. 107-114. Noch zu den primitiven germanischen Gerichts- und Strafverfahrensinstitutionen und ihren altrömischen Vorgängern Mittermaier, in: Esmein (Verf.), History, S. 13-36.

132 Dazu und zu Einzelheiten über die Entstehung und Form des kirchlichen Inquisitionsverfahrens Esmein, History, S. 78-94, 314-317. Mehr zu den geschichtlichen Entstehungs- und Abgrenzungstheorien bezüglich der Inquisition u.a. Grigulevič, Ketzer, S. 21-33 (und S. 110-157 zur Organisation und Entwicklung des kirchlichen Gerichtsverfahrens). Ausführlicher und kritisch Trusen, ZRG KA 74 (1988), 168 (170-230). Nach der Meinung von E. Schmidt, Einführung, S. 93-94 entstand das Inquisitionsverfahren im mittelalterlichen Deutschland eher selbstständig, ohne kirchliche Einflüsse; siehe auch E. Schmidt, Inquisitionsprozess, S. 9-11, 53-61. Zur Auffassung, welche „die Durchsetzung des Inquisitionsverfahrens und der Folter insgesamt als Rezeptionsergebnis“ ansieht, siehe Rüping/Jerouschek, Strafrechtsgeschichte, S. 54. Eingehend Ignor, Geschichte, S. 44-60 m.w.N. 
Wahrheit, ${ }^{133}$ sowie mehr oder weniger auch folgende Charakteristika eingeschlossen:

- einen (faktisch oder anhand gesetzlicher Vorschriften) gleichzeitig anklagenden, ermittelnden und bei der Urteilsfindung mitwirkenden - unter „unnatürlichen“ psychologischen Bedingungen ${ }^{134}$ fast den ganzen Prozess bestimmenden - Richter;

- die Nichtöffentlichkeit des (Vor-)Verfahrens; sowie

- die grundsätzlich schriftlichen Verfahrensweisen.

Verschiedene Varianten bzw. grundlegende Komponenten des im Mittelalter und in der frühen Neuzeit vorherrschenden Inquisitionsverfahrens und des römischkanonischen Prozesses konnten sich im weiteren Verlauf mit Blick auf die Mehrheit der strafrechtlichen Angelegenheiten auch vor den weltlichen, insbesondere spanischen, französischen und deutschen Städte-, Hof- bzw. den späteren Königsund Reichsgerichten, Rechtskammern und Richterkollegien durchsetzen. Zum Teil waren jedoch verschiedene Formen des Privatklagesystems und Akkusationsverfahrens, hinsichtlich vor allem der Verfahrenseinleitung, fast überall noch formell vorgesehen oder wurden nebenbei tatsächlich angewandt. Die Untersuchungs- und Spruchkörper setzten sich zusammen aus Landesherren, Landsleuten und beauftragten Amtspersonen als Richter und gegebenenfalls (zumindest ursprünglich) auch aus bei der Urteilsfindung mitwirkenden Laien und Schöffen, später jedoch grundsätzlich aus gelehrten Richtern.

Darüber hinaus waren die alten Beweisarten (Reinigungseid und Eideshelfer, Gottesurteil, Zweikampf) sowohl in der kirchlichen als auch in den weltlichen Strafzuständigkeiten in Zentraleuropa graduell durch ein eher ,rationales“ Verfahren ersetzt worden. Die „Untersuchungen“135 und gerichtlichen Entscheidungen im Rahmen eines solchen Verfahrens gründeten sich ab der Mitte des 13. Jahrhunderts bis in die Zeit der Aufklärung grundsätzlich auf unflexible Beweisregeln zur restriktiven Kontrolle des richterlichen Ermessensspielraums. Diese Regelungen betrafen den Einsatz von Zeugen (z.B. die Zwei-Zeugen-Regel), Urkunden und Indizien sowie vor allem das überwiegend durch diverse Foltermethoden ${ }^{136}$ erzwungene Geständnis $^{137}$ des Beschuldigten. Außerdem waren allgemein in Strafsachen seit

133 E. Schmidt, Einführung, S. 86-87.

134 Küper, Richteridee, S. 113.

135 Laut Zachariä, Gebrechen, S. 43: „Untersuchen heißt: Alle diejenigen Mittel und Wege gebrauchen, welche zur Erkenntniß der wahren Beschaffenheit eines Objects hinführen können."

$136 \mathrm{Zu}$ den historischen Wurzeln der Folter und weiteren Hintergründen zusammengefasst Langbein, Torture, S. 3-8. Siehe auch Krey, FS für Kühne, insb. S. 780-790. Zum historischen Folterphänomen als Grund für die Ablehnung der kontinentaleuropäischen Strafverfahrensformen in England siehe kurz Langbein, Origins, S. 339-343.

137 Für eine ausführliche historische Betrachtung des Geständnisses Sickor, Geständnis, S. 64-149. 
dem Spätmittelalter und bis in die Anfänge der modernen Zeit keine ordentlichen bzw. selbstständigen oder umfassenden Verteidigungsmöglichkeiten und Rechtsmittelverfahren vorhanden. ${ }^{138}$

bb) Die Strafprozessreformen im modernen Nationalstaat

\section{- Der reformierte Strafprozess}

Unter dem Einfluss der Aufklärungsideen, der großen politischen und wirtschaftlichen Revolutionen der Neuzeit und der umfassenden Kodifikationsbewegungen wurden um die Wende zum 19. Jahrhundert in den neuen bzw. in Entstehung befindlichen Nationalstaaten Kontinentaleuropas auch die ersten großen Reformen der Gerichtsverfassungen und der Beweisrechtssysteme geplant. In Lehre und Gesetzgebung des 19. Jahrhunderts herrschte eine allgemeine Tendenz zur strikten Gewaltenteilung, zur richterlichen Unabhängigkeit und gleichzeitig zum Misstrauen gegen die uneingeschränkte Machtfülle des Berufsrichters. Zudem wurden die Einführung von Geschworenengerichten nach englischem Vorbild für die Beurteilung der Tat- und Schuldfragen, mehr Öffentlichkeit, Mündlichkeit und Unmittelbarkeit im (Haupt-)Verfahren sowie eine vereinfachte und einheitlichere Gerichtsorganisation mit mehreren Gerichtsbarkeitsinstanzen gefordert.

Neben der überfälligen Abschaffung der Folter wurde immer vehementer die Einführung von Formen der freien Beweiswürdigung in das Strafverfahren gefordert. Rechtspolitisch war die Letztere jedoch anfangs, insbesondere in Bezug auf den Ermessensspielraum der Berufsrichter und vor allem in Deutschland, nicht völlig unumstritten geblieben. Außerdem wurden graduell - insbesondere wegen der Verbreitung des in der Mehrheit der Länder einflussreichen Code d'instruction criminelle von 1808 - modernere staatliche Anklageformen zur Verfahrenseinleitung und die dafür zuständige vom Gericht unabhängige Behörde (Staatsanwalt-

138 Insgesamt zu diesen strafrechtlichen und prozessualen Entwicklungen in Europa $\mathrm{We}$ sel, Geschichte, S. 196-198, 236-247, 252-258, 276-285, 341-358, 364-372, 410-413, 464-465. Informativ auch Rüping/Jerouschek, Strafrechtsgeschichte, S. 14-35, 37-63. Zusammenfassend am Beispiel der geschichtlichen Entstehung und Entwicklung des Inquisitionsprozesses in deutschen Territorien Sellert, FS für Scupin, S. 162-177. Grundlegend dazu (wenn auch teilweise ältere Thesen vertretend) E. Schmidt, Einführung, S. 76107, 122-139, 176-178, 179-181, 183-184, 194-211. Vgl. noch Geppert, Unmittelbarkeit, S. 11-24. Siehe auch Lieber, Schöffengericht, S. 115-136. Bezüglich der Richterstellung auch Küper, Richteridee, S. 107-118, 125-131. Für Einzelheiten zur entsprechenden Entwicklung des weltlichen Straf(beweis)verfahrens in französischen Territorien Esmein, History, insb. S. 94-144, 145-165, 211-271 (und noch S. 288-322 zu üblichen kerneuropäischen, namentlich italienischen, spanischen, deutschen und niederländischen Verfahren). Resümierend zum alten Inquisitionssystem und $\mathrm{zu}$ den verschiedenen historischen Phasen des Beweisrechts (,ethnische“, „religiöse“, „rechtliche", ,,ideelle bzw. moralische" und „wissenschaftliche“" Phase) Garraud, in: Esmein (Verf.), History, S. 8-11, 617-630. Dazu schon früher Mittermaier, Lehre, S. 8-29. 
schaft) sowie letzten Endes umfassendere Verteidigungsmöglichkeiten in Kontinentaleuropa geschaffen. ${ }^{139}$

Dies heißt aber keineswegs, dass in der modernen kontinentalen Strafverfahrensgeschichte wegen der seit Mitte des 19. Jahrhunderts zunehmenden Reformbewegungen auch sämtliche älteren Verfahrenspräferenzen insgesamt aufgegeben wurden: Staatliche (richterliche und/oder staatsanwaltliche) Ermittlungen der Wahrheit im Einklang mit der Offizialmaxime, die richterliche Steuerung aller Beweisrechtshandlungen sowie das schriftliche und nichtöffentliche Vorverfahren mit übergreifender Bedeutung sind nämlich wichtige Prozessbestandteile für die civil lawSysteme geblieben. ${ }^{140}$ Nur vereinzelt sind, zumindest in Europa, derartige bis ins 20. Jahrhundert überlebende Identitätselemente der kontinentaleuropäischen Verfahrenstradition in beachtlichem Maße durch angloamerikanische Vorbilder verdrängt worden. Charakteristisch hierfür ist die massive italienische Strafprozessreform von 1989, die noch viele Jahre nach ihrer Einführung vom traditionellen Richtertum abgelehnt wurde, was sogar zu Verfassungsänderungen geführt hat, welche die letztendliche Durchsetzung der neuen, von common law-Ideen geprägten Verfahrensformen absichern sollten. Die italienische Prozessordnung ist nun zumindest auf Gesetzesebene im Vergleich zu anderen kontinentaleuropäischen Rechtsordnungen in einzigartiger Weise gekennzeichnet vor allem durch die erhebliche Einschränkung der Verwertung von Vorverfahrensakten in der mündlichen

139 Siehe eine Gesamtdarstellung bei Wesel, Geschichte, S. 456-459, 464-468, 522524. Siehe auch Rüping/Jerouschek, Strafrechtsgeschichte, S. 70-71, 84-89, 94-95. Insb. in Bezug auf die deutschen Verläufe im 19. und zu Beginn des 20. Jahrhunderts $E$. Schmidt, Einführung, S. 268-281, 324-342, 345-346, 413-420; siehe auch Vormbaum, Einführung, S. 89-107, 151-152, 177-181. Mehr über, ,die Leitidee und die Wegbereiter der Reform" Ignor, Geschichte, S. 211-230. Zur Bedeutung des angloamerikanischen Strafverfahrens als „Leitbild für die Reformbestrebungen“ im 19. Jahrhundert Herrmann, Reform, S. 49-72. Zur Stellung des Richters und der Geschworenen in den (deutschen) Reformbewegungen Küper, Richteridee, S. 118-124, 132-143, 166-245 m.w.N. Zur kritischen Betrachtung der Argumente für die Einsetzung von Geschworenengerichten i.V.m. der damals strittigen Frage der freien Beweiswürdigung durch Geschworene oder durch Berufsrichter Mittermaier, Mündlichkeit, S. 362-401, 401-419; siehe auch Schmitz, in: Jerouschek/Rüping (Hrsg.), Auss liebe, S. 165-177. Über die Neuerungen des maßgebenden Code d'instruction criminelle und auch den Einfluss des englischen Rechts Jung/Weigend, in: Jung u.a. (Hrsg.), 200 Jahre, S. 18-19. Mehr dazu Geppert, Unmittelbarkeit, S. 41-66. Ausführlicher zum französischen Recht Esmein, History, insb. S. 500527, 528-569; Garraud, in: Esmein (Verf.), History, S. 11-12, 626-630.

$140 \mathrm{Vgl}$. an dieser Stelle nur exemplarisch für das 19. Jahrhundert und um die Wende zum 20. Jahrhundert Esmein, History, S. 547-569; Garraud, in: Esmein (Verf.), History, S. 570-588, 596-606; konkreter zur deutschen Rechtslage Rüping/Jerouschek, Strafrechtsgeschichte, S. 87-89, 114-116; E. Schmidt, Einführung, S. 327-332, 413-418; vgl. auch Vormbaum, Einführung, S. 92, 94-95, 106-107. Vgl. noch am Beispiel der rechtsdogmatisch problematischen Annahme des Verständigungsverfahrens Fezer, NStZ 2010, 177 (177-178, 184). 
Hauptverhandlung sowie durch die grundsätzlich von den Parteien dominierten kontradiktorischen Beweiserhebungsformen. ${ }^{141}$

\section{- Moderne Entwicklungen: Fairness, Berufsrichter und Absprachen}

Immerhin scheinen heute allgemein die fair trial-Mitwirkungsrechte und Teilnahmemöglichkeiten der Verteidigung in der von Richtern und Staatsbeamten weiterhin beherrschten kontinentalen Verfahrenspraxis vollständiger als je zuvor verankert zu sein. Dies könnte etwa an der Aufnahme von rigiden Schutzvorschriften in die modernen Staatsverfassungen der Nachkriegsära oder auch an den nun stark menschenrechtlich orientierten Bewegungen im Völkerrecht liegen. ${ }^{142}$ Gleichwohl kam es im Gerichtsbarkeitsbereich schon seit Ende des 19. Jahrhunderts und während der ersten Jahrzehnte des 20. Jahrhunderts auch rechtspolitisch zu einer Wiederherstellung des Vertrauens in die Stellung des Berufsrichters im Verfahren.

Diese auf diversen politisch-ökonomischen und rechtstechnischen Gründen und Effektivitätsüberlegungen basierte Entwicklung hat letztendlich zur Schwächung eines ohnehin im Grunde englischtypischen Charakteristikums, namentlich der starken Laienbeteiligung im Strafverfahren, beigetragen. ${ }^{143}$ Die vorher auch auf dem Kontinent durchgesetzten reinen Geschworenengerichte sind somit inzwischen fast überall abgeschafft worden. An ihrer Stelle sind nun auch für die schwerwiegenden Delikte grundsätzlich einheitliche Spruchkörper vorgesehen, die sich ausschließlich aus professionellen Richtern oder gemischt aus Laien und Berufsrichtern mit (mehr oder weniger) gleichwertiger Verteilung der Entscheidungsmacht zusammensetzen. In Kontinentaleuropa sind (ausnahmsweise) „klassische“ Geschworenengerichte z.B. in Spanien, Belgien und Österreich noch anzutreffen, die aber eine rechtlich oder faktisch begrenzte Kompetenz besitzen und nicht unerhebliche Besonderheiten gegenüber ihren angloamerikanischen „Vorbildern“ aufweisen. ${ }^{144}$

141 U.a. Art. 190, 195, 431, 498, 506, 507, 526 Codice di procedura penale. Über die Reform und ihre Probleme Maiwald, Einführung, S. 169-172, 185; Marafioti, in: Jackson u.a. (Hrsg.), Crime, S. 81-87, 91-94; Parlato, ZIS 2012, 513 (513-520); Pizzi/Montagna, Mich. J. Int'l L. 25 (2004), 429 (430-447).

142 Vgl. zur zunehmenden Bedeutung der Menschenrechte in der nationalen und internationalen Strafrechtspflege Jackson, in: Doran/Jackson (Hrsg.), Judicial Role, S. 109-110. Vgl. auch Bassiouni, Duke J. Comp. \& Int'l L. 3 (1993), 235 (235-236, 240-243).

143 Vgl. Dölling, FS für Böttcher, S. 41-43; Ehrmann, Comparative Legal Cultures, S. 100-104. Vgl. zu den historischen Wurzeln der gemischten "Schöffengerichte" in Deutschland bis (schließlich) zu ihrer Durchsetzung im Jahr 1924 Landau, in: Schioppa (Hrsg.), Trial Jury, S. 290-304. Ebenso Grube, Richter, S. 55-63, 98-108, und Lieber, Schöffengericht, S. 163-177. Siehe auch Thaman, Chi.-Kent L. Rev. 86 (2011), 613 (614620). Vgl. zu den französischen Entwicklungen Hans/Germain, Chi.-Kent L. Rev. 86 (2011), 737 (739-747).

144 Rechtsvergleichende Bemerkungen zur Laienbeteiligung in europäischen Territorien Lagodny, FS für Jung, S. 501-503; Linkenheil, Laienbeteiligung, S. 164-174; Pakes, 
Darüber hinaus sind gegenwärtig Einflüsse der (moderneren) angloamerikanischen Verfahrenspraxis vor allem mit Blick auf die aus prozessökonomischen Gründen erfolgte massive Einführung von diversen Absprachemechanismen auf dem Kontinent und die entsprechenden Verkürzungen des gerichtlichen Beweisverfahrens zu erkennen. Solche konsensualen Verfahrensarten und die konkreten Formen ihrer gesetzlichen Verankerung werden jedoch, wie beispielsweise im Fall Deutschlands, nicht selten in wissenschaftlichen und rechtspolitischen Diskussionen kritisiert. ${ }^{145}$ Kritiker berufen sich nicht zuletzt auf Fragen der Vereinbarkeit der neuen Prozesserledigungsformen mit den im Vorangehenden beschriebenen überlieferten Strukturelementen und Prinzipien der kontinentaleuropäischen Strafverfahrenstradition. ${ }^{146}$

\section{Zwischenbetrachtung}

\section{- Bedeutung der Rechtstraditionen}

In den bisherigen Ausführungen wurde die Frage angesprochen, ob und wie bzw. inwieweit zwischen verschiedenen westlichen Rechtsordnungen über die Jahrhunderte mehrere gemeinsame Strafrechts- und Prozessverständnisse - und nicht nur ein gemeinsames Verständnis - erschaffen worden sind, die eine theoretische Differenzierung der (Verfahrens-)Rechte in größere „Stilgruppen“ erlauben könnten. Es ist nicht zu bestreiten, dass sich bestimmte strafprozessuale Elemente und Institutionen bzw. die dahinter stehenden Grundideen in zentralen Rechtsordnungen (West-)Europas einerseits und der angloamerikanischen Welt andererseits historisch gegensätzlich ausdifferenziert und bis in die heutige Zeit eigenständig überlebt bzw. sich weiterentwickelt haben. Dies hat zumindest auf einer quasi ,auto-

Comparative, S. 113-122; Sadoghi, Thesen, S. 253-277; Vidmar, in: ders. (Hrsg.), Jury, S. 421, 428-432, 444-446. Speziell über Spanien Bachmaier/Moral García, Spain, S. 297-300; Thaman, in: Vidmar (Hrsg.), Jury, S. 323-351. Über Österreich Bertel/Venier, Strafprozessrecht, Rn. 46-49, 543-568. Über Belgien i.Z.m. der vom EGMR kürzlich abgeurteilten Frage der Begründungspflicht bei jury-Entscheidungen Thaman, Chi.-Kent L. Rev. 86 (2011), 613 (621-626). Zur gegenwärtigen relevanten Rechtslage in Deutschland u.a. Lieber, Schöffengericht, S. 251-284, und in Frankreich Hans/Germain, Chi.-Kent L. Rev. 86 (2011), 737 (747-760).

145 Vgl. Langer, Harv. Int'1 L. J. 45 (2004), 1 (3).

146 Siehe diesbezügliche rechtsvergleichende Betrachtungen bei Langer, Harv. Int'l L. J. 45 (2004), 1 (39-64); Müller, Probleme, S. 324-362; J. Peters, Urteilsabsprachen, S. 6667, 80-100, 111-129, 140-159; Thaman, in: ders. (Hrsg.), World, S. 331-396. Speziell zu den relevanten Entwicklungen in Spanien Navarro, ZStW 123 (2011), 163 (163-178); und in Frankreich Jung/Nitschmann, ZStW 116 (2004), 785 (785-795). Über die rechtsdogmatisch problematische Einführung des Verständigungsverfahrens in Deutschland zunächst durch die Rechtsprechungspraxis und kürzlich auch durch Gesetzesregelung u.a. Altenhain/Haimerl, JZ 2010, 327 (327-333); Fezer, NStZ 2010, 177 (178-183); Murmann, ZIS 2009, 526 (526-534). 
poietischen“147 oder selbstreferenziellen Ebene zur Identifizierung zweier zentraler Strafverfahrenstraditionen geführt.

In der täglichen Rechtspraxis erscheinen jedoch sogar die markantesten solcher Elemente heute manchmal nur in abgeschwächter Form. Die Bedeutung von lediglich quantitativen bzw. statistischen Betrachtungen der heutigen Systemwirklichkeit darf trotzdem bei der Identifizierung der jeweils „,eigenen“ Haltung zum Recht nicht überschätzt werden. Auch die tatsächlich zwischen verschiedenen Rechtsordnungen desselben „Rechtskreises“ existierenden Teilunterschiede reichen alleine nicht aus, um die andauernde Wirkung von historisch gemeinsam tradierten, übergeordneten Rechtsmerkmalen und Präferenzen auf die weitere Entwicklung der jeweiligen Verfahrenssysteme aufzuheben. ${ }^{148}$

\section{- Rechtsquellen}

Es lässt sich zunächst nicht leugnen, dass die Regulierung der angloamerikanischen (Beweis-)Verfahren auch heute noch durch die starke Präsenz des case law gekennzeichnet ist. Die jüngeren Bestrebungen zur systematischen Anpassung des Rechts an die Erfordernisse der modernen Gesellschaft und die dafür eventuell notwendige Abweichung von veralteten Anweisungen des richterlichen Common Law schlagen sich fast ausschließlich in Form von Einzelgesetzen nieder. Echte zentrale Kodifikationswerke zu jedem einzelnen Rechtsgebiet existieren grundsätzlich, vor allem im englischen Mutterland, noch nicht.

In den kontinentaleuropäischen Systemen stehen dagegen die Tradition des systematisch gelehrten Rechts und die daran anschließenden umfassenden Kodifikationen des Strafrechts und Verfahrens im Vordergrund. Eine Vielfalt von Reformund Nebengesetzen und internationalen Verträgen hat jedoch zur erheblichen Verstreuung der nationalen Rechtsquellen auf dem Kontinent geführt. Die immer aktivere Rolle des Richters bei der Weiterentwicklung des Rechts durch die Interpretation der Gesetze, das Schließen von Gesetzeslücken und die konkrete Wahrnehmung der abstrakten Rechtsprinzipien und Verfahrens- und Mitwirkungsrechte ist ebenfalls nicht von der Hand zu weisen.

147 Laut Duden Fremdwörterbuch, S. 166, „Autopoiese“ (aus auto und griechisch poíēsis „das Machen, Verfertigen“) ist die „Fähigkeit, sich selbst erhalten, wandeln, erneuern zu können“. Vgl. zu den autopoietischen Systemen im rechtssoziologischen Kontext Luhmann, Law, S. 70, 81-88.

148 Vgl. Salas, in: Delmas-Marty/Spencer (Hrsg.), European Criminal Procedures, S. 489: „Legal systems are in a constant state of flux and consequently the roles played by those who operate them must constantly be adjusted. Even when the continental systems borrow certain elements of the English model, as is the case in Italy for example, they cannot disregard the sociological burdens that they have inherited along with the inquisitorial system, a system rooted in a centuries-old tradition of State authority." 


\section{- Gerichtsbarkeit, Beweisrecht und Beweisverfahren}

Von noch größerer Bedeutung für das Strafverfahren sind darüber hinaus die Unterschiede zwischen den zwei Rechtstraditionen seit dem 12. Jahrhundert in Bezug auf die zentralen Fragen der Gerichtsbarkeit und des Beweisrechts. Eine besonders wichtige Rolle spielen dabei die parallelen historischen Verläufe in England und in den Ländern Kontinentaleuropas nach der ersten großen Rationalisierung des Strafrechts im Mittelalter, die sich auch auf die heutige Ausformung des Beweisverfahrens und der Rollenverteilung zwischen den Verfahrensbeteiligten ausgewirkt haben. Es klingt wie ein (ideo-)logisches Paradoxon, doch es war grundsätzlich die römisch-katholische Kirche, die im 13. Jahrhundert auf beiden Seiten des Ärmelkanals die Aufgabe der alten Beweismodi in erheblichem Maße gefördert hat. Diese Entwicklung stellte eine große Herausforderung auch für sämtliche weltlichen Strafzuständigkeiten dar, die nun unabhängig vom Willen Gottes auf neue Wege der Gerechtigkeit und neue Autoritäten zur Beurteilung der Straffälle vertrauen mussten.

In England wurde der Urteilsspruch - historisch gesehen symptomatisch oder nicht - den peers ${ }^{149}$ einer beschuldigten Person überlassen. Dies geschah zunächst und für lange Zeit, ohne dass konkrete Beweisregeln existierten. Das zumindest anfangs „blinde“ Vertrauen in die Richtigkeit der Entscheidung von zwölf Landsleuten war somit der Logik der vorherigen Gottesurteile nicht völlig fremd. Das englische jury-Hauptverfahren ist in der Folge zu einer der typischen Institutionen sämtlicher angloamerikanischen Systeme herangereift.

Gleichzeitig wurde in Kontinentaleuropa die Mitwirkung von Laien bei der gerichtlichen Entscheidung nach antikem bzw. frühmittelalterlichem Vorbild allmählich immer seltener. Vielmehr wurde die Stellung von gelehrten Richtern innerhalb der unzähligen Gerichte, die unter anderem die weltlichen und kirchlichen Inquisitionsprozesse führten, im Mittelalter und in der frühen Neuzeit stärker gefestigt. Die Durchsetzung eines weiten Entscheidungsspielraums der Berufsrichter begegnete aber anfangs noch dem Echo der vorhergehenden ,theokratischen“ Justiz und stieß auf die Weigerung der mittelalterlichen Gesellschaft, bei der Aufklärung von Straftaten ohne Weiteres auf die menschlichen Fähigkeiten (insbesondere auf das menschliche Urteilsvermögen) zu vertrauen. Deswegen wurden strikte Beweisregeln als vermutete einzige geeignete Ersatzlösung in das Strafverfahren eingeführt, um die größtmögliche Richtigkeit einer Verurteilung sicherzustellen. Die Verlagerung der Wahrheitserforschungsfunktion auf „übereifrige“ säkulare Hände hat jedoch in dieser ersten Phase der amtlichen Strafverfolgung auf dem Kontinent zur Verbreitung des massiven, bis in die Neuzeit andauernden Phänomens der Folter

149 Vgl. Art. 39 Magna Carta (1215). 
beigetragen. England und das jury-Verfahren haben dagegen keine lange Folterepoche erlebt. $^{150}$

Über die Aufklärungsrevolutionen und bis in die moderne Epoche der Nationalstaatlichkeit und des Rechtspositivismus orientierten sich sowohl die angloamerikanischen als auch die kontinentaleuropäischen Strafverfahrenssysteme in den folgenden Jahrhunderten graduell immer stärker an humanitären Institutionen. Im 19. Jahrhundert fanden dann die Reformbewegungen vor allem in Europa ihren Höhepunkt, ohne aber alle bisherigen tragenden Merkmale der jeweiligen Rechtstradition zu verdrängen. Die Autonomisierung und Zentralisierung der Anklagemechanismen, die Laienbeteiligung in der Justiz, die Stärkung der richterlichen Unabhängigkeit und der Verteidigungsrechte sowie die Neubewertung des Beweisverfahrenssystems prägten zunächst die rechtspolitischen Programme.

In England begann sich das moderne Beweisausschlussrecht parallel mit der Zunahme der Anwaltspräsenz, der cross-examination von Zeugen und der förmlichen Rollenverteilung im Prozess herauszubilden. Das reine jury-Verfahren hat unter diesen Bedingungen fast unverändert bis in die heutige Zeit überlebt, auch wenn es nicht mehr für das ganze Kriminalitätsspektrum angewandt wird. Auf dem Kontinent ist dagegen die nach-revolutionäre Einführung der jury nach englischem Vorbild eher als eine vorläufige Unterbrechung der langen Tradition der Richterdominanz im Erkenntnis- und Urteilsfindungsverfahren zu betrachten. Das interimistische Einsetzen von Laien zur Tatsachenfeststellung und Urteilsfindung zu Beginn der Neuzeit hat aber zumindest zur Abschaffung der vorherigen strikten Beweisregeln und später zur Durchsetzung der Idee der freien Beweiswürdigung auch in der berufsrichterlichen Zuständigkeit beigetragen.

\section{- Jüngere Entwicklungen und Konsequenzen für die Folgedarstellungen}

Letztendlich mussten sich jedoch beide Rechtstraditionen im 20. Jahrhundert großen Herausforderungen stellen, vor allem bezüglich der Probleme der Prozessökonomie. Zunächst in angloamerikanischen Territorien und in den letzten Jahrzehnten auch in Kontinentaleuropa wurden neue summarische Strafverfahrensarten und Prozesserledigungsformen entwickelt; diese haben nicht unerhebliche Veränderungen des bisher beschriebenen Verfahrensbilds der Rechtstraditionen hervorgerufen. Die Maßnahmen zur Entlastung der Justiz haben aber insbesondere die nach-revolutionären Konturen des traditionellen (Haupt-)Beweisverfahrens - in dem nach herrschendem gesellschaftlichem Verständnis die Schuldfrage letztend-

${ }^{150}$ Ferner Langbein, Torture, S. 3-8, 73-80. Für einen interessanten Vergleich zwischen den mittelalterlichen kontinentaleuropäischen Folterpraktiken und dem amerikanischen plea bargaining-Prozess des 20. Jahrhunderts Langbein, U. Chi. L. Rev. 46 (1978), $3(12-19)$. 
lich $\mathrm{zu}$ ermitteln ist - nicht unbedingt substantiell verändert. ${ }^{151}$ Außerdem ist in sämtlichen Rechtssystemen die große theoretische und rechtspolitische Bedeutung der andauernden Interaktion bzw. Kollision von ,klassischen“ Beweis-/Hauptverfahrensformen und moderneren (alternativen) Ausprägungen des Strafprozesses, wie etwa den Absprachemechanismen, nicht von der Hand zu weisen. ${ }^{152}$

Darüber hinaus lässt sich nach heutigem Stand nicht leugnen, dass auf der Basis von internationalen menschenrechtlichen Mindeststandards und Bestrebungen zur einheitlichen Stärkung der Mitwirkungs- und Verteidigungsrechte die Konvergenz der gegenwärtigen westlichen Rechtssysteme möglicherweise reibungsloser erfolgen kann. Fraglich ist, inwieweit eine solche Konvergenz die tief verwurzelten Eigenverständnisse in Bezug auf die geeignete Form des Beweisverfahrens und die Funktion seiner Teilinstitutionen tatsächlich beeinflussen kann. ${ }^{153}$ Insbesondere die Tendenzen im EMRK-System ${ }^{154}$ sowie auch die Diskussionen im Rahmen einer tauglichen Beweisverfahrensauswahl für die internationalen Strafgerichte ${ }^{155}$ deuten eher auf eine andere Realität hin: nämlich dass zumindest ein Teil der beteiligten Interessenparteien den Bezug zu den Grundmerkmalen und Ausgestaltungsformen der jeweils „eigenen“ (Beweis-)Verfahrenstradition weiterhin aufrechterhält oder sogar ihre Durchsetzung auch auf internationaler Ebene fordert. Dementsprechend ist es auch mit Blick auf zukünftige rechtspolitische Planungen im strafprozessua-

151 Dazu vgl. auch Langer, Harv. Int'l L. J. 45 (2004), 1 (16-17). Zur Notwendigkeit von „starken“ Gerichtsbarkeiten und Hauptverfahren, ungeachtet der tatsächlichen Verbreitung von vereinfachten und außergerichtlichen Prozessformen, Pizzi, Trials, S. 69-71. Zur Bedeutung einer ebenso starken ,theory of the criminal trial" A. Duff/Farmer/ Marshall/Tadros, in: A. Duff u.a. (Hrsg.), Trial on Trial 1, S. 8-17; vgl. auch Roberts/ Zuckerman, Criminal Evidence, S. 44-45.

152 Vgl. hierzu Langbein, U. Chi. L. Rev. 46 (1978), 3 (19-20), bezüglich der Schwierigkeit, auch aus politisch-ideologischen Gründen, für jede Rechtskultur selbst die tief verwurzelten aber eventuell äußerst problematischen strukturellen Eigenpräferenzen, vor allem im Bereich des Beweisverfahrens, als solche zu identifizieren und insgesamt zu verdrängen (am Beispiel der uneffektiven Anwendung der amerikanischen adversary jury trial, die letztendlich zur praktischen Dominanz des alternativen, aber ebenso hochproblematischen plea bargaining-Prozesses geführt hat). Vgl. diesbezüglich auch van Kessel, Notre Dame L. Rev. 67 (1992), 403 (407-409). Vgl. darüber hinaus Duff/Farmer/Marshall/ Tadros, in: A. Duff u.a. (Hrsg.), Trial on Trial 1, S. 11, die zu dem Schluss kommen: „Even if the criminal trial does not always occur when an individual is accused of a criminal offence, it does provide fundamental background to the operation of the criminal justice process as a whole."

153 Vgl. Pradel, RIDP 63 (1992), 13 (31): „Mais sur les techniques et spécialement sur le rôle respectif du juge et des parties, les droits se séparent toujours et se sépareront encore longtemps. Le système romano-germanique et celui du common law sont comme deux frères qui se regardent et qui, l'un et l'autre, restent persuadés d'être le meilleur des deux."

154 Vgl. hierzu z.B. Jung, GA 2009, 235 (235-236); Renzikowski, FS für Mehle, S. 529530. Vgl. auch Delmas-Marty, in: dies. (Hrsg.), Criminal Process, S. 191, 196-198; Jackson, in: Jackson u.a. (Hrsg.), Crime, S. 228, 233-235.

155 Vgl. etwa Eser, in: Swart u.a. (Hrsg.), Legacy, S. 119-120; Zappalà, in: Sluiter u.a. (Hrsg.), International, S. 44-45. 
len Bereich sowohl auf nationaler als auch auf internationaler Ebene von Wert, die Gegenüberstellung von angloamerikanischen und kontinentaleuropäischen Beweisverfahrenstypen aus heutiger Sicht grundlegend zu behandeln. Dies soll vorliegend in folgenden Schritten geschehen:

Zunächst setzt sich der folgende Abschnitt (unter II.) dieses ersten Teils der Arbeit mit den in der westlichen Rechtspraxis und Lehre dominierenden abstrakten Theorien und Modellkonstruktionen auseinander, die zwischen ,adversatorischen“ und „inquisitorischen“ (Beweis-)Verfahrensarten differenzieren. Dabei sind die Variablen ${ }^{156}$ und die Merkmale, welche in abstrakt-theoretischer Weise jeweils als kennzeichnend für die unterschiedlichen Strafbeweiskreise betrachtet werden können, logisch-systematisch zu identifizieren. Besonderes Gewicht soll auf die Rolle von Institutionen und Personen (Verfahrensbeteiligten) gelegt werden, die das Beweisverfahren ständig prägen und auf die Entwicklung von sich unterscheidenden Verfahrensrechtsverständnissen direkt oder indirekt Einfluss haben. Dies bezweckt insbesondere, die heutigen abstrakten (Extrem-)Fassungen der unterschiedlichen Beweisverfahrensarten genauer zu definieren, mit deren Grundhaltungen sich die themarelevanten rechtspolitischen Diskussionen und Reformprozesse weitgehend noch beschäftigen. ${ }^{157}$ Die daraus gewonnenen Erkenntnisse zu den modernen westlichen Beweisverfahrenstypen werden danach im zweiten, rechtsvergleichenden Teil der Arbeit in concreto anhand jeweils eines zentralen Vertreters des angloamerikanischen und des kontinentaleuropäischen Strafprozesses angewendet und überprüft. Relevante internationalrechtliche Dimensionen der Problematik der Beweisverfahrenstypen werden weiterhin im dritten und letzten Teil der Forschungsarbeit diskutiert.

\section{II. „Adversatorische“" und ,inquisitorische" Typen des Straf- und Beweisverfahrens}

Die Auseinandersetzung mit der Theorie der Rechtskreise und mit den Hauptmerkmalen der zwei zentralen Strafrechtstraditionen des Westens sollte vor allem als Einführung in die sich durch getrennte historische Verläufe und trotz kontinuierlicher Teilreformen und Anpassungen unterschiedlich entwickelnden Grundverständnisse des Strafverfahrens dienen. Die nachfolgenden Ausführungen enthalten nun eine speziellere, großenteils beweisverfahrensbezogene Auseinandersetzung mit gegenwärtigen Strafprozesssystemen und -formen angloamerikanischer und kontinentaleuropäischer Prägung. Zunächst sollen die folgenden Analysen mit Blick auf die moderne abstrakt-theoretische (sich im Wesentlichen auf die Rolle

\footnotetext{
156 Vgl. Damaška, Zbornik PFZ 51 (2001), 477 (478).

157 Vgl. Jackson/Summers, Internationalisation, S. 6-9.
} 
der Verfahrensbeteiligten konzentrierende) Unterscheidung zwischen Strafverfahrenstypen bzw. Beweisverfahrensmodellen vorgenommen werden (unter II.). Die daran anschließenden Teile 2 und 3 der Arbeit befassen sich des Weiteren mit konkreteren national- und internationalrechtlichen Dimensionen der aktuellen Verfahrensrealität.

\section{A. Einführung in die klassische Dichotomie der (Beweis-)Verfahrensmodelle}

Modernere Abhandlungen ${ }^{158}$ mit mehr oder weniger rechtsvergleichendem Charakter sowie die Justizpraxis ${ }^{159}$ von Rechtsordnungen unterschiedlicher Rechtstraditionen beziehen sich mehrfach auf die Gegenüberstellung von angloamerikanischen ,adversatorischen“ (adversarial) und kontinentaleuropäischen ,inquisitorischen“ (inquisitorial) Verfahren. Dies geschieht vor allem dann, wenn wesentliche Einrichtungen, Strukturen und Rollenverteilungen, Aufgaben oder Ziele des Straf-

158 Nur exemplarisch hier: Brouwer, ALJ 55 (1981), 207 (207-208, 219-223); Damaška, U. Pa. L. Rev. 121 (1973), 506 (insb. 507-513, 525-536, 554-589); Damaška, Zbornik PFZ 51 (2001), 477 (478-494, 497); Dannecker, ZVglRWiss 97 (1998), 407 (409); Devlin, The Judge, S. 54-83; Eser, FS für Miyazawa, S. 562-569; Gaede, Fairness, S. 344-353; Grande, in: Jackson u.a. (Hrsg.), Crime, S. 145-164; C. Harding, in: Eser/ Rabenstein (Hrsg.), Strafjustiz, S. 10-12; Herrmann, SACC 2 (1978), 3 (3-13); Hodgson, in: Duff u.a. (Hrsg.), Trial on Trial 2, S. 223-226; Hodgson, in: Weigend u.a. (Hrsg.), Strafverteidigung, S. 45-59; Jackson, MLR 68 (2005), 737 (740-747); Jackson/Summers, Internationalisation, S. 9-14; Jung, FS für Waltoś, S. 31-33; Maffei, Right to Confrontation, S. 116-123; Pakes, Comparative, S. 87-96; Perron, in: ders. (Hrsg.), Beweisaufnahme, S. 560-567; Pizzi, Trials, S. 92-94, 110-115; Safferling, Towards, S. 1-3, 16-21, 207-225; Schünemann, FS für Fezer, S. 557-564; Spencer, in: Delmas-Marty/Spencer (Hrsg.), European Criminal Procedures, S. 20-27; Summers, Fair Trials, S. 3-13; Trüg, Lösungskonvergenzen, S. 25-29; van Koppen/Penrod, in: dies. (Hrsg.), Adversarial, S. 15; Weigend, in: Dressler (Hrsg.), Encyclopedia, S. 444-446; Weigend, FS für Rissing-van Saan, S. 750-760; Zappalà, Human Rights, S. 1-28; Zeidler, ALJ 55 (1981), 390 (390392, 397-400). Im rechtsethisch-professionellen Kontext Nagorcka/Stanton/Wilson, Melb. U. L. Rev. 29 (2005), 448 (452-468). Für eine Gegenüberstellung der zwei Beweissysteme aus „ökonomischer“ Sicht: Posner, Stan. L. Rev. 51 (1998-1999), 1477 (1487-1502).

159 Vgl. z.B.: US Supreme Court Crawford v. Washington, 541 U.S. 36, $42-53$ (2004); $R$ v. Cameron, [2001] EWCA Crim 562, Rn. 22; $R$ v. Horncastle a.o., [2009] UKSC 14, insb. Rn. 15, 16, 26, 59 i.V.m. EGMR (GK) Al-Khawaja and Tahery v. the United Kingdom, Urt. v. 15.12.2011 (26766/05, 22228/06), insb. $\S \S 49-62,109,115,129$. Vgl. auch: Royal Commission on Criminal Procedure Report 1981, $\$ \S 1.6-1.8$ und Royal Commission on Criminal Justice Report 1993, S. 3-4; Auld Report 2001, S. 16; die Ergebnisse der 7. Arbeitsgruppe des 35. Strafverteidigertages (Berlin, 2011) in Strafverteidigervereinigungen (Hrsg.), Abschied, S. 342-343; das Summary Report von „Concluding Conference: International Criminal Procedure Expert Framework" (The Hague, 2011), abrufbar unter http://ief2011.hiil.org/assets/1999/Summary_Report_031111_IvdZ.pdf [Stand: Oktober 2014]; sowie Kirchengast, Criminal Trial, S. $192-\overline{200}$ mit weiteren Rechtsprechungsverweisen. Siehe auch Eser, FS für Jung, S. 167-169 und Sluiter, in: Cassese (Hrsg.), Oxford Companion, S. 230-234. Zur Frage der, internalization of the procedural structures of interpretation and meaning“'Langer, Harv. Int'1 L. J. 45 (2004), 1 (11-13). 
verfahrens mit allgemeineren bzw. zugrunde liegenden Prozesstypen und/oder Beweisverfahrensarten in Bezug gebracht werden. Im Fokus der relevanten Diskussionen stehen meistens die Antithesen bzw. Spannungsverhältnisse zwischen einem forensischen Parteienwettstreit und der amtlichen Ermittlung eines Strafgeschehens, zwischen einem passiven und einem aktiven Richter, zwischen der Fairness und der Wahrheitssuche als Zielsetzung des Strafverfahrens oder zwischen einer reinen jury trial und einer non-jury trial.

Dabei sind insbesondere im Rahmen von einführenden bzw. pauschalen Betrachtungen oft interpretatorische Ungenauigkeiten zu erkennen. ${ }^{160}$ Diese können sich z.B. im Wege einer unsystematischen, übersimplifizierten und verallgemeinerten Verwechslung bzw. Vermengung von historischen Verläufen, gegenwärtigen Verfahrensnormen, allgemeinen Prinzipien des Strafverfahrens, technischen Prozesselementen zweitrangiger Bedeutung, rechtspolitischen Bewertungen und Idealtypen des Beweisverfahrens ergeben. Noch komplizierter gestaltet sich die Diskussion, wenn - insbesondere in der rechtsvergleichenden Literatur - neben den oder statt der üblichen Bezeichnungen ,adversatorisch“ und ,inquisitorisch“ auch weitere Begriffe verwendet werden, wie z.B. ,non-adversarial model“, ,accusatorial model $^{\text {“ }}$ oder ,,instruktorisches“" Verfahren. ${ }^{161}$

Aber auch im Rahmen von tiefgehenden strafprozessualen Untersuchungen lässt sich eine eindeutige Gegenüberstellung aller verschiedenen Strafverfahrensformen bzw. eine klare Identifizierung von unterschiedlichen Beweisverfahrenssystemen auf abstrakter Ebene und anhand allgemein geltender Kriterien nicht ohne Weiteres bewerkstelligen. Insbesondere sind dabei die folgenden, von einem Pionier der modernen Verfahrensmodelltheorie, Mirjan Damaška, einst angesprochenen kritischen Punkte nicht außer Acht zu lassen: ${ }^{162}$ Erstens unterschieden sich die konkreten Beweisprozesse der verschiedenen Rechtsordnungen innerhalb des common law-wie auch des civil law-Systemkreises, sodass gemeinsame Charakteristika von Beweisstilen nur auf einer ganz generellen Ebene erfassbar seien. Zweitens würden sogar innerhalb derselben Rechtsordnung die Beweisregeln nicht immer im gleichen Maße bzw. einheitlich für alle verschiedenen Kategorien von Straffällen angewandt. Drittens sehe die (Beweis-)Rechtslage in den common law-Ländern (zumindest auf den ersten Blick) ,komplexer“ aus als in den civil law-Rechtsordnungen, wobei in beiden Fällen meistens eine „Disparität“ zwischen ,law on the books“" und ,actual practice“ zu bemerken sei. Viertens unterschieden sich die konzeptionellen Mechanismen und Systemgestaltungen im Rahmen des Beweisrechts zwischen common law und civil law in solchem Ausmaß, dass man oft nach den

${ }^{160} \mathrm{Vgl}$ z.B. die Ausführungen von Bradley, in: ders. (Hrsg.), Criminal Procedure, S. xvii-xxv, oder von Mack, Comparative, S. 1-20.

161 Siehe zu den Problemen der Terminologie unter Teil 1, II.B.2.

162 Damaška, U. Pa. L. Rev. 121 (1973), 506 (509). 
gemeinsamen Nennern ,tasten“ müsse, welche die strittigen Punkte überhaupt vergleichbar machen könnten.

Trotz solcherlei Schwierigkeiten und potenzieller Einwände gegen ihren eigentlichen Wert sind abstrakte und simplifizierende Betrachtungen der verschiedenen (Beweis-)Verfahrensstile, die in der common law- und der civil law-Welt zur Feststellung der kriminellen Schuld angewandt bzw. gefördert werden, keine Seltenheit. Die vorliegenden Ausführungen und Definitionsarbeiten befassen sich nun vor allem mit dem konkreten Inhalt und der systematischen Analyse solcher weitverbreiteter Betrachtungen, deren Hypothesen und Grundschemata der Verfahrensrealität in eigentlichen Rechtsordnungen nahestehen, mit ihr aber nicht gleichzusetzen sind. Dabei ist immerhin zu beachten, dass insbesondere für Studien, welche auf die ernsthafte Untersuchung der (Kontinuität der) Dichotomie der Straf- und Beweisverfahrensarten abzielen, zumindest die wesentlichen Hintergründe und Entwicklungen innerhalb der betreffenden Rechtstraditionen wahrgenommen, zusammengefasst und beschrieben bzw. gründlich gelesen werden müssen; solche Studien können ihrerseits die weitere Entwicklung möglicherweise (auf der Ebene der rechtspolitischen Planung) sogar mitbestimmen.

Dementsprechend ist es nicht das Ziel der folgenden Untersuchungen, den Sinn relevanter abstrakter Betrachtungen und Modellkonstruktionen für die rechtsvergleichende Wissenschaft sowie ihre Aussagekraft in Zweifel zu ziehen. Vielmehr wird eine systematische Herausarbeitung der Kriterien zur generellen Trennung der Beweisverfahrenssysteme bzw. eine klare Bestimmung der essenziellen Elemente von auf abstrakter Ebene weitgehend anerkannten zentralen Verfahrensbildern bezweckt. Die dazu notwendigen Systematisierungs-, Vergleichungs- und Zuordnungsarbeiten sollen zwar in möglichst vereinfachter Weise, aber unter ,wertfreier“163 Berücksichtigung von logischen, aktuellen und historischen Zusammenhängen und im Wissen um die Gefahr ,folkloristischer"164 Verallgemeinerungen durchgeführt werden. Die sich daraus ergebenden Muster in Bezug auf das „,adversatorische“ und ,,inquisitorische“ Verfahren können dann als ,propädeutischer" Orientierungsansatz für konkretere rechtsvergleichende Arbeiten dienen bzw. ein weiteres Analyseinstrument bei der beweisprozessualen Beschäftigung mit substantiellen Fragen zum Wesen, zu den Hintergründen und den Reformerfordernissen der (nationalen und internationalen) Strafjustizsysteme bereitstellen. ${ }^{165}$

163 Göppinger (Begr.), Kriminologie, § 5 Rn. 74-75. Vgl. zu den politisch-ideologisch „,beladenen“ Modellen Damaška, Zbornik PFZ 51 (2001), 477 (484, 498-500); Jackson, MLR 68 (2005), 737 (740-741).

164 Vgl. Damaška, Zbornik PFZ 51 (2001), 477 (488-489).

165 Vgl. Damaška, U. Pa. L. Rev. 121 (1973), 506 (508-509): „Assuming that the two evidentiary styles, that of the common and that of the civil law, generate disparate problems of proving guilt, can this phenomenon be related to the opposition between the adversary and non-adversary models of criminal procedure? [...] In an age so fascinated with constructing models it is tempting to test their explanatory force in the highly technical 


\title{
B. Grundlagen der herrschenden Unterscheidung zwischen (Beweis-)Verfahrenstypen
}

\section{Zur Bildung von Modellen in der Strafverfahrenstheorie}

\author{
a) Modellkategorien
}

In der modernen Lehre des 20. und 21. Jahrhunderts sind im straf- und beweisprozessualen Bereich umfassende Taxonomien ${ }^{166}$ anzutreffen, die unter anderem das rechtsvergleichende Studium komplexer Rechtssysteme ermöglichen sollen. Dabei werden insbesondere bestimmte strafprozessuale Charakteristika verschiedener Rechtsordnungen mit generelleren Modellen oder Typen des (Beweis-)Verfahrens in Beziehung gebracht. ${ }^{167}$ Entsprechend ihren (je nach Betrachtungsweise des jeweiligen „Theoretikers" unterschiedlichen, deskriptiven oder normativen) Zwecken hat Damaška versucht, die Modellkonstruktionen folgendermaßen zu kategorisieren: ${ }^{168}$

Für einen Teil des theoretischen Denkens seien die Prozessmodelle synoptische Darstellungen (,representations“) bestehender oder historischer Verfahren; solche Abbildungen könnten sich bei Orientierungsarbeiten als nützlich erweisen, nämlich durch Bestimmung der Elemente eines Klassifizierungssystems. Im Rahmen einer zweiten Kategorie von Theorien würden die Modelle als idealtypische ${ }^{169}$ konzep-

field of comparative law of evidence. Equally interesting, perhaps, is the necessary propaedeutic to any such pursuit: one must seek to ascertain [...] which procedural ideas and structural patterns are embraced by the two broad classificatory labels of 'adversary' and 'nonadversary' procedure.“ Vgl. auch Bohigian, in: Nagel (Hrsg.), Modeling, S. 15-16. Vgl. zu den „Idealtypen“ als Erkenntnismittel Göppinger (Begr.), Kriminologie, § 5 Rn. 72-73.

$166 \mathrm{Vgl}$. allgemein zur Bedeutung von taxonomy auch für die Rechtsvergleichung Mattei, Am. J. Comp. L. 45 (1997), 5 (5-7).

167 Zur Herkunft und sprachlichen Bedeutung des Wortes „Modell“ gibt Duden Herkunftswörterbuch, S. 535, an: „Das Substantiv bedeutet ,Muster, Form; Vorbild; Entwurf $[\ldots]^{6}$. Es wurde um 1600 [...] aus [gleichbedeutend] [italienisch] modello entlehnt, das auf [vulgärlateinisch] modellus zurückgeht. Dies steht für [klassisch-lateinisch] modulus, Maß; Maßstab“, eine Verkleinerungsbildung zu [lateinisch] modus ,Maß“" Siehe zum oft synonym verwendeten Begriff „Typ(us)“ (aus dem lateinischen typus, übernommen aus dem griechischen týpos ,Schlag; Gepräge, Form, Gestalt, Abbild; Vorbild, Muster, Modell'), Duden Herkunftswörterbuch, S. 873-874. Zum allgemeinen Gebrauch von Modellen in der Wissenschaft: Frigg/Hartmann, Models in Science (Stanford Encyclopedia of Philosophy, online); auch IEP (http://www.iep.utm.edu/models/ [Stand: Oktober 2014]). Nach Stachowiak, Allgemeine Modelltheorie, S. 128-133, z.B. sind die allgemeinen, wesentlichen Merkmale eines Modells die Abbildung, die Verkürzung und der Pragmatismus. Vgl. auch Lave/March, Introduction, S. 3-4. Im strafjustiziellen Kontext Bohigian, in: Nagel (Hrsg.), Modeling, S. 15-20.

168 Damaška, Zbornik PFZ 51 (2001), 477 (477-478).

169 Duden Fremdwörterbuch, S. 588-589 gibt zum Adjektiv ,ideal“ an: ,,,aus [gleichbedeutend] [spätlateinisch] idealis zu [lateinisch] idea, dies aus [griechisch] idéa, vgl. Idee“: 1. den höchsten Vorstellungen entsprechend, vollkommen. 2. nur gedacht, nur in der Vorstellung so vorhanden, der Idee entsprechend [...]“; und zum „Idealtypus“: „Idealbild, das durch gedanklich einseitige Steigerung bestimmter Elemente der Wirklichkeit gewonnen wird ([Soziologie]) [...]“. Aus sozialwissenschaftlicher Perspektive siehe vor allem Weber, 
tionelle Konstrukte behandelt (,constructs, that is, with respect to which actual procedural systems, like Platonic ideals, are but approximations, pale reflections, or distortions"); solche Modelle würden dann für Klassifizierungszwecke sowie als Instrumente zur Ermittlung von mutmaßlichen strukturellen Affinitäten zwischen Prozessformen verwendet. Eine dritte theoretische Auffassung verstehe Modelle weder als Beschreibungen von tatsächlichen Systemen noch als Instrumente für ihre Analyse, sondern als Blaupausen oder Programme für die Gestaltung des Strafprozesses (, 'models for' rather than 'models of"“). Ein weiterer Teil der Lehre schließlich orientiere sich an Modellen, welche gegensätzliche Tendenzen oder Spannungen ausdrücken, die sich im Strafprozess - unabhängig von dessen Gestaltung - als Ergebnis seiner konkurrierenden Ziele erkennen lassen.

Gleichwohl sind Art und Umfang der Modellkonstruktionen im Strafprozess nicht immer klar zu erkennen. In Bezug auf die abstrakte Unterscheidung der Strafjustizsysteme in prozessstruktureller Hinsicht, die in dieser Forschungsarbeit von zentraler Bedeutung ist, sind vor allem folgende Sichtweisen üblich, die mehr oder weniger den ersten zwei der von Damaška identifizierten Modellkategorien gerecht werden könnten: Einerseits wird oft, in historischer Hinsicht und meistens aus kontinentaleuropäischer Perspektive, zwischen ,akkusatorischen“ (,,accusatorial“), „,inquisitorischen“ und „gemischten“ („mixed“) Strafverfahren im Allgemeinen differenziert. Andererseits werden hauptsächlich in moderneren, vorwiegend analytischen Zusammenhängen die sogenannten ,adversatorischen“ und ,inquisitorischen“" Modelle des Strafprozesses und konkreter des angloamerikanischen und des kontinentaleuropäischen Beweisverfahrens gegenübergestellt. ${ }^{170}$ Nicht selten werden jedoch vor allem die Begriffe ,akkusatorisch“ und ,adversatorisch“ undiffe-

Wissenschaftslehre, S. 191, z.B. aus Anlass der Bildung des Begriffs „Stadtwirtschaft“ als eines „Idealtypus“: „Er wird gewonnen durch eine einseitige Steigerung eines oder einiger Gesichtspunkte und durch Zusammenschluß einer Fülle von diffus und diskret, hier mehr, dort weniger, stellenweise gar nicht, vorhandenen Einzelerscheinungen, die sich jenen einseitig herausgehobenen Gesichtspunkten fügen, zu einem in sich einheitlichen Gedankenbilde." Vgl. auch im religionssoziologischen Kontext Weber, Wirtschaftsethik, S. 209: „Das konstruierte Schema hat natürlich nur den Zweck, ein idealtypisches Orientierungsmittel zu sein, nicht aber eine eigene Philosophie zu lehren. [...] Die Konstruktion ermöglicht es, da, wo sich eine historische Erscheinung einem von diesen Sachverhalten in Einzelzügen oder Gesamtcharakter annähert, deren - sozusagen - typologischen Ort durch Ermittlung der Nähe oder des Abstandes vom theoretisch konstruierten Typus festzustellen. Insoweit ist die Konstruktion also lediglich ein technischer Behelf zur Erleichterung der Übersichtlichkeit und Terminologie.“ Cotterrell, in: Nelken (Hrsg.), Comparing Legal Cultures, S. 24-25, definiert für die Zwecke der Rechtsvergleichung, ,ideal types“ als „logically constructed concepts deliberately designed not to represent empirical reality but to organize interpretation of it“. Zur Bildung und Anwendung von Idealtypen als „Vergleichsmaßstab" Göppinger (Begr.), Kriminologie, § 5 Rn. 70-75. Konkret bezogen auf die Nützlichkeit einer idealtypischen Verfahrensdichotomie und ihre Probleme siehe auch Jackson, MLR 68 (2005), 737 (740-747); Langer, Harv. Int'l L. J. 45 (2004), 1 (7-9).

170 Vgl. etwa Damaška, Zbornik PFZ 51 (2001), 477 (478-494), Damaška, Faces, S. 36, und Goldstein, Stan. L. Rev. 26 (1974), 1009 (1016-1021), i.V.m. den einführenden Verweisen in Fn. 158 und 159 in diesem Teil. 
renziert zur Bezeichnung von im Wesentlichen ähnlichen Modellkonstruktionen der letzteren (moderneren und analytischeren) Art verwendet. ${ }^{171}$ Dies sollte dann aber nur eine Frage der Etikettierung sein. Komplizierter wird es jedoch, wenn, wie bereits angedeutet, die unterschiedliche Begriffswahl auch auf zwei verschiedene Modellbetrachtungen hindeutet:

- eine grundsätzlich historisch und örtlich gebundene, aber inhaltlich umfangreiche Anschauung, die zwischen allgemeinen (weite Teile des Strafprozesses betreffenden) all inclusive-Verfahrenstypen differenzieren will (,akkusatorisch“ / ,inquisitorisch“/, „gemischt"); und

- eine „engere““172 Betrachtung, die vorrangig die Rolle grundlegender Institutionen und die gegensätzlichen Strukturformen des geltenden Beweis- und Gerichtsverfahrens in weiten Gebieten des Westens rechtsvergleichend anspricht (,adversatorisch"/,,inquisitorisch").

\section{b) Der historische Ansatz für die Modellbildung}

Die vorliegende Studie setzt sich vor allem mit dem ,adversatorischen“ und dem „,inquisitorischen“ Idealtyp des (Beweis-)Verfahrens auseinander und nicht mit historischen Modellbetrachtungen des Strafprozesses. Die Letzteren sind meistens all inclusive-Konstruktionen, die hauptsächlich auf geschichtlichen Beobachtungen zentraler Formen des kontinentaleuropäischen Verfahrens (manchmal auch dessen englischer Vorbilder) basieren. ${ }^{173}$ Sie sind für die konkreten Erfordernisse der heutigen Klassifizierungstheorien und der analytischen Rechtsvergleichung freilich wahrzunehmen, gleichzeitig aber nicht zu überschätzen. ${ }^{174}$ Durch Bezeichnungen wie ,akkusatorisch“, ,inquisitorisch“ und ,gemischt“ wird in diesem Sinne nämlich besonders mit Hilfe von zusammenfassenden, aber fragmentarischen Abbildungen historischer Verfahren versucht, das Verhältnis zwischen u.a. folgenden Punkten vereinfacht auszudrücken: den in älteren Zeiten weitverbreiteten Prozessformen (primitive und mittelalterliche Akkusations- und Inquisitionsprozesse), den reformierten Verfahrenssystemen nach dem 19. Jahrhundert, den (sich häufig wandelnden) rechtspolitischen bzw. ideologischen Hintergründen zur Justizorganisation und einer (eher unstabilen) Vielfalt von geläufigen strafprozessualen Merkmalen. ${ }^{175}$

\footnotetext{
171 Z.B. Herrmann, SACC 2 (1978), 3 (4).

172 Vgl. Fuller, in: Berman (Hrsg.), Talks, S. 34.

173 Für eine der seltenen Betrachtungen der „akkusatorischen“, ,inquisitorischen“ und „gemischten“ Systeme aus amerikanischer Sicht siehe Goldstein, Stan. L. Rev. 26 (1974), 1009 (1016-1020). Mehr zu den angloamerikanischen, von übersimplifizierten geschichtlichen Beobachtungen ebenso inspirierten „folkloristischen“ Systembeschreibungen unter Teil 1, II.B.1.c)aa).

174 Vgl. auch Damaška, U. Pa. L. Rev. 121 (1973), 506 (555, 560).

$175 \mathrm{Zu}$ allen drei historischen Verfahrenstypen und zum historischen Ansatz für die Bildung von Strafverfahrensmodellen Ambos, JURA 2008, 586 (586-593); Damaška,
} 
So schlossen die ,akkusatorischen“ Strafverfahrenssysteme in ihrer historischen Entwicklung nach verbreiteter Ansicht solche Elemente einer privatrechtsähnlichen Konflikterledigung bzw. eines Parteienstreits ein wie:

- die Privatklage;

- die passive Rolle des Richters als Vermittler in einem durch die Parteien durchgeführten öffentlichen Prozess bzw. formalen Beweiskampf;

- das Fehlen von ständigen Rechtsmittelverfahren und

- den Einsatz von Laienrichtern.

Nach dem rechtshistorischen Stereotyp waren dagegen die originären „Inquisitionssysteme" des Mittelalters und der frühen Neuzeit vor allem durch folgende Aspekte charakterisiert:

- das (häufige) Fehlen einer institutionellen und physischen Trennung zwischen amtlichem Ankläger, Ermittler und Richter;

- die umfassende richterliche Ermittlung der Wahrheit und die Durchführung des Verfahrens von Amts wegen;

- die starren Beweisregeln;

- die Stellung des Beschuldigten als Beweismittel auch gegen sich selbst und als potenzielles Objekt von Folter sowie

- die Nichtöffentlichkeit und Schriftlichkeit der eigentlichen Entscheidungsprozesse und die öffentliche Durchführung von reinen Scheinprozessen.

Schließlich erfassten die ,gemischten“ Modelle, die sich ab dem 19. Jahrhundert herausbildeten, grundsätzlich die nach-revolutionären, reformierten Strafprozesse auf dem Kontinent durch:

- die Zuständigkeit eines separaten staatlichen Organs (und nicht des aburteilenden Richters) für die Einleitung des Strafverfahrens (Anklageerhebung);

- die Beibehaltung des inquisitorischen, schriftlichen und nichtöffentlichen Charakters der amtlichen Vorermittlungen, zwar ohne Folter und starre Beweisregeln, aber weiterhin mit dem Beschuldigten als ihrem zentralen Beweisobjekt;

- die Gewährung von substantiellen Mitwirkungs- und Informationsrechten für die Verteidigung;

- die öffentliche und mündliche Durchführung der gerichtlichen Beweisverhandlungen unter Mitwirkung der Verteidigung sowie

U. Pa. L. Rev. 121 (1973), 506 (555-560), und Damaška, Zbornik PFZ 51 (2001), 477 (478-482). Solcherlei historisch-zentrische Systembetrachtungen finden sich z.B. bei Garraud, in: Esmein (Verf.), History, S. 3-12, 39-46, 570-571; Ignor, Geschichte, S. 1628; E. Schmidt, Inquisitionsprozess, S. 3-9. Vgl. auch Pradel, RIDP 68 (1997), 213 (213216); Tulkens, in: Delmas-Marty (Hrsg.), Criminal Process, S. 8-9; Volkmann-Schluck, Am. J. Crim. Law 9 (1981), 1 (2-3). 
- die Beibehaltung der zentralen Rolle des Vorsitzenden Richters bei allen Beweisvorgängen.

Inhaltlich umfangreiche gemischte Modelle werden in ähnlicher (angepasster) Weise teilweise immer noch verwendet, um die historischen Überlieferungen und Entwicklungen in der Verfahrenswirklichkeit von heutigen Rechtsordnungen kontinentaleuropäischer Prägung zusammenfassend zu beschreiben. Die Ausführungen im vorhergehenden „historischen“ Abschnitt dieses ersten Teils der vorliegenden Arbeit (unter I.) haben jedoch nicht zur Bildung allumfassender Modelle geführt, und ebenso wenig wurde die pauschale Verwendung der Begriffe „,inquisitorische“, „akkusatorische“ und ,gemischte" Strafverfahren befürwortet.

Stattdessen wurden bestimmte prägende Ereignisse, grundlegende Elemente und Institutionen, Prinzipien und rechtspolitische Bewegungen in den angloamerikanischen und kontinentaleuropäischen strafprozessualen Rechtstraditionen jeweils für sich genommen identifiziert und einander gegenübergestellt, wenn auch möglichst in historischer und logisch konsequenter Ordnung. ${ }^{176}$ Wie bereits festgestellt, haben manche der über mehrere Jahrhunderte sporadisch zu beobachtenden Verfahrensmerkmale und Prozesseinrichtungen die geschichtlichen Entwicklungen in der einen oder anderen Form letztendlich überlebt bzw. stark mitgeprägt. Solche auffälligen Elemente und Ereignisse sind somit für das tiefer gehende Hintergrundverständnis der heutigen Rechtssysteme und für ihre rechtsvergleichende Bearbeitung von Bedeutung. Ein stark typisierender, historisch orientierter Modellansatz zur noch abstrakteren Erfassung einer teilweise inkohärenten Vielfalt von rechtstraditionell ausdifferenzierten Merkmalen und Verfahrensprinzipien wurde für die Zwecke dieser Abhandlung trotzdem abgelehnt. ${ }^{177}$

Dadurch wurde unter anderem versucht, vereinfachte Darstellungen zu vermeiden, durch die verschiedene Erscheinungsformen des Strafverfahrens unter dasselbe Dach gebracht und gemeinsam bewertet würden, die in der Realität nicht unbedingt voneinander untrennbar bzw. ausschließlich miteinander verbunden waren/ sind: Dies könnte z.B. der Fall sein, wenn die Offizialmaxime und die Folter bzw. andere erhebliche Zwangsphänomene in einem Zug betrachtet würden, oder auch bei der Betrachtung des offiziellen, nach Wahrheit strebenden historischen Inquisitionsprozesses zusammen mit der amtlichen Einleitung des Strafverfahrens, obwohl heute bekannt ist, dass sogar die (nach-)mittelalterlichen richterlichen (inquisitorischen) Ermittlungen auf dem Kontinent oft im Wege eines gesonderten privaten

176 Siehe unter Teil 1, I.B. u.a. über folgende Punkte: über die primitiven Beweismodi, die adversary criminal procedure, die „Inquisition“ und das reformierte Strafverfahren, über die jury trial, das exclusionary law of evidence, die strikt-formalen Beweisrechtssysteme und die freie Beweiswürdigung über das Prinzip der Mündlichkeit, die Offizialmaxime und die materielle Wahrheit sowie über die Rationalisierung und Verstaatlichung des Strafrechts, die Menschenrechte, die Laienbeteiligung und die Rolle des Berufsrichters in der Strafjustiz.

177 Vgl. Damaška, Faces, S. 5; auch Vormbaum, Einführung, S. 92, 94, 96, 105. 
Akkusationsverfahrens eingeleitet wurden, was darauf hindeutet, dass es schon seit langem eine Vermischung der Verfahrensarten gibt. ${ }^{178}$ Ferner war hierbei auch die Förderung von politisch-ideologisch wertenden Modellen nicht erwünscht. Solche Betrachtungen differenzieren zunächst aufgrund historischer Tatsachen etwa zwischen - vereinfacht ausgedrückt - ,guten“, „liberalen“ ,,akkusatorischen“ Verfahren und „schlechten“, ,autoritären“ „,inquisitorischen“ Verfahren; ihre ,diskriminierende" bzw. einseitig missbilligende Wirkung ist aber zum Teil auch in der Gegenwart noch spürbar. ${ }^{179}$

\section{c) Der idealtypische Ansatz für die Modellbildung}

aa) Historische Folklore versus prozessuales Ideal

Gegenüber dem historischen Ansatz bei der Konstruktion von Verfahrensmodellen hat sich auch Damaška kritisch geäußert. ${ }^{180}$ Im Rahmen der Diskussion über die notwendige Neudefinierung der kontinentaleuropäischen Modelle für die Erfordernisse der Rechtsvergleichung in der heutigen ,gemischten Welt" hat er insbesondere die Relativität und Verschwommenheit der historischen Methode für die Bildung von reinen Modellen und für die klare Identifizierung von essenziellen Modellelementen hervorgehoben. ${ }^{181}$ Im gleichen Kontext hat er die Modellbildung auf Basis des kleinsten gemeinsamen Nenners von Regelungen in verschiedenen Verfahren, die den common law- und civil law-Traditionen lose zugeordnet sind, wegen ihrer Zirkularität und der mangelnden Stabilität der produzierten Modelle (,their precise meaning remains hostage to procedural change in a single country assigned to a tradition“) abgelehnt. ${ }^{182}$

Ferner hat Damaška die mit dem kontinentaleuropäischen historischen Ansatz verwandten, hauptsächlich angloamerikanischen, „folkloristischen " Systembeschreibungen attackiert: ${ }^{183}$ Diese basieren nämlich auf pauschalen veralteten Ge-

178 Vgl. zusammengefasst Ambos, JURA 2008, 586 (589-593). Mehr historische Details in dieser Arbeit unter Teil 1, I.B.2.a), I.B.3., I.B.4.

179 Vgl. u.a. Ambos, JURA 2008, 586 (586); Damaška, Faces, S. 4; Damaška, Zbornik PFZ 51 (2001), 477 (488, 500); Sellert, FS für Scupin, S. 161; Trusen, ZRG KA 74 (1988), 168 (168); Volkmann-Schluck, Am. J. Crim. Law 9 (1981), 1 (2-3).

180 Damaška, Zbornik PFZ 51 (2001), 477 (481-482). Dazu auch Jackson, MLR 68 (2005), 737 (741-742).

181 Damaška, Zbornik PFZ 51 (2001), 477 (481): ,[...] the historical method, in and of itself, cannot lead to the discovery of pure forms [...] depictions of procedural models according to the historical approach do not embody pure forms, but variously selected features taken from actual systems. What followers of this approach offer are not theoretical statements of traits essential to the models, but rather illustrations of forms that can loosely be assigned to them."

182 Damaška, Zbornik PFZ 51 (2001), 477 (481). Mehr dazu bei Damaška, Faces, S. 4 5; Langer, Harv. Int'l L. J. 45 (2004), 1 (7-8).

183 Damaška, Zbornik PFZ 51 (2001), 477 (488-489). 
genüberstellungen und ,polarisierenden“" politisch-ideologischen Wertungen. In einem solchen Rahmen wurden insbesondere früher dem populären ,adversarial/ accusatorial system“ grundsätzlich einseitig fair trial und verteidigungsfreundliche Merkmale (wie: jury trial, presumption of innocence, privilege against selfincrimination, accurate lawyer-driven fact-finding method) zugebilligt. Dem ,inquisitorial system“ wurden dagegen hauptsächlich „repressive“ Charakteristika (z.B. judicial investigative activism, unlimited pre-trial detention, presumption of guilt, coerced confessions, no right to defense counsel) zugeordnet. Auch heute noch deute auf ,rechtsfolkloristischer“ Ebene vor allem in den USA das ,,inquisitorial system“ auf eine, ,inhumane Justizverwaltung“ hin. Solche Betrachtungen würden, nicht ohne eine gewisse „Polarisationsabsicht“, meistens eingesetzt als „rhetorical, hortatory device, aimed at mobilizing consent and winning points in legal argumentation, rather than a conceptual instrument aimed at improving clarity of vision““ ${ }^{184}$ Sie sind daher mit Recht, auch wegen der ,,promiskuitiven Kombinierung von deskriptiven Elementen, Aspirationen und Werturteilen“, als geringwertige oder eben wertlose Analyseinstrumente zu behandeln. ${ }^{185}$ Letztendlich scheinen solche Dichotomien aus einem einseitigen, fragmentarischen und willkürlich simplifizierenden Verständnis rechtstraditioneller Daten hervorzugehen, ohne dabei die heutige Rechts- und Verfahrensrealität in den Systemen kontinentaleuropäischer Prägung genügend wahrzunehmen.

Nach Meinung von Damaška ist nun eine Bestimmung der essenziellen Elemente eines für analytische und taxonomische Zwecke wertvollen Modells nicht möglich, ohne vorher von den Eventualitäten (,contingencies“) der Geschichte abzusehen; vielmehr sind für die Konstruktion von reinen Modellen eine Theorie und ein prozessuales Ideal (,,a procedural ideal“) nötig: ${ }^{186}$

Increasingly visible in the second part of the twentieth century is an alternative approach to procedural models. It involves a search for ideas capable of linking procedural arrangements into recognizable patterns. Once obtained from the observation of real-life systems, these ideas are used as vehicles for organizing a whole range of procedural issues. The sum total of these issues, appearing now as entailed in the animating ideas,

184 Damaška, Zbornik PFZ 51 (2001), 477 (489).

185 Damaška, Zbornik PFZ 51 (2001), 477 (489). Vgl. ferner zur (wenn auch nicht mehr so scharfen) einseitigen Einstellung der common law-Welt Brants/Ringnalda, Issues, S. 14; Eser, FS für Jung, S. 167; Herrmann, SACC 2 (1978), 3 (3-4); Jackson, MLR 68 (2005), 737 (740); McEwan, in: A. Duff u.a. (Hrsg.), Trial on Trial 1, S. 51; Nijboer, Cardozo J. of Int'l \& Comp. L. 5 (1997), 79 (81, 92); Schlesinger, Buff. L. Rev. 26 (1976-1977), 361 (363-364); Sklansky, Harv. L. Rev. 122 (2009), 1634 (1635-1640); Spencer, in: DelmasMarty/Spencer (Hrsg.), European Criminal Procedures, S. 20-25; van Kessel, Notre Dame L. Rev. 67 (1992), 403 (409-420); Weigend, FS für Rissing-van Saan, S. 758-759. Spuren solcherart einseitiger bzw. übersimplifizierter Systembetrachtungen sind sogar in Entscheidungen des US-Supreme Court zu entdecken, z.B. US Supreme Court Watts v. Indiana, 338 U.S. 49, 54-55 (1949), US Supreme Court Arizona v. Fulminante, 499 U.S. 279, 293-294 (1991), und neuerdings US Supreme Court Crawford v. Washington, 541 U.S. 36, 43-53 (2004).

186 Damaška, Zbornik PFZ 51 (2001), 477 (482). 
constitutes a procedural model in its "pure" or "ideal" form. Models so conceived, although fictitious creatures, seldom if ever encountered in reality, can be employed for a variety of purposes. Insights derived from them can be of help in spotting unsuspected connections among procedural forms. A debate about a procedural rule or institution can turn into a debate about the relative merits of ideas that animate pure models to which this rule or institution is related. Most clearly, however, pure models are useful for taxonomic purposes. Just as works of art can be recognized in terms of a particular style, so an existing procedure can be assigned to a particular model. And just as to classify a work of art as pertaining to a particular style, it is considered sufficient that the work encompass some, though not all, elements of a stylistic idea, so a particular procedure need not display all elements of a model to be assigned to it. Of course, a procedure can also be recognized as a combination of elements taken from pure models.

bb) Die modernen Idealtypen des (Beweis-)Verfahrens

Dementsprechend zeigt sich hauptsächlich die Machtverteilung zwischen den verschiedenen Verfahrensbeteiligten hinsichtlich der Prozesskontrolle in realen Rechtssystemen als herrschende Idee hinter der Bildung von modernen Strafverfahrensmodellen. ${ }^{187}$ Dabei kann, wie noch ausführlicher zu zeigen ist, vor allem die passive oder aktive Rolle des Richters und entsprechend der anderen Kernbeteiligten in Beweiserhebungsprozessen als zentrales modelltrennendes Charakteristikum identifiziert werden (party contest versus official inquiry). ${ }^{188}$ Dieses Charakteristikum steht unter der dominierenden dichotomisierenden Bezeichnung, ,adversatorisch / inquisitorisch" auch im Vordergrund der nachfolgenden vergleichenden Analysen und Klassifizierungen der Prozesssysteme.

Selbstverständlich geht es bei einem solchen Anknüpfungspunkt zunächst um gedanklich und abstrakt konstruierte heuristische Instrumente. Diese Modelle können weiterhin zur Förderung der analytischen ${ }^{189}$ - u.a. das eigentliche Konvergenz/ Divergenz-Verhältnis zwischen bestimmten Verfahrensformen ermittelnden - und klassifizierenden Rechtsvergleichung verwendet werden. Im begrenzten Rahmen dieser forschungseinleitenden, stark typisierenden und vereinfachenden Dichotomie ist aber eine unmittelbare, genaue und detaillierte deskriptive Widerspiegelung realer und komplexer Verfahrenssysteme, die insbesondere in der heutigen Weltordnung erheblich gemischte bzw. ausgetauschte Charakteristika aufweisen, per definitionem ausgeschlossen. ${ }^{190}$ Die Auseinandersetzung mit reinen, der exakten

187 Einführend Damaška, Faces, S. 3.

188 Damaška, in: Kadish (Hrsg.), Encyclopedia, S. 28.

189 Vgl. zur ,wissenschaftlich-theoretischen Rechtsvergleichung“ Eser, FS für Kaiser, S. 1516; ferner Schlesinger/Baade/Herzog/Wise, Comparative Law, S. 47-52. Vgl. auch Frankenberg, Harv. Int'l. L. J. 26 (1985), 411 (425-426).

190 Siehe Damaška, U. Pa. L. Rev. 121 (1973), 506 (577-578 und Fn. 190): „For all models are by definition suggestive caricatures and simplifications departing from reality. I believe it is to Weber that we owe the paradoxical dictum to the effect that in order to grasp the real context we have to construct an unreal one. Thus, even if the descriptive utility of the two procedural models is denied - and I believe it cannot fairly be - there remains the heuristic 
Realität fremden Modellkonstruktionen soll dennoch den Wert rechtsvergleichender Gegenüberstellungen von konkreten realen Verfahrenssystemen und Rechtsordnungen nicht mindern; sie soll vielmehr der sinnvollen Hypothesenerstellung und der Vorbereitung solcher funktional vergleichenden Analysen sowie den anschließenden Klassifizierungen und Bewertungen dienen. ${ }^{191}$

Bevor jedoch die Untersuchung der Idealtypen des (Beweis-)Verfahrens fortgesetzt wird, ist zuerst Folgendes klarzustellen: Eventuell sollte man keine besonderen Imaginationsfähigkeiten ${ }^{192}$ brauchen, um zum Schluss zu kommen, dass die historische Methode zur Konstruktion von reinen Modellen nicht geeignet ist. Ebenso wenig sollten jedoch aufwendige Denkprozesse nötig sein, um die allgemeine Bedeutung von rechtstraditionellen Wahrnehmungen für die eigentliche Bildung von idealen Verfahrenstypen und ihre Anwendung für analytische Zwecke zu begreifen. ${ }^{193}$ Auch wenn die einseitige Steigerung (Idealisierung) von realen Erscheinungsformen unterschiedlicher Strafverfahren mit der Hoffnung auf möglichst neutrale Modelle mit universalem Anwendungspotenzial verbunden ist, ${ }^{194}$ darf

value. [...] The descriptive value of the two models is, of course, limited. By liberating us from the tyranny of details [...] the models enable us to perceive the grand contours of reallife contrast. The heuristic value inheres in the conceptual framework provided by the two models for the comparative analysis of such diverse issues as the relative importance of counsel and procedural form, and [...] the commitment to the pursuit of truth in the criminal process“". Vgl. auch Brants, in: Nelken (Hrsg.), Comparative, S. 60: „The dichotomy is a useful analytical tool, not a universally applicable descriptive mechanism."

191 Vgl. Damaška, U. Pa. L. Rev. 123 (1975), 1083 (1084): ,[...] our modern eagerness for empirical information must not blind us to the need for careful theoretical preparation before we descend to the empirical plane.“ Vgl. auch Damaška, Faces, S. 241-242: „[...] without a suitable typology, comparative studies of procedural form cannot even begin. [...] If the real world is one of mixtures [...] what is the point in developing pure styles? $[\ldots]$ have we not fixated most of the time on the coffee and the milk, forgetting that cappuccino will be the norm? The answer to this query $[\ldots]$ is similar to the one a student of chemical elements would give to a critic pointing to the ubiquity of compounds: it is hoped that a kind of analytical chemistry can be performed on existing procedures and that, in the process, some of their mysteries can be brought to the surface and observed. Of course, one should not expect more from this type of analysis than it can deliver: that a building may be classified as an exemplar of a particular style, or as a mixture thereof, tells us very little about the individuality of the building. But one must realize that explorations of individuality become possible only after one has first obtained conceptual instruments with which to see and discuss individuality in terms of generic notions." In diesem Sinne erscheint etwa die Kritik an den clichés bei Kunert, Buff. L. Rev. 16 (1966-1967), 122 (122), soweit sie sich nicht nur gegen die übersimplifizierte „folkloristische“ Einordnung der Rechtsordnungen, sondern allgemein gegen jede wissenschaftliche Modellbildung richten könnte, eher als ungerechtfertigt.

192 Damaška, Zbornik PFZ 51 (2001), 477 (481).

193 Vgl. auch Brants/Ringnalda, Issues, S. 13-17.

194 So Damaška, Faces, S. 5-6: „Thus conceived, the typology can be used as a neutral map across Continental and Anglo-American countries: adversarial traits can be identified in continental Europe and can even be quite conspicuous in some branches of the administration of justice, while inquisitorial features, sometimes quite conspicuous, can be found 
dabei nicht außer Acht gelassen werden, dass die als Musterquellen verwendeten westlichen Verfahrenssysteme ihre Wurzeln und Grundhaltungen zum Recht für gewöhnlich selbst in bestimmte Rechtstraditionen einordnen. Nicht nur die Beobachtung von Grundideen hinter realen und aktuellen Systemen, sondern auch die Inanspruchnahme ihrer gemeinsamen rechtshistorischen Identität ermöglicht nämlich die Erstellung von weithin erkennbaren Figuren (,recognizable patterns“) ${ }^{195}$ auf abstrakter Ebene. Es ist, wie bereits erwähnt, praktisch nicht möglich - aber auch nicht unbedingt erwünscht - dass die sich dadurch ergebenden Elemente eines Verfahrensmodells die Gesamtheit der Entwicklungen, überlieferten Verfahrensmerkmale und historischen Produkte, Institutionen und politisch-ideologischen Faktoren innerhalb einer Rechtstradition widerspiegeln. Ebenso schwer lässt sich jedoch, wie auch sonst in jeder theoretischen oder rechtspolitischen Diskussion, der Einfluss des gemeinsamen Verständnisses von der Vorexistenz substantiell unterschiedlicher Rechtstraditionen auf die Art und Weise der Verwendung von modernen Modellen von der Hand weisen.

In dem heute immer noch nationalzentrischen Strafrechtsbereich ist es zudem für die Forscher, die Modellkonstruktionen verwirklichen bzw. weiteranalysieren und anwenden, nicht einfach, sich von ,ihrer“ Rechtstradition und dem vertrauten legal background zu lösen. ${ }^{196}$ Historische Hintergrundkenntnis der zwei herrschenden Traditionen im Westen ist daher für das Nachvollziehen und weitere Verwenden abstrakter Verfahrensmodelle Voraussetzung. Sogar in der Namensbezeichnung idealtypischer Konstrukte sind historische Spuren zu entdecken, was gleichwohl nicht selten zu Ungenauigkeiten und simplifizierten Bewertungen führen kann, die folglich einer gesonderten Erklärung bedürfen.

\section{Ursprungs- und Bezeichnungsfragen}

\section{a) Wurzeln der modernen Modellbetrachtungen}

Zentraler Ausgangspunkt für die folgenden abstrakt-theoretischen Untersuchungen und die daran anschließenden rechtsvergleichenden und klassifizierenden Analysen sind die erst im 20. Jahrhundert gedanklich systematischer ausgearbeiteten reinen (Beweis-)Verfahrensmodelle. Dadurch wird beabsichtigt, bei der Auseinandersetzung mit den gegenwärtigen westlichen Systemen und ihren vielfältigen kulturellen, politischen und rechtlichen Konvergenzen und Wechselwirkungen einen zweckmäßigen Analyserahmen bereitzustellen: Dieser soll zur eingehenderen Untersuchung der Verschiedenheit von bestimmten beweisbezogenen strukturellen

in Anglo-American lands. Of course, the typology can also be applied to actual systems outside the Western legal tradition."

195 Damaška, Faces, S. 5.

196 Mehr zur Funktion und Bedeutung der Rechtstraditionen unter Teil 1, I.A.2., I.B.1., I.B.4. 
Aspekten des Strafprozesses, ihrer Ziele und der zur Feststellung der Schuld angewandten Methoden beitragen. Dabei sind die bereits angesprochenen ,folkloristischen" oder all inclusive-Systembetrachtungen, die diverse tatsächliche, historisch entwickelte (aufgrund rasanter globaler rechtspolitischer Entwicklungen und Durchmischungen nicht reine) Formen des rechtstraditionellen und nationalen Strafprozesses beinhalten, zunächst von begrenztem Erkenntniswert. Im Voraus ist zu bemerken, dass die Hauptversion der reinen Modelle, die hier von Interesse sind, auf der Idee der prozeduralen Kontrolle und der Rollenverteilung zwischen Richter (official inquiry) und Anklage und Verteidigung (party contest) bei den Beweisführungen basiert. ${ }^{197}$

Inzwischen werden bestimmte unterschiedliche Termini für die Benennung der zwei einander gegenübergestellten (Beweis-)Verfahrensmodelle in ähnlicher Weise und nach der jeweiligen nationalsprachlichen Anpassung in zentralen Rechtsordnungen sowohl der common law- (z.B. England, USA, Australien) als auch der civil law-Welt (z.B. Deutschland, Frankreich, Spanien, Niederlande) verwendet. ${ }^{198}$ Einerseits werden für den idealen (Beweis-)Verfahrenstyp angloamerikanischer Prägung neben dem dominierenden Begriff ,,adversatorisch“ (adversarial) auch Ausdrücke wie ,akkusatorisch“ (accusatorial; hier, trotz geschichtlicher Wurzeln, nicht mehr zur ausschließlichen Beschreibung historisch sich ergebender Verfahren verwendet), „kontradiktorisch“ und „Parteiprozess“ benutzt. Andererseits werden für den entsprechenden Verfahrenstyp kontinentaleuropäischer Prägung neben der (ebenfalls althergebrachten) dominierenden Bezeichnung ,inquisitorisch“ (inquisitorial) auch die Begriffe ,instruktorisch“ oder „,nicht-adversatorisch“ (non-adversarial) vorgeschlagen. ${ }^{199}$

Die bewusste Auseinandersetzung der modernen Verfahrenstheorie mit diesen „klassischen“ strafprozessualen Modellen, ihren Hintergründen, Zielen, Elementen, Bezeichnungen und ihrer Stichhaltigkeit wurzelt maßgeblich in Studien aus dem

197 Ausführlicher unter Teil 1, II.C.1.

198 Siehe auch Lilie, in: Schroeder/Kudratov (Hrsg.), Vorverfahren, S. 105.

199 Vgl. u.a. Ambos, JURA 2008, 586 (593-594); Eser, FS für Miyazawa, S. 565; Damaška, U. Pa. L. Rev. 121 (1973), 506 (507-513, 525, 554, 562, 577); Damaška, ZStW 87 (1975), 713 (714); Damaška, Zbornik PFZ 51 (2001), 477 (489-490); Herrmann, SACC 2 (1978), 3 (3-4); Hörnle, ZStW 117 (2005), 801 (803-804, 826); Jörg/Field/ Brants, in: Fennell u.a. (Hrsg.), Criminal Justice, S. 41-44; Jung, in: ders. (Hrsg.), Der Strafprozeß, S. 2-3; Jung, FS für Waltoś, S. 31; Schünemann, FS für Fezer, S. 555-562; Weigend, FS für Rissing-van Saan, S. 750-755, 759-760. Vgl. zu den entsprechenden Klassifikationen bzw. Begriffsbestimmungen für die Niederlande Nijboer, Cardozo J. of Int'l \& Comp. L. 5 (1997), 79 (80, 82); für Frankreich Hodgson, French Criminal Justice, S. 26-32, und Pfützner/Adams/Neumann, in: Sieber/Cornils (Hrsg.), Nationales Strafrecht, S. 228-233; für Spanien Mülfarth, Grundlagen, S. 41-42, 71-83, i.V.m. VolkmannSchluck, Der spanische Strafprozeß, S. 25-35, 65-86, 145-150; zur sui generis-Lage in Italien Maiwald, Einführung, S. 169-172, 185, 208, 220-224, und Marafioti, in: Jackson u.a. (Hrsg.), Crime, S. 81-98. 
dritten Viertel des 20. Jahrhunderts. ${ }^{200}$ Prägnante Unterschiede zwischen eigentlichen Verfahrenssystemen der common law- und civil law-Welt und insbesondere die unterschiedliche Art und Weise der Beweisaufnahme im Hinblick auch auf die effektive Erfüllung der jeweiligen Verfahrensziele kamen jedoch schon viel früher im nach-revolutionären (vor allem kontinentalen) wissenschaftlichen und rechtspolitischen Reformdiskurs zur Sprache. ${ }^{201}$ Die Verselbstständigung relevanter Ideen in Form der nun herrschenden Verfahrensmodelle schließt sich zum Teil ebenso an die Fortwirkung bzw. -entwicklung solcher Diskussionen an. Die Inanspruchnahme von historisch prägenden und sich ergebenden Prozessstrukturen steht dabei außer Zweifel. Im Fokus der neuzeitlichen rechtsvergleichenden Recherchen zur Weiterentwicklung des Strafverfahrens durch die Aufdeckung zunächst der wesentlichen Ursprünge und Gründe von modernen (Beweis-)Verfahrensformen standen immer wieder etwa: die Entwicklungen in der Beziehung zwischen Verfahrensbeteiligten in der alten reinen jury trial; die Zunahme des anwaltsbeherrschten Strafverfahrens ab dem 18. Jahrhundert und die dazugehörige Entstehung des modernen angloamerikanischen Beweisrechts und -verfahrens; sowie die weitgehend kontinuierlich dominierende Rolle des inquirierenden Richters in beweisverfahrensrelevanten Sachen auf dem Kontinent in Verbindung auch mit den Problemen der möglichen Einleitungsformen des Strafverfahrens. ${ }^{202}$ Solche historischen Gegebenheiten haben in der Folge auch bei der Auswahl der Begriffe zur Bezeichnung der aktuellen Verfahrenstypen eine Rolle gespielt.

$200 \mathrm{Zu}$ erwähnen sind insb. Beiträge von: Damaška, U. Pa. L. Rev. 121 (1973), 506 (insb. 561-589), und Damaška, Yale L.J. 84 (1975), 480 (insb. 481-483, 523-544); Goldstein, Stan. L. Rev. 26 (1974), 1009 (1015-1021); Goldstein/Marcus, Yale L.J. 87 (1977), 240 (242-246, 279-283), kritisiert von Langbein/Weinreb, Yale L.J. 87 (1978), 1549 (insb. 1549-1551, 1567-1569); Herrmann, ZStW 80 (1968), 775 (777-781, 810-814) m.w.N., und Herrmann, SACC 2 (1978), 3 (4-19); Roxin, in: Lüttger (Hrsg.), Probleme, S. 52-62; Thibaut/Walker/Lind, Harv. L. Rev. 86 (1972), 386 (insb. 387-391); Williams, Proof, S. 29-36. Vgl. tiefergehende ideologische Zusammenhänge bei Griffiths, Yale L.J. 79 (1970), 359 (insb. 367-417), Llewellyn, Jurisprudence, S. 444-450, und (zunächst in nichtrechtsvergleichender Hinsicht) Packer, U. Pa. L. Rev. 113 (1964), 1 (insb. 2-23). Gegenüberstellungen abstrakt-analytischer Art teilweise sogar bei E. Schmidt, in: Mueller (Hrsg.), German Code, S. 10, 18; vgl. auch E. Schmidt, Strafprozeß, S. 203-217. Erste Anzeichen für solcherlei Betrachtungen sind bereits in älterer Literatur zu entdecken, z.B. in Howard, Criminal Justice, S. 381-399, und Ploscowe, Harv. L. Rev. 48 (1935), 433 (433437, 471-473).

201 Dazu u.a. m.w.N. Damaška, U. Pa. L. Rev. 123 (1975), 1083 (1083, Fn. 1); Herrmann, ZStW 80 (1968), 775 (775-778); Jescheck, Va. L. Rev. 56 (1970), 239 (239-241). Vgl. auch Damaška, Faces, S. 3.

202 Siehe z.B. Langbein, U. Chi. L. Rev. 45 (1978), 263 (263, 272-273, 307-316); Snyman, CILSA 1975, 100 (101-104); Thaman, in: ders. (Hrsg.), World, S. 321-325; van Kessel, Notre Dame L. Rev. 67 (1992), 403 (405-409, 426-435). Vgl. auch Landsman, Readings, S. 5-39. Mehr Details und Verweise in Teil 1, I.B.2.a), I.B.3.b), I.B.4. 


\section{b) Terminologische Streitpunkte und Begriffsauswahl}

Nachfolgend werden nun die aus historischen Erscheinungsformen des Strafverfahrens entlehnten, heute weithin verwendeten Modellbezeichnungen ,adversatorisch" und ,inquisitorisch" befürwortet. Sie werden jedoch durchgehend in Anführungszeichen gesetzt, um auf den nicht absoluten bzw. nicht zwingenden Charakter der Verwendung dieser Begriffe hinzudeuten. Letztere haben sich nämlich im Laufe der Zeit lediglich als die üblichsten Termini für bestimmte gedankliche Konstrukte durchgesetzt, können aber somit zunächst die unmittelbare Erkennbarkeit des allgemeinen Sinns dieser Abstraktionen für rechtsvergleichende Zwecke auch weiterhin sicherstellen. Auch wenn gleichzeitig alternative Bezeichnungen oft als passender protegiert werden, greift doch die Mehrheit der in dieser Untersuchung zitierten relevanten Werke mehr oder weniger auf die vorrangig verwendete begriffliche Trennung zurück. Diese lässt die Kategorisierung relevanter Verfahrensfiguren leichter und schneller erkennen, was zu einer Vereinfachung der (vergleichenden) Forschung als Ziel jeder Modellverwendung führt.

In diesem Sinne wird der Ausdruck ,adversatorisch“203 zur Bezeichnung des parteienzentrierten Verfahrensmodells angloamerikanischen Ursprungs insbesondere dem Begriff ,akkusatorisch“ gegenüber vorgezogen. Der Letztere behält zwar, wie schon gezeigt wurde, eine zentrale Stellung in den all inclusive historischen und „folkloristischen“ Systembetrachtungen, kann jedoch deswegen für die Zwecke der reinen Beweisverfahrensmodelle irreführend wirken. Vor allem ist dabei zu beachten, dass Begriffe wie „Akkusationsverfahren und -prinzip“ unter anderem mit der (zunächst privaten und später staatlichen) Form einer nicht vom Richter abhängigen Einleitung des Strafverfahrens verbunden waren/sind. ${ }^{204}$ Spätestens seit den großen Reformen des 19. Jahrhunderts sind aber kaum mehr westliche Strafverfahren vorstellbar, die für ihre Einleitung eine formale Anklage durch ein vom Gericht klar gesondertes Organ nicht voraussetzen.

Durch die Ablehnung einer terminologischen Gegenüberstellung der Art ,akkusatorisch“ / „,inquisitorisch“ könnten nun a priori unnötige Missverständnisse im Hinblick auf den weiteren Analyse- und Vergleichungsrahmen und insbesondere in Bezug auf die in der Gegenwart ähnliche Einleitungsform sämtlicher westlicher

203 Laut Wahrig Wörterbuch, S. 117, bedeutet ,adversativ“: gegensätzlich, entgegensetzend, entgegenstellend [zu lateinisch adversus ,gegenüberstehend"]. Siehe auch Oxford Dictionary, S. 24, zu: ,adversarial, adversary“. Sprachlich ähnlich ist die Bedeutung von „kontradiktorisch“: widersprechend, widersprüchlich, so Wahrig Wörterbuch, S. 874.

204 Dazu u.a. Ambos, JURA 2008, 586 (586, 593); E. Schmidt, Inquisitionsprozess, S. 39; Vormbaum, Einführung, S. 94. Siehe auch Damaška, ZStW 87 (1975), 713 (714 Fn. 2); Jung, FS für Waltoś, S. 31. Vgl. auch in sprachlicher Hinsicht Duden Fremdwörterbuch, S. 63: ,akkusatorisch , aus [lateinisch] accusatorius , anklagend“ (veraltet) auf Antrag eines [An]klägers geführt.“ Ebenso Wahrig Wörterbuch, S. 123: „Akkusationsprinzip [..., lateinisch accusatio ,Anklage, Anschuldigung “].“ Siehe auch zu den Begriffen ,,accusation, accusatorial, accusatory" Oxford Dictionary, S. 11-12. 
Strafverfahren vermieden werden. Das Wort ,akkusatorisch“ ist darüber hinaus auch deswegen nicht für die reinen Modelle zu bevorzugen, weil es schon sprachlich und historisch gesehen gleichzeitig auf mehrere Aspekte des Strafverfahrens hindeuten könnte, wie z.B. auf die vorgenannte formale Einleitungsphase. Die Letztere steht zumindest auf den auf begrifflicher Ebene wichtigen ersten Blick nicht in unmittelbarer bzw. untrennbarer Verbindung mit den Beweisverfahrensmodi, die für die hier diskutierten Modelle von zentralem Interesse sind. ${ }^{205}$ Darüber hinaus kann auch der Begriff „Parteiprozess“ hier eher nicht erste Wahl sein, um „unscharfe“206 Übersetzungen des englischen Zentralbegriffs „adversarial“ sowie unmittelbare Relationen zu den streng formellen Prinzipien des Zivilrechts nicht zu stark zu gewichten. ${ }^{207}$

Überdies muss das herkömmliche Wort „,inquisitorisch“208 als auch sprachlich passender Gegenpol für die Bezeichnung des auf die aktive Aufklärungsrolle des Richters Gewicht legenden Verfahrensmodells kontinentaleuropäischen Ursprungs nicht mehr aufgrund seines mittelalterlichen "Schattenhintergrunds“ abgelehnt werden. Der „folkloristische“ und jedenfalls veraltete Charakter negativer Konnotationen ist nämlich heute ohne besondere Schwierigkeiten zu erkennen. ${ }^{209}$ Die normative Verankerung von Foltermethoden zur Erlangung eines ,sicheren“ Beweisergebnisses sowie die Personalunion von Ankläger und Richter ${ }^{210}$ im Strafprozess gehören im modernen westlichen Rechtsstaat nun offensichtlich der Vergangenheit an. Diese im Mittelalter und in der vorrevolutionären Zeit weitverbrei-

205 Vgl. auch Roberts/Zuckerman, Criminal Evidence. S. 49.

206 Jung, JuS 1998, 1 (3 Fn. 25). Siehe auch Eser, FS für Tiedemann, S. 1456-1457 (Fn. 16).

207 Vgl. Damaška, in: Kadish (Hrsg.), Encyclopedia, S. 27; Jung, FS für Waltoś, S. 31.

208 Siehe Duden Herkunftswörterbuch, S. 364: „Inquisition: [...] strenge Untersuchung, Verhör: [...] bereits im Mittelalter aus [lateinisch] inquisitio ,Untersuchung' entlehnt. Dies ist eine Bildung zu inquisitus [...] von [lateinisch] inquirere ,untersuchen' [...]." Ebenso Duden Universalwörterbuch, S. 885: „Inquisitor [... lateinisch inquisitor = Untersucher]. [...] inquisitorisch: in der Art eines Inquisitors, eines strengen Untersuchungsrichters [...]." Siehe entsprechend auf Englisch für die Begriffe ,,inquisition, inquisitor, inquisitorial", Oxford Dictionary, S. 903. Siehe auch Trusen, ZRG KA 74 (1988), 168 (170-171).

209 Dazu bereits unter Teil 1, II.B.1.b) und II.B.1.c)aa).

$210 \mathrm{Zu}$ dieser psychologisch notwendigen Trennung der Funktionen, aber auch zur lediglich formalen Durchsetzung des Anklagegrundsatzes im reformierten Strafprozess, wobei der Richter neben seiner Entscheidungsfunktion letztendlich materiell seine ,inquisitorische" Verfolgungsfunktion behalten hat und ihm nur ein gesondertes Klageerhebungsorgan gegenübergestellt worden war: Küper, Richteridee, S. 193-213. Siehe auch Ignor, Geschichte, S. 231-237, 244-248. In materiellerer Hinsicht (zusätzliche Trennung von Ermittler und Richter) versteht das Akkusationsprinzip Eser, FS für Tiedemann, S. 1457 (Fn. 17); diese Ansicht trifft jedoch nur teilweise zu, etwa im Hinblick auf die begrenzten Untersuchungstätigkeiten des Richters im Rahmen des heutigen deutschen Vorverfahrens, nicht aber hinsichtlich seiner Ermittlungsfunktion in der Hauptverhandlung, vgl. dazu Haas, Strafbegriff, S. 7-8; Lüderssen, abgedruckt in Lelieur, in: Eser/Rabenstein (Hrsg.), Strafjustiz, S. 66; und früher schon Schünemann, in: Bierbrauer u.a. (Hrsg.), Verfahrensgerechtigkeit, S. 216. 
teten Verfahrensweisen gelten außerdem als die grausamsten Manifestationen des alten Inquisitionsprozesses und sind nicht pauschal mit ihm und seinen konstitutiven Elementen gleichzusetzen, ${ }^{211}$ im Gegensatz dazu ist nicht $\mathrm{zu}$ bezweifeln, dass das konstitutive Charakteristikum des historischen Inquisitionsprozesses, namentlich die inquisitio der materiellen Wahrheit von Amts wegen, von essenzieller Bedeutung auch für die gegenwärtigen kontinentaleuropäischen Strafverfahrensarten ist. $^{212}$

In demselben Kontext ist nicht der im deutschen Schrifttum teilweise vertretenen Bezeichnung ,instruktorisch“213 der Vorzug zu geben; restriktive Bezüge zum speziellen deutschen Verständnis der Wahrheitsermittlung im Rahmen der Instruktionsmaxime $^{214}$ sind somit $\mathrm{zu}$ vermeiden, da sie den abstrakteren und inhaltlich weiteren Erfordernissen rechtsordnungsübergreifender Modelle eventuell nicht gerade dienlich sind. Schließlich wird auch die - hauptsächlich in angloamerikanischen Studien oft alternativ verwendete - Bezeichnung „nicht-adversatorisch“ (non-adversarial) ${ }^{215}$ hier nicht bevorzugt: Erstens weil aus dieser Bezeichnung nicht unmittelbar auf den ersten Blick die dynamische Art und Weise der Beweisführung und Wahrheitsermittlung hervorgeht; zweitens, weil durch sie einem Modell, dessen Hintergrundideen eine autonome lange Entwicklungsgeschichte zeigen, ein begrifflich selbstständiger Charakter vorenthalten wird; drittens, weil diese

211 Über die Folter als nicht essenzielles und ausschließliches Element der inquisitorischen Verfahrensart Damaška, U. Pa. L. Rev. 121 (1973), 506 (558); Ignor, Geschichte, S. 16, 63; Rüping/Jerouschek, Strafrechtsgeschichte, S. 35; Trusen, ZRG KA 74 (1988), 168 (230); Vormbaum, Einführung, S. 90-92, 105. Vgl. auch Kelly, Church History 58 (1989), 439 (450-451). Zur schon seit dem Mittelalter sporadisch auftretenden Vermischung der Akkusation seitens eines (privaten oder sogar öffentlichen) Anklägers als Verfahrenseinleitungsform mit der amtlichen Inquisition als Form für die weiteren Prozeduren E. Schmidt, Einführung, S. 125-126, 198-203. Zusammengefasst Ambos, JURA 2008, 586 (589-593).

$212 \mathrm{Zu}$ den essenziellen Elementen des alten Inquisitionsprozesses E. Schmidt, Einführung, S. 86-87; Sellert, FS für Scupin, S. 163-164, 181; Weigend, Deliktsopfer, S. 83-84; Ziegler, Möglichkeiten, S. 2-5. Vgl. auch Maier, FS für Roxin 2001, S. 1218-1219, 12211222. Mehr bereits unter Teil 1, I.B.3.b), I.B.4., II.B.1.b).

213 Vorwiegend Eser, FS für Miyazawa, S. 565; Eser, FS für Tiedemann, S. 1457. Vgl. auch Ambos, JURA 2008, 586 (586, 593); Perron, in: ders. (Hrsg.), Beweisaufnahme, S. 6. Zur sprachlichen Bedeutung Duden Fremdwörterbuch, S. 625-626: „Instruent , aus lat. instruens $[\ldots]$ von instruere $[\ldots]^{6}: 1$. (Rechtsspr.) mit der Voruntersuchung für einen Prozess beauftragter Beamter. [...]. ,Instruieren' , aus gleichbed. lat. instruere, eigtl. ,herrichten; ausrüsten'": 1. In Kenntnis setzen; unterweisen, lehren, anleiten. 2. (veraltet) eine Rechtssache zur Entscheidung vorbereiten. [...],Instruktion“ , aus gleichbed. lat. instructio zu instruere, vgl. instruieren': Anleitung; Vorschrift; Richtschnur, Dienstanweisung."

214 Diese wird übrigens oft als Inquisitions- oder Untersuchungsgrundsatz bezeichnet, dazu u.a. Beulke, Strafprozessrecht, Rn. 21; Roxin/Schünemann, Strafverfahrensrecht, $§ 15$ Rn. 3-5.

215 Erst Damaška, U. Pa. L. Rev. 121 (1973), 506 (513, 554, 562, 577), weiterhin Damaška, ZStW 87 (1975), 713 (714), und Damaška, Zbornik PFZ 51 (2001), 477 (490). U.a. auch Grande, in: Jackson u.a. (Hrsg.), Crime, S. 145; Volkmann-Schluck, Am. J. Crim. Law 9 (1981), 1 (3). 
Bezeichnung, wenn auch zunächst zur Eliminierung von negativen Vorurteilen ausgewählt, weitere rhetorische (,polarisierende“) Superioritätseffekte eigentlich nicht ausschließen lässt, denn für die Bildung des gemeinsamen Basisbegriffs und als ansonsten ,neutraler“ Maßstab für die trennende Bezeichnung werden einseitig Assoziationen nur zu dem einen der zwei einander gegenübergestellten Verfahrensmodelle wahrgenommen. ${ }^{216}$ Im Ergebnis wird die im Vergleich zur terminologischen Auseinandersetzung viel bedeutsamere Untersuchung des Inhalts der Beweisverfahrensmodelle, die für analytisch-vergleichende Zwecke eingesetzt werden, unter Verwendung der allgemein dominierenden und auch hier befürworteten Bezeichnungen ,adversatorisch“ und ,inquisitorisch“ durchgeführt.

\section{Die Bestandteile des, ,adversatorischen“" und des ,inquisitorischen“ Beweisverfahrensmodells}

Wie bereits dargelegt, gehen die nachfolgenden Untersuchungen von den modernen abstrakten Konzeptionen der westlichen Prozessstile aus, die sich in Form von Beweisverfahrensmodellen realisieren lassen. Insbesondere werden hier extensive Betrachtungen nicht weiter berücksichtigt, die alle Phasen und Aspekte der angloamerikanischen bzw. der kontinentaleuropäischen Strafverfahren unter einem Dach $\mathrm{zu}$ vereinen versuchen. Für eine gegenüberstellende all inclusive-Beschreibung sämtlicher common law- und civil law-Verfahrensbesonderheiten wäre ohnehin die Einbeziehung von sehr „komplexen und heterogenen Faktoren“ Voraussetzung; diese würden jedoch die Bildung von wenigen, ,intern konsequenten“217 Typen des Strafprozesses und somit die in diesem Analyserahmen durchgeführten Vergleichungen erschweren.

Gleichwohl ergeben sich genügend Bestimmtheits- und Einheitlichkeitsprobleme schon innerhalb der hier diskutierten, inhaltlich begrenzten Modelle. Allgemein anerkannt ist nur, dass das Rollenverhältnis ${ }^{218}$ - insbesondere: Aktivität versus Passivität - zwischen dem Richter und den sonstigen Kernbeteiligten während der Beweisführung einen wichtigen Ausgangspunkt für die Dichotomie zwischen „adversatorischem“ und ,inquisitorischem“ Modell und somit einen zentralen Anknüpfungspunkt für die Erstellung von Hypothesen für konkretere rechtsvergleichende Arbeiten darstellt. Bei der präzisen Definition der strukturellen Kernelemente der Modelle (unter 1.) und vor allem der Ziele, die durch die Verwendung

216 Für weitere Überlegungen vgl. van Kessel, Notre Dame L. Rev. 67 (1992), 403 (415-416).

217 Damaška, in: Kadish (Hrsg.), Encyclopedia, S. 29 (bezüglich der angloamerikanischen Strafprozesse); siehe auch Damaška, Zbornik PFZ 51 (2001), 477 (503). Vgl. auch Langbein/Weinreb, Yale L.J. 87 (1978), 1549 (1550-1551).

218 Zur Bedeutung des Rollenbegriffs auch für die Strafprozessvergleichung Jung, FS für Roxin 2011, S. 1240. Siehe auch Schreiber, ZStW 88 (1976), 117 (132-135). 
der entsprechenden Verfahrensformen verfolgt werden (unter 2.), ergeben sich jedoch Schwierigkeiten. Ob weitere prozesstechnische Elemente - und wenn ja, welche - der strukturellen Komponente und der Zielsetzungskomponente dieser idealen Verfahrenstypen zugeordnet werden sollen/können, bleibt eine noch umstrittenere, im Folgenden ausführlich zu untersuchende Frage (unter 3.). ${ }^{219}$

\section{Kernelemente: Strukturelle Komponente und Rollenverteilung}

\section{a) Die zentrale Idee hinter der Dichotomie der Modelle}

Die wenigen eingehenden rechtsvergleichenden Betrachtungen der Extremtrennung zwischen ,,adversatorischem“ und ,inquisitorischem“ Strafverfahrenstypus werden erst aufgrund der Idee der Steuerung des Prozesses durch unterschiedliche Verfahrensbeteiligte angestellt, wobei im prozessstrukturellen Kontext daher zwischen „Parteienwettstreit“" und ,amtlicher Ermittlung“ unterschieden wird. ${ }^{220}$ Nach einer eng begrenzten (an den Anforderungen kohärenter Untersuchungen sich orientierenden) beweisprozessualen Betrachtung können dann als Kernelemente des „adversatorischen“ Modells die Beweisführung durch gegensätzliche nicht richterliche Parteien (Anklage und Verteidigung) und die Einhaltung der Gerichtsprozessund Fairnessregeln durch passiv-neutrale Richter akzeptiert werden. Bezüglich des Hauptgehalts des ,inquisitorischen“ Beweisverfahrensmodells kann Folgendes festgestellt werden: Nicht nur die Einhaltung der Verfahrensregeln, sondern auch sämtliche Beweisführungen konstituieren dabei eine einseitig amtliche Angelegenheit und werden im Gerichtsprozess von der Richteraktivität beherrscht.

Trennendes Hauptkriterium scheint schlüssig die Art und Weise der Beschaffung des Beweismaterials und der Gestaltung der Beweisbasis von Gerichtsverhandlung und schuldfeststellendem ${ }^{221}$ Urteil zu sein: Im Zentrum des Interesses relevanter Modellerwägungen steht insbesondere die dominierende Rolle des Richters (,,inquisitorisches“ Modell) oder der Verfahrensbeteiligten/Parteien (,,adversatorisches“ Modell) bei der Bestimmung des Umfangs der Beweiserhebungen sowie bei der gerichtlichen Erhebung, Präsentation und Prüfung der Stichhaltigkeit von Beweisen. ${ }^{222}$

219 Vgl. u.a. Damaška, Zbornik PFZ 51 (2001), 477 (483); Jackson, MLR 68 (2005), 737 (742); Pizzi/Montagna, Mich. J. Int'l L. 25 (2004), 429 (432).

${ }_{220}$ Grundlegend Damaška, U. Pa. L. Rev. 121 (1973), 506 (563-564, 577); Damaška, Zbornik PFZ 51 (2001), 477 (482, 490, 502-503).

221 Eine besondere Beschäftigung mit Beweisaspekten der Strafzumessungsphase ist im Rahmen der dominierenden Modelle nicht sichtbar, auch wenn es bezüglich der reinen, schuldrelevanten Beweisführung einerseits und der Erledigung der Straffrage anderseits in angloamerikanischen Systemen meistens um klar getrennte Verfahrensabschnitte (im Gegensatz zu den meisten kontinentaleuropäischen Verfahren) geht, dazu z.B. Pizzi/ Montagna, Mich. J. Int'l L. 25 (2004), 429 (433).

222 In diesem Sinne verstehen den Kern der Dichotomie u.a. Damaška, U. Pa. L. Rev. 121 (1973), 506 (510, 563-564); Damaška, Zbornik PFZ 51 (2001), 477 (482-483, 489- 


\section{b) Blick in das Modellinnere}

Zur weiteren Veranschaulichung des wesentlichen Modellinhalts sind Kurzbeschreibungen üblich, die weiterhin innerhalb der Rechtstraditionen einfach erkennbare und detailfreie Beweisverfahrensbilder vermitteln. ${ }^{223}$ Im ,,adversatorischen“" Modell stehen Anklage (prosecution, hauptsächlich vertreten durch Justizbzw. Verwaltungsbeamte oder Anwälte im Auftrag des Staates/,Volkes“" ${ }^{224}$ und Verteidigung (defence, Angeklagter und sein Anwalt) ${ }^{225}$ einander gegenüber. Even-

491, 502-503); Elser, Rolle, S. 2; Eser, FS für Tiedemann, S. 1458-1459; Fedorova, Principle, S. 99; Herrmann, SACC 2 (1978), 3 (5-6); Hodgson, in: Duff u.a. (Hrsg.), Trial on Trial 2, S. 223-224; Hörnle, ZStW 117 (2005), 801 (804); Jackson, MLR 68 (2005), 737 (742); Jörg/Field/Brants, in: Fennell u.a. (Hrsg.), Criminal Justice, S. 42; Jung, FS für Waltoś, S. 31; Kirsch, StV 2003, 636 (638); Langer, Harv. Int'l L. J. 45 (2004), 1 (9, 17, 20-24); Schünemann, FS für Fezer, S. 557-558; Tiedemann, ZRP 1992, 107 (108); Tomlinson, Md. L. Rev. 42 (1983), 131 (134); Trüg, Lösungskonvergenzen, S. 25-27; van Kessel, Notre Dame L. Rev. 67 (1992), 403 (416); Weigend, ZStW 104 (1992), 486 (489); Weigend, FS für Rissing-van Saan, S. 750-751, 755; Weigend, in: Smits (Hrsg.), Elgar Encyclopedia, S. 271-272; Williams, Proof, S. 29-30. Auch US Supreme Court McNeil v. Wisconsin, 501 U.S. 171, 181-182 Fn. 2 (1991).

223 Vgl. u.a. Damaška, ZStW 87 (1975), 713 (715-718); Eser, in: Schroeder/Kudratov (Hrsg.), Hauptverhandlung, S. 12-13; Herrmann, SACC 2 (1978), 3 (4-6); Jackson, MLR 68 (2005), 737 (742-745); LaFave/Israel/King/Kerr, Criminal Procedure, S. 43-44; Langer, Harv. Int'l L. J. 45 (2004), 1 (20-24).

${ }^{224}$ Der Stellung der „Anklage“ im ,,adversatorischen“ Modell liegen üblicherweise grobe Beobachtungen der englischen und amerikanischen Rechtssysteme zugrunde, im ,inquisitorischen" Modell etwa die französische oder die deutsche Justizorganisation. Für einen kurzen Einblick in die behördliche Stellung der Staatsanwaltschaft in verschiedenen europäischen Rechtsordnungen Kühne, Strafprozessrecht, Rn. 130, 1169, 1220, 1272, 1328, 1373, 1419; Perrodet, in: Delmas-Marty/Spencer (Hrsg.), European Criminal Procedures, S. 416-432. Zur entsprechenden Lage in den USA LaFave/Israel/King/Kerr, Criminal Procedure, S. 29-30.

225 Für die rechtsordnungsübergreifenden Modelle wird der sprachlich übliche Begriff „Angeklagter“ zur Bezeichnung der Person, der die Begehung einer Straftat offiziell vorgeworfen wird (vgl.: charged with a criminal offence), nicht in irgendeinem nationalrechtlichen bzw. technischen Sinne (z.B. § 157 deutsche StPO) verwendet, vgl. auch die wegweisende autonome Auslegung des EGMR für die Zwecke des Art. 6(1, 3) EMRK etwa in EGMR Öztürk v. Germany, Urt. v. 21.2.1984 (8544/79), § 55. Darüber hinaus schließt die EGMR-Rechtsprechung in Beweisvorgängen, wie etwa die Zeugenbefragung nach Art. 6(3d) EMRK, eine Gleichsetzung des Angeklagten mit seinem Verteidiger grundsätzlich nicht aus, dazu z.B. EGMR Doorson v. the Netherlands, Urt. v. 26.3.1996 (20524/92), $\S 74$, vgl. auch EGMR Isgrò v. Italy, Urt. v. 19.2.1991 (11339/85), § 36. Ungeachtet besonderer innerstaatlicher Rollenverteilungen wird nun auch hinsichtlich der hier diskutierten Modelle bei Gesamtwahrnehmung der Verteidigung als vollwertige beweisführende Partei eines prozessualen „Kampfes“ zwischen Verteidiger und Angeklagtem in erster Linie nicht speziell differenziert; vgl. zur notwendigen Präsenz eines Rechtsanwalts im Verfahren als nicht konstitutivem Element der Modelle, US Supreme Court McNeil v. Wisconsin, 501 U.S. 171, 181-182 Fn. 2 (1991). Zum Spannungsverhältnis zwischen der unverzichtbaren (gegenwärtig auch menschenrechtlich weithin verankerten) Rolle des Verteidigers für die effektive Erfüllung der Prozessaufgaben und dem mit der Autonomie-Idee des ,adversatorischen“ Modells kompatiblen Recht, sich selbst zu verteidigen, insb. zur amerikanischen Lage, siehe Damaška, ZStW 90 (1978), 829 (852-854 und auch 858-860 
tuellen Deliktsopfern wird nach wie vor - wie auch beim klassischen richterzentrierten (wenn auch in Bezug auf die Teilnahme von Verletzten im Strafverfahren allgemein offeneren) ${ }^{226}$,inquisitorischen“ Modell - keine selbstständige Kernrolle in der Beweisführung zugebilligt. ${ }^{227}$ Im Vordergrund des ,adversatorischen“ Verfahrenstypus stehen also zwei gegensätzliche Parteien ${ }^{228}$ und ihre aktive beweisprozessuale Stellung:

- Die Anklage (Staatsanwaltschaft) trägt zur Unterstützung ihres Anklagevorbringens $^{229}$ alle notwendigen Beweise zusammen, präsentiert diese vor dem Gericht und stellt die Stichhaltigkeit der von der Verteidigung beigebrachten Gegenbeweise in Frage.

zu Meinungsverschiedenheiten zwischen Anwalt und Angeklagtem). In dieser Arbeit nicht eingehend diskutiert wird darüber hinaus die Stellung des Angeklagten als selbstständiger Gegenstand von Beweiserhebungen, vgl. dazu kurz Damaška, U. Pa. L. Rev. 121 (1973), 506 (526-530); Damaška, ZStW 87 (1975), 713 (716,717 insb. Fn. 6, 7); Herrmann, SACC 2 (1978), 3 (6); Pakes, Comparative, S. 93-94.

226 Vgl. Damaška, UCLA J. INT’L L. \& FOREIGN AFF. 14 (2009), 19 (29): „Where fact-finding is court-directed, tendering evidence and participation in proof-taking need not be limited to the parties: fact-finding is like a conference at which many voices can be heard. But where two fact-finding hypotheses are advanced by the parties and are rival suitors for the judges' attention, a bi-polar force field emerges, making it difficult to include successfully a third side in the development of evidence."

227 Vgl. zur Opferproblematik Blondel, Duke L.J. 58 (2008), 237 (239); Horovitz, in: Carter/Pocar (Hrsg.), International, S. 166-170; Jackson, in: McConville/Wilson (Hrsg.), Handbook, S. 341, 345; Schünemann, in: Schünemann/Dubber (Hrsg.), Stellung, S. 6-9; Sebba, Am. J. Comp. L. 30 (1982), 217 (225-229); Vogler, in: Vogler/Huber (Hrsg.), Criminal Procedure, S. 23; Weigend, Deliktsopfer, S. 16-20, 79-96, 167, 544-545. Jenseits der beweisverfahrensbezogenen Modellunterscheidung, zur neuerdings zunehmenden Verbesserung der Rolle des Opfers in eigentlichen Strafverfahrenssystemen u.a. Safferling, ZStW 122 (2010), 87 (87-89, 114-116); Spinellis, Is.L.R. 31 (1997), 337 (337, 342-346).

228 Der Begriff „Partei“ wird an dieser Stelle nicht im strikt-technischen Sinne verwendet. Er soll die innerhalb eines Beweisstreits herrschende Gegnerschaft zwischen nicht richterlichen Beteiligten ausdrücken, die dem hier betreffenden idealen ,adversatorischen“ Verfahrenstypus zugrunde liegt, vgl. auch Langer, Harv. Int'l L. J. 45 (2004), 1 (23-24). Andere Verfahrensaspekte, wie etwa die Objektivitätserwägungen und Abwägungen zwischen Opportunitäts- und Legalitätsprinzip im Rahmen der staatsanwaltlichen Verfahrenseinleitung, sind mit dieser Begriffsverwendung nicht (unmittelbar) zu korrelieren. Zur konkreten Ablehnung einer auf die Staatsanwaltschaft bezogenen Anwendung des Parteibegriffs im deutschen Strafprozess u.a. Roxin/Schünemann, Strafverfahrensrecht, § 17 Rn. 5. Siehe aber gegenüber dieser Auffassung die sich aus der Verfahrenswirklichkeit ergebenden Vorbehalte von Gaede, StV 2012, 51 (51). Siehe auch Weigend, in: Luna/ Wade (Hrsg.), Prosecutor, S. 382. Ferner zu dieser Diskussion Haas, Strafbegriff, S. 39-50 m.w.N.

229 Die Erhebung der Klage per se gehört nicht zum Modellinhalt; sie soll nicht im Rahmen einer parteilichen Entscheidung, sondern grundsätzlich objektiv, ungeachtet bekannter Opportunitätserwägungen, erfolgen: „Erst wenn es für [den Staatsanwalt] feststeht, daß der Angeklagte schuldig ist, entscheidet er sich dafür, in die Hauptverhandlung zu gehen. In diesem Fall nimmt er aber dann eine parteiische Haltung ein und betrachtet den Fall je nach Ausgang als gewonnen oder verloren“, so Damaška, ZStW 87 (1975), 713 (715-716 Fn. 5). Vgl. auch Paulsen, ZStW 77 (1965), 637 (656); Weigend, ZStW 100 (1988), 733 (749-750). 
- Die Verteidigung sucht die geeigneten Strategien und Beweismittel aus, die der Durchsetzung ihrer eigenen Thesen und der Widerlegung der belastenden, von der Anklage behaupteten Tatsachen dienen können. ${ }^{230}$

- In der herkömmlichen Hauptverhandlung, in der Beweispraktiken wie das Kreuzverhör (cross-examination) von Zeugen der einen Partei durch die Gegenpartei zum Einsatz kommen, wirkt dann der verfahrensleitende Richter neutral und passiv. Er führt keine eigentlichen Beweiserhebungen. Der Richter ist zunächst lediglich für die unparteiische Einhaltung der Verfahrensfairness- bzw. Verhaltensregeln des Wettstreits und die Entscheidung über die von den Parteien vorgebrachten Einwände (objections) verantwortlich. Dabei ist nicht von Bedeutung, ob er am Verhandlungsende selbst die Urteilsfindungsaufgabe übernimmt oder die eventuell dafür zuständigen, beweisprozessual ebenso passiven jurors hinsichtlich Rechts- und/oder Beweisfragen instruieren muss.

- Nicht nur in jury trials, sondern sogar in bench trials (ohne getrennte Geschworenenbank) ist eine strikte Anwendung von Beweisregeln seitens des Richters zur „Abschirmung“ des kontradiktorischen Verfahrenscharakters bzw. zum Ausgleich der schwierigen Lage des Angeklagten sowie wegen anderer Fairness- und Gleichheitserwägungen idealtypisch nicht ausgeschlossen. Bestimmte Beweisregeln, die etwa den Ausschluss von nicht konfrontierten hearsay-Beweisen oder character-Beweisen betreffen, dienen nicht nur der ,adversatorischen“ (insbesondere: unmittelbar kontradiktorischen) Verfahrensausgestaltung; sie stehen mutmaßlich auch in spezifischem Sinnzusammenhang mit der aufgeteilten Struktur der jury trial und insbesondere mit der schutzbedürftigen urteilsfindenden Funktion der Geschworenen. ${ }^{231}$

Beim ,inquisitorischen“ Modell stehen dagegen nicht die Beweisaktivitäten irgendwelcher Parteien im Vordergrund, die in ihrem Umfang einseitig bestimmt und gegensätzlich ausgeführt werden, sondern umfassende zentral-amtliche (insbesondere richterliche) Ermittlungen des Sachverhalts:

230 Die Ausübung des Schweigerechts stellt eine modellunabhängige beweisprozessuale Frage dar.

231 Problematisch kann bei bench trials für System und Zweck der Beweisausschlussregeln in ,adversatorischen“ Strafverfahren die Personalunion von verfahrensleitendem Richter und Urteilsfinder insb. deswegen sein, weil diejenige Person über die Schuld entscheidet, welche die ausgeschlossenen Beweise eigentlich schon vorher während des Beweisausschlussprozesses wahrgenommen hat; insgesamt dazu und zu konkreten Lösungsalternativen (z.B. Einführung der richterlichen Begründungspflicht) Jackson/Doran, Is.L.R. 31 (1997), 645 (654-655, 658-664, 672-689). Vgl. auch Davis, A.B.A.J. 50 (1964), 723 (724-725). Siehe auch Damaška, Law, Probability and Risk 5 (2006), 255 (260-265). Zum Verhältnis zwischen Beweisausschlussregeln und jury-Verfahren und zur relevanten Beweisfilterung auch Eser, FS für Miyazawa, S. 564-569; Jackson, in: A. Duff u.a. (Hrsg.), Trial on Trial 1, S. 135-136; Roberts/Zuckerman, Criminal Evidence, S. 43; van Koppen/Penrod, in: dies. (Hrsg.), Adversarial, S. 3. Besonders zum Verhältnis zwischen Beweisausschluss, ,adversatorischem" Verfahren und jury-Verfahren McEwan, Evidence, S. 26-27; auch in dieser Arbeit kurz unter Teil 1, I.B.2.a)aa). 
- Anklage und Verteidigung können nicht durch Entgegensetzung der ,eigenen Fälle“ (cases) den Umfang der Beweiserhebung determinieren. Vielmehr wirken parteiliche Beweisinitiativen nicht verbindlich für die Untersuchungsbehörden, die selbst sämtliche Beweisführungen in die Hand nehmen.

- Im Hauptverfahren hat vor allem der verfahrensleitende Richter die Kontrolle über alle Aspekte des Prozesses. Er entscheidet grundsätzlich frei, wie viele Beweise zu erheben oder etwa welche (zusätzlichen) Zeugen zu laden und in welcher Reihenfolge diese zu vernehmen sind. Er ist auch primär verantwortlich für die objektive Prüfung der Stichhaltigkeit der Beweise, beispielsweise durch direkte Zeugenbefragungen. Der Richter hat die Pflicht, in alle Beweisverfahrensphasen autoritativ und aktiv einzugreifen, unabhängig davon, ob letzten Endes er etwa allein oder gemeinsam mit anderen Berufs- bzw. Laienrichtern für die Entscheidung über die Schuldfrage zuständig ist.

- Die richterliche Anwendung von strikten Beweis(ausschluss)regeln während des Beweisverfahrens steht nicht im Vordergrund der Modellerwägungen. Der Richter ist jedenfalls bei der Vornahme weiterer Beweisführungen nicht an den Willen der Verfahrensbeteiligten gebunden.

\section{Zielsetzungskomponente}

\section{a) Einführung: Traditionelle und ,,ideologische“ Betrachtungen}

aa) Modelle zu Organisation und Zielsetzung der Strafjustiz

Der breite oder eingeschränkte Ermessensspielraum des Richters während der Beweisführung sowie die Anwendung oder Nichtanwendung seinerseits von strikten Beweisausschlussregeln stehen in Zusammenhang mit der Problematik der Prozessziele als ebenfalls wesentlicher Parameter (jedoch nicht unbedingt als Dichotomisierungsfaktor) der Beweisverfahrensmodelle. Es wird zunächst oft behauptet, dass den ausdifferenzierten Prozesserscheinungsformen angloamerikanischen und kontinentaleuropäischen Ursprungs, die für die bereits beschriebenen Verfahrensbilder wahrgenommen worden sind, ein ideologischer Hintergrund zugeschrieben werden kann.

Insbesondere wird dabei vermutet, dass die angloamerikanischen Verfahrenssysteme von einem starken Misstrauen gegenüber der Staatsgewalt und von der Notwendigkeit einer Verteidigung gegen ihre willkürliche Ausübung ausgehen. ${ }^{232}$ Die kontinentaleuropäischen Systeme zeigen dagegen ein erheblich größeres Vertrauen in den Staat und seine Strafverfolgungs- und Justizbehörden. ${ }^{233}$ Darauf gründen

232 Vgl. auch US Supreme Court Crawford v. Washington, 541 U.S. 36, 67-68 (2004).

233 Dazu Damaška, U. Pa. L. Rev. 121 (1973), 506 (565, 583-584). Siehe auch Weigend, FS für Rissing-van Saan, S. 758-759. Vgl. auch Herrmann, RIDP 53 (1982), 841 (847-848); Paulsen, ZStW 77 (1965), 637 (668); Vogel, GA 2010, 1 (7). 
sich dann entsprechend unterschiedliche Vorstellungen von der Verteilung von Prozesskontrolle und Verantwortlichkeit zwischen Staat und autonomen Verfahrensparteien bei der Sachverhaltsaufklärung. ${ }^{234}$ Ferner bleibt davon die Haltung zur Anwendung bestimmter strikter Beweisverfahrensregeln (z.B. fruit of the poisonous tree) nicht unbeeinflusst: Die eine oder andere dieser Regeln kann folglich etwa als technische (korrektive bzw. präventive) Maßnahme gegen staatliche Willkür, manchmal aber auch als unnötiges Hindernis für die offizielle Wahrheitssuche verstanden werden.

Die vorliegende Studie verfügt über keinen angemessenen rechtssoziologischen Diskursrahmen zur Beantwortung der Frage, ob derartige Ansichten hinsichtlich der tiefliegenden Gründe von Strafverfahrensorganisation und Machtverhältnissen in der Gegenwart einen allgemeinen Geltungsanspruch haben. Ebenso wenig können hier die parallel entwickelten und früher viel diskutierten Modelle des Strafprozesses weitergehend angesprochen werden, die sich in verschiedenen staatsstrukturellen Kontexten auf die Organisation der Strafjustiz in Zusammenhang auch mit primären sozialpolitischen Hintergründen, Entscheidungen und Zielen beziehen - insbesondere die weithin bekannten hierarchical, coordinate, conflictsolving und policy-implementing models, das family bzw. parental und das battle bzw. arm's-length model, sowie das crime control und das due process model spiegeln solche Betrachtungen wider. ${ }^{235}$ Es ist dennoch möglich, an dieser Stelle einige hierzu einführende, auch für die bessere Nachvollziehung der zentralen Forschungsfragen hilfreiche Bemerkungen zu machen:

\section{- Hierarchie- und Koordinationsmodelle}

Vereinfacht ausgedrückt hat zunächst Damaška versucht, ergänzend zur herrschenden Modelldichotomie (,inquisitorisch“/,adversatorisch“) die Gestaltungsdivergenzen zwischen dem kontinentaleuropäischen und dem angloamerikanischen Strafprozess mit seinem Hierarchie- und Koordinationsmodell anhand der allgemeineren Organisationsstrukturen der jeweiligen Staatsgewalt weitergehend zu „,illuminieren“. ${ }^{236}$ Angesichts der unterschiedlichen Strukturen der Machtverteilung und Gewaltenorganisation in der Strafjustizverwaltung wird dabei idealerweise zwischen zwei Systemen differenziert:

- einem vertikalen zentralisierten, bürokratischen, professionalisierten, auf abstrakt-technischen Normen basierenden und distanzierten Hierarchiesystem in der civil law-Welt und

234 Vgl. auch Roberts/Zuckerman, Criminal Evidence, S. 52.

235 Für einen kurzen Überblick siehe Damaška, Zbornik PFZ 51 (2001), 477 (494-502). Ebenso u.a. Herrmann, SACC 2 (1978), 3 (14-19); Hörnle, ZStW 117 (2005), 801 (803806); Jung, FS für Waltoś, S. 28-35; Vogler, A World View, S. 5-11.

236 Damaška, Yale L.J. 84 (1975), 480 (481-482). 
- einem horizontalen dezentralisierten, formlosen, laienbasierten, einzelstufigen, bei der Entscheidungsfindung auf Gemeinschaftsnormen und breiten Ermessensbefugnissen basierenden Koordinationssystem in der common law-Welt.

In diesem Analyserahmen lassen sich dann nach Damaškas Meinung auch Unterschiede zwischen den Rechtsordnungen hinsichtlich etwa der Verfahrenskonzentration, der Funktionenzersplitterung, der Laiengerichtsbarkeit, der Mündlichkeit im Verfahren, des Rückgriffs auf die amtlichen Ermittlungsakten oder des Rechtsmittelsystems besser erklären. ${ }^{237}$

\section{- Conflict-solving- und policy-implementing-Justizmodelle}

Neben diesen Koordinations- und Hierarchiemodellen sowie den klassischen „adversatorischen“ und „inquisitorischen“ Modellen hat Damaška eine weitere, politisch inspirierte Modelltheorie zu den unterschiedlichen Konturen des Strafprozesses entwickelt. Diese Theorie nimmt zunächst die traditionellen Anschauungen zum reaktiven bzw. laissez-faire und zum proaktiven bzw. interventionistischen Staatstypus wahr. Sie knüpft demgemäß bewusst an mögliche politische Extremziele der Handhabung der Strafjustiz an - es geht dabei insbesondere um die Antithese zwischen der Bereitstellung einer geeigneten Plattform für die „Selbstlösung“ von sozialen Konflikten und der autoritativen Realisierung des strafrechtlichen Regierungsprogrammes. Je nach der entsprechenden Zielsetzung wird daher zwischen conflict-solving- und policy-implementing-Justizmodellen unterschieden.

Diese Betrachtungsweise basiert also erheblich auf idealtypischen Erwägungen bezüglich der prozessualen Fernziele als Teilstück der allgemeinen Zielsetzung der Strafjustiz. Die conflict-solving- / policy-implementing-Dichotomie kann sich dann nicht nur hinsichtlich Fragen etwa zu den ,privaten“ bzw. außerprozessualen Erledigungsmechanismen, zur Verfahrensautonomie des Individuums oder zur „Waffengleichheit" als analytisch nützlich erweisen; sie kann auch (muss aber nicht) ${ }^{238}$ in direkte Verbindung mit der jedenfalls inhaltlich engeren Gegenüberstellung von „adversatorischer“ (parteilicher statt autoritativer) und „inquisitorischer“ (einseitigamtlicher) Prozesssteuerung gebracht werden. ${ }^{239}$

\section{- Arm's-length bzw. battle und parental bzw. family Modelle}

Des Weiteren werden mit mutmaßlichen Makro-Zielsetzungen innerhalb der „adversatorischen“ und der ,,inquisitorischen“ Verfahren zuweilen „,ideologischere“ Systemerklärungen in Zusammenhang gebracht, die sich vormals insbesondere in der Dichotomie zwischen arm's-length bzw. battle und parental bzw. family Mo-

237 Ausführlich Damaška, Faces, S. 16-70.

238 Vgl. Jackson/Doran, Judge, S. 60.

239 Ausführlich Damaška, Faces, S. 71-180. 
dellen erkennen ließen. ${ }^{240}$ Derartige Betrachtungen basieren noch etwas stärker auf hypothetischen sozialpolitischen Zielen der Handhabung der Strafjustiz. Sie konzentrieren sich noch deutlicher auf ideologische Hintergrundtheorien bezüglich der Vertrauens- und Interessenbeziehung zwischen Staat und Bürger/Beschuldigtem und bezüglich der allgemeinen Haltung, Orientierung und Organisation des Staatsapparates bei der Kriminalitätsbekämpfung. Staatliche Abschreckung oder Vergeltung als Bestrafungsziel, strikt regulierte kampfartige Auseinandersetzungen zwischen Staat und Individuum, Misstrauen gegenüber den Staatsbehörden und ein entsprechender Bedarf an verfahrensrechtlichen Garantien werden dabei oft einem „feeling of groupness, of We-ness, [...] of love“241 und einem ,elterlichen“ staatlichen vertrauensvollen und vertrauenswürdigen Strafsystem gegenübergestellt, der für den Verbrecher als Gelegenheit, Reue zu zeigen, und als „Beichtgelegenheit“ bzw. als Resozialisierungs-, Bildungs- oder Behandlungsmethode wirkt. ${ }^{242}$

\section{- Crime control model und due process model}

Teilweise wurden solche Betrachtungen schließlich als Kontrast ${ }^{243}$ zur bzw. Weiterführung von Packers weithin bekannter strafprozessualer Dichotomie zwischen crime control model und due process model angestellt, ${ }^{244}$ die heute immer noch, sogar auf dem europäischen Kontinent, als ein Referenzpunkt für die allgemeine Prozesstheorie dient. ${ }^{245}$ Ursprünglich waren Packers Modelle hauptsächlich als zwei extreme Pole eines analytischen Werkzeugs für die systematische, abstrakt-theoretische Identifizierung, Auslegung und Einordnung unterschiedlicher grundlegender Werte, Zielsetzungen und möglicher Verfahrenspräferenzen ins-

240 Das arm's-length und das parental Modell wurde von Llewellyn, Jurisprudence, S. 444-450, entwickelt. Zu den verwandten, mit dem, ,adversatorischen“ und dem ,inquisitorischen" Modell jedoch nicht unmittelbar korrelierten battle und family Modellen Griffiths, Yale L.J. 79 (1970), 359 (367-417). Dazu u.a. Damaška, U. Pa. L. Rev. 121 (1973), 506 (571-573); Herrmann, SACC 2 (1978), 3 (15-16).

241 Llewellyn, Jurisprudence, S. 448-449.

242 Damaška, Zbornik PFZ 51 (2001), 477 (500), bemerkt: „Little reflection is needed to discover that the 'battle' model exhibits a bias toward the contest form, central to the definition of the accusatorial process. The leaning of the 'family' model toward the inquisitorial process is at first concealed from view because of the model's emphasis on love, and because of the frequent association of the inquisitorial process with extorted confessions and the torture of defendants. Yet the leaning is there. Even the most repressive practices of the Holy Inquisition were 'ideologically' rationalized by the desire to effect reconciliation with the sinner and assure his salvation."

243 So z.B. Griffiths, Yale L.J. 79 (1970), 359 (360).

244 Packer, U. Pa. L. Rev. 113 (1964), 1 (1-68), und Packer, Limits, S. 149-246. Zur Modellbildung von Packer u.a. Damaška, U. Pa. L. Rev. 121 (1973), 506 (574-577); Griffiths, Yale L.J. 79 (1970), 359 (360-371); Herrmann, SACC 2 (1978), 3 (16-19); Jung, FS für Waltoś, S. 29-30.

245 Vgl. Damaška, Zbornik PFZ 51 (2001), 477 (500). 
besondere innerhalb des amerikanischen adversary system gedacht, ${ }^{246}$ sie wurden sicherlich nicht für rechtsvergleichende Zwecke konzipiert. Zusammengefasst ${ }^{247}$ basiert das crime control model auf der Annahme, dass die zentrale Funktion des Strafprozesses die ,effiziente“248 Verbrechensrepression zur Sicherstellung der öffentlichen Ordnung und der sozialen Freiheit ist. Von vorrangiger Bedeutung ist dabei die möglichst zügige Ermittlung der Schuldigen im Wege von schnellen, zweckmäßigen (finality, d.h. ,minimizing the occasions for challenge“ $),{ }^{249}$ informellen und präzisen administrativen (insbesondere polizeilichen) Tatsachenfeststellungen an Stelle von langsamen, zeremoniellen, schrankenvollen und somit ineffizienten und weniger präzisen Gerichtsprozessen.

Das due process model konzentriert sich dagegen auf „,antiautoritäre“ Wertvorstellungen hinsichtlich des Primats des Individuums und hinsichtlich der notwendigen Einschränkung der staatlichen Strafgewalt - bei der durchaus die Gefahr einer willkürlichen Ausübung besteht - zugunsten des Beschuldigten und auf Kosten der Leistungsfähigkeit des Prozesses. ${ }^{250}$ Effektivität in der Kriminalitätsrepression ist hierbei ein, aber nicht mehr das dominante Prozessziel, wobei eine rapide und unkontrollierte (gegenüber Fehlern zuungunsten des Beschuldigten teilweise tolerante) Tatsachenfeststellung durch Verwaltungsbehörden ebenso wenig die bevorzugte Methode des Prozedierens ist. Im Vordergrund der Gerechtigkeitserwägungen stehen vielmehr unter anderem: die Durchführung öffentlicher und kontradiktorischer gerichtlicher Verfahren zur verlässlichen Tatsachenfeststellung; die Doktrin über die legal guilt und die Unschuldsvermutung, der Strafprozess als Forum zur Überprüfung und Berichtigung eigener Missbräuche ${ }^{251}$ sowie die gleichmäßige Sicherstellung der Verfahrensgarantien und Rechte des Individuums.

bb) Das klassische Problem des Gerechtigkeitszieles: Zwischen Wahrheit und fairer Konflikterledigung

Die im Vorangehenden genannten Betrachtungsweisen haben ohne Zweifel neue Perspektiven für das strafprozessuale Studium der Justiz allgemein aufgezeigt wie auch einen alternativen Einblick in die inhaltlich engere Dichotomie zwischen ,ad-

246 Packer, Limits, S. 152-157.

247 Ausführlicher Packer, Limits, insb. S. 158-173.

248 Packer, Limits, S. 158: „By 'efficiency' we mean the system's capacity to apprehend, try, convict, and dispose of a high proportion of criminal offenders whose offenses become known."

249 Packer, Limits, S. 159.

${ }^{250}$ Packer, Limits, S. 166: „According to this ideology, maximal efficiency means maximal tyranny.“

251 So z.B. Packer, Limits, S. 168: „Only by penalizing errant police and prosecutors within the criminal process itself can adequate pressure be maintained, so the argument runs, to induce conformity with the Due Process Model." 
versatorischem“ und „,inquisitorischem“ Beweisverfahren und insbesondere in die dahinter stehende „Philosophie“ hinsichtlich der möglichen Ziele vermittelt, die durch die jeweiligen Strukturelemente dieser zwei Idealtypen bedient werden können. ${ }^{252}$ Außerdem deuten derartige Parallelmodelle eventuell auf eine breitere Auswahl an Analysemitteln hin, die es ermöglichen, Erkenntnisse aus der Rechtsphilosophie, -politik und -soziologie stärker in die traditionellen Strafprozesstheorien einzubeziehen. Ihr grundsätzlicher Zweck besteht nichtsdestoweniger darin, selbstständige und tiefgründige Untersuchungen der ideologischen Hintergründe, der Organisationswerte und der allgemeineren sozialpolitischen Ziele der Strafjustiz- und Prozessordnungen systematisch zu ermöglichen bzw. zu fördern.

Solche „,ideologischen“ Überlegungen zum Strafprozess wurden in der Vergangenheit mit Beifall oder auch mit Kritik aufgenommen, und es ist eventuell weiterhin sinnvoll, in gesonderten spezialisierten Studien die Stichhaltigkeit ähnlicher möglicher Grenzsetzungen zwischen den Verfahrenssystemen genauer zu prüfen oder auch auf der Basis der schon identifizierten Extrempole den Versuch der Bildung neuer theoretischer Modelle in Bezug auf die übergeordnete Zielsetzung der Strafjustiz per se zu unternehmen. Dies sollte nun auch im Hinblick auf die modernen Tendenzen der Internationalisierung und Transnationalisierung des Verbrechens und der Globalisierung und Harmonisierung der Kriminalitätsbekämpfungsformen und -programme versucht werden. Wegen dieser Entwicklungen wird sich die Prozesstheorie möglicherweise früher oder später von üblichen staatszentrierten System-Antithesen der Art hierarchical / coordinate, conflict-solving / policy-implementing, family / parental und crime control / due process stärker distanzieren müssen.

Für solche gewiss komplexen und vielseitigen Untersuchungen lässt der enge Arbeitsrahmen der vorliegenden rechtsvergleichenden Grundlagenforschung jedoch keinen Spielraum. Ebenso wenig kann hier, wie bereits angedeutet, jeder denkbare ideologische Hintergrund bzw. Strafjustizzweck unterschiedlicher Rechtstraditionen gründlich betrachtet und rechtssoziologisch überprüft werden. Darüber hinaus ist $\mathrm{zu}$ bemerken, dass die verschiedenen politisch-ideologischen Modelle zur Strafjustiz und zur Organisation der Strafgewalt bis dato die hier zentral diskutierte Dichotomie ,adversatorisch“ / ,inquisitorisch“ als taxonomisches Werkzeug und wichtigen Analyserahmen für die westliche prozessvergleichende Lehre nicht wirklich verdrängen konnten. ${ }^{253}$

Auf der Ebene der Zielsetzung werden vorliegend im Rahmen der herrschenden Dichotomie ,adversatorisch“,,inquisitorisch“ grundsätzlich ,mikroskopisch“ die konkret vorgebrachten (Zwischen-)Ziele der diversen angloamerikanischen und

${ }^{252}$ Vgl. z.B. die Schlussfolgerungen von Damaška, Faces, S. 88. Vgl. auch Brants/ Ringnalda, Issues, S. 17-18.

253 Vgl. Damaška, Zbornik PFZ 51 (2001), 477 (497-498). 
kontinentaleuropäischen (Beweis-)Verfahrensformen und nicht die möglichen Gesamtzwecke und -funktionen der (nationalen und internationalen ${ }^{254}$ ) Strafrechtspflege angesprochen. Vor allem die Erwägungen zur Gerechtigkeit, die durch das Strafverfahren systemübergreifend angestrebt wird, betreffen hierbei überall diskutierte Ziele wie beispielsweise Wahrheitssuche, Fairness, Konflikterledigung und Rechtsfrieden. Zunächst ist zu betonen, dass die historischen Wurzeln der Gegenüberstellung von Wahrheit und anderen Zielen des Strafprozesses in der common law- und civil law-Welt in dieser Arbeit nicht genauer betrachtet werden können. ${ }^{255}$ Vielmehr ist in der Folge zu untersuchen, welche überhaupt die konkreten Verfahrensziele sind, die im Einklang mit der bereits beschriebenen strukturellen Organisation und Rollenverteilung innerhalb der zwei modernen idealen Beweisverfahrenstypen stehen, und ob sich diese Ziele zwischen den Modellen letztendlich wirklich differenzieren lassen.

Nach einer Auffassung zielen nun solche common law-Verfahrensformen, die zum „adversatorischen“ Strafprozessmodell gehören, auf die gerechte Erledigung eines Konflikts ab statt auf reine Wahrheitserforschung, ${ }^{256}$ ungeachtet der Meinung, dass ein gerechtes Ergebnis die Wahrheitssuche voraussetzt. ${ }^{257}$ Damaška hat früh die eventuelle Übertreibung von derartigen absoluten Thesen in der common law-Literatur erkannt. Er hat aber auch behauptet, dass das kontinentale ,inquisitorische" Verfahrenssystem schon in struktureller Hinsicht der Wahrheitserforschung stärker verpflichtet ist als das angloamerikanische ,adversatorische“ System. Im Wettstreitmodell verschiebe sich nämlich der Schwerpunkt fast unmerklich von Erkenntnisfragen hin zur Relevanz der Einhaltung von Verfahrensregeln zwischen den Parteien. Die Verletzung der technischen Wettstreitregeln durch die eine Partei könne sogar zu einem formalen Sieg führen, den die andere Partei annehmen kann. In Verfahren mit zentral-amtlicher Ermittlungsstruktur sei dagegen die Aufklärung der Tatsachen des Sachverhaltes von höherer Bedeutung. Ein unterschiedlicher

254 Vgl. z.B. Ohlin, in: Sluiter u.a. (Hrsg.), International, S. 55-68, zu den Zielen und Funktionen des internationalen Strafrechts allgemein (wie: restoring international peace; strengthening international humanitarian law; creating a historical record of atrocities) i.V.m. den konkreteren Zielen des internationalen Strafprozesses (wie: historical truthfinding; protecting due process rights).

255 Dazu etwa Damaška, U. Pa. L. Rev. 121 (1973), 506 (584-587), i.V.m. den historischen Ausführungen in dieser Arbeit insb. unter Teil 1, I.B.2.a), I.B.3.b) und I.B.4.

256 Über derartige Betrachtungen hat schon Damaška, U. Pa. L. Rev. 121 (1973), 506 (581), berichtet; dazu auch Weigend, FS für Rissing-van Saan, S. 751-752. Siehe auch Fairlie, Int'l Crim. L. Rev. 4 (2004), 243 (248). Vgl. auch Coutts, in: ders. (Hrsg.), The Accused, S. 14; Goldstein, Yale L.J. 69 (1960), 1149 (1149); Hammelmann, L.Q.Rev. 67 (1951), 67 (78).

257 U.a. K. Peters, Strafprozeß, S. 82; Stamp, Wahrheit, S. 21-23 (zur Wahrheit als Zwischenziel). Siehe auch Hörnle, Rechtstheorie 35 (2004), 175 (177) m.w.N. Ferner zum Begriff der Gerechtigkeit und zur Trennung zwischen „materialer und prozeduraler Gerechtigkeit“ Neumann, ZStW 101 (1989), 52 (insb. 67-74). Vgl. hierzu auch Damaška, ZStW 90 (1978), 829 (842-843); Trüg, Lösungskonvergenzen, S. 68-70. 
Wahrheitsverpflichtungsgrad steht nach dieser Meinung auch im Einklang etwa mit den verschiedenen Haltungen gegenüber der Wirkung von Geständnissen im Verfahren. ${ }^{258}$

Eine solche Annahme schließt aber keinesfalls aus, dass, wie noch zu sehen sein wird, alle Verfahrenssysteme unter anderem (mehr oder weniger) auch auf Wahrheit(sausschnitte) ${ }^{259}$ zielen. Die umfassende Problematik der unterschiedlich starken Verpflichtung zur Wahrheitssuche und ihres Verhältnisses zu anderen Verfahrenszielen sollte auch nicht $\mathrm{zu}$ Vorurteilen bezüglich der engeren und unabhängigen Frage führen, ob in der Praxis das eine oder das andere System größere Präzision und Zuverlässigkeit ${ }^{260}$ bei den Tatsachenfeststellungen garantieren kann. $^{261}$

\section{b) Der Wahrheitsbegriff}

aa) $\mathrm{Zu}$ den Wahrheitstheorien

Für das Verständnis der (Rekonstruktion ${ }^{262}$ bzw. Herstellung ${ }^{263}$ der) Wahrheit als Ideal $^{264}$ und Verfahrensziel wurden in der strafjuristischen und rechtssoziologischen Lehre verschiedene Wahrheitsbegriffe und -theorien verwendet bzw. entwickelt; diese lassen sich zwar nicht immer, aber relativ häufig unmittelbar mit konkreten forensischen Prozessstrukturen und Erkenntnismethoden korrelieren. ${ }^{265}$ Hier ist nur an eine für den Untersuchungsgegenstand relevante Auswahl kurz zu erinnern. ${ }^{266}$ So legt die herrschende, aber schon in der Philosophie nicht unumstrittene Korrespondenztheorie bei der Definition der Wahrheit Gewicht auf „Objektivität““ und (weitgehende) Übereinstimmung einer Behauptung/Aussage mit dem histori-

\footnotetext{
258 Damaška, U. Pa. L. Rev. 121 (1973), 506 (580-583).

259 Dazu Hörnle, Rechtstheorie 35 (2004), 175 (177).

260 Vgl. zu den Begriffen ,accuracy“ und ,reliability“ Ho, Philosophy, S. 66-68.

261 Vgl. Damaška, U. Pa. L. Rev. 121 (1973), 506 (587-589).

262 Siehe u.a. Jung, FS für Fiedler, S. 904; Kühne, GA 2008, 361 (361); Volk, FS für Salger, S. 415.

263 Dazu etwa Grasnick, in: Wolter (Hrsg.), 140 Jahre, S. 69; Trüg/Kerner, FS für Böttcher, S. 195-198.

264 Vgl. eingehend zum diesbezüglichen Gebrauch des Begriffs „Ideal“ Stübinger, Strafrecht, S. 26-34, 38-40.

265 Vgl. auch die von Jung, JZ 2009, 1129 (1130, 1134), im Rahmen der Wahrheitsfrage vorgeschlagene Differenzierung zwischen Ziel des Verfahrens, Methoden der Beweiserhebung, Gegenstand der Wahrheitsfindung, Definitionsmacht (Entscheidungskompetenz) und Rahmenbedingungen (Modalitäten des Wahrheitsfindungsprozesses).

266 Wie Hilgendorf, GA 1993, 547 (547), für die Wahrheitsfrage als Kernproblem der Philosophie zutreffend bemerkt hat: „Ganze Bibliotheken sind schon darüber geschrieben worden, wobei freilich das Problem nicht selten in völlig unterschiedlicher Weise verstanden wurde.“
} 
schen Geschehen/der Wirklichkeit. ${ }^{267}$ Sie ist die „Wahrheitstheorie des common sense. “268

Die konsensualen Wahrheitstheorien beziehen sich dagegen vielfach auf die prozedurale Herstellung eines legitimierenden Konsenses zwischen aussagenden Menschen, beispielsweise den Verfahrensbeteiligten; somit konzentriert sich dann die Aufmerksamkeit eher auf Fragen des Prozedierens, der gleichen Teilnahmemöglichkeiten aller Aussagenden und der Verfahrensgerechtigkeit statt auf den tatsächlichen Sachverhalt. ${ }^{269}$ Darüber hinaus gibt es auch rechtssoziologische Systemthesen, beispielsweise von Luhmann. Ohne die Bedeutung von Wahrheit und Gerechtigkeit grundsätzlich zu verneinen, stellt Luhmann nicht diese Werte, sondern das effektive, formalisierte und institutionalisierte Verfahren an sich - vor allem die Mitwirkung der Verfahrensbeteiligten - in das Zentrum seiner deskriptiven Analysen zur (nicht inhaltlichen) Legitimation einer Entscheidung. ${ }^{270 ~ „ W a s ~}$ nottut, ist eine Theorie, die [...] nicht a priori schon annimmt, daß Verfahren der Wahrheit dienen. Eine solche Theorie kann die Soziologie aufbauen, indem sie die Wahrheit nicht länger nur als Wert, sondern genauer als einen sozialen Mechanismus begreift, der Bestimmtes leistet [...]. Was Wahrheit im sozialen Verkehr leistet, ist Übertragung reduzierter Komplexität.“271

bb) Materielle und formelle Wahrheit: Unterscheidung zwischen

Wahrheitsbegriffen?

\section{- Die These der zwei Wahrheiten}

Strafjuristisch und in normativer Hinsicht relevanter ist die insbesondere im kontinentalen Schrifttum weitverbreitete Gegenüberstellung von materieller und for-

267 Dazu u.a. Jung, JZ 2009, 1129 (1130); Stuckenberg, in: Schroeder/Kudratov (Hrsg.), Hauptverhandlung, S. 39-43; Volk, Wahrheit, S. 7. Ferner Hörnle, Rechtstheorie 35 (2004), 175 (177-179) m.w.N. und Ausführungen bezüglich u.a. auch der Kohärenztheorien.

268 Grasnick, in: Wolter (Hrsg.), 140 Jahre, S. 57. Vgl. auch Ho, Philosophy, S. 56-57.

269 Zusammenfassend und kritisch Hörnle, Rechtstheorie 35 (2004), 175 (179-185 und 185-191 zur möglichen rechtfertigenden Wirkung von Fairness und zur „Kompensationsthese“, der zufolge Wahrheitsdefizite in der herrschenden Korrespondenztheorie ,durch Verfahrensgerechtigkeit aufgefangen und kompensiert würden“). Siehe auch Jung, FS für Fiedler, S. 907-908. Zur „Herstellung von Wahrheit in einem Diskurs“ (Diskurstheorien) Radtke, FS für Schreiber, S. 379-385. Für eine analytischere Erläuterung der im deutschen Schrifttum am häufigsten diskutierten Wahrheitstheorien insb. im Hinblick auf das Strafverfahren Stamp, Wahrheit, S. 30-63. Siehe auch Eicker, Prinzipien, S. 9-14; Hetzer, Wahrheitsfindung, S. 44-73; Hilgendorf, GA 1993, 547 (549-554); Löffelmann, Wahrheitserforschung, S. 23-32, 99-105. Allgemeiner Krimphove, Rechtstheorie 39 (2008), 105 (107-118); J. Schmidt, JuS 1973, 204 (205-207).

270 Für eine Zusammenfassung auch der strafverfahrensbezogenen Gegenargumente Stamp, Wahrheit, S. 196-208. Siehe auch Paeffgen, Vorüberlegungen, S. 34-39; D. Krau $\beta$, FS für Schaffstein, S. 420-422.

271 Luhmann, Legitimation, S. 23. 
meller Wahrheit. Dieser Gegenüberstellung entsprechend wird oft zwischen strafund zivilprozessualer Wahrheit (grundsätzlich im Sinne: Untersuchungsgrundsatz versus Verhandlungs- und Dispositionsmaxime), ${ }^{272}$ manchmal aber auch zwischen Wahrheiten in kontinentaleuropäischen und angloamerikanischen Strafverfahren unterschieden. ${ }^{273}$ Im Rahmen der letzteren Unterscheidung, die hier von Interesse ist, könnte zunächst behauptet werden, dass es schon inhaltlich um zwei verschiedene Wahrheiten als mögliche Ziele des Strafprozesses geht.

Mit der Suche nach „materieller Wahrheit“ ist hiernach oft die Erforschung des „wahren“ Sachverhaltes gemeint, wobei das wirkliche Geschehen grundsätzlich anhand eines kontinentaleuropäischen Amtsermittlungsgrundsatzes festzustellen ist. ${ }^{274}$ Im selben Kontext wird unter dem Begriff ,formelle Wahrheit“ dagegen ,,der von den Parteien unterstellte Sachverhalt ${ }^{6275}$ als Urteilsgrundlage verstanden. Unabhängig von der Problematik der konkreten Ausgestaltung des Verfahrens hätte dann die vorgenannte Gegenüberstellung die Frage betreffen können,

ob am Ende der Hauptverhandlung eine materielle Wahrheit stehen soll oder ob unter maßgeblicher Beteiligung von Parteien eine formelle Wahrheit zu bilden ist [...]. Von Interesse ist dementsprechend, ob tendenziell eine auch inhaltlich nur formelle Wahrheit, die insbesondere von Beschuldigtem und Staatsanwaltschaft mit ausgestaltet wird, den Problemen strafprozessualer Sachverhaltsermittlung besser gerecht wird als das Prinzip der materiellen Wahrheit. ${ }^{276}$

Freilich sind auch hier Parallelen zu der Entgegensetzung von Korrespondenzund Konsenstheorien zum Wahrheitsbegriff zu ziehen.

\section{- Widerlegung: Ein Wahrheitsbegriff}

Überzeugender und auch für die betreffenden Beweisverfahrensmodelle von Bedeutung scheint jedoch die Ansicht zu sein, dass es hierbei eigentlich nicht um zwei inhaltlich unterschiedliche Wahrheitsbegriffe geht, sondern eher um zwei verschiedene Methoden zur Erfüllung des gemeinsamen Anspruchs auf bestmögliche Aufklärung der jeweiligen Tatsachenlage. Unter Sachverhaltsaufklärung ist dabei hauptsächlich das Feststellen einer Wahrheit zu verstehen, die sich möglichst an der verfahrensexternen historischen Wirklichkeit (Geschehen) und somit an den (in

272 Dazu u.a. Beulke, Strafprozessrecht, Rn. 21; Kühne, Strafprozessrecht, Rn. 299; Roxin/Schünemann, Strafverfahrensrecht, § 15 Rn. 1-5.

273 Siehe etwa Stamp, Wahrheit, S. 17-19. Früher u.a. Henkel, Strafverfahrensrecht, S. 423; Reichard, GS für Cüppers, S. 103.

274 Vgl. auch Volkmann-Schluck, Der spanische Strafprozeß, S. 65-66. Zum Begriff der „materiellen Wahrheit“ im deutschen Recht u.a. Beulke, Strafprozessrecht, Rn. 21; Eisenberg, Beweisrecht, Rn. 1-2; Radtke, GA 2012, 187 (189-192); Roxin/Schünemann, Strafverfahrensrecht, § 15 Rn. 3-5; Stamp, Wahrheit, S. 16-17; Trüg, Lösungskonvergenzen, S. 60-62.

\footnotetext{
275 Spendel, JuS 1964, 465 (467).

276 Stamp, Wahrheit, S. 209.
} 
der Praxis unerreichbaren) $)^{277}$ Anforderungen der Korrespondenztheorie orientiert. ${ }^{278}$ Es ist zwar auch behauptet worden, dass

es ersichtlich auch im amerikanischen Strafverfahren um das Ziel der Wahrheitserforschung und um das Finden eines gerechten Ergebnisses geht. [...] Wahrheit wird hier allerdings nicht durch den richterlichen Versuch einer historischen Rekonstruktion des Geschehenen gewonnen. Sie ist methodisch vielmehr als ein prozedural hergestelltes Konstrukt zu verstehen. Wahrheit schält sich in dialektischer Weise nach und nach eben genau dadurch heraus, dass jedes Beweismittel der einen Seite von der anderen Seite intensiv und notfalls auch unnachsichtig geprüft und hinterfragt wird. Das amerikanische Wahrheitsverständnis ist daher nicht mit der hiesigen Vorstellung einer materiellen Wahrheit und jenem der Korrespondenztheorie zugrunde liegenden Konzept deckungsgleich, sondern es ist ein formalisiertes Verständnis. Pointiert formuliert stellt der amerikanische Wahrheitsbegriff mithin kein ontologisches, sondern ein eher soziales Konzept dar, er ist im Kern sozial positioniert und diskursbezogen. ${ }^{279}$

Zunächst ist dazu zu bemerken, dass es durchaus naheliegend ist, verschiedene Bezeichnungen wie ,materielle“, „,formelle“ oder „formalisierte“ Wahrheit zu verwenden, um unterschiedliche methodische Erkenntniswege zu beschreiben, auch wenn die terminologische Zersplitterung der „Wahrheiten“ für die Zwecke der nachfolgenden Ausführungen eine irreführende ${ }^{280}$ Wirkung haben könnte. Jedenfalls ist darauf zu achten, dass die methodischen Wahrheitserforschungsprobleme nicht mit substantiellen Definitionsfragen (Verständnis) zur Wahrheit gleichgesetzt

277 Siehe neben anderen Kritikpunkten etwa die These von Damaška, Hastings L.J. 49 (1998), 289 (291), in Bezug auf die absolute, primitive „Spiegel“-Fassung (nicht aber in Bezug auf die relativierte, „verfeinerte“ Fassung) der Korrespondenztheorie: „[...] the embrace of social constructivism is fatal to the 'mirror' version of correspondence theory, a version holding that true thought or language reflects what is out there in reality. For to establish whether something corresponds to our views, we must first conceptualize it, with the result that human constructs inevitably appear on the reality side of the correspondence equation."

278 In dieser Richtung Herrmann, Reform, S. 158-159, 167-169, auch mit Verweis auf entsprechende Ansichten in der früheren common law-Lehre und Rechtsprechung; Herrmann, in: Jung (Hrsg.), Der Strafprozeß, S. 155-157; Honert, ZStW 106 (1994), 427 (443444). Ebenso im Ergebnis Stamp, Wahrheit, S. 214. Vgl. auch u.a. Hassemer/Matussek, Opfer, S. 33; Henkel, Strafverfahrensrecht, S. 108; Jackson/Doran, Judge, S. 78-79; Jescheck, JZ 1970, 201 (204); LaFave/Israel/King/Kerr, Criminal Procedure, S. 42-45; Paulsen, ZStW 77 (1965), 637 (657); Roberts/Zuckerman, Criminal Evidence, S. 3-8, 16, 18-19; Safferling, Towards, S. 17-19; Stock, FS für Rittler, S. 308-309; Weigend, ZStW 113 (2001), 271 (271-272). Auch dazu (sowie zu den Schwächen der Korrespondenztheorie und der ,classic scientific method of proof") Jackson, MLR 51 (1988), 549 (552-561). Vgl. auch die amerikanischen Diskussionen bei van Kessel, Notre Dame L. Rev. 67 (1992), 403 (448-459).

279 Trüg/Kerner, FS für Böttcher, S. 196-197. Ferner zu den relevanten epistemologischen Diskussionen Dennis, Evidence, Rn. 4.010-4.015.

280 Vgl. auch Fabricius, FS für Dencker, S. 74 (Fn. 13): „Das Begriffspaar materielle versus formelle Wahrheit scheint mir irreführend. Der, formell wahre' Sachverhalt erzählt eine fiktive Geschichte, deren Fiktionalität die Beteiligten sich bewusst sind. Auch im Zivilprozess sind formelle Wahrheiten illegal (§ $138 \mathrm{ZPO})$ - die Parteien können nur über ihre Anträge und damit über den Prozessstoff verfügen. Zweifellos wird das Ziel oft nicht erreicht, aber es behält seine Bedeutung [...].“ 
werden dürfen. Die vorgenannte Ansicht scheint zum Schluss zu kommen, dass das erwartete Wahrheitsergebnis bei einer gegenseitigen intensiven Prüfung des Beweismaterials durch verfahrensbeherrschende Parteien grundsätzlich nicht einem korrespondenztheoretischen und ontologischen Konzept entspricht.

Dazu ist allerdings Folgendes zu bemerken: Der Umstand, dass es in den common law-Gerichtsverfahren grundsätzlich keine zentrale Untersuchungsfigur und keinen Amtsermittlungsgrundsatz, sondern eine eventuell eher dialektische Verhandlungssituation gibt, sollte nicht automatisch zu der Annahme führen, dass eine Annäherung an die historische Wirklichkeit nicht angestrebt wird. ${ }^{281}$ Umgekehrt kann eine Differenzierung zwischen Wahrheit als „historische Rekonstruktion“ und Wahrheit als ,prozedural hergestelltes Konstrukt", die allein davon abhängt, ob eine richterliche Untersuchung oder entsprechend eine dialektische Prüfung des Beweismaterials durch die Parteien stattgefunden hat, ebenso wenig problemlos akzeptiert werden.

Auch im Idealfall beinhaltet nämlich sogar ein eher dialektischer Gerichtsvorgang die umfassende Prüfung von Zeugenaussagen und anderem objektiven Beweismaterial, wenn auch als Teil eines Diskurses zwischen den zentralen Verfahrensbeteiligten. Verlangt wird die (Neu-)Synthese einer „wahren“ Tatsachenlage der Vergangenheit durch Überprüfung mehrerer gegensätzlicher Beweisquellen; dies ist letztlich für die herrschaftliche Schuldfeststellung hinsichtlich des angeklagten Delikts außerhalb des eigentlichen Diskurses notwendig. Insbesondere von Zeugen wird in sämtlichen Gerichtsverfahrenssystemen erwartet, dass sie über ihr Wissen bezüglich konkreter historischer Fakten berichten und ihre Erfassung der betreffenden Realität ausdrücken - ungeachtet dessen ob diese Realität ihrerseits aus ,natürlichen“ oder auch ,,sozialen“ Fakten zusammengestellt sein kann. ${ }^{282}$ Dieses Wissen in Bezug auf vergangene Tatsachen muss im Verfahren hergeleitet, geprüft und verglichen werden, und es muss dann am Verhandlungsende vom erkennenden Spruchkörper für die materiell-rechtlich relevante Entscheidung über die Schuld berücksichtigt werden.

Obwohl Wirklichkeitsverzerrungen allgemein immer möglich sind, ist im Rahmen der heutigen gerichtlichen Strafverfahrenseinrichtungen die Suche nach einer

281 Vgl. selbst Trüg, Lösungskonvergenzen, S. 69-70.

282 Vgl. Damaška, Hastings L.J. 49 (1998), 289 (291): „To establish the truth, sophisticated versions of the correspondence theory maintain, is to ascertain a 'match' between a cognizer's statement and phenomena that can be either intrinsic to nature or socially constructed. For example, days of the week are social artifacts unknown to nature, but this does not render meaningless the inquiry whether testimony that an event occurred on a particular day matches with reality.“ Vgl. auch Dennis, Evidence, Rn. 20.003: „Whenever a witness engages in the process of observing an event, storing the event in memory, retrieving it subsequently and narrating it to a court, the witness cannot help using inference, explanation and classification to make sense of what has been observed. These are the fundamental elements of the social construction of all knowledge." 
Wahrheit, die als ausschließlich sozial-dialektisches ${ }^{283}$ - nicht direkt auf externe verifizierbare (wenn auch sozial klassifizierte) Fakten bezogenes - Prozesskonstrukt verstanden wird, nicht vorstellbar. ${ }^{284}$ Bei der Präsentation und Prüfung von „hartem“ Beweismaterial (real evidence, wie etwa Videoaufzeichnungen) sind der Objektivitätsbezug und, folgerichtig, die generell ablehnende Haltung der bestehenden Beweissysteme gegenüber Wirklichkeitsmanipulationen bzw. gegenüber exklusiv kommunikativ-sozial hergestellten (erst im Verfahren konstruierten) „Fakten“ noch weniger zu leugnen. ${ }^{285}$ Die Entscheidung, wer der hauptsächliche Träger aller nun objektivitätsbezogenen Beweisvorgänge sein soll, kann an sich die Realitätserwägungen im Rahmen der Verfahrenszielproblematik nicht beeinflussen. ${ }^{286}$ Letztendlich unterscheiden sich die gerichtlichen Wahrheitssysteme voneinander nicht durch das Wesen ihres endgültigen Zieles, sondern hauptsächlich durch die beweisführenden Personen, die angewandten Prüfungsmethoden und eventuell auch den Präzisionsgrad - ,the likelihood of [...] truth [of a finding of fact] ${ }^{6287}$ bei der Annäherung an das Geschehen.

Darüber hinaus wird manchmal als zusätzliches Argument für eine inhaltliche Unterscheidung zwischen materieller und formeller Wahrheit geltend gemacht, dass in angloamerikanischen Verfahren der Umfang des vorgebrachten Beweismaterials ausschließlich durch nicht neutrale Parteien bestimmt wird; das kann heißen, dass die Beweissammlung und die Beweispräsentation eher offen für Verzerrungen sind. ${ }^{288}$ Dabei ist aber zumindest Folgendes zu beachten: Wie nachfolgend ausführlicher dargelegt wird, interessieren sich alle westlichen Justizsysteme im Rahmen eines gerichtlichen Strafverfahrens für die Verurteilung der angeklagten Person, nur soweit diese der Begehung einer materiell-rechtlich bestimmten Tat wirklich

283 Vgl. im Rahmen der Diskussionen zur Einrichtung der Truth and Reconciliation Commission of South Africa, Sachs, in: Boraine/Levy (Hrsg.), Healing, S. 105: ,[...] there are two kinds of truth - 'microscope truth' and 'dialogue truth'. The first is factual, verifiable and can be documented and proved. Dialogue truth, on the other hand, is social truth, the truth of experience that is established through interaction, discussion and debate."

284 Vgl. auch Damaška, Hastings L.J. 49 (1998), 289 (292): „Adjudicators are expected to accept a story as true when it is amply supported by items of evidence relating to the facts of the case. And what these small foot soldiers of verity are expected to achieve is to establish that a match exists between factual propositions woven into the fabric of a story and the way the world really is." Vgl. ferner Nijboer, Beweisprobleme, S. 26-29.

285 Ähnlich Dennis, Evidence, Rn. 4.015. Vgl. insgesamt Damaška, Hastings L.J. 49 (1998), 289 (290-301). Vgl. auch (mit weiteren Beispielen aus der deutschen Rechtsordnung) Gössel, Ermittlung, S. 14-20; und noch die Diskussionen bei Stübinger, Strafrecht, S. 538-551.

286 Vgl. auch Roberts/Zuckerman, Criminal Evidence, S. 51. Auch Herrmann, RIDP 53 (1982), 841 (846). Vgl. auch Damaška, Evidence, S. 95.

287 Ho, Philosophy, S. 66.

288 Siehe z.B. die Verweise bei Herrmann, Reform, S. 115, 129-130, und bei Ho, Philosophy, S. 61-63. Vgl. auch Haas, in: Schroeder/Kudratov (Hrsg.), Vorverfahren, S. 26; Jackson, MLR 51 (1988), 549 (559-560). 
schuldig ist. Es geht somit immer um die Aufklärung von in vielerlei Hinsicht abgegrenzten Manifestationen einer breiteren Tatsachenlage. Das Ziel besteht von vornherein darin, ein ganz bestimmtes Realitätsstück aufzudecken, was systemübergreifend hauptsächlich durch Wiedergabe und Bewertung der „Erfahrungen“ und „Ermittlungen“ der zentralen nicht richterlichen Verfahrensbeteiligten geschieht.

Eine umfassende oder weniger umfassende Bestimmung und Prüfung des Beweismaterials betrifft daher überall die pragmatische Erzielung eines entsprechend mehr oder weniger vollständigen Bildes desselben jeweils normativ verlangten Wahrheitsausschnittes. Die Vielfalt der Akteure, die für die technische Präsentation des Beweismaterials in den unterschiedlichen Verfahrenssystemen zuständig sein können, sowie die diversen Möglichkeiten zur Umgehung einer umfassenden Beweispräsentation, ändern nichts am normativen Verständnis der historischen Wirklichkeit, deren Rekonstruktion idealerweise das Ziel ist. ${ }^{289}$ Sowohl faktisch als auch in normativer Hinsicht kann letztlich in keinem Beweisverfahren eine absolute und vollständige Tatsachenfeststellung erwartet werden. ${ }^{290}$ Limitationen, Verzerrungen und Fragmentierungen der Wirklichkeitserkenntnis im Rahmen einer im Parteiprozess sich ergebenden Wahrheit wären auch bei einer amtlichen Ermittlung desselben Geschehens zu erwarten, etwa aufgrund der begrenzten menschlichen Untersuchungs- und Erkenntnisfähigkeiten oder der Beschränkungen des materiellen Strafrechts. Zudem sind die Unverwertbarkeit von maßgebenden Beweisen und somit möglicherweise die „Unverwendbarkeit“ eines Teils des Wirklichkeitsbildes, zu denen vor allem der Vorrang und die prozessuale Anwendung von menschenrechtlichen Garantien führen können, in sämtlichen westlichen Rechtssystemen keine Seltenheit.

\section{c) Jenseits des Wahrheitsbegriffs}

Gleichwohl sind im Schrifttum auch weitere Kategorisierungen zu finden, die Ähnlichkeiten mit der Gegenüberstellung von materieller und formeller Wahrheit aufweisen. So differenziert beispielsweise eine Ansicht zwischen „ontological truth“ (in ,inquisitorischen“ Systemen) und ,,interpretive truth“ (in ,adversatorischen" Systemen). ${ }^{291}$ Soweit es dabei lediglich um eine Differenzierung anhand der unterschiedlichen Wege (party-controlled contest versus neutral officially-con-

289 Vgl. auch Ho, Philosophy, S. 64.

290 Vgl. etwa Volk, Wahrheit, S. 7-10. Vgl. auch Stuckenberg, in: Schroeder/Kudratov (Hrsg.), Hauptverhandlung, S. 44-45; Weigend, Harvard JLPP 26 (2003), 157 (161). Siehe ferner Teil 1, II.C.2.d).

291 Grande, in: Jackson u.a. (Hrsg.), Crime, S. 146-148. Vgl. auch die Kategorisierungen bei Hodgson, in: Duff u.a. (Hrsg.), Trial on Trial 2, S. 224-225; M. King, Int'l Legal Persp. 12 (2001-2002), 185 (187-189). 
trolled inquest) zur Annäherung an die historische Wirklichkeit geht, können solche Schemata eventuell auch für die Konkretisierung der Modellinhalte von Wert sein. Dagegen trifft die Annahme ${ }^{292}$ einer inhaltlich autonomen, rein prozessualen „,interpretive truth“ als Ziel der ,adversatorischen“ Verfahren nicht zu, soweit dabei das universelle Streben nach bestmöglicher Aufklärung der Tatsachenlage etwa durch die Idee der ,justice as fairness “293 komplett ersetzt wird. Ähnliches wurde vorangehend im Rahmen der Diskussion zur materiellen und formellen Wahrheit angedeutet. Thomas Weigend bemerkt dazu:

Auf der einen Seite steht die Theorie vom „,verborgenen Goldstück“ - die Wahrheit existiert irgendwo, man muss sie nur finden. Den Gegensatz dazu bildet die prozessuale Wahrheitstheorie: Wahrheit entsteht erst durch prozessuale Interaktion, und was sich aufgrund eines fairen Verfahrens ergibt, ist „automatisch“ die Wahrheit. Oft wird das inquisitorische Verfahren des kontinentaleuropäischen Strafprozesses mit der erstgenannten Theorie gleichgesetzt, das adversatorische Verfahren der common law-Rechtsordnungen mit der prozessualen Wahrheitstheorie. Dies überzeichnet jedoch den Gegensatz zwischen den beiden Systemen. Auch im Verfahren nach common law geht es um die Feststellung dessen, was ,wirklich“ geschehen ist. Allerdings gibt es einen tendenziellen Unterschied gegenüber der ,inquisitorischen“ Denkweise: Man betont im angloamerikanischen Bereich stärker den Umstand, dass die Regeln des fairen Verfahrens die Wahrheitssuche begrenzen - Wahrheit soll sich in einem fairen Verfahren herausstellen, und die Einhaltung der Regeln ist mindestens so wichtig wie die „objektive Richtigkeit““ des Ergebnisses. ${ }^{294}$

Somit rückt die Diskussion über einen vermeintlich unterschiedlichen Wahrheitsverpflichtungsgrad wieder in den Vordergrund. Durch die Anerkennung von grundsätzlich gemeinsamen forensischen Zielsetzungen in der common law- und der civil law-Welt verschiebt sich gleichzeitig die Debatte weg von den inhaltlichen Unterschieden der Wahrheitsverständnisse hin zur Konkretisierung des modernen Verhältnisses zwischen universellen Strafprozesszielen und Strukturen der Beweisverfahrensmodelle. Das allgemeine strafphilosophische Definitionsproblem der Wahrheit kann ohnehin in dieser Arbeit nicht tiefgründiger als in der schon vorhandenen spezialisierten Literatur dargestellt werden. Ebenfalls keinen gesonderten Analysegegenstand stellen mögliche diverse innerstrafprozessuale Wahrheiten dar, wie z.B. diejenigen, die Klaus Volk ausgehend vom deutschen Strafprozess identifiziert hat (namentlich: Strafbefehlswahrheit und Schwurgerichtswahrheit, Indizienwahrheit und Geständniswahrheit, Freispruchswahrheit und Verurteilungswahrheit). ${ }^{295}$ Ebenso wenig kann hier näher eingegangen werden auf im Kontext internationaler gravierender Menschenrechtsverbrechen und transitional justiceVerfahren rechtspolitisch oft diskutierte Wahrheitsbegriffe wie ,factual or forensic

${ }^{292}$ In dieser Richtung etwa die nicht ganz eindeutigen Annahmen von Grande, in: Jackson u.a. (Hrsg.), Crime, S. 148.

293 Ablehnend dazu auch Hörnle, Rechtstheorie 35 (2004), 175 (191-194). Siehe auch Ho, Philosophy, S. 64-66.

294 Weigend, FS für Rissing-van Saan, S. 752-753 (Fußnoten wurden ausgelassen).

295 Dazu Volk, FS für Salger, 411 (418). 
truth“, ,personal and narrative truth“, ,social truth“ und ,healing and restorative truth", welche die Truth and Reconciliation Commission of South Africa verwendet hat. ${ }^{296}$

Hier geht es vielmehr um die Beziehung zwischen dem allgemeinen strafprozessualen Wahrheitsziel im Sinne des Strebens nach einer historisch präzisen Sachverhaltsaufklärung und den strukturellen Elementen von im Sinne der beschriebenen Idealtypen vollwertigen Beweisverfahren. Das Problem der Zielsetzung innerhalb der betreffenden Beweisverfahrensmodelle wird oft, wie bereits erwähnt, mit der alten Diskussion über den Wahrheitsverpflichtungsgrad - insbesondere mit der Frage „mehr inquisitorische Wahrheit oder mehr adversatorische Fairness“ - in Verbindung gebracht. Es muss an dieser Stelle bedacht werden, ob eine derartige Diskussion ihre absoluten Ansätze bei der Rechtsvergleichung von Verfahrenssystemen unterschiedlicher Rechtstraditionen weiterhin beibehalten sollte. Dies soll geschehen, ohne in der labyrinthischen Ansammlung gegensätzlicher technischer oder außerbeweisprozessualer Details verloren zu gehen.

\section{d) Zum Spannungsverhältnis zwischen den Verfahrenszielen}

aa) Materielle Gerechtigkeit und Verfahrensgerechtigkeit

\section{- Materielle Gerechtigkeit}

Zunächst ist es sinnvoll, im Anschluss an die vorherige Gegenüberstellung von materieller und formeller Wahrheit festzuhalten, dass die Mehrheit der heutigen rechtsstaatlichen Justizsysteme, welche die Entwicklungen innerhalb der zwei herrschenden westlichen Rechtstraditionen mitbestimmen, ihre Verfahrensordnungen so einzurichten versuchen, dass die Schuldigen verurteilt und die Unschuldigen freigesprochen werden. ${ }^{297}$ Einen gemeinsamen Anknüpfungspunkt bildet die Re-

296 Truth and Reconciliation Commission of South Africa Report, Volume One (1998), S. 110-117, unter http://www.justice.gov.za/trc/report/index.htm abrufbar [Stand: Oktober 2014]. Kurz hierzu Foster, Social Justice Research 19 (2006), 527 (532-534) m.w.N. Siehe auch Knust, Strafrecht, S. 93-95.

297 U.a. Bradley/Hoffmann, S. Cal. L. Rev. 69 (1996), 1267 (1271); Roberts/Zuckerman, Criminal Evidence, S. 19; Stamp, Wahrheit, S. 247. Nachweisende Wahrheits- und Wirklichkeitsbezüge in den USA und England z.B. in: R. 102, 611(a) Federal Rules of Evidence (2014) [unter http://federalevidence.com/rules-of-evidence abrufbar, Stand: Oktober 2014]; R. 1.1.(2)(a) CPR 2014 [unter http://www.justice.gov.uk/courts/procedurerules/criminal abrufbar, Stand: Oktober 2014] i.V.m. Statement dated March 2005: The objectives and content of the first Criminal Procedure Rules [unter http://www.justice. gov.uk/courts/procedure-rules/criminal/notes abrufbar, Stand: Oktober 2014]; Auld Report 2001, S. 11; US Supreme Court Tehan v. Shott, 382 U.S. 406, 416 (1966). Darüber hinaus vgl. etwa in Supreme Court of Canada R. v. Nikolovski, [1996] 3 S.C.R. 1197, 1206: „The ultimate aim of any trial, criminal or civil, must be to seek and to ascertain the truth. In a criminal trial the search for truth is undertaken to determine whether the accused before the court is, beyond a reasonable doubt, guilty of the crime with which he is charged." 
konstruktion einer bestimmten (materiell-rechtlich relevanten) Vergangenheit vor Gericht, nämlich dessen, was im konkreten angeklagten Fall wirklich geschehen ist. Es geht hier um das ,Ziel größtmöglicher Annäherung an das historische Geschehen“‘298 - „to establish as accurately as possible what happened.“299 Richtungweisend für das notwendige Ausmaß der Aufklärungsversuche können dabei die für eine sachlich zuverlässige Verurteilung erforderlichen Beweisstandards (wie proof beyond reasonable doubt $)^{300}$ oder entsprechende Ausprägungen des Zweifelssatzes (in dubio pro reo) ${ }^{301}$ sein, die sich zumindest bezüglich ihres Anspruchs, dass ein Unschuldiger niemals verurteilt werden darf, voneinander nicht wesentlich unterscheiden. $^{302}$

Jedenfalls ist, schon aufgrund der beschränkten Erkenntnismöglichkeiten und menschlichen Erkenntnisfähigkeiten, eine vollständige Rekonstruktion nicht wirklich erreichbar - es kann kein Anspruch auf absolute Wahrheit bestehen. ${ }^{303}$ Jedoch finden die Justizordnungen aufgrund des Wahrheitswertes - unter bewusster oder unbewusster Berücksichtigung der Ansätze der vergleichsweise klaren und praktikablen, wenn auch freilich lückenhaften Korrespondenztheorie - eine eindeutige Leitlinie für die strafprozessuale „Konfliktlösung“ vor Gericht, ${ }^{304}$ zumindest dort, wo eine gerichtliche Verhandlung weiterhin als gesellschaftlich erforderlich angesehen wird. Durch die Orientierung am wirklichen Geschehen und somit an traditionell hochgestellten Werten der Menschlichkeit (wie der Wahrheitserkenntnis) wird die nachträgliche Akzeptanz der Entscheidung am wenigsten gefährdet. Wegen des überwiegend staatlichen Charakters der Strafrechtsordnungen und ihrer

\footnotetext{
298 Radtke, GA 2012, 187 (191).

299 Ashworth/Redmayne, Criminal Process, S. 25.

300 Hierzu u.a. Dennis, Evidence, Rn. 11.002-11.004, 11.044-11.045; Roberts/Zuckerman, Criminal Evidence, S. 253-258. Siehe auch LaFave/Israel/King/Kerr, Criminal Procedure, S. 46.

301 Dazu kurz Stuckenberg, JA 2000, 568 (568-569, 572). Vgl. auch Zopfs, Grundsatz,
} S. 273-275, 278-282. Zur Rechtsnatur, prozessualen Notwendigkeit sowie zum Geltungsgrund und Inhalt des Zweifelssatzes hauptsächlich aus deutscher Sicht Schwabenbauer, Zweifelssatz, S. 13-65.

302 Vgl. in Verbindung: Ashworth/Redmayne, Criminal Process, S. 25; Eser, FS für Miyazawa, S. 563; Roberts/Zuckerman, Criminal Evidence, S. 220-224, 247-252; Walter, JZ 2006, 340 (345). Relevante (auch rechtsvergleichende) Ausführungen zum Teil auch bei Stuckenberg, Untersuchungen, insb. S. 98-100, 261-263, 321-322, 362-365, 369-370, 510-513, 521-522, 573-574.

303 Hierzu etwa Jung, JZ 2009, 1129 (1130); Kühne, GA 2008, 361 (361); Radtke, GA 2012, 187 (191); Stamp, Wahrheit, S. 50-60. Vgl. auch Schünemann, FS für Pfeiffer, S. 474-475.

304 Dazu Stamp, Wahrheit, S. 247 m.w.N. Vgl. auch Damaška, Evidence, S. 95: „unless some variant of the view that truth is a matter of correspondence to facts is accepted, our present evidentiary arrangements are deprived of meaning. Where the covenant between word und world' is broken, it makes no sense to worry about accuracy in fact-finding or about judgments that fail to reflect the truth." Siehe auch Ho, Philosophy, S. 55-57 m.w.N. 
breiten und vielfältigen gesellschaftlichen Bedeutung bzw. Wirkung (auch im Einklang mit den modernen Strafzwecken $)^{305}$ kann das Strafverfahren nicht mit Mechanismen zur privaten Lösung bzw. zur inter partes-Erledigung von Konflikten gleichgesetzt werden. ${ }^{306}$ Vor allem darf nicht in Fiktionen und „Erfindungen“ der Verfahrensbeteiligten nach Grundlagen für die Schuldfeststellung gesucht werden. Nach den immer noch weitgehend geltenden Gerechtigkeitsvorstellungen ist die gesellschaftliche Anerkennung der Ausübung (oft erheblicher) staatlicher Gewalt nicht wirklich garantiert, wenn Letztere im Ergebnis eines gerichtlichen Strafverfahrens veranlasst wird, das a priori bzw. programmatisch Wahrheitserwägungen ausschließt. ${ }^{307}$

Innerhalb des engen Untersuchungsbereichs der Beweisverfahrensmodelle ist ferner nicht gesondert auf die breite Thematik der verschiedenen debattierten Aufgaben bzw. Zwischen- und Endziele des Strafprozesses - wie (stichwortartig): Wahrheit und Gerechtigkeit, Rechtsstaatlichkeit/Fairness, Rechtssicherheit, Rechtsfrieden - und ihres potenziellen Konflikts einzugehen. ${ }^{308}$ Vor allem die Durchsetzung/Verwirklichung des materiellen Strafrechts als universelles Prozessziel und die Einrichtung beweisprozessualer Strukturen für seine Handhabung sind jedoch nicht zu verneinen. ${ }^{309}$ Wie auch die bisherigen Ausführungen gezeigt haben, orientieren sich die (Beweis-)Verfahrenssysteme eben an materieller Gerechtigkeit

305 Überlegungen zur Beziehung zwischen den absoluten und relativen Straftheorien und dem Prozessziel der Wahrheitssuche bei Stamp, Wahrheit, S. 255-257. Vgl. auch Trüg, Lösungskonvergenzen, S. 69-70.

306 Auch in der common law-Welt gilt offensichtlich: ,Whilst civil trials may be characterized as a mechanism for resolving disputes between the parties' symmetrically competing claims, criminal trials are organized around a state-sponsored examination of an accused's alleged criminal wrongdoing“, so Roberts/Zuckerman, Criminal Evidence, S. 9. Siehe auch Auld Report 2001, S. 9: „The undertaking and outcome of criminal proceedings are usually of much greater consequence to the public than in civil proceedings." Vgl. auch Jackson/Doran, Judge, S. 103-104.

307 Dazu Weigend, FS für Rissing-van Saan, S. 751-752; Weigend, Harvard JLPP 26 (2003), 157 (157-158, 169, 172-173). Siehe auch Jung, JZ 2009, 1129 (1130); Stuckenberg, in: Schroeder/Kudratov (Hrsg.), Hauptverhandlung, S. 51-52. Vgl. auch Arenella, Geo. L. J. 72 (1983), 185 (188, 200); Bradley/Hoffmann, S. Cal. L. Rev. 69 (1996), 1267 (1271-1273); Roberts/Zuckerman, Criminal Evidence, S. 19; auch Herrmann, RIDP 53 (1982), 841 (845), bei der Widerlegung der Legitimation durch Verfahren-Theorie von Luhmann.

308 Dazu u.a. Ashworth/Redmayne, Criminal Process, S. 22-26; Beulke, Strafprozessrecht, Rn. 3-7; Kröpil, JR 2013, 14 (14-15) m.w.N.; LaFave/Israel/King/Kerr, Criminal Procedure, S. 40-51; Murmann, GA 2004, 65 (65-70); Paeffgen, Vorüberlegungen, S. 14 m.w.N.; Rieß, JR 2006, 269 (270-277); Roxin/Schünemann, Strafverfahrensrecht, § 1 Rn. 1-8; Schmidhäuser, FS für E. Schmidt, S. 511-524; Stamp, Wahrheit, S. 21-23, 231-234; Weigend, Deliktsopfer, S. 173-219.

309 Hierzu u.a. auch Beulke, Strafprozessrecht, Rn. 3; Dennis, Evidence, Rn. 2.0012.003; LaFave/Israel/King/Kerr, Criminal Procedure, S. 40-42; Radtke, FS für Schreiber, S. 375-376; Stamp, Wahrheit, S. 21-23. 
durch Erlangung sachlich/inhaltlich und materiell-rechtlich richtiger Entscheidungen (d.h. insb. umfassende Tatsachenfeststellung und korrekte Strafnormenanwendung).

\section{- Verfahrensgerechtigkeit}

Gleichwohl gewinnen auch Verfahrensgerechtigkeitserwägungen in sämtlichen modernen Rechtssystemen immer größere, selbstständige Bedeutung. Als Elemente strafprozessualer Gerechtigkeit werden meistens der vorrangige Schutz der Menschenwürde und relevanter hochrangiger persönlicher Interessen der Verfahrensbeteiligten sowie die Wahrung der Verfahrensfairness in ihren verschiedenen Manifestationen, insbesondere in Bezug auf die Mitwirkungs- und Gleichheitsrechte, angesehen. ${ }^{310}$ Ausschlaggebende Garantien und Rechte sind heute größtenteils in nationalen Verfassungsvorschriften und/oder in nationalrechtlich verbindlichen internationalen Menschenrechtsinstrumenten verankert. ${ }^{311}$

Dementsprechend sind Wahrheit und materielle Gerechtigkeit zentrale, aber nicht alleinige oder absolute Werte der modernen westlichen Strafrechtssysteme. Unabhängig von dem jeweiligen Verfahrensstadium und der genauen Art und Weise ihrer Umsetzung werden normative Grenzen der Wahrheitssuche sowohl in der common law- als auch in der civil law-Welt aufgrund der auf unentbehrlichen Menschen- und Persönlichkeitsrechte beruhenden Interessen gezogen. ${ }^{312}$ Allgemein charakteristische Beispiele für die der Wahrheitssuche durch verschiedenartige Beweisverbote gesetzten Schranken betreffen etwa: Regeln zum Schutz der Integrität bestimmter Familienbeziehungen und Berufsgeheimnisse sowie Regeln gegen die Verwertung von unrechtmäßig, insbesondere menschenrechtswidrig (z.B. durch Folter $^{313}$ oder sonstige Verstöße gegen die Selbstbelastungsfreiheit) erlangten Beweisen und Geständnissen.

310 Vgl. A. Duff, Trials, S. 110-119; McEwan, in: A. Duff u.a. (Hrsg.), Trial on Trial 1, S. 55-63; Neumann, ZStW 101 (1989), 52 (59-69); Stamp, Wahrheit, S. 260-262.

311 Siehe z.B. die älteren vergleichenden Auflistungen bei Bassiouni, Duke J. Comp. \& Int'l L. 3 (1993), 235 (253-297).

312 Vgl. mit weiteren Gedanken, Details und Verweisen u.a.: Damaška, Hastings L.J. 49 (1998), 289 (289, 301, 305); Hetzer, Wahrheitsfindung, S. 23, 25; Jackson, in: A. Duff u.a. (Hrsg.), Trial on Trial 1, S. 124-129; Jung, FS für Fiedler, S. 906-907; Trüg, Lösungskonvergenzen, S. 64-70; Trüg, StV 2010, 528 (530-531); Weigend, Harvard JLPP 26 (2003), 157 (167-168); Weigend, FS für Rissing-van Saan, S. 754. Siehe auch neuerdings die Zusammenfassung der Ergebnisse des umfangreichen rechtsvergleichenden Werkes „Exclusionary Rules in Comparative Law" bei Thaman, in: ders. (Hrsg.), Exclusionary Rules, S. $403-442$.

313 Obwohl die Erlangung einer Aussage durch Folter eventuell auch aus Gründen der effektiven Wahrheitserforschung nicht erwünscht sein sollte, ist die Selbstständigkeit des menschenrechtlichen Verbots zur Verwertung einer derartigen Aussage unabhängig von Wahrheitserwägungen nun allgemein anerkannt, vgl. hierzu etwa Duff/Farmer/Marshall/ 
Es wäre daher übertrieben zu behaupten, dass nur die angloamerikanischen Systeme etwa den verfahrensrechtlichen Schutz der Menschenwürde selbstständig in den Vordergrund stellen. Allerdings existieren in der common law-Welt neben technischen, teilweise wahrheitsdienenden Verwertungsregeln (z.B. der hearsayRegel) auch bestimmte, den Wahrheitszwecken grundsätzlich fremde Beweisausschlussregeln, die immer noch als vergleichsweise zu starr ${ }^{314}$ angesehen werden eventuell auch im Einklang mit der vorgenannten politischen Einstellung, die für ein starkes Misstrauen gegenüber der Ausübung staatlicher Gewalt spricht. Letztendlich gilt aber als moderne universelle Ausrichtung der nationalen und internationalen Systeme in Übereinstimmung mit den Prinzipien des rule of law/der Rechtsstaatlichkeit $^{315}$ und des due process, dass die Wahrheit (vor allem in Fällen erheblicher Menschenrechtsverletzungen) nicht „um jeden Preis ${ }^{\text {‘316 }}$ erforscht werden darf. Gleichzeitig ist jedoch zu bezweifeln, dass das letztgenannte Prinzip in den verschiedenen Strafverfolgungs- und Justizordnungen - insbesondere in Zeiten des sogenannten Kampfes gegen den (internationalen) Terror - faktisch immer eingehalten wird.

Darüber hinaus wird im Rahmen der Verfahrensgerechtigkeitserwägungen auch die Sicherstellung der Fairness im Sinne der Einhaltung von Gehör-, Mitwirkungsund Freiwilligkeitsregeln immer häufiger, auch auf dem Kontinent, als selbstständige Voraussetzung der Legitimation einer Entscheidung, ${ }^{317}$ manchmal sogar als Ausgleich für die prozessualen Wahrheitsdefizite angesehen. ${ }^{318}$ Aus den bisherigen Ausführungen folgt jedenfalls: Wird im gerichtlichen Verfahren reine Verfahrensfairness per se ohne irgendeine materielle Wahrheitsausrichtung angestrebt, er-

Tadros, in: A. Duff u.a. (Hrsg.), Trial on Trial 1, S. 23. Ferner Damaška, Hastings L.J. 49 (1998), 289 (306-307).

314 Vgl. z.B. van Kessel, Notre Dame L. Rev. 67 (1992), 403 (451).

315 Ohne Vertiefungsanspruch hinsichtlich der Frage, ob es substantielle Unterschiede zwischen dem Rechtsstaatsbegriff und dem angloamerikanischen Begriff des „rule of law“ gibt, ist hier nur an die These von MacCormick, JZ 1984, 65 (66-67), zu erinnern, dass „die Begriffe 'Rechtsstaat' und 'rule of law' heutzutage schon prototypisch als Familiennamen für eine Gruppe ähnlicher Konzeptionen stehen, Konzeptionen, die auf verschiedene Art und mit verschiedener Betonung das Bemühen um das Ideal der Rechtmäßigkeit im modernen Staat ausdrücken. [...] beide Begriffe [sind] durch die gleichen Grundprinzipien konstituiert. [...] hinter den beiden Begriffen [dürfte] das gleiche Ideal stecken. Folglich gilt: die beste Konzeption des Rechtsstaats ist auch die beste Konzeption der rule of law und umgekehrt. Natürlich liefern dieselben Prinzipien nicht dieselben Resultate, wenn sie sich auf unterschiedliche Verfassungswirklichkeiten beziehen. [...] Aber daraus folgt keineswegs, daß der Rechtsstaat und die rule of law konträre Grundprinzipien enthalten."

316 Vgl. BGHSt 14, 358 (365). U.a. Herrmann, RIDP 53 (1982), 841 (842-843). Auch Wigmore, Evidence 1 ( $\$ 11)$, S. 689 (Tillers rev. 1983), hat früh innerhalb des angloamerikanischen Beweissystems extrinsic policies identifiziert, „that override the policy of ascertaining the truth by all available means."

317 Vgl. Neumann, ZStW 101 (1989), 52 (67-69). Siehe auch A. Duff, Trials, S. 114-119.

318 Mehr dazu bei Stamp, Wahrheit, S. 262-265. Kritisch Hörnle, Rechtstheorie 35 (2004), 175 (185-194). 
schwert das die soziale Akzeptanz der Entscheidung. ${ }^{319}$ Ebenso wenig erwünscht ist die ,automatische ${ }^{\text {(320 }}$ Gleichsetzung eines ,fairen“" mit einem ,wahren“" gerichtlichen Ergebnis in all denjenigen Justizsystemen, die ihre Hauptverfahren weiterhin entsprechend dem Interesse an der Rekonstruktion eines historischen Geschehens ausrichten.

\section{bb) Wahrheit, Fairness und Absprachen}

Bestimmte (extreme) Fälle geben Anlass zu behaupten, dass in angloamerikanischen Systemen reine (formale) Fairness und konsensuale „Spielregeln“ einen absoluten Vorrang vor einer umfassenden Sachverhaltsaufklärung haben können. Dies könnte besonders dadurch zum Ausdruck kommen, dass ein justizförmig (vor allem freiwillig) abgelegtes Geständnis vom Gericht zur unmittelbaren Beendigung des Rechtsstreits eventuell auch dann angenommen werden kann, wenn der Angeklagte gleichzeitig mit der formellen Geständnisablegung erklärt hat, dass sein Schuldbekenntnis eigentlich nicht der Realität entspricht.

Dies kann vor allem im Rahmen der übermäßig verbreiteten Absprachenpraxis geschehen, welche die Abkürzung des herkömmlichen Beweisverfahrens und die Verhinderung einer allumfassenden und logistisch aufwendigen Wahrheitssuche, meistens durch das Angebot einer Strafmilderung als Ausgleich für das Geständnis, bezweckt. Charakteristisch hierfür ist der Fall US Supreme Court North Carolina v. Alford: ${ }^{321}$ Der Angeklagte hatte ausdrücklich vor dem Gericht erklärt, dass sein Geständnis für second-degree murder im Wege eines plea bargaining eigentlich nicht deswegen erfolgte, weil er schuldig war, sondern weil er Angst vor der Todesstrafe hatte, die im Rahmen eines jury-Verfahrens und aufgrund des belastenden Beweismaterials für first-degree murder verhängt werden könnte. Das erstinstanzliche Gericht hat trotzdem sein plea angenommen und ihn für second-degree murder zu einer Freiheitsstrafe von 30 Jahren verurteilt; diese Entscheidung wurde in der Folge auch vom Supreme Court bestätigt.

Es existiert ein deutlicher Widerspruch, wenn ein Rechtssystem, wie bereits gezeigt, $^{322}$ die Wahrheitssuche zur Verurteilung des ,wirklich“ Schuldigen als zentra-

319 Neumann, ZStW 101 (1989), 52 (70), bemerkt: „Ungerecht ist ein Urteil jedenfalls dann, wenn es unter Verletzung elementarer prozessualer Rechte zustandegekommen ist. Die Verfahrensgerechtigkeit ist nur eine notwendige, nicht aber eine hinreichende Bedingung der Gerechtigkeit der Entscheidung. Das Problem des Verhältnisses von materialer und prozeduraler Gerechtigkeit ist nicht dadurch zu lösen, daß man beide in einen funktionalen Zusammenhang stellt.“

320 Weigend, FS für Rissing-van Saan, S. 753. Vgl. auch A. Duff/Farmer/Marshall/ Tadros, Trial on Trial 3, S. 68-69.

321 US Supreme Court North Carolina v. Alford, 400 U.S. 25 (1970). Dazu Ransiek, ZIS 2008, 116 (118-121).

${ }^{322}$ Siehe auch Ransiek, ZIS 2008, 116 (116-117), mit weiteren Verweisen zur amerikanischen Rechtsprechung. 
les Verfahrensziel allgemein anerkennt und gleichzeitig dieses Ziel im Rahmen solcher Prozesse von Grund auf verneint - und dies nicht immer aus wirklich übergeordneten (insb. menschenrechtlichen) Gründen, sondern manchmal nur zur Wahrung eines oberflächlichen Erscheinungsbilds ${ }^{323}$ von Fairness und individueller Autonomie. Vielleicht deshalb und aus einer gewissen Furcht vor Legitimationsdefiziten schien auch das amerikanische Höchstgericht im betreffenden Fall zu versuchen, seine Entscheidung dadurch zu begründen, dass die grundsätzliche Gesamtorientierung an Wahrheit und Fairness doch sichergestellt war: Neben der Einhaltung von grundsätzlichen Verfahrensgerechtigkeitsstandards ${ }^{324}$ wurden nämlich zusätzlich materielle (beweisbezogene) Erwägungen zur Rechtfertigung der Annahme des Geständnisses vorgebracht. ${ }^{325}$

${ }^{323}$ Vgl. McEwan, in: A. Duff u.a. (Hrsg.), Trial on Trial 1, S. 58; Weinreb, Denial, S. 79. Siehe auch die dissenting opinion von Justice Brennan in US Supreme Court North Carolina v. Alford, 400 U.S. 25, 40 (1970): „I adhere to the view that, in any given case, the influence of such an unconstitutional threat 'must necessarily be given weight in determining the voluntariness of a plea.' [...] And, without reaching the question whether due process permits the entry of judgment upon a plea of guilty accompanied by a contemporaneous denial of acts constituting the crime, I believe that at the very least such a denial of guilt is also a relevant factor in determining whether the plea was voluntarily and intelligently made. With these factors in mind, it is sufficient in my view to state that the facts set out in the majority opinion demonstrate that Alford was 'so gripped by fear of the death penalty' that his decision to plead guilty was not voluntary but was 'the product of duress as much so as choice reflecting physical constraint'. "Vgl. noch die Überlegungen von Hörnle, Rechtstheorie 35 (2004), 175 (186-191).

324 Vgl. US Supreme Court North Carolina v. Alford, 400 U.S. 25, 31 (1970): „The standard was and remains whether the plea represents a voluntary and intelligent choice among the alternative courses of action open to the defendant. [...] That he would not have pleaded except for the opportunity to limit the possible penalty does not necessarily demonstrate that the plea of guilty was not the product of a free and rational choice, especially where the defendant was represented by competent counsel whose advice was that the plea would be to the defendant's advantage."

325 Vgl. US Supreme Court North Carolina v. Alford, 400 U.S. 25, 32 (1970): „Ordinarily, a judgment of conviction resting on a plea of guilty is justified by the defendant's admission that he committed the crime charged against him and his consent that judgment be entered without a trial of any kind. The plea usually subsumes both elements [...] Here Alford entered his plea but accompanied it with the statement that he had not shot the victim. If Alford's statements were to be credited as sincere assertions of his innocence, there obviously existed a factual and legal dispute between him and the State. Without more, it might be argued that the conviction entered on his guilty plea was invalid, since his assertion of innocence negatived any admission of guilt, which, as we observed last Term in Brady, is normally '[c]entral to the plea and the foundation for entering judgment against the defendant ...'397 U.S., at 748. In addition to Alford's statement, however, the court had heard an account of the events on the night of the murder, including information from Alford's acquaintances that he had departed from his home with his gun stating his intention to kill and that he had later declared that he had carried out his intention. Nor had Alford wavered in his desire to have the trial court determine his guilt without a jury trial. Although denying the charge against him, he nevertheless preferred the dispute between him and the State to be settled by the judge in the context of a guilty plea proceeding rather than by a formal trial. Thereupon, with the State's telling evidence and Alford's denial 
Solche Verfahrensparadoxe wie im Alford-Fall sind sogar als „Anomalien“ betrachtet worden. ${ }^{326}$ Antinomien auf der Ebene der Zielsetzung sind aber gegenwärtig auch in Rechtssystemen kontinentaleuropäischer Prägung nicht ausgeschlossen. So scheint insbesondere die Begründung eines konsistenten Zusammenhangs zwischen Amtsaufklärungsgrundsatz bzw. Schuldprinzip, der ernsthaften Wahrnehmung von Opferinteressen gemäß den modernen internationalen Trends und den Beweis- und Strafmilderungen aufgrund von Absprachemechanismen auch für die deutsche dogmatische Lehre ein Gordischer Knoten zu sein. ${ }^{327}$ Verschiedene Bezüge zur Wahrheit als Ziel des Strafverfahrens sind in absprachenbezogenen Regelungen und Prozessen beider Systemkreise zu finden. ${ }^{328}$ Dem Sinn der deals immanent bleibt jedenfalls der allgemeine Zweck, die Durchführung eines vollständigen Beweisverfahrens zu vermeiden. Jeder Versuch zur Annäherung an bestimmte Aspekte des historischen Geschehens „soll“ dann, wenn überhaupt, sehr zurückhaltend erfolgen. Sonst würden - falls immer im Voraus eine umfassendere Prüfung der Tatsachenlage stattfinden müsste - solche summarischen Verfahrensalternativen für die staatlichen Verfolgungsmechanismen ihre eigentliche Bedeutung verlieren. $^{329}$

before it, the trial court proceeded to convict and sentence Alford for second-degree murder."

326 So Weigend, FS für Rissing-van Saan, S. 752.

327 Vgl. etwa die Diskussionen bei Gössel, FS für Fezer, S. 500-529; Hamm, FS für Dencker, S. 148-154; Hettinger, JZ 2011, 292 (296-301); Hörnle, Rechtstheorie 35 (2004), 175 (186-191); Murmann, FS für Roxin 2011, S. 1387-1390.

328 Vgl. z.B. § 257c Abs. 1 deutsche StPO i.V.m. den wahrheits- und fairnessbezogenen Absprachengrundsätzen in BVerfG, 2 BvR 2628/10 vom 19.3.2013, Absatz-Nr. 4-8, 5372, http://www.bverfg.de/entscheidungen/rs20130319_2bvr262810.html. Vgl. in den USA: R. 11(b)(3) US Federal Rules of Criminal Procedure. Siehe ferner zu den englischen Newton hearings, wobei die tatsächliche Stichhaltigkeit einer guilty plea sogar von Amts wegen richterlich überprüft werden kann, und zu weiteren englischen Paradigmen, Ashworth/Redmayne, Criminal Process, S. 291-293, 300-301, sowie Doran, in: Doran/Jackson (Hrsg.), Judicial Role, S. 5. Im fact bargaining-Fall $R v$. Beswick, [1996] $1 \mathrm{Cr}$ App R 427, The Times 10 October 1995, hat das englische Appeal-Gericht z.B. bemerkt: ,$[\ldots]$ the court should seek to sentence a defendant on a true basis, and therefore the prosecution should not agree any facts which are unreal or untrue concerning the offence to which a plea of guilty is to be tendered. [...] the prosecution should not lend itself to any agreement whereby a case is presented to the sentencing judge to be dealt with so far as that basis is concerned on an unreal and untrue set of facts concerning the offence to which a plea of guilty is to be tendered." Siehe auch sect. 38.4. CPR 2014. Vgl. auch Damaška, JICJ 2 (2004), 1018 (1026).

329 Hierzu Ransiek, ZIS 2008, 116 (120-121). Siehe auch Hamm, FS für Dencker, S. 153-154; Meyer-Goßner, StPO, § 257c Rn. 1-3 m.w.N. Charakteristisch zu den Problemen des deutschen Regelungskomplexes, BVerfG, 2 BvR 2628/10 vom 19.3.2013, Absatz-Nr. 71-72: „Vor dem Hintergrund des Regelungsziels, die Grundsätze der Amtsaufklärungspflicht des Gerichts und der richterlichen Überzeugungsbildung unangetastet zu lassen, kann $\S 257$ c Abs. 1 Satz 2 StPO zudem nur so verstanden werden, dass das verständigungsbasierte Geständnis zwingend auf seine Richtigkeit zu überprüfen ist. Diese Überprüfung hat sich [...] durch Beweiserhebung in der Hauptverhandlung (vgl. § 261 StPO) zu vollziehen. [...] Es genügt jedoch nicht, das verständigungsbasierte Geständnis 
Letztendlich handelt es sich bei dem in der Theorie bisher vielfach als unfair, undurchsichtig oder zwangausübend ${ }^{330}$ kritisierten $^{331}$ „Justiz“-Mechanismus der Absprachen eigentlich um eine verallgemeinerte, die Verschiedenartigkeiten der Rechtstraditionen insgesamt ungenügend wahrnehmende rechtspolitische Entwicklung. ${ }^{332}$ Reines Ziel der Durchsetzung bzw. Annahme von formellen und informellen Verständigungen ist allgemein die Eliminierung des vollständigen Beweisverfahrens durch ,Austausch von Vorteilen“6333 zur Reduzierung der Überlastungsprobleme und zur Sicherstellung der (meist kurzsichtig verstandenen) Effektivität der Justiz. Auch in diesem Rahmen verliert dann die trennende Unterscheidung zwischen Prozesssystemen auf der Basis von Gerechtigkeits- und Wahrheitstypen heute ihren Ansatz; vielmehr handelt es sich bei den in unterschiedlichen Verfahrens- und Wahrheitssystemen horizontal durchgesetzten Absprachen um ein in traditioneller Hinsicht „wahrheitsneutrales ${ }^{\text {‘334 }}$ Problem.

Mit der zunehmenden strategischen Verbreitung der Absprachemechanismen wird sich in Zukunft wahrscheinlich auch die Tendenz in sämtlichen Rechtssystemen verstärken, sich von alltäglichen Wahrheitsverständnissen oder überhaupt von der Wahrheit als Zielsetzung ausdrücklich zu verabschieden; gleichzeitig sind dabei immense Bedenken hinsichtlich der Sicherstellung der Verfahrensgerechtigkeit

durch einen bloßen Abgleich mit der Aktenlage zu überprüfen [...], da dies keine hinreichende Grundlage für die erforderliche Überzeugungsbildung aus dem Inbegriff der Hauptverhandlung (§ 261 StPO) darstellt [...]. Dieses Verständnis des $\S 257$ c Abs. 1 Satz 2 StPO wird nicht dadurch in Frage gestellt, dass hiernach der Raum für Verständigungen insbesondere mit Blick auf das Ausmaß der ermöglichten Verfahrensabkürzung - spürbar eingeengt wird. [...] Die Beschränkung des praktischen Anwendungsbereichs von Verständigungen ist die zwangsläufige Konsequenz der Einfügung von Verständigungsmöglichkeiten in das System des geltenden Strafprozessrechts."

330 Vgl. in der englischen Gerichtspraxis $R$ v. Clark a.o., [2008] EWCA Crim 3221, Rn. 48: „Pressure is inherent in the giving of credit for plea." Zwischen erlaubtem und unerlaubtem pressure-Grad hat u.a. das House of Lords im Fall McKinnon v. US, [2008] UKHL 59, Rn. 38, differenziert: „In one sense all discounts for pleas of guilty could be said to subject the defendant to pressure, and the greater the discount the greater the pressure. But the discount would have to be very substantially more generous than anything promised here $[\ldots]$ before it constituted unlawful pressure such as to vitiate the process."

331 Auch in den Mutterländern: vgl. etwa die Verweise bei Scott/Stuntz, Yale L.J. 101 (1992), 1909 (1909). Siehe auch Dielmann, GA 1981, 558 (566-569). Zur englischen Kritik u.a. Ashworth/Redmayne, Criminal Process, S. 308-320.

332 Vgl. auch Damaška, JICJ 2 (2004), 1018 (1019); Weigend, in: Jackson u.a. (Hrsg.), Crime, S. , 40-43, 62-64. Zu dieser ,globalen“ Verbreitung der Absprachen siehe bereits unter Teil 1, I.B.2.a), I.B.3.b)bb), I.B.4. Vgl. auch Schünemann, FS für Fezer, S. 569-571. Zur Verbreitung der Absprachen auch in der internationalen Strafjustiz und zu den darauf bezogenen Problemen und Antinomien Turner, in: Carter/Pocar (Hrsg.), International, S. $34-43,56-65$.

333 So der charakteristische Titel des Aufsatzes von Damaška, StV 1988, 398 (398).

334 So (in einem leicht unterschiedlichen Sinn) Volk, FS für Salger, S. 412, 416-417. Vgl. auch Herrmann, Reform, S. 164; Kühne, GA 2008, 361 (365-366). 
und Gleichheit nicht auszuschließen. ${ }^{335}$ Gegenwärtig weisen jedenfalls die insgesamt positiven (rechts-)politischen Einstellungen gegenüber Absprachen in den unterschiedlichen westlichen Systemkreisen immer größere Ähnlichkeiten auf. Auch die gerichtlichen Auswertungsweisen eines freiwilligen ${ }^{336}$ Geständnisses (nach den Standards der Privatautonomie) ${ }^{337}$ sowie eines unfreiwilligen Geständnisses (nach den allgemein anerkannten Vorgaben des Menschenrechtsschutzes) unterscheiden sich heute auf normativer Ebene bzw. in der Rechtspraxis der verschiedenen westlichen Rechtssysteme nicht wesentlich. Im Ergebnis bieten somit solche Konvergenzen auch bei der Diskussion rund um die Beweismodelle noch ein zusätzliches Argument für die heutige Relativierung der Bedeutung der traditionellen Frage, welche Kategorie von Systemen bzw. Verfahrenstypen sich stärker an Wahrheit und welche sich stärker an Verfahrensgerechtigkeit/Fairness orientiert.

\section{e) Modellbezogene Auswertung der Prozessziele}

\section{aa) Eine Wahrheit, zwei Erforschungsmethoden}

Die tiefer gehende Analyse der rechtspolitischen Entwicklungen und Werte, die generell die modernen westlichen Prozesssysteme eventuell näher zueinander bringen können, bedarf sicherlich der weiteren Durchführung gesonderter Untersuchungen; diese sollen sich ebenfalls mit den gegenwärtig weitverbreiteten alternativen Verfahrensformen auch auf Modell- und Makroebene selbstständiger auseinandersetzen. Im Hinblick auf die vorliegende Untersuchung der herkömmlichen (Gerichts-)Verfahrensformen ist allerdings festzuhalten, dass ihr progressiver Ersatz durch vereinfachte Erledigungsformen mit de facto unterschiedlicher Zielsetzung die eigenständige Bestimmung der Zielverhältnisse bei den daneben weiterhin stattfindenden ordentlichen Beweisverfahren nicht beeinträchtigen darf. Die Ergebnisse der bisherigen Ausführungen betreffen eher die allgemeine, zumindest programmmäßig konvergierende Orientierung der Strafverfahrenssysteme an einer gleichzeitigen Verfolgung der Ziele der materiellen und der prozessualen Gerech-

335 Vgl. auch Neumann, ZStW 101 (1989), 52 (71). Siehe auch die Zusammenfassung der allgemeinen Einwände gegen die Absprachemechanismen bei Mylonopoulos, FS für Kühne, S. 259-262.

336 Meyer-Goßner, NStZ 2007, 425 (429), bemerkt (zur deutschen Rechtslage): „Man solle doch nicht immer so tun, als ob bei einem ohne Absprache abgelegten Geständnis im Gegensatz zu dem auf einer Absprache beruhenden in der Hauptverhandlung noch eine umfangreiche Beweisaufnahme durchgeführt wird. In beiden Fällen gibt sich das Gericht in der Regel mit einem glaubhaften - nämlich der Aktenlage entsprechenden - Geständnis zufrieden und erhebt keine weiteren Beweise." Diesbezüglich auch Herrmann, U. Pitt. L. Rev. 53 (1992), 755 (763). Vgl. auch im Kontext der vereinfachten Verfahren bei unstreitigen Fällen Weigend, in: Jackson u.a. (Hrsg.), Crime, S. 61.

${ }_{337}$ Vgl. Herrmann, in: Jung (Hrsg.), Der Strafprozeß, S. 148-152; auch Herrmann, in: Wise (Hrsg.), Criminal Science, S. 75-76. 
tigkeit. Bei der Zielsetzung innerhalb der immer noch theoretisch konstruierten und auch bei der Planung der weiteren Justizentwicklungen allgemein als wichtig angesehenen $^{338}$ sowie der national- und internationalrechtlich variiert angewandten Beweisverfahrensmodelle geht es nun grundsätzlich um das Problem der Wahrheitssuche (im Sinne einer historisch präzisen Sachverhaltsaufklärung). Im generellen Verfahrensrahmen darf diese Suche jedenfalls nur auf einem sozial verträglichen, vor allem fairen Weg erfolgen. ${ }^{339}$

Die herkömmlichen Verfahrensformen, die auch in den beiden dominanten Beweisverfahrensmodellen beinhaltet sind, zielen ihrem Wesen nach auf eine akkurate $^{340}$ Diagnose einer bestimmten ,wahren“ Situation der Vergangenheit. Die relative Natur der erzielten Wahrheit sowie die gesellschaftliche Notwendigkeit eines auch prozessual gerechten Ergebnisses werden heute allgemein anerkannt. ${ }^{341}$ Eine sozial ausreichende Balance zwischen Wahrheit und Fairness zu wahren, stellt insofern allgemein eine primäre Angelegenheit sämtlicher moderner, nationaler und internationaler Strafverfahrenssysteme des Westens dar. Was sich in concreto bei den Rechtstraditionen immer noch unterscheidet und daher ebenso in den idealen Beweisverfahrenstypen widerspiegelt werden soll, ist vor allem die Existenz zweier verschiedener Wege zum Erreichen des Wahrheitszieles, also der bestmöglichen Sachverhaltsaufklärung.

Die universelle Ausrichtung der modernen westlichen Justizsysteme auf factfinding und auf den jeweiligen materiell-rechtlich relevanten - historischen, wenn auch faktisch und normativ relativierten und unter fairen Prozessbedingungen zu erlangenden - Wahrheitsausschnitt ergibt sich wiederum aus dem tatsächlichen Bestehen verschiedener Beweisverfahrensstrukturen. ${ }^{342}$ Ihrerseits stellen die ,adversatorischen“ und „inquisitorischen“ Beweisverfahrensarten, und insbesondere die gegensätzliche Rollenverteilung der zentralen Prozessakteure bei der Beweisführung, eigentlich unterschiedliche idealtypische Methoden zum Erreichen dieser

338 Vgl. schon in dieser Arbeit unter Teil 1, I.B.4. und II.A.

339 Vgl. auch Eser, FS für Miyazawa, S. 562-563; Jörg/Field/Brants, in: Fennell u.a. (Hrsg.), Criminal Justice, S. 42.

${ }_{340} H o$, Philosophy, S. 66, bemerkt: „The reference to 'accuracy' when speaking of a finding of fact must be to the likelihood of its truth, and not how close it is to the truth."

341 Vgl. A. Duff, Trials, S. 110; Eser, FS für Miyazawa, S. 568.

342 Vgl. auch Damaška, Evidence, S. 95. Siehe auch Ho, Philosophy, S. 3 m.w.N. Vgl. ferner Stein, Foundations, S. 1-3, 10. Auch früher wurde im Fall US Supreme Court Funk v. United States, 290 U.S. 371, 381 (1933), bestimmt, dass: „The fundamental basis upon which all rules of evidence must rest - if they are to rest upon reason - is their adaptation to the successful development of the truth." Vgl. auch Wigmore, Evidence 1A (§ 37.1), S. 1019 (Tillers rev. 1983): ,It does not appear likely [...] that many judges or academics will take seriously the claim that the law of evidence, considered as a whole, should have as its predominant purpose something other than the search for truth. The conviction in the importance of accurate factfinding is deeply imbedded in the way we think about law." 
einen Wahrheit dar. „Nicht der Wahrheitsbegriff [unterscheidet] die Modelle [...], sondern die Methode, mit der man die Wahrheit erforscht. “343

bb) Vor- und Nachteile der diversen Wahrheitserforschungsmethoden

Die Auswahl der wirksamsten Wahrheitserforschungsmethode aus den zwei in den Beweisverfahrensmodellen vorgeschlagenen Vorgehensweisen bleibt freilich auch für die heutige Verfahrenslehre eine offene, unter vielfältigen Gesichtspunkten behandelte Frage. Vor allem wird dabei die Tauglichkeit der starken beweisführenden Position von am Verhandlungsergebnis primär interessierten Parteien einerseits und von neutralen sachkundigen Richtern andererseits für eine umfassende Sachverhaltsaufklärung diskutiert. Im Einklang mit den bisherigen Analysen ist zunächst zu bemerken, dass die differenzierte Beweisführungsautonomie der Verfahrensbeteiligten von Bedeutung für die betreffenden Erwägungen ist. Dagegen sind die normativen und faktischen Möglichkeiten der Parteien bzw. des Richters für eine ,verfrühte“ Beendigung des Beweisverfahrens und insbesondere die prozessuale Haltung gegenüber Geständnissen nicht mehr zentral in den relevanten Auswertungen der Verfahrensziele zu berücksichtigen.

Wie vorangehend angedeutet, zeigen nämlich solche Verfahrenserledigungsmöglichkeiten in der Gegenwart systemübergreifend ähnliche, im Ganzen modellneutrale Charakteristika: Sie beziehen sich bei unfreiwillig erlangten Geständnissen meistens einheitlich auf den effektiven Schutz der Menschenrechte und die Wahrung des fairen Verfahrens, bei justizförmig abgelegten Geständnissen auf die rechtspolitische Notwendigkeit abgekürzter Verhandlungen. Die in der vorliegenden Arbeit definierten Modelle setzen sich jedoch inhaltsgetreu mit den wichtigsten Wegen zur Annäherung an die Wirklichkeit des Sachverhaltes, nicht aber mit den (aus welchen Gründen auch immer) vorhandenen Optionen für ihr Außerachtlassen auseinander. Daher sind hier Effektivitätserwägungen mit Blick auf solche strukturellen Elemente und Rollenverteilungen innerhalb der idealtypischen Strafverfahren von primärem Interesse, welche die unterschiedlichen Arten einer möglichst umfassenden Wahrheitssuche in streitigen Verhandlungen bestimmen.

Diesbezüglich ist üblicherweise behauptet worden, der Vorteil des „Parteiprozesses" liege darin,

daß jedes Glied in der Beweiskette der einen Partei durch die andere Partei sorgfältig und unter völlig neuen Gesichtspunkten überprüft werden kann. Der Parteiprozeß hat

343 Jung, FS für Fiedler, S. 908. Siehe auch Jörg, in: Eser/Rabenstein (Hrsg.), Strafjustiz, S. 221; Jung, JZ 2009, 1129 (1130); Weigend, Harvard JLPP 26 (2003), 157 (158); Weigend, FS für Rissing-van Saan, S. 755. Vgl. auch Gleß, Beweisrechtsgrundsätze, S. 93-94; Jackson/Doran, Judge, S. 78-79; Jescheck, JZ 1970, 201 (204); Jescheck, Va. L. Rev. 56 (1970), 239 (240-241); LaFave/Israel/King/Kerr, Criminal Procedure, S. 42-44; Paulsen, ZStW 77 (1965), 637 (657); Schünemann, FS für Fezer, S. 558-559; Stamp, Wahrheit, S. 214. 
den Vorzug, daß die Richtigkeit der Tatsachenfeststellung in der Hauptverhandlung durch die Kritik, die von beiden Seiten kommt, immer wieder in Frage gestellt und deshalb stets neu geprüft wird. Beide Parteien haben allen Grund zur Kritik, der Staatsanwalt, weil er den Angeklagten überführen will, und der Angeklagte bzw. sein Verteidiger, weil der Angeklagte damit rechnen muß, bestraft zu werden, sich also einer durchaus unangenehmen Tatsache gegenübersieht. Stellt der Richter selbst die Fragen an den Zeugen, so hat er keine vergleichsweise zwingenden Gründe, die ihn zu Zweifeln an der Richtigkeit der Aussage veranlassen könnten. ${ }^{344}$

Als Gegenargument wurde andererseits vorgebracht, dass dieser mutmaßliche Vorzug des „Adversary Process“ insbesondere im Rahmen der jury trial „nicht einmal erkenntnistheoretisch zutreffend" ist,

weil ein stummer Zuhörer einer fremden, von ihm notwendig nur partiell verstandenen Kommunikation ohne ein eigenes Fragerecht nur beurteilen kann, welcher Akteur ,besser $^{e}$ war, nicht aber die hinter dem ihm vorgeführten Wettkampf existierende Wahrheit $\mathrm{zu}$ erfassen vermag. Und in rechtlicher Hinsicht ist es [...] unzutreffend, weil es im Adversary System an einem zur Sicherstellung einer vollständigen Beweisaufnahme verpflichteten Prozessorgan fehlt $[\ldots]]^{345}$

Aber auch im Allgemeinen wurde der, ,prinzipielle Nachteil des adversatorischen Verfahrens“ darin gesehen, „dass keine der Verfahrensparteien darauf abzielt, ein objektives und vollständiges Bild der, wahren ' Tatsachen zu zeichnen, sondern dass jede Partei nur das vorträgt, was für ihre Verfahrensposition günstig ist. “346

Wird der strikt normative Blick vorübergehend beiseitegelassen, so ist nicht von der Hand zu weisen, dass die Praxis der Präsentation und Prüfung von Beweisen durch die jeweilige Partei in Verfahren, die dem ,adversatorischen“ Modell nahe stehen, eventuell extrem einseitig und selektiv sein kann. ${ }^{347}$ Ebenso wenig kann aber sichergestellt werden, dass die Beweisführung seitens des prozessbeherrschenden Richters in ,inquisitorischartigen“ Verfahren immer neutral und hinreichend umfassend erfolgt. Übermäßiges Vertrauen in die Arbeitsleistung der staatlichen Richter ist nämlich nicht mehr selbstverständlich, und zwar ungeachtet dessen, wie und nach welchen Kriterien und Qualifikationen diese ausgewählt bzw. eingesetzt werden, welcher Verfassungsrang und welche soziale Bedeutung als

344 Paulsen, ZStW 77 (1965), 637 (657-658). Nach Lord Eldon (in: Ex parte Lloyd (1822), Montague's Reports 70, 72): „Truth is best discovered by powerful statements on both sides of the question." Siehe auch u.a. Herrmann, Reform, S. 167-169; Roberts/Zuckerman, Criminal Evidence, S. 51; Schwarzer, Harv. L. Rev. 93 (1980), 633 (636-637); Weigend, ZStW 113 (2001), 271 (272). Vgl. auch Walpin, Harvard JLPP 26 (2003), 175 (177). Siehe weitere Verweise bei van Kessel, Notre Dame L. Rev. 67 (1992), 403 (409).

345 Roxin/Schünemann, Strafverfahrensrecht, $§ 15$ Rn. 6. Siehe auch Schünemann, FS für Fezer, S. 562-564; Schünemann, StraFo 2010, 90 (91-92).

346 Weigend, FS für Rissing-van Saan, S. 757-758. Vgl. auch Eser, FS für Tiedemann, S. 1464-1465; Frankel, U. Pa. L. Rev. 123 (1975), 1031 (1035-1039). Vgl. noch Damaška, Law, Probability and Risk 2 (2003), 117 (120-121).

347 Zum möglichen Problem der Vertretung des Angeklagten durch „inkompetente“ Anwälte siehe unten Teil 1, II.C.2.e)dd). 
Justizorgane ihnen zugebilligt werden, oder inwieweit ihre Unabhängigkeit und Neutralität normativ verankert sind. Insbesondere die nationalen Berufsstrafrichter in den westlichen Ländern sind aufgrund der auf globaler Ebene ablaufenden rapiden und überkomplexen technologischen und sozialen Entwicklungen fast überall erheblich überlastet - was nun auch die Verbreitung von Absprachen selbst für das Richtertum attraktiver macht. ${ }^{348}$ Dabei ist ab einem gewissen Punkt auch die Gefahr einer routinierten ${ }^{349}$ Durchführung des maßgebenden Beweisverfahrens nicht auszuschließen.

cc) Cross-examination als diagnostische Methode

Die Debatte in Bezug auf eine bestimmte Ausprägung des ,adversatorischen“ Beweisführungssystems, namentlich die Prüfung des (Zeugen-)Beweises im Wege der in der common law-Welt höchst beliebten Technik der cross-examination ${ }^{350}$ (Kreuzverhör), kann konkreter auf mögliche wahrheitsbeeinträchtigende Konsequenzen der Einseitigkeit der beweisführenden Parteien hindeuten. Wie Weigend hierzu anschaulich beschreibt, kann das Kreuzverhör von Zeugen der Gegenpartei

in der Hand geschickter und zielorientierter Anwälte dazu führen, dass auch wahrheitsgemäß aussagende Zeugen so verunsichert oder eingeschüchtert werden, dass ihre Aussagen am Schluss nicht mehr als glaubhaft erscheinen. Es kann also bei der kritischen Prüfung der Aussagen von Zeugen und Sachverständigen aufgrund der strikten Parteilichkeit des Verfahrens zu einem overkill kommen, der dem Gericht letztlich nicht mehr viel an verlässlicher Tatsachengrundlage für seine Entscheidung übrig lässt. ${ }^{351}$

Nach der konträren Ansicht kann aber eine rigorose, jeweils auf beiden Seiten erfolgende Befragung zur Sicherstellung vollständiger Aussagen bzw. zur erfolgreichen Feststellung der Glaubwürdigkeit der Zeugen führen. Sogar eine gewisse „Aggressivität“ seitens der Anwälte während des Verhörs könne aus Wahrheitsgründen, insbesondere wegen des allgemein zurückhaltenden Auftretens der Zeugen vor Gericht und des höheren Interesses des Angeklagten an seiner Freiheit, gerechtfertigt sein. ${ }^{352}$

348 Vgl. BVerfG, 2 BvR 2628/10 vom 19.3.2013, Absatz-Nr. 3, http://www.bverfg.de/ entscheidungen/rs20130319_2bvr262810.html.

349 Vgl. Damaška, Law, Probability and Risk 2 (2003), 117 (119). Vgl. auch Jackson/ Doran, Judge, S. 68.

${ }_{350}$ Hierzu einführend z.B. Dennis, Evidence, Rn. 14.024; Weigend, ZStW 100 (1988), 733 (736-737, 746-749) m.w.N.

351 Weigend, FS für Rissing-van Saan, S. 757. Siehe auch Damaška, U. Pa. L. Rev. 123 (1975), 1083 (1093-1094); Spencer, in: Delmas-Marty/Spencer (Hrsg.), European Criminal Procedures, S. 629. Vgl. auch mit Beispielen McEwan, in: A. Duff u.a. (Hrsg.), Trial on Trial 1, S. 59-60.

352 Paulsen, ZStW 77 (1965), 637 (658). Vgl. auch Damaška, U. Pa. L. Rev. 123 (1975), 1083 (1092). 
Es ist jedoch zweifelhaft, ob vor allem die Aggressivitätsthese auf erkenntnistheoretischer Ebene sowie unter Berücksichtigung des in der modernen Zeit national und international deutlich verstärkt angestrebten respektvollen gerichtlichen Opfer- und Zeugenschutzes überzeugen kann. ${ }^{353}$ Nichtsdestoweniger sind bei Besuchen in kontinentaleuropäischen wie auch angloamerikanischen Gerichtssälen eventuell tatsächlich genügend Fälle zu beobachten, die ungeachtet der Existenz von relevanten Schutzvorschriften ${ }^{354}$ in beiden Systemkreisen weiterhin vorsichtig formuliert „unangenehme“ Verhörsituationen für die Zeugen darstellen. Ursächlich dafür kann die generelle Art der Verhandlung einschließlich des tatsächlich erlaubten Spielraums der Verteidigung und der Anklage, aber auch die eingreifende Art und Weise einer richterlichen Zeugenbefragung selbst sein. Wichtig ist eben bei der Betrachtung idealtypischer Verfahren, dass unverhältnismäßig belastende, einschüchternde und somit möglicherweise auch den Wahrheitsgehalt der Aussage gefährdende Verhaltensweisen der Richter oder Parteien gegenüber den Zeugen den Inhalt der Modelle nicht mitbestimmen dürfen - worin auch immer ein solches Verhalten begründet sein könnte: in der übereifrigen Persönlichkeit des betreffenden Akteurs, in ,politischen“ Gründen, in der Kenntnis der Vorverfahrensakten bzw. in den störenden Widersprüchen früherer Aussagen oder vielleicht in den vorgenannten Routinierungserwägungen.

Letztendlich muss doch zugegeben werden, dass bei Strukturen, die schon mustermäßig stärker zu ,kampfartigen“ bzw. ,antagonistischen“ Beweisführungen tendieren oder jedenfalls nach traditioneller Überzeugung der Modellanwender als solche angesehen werden, ${ }^{355}$ die Gefahr einer nicht präzisen Abbildung der Wahrheit eher gegeben ist. Die einseitige Verfolgung eventuell rein strategischer Ziele, mögliche Verschleierungstaktiken (z.B. unterlassene Zeugenladungen) und allgemein die Förderung von gerichtlichen Auseinandersetzungen mit dem Ziel der Durchsetzung des Stärksten (vor allem hier: der überzeugenderen Partei) können nämlich das generelle prozessuale Streben nach umfassender Sachverhaltsaufklärung eher untergraben als ihm effektiv dienen. ${ }^{356}$ Deswegen scheinen hierbei besonders die Fairness- und „Spielregeln“ und ihre richterliche Gewährleistung eine zentrale, teilweise wahrheitsdienende und teilweise allgemein verfahrenslegitimie-

353 Vgl. auch McEwan, Evidence, S. 11-12; Park, in: van Koppen/Penrod (Hrsg.), Adversarial, S. 163-164.

${ }_{354}$ Vgl. ebenso Paulsen, ZStW 77 (1965), 637 (659-660); McEwan, in: A. Duff u.a. (Hrsg.), Trial on Trial 1, S. 60-63; Weigend, FS für Rissing-van Saan, S. 757 m.w.N.

355 Vgl. etwa Macchiarola, in: Nijboer/Reijntjes (Hrsg.), Proceedings, S. 87; Williams, Proof, S. 30. Schon früher Newman, Beweisrecht, S. 31. Vgl. ferner die Verweise bei Herrmann, ZStW 80 (1968), 775 (778-780).

356 Vgl. u.a. Jackson/Doran, Judge, S. 61; Weigend, ZStW 100 (1988), 733 (748, 753); Weigend, Harvard JLPP 26 (2003), 157 (158-160). Vgl. auch Goodpaster, J. Crim. L. \& Criminology 78 (1987), 118 (121-124); Park, in: van Koppen/Penrod (Hrsg.), Adversarial, S. $143,152-153$. 
rende Rolle zu spielen, auch wenn, wie sich aus den bisherigen Analysen ergibt, die Planung und Durchführung von lediglich fairen Verfahren keinen Selbstzweck der Beweismodelle darstellen soll.

\section{dd) Die Bedeutung der Anwälte im Wahrheitserforschungsprozess}

Ferner kann auch eine gleich starke Positionierung der Verteidigungs- und Anklageanwälte von besonderer Bedeutung für die zweckmäßige Ausbalancierung extremer Ausprägungen des parteiprozessualen Kampfes sein. Ungleichheiten lassen sich dabei jedoch nicht vermeiden, insofern als es für bestimmte, wirtschaftlich besser gestellte Angeklagte immer einfacher als für andere sein wird, den geeigneten Verteidiger bereitzustellen, der nicht nur wirklich interessiert am Ergebnis des Wettstreits mitwirken wird, sondern auch über die notwendigen Mittel zur wirksamen Widerlegung des Anklagevorbringens verfügt. ${ }^{357}$ Von ,inquisitorischen“ Systemen wird dagegen behauptet, dass in solchen Fällen entsprechende Verteidigungsschwierigkeiten durch die allseitigen Ermittlungsaktivitäten des Richters kompensiert werden können. ${ }^{358}$

Mutmaßlich befindet sich im Allgemeinen der Angeklagte in einer schwierigen Position gegenüber dem massiven staatlichen Strafverfolgungsapparat, wenn es darum geht, seine Wirklichkeitsthesen konstruktiv zu unterstützen. Eine benachteiligte Stellung des Angeklagten ist jedoch auch in Systemen nicht ausgeschlossen, in denen die Kenntnis der Vorverfahrensakten seitens des ,inquirierenden“ Richters und die möglicherweise zwischen objektiven voruntersuchenden und objektiven gerichtlichen Justizorganen entwickelte enge Vertrauensbeziehung ${ }^{359}$ eventuell einseitig auf die Leitung der maßgebenden Beweisführungen wirken können. Hierbei ist nämlich eine wirklich umfassende, neutrale (Neu-)Ermittlung des Geschehens im Gerichtssaal nicht immer sichergestellt, vor allem dann nicht, wenn die normalerweise druckausübende Mitwirkung engagierter und „vollbewaffneter“ Verteidiger als Gegengewicht zu den mächtigen, womöglich einheitlichen staatlichen Stimmen fehlt. ${ }^{360}$ Das rechtsstaatliche und menschenrechtliche Problem der Bereitstellung eines Verteidigerbeistandes unter immer möglichst gleichen Kondi-

357 Vgl. auch Bradley, CLF 7 (1996), 471 (473).

358 Weigend, FS für Rissing-van Saan, S. 758. Vgl. auch Hörnle, ZStW 117 (2005), 801 (833); Perron, in: Eser/Rabenstein (Hrsg.), Strafjustiz, S. 302; Renzikowski, FS für Lampe, S. 803.

359 Vgl. Nijboer, in: Doran/Jackson (Hrsg.), Judicial Role, S. 29: „Continental judges usually consider themselves as being neutral and independent. Nevertheless they are educated in a system where state activity in itself is considered to be in the general interest. [...] And because they consider the prosecutor as being loyal to the same public interest, they have a tendency to follow the prosecutor's opinions and they adopt the official state perspective quite easily." Vgl. auch Roxin/Schünemann, Strafverfahrensrecht, § 9 Rn. 1.

360 Vgl. Bradley, CLF 7 (1996), 471 (472). 
tionen bzw. das Problem seiner effektiven Mitwirkung im Verfahren ist letztendlich den engen dichotomisierenden Modellerwägungen übergeordnet; es kann insgesamt die eigentliche Verwirklichung der wahrheitsbezogenen Prozessziele auch unabhängig von der jeweils vorgeschlagenen Beweismethode betreffen.

\section{ee) Aktenkenntnis und Beweisführung}

Einen weiteren strittigen Punkt in ähnlichem Kontext stellt schließlich die Frage dar, ob die Vorkenntnis der Beweislage insbesondere seitens des verfahrensleitenden Richters ein Hindernis für die strafprozessuale Wahrheitserforschung sein kann. Die Einführung der Ermittlungsergebnisse aus dem Vorverfahren in die Hauptphase der Beweisaufnahme vor Gericht entweder durch Zusammenstellung eines ,objektiven“ Dossiers mit wichtigen Verfahrensdaten einerseits oder erst über die Eigenaktivitäten der Parteien andererseits kann allgemein als wichtiger Parameter der Beweisverfahrensmodelle betrachtet werden, auf den später noch einmal zurückzukommen ist. ${ }^{361}$

An dieser Stelle ist im Rahmen der Evaluation der „Wahrheitsbereitschaft“ diverser Beweisverfahrensformen Folgendes zu bemerken: Der Vorsitzende Richter muss gemäß dem ,adversatorischen“ Verfahrensstil nicht aktiv in die Beweisführung eingreifen und kann demnach in den meisten Fällen auch ohne Kenntnis der Ermittlungsakten das bloße Einhalten der Verfahrensregeln sicherstellen. Dagegen ist der verfahrensleitende Richter in der ,inquisitorischen“ Hauptverhandlung hauptverantwortlich auch für die materielle Beweisführung. Daher muss er notwendigerweise weitgehende Vorkenntnis des bisher ermittelten Sachverhaltes haben, um die Verhandlung danach effektiv leiten zu können; denn vor Gericht findet keine selbstständige Präsentation von ,eigenen“ Fällen und Beweismitteln durch die Parteien und somit keine Darstellung aller möglichen (gegensätzlichen) Schattierungen des Sachverhaltes von außen statt. Es ist freilich nicht ausgeschlossen, dass der Richter aufgrund einer eigenen, lediglich durch Studium der Akten frühzeitig erworbenen Wahrheitsvorstellung schon während der Beweisführung beispielsweise durch eine ,skeptische“ Ausrichtung und Art und Weise der Befragungen oder eine selektive Auswahl der belastenden Beweismittel, die vorrangig zu überprüfen sind - voreingenommen wirken wird. ${ }^{362}$

\footnotetext{
361 Siehe unter Teil 1, II.C.3.b).

362 Vgl. dazu u.a. Damaška, U. Pa. L. Rev. 123 (1975), 1083 (1089, 1092); Damaška, Law, Probability and Risk 2 (2003), 117 (121); Eser, FS für Miyazawa, S. 566; Eser, FS für Tiedemann, S. 1459; Herrmann, SACC 2 (1978), 3 (13); Hirschberg, Strafverfahren, S. 7; Paulsen, ZStW 77 (1965), 637 (659); Roxin/Schünemann, Strafverfahrensrecht, § 15 Rn. 7; Schünemann, in: Bierbrauer u.a. (Hrsg.), Verfahrensgerechtigkeit, S. 216; Schünemann, StraFo 2010, 90 (92); Weigend, ZStW 100 (1988), 733 (735); Weigend, FS für Rissing-van Saan, S. 756. Vgl. aber auch Gössel, FS für Meyer-Gossner, S. 190-194.
} 


\section{f) Ausblick: Zum Bewertungsmaßstab für die konkrete Rechtsvergleichung}

Die bisherigen Auswertungen können als etwaiges Zwischenergebnis zeigen, dass der offene Spielraum für extrem parteiliches Verhalten während der Beweisführungen in ,adversatorischen“ Verfahren und die mögliche Befangenheit des aktiv und autoritativ in die Beweisführungen eingreifenden Richters in , inquisitorischen" Verfahren entsprechend charakteristische Schwachpunkte der beiden Modelle bilden. Gleichwohl bleibt die Frage weiterhin unbeantwortet, welche Beweisverfahrensstrukturen im Allgemeinen mit höherer Wahrscheinlichkeit zu präzisen Wahrheitsergebnissen durch ,,verlässliche Klärung der Sachlage“363 führen könnten. Zunächst ist noch einmal darauf hinzuweisen, dass die vorherigen Analysen abstrakter Natur waren und grundsätzlich die zwei dominanten theoretischen Idealformen des Beweisverfahrens - und nicht etwa ihre tatsächlichen nationalen oder internationalen Mischungen - betreffen.

Ferner geht es hierbei in der Tat um Behauptungen, die empirisch enorm schwierig zu beweisen sind. ${ }^{364}$ Umfassende erkenntnistheoretische und interdisziplinäre Untersuchungen, die insbesondere auch Forschungen und Standards aus verschiedenen wissenschaftlichen Bereichen der Psychologie einbeziehen, könnten dabei trotz der sicherlich erheblichen Schwierigkeiten einer praktisch sinnvollen Umsetzung - von beträchtlichem informatorischem Wert sein. ${ }^{365}$ Auch dann lassen sich aber etwa die Frage, ob die Richter wegen bestimmter ,inquisitorischer" Verfahrenspräferenzen bei der Beweisführung tatsächlich voreingenommener wirken, oder die Frage, ob die parteiliche Präsentation eines Sachverhalts durch Entgegensetzung der "Teilwahrheiten“ besser für den Urteilsfinder nachzuvollziehen ist, nicht wirklich definitiv beantworten. ${ }^{366}$ Weitere potenzielle Stärken und Schwachpunkte gegensätzlicher Beweisformen könnten eventuell bei der eigentlichen Rechtsvergleichung konkreter Rechtsordnungen identifiziert werden. Aber auch in

363 Jung, JZ 2009, 1129 (1130).

364 Damaška, Law, Probability and Risk 2 (2003), 117 (120), schreibt: „Which of these two structures is more likely to generate accurate factual outcomes is a hotly debated and unresolved empirical question - a great challenge to cognitive scientists." Siehe auch Damaška, U. Pa. L. Rev. 121 (1973), 506 (588). Vgl. auch Herrmann, RIDP 53 (1982), 841 (853-856); Jackson/Summers, Internationalisation, S. 10-11; Jescheck, Va. L. Rev. 56 (1970), 239 (240).

365 Siehe z.B. die diversen experimentellen Versuche von: Haisch, MschrKrim 62 (1979), 157 (157-162); Lind/Thibaut/Walker, Mich. L. Rev. 71 (1973), 1129 (1129-1144); Marshall/Marquis/Oskamp, Harv. L. Rev. 84 (1971), 1620 (1620-1643); Schünemann, in: Kerner u.a. (Hrsg.), Deutsche Forschungen, S. 1110-1148; Schünemann, in: Bierbrauer u.a. (Hrsg.), Verfahrensgerechtigkeit, S. 216-232; Thibaut/Walker/Lind, Harv. L. Rev. 86 (1972), 386 (386-401); Weißmann, Stellung, S. 142-231. Siehe auch m.w.N. Haisch, in: Seitz (Hrsg.), Rechtspsychologie, S. 169-171; Schünemann/Bandilla, in: Wegener u.a. (Hrsg.), Criminal Behavior, S. 182-190; Thibaut/Walker, Procedural Justice, S. 22-124; Thibaut/Walker, Cal. L. Rev. 66 (1978), 541 (541-566).

366 Vgl. hierzu auch Damaška, U. Pa. L. Rev. 123 (1975), 1083 (1091-1095, 1106); Schünemann, StraFo 2010, 90 (91); Weigend, FS für Rissing-van Saan, S. 758. 
diesem Rahmen ist es nicht möglich, mit Sicherheit festzustellen, ob und wann eine Rechtsordnung ihr Wahrheitsfindungssystem einer weitgehenden Reform unterziehen bzw. es durch ein fremdes ersetzen sollte - nicht zuletzt, weil: ,it is hard to see how it could be empirically proved that one system is better at truth finding, for the simple reason that it is impossible to know in any particular system how many truly guilty are convicted and how many truly innocent are acquitted.“367

Demzufolge kommt mit Blick auch auf die im Grunde prozesstheoretische Orientierung und auf die de facto begrenzten Untersuchungsressourcen einer strafrechtsvergleichenden Arbeit wie der vorliegenden der Versuch nicht in Frage, in absoluter Weise festzustellen, welches Beweisverfahrensmodell bzw. welches eigentliche Beweissystem für die Zwecke einer präzisen Sachverhaltsaufklärung tatsächlich geeigneter ist. Erwünscht ist eher, anhand der bisher abstrakt beschriebenen Vor- und Nachteile der zwei extremen Beweisverfahrensstile die Suche nach „positiven“ und „negativen“ prozessstrukturellen Aspekten der Wahrheitserforschung auf konkrete Rechtsordnungen zu erstrecken, die eventuell näher an dem einen oder dem anderen idealen Verfahrenstypus stehen. Die kombinierte Wahrnehmung von abstrakt-definitorischen und konkret-vergleichenden Ergebnissen könnte vielleicht danach, wenigstens zum Teil, als Grundlagen- bzw. Ideenaustauschplattform $^{368}$ für weitere theoretische und empirische ${ }^{369}$ Untersuchungen sowie rechtspolitische Reformvorschläge dienen; diese könnten eventuell etwa das Problem der Aktenkenntnismöglichkeiten oder des Wettkampfcharakters des Gerichtsverfahrens erneut ansprechen.

Ebenso wenig wie die bereits vorgelegten Analysen befassen sich nun die nachfolgenden Auseinandersetzungen mit der (zumindest partiell veralteten) Frage, welche Verfahrensordnungen und -traditionen sich stärker an der Wahrheit und welche sich stärker an Verfahrensgerechtigkeit orientieren, und auch nicht mit der Chimäre der ,perfekten“ Systeme, die eine widerspruchsfreie Gesamtverwirklichung sämtlicher Prozessziele durchaus garantieren könnten. So stellt etwa auch das Problem der Kollision von effektiver Wahrheitssuche und den menschenrechtlich gebotenen Beweisverboten in Bezug auf die hier diskutierten Beweisverfahrensmodelle und ihren konkreteren rechtsvergleichenden Gebrauch keinen selbstständigen Analysegegenstand dar. Von zentralem Interesse sind dagegen die verschiedenen Sachverhaltsaufklärungsstrukturen per se und die bei ihrer Einsetzung zur Verwirklichung des einheitlichen Wahrheitszweckes manifestierten Mängel, die hauptsächlich mit der unterschiedlichen Rollenverteilung der Hauptakteure des Verfahrens verbunden sind. Keinesfalls wird dabei beabsichtigt, die enorme

367 Jackson, Cardozo L. Rev. 10 (1988), 475 (485). Vgl. auch im Kontext der Fehlverurteilungen Killias, in: Huff/Killias (Hrsg.), Wrongful Convictions, S. 61-62, 73-74.

368 Vgl. Engelhart, Sanktionierung, S. 17 m.w.N.

369 Vgl. Ho, Philosophy, S. 339: ,[...] indeed, the usefulness and relevance of empirical data can only be judged against a prior understanding of the value and purpose of the rule under investigation." 
(legitimierende) Bedeutung anderer, wahrheitsexterner Prozessziele und Fairnessideale für die modernen Rechtssysteme zu leugnen. Das Spannungsverhältnis, in dem diese Ziele und Ideale zur materiellen Gerechtigkeit stehen, kann jedoch im Rahmen der vorliegenden Arbeit nicht viel genauer als bisher betrachtet werden.

Gleichwohl können normative Erscheinungen der Verfahrensgerechtigkeit, insbesondere in Form von Informations-, Verteidigungs-, Mitwirkungs- und Gleichheitsrechten, eventuell gleichzeitig der Wirklichkeitsermittlung im Strafprozess dienen. ${ }^{370}$ Neben dem zentralen Wahrheitserforschungsziel müssen ohnehin solche Fairness- und Menschenwürdegarantien in den meisten modernen westlichen Rechtsordnungen selbstständig respektiert werden, nicht zuletzt wegen internationaler menschenrechtlicher Verpflichtungen. Soweit aber die Wahrung der menschenrechtlich geförderten Garantien überall selbstständig und unabhängig von Wahrheitskriterien erfolgen muss, kann ihre möglicherweise zusätzliche wahrheitsdienende Funktion nicht als eigenständiger Maßstab bei der rechtsvergleichenden Betrachtung konkreter Beweisverfahren berücksichtigt werden. Somit stellen vor allem die bisherige Definition der Kernkomponenten der idealen Verfahrenstypen sowie die im Anschluss folgende Schilderung weiterer essenzieller Modellelemente einen möglichst kohärenten Vergleichs- und Bewertungsrahmen für die Gegenüberstellung von konkreten Beweisführungspräferenzen zumindest in den zwei dominanten westlichen Rechtstraditionen bereit.

\section{Bestimmung der ergänzenden Elemente der Beweisverfahrensmodelle}

Neben den in der Strafprozesstheorie allgemein anerkannten trennenden Kerncharakteristika der zwei herrschenden Beweisverfahrensstile lassen sich zusätzlich auch weitere Prozesserscheinungsformen und Prozessideen in die abstrakte Erfassung der diversen Strukturen zur bestmöglichen Aufklärung eines Straftatverdachts einbeziehen; diese sind grundsätzlich in zentralen Rechtsordnungen der westlichen Rechtstraditionen historisch zu beobachten. Hierfür werden bei der Darlegung von potenziellen Elementen der Modelle meist die diversen Ermittlungskonturen des Vorverfahrens, die Aktenkenntnis- und Beweisoffenlegungsmöglichkeiten, die Gegenpole Öffentlichkeit / Nichtöffentlichkeit und Mündlichkeit/Schriftlichkeit des Verfahrens, die funktionsmäßige Dichotomie zwischen jury trial und bench trial sowie die Abspracheformen diskutiert. ${ }^{371}$

In den folgenden Analysen ist nun näher zu erläutern, ob solche Elemente jeweils einen typischen bzw. logisch notwendigen Modellinhalt darstellen oder ob sie dagegen in den bisher beschriebenen Hauptstrukturen der idealen Beweisver-

370 Vgl. Neumann, ZStW 101 (1989), 52 (68-69). Vgl. auch Brants/Ringnalda, Issues, S. 12; A. Duff, Trials, S. 111-119.

371 Siehe z.B. Bradley, in: ders. (Hrsg.), Criminal Procedure, S. xvii. Dazu u.a. auch Grande, in: Jackson u.a. (Hrsg.), Crime, S. 146. 
fahrenstypen konsequenterweise nicht erfasst werden können bzw. als modellneutrale Erscheinungen - im Sinne einer selbstständigen Existenz unabhängig von den modellhaften Kerndifferenzierungen - zu betrachten sind. ${ }^{372}$ Die diesbezüglichen abstrakt-theoretischen Feststellungen sollen des Weiteren die Festlegung eines konkreten Arbeitsrahmens für die Vergleichung von realen Beweisführungssystemen entsprechend mitbestimmen.

\section{a) Die Beweisvorgänge im Vorfeld des Hauptverfahrens}

\section{aa) Vor der Klageerhebung}

Die der Zweiteilung der idealen Verfahrenstypen zugrunde liegende Idee, namentlich die Gegenüberstellung von „Parteienwettstreit“ und ,amtlicher Ermittlung“, bezieht sich nicht auf bestimmte Prozessstadien. Es wird jedoch aus den bisherigen Ausführungen deutlich, dass die spezielleren Ausprägungen der theoretisch entwickelten modernen Beweisverfahrensmodelle, die sich auf diese Basisidee stützen, grundsätzlich auf das Hauptverfahren konzentriert sind; ${ }^{373}$ insbesondere die gesamte strukturelle Organisation der Aufklärungsaktivitäten im Vorverfahren und die entsprechenden Rollenverteilungen werden dabei nicht genug berücksichtigt. Um von vornherein eine eventuelle Verschmelzung von heterogenen Faktoren und intern inkonsequenten Verfahrensarten bei der rechtsvergleichenden Evaluation und Einordnung der Prozesssysteme zu vermeiden, wäre es eventuell sinnvoller, wenn sich die Prozesstheorie eingehender mit der Konstruktion von selbstständigen Vergleichungsmodellen zum Vorverfahren befassen würde. ${ }^{374}$ Solche neuen Modelle könnten sich dann hauptsächlich auf die Bereitstellung eines kohärenten Analyse- und Vergleichsrahmens bezüglich der Ermittlungstätigkeiten der Polizei im Zeitraum vor der Erhebung der Strafklage (commencing a prosecution) orientieren - ungeachtet dessen, ob die Polizei bei der Vorbereitung

372 Vgl. auch die Differenzierung der Modellelemente zwischen essentialia und naturalia bei Damaška, U. Pa. L. Rev. 121 (1973), 506 (563-564). Dazu auch Crombag, in: van Koppen/Penrod (Hrsg.), Adversarial, S. 22-23. Zu „logical analysis“ und „functional inquiry“ als möglichen Methoden zur Determinierung der Kompatibilität von bestimmten Prozessgestaltungen mit den breiten (teilweise über den begrenzten beweisprozessualen Forschungsgegenstand hinausgehenden) Organisationsbildern eines ,party-controlled contest“ und einer „officially-controlled inquest“, Damaška, Zbornik PFZ 51 (2001), 477 (483).

373 Nach Herrmann, SACC 2 (1978), 3 (4-5): ,The special qualities of the two models are best observed at the trial stage because everywhere investigative proceedings tend to be mainly inquisitorial. Yet, some interesting peculiarities of the adversary and the inquisitorial model may also be found in the investigative stages. Furthermore, different less formal and less elaborate procedures exist in both the adversary and the inquisitorial system to handle the great majority of the cases." Vgl. noch Brants/Ringnalda, Issues, S. 21. Vgl. auch US Supreme Court McNeil v. Wisconsin, 501 U.S. 171, 181-182 Fn. 2.

374 Vgl. Damaška, U. Pa. L. Rev. 121 (1973), 506 (578). 
einer möglichen Klageerhebung eventuell die Anweisungen anderer Strafverfolgungs- und Justizbehörden (vor allem der Staatsanwaltschaft) befolgen muss.

Es lässt sich nicht leugnen, dass die ,polizeilichen“ Ermittlungen des mächtigen westlichen Staatsapparates systemübergreifend ohne ebenbürtiges institutionelles Gegengewicht, zwar normativ neutral, aber in der Praxis möglicherweise stark eingreifend und gezielt erfolgen. ${ }^{375}$ Immerhin existieren gegenwärtig überall zahlreiche und vielfältige Justizmechanismen und (verfassungs-, menschen- und internationalrechtliche) Garantien, deren gemeinsames Ziel der Schutz vor einer möglichen willkürlichen Machtausübung seitens der Strafverfolgungsorgane ist. „Private Gegenermittlungen“" seitens des Verdächtigen - außerhalb der Grenzen eines formal noch nicht eröffneten „Rechtsstreits“ und zu seiner Vorbereitung - sind logischerweise ebenfalls nirgendwo ausgeschlossen, auch wenn es in dieser ,polizeilichen“ Verfahrensphase aufgrund bestimmter Umstände (z.B. Inhaftierung und begrenzter Zugang zum Anwalt bzw. zu wesentlichen Informationen) allgemein zu großen Verteidigungsschwierigkeiten kommen kann. In dieser Hinsicht ist es zweifelhaft, ob es eindeutig genug bzw. überhaupt möglich ist, alle verschiedenen (prozessualen und außerprozessualen) Aktivitäten zur frühzeitigen Sicherung bzw. Aufdeckung des Beweismaterials als ,adversatorisch“ oder ,inquisitorisch“ im Sinne der schon diskutierten Kerndichotomie zu betrachten und zu typisieren.

Gleichwohl ist auch bemerkt worden: „In the traditional inquisitorial model, a theoretically neutral judicial officer conducts the criminal investigation [...] The accusatorial model, by contrast, starts with a police investigation that is openly non-neutral but rather, at least after it has focused on a suspect, is aimed at collecting evidence that will prove his guilt. ${ }^{6376}$ Es ist jedoch fraglich, ob vereinfachte Schematisierungen und Gesamtbetrachtungen, die versuchen, die Kernidee (parteiliche versus zentral-amtliche Prozesskontrolle) hinter den hier diskutierten Idealtypen wahllos auf sämtliche, funktional grundlegend unterschiedlichen Verfahrensphasen anzuwenden, den nötigen klaren, simplen und möglichst realistischen analytischen Hintergrund für weitere rechtsvergleichende Untersuchungen diverser Verfahrenstraditionen bereitstellen können. ${ }^{377}$ Eine selbstständige systematischere

375 Vgl. die vergleichenden Bemerkungen von Spencer, in: Delmas-Marty/Spencer (Hrsg.), European Criminal Procedures, S. 624-627. Vgl. auch Kühne, Strafprozessrecht, Rn. 350. Siehe auch Schünemann, GS für Vogler, S. 83-84.

376 Bradley, in: ders. (Hrsg.), Criminal Procedure, S. xvii. Siehe jedoch z.B. die gemischten Resultate beim älteren Versuch von Leigh, Int'l \& Comp. L.Q. 26 (1977), 516 (518-529), kontinentaleuropäische Modelle für die Vorermittlungen herauszuarbeiten.

377 Vgl. auch Damaška, Zbornik PFZ 51 (2001), 477 (503): „The final impression of the distinction between accusatorial and inquisitorial systems is that it is surrounded by a fog of imprecision. Too many vague concepts are being employed. In the face of this situation, any tendency toward constriction and parsimonious modeling seems like an improvement. One possible step in this direction would be renunciation of the desire to capture in this opposition the many divergences between continental and Anglo-American criminal procedure. $[\ldots]$ this desire is one of the main sources of definitional ambiguity. If these diver- 
(modellierte) Betrachtung der vorprozessualen Stadien, die auch das Ausarbeiten von Reformvorschlägen etwa in Bezug auf die Stärkung des partizipatorischen Elements schon im ,polizeilichen“ Vorverfahren für beweisprozessuale Zwecke ermöglichen könnte, ${ }^{378}$ ist daher auch für die Rechtsvergleichung vonnöten. Ein solches Unterfangen stellt jedoch keine Frage der vorliegenden Forschung dar.

bb) Nach der Klageerhebung

Dagegen sind die beweisstrukturellen Besonderheiten nach Erhebung der Klage grundsätzlich im Rahmen der hier diskutierten Modelle auch für die Zwecke der zunächst abstrakten Vergleichungen besser erfassbar, wobei mit Klageerhebung an dieser Stelle möglichst systemneutral die gegen eine bestimmte Person von der Anklagebehörde konkret vorgebrachte strafrechtliche Beschuldigung vor Gericht gemeint ist. ${ }^{379}$ Mehr oder weniger ab diesem Punkt setzt nämlich die rein justizielle Erkenntnisphase ein: Die tatsächlichen Umstände des Anklageinhalts, die betreffenden Personen und manchmal auch die zuständige Gerichtsbehörde sind größtenteils schon bestimmt worden. Die zentralen Verfahrensbeteiligten müssen sich daher nun auf ein bevorstehendes gerichtliches Verfahren vorbereiten, auch wenn in der Zwischenzeit überall abschließende amtliche Ermittlungen und richterliche Zwischenprüfungen und Neuevaluationen der Stichhaltigkeit bzw. Genauigkeit des Anklagevorbringens stattfinden können. Da nunmehr konkrete „Rechtsbehauptungen“380 einander gegenüberstehen, besitzt entsprechend auch die begreifliche Schaffung einer soliden Tatsachenbasis bzw. die Förderung überzeugender Beweisthesen für alle Verfahrensseiten großen Stellenwert.

Modellkontextuell von wesentlicher Bedeutung sind dabei vor allem die Möglichkeiten der Parteien einerseits und des Gerichts andererseits zur Vorbereitung der Beweisführung in der Hauptverhandlung (z.B. durch die Ladung von Zeugen) und insbesondere die Möglichkeiten zur systematischen Kenntnisnahme und Verarbeitung des während der Vorverfahrensermittlungen allerseits gesammelten bzw.

\footnotetext{
gences are to be typologically expressed, more than two models will have to be employed. Unburdened by open-ended comparative tasks, the inquisitorial and accusatorial model could then refer to relatively simple matters, such as the alternative of entrusting the principal responsibility for procedural action either to the court or to the parties. In an even narrower sense, the two models could denote two alternative methods of allocating control over factfinding [...]. Conceived in simple, well-defined ways, the accusatorial and the inquisitorial models could be used in empirical research, $[\ldots]$, or in quantitative analyses of alternatively structured procedural systems $[\ldots]$. The abandonment of the larger comparative ambition appears advisable only in procedural theory, however. Ordinary legal discourse could continue to employ the terms accusatorial and inquisitorial process as a shorthand reference to, or as a metaphor for, the contrasts between continental and AngloAmerican criminal justice."

378 Vgl. etwa Haas, in: Schroeder/Kudratov (Hrsg.), Vorverfahren, S. 27.

379 Vgl. auch Deu, in: Eser/Rabenstein (Hrsg.), Strafjustiz, S. 316.

380 Haas, in: Schroeder/Kudratov (Hrsg.), Vorverfahren, S. 27.
} 
vorgebrachten Beweismaterials, die weiter unten gesondert zu untersuchen sind. ${ }^{381}$ Aber auch umfassende richterliche bzw. zentral-amtliche Voruntersuchungen, ${ }^{382}$ die eventuell sogar erst nach der ersten Anklagephase und vor dem Beginn der gerichtlichen Verhandlung stattfinden, können als (extreme/althergebrachte) Ausprägungen des ,inquisitorischen“ Modells betrachtet werden, insbesondere dann, wenn die anschließende Beweisaufnahme im Hauptverfahren nur noch als eine Fortsetzung der amtlichen Ermittlung durch den Untersuchungsrichter zu betrachten ist. Darüber hinaus ist die Hauptverhandlung die natürliche „Arena“ für den „adversatorischen“ Wettstreit und die de novo-Auseinandersetzung mit dem Beweismaterial, sodass unmittelbare und materielle Beweisstreitigkeiten in den vorgerichtlichen Stadien wenig Sinn ergeben; somit entsprechen begrenzte vorverfahrensrechtliche Auseinandersetzungen mit dem anfänglichen Anklagevorbringen zur Rechtfertigung der Durchführung eines späteren Hauptverfahrens ebenso wenig dem klassischen Modellinhalt.

Keinesfalls einen Vergleichungsgegenstand im Kontext der modernen Gegenüberstellung von ,adversatorischem“ und ,inquisitorischem“ Beweisverfahrensmodell stellt die jeweilige Art und Weise der ursprünglichen Klageerhebung per se dar. Diese kann/muss nämlich allerwärts durch nicht richterliche und (noch) nicht parteiisch handelnde Staatsorgane erfolgen bzw. nachgeprüft werden. ${ }^{383}$ Außerdem ist bei der Deliktsverfolgung die Auswahl zwischen Legalitäts- und Opportunitätsprinzip nicht unmittelbar mit bestimmten Verfahrenstraditionen und insbesondere nicht mit einer Vorliebe für amtliche Ermittlungen oder Parteienwettstreit zu korrelieren. Es handelt sich hierbei eher um systemneutrale rechtspolitische Entscheidungen zur gesellschaftlich wirksamen Kriminalitätsbekämpfung ${ }^{384}$ als um Fragen der (Beweis-)Verfahrenssteuerung. ${ }^{385}$ Letztlich setzt die konkrete formale Beschuldigung im Vorverfahren logischerweise keine vollständige Beweisführung zur Nachweisung der Schuld voraus, sondern lediglich eine ausreichende Beweissammlung zur Begründung des für die Verfahrensfortsetzung jeweils nötigen Tatverdachts, und steht daher nicht in Verbindung mit der Ausgestaltung verschiede-

381 Siehe auch Herrmann, SACC 2 (1978), 3 (5-6).

382 Vgl. z.B. zur französischen instruction préparatoire Dervieux, in: Delmas-Marty/ Spencer (Hrsg.), European Criminal Procedures, S. 229-230, 236-237, 239-243; Kühne, Strafprozessrecht, Rn. 1209-1211. Vgl. auch im angloamerikanischen Kontext etwa die verschiedenen Ansichten über den ,inquisitorischen“" Charakter der schottischen intermediate diets (d.h. Zwischenverfahren für die Klärung u.a. von bestimmten Beweisthemen, insb. von agreements of evidence) bei P. Duff, in: A. Duff u.a. (Hrsg.), Trial on Trial 1, S. 34-39, 48-50.

383 Siehe auch unter Teil 1, II.C.1.b) Fn. 229.

384 Vgl. etwa im Kontext der deutschen Diskussionen Erb, Legalität, S. 21-23, 149180.

385 Charakteristisch ist hierbei die Geltung des Opportunitätsprinzips in Frankreich, dazu u.a. Dervieux, in: Delmas-Marty/Spencer (Hrsg.), European Criminal Procedures, S. 232; Vogler, in: Vogler/Huber (Hrsg.), Criminal Procedure, S. 202-203. Anderer Ansicht jedoch Langer, Harv. Int'1 L. J. 45 (2004), 1 (21-22). 
ner umfassender Beweisstrukturen. Ähnliches gilt schließlich auch für gerichtliche Zwischenverfahren und preliminary hearings zur Kontrolle der Zulässigkeit der Strafverfolgung und zur Eröffnung der Hauptverhandlung, für Haftprüfungs- und Sicherheitsleistungsverhandlungen, und für weitere prozesstechnische Vorverhandlungen und pre-trial motions. Diese können in allen Systemtypen (und in zahllosen Einzelvarianten) stattfinden und sind unter dem ,kompakten“ Vergleichungsdach der hier berücksichtigten Beweisführungsmodelle nicht eingehender zu untersuchen.

\section{b) Vorgerichtliche Kenntnisnahme der Beweise}

aa) Richterliche Aktenkenntnis

Die Sammlung bzw. Sicherung von Beweisen im Vorverfahren ist für die Vorbereitung und Durchführung des anschließenden maßgebenden Sachaufklärungsprozesses vor Gericht in sämtlichen Verfahrenssystemen von zentraler Bedeutung. Die vorhandenen Beweise können faktisch auf verschiedenen Wegen ganz oder fragmentarisch in die Hauptverhandlung eingeführt werden, wobei ihre Vorkenntnis seitens der Verfahrensbeteiligten die eigentliche Durchführung des streitigen Beweisverfahrens beeinflussen kann.

Im ,inquisitorischen“ Prozesstypus kann nun, wie bereits angedeutet, ${ }^{386}$ die Einführung des im Vorverfahren gesammelten Beweismaterials in die Hauptverhandlung durch die amtliche Zusammenstellung und Übermittlung eines umfassenden Dossiers geschehen. Zum Teil auf der Grundlage der in diesem Dossier zusammengestellten Informationen finden dann die maßgebenden Beweiserhebungen statt. Ohne Kenntnis der Vorverfahrensakte und daher der verschiedenen Aspekte des Straffalles kann der objektive, das Hauptverfahren allein dominierende Richter seine Aufgabe der allseitigen Ermittlung des Sachverhalts nicht erfüllen. ${ }^{387}$ Die Aktenkenntnis des verfahrensleitenden Richters ist als ein wesentliches Element des ,inquisitorischen“ Modells zu betrachten.

Dagegen muss der Vorsitzende Richter des „adversatorischen“ Modells kein Wissen von den Ermittlungen des Vorverfahrens haben. Eine grundlegende Idee hinter diesem Modell ist nämlich, dass der Sachverhalt allein durch die Parteien dem Gericht präsentiert wird. Die Aufgabe des verfahrensleitenden Richters besteht hauptsächlich darin, das Einhalten der (Fairness-)Regeln für eine paritätische Vorstellung der gegensätzlichen „Fälle“ (cases) sicherzustellen und nicht darin, selbst Beweiserhebungen zu unternehmen. Die umfassende Vorkenntnis der Beweislage kann für das bloße Einhalten der Prozessregeln nicht viel leisten; vielmehr kann sie

\footnotetext{
386 Siehe Teil 1, II.C.2.e)ee) mit weiteren Verweisen.

387 Siehe auch Damaška, U. Pa. L. Rev. 121 (1973), 506 (517 Fn. 16, 544).
} 
die verlangte Passivität und Neutralität bei der Erfüllung der quasi schiedsrichterlichen Aufgaben eventuell beeinträchtigen. ${ }^{388}$

$\mathrm{Zu}$ betonen ist hierbei allgemein, dass es im vorliegenden Untersuchungsrahmen keine gesonderte Rolle spielt, ob der verfahrensleitende Richter an der Entscheidung über die Schuld selbst teilnimmt oder nicht. Bei den betreffenden Beweisverfahrensmodellen steht nämlich nicht der potenzielle Einfluss einer Vorkenntnis der Beweise auf das letztendliche Treffen der Entscheidung durch den/die Richter (mit/ohne Laien) oder durch eine jury im Vordergrund, sondern ihr Einfluss auf die Art und Weise der Beweisführung im gerichtlichen Hauptverfahren, das zur Ermittlung der Tatsachenlage stattfindet. Die Basisidee für die Dichotomisierung der idealen Verfahrenstypen, namentlich die Gegenüberstellung von amtlicher Ermittlung und Parteienwettstreit, schreibt logischerweise nicht zwingend vor, ob die Entscheidung über die Schuld von einem Justizorgan mit Kenntnis des Vorverfahrensmaterials oder ob sie dagegen von einem auf dem tabula rasa-Prinzip basierenden Gremium getroffen werden soll. Dass die Kenntnis der Ergebnisse der Vorverfahrensermittlungen seitens eines oder mehrerer Mitglieder des urteilenden Gerichts seine letztendliche Entscheidung beeinflussen kann, ist freilich nicht zu bezweifeln. ${ }^{389}$ Dies bleibt jedoch eine (hier nicht tiefer gehend analysierte) Angelegenheit jedes einzelnen Rechtssystems, die im Grunde unabhängig von der Zugehörigkeit zu bestimmten Verfahrenstraditionen bzw. von der Annäherung an bestimmte Beweisverfahrensmodelle beurteilt werden kann. ${ }^{390}$

\section{bb) Die Beweisoffenlegung inter partes}

Komplizierter wird es bei der Problematik der Akteneinsichtsrechte bzw. der vorgerichtlichen Offenlegung (disclosure) von Beweisen durch die jeweilige Gegenpartei. Da es im ,inquisitorischen“ Modell theoretisch keine Parteien sensu stricto gibt und alle Behörden während der amtlichen Vor- und Hauptermittlungen für die Sicherstellung der Interessen sowohl der Gesellschaft und als auch des Beschuldigten sorgen, steht die Frage der Beweisoffenlegung durch die Staatsanwaltschaft nicht im Zentrum der beweisstrukturellen Erwägungen. Insbesondere bedeutet dies, dass dieses Modell nicht zwingend bestimmt, ob der Angeklagte eine Möglichkeit zur Akteneinsicht haben muss. Somit ist aber eine solche Möglichkeit gleichzeitig idealtypisch keinesfalls ausgeschlossen. Die neutral ermittelnden staatlichen Behörden stellen keinen Prozessgegner des Angeklagten dar und müssen

\footnotetext{
388 Vgl. etwa Perron, FS für Stürner, S. 877-878.

389 Vgl. u.a. Damaška, U. Pa. L. Rev. 121 (1973), 506 (544-545).

390 Vgl. z.B. das Problem der Aktenkenntnis der Schöffen in Deutschland bei Roxin/ Schünemann, Strafverfahrensrecht, § 6 Rn. 16-17 und § 46 Rn. 6. Siehe dazu auch ausführlich (auch in empirischer Hinsicht) Rennig, Entscheidungsfindung, insb. S. 149-170, $177-190,508-510,586$.
} 
daher nichts vor ihm geheim halten, zumindest soweit sich dadurch keine wirklichen Belastungen für den objektiven Verlauf der amtlichen Tatsachenfeststellungen ergeben. ${ }^{391}$ Aus denselben Gründen ist es für die staatlichen Ermittler nicht notwendig, vom Angeklagten umfassende vorgerichtliche Offenlegungen hinsichtlich eventueller Verteidigungsstrategien und der seinerseits gesammelten Beweise zu verlangen. So steht der moderne ,inquisitorische“ Verfahrenstypus per se einer Offenlegung der amtlich zusammengestellten Vorverfahrensakte grundsätzlich neutral gegenüber; gleichzeitig bezieht er sich auf vorgerichtlicher Ebene nicht unmittelbar auf die Vorbereitung und die Offenlegung des konkreten Inhalts der vorzubringenden Beweisthesen der Verteidigung.

Der immanente „kampffreudige“ Antagonismus der Parteien im ,adversatorischen" Modell begünstigt dagegen die Vorbereitung von umfassenden und selbstständigen „Fällen“ seitens der Anklage und der Verteidigung, die anschließend vor dem Gericht in gegensätzlicher Weise zu präsentieren sind, schon im Vorverfahren. Die Geheimhaltung von zentralen „Strategien“ und Beweisen bis zum letzten möglichen Moment ist dann logischerweise von den Parteien zu bevorzugen, soweit es darum geht, den jeweiligen Gegner in der Gerichtsarena zu überraschen. Zumindest die extremsten Ausprägungen eines prozessualen Wettstreits zwischen den einander gegenüberstehenden Parteien sind also mit dem Fehlen einer gegenseitigen Verpflichtung zur vollständigen disclosure vereinbar. Ob damit auch die dialektische Wahrheitserforschung besser bedient wird oder ob dagegen eine komplette Vorkenntnis der vorhandenen (Gegen-)Beweise allseitig zur „effektiveren“ Vorbereitung der trial und dadurch zur umfassenden Feststellung des wahren Sachverhaltes führen kann, ${ }^{392}$ ist eine pragmatische Frage, die in absoluter Weise nicht einfach $\mathrm{zu}$ beantworten ist. ${ }^{393}$ Auch eine vorgerichtliche full disclosure kann jedenfalls die Vermeidung von Verschleierungstaktiken nicht durchweg garantieren, sondern gewisse Verdunkelungsstrategien faktisch eventuell sogar befördern. ${ }^{394}$

Freilich stellt gegenwärtig die Einsicht in das Vorverfahrensmaterial eine modellübergreifende Notwendigkeit dar, soweit dadurch eine menschenrechtlich gebotene effektive Verteidigung verankert werden kann und faktische Ungleichheiten

391 Vgl. auch Damaška, U. Pa. L. Rev. 121 (1973), 506 (533-534); Damaška, ZStW 90 (1978), 829 (833).

392 So Jackson/Doran, Judge, S. 61-62. Siehe auch Brennan, Wash. U. L. Q. 68 (1990), 1 (2-3); Sprack, in: Breur u.a. (Hrsg.), New Trends, S. 581-582.

393 Vgl. auch LaFave/Israel/King/Kerr, Criminal Procedure, S. 44: „Disagreements also exist as to whether certain obligations imposed upon both sides (e.g., providing pretrial discovery to the opponent) detract from or add to the effectiveness of the adversary system in seeking the truth."

394 Vgl. Fedorova, Principle, S. 116: „Other dangers of liberal disclosure in a criminal case have been considered, including the risk of perjury, suppression of evidence, bribery or intimidating witnesses and general interference with the administration of justice." Vgl. ferner Sprack, in: Breur u.a. (Hrsg.), New Trends, S. 583-585. 
im Verfahren zu vermeiden sind. ${ }^{395}$ Die Behörden und Richter wirken nämlich, nicht zuletzt wegen ihrer eigenen Kenntnis der Verfahrensakte, im Rahmen einer amtlichen Ermittlung nicht immer unbefangen, sodass die Sicherstellung von prozessualen Gegengewichten im Hinblick auf eine angemessene Vorbereitung der Verteidigung als nötig erscheint. Darüber hinaus kann sich der (prozessual als unschuldig angesehene) Angeklagte auch im Rahmen eines reinen Beweiskampfes meistens wegen begrenzter Verteidigungsmittel in einer benachteiligten Position befinden angesichts der mächtigen technischen Ausstattung der staatlichen Behörden/Angestellten und gegenüber ihrem mit allen möglichen Ermittlungs- und Zwangsmitteln zusammengestellten Anklagevorbringen. ${ }^{396}$ Die möglichst umfassende und rechtzeitige Kenntnisnahme von entlastenden und belastenden Beweisen kann eventuell solche Verteidigungsschwierigkeiten zum Teil ausbalancieren.

Ein „Handicap“ für die de facto meist stark eingreifenden Beweisaktivitäten der Strafverfolgungsmechanismen stellt sicherlich die im Westen systemübergreifend existierende Freiheit des Angeklagten dar, belastendes Material gegen sich selbst nicht offenzulegen. Diese Freiheit geht aus der rechtsstaatlichen Garantie der Unschuldsvermutung, der menschenwürdigen Behandlung des Beschuldigten als Subjekt des Verfahrens und dem sich daraus ergebenden nemo tenetur-Prinzip hervor. Fragen zu derartigen grundlegenden, modellübergreifend geltenden Menschenrechten und fair trial-Garantien werden in dieser Arbeit jedoch nicht tiefer gehend berücksichtigt, soweit sie nicht unmittelbar forensische Prozessstrukturen betreffen. Sie deuten dennoch auf die Vielseitigkeit und Komplexität der Problematik der Beweisoffenlegung im Strafverfahren hin, was auch die Planung und Anfertigung von abstrakt-theoretischen und konkret-technischen rechtsvergleichenden Arbeiten in jenem Bereich enorm erschweren kann.

Für die Zwecke der vorliegenden Abhandlung kann nun schlüssig bemerkt werden, dass die Möglichkeiten zur disclosure und Akteneinsicht kein wirkliches modelltrennendes Hauptkriterium darstellen. Es lässt sich jedoch festhalten, dass das Vorbringen ,eigener“ Beweisthesen und Strategien in Verbindung mit der Vermeidung von umfassenden vorgerichtlichen gegenseitigen Offenlegungen des Beweismaterials strukturell eher zu der reinen ,,adversatorischen“ Beweiskultur passt. ${ }^{397}$ Jedenfalls scheinen die meisten heutigen westlichen Rechtssysteme, unter Berücksichtigung der faktischen prozessualen Ungleichheiten zwischen den zentralen Verfahrensbeteiligten, zumindest in einem gewissen Maße die Möglichkeit der

395 Vgl. auch unter Teil 1, II.C.2.e)dd).

396 Vgl. Fedorova, Principle, S. 115; McEwan, Evidence, S. 19.

397 Vgl. McEwan, Evidence, S. 17; auch (im zivilprozessualen Kontext) Sward, Ind. L.J. 64 (1989), 301 (328-329). Damaška, U. Pa. L. Rev. 121 (1973), 506 (583), hat bemerkt: „,...] lack of discovery is not of the essence of adversary proceedings. It can hardly be gainsaid, however, that a 'battle' model is more hospitable to the idea of 'procedural ambush' and surprise, while the 'inquiry' model will have nothing but scorn for this 'perverted' way of searching for the truth." Siehe auch Jackson, MLR 68 (2005), 737 (743). 
Verteidigung zur frühestmöglichen Akteneinsicht bzw. Beweiskenntnisnahme zu garantieren. ${ }^{398}$ Es ist freilich interessant, anhand der Gegenüberstellung konkreter Rechtsordnungen festzustellen, wie weit sich solche Einsichtsrechte erstrecken können. Dadurch ließe sich beispielsweise sinnvoll untersuchen, welches die festgelegten Grenzen bei der Vorbereitung eines strafprozessualen Beweiskampfes innerhalb von Rechtsordnungen des common law sind; ${ }^{399}$ oder auch wie offen civil law-Rechtsordnungen für gut ,bewaffnete“ Verteidigungen und für direkte beweisbezogene Auseinandersetzungen bzw. für die Zunahme von partizipatorischen Elementen im Rahmen einer amtlichen Strafermittlung sind.

\section{c) Öffentlichkeit und Mündlichkeit im idealtypischen Beweisverfahren}

Die Entwicklungen innerhalb der kontinentaleuropäischen und der angloamerikanischen Rechtstradition hinsichtlich des Öffentlichkeits- und des Mündlichkeitsprinzips wurden zum Teil in den vorherigen geschichtlichen Kapiteln dieser Arbeit angesprochen. ${ }^{400}$ Unabhängig davon geht es an dieser Stelle nun um die Beantwortung der Frage, ob ein notwendiger Zusammenhang zwischen der Kernidee hinter der Dichotomisierung der modernen Beweisverfahrensarten und den prozessualen Gegenpolen „Öffentlichkeit / Nichtöffentlichkeit“ und „Mündlichkeit / Schriftlichkeit" existiert.

In diesem logisch-analytischen Rahmen gelangt man relativ leicht $\mathrm{zu}$ dem Ergebnis, dass sowohl der ,adversatorische“ als auch der ,inquisitorische“ Idealtypus unabhängig von der weiteren Auswahl zwischen einem öffentlichen, nichtöffentlichen, mündlichen, schriftlichen oder auch gemischten Strafprozess eingesetzt werden kann. Keines dieser Verfahrenselemente stellt somit einen wesentlichen Modellinhalt dar; sie sind vielmehr modellneutral: Diese oder jene Prozessform bzw. ihre Mischung kann, etwa nach den jeweils herrschenden allgemeinen rechtspoliti-

398 Siehe z.B. zur amerikanischen Rechtslage Bradley, in: ders. (Hrsg.), Criminal Procedure, S. 541; zum englischen Recht Feldman, in: Bradley (Hrsg.), Criminal Procedure, S. 177-180; zum französischen Recht Frase, in: Bradley (Hrsg.), Criminal Procedure, S. 225226; zum niederländischen Recht Groenhuijsen/Simmelink, in: Vogler/Huber (Hrsg.), Criminal Procedure, S. 408-409; zum deutschen Recht Huber, in: Vogler/Huber (Hrsg.), Criminal Procedure, S. 295, 304; zum kanadischen Recht Roach, in: Bradley (Hrsg.), Criminal Procedure, S. 82-83; zum italienischen Recht Van Cleave, in: Bradley (Hrsg.), Criminal Procedure, S. 342 .

399 Vgl. z.B. im Voraus zu möglichen englischen Tendenzen Roberts/Zuckerman, Criminal Evidence, S. 61: ,[...] the form of adversarialism practised in English criminal litigation involves a significant, and progressively growing, element of 'cards-on-the-table' pretrial disclosure in contrast to the 'cards-to-chest' style of legal contest often associated with the common law adversarial model in which the parties are permitted, and even expected, to 'keep their powder dry' for the main-event trial. [...] Steeply asymmetric obligations of pre-trial disclosure therefore continue to function as important procedural correctives to inequality of arms, notwithstanding a more generalized drift towards cards-on-the-table litigation affecting the defence as well as the prosecution in English criminal proceedings."

400 Siehe insb. unter Teil 1, I.B.2.a), 3.b), 4. 
schen Standards für die Justizverwaltung, in sämtlichen Rechtsordnungen realisiert werden, ungeachtet dessen ob dieselben Rechtsordnungen sich in beweisstruktureller Hinsicht letztendlich eher an der Organisationsidee des Parteienwettstreits (,adversatorisches“ Modell) oder eher an der Idee der amtlichen Ermittlung (,,inquisitorisches“" Modell) orientieren. ${ }^{401}$

\section{d) Laiengerichtsbarkeit und Geschworenengerichte}

aa) Laienrichter und Berufsrichter

Grundsätzlich sind folgende Arten der strafrechtlichen Laienbeteiligung in westlichen (erstinstanzlichen) Gerichtsverfahren üblich: Einerseits nehmen die Laien die eigentliche Urteilsfindung im Rahmen einer reinen jury trial in die Hand; sie wirken als selbstständiges, vom verfahrensleitenden (und primär für Rechtsfragen zuständigen) Richter getrenntes Gremium. Andererseits können Laien und professionelle Richter, als einheitliches Gremium und meistens unter der Verfahrensleitung eines Vorsitzenden Berufsrichters, an allen wichtigen (rechtlichen und tatsächlichen) Aspekten der Schuldfeststellung mitwirken. ${ }^{402}$

Wie vor allem das Paradigma der englischen Justizorganisation zeigt, können jedoch ebenso Laienrichter (z.B. lay magistrates) allein die Hauptverhandlung führen und müssen anschließend selbst alle Rechts- und Tatsachenentscheidungen treffen. Abgesehen von der mangelnden juristischen Ausbildung der Laien (die immerhin im Rahmen ihrer Aufgabenerfüllung etwa von juristisch ausgebildeten Gerichtsangestellten unterstützt werden können), müssen sich solche Laiengerichtsbarkeiten in prozessstruktureller Hinsicht nicht unbedingt substantiell von den ausschließlich professionellen Gerichtsbarkeiten unterscheiden. Die letztgenannten, nur mit Berufsrichtern besetzten Gerichte sind übrigens von wachsender Bedeutung nicht nur für die Strafjustizpraxis auf dem Kontinent, sondern inzwischen auch in der angloamerikanischen Rechtswelt. ${ }^{403}$

401 Vgl. auch Roberts/Zuckerman, Criminal Evidence, S. 48-50; Weigend, ZStW 100 (1988), 733 (753). Damaška, Zbornik PFZ 51 (2001), 477 (483-484), hat dies eingehend dargelegt: „Another source of uncertainty about the details of the accusatorial and inquisitorial process is the vacillation of model-builders between analytical and other impulses. This is the reason why, in their statements of the two models, one often finds features that are unrelated - or, at best, remotely related - to the opposition between party contest and official inquest. Thus, for example, descriptions of the inquisitorial model often include reliance on career judiciary, secrecy, and written evidence, and description of the accusatorial model's reliance on jurors, publicity and oral testimony. [...] But observe that a forensic contest can unfold in secrecy, before career judges, with disputation centering on documentary evidence, while an official inquiry can be conducted in public, by lay persons who rely on oral testimony."

402 Siehe bereits unter Teil 1, I.B.2.a), 3.b)bb) m.w.N.

403 Das beste Beispiel hierfür bieten die englischen magistrates' courts, die regelmäßig entweder aus einem ausgebildeten Juristen als Berufsrichter (District Judge) oder aus ei- 
Infolge der historischen Gegebenheiten bzw. der modernen rechtspolitischen Besonderheiten einzelner Rechtsordnungen kann es somit (wie z.B. im englischen Fall) zu diversen prozessualen Einsätzen von Laiengerichtsbarkeiten und professionellen Richtern bzw. zu entsprechenden Mischungen kommen. Dessen ungeachtet ist auch hier die modellbezogene Auswahl zwischen Beweisverfahrensarten nicht mit der Auswahl zwischen Berufs- und Laienrichtern zur Durchführung des Strafverfahrens und/oder zur Urteilsfindung in Verbindung zu bringen. Denn logischerweise kann eine offizielle Strafermittlung sowohl von Laienrichtern (d.h. Laien, die zumindest für den konkreten Fall als amtliche Richter tätig werden) als auch von Berufsrichtern durchgeführt werden; und ein forensischer Wettstreit kann ebenso vor Laienrichtern wie auch vor Berufsrichtern stattfinden. ${ }^{404}$ Die persönlichen und beruflichen Eigenschaften des Richters (insbesondere: juristisch nicht ausgebildeter Laie versus vollzeitiger Jurist) stellen daher kein eigentliches Element der Beweisführungsmodelle dar.

\section{bb) „Jury trial“" und ,bench trial““}

Von größerem Interesse für die betreffenden Modellbetrachtungen kann die Gegenüberstellung von bench trial und reiner jury trial sein: Diese basiert auf den unterschiedlichen Funktionen einerseits des Richters als alleiniger entscheidender Justizfigur (bench trial) und andererseits des Richters als über die Schuldfrage nicht selbst entscheidendem Vorsitzenden einer getrennten Geschworenenbank (jury trial). Vorausschickend sei bemerkt, dass die nachfolgenden Erwägungen nicht nur das klassische, reine Geschworenenverfahren (jury trial) betreffen müssen; sie könnten eventuell auch ein gerichtliches Verfahren mit einem nicht selbst entscheidenden Vorsitzenden Richter und einem getrennt entscheidenden Berufsrichter bzw. einem getrennten Gremium, das aus Berufsrichtern (oder auch aus Berufs- und Laienrichtern) besteht und über die Schuldfrage entscheidet, entsprechend betreffen. Solche Gerichtsbarkeiten sind jedoch rechtstraditionell kaum bekannt. Deswegen gilt als gedanklicher Ausgangspunkt hier grundsätzlich die Teilung der Verantwortlichkeiten innerhalb der reinen jury-Gerichte angloamerikanischer Prägung als Gegensatz zu den im ganzen Gerichtsverfahren einheitlich wirkenden Spruchkörpern (bench); die Letzteren bestehen aus einem oder mehreren Berufs- und/oder Laienrichter(n) und sind heute hauptsächlich in der civil law-, aber auch in der common law-Welt anzutreffen.

nem bench mit zwei oder drei lay justices bestehen, dazu Darbyshire, Legal System, S. 183-185, 501-525. Siehe auch Ashworth/Redmayne, Criminal Process, S. 337-339; Jackson/Doran, MLR 60 (1997), 759 (762). Vgl. auch Nijboer, in: Doran/Jackson (Hrsg.), Judicial Role, S. 23-24.

404 Siehe Damaška, Zbornik PFZ 51 (2001), 477 (484). Siehe auch Bohlander, in: Schroeder/Kudratov (Hrsg.), Hauptverhandlung, S. 173; Weigend, ZStW 100 (1988), 733 (753). 
Zentral gestellt wird hierbei etwa die Frage, wie die Art und Weise der gerichtlichen Vorgänge zur Aufklärung des angeklagten Sachverhalts einerseits von der Konzentration und andererseits von der Aufteilung der verfahrensleitenden und urteilsfindenden Funktionen beeinflusst werden kann. Dabei ist es wichtig zu sehen, inwieweit eine bench trial (ohne getrenntes Geschworenengremium zur letztendlichen Entscheidung der Tat- und Schuldfragen) mit einem „adversatorischen“ parteienzentrierten Beweisführungsmodell vereinbar ist. So stellt sich vor allem die Frage, ob ein verfahrensleitender bench-Richter, der am Verhandlungsende selbst (allein oder gemeinsam mit anderen richterlichen Personen) auch über die Schuldfrage entscheidet, notwendigerweise die für das ,adversatorische“ Modell typische passive Beweisführungsrolle aufgeben und aktiver in die Beweiserhebungen eingreifen muss.

Dass sich heute bench (non-jury) trials in der angloamerikanischen Rechtswelt durchgesetzt haben - ohne dass damit allerdings ausdrücklich die Rhetorik zur Wichtigkeit der klassischen adversary procedure in den common law-Systemen überwunden wurde -, zeigt jedenfalls, dass es zumindest prinzipiell nicht erwünscht ist, traditionelle Elemente des Parteienwettstreits (wie die eher passive Rolle des Vorsitzenden Richters und die Anwendung von strikten rules of evidence ${ }^{405}$ aufzugeben. Von noch größerer Bedeutung für die Zwecke der vorliegenden Untersuchung ist die folgende logische Schlussfolgerung: nämlich dass die Beherrschung der Beweisführung durch die nicht richterlichen Parteien nicht nur innerhalb einer reinen jury trial (mit einem passiven Vorsitzenden und den urteilsfindenden Geschworenen), sondern auch vor einem (theoretisch passiven) verfahrensleitenden und anschließend selbst urteilsfindenden Richter funktionieren kann.

Die Entscheidung für eine parteienzentrierte Hauptverhandlung wird nicht zwingend durch die Trennung der Befugnisse zwischen Richter und Geschworenen bestimmt, und auch umgekehrt diktiert eine Beweisführung durch die Parteien nicht unbedingt die Annahme der jury trial als ausschließlicher Verfahrensform. Darüber hinaus ist es hinsichtlich der „Konnektivität“ zwischen einer jury trial und einem beweisführenden Richter ebenso als logisch betrachtet nicht unmöglich zu akzeptieren, dass etwa der Vorsitzende autoritativ den ganzen Sachverhalt ermittelt, auch wenn am Verhandlungsende eine Geschworenenbank ohne seine Mitwirkung über die Schuldfrage entscheiden muss. Dementsprechend ist zu bemerken, dass die Gegenüberstellung von jury trial und bench trial kein essenzielles Element der Dichotomie zwischen ,adversatorischem“ und ,inquisitorischem“ Beweisverfahrenstypus darstellt. ${ }^{406}$

405 Vgl. Jackson/Doran, Judge, S. 64, 72, 76 m.w.N.; Jackson/Doran, Is.L.R. 31 (1997), 645 (647-648, 664-665, 687-689).

406 Siehe auch Brants/Ringnalda, Issues, S. 20; Damaška, Evidence, S. 74-75; Hörnle, ZStW 117 (2005), 801 (814-815); Jackson/Doran, Judge, S. 60; Roberts/Zuckerman, Criminal Evidence, S. 48-51. Auf die gegensätzliche Richtung deuten etwa hin: Jörg/ 
Ungeachtet dieser theoretischen Festlegungen bleibt gleichwohl die Frage offen, ob ein bench-Richter mit urteilsfindenden Befugnissen im Rahmen eines formalnormativ als Parteienwettstreit konzipierten Verfahrens zur Förderung der Wahrheitssuche de facto (informell) eine aktivere Untersuchungsrolle einnimmt; ${ }^{407}$ oder ob er wenigstens ein dahingehendes kognitiv-psychologisches ${ }^{408}$ Bedürfnis hat, das sein förmlich passives Verhalten zumindest indirekt „beeinträchtigen“ könnte. Solche Potenzialitäten sind empirisch schwierig zu überprüfen, insofern als dafür unter anderem die vorsichtige vergleichende Beobachtung einer großen Anzahl von eigentlichen bench trials und jury trials vorausgesetzt wird, die formell nach einheitlichen Beweisregeln und -strukturen funktionieren.

Derartige faktische Beobachtungen könnten eventuell innerhalb eines einzelnen Rechtssystems möglich sein, das gleichzeitig beide Gerichtsbarkeiten kennt und im Prinzip einheitlich übermäßiges Gewicht auf die Beweisaktivität der Parteien legt, was vor allem in verschiedenen modernen common law-Systemen zutrifft. Ähnliche empirische Untersuchungen, die auf ein möglicherweise sich de facto differenzierendes Verhalten eines formal-normativ aktiven „Ermittlungsrichters“ zum einen innerhalb einer bench trial und zum anderen innerhalb einer jury trial hindeuten könnten, gestalten sich dagegen in der Realität problematisch: In der westlichen (insbesondere kontinentaleuropäischen) Rechtswelt sind nämlich innerhalb eines einzelnen, traditionell richterzentrierten Rechtssystems zurzeit kaum reine jury trials neben den vorherrschenden bench trials zu finden.

Immerhin können sich solche Erwägungen insgesamt auch im Rahmen konkreter Rechtsvergleichungen als nützlich erweisen, soweit sie dabei helfen können, gedanklich die jeweilige Position der einzelnen Rechtssysteme innerhalb des Spektrums zwischen den zwei Extremmodellen bzw. ihre mögliche Ausrichtung auf Prozessmischungen genauer (und möglichst nahe an der Realität) zu identifizieren. ${ }^{409}$ Allerdings muss bei der Vergleichung bestimmter Rechtsordnungen in jenem Analyserahmen zuerst nachgeprüft werden, ob sich innerhalb jeder berücksichtigten

Field/Brants, in: Fennell u.a. (Hrsg.), Criminal Justice, S. 42, 51-52; Langer, Harv. Int'1 L. J. 45 (2004), 1 (17-18).

407 Siehe etwa anhand einer umfassenden Untersuchung der „Diplock Trials“ in Nordirland Jackson/Doran, Judge, insb. S. 7-14, 71-77, 129-163, 179-210, 288-304. Auch Jackson, in: McConville/Wilson (Hrsg.), Handbook, S. 348-349.

408 Vgl. Damaška, Evidence, S. 96; auch Schünemann, FS für Fezer, S. 562-564, der in ,informationstheoretischer und informationspsychologischer Hinsicht“ zusätzlich für die Notwendigkeit eines eigenen Fragerechts der passiven Geschworenen im Rahmen einer reinen jury trial plädiert.

409 Vgl. Jackson/Doran, Judge, S. 71: ,[...] to locate a particular process on the spectrum between the two ideals." Vgl. auch (in einem anderen Kontext) P. Duff, in: A. Duff u.a. (Hrsg.), Trial on Trial 1, S. 31:, ,[...] the models provided useful analytical tools for locating these changes to the criminal justice process within a broader context of reform $[\ldots]$ the adversarial/inquisitorial polarity can help to anticipate, identify and explain possible tensions with other elements of the process that might be created by such reforms." 
Verfahrensordnung die Regeln und Strukturen für die Erhebung und Präsentation von Beweisen im Rahmen von unterschiedlichen gerichtlichen Verfahrensformen (jury trial versus bench trial - soweit diese gleichzeitig existieren) differenzieren lassen. Falls dabei schon normativ eine substantielle Änderung hinsichtlich beispielsweise der verlangten richterlichen Aktivität bzw. Passivität während der Beweisführung $\mathrm{zu}$ beobachten ist, kann dies sogar bedeuten, dass eine einzelne Rechtsordnung sich $a b$ initio bei unterschiedlichen Gerichtstypen unterschiedlichen Beweisführungsmodellen annähert. Falls aber die Prinzipien, Regeln, Strukturen und Rollenverteilungen bei der Beweisführung für sämtliche (z.B. englischen) Gerichtstypen auf normativer Ebene gleich bleiben, können weitere empirische Untersuchungen im vorgenannten Sinne nützlich sein. Solche eigenständigen Forschungsarbeiten können unter anderem eventuell auch mehr Licht auf die wirklichen kognitiven Bedürfnisse aller an der Beweisführung Beteiligten und entsprechend auf die möglichen faktischen Metamorphosen der zur Feststellung des wahren Sachverhaltes verwendeten Methoden werfen.

\section{e) Das Problem der Verfahrensabsprachen}

Wie bereits dargelegt, ist die Verbreitung von Abspracheformen in der heutigen westlichen Rechtswelt ein systemübergreifendes Phänomen. Die These dieser Arbeit, dass die Realität der Anwendung von Strafverfahrensabsprachen in angloamerikanischen und nun auch in kontinentaleuropäischen Rechtsordnungen eigentlich modellneutral zu betrachten und somit in die Erwägungen zu den hier behandelten Idealtypen des Beweisverfahrens nicht einzubeziehen ist, soll an dieser Stelle nicht ausführlich wiederholt werden. ${ }^{410}$ Den bisherigen Ausführungen ist noch folgendes Paradigma unterschiedlicher Betrachtungsweisen hinzuzufügen, das charakteristische rechtsvergleichende Schwierigkeiten und potenzielle Verwirrungen bezüglich der Begründung bzw. Einordnung der Absprachemechanismen innerhalb der modernen Rechtssysteme impliziert.

Es wird manchmal behauptet, dass zumindest in ,deskriptiver“411 Hinsicht die Absprachen (in Form von plea bargainings) eher $\mathrm{zu}$ den ,adversatorischen“

${ }^{410}$ Siehe zur Absprachenproblematik unter Teil 1, I.B.2.a); I.B.3.b)bb); I.B.4.; II.C.2.d) bb); II.C.2.e)aa) und bb).

411 Nach Langer, Harv. Int'l L. J. 45 (2004), 1 (35 Fn. 170): „I use the term 'adversarial' in a descriptive way. At the descriptive level, since plea bargains are widely practiced in the U.S. system, it is reasonable to consider this practice highly characteristic of U.S. criminal procedures. In addition, this practice also matches well with the conception of criminal procedure as a dispute between two parties before a passive umpire, a conception that extends to the American criminal justice system. If instead of using this expression in a descriptive way, one understands the adversarial system as a prescriptive ideal - according to which, for instance, all or most cases should be decided through a trial by jury - one could consider that plea bargains are not part of the American adversarial system, but rather, are undermining it.“ 
Grundsätzen eines Parteienwettstreits hauptsächlich amerikanischer Prägung und der dazugehörigen Parteienautonomie passen:

Plea bargains seem to have their origin in a criminal procedure system understood as a dispute between parties [...] Plea bargains can also be explained through the dispute model because it is natural in any dispute that the parties can negotiate a resolution. [...] In the model of the official investigation $[\ldots]$ there are no plea bargains, not only because there are no guilty pleas but also because the truth cannot be negotiated or compromised. $^{412}$

In einer anderen Sichtweise werden die (amerikanischen) Absprachemechanismen und ihre Funktion mit bestimmten historischen Aspekten des ,inquisitorischen“ Prozedierens, mit der früher üblichen Konzentration der Macht in den Händen des Richters und sogar mit der mittelalterlichen Anwendung von Foltermethoden zur Erlangung eines Geständnisses in der kontinentaleuropäischen Rechtstradition verglichen:

Our law of plea bargaining has not only recapitulated much of the doctrinal folly of the law of torture, complete with the pathetic safeguards of voluntariness and factual basis $[\ldots]$, but it has also repeated the main institutional blunder of the law of torture. Plea bargaining concentrates effective control of criminal procedure in the hands of a single officer. [...] Plea bargaining merges these accusatory, determinative, and sanctional phases of the procedure in the hands of the prosecutor. Students of the history of the law of torture are reminded that the great psychological fallacy of the European inquisitorial procedure of that time was that it concentrated in the investigating magistrate the powers of accusation, investigation, torture, and condemnation. [...] The dominant version of American plea bargaining makes similar demands: it requires the prosecutor to usurp the determinative and sentencing functions, hence to make himself judge in his own cause. I cannot emphasize too strongly how dangerous this concentration of prosecutorial power can be. ${ }^{413}$

Nach diesen zwei unterschiedlichen Ansichten werden die Absprachen in der common law-Welt einerseits als ,adversatorische“ Prozessmechanismen zur konsensualen Erledigung eines Strafkonflikts und andererseits als Nachfolger von ,inquisitorischen“ Verfahrenspraktiken zur „Aufklärung“ der Straffälle betrachtet. In der vorliegenden Arbeit werden dagegen die Absprachen als (vermeintlich notwendige) rechtspolitische Alternative zur Umgehung des traditionellen Strafverfahrens nicht in direkten analytischen Zusammenhang mit der umfassenden Erforschung eines Straffalles im Wege einer amtlichen Ermittlung (nach dem ,inquisitorischen“ Modell) oder eines Parteienwettstreits (nach dem ,adversatorischen“ Modell) gebracht. Hierbei geht es nämlich vor allem um die Definition von inhaltlich möglichst kohärenten modernen Idealtypen des Beweisverfahrens für rechtsvergleichende Zwecke. Eine deskriptive Gegenüberstellung sämtlicher (klassischer wie auch alternativer) Prozessformen in den kontinentaleuropäischen und den anglo-

412 Langer, Harv. Int'l L. J. 45 (2004), 1 (20, 22; auch 35-37). Vgl. auch Trüg, ZStW 120 (2008), 331 (348-349).

413 Langbein, U. Chi. L. Rev. 46 (1978), 3 (17-18). Vgl. auch Goldstein, Stan. L. Rev. 26 (1974), 1009 (1020); und im Kontext der auch auf dem Kontinent weitverbreiteten penal orders, Thaman, in: Luna/Wade (Hrsg.), Prosecutor, S. 173. 
amerikanischen Rechtssystemen auf abstrakter oder konkreter rechtsvergleichender Basis wird dabei nicht angestrebt. Ebenso wenig erwünscht ist hier die analytische Mischung und gemeinsame Bewertung von gegenwärtigen und historischen Prozesserscheinungsformen, ungeachtet etwa der eventuellen inhaltlichen Stichhaltigkeit solcher Metaphern, welche die Absprachen als die neuen inquisitorischen Foltermethoden betrachten.

Dass sich Absprachen in der modernen westlichen Rechtswelt verbreitet durchgesetzt haben, ist gleichwohl nicht zu übersehen. Diese horizontale Verbreitung zeigt folgende systemübergreifenden Charakteristika auf: Eine grundsätzliche (zumindest normativ gefordert: freiwillige) Verständigung zwischen Parteien bzw. hauptsächlichen Verfahrensbeteiligten wird für den „frühzeitigen“ Abschluss des Strafverfahrens zunächst vorausgesetzt. Die Staatsbehörden (Staatsanwälte und/oder Richter) als Verfahrensparteien oder amtliche Ermittler sitzen jedoch während der Verständigungsverhandlungen faktisch im Vergleich zum Angeklagten, dem für den Fall einer misslungenen Verhandlung sogar eine hohe Freiheitsstrafe drohen kann, meist am längeren Hebel. Schließlich bleibt im Fall von Absprachemechanismen die beträchtliche Abkürzung des Beweisverfahrens eine gemeinsame Angelegenheit, trotz der technischen Vielfalt der verschiedenen Verständigungsformen und ungeachtet der Verfahrensgrundsätze der jeweiligen Rechtstradition.

Dementsprechend stellen die gegenwärtig überall vorhandenen bzw. geförderten Verfahren zum konsensualen Ersatz des klassischen Beweisverfahrens ein systemübergreifendes $^{414}$ und modellneutrales Problem dar. Insbesondere die richterzentrierte oder parteienzentrierte Ausrichtung des herkömmlichen Strafverfahrens spielt zumindest in der Gegenwart keine substantielle Rolle bei der Begründung und zielgerichteten Anwendung von Absprachemechanismen. ${ }^{415}$ Die vorliegende Grundlagenuntersuchung des ,adversatorischen“ und des ,inquisitorischen“ Beweisverfahrens erstreckt sich jedenfalls auf die Vergleichung unterschiedlicher Methoden zur Annäherung an die Wirklichkeit eines streitigen Sachverhaltes, auf ihre Schwachpunkte und eventuell auch auf die Darstellung einer geeigneten Basis für die Planung zukünftiger Optimierungsversuche. Die rechtspolitischen Programme, die für die Umgehung des ordentlichen Gerichtsverfahrens als zumindest bis vor kurzem einzigem gesellschaftlich weithin anerkannten Weg zur möglichst fairen und objektiven Lösung von Strafkonfilkten plädieren, werden dabei nicht erfasst.

Selbstverständlich soll die strafprozessuale Lehre die in den modernen rechtspolitischen Reformdiskussionen allgemein dominierende Thematik der Absprachen nicht außer Acht lassen. Bei der Darlegung der Grundlagen für weitere analytisch

${ }^{414}$ Vgl. noch einmal an dieser Stelle u.a. Bradley, in: Luna/Wade (Hrsg.), Prosecutor, S. 92-97; Luna/Wade, in: dies. (Hrsg.), Prosecutor, S. 84, 90.

415 Vgl. auch Jung, EJCCC 1997, 112 (113-114, 121); Jung, FS für Waltoś, S. 32; Tiedemann, ZRP 1992, 107 (108-109). 
sinnvolle rechtsvergleichende Untersuchungen der Konturen und Verbesserungsdynamiken der verschiedenen Absprachemechanismen wäre jedoch die Bildung neuer intern kohärenter Modelle und abstrakter Ausgangstheorien vielleicht praktischer. Die Heranziehung verschiedenartiger Prozessformen mit unterschiedlichen Zielsetzungen unter demselben analytischen Dach der Dichotomie ,inquisitorisch“/ „adversatorisch“ kann dagegen schon existierende Missverständnisse, Vorurteile und folkloristische bzw. rhetorische Polarisierungen hinsichtlich des heutigen Verhältnisses zwischen kontinentaleuropäischen und angloamerikanischen Strafverfahren weiter befördern. ${ }^{416}$

Letztendlich verweist das begriffliche Gegenpaar „inquisitorisch“ / ,adversatorisch" in terminologischer, ${ }^{417}$ historischer ${ }^{418}$ und vor allem idealtypischer ${ }^{419}$ Hinsicht grundsätzlich auf Verfahrensformen, die (ihrer Substanz nach) auf die allseitige materielle Erforschung von streitigen, schließlich vom Gericht aufzuklärenden Straffällen zielen. Eventuell könnten zukünftige rechtsvergleichende Modelle in Bezug auf konsensual abgekürzte Verfahren auch als verwandt mit der klassischen Dichotomie angesehen werden. In die relevanten Erwägungen können beispielsweise auch die Machtverhältnisse zwischen dem Richter und den anderen Verfahrensbeteiligten während der Verständigungsverhandlungen einbezogen werden. Eine relevante Fragestellung kann sich etwa auf die Bestimmung desjenigen traditionellen Verfahrenstypus beziehen, der im Bereich der Absprachen bessere Ergebnisse bringen kann. Die systematisch klare Analyse bzw. die Hintergrundkenntnis der ordentlichen westlichen Beweisverfahrenstypen und der dazugehörigen traditionellen Rollenverteilungen, auf die im Endeffekt die vorliegende Arbeit zielt, könnte dann auch für die Konstruktion und die Anwendung solcher neuer Prozessmodelle von Nutzen sein.

\section{Zusammenfassung der Modellelemente und Zwischenausblick}

Aus der in Lehre und Praxis anerkannten prozeduralen Idee der Gegenüberstellung von ,amtlicher Ermittlung“ und „Parteienwettstreit“, die ihrerseits an Beobachtungen zentraler Prozessfiguren in der civil law- und der common law-Welt anknüpft, sowie aus den vorhergehend ausgeführten logischen und inneren $\mathrm{Zu}$ sammenhängen, die sich ebenso darauf beziehen, ergeben sich zusammenfassend folgende für die theoretische Differenzierung zwischen dem ,inquisitorischen“ und dem ,adversatorischen“"Beweisverfahrensmodell essenziellen Punkte:

416 Vgl. zu möglichen Komplikationen Damaška, Zbornik PFZ 51 (2001), 477 (483, $489,504)$, der im Allgemeinen sonst die deals als eher kompatibel mit der organisatorischen Idee (party control) hinter dem accusatorial model bezeichnet.

417 Siehe unter Teil 1, II.B.2.

418 Siehe unter Teil 1, I.B.2.a) und 3.b), II.B.1.b).

419 Siehe unter Teil 1, II.B.1.c), II.C.1. 
- Zunächst muss die Art und Weise der beweisbezogenen Vorbereitung eines streitigen Hauptverfahrens nach Erhebung der Strafklage berücksichtigt werden: Die Ermittlung, die „Aufbereitung“, das Zusammentragen und die Erbringung der Beweise sowie die Bestimmung des Umfangs der maßgebenden Beweiserhebungen können nämlich einerseits (im ,inquisitorischen“ Verfahren) konzentriert durch aktiv und autoritativ handelnde amtliche Justizorgane und andererseits (im ,adversatorischen“ Verfahren) in jeweils autonomer Weise durch einander gegenüberstehende Verfahrensparteien (Anklage/Verteidigung) erfolgen.

- Von zentraler Bedeutung ist auch die Frage der Kenntnis (im „inquisitorischen“ Verfahren) oder Nicht-Kenntnis (im ,,adversatorischen“ Verfahren) seitens des (verfahrensleitenden) Richters der Beweisergebnisse des Vorverfahrens bzw. des Inhalts des zusammengestellten Dossiers. Daneben können auch die Bestimmungen hinsichtlich der (gegenseitigen) Offenlegung des Vorverfahrensmaterials zwischen den Verfahrensbeteiligten bzw. Parteien für die präzisere Positionierung einzelner Rechtssysteme innerhalb des Spektrums zwischen den zwei Modellen eine Rolle spielen.

- Schließlich ist die beherrschende Rolle einerseits des Richters (im ,inquisitorischen“ Verfahren) und andererseits der zentralen Verfahrensbeteiligten/Parteien (im ,adversatorischen“ Verfahren) bei den maßgebenden Beweisführungen zu beachten, die entweder vor einem ,einspurig“ (mit Berufsrichtern, Laienrichtern oder in gemischter Weise) besetzten Strafgericht (bench-Verfahren) oder im Rahmen eines reinen jury-Verfahrens (mit getrennter Geschworenenbank) stattfinden können. $\mathrm{Zu}$ berücksichtigen ist hierbei insbesondere die Art und Weise der zulässigen Erhebung und Ausschließung, der Präsentation sowie der Prüfung der Stichhaltigkeit von Beweisen bis einschließlich zum tatsächlichen Abschluss des gerichtlichen Beweisverfahrens, der etwa durch anwaltliche Schlussvorträge oder zusammenfassende richterliche Anweisungen (summing-up) ${ }^{420}$ an die jurors erfolgen kann. Davon ausgenommen ist dagegen die Phase der Beweiswürdigung (z.B. während der jury deliberations bzw. während nichtöffentlicher richterlicher Beratungen zum Treffen der Entscheidung), die letztendlich keine eigentlichen Beweisführungstaten und vor allem keine unmittelbaren Bezüge zur hier maßgebenden Antithese „Parteienwettstreit versus amtliche Ermittlung“ beinhaltet.

Nicht von substantieller Bedeutung für die moderne Dichotomisierung der westlichen idealen Beweisführungstypen sind dagegen unter anderem:

- die Gewährleistung der gegenwärtig systemübergreifend, auch auf internationalrechtlicher Ebene weithin geltenden Menschenrechte und prozessualen Fairnessgarantien (wie z.B. des Schweigerechts). Diese Problematik steht sonst oft im Vordergrund deskriptiver und historischer all inclusive-Betrachtungen oder folkloristischer Anschauungen der angloamerikanischen accusatorial/adversarial

420 Dazu in diesem Kontext Jackson/Doran, Is.L.R. 31 (1997), 645 (680-683). 
und der kontinentaleuropäischen inquisitorial Strafverfahrenssysteme, ohne sich jedoch unmittelbar auf gegenwärtige Beweisführungsstrukturen und strafprozessuale Rollenverteilungen zu beziehen;

- die vielfältigen prozessualen Besonderheiten der (zumindest auf den ersten Blick in den meisten westlichen Nationalstaaten eher autoritativ und einseitig stattfindenden) „polizeilichen“ Ermittlungen im Vorverfahren. Die Letzteren dienen hauptsächlich der rechtzeitigen Sicherung des vorhandenen Beweismaterials und der Zusammenstellung einer ausreichenden Tatsachenbasis für die Erhebung der Strafklage vor Gericht;

- die Art und Weise und insbesondere die Voraussetzungen der Klageerhebung per se sowie die diversen amtlichen Zwischenprozesse, die begrenzt auf die Überprüfung der Stichhaltigkeit des Anklagevorbringens für eine Fortsetzung des Hauptverfahrens oder auf die vorverfahrensrechtliche Klärung eher technischer Angelegenheiten zielen (und sich somit nicht unmittelbar auf maßgebende Beweisvorgänge beziehen);

- die moderne rechtskreisübergreifende Durchsetzung von modellneutral wirkenden Absprachemechanismen;

- solche modellneutralen Angelegenheiten, die ausschließlich die Öffentlichkeit, Nichtöffentlichkeit, Mündlichkeit und Schriftlichkeit der verschiedenen Strafund Beweisverfahrensstadien betreffen;

- die Vielfalt der eingesetzten Gerichtsbarkeiten und -besetzungen zur Beurteilung der Straffälle und insbesondere die Trennung per se zwischen Laienrichtern und Berufsrichtern sowie zwischen jury trial und bench trial. Allerdings ist es nicht ausgeschlossen, dass die Einbeziehung der letzteren Gegenüberstellung (jury trial versus bench trial) besonders in empirisch orientierten Rechtsvergleichungen eventuell auf faktisch verschwommene Grenzen zwischen den eigentlichen Anwendungsweisen der sonst formal-normativ klar getrennten Modelle hinweisen kann.

Diese abstrakten Schlussfolgerungen bieten sich nun als Anknüpfungspunkt für möglichst kohärente und „kompakte“ Vergleichungen konkreter gegenwärtiger Beweisverfahrenssysteme (genauer: Beweisführungssysteme) an. In diesem Analyserahmen sollen nämlich vor allem die erleichterte und konsistente Identifizierung und Bewertung der strukturellen und funktionalen Besonderheiten verschiedener Beweisverfahren sowie der Unterschiede und Ähnlichkeiten zwischen Verfahrensordnungen unterschiedlicher Rechtstraditionen oder auch der Entwicklungen und Tendenzen innerhalb derselben Verfahrenstradition erfolgen. Darüber hinaus wird anhand der Erfüllung aller oder mehrerer der vorgenannten idealtypischen Kriterien eine Einsortierung des Beweisverfahrens einzelner Rechtsordnungen innerhalb des Spektrums zwischen den Modellen und somit zwischen den entsprechend vorgeschlagenen Methoden zur bestmöglichen Sachverhaltsaufklärung ermöglicht (am „,inquisitorischen“ oder am ,adversatorischen“ Ende oder dazwischen). Die ent- 
sprechenden Klassifizierungen und Taxonomien können dabei dann als Ausgangspunkt oder Ablaufplan für weitere rechtsvergleichende, empirische und interdisziplinäre Forschungen bzw. für rechtspolitische Reformarbeiten in diesem Bereich dienen.

Nicht außer Acht gelassen werden dürfen hierbei schließlich die internationalen Dimensionen der ,,adversatorischen“ und der ,inquisitorischen“ Beweisführung. In der vorliegenden Arbeit werden solche internationalrechtlichen Aspekte und Perspektiven in Teil 3 hauptsächlich anhand der EMRK-,,Rechtsordnung“ und des IStGH-Verfahrenssystems diskutiert. Zuerst folgt allerdings der konkret-rechtsvergleichende Teil 2 der Untersuchung. Wie im Vorangehenden erklärt, findet in diesem Teil, ausgehend von den analytischen und taxonomischen Vorgaben der idealtypischen Dichotomie zwischen ,adversatorischem“ und „,inquisitorischem“ Beweisverfahren, ein Vergleich zwischen dem englischen und dem deutschen Beweisführungssystem statt. 
Teil 2

\section{Rollenverteilung bei der Beweisführung im englischen und im deutschen Strafprozess}

\section{Darstellungs- und Vergleichsrahmen}

Die nachfolgenden Darstellungen und Vergleichungen betreffen die Art und Weise der Beweisführung mit Blick insbesondere auf die Rollenverteilung zwischen den Hauptakteuren im Verfahren zur Feststellung der kriminellen Schuld. Die bisherigen Ausführungen befassten sich mit der genauen Definition des ,,adversatorischen“ und des ,inquisitorischen“ Modells des westlichen (Beweis-)Verfahrens. Relevante abstrakte Modellvarianten wurden in der analytischen und taxonomischen Rechtsvergleichung vielfach zugrunde gelegt. Deren Grundkonzeption basiert meistens auf der Beobachtung von prägenden strafprozessualen Elementen der angloamerikanischen und der kontinentaleuropäischen Rechtstradition. Der „adversatorische“ und der, ,inquisitorische“ Idealtypus spiegeln aber weder exakte Verfahrenssysteme bestimmter Rechtsordnungen im Ganzen noch eventuelle Prozessmischungen wider. ${ }^{1}$

Vorliegend werden nun mit der englischen und der deutschen Verfahrensordnung zwei konkrete (reale) Verfahrensordnungen grundsätzlich auf normativer $^{2}$ Ebene einander gegenübergestellt, welche die Entwicklungen innerhalb der common law- und der civil law-Tradition entsprechend stark mitgeprägt haben. Die Darstellungsweise der strafprozessualen Besonderheiten auf beiden Seiten orientiert sich an den in dieser Arbeit bereits definierten Kernelementen der Beweisführungsmodelle: Vor allem sind dabei die beweisrelevanten Vorgänge, Strukturen und Rollenverteilungen im Rahmen der Vorbereitung und Durchführung eines streitigen Erkenntnisverfahrens zu berücksichtigen. ${ }^{3}$ In den anschließenden Vergleichungen und Auswertungen wird dann das Verhältnis der Einzelsysteme zu den zwei theoretischen Extrempolen des Beweisverfahrens weiter konkretisiert. Es wird insbesondere nach Konvergenzen und Divergenzen der

\footnotetext{
1 Vgl. u.a. Weigend, in: Dressler (Hrsg.), Encyclopedia, S. 446.

2 Siehe zur Rechtsquellenproblematik (insb. zum Gesetzesrecht, zum Richterrecht und zur Funktion der Rechtsprechung) bereits unter Teil 1, I.B.2.b)aa) und Teil 1, I.B.3.b)bb).

3 Siehe zu den essenziellen und nicht essenziellen Modellelementen zusammengefasst Teil 1, II.C.4.
} 
Verfahrensformen gesucht, die nationalrechtlich zur bestmöglichen Sachverhaltsaufklärung eingesetzt werden. ${ }^{4}$

Nicht zuletzt aus praktischen Gründen können in dieser Forschungsarbeit nicht alle bestehenden Gerichtsbarkeitsformen und nicht alle Varianten von schuldfeststellenden Strafverfahren in England und Deutschland innerhalb des Analyserahmens der hier definierten Beweisführungsmodelle berücksichtigt werden. ${ }^{5}$ Insbesondere werden hierbei nur „ordentliche“ erstinstanzliche Erkenntnisverfahren mit möglichst umfassenden Beweisverfahrensstrukturen wahrgenommen. Solche Verfahren stellen ohnehin den üblichen Ausgangs- oder Bezugspunkt bzw. das zentrale Interessengebiet für verschiedene theoretische und empirische Forschungen in sämtlichen prozessualen Teilbereichen sowie für entsprechende rechtspolitische Planungen auf nationaler und internationaler Ebene dar.

Die zahlreichen, in technischer Hinsicht vielfältig entwickelten abgekürzten Prozessformen zur Klärung von hauptsächlich ,leichten“ Deliktstypen dürften dagegen für die Identifizierung zentraler Beweisführungspräferenzen und -tendenzen von minderem Erkenntniswert sein. Die systematische und rechtsvergleichende Grundlagenuntersuchung von vollständigen gerichtlichen Beweisverfahrensabläufen kann vielmehr eventuell auch der sinnvollen Vorbereitung von ,abweichenden“ Prozessmodellen bzw. der stimmigen Planung alternativer (abgekürzter) Verfahrensformen dienen. Gleiches ließe sich sogar auch in Bezug auf die Verwendung von „administrativen“ Erledigungsformen vor der Klageerhebung oder von Absprachemechanismen auch in schwerwiegenden Deliktsfällen sagen; diese eliminieren, wie bereits erwähnt, das eigentliche Beweisverfahren und werden somit nicht von den modellbezogenen Untersuchungsparametern dieser Arbeit erfasst.

Darüber hinaus betreffen die nachfolgenden Landesberichte und Vergleiche hauptsächlich die beweisführende Rolle von Richter, Anklage und Verteidigung ${ }^{6}$ nach Erhebung der Strafklage und bis zum Abschluss der streitigen ${ }^{7}$ Beweisvor-

\footnotetext{
${ }^{4}$ Vgl. zur Durchführung einer Rechtsvergleichung Engelhart, Sanktionierung, S. 29-31.

5 Außer Betracht bleiben z.B. eventuelle Besonderheiten von Jugendstrafverfahren bzw. von weiteren Strafverfahren, die ausschließlich spezielle Personengruppen betreffen, sowie die diversen Möglichkeiten zur weitgehend summarischen, beschleunigten, ,polizeilichen“ bzw. quasi administrativen Behandlung bestimmter Straffälle in England und Deutschland.

6 Siehe dazu die modellhaften Definitionen schon unter Teil 1, II.C.1.b) und Teil 1, II.C.2.e)dd). Die modellunabhängige Stellung und die (Teilnahme-)Rechte des Opfers/ Verletzten (victim) sind hier nicht zu behandeln, siehe dazu schon unter Teil 1, II.C.1.b) m.w.N. Überblick zur relevanten deutschen Rechtslage bei Beulke, Strafprozessrecht, Rn. 590-605; siehe auch Herrmann, in: Rosenau/Kim (Hrsg.), Straftheorie, S. 90-107. $\mathrm{Zu}$ den englischen Diskussionen Ashworth/Redmayne, Criminal Process, S. 43-44, 5155, 186-187, 216-218, 422-423; Feldman, in: Bradley (Hrsg.), Criminal Procedure, S. $189-191$.
}

7 Somit bleiben nicht nur abgesprochene Verfahrenserledigungen bzw. Prozesse, die auf der Basis von Verständigungen und Geständnissen hinsichtlich der Tatsachenlage erfolgen, 
gänge innerhalb der Hauptverhandlung, die mit Blick vor allem auf die Feststellung der Schuldfrage stattfinden. Dies entspricht den bereits definierten Modellelementen und insbesondere der Basisidee der Trennung zwischen Parteienwettstreit und amtlicher Ermittlung eines Straffalles. Die Phasen der endgültigen Beweiswürdigung zum Zwecke des eigentlichen Treffens der Entscheidung und der Strafzumessung sind nicht darin eingeschlossen und werden in der Arbeit nicht selbstständig berücksichtigt. Im Hinblick schließlich auf das ordentliche Hauptverfahren darf die Unterscheidung zwischen zwei grundsätzlichen Gerichtsverfahrensarten des westlichen Strafprozesses, nämlich dem reinen jury-Verfahren und dem bench-Verfahren, nicht außer Acht gelassen werden, insbesondere soweit für ein und dieselbe Deliktskategorie beide Spruchkörper zum Einsatz kommen können (wie etwa bei den im Folgenden diskutierten englischen triable either way offences). Somit ist unter anderem festzustellen, ob sich die Beweisverfahrensabläufe vor grundlegend unterschiedlichen Spruchkörpern substantiell differenzieren.

Die Darstellung der Beweisführungseigenheiten zuerst in der englischen und anschließend in der deutschen Rechtsordnung findet nun in diesem Teil der Arbeit nach den gerade genannten Parametern wie folgt statt: Am Anfang steht zum Zweck der besseren Veranschaulichung jeweils eine allgemeine Einführung in die verschiedenen Ziele und Phasen des nationalen Strafprozesses sowie in die Grundzüge des Beweisrechts und -verfahrens (unter II.A. und III.A.). Danach werden die vorbereitenden Beweisvorgänge, insbesondere die Art und Weise der „Aufbereitung“ des Beweismaterials und der Bestimmung der Beweiserhebungen, ab dem Zeitpunkt der Erhebung der Strafklage - hauptsächlich anhand charakteristischer Beispiele, wie vor allem des Zeugenbeweises - untersucht (unter II.B. und III.B.). Es folgt die selbstständige Betrachtung einer weiteren zentralen Beweisangelegenheit, die ebenso die Vorbereitung der Hauptverhandlung betrifft, namentlich der Kenntnisnahme und Offenlegung der Akten und Beweise des Vorverfahrens (unter II.C. und III.C.). Zuletzt setzt sich der jeweilige Landesbericht mit der Beweisführung im Hauptverfahren auseinander (unter II.D. und III.D.). Den Abschluss jedes Landesberichts bilden die erforderlichen Teilzusammenfassungen (unter II.E. und III.E.). An diese aufeinanderfolgenden Einzeldarstellungen der nationalen Beweisführungssysteme schließen sich der Vergleich der betreffenden Strafverfahrensaspekte der nationalen Rechtssysteme und die entsprechenden zusammenfassenden Klassifizierungserwägungen (unter IV.) sowie die abschließenden Bewertungen (unter V.) an.

in der vorliegenden Untersuchung außer Betracht, sondern grundsätzlich auch Strafverfahren, die z.B. in Abwesenheit des Angeklagten/der Verteidigung stattfinden. 


\section{Das englische Beweisführungssystem}

\section{A. Überblick über den Strafprozess}

\section{Die Ziele und Grundprinzipien des Strafverfahrens und die EMRK}

Die allgemeinen, den kontinentaleuropäischen Juristen fernstehenden Besonderheiten des englischen Rechtssystems als Teil der common law-Tradition wurden bereits angesprochen. ${ }^{8}$ Diese betreffen unter anderem die ab initio eher praktische und weniger „dogmatische“9 Orientierung der Juristerei, das Fehlen echter Rechtskodifikationswerke und die - sogar auf Verfassungsebene - erhebliche Verstreuung der Rechtsquellen. Solche Charakteristika erschweren die klare Herausarbeitung von Zielen und Leitprinzipien bzw. grundlegenden Bestandteilen des englischen Strafverfahrens.

Gleichwohl ist im Hinblick auf die allgemein deklarierten ${ }^{10}$ übergeordneten Ziele der Strafjustiz - und unter Berücksichtigung der vorherigen Ausführungen zur Zielsetzungsproblematik und der darin enthaltenen Verweise ${ }^{11}$ - zunächst Folgendes festzuhalten: der Strafprozess wird nämlich in Lehre und Praxis nicht mehr als bloßer, eher der Fairness als der Wahrheit verpflichteter Wettkampf angesehen. Die Verurteilung der Schuldigen durch menschenwürdige, rechtsstaatliche und faire Sachverhaltsaufklärungsprozesse, die sich auf präzise Tatsachenfeststellungen (fact-finding) konzentrieren, stellt vielmehr ein weithin anerkanntes zentrales Verfahrensziel dar. ${ }^{12}$ Lord Justice Auld hat in seinem rechtspolitisch richtungweisenden Report Review of the Criminal Courts of England and Wales hierzu bemerkt: ${ }^{13}$

Procedural fairness has always been a feature of our law. [...] In determining the provision of courts, manner of trial and the search for fair, speedy and otherwise efficient procedures, it should be remembered that they are not there just to protect defendants. They also serve the community. And the criminal process is not a game. It is a search

8 Siehe die Gegenüberstellung der zwei zentralen westlichen Rechtstraditionen, auch anhand des englischen Beispiels, unter Teil 1, I.B.

9 Als Hauptaufgabe der Rechtsdogmatik wird hier vor allem die ,rational reconstruction of legal materials“ verstanden, die MacCormick, O.J.L.S. 10 (1990), 539 (556), folgendermaßen definiert hat: „In legal scholarship - in legal dogmatics, that is to say - rational reconstruction means the production of clear and systematic statements of legal doctrine, accounting for statute law and case law in terms of organizing principles, relating actual or hypothetical decisions both to their factual bases and to governing norms elaborated out of the authoritative materials."

10 Zur diesbezüglichen rechtspolitischen Richtung in letzter Zeit etwa Slapper/Kelly, English Legal System, S. 277, 280.

11 Siehe insb. unter Teil 1, II.C.2.b)-d).

12 Zusammenfassend u.a. Ashworth/Redmayne, Criminal Process, S. 22-26.

13 Auld Report 2001, S. 11, 459-460; auch in diesem Sinne u.a. $R$ v. Gleeson, [2004] 1 Cr App R 406, Rn. 36. Vgl. auch Royal Commission on Criminal Justice Report 1993, S. 3. 
for truth according to law, albeit by an adversarial process in which the prosecution must prove guilt to a heavy standard. [...] A criminal trial is not a game under which a guilty defendant should be provided with a sporting chance. It is a search for truth in accordance with the twin principles that the prosecution must prove its case and that a defendant is not obliged to inculpate himself, the object being to convict the guilty and acquit the innocent.

In ähnlichem Kontext haben Roberts und Zuckerman fünf generelle Grundprinzipien bzw. objectives des englischen Strafbeweissystems identifiziert. Diese betreffen die Wahrheitsfindung, den Schutz des Unschuldigen, das Prinzip der Freiheit und der minimalen staatlichen Intervention, das Prinzip der menschenwürdigen Behandlung und die Gewährleistung der Ordnungsgemäßheit im Strafprozess: ${ }^{14}$

Five general principles can be distilled from the relevant institutional materials and treated as foundational. [...] The aspiration that judicial verdicts should conform as nearly as possible with the truth, not surprisingly, merits pride of place as the first principle of criminal evidence. Criminal adjudication is supposed to determine who did what, to whom, when, and why. The fact-finder is meant to get the facts straight. Buttressing the first principle of promoting factual accuracy, English criminal procedure treats four further principles as foundational: (2) the principle of protecting the innocent from wrongful conviction; (3) the principle of liberty, or minimum state intervention; (4) the principle of humane treatment; and (5) the principle of maintaining high standards of propriety in the criminal process.

Derartige Erwägungen spiegeln sich auf rechtstechnischer Ebene mehr oder weniger in der Kodifizierung - oder genauer Konsolidierung - diverser (gesetzlicher und Common Law-) Gerichts- und Strafverfahrensregeln in den Criminal Procedure Rules 2014 (CPR 2014) wider. Insbesondere im Rahmen der Bestimmung der „overriding objective“ (sect. 1.1.) dieses „Kodifikationswerkes“ werden die Bestandteile der gerechten Erledigung eines Straffalles dargelegt. Diese sind insbesondere die Verurteilung des Schuldigen und der Freispruch des Unschuldigen, die faire Auseinandersetzung mit der Anklage und der Verteidigung, die Anerkennung der Menschenrechte des Angeklagten, der Schutz der Interessen von Zeugen, Opfern und jurors sowie die effektive, schnelle und proportionale Durchführung des Verfahrens: ${ }^{15}$

The overriding objective

1.1.- (1) The overriding objective of this new code is that criminal cases be dealt with justly. (2) Dealing with a criminal case justly includes - (a) acquitting the innocent and convicting the guilty; (b) dealing with the prosecution and the defence fairly; (c) recog-

14 Roberts/Zuckerman, Criminal Evidence, S. 18-19. Siehe ausführlicher zu den ,aims of the law of evidence“ Dennis, Evidence, Rn. 2.001-2.029.

15 Siehe CPR 2014 [unter http://www.justice.gov.uk/courts/procedure-rules/criminal abrufbar, Stand: Oktober 2014] i.V.m. Statement dated March 2005: The objectives and content of the first Criminal Procedure Rules [unter http://www.justice.gov.uk/courts/ procedure-rules/criminal/notes abrufbar, Stand: Oktober 2014]. Dazu u.a. Darbyshire, Legal System, S. 310-312; Roberts/Zuckerman, Criminal Evidence, S. 35-37; Sprack, Criminal Procedure, Rn. 2.01-2.13. 
nising the rights of a defendant, particularly those under Article 6 of the European Convention on Human Rights; (d) respecting the interests of witnesses, victims and jurors and keeping them informed of the progress of the case; (e) dealing with the case efficiently and expeditiously; (f) ensuring that appropriate information is available to the court when bail and sentence are considered; and (g) dealing with the case in ways that take into account (i) the gravity of the offence alleged, (ii) the complexity of what is in issue, (iii) the severity of the consequences for the defendant and others affected, and (iv) the needs of other cases.

Weitere auch gegenwärtig essenzielle (verfassungsrechtliche) Garantien, Rechte und Grundprinzipien des Strafverfahrens finden sich ansatzweise großenteils schon im englischen Common Law sowie in alten „klassischen“ Gesetzesinstrumenten (wie der Magna Carta 1215 oder der Bill of Rights 1689). Von zentraler prozessualer Bedeutung sind unter anderem solche Prinzipien und Regeln wie: the writ of habeas corpus; the rule of law / due process; the presumption of innocence; the proof beyond reasonable doubt; the right to speedy trial; the double jeopardy rule; the privilege against self-incrimination; the audi alteram partem principle; the rule against torture. ${ }^{16}$

Zugleich werden als maßgebende Ausprägungen eines rechtsstaatlichen und fairen Strafverfahrens heute die Garantien, Rechte und Mindeststandards anerkannt, die im Text der EMRK und insbesondere in den Vorschriften der Artikel 5 (Freiheits- und Sicherheitsrechte) und 6 (Justiz- und Verfahrensgarantien wie z.B. das Öffentlichkeitsprinzip sowie die Informations- und Verteidigungsrechte) aufgeführt sind. ${ }^{17}$ Diese werden ohnehin aufgrund ihrer Entstehungsgeschichte und der (teilweise alt-englischen) Entwurfsgrundlagen oft als ursprünglich englisches Produkt angesehen. $^{18}$

Gegenwärtig gelten die Konventionsrechte aufgrund des Human Rights Act 1998 $(\text { HRA })^{19}$ als Teil des Rechts des Vereinigten Königreichs; ihr Einfluss bzw. der Einfluss der EGMR-Rechtsprechung auf die nationale Verfahrenspraxis hat inzwi-

16 Mehr dazu u.a. bei Darbyshire, in: Vogler/Huber (Hrsg.), Criminal Procedure, S. 5774; Darbyshire, Legal System, S. 301-308. Siehe auch Forster, in: Sieber u.a. (Hrsg.), National Criminal Law, S. 34-37.

17 Darbyshire, in: Vogler/Huber (Hrsg.), Criminal Procedure, S. 49-51; Darbyshire, Legal System, S. 301. Zum Inhalt dieser Garantien und fair trial-Rechte siehe u.a. Grabenwarter/Pabel, Menschenrechtskonvention, § 21 Rn. 1-39, § 24 Rn. 16-131.

18 Darbyshire, Legal System, S. 99, 301-302. Allgemein zu den rechtspolitischen Verhältnissen bei der Entstehung des EMRK-Systems u.a. Madsen, Law \& Social Inquiry 32 (2007), 137 (139-151). Zusammenfassend zur Entstehungsgeschichte und Entwicklung der Konvention Grabenwarter/Pabel, Menschenrechtskonvention, §1 Rn. 1-6; ferner SKStPO-Paeffgen, Einl. EMRK Rn. 1-48f.

19 „An Act to give further effect to rights and freedoms guaranteed under the European Convention on Human Rights; to make provision with respect to holders of certain judicial offices who become judges of the European Court of Human Rights; and for connected purposes." (Introductory Text). 
schen enorm zugenommen. ${ }^{20}$ Nach sect. 2 HRA muss ein nationales Gericht, das sich mit Fragen zu den Konventionsrechten befasst, relevante Entscheidungen des EGMR und der anderen Justizorgane des EMRK-Systems immer berücksichtigen (,must take into account"). Nach sect. 3 HRA muss eine konventionskonforme Auslegung und Anwendung der nationalen Gesetze stattfinden, soweit dies möglich ist (,so far as it is possible to do so“). Darüber hinaus ist es nach sect. 6(1) HRA ,unlawful for a public authority to act in a way which is incompatible with a Convention right." Die sovereignty of parliament bleibt jedoch (zumindest förmlich) unberührt: Auch wenn eine konventionskonforme Auslegung des Gesetzes unmöglich ist und seine Unvereinbarkeit mit den Konventionsrechten festgestellt wird, tritt das betreffende Gesetz nicht außer Kraft, sondern muss weiter angewandt werden; jedenfalls können bestimmte Obergerichte in solchen Fällen nach sect. 4 HRA eine (für die jeweiligen Verfahrensbeteiligten unverbindliche), ,declaration of incompatibility“ ausstellen, was in der Folge eventuell zu konventionskonformen Gesetzesreformen führen kann. ${ }^{21}$

\section{Der Ablauf des herkömmlichen Strafverfahrens}

\section{- Einleitung der Strafverfolgung und Klageerhebung}

Das englische Strafjustiz- und Verfahrenssystem hat in struktureller Hinsicht und bei seiner rechtstatsächlichen Anwendung einen überaus komplexen, ${ }^{22}$ verflochtenen sowie disparaten bzw. dezentralisierten Charakter, ${ }^{23}$ sodass eine klar untergliederte, zusammenfassende Darstellung der einzelnen Verfahrensschritte Schwierigkeiten bereitet. ${ }^{24}$ Der gewöhnliche Strafprozess beginnt, vereinfacht betrachtet, mit

${ }^{20}$ In diesem Zusammenhang zur Möglichkeit der ,, constitutionalization of criminal evidence" Roberts/Zuckerman, Criminal Evidence, S. 34-35 m.w.N.

21 Siehe insgesamt u.a. Darbyshire, Legal System, S. 99-105, 121-135; Roberts/ Zuckerman, Criminal Evidence, S. 31-35. Siehe auch Grabenwarter/Pabel, Menschenrechtskonvention, § 3 Rn. 5; Huber, FS für Waltoś, S. 212-214.

22 Vgl. auch Auld Report 2001, S. 17-18: „The strongest impression that I have formed of the criminal justice system in the course of the Review is of the complexities in every corner of it. Their consequence is much damage to justice, efficiency and effectiveness of the system and to the public's confidence in it. [...] The 'system', a legacy of centuries of piecemeal change, is a mix of autonomous national and local bodies attempting to collaborate and consult with each other through a network of committees at different levels. There is no over-all direction [...] The criminal law as a whole suffers from centuries of haphazard statutory and common law accretion, a process that has accelerated dramatically in recent years. It is all immensely complicated for lawyers and laymen alike, and urgently in need of codification $[\ldots]$. “

23 Vgl. dazu auch White, in: McConville/Wilson (Hrsg.), Handbook, S. 5.

${ }_{24}$ Siehe frühere Zusammenfassungen u.a. bei Darbyshire, in: Vogler/Huber (Hrsg.), Criminal Procedure, S. 53-55; Elliott/Quinn, English Legal System, S. 422-436; Huber, in: Perron (Hrsg.), Beweisaufnahme, S. 23-36; Kühne, Strafprozessrecht, Rn. 1154-1161; Partington, Introduction, S. 94-135. 
der polizeilichen Identifizierung bestimmter, der Begehung von Straftaten verdächtiger Personen, der Sammlung und Sicherstellung von relevanten Beweisen und der allgemeinen Vorbereitung der Klageerhebung. ${ }^{25}$

Es gibt unterschiedliche Arten der Klageerhebung (commencing a prosecution). ${ }^{26}$ In ,leichten Fällen“, etwa bei Verkehrsdelikten, wird traditionellerweise die Strafklage oft (aber nicht ausschließlich) von der Polizei - die Ermittlungs- und auch heute noch Anklagebefugnisse besitzt - oder von nicht amtlichen Anklägern im Wege des Vorlegens einer „information“ ${ }^{\text {27 }}$ (eine Art Beschuldigungsschrift) beim magistrates' court erhoben. In solchen Fällen ist für den Verweis des Angeklagten an das Gericht zuerst das gerichtliche Ergehen einer justiziellen Ladung (,,issue of a summons“") ${ }^{28}$ und ihre Zustellung erforderlich. Nachdem die ,information“" vorgelegt wurde, werden normalerweise die Verfahrensakten der zuständigen Zweigstelle der Crown Prosecution Service (CPS) übermittelt, deren Anwälte in der Folge über diverse Entscheidungsbefugnisse hinsichtlich der Evaluation des anfänglichen Anklagevorbringens und der Fortsetzung der Strafverfolgung verfügen. Ausschließlich in Bezug auf die Klageerhebung durch public prosecutors (z.B. Polizei, CPS, Serious Fraud Office) wurde mit sect. 29 CJA 2003 - wenngleich bis dato nicht völlig implementiert - ein neues Anklageverfahren (,new method of instituting proceedings") auch für die leichteren Straffälle eingeführt: An Stelle einer ,information“ wird dabei eine „written charge“ ausgestellt, die - zusammen mit einer schriftlichen Ladung vor das magistrates' court (,,requisition“) - direkt von der Anklagebehörde (also ohne das Ergehen einer justiziellen Ladung/a summons) dem Angeklagten zugestellt werden muss. ${ }^{29}$

In schwerwiegenderen Fällen finden vor einer eventuellen Klageerhebung üblicherweise vorläufige Inhaftierungen auf der Polizeiwache, Verdächtigenverhöre und Opfer- bzw. Zeugenbefragungen sowie weitere umfassende polizeiliche Ermittlungen und Beweissammlungen statt. Hauptsächlich bei schweren Straftaten wird dann eine weitere traditionelle Methode zur Klageerhebung angewandt:

25 Abgesehen vom Regelfall, in dem die Klageerhebung durch die Polizei und die Staatsanwälte der Crown Prosecution Service (CPS) erfolgt, kann die Strafverfolgung auch durch Privatpersonen (private prosecutors) initiiert werden. Siehe dazu und zu den anderen nicht polizeilichen Anklagepersonen bzw. -behörden Sprack, Criminal Procedure, Rn. 4.01, 4.13, 4.19-4.22.

26 Siehe insb. sect. 37-37B PACE und sect. 28-30 CJA 2003 m.w.N.

27 Im Glossar der CPR 2014 wird der Begriff ,,information“ folgendermaßen definiert: „statement by which a magistrate is informed of the offence for which a summons or warrant is required - the procedure by which this statement is brought to the magistrates' attention is known as laying an information."

${ }^{28}$ Im Glossar der CPR 2014 wird der Begriff „,summons“ folgendermaßen definiert: ,a document signed by a magistrate after an information is laid before a him which sets out the basis of the accusation against the accused and the time and place when he must appear."

${ }_{29}$ Mehr dazu bei Sprack, Criminal Procedure, Rn. 3.33-3.47, 4.10, 4.14-4.17. 
Sobald hinreichende Beweise vorliegen, kann die Klage im Wege der formalen Beschuldigung (commencing a prosecution with a charge) des in solchen Fällen oft schon festgehaltenen Verdächtigen (suspect) von der Polizei und/oder der CPS erhoben werden - die betreffende Person ist daher als Angeklagter (defendant) ${ }^{30} \mathrm{zu}$ bezeichnen. Die Entscheidung, ob ein Verdächtiger auf diesem Weg beschuldigt (charged) werden soll oder nicht, wurde früher hauptsächlich von der Polizei getroffen. Heute ist meistens die CPS - als primäre Anklagebehörde ${ }^{31}$ in Zusammenarbeit mit der Polizei - für die (anfängliche) Entscheidung über derartige staatliche Beschuldigungen verantwortlich. Außerdem übernimmt die CPS die Abwicklung aller von der Polizei initiierten Strafverfolgungen - sie kann darüber hinaus sogar sämtliche nicht polizeilichen (z.B. privaten) Strafverfolgungen übernehmen. Die Anwälte der CPS bzw. die von ihr beauftragten privaten Anwälte sind außerdem die hauptsächlichen Anklagevertreter vor Gericht. ${ }^{32}$

Die CPS kann somit die Strafverfolgung in verschiedenen Stadien einstellen bzw. abbrechen. ${ }^{33}$ Schon im Vorfeld einer Klageerhebung können aber die Behörden mit Anklagebefugnissen (insbesondere die Polizei und die CPS) vor allem wegen Beweisschwierigkeiten ${ }^{34}$, Erwägungen zur Funktionstüchtigkeit des Strafjustizsystems oder aufgrund von mangelndem öffentlichem Interesse ${ }^{35}$ von der

30 Zur begrifflichen Unterscheidung vgl. sect. 1.4 CCP 2013.

31 Siehe sect. 1.2-2.6 CCP 2013. Die CPS ist keine Ermittlungsbehörde, dazu u.a. Sprack, Criminal Procedure, Rn. 4.11.

32 Zusammenfassend zu diesen Vorverfahrensstadien Ashworth/Redmayne, Criminal Process, S. 2-6. Ausführlicher (auch zur polizeilichen Praxis und zu den Ermittlungsmaßnahmen sowie zum neuen charge and requisition-Anklageverfahren) Sprack, Criminal Procedure, Rn. 3.01-4.22.

${ }^{33}$ Nach Sanders/Young/Burton, Criminal Justice, S. 428: ,„[...] prosecution decisions are part of a continuous process of evaluation and construction."

${ }^{34}$ Nach sect. 4.4-4.5 CCP 2013: „Prosecutors must be satisfied that there is sufficient evidence to provide a realistic prospect of conviction against each suspect on each charge. They must consider what the defence case may be, and how it is likely to affect the prospects of conviction. A case which does not pass the evidential stage must not proceed, no matter how serious or sensitive it may be. The finding that there is a realistic prospect of conviction is based on the prosecutor's objective assessment of the evidence, including the impact of any defence and any other information that the suspect has put forward or on which he or she might rely. It means that an objective, impartial and reasonable jury or bench of magistrates or judge hearing a case alone, properly directed and acting in accordance with the law, is more likely than not to convict the defendant of the charge alleged. This is a different test from the one that the criminal courts themselves must apply. A court may only convict if it is sure that the defendant is guilty. "

35 Nach sect. 4.8 CCP 2013: „It has never been the rule that a prosecution will automatically take place once the evidential stage is met. A prosecution will usually take place unless the prosecutor is satisfied that there are public interest factors tending against prosecution which outweigh those tending in favour. In some cases the prosecutor may be satisfied that the public interest can be properly served by offering the offender the opportunity to have the matter dealt with by an out-of-court disposal rather than bringing a prosecution." 
Strafverfolgung sogar ganz absehen. ${ }^{36}$ Sie können auch darauf entscheiden, dass im konkreten Fall eine (informal) warning statt einer formalen Anklage zu befürworten oder dass eine formal (police or conditional) caution zweckmäßiger als eine offizielle Strafverfolgung ist. Auch weitverbreitet sind die out-of-court penalties. ${ }^{37}$ Es ist beispielsweise möglich, dass im Gegenzug zur Zahlung eines erhöhten Geldbetrags seitens eines der Steuerhinterziehung Verdächtigten die zuständige Behörde (z.B. das Zollamt) von der Klageerhebung absieht. Die Polizei kann ebenfalls nach ihrem Ermessen bei Verkehrsdelikten fixed penalty notices verhängen; außerdem gibt es die Möglichkeit der penalty notices for disorder, die bei Delikten minderer Schwere wie etwa theft from a shop von der Polizei verhängt werden können. ${ }^{38}$

Darüber hinaus können nach der Klageerhebung und bis zum Beginn des Hauptverfahrens diverse „Zwischenverfahren“ (wie bail hearings, pre-trial reviews oder plea and case management hearings) zur Evaluation des Anklageinhalts sowie zur vorläufigen Klärung bestimmter Beweisangelegenheiten und anderer technischer Fragen stattfinden. Kontinuierlich finden zudem in mehreren Verfahrensstadien plea bargaining-Kontakte zwischen Anklage und Verteidigung statt, die eventuell zu einer abgesprochenen Erledigung des Straffalles führen können. ${ }^{39}$

\section{- Erkenntnisverfahren und Gerichtsbarkeit}

Im Rahmen des herkömmlichen Erkenntnisverfahrens werden nun hauptsächlich Straftaten ermittelt, die erstinstanzlich ${ }^{40}$ entweder im Wege einer sogenannten trial on indictment oder im Wege einer sogenannten summary trial abgeurteilt werden müssen. Eine trial on indictment findet grundsätzlich ${ }^{41}$ als reine jury trial vor dem Crown Court - in der Regel öffentlich und in Anwesenheit des Angeklagten - ${ }^{42}$ statt. Der Angeklagte muss sich zunächst zu einem formal written statement of

36 Siehe insgesamt sect. 3.3, 4.1-5.12 CCP 2013.

37 Siehe zu den „out-of-court disposals“ sect. 7.1-7.2 CCP 2013.

38 Mehr Details dazu und zum Ermessensspielraum bei der Einleitung einer Strafverfolgung bei Sprack, Criminal Procedure, Rn. 5.01-5.41.

39 Siehe die Alternativen zu einer prosecution bzw. zu einer vollständigen trial zusammenfassend bei Ashworth/Redmayne, Criminal Process, S. 4-7, 8-9. Zu der plea-Phase i.V.m. den plea bargaining-Möglichkeiten Sprack, Criminal Procedure, Rn. 10.51-10.53, 17.17-17.32.

40 Für einen Überblick zu den englischen Strafgerichten, einschließlich der höheren Gerichtsbarkeit, insb. the High Court / (the Divisional Court of) the Queen's Bench Division, the Court of Appeal (Criminal Division), the House of Lords und sein Nachfolger, the UK Supreme Court, sowie speziellerer Gerichtsarten (z.B. the Youth Court), Darbyshire, Legal System, S. 183-192; ausführlicher Slapper/Kelly, English Legal System, S. 233-274.

${ }^{41}$ Es ist auch möglich, dass bestimmte trials on indictment vor einem einzigen Berufsrichter stattfinden, z.B. in jury tampering-Fällen, dazu Blackstone's Criminal Practice, $\S$ D13.74-D13.81; Sprack, Criminal Procedure, Rn. 19.01-19.12.

42 Siehe sect. 38.2. CPR 2014. 
charges, das ,indictment ${ }^{\text {43 }}$ genannt wird, und $\mathrm{zu}$ jedem einzelnen darin enthaltenen Anklagepunkt (counts) darüber äußern, ob er sich für schuldig (guilty) oder nicht schuldig (not guilty) erklärt. ${ }^{44}$ Das Gericht wird mit einem vorsitzenden verfahrensleitenden Berufsrichter (judge) besetzt, der primär für Fragen zur Zulässigkeit von Beweismitteln (admissibility of evidence) und für alle Rechtsfragen (matters of law) zuständig ist; daneben gibt es die Geschworenenbank (d.h. ausschließlich aus zwölf Laien bestehende jury), ${ }^{45}$ die kollektiv für die Beurteilung der Tatsachenfragen (matters of fact) und für das endgültige Treffen der Entscheidung hinsichtlich der Schuld (verdict) zuständig ist. Die jurors sind weder berechtigt noch verpflichtet, ihre Entscheidung zu begründen. Die Verhängung der Strafe (sentencing) obliegt dem Richter allein. ${ }^{46}$ Die reinen jury trials sind tief in der altenglischen Tradition verwurzelt und nach wie vor als ein zentrales Element der angloamerikanischen Rechtstradition allgemein anerkannt. Ihre Besonderheiten werden als primäre Grundlage für theoretische Untersuchungen und rechtspolitische Reformdiskussionen im Bereich des Straf- und Beweisverfahrens herangezogen, obwohl solche reinen jury-Verfahren gegenwärtig in der englischen Rechtsordnung tatsächlich sehr selten stattfinden. ${ }^{47}$

Die heute für die Mehrheit der streitigen Straffälle angewandten summary trials sind bench trials vor dem magistrates' court. Es wird allgemein angenommen, dass solche Gerichtsverfahren in der Praxis weniger formal als die Crown CourtVerfahren ablaufen, dass sich aber die diagnostischen Beweisverfahrensstrukturen nicht erheblich unterscheiden bzw. dass solche trials nicht unbedingt weniger umfassend sind. ${ }^{48}$ Bei einer summary trial muss sich zunächst der Angeklagte für schuldig oder nicht schuldig bezüglich der Begehung des Delikts erklären, das in der bzw. in jeder einzelnen Beschuldigungsschrift (,information“ oder „written charge") aufgeführt ist. Die Hauptverhandlung findet nur vor Richtern/magistrates

43 Im Glossar der CPR 2014 wird der Begriff ,,indictment“ wie folgt definiert: ,the document containing the formal charges against a defendant - a trial in the Crown Court cannot start without this." Siehe auch die Definition in Archbold, § 1-1.

44 Siehe zu den technischen Details sect. 3.24., 38.4.-38.5., 38.9.-38.10. und Part 14 CPR 2014.

45 Zur Besetzung der jury siehe u.a. Sprack, Criminal Procedure, Rn. 18.01-18.62. Siehe auch die neu eingeführten Regeln in sect. 38.6.-38.8. und Part 39 CPR 2014.

46 Weitere Details zur trial on indictment u.a. bei Slapper/Kelly, English Legal System, S. 245-249, 272; analytischer Sprack, Criminal Procedure, Rn. 1.01-1.05, 14.03-21.44, 22.02-22.04.

${ }^{47}$ Hierzu siehe schon unter Teil 1, I.B.2.a) m.w.N.

48 Zusammenfassend zur praktischen Bedeutung der Unterscheidung zwischen trial on indictment und summary trial u.a. Sprack, Criminal Procedure, Rn. IN.08, 8.45-8.47, 10.50-10.74. Der Begriff „,summary“ deutet nicht auf abgekürzte Hauptverhandlungen hin; nach Elliott/Quinn, English Legal System, S. 429: „Summary' refers to the process of ordering the defendant to attend the court by summons, a written order usually delivered by post which is the most frequent procedure adopted in the magistrates' courts." 
(oft auch als justices of the peace bezeichnet) ohne getrennte Geschworenenbank statt. Besetzt wird das Gericht dabei meistens entweder mit einem Berufsrichter (district judge) oder mit zwei bzw. drei Laien-magistrates; ${ }^{49}$ die Laienrichter werden insbesondere bei Rechtsfragen und bei prozesstechnischen Angelegenheiten in weitem Umfang von juristisch ausgebildeten clerks oder legal advisers unterstützt. Die Entscheidung über sämtliche Angelegenheiten obliegt aber letztendlich allein den richterlichen Personen: Die magistrates, Laien oder Berufsrichter, sind gleichzeitig für alle Beweis-, Rechts- und Tatsachenfragen und somit für die Entscheidung über die Schuld verantwortlich. Für Rechtsmittelzwecke können schriftliche (Teil-)Begründungen des Urteils der magistrates verlangt werden. ${ }^{50}$ Die Verhängung der Strafe obliegt ebenso den magistrates, jedoch kann der bench unter Umständen den Verurteilten an das Crown Court für die Strafzumessungsphase verweisen. $^{51}$

Die für jeden konkreten Straffall passende Gerichts- und Verfahrensart (mode of trial) wird bei ordentlichen Prozessen durch Einteilung der Delikte in die drei im Folgenden genannten großen Kategorien und entsprechend der vorgebrachten Beschuldigung bestimmt. Vor dem Crown Court werden hauptsächlich die offences triable only on indictment verhandelt, die die schwersten Straftaten umfassen (wie z.B. murder, manslaughter, rape, robbery). Vor dem magistrates' court werden zunächst die offences triable only summarily verhandelt, die Deliktsformen minderer Schwere betreffen (wie z.B. dropping litter, road traffic offences, drinkdriving offences, assaulting a constable in the execution of his duty, common assault). Darüber hinaus gibt es Delikte mittlerer Schwere, die mit Blick unter anderem auf ihre konkrete Schwere nach den jeweiligen Fallumständen als offences triable either way klassifiziert werden können (wie z.B. theft, dangerous driving, most forms of burglary, unlawful wounding, indecent assault, handling stolen goods, obtaining property by deception). ${ }^{52}$

49 Sprack, Criminal Procedure, Rn. 1.06, bemerkt: „The great majority of magistrates are lay men and women, but since most magistrates serve as such for many years, and will normally sit in court at least twice a month, they become familiar with summary proceedings and are not 'complete amateurs' like the average juror. [...] A minority of magistrates are district judges, i.e., full-time, paid magistrates [...] One major difference between district judges and lay magistrates is that the former may, and normally do, sit alone to try cases, whereas at least two lay magistrates are required to try a case, and it is normal for them to sit in benches of three." Zur Besetzung des magistrates' court siehe insb. sect. 10, 14, 27A, 121, 148, 150 MCA und The Justices of the Peace (Size and Chairmanship of Bench) Rules 2005.

50 Siehe auch sect. 37.3.(5)-(6), 37.14.(2)(c) CPR 2014.

${ }^{51}$ Mehr zu den magistrates' courts bei Darbyshire, Legal System, S. 183-185; Slapper/Kelly, English Legal System, S. 234-240, 248-249, 272; eingehend Sprack, Criminal Procedure, Rn. 1.06, 6.01-6.15, 10.01-10.76.

52 Dazu und zu den Klassifizierungskriterien Sprack, Criminal Procedure, Rn. 1.07, 8.01-8.08. Siehe auch die Definitionen in Schedule 1 to the Interpretation Act 1978. 
Die offences triable either way - in der Praxis eine große Anzahl von Straffällen - können entweder on indictment vor dem Crown Court oder summarily vor dem magistrates' court verhandelt werden. Äußert der Angeklagte schon im Einleitungsverfahren zur Bestimmung der Gerichtsart seine Absicht, sich für schuldig zu erklären, wird sein Geständnis als guilty plea im Rahmen einer summary trial behandelt, an die sich meistens direkt die Strafzumessungsphase anschließen wird. Falls er dagegen die Absicht ausdrückt, sich für nicht schuldig hinsichtlich eines Delikts triable either way zu erklären, muss anschließend das magistrates' court nach den diversen konkreten Fallumständen die geeignete Art des Hauptverfahrens bestimmen. Auch wenn die magistrates befinden, dass der betreffende Fall eher zur Verhandlung vor dem magistrates' court geeignet ist, kann sich der Angeklagte trotzdem für das jury-Verfahren vor dem Crown Court entscheiden. Dagegen kann der Angeklagte ein Verfahren vor dem magistrates' court nicht erzwingen. Die Anklage kann ihrerseits ihren Standpunkt zur geeigneten mode of trial erläutern, hat aber grundsätzlich keine entsprechenden Entscheidungsbefugnisse. Nachdem die Gerichtsart endgültig festgelegt wurde, können wie bei den anderen Deliktskategorien (triable only summarily und triable only on indictment) die eigentlichen Schulderklärungen und Beweisführungsprozesse direkt vor dem magistrates' court bzw. das Verfahren vor dem Crown Court folgen, wobei Letzterem eventuell (heute nur noch begrenzt) bestimmte ,Zwischenverfahren“ zur Überprüfung der Tragweite des Anklagevorbringens und der Beweise und somit zur Filtrierung der Anklagepunkte vorangehen können. ${ }^{53}$

\section{Die Grundsätze des Beweisrechts und -verfahrens}

Im funktionalen Sinne reguliert das englische Beweisrecht (law of evidence) allgemein die Sammlung und Bewertung von Beweisen durch die verschiedenen Akteure des (Straf-)Prozesses. Die Erforschung der Wahrheit hinsichtlich umstrittener oder unsicherer Tatsachenfragen (questions of fact), die sich auf materielle Rechte, Verpflichtungen und rechtliche Haftung beziehen, steht dabei im Mittelpunkt: $^{.54}$

In the criminal process crucial decisions about the guilt of a suspect have to be made at an early stage by the police officers and prosecutors on the basis of the evidence available to them. The ultimate inquirer is the court or tribunal charged with the determination of the particular legal dispute or other proceeding. If the proceeding reaches the stage of a trial or hearing before the court or tribunal it is the law of evidence which regulates the

${ }^{53}$ Mehr Details zur Bestimmung der mode of trial sowie zu den verschiedenen ,Zwischenverfahren", die den Verweis eines Straffalles an das Crown Court (konkreter) determinieren können (insb. preliminary hearings, sending for trial hearings bzw. committal proceedings, die jedoch seit dem 28.5.2013 komplett abgeschafft worden sind, und application to dismiss proceedings), bei Sprack, Criminal Procedure, Rn. 8.09-8.49, 13.0113.83; siehe auch zu den technischen Details Part 9 CPR 2014.

${ }^{54}$ Dennis, Evidence, Rn. 1.002. Vgl. auch Spencer, in: Delmas-Marty/Spencer (Hrsg.), European Criminal Procedures, S. 636-637. 
process of proof in the trial or hearing. This is not to say that the law of evidence is exclusively trial-centred, although the trial tends to be the focus of attention [...]. Much of the law of evidence is concerned with the presentation and use of evidence at trial but an important part deals with the pre-trial processes involving the collection of evidence. For example, the Police and Criminal Evidence Act 1984 ("PACE") and its associated Codes of Practice contain a detailed set of rules of conduct for police officers engaged in obtaining evidence relating to the commission of an offence. The reception of evidence at trial may be significantly affected by non-compliance with these rules.

Im rechtstechnischen Sinne gibt es grundsätzlich drei Kategorien von formellen Beweismitteln zum gerichtlichen Gebrauch (judicial evidence): „the testimony of witnesses“ (zeugenbasierter Beweis); „documentary evidence“ (urkundenbasierter Beweis); und „real evidence/exhibits“ (insb. material objects, reconstructions, mechanical recordings usw.). ${ }^{55}$ Sämtliche Beweise werden nur dann in Form der vorgenannten Beweismittel in das Hauptverfahren eingeführt und vom jeweiligen schuldfeststellenden Spruchkörper für seine Entscheidung wahrgenommen, wenn sie: erstens relevant für die bessere Determinierung der Wahrscheinlichkeit der Existenz oder Nichtexistenz einer im Verfahren infrage gestellten materiellen Tatsache sind (relevance); zweitens nicht aus dem Verfahren durch den verfahrensleitenden Richter (als Zuständigen für Rechtsfragen) ausgeschlossen werden, was aufgrund einer der vielen exclusionary rules, wie etwa der hearsay-Regel, möglich wäre (admissibility); drittens vom verfahrensleitenden Richter nach seinem (aus dem Gesetz oder dem Common Law sich ergebenden) Ermessen und in Bezug auf die konkreten Fallumstände nicht als unzulässig angesehen werden (exclusionary discretion). ${ }^{56}$

Hinsichtlich des letztgenannten richterlichen Ermessens zum Beweisausschluss hebt sich vor allem die „,common law-Warnung“ heraus, dass Beweise mit einer erheblichen ,prejudicial" ${ }^{\text {"57 }}$ Wirkung - etwa bei cases of similar fact evidence; cases of cross-examination of the accused on his previous convictions and bad character; cases of voluntary but unreliable confessions; cases of gruesome pictures - auszuschließen sind. ${ }^{58}$ Von größerer praktischer Bedeutung ist

55 Siehe dazu Dennis, Evidence, Rn. 12.001-12.021. Siehe auch weitere Klassifizierungen (direct evidence, circumstantial evidence, real evidence, collateral evidence, testimonial evidence, formalities, agreed evidence, views and demonstrations, informal evidence) bei Roberts/Zuckerman, Criminal Evidence, S. 109-126.

${ }^{56}$ Hierzu Dennis, Evidence, Rn. 1.003-1.014, 3.001-3.046; siehe auch Roberts/Zuckerman, Criminal Evidence, S. 96-109, die jedoch unter der allgemeinen Kategorie der ,admissibility standards" sowohl die exclusionary rules als auch die exclusionary discretionFälle betrachten.

57 Dennis, Evidence, Rn. 1.003: „The main application of the common law discretion is to exclude evidence the prejudicial effect of which outweighs its probative value. Probative value refers to the potential weight of the evidence [...], whereas prejudicial effect refers to the tendency of evidence to prejudice the court against the accused, so as to lead the court to make findings of fact against him for reasons not related to the true probative value of the evidence."

58 Dennis, Evidence, Rn. 3.028 m.w.N. 
das gesetzliche richterliche Ermessen zum Beweisausschluss, das in sect. 78 PACE $^{59}$ vorgesehen ist: Es geht hierbei um den Ausschluss ${ }^{60}$ von rechtswidrig oder in unfairer Weise erlangten Beweisen (improperly obtained evidence, z.B. im Rahmen von polizeilichen Durchsuchungen oder agent provocateur-Fällen) der Anklage, die sonst durch ihre Zulassung zu erheblichen Verletzungen der Verfahrensfairness führen könnten. ${ }^{61}$ In der Originalfassung lautet die Regelung in sect. 78(1) PACE, die meistens in Zusammenhang mit den vorgenannten FairnessPrinzipien der EMRK anzuwenden ist:

78. Exclusion of unfair evidence

(1) In any proceedings the court may ${ }^{62}$ refuse to allow evidence on which the prosecution proposes to rely to be given if it appears to the court that, having regard to all the circumstances, including the circumstances in which the evidence was obtained, the admission of the evidence would have such an adverse effect on the fairness of the proceedings that the court ought not to admit it.

Soweit nun die vorgebrachten Beweise nach den vorgenannten Regeln zugelassen werden, müssen sie am Verfahrensende vom erkennenden Spruchkörper (jury bzw. Berufs- oder Laien-magistrates) berücksichtigt werden. Sie sind dann hinsichtlich ihres Wahrheitsgehalts (truthfulness) vor allem nach Glaubwürdigkeits/Ehrlichkeits- (credibility/honesty) und Zuverlässigkeits-/Genauigkeitserwägungen (reliability/accuracy) zu bewerten. ${ }^{63}$ Heute braucht ein zur Feststellung einer Tatsache allein vorgebrachtes Beweismittel durch weitere Beweismittel grundsätzlich nicht bestätigt zu werden; eine richterliche Warnung an die jury, dass eine Verurteilung lediglich aufgrund unbestätigter Beweise unsicher sein kann, ist ebenso nicht obligatorisch. ${ }^{64}$ Zum Treffen einer verurteilenden Entscheidung müssen je-

59 Siehe auch die „Generalklausel“ in sect. 82(3) PACE und die Regel hinsichtlich der rechtswidrigen Erlangung von Geständnissen in sect. 76 PACE.

${ }^{60} \mathrm{Zu}$ den möglichen Hintergründen (insb. reliability, rights protection, deterrence/ disciplining the police und moral integrity and the legitimacy of the verdict) des Ausschlusses von improperly obtained evidence, siehe Roberts/Zuckerman, Criminal Evidence, S. 179-191; siehe auch Dennis, Evidence, Rn. 3.042-3.046.

${ }^{61}$ Ausführlich dazu Dennis, Evidence, Rn. 3.026-3.046, 8.001-8.035; Roberts/ Zuckerman, Criminal Evidence, S. 176-219.

${ }^{62}$ Siehe jedoch $R v$. Chalkley, [1998] 2 Cr App R 79, 105: ,[...] the task of determining admissibility under s 78 does not strictly involve an exercise of discretion. It is to determine whether the admission of the evidence - 'having regard to all the circumstances, including the circumstances in which the evidence was obtained ... would have such an adverse effect on the fairness of the proceedings that the court ought not to admit it.' If the court is of that view, it cannot logically 'exercise a discretion' to admit the evidence, despite the use of the permissive formula in the opening words of the provision that it 'may refuse' to admit the evidence in that event."

${ }^{63}$ Dennis, Evidence, Rn. 1.003 (sogar die Bewertung des Expertenbeweises ist in diesem Sinne frei, dazu Rn. 20.011).

${ }^{64}$ Zur corroboration and care warnings-Problematik, insb. zu den gesetzlichen Ausnahmen von der Regel, dass keine Bestätigungsbeweise nötig sind (bei treason, perjury, offences of speeding), und zu den (nicht mehr obligatorischen) Anweisungen an die jurors hinsichtlich der „Gefährlichkeit“ jener unbestätigten Beweise, die vor allem die Aussagen 
denfalls die belastenden Beweise eine sehr große Überzeugungskraft gegenüber dem Urteilsfinder ausweisen; Hauptziel ist die Vermeidung von Fehlverurteilungen. Es geht hierbei um die Frage des Beweisstandards proof beyond reasonable doubt, ${ }^{65}$ deren Klärung auf dem grundlegenden Prinzip presumption of innocence (Unschuldsvermutung) basiert, in Verbindung mit der Regelung des burden of proof, die im englischen Strafverfahren grundsätzlich ,zuungunsten“ der Anklage gilt. ${ }^{66}$ Dabei sieht ein zentraler Grundsatz des Beweisverfahrens vor, dass die Anklage die Pflicht zur umfassenden Beweissammlung und zur Präsentation eines überzeugenden (vernünftigerweise zweifelsfreien) Falles hat, wobei der Angeklagte grundsätzlich zu keinem aktiven beweisbezogenen Beitrag verpflichtet ist:

[...] the burden and standard of proof also incidentally structure criminal proceedings so that the prosecution is obliged to make all the running in gathering, organizing, and presenting evidence of crime. In the investigative and pre-trial stages, the accused is not obliged to assist the police or the prosecution to assemble their case, though he may be detained for interview for an initial period [...] and then possibly held 'on remand' if there is sufficient evidence to constitute a prima facie case against him. At trial, the state is required to present convincing evidence proving its case to an exacting standard, whilst the accused is entitled to sit back and say nothing, safe in the knowledge that he will enjoy the benefit of any reasonable doubt. ${ }^{67}$

\section{B. Die vorbereitenden Beweisführungsvorgänge}

Die nachfolgenden Ausführungen betreffen in Übereinstimmung mit der in Teil 1 definierten Modelldichotomie die beweisrelevanten Verfahrensschritte nach der Erhebung der Strafklage, also nach der offiziellen Initiierung eines konkreten

von Komplizen, mutmaßlichen Opfern (in Fällen sexueller Gewalt), Mitangeklagten und Kindern betreffen können, siehe Blackstone's Criminal Practice, §§ F5.1-F5.19.

${ }^{65}$ In der heutigen Gerichtspraxis wird oft eine andere Formulierung verwendet, wie im Fall $R$ v. Majid, [2009] EWCA Crim 2563, Rn. 11 bestimmt wird: ,Judges are advised by the Judicial Studies Board, as they have been for many years, to direct the jury that before they can return a verdict of guilty, they must be sure that the defendant is guilty". Dazu auch Dennis, Evidence, Rn. 11.044-11.045. Zur konkreteren Determinierung des Inhalts des Beweisstandards kann die bekannte Darstellung von Lord Denning im Fall Miller $v$. Minister of Pensions, [1947] 2 All ER 372, hilfreich sein: ,[...] the [...] degree of cogency $[\ldots]$ required in a criminal case before an accused person is found guilty $[\ldots]$ is well settled. It need not reach certainty, but it must carry a high degree of probability. Proof beyond reasonable doubt does not mean proof beyond the shadow of a doubt. The law would fail to protect the community if it admitted fanciful possibilities to deflect the course of justice. If the evidence is so strong against a man as to leave only a remote possibility in his favour which can be dismissed with the sentence 'of course it is possible, but not in the least probable,' the case is proved beyond reasonable doubt, but nothing short of that will suffice."

${ }^{66}$ Ferner dazu mit genaueren Definitionen und Details auch zur gerichtlichen Praxis sowie zu Ausnahmefällen Dennis, Evidence, Rn. 11.001-11.045; Roberts/Zuckerman, Criminal Evidence, S. 220-290.

${ }^{67}$ Roberts/Zuckerman, Criminal Evidence, S. 60 (Fußnoten wurden ausgelassen). 
„Rechtsstreits“ durch Beschuldigung einer bestimmten Person vor Gericht. ${ }^{68}$ Die „polizeilichen“ Ermittlungen im Vorverfahren werden somit hier nicht angesprochen. ${ }^{69}$ Ebenso wenig näher berücksichtigt werden die diversen Absprachemechanismen und die Möglichkeiten für die Verfahrensbeteiligten, auch zu einer Verständigung hinsichtlich der vorzubringenden Tatsachen zu kommen. ${ }^{70}$ Auch nach der Klageerhebung vor dem magistrates' court oder vor dem Crown Court finden gleichwohl gegenwärtig derartige Versuche für eine frühzeitige bzw. vereinfachte Verfahrenserledigung durch Austausch von Vorteilen häufig statt. ${ }^{71}$ Hier geht es jedoch vielmehr, wie schon dargelegt, um die strukturellen Plattformen, die zur institutionellen Infragestellung, Ermittlung und Aufklärung eines streitigen Sachverhalts rechtlich gewährleistet sind.

\title{
1. Die „Aufbereitung“ des Beweismaterials
}

\author{
a) Allgemeine Grundsätze: \\ Strukturen, Waffengleichheit und Objektivitätspflichten
}

Es ist zunächst festzuhalten, dass im englischen Verfahrenssystem keine zentrale (justizielle) Ermittlungsbehörde existiert, die nach der Klageerhebung und bis zur Gerichtsverhandlung alle Beweisaktivitäten in neutraler und autoritativer Weise von der Polizei übernimmt - nicht einmal die erst im Jahr 1985 gegründete „Staatsanwaltschaft" (CPS) besitzt amtliche Ermittlungsbefugnisse. ${ }^{72}$ Dagegen finden ab

${ }^{68}$ Siehe die relevanten Argumente unter Teil 1, II.C.3.a).

${ }^{69}$ Siehe zu den Ermittlungen vor Erhebung der Strafklage, die in England grundsätzlich unabhängig durch die Polizei erfolgen, einführend Sprack, Criminal Procedure, Rn. 3.023.109. Ausführlicher und mit vielen Verweisen auf die eigentliche Praxis Sanders/Young/ Burton, Criminal Justice, S. 60-437.

70 Ausführlich zu den guilty pleas sowie der plea bargaining- und fact bargainingPraxis in England Sanders/Young/Burton, Criminal Justice, S. 438-498. Siehe ferner zur Absprachenproblematik bereits unter Teil 1, I.B.2.a)aa)-bb); Teil 1, I.B.3.b)bb); Teil 1, I.B.4.; Teil 1, II.C.2.d)bb); Teil 1, II.C.2.e)aa)-bb); Teil 1, II.C.3.e) m.w.N.

71 Sanders/Young/Burton, Criminal Justice, S. 438-439, bemerken: „One of the most remarkable features of criminal justice in England and Wales is the tiny proportion of prosecuted cases that result in contested trials. The majority of defendants give up their right to trial by pleading guilty. In 2007 the guilty plea rate in the Crown Court rose to $68 \%$, up 3\% from the year before. A similarly high level of guilty pleas is evident in the magistrates' court, where $67.5 \%$ of cases in $2007 / 08$ resulted in guilty pleas. [...] There are four ways of securing a lighter sentence by pleading guilty: the sentence discount principle, the restrictions on the sentencing powers of magistrates, charge bargaining and 'fact bargaining'. "(Fußnoten wurden ausgelassen).

72 Siehe u.a. Spencer, in: Delmas-Marty/Spencer (Hrsg.), European Criminal Procedures, S. 625. Vgl. sect. 3.2 CCP 2013: „The police and other investigators are responsible for conducting enquiries into any alleged crime and for deciding how to deploy their resources. This includes decisions to start or continue an investigation and on the scope of the investigation. Prosecutors often advise the police and other investigators about possible lines of inquiry and evidential requirements, and assist with pre-charge procedures. [...] 
diesem Zeitpunkt das Zusammentragen der Beweise und die Vorbereitung der Hauptverhandlung in einer solchen Art und Weise statt, dass die beiden zentralen Verfahrensparteien (parties) ${ }^{73}$, namentlich sowohl die Anklage (CPS) als auch die Verteidigung, letztendlich eigene (selbstständige) cases zur nachfolgenden Präsentation vor Gericht „,konstruieren“ bzw. „verfeinern“. 74 Die herrschende Meinung verlangt, dass dabei zwischen den Parteien Waffengleichheit (,equality of arms") herrschen muss. Es ist jedoch zweifelhaft, inwieweit ein ausgeglichenes Kräfteverhältnis tatsächlich möglich ist: Denn die eine Partei, nämlich die Anklage bzw. ihr gerichtlicher Vertreter, ist eigentlich Teil des in wirtschaftlicher, institutioneller und informatorischer Hinsicht meistens besser ,,bewaffneten“ staatlichen Strafverfolgungsmechanismus. ${ }^{75}$ Sämtliche Verfahrensbeteiligten sind jedenfalls normativ verpflichtet, bei der Vorbereitung und Durchführung eines Strafprozesses gemäß der bereits angesprochenen overriding objective nach Part 1 CPR 2014 zu handeln.

Sobald nun eine Person in einem der vorgenannten Wege ${ }^{76}$ offiziell beschuldigt wird, werden die bisher zusammengestellten Verfahrensakten und gesammelten Beweismaterialien normalerweise bei der zuständigen Zweigstelle der CPS eingereicht. Die Letztere wirkt bzw. entscheidet, zumindest formell, unabhängig von der Polizei - auch wenn sie tatsächlich mit ihr eng kooperieren kann. ${ }^{77}$ Die Ankläger nehmen grundsätzlich polizeilich dokumentierte ${ }^{78}$ Beweise bei ihren (Teil-)Entscheidungen zur Fortsetzung einer Strafverfolgung wahr. Sie müssen jedoch die tatsächliche Stichhaltigkeit des polizeilichen Vorbringens auch im Hinblick auf die von der Verteidigung vorgelegten Informationen ständig überprüfen und evaluieren. ${ }^{79}$ Nach Erhebung der Strafklage ist (in der Praxis meistens auf Anweisung der

This is to assist the police and other investigators to complete the investigation within a reasonable period of time and to build the most effective prosecution case. However, prosecutors cannot direct the police or other investigators."

73 Vgl. im Glossar der CPR 2014 zum Wort „party“: ,,a person or organisation directly involved in a criminal case, either as prosecutor or defendant."

${ }^{74}$ Siehe u.a. Dennis, Evidence, Rn. 1.015.

75 Roberts/Zuckerman, Criminal Evidence, S. 14-15, 58-59.

76 Siehe unter Teil 2, II.A.2.

77 Sprack, Criminal Procedure, Rn. 4.10-4.11.

${ }^{78}$ Für das Dokumentieren der polizeilichen Ermittlungen und Beweiserhebungen gelten als Rechtsgrundlage die sect. 22-27 CPIA 1996 und die entsprechend publizierten Codes of Practice. Siehe auch Sprack, Criminal Procedure, Rn. 9.06-9.12.

79 Vgl. sect. 3.3, 3.6 CCP 2013: ,[...] prosecutors primarily consider the evidence and information supplied by the police and other investigators. [...] Prosecutors review every case they receive from the police or other investigators. Review is a continuing process and prosecutors must take account of any change in circumstances that occurs as the case develops, including what becomes known of the defence case. Wherever possible, they should talk to the investigator when thinking about changing the charges or stopping the case. Prosecutors and investigators work closely together, but the final responsibility for the decision whether or not a case should go ahead rests with the CPS.“ 
Anklage) die Durchführung von weiteren offiziellen polizeilichen Ermittlungen nicht ausgeschlossen. ${ }^{80}$

Die Beweisbasis des „Anklagefalles“ (prosecution case) besteht typischerweise aus Protokollen bzw. elektronischen Aufzeichnungen von Zeugen- und Verdächtigenverhören, aus schriftlichen Zeugenerklärungen sowie aus weiterem Urkundenund Sachbeweis. Gleichwohl gibt es oft auch polizeilich gesammelte bzw. in den Händen eines Dritten befindliche Beweise, welche die Anklage im Verfahren gar nicht verwenden möchte; solches ,unused material“ kann aber eventuell Gegenstand von Beweisoffenlegungsvorgängen inter partes sein, insbesondere dann, wenn es sich um Beweise handelt, die zugunsten des „Verteidigungsfalles“ (defence case) wirken können. ${ }^{81}$

Die Verteidigung kann ihrerseits schon nach Erhebung der Klage einen (teilweise beschränkten) Zugang zum Inhalt des prosecution case haben. ${ }^{82}$ Sie besitzt insbesondere ein Einsichtsrecht in Bezug auf die Dokumente, welche die dem Anklagevorbringen zugrunde liegenden Beweise beinhalten, bevor die Crown Court trial beginnt. Ebenfalls vor dem Beginn der ersten magistrates' court-Verhandlung können der Verteidigung die initial details of the prosecution case mitgeteilt werden. Somit wird ihr eine bessere Vorbereitung im Hinblick auf die Verhandlungen ermöglicht, die zur Anhörung der beabsichtigten Schulderklärung (intended plea) des Angeklagten und zur anschließenden Entscheidung über die geeignete mode of trial (bei triable either way offences) bzw. zur anschließenden Beurteilung des Straffalles (bei offences triable only summarily) stattfinden. Hierbei geht es jedoch noch nicht um die umfassenden disclosure-Mechanismen, die auch nicht vorzubringende („unused“ und eventuell entlastende) Beweise betreffen und die des Weiteren selbstständig angesprochen werden. ${ }^{83}$ Jedenfalls kann die hier beschriebene im Voraus stattfindende Kenntnisnahme der grundlegenden Beweisthesen der Anklage dem Anwalt des Angeklagten dabei helfen, sich unter anderem auch in Bezug auf die beweistechnisch geeigneten Verteidigungsstrategien für die Hauptverhandlung zu entscheiden und die entsprechenden „Gegenbeweise“ zusammenzutragen.

Eine extreme Parteilichkeit bei der Vorbereitung der selbstständigen cases der Anklage und der Verteidigung wird normativ keinesfalls gefördert. So wird mit Blick auf die Objektivitätspflichten der Anklage unter anderem in den - den alten

$80 \mathrm{Vgl}$. http://www.cps.gov.uk/legal/d_to_g/disclosure_manual/disclosure_manual_chap ter_15/ (z.B. Nr. 15.14, 15.19, 15.31-15.42) [Stand: Oktober 2014].

$81 \mathrm{Zu}$ diesen Differenzierungen Heaton-Armstrong/Corker/Wolchover, in: Heaton-Armstrong u.a. (Hrsg.), Witness, S. 381-382.

82 Siehe insb. Part 10 CPR 2014 für Verfahren vor dem magistrates' court sowie sect. 9.15. CPR 2014 i.V.m. The Crime and Disorder Act 1998 (Service of Prosecution Evidence) Regulations 2005 bezüglich des Crown Court. Siehe auch Sprack, Criminal Procedure, Rn. 8.09-8.15, 8.49.

83 Siehe unter Teil 2, II.C.2. 
Code of Conduct of the Bar of England \& Wales (CCB 2004) ${ }^{84}$ ergänzenden Written Standards for the Conduct of Professional Work ${ }^{85}$ (in $\S 10.1$ ) Folgendes bestimmt:

Prosecuting counsel should not attempt to obtain a conviction by all means at his command. He should not regard himself as appearing for a party. He should lay before the Court fairly and impartially the whole of the facts which comprise the case for the prosecution and should assist the Court on all matters of law applicable to the case.

Auch die für die Praxis der Anklagebehörde sehr wichtigen Leitlinien des Code for Crown Prosecutors (CCP 2013) ${ }^{86}$ sehen vor, dass die faire, unparteiische, rechtmäßige und objektive Erledigung der Straffälle Priorität hat:

It is the duty of prosecutors to make sure that the right person is prosecuted for the right offence and to bring offenders to justice wherever possible. Casework decisions taken fairly, impartially and with integrity help to secure justice for victims, witnesses, defendants and the public. Prosecutors must ensure that the law is properly applied; that relevant evidence is put before the court; and that obligations of disclosure are complied with. [...] Prosecutors must be fair, independent and objective. [...] Prosecutors must always act in the interests of justice and not solely for the purpose of obtaining a conviction. $^{87}$

Der Verteidiger hat ebenso eine ethisch-rechtliche ${ }^{88}$ Verantwortung gegenüber dem Gericht: Er muss insbesondere das Gericht bei der Justizhandhabung unterstützen; er darf keine rechtswidrigen Mittel zur Förderung und Sicherstellung der Interessen seines Mandanten verwenden; und er darf das Gericht nicht täuschen oder es bewusst bzw. leichtsinnig verleiten. ${ }^{89}$ Die in der Praxis eher einseitige Verfahrensstellung des Verteidigers mit Blick auf seine beweisbezogenen Tätigkeiten

${ }^{84}$ Abrufbar unter https://www.barstandardsboard.org.uk/regulatory-requirements/theold-code-of-conduct/ [Stand: Oktober 2014]. Der CCB wurde seit 6.1.2014 durch das Bar Standards Board Handbook, abrufbar unter http://handbook.barstandardsboard.org.uk/hand book/ [Stand: Oktober 2014] ersetzt.

85 Abrufbar unter https://www.barstandardsboard.org.uk/regulatory-requirements/theold-code-of-conduct/written-standards-for-the-conduct-of-professional-work/

[Stand: Oktober 2014].

86 Unter http://www.cps.gov.uk/publications/code_for_crown_prosecutors/ [Stand: Oktober 2014].

87 Siehe sect. 2.2, 2.4 CCP 2013.

88 Hierzu Roberts/Zuckerman, Criminal Evidence, S. 62-63.

89 Vgl. sect. 302 CCB 2004: ,A barrister has an overriding duty to the Court to act with independence in the interests of justice: he must assist the Court in the administration of justice and must not deceive or knowingly or recklessly mislead the Court." Siehe auch $\S 5.2$ CCB-Written Standards for the Conduct of Professional Work. Vgl. auch Arthur J.S. Hall and Co. v. Simons, [2000] UKHL 38 (Lord Hoffmann, Rn. 3): „Lawyers conducting litigation owe a divided loyalty. They have a duty to their clients, but they may not win by whatever means. They also owe a duty to the court and the administration of justice. They may not mislead the court or allow the judge to take what they know to be a bad point in their favour. They must cite all relevant law, whether for or against their case. They may not make imputations of dishonesty unless they have been given the information to support them. They should not waste time on irrelevancies even if the client thinks that they are important. Sometimes the performance of these duties to the court may annoy the client." 
spiegelt sich allerdings auch auf normativer Ebene offensichtlich wider: ${ }^{90}$ Der Verteidiger ist u.a. verpflichtet, seinen Mandanten vor einer Verurteilung auf der Basis rechtlich unzulässiger Beweise zu schützen. Er soll sich mit seinem Mandanten über die Fallaspekte beraten, und er muss erforderlichenfalls für die Durchführung weiterer privater Ermittlungen sowie für die Ladung von Entlastungszeugen und Experten sorgen.

\section{b) Speziell zum aussagenbasierten Beweis}

aa) Die Beweismittel und der zeugenbasierte Beweis

\section{- Bedeutung des Zeugenbeweises}

Bei der Vorbereitung der gegensätzlichen cases legt sowohl die Anklage als auch die Verteidigung besonderen Wert auf den Zeugenbeweis (testimony of witnesses). Im allgemeinen Sinne ist zunächst unter dem Begriff, ,witness“ eine Person zu verstehen, die ein Ereignis wahrgenommen hat und darüber Auskunft gibt. Im rein prozessualen Kontext wird nach den CPR 2014 als ,witness“ grundsätzlich ,a person who gives evidence, either by way of a written statement or orally in court" bezeichnet. $^{91}$ Auch wenn heute der Zeuge nicht mehr das einzige wichtige und in forensisch komplizierten Straffällen eventuell nicht einmal das zentrale Beweismittel ist, hat der Zeugenbeweis nicht nur eine symbolische ${ }^{92}$ Bedeutung im englischen Strafverfahren. ${ }^{93}$ Eine große Anzahl von komplexen Beweisregeln (darunter die hearsay-Regeln und die testimonial privileges) ${ }^{94}$ betrifft vor allem die Zeugenpraxis. Gleichzeitig hält die prozessual-technische Gestaltung des Zeugenund Expertenbeweises mehr oder weniger Schritt mit den modernen technologischen Entwicklungen, wie etwa die diversen Möglichkeiten zur elektronischen Aufzeichnung der Beweiserhebungen oder zur Durchführung von live-link-Verhören zeigen. ${ }^{95}$

Richtungweisend kann die verfahrensrechtliche Auseinandersetzung mit dem Zeugenbeweis für die konkretere Untersuchung der klassischen Prozessstrukturen und Methoden zur Erhebung und Prüfung von Beweisen sein, die im Zentrum dieser Forschungsarbeit stehen. ${ }^{96}$ Selbstverständlich können die Parteien auch Urkun-

\footnotetext{
${ }^{90}$ Siehe etwa in Bezug auf die Vorbereitung der Verteidigung für eine Verhandlung vor dem Crown Court $\$ 11$ der CCB-Written Standards for the Conduct of Professional Work.

91 Siehe im Glossar der CPR 2014.

92 Dazu Roberts/Zuckerman, Criminal Evidence, S. 291.

93 Vgl. auch Beijer/Cobley/Klip, in: Fennell u.a. (Hrsg.), Criminal Justice, S. 283-286.

94 Siehe u.a. Roberts/Zuckerman, Criminal Evidence, S. 309-320, 364-441.

95 Vgl. z.B. Part 29 CPR 2014. Siehe auch Roberts/Zuckerman, Criminal Evidence, S. 292-294.

96 Vgl. Tapper, Evidence, S. 223: „The most common vehicle of proof is the evidence of witnesses $[\ldots] .$.
} 
den und real evidence (etwa Kameraaufnahmen oder E-Mails) als Beweismittel nach den allgemeinen Regeln und Prinzipien in das Verfahren einführen. Deren Beweiskraft und technische Zulässigkeitsvoraussetzungen - z.B. ob ein Dokument korrekt unterschrieben ist, ob Zeugen für die Bestätigung der Echtheit einer Videoaufnahme vorhanden sind oder ob es sich um eine amtlich beglaubigte bzw. allgemein zuverlässige Kopie oder Aufnahme handelt - sind jedoch in prozessstruktureller Hinsicht von geringem Interesse und daher hier nicht eingehender zu betrachten. Ebenso wenig werden hier die materiellen Voraussetzungen für die Einnahme des Augenscheinsbeweises (views and reconstructions, z.B. eine Ortsbesichtigung) tiefer gehend berücksichtigt; der Augenscheinsbeweis kann sogar während eines jury-Hauptverfahrens angeordnet werden, wobei dann sämtliche Verfahrensbeteiligten (Richter, jurors, Anklage und Verteidigung) auch bei eventuellen out of court-Beweishandlungen immer anwesend sein müssen. ${ }^{97}$

\section{- Vernehmungen im Vor- und Hauptverfahren}

Im Rahmen des umfassender regulierten und auch theoretisch detaillierter bearbeiteten Zeugenbeweises lassen sich die Rollenverteilungen und der Autonomiegrad der Verfahrensparteien während der Beweiserhebungen besonders gut veranschaulichen. Wie bereits angedeutet, finden schon während der staatlichen Ermittlungen im Vorverfahren üblicherweise Zeugenvernehmungen statt; diese werden von der Polizei bzw. anderen Ermittlungsbehörden (möglicherweise elektronisch) aufgezeichnet und danach der CPS sowie eventuell auch der Verteidigung zur Vorbereitung ihrer Beweisthesen mitgeteilt. Umfassende vorgerichtliche Zeugenvernehmungen durch richterliche Behörden finden allgemein nicht statt. ${ }^{98}$ Die (zunächst nach Ansicht der Parteien) wichtigsten Zeugen müssen, soweit sie dazu „fähig“ (competent) ${ }^{99}$ und aussagepflichtig (compellable) ${ }^{100}$ sind, auch vor Gericht im Hauptverfahren persönlich aussagen.

$97 \mathrm{Zu}$ diesen Beweismitteln Dennis, Evidence, Rn. 12.004-12.021; Tapper, Evidence, S. 55-64.

98 Vgl. aber sect. 42-43 Children and Young Persons Act 1933 zu den außergerichtlichen richterlichen Vernehmungen (depositions) von Kindern, die z.B. Opfer sexueller Gewalt sind.

99 Nach sect. 53 Youth Justice and Criminal Evidence Act 1999: „, (1) At every stage in criminal proceedings all persons are (whatever their age) competent to give evidence. [...] (3) A person is not competent to give evidence in criminal proceedings if it appears to the court that he is not a person who is able to - (a) understand questions put to him as a witness, and (b) give answers to them which can be understood. (4) A person charged in criminal proceedings is not competent to give evidence in the proceedings for the prosecution (whether he is the only person, or is one of two or more persons, charged in the proceedings). (5) In subsection (4) the reference to a person charged in criminal proceedings does not include a person who is not, or is no longer, liable to be convicted of any offence in the proceedings (whether as a result of pleading guilty or for any other reason).“ 
Ausnahmsweise können bestimmte vorgerichtliche (meistens polizeiliche) Aufzeichnungen von Zeugenvernehmungen, vor allem Videoaufnahmen der Vernehmungen von Minderjährigen (child witnesses), eigenständig als evidence in chief in das Hauptverfahren eingeführt werden. Ein Kreuzverhör solcher Zeugen im Hauptverfahren ist jedoch keinesfalls ausgeschlossen, auch wenn dieses zum Schutz der Zeugen mit elektronischen Hilfsmitteln (z.B. als live-link-oder screening-Verhör) erfolgen kann. ${ }^{101}$

\section{- Der Angeklagte als Beweisperson}

Der Angeklagte kann nach sect. 53 Youth Justice and Criminal Evidence Act 1999 nur seitens der Verteidigung als Zeuge vorgebracht werden, und nur soweit er sich dafür entscheidet, vor Gericht auszusagen. Dabei gelten jedoch oft besondere Regeln bezüglich der Zulässigkeit, der Beweiskraft und der Art und Weise seiner Vernehmung sowie bezüglich der möglichen Schlussfolgerungen aus einer (unbegründet) ausgebliebenen Aussage nach sect. 35 CJPOA $1994 .{ }^{102}$

bb) Die „Zusammenstellung“ des zeugenbasierten Beweises

\section{- Subjekt und Objekt der Beweisführung}

Der Regelfall in sämtlichen Strafprozessen ist also, dass die Anklage und die Verteidigung ihre Belastungs- und Entlastungszeugen entsprechend bestimmen. ${ }^{103}$ Diese Zeugen müssen dann im Hauptverfahren öffentlich, persönlich und mündlich de novo - wenn auch eventuell unter Berücksichtigung ${ }^{104}$ früherer Aussagen Auskunft geben: Dies geschieht traditionellerweise im Wege von examinations-

100 Dazu Roberts/Zuckerman, Criminal Evidence, S. 307: „The general principle is that all persons competent to give evidence may also lawfully be summoned to testify, and must answer all relevant questions addressed to them in the witness-box". Ausnahmen bilden die diversen testimonial privileges.

$101 \mathrm{Zu}$ den pre-trial recordings von Minderjährigen Tapper, Evidence, S. 237-241. Siehe allgemein die Regeln zu schutzbedürftigen (vulnerable and intimidated) Zeugen und die Möglichkeiten zur richterlichen Anordnung von special measures aufgrund eines Antrags seitens einer Partei oder von Amts wegen in Part 2 Youth Justice and Criminal Evidence Act 1999, wobei insb. hinsichtlich eines child witness die sect. 19, 21, 27-28 anwendbar sind. Siehe auch Part 29 CPR 2014. Vgl. auch die allgemeinen Voraussetzungen für das Abspielen von früher aufgezeichneten video recordings von witness statements anstatt einer mündlichen Aussage vor Gericht in sect. 137-138 CJA 2003 (noch nicht in Kraft). Siehe ferner unter Teil 2, II.D.2.c).

102 Siehe ausführlich dazu Dennis, Evidence, Rn. 13.005-13.015 m.w.N. Thematisch anders gelagert ist das Vorbringen eines Geständnisses (confession) des Angeklagten durch die Anklage, dessen Zulässigkeit im Verfahren der Angeklagte (insb. wenn es erzwungen oder auf unzuverlässiger Weise erlangt wurde) bestreiten kann. Dazu Roberts/Zuckerman, Criminal Evidence, S. 510-537.

103 Siehe ferner unter Teil 2, II.B.2.

104 Siehe sect. 119-120, 122 CJA 2003; sect. 37.4.(5) CPR 2014. 
in-chief (d.h. Verhör durch die Partei, die den jeweiligen Zeugen geladen hat) und von direkt daran anschließenden cross-examinations (durch die Gegenpartei), ${ }^{105}$ wobei jeder Zeuge grundsätzlich nur über Tatsachen berichten darf, von denen er persönliche Kenntnis hat. ${ }^{106}$

\section{- Direkter und indirekter Beweis}

Weitere außergerichtliche Auskünfte und statements ${ }^{107}$ dürfen als indirekter Beweis in die Hauptverhandlung nicht eingeführt werden, soweit keine relevante Ausnahme von den hearsay-Ausschlussregeln existiert. ${ }^{108}$ Der materielle Inhalt dieser komplexen Regeln zum second hand-Beweis kann per se hier nicht gesondert untersucht werden. ${ }^{109}$

105 Zur Präsentation und Prüfung der Beweise siehe unter Teil 2, II.D.2.

$106 \mathrm{Zu}$,the principle of orality“ im englischen Strafprozess Roberts/Zuckerman, Criminal Evidence, S. 291-301. Siehe auch Dennis, Evidence, Rn. 12.002-12.003, 20.001; Ellison, Adversarial, S. 11-12. In $R$ v. Horncastle a.o., [2009] EWCA Crim 964, Rn. 7, 33, wurde u.a. bestimmt: ,The law in England and Wales has [...] always insisted that it is ordinarily essential that evidence of the truth of a matter be given in person by a witness who speaks from his own observation or knowledge. It uses the legal expression 'hearsay' to describe evidence which is not so given, but rather is given second hand, whether related by a person to whom the absent witness has spoken, contained in a written statement of the absent witness, given in the form of a document or record created by him, or otherwise. $[\ldots]$ the ordinary rule must be that witnesses are examined in court - often described as the right of confrontation. As we have said, the law of England and Wales has always recognised that as a vital principle; it is the reason for the rule that hearsay is inadmissible unless there is specific provision for it.“

107 Für die Zwecke des hearsay-Beweises wird in sect. 115(2) CJA 2003 bestimmt: „A statement is any representation of fact or opinion made by a person by whatever means; and it includes a representation made in a sketch, photofit or other pictorial form."

108 Nach $R$ v. Horncastle a.o., [2009] EWCA Crim 964, Rn. 8-9: „The obvious potential weakness of hearsay evidence is that the fact finder never sees the person who gives the evidence which he must evaluate, and the parties cannot ask supplementary or testing questions which are likely to help judge the truthfulness and accuracy of the evidence, when those attributes are in doubt. Conversely, if the person cannot be brought to court, an exclusionary rule will deprive the fact finder of evidence which may well help him to arrive at the correct answer in the case, and in many instances will eliminate evidence of whose truthfulness and/or accuracy there is little room for real doubt. The default rule of the criminal law of England and Wales has always been that hearsay is inadmissible. Unmodified, however, such a blanket rule created many examples of injustice so that it was always subject to many exceptions, some recognised by the courts as developments of the common law, and others created by statute. In consequence the law of hearsay in England and Wales became complex and not always internally consistent $[\ldots]$. “

109 Nach Part 11 CJA 2003 betreffen wichtige Kategorien von hearsay statements, die als Beweismittel zugelassen werden können: die Fälle, in denen die Auskunftsperson im Hauptverfahren unerreichbar ist (z.B. wegen Todes, Krankheit oder weil sie faktisch nicht ergreifbar ist), wobei der Zeuge aber identifiziert sein muss; die Fälle, in denen die betroffene Person aus Furcht (,fear") kein Zeugnis geben will, wobei aber die Einführung der Auskunft in die Hauptverhandlung nur dann zulässig ist, wenn dies aus Justizinteressen geboten ist und durch das Fehlen der Möglichkeit zur Prüfung des Beweises die Verfah- 
Das prozessuale Vorbringen von hearsay evidence ${ }^{110}$ seitens der Parteien erfolgt nach Part 34 CPR 2014: Bei bestimmten Kategorien von hearsay evidence (wie: evidence admissible in the interests of justice; evidence where a witness is unavailable; multiple hearsay) muss die Partei, die den entsprechenden Beweis in die Hauptverhandlung einführen will, zuerst der anderen Partei und der Gerichtsbehörde eine diesbezügliche Benachrichtigung (,notice“) zustellen. ${ }^{11}$ Falls keine Benachrichtigung stattfindet, steht es dem Gericht frei, entweder den hearsayBeweis nicht zuzulassen oder aus dem Ausbleiben der Benachrichtigung eventuell negative Schlussfolgerungen zu ziehen. Bei anderen hearsay-Kategorien (wie: $b u$ siness documents; res gestae; previous statements of witness) ist eine Im-VorausZustellung einer solchen Benachrichtigung nicht notwendig. In jedem Fall kann eine Partei innerhalb bestimmter Fristen Einwand (objection) gegen die Einführung von hearsay evidence erheben, worauf das Gericht über die Zulässigkeit der hearsay statement als Beweis entsprechend dem materiellen Gehalt der hearsayRegeln ${ }^{112}$ entscheiden muss. Immerhin ist es für die Parteien möglich, hearsay evidence durch Einverständnis (bzw. Nicht-Widerlegung) in das Verfahren verbindlich einzuführen. ${ }^{113}$

Darüber hinaus ist es unter bestimmten Voraussetzungen ${ }^{114}$ für die Zeugen möglich, förmliche written statements (zusammen mit einer Erklärung zur „Wahrheit““ des betreffenden Inhalts) vorgerichtlich anzufertigen; diese statements können dann in sämtliche Hauptverfahren durch diejenige Partei eingeführt werden, zu deren Gunsten die Zeugen Auskunft geben. Eine written statement kann im gleichen

rensfairness nicht riskiert wird; die Fälle, in denen business documents ausgefertigt und mitgeteilt worden sind; und auch die Fälle, in denen die Äußerungen unter solchen Bedingungen gemacht wurden, die zugleich für ihre Zuverlässigkeit sprechen (z.B. wegen starker Gefühle oder Erregung der Person zur Zeit ihrer Äußerung, wodurch diese glaubhaft wird, oder bei Geständnissen, bei Komplizenaussagen und bei Schlussfolgerungen von expert witnesses). Ausführlich zu rule against hearsay u.a. Blackstone's Criminal Practice, $\S \S \mathrm{F} 15.1-\mathrm{F} 17.102$.

110 Im Glossar der CPR 2014 wird der Begriff „hearsay evidence“ folgendermaßen definiert: „oral or written statements made by someone who is not a witness in the case but which the court is asked to accept as proving what they say."

111 In dieser Benachrichtigung muss die Partei nach sect. 34.2.(2) CPR 2014 Folgendes mitteilen: ,(i) identify the evidence that is hearsay, (ii) set out any facts on which that party relies to make the evidence admissible, (iii) explain how that party will prove those facts if another party disputes them, and (iv) explain why the evidence is admissible; and (c) attach to the notice any statement or other document containing the evidence that has not already been served."

112 Als Ausgangspunkt dient sect. 114(1) CJA 2003: „In criminal proceedings a statement not made in oral evidence in the proceedings is admissible as evidence of any matter stated if, but only if - (a) any provision of this Chapter or any other statutory provision makes it admissible, (b) any rule of law preserved by section 118 makes it admissible, (c) all parties to the proceedings agree to it being admissible, or (d) the court is satisfied that it is in the interests of justice for it to be admissible."

113 Siehe sect. 114(1)(c) CJA 2003 i.V.m. sect. 34.4. CPR 2014.

114 Siehe sect. 9 CJA 1967. 
Maße wie eine persönliche gerichtliche Aussage derselben Person als Beweis zugelassen werden. Diejenige Partei, die eine solche written statement als Beweis in das Hauptverfahren einführen will, muss den anderen Parteien und der Gerichtsbehörde vor der Verhandlung eine Kopie der schriftlichen Auskunft zustellen. Der Angeklagte kann unter Einhaltung einer bestimmten Frist gegen die Einführung einer written statement als Ersatz für eine direkte mündliche Aussage Einspruch erheben. Das Gericht kann aufgrund eines Antrags seitens einer Partei oder von Amts wegen die Einführung der schriftlichen Äußerung als Beweis ablehnen und stattdessen die persönliche Vernehmung des Zeugen vor Gericht anordnen. ${ }^{115}$

\section{cc) Die „Vorbereitung“ des zeugenbasierten Beweises}

In Bezug auf die Möglichkeiten der Parteien zur vorgerichtlichen Vorbereitung der Zeugen in der Hoffnung, strategisch günstige Beweisergebnisse im Hauptverfahren zu erzielen, sei hier nur auf die normative Lage in England hingewiesen; diese unterscheidet sich eventuell erheblich von der informellen Anwaltspraxis, wie sie unter anderem in angloamerikanischen Filmen oft dargestellt wird. Allgemein sind die parteiliche Vorbereitung der zu ladenden Zeugen im Vorfeld eines gerichtlichen Verhörs durch intensives coaching (Training), intensive rehearsals (Proben) oder Mitteilung der Auskünfte anderer Zeugen sowie auch solche (eventuell strafbare) Verhaltensweisen, welche die Zeugen ermuntern, unwahre bzw. unvollständige Aussagen zu machen, grundsätzlich nicht erlaubt. ${ }^{116}$ In der grundlegenden Entscheidung des Court of Appeal im Fall $R v$. Momodou wurde zum Thema Zeugenvorbereitung festgelegt, dass es auch in prozesspsychologischer Hinsicht einen großen Unterschied zwischen einem verbotenen gezielten (fallspezifischen) Training und der erlaubten Vorbereitung (Vertrautwerden) des Zeugen auf allgemein übliche Umstände einer gerichtlichen Vernehmung gibt: ${ }^{117}$

There is a dramatic distinction between witness training or coaching, and witness familiarisation. Training or coaching for witnesses in criminal proceedings (whether for prosecution or defence) is not permitted. This is the logical consequence of well-known principle that discussions between witnesses should not take place, and that the statements and proofs of one witness should not be disclosed to any other witness. [...] The witness should give his or her own evidence, so far as practicable uninfluenced by what anyone else has said, whether in formal discussions or informal conversations. The rule reduces, indeed hopefully avoids any possibility, that one witness may tailor his evidence in the light of what anyone else said, and equally, avoids any unfounded perception that he may have done so. These risks are inherent in witness training. Even if the training takes place one-to-one with someone completely remote from the facts of the case itself, the witness may come, even unconsciously, to appreciate which aspects of

115 Siehe ferner Part 27 CPR 2014.

116 Tapper, Evidence, S. 228 m.w.N. Siehe auch sect. 705 CCB 2004; praxisorientierter $\S 6$ CCB-Written Standards for the Conduct of Professional Work. Ferner Blackstone's Criminal Practice, $\S \S$ D15.100-D15.105. Siehe auch Ambos, FS für Volk, S. 10-12.

$117 R$ v. Momodou, [2005] EWCA Crim 177, Rn. 61-62. 
his evidence are perhaps not quite consistent with what others are saying, or indeed not quite what is required of him. An honest witness may alter the emphasis of his evidence to accommodate what he thinks may be a different, more accurate, or simply better remembered perception of events. A dishonest witness will very rapidly calculate how his testimony may be "improved". [...] the risk that training or coaching may adversely affect the accuracy of the evidence of the individual witness is constant. [...] This principle does not preclude pre-trial arrangements to familiarise witness with the layout of the court, the likely sequence of events when the witness is giving evidence, and a balanced appraisal of the different responsibilities of the various participants. [...] None of this however involves discussions about proposed or intended evidence.

Zulässig scheinen dagegen einfache „ermittelnde“ Gespräche zwischen einer Partei und den ,eigenen“ Zeugen zu sein, wie vor allem das Beispiel der pre-trial interviews von Zeugen durch die Anklage zeigt: Solche Gespräche können insbesondere zum Zweck der Würdigung der Zuverlässigkeit eines Zeugen bzw. der betreffenden Beweislage stattfinden, und ihre Ergebnisse sind grundsätzlich auch der Verteidigung mitzuteilen. ${ }^{118}$ Neuerdings wurden aber auch Vorschriften aufgenommen, welche die Durchführung von pre-trial interviews der durch die Verteidigung zu ladenden Zeugen durch die Strafverfolgungsbehörden erlauben. Konkreter: nach Erhebung der Strafklage können - meistens auf Anweisung der Anklage und im Rahmen der disclosure-Tätigkeiten, ${ }^{119}$ wobei die Verteidigung unter anderem nun auch ausführliche Angaben hinsichtlich der zu ladenden Zeugen machen muss - weitere offizielle Ermittlungen ${ }^{120}$ und vor allem ,ppolizeiliche Interviews“ von „Zeugen der Verteidigung“ stattfinden; solche Zeugen können jedoch in diesem Fall nicht zur Aussage gezwungen werden. ${ }^{121}$

\section{dd) Zum Expertenbeweis}

\section{- Expertenbegriff}

Ein Zeuge darf im englischen Strafverfahren normalerweise nur über sein persönliches Wissen bezüglich konkreter Tatsachen aussagen, wobei die Äußerung eigener Meinungen, Vermutungen, Schlussfolgerungen und wertender Beurteilun-

118 Siehe dazu das von der CPS erlassene Pre-trial witness interviews: Code of practice, abrufbar unter http://www.cps.gov.uk/victims_witnesses/resources/interviews.html [Stand: Oktober 2014].

119 Dazu unter Teil 2, II.C.2.

$120 \mathrm{Mehr}$ dazu unter http://www.cps.gov.uk/legal/d_to_g/disclosure_manual/disclosure manual_chapter_15/[Stand: Oktober 2014].

121 Siehe sect. 21A CPIA 1996 und Code of practice for arranging and conducting interviews of witnesses notified by the accused, abrufbar unter http://www.legislation .gov.uk/ukpga/1996/25/pdfs/ukpgacop_19960025_en.pdf [Stand: Oktober 2014], wobei in der Preamble des Letzteren bemerkt wird: ,This code of practice is issued under section $21 \mathrm{~A}$ of the Criminal Procedure and Investigations Act 1996 ('the Act'). It sets out guidance that police officers and other persons charged with investigating offences must follow if they arrange or conduct interviews of proposed witnesses whose details are disclosed to the prosecution by an accused person pursuant to the disclosure provisions in Part I of the Act." 
gen zum Geschehen verboten ist. ${ }^{122}$ Eine grundsätzliche Ausnahme von dieser Regel betrifft die Meinungen und Schlussfolgerungen von Experten: Für die Zwecke eines ,fair and accurate factfinding ${ }^{\text {"123 }}$ kann das Gericht unter bestimmten Voraussetzungen als Beweis die wertenden Aussagen von Personen zulassen, die über spezielle (insbesondere berufliche oder wissenschaftliche) Fähigkeiten und Fachkenntnisse verfügen. Solche Expertenzeugen (expert witnesses) sollen mit ihrem besonderen Wissen die mangelnden Erfahrungen und Kenntnisse des Gerichts auf ihrem spezifischen Fachgebiet ergänzen. ${ }^{124}$

Für die Parteien ist die praktische Bedeutung des Expertenvorbringens als formaler Haupt- oder Gegenbeweis angesichts der heutigen rasanten und höchst komplexen forensischen und technologischen Entwicklungen besonders groß. Aber auch im Rahmen von ,privaten“ Vorermittlungen können sogar nicht offengelegte Untersuchungen von Experten für die strategische Planung der Parteien (insbesondere der Verteidigung) von Wert sein. ${ }^{125}$

\section{- Einführung des Beweises}

Im förmlichen Verfahren kann jede Partei neben den normalen Zeugen zur Ermöglichung des Beweises konkreter Tatsachen ihre „eigenen“ Expertenzeugen vorbringen. Die Entscheidung über die Zulassung der Aussage der Expertenzeugen, die vor allem nach Notwendigkeitskriterien, z.B. aufgrund von Schwierigkeiten bei der Analyse von real evidence, erfolgt, obliegt letztendlich dem Richter. ${ }^{126}$ Die Expertenzeugen werden unmittelbar von der einen oder der anderen Partei ausgewählt und mit der vorgerichtlichen Anfertigung von Gutachten ${ }^{127}$ und/oder mit der persönlichen Aussage vor Gericht beauftragt. Die Partei, die Expertenbeweise in das Verfahren einführen will, muss zuerst - unter Vorbehalt anderer disclosureVorschriften $^{128}$ - den Gerichtsbeamten und jeder anderen Partei einen Expertenbericht mit dem wesentlichen Beweisinhalt und mit Informationen über die Glaub-

122 Detaillierter (auch zu den Problemen einer klaren Trennung zwischen fact und opinion) Dennis, Evidence, Rn. 20.001-20.004.

123 Dennis, Evidence, Rn. 20.002. Nach der grundlegenden schottischen Entscheidung zu den Expertenzeugen Davie v. Magistrates of Edinburgh, 1953 S.C. 34, 40: ,[...] their duty is to furnish the judge or jury with the necessary scientific criteria for testing the accuracy of their conclusions, so as to enable the judge or jury to form their own independent judgment by the application of these criteria to the facts proved in evidence."

$124 \mathrm{Zu}$ den materiellen Definitionen, Zulässigkeitsvoraussetzungen und weiteren Aspekten des Expertenbeweises u.a. Dennis, Evidence, Rn. 20.005-20.025.

125 Hierzu Roberts/Zuckerman, Criminal Evidence, S. 469-471, 502.

126 Dennis, Evidence, Rn. 20.006.

127 Ein schriftliches Gutachten kann nur mit Zustimmung des Gerichts oder der Parteien in das Verfahren eingeführt werden, soweit der Experte mündlich nicht aussagt; siehe zu den Zulässigkeitsvoraussetzungen von „expert reports“ sect. 30 CJA 1988. Siehe auch die neue Regel in sect. 33.3.(4) CPR 2014.

128 Vgl. sect. 81 PACE und sect. 20(3) CPIA 1996. 
würdigkeit des Experten zustellen. ${ }^{129}$ Sie muss auf Antrag der Gegenpartei Kopien von grundlegenden Untersuchungsprotokollen (z.B. Testergebnissen) einreichen bzw. deren Inspektion erlauben. Bei Verstoß gegen die vorgenannte Regel ist die Einführung des Expertenbeweises in das Verfahren nicht möglich, wenn jede andere Partei oder das Gericht der Einführung nicht zustimmen. ${ }^{130}$

\section{- Stellung und Pflichten des Experten und Gefahr der Befangenheit}

In allen Fällen ergibt sich das Problem der Einseitigkeit des Expertenbeweises, die im Gegensatz zu der anerkannten Rolle des Experten als gerichtliches Hilfsmittel für die Zwecke einer präzisen Tatsachenfeststellung steht. In normativer Hinsicht hat der Experte nicht nur eine Pflicht gegenüber seinem Mandanten (d.h. der jeweiligen Partei), sondern primär eine „Hilfspflicht“ gegenüber dem Gericht. ${ }^{131}$ In sect. 33.2. CPR 2014 wird dazu Folgendes bestimmt:

(1) An expert must help the court to achieve the overriding objective by giving opinion which is - (a) objective and unbiased; and (b) within the expert's area or areas of expertise. (2) This duty overrides any obligation to the person from whom the expert receives instructions or by whom the expert is paid [...].

Dessen ungeachtet sind für die Auswahl (und die Instruktion) der Expertenzeugen im Strafverfahren weiterhin die Parteien verantwortlich. Das englische Strafgericht hat - im Gegensatz zum Zivilgericht - im vorhandenen normativen und strukturellen Rahmen grundsätzlich nicht die Möglichkeit, Sachverständige aus irgendeiner Liste auszuwählen und selbstständig zu laden bzw. weitere forensische Expertenuntersuchungen anzuordnen. ${ }^{132}$ Das gilt sogar dann, wenn es Uneinigkeit zwischen den Experten der Parteien gibt, eventuell mit der seltenen Ausnahme des allgemeinen Common Law-Ermessens zur richterlichen Ladung von Zeugen für die Sicherstellung der fair trial. ${ }^{133}$ Die Gefahr der Voreingenommenheit ist daher keinesfalls ausgeschlossen. ${ }^{134}$ Logischerweise werden die von einer Partei beauftrag-

129 Zum Inhalt dieses Expertenberichts siehe sect. 33.4. CPR 2014.

130 Sect. 33.3. CPR 2014 (auch bezüglich der neuen Möglichkeit zur einverständlichen Einführung von summary conclusions).

131 Siehe eingehender Dennis, Evidence, Rn. 20.017 mit Rechtsprechungsverweisen.

132 Siehe aber die Ausnahme der richterlichen Auswahl eines gemeinsamen Experten für mehrere Mitangeklagte in sect. 33.7.-33.8. CPR 2014.

133 Dazu und zu den Reformvorschlägen hinsichtlich der „,court-appointed expert witnesses“ Roberts/Zuckerman, Criminal Evidence, S. 504-509. Zu früheren Justizirrtümern aufgrund von befangenem expert evidence, die zu solchen (bis heute jedoch nicht realisierten) Reformvorschlägen geführt haben, Jackson, in: McConville/Wilson (Hrsg.), Handbook, S. 343.

134 Im Fall $R v$. Ward, [1993] 2 All ER 577, 627, wurde z.B. bemerkt: „Forensic scientists may become partisan. The very fact that the police seek their assistance may create a relationship between the police and the forensic scientists. And the adversarial character of the proceedings tend to promote this process. Forensic scientists employed by the government may come to see their function as helping the police. They may lose their objectivity." 
ten Experten letztendlich nach dem Kriterium ausgewählt, inwieweit sie das Vorbringen (case) dieser Partei tatsächlich unterstützen können. Eine auf dem Zufallsprinzip beruhende objektive Auswahl der auf dem jeweiligen Fachgebiet aussagenden Personen kann nicht sichergestellt werden; es ist beispielsweise auch möglich, dass ein von einer Partei vorgeschlagener Medizinexperte nicht als wissenschaftlich vollwertiger Vertreter der medizinischen Gemeinde anerkannt ist und trotzdem vor Gericht Auskunft gibt. ${ }^{135}$

Immerhin wurde zumindest mit Blick auf die Vermeidung von Manipulationen des Expertenbeweises im Fall $R v$. Momodou prinzipiell gegen eine gezielte vorgerichtliche Vorbereitung (training) der Expertenzeugen durch die Parteien Folgendes geäußert: ${ }^{136}$

[...] the principle does not prohibit training of expert and similar witnesses in, for example, the technique of giving comprehensive evidence of a specialist kind to a jury, both during evidence-in-chief and in cross-examination, and, another example, developing the ability to resist the inevitable pressure of going further in evidence than matters covered by the witnesses' specific expertise. The critical feature of training of this kind is that it should not be arranged in the context of nor related to any forthcoming trial, and it can therefore have no impact whatever on it.

\section{Die Bestimmung des Umfangs der Beweiserhebungen}

\section{a) Beweisführung und Offenkundigkeit}

Durch die bisherigen Ausführungen ist bereits klar geworden, dass jede Partei (Anklage und Verteidigung) im englischen Strafverfahren ihre ,eigenen“ Beweismittel vorbringt und die von der anderen Partei vorgebrachten Beweismittel in der Hauptverhandlung prüfen kann. Es gibt gleichwohl bestimmte sachliche Angelegenheiten, deren Plausibilität der Richter allein erklärt, der gleichzeitig entscheidet, dass keine gesonderte Beweisvorbringung seitens der Parteien erforderlich ist. Hierbei handelt es sich um die ,judicial notice" von facts, wie bei matters of common knowledge oder historical issues. Solche facts können so offensichtlich und unbestreitbar sein, dass das Gericht selbst sichere Kenntnis davon (eventuell nach gewissen begrenzten Ermittlungen) haben kann und dass deswegen diesbezüglich keine formelle (zeitverschwendende) Beweisführung durch die Parteien nötig ist. ${ }^{137}$

Einen Grenzfall bildet hierbei die ,judicial notice“ von Tatsachen auf der Basis einer lediglich persönlichen Vorkenntnis des Richters, die nicht als common knowledge angesehen werden kann. Charakteristisch ist der Fall Ingram v. Percival, ${ }^{138}$

135 Dazu Dennis, Evidence, Rn. 20.018 m.w.N. Siehe auch Roberts/Zuckerman, Criminal Evidence, S. 478-481, 504-509.

$136 R$ v. Momodou, [2005] EWCA Crim 177, Rn. 62.

137 Zum judicial notice-Regelungskomplex Dennis, Evidence, Rn. 12.028-12.037; Roberts/Zuckerman, Criminal Evidence, S. 169-175.

138 Ingram v. Percival, [1969] 1 Q.B. 548. 
wobei für das angeklagte Delikt ,illegal fishing in tidal waters“ kein Beweis seitens der Anklage hinsichtlich der Existenz von ,tidal water“ am Tag des Geschehens vorgebracht wurde. Die Richter haben durch ,judicial notice“ ihre Kenntnis erklärt, dass das Wasser zu diesem Zeitpunkt tatsächlich ,tidal“ war; der Angeklagte wurde daher verurteilt, obwohl die betreffende Tatsache in der lokalen Gemeinde nicht unbedingt allgemein bekannt war und obwohl keine relevante Beweisführung durch die Parteien stattgefunden hatte. Wie problematisch eine solche Entscheidung im Hinblick auf den Grundsatz sein kann, dass die Beweisbestimmung und -führung primär in den Händen der Parteien liegen müssen, zeigt die Bewertung von Dennis: ${ }^{139}$

The justices had in effect acted as extra prosecution witnesses to supply the missing proof of an element of the offence. Since the "proof" was by way of judicial notice, no cross-examination or evidence in rebuttal was possible. If this case were to recur today it would probably involve a breach of art. 6 of the ECHR. The defendant would effectively be denied the opportunity to examine the witnesses against him; the principle of "equality of arms" would be violated.

\section{b) Das Vorbringen von Beweisen: Zeugenladungen und Beweisanträge}

\section{- Verantwortlichkeit für die Bestimmung des Umfangs der Beweiserhebungen}

Im Allgemeinen besitzen die Parteien beträchtliche Autonomie bei der Beweisführung und insbesondere bei der Bestimmung des Umfangs der Beweiserhebungen. Ein wichtiges Paradigma stellt hierfür die Befugnis zu Zeugenladungen (the power to call witnesses) dar. Nach dem allgemeinen Prinzip der party autonomy ${ }^{140}$ können sowohl die Anklage als auch die Verteidigung entscheiden, welche Zeugen zur Aussage vor Gericht zu laden bzw. aufzurufen sind und in welcher Reihenfolge $^{141}$ diese $\mathrm{zu}$ vernehmen sind.

\section{- Zeugenladungen, Beweisanträge und die Rolle des Richters}

Die Verteidigung ist keinesfalls verpflichtet, Zeugen aufzurufen, auch wenn das Nichtaufrufen von Zeugen, welche den case der Verteidigung unterstützen könnten, vor allem faktische Konsequenzen zulasten des Angeklagten haben kann. ${ }^{142}$ Die Beweislast der Anklage ist dagegen schon in normativer Hinsicht viel größer. Ihre Beweiserhebungsautonomie und das weite Ermessen bei der (Nicht-)Ladung

139 Dennis, Evidence, Rn. 12.037.

140 Dazu Dennis, Evidence, Rn. 13.003.

141 Eine Begrenzung des diesbezüglichen Ermessens der Parteien existiert im Fall einer eventuellen Vernehmung des Angeklagten, der laut sect. 79 PACE grundsätzlich vor der Vernehmung der übrigen Verteidigungszeugen aussagen muss (, unless the court in its discretion otherwise directs"), dazu auch Tapper, Evidence, S. 292 m.w.N.

${ }_{142}$ Mehr dazu bei Dennis, Evidence, Rn. 13.004. Vgl. zu den Voraussetzungen einer (Experten-)Zeugenladung sect. 22.4. CPR 2014 i.V.m. sect. 6C-6D CPIA 1996. 
von Zeugen zur Verankerung des prosecution case können jedoch teilweise wegen Fairnesserwägungen ${ }^{143}$ eingeschränkt werden. Letztendlich muss die Anklage alle Personen, die unmittelbare Zeugen zentraler Tatsachen und gleichzeitig (nach Meinung der Anklage) ${ }^{144}$ glaubwürdig sind, laden, auch wenn solche Zeugen in negativer bzw. widersprüchlicher Weise für das Anklagevorbringen wirken könnten. Von Bedeutung für die Verfahrensfairness kann dabei ebenso die vollständige Durchführung von Beweisoffenlegungen bezüglich der zu ladenden und der nicht zu ladenden Zeugen sein; somit kann die Verteidigung selbst unter anderem die für sie ,passenden“ Zeugen laden oder die Vermeidung einer Zeugenladung seitens der Anklage bestreiten.

Insgesamt gelten die folgenden Prinzipien: Die Anklage hat grundsätzlich ein Ermessen bei der Auswahl der Zeugen, auf die sie ihren Fall stützen will. Die Aussagen dieser Zeugen muss sie der Verteidigung zustellen. Gleichzeitig hat die Anklage in der Regel Offenlegungspflichten hinsichtlich eventueller substantieller Aussagen von nicht zu ladenden Zeugen. Die Zeugen, deren Aussagen die Anklage zugestellt hat, müssen von ihr auch vor Gericht geladen werden; die Anklage hat jedoch ein gewisses Ermessen bei der Entscheidung, ob die von ihr geladenen Zeugen überhaupt zur mündlichen Aussage aufgerufen bzw. der Verteidigung zur Verfügung gestellt werden. Die Anklage muss in fairer und gerechter Weise handeln; sie ist aber nicht verpflichtet, Zeugen aufzurufen, die das Anklagevorbringen untergraben können, soweit diese Zeugen unglaubwürdig sind. Die Anklage muss im Prinzip alle Zeugen aufrufen, deren Aussage ihrer Meinung nach einen unmittelbaren Beweis zentraler Tatsachen darstellt, es sei denn, die Anklage betrachtet diese Zeugen als nicht glaubwürdig. Die Anklage ist nicht verpflichtet, Zeugen aufzurufen, die nur das Anklagevorbringen untergraben können; sie ist aber grundsätzlich verpflichtet, solche Zeugen der Verteidigung zur Verfügung zu stellen, sodass die Letztere diese Zeugen selbst laden kann. Genauer: ${ }^{145}$

(1) The prosecution have a discretion in deciding which witnesses it will rely on [...] and will serve their statements accordingly. It must normally disclose any potentially material statement not served.

(2) Counsel for the prosecution must have at court all witnesses whose statements have been served, whether as part of the depositions or as additional evidence, upon whom he intends to rely, unless any such witness is conditionally bound or the defence agree that he need not attend because, for example, his evidence can be admitted.

143 In diesem Kontext zu „overall duty of fairness“ und zur Anklage ,as a minister of justice“" siehe $R$ v. Russell-Jones, [1995] 1 Cr App R 538, 544.

144 Mehr dazu bei Tapper, Evidence, S. 291-292.

${ }_{145} R$ v. Brown and Brown, [1997] 1 Cr App R 112, 113-114. Siehe auch die grundlegende Entscheidung $R v$. Haringey Justices, ex parte Director of Public Prosecutions, [1996] 1 All ER 828; und die relevanten CPS-Leitlinien zur Auswahl der Anklagezeugen, abrufbar unter http://www.cps.gov.uk/legal/v_to_z/selection_of prosecution_witnesses/ [Stand: Oktober 2014]; zur Wahrnehmung der Zeugeninteressen siehe auch Rn. 2.11 in http://www.justice.gov.uk/downloads/victims-and-witnesses/vulnerable-witnesses/achievingbest-evidence-criminal-proceedings.pdf [Stand: Oktober 2014]. 
(3) Counsel for the prosecution enjoys a discretion whether to call or to tender a particular witness whom he has required to attend. Further, counsel may refuse even to tender a witness, notwithstanding that the witness's statement has been included in the depositions, if he decides that the witness is unworthy of belief. Our adversarial system requires counsel for the prosecution to present a case against the defendant. He must always act in the interests of justice and to promote a fair trial, and his discretion must be exercised with these objects in mind. He should not refuse to call a witness merely because his evidence does not fit in exactly with the case he is seeking to prove. But he need not call a witness whose evidence is inconsistent with, or contrary to, the case he is prosecuting since such witnesses' evidence will be unworthy of belief if his case be correct.

(4) Counsel for the prosecution ought normally to call, or offer to call, all the witnesses who give direct evidence of the primary facts of the case unless the prosecutor regards the witness's evidence as unworthy of belief.

(5) It is for counsel for the prosecution to decide which witnesses give direct evidence of the primary facts of the case. He may reasonably take the view that what a particular witness has to say is, at best, marginal.

(6) Counsel for the prosecution is also the primary judge of whether or not a witness to the material events is unworthy of belief.

(7) Counsel for the prosecution, properly exercising his discretion, is not obliged to offer a witness upon whom the Crown does not rely merely in order to give the defence material with which to attack the credit of other witnesses on whom the Crown does rely. The law does not insist that the prosecution are obliged to call a witness for no purpose other than to assist the defence in its endeavours to destroy the Crown's own case. Such a course would merely serve to confuse a jury. The Crown's obligation is to make such witnesses available to the defence so that the defence can call them if they choose to do so. The jury will then be clear that evidence is led by the party who wishes to rely upon it and can be tested by cross-examination by the other party, if that party wishes to challenge the evidence.

Die Anklage muss also im Rahmen ihres Ermessens bei den Zeugenladungen und -vorführungen gerecht und in fairer Weise für den Angeklagten handeln. Sonst kann der Richter als ultima ratio die von der Anklage unterlassenen Zeugenladungen selbst übernehmen. ${ }^{146}$ Die Befugnis des Richters zur Zeugenladung bleibt allerdings in der Gerichtspraxis ein Ausnahmefall - der ,neutrale“ Richter greift in die Bestimmung der Beweiserhebungen durch die Parteien grundsätzlich nicht ein, es sei denn, dies erscheint vor allem wegen unerwarteter Umstände im Interesse der Gerechtigkeit als notwendig. ${ }^{147}$ Nach den gesetzlichen Vorschriften können jeden-

146 Siehe $R$ v. Oliva, [1965] 3 All ER 116, 122: „The prosecution do not, of course, put forward every witness as a witness of truth, but where the witness's evidence is capable of belief then it is their duty, well recognised, that he should be called, even though the evidence that he is going to give is inconsistent with the case sought to be proved. Their discretion must be exercised in a manner which is calculated to further the interest of justice, and at the same time be fair to the defence. If the prosecution appear to be exercising that discretion improperly, it is open to the judge of trial to interfere and in his discretion in turn to invite the prosecution to call a particular witness, and if they refuse there is the ultimate sanction in the judge himself calling that witness." Siehe auch $R v$. Brown and Brown, [1997] 1 Cr App R 112, 113-115.

147 Nach $R$ v. Grafton, [1992] 4 All ER 609, 610, 613 m.w.N.: „Trials on indictment in England and Wales are adversarial. The prosecution decides who to charge and with what 
falls sämtliche Strafgerichte nicht nur auf Antrag der Parteien, sondern auch aus eigener Initiative die Anwesenheit und Aussage von Zeugen durch Erlass von witness summonses, warrants oder orders verlangen. ${ }^{148}$ Auch im Fall der vorgerichtlichen Anfertigung von schriftlichen witness statements seitens der Parteien kann das Gericht, wie schon gesehen, sogar von Amts wegen die Einführung der schriftlichen Äußerung als Beweis ablehnen und stattdessen die persönliche Vernehmung des Zeugen anordnen. ${ }^{149}$

\section{c) Einverständliche Bestimmung der Beweiserhebungen}

Demgemäß gilt, trotz des gerade beschriebenen Ermessensspielraums des Richters, weiterhin die strukturelle Besonderheit, dass die Parteien (und nicht das Gericht) für die Bestimmung des Umfangs der Beweiserhebungen primär verantwortlich sind, als zentrales Prinzip des englischen Beweisverfahrens. Ein weiteres Beispiel hierfür betrifft die verbindliche Einführung von hearsay evidence in das Verfahren durch Zustimmung der Parteien (admissible by agreement). ${ }^{150}$

Ferner gibt es im Allgemeinen die Möglichkeit, dass die eine Partei die von der anderen Partei eventuell zugegebenen Fakten als eindeutigen - nicht mehr bestreitbaren - Beweis einführt (a party introduces in evidence a fact admitted by another party), bzw. die Möglichkeit für beide Parteien, die Existenz eines Faktes gemeinsam zuzugeben (parties jointly admit a fact). ${ }^{151}$ Die Umgehung der normalen Be-

offences. They present the case for the Crown. Counsel for the defence presents the case for the accused. The judge is there to hold the ring impartially and to direct the jury on the law [...] It is well established that the judge in a criminal trial has power to call a witness. It is, however, a power which should be used most sparingly and rarely exercised [...] Where the power is exercised, it should be for achieving the ends of justice and fairness." Siehe auch $R v$. Haringey Justices, ex parte Director of Public Prosecutions, [1996] 1 All ER 828, 835 m.w.N. Ferner Dennis, Evidence, Rn. 13.003; Pattenden, Judicial Discretion, S. 102-106; Tapper, Evidence, S. 291. Siehe auch Blackstone's Criminal Practice, $\S \S \mathrm{D} 18.10-\mathrm{D} 18.12$.

148 Details in Part 28 CPR 2014 i.V.m. sect. 97 MCA und sect. 2, 2D, 3, 4 Criminal Procedure (Attendance of Witnesses) Act 1965.

149 Sect. 27.4.(4) CPR 2014.

150 Siehe sect. 114(1)(c) CJA 2003 i.V.m. sect. 34.4. CPR 2014. Vgl. auch zur Einführung von evidence of bad character sect. 100(1), 101(1) CJA 2003 i.V.m. sect. 35 CPR 2014.

151 Sect. 37.6. CPR 2014 und generell sect. 10 CJA 1967: „Proof by formal admission. (1) Subject to the provisions of this section, any fact of which oral evidence may be given in any criminal proceedings may be admitted for the purpose of those proceedings by or on behalf of the prosecutor or defendant, and the admission by any party of any such fact under this section shall as against that party be conclusive evidence in those proceedings of the fact admitted. (2) An admission under this section - (a) may be made before or at the proceedings; (b) if made otherwise than in court, shall be in writing; (c) if made in writing by an individual, shall purport to be signed by the person making it [...]; (d) if made on behalf of a defendant who is an individual, shall be made by his counsel or solicitor. (3) An admission under this section for the purpose of proceedings relating to any matter shall be 
weisverfahrensstrukturen durch die Einführung von agreed evidence wird hauptsächlich durch Erwägungen der Verfahrensökonomie begründet. ${ }^{152}$

\section{d) Case Management}

\section{- Verfahrensökonomie}

Ebenfalls aus Gründen der Verfahrensökonomie ${ }^{153}$ sollen schließlich heute im Vorfeld sowie während einer Hauptverhandlung vor dem magistrates' court oder dem Crown Court richterliche case management-Tätigkeiten stattfinden. Diese können unter anderem die (autoritative) Klärung diverser Beweisangelegenheiten im Voraus bzw. in einem möglichst frühen Stadium betreffen. ${ }^{154}$

\section{- Gegenstand, Ziele und Rollenverteilung}

Dabei kann die Art und Weise der Beweiserhebungen sowie (wenn auch eher indirekt ${ }^{155}$ die Bestimmung ihres Umfangs von eventuellen richterlichen Initiativen beeinflusst werden - etwa in Bezug auf den Umfang der Zeugenladungen, die Rei-

treated as an admission for the purpose of any subsequent criminal proceedings relating to that matter (including any appeal or retrial). (4) An admission under this section may with the leave of the court be withdrawn in the proceedings for the purpose of which it is made or any subsequent criminal proceedings relating to the same matter." Mehr dazu bei Dennis, Evidence, Rn. 12.022. Siehe auch die neue Regel zur Möglichkeit der einverständlichen Einführung von summary conclusions von Expertenzeugen in sect. 33.3. CPR 2014.

152 Roberts/Zuckerman, Criminal Evidence, S. 120-121, bemerken dazu: „It is difficult to know how much evidence is routinely presented to the jury in this consensual fashion, but the practice is probably endemic - just as guilty pleas and directed acquittals, rather than contested trials, are the humdrum reality of the greater part of criminal litigation. 'Section 9 witness statements' and formal admissions under section 10 reflect the pragmatic imperatives of expediting trial proceedings and minimizing avoidable costs, considerations which appear especially compelling where there is no material dispute between the parties about a particular matter. Moreover, paring down the issues should help the jury get to the heart of the matter and concentrate its fact-finding energies on the main points in dispute. Restricting the jury's focus to a limited number of disputed facts might therefore conceivably be in everybody's best interests, though this is by no means inevitable. A guilty accused with no real defence may prefer to see the fact-finder confused and diverted away from a clear-headed appraisal of the evidence, for example, whilst prosecutors also sometimes have tactical reasons for seeking to open up or close down particular lines of inquiry." (Fußnoten wurden ausgelassen).

153 U.a. $R$ v. Jisl, [2004] EWCA Crim 696, Rn. 114-118.

154 Siehe Part 3 CPR 2014. Siehe auch die Vorschriften zu den Vorverhandlungen bzw. zu den Anfangsstadien einer Gerichtsverhandlung (pre-trial und preparatory hearings), welche die Zulassung von Beweisen sowie die richterliche Klärung anderer (technischer) Rechts- und Beweisfragen (einschließlich der Bestimmung/Offenlegung der Anklage- und Verteidigungs-cases) betreffen können, in sect. 9 CJA 1987, sect. 29, 31, 40 CPIA 1996 und sect. 8A MCA. Dazu Archbold, §§ 4-112-4-156; siehe auch sect. 33.6. CPR 2014 zur pre-hearing discussion of expert evidence, dazu auch Dennis, Evidence, Rn. 20.015.

155 Vgl. Otton, in: McConville/Wilson (Hrsg.), Handbook, S. 325. 
henfolge der Beweispräsentationen oder die Dauer der Beweisführungen. Im selben Rahmen können außerdem sämtliche Parteien (und somit auch die Verteidigung) verpflichtet werden, die streitigen Punkte des jeweiligen Konflikts so früh wie möglich eindeutig und öffentlich zu bestimmen - dadurch sollen vor allem parteiliche Angriffe aus dem Hinterhalt verhindert werden. Charakteristisch wurde hierzu im Fall $R(D P P) v$. Chorley Justices Folgendes bestimmt: ${ }^{156}$

If a Defendant refuses to identify what the issues are, one thing is clear: he can derive no advantage from that or seek, as appears to have happened in this case, to attempt an ambush at trial. The days of ambushing and taking last-minute technical points are gone. They are not consistent with the overriding objective of deciding cases justly, acquitting the innocent and convicting the guilty.

Die grundlegenden beweisrelevanten case management-Vorschriften befinden sich in Part 3 CPR 2014. ${ }^{157}$ Sie bestimmen die Pflicht des Gerichts zum andauernden aktiven case management des jeweiligen konkreten Falls. Dies beinhaltet unter anderem: die frühe Bestimmung der faktischen Fragen; die Bereitstellung von sinnvollen timetables und Beobachtungsmechanismen; die effektive und prozessökonomische Bestimmung der Art und Weise der Beweispräsentationen; die Verwendung von technologischen Hilfsmitteln im Verfahren; die Möglichkeiten zur Zusammenarbeit der Parteien; sowie mit Blick auf das Crown Court-Verfahren die Durchführung von vorbereitenden plea and case management hearings. ${ }^{158}$ Die Parteien selbst haben die Verpflichtung zur Förderung eines effektiven case management:

Part 3 CPR

The duty of the court

3.2.-(1) The court must further the overriding objective by actively managing the case.

(2) Active case management includes- (a) the early identification of the real issues; (b)

$156 R(D P P)$ v. Chorley Justices, [2006] EWHC 1795 (Admin), Rn. 26. Siehe auch u.a. Malcolm v. DPP (DC), [2007] 1 WLR 1230, 1239-1241; und $R$ v. Gleeson, [2004] $1 \mathrm{Cr}$ App R 406, Rn. 36, wobei folgende Schlussfolgerungen des Auld Report 2001, S. 459460 , angenommen werden: ,To the extent that the prosecution may legitimately wish to fill possible holes in its case once issues have been identified by the defence statement, I can understand why, as a matter of tactics, a defendant might prefer to keep his case close to his chest. But that is not a valid reason for preventing a full and fair hearing on the issues canvassed at the trial. A criminal trial is not a game under which a guilty defendant should be provided with a sporting chance. It is a search for truth in accordance with the twin principles that the prosecution must prove its case and that a defendant is not obliged to inculpate himself, the object being to convict the guilty and acquit the innocent. Requiring a defendant to indicate in advance what he disputes about the prosecution case offends neither of those principles. Equally untenable is the suggestion that defence by ambush is a permissible protection against the possibility of dishonesty of police and/or prosecutors in the conduct of the prosecution. It may not be "the function of law to trust those who exercise lawful powers.' But a criminal justice process cannot sensibly be designed on a general premise that those responsible for law are likely to break it. In those cases where, unfortunately, the police or other public officers are dishonest, the criminal trial process itself is the medium for protection and exposure."

157 Dazu Sprack, Criminal Procedure, Rn. 2.14-2.17.

158 Über die Vorbereitung des Crown Court-Verfahrens siehe die neuen Regeln in sect. 3.13.-3.26. CPR 2014, die den Part 15 CPR 2013 ersetzt haben. 
the early identification of the needs of witnesses; (c) achieving certainty as to what must be done, by whom, and when, in particular by the early setting of a timetable for the progress of the case; (d) monitoring the progress of the case and compliance with directions; (e) ensuring that evidence, whether disputed or not, is presented in the shortest and clearest way; (f) discouraging delay, dealing with as many aspects of the case as possible on the same occasion, and avoiding unnecessary hearings; (g) encouraging the participants to co-operate in the progression of the case; and (h) making use of technology. (3) The court must actively manage the case by giving any direction appropriate to the needs of that case as early as possible.

The duty of the parties

3.3. Each party must- (a) actively assist the court in fulfilling its duty under rule 3.2 , without or if necessary with a direction; and (b) apply for a direction if needed to further the overriding objective.

The court's case management powers

3.5.-(1) In fulfilling its duty under rule 3.2 the court may give any direction and take any step actively to manage a case unless that direction or step would be inconsistent with legislation, including these Rules. (2) In particular, the court may- (a) nominate a judge, magistrate or justices' legal adviser to manage the case; (b) give a direction on its own initiative or on application by a party; (c) ask or allow a party to propose a direction; (d) for the purpose of giving directions, receive applications and representations by letter, by telephone or by any other means of electronic communication, and conduct a hearing by such means; (e) give a direction (i) at a hearing, in public or in private, or (ii) without a hearing; (f) fix, postpone, bring forward, extend, cancel or adjourn a hearing; (g) shorten or extend (even after it has expired) a time limit fixed by a direction; (h) require that issues in the case should be (i) identified in writing, (ii) determined separately, and decide in what order they will be determined; and (i) specify the consequences of failing to comply with a direction. ${ }^{159}$

Case preparation and progression

3.9. - (1) At every hearing, if a case cannot be concluded there and then the court must give directions so that it can be concluded at the next hearing or as soon as possible after that. (2) At every hearing the court must, where relevant- [...] (c) set, follow or revise a timetable for the progress of the case, which may include a timetable for any hearing including the trial or (in the Crown Court) the appeal; [...] (3) In order to prepare for the trial, the court must take every reasonable step- (a) to encourage and to facilitate the attendance of witnesses when they are needed; and (b) to facilitate the participation of any person, including the defendant.

Conduct of a trial or an appeal

3.11. In order to manage a trial or an appeal, the court - (a) must establish, with the active assistance of the parties, what are the disputed issues; (b) must consider setting a

159 Sect. 3.5. CPR 2014, Note: „Under some other legislation, including Parts 33, 34 and 35 of these Rules, if a party fails to comply with a rule or a direction then in some circumstances - (a) the court may refuse to allow that party to introduce evidence; (b) evidence that that party wants to introduce may not be admissible; (c) the court may draw adverse inferences from the late introduction of an issue or evidence. See also- (a) section 81(1) of the Police and Criminal Evidence Act 1984(a) and section 20(3) of the Criminal Procedure and Investigations Act 1996(b) (advance disclosure of expert evidence); (b) section 11(5) of the Criminal Procedure and Investigations Act 1996(c) (faults in disclosure by accused); (c) section 132(5) of the Criminal Justice Act 2003(d) (failure to give notice of hearsay evidence).“ 
timetable that (i) takes account of those issues and of any timetable proposed by a party, and (ii) may limit the duration of any stage of the hearing; (c) may require a party to identify (i) which witnesses that party wants to give evidence in person, (ii) the order in which that party wants those witnesses to give their evidence, (iii) whether that party requires an order compelling the attendance of a witness, (iv) what arrangements are desirable to facilitate the giving of evidence by a witness, (v) what arrangements are desirable to facilitate the participation of any other person, including the defendant, (vi) what written evidence that party intends to introduce, (vii) what other material, if any, that person intends to make available to the court in the presentation of the case, and (viii) whether that party intends to raise any point of law that could affect the conduct of the trial or appeal; and (d) may limit (i) the examination, crossexamination or re-examination of a witness, and (ii) the duration of any stage of the hearing.

\section{Kenntnisnahme und Offenlegung von Beweisen}

\section{Die Kenntnis der Beweisergebnisse des Vorverfahrens seitens des Richters}

Im Vorfeld einer Hauptverhandlung vor dem magistrates' court oder dem Crown Court werden, wie schon erläutert, die vorhandenen Beweise von den Parteien eigenständig zusammengetragen, und gegensätzliche Beweisthesen werden selbstständig vorbereitet. ${ }^{160}$ Nach Erhebung der Strafklage und bis zum tatsächlichen Beginn des Gerichtsverfahrens findet keine zentral-amtliche Untersuchung des Geschehens statt, auch wenn ergänzende polizeiliche Ermittlungen nun auf Anweisung der Anklagebehörde weiterhin möglich sind. Ebenso wenig wird ein umfassendes amtliches Dossier, das alle Verfahrensdaten und Beweise erschöpfend beinhaltet bzw. dokumentiert, zusammengestellt. Die Ergebnisse und Materialien der polizeilichen Ermittlungen, einschließlich der Zeugenverhörprotokolle, werden meistens der CPS zur Vorbereitung des prosecution case mitgeteilt, und in manchen Fällen zum Teil auch dem Verdächtigen unmittelbar vorgelegt.

Die Anklage muss dann vor Beginn der Hauptverhandlung die Grundzüge ihrer vorzubringenden Beweisthesen - eventuell einschließlich Verhörprotokollen und anderer beweiskräftiger Dokumente - der Verteidigung und dem Gericht (konkreter: dem court officer) mitteilen. ${ }^{161}$ Im Anschluss an die Offenlegungen seitens der

160 Siehe insb. unter Teil 2, II.B.1.a).

161 In Part 10 CPR 2014 (zum magistrates' court) wird Folgendes bestimmt: „10.2.(1) The prosecutor must serve initial details of the prosecution case on the court officer(a) as soon as practicable; and (b) in any event, no later than the beginning of the day of the first hearing. [...] 10.3. Initial details of the prosecution case must include - (a) a summary of the evidence on which that case will be based; or (b) any statement, document or extract setting out facts or other matters on which that case will be based; or (c) any combination of such a summary, statement, document or extract; and (d) the defendant's previous convictions.“ In sect. 9.15. CPR 2014 (zum Crown Court) wird bestimmt: „Service of prosecution evidence 9.15.- (1) This rule applies where - (a) a magistrates' court 
Anklage muss die Verteidigung bei einem bevorstehenden Crown Court-Verfahren bzw. kann sie bei einem bevorstehenden magistrates' court-Verfahren eine defence statement anfertigen; sie muss außerdem für sämtliche Gerichtsverfahren eine defence witness notice aufsetzen. Diese Erklärungen müssen unter anderem eventuelle Alibibehauptungen und andere Verteidigungs-defences bzw. die Namen von zu ladenden Verteidigungszeugen beinhalten; sie sind der Anklage sowie auch dem Gericht zuzustellen. ${ }^{162}$ Darüber hinaus finden die Beweisoffenlegungen, die nicht vorzubringendes Beweismaterial (,unused material“) betreffen, grundsätzlich zwischen der Anklage und der Verteidigung statt; das Gericht kann jedoch angerufen werden, um insbesondere aufgrund von public interest-Erwägungen über die (Nicht-)Offenlegung bestimmter Beweise zu entscheiden. ${ }^{163}$

Dementsprechend ist zu bemerken, dass die Richter, nicht zuletzt wegen der verschiedenen disclosure-Prozesse, case management-Aktivitäten und pre-trial hearings, schon im Vorfeld der Hauptverhandlung Kenntnis zumindest von einem Teil der gegensätzlichen Beweisthesen haben können. ${ }^{164} \mathrm{Ob}$ eine solche Kenntnis zu einer frühen vollständigen Erfassung sämtlicher Aspekte des ganzen Falles führen kann, ist jedoch - insbesondere im Hinblick auf die begrenzte vorgerichtliche Dokumentation und Offenbarung des genauen Inhalts der vorzubringenden Verteidigungsbeweise sowie auf das Fehlen einer umfassenden neutralen Sammlung sämtlicher Verfahrensakten - zweifelhaft.

Die Geschworenen des reinen jury-Verfahrens dürfen jedenfalls keine konkrete Vorkenntnis des Straffalles haben. Ihnen wird der ganze Sachverhalt erst durch die Parteien präsentiert. Dies schließt jedoch nicht aus, dass der Vorsitzende Richter im jury-Verfahren aufgrund einer Vorkenntnis bestimmter Einzelheiten der gegensätzlichen cases in der Tat bei der Verfahrensleitung einseitig(er) wirken kann. Einen größeren faktischen Einfluss kann die Vorkenntnis der Beweise eventuell im bench-Verfahren ausüben: „Where judges preside alone [...] they have often read the statements of the witnesses before trial and they do not come nearly so cold to the trial. “ ${ }^{165}$

sends the defendant to the Crown Court for trial; and (b) the prosecutor serves on the defendant copies of the documents containing the evidence on which the prosecution case relies. (2) The prosecutor must at the same time serve copies of those documents on the Crown Court officer." Siehe auch unter Teil 2, II.B.1.a) und unter Teil 2, II.C.2.

162 Siehe sect. 22.4. CPR 2014 i.V.m. sect. 5-6C CPIA 1996.

163 Siehe sect. 22.1.-22.3., 22.5.-22.6. CPR 2014.

164 Vgl. auch sect. 37.12., 37.14. CPR 2014 zur Kenntnisnahme der Verfahrensdokumente seitens der Richter und der legal advisers im magistrates' court. Vgl. auch zur früheren Rechtslage Herrmann, Reform, S. 313-316.

165 Jackson, in: McConville/Wilson (Hrsg.), Handbook, S. 348. 


\section{Akteneinsicht und Offenlegung des Vorverfahrensmaterials}

\section{- Allgemeines}

In den neunziger Jahren wurde in England auf rechtspolitischer Ebene das Thema der Beweisoffenlegungen, die vorgerichtlich zwischen den Verfahrensparteien stattfinden müssen, häufig diskutiert. Hauptanlass waren diverse Justizirrtümer. Im Zentrum dieser Diskussion stand die erhebliche Ungleichheit zwischen Anklage und Verteidigung hinsichtlich der vorhandenen Ressourcen zur Vorbereitung des Rechtsstreits. Es gab aber auch Bedenken in Bezug auf die vielen Möglichkeiten der Verteidigung mit ihren begrenzten Offenlegungspflichten, die Anklage vor Gericht zu ,überraschen“. ${ }^{166}$ Die diesbezüglichen Diskussionen haben in der Folge zu Reformen der Rechtslage geführt, deren Hauptziel die Neudefinition der entsprechenden (Fairness-)Regeln war:

Although these changes may be viewed as challenging the adversary ideology whereby the onus is on the prosecution to make its case without assistance from the defence, they have not posed any fundamental challenge to the adversarial trial. The arguments have been over how the contest between prosecution and defence may be made fairer to both sides rather than about the nature of the adversarial trial itself. ${ }^{16 T}$

Gleichzeitig wurden auch Überlegungen zur Notwendigkeit einer stärkeren Stellung des Richters bei der Erledigung der Beweisoffenlegungskonflikte laut. Im Fall $R v$. Ward wurde letztendlich bemerkt: ${ }^{168}$

What are the lessons to be learnt from this miscarriage of justice? The law is of necessity concerned with practical affairs, and it cannot effectively guard against all the failings of those who play a part in the criminal justice system. But that sombre realism does not relieve us, as judges, from persevering in the task to ensure that the law, practice and methods of trial should be developed so as to reduce the risk of conviction of the innocent to an absolute minimum. At the same time we are very much alive to the fact that, although the avoidance of the conviction of the innocent must unquestionably be the primary consideration, the public interest would not be served by a multiplicity of rules which merely impede effective law enforcement. [...] Given the undoubted inequality as between prosecution and defence [...], we regard it as of paramount importance that the common law duty of disclosure, as we have explained it, should be appreciated by those who prosecute and defend in criminal cases. And, if difficulties arise in a particular case, the court must be the final judge.

\section{- Beweisoffenlegung seitens der Anklage}

Die Anklage muss nach Erhebung der Strafklage, wie bereits erwähnt, ${ }^{169}$ der Verteidigung den Zugriff auf grundlegende Materialien des prosecution case

166 Hierzu Jackson, in: McConville/Wilson (Hrsg.), Handbook, S. 341-344 m.w.N.; siehe auch Heaton-Armstrong/Corker/Wolchover, in: Heaton-Armstrong u.a. (Hrsg.), Witness, S. 383-385; Roberts/Zuckerman, Criminal Evidence, S. 60-61.

167 Jackson, in: McConville/Wilson (Hrsg.), Handbook, S. 342 (Fußnoten wurden ausgelassen).

$168 R$ v. Ward, [1993] 2 All ER 577, 628. 
ermöglichen. Zum einen sollen im Anschluss an den gerichtlichen Verweis eines Straffalles an das zuständige Crown Court und nicht später als 70 Tage nach diesem Verweis dem Angeklagten - bzw. nicht später als 50 Tage nach dem Verweis dem inhaftierten Angeklagten - Kopien der Dokumente übermittelt werden, welche die dem Anklagevorbringen zugrunde liegenden Beweise beinhalten. ${ }^{170} \mathrm{Zum}$ anderen findet bei Straffällen, die vor dem magistrates' court verhandelt werden können (vor allem: offences triable only summarily und offences triable either way), ${ }^{171}$ eine Offenlegung der initial details of the prosecution case statt: Eine solche Mitteilung muss nach Wahl der Anklage die von ihr vorzubringenden Grundthesen und Beweise (wie belastende Zeugenverhörprotokolle) und/oder eine schriftliche zusammenfassende Beschreibung ihrer grundlegenden Beweisthesen enthalten. Diese Offenlegungen müssen im Vorfeld oder spätestens am Tag der ersten Verhandlung (first hearing) vor dem magistrates' court erfolgen. ${ }^{172}$

In umfassender Weise ist aber auch die Offenlegung derjenigen Beweise reguliert, deren Einführung in das Verfahren die Anklage als Teil ihres case nicht beabsichtigt (,unused material“), deren Gehalt jedoch für die Unterstützung des defence case bzw. für die Schwächung des prosecution case von Bedeutung sein könnte. Die Anklage hat die allgemeine und kontinuierliche Pflicht, derartige nicht vorzubringende Beweismaterialien - die in erster Linie oft von den Ermittlungsbehörden gesammelt und dokumentiert und durch den disclosure officer ${ }^{173}$ der Anklage bekannt gegeben wurden - der Verteidigung so bald wie möglich zukommen zu lassen bzw. zur Einsichtnahme verfügbar zu machen. ${ }^{174}$ Gleichwohl kann die Anklage auf der Basis von public interest-Erwägungen (etwa im Interesse der Staatssicherheit oder in Fällen von Informanten und Verdeckten Ermittlern) einen Antrag auf gerichtliche Anordnung der Nicht-Offenlegung von bestimmten Beweismaterialien stellen. Die letztendliche Entscheidung über die Nicht-Offenlegung obliegt dabei

169 Unter Teil 2, II.B.1.

170 Siehe sect. 9.15. CPR 2014 i.V.m. The Crime and Disorder Act 1998 (Service of Prosecution Evidence) Regulations 2005.

171 Dazu unter Teil 2, II.A.2.

172 Siehe insb. Part 10 CPR 2014. Siehe auch Sprack, Criminal Procedure, Rn. 8.09$8.15,8.49,9.01$.

173, ,...] defined as the person responsible for examining the records created during the investigation and criminal proceedings and disclosing material as required to the prosecutor or the accused [...]", so Sprack, Criminal Procedure, Rn. 9.09.

174 Die Rechtsfolgen bei einer unterbliebenen bzw. mangelhaften disclosure seitens der Anklage sind von Tapper, Evidence, S. 285-286 mit Rechtsprechungsverweisen, zusammengefasst: "If the prosecution fails in its obligation to make primary disclosure, it runs the risk of any conviction being overturned as unsafe, as at common law; if it fails even to purport to comply, no obligation upon the defence to disclose arises. Failure to disclose may be regarded as providing a tenable claim of abuse of process. Delay in compliance will amount to abuse of process, only if as a result the accused is denied a fair trial. [...]" (Fußnoten wurden ausgelassen). 
dem Gericht, und das Gericht kann aufgrund eines Antrags seitens der Verteidigung oder von Amts wegen eine solche Entscheidung jederzeit zurücknehmen. ${ }^{175}$ Es gilt in allen Fällen die Grundregel nach sect. 3 CPIA 1996: ${ }^{176}$

(1) The prosecutor must- (a) disclose to the accused any prosecution material which has not previously been disclosed to the accused and which might reasonably be considered capable of undermining the case for the prosecution against the accused or of assisting the case for the accused, or (b) give to the accused a written statement that there is no material of a description mentioned in paragraph (a).

(6) Material must not be disclosed under this section to the extent that the court, on an application by the prosecutor, concludes it is not in the public interest to disclose it and orders accordingly.

\section{- Beweisoffenlegung seitens der Verteidigung}

In Bezug auf die vorgerichtlichen Offenlegungen seitens des Angeklagten ist zunächst zu erwähnen, dass die Verteidigung nicht vorzubringendes Beweismaterial grundsätzlich nicht offenbaren muss. Die disclosure-Verpflichtungen hinsichtlich des eigentlichen (Beweis-)Vorbringens werden, ungeachtet des burden of proof der Anklage und des nemo tenetur-Prinzips, in Verbindung mit den modernen defence statements reguliert: ${ }^{177} \mathrm{Im}$ Anschluss an die Offenlegung des Anklagevorbringens und der nicht vorzubringenden Beweise seitens der Anklage muss die Verteidigung bei einem bevorstehenden Crown Court-Verfahren eine ziemlich ausführliche ${ }^{178}$ defence statement anfertigen, die sowohl dem Gericht als auch der Anklage recht-

175 Eingehend Sprack, Criminal Procedure, Rn. 9.01-9.15, 9.30-9.40, 9.54-9.56 (und 9.57-9.62 zur „third party disclosure“). Siehe auch Darbyshire, in: Vogler/Huber (Hrsg.), Criminal Procedure, S. 92-96; Dennis, Evidence, Rn. 9.006-9.014, 9.038-9.043; http:// www.cps.gov.uk/legal/a_to_c/attorney_generals_guidelines_on_disclosure/ [Stand: Oktober 2014]; und http://www.cps.gov.uk/legal/d_to_g/disclosure_manual/[ [Stand: Oktober 2014].

176 Siehe ferner die technischen Details in sect. 1, 3, 4, 7A, 8(5), 13-18, 21, 23-24 CPIA 1996 i.V.m. sect. 22.1.-22.3., 22.6.-22.8., 28.5.-28.6. CPR 2014.

177 Insgesamt dazu Sprack, Criminal Procedure, Rn. 9.16-9.30, 9.41-9.56.

178 Nach Ansicht von Sprack, Criminal Procedure, Rn. 9.22-9.23, sollte sich der Umfang der Verteidigungsoffenlegungen von den entsprechenden Offenlegungspflichten der Anklage abhängig machen: Da die Anklage meistens keine vorgerichtlichen Offenbarungen hinsichtlich ihrer eigenen Auswertung des vorhandenen Beweismaterials und der darauf basierten ,strategischen" Ausrichtung der Beweiserhebungen (,the way in which they intend to put the case") macht, könne dies zur "Ungleichheit der Waffen“ führen, soweit die Verteidigung nach sect. 6A CPIA 1996 verpflichtet ist, frühe Offenbarungen bezüglich der bestreitbaren Rechtsfragen oder bezüglich sogar ihrer Argumente für das Bestreiten der vorgebrachten Tatsachenfragen zu machen. Vgl. hierzu auch die inhaltlich erweiterten Offenlegungen (statements), die in vorbereitenden preparatory hearings vor dem Crown Court (d.h. im Rahmen einer schon laufenden jury trial, aber in Abwesenheit der Geschworenen) primär von der Anklage sowie auch von der Verteidigung richterlich verlangt werden können, in sect. 31-34 CPIA 1996, mehr dazu bei Sprack, Criminal Procedure, Rn. 16.14. 
zeitig $^{179}$ zuzustellen ist. Bei einem bevorstehenden magistrates' court-Verfahren ist sie berechtigt, aber nicht verpflichtet eine solche defence statement abzugeben. ${ }^{180}$ Zum erforderlichen Inhalt (insbesondere: Verteidigungsstrategie und vorzubringende rechtliche defences, bestrittene Tatsachen, strittige Rechts- und Beweisfragen, Alibibehauptung) einer schriftlichen defence-Erklärung bestimmt sect. 6A CPIA 1996 Folgendes:

6A. Contents of defence statement.

(1) For the purposes of this Part a defence statement is a written statement- (a) setting out the nature of the accused's defence, including any particular defences on which he intends to rely, (b) indicating the matters of fact on which he takes issue with the prosecution, (c) setting out, in the case of each such matter, why he takes issue with the prosecution, and (d) indicating any point of law (including any point as to the admissibility of evidence or an abuse of process) which he wishes to take, and any authority on which he intends to rely for that purpose. (2) A defence statement that discloses an alibi must give particulars of it, including - (a) the name, address and date of birth of any witness the accused believes is able to give evidence in support of the alibi, or as many of those details as are known to the accused when the statement is given; (b) any information in the accused's possession which might be of material assistance in identifying or finding any such witness in whose case any of the details mentioned in paragraph (a) are not known to the accused when the statement is given. (3) For the purposes of this section evidence in support of an alibi is evidence tending to show that by reason of the presence of the accused at a particular place or in a particular area at a particular time he was not, or was unlikely to have been, at the place where the offence is alleged to have been committed at the time of its alleged commission. [...]

Gleichzeitig muss die Verteidigung für sämtliche bevorstehenden Gerichtsverfahren eine defence witness notice bei der Anklage sowie bei Gericht einreichen. ${ }^{181}$ Eine solche Benachrichtigung über die eventuell aufzurufenden Zeugen der Vertei-

179 Nach den Criminal Procedure and Investigations Act 1996 (Defence Disclosure Time Limits) Regulations 2011: „2. (1) The relevant period for section 5 (compulsory disclosure), section 6 (voluntary disclosure) and section 6C (notification of intention to call defence witnesses) begins with the day on which the prosecutor complies or purports to comply with section 3 (initial duty of the prosecutor to disclose). (2) In a case where Part 1 applies by virtue of section 1(1) (application of Part 1 in respect of summary proceedings), the relevant period for section 6 and section $6 \mathrm{C}$ expires at the end of 14 days beginning with the first day of the relevant period. (3) In a case where Part 1 applies by virtue of section 1(2) (application of Part 1 in respect of Crown Court proceedings), the relevant period for section 5 and section $6 \mathrm{C}$ expires at the end of 28 days beginning with the first day of the relevant period. [...] 3.- (1) The court may by order extend (or further extend) the relevant period by so many days as it specifies $[\ldots] . . "$

180 Siehe sect. 5-6B, 6E CPIA 1996 i.V.m. sect. 22.4. CPR 2014.

181 Zur möglichen (jedoch nicht obligatorischen) Durchführung von pre-trial interviews der von der Verteidigung in der Benachrichtigung angegebenen Zeugen durch die Strafverfolgungsbehörden siehe sect. 21A CPIA 1996 und Code of practice for arranging and conducting interviews of witnesses notified by the accused (abrufbar unter http:// www.legislation.gov.uk/ukpga/1996/25/pdfs/ukpgacop_19960025_en.pdf, Stand: Oktober 2014). 
digung muss nach sect. 6C CPIA 1996 vor allem die persönlichen Daten der Zeugen (soweit bekannt) beinhalten. ${ }^{182}$

Insbesondere kann die Abgabe von vollständigen defence statements die zusätzlichen Beweisoffenlegungen seitens der Anklage zum Ergebnis haben bzw. die entsprechende Antragstellung bei Gericht seitens der Verteidigung ermöglichen. ${ }^{183}$ Sie kann aber auch viele ,strategische“ Schwierigkeiten für die Verteidigung mit sich bringen. ${ }^{184}$ Jedenfalls kann die Nicht-Offenlegung bzw. eine mangelhafte disclosure - d.h. unrechtmäßige, verspätete oder widersprüchliche Abgabe von defence statements und/oder defence witness notices - negative prozessuale Folgen für die Verteidigung haben. Das äußert sich vor allem im Rahmen der für solche defence disclosure-Missstände vorgesehenen Möglichkeit des Spruchkörpers, angemessene Schlussfolgerungen ${ }^{185}$ hinsichtlich der Schuld des Angeklagten zu ziehen - auch wenn eine Verurteilung allein auf der Basis derartiger Schlussfolgerungen nicht erfolgen darf. Die ausführliche technische Regelung hierzu ist in sect. 11 CPIA 1996 enthalten. ${ }^{186}$

\section{Die Beweisführung im Hauptverfahren}

\section{Zulässigkeit und Ausschluss von Beweisen}

\section{- Beweisregeln und richterliches Ermessen}

Die englischen Gerichte müssen in den meisten streitigen Straffällen eine vollständige Beweisführung durch die Parteien abwarten, bevor sie über die Verurteilung oder den Freispruch des Angeklagten entscheiden. ${ }^{187}$ In Ausnahmefällen haben die (Berufs- bzw. Laien-)Richter im magistrates' court bzw. der Berufsrichter im Crown Court eine strikt begrenzte Befugnis, die Strafklage wegen abuse of pro-

$182 \mathrm{Zu}$ den disclosure-Vorschriften in Bezug auf die Expertenzeugen siehe sect. 6D CPIA 1996 und sect. 33.3.-33.4. CPR 2014.

183 Siehe sect. 7A(5), 8 CPIA 1996 i.V.m. sect. 22.5. CPR 2014. Sprack, Criminal Procedure, Rn. 9.30, bemerkt hierzu: „In practice, the defence may find it difficult to mount a successful challenge to prosecution disclosure. First, the scope of any such challenge is limited to matters which were raised in the defence statement. [...] Secondly, there is the problem of identifying the material which has not been disclosed. [...] The operation of s 8 is crucial to the whole disclosure scheme, for it provides the means whereby the court can monitor its operation. It is therefore important, if there is to be some corrective to the disparity of resources between prosecution and defence, that the courts should recognize the practical difficulties faced by the defence in mounting a successful challenge to what is suspected to be inadequate disclosure [...].“

184 Hierzu Sprack, Criminal Procedure, Rn. 9.18, 9.41-9.42.

185 Zur relevanten Rechtsprechung siehe Sprack, Criminal Procedure, Rn. 9.48-9.53.

186 Siehe auch sect. 6E CPIA 1996.

187 Vgl. sect. 9(2-3) MCA. Vgl. auch Otton, in: McConville/Wilson (Hrsg.), Handbook, S. 326. 
cess (Verfahrensmissbrauch) schon vor dem Beginn der eigentlichen Beweiserhebungen abzuweisen bzw. die Strafverfolgung einzustellen. ${ }^{188}$ Das Gericht muss hierfür die Anträge und Äußerungen beider Parteien hinsichtlich der möglichen abuse of process-Gründe hören, die sehr oft auf Erwägungen zum Art. 6 EMRK und zur „overriding objective“ des sect. 1 CPR 2014 basieren. Die abuse of process-Gründe beziehen sich meistens auf Extremfälle wie erhebliche zeitliche Verzögerungen der trial, unterlassene Beweissicherungen bzw. Beweisvernichtungen und Machtmissbräuche (z.B. entrapment) oder andere Fälle bösgläubigen Verhaltens seitens der Anklage. Hauptkriterium soll jedenfalls die Gefährdung bzw. Beeinträchtigung der Verfahrensfairness - „(a) where the court concludes that the defendant cannot receive a fair trial; and (b) where the court concludes that it would be unfair for the defendant to be tried"“_ ${ }^{189}$ sein. ${ }^{190}$

Darüber hinaus findet vor Gericht eine umfassende Präsentation und Prüfung nur solcher Beweise statt, die für den konkreten Fall relevant sind (relevance), nach den obligatorischen Beweisausschlussregeln nicht unzulässig sind und nach richterlichem Ermessen im Rahmen von fair trial-Erwägungen nicht ausgeschlossen werden. ${ }^{191}$ Hierbei spielen vor allem die diversen gesetzlichen und Common LawRegeln zur admissibility und zur exclusionary discretion eine Rolle: Solche Regeln müssen/können etwa bei hearsay evidence und anderen ,prejudicial“-Beweisen, torture evidence, unter Zwang erpressten Geständnissen, rechtswidrigen Kommunikationsüberwachungen sowie weiteren rechtswidrig oder in unfairer Weise erlangten Beweisen angewandt werden.

Der verfahrensleitende Richter muss üblicherweise über Einwände oder Anträge der Parteien hinsichtlich der Zulässigkeit bzw. des Ausschlusses von vorgebrachten Beweisen entscheiden. Die Gerichte besitzen in vielen Fällen die Befugnis, Beweise nach eigenem Ermessen - etwa im Wege des Verbots, Fragen zu stellen, oder in einer anderen Art und Weise - auszuschließen. ${ }^{192}$ Vor allem im Fall von durch Folter (oder andere oppression-Verhaltensweisen) erlangten Geständnissen ist der Richter gesetzlich verpflichtet, die Aussage - auch wenn diese ernsthaft sein könnte - aus den weiteren Beweisführungen auszuschließen, soweit die Anklage nicht zweifelsfrei (,,beyond reasonable doubt“) nachweisen kann, dass die FolterBehauptungen der Verteidigung nicht wahrhaftig sind; einen solchen Nachweis kann das Gericht sogar von Amts wegen verlangen. ${ }^{193}$ In den meisten übrigen Fäl-

188 Vgl. sect. 3.20. CPR 2014.

$189 R$ v. Beckford, [1996] 1 Cr App R 94, 101.

190 Insgesamt dazu m.w.N. Sprack, Criminal Procedure, Rn. 10.26-10.31, 13.53-13.58, 20.14-20.20.

191 Siehe weitere Details unter Teil 2, II.A.3., Teil 2, II.B.1.b)bb) m.w.N. Im Glossar der CPR 2014 wird der Begriff, ,admissible evidence“ wie folgt definiert: „evidence allowed in proceedings (not all evidence introduced by the parties may be allowable in court).“

192 Vgl. sect. 82(3) PACE und sect. 126 CJA 2003.

193 Sect. 76(2-3) PACE. 
len einer unfairen/rechtswidrigen Erlangung von Beweisen oder bei der sogenannten fruit of the poisonous tree stehen dagegen anscheinend die Überlegungen zur effektiven Wahrheitssuche im Vordergrund: Der Richter muss nämlich derartige Beweise, die nicht unbedingt unglaubwürdig sein müssen, meistens nicht automatisch ausschließen; es steht jedoch allgemein in seinem Ermessen, solche Beweise entsprechend den jeweiligen Fallumständen zur Wahrung der Verfahrensfairness nicht zuzulassen. ${ }^{194}$ Im Fall $R v$. Quinn wurde von Lord Lane C.J. Folgendes bestimmt: ${ }^{195}$

The function of the judge is therefore to protect the fairness of the proceedings, and normally proceedings are fair if a jury hears all relevant evidence which either side wishes to place before it, but proceedings may become unfair if, for example, one side is allowed to adduce relevant evidence which, for one reason or another, the other side cannot properly challenge or meet, or where there has been an abuse of process, e.g. because evidence has been obtained in deliberate breach of procedures laid down in an official code of practice.

Des Weiteren kann das Gericht für bestimmte Kategorien von hearsay evidence bei einem Verstoß gegen die Benachrichtigungspflichten seitens der Partei, die den entsprechenden Beweis in die Hauptverhandlung einführen will, entweder den hearsay-Beweis nicht zulassen oder aus diesem Verstoß eventuell negative Schlussfolgerungen ziehen. Für alle Kategorien von hearsay evidence kann eine Partei innerhalb bestimmter Fristen Einwand gegen ihre Einführung erheben, wobei dann das Gericht über die Zulassung der hearsay statements nach den entsprechenden Beweisausschlussregeln ${ }^{196}$ - denen zufolge in bestimmten Situationen dem Richter ein erheblicher Ermessensspielraum zusteht - entscheiden muss. Bei hearsay-Beweisen, gegen die kein Einwand seitens der Parteien erhoben wurde, muss das Gericht deren Einführung in das Verfahren, der nun quasi zugestimmt worden ist, erlauben. ${ }^{197}$ Entsprechendes gilt für die Einführung des sogenannten bad character-Beweises. ${ }^{198}$ In ähnlichem Kontext kann das Gericht, aufgrund eines Antrags seitens einer Partei oder von Amts wegen, anordnen, dass an Stelle der

194 Siehe zu den relevanten Vorschriften (insb.: sect. 76, 78 PACE) und der charakteristischen Rechtsprechung vor allem in Bezug auf die (menschen-)rechtswidrig erlangten Beweise Choo, in: Thaman (Hrsg.), Exclusionary Rules, S. 331-352. Vgl. auch Otton, in: McConville/Wilson (Hrsg.), Handbook, S. 327; Sprack, Criminal Procedure, Rn. 3.89. Zu den diesbezüglichen Entwicklungen, der relevanten Rechtsprechung und dem Verhältnis zwischen reliability of evidence und fairness siehe McEwan, Evidence, S. 205-227.

195 R v. Quinn, [1990] Crim.L.R. 581 (583).

196 Siehe insb. Part 11 Chapter 2 CJA 2003.

197 Siehe insgesamt Part 34 CPR 2014. In sect. 132(5) CJA 2003 wird allgemein Folgendes bestimmt: "If a party proposing to tender evidence fails to comply with a prescribed requirement applicable to it - (a) the evidence is not admissible except with the court's leave; (b) where leave is given the court or jury may draw such inferences from the failure as appear proper; (c) the failure may be taken into account by the court in considering the exercise of its powers with respect to costs."

198 Siehe Part 35 CPR 2014 i.V.m. Part 11 Chapter 1 CJA 2003. 
Einführung vorgerichtlicher schriftlicher witness statements im Beweisweg der Zeuge persönlich vor Gericht vernommen wird. ${ }^{199}$

\section{- Verfahren und Strukturprobleme}

Insgesamt hat somit der Richter eine ganz entscheidende Funktion bei der Auseinandersetzung mit den komplexen Fragen zur Zulässigkeit und zum Ausschluss von Beweisen, die meistens aufgrund von Anträgen/Einwänden einer Partei - aber auch von Amts wegen ${ }^{200}$ - richterlich behandelt werden können und die für das englische Beweisrecht und -verfahren weiterhin von zentraler Bedeutung sind. Heute können (müssen aber nicht) die meisten Beweisausschlussangelegenheiten, wie auch die übrigen Rechtsfragen und technischen Angelegenheiten, aus prozessökonomischen ${ }^{201}$ Gründen im Rahmen diverser Vorverhandlungen (pre-trial hearings) oder vorbereitender Verhandlungen innerhalb des Hauptverfahrens (preparatory hearings) ${ }^{202}$ beim magistrates' court und insbesondere beim Crown Court verbindlich erledigt werden. ${ }^{203}$ Generell ist der moderne Ansatz dahingehend ausgerichtet, dass sämtliche Rechtsfragen möglichst früh durch richterliche case management-Tätigkeiten entschieden werden sollen. ${ }^{204}$ Auch bei bereits laufender Hauptverhandlung wird es allgemein für wünschenswert gehalten, dass die Beweisausschlussfragen so früh wie möglich - schon vor Beginn der eigentlichen Beweisführungen - angesprochen werden. ${ }^{205}$

Sämtliche Fragen zur Beweiszulässigkeit können des Öfteren (jedoch nicht immer, im Hinblick auch auf die jeweilige Verfahrensphase und die praktischen Gegebenheiten) von dem die Hauptverhandlung leitenden trial judge ${ }^{206}$ selbst bzw.

199 Siehe ferner sect. 9 CJA 1967 und Part 27 CPR 2014.

200 So wird z.B. in sect. 40 CPIA 1996 Folgendes bestimmt: „,(1) A judge may make at a pre-trial hearing a ruling as to- (a) any question as to the admissibility of evidence; (b) any other question of law relating to the case concerned. (2) A ruling may be made under this section- (a) on an application by a party to the case, or (b) of the judge's own motion." Siehe auch sect. 29(4) CPIA 1996 und sect. 8A(6) MCA.

${ }^{201} \mathrm{Zu}$ dieser Entwicklung u.a. Jackson, in: McConville/Wilson (Hrsg.), Handbook, S. 346-347.

202 Im Glossar der CPR 2014 wird der Begriff „preparatory hearing“ wie folgt definiert: ,a hearing forming part of the trial sometimes used in long and complex cases to settle various issues without requiring the jury to attend."

203 Siehe sect. 7, 9 CJA 1987; sect. 29, 31, 39-43 CPIA 1996; sect. 8A, 8B MCA; siehe auch Parts 3, 15 und sect. 3.13., 33.6., 34.3.(3)(d), 38.3. CPR 2014. Insgesamt zu den pretrial und preparatory hearings u.a. Sprack, Criminal Procedure, Rn. 10.49, 16.01-16.26.

204 Siehe auch unter Teil 2, II.B.2.d) m.w.N.

205 Pattenden, O.J.L.S. 29 (2009), 1 (10) m.w.N. Vgl. auch sect. 38.3. CPR 2014.

206 Vgl. Sprack, Criminal Procedure, Rn. 16.01 (siehe auch Rn. 16.03, 16.05, 16.08$16.11,16.13)$ : „In recent years, various reforms have aimed to increase the scope of pretrial proceedings in the Crown Court. The underlying aim is to enable the judge (preferably the one who will preside at trial but, if that is impossible, one of the other judges who are 
von den verfahrensleitenden magistrates entschieden werden. Im magistrates' court-Verfahren kann es demnach passieren, dass dieselben Richter (magistrates) Beweise ausschließen müssen/können, deren Existenz sie dann bei der Beurteilung der Schuldfrage verpflichtet sind zu ,vergessen“. ${ }^{207}$ Nicht nur im Rahmen von pretrial/preparatory hearings, sondern auch in der sogenannten voir dire-Phase ${ }^{208}$ innerhalb einer bereits laufenden jury trial kann hingegen der verfahrensleitende Richter in Abwesenheit der Geschworenen über die admissibility-Fragen entscheiden; ${ }^{209}$ dafür muss er zuerst die Argumente der Parteien über die Zulässigkeit der strittigen Beweise hören und eventuell relevante Beweisführungen erlauben. Die Geschworenen müssen daher ihrerseits am Verfahrensende im Grunde ohne Kenntnis der ausgeschlossenen Beweise über die Schuldfrage entscheiden. ${ }^{210}$

\section{Erhebung, Präsentation und Prüfung der Stichhaltigkeit der Beweise}

\section{a) Grundlagen}

\section{- Allgemeine Charakteristika der Beweisführung in der Hauptverhandlung}

Grundsätzlich existieren keine großen Unterschiede zwischen einem magistrates' court- und einem Crown Court-Verfahren hinsichtlich der Regeln und Teilstadien der herkömmlichen Beweisführung vor Gericht für die erstinstanzlichen streitigen Straffälle, die hier von Interesse sind. ${ }^{211}$ Bei den Letzteren hat keine abgekürzte Verfahrenserledigung im Rahmen insbesondere der anfänglichen pleaPhasen $^{212}$ stattgefunden. Vielmehr hat sich der Angeklagte für nicht schuldig erklärt, und die Anklage versucht folglich beyond reasonable doubt nachzuweisen, dass die angeklagten Tatbestände nach den Definitionen des materiellen Strafrechts

available at that Crown Court centre) to start the business of managing the trial before it begins." Vgl. auch sect. 40(6) CPIA 1996.

207 Dazu McEwan, Evidence, S. 209 m.w.N.; Sprack, Criminal Procedure, Rn. 10.57.

208 Dazu z.B. Dennis, Evidence, Rn. 1.013: „If an accused [...] claims, for example, to have been tortured into confessing, the trial judge may hear evidence of the circumstances of the interrogation before ruling on the admissibility of the confession. In the Crown Court such evidence is heard by the judge in the absence of the jury, using the procedure known as the voir dire, or the trial within the trial. This procedure follows the normal rules for taking evidence, so that witnesses as to the facts relating to the admissibility of the evidence in question are called, examined and cross-examined as in the main trial."

209 Siehe auch sect 38.3. CPR 2014.

210 Siehe Dennis, Evidence, Rn. 4.006. Ausführlich Pattenden, O.J.L.S. 29 (2009), 1 (710) mit weiteren Rechtsprechungsverweisen. Siehe auch zu den technischen Details Sprack, Criminal Procedure, Rn. 20.35-20.42.

211 Vgl. Sprack, Criminal Procedure, Rn. 10.50. Zu den wenigen Unterschieden in Bezug auf das Beweisrecht Dennis, Evidence, Rn. 1.018. Zu den general principles of evidence in criminal cases siehe Blackstone's Criminal Practice, $\S$ F1.1-F.1.38.

212 Allgemein zu den Schulderklärungen (guilty/not guilty pleas) u.a. Sprack, Criminal Procedure, Rn. 10.51-10.53, 17.01-17.62. 
erfüllt sind. In den meisten Fällen muss die Anklage ebenso nachweisen, dass die eventuell vorgebrachten defences (Verteidigungsargumente, wie z.B. self-defence) nicht begründet sind - eine anerkannte Ausnahme von dieser Regel bilden etwa die Fälle der strafrechtlichen Unverantwortlichkeit wegen seelischer Störungen, bei denen die Verteidigung selbst die Stichhaltigkeit solcher vorgebrachter Argumente beweisen muss. ${ }^{213}$

Gleichwohl kann die Anklage - neben ihrer Befugnis, eine Strafverfolgung vor dem Beginn der Beweisführungen formal einzustellen (discontinuing prosecutions) ${ }^{214}$-, sogar nachdem der Angeklagte vor Gericht eine not guilty-Erklärung zu einigen oder allen Klagepunkten abgegeben hat, die Entscheidung treffen, hinsichtlich der nicht zugestandenen Klagen keine Beweise vor Gericht zu präsentieren (offering no evidence). ${ }^{215}$ Nach herrschender Meinung hat das Gericht dabei (immer unter dem Vorbehalt eines abuse of process-Falles), nicht zuletzt aufgrund seiner allgemein eng begrenzten Beweiserhebungsbefugnisse, tatsächlich keine andere Wahl, als den Angeklagten entsprechend freizusprechen - auch wenn die gesetzlichen Vorschriften eher auf einen diesbezüglichen Ermessensspielraum des Richters hindeuten. ${ }^{216}$ Eine solche Entwicklung kann das Ergebnis einer vorherigen Absprache zwischen Anklage und Verteidigung sein, sie kann aber auch auf anderen sachlichen Gründen (z.B. Neuevaluation von vorhandenen oder Inanspruchnahme von neuen Beweisen) oder public interest-Erwägungen beruhen. Im Allgemeinen kann die Anklage eine Strafverfolgung grundsätzlich nur vor dem Anfang, während und bis zum Abschluss der gerichtlichen Präsentation ihrer eigenen Beweisthesen (case) abbrechen; ab dem Ende des prosecution case ist für die Verfah-

213 Vgl. Sprack, Criminal Procedure, Rn. 17.07-17.08.

214 Dazu u.a. Blackstone's Criminal Practice, §§ D3.65-D3.66; Sprack, Criminal Procedure, Rn. 4.14-4.17.

215 Mehr dazu (und auch zur alternativen Möglichkeit einer eventuell nur vorläufigen Verfahrenseinstellung im Wege von letting counts lie on the file) m.w.N. bei Blackstone's Criminal Practice, $\S \S$ D3.67, D12.69, D12.79, D12.81-D12.92; Sprack, Criminal Procedure, Rn. 4.17, 17.09, 17.22-17.26, 17.29-17.32.

216 Sect. 17 CJA 1967 bestimmt Folgendes: „Where a defendant arraigned on an indictment or inquisition pleads not guilty and the prosecutor proposes to offer no evidence against him, the court before which the defendant is arraigned may, if it thinks fit, order that a verdict of not guilty shall be recorded without the defendant being given in charge to a jury, and the verdict shall have the same effect as if the defendant had been tried and acquitted on the verdict of a jury." Nach Blackstone's Criminal Practice, § D12.82 ist gleichwohl in Betracht zu ziehen, dass: "Whilst the plain wording of S. 17 gives the court a discretion to decline to order a verdict of not guilty to be entered even though the prosecution intimate that they do not wish to proceed, in the last resort, the prosecution cannot be forced by the court to call evidence." Die Rechtsprechung hat keine endgültig klare Antwort gegeben, vgl. z.B. $R$ v. Canterbury and St. Augustine Justices, ex parte Klisiak, [1982] Q.B. 398, 411 m.w.N.; Raymond v. Attorney-General, [1982] Q.B. 839, 846-847; $R$ v. Horseferry Road, ex parte O'Regan, [1986] 150 JP 353 und 412; $R$ v. Renshaw, [1989] Crim.L.R. 811-812. 
renseinstellung eine Zustimmung des Richters nötig. Ohne diese Zustimmung muss der Prozess mit der Präsentation der Verteidigungsthesen fortgesetzt werden. ${ }^{217}$

Die bisherigen Ausführungen haben darüber hinaus gezeigt, dass die (Berufsoder Laien-)Richter eines bench-Verfahrens vor dem magistrates' court für die technische Verfahrensleitung und für die Beurteilung sowohl der Rechts- als auch der Tatsachenfragen zuständig sind; die Laien-magistrates werden allerdings bei der Auseinandersetzung mit Rechtsfragen von juristisch ausgebildeten Gerichtsangestellten (court clerks) ${ }^{218}$ unterstützt. In einer jury trial vor dem Crown Court ist dagegen der Vorsitzende Berufsrichter hauptsächlich für die ordnungsgemäße und faire Verfahrensleitung und für die Entscheidung über sämtliche Rechtsfragen verantwortlich, wobei die Beurteilung der präsentierten Tatsachen und die letztendliche Entscheidung über die Schuld durch die Laien der getrennten Geschworenenbank erfolgen. ${ }^{219}$

217 Siehe $R$ v. Grafton, [1992] 4 All ER 609, 613: „Before the completion of the case for the Crown, the decision whether to continue or not must be that of the prosecution. No doubt the judge, if he does not agree with the course proposed, is fully entitled to convey that to counsel and discuss it in the absence of the jury. One would hope and expect that cases where any disagreement remains after such discussion will be rare. In such a case, however, we can see no way in which the judge could properly continue to call evidence for the Crown consistently with his judicial role." In derselben Entscheidung (S. 612) wurden die relevanten Schlussfolgerungen des Farquharson Committee Report on the Role of Prosecuting Counsel (1986) zitiert: „Sometimes a decision has to be made to offer no evidence during the course of the trial; and similarly pleas of guilty may be tendered to lesser counts. While the prosecution case is being presented the decision as to what course to take in these circumstances remains with counsel. After the prosecution case is completed, once the judge has ruled that there is a case to answer or where he has not been invited to do so but the case is proceeding, then in our view the prosecution cannot be discontinued nor pleas of guilty to lesser charges be accepted without the consent of the judge. Ex hypothesi there is at this stage a case to answer and it would, in our view, be an abuse of process for the prosecution to discontinue without leave. In such a situation while the judge may rule that the case shall proceed and be considered by the jury it would not be the duty of counsel to cross-examine the defence witnesses or address the jury if he was of the view that it would not be proper to convict. The only exception to this rule is when the AttorneyGeneral enters a nolle prosequi which can be done at any stage of the proceedings."

218 Dazu Sprack, Criminal Procedure, Rn. 10.75-10.76 m.w.N.: „During the course of a hearing, the clerk's tasks include putting the information to the accused; taking a note of the evidence; helping an unrepresented accused in the presentation of his case, and advising the magistrates upon points of law or procedure as they arise. [...] although the magistrates are the judges of both law and fact, lay magistrates do, as a matter of practice, accept their clerk's advice on matters of law. [...] the clerk should neither interfere with the magistrates' decision on the facts, nor, [...] put himself in a position where he might appear to be interfering with their decision." Auch Darbyshire, in: Vogler/Huber (Hrsg.), Criminal Procedure, S. 101. Siehe auch sect. 37.14. CPR 2014.

219 Siehe auch Blackstone's Criminal Practice, § F1.32-F1.38. Zur in der Praxis manchmal notwendigen Beteiligung des verfahrensleitenden Richters an der Ermittlung bzw. Beurteilung von Tatsachenfragen u.a. Dennis, Evidence, Rn. 4.003-4.006; Doran, in: Doran/Jackson (Hrsg.), Judicial Role, S. 5; Jackson/Doran, Judge, S. 101-104. Siehe auch Jackson/Doran, MLR 60 (1997), 759 (767-768). 
Die eigentlichen Beweiserhebungen und die mündlichen Präsentationen und Gegenpräsentationen der strittigen Tatsachen finden in sämtlichen Strafprozessen größtenteils durch die Parteien nach dem Grundsatz der Parteienautonomie statt. Wie bereits dargelegt wurde, besteht unter bestimmten Voraussetzungen trotzdem die Möglichkeit der, judicial notice“ von offensichtlichen facts (wie z.B. matters of common knowledge), wobei hinsichtlich solcher vom Richter leicht wahrzunehmender Tatsachen keine umfassenden Beweisführungen durch die Parteien nötig sind. Außerdem können die Parteien selbst die Vermeidung zeitaufwendiger gegensätzlicher Beweiserhebungen und Tatsachenpräsentationen in Bezug auf unbestreitbare Aspekte des Sachverhaltes entscheiden: Dies geschieht meistens durch die verbindliche einverständliche Einführung bestimmter (sonst eventuell unzulässiger) Beweismittel in das Verfahren (wie bei hearsay evidence) oder durch die Einführung von vorher zugegebenen Fakten als eindeutigem Beweis (,,agreed evidence“"). ${ }^{220}$

\section{- Leitsätze zur Rollenverteilung}

Die Leitlinien des englischen case law hinsichtlich der (wie aus ihnen hervorgehend: nicht absolut passiven) Rolle des Richters während der Beweisführungen durch die Parteien, die weiterhin im Einklang mit den bisherigen Analysen stehen, wurden von Colin Tapper folgendermaßen zusammengefasst: Der englische Richter ist nicht lediglich ein Schiedsrichter. Er darf nicht die Beweisaufnahme durchführen und weder in die Ausführungen der Anwälte noch in die Zeugenbefragungen eingreifen. Sogar nach einer re-examination kann er begrenzt Klarstellungsfragen stellen, die aber nicht zur Durchführung einer neuen cross-examination führen dürfen. Der Richter kann, auch ohne dass die Parteien Einwand erhoben haben, eingreifen, um offensichtlich unzulässige Beweise auszuschließen. Er kann des Weiteren beachtlichen Einfluss auf die jurors ausüben: ${ }^{221}$

The power to call a witness in criminal cases serves as a reminder that the English judge is more than an umpire in the strict sense of the word, and nowadays much more than he was fifty years ago. It is true that he must not descend into the dust of the arena, for example by conducting the trial, and intervening in the addresses of counsel and the examination of witnesses so as to appear to have determined issues before hearing evidence. Even after re-examination, his power to ask questions must be restricted to clarification, and not amount to cross-examination. He may nevertheless intervene to exclude clearly inadmissible evidence, despite the absence of any objection by counsel. [...] he may exert a very considerable influence over the jury, he has a discretion to exclude certain types of evidence, and he can question witnesses in the cause of clarification.

${ }^{220}$ Mehr dazu unter Teil 2, II.B.2. m.w.N. Zu den formal admissions siehe auch Sprack, Criminal Procedure, Rn. 20.44-20.47.

221 Tapper, Evidence, S. 294 mit Rechtsprechungsverweisen. Siehe auch Doran, in: Doran/Jackson (Hrsg.), Judicial Role, S. 5-6. 
Moderne empirische Beobachtungen deuten auf eine in der Gerichtspraxis sich ständig erweiternde, interventionistischere Rolle des Richters bzw. auf entsprechende Tendenzen hin: ${ }^{222}$ Auch wenn der Richter nur begrenzt vor allem zur Sicherstellung von zügigen, ordnungsgemäßen, klaren und widerspruchsfreien Beweispräsentationen intervenieren darf, ${ }^{223}$ scheint er oft bereit zu sein, etwa in die Zeugenbefragungen aktiver einzugreifen; und auch die Hochgerichte scheinen den diesbezüglichen Ermessensspielraum des Richters meistens nur in extremen Fällen von Unfairness unter Kontrolle zu bringen. ${ }^{224}$ Förmlich wird jedenfalls als Grundsatz auch für das englische Strafverfahren in Bezug auf die Rollenverteilung während der gerichtlichen Beweisaufnahmen weiterhin das angesehen, was Lord Denning im zivilrechtlichen Fall Jones v. National Coal Board bestimmt hat: ${ }^{225}$

In the system of trial which we have evolved in this country, the judge sits to hear and determine the issues raised by the parties, not to conduct an investigation or examination on behalf of society at large, as happens, we believe, in some foreign countries. Even in England, however, a judge is not a mere umpire to answer the question 'How's that?' His object, above all, is to find out the truth, and to do justice according to law; and in the daily pursuit of it the advocate plays an honourable and necessary role. Was it not Lord Eldon L.C. who said in a notable passage that 'truth is best discovered by powerful statements on both sides of the question' : see Ex parte Lloyd ((1822) Mont. 70, 72n.). And Lord Greene M.R. who explained that justice is best done by a judge who holds the balance between the contending parties without himself taking part in their disputations? If a judge, said Lord Greene, should himself conduct the examination of witnesses, 'he, so to speak, descends into the arena and is liable to have his vision clouded by the dust of the conflict' : see Yuill v. Yuill ([1945] 1 All E.R. 183). Yes, he must keep his vision unclouded. It is all very well to paint justice blind, but she does better without a bandage round her eyes. She should be blind indeed to favour or prejudice, but clear to see which way lies the truth: and the less dust there is about the better. Let the advocates one after the other put the weights into the scales - the 'nicely calculated less or more' - but the judge at the end decides which way the balance tilts, be it ever so slightly. [...] it is for the advocates, each in his turn, to examine the witnesses, and not for the judge to take it on himself lest by so doing he appear to favour one side or the other: see Rex v. Cain

222 Nach Doran, in: Doran/Jackson (Hrsg.), Judicial Role, S. 3-4: ,[...] in the context of the modern English criminal trial, there is an increasing awareness (in judicial circles and beyond) of the responsibility of trial judges for matters beyond the confines of legal moderation and extending to direct responsibility for the outcome as well as the management of the trial process. The problem is that the discharge of such responsibility in practice tends to be dependent more on the preferred approach of individual judges than on a commonly agreed and clearly articulated rationale of the judicial function."

223 Vgl. z.B. den Fall $R$ v. Whybrow and Saunders, The Times 14 February 1994 i.V.m. $R$ v. Hulusi and Purvis, [1973] 58 Cr App R 378, 382, 385. In $R$ v. Harirbafan, [2008] EWCA Crim 1967, Rn. 33, wurde ausdrücklich Folgendes bestimmt: „Further, the nature and tone of the interventions crossed by far the line between clarification and crossexamination. Cross-examination by a judge is unacceptable."

224 Zusammenfassend mit Nachweisen Doran, in: Doran/Jackson (Hrsg.), Judicial Role, S. 9-10, 13. Vgl. auch Royal Commission on Criminal Justice Report 1993, S. 119-124, zu entsprechenden rechtspolitischen Tendenzen.

225 Jones v. National Coal Board, [1957] 2 Q.B. 55, 63-64. Siehe dazu C. Allen, ZStW 72 (1960), 650 (653-654); Darbyshire, Legal System, S. 206; Jackson, in: McConville/Wilson (Hrsg.), Handbook, S. 339-340; Tapper, Evidence, S. 294. 
((1936) 25 Cr.App.R. 204), Rex v. Bateman ((1946), 31 Cr.App.R. 106), and Harris v. Harris (The Times, Apr. 9, 1952) by Birkett L.J. especially. And it is for the advocate to state his case as fairly and strongly as he can, without undue interruption, lest the sequence of his argument be lost: see Reg. v. Clewer ((1953) 37 Cr.App.R. 37). The judge's part in all this is to hearken to the evidence, only himself asking questions of witnesses when it is necessary to clear up any point that has been overlooked or left obscure; to see that the advocates behave themselves seemly and keep to the rules laid down by law; to exclude irrelevancies and discourage repetition; to make sure by wise intervention that he follows the points that the advocates are making and can assess their worth; and at the end to make up his mind where the truth lies. If he goes beyond this, he drops the mantle of a judge and assumes the robe of an advocate; and the change does not become him well.

\section{b) Der Ablauf der Beweisvorgänge im Gerichtsverfahren}

\section{- Das Verfahren vor dem magistrates' court}

Die Beweisführungen nach Abgabe einer not guilty-Erklärung seitens des Angeklagten beginnen im ordentlichen magistrates' court-Verfahren (wie auch vor dem Crown Court) mit der Darlegung des prosecution case, in der die Anklage ihre Sicht des Geschehens und die von ihr vorgebrachten Beweise darstellt. ${ }^{226}$ Der Anklagevertreter hat zunächst das Recht auf eine Eingangsansprache (opening speech), in der die Hauptpunkte des Anklagevorbringens vorgetragen werden können. ${ }^{227}$ In der magistrates' court-Praxis finden (wenn überhaupt) solche Ansprachen üblicherweise, insbesondere weil es keine in informatorischer Hinsicht unterstützungsbedürftige Geschworenenbank gibt und weil die betreffenden Straffälle meistens unkomplizierter Natur sind, nur in begrenztem Umfang statt. ${ }^{228}$

Im Anschluss an die Eingangsansprache muss die Anklage die Beweise, auf denen ihr Vorbringen basiert, präsentieren. ${ }^{229}$ Insbesondere müssen die Anklage-

226 Part 37 CPR 2014 fasst die Regelungen zum magistrates' court-Verfahren zusammen. Bei Verfahren in Abwesenheit einer der beiden Parteien gilt nach sect. 37.11. CPR 2014 grundsätzlich, dass: ,[...] (2) Where the prosecutor is absent, the court may- (a) if it has received evidence, deal with the case as if the prosecutor were present; and (b) in any other case- (i) enquire into the reasons for the prosecutor's absence, and (ii) if satisfied there is no good reason, exercise its power to dismiss the allegation. (3) Where the defendant is absent- (a) the general rule is that the court must proceed as if the defendant(i) were present, and (ii) had pleaded not guilty (unless a plea already has been taken) and the court must give reasons if it does not do so; but (b) the general rule does not apply if the defendant is under 18; (c) the general rule is subject to the court being satisfied that(i) any summons or requisition was served on the defendant a reasonable time before the hearing, or (ii) in a case in which the hearing has been adjourned, the defendant had reasonable notice of where and when it would resume [...]." Siehe ferner Sprack, Criminal Procedure, Rn. 10.34-10.45, 10.48 .

227 Sect. 37.3.(3)(a) CPR 2014:, ,[...] the prosecutor may summarise the prosecution case, identifying the relevant law and facts."

228 Sprack, Criminal Procedure, Rn. 10.54.

229 Sect. 37.3.(3)(b) CPR 2014. 
zeugen aufgerufen (und falls nötig: zwangsmäßig zur Aussage vor Gericht gebracht) ${ }^{230}$ sowie die zulässigen schriftlichen Zeugenerklärungen (witness statements), Expertengutachten und hearsay-Beweise vorgelesen werden. ${ }^{231}$ In ähnlicher Weise wie im Crown Court-Verfahren finden vor dem magistrates' court für jeden Anklagezeugen, dessen Aussage nach den Beweisregeln als zulässig angesehen wird, üblicherweise folgende Verhöre statt: zuerst die examination-in-chief ${ }^{232}$ (Hauptverhör) durch die Anklage, dann die cross-examination ${ }^{233}$ (Kreuzverhör) durch die Verteidigung (d.h. durch den Angeklagten oder seinen Anwalt) und abschließend die mögliche re-examination ${ }^{234}$ (Nachvernehmung) durch die Anklage hinsichtlich der sich während der Kreuzverhöre ergebenden Fragen sowie eventuelle Befragungen durch die bench-Richter bzw. durch ihre legal advisers (Rechtsberater). Die Richter und Rechtsberater können ihre Fragen nach eigenem Ermessen stellen, jedoch immer unter dem Vorbehalt der Beweisausschlussregeln und der Regeln zur Förderung der overriding objective nach sect. 1.3. CPR 2014; sie können darüber hinaus notwendige Fragen im Interesse eines Angeklagten, der ohne Anwalt vor Gericht erscheint, an die Zeugen stellen. ${ }^{235}$

Soweit die Anklage bereits die Verteidigung darüber informiert hat, dass sie einen bestimmten Zeugen zur Aussage laden wird, muss sie der Verteidigung jenen Zeugen für eine mögliche cross-examination zur Verfügung stellen; das gilt auch dann, wenn die Anklage ihrerseits keine examination-in-chief mehr beabsichtigt. ${ }^{236}$ In jedem Fall haben auch die magistrates, wie schon erläutert, die selbstständige

230 Siehe Part 28 CPR 2014 i.V.m. sect. 97 MCA und sect. 2, 2D, 3, 4 Criminal Procedure (Attendance of Witnesses) Act 1965.

231 Zur Einführung von schriftlichen Erklärungen und Dokumenten in das Verfahren siehe sect. 37.5. und 37.12. sowie Parts 27, 33, 34 CPR 2014.

232 Siehe Blackstone's Criminal Practice, § F6.1: „The object of examination-in-chief (examination of a witness by the party calling him) is to elicit from the witness evidence supportive of the party's case.“"

233 Im Glossar der CPR 2014 wird der Begriff „,cross examination“ wie folgt definiert: „questioning of a witness by a party other than the party who called the witness." Siehe ferner Blackstone's Criminal Practice, § F7.1: „Cross-examination is the questioning of a witness by (a) the opponent of the party calling him or (b) any other party to the proceedings. Thus, as to the latter, an accused has the right to cross-examine a co-accused who has chosen to give evidence (and any witnesses called by the co-accused). [...] Usually crossexamination follows immediately after examination-in-chief, but witnesses are sometimes merely tendered by the prosecution for cross-examination. Such a witness is called by the prosecution, sworn, asked no questions in chief other than his name and address, and then cross-examined by the defence."

234 Siehe Blackstone's Criminal Practice, § F7.60: „After cross-examination, a witness may be re-examined by the party who called him."

235 Siehe insgesamt sect. 37.4.-37.5., 37.12. CPR 2014.

236 Siehe $R v$. Wellingborough Magistrates' Court, ex parte Francois, [1994] 158 JP 460 und 587. 
ultima ratio-Befugnis, die von den Parteien nicht geladenen Zeugen vor Gericht aufzurufen. $^{237}$

Darüber hinaus können sich in der Hauptverhandlung diverse Beweisausschlussfragen und -einwände ergeben, die nicht schon in früheren Verfahrensphasen ${ }^{238}$ angesprochen worden sind. Solche Angelegenheiten können daher in den meisten Fällen ${ }^{239}$ nach richterlichem Ermessen entweder unmittelbar im Vorfeld bzw. während der entsprechenden Beweispräsentationen oder erst nachträglich am Ende aller Anklageausführungen - da nunmehr alle relevanten Umstände klar dargestellt sind - durch Entscheidung der magistrates erledigt werden. Die oben bereits diskutierte Frage ${ }^{240}$ inwieweit die magistrates tatsächlich in der Lage sind, die durch sie selbst formell ausgeschlossenen Beweise für ihre letztendliche Entscheidung über die Schuld zu ,vergessen“, also nicht unterbewusst wahrzunehmen, bleibt jedenfalls bestehen. $^{241}$

Am Ende der umfassenden Auseinandersetzung mit den Anklagebeweisen kann die Verteidigung die sofortige Einstellung des Verfahrens beantragen, wenn es nach ihrer Ansicht keinen substantiellen Grund mehr für die Weiterführung der Verhandlungen gibt - diese Möglichkeit wird als submission of no case to answer bezeichnet. Das Gericht kann einem solchen Antrag - nach Anhörung der möglichen Gegenargumente der Anklage - stattgeben und den Angeklagten freisprechen, insbesondere dann, wenn durch die bis zu diesem Zeitpunkt vorgebrachten Beweise die Deliktselemente nicht nachgewiesen werden können; oder wenn die Anklagebeweise durch die cross-examinations in erheblichem Maße diskreditiert worden sind; oder wenn die Anklagebeweise so offensichtlich unzuverlässig sind, dass kein Gericht den Angeklagten auf ihrer Basis mit Sicherheit verurteilen könnte. ${ }^{242}$ Das Gericht darf aus denselben Gründen ein Verfahren nicht nur auf Antrag der Verteidigung, sondern auch von Amts wegen einstellen. ${ }^{243}$ Zur Wiedergutmachung von kleinen (nicht substantiellen) Mängeln im prosecution case kann jedoch der Richter nachträgliche Beweisführungen durch die Anklage eventuell erlauben. Jedenfalls muss die Verteidigung ihre Absicht, einen no case-

237 Siehe unter Teil 2, II.B.2.b) m.w.N.

238 Siehe schon unter Teil 2, II.D.1.

239 Insb. die Frage der Zulässigkeit nach sect. 76 PACE von vermeintlich durch Zwang erlangten Geständnissen muss im Rahmen von gezielt ausgerichteten, quasi selbstständigen Verfahren innerhalb (und möglicherweise am Anfang) der Hauptverhandlung - ähnlich wie bei der voir dire-Phase vor dem Crown Court - beurteilt werden. Siehe weitere Details in Blackstone's Criminal Practice, §§ F1.43-F1.45.

240 Unter Teil 2, II.D.1.

241 Mehr Details bei Sprack, Criminal Procedure, Rn. 10.55-10.59.

${ }^{242}$ Ferner Sprack, Criminal Procedure, Rn. 10.60. Siehe auch sect. 37.3.(3)(c) CPR 2014.

243 Siehe auch $R v$. Barking and Dagenham Justices, ex parte DPP, [1995] 159 JP 169, 318 und 329. 
Antrag zu stellen, sowie die diesbezüglichen Gründe soweit möglich im Voraus bekannt-geben: Es ist gegenwärtig allgemein anerkannt, ${ }^{244}$ dass das Verfahren letztendlich nicht in ein Spiel bzw. einen Wettstreit der technischen „Überraschungen" ausarten darf. ${ }^{245}$

Ist das Verfahren nach den gerade beschriebenen Regeln nicht einzustellen, werden im Anschluss an den prosecution case in ähnlicher Weise die Verteidigungsthesen und Beweise (defence case) vorgebracht und untersucht, soweit der Angeklagte oder sein Anwalt ${ }^{246}$ überhaupt Beweise vor Gericht präsentieren möchten. ${ }^{247}$ Auch hierbei gelten entsprechend die schon diskutierten Regeln zur Offenlegung ${ }^{248}$ und Zulässigkeit von Beweisen. ${ }^{249}$ Der Rechtsberater bzw. das Gericht muss zunächst den Angeklagten über sein Recht informieren, als Zeuge auszusagen, sowie über die potenziellen negativen Folgen einer (auch partiellen) Aussageverweigerung. ${ }^{250}$ Danach kann die Verteidigung ihre Beweise vorbringen. Bei der Präsentation und Prüfung der Stichhaltigkeit der Verteidigungsbeweise durch die Verfahrensbeteiligten gilt die entsprechende Reihenfolge wie beim Anklagevorbringen (d.h. insbesondere für die Vernehmung jedes einzelnen Zeugen, dass zuerst die examination-in-chief durch die Verteidigung erfolgt, dann die cross-examination durch die Anklage, die re-examination durch die Verteidigung und die Befragungen durch die Richter). ${ }^{251}$ Der Angeklagte ist (wenn überhaupt) grundsätzlich vor den übrigen Verteidigungszeugen zu vernehmen. ${ }^{252}$

Im Anschluss an die Untersuchung der Verteidigungsbeweise kann jede Partei zusätzliche, zu diesem Punkt zulässige Beweise vor allem zur Widerlegung (in rebuttal) von bereits eingeführten Beweisen vorbringen. Danach kann die Anklage

244 Siehe bereits unter Teil 2, II.A.1., Teil 2, II.B.2., Teil 2, II.C.2.

245 Vgl. Hughes v. DPP, [2003] EWHC 2470 (Admin), Rn. 16; R (DPP) v. Chorley Justices, [2006] EWHC 1795 (Admin), Rn. 26; Malcolm v. DPP (DC), [2007] 1 WLR 1230, 1239-1241. Siehe auch den Fall $R$ (CPS) v. Norwich Magistrates' Court, [2011] EWHC 82 (Admin).

246 Zur legal representation vor dem magistrates' court zusammenfassend Sprack, Criminal Procedure, Rn. 10.46-10.48.

247 Dazu auch unter Teil 2, II.B.2.b).

248 Siehe z.B. bei Sprack, Criminal Procedure, Rn. 10.61, das Beispiel der von der Anklage nicht geladenen Zeugen, deren Aussage für die Unterstützung der Verteidigungsthesen von Bedeutung sein könnte und über deren Existenz die Verteidigung deswegen informiert werden muss.

249 Siehe unter Teil 2, II.C.2. und Teil 2, II.D.1.

250 Sect. 37.3.(3)(d) CPR 2014 i.V.m. sect. 35 CJPOA 1994: ,(3) Where this subsection applies, the court or jury, in determining whether the accused is guilty of the offence charged, may draw such inferences as appear proper from the failure of the accused to give evidence or his refusal, without good cause, to answer any question." Siehe dazu auch unter Teil 2, II.B.1.b)aa).

251 Siehe sect. 37.4.-37.5. CPR 2014.

252 Siehe sect. 79 PACE. Siehe auch unter Teil 2, II.B.2.b). 
zusammenfassende Abschlussdarstellungen (final representations) zur Unterstützung ihres case vortragen, soweit der Angeklagte sich durch einen Rechtsanwalt vertreten lässt oder soweit der Angeklagte (mit oder ohne Verteidiger) nicht nur selbst als Zeuge ausgesagt hat, sondern auch weitere Beweise in den Prozess eingeführt hat. Zum Schluss kann auch die Verteidigung Darstellungen zur Unterstützung ihres case vortragen. ${ }^{253}$ Weitere Beweise bzw. Darstellungen, die eine Partei nachträglich - also außerhalb des jeweils dafür geeigneten Rahmens - eventuell in das Verfahren einführen bzw. vortragen will, können vom Gericht nach seinem Ermessen $^{254}$ abgelehnt werden; nach Verkündung des Urteils (verdict) sind jedenfalls keine Beweisaufnahmen mehr möglich. ${ }^{255}$ Die Verkündung des Urteils in einem magistrates' court-Verfahren mit einem Berufsrichter schließt sich in der Praxis des Öfteren direkt an den Schlussvortrag der Verteidigung an; bei Laienmagistrates ist dagegen meistens zuerst eine Beratung zwischen den Richtern erforderlich. $^{256}$

\section{- Das Verfahren vor dem Crown Court}

Das jury-Beweisverfahren vor dem Crown Court weist vom Ablauf her größtenteils ähnliche Grundzüge auf wie das vorangehend beschriebene Verfahren vor dem magistrates' court. Zunächst muss das Gericht die jurors über die Anklagepunkte informieren und ihnen erklären, dass die Verurteilung oder der Freispruch des Angeklagten am Ende der Beweispräsentationen ihre Pflicht ist. ${ }^{257}$ Dann kann die Anklage in ihrer Eingangsansprache vor der jury den Sachverhalt, die Anklagepunkte, relevante komplizierte Rechtsfragen und die von ihr vorzubringenden Beweise - mit Ausnahme von Beweisen, deren Zulässigkeit die Verteidigung im weiteren Verfahren bestreiten wird - zusammenfassen. ${ }^{258}$ Insbesondere in Bezug auf den Zeugenbeweis kann die Anklage (aufgrund ihrer Kenntnis von vorherigen außergerichtlichen Verhörprotokollen) den Geschworenen mitteilen, welches die durch die hauptgerichtlichen Zeugenvernehmungen zu erzielenden Beweisergebnisse sind sowie in welcher Form genau die Aussagen aufeinander aufbauen und die Schuld des Angeklagten nachweisen werden. ${ }^{259}$

253 Sect. 37.3.(3)(f)-(h) CPR 2014 i.V.m. sect. 2 Criminal Procedure Act 1865 und sect. 3 Criminal Evidence Act 1898. Siehe auch Sprack, Criminal Procedure, Rn. 10.6110.62 .

254 Vgl. Malcolm v. DPP (DC), [2007] 1 WLR 1230, 1235-1241 m.w.N.

255 Sect. 37.3.(4) CPR 2014.

256 Ausführlicher Sprack, Criminal Procedure, Rn. 10.63-10.64.

257 Sect. 38.9.(2)(a) CPR 2014.

258 Siehe auch sect 38.9.(2)(b) CPR 2014.

259 Mehr Details bei Blackstone's Criminal Practice, §§ D16.10-D16.16; Sprack, Criminal Procedure, Rn. 20.21-20.22. Siehe auch Huber, in: Perron (Hrsg.), Beweisaufnahme, S. 33. 
Anschließend muss die Anklage die Beweise einführen und präsentieren, auf die sie ihren case stützt. ${ }^{260}$ Sie soll vor allem die vorgeladenen ${ }^{261}$ Anklagezeugen zur Aussage aufrufen und/oder die unter bestimmten Voraussetzungen als Beweise zulässigen schriftlich aufgezeichneten Aussagen und written statements ${ }^{262}$ vorlesen. Ein (meistens spät ,,aufgetauchter“) Zeuge, der nicht vorgeladen ist und dessen vorherige Aussagen in den verschiedenen Stadien des Vorverfahrens nicht offengelegt worden sind, kann trotzdem zur mündlichen Aussage aufgerufen werden: Einem solchen Aufruf muss in der Regel eine Benachrichtigung der Verteidigung und des Gerichts über die Absicht der Anklage, einen zusätzlichen Zeugen aufzurufen (notice of intention to call an additional witness), sowie eine schriftliche Mitteilung des beabsichtigten Beweisinhalts vorangehen; auch eine Vertagung (adjournment) des Verfahrens, um der Verteidigung die Möglichkeit zur besseren Vorbereitung auf den zusätzlichen Beweis zu geben, kommt in Frage. ${ }^{263}$

Darüber hinaus darf die Anklage im Allgemeinen alle ihre Beweise nur während der formalen Präsentation ihres case (also nach ihrer Eröffnungsrede und bis zum Beginn der Verteidigungspräsentationen) und nicht nachträglich vorbringen - eine „Neueröffnung“ (reopening) des prosecution case ist also grundsätzlich nicht erlaubt. ${ }^{264}$ Von dieser Regelung ausgenommen sind rein formale Beweise, die von der Anklage aus Nachlässigkeit und durch Unterlassung nicht vorgebracht worden sind und die zur Wiedergutmachung der Unterlassung auch nachträglich in das Verfahren eingeführt werden können. ${ }^{265}$ Die wichtigste Ausnahme betrifft hierbei Sachprobleme, die hauptsächlich erst im Rahmen der Verteidigungsausführungen

260 Sect. 38.9.(2)(c) CPR 2014.

261 Zur Problematik der Zeugenladungen siehe unter Teil 2, II.B.2.b). Zusammenfassend Sprack, Criminal Procedure, Rn. 20.24-20.31. Siehe auch Blackstone's Criminal Practice, $\S \S \mathrm{D} 16.17-\mathrm{D} 16.30$.

262 Siehe sect. 38.12. CPR 2014. Zu den diversen möglichen Kategorien von zulässigen schriftlichen aussagenbasierten Beweisen, wie witness statements, hearsay evidence und expert evidence, siehe Parts 27, 33, 34 CPR 2014; sect. 9 CJA 1967; sect. 114-120 CJA 2003; und in der vorliegenden Arbeit insb. unter Teil 2, II.B.1.b). In Schedule 2 CPIA 1996 ist die schriftliche Einführung von Aussagen, die schon im Rahmen der (heute größtenteils abgeschafften) committal proceedings vorgebracht wurden, in das Hauptverfahren geregelt. Die sect. 42-43 Children and Young Persons Act 1933 betreffen die Einführung in den Prozess von Protokollen außergerichtlicher richterlicher Vernehmungen (depositions) von Kindern, die z.B. Opfer sexueller Gewalt sind und die wegen erheblicher Gesundheitsgefahr vor Gericht nicht persönlich aussagen sollten - eine wichtige Voraussetzung für die Zulässigkeit solcher Beweise ist, dass die Verteidigung vorher während der außergerichtlichen Vernehmung die Möglichkeit zum Kreuzverhör des Kindes hatte. Siehe zusammenfassend Blackstone's Criminal Practice, §§ D16.35-D16.40; Sprack, Criminal Procedure, Rn. 20.28, 20.34.

263 Mehr dazu bei Sprack, Criminal Procedure, Rn. 20.32-20.33, 20.84. Siehe auch Huber, in: Perron (Hrsg.), Beweisaufnahme, S. 33.

264 Ferner Blackstone's Criminal Practice, §§ D18.2-D18.8.

265 Siehe weitere Beispiele im selben Kontext bei Sprack, Criminal Procedure, Rn. 20.82-20.85. 
ex improviso auftreten und die kein menschlicher „Einfallsreichtum“ (ingenuity) vorhersehen konnte: ${ }^{.66}$ In solchen Fällen kann nach richterlichem Ermessen die nachträgliche Einführung in den Prozess - während oder am Ende der Verteidigungspräsentationen oder sogar nach den anwaltlichen Schlussvorträgen ${ }^{267}$ - von neuen Beweisen seitens der Anklage zur Widerlegung der betreffenden Verteidigungsbeweise erlaubt werden. ${ }^{268}$

Üblicherweise können sich darüber hinaus während der Präsentation des prosecution case auch vor dem Crown Court diverse rechtliche Fragen und Einwände bezüglich der Offenlegung und insbesondere der Zulässigkeit der vorgebrachten (mündlichen und schriftlichen) Beweise ergeben. Oft werden solche Fragen (manchmal von Amts wegen) $^{269}$ bzw. die relevanten Einwände der Verteidigung direkt vor der Präsentation des jeweils strittigen Beweises und grundsätzlich in Abwesenheit der jury diskutiert, wie etwa im Rahmen der voir dire-Phase. ${ }^{270}$ Es ist jedoch auch möglich, dass derartige Rechtsfragen im Rahmen von pre-trial/preparatory hearings oder im Vorfeld der Eingangsansprache der Anklage oder umgekehrt sogar erst am Ende sämtlicher Beweispräsentationen vor Gericht angesprochen werden. Im letzteren (von den Hochgerichten nicht für wünschenswert gehaltenen) Fall haben die Geschworenen alle Beweise tatsächlich schon gehört, und der Richter muss daher bei seiner Zusammenfassung der Einzelheiten des präsentierten Straffalles (summing-up) die Geschworenen anweisen, die durch ihn ausgeschlossenen Beweise für ihre Entscheidung nicht wahrzunehmen. ${ }^{271}$

In Bezug auf die Anklagezeugen findet die Präsentation und die Prüfung der Stichhaltigkeit der betreffenden (zulässigen) Aussagen, wie es auch vor dem $m a-$ gistrates' court der Fall ist, jeweils im Wege von examinations-in-chief durch die Anklage und cross-examinations durch die Verteidigung (also durch den Angeklagten oder seinen Anwalt) ${ }^{272}$ sowie von möglichen re-examinations durch die Anklage statt. ${ }^{273}$ Die Befragung der Zeugen durch den verfahrensleitenden Richter

266 Siehe grundlegend $R v$. Day, [1940] 1 All ER 402, 404-406; siehe auch $R$ v. Blick, [1966] 50 Cr App R 280, 282-284.

267 Vgl. $R$ v. Flynn, [1958] 42 Cr App R 15, 15-19.

268 Siehe auch sect. 38.9.(2)(h), 38.9.(6) CPR 2014.

269 Siehe z.B. sect. 76(3) PACE zur Befugnis des Richters, die Zulässigkeit eines Geständnisses von Amts wegen infrage zu stellen.

270 Siehe bereits unter Teil 2, II.D.1. Zu den hearings on the voir dire auch Blackstone's Criminal Practice, §§ F1.39-F1.42. Siehe auch sect. 38.3. CPR 2014.

271 Weitere prozessuale Details mit Rechtsprechungsverweisen bei Blackstone's Criminal Practice, §§ D16.41-D16.53; Sprack, Criminal Procedure, Rn. 20.35-20.42.

${ }^{272} \mathrm{Zu}$ dem unvertretenen und dem abwesenden Angeklagten im Crown CourtVerfahren Sprack, Criminal Procedure, Rn. 20.69-20.73. Siehe auch sect. 38.2. CPR 2014.

273 Sect. 38.11.(4) CPR 2014. Siehe die Einzelheiten in Blackstone's Criminal Practice, $\S \S$ F6.1-F7.60. 
ist allgemein jederzeit möglich. ${ }^{274}$ Der Richter soll einem Angeklagten, der sich nicht durch einen Anwalt vertreten lässt, während der Beweisführungen die notwendige Unterstützung auch im Wege der Zeugenbefragungen leisten. Im Fall eines abwesenden und „unvertretenen“ Angeklagten soll der Richter während der Beweisführungen und der abschließenden Zusammenfassung des Sachverhaltes soweit er überhaupt entscheidet, dass das Verfahren ausnahmsweise in Abwesenheit des Angeklagten fortzusetzen ist - die eventuellen Schwachpunkte des prosecution case den Geschworenen möglichst klar darstellen. ${ }^{275}$ Die Geschworenen können ihrerseits während der ganzen trial in begrenztem Maße Fragen an die Zeugen stellen, was aber grundsätzlich indirekt (durch den Richter, der die ihm schriftlich mitgeteilten Fragen laut vorlesen muss) und in der Praxis eher selten geschieht. $^{276}$

Im Anschluss an die Anklagepräsentationen werden in Abwesenheit der Geschworenen auch im Crown Court-Verfahren die oben analysierten no case to answer-Angelegenheiten auf Antrag der Verteidigung oder von Amts wegen angesprochen. Falls der Richter dabei zu dem Schluss kommt, dass das Verfahren hinsichtlich eines oder sämtlicher Klagepunkte infolge der substantiellen Beweismängel im Anklagevorbringen nicht fortgesetzt werden soll, muss er die Geschworenen anweisen, den Angeklagten entsprechend freizusprechen. ${ }^{277}$ Der Richter kann sogar erst nach dem Ende der Verteidigungspräsentationen auf Antrag oder von Amts wegen auf Abbruch des Verfahrens im Wege einer no case to answerBegründung entscheiden, wobei damit die Entscheidungsbefugnis über den Sach-

274 Sect. 38.11.(6) CPR 2014. Siehe ferner unter Teil 2, II.D.2.c).

275 Hierzu m.w.N. Sprack, Criminal Procedure, Rn. 20.69, 20.73.

276 Archbold, §§ 4-327, 8-302. Siehe auch Gerding, Trial, S. 353-354.

277 Sect. 38.9.(2)(d) CPR 2014. In $R$ v. Galbraith, [1981] 1 WLR 1039, 1042, wurden die relevanten Kriterien dargestellt: „How then should a judge approach a submission of 'no case"? (1) If there is no evidence that the crime alleged has been committed by the defendant, there is no difficulty. The judge will of course stop the case. (2) The difficulty arises where there is some evidence but it is of a tenuous character, for example because of inherent weakness or vagueness or because it is inconsistent with other evidence. (a) Where the judge comes to the conclusion that the prosecution evidence, taken at its highest, is such that a jury properly directed could not properly convict upon it, it is his duty, upon a submission being made, to stop the case. (b) Where however the prosecution evidence is such that its strength or weakness depends on the view to be taken of a witness's reliability, or other matters which are generally speaking within the province of the jury and where on one possible view of the facts there is evidence upon which a jury could properly come to the conclusion that the defendant is guilty, then the judge should allow the matter to be tried by the jury. [...] There will of course, as always in this branch of the law, be borderline cases. They can safely be left to the discretion of the judge." Dazu u.a. Dennis, Evidence, Rn. 4.007; Doran, in: Doran/Jackson (Hrsg.), Judicial Role, S. 10-11; Jackson/Doran, MLR 60 (1997), 759 (768-770). Siehe ferner Blackstone's Criminal Practice, §§ D16.54-D16.73; Sprack, Criminal Procedure, Rn. 20.48-20.55. Siehe auch zum Spezialfall bei hearsay evidence sect. 125 CJA 2003. 
verhalt den Geschworenen eigentlich entzogen wird. ${ }^{278}$ Auch die Geschworenen können nach dem Ende der Anklagepräsentationen zu jedem Zeitpunkt das Verfahren selbstständig (nach Erteilung der entsprechenden Erlaubnis durch den Richter) abbrechen und den Angeklagten freisprechen - zum Treffen einer verurteilenden Entscheidung müssen sie dagegen auch die durch die Verteidigung vorgebrachten Beweise zuerst wahrgenommen haben. ${ }^{279}$

Wird dagegen das Verfahren nach dem Ende der Anklageausführungen normal fortgesetzt, hat der Verteidiger (bzw. der Angeklagte) das Recht auf eine Eingangsansprache, soweit er in der Folge nicht nur den Angeklagten als Zeugen aufrufen, sondern auch andere Sachzeugen und -beweise (nicht lediglich character witnesses) in das Verfahren einführen will; diese Ansprache kann die Grundzüge des defence case sowie auch die Widerlegung der bisher vorgebrachten Anklagebeweise betreffen. ${ }^{280}$ Danach ist der Verteidiger berechtigt, aber nicht verpflichtet, den Angeklagten als (normalerweise ersten) ${ }^{281}$ Zeugen aufzurufen. Der Verteidigung (und insbesondere einem „unvertretenen“ Angeklagten) muss jedoch ausdrücklich im Voraus erklärt werden, dass die jury aus einem unbegründet unterbliebenen Verhör des Angeklagten oder aus seinem Teilschweigen negative Schlussfolgerungen für die Entscheidung über die Schuld ziehen darf. ${ }^{282}$ Die Verteidigung ist im Allgemeinen überhaupt nicht verpflichtet Beweise vorzubringen, auch wenn eine solche Unterlassung faktisch einen erheblichen negativen Einfluss auf die Entscheidung der jury haben könnte. ${ }^{283}$

Ruft die Verteidigung den Angeklagten und/oder weitere Personen als Zeugen zur Aussage über die betreffenden Tatsachen oder über den Charakter des Angeklagten auf, durchläuft jeder einzelne Zeuge anschließend die examination-in-chief durch die Verteidigung, die cross-examination durch die Anklage, die re-examination durch die Verteidigung und jederzeit möglicherweise auch Befragungen durch den Richter. Der Richter kann nach freiem Ermessen und unter Berücksich-

278 Siehe $R$ v. Brown, [1998] Crim.L.R. 196, 197: ,[...] throughout a trial, the judge has a responsibility not to allow a jury to consider evidence on which they could not safely convict. [...] if, at the conclusion of all the evidence, a trial judge is of the view that no reasonable jury, properly directed, could safely convict, he should, generally speaking, whether a submission of no case has been made at the conclusion of the prosecution case or not, raise that view for discussion with counsel, in the absence of the jury. If, having heard submissions, he remains of that view, then he should, in our judgment, withdraw the case from the jury." Siehe auch sect. 38.9.(7) CPR 2014.

279 Dazu Sprack, Criminal Procedure, Rn. 20.76.

280 Siehe sect. 38.9.(2)(f) CPR 2014. Vgl. sect. 2 Criminal Evidence Act 1898; siehe auch Sprack, Criminal Procedure, Rn. 20.57.

281 Sect. 38.9.(2)(g) CPR 2014.

282 Siehe sect. 38.9.(2)(e) CPR 2014 und sect. 1 Criminal Evidence Act 1898 i.V.m. sect. 35 CJPOA 1994. Ferner Blackstone's Criminal Practice, §§ D17.8-D17.13, D17.17D17.18; Sprack, Criminal Procedure, Rn. 20.58-20.60.

283 Siehe auch Sprack, Criminal Procedure, Rn. 20.56. 
tigung der jeweiligen Fallumstände die „Neueröffnung“ des defence case und somit die Einführung von zusätzlichen Beweisen sogar erst nach dem Ende der richterlichen summing-up erlauben. ${ }^{284}$ Es gilt jedenfalls die allgemeine Regel, dass nach dem Beginn der nichtöffentlichen jury-Beratungen (deliberations) die Parteien (und ebenso der Richter) keine Beweise mehr in den Prozess einführen dürfen. ${ }^{285}$

An dieser Stelle ist noch einmal zu betonen, dass auch im Crown CourtVerfahren der Richter die ultima ratio-Befugnis hat, die von den Parteien nicht geladenen Zeugen selbst aufzurufen, wenn ihm dies im Interesse der Gerechtigkeit als notwendig erscheint. ${ }^{286}$ Der Richter stellt dabei selbst Fragen an jene Zeugen und kann danach die Durchführung von Kreuzverhören durch die (von der Aussage negativ betroffenen) Parteien erlauben. Dem Richter wird ebenso das allgemeine Ermessen eingeräumt, sämtliche Zeugen - einschließlich des Angeklagten, soweit er bereits als Zeuge während der Verteidigungspräsentationen ausgesagt hat - jederzeit bis zur abschließenden richterlichen Zusammenfassung des Straffalles erneut $\mathrm{zu}$ weiteren (richterlichen oder parteilichen) Vernehmungen aufzurufen bzw. aufrufen zu lassen (recalling witnesses). ${ }^{287}$

Nach der Präsentation und Prüfung der Verteidigungsbeweise hat nun die Anklage das Recht auf den Schlussvortrag (final representations), soweit der Angeklagte sich durch einen Rechtsanwalt vertreten lässt, soweit der Angeklagte nicht lediglich selbst als Zeuge ausgesagt hat, sondern auch weitere Sachzeugen in den Prozess aufgerufen hat, oder soweit das Gericht dies erlaubt. ${ }^{288}$ Die Anklage muss als minister of justice ihren Schlussvortrag möglichst objektiv, in Übereinstimmung mit den vorhandenen Beweisen und in unemotionaler Weise halten. Anschließend hat die Verteidigung (Angeklagter oder Anwalt) das Recht auf Schlussvortrag. ${ }^{289}$ Die Verteidigung (wie auch die Anklage) kann einen inhaltlich umfangreichen Schlussvortrag zur kritischen Zusammenfassung ihres Vorbringens und der übrigen Beweisführungen halten, der aber nur solche Tatsachenbehauptungen enthalten darf, bezüglich derer im Verfahren Beweise schon erhoben worden sind. ${ }^{290}$

${ }^{284}$ Siehe $R$ v. Sanderson, [1953] 1 WLR 392, 393. Siehe auch sect. 38.9.(2)(h), 38.9.(6) CPR 2014.

285 Dazu mit einigen neueren Ausnahmen Blackstone's Criminal Practice, §§ D18.9, D19.12-D19.17; Sprack, Criminal Procedure, Rn. 21.07. Siehe auch Tapper, Evidence, S. 293.

286 Siehe unter Teil 2, II.B.2.b).

287 Hierzu Blackstone's Criminal Practice, §§ D18.10-D18.12, F7.7; Sprack, Criminal Procedure, Rn. 20.86-20.88. Siehe auch Archbold, §§ 8-303-8-305.

288 Sect. 38.9.(2)(i) CPR 2014.

289 Sect. 38.9.(2)(j) CPR 2014.

290 Siehe sect. 2 Criminal Procedure Act 1865 und sect. 3 Criminal Evidence Act 1898. Mehr Details bei Blackstone's Criminal Practice, §§ D18.15-D18.20 m.w.N.; siehe auch Sprack, Criminal Procedure, Rn. 20.74-20.75. 
Zum Schluss fasst der verfahrensleitende Richter die wesentlichen Rechtsfragen und Beweispunkte des Sachverhalts zusammen und trägt diese samt den notwendigen Anweisungen zur Unterstützung der Geschworenen bei ihrer Tatsachenfeststellungsaufgabe öffentlich vor (the judge's summing-up); nach richterlichem Ermessen kann auch eine Liste mit schriftlichen Anweisungen und Fragen an die jurors verteilt werden. ${ }^{291}$ Insbesondere vor dem Beginn der summing-up Ausführungen kann der Richter (in Abwesenheit der jury) die Hilfe der Anwälte zur Vorbereitung einer klaren (nicht widersprüchlichen) Ausformulierung der anzusprechenden Rechts- und Tatsachenfragen verlangen. Von den Anwälten beider Seiten wird allgemein in Übereinstimmung mit ihren rechtlichen und ethischen Pflichten gegenüber dem Gericht erwartet, dass sie das Gericht vollständig über die betreffende Rechtslage und die entsprechende case law-Materie informieren werden. Aufgedeckte prozessuale Unregelmäßigkeiten (etwa, dass ein Geschworener mit einem Zeugen kommuniziert hat) sind ebenso dem Richter unmittelbar mitzuteilen und nicht aus strategischen Gründen vor allem mit Blick auf künftige Berufungsmöglichkeiten zu verheimlichen. Die Anwälte können - genauer: die Anklage soll, die Verteidigung muss nicht - am Ende der summing-up Phase und vor dem Beginn der jury-Beratungen den Richter auf eventuelle falsche Belehrungen hinsichtlich der Rechts- und Tatsachenfragen aufmerksam machen. ${ }^{292}$

Der verfahrensleitende Richter kann im Rahmen der summing-up Phase unter anderem folgende Punkte ansprechen: ${ }^{293}$ Er erklärt den Geschworenen, dass sie nur an seine Entscheidungen über die rechtlichen Fragen gebunden sind und dass sie dagegen frei und unabhängig von eventuellen richterlichen Kommentaren entscheiden können, welche Tatsachen im Verfahren nachgewiesen worden sind. Er erklärt ebenso, dass die Anklage die Schuld des Angeklagten nachweisen muss, dass der Angeklagte seinerseits nichts nachzuweisen braucht und dass zum Treffen einer

291 Siehe sect. 38.14. CPR 2014. Nach Jackson/Doran, Is.L.R. 31 (1997), 645 (681): ,[...] the judge's putting of the issues to the jury is still an integral part of the argumentative process which has continued throughout the trial. $[\ldots]$ the jury cannot form a collective opinion until it retires at the end of the evidence, with the judicial summing-up as the final external input into its process of decision-making. In a sense then the summing-up could be described as a crystallisation of the debate which has been conducted throughout the course of the trial." Siehe zu den notwendigen richterlichen Anweisungen an die jurors das Crown Court Bench Book, abrufbar unter http://www.judiciary.gov.uk/publicationsand-reports/judicial-college/Pre+2011/crown-court-bench-book-directing-the-jury [Stand: Oktober 2014].

292 Siehe Blackstone's Criminal Practice, §§ D18.13-D18.14, D18.21-D18.24; Sprack, Criminal Procedure, Rn. 20.79-20.81. Zu diesen Möglichkeiten der parteilichen Beeinflussung der richterlichen Zusammenfassungen auch Jackson/Doran, Is.L.R. 31 (1997), 645 (681-682).

293 Weitere Details in Blackstone's Criminal Practice, §§ D18.25-D18.45; Roberts/ Zuckerman, Criminal Evidence, S. 82-86; Sprack, Criminal Procedure, Rn. 20.77-20.78 mit entsprechenden Rechtsprechungsverweisen. Siehe auch Pattenden, Judicial Discretion, S. 177-212; Uglow, Evidence, S. 65-69. 
verurteilenden Entscheidung die Geschworenen „sicher“ („sure“ als alternativer Ausdruck zur Phrase ,,beyond reasonable doubt") sein müssen. Der Richter stellt darüber hinaus die rechtlichen Tatbestandselemente dar, deren Existenz im konkreten Fall die Anklage nachweisen muss; dabei kann sich der Richter auch mit der rechtlichen Definition der von der Verteidigung vorgebrachten defences (z.B. selfdefence, alibi, diminished responsibility) und mit entsprechenden Beweislastfragen auseinandersetzen. Der Richter kann ausnahmsweise im Rahmen seiner Zusammenfassungen aufgrund einer eindeutigen Beweislage selbst defences zugunsten des Angeklagten vorbringen, welche die Verteidigung während der Beweisführungen nicht vorgebracht hatte (alternative defences). ${ }^{294}$ Des Weiteren fasst der Richter die vorgebrachten Beweise zusammen, identifiziert die beweisrelevanten Hauptfragen des Straffalles und macht entsprechende (direkte oder indirekte) unverbindliche, möglicherweise tiefgehende und umfangreiche Kommentare zu ihrer Bedeutung und $\mathrm{zu}$ den bestrittenen Tatsachen. ${ }^{295}$

Zuletzt folgt in einem Crown Court-Verfahren die nichtöffentliche Beratung der Geschworenen. Die jurors dürfen ihre endgültige Entscheidung über die Schuld nur auf der Basis der im Verfahren präsentierten Beweise und Argumente treffen. ${ }^{296}$ Grundsätzlich wird eine einstimmige Entscheidung der jury angestrebt, wobei heute unter bestimmten Voraussetzungen auch Mehrheitsentscheidungen zulässig sind. ${ }^{297}$ Im Fall einer Verurteilung liegt dann die anschließende Strafzumessungsphase in den Händen des Richters (und nicht der jury). ${ }^{298}$

294 Doran, in: Doran/Jackson (Hrsg.), Judicial Role, S. 9 m.w.N., bemerkt: „[...] judges have a responsibility to ensure that the outcome of a trial is in tune with the evidence presented, a responsibility that trumps the capacity of one party to place tactics before truth finding. On a broader level, the English courts [...] have accepted that a judge is entitled to comment on all matters which have been dealt with in the evidence, even if they are not raised in the arguments propounded by the prosecution and defence. [...] Given this formal acceptance that judges may at the conclusion of the evidence be drawn into a more inquisitorially driven role in drawing out interpretations that have not been developed by the parties, it is hardly surprising that judges also become inclined towards interventionist tendencies at other junctures in the trial process." Mehr zu den alternative defences bei Doran, [1991] Crim.L.R. 878 (879-888).

295 Zum Vergleich diesbezüglich mit der US-amerikanischen summing-up Praxis, wobei grundsätzlich keine richterlichen Kommentare hinsichtlich der Tatsachenfragen erlaubt sind, Jackson/Doran, Is.L.R. 31 (1997), 645 (680); siehe auch Otton, in: McConville/ Wilson (Hrsg.), Handbook, S. 328-329.

296 Siehe zu den Anweisungen, welche die Geschworenen am Anfang der trial bezüglich ihrer Rolle erhalten, u.a. Archbold, §§ 4-235-4-236.

297 Blackstone's Criminal Practice, §§ D19.34-D19.40.

298 Siehe zum relevanten Verfahren sect. 38.16. CPR 2014. Zu Fragen von verdict und sentencing u.a. Sprack, Criminal Procedure, Rn. 21.01-25.117. Siehe auch unter Teil 2, II.A.2., II.A.3. 


\section{c) Die Methoden der Beweisprüfung}

aa) Allgemeine Bemerkungen

In unmittelbarem Zusammenhang mit den bisherigen Ausführungen zum Ablauf des streitigen Beweisverfahrens wird im Folgenden vor allem die Erhebung des mündlichen Zeugenbeweises detaillierter angesprochen. Die Betrachtung derartiger Beweisführungen kann nämlich genauer hindeuten auf die generelle Ausrichtung und den vollen Umfang der Untersuchung in der Hauptverhandlung der vor Gericht vorgebrachten Beweise, die letztendlich unter Glaubwürdigkeits-, Ehrlichkeits-, Zuverlässigkeits- und Genauigkeitskriterien ${ }^{299}$ auf Stichhaltigkeit geprüft werden müssen.

Andere bereits erwähnte Kategorien von Beweisen - der schriftliche aussagenbasierte Beweis und der Urkundenbeweis, die real evidence und der Augenscheinsbeweis - sind in sämtlichen Gerichtsverfahren mit Blick auf ihre Erhebung zunächst nach den diversen Beweisoffenlegungs- und Beweisausschlussregeln bzw. nach den Regeln zur Einführung von Beweisen durch Zustimmung der Parteien zu beurteilen. ${ }^{300}$ Soweit derartige Beweise im Verfahren aufgrund richterlicher Entscheidung verbindlich zugelassen worden sind bzw. soweit ihre Einführung nicht widerlegt worden ist, werden diese vor sämtlichen Verfahrensbeteiligten, dem Richter und (im Rahmen einer jury trial) den Geschworenen präsentiert. Dies kann beispielsweise durch die Verlesung der relevanten Schriftstücke, das Abspielen von Videoaufzeichnungen oder das (Kreuz-)Verhör der Personen, welche die betreffenden Beweismittel besitzen, geschehen. Umfassende Beweiskommentierungen und die Abgabe von Erklärungen zu den sich bezüglich solcher Beweise ergebenden Rechts- und Stichhaltigkeitsfragen sind des Weiteren im Rahmen der anwaltlichen Anfangs- und Schlussvorträge oder auch (beim jury-Verfahren) während der abschließenden richterlichen Zusammenfassungen möglich.

\section{bb) Die Art und Weise der Vernehmungen}

Es wurde bereits dargelegt, dass die hauptsächlichen Verhöre der Zeugen, die mündlich im magistrates' court- oder im Crown Court-Verfahren aussagen müssen/können, während und als Teil der ordentlichen gegensätzlichen Anklage- und Verteidigungspräsentationen stattfinden - also weder im Wege irgendeiner neutralamtlichen Untersuchung noch in Form einer freien, umfassenden Nacherzählung der beobachteten Fakten. ${ }^{301}$ Die Befragung sämtlicher Zeugen durch den verfah-

299 Vgl. dazu unter Teil 2, II.A.3.

300 Siehe unter Teil 2, II.A.3.; Teil 2, II.B.; Teil 2, II.C.2.; Teil 2, II.D.1. und 2.a)-b). Weitere Details zu documentary evidence und real evidence siehe in Blackstone's Criminal Practice, $\S \S$ F7.19-F7.21, F8.1-F8.64.

301 Vgl. auch Dennis, Evidence, Rn. 14.002. 
rensleitenden Richter nach eigenem Ermessen ist gleichwohl in jedem Verfahrensstadium möglich. ${ }^{302}$ Der Richter muss trotzdem beim Eingreifen in die Beweiserhebungen und insbesondere bei der Unterbrechung der durch die Parteien vorgenommenen (Kreuz-)Verhöre erhebliche Zurückhaltung an den Tag legen; Unterbrechungen sind grundsätzlich nur aus Klarstellungsgründen erlaubt. ${ }^{303}$

Jeder einzelne Zeuge durchläuft üblicherweise zuerst die examination-in-chief durch die Partei, die ihn aufgerufen hat, dann die cross-examination durch die Gegenpartei(en) und am Ende eventuell auch eine re-examination durch die erstere Partei - der Angeklagte kann (soweit er sich dafür entschieden hat) ausschließlich als Zeuge der Verteidigung geladen und daher grundsätzlich nur im Rahmen der Präsentation des defence case verhört und ins Kreuzverhör genommen werden. ${ }^{304}$ Die Durchführung sämtlicher Verhöre durch die Parteien erfolgt allerdings nicht auf unkontrollierte Weise. Vielmehr kann bzw. muss der verfahrensleitende Richter unter bestimmten Voraussetzungen und oft aufgrund eines parteilichen Einspruchs eingreifen, um die Einhaltung gewisser Prozess- und Fairnessregeln sicherzustellen

302 U.a. Pattenden, Judicial Discretion, S. 98-102 m.w.N.

303 Dazu mit Rechtsprechungsverweisen Archbold, §§ 8-300-8-301; Blackstone's Criminal Practice, $\S$ F7.5. Im grundlegenden Fall $R$ v. Sharp, [1993] 3 All ER 225, 235, wurden folgende Grenzen festgelegt: „When a judge intervenes in the course of examination, or particularly cross-examination, a number of problems can arise depending on the frequency and manner of the interruptions. First the judge may be in danger of seeming to enter the arena in the sense that he may appear partial to one side or the other. This may arise from the hostile tone of questioning or implied criticism of counsel who is conducting the examination or cross-examination, or if the judge is impressed by a witness, perhaps suggesting excuses or explanations for a witness' conduct which is open to attack by counsel for the opposite party. Quite apart from this, frequent interruptions may so disrupt the thread of cross-examination that counsel's task may be seriously hampered. [...] crossexamination of the principal witnesses is something that calls for careful preparation and planning. It is the most important part of the advocate's art, because a competent crossexamination is designed to weaken or destroy the opponent's case and to gain support for the client's case. [...] If the judge intervenes at a crucial point where the witness is being constrained to make an important admission, it can have an adverse effect on the trial. In general, when a cross-examination is being conducted by competent counsel a judge should not intervene, save to clarify matters he does not understand or thinks the jury may not understand. If he wishes to ask questions about matters that have not been touched upon it is generally better to wait until the end of the examination or cross-examination. This is no doubt a counsel of perfection and a judge should not be criticised for occasional transgressions; still less can it be said in such cases that there is any irregularity in the conduct of the trial or that the verdict is unsafe or unsatisfactory. But there may come a time, depending on the nature and frequency of the interruptions that a reviewing court is of the opinion that defence counsel was so hampered in the way he properly wished to conduct the cross-examination that the judge's conduct amounts to a material irregularity." Dazu und zu weiteren Beispielen aus der Rechtsprechung Jackson/Doran, Judge, S. 100, 105110. Siehe auch neuerdings $M M v . R$ (Rev 1), [2011] EWCA Crim 1291, Rn. 35.

304 Weitere Details zur Reihenfolge der Vernehmungen sowie zu den Möglichkeiten für nachträgliche Einführungen von Beweisen und für „Neueröffnungen“ der cases siehe unter Teil 2, II.D.2.b). 
und dafür zu sorgen, dass ein hohes Qualitätsniveau der wahrzunehmenden Beweise sowie allgemein die Förderung der Wahrheitsermittlung gewährleistet sind. ${ }^{305}$

\section{- Struktur und Umfang der Vernehmungen: Examination-in-chief}

Jeder Zeuge muss zunächst von der Partei verhört werden, die ihn aufgerufen hat (examination-in-chief). Eine Ausnahme stellt die Vermeidung des Hauptverhörs bei bestimmten Kategorien ${ }^{306}$ von gefährdeten und schutzbedürftigen (z.B. minderjährigen oder eingeschüchterten) Zeugen dar: Dabei kann im Hauptverfahren nach richterlichem Ermessen unter Wahrnehmung der Justizinteressen statt des Hauptverhörs das Abspielen der Videoaufnahme einer vorherigen Zeugenvernehmung angeordnet werden - bei Minderjährigen gilt dies sogar als primary rule. Eine solche richterliche Anordnung schließt keinesfalls das Kreuzverhör jenes Zeugen aus, kann jedoch unter anderem die außergerichtliche Durchführung des Kreuzverhörs in Abwesenheit des Angeklagten, die Videoaufzeichnung des Verhörs und das nachfolgende Abspielen der Aufnahme im Hauptverfahren verlangen. ${ }^{307}$ Weitere technische Schutzmaßnahmen, die unter strengen Voraussetzungen auf Antrag einer Partei oder von Amts wegen bei derartigen Zeugenkategorien mutmaßlich zur Verbesserung der Beweisqualität ${ }^{308}$ richterlich angeordnet werden können und die dabei die physische Unmittelbarkeit der üblichen (Kreuz-)Verhörsituation mehr oder weniger mindern dürfen, sind unter anderem folgende: screening witness from accused, evidence by live link, examination of witness through intermediary, und witness anonymity orders. ${ }^{309}$

305 Dennis, Evidence, Rn. 14.002 m.w.N., der auch bemerkt: „Both principles, party autonomy and the truth-finding role of the court, are in turn subject to the disciplines of necessity and efficiency. Human beings are mortal, and the resources of the legal system are not infinite. Therefore limits have to be set to the scope of the inquiry and to the length and cost of the proceedings. The interaction of these principles and policies helps to explain much of the complex, and apparently arbitrary, nature of the law."Vgl. auch $R$ v. A, [2001] UKHL 25, Rn. 55:,[...] it is fundamental to our system of justice that the rules of evidence should permit the judge and jury to get at the truth and properly determine the issues in the case." Vgl. auch früher zur Befugnis des englischen Richters zum Eingreifen in die Beweiserhebungen von Amts wegen Herrmann, Reform, S. 300, 304, 306.

306 Siehe sect. 16-19, 21 Youth Justice and Criminal Evidence Act 1999.

307 Siehe sect. 27-28 Youth Justice and Criminal Evidence Act 1999. Vgl. auch die allgemeineren Vorschriften in sect. 137-138 CJA 2003 (noch nicht in Kraft).

308, ,[...] likely to improve the quality of evidence given by the witness“, siehe sect. 16(1), 17(1), 19(2)(a) Youth Justice and Criminal Evidence Act 1999.

309 Siehe sect. 21-33 Youth Justice and Criminal Evidence Act 1999 (special measures directions in case of vulnerable and intimidated witnesses) i.V.m. sect. 86-97 Coroners and Justice Act 2009 (anonymity of witnesses) und Part 29 CPR 2014. Vgl. auch sect. 32 CJA 1988 i.V.m. sect. 51-52 CJA 2003 (live links in criminal proceedings). Mehr zu den technischen Details u.a. in Blackstone's Criminal Practice, $\S$ D14.1-D14.60, D15.97D15.99; Dennis, Evidence, Rn. 14.003, 15.020-15.037. Siehe auch Tapper, Evidence, S. 227-234. 
Darüber hinaus gilt als allgemeine Regel bei den examinations-in-chief, dass den Zeugen nur solche Fragen gestellt werden dürfen, die relevant für die bestrittenen Tatsachen und nicht unzulässig nach den Beweisausschlussregeln (vor allem: nach den hearsay-Regeln) sind. Fragen, die ausschließlich die Glaubwürdigkeit des Zeugen betreffen, sind im Rahmen des Hauptverhörs - wobei die examinierende Partei die von ihr aufgerufenen Zeugen im Grunde für vertrauenswürdig hält nicht relevant genug (und daher nicht erlaubt). ${ }^{310}$ Auch die Einführung vorheriger inhaltsgleicher Aussagen des Zeugen, die auf die Stimmigkeit der Aussagen vor Gericht hindeuten könnten, in das Verfahren ist grundsätzlich - nach den Regeln des hearsay-Beweises sowie wegen des praktisch meistens zweifelhaften Beweiswertes - nicht zulässig. ${ }^{311}$ Dagegen sind frühere widersprüchliche (inconsistent) Aussagen des Zeugen, deren Existenz nachgewiesen wird oder deren Existenz der Zeuge während des Verhörs zugibt, nach den hearsay-Regeln auch als substantieller Tatsachenbeweis zulässig. ${ }^{312}$

Weitere wichtige Regeln zur Durchführung der Hauptverhöre betreffen das Verbot von leading questions (Suggestivfragen) und die Möglichkeit der Zeugen, während ihres Verhörs vorherige schriftliche Aussagen zur „Auffrischung“ des Gedächtnisses einzusehen. Unter leading questions sind hauptsächlich Fragen zu verstehen, die vom Anwalt so gestellt werden, dass sie auf die erwünschte Antwort bereits unmittelbar hindeuten oder die (noch zu überprüfende) Existenz einer Tatsache voraussetzen. ${ }^{313}$ Eine Ausformulierung der sich auf bestrittene Tatsachen

310 Dennis, Evidence, Rn. 14.005 m.w.N.

311 Zur rule against narrative und den komplexen Ausnahmen von dieser Regelung (z.B. bei der Einführung als Beweis von previous identifications, von statements rebutting suggestions of recent fabrication und von complaints by victims sowie bei der res gestaeRegel) Dennis, Evidence, Rn. 14.006-14.014, 14.043. Siehe auch Blackstone's Criminal Practice, §§ F6.32-F6.49.

312 Siehe sect. 119 CJA 2003 und Blackstone's Criminal Practice, §§ F6.24, F6.49, F6.56-F6.59.

313 Die möglichen Formen der leading questions und die Begründung ihres Verbots beschreibt Dennis, Evidence, Rn. 14.015, anschaulich: „A leading question may take one of two forms. Most commonly it is a question that suggests the desired answer, such as 'Did you see D hit P?'. This is leading the witness to give the answer 'Yes', since this is clearly the answer counsel is expecting. A proper line of questioning would be to ask the witness where he was on the particular day, whether he saw anything happen, and then to ask the witness what he saw. Questions that simply invite the witness to assent to a proposition about the facts in issue will frequently be leading. The reasons why an examiner in chief should not use leading questions are: first, the witness can be expected to favour the party calling him and is likely therefore to agree with counsel who puts words in his mouth; secondly, allowing counsel to lead a witness increases the risk that only favourable testimony will emerge and that unfavourable testimony will be suppressed, thus impairing the truthfinding function of the proceedings; thirdly, a witness may be misled into agreeing to a question put in terms that do not completely express the true meaning of his evidence. [...] The other form of leading question is one that assumes the existence of a disputed fact. A question such as 'When did you stop beating your wife?' is plainly objectionable if it is in 
beziehenden Fragen, die direkt auf die erwünschte Antwort hindeutet, ist im Rahmen des Hauptverhörs nicht erlaubt und kann zur Erhebung eines relevanten Einwands seitens der Gegenpartei führen. Derartige leading questions dürfen gleichwohl von einer Partei an einen ,eigenen“ Zeugen gestellt werden, falls der Letztere, wie noch zu sehen ist, nach richterlicher Erlaubnis als „feindlich“ (hostile) betrachtet wird. Ebenso sind leading questions durch die Gegenpartei im Rahmen eines Kreuzverhörs erlaubt. Außerdem kann der Richter allgemein im Fall von Zeugen, die etwa ein mangelhaftes Erinnerungsvermögen haben, einen gewissen Spielraum hinsichtlich der Art und Weise der anwaltlichen Befragungen einräumen. Beweise, die durch Suggestivfragen erbracht worden sind, sind nicht unbedingt per se unzulässig, können aber jedenfalls im Hinblick auf ihren Beweiswert negativ gewürdigt werden. $^{314}$

In Bezug auf die Möglichkeit eines Zeugen (einschließlich des Angeklagten, wenn er als Zeuge aussagt), während ${ }^{315}$ des Verhörs eine vorherige schriftliche bzw. schriftlich protokollierte oder transkribierte Aussage zur „Auffrischung“ seines Gedächtnisses (refreshing memory) einzusehen, ist zunächst zu bemerken, dass eine derartige Einsichtnahme auf Antrag des Anwalts oder auch aufgrund einer richterlichen Anweisung von Amts wegen erfolgen kann. Der verfahrensleitende Richter kann aber nach eigenem Ermessen eine derartige „Auffrischung“ des Zeugengedächtnisses ablehnen, auch wenn alle gesetzlichen Voraussetzungen dafür erfüllt sind. ${ }^{316}$ Die Voraussetzungen für eine zulässige „Auffrischung“ des Gedächtnisses während der mündlichen Vernehmungen im Hauptverfahren sind in sect. 139 CJA 2003 beinhaltet. Diese beziehen sich vor allem auf die Anerkennung des Inhalts des Dokuments durch den Zeugen als Widerspiegelung seiner damaligen Erinnerung an die Tatsache sowie auf die Wahrscheinlichkeit, dass diese frühere Erinnerung deutlich besser ist als die Erinnerung während der mündlichen Beweiserhebung vor Gericht: ${ }^{317}$

issue whether the witness does beat his wife. This is in effect a trick question, unfair to the witness, and is never permissible."

314 Dennis, Evidence, Rn. 14.015 m.w.N. Siehe auch Blackstone's Criminal Practice, $\S \S$ F6.13, F7.12.

315 Zur erlaubten „Auffrischung“ des Zeugengedächtnisses im Vorfeld des Hauptverfahrens, die in der Praxis schwer zu verhindern ist: Blackstone's Criminal Practice, §§ F6.27F6.31; Dennis, Evidence, Rn. 14.019-14.020.

316 Blackstone's Criminal Practice, §§ F6.14-F6.15 mit Rechtsprechungsverweisen.

317 Siehe auch sect. 120 CJA 2003: ,(1) This section applies where a person (the witness) is called to give evidence in criminal proceedings. [...] (3) A statement made by the witness in a document- (a) which is used by him to refresh his memory while giving evidence, (b) on which he is cross-examined, and (c) which as a consequence is received in evidence in the proceedings, is admissible as evidence of any matter stated of which oral evidence by him would be admissible. (4) A previous statement by the witness is admissible as evidence of any matter stated of which oral evidence by him would be admissible, if - (a) any of the following three conditions is satisfied, and (b) while giving evidence the witness indicates that to the best of his belief he made the statement, and that to the best of 
(1) A person giving oral evidence in criminal proceedings about any matter may, at any stage in the course of doing so, refresh his memory of it from a document made or verified by him at an earlier time if- (a) he states in his oral evidence that the document records his recollection of the matter at that earlier time, and (b) his recollection of the matter is likely to have been significantly better at that time than it is at the time of his oral evidence. (2) Where- (a) a person giving oral evidence in criminal proceedings about any matter has previously given an oral account, of which a sound recording was made, and he states in that evidence that the account represented his recollection of the matter at that time, (b) his recollection of the matter is likely to have been significantly better at the time of the previous account than it is at the time of his oral evidence, and (c) a transcript has been made of the sound recording he may, at any stage in the course of giving his evidence, refresh his memory of the matter from that transcript.

Schließlich ist im Rahmen der examination-in-chief-Problematik noch zu bemerken, dass ein Zeuge, der üblicherweise unter Eid über ein wahres Geschehen aussagen muss, von der Partei, die ihn aufgerufen hat, bezüglich seiner Glaubwürdigkeit nicht durch cross-examination-Praktiken angegriffen werden darf, auch dann nicht, wenn der Inhalt seiner Aussage vor Gericht nicht der erwünschte/erwartete war (unfavourable witness). ${ }^{318}$ Eine Ausnahme stellt der Fall des hostile witness dar. Ein ,feindlicher Zeuge“ ist: ,,a witness who is not desirous of telling the truth at the instance of the party calling him. ${ }^{\text {" }}{ }^{319}$ In einem solchen Fall kann die Partei, die den Zeugen aufgerufen hat, sofort die Erlaubnis des Richters beantragen, jenen Zeugen als hostile zu betrachten; der Richter verfügt dabei über eine freie Entscheidungsbefugnis. ${ }^{320}$ Nach den Regeln des Common Law kann daher eine Partei an den von ihr aufgerufenen hostile witness quasi im Wege eines Kreuzverhörs leading questions hinsichtlich früherer widersprüchlicher Aussagen stellen. ${ }^{321}$ Nach der Vorschrift in sect. 3 Criminal Procedure Act 1865 kann die Partei, die den hostile witness aufgerufen hat, mit richterlicher Erlaubnis die Existenz einer früheren widersprüchlichen Aussage des Zeugen nachweisen: ${ }^{322}$

A party producing a witness shall not be allowed to impeach his credit by general evidence of bad character; but he may, in case the witness shall in the opinion of the judge prove adverse, contradict him by other evidence, or, by leave of the judge, prove that he has made at other times a statement inconsistent with his present testimony; but before such last-mentioned proof can be given the circumstances of the supposed statement, sufficient to designate the particular occasion, must be mentioned to the witness, and he must be asked whether or not he has made such statement.

his belief it states the truth. [...] (6) The second condition is that the statement was made by the witness when the matters stated were fresh in his memory but he does not remember them, and cannot reasonably be expected to remember them, well enough to give oral evidence of them in the proceedings." Mehr Details dazu in Blackstone's Criminal Practice, $\S \S \mathrm{F} 6.21-\mathrm{F} 6.25$.

318 Dazu Dennis, Evidence, Rn. 14.021.

319 Definition von James Fitzjames Stephen in Digest of the Law of Evidence, Art. 147 (12. Aufl.), wie diese Definition bei Dennis, Evidence, Rn. 14.021 zitiert wird.

320 Blackstone's Criminal Practice, §§ F6.52-F6.53 m.w.N.

321 Dazu Blackstone's Criminal Practice, § F6.55 m.w.N.

322 Dazu Blackstone's Criminal Practice, § F6.54; Dennis, Evidence, Rn. 14.02114.023 . 


\section{- Struktur und Umfang der Vernehmungen: Cross-examination}

Im Anschluss an das Hauptverhör durch die Partei, die den Zeugen aufgerufen hat, findet normalerweise ein Kreuzverhör durch die Gegenpartei statt. ${ }^{323}$ Die Durchführung von cross-examinations kann in der Praxis folgenden Zwecken dienen: der Vervollständigung bzw. Korrektur der Aussage, die ein Zeuge während der examination-in-chief gemacht hat, zugunsten der befragenden Partei; der Prüfung der Stichhaltigkeit, der Infragestellung und der Widerlegung einer Aussage, die für die befragende Partei ungünstig ist; oder auch dem Angriff auf die Glaubwürdigkeit (credibility) des Zeugen. ${ }^{324}$ Die Befragungen während einer crossexamination finden, wie sonst auch, unter dem Vorbehalt der diversen Beweisausschlussregeln statt (wie der hearsay- oder der bad character-Regel ${ }^{325}$ ).

Eine cross-examination darf nicht nur den Inhalt einer vorherigen examinationin-chief, sondern kann sämtliche primär bestrittenen/relevanten Tatsachen betreffen. Gegenstand der Befragungen können zusätzlich oder sogar ausschließlich die (indirekt fallrelevanten) Angelegenheiten hinsichtlich der Glaubwürdigkeit des Zeugen sein - wie z.B. seine Beweggründe, die Widersprüchlichkeit der Aussagen bzw. die Unstimmigkeit ${ }^{326}$ in Bezug auf frühere Aussagen, die Erkenntnisfähigkeit und die Gedächtnisqualität, die geistige Behinderung bzw. Körperbehinderung, die Vorstrafen $^{327}$ und die Befangenheitsbehauptungen. Es gilt jedenfalls die allgemeine Regel (mit Ausnahmen wie im Fall von previous inconsistent statements und previous convictions evidence), dass bei nebensächlichen Glaubwürdigkeitsfragen (collateral issues) die Antworten des Zeugen während des Kreuzverhörs durch die Einführung von weiteren Beweisen seitens des cross-examiners nicht widerlegt werden dürfen. ${ }^{328}$ Darüber hinaus sind leading questions im Rahmen des Kreuzverhörs grundsätzlich erlaubt. ${ }^{329}$

In Bezug auf die normativen Beschränkungen der Möglichkeit zur cross-examination gilt im Allgemeinen zunächst die Regel, dass ein Angeklagter persönlich sämtliche Zeugen im Wege von Kreuzverhören unmittelbar (und nicht nur durch

323 Der Angeklagte hat jedenfalls das Recht aus Art. 6(3d) EMRK ,to examine or have examined witnesses against him $[\ldots]$. .

324 Dennis, Evidence, Rn. 14.024. Siehe auch Blackstone's Criminal Practice, § F7.4.

325 Siehe die allgemeine Rechtslage hinsichtlich der zulässigen Einführung in den Prozess von bad character evidence u.a. bei Blackstone's Criminal Practice, §§ F12.1F14.20; Dennis, Evidence, Rn. 14.033-14.038, 18.001-19.059.

326 Siehe sect. 4-5 Criminal Procedure Act 1865 und sect. 119 CJA 2003.

327 Soweit diese hauptsächlich nach Part 11 (insb. sect. 100-101) CJA 2003 ein zulässiges bad character-Beweismittel darstellen. Siehe auch sect. 6 Criminal Procedure Act 1865 .

328 Insgesamt Blackstone's Criminal Practice, §§ F7.11-F7.13, F7.16-F7.17, F7.42F7.59; Dennis, Evidence, Rn. 14.025-14.042; Sprack, Criminal Procedure, Rn. 20.43. Siehe auch Smith, in: McConville/Wilson (Hrsg.), Handbook, S. 200.

329 U.a. Blackstone's Criminal Practice, § F7.12. 
einen Verteidiger) befragen kann. Die gesetzlichen Vorschriften verbieten jedoch besonders im Fall von Beschwerdeführern (complainants) bei Sexualdelikten und von minderjährigen Beschwerdeführern bzw. Zeugen bei diversen Sexualdelikten und Delikten gegen Kinder die persönliche Vernehmung durch den Angeklagten. Aber auch in Bezug auf alle anderen Zeugenkategorien kann das Gericht auf Antrag der Anklage oder von Amts wegen die cross-examination durch den Angeklagten verbieten, soweit eine persönliche Vernehmung die Beweisqualität gefährden könnte - während sie durch das Verbot hingegen möglicherweise verbessert würde - und soweit eine solche richterliche Anordnung den Justizinteressen nicht entgegensteht. Bei einem solchen Verbot des persönlichen Kreuzverhörs muss das Gericht den „unvertretenen“ Angeklagten darauf hinweisen, einen Prozessvertreter (legal representative) für die Befragung der betreffenden Zeugen zu bestellen, wobei als ultima ratio das Gericht auch selbst einen unabhängigen Prozessvertreter für diesen konkreten Zweck berufen kann. ${ }^{330}$

Außerdem darf im Kontext der Sexualdelikte ein Angeklagter oder sein Verteidiger ohne richterliche Erlaubnis keine Beweise erbringen und keine Fragen während des Kreuzverhörs stellen, die das sexuelle Verhalten des Beschwerdeführers betreffen. ${ }^{331}$ Der Richter kann aber auch allgemein in die Befragungen eingreifen, insbesondere wenn diese durch einen ,unvertretenen“ Angeklagten durchgeführt werden, und die Kreuzverhörbefugnis begrenzen, sodass jener Angeklagte letztendlich nicht inhaltlich und zeitlich uneingeschränkt Fragen an die Zeugen stellen kann:

$[\ldots]$ the British tradition $[\ldots]$ has permitted individuals to represent themselves in $[\ldots]$ criminal proceedings. [...] When defendants represent themselves in criminal trials problems regularly arise. Such defendants lack that knowledge of procedure, evidence and substantive law; that appreciation of relevance; that ability to examine and crossexamine witnesses and present facts in an orderly and disciplined way; and that detachment which should form part of the equipment of the professional lawyer. [...] the problems are magnified one hundred-fold where the defendant is motivated by a desire to obstruct the proceedings or to humiliate, intimidate or abuse any one taking part in it. The trial judge's duty is to ensure to the utmost of his ability that the defendant, even if unrepresented, or perhaps particularly if unrepresented, has a fair trial. [...] The trial judge is, however, obliged to have regard not only to the need to ensure fair trial for the defendant but also to the reasonable interests of other parties to the court process, in particular witnesses [...] Judges do not lack power to protect witnesses and control questioning. The trial judge is the master of proceedings in his court. He is not obliged to give an unrepresented defendant his head to ask whatever questions, at whatever length,

330 Siehe die technischen Details in sect. 34-39 Youth Justice and Criminal Evidence Act 1999 i.V.m. Part 31 CPR 2014. Dazu auch Blackstone's Criminal Practice, §§ F7.2F7.3; Dennis, Evidence, Rn. 15.019.

$331 \mathrm{Zu}$ den komplexen Voraussetzungen, unter denen eine Befragung in Bezug auf das sexuelle Verhalten des Beschwerdeführers erlaubt sein kann, siehe sect. 41-43 Youth Justice and Criminal Evidence Act 1999. Ausführlich, auch zu den relevanten Fairnesserwägungen, Blackstone's Criminal Practice, §§ F7.22-F7.41; Dennis, Evidence, Rn. 15.004-15.018. 
the defendant wishes. [...] It will almost always be desirable in the first instance to allow a defendant to put questions to a complainant, but it should be made clear in advance that the defendant will be required, having put a point, to move on, and if he fails to do so the judge should intervene and secure compliance. [...] the judge should, if necessary in order to save the complainant from avoidable distress, stop further questioning by the defendant or take over the questioning of the complainant himself. ${ }^{332}$

\section{- Kreuzverhör und Verfahrensstruktur}

Die cross-examination ist von zentraler struktureller Bedeutung für das englische diagnostische Beweisverfahren. Wenn zum Beispiel eine Partei einzelne Tatsachen- und Glaubwürdigkeitsfragen im Wege des Kreuzverhörs und durch die Einführung von Gegenbeweisen nicht widerlegt bzw. nicht infrage stellt, kann ein solcher Verzicht auf cross-examination eventuell, zumindest im Rahmen einer jury trial, mit der stillschweigenden Anerkennung der Wahrheit des betreffenden in chief vorgebrachten Beweises gleichgesetzt werden. Es ist einem Anwalt grundsätzlich nicht erlaubt, solche unwiderlegten Fragen erst im Rahmen seines Schlussvortrags anzusprechen und entsprechende Vorwürfe zu erheben. ${ }^{33}$

\section{- Richterliche Kontrolle der Befragungen}

Das Gericht hat nach sect. 3.11.(d) CPR 2014 die generelle Befugnis, die examination, die cross-examination oder die re-examination ${ }^{334}$ eines Zeugen sowie die Dauer sämtlicher Verhandlungen einzuschränken; dies kann etwa bei lang andauernden Kreuzverhören sowie weitschweifigen und sich wiederholenden Befragungen als notwendig erscheinen. ${ }^{335}$ Ebenso kann der verfahrensleitende Richter nach eigenem Ermessen überflüssige, unanständige, aggressive, erdrückende oder provozierende Fragen bzw. derartige anwaltliche Kommentare im Rahmen eines Kreuzverhörs verbieten. ${ }^{336}$ Schließlich haben im selben Kontext auch die Anwälte

\footnotetext{
332 Rv. Brown (Milton), [1998] 2 Cr App R 364, 369-371.
}

333 Blackstone's Criminal Practice, §§ F7.8-F7.10.

334 Die Funktion und Bedeutung der re-examination beschreibt Dennis, Evidence, Rn. 14.043, wie folgt: „The party calling a witness has a right to re-examine the witness after he or she has been cross-examined. However, the re-examination may not be used to rehearse again the evidence given in chief or to introduce new matters. Its purpose is to allow the party to deal with matters arising out of the cross-examination - for example, to get the witness to clarify or qualify the meaning of the answers given in cross-examination. New matters can be introduced at this stage only with the leave of the judge. [...] In general the rules that apply to examination-in-chief apply also to re-examination. Thus a witness cannot be asked leading questions, or about his previous consistent statements, unless one of the exceptional cases applies. [...] In the hands of a skilful and well-prepared advocate, re-examination can do much to lessen the impact of a damaging cross-examination." Siehe auch Blackstone's Criminal Practice, § F7.60; Tapper, Evidence, S. 322-323.

335 Siehe $R$ v. B, [2006] Crim.L.R. 54, 55; dazu Blackstone's Criminal Practice, § F7.15; Sprack, Criminal Procedure, Rn. 2.16.

336 Blackstone's Criminal Practice, § F7.14 mit Rechtsprechungsverweisen. 
während der Beweisführungen entsprechende ethisch-rechtliche Verpflichtungen gegenüber dem Gericht, welche die Vermeidung solcher Verhaltensweisen betreffen. ${ }^{337}$

\section{E. Zusammenfassung: Besonderheiten des Beweisführungssystems}

Mit Blick auf den sich auf die strafprozessualen Strukturen und Rollenverteilungen beziehenden Schwerpunkt des Forschungsvorhabens sind insbesondere folgende Besonderheiten des im Vorangehenden dargestellten herkömmlichen erstinstanzlichen englischen Beweisführungssystems im Rahmen einer zusammenfassenden Kurzbetrachtung hervorzuheben: ${ }^{338}$

\section{Die vorbereitenden Beweisführungsvorgänge}

In Bezug auf die Problematik der „Aufbereitung“ des Beweismaterials und der Bestimmung des Umfangs der Beweiserhebungen ist vor allem Folgendes festzuhalten:

- Der Strafprozess wird in der englischen Lehre und Praxis nicht als bloßer, eher der Fairness statt der Wahrheit verpflichteter Wettkampf angesehen. Die Verurteilung der (wirklich) Schuldigen durch menschenwürdige und faire Sachverhaltsaufklärungsprozesse, die auf präzise und zuverlässige Tatsachenfeststellungen zielen, stellt vielmehr einen weithin anerkannten zentralen Verfahrenszweck dar (vgl. auch

$337 \mathrm{Zu}$ den ,ethischen“ Pflichten der Anwälte bei der Durchführung des Gerichtsverfahrens vgl. insb. sect. 302, 708 CCB 2004 i.V.m. $\S \S 5.1,5.2,5.10,10-12$ CCB-Written Standards for the Conduct of Professional Work. Nach Williams, Proof, S. 77: „The importance of $[\ldots]$ standards of professional conduct cannot be stressed too strongly in a system which leaves so much to the discretion of advocates retained by the parties." In diesem Kontext hat Jackson, in: McConville/Wilson (Hrsg.), Handbook, S. 339, folgende empirisch-vergleichende Bemerkung gemacht: ,In England and Wales [...] the advocate owes a strong loyalty to the court as well as to his or her client. This does not mean that advocates are necessarily restrained in their cross-examination of witnesses for the opposing side. But in presenting the case for their own side either through the examination of witnesses or in arguments to the judge or jury, they appear to be more restrained than their American counterparts." Vgl. auch Herrmann, RIDP 53 (1982), 841 (856-857). Siehe aber auch Beispiele von abusive cross-examination in England bei Roberts/Zuckerman, Criminal Evidence, S. 295-297. Zum Anwalt der Anklage als minister of justice i.G.z. der einseitigen Stellung des Verteidigers, der gleichwohl die faire und effektive Handhabung der Justiz durch das Gericht ermöglichen bzw. fördern muss, siehe insb. in Bezug auf das Crown Court-Verfahren Sprack, Criminal Procedure, Rn. 20.03-20.13, 20.43, mit Beispielen aus den rechtspolitischen Diskussionen und der Rechtsprechung. Ferner Blackstone's Criminal Practice, $\S \S$ D16.2-D16.9, D16.34, D17.2-D17.6, F7.18. Siehe auch in der vorliegenden Arbeit unter Teil 2, II.B.1.a) m.w.N.

338 Vgl. inbs. an dieser Stelle noch einmal die Zusammenfassung der definierten Modellelemente unter Teil 1, II.C.4. 
die overriding objective in Part 1 CPR 2014). Die Erforschung der Wahrheit hinsichtlich umstrittener oder unsicherer Tatsachenfragen, die sich auf materielle Rechte, Verpflichtungen und rechtliche Haftungen beziehen, steht im Mittelpunkt der Funktionen des Beweissystems.

- Sämtliche Beweise dürfen durch die formalen Beweismittel nur nach den relevance-, admissibility- und exclusionary discretion-Regeln und Kriterien in das Hauptverfahren eingeführt werden. Soweit die vorgebrachten Beweisinformationen nach den vorgenannten Regeln zulässig sind bzw. zugelassen werden, müssen sie am Verfahrensende vom erkennenden Spruchkörper (jury bzw. Berufs- oder Laienmagistrates) berücksichtigt werden. Sie sind hinsichtlich ihres Wahrheitsgehalts vor allem nach Glaubwürdigkeits-/Ehrlichkeits- und Zuverlässigkeits-/Genauigkeitserwägungen zu bewerten. Zum Treffen einer verurteilenden Entscheidung müssen jedenfalls die belastenden Beweise eine sehr große Überzeugungskraft gegenüber dem Urteilsfinder ausweisen (proof beyond reasonable doubt); die Beweislast (burden of proof) ist dabei grundsätzlich ,zuungunsten“ der Anklage geregelt.

- Im englischen Verfahrenssystem existiert keine justizielle Ermittlungsbehörde, die nach der Klageerhebung alle Beweisaktivitäten in neutraler und autoritativer Weise von der Polizei übernimmt. Ab diesem Zeitpunkt erfolgen das Zusammentragen der Beweise und die Vorbereitung für die Hauptverhandlung dergestalt, dass sowohl die Anklage als auch die Verteidigung eigene cases zur nachfolgenden Präsentation vor Gericht ,,aufbauen“. Dabei muss zwischen den Parteien Waffengleichheit herrschen. Eine extreme Parteilichkeit bei der Vorbereitung der selbstständigen cases ist normativ keinesfalls gefördert. Sowohl der Ankläger (als minister of justice) als auch der Verteidiger haben gewisse ethisch-rechtliche Objektivitäts- und Legalitätspflichten gegenüber dem Gericht, was die faire und effektive Justizhandhabung und die Förderung der overriding objective des Strafprozesses anbelangt.

- In Bezug insbesondere auf den aussagenbasierten Beweis gilt im Regelfall, dass die Anklage und die Verteidigung in sämtlichen Strafprozessen ihre Belastungsbzw. Entlastungszeugen selbst bestimmen. Diese Zeugen müssen dann im Hauptverfahren öffentlich, persönlich und mündlich Auskunft hauptsächlich im Wege von durch die Parteien geführten examinations-in-chief und cross-examinations geben. Jeder Zeuge darf grundsätzlich nur über Tatsachen berichten, von denen er persönliche Kenntnis hat (vgl. die Problematik der Einführung von hearsay evidence und von vorgerichtlichen schriftlichen witness statements in den Prozess). ${ }^{339}$ Die Vorbereitung der aufzurufenden Zeugen durch die jeweilige Partei im Vorfeld eines gerichtlichen Verhörs durch intensives coaching, durch rehearsals oder durch die Mitteilung der Auskünfte anderer Zeugen ist grundsätzlich nicht erlaubt.

339 Unter Teil 2, II.B.1.b)bb). 
- Das Gericht kann unter bestimmten Voraussetzungen die wertenden Aussagen von expert witnesses als Beweis zulassen. Die Expertenzeugen werden unmittelbar von der einen oder der anderen Partei ausgewählt und mit der vorgerichtlichen Anfertigung von Gutachten und/oder mit der persönlichen Aussage vor Gericht beauftragt. In normativer Hinsicht hat der Experte nicht nur eine Pflicht gegenüber seinem Mandanten, sondern primär eine „Hilfspflicht“ gegenüber dem Gericht. Dennoch sind für die Auswahl und die Instruktion der Expertenzeugen weiterhin die Parteien verantwortlich.

• Jede Partei bringt im englischen Strafverfahren ihre „eigenen“ Beweismittel vor und kann die von der anderen Partei vorgebrachten Beweismittel eingehend prüfen. Im Allgemeinen besitzen die Parteien erhebliche Autonomie bei der Bestimmung des Umfangs der Beweiserhebungen. Sowohl die Anklage als auch die Verteidigung können grundsätzlich frei entscheiden, welche Zeugen zur Aussage vor Gericht zu laden sind. Die Verteidigung ist grundsätzlich überhaupt nicht verpflichtet, Zeugen zu laden. Die Beweiserhebungsautonomie der Anklage und ihr weites Ermessen bei der (Nicht-)Ladung von Zeugen zur Verankerung der prosecution case können teilweise wegen Fairnesserwägungen eingeschränkt werden. Letztendlich muss die Anklage alle Personen, die (nach Meinung der Anklage) unmittelbare Zeugen von zentralen Tatsachen und gleichzeitig glaubwürdig sind, laden bzw. für die Ladung verfügbar machen, auch wenn solche Zeugen in negativer bzw. widersprüchlicher Weise für das Anklagevorbringen wirken könnten. Die Anklage muss also gerecht und in für den Angeklagten fairer Weise handeln. Tut sie das nicht, kann der Richter als ultima ratio die von der Anklage unterlassenen Zeugenladungen selbst übernehmen. Die Befugnis des Richters zur Zeugenladung bleibt in der Gerichtspraxis ein Ausnahmefall: Der Richter soll in die Bestimmung des Umfangs der Beweiserhebungen durch die Parteien grundsätzlich nicht eingreifen, es sei denn, dies erscheint vor allem im Interesse der Gerechtigkeit als notwendig.

• In der gegenwärtigen Praxis soll im Vorfeld sowie während einer Hauptverhandlung durch aktive richterliche case management-Tätigkeiten unter anderem die frühestmögliche Klärung diverser Beweisangelegenheiten angestrebt werden. Dabei kann die Art und Weise der Beweiserhebungen sowie die Bestimmung ihres Umfangs von richterlichen Initiativen beeinflusst werden. Im selben Rahmen sind außerdem sämtliche Parteien grundsätzlich verpflichtet, die streitigen Punkte des jeweiligen Konflikts so früh wie möglich eindeutig und öffentlich zu identifizieren; dadurch sollen vor allem gegenseitige parteiliche Angriffe aus dem Hinterhalt verhindert werden, um das Ziel der Aufdeckung der Wahrheit nicht zu gefährden.

\section{Kenntnisnahme und Offenlegung von Beweisen}

In Bezug auf die Problematik der Kenntnis der Beweisergebnisse des Vorverfahrens seitens des Richters sowie der Akteneinsicht und Offenlegung des Vorverfahrensmaterials durch die Prozessbeteiligten ist vor allem Folgendes festzuhalten: 
- Im Vorverfahren wird kein umfassendes amtliches Dossier, das alle Verfahrensdaten und Beweise beinhaltet bzw. dokumentiert, zusammengestellt. Der verfahrensleitende Richter kann jedoch, nicht zuletzt wegen der verschiedenen disclosure-Prozesse, case management-Aktivitäten und pre-trial hearings, schon im Vorfeld der Hauptverhandlung Kenntnis zumindest von einem Teil der gegensätzlichen Beweisthesen haben. Die Geschworenen des reinen jury-Verfahrens dürfen jedenfalls keine konkrete Vorkenntnis des Straffalles haben; ihnen wird der ganze Sachverhalt erst durch die Parteien präsentiert. Dies schließt jedoch nicht aus, dass der Vorsitzende Richter im jury-Verfahren aufgrund einer Vorkenntnis bestimmter Einzelheiten der gegensätzlichen cases bei der Verfahrensleitung einseitig(er) wirken kann. Einen größeren Einfluss auf die Art und Weise der Verfahrensleitung kann die Vorkenntnis der Beweise eventuell im bench-Verfahren ausüben.

- Durch die moderne Regulierung der vorgerichtlichen Beweisoffenlegungen zwischen den Verfahrensparteien wurde sowohl versucht, die Ungleichheiten zwischen Anklage und Verteidigung hinsichtlich der vorhandenen Ressourcen zur Vorbereitung des Rechtsstreits auszugleichen als auch das eventuelle „Überraschen“ der Anklage durch die Verteidigung zu vermeiden und ferner die Stellung des Richters bei der Erledigung der Beweisoffenlegungskonflikte zu stärken. Die Anklage muss nun nach Erhebung der Strafklage der Verteidigung den Zugriff auf grundlegende Materialien der prosecution case ermöglichen. Die Anklage hat ebenso die allgemeine und kontinuierliche Pflicht, nicht vorzubringende Beweismaterialien (,unused material"), die jedoch inhaltlich für die Unterstützung der defence case bzw. für die Schwächung der prosecution case von Bedeutung sein könnten, der Verteidigung so bald wie möglich zukommen zu lassen. Gleichwohl kann die Anklage auf der Basis von public interest-Erwägungen einen Antrag auf gerichtliche Anordnung der Nicht-Offenlegung bestimmter Beweismaterialien stellen; die letztendliche Entscheidung über die Nicht-Offenlegung obliegt dabei dem Gericht. Die disclosure-Verpflichtungen der Verteidigung werden im Rahmen der Regelung der defence statements und defence witness notices diskutiert. Die Nicht-Offenlegung bzw. eine mangelhafte disclosure kann negative prozessuale Folgen für die Verteidigung haben (vor allem, indem durch den Spruchkörper erlaubterweise Schlussfolgerungen hinsichtlich der Schuldfrage gezogen werden können).

\section{Die Beweisführung im Hauptverfahren}

In Bezug auf die Problematik des Beweisausschlusses sowie der Erhebung, Präsentation und Prüfung der Stichhaltigkeit der Beweise vor Gericht ist vor allem Folgendes festzuhalten:

- Die englischen Gerichte müssen in den meisten streitigen Straffällen eine vollständige Beweisführung durch die Parteien abwarten, bevor sie über die Verurteilung oder den Freispruch des Angeklagten entscheiden. In Ausnahmefällen haben die (Berufs- bzw. Laien-)Richter im magistrates' court bzw. der Berufsrichter im 
Crown Court eine begrenzte Befugnis, die Strafklage nach Verfahrensfairnesskriterien wegen abuse of process sogar schon vor dem Beginn der eigentlichen Beweiserhebungen abzuweisen bzw. die Strafverfolgung einzustellen.

- Vor Gericht findet eine umfassende Präsentation und Prüfung nur solcher Beweise statt, die für den konkreten Fall relevant sind, nach den obligatorischen Beweisausschlussregeln (z.B. bei hearsay evidence und torture evidence) nicht unzulässig sind und nach richterlichem Ermessen im Rahmen von fair trial-Erwägungen nicht ausgeschlossen werden. Insgesamt hat der Richter eine entscheidende Funktion bei der Auseinandersetzung mit den komplexen Fragen zur Zulässigkeit und zum Ausschluss von Beweisen, die meistens aufgrund von Parteianträgen/-einwänden, oft aber auch von Amts wegen richterlich behandelt werden können. Die moderne Anschauung ist generell dahingehend ausgerichtet, dass sämtliche Rechtsfragen möglichst früh durch vorgerichtliche oder hauptgerichtliche case management-Tätigkeiten entschieden werden sollen. Die Fragen zur Zulässigkeit von Beweisen werden jedoch sehr oft von dem die Hauptverhandlung leitenden trial judge selbst bzw. von den verfahrensleitenden magistrates erst während der relevanten gerichtlichen Beweispräsentationen oder (seltener) nachträglich am Ende der parteilichen Präsentationen entschieden; im Rahmen einer jury trial werden derartige Fragen meistens in Abwesenheit der Geschworenen diskutiert.

- Mit Blick auf die erstinstanzlichen streitigen Straffälle existieren zwischen einem magistrates' court- und einem Crown Court-Verfahren keine großen Unterschiede hinsichtlich der Regeln und Teilstadien der normalen Beweisführung vor Gericht. Im Allgemeinen sind die (Berufs- oder Laien-)Richter eines bench-Verfahrens vor dem magistrates' court für die technische Verfahrensleitung und für die Beurteilung sowohl der Rechts- als auch der Tatsachenfragen zuständig. In einer jury trial vor dem Crown Court ist dagegen hauptsächlich der Vorsitzende Berufsrichter für die ordnungsgemäße und faire Verfahrensleitung und für die Entscheidung über die sich ergebenden Rechtsfragen verantwortlich, wobei die Beurteilung der präsentierten Tatsachen und die endgültige Entscheidung über die Schuld durch die Laien der Geschworenenbank erfolgen.

- Die eigentlichen gerichtlichen Beweiserhebungen und die mündlichen Präsentationen und Gegenpräsentationen der strittigen Tatsachen finden in sämtlichen Strafprozessen größtenteils durch die Parteien nach dem Grundsatz der Parteienautonomie statt. Die Anklage kann sogar nach der Abgabe einer not guilty-Erklärung seitens des Angeklagten aufgrund einer Absprache oder aus anderen sachlichen Gründen bzw. public interest-Erwägungen die Entscheidung treffen, hinsichtlich der nicht zugestandenen Klagen keine Beweise vor Gericht zu präsentieren (offering no evidence). Nach herrschender Meinung hat das Gericht dabei, nicht zuletzt aufgrund seiner allgemein eng begrenzten Beweiserhebungsbefugnisse, tatsächlich keine andere Wahl, als den Angeklagten entsprechend freizusprechen. Der Richter hat darüber hinaus unter bestimmten Voraussetzungen die Möglichkeit zur „judicial notice“ von offensichtlichen facts; hinsichtlich solcher Tatsachen sind 
keine umfassenden Beweisführungen durch die Parteien nötig. Außerdem können die Parteien selbst die Vermeidung zeitaufwendiger gegensätzlicher Beweiserhebungen und Tatsachenpräsentationen in Bezug auf unbestreitbare Aspekte des Sachverhaltes fordern: Dies geschieht meistens durch die für das Gericht verbindliche einverständliche Einführung bestimmter Beweismittel in das Verfahren (wie bei hearsay evidence) oder durch die Einführung von vorher zugegebenen Fakten als eindeutigem Beweis. Die Umgehung der normalen Beweisverfahrensstrukturen durch die Einführung von ,,agreed evidence“ wird hauptsächlich mit Erwägungen zur Verfahrensökonomie begründet.

- In Übereinstimmung mit den allgemeinen Leitlinien des englischen case law wird dem verfahrensleitenden Richter während der Beweisführungen im Hauptverfahren, die grundsätzlich durch die Parteien stattfinden, keine absolut passive Rolle zugewiesen. Moderne empirische Beobachtungen deuten außerdem auf eine in der Gerichtspraxis sich ständig erweiternde, interventionistischere Rolle des Richters bzw. auf entsprechende Tendenzen hin: Auch wenn der Richter nur begrenzt vor allem zur Sicherstellung von zulässigen, fairen, zügigen, ordnungsgemäßen, klaren und widerspruchsfreien Beweispräsentationen intervenieren darf, scheint er oft bereit zu sein, etwa in die Zeugenbefragungen aktiver einzugreifen; auch die Hochgerichte scheinen den diesbezüglichen Ermessensspielraum des Richters meistens nur in extremen Fällen von Unfairness zu beschneiden.

- Die streitigen Beweisführungen beginnen im magistrates' court-Verfahren mit der Darstellung der prosecution case. Der Anklagevertreter hat zunächst das Recht auf opening speech. Im Anschluss an die Eingangsansprache muss die Anklage die Beweise, auf denen ihr Vorbringen basiert, präsentieren. Insbesondere müssen die Anklagezeugen aufgerufen und entsprechend den Beweisausschlussregeln im Wege von examinations-in-chief, cross-examinations, möglichen re-examinations und Befragungen durch die bench-Richter vernommen werden; außerdem werden die zulässigen schriftlichen Zeugenerklärungen, Expertengutachten und hearsay-Beweise vorgelesen. Die Richter und ihre Rechtsberater können ihre Fragen an die Zeugen nach eigenem Ermessen stellen, jedoch immer unter dem Vorbehalt der Beweisausschlussregeln und der Regeln zur Förderung des übergeordneten Verfahrenszieles (overriding objective) nach sect. 1.3 CPR 2014. Die magistrates haben darüber hinaus die ultima ratio-Befugnis, die von den Parteien nicht geladenen Zeugen vor Gericht zu laden. Am Ende der umfassenden Auseinandersetzung mit den Anklagebeweisen kann die Verteidigung die sofortige Einstellung des Verfahrens beantragen bzw. die Richter können von Amts wegen entscheiden, dass es wegen der mangelhaften Anklagepräsentationen keinen substantiellen Grund mehr für die Weiterführung der Verhandlungen gibt (submission of no case to answer). Falls jedoch das Verfahren nicht einzustellen ist, werden im Anschluss an die prosecution case in entsprechender Weise die Verteidigungsthesen und Beweise (defence case) vorgebracht und untersucht, soweit der Angeklagte oder sein Anwalt überhaupt Beweise vor Gericht präsentieren möchten. Im Anschluss an die Unter- 
suchung der Verteidigungsbeweise kann jede Partei zusätzliche, zu diesem Zeitpunkt zulässige Beweise vor allem zur Widerlegung von bereits eingeführten Beweisen vorbringen. Danach darf die Anklage unter bestimmten Voraussetzungen zusammenfassende Abschlussdarstellungen zur Unterstützung ihrer case vortragen. Zum Schluss kann auch die Verteidigung Darstellungen zur Unterstützung ihrer case einbringen.

- Die Beweisführungen vor dem Crown Court laufen in ähnlicher, wenn auch förmlicherer Weise ab. Zunächst kann die Anklage in ihrer Eingangsansprache vor der jury den Sachverhalt, die Anklagepunkte, relevante komplizierte Rechtsfragen und die von ihr vorzubringenden Beweise zusammenfassen. Anschließend muss die Anklage ihre Beweise präsentieren und vor allem die vorgeladenen Anklagezeugen zur Aussage aufrufen und/oder die zulässigen schriftlich aufgezeichneten Aussagen und written statements vorlesen. Die Anklage darf im Allgemeinen alle ihre Beweise nur während der formalen Präsentation ihrer case und nicht nachträglich vorbringen - eine „Neueröffnung“ der prosecution case ist also grundsätzlich (mit Ausnahmen) nicht erlaubt. In Bezug auf die Anklagezeugen finden die Präsentation und die Prüfung der Stichhaltigkeit der betreffenden (zulässigen) Aussagen, genau wie beim Verfahren vor dem magistrates' court, jeweils im Wege von examinations-in-chief, cross-examinations und möglichen re-examinations statt. Die Befragung der Zeugen durch den verfahrensleitenden Richter ist allgemein jederzeit möglich. Im Anschluss an die Anklagepräsentationen werden in Abwesenheit der Geschworenen auch im Crown Court-Verfahren die no case to answer-Angelegenheiten auf Antrag der Verteidigung oder von Amts wegen angesprochen. Auch die Geschworenen können nach dem Ende der Anklagepräsentationen zu jedem Zeitpunkt das Verfahren selbstständig abbrechen und den Angeklagten freisprechen. Falls jedoch das Verfahren nach dem Ende der Anklageausführungen in normaler Weise fortgesetzt wird, hat der Verteidiger das Recht auf eine Eingangsansprache, soweit er in der Folge nicht nur den Angeklagten als Zeugen aufrufen, sondern auch andere Tatsachenbeweise in das Verfahren einführen will. Danach ist der Verteidiger berechtigt, aber nicht verpflichtet, den Angeklagten als (normalerweise ersten) Zeugen aufzurufen. Ruft die Verteidigung den Angeklagten und/oder weitere Personen als Zeugen zur Aussage auf, finden dann für jeden einzelnen Zeugen die entsprechenden (Kreuz-)Verhöre und richterlichen Befragungen statt. Der Richter kann nach eigenem Ermessen und unter Berücksichtigung der jeweiligen Fallumstände die „Neueröffnung“ der defence case und somit die Einführung von zusätzlichen Beweisen sogar nach dem Ende der richterlichen summing-up erlauben. Nach dem Beginn der nichtöffentlichen jury-Beratungen dürfen die Parteien (sowie auch der Richter) jedenfalls keine Beweise mehr in den Prozess einführen. Auch im Crown Court-Verfahren hat der Richter die ultima ratio-Befugnis, die von den Parteien nicht geladenen Zeugen selbst aufzurufen, wenn ihm dies im Interesse der Gerechtigkeit als notwendig erscheint. Der Richter stellt dabei selbst Fragen an jene Zeugen und kann danach die Durchführung von Kreuzverhören 
durch die Parteien erlauben. Dem Richter wird darüber hinaus das allgemeine Ermessen eingeräumt, sämtliche Zeugen jederzeit bis zur abschließenden richterlichen Zusammenfassung des Straffalles erneut zu weiteren Vernehmungen aufzurufen bzw. aufrufen zu lassen. Nach der Präsentation und Prüfung der Verteidigungsbeweise hat nun die Anklage (unter bestimmten Voraussetzungen) das Recht auf einen Schlussvortrag. Die Anklage muss ihren Schlussvortrag möglichst objektiv, in Übereinstimmung mit den vorhandenen Beweisen und sachlich halten. Anschließend kann auch die Verteidigung einen inhaltlich umfangreichen Schlussvortrag zur kritischen Zusammenfassung ihres Vorbringens und der übrigen Beweisführungen halten, der aber nur solche Tatsachenbehauptungen enthalten darf, bezüglich derer im Verfahren Beweise schon erhoben worden sind. Zum Schluss fasst der verfahrensleitende Richter die wesentlichen Rechtsfragen und Beweispunkte des Sachverhalts zusammen und trägt diese samt den notwendigen Anweisungen und Kommentaren zur Unterstützung der Geschworenen bei ihrer Tatsachenfeststellungsaufgabe öffentlich vor.

- Die Verhöre der Zeugen, die mündlich im magistrates' court- oder im Crown Court-Verfahren aussagen, finden grundsätzlich während der ordentlichen Anklage- und Verteidigungspräsentationen statt, also weder im Wege irgendeiner neutralamtlichen Untersuchung noch als freie, umfassende Nacherzählung der beobachteten Fakten. Die Befragung sämtlicher Zeugen durch den verfahrensleitenden Richter ist gleichwohl in jedem Verfahrensstadium möglich. Der Richter muss trotzdem bei seinem Eingreifen in die Beweiserhebungen und insbesondere bei der Unterbrechung der durch die Parteien stattfindenden (Kreuz-)Verhöre erhebliche Zurückhaltung an den Tag legen; Unterbrechungen sind grundsätzlich nur aus Klarstellungsgründen erlaubt. Jeder einzelne Zeuge durchläuft üblicherweise zuerst die examination-in-chief durch die Partei, die ihn aufgerufen hat, dann die cross-examination durch die Gegenpartei(en) und am Ende eventuell auch eine re-examination durch die erstere Partei. Die Durchführung sämtlicher Verhöre durch die Parteien erfolgt nicht auf unkontrollierte Weise; vielmehr kann bzw. muss der verfahrensleitende Richter unter bestimmten Voraussetzungen und oft aufgrund eines parteilichen Einspruchs eingreifen, um die Einhaltung gewisser Prozess- und Fairnessregeln sicherzustellen und dafür zu sorgen, dass ein hohes Qualitätsniveau der wahrzunehmenden Beweise sowie allgemein die Förderung der Wahrheitsermittlung gewährleistet sind.

- Bei sämtlichen examinations-in-chief gilt die Regel, dass den Zeugen nur solche Fragen gestellt werden dürfen, die einen Bezug zu den bestrittenen Tatsachen haben und nicht unzulässig nach den Beweisausschlussregeln sind. Fragen, die ausschließlich die Glaubwürdigkeit des Zeugen betreffen, sind im Rahmen des Hauptverhörs nicht erlaubt. Weitere wichtige Regeln zur Durchführung der Hauptverhöre betreffen das Verbot von leading questions und die Möglichkeit der Zeugen, während ihres Verhörs vorherige schriftliche Aussagen zur „Auffrischung“ des Gedächtnisses einzusehen. Eine cross-examination kann sämtliche fallrelevanten Tat- 
sachen betreffen. Gegenstand der Befragungen können auch diverse Angelegenheiten hinsichtlich der Glaubwürdigkeit des Zeugen sein. Das Gericht hat letztendlich die generelle Befugnis, die examination, die cross-examination oder die re-examination eines Zeugen sowie die Dauer sämtlicher Verhandlungen einzuschränken; dies kann etwa bei lang andauernden Kreuzverhören sowie weitschweifigen und sich wiederholenden Befragungen als notwendig erscheinen. Der verfahrensleitende Richter kann außerdem nach eigenem Ermessen überflüssige, unanständige oder provokatorische Fragen im Rahmen eines Kreuzverhörs zurückweisen.

\section{Das deutsche Beweisführungssystem}

\section{A. Überblick über den Strafprozess}

\section{Die Ziele und Grundprinzipien des Strafverfahrens und die EMRK}

Im Rahmen der allgemeinen Ausführungen zu den abstrakten Verfahrensmodellen in Teil 1 wurde bereits ausführlich dargelegt, dass die gegenwärtigen rechtsstaatlichen Strafverfahrenssysteme sowohl materielle als auch prozessuale Gerechtigkeit zu erreichen suchen. ${ }^{340}$ Überdies ist in der heutigen deutschen Lehre als zentrales, die diversen Erscheinungen des Strafprozessrechts weitgehend umfassendes (End-)Ziel des Strafverfahrens die Schaffung des Rechtsfriedens anerkannt. ${ }^{341}$ Als wichtiger Vorläufer der modernen herrschenden Ansicht gelten diesbezüglich die Thesen von Eberhard Schmidhäuser:

Es leuchtet wohl ein, daß der Strafprozeß sein ideales Ziel gegenüber dem unschuldigen Verdächtigen am besten erreicht durch die möglichst frühe überzeugende Klärung der Unschuld und gegenüber dem schuldigen Verdächtigen am sichersten durch die baldige [...] gerechte Verurteilung, und zwar unter Formen, die die Gemeinschaft als mit dem sittlichen Bewußtsein vereinbar erlebt und die Vertrauen in die Rechtmäßigkeit des Urteils wie des Verfahrens überhaupt begründen. [...] Es muß [...] von den Strafverfolgungsorganen alles, was vernünftigerweise erwartet werden kann, zum Zwecke der gerechten Entscheidung über den Verdacht unternommen worden sein [...]. Ziel des Strafprozesses ist zwar der Rechtsfriede und nicht die Gerechtigkeit; der Weg zum

340 Siehe insb. unter Teil 1, II.C.2.b)-d) mit entsprechenden Verweisen und Nachweisen.

341 Siehe (teilweise abweichend bzw. weiter differenzierend) u.a. Beulke, Strafprozessrecht, Rn. 3-7; Dippel, FS für Widmaier, S. 113-116; Gusy, StV 2002, 153 (154-155); Huber, in: Vogler/Huber (Hrsg.), Criminal Procedure, S. 275-276; Kindhäuser, Strafprozessrecht, § 1 Rn. 5-19; Knust, Strafrecht, S. 47-48; Kröpil, JR 2013, 14 (14-15); Kühne, Strafprozessrecht, Rn. 1-4; Meyer-Goßner, StPO, Einl. Rn. 2-5; Radtke, GA 2012, 187 (187); Rieß, FS für Schäfer, S. 168-173; Schlüchter, in: Wolter (Hrsg.), Theorie, S. 214 216; Sieber, FS für Spendel, S.765-767 und Sieber, FS für Roxin 2001, S. 1127-1128. Kritisch gegenüber den traditionellen Betrachtungen zur Zielsetzungsproblematik Murmann, GA 2004, 65 (65-70). 
Rechtsfrieden führt jedoch immer nur über das gewissenhafte Streben nach Gerechtigkeit. Ist jedoch dieser Weg beschritten worden, dann vermag das Verfahren dem Rechtsfrieden auch dann noch zu dienen, wenn sich hernach herausstellen sollte, daß falsch entschieden worden ist. [...] der Rechtsfriede läßt sich nur erreichen über ein Verfahren, das schon als Verfahren das rechte Verhältnis von Staat zu einzelnem zu verwirklichen sucht. $^{342}$

Auch Claus Roxins Zusammenfassung zur vielschichtigen Zielsetzung des deutschen Strafverfahrens stellt dies anschaulich dar:

Ziel des Strafverfahrens ist [...] die (1) materiell richtige, (2) prozessordnungsmäßig zustande kommende, (3) Rechtsfrieden schaffende Entscheidung über die Strafbarkeit des Beschuldigten. Der Spruch des Gerichts - in der Regel das Urteil - soll also nach der Idee des Gesetzgebers drei Qualitäten aufweisen, die in der Realität nicht notwendig vereinigt sind [...] Es ist nicht das Ziel des Strafverfahrens, um jeden Preis ein der materiellen Rechtslage entsprechendes Urteil zu erreichen; eine wesentliche Aufgabe des Strafprozessrechts liegt gerade darin, bei formell oder inhaltlich fehlerhaften Entscheidungen die drei geschilderten Kriterien gegeneinander abzuwägen und rechtliche Maßstäbe dafür aufzurichten, welchem von ihnen im Einzelfall der Vorrang gebührt. ${ }^{343}$

Derartige Annahmen spiegeln wider, dass auf Gesetzesebene manchmal gegensätzliche bzw. kollidierende Grundregeln und Prozessinstitutionen definiert sind, wie z.B. die amtliche Pflicht zur umfassenden Sachverhaltsaufklärung (materielle Wahrheitssuche) und die Beweisverbote sowie andere Menschenrechts- und Fairnessgebote, die Rechtskraft und das Wiederaufnahmeverfahren. ${ }^{344}$ Zur Lösung eventueller Konflikte aufgrund eines solchen Regelungskomplexes sind zumeist Abwägungen nach den jeweiligen gesetzlichen Maßstäben und Rechtsprechungsinterpretationen geboten. ${ }^{345}$

Die höchstrichterliche Rechtsprechung hat bereits des Öfteren zu den verschiedenen Facetten der Zielsetzungsproblematik auch durch Leitlinien Stellung genommen. Neben der klassischen Erwägung, dass es nicht Grundsatz der Strafprozessordnung ist, die Wahrheit ,um jeden Preis ${ }^{\text {‘3 } 346}$ zu erforschen, wird als Aufgabe einer an rechtsstaatlichen Garantien ausgerichteten ,funktionstüchtigen““347 Rechtspflege die Gerechtigkeitsverwirklichung angesehen. ${ }^{348}$ Das Bundesverfassungsgericht (BVerfG) hat insbesondere

die Bedürfnisse einer wirksamen Strafverfolgung wiederholt anerkannt, das Interesse an einer möglichst umfassenden Wahrheitsermittlung im Strafverfahren betont und

\footnotetext{
342 Schmidhäuser, FS für E. Schmidt, S. 522-523.

343 Roxin/Schünemann, Strafverfahrensrecht, § 1 Rn. 3.

344 Siehe z.B. $\S \S 52-57,69,136,136 \mathrm{a}, 155(2), 160,244(2), 245,252,261,359,362$, 449 StPO und Art. 103(3), 104 GG.

345 Siehe u.a. neuerdings Kröpil, JR 2013, 553 (553-555, 557-558).

346 BGHSt 14, 358 (365); BGHSt 31, 304 (309); BGHSt 38, 214 (220). Vgl. auch BVerfG, JZ 2011, 249 (250).

347 Zur „Funktionstüchtigkeit der Strafrechtspflege“ mit Rechtsprechungsverweisen u.a. Roxin/Schünemann, Strafverfahrensrecht, § 1 Rn. 7.

348 BVerfG, NJW 2001, 507 (507).
} 
die Aufklärung schwerer Straftaten als wesentlichen Auftrag eines rechtsstaatlichen Gemeinwesens bezeichnet. Zur funktionsfähigen Strafrechtspflege gehört auch der Anspruch des Beschuldigten auf ein faires, rechtsstaatliches Strafverfahren. ${ }^{349}$

In Zusammenhang mit solchen Zielbestimmungen sind des Weiteren die traditionellen Prozessmaximen zu beachten, die nicht ausnahmslos bzw. nicht unbedingt für alle Prozessstadien im Strafverfahrensrecht verankert sind, die aber in ihrer Gesamtheit auf die grundlegende Ausrichtung des deutschen Verfahrenssystems hindeuten. Auch diese Grundsätze können teilweise im Widerspruch zueinander stehen und sind bei ihrer Anwendung eventuell abwägungsbedürftig. Zentrale Prinzipien, Garantien und Rechte, die oft unmittelbar aus der verfassungsrechtlichen Verpflichtung zum Respekt und zum Schutz der Menschenwürde und des Rechtsstaates hervorgehen und die aus diversen gesetzlichen Vorschriften (direkt oder indirekt) abzuleiten sind, umfassen insbesondere: das Offizialprinzip i.V.m. dem Akkusationsprinzip und dem Legalitätsprinzip, den Untersuchungsgrundsatz und den Grundsatz des rechtlichen Gehörs, das Beschleunigungsgebot, die Unschuldsvermutung und den Grundsatz in dubio pro reo, die fair trial-Garantien und Rechte i.V.m. dem nemo tenetur- und dem ne bis in idem-Prinzip, die Grundsätze der Unmittelbarkeit und der freien Beweiswürdigung, sowie die Grundsätze der Öffentlichkeit und Mündlichkeit. ${ }^{350}$

Neben diesen integralen Bestandteilen des nationalen Verfahrenssystems sind die Mindestgarantien und die Fairness- und Mitwirkungsrechte der EMRK zu erwähnen; vor allem ihre Auslegung durch den EGMR spielt in der heutigen deutschen Strafjustizpraxis eine wichtige Rolle. ${ }^{351}$ Die EMRK steht innerstaatlich im formalen Rang eines einfachen Bundesgesetzes unter dem Grundgesetz (GG). ${ }^{352}$

349 BVerfG, NJW 2001, 507 (507-508) mit weiteren Verweisen. Grundlegend BVerfGE 33, 367 (383); siehe auch BVerfGE 57, 250 (274-278); BVerfGE 80, 367 (375). Nach BVerfGE 34, 238 (248-249): „Das Bundesverfassungsgericht hat deshalb wiederholt die unabweisbaren Bedürfnisse einer wirksamen Strafverfolgung und Verbrechensbekämpfung, das öffentliche Interesse an einer möglichst vollständigen Wahrheitsermittlung im Strafprozeß - zur Überführung von Straftätern ebenso wie zur Entlastung Unschuldiger betont, die wirksame Aufklärung gerade schwerer Straftaten als einen wesentlichen Auftrag eines rechtsstaatlichen Gemeinwesens gewürdigt und auf die Aufrechterhaltung einer funktionstüchtigen Rechtspflege, ohne die der Gerechtigkeit nicht zum Durchbruch verholfen werden könne, abgehoben.“"Weitere Verweise bei Gusy, StV 2002, 153 (154-155).

350 Ausführlich Roxin/Schünemann, Strafverfahrensrecht, §§ 10-16, § 25 Rn. 31-35, $\S 26$ Rn. 33-38, §§ 45-47, §52. Siehe auch Beulke, Strafprozessrecht, Rn. 15-30, 125, 195, 280; Kühne, Strafprozessrecht, Rn. 103-104.2, 264-313, 640-661.2, 695-713, 914966.2; Schroeder/Verrel, Strafprozessrecht, Rn. 34, 36-48, 364-375.

351 Siehe etwa die Paradigmen bei Grabenwarter, in: Leutheusser-Schnarrenberger (Hrsg.), Recht, S. 112-121, und bei Jaeger/Schmaltz, in: Leutheusser-Schnarrenberger (Hrsg.), Recht, S. 101-105.

352 Zusammenfassend BVerfGE 128, 326 (366-367). Ausführlich zur „Rangfrage“ m.w.N. Grabenwarter/Pabel, Menschenrechtskonvention, § 3 Rn. 6-10; Kühne, Strafprozessrecht, Rn. 29-30; Satzger, Internationales Strafrecht, §11 Rn. 10-13. Siehe auch Peters/ Altwicker, Menschenrechtskonvention, § 1 Rn. 3-14; SK-StPO-Paeffgen, Art. 6 EMRK Rn. 6-11. Ferner zur Frage des „Verfassungsrangs“ der EMRK und zur „Völkerrechts- 
Dass jedoch sogar das GG (und nicht nur sämtliche einfachgesetzlichen Vorschriften) konventionsfreundlich auszulegen und die Rechtsprechung des EGMR als Auslegungshilfe für die Bestimmung von Inhalt und Reichweite von Grundrechten und rechtsstaatlichen Grundsätzen heranzuziehen ist, ist jedenfalls allgemein anerkannt. ${ }^{353}$ Darüber hinaus gehört „die Berücksichtigung der Gewährleistungen der Europäischen Menschenrechtskonvention und der Entscheidungen des Gerichtshofs im Rahmen methodisch vertretbarer Gesetzesauslegung“ zur Bindung an Gesetz und Recht nach Art. 20(3) GG. ${ }^{354}$ Die EMRK ist auch ,bei der Anwendung des deutschen Strafprozessrechts [...] in der Auslegung, die sie durch Rechtsprechung des EGMR erfahren hat, zu berücksichtigen. ${ }^{\text {"355 }}$ Die grundsätzliche inter partes-Wirkung ${ }^{356}$ der Urteile des EGMR steht der jedenfalls faktischen erga om$n e s-L e i t f u n k t i o n$ der Konventionsauslegung durch die EGMR-Rechtsprechung und ihrer Orientierungswirkung für die nationalen Rechtsordnungen des Europarats letztendlich nicht entgegen. ${ }^{357}$

\section{Der Ablauf des herkömmlichen Strafverfahrens}

\section{- Einleitung der Strafverfolgung und Klageerhebung}

Das deutsche Strafverfahren besteht aus zwei Hauptteilen, dem Erkenntnisverfahren und dem Vollstreckungsverfahren. ${ }^{358}$ Das herkömmliche erstinstanzliche Erkenntnisverfahren gliedert sich in das Vorverfahren (Ermittlungsverfahren), das

freundlichkeit“" des GG u.a. Bleckmann, EuGRZ 1994, 149 (149-150, 152-155); Weigend, StV 2000, 384 (386-387).

353 Siehe BVerfGE 74, 358 (370); auch BVerfGE 128, 326 (366-372).

354 BVerfGE 111, 307 (323).

355 BGH, NStZ 2007, 166 (167). Vgl. auch BVerfGE 74, 358 (370).

356 Die Wahl der möglichen Wege zur Beendigung und Wiedergutmachung einer Konventionsverletzung und der Art und Weise der obligatorischen Urteilsumsetzung (durch Maßnahmen des nationalen Gesetzgebers, Richters oder der Verwaltungsbehörde - vgl. auch das Wiederaufnahmeverfahren nach $\S 359$ Nr. 6 StPO) obliegt grundsätzlich dem betroffenen Staat, siehe Art. 41, 46 EMRK und u.a. EGMR Papamichalopoulos a.o. v. Greece (Art. 50), Urt. v. 31.10 .1995 (14556/89), § 34. Detailliert zur Rechtswirkung der EGMR-Urteile Grabenwarter/Pabel, Menschenrechtskonvention, §16 Rn. 1-16. Siehe auch Bárd, in: Aromaa/Viljanen (Hrsg.), International Key Issues, S. 45-51; Gusy, JA 2009, 406 (408-410). Zu den möglichen individuellen und generellen Maßnahmen zur Wiedergutmachung einer Konventionsverletzung in Deutschland (sowie in der Schweiz, in Österreich und im Vereinigten Königreich) auch Werwie-Haas, Umsetzung, S. 58-79.

357 BVerfGE 111, 307 (320); BVerfGE 128, 326 (368). Siehe auch Ambos, Internationales Strafrecht, § 10 Rn. 6-9; Grabenwarter/Pabel, Menschenrechtskonvention, § 16 Rn. 8-9. Vgl. auch zur "principle of solidarity" Parliamentary Assembly of the Council of Europe: Resolution 1226 (2000), Rn. 3 abrufbar unter http://assembly.coe.int/Main.asp? link=/Documents/AdoptedText/ta00/ERES1226.htm [Stand: Oktober 2014].

358 Siehe auch die Zusammenfassungen von Huber, in: Vogler/Huber (Hrsg.), Criminal Procedure, S. 280-288; Kindhäuser, Strafprozessrecht, § 3 Rn. 1-15; Putzke/Scheinfeld, Strafprozessrecht, Rn. 14-28; Roxin/Schünemann, Strafverfahrensrecht, § 4 Rn. 1-10. 
Zwischenverfahren und das Hauptverfahren. ${ }^{359}$ Außer den richterlichen Personen sind zentrale ${ }^{360}$ Verfahrensbeteiligte in allen diesen Prozessphasen üblicherweise die Staatsanwaltschaft (StA) und die Verteidigung (der Beschuldigte ${ }^{361}$ und sein Verteidiger). Das streitige Hauptverfahren, das hier von primärem Interesse ist, teilt sich auf in die Phase der Vorbereitung der Hauptverhandlung und die gerichtliche Hauptverhandlung. Letztere bildet weiterhin, zumindest nach den Vorschriften der deutschen Strafprozessordnung (StPO), ${ }^{362}$ die grundlegende Verfahrensplattform für die endgültige Tatsachen- und Schuldfeststellung. ${ }^{363}$

Für die Einleitung und Fortsetzung einer Strafverfolgung bis zur Eröffnung einer gerichtlichen Untersuchung ist primär die Staatsanwaltschaft verantwortlich. ${ }^{364}$ Nach dem Legalitätsprinzip ist diese grundsätzlich verpflichtet, ,wegen aller verfolgbaren Straftaten einzuschreiten, sofern zureichende tatsächliche Anhaltspunkte

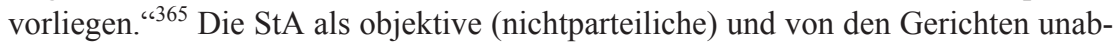
hängige Justizbehörde ist ein selbstständiges Organ der Rechtspflege und nach den

359 Die Rechtsmittelverfahren, die Verfahrensweisen gegen Ausgebliebene und Abwesende, die vereinfachten Strukturen und erheblich abgekürzten Formen des Strafbefehlsverfahrens, die Besonderheiten des Privatklageverfahrens und anderer besonderer Verfahrensarten (wie das beschleunigte Verfahren, das Sicherungsverfahren und das vereinfachte Jugendstrafverfahren) sowie die akzessorischen Mitwirkungsmöglichkeiten des Verletzten im Rahmen des Nebenklageverfahrens und seine sonstigen Befugnisse werden in Übereinstimmung mit dem bereits definierten Vergleichsrahmen (unter Teil 2, I.) nicht bzw. nicht gesondert untersucht, siehe dazu $\S \S 205,230-236,276-444$ StPO und u.a. Beulke, Strafprozessrecht, Rn. 122, 215a, 277, 319, 364, 526-606.

360 Vgl. Beulke, Strafprozessrecht, Rn. 2a.

361 Zum Begriff „Beschuldigter“ und zu den relevanten terminologischen Differenzierungen entsprechend der jeweiligen Prozessphase siehe $\S \S 152,157,170(1)$ StPO; vgl. auch § 397(1) AO und siehe dazu Beulke, Strafprozessrecht, Rn. 110-114; Putzke/Scheinfeld, Strafprozessrecht, Rn. 14; Roxin/Schünemann, Strafverfahrensrecht, § 4 Rn. 10. Im Gegensatz zum neutralen Gebrauch der Worte „Beschuldigter“, „Angeklagter“ und „Verdächtiger" in anderen Teilen der vorliegenden Arbeit (vgl. etwa Teil 1, II.C.1.b) und Teil 2, II.A.2.) wird in diesem Kapitel zum deutschen Prozessrecht soweit nötig neben dem allgemein verwendeten Begriff „Verteidigung“ der für jede Prozessphase im Gesetz definierte Terminus technicus („Beschuldigter“/,Angeschuldigter“/,Angeklagter“) zur Bezeichnung der Person verwendet, gegen die das Strafverfahren durchgeführt wird.

$362 \mathrm{Zu}$ den Quellen des Strafprozessrechts u.a. Roxin/Schünemann, Strafverfahrensrecht, $\S 3$ Rn. 1-29. Zusammenfassend Schroeder/Verrel, Strafprozessrecht, Rn. 31-35.

363 Siehe $\S \S 261,264$ StPO. Nach BVerfGE 74, 358 (372): „[Das] Kernstück des Strafprozesses ist die Hauptverhandlung. In ihr soll der Sachverhalt endgültig aufgeklärt und festgestellt werden; dies hat in einer Weise zu geschehen, die nach allgemeiner Prozeßerfahrung die größte Gewähr für die Erforschung der Wahrheit und zugleich für die bestmögliche Verteidigung des Angeklagten und damit für ein gerechtes Urteil bietet [...].“ Zur abgeschwächten heutigen Bedeutung der Hauptverhandlung Roxin/Schünemann, Strafverfahrensrecht, § 44 Rn. 1; Schünemann, GS für Vogler, S. 82-83.

364 Zur polizeilichen Pflicht des ,ersten Zugriffs“ und zu den selbstständigen Eingriffsrechten der Polizei siehe Roxin/Schünemann, Strafverfahrensrecht, § 9 Rn. 16-20.

$365 \S 152(2)$ StPO. Zum Legalitätsprinzip u.a. Roxin/Schünemann, Strafverfahrensrecht, $\S 14$ Rn. 1-4. 
gesetzlichen Vorschriften die Herrin des Ermittlungsverfahrens. ${ }^{366}$ Sobald sie von dem Verdacht einer Straftat Kenntnis ${ }^{367}$ erhält, ,hat sie zu ihrer Entschließung darüber, ob die öffentliche Klage zu erheben ist, den Sachverhalt zu erforschen“. 368

Die StA kann im Rahmen des (grundsätzlich geheimen, aber in gewissem Umfang ,parteiöffentlichen“" $)^{369}$ Ermittlungsverfahrens zum Zweck der Beweissammlung und -sichtung unter anderem: ${ }^{370}$

- den Verfahrensstand mit den Verfahrensbeteiligten zur allgemeinen Förderung des Strafverfahrens erörtern, wobei auch Diskussionen hinsichtlich einer möglichen abgesprochenen ${ }^{371}$ Beendigung des Verfahrens stattfinden können;

- von allen Behörden Auskunft verlangen;

- Ermittlungen jeder Art entweder selbst vornehmen oder durch die Polizei vornehmen lassen, wobei in der Praxis ${ }^{372}$ die polizeilichen Ermittlungen (im Auftrag der StA oder bis zu einem gewissen Punkt sogar eigenständig) den Regelfall darstellen;

- Zeugen und Sachverständige zur (uneidlichen) Vernehmung ${ }^{373}$ bzw. zum Erstatten ihrer Gutachten bindend laden;

- den Beschuldigten ${ }^{374}$ bindend laden und vernehmen sowie

- Anträge zur Vornahme erforderlicher richterlicher Untersuchungshandlungen (z.B. eidlicher Zeugenvernehmungen, richterlicher Beschuldigtenvernehmungen und Augenscheinnahmen) durch den Ermittlungsrichter ${ }^{375}$ und Anträge zur rich-

366 Siehe insb. $\S$ 160(2), 161(1), 163, 167, 296(2) StPO; § 150 GVG. Dazu Beulke, Strafprozessrecht, Rn. 79; Putzke/Scheinfeld, Strafprozessrecht, Rn. 16; Roxin/Schünemann, Strafverfahrensrecht, § 4 Rn. 3, § 9 Rn. 1-15, 21, 26.

367 Siehe $\S 158$ StPO.

$368 \S 160(1)$ StPO.

369 Roxin/Schünemann, Strafverfahrensrecht, § 39 Rn. 29-33. Zu den Beteiligungsrechten der Verteidigung im Vorverfahren siehe insb. 147, 163a(2-3), 168c-168e StPO.

370 Siehe insgesamt zu den staatsanwaltlichen, polizeilichen und richterlichen Ermittlungen im Vorverfahren sowie zu den Ermittlungs- und Zwangsmaßnahmen $\S \S 151-177$ i.V.m. 48-136a StPO. Kühne, Strafprozessrecht, Rn. 314-577; Roxin/Schünemann, Strafverfahrensrecht, §§ 4, 9, 29-39; Schroeder/Verrel, Strafprozessrecht, Rn. 93-145.

371 Siehe Roxin/Schünemann, Strafverfahrensrecht, § 39 Rn. 21.

372 Hierzu Roxin/Schünemann, Strafverfahrensrecht, § 9 Rn. 19-23. Siehe auch Gleß, Beweisrechtsgrundsätze, S. 55.

373 Allgemein zur Durchführung von Vernehmungen im Vorverfahren Kühne, Strafprozessrecht, Rn. 353-366.

$374 \mathrm{Zu}$ den diversen möglichen Vernehmungen des Beschuldigten im Vorverfahren siehe insb. $\S \S 115,133-136 \mathrm{a}, 163 \mathrm{a}, 166,168 \mathrm{c}$ StPO. Dazu auch Volk/Engländer, Grundkurs, $\S 9$ Rn. 8.

375 Der Ermittlungsrichter prüft nur die rechtliche Zulässigkeit, nicht die Zweckmäßigkeit der beantragten Handlungen und darf nur bei Gefahr im Verzug ohne Antrag der StA Untersuchungen vornehmen. Siehe zum Ermittlungsrichter hauptsächlich §§ 162, 165-169 StPO sowie für eine Zusammenfassung weiterer relevanter (auch verfassungsrechtlicher) 
terlichen Anordnung von Zwangsmaßnahmen (z.B. Untersuchungshaft) stellen. Über jede richterliche Untersuchungshandlung sowie grundsätzlich über sämtliche Vernehmungen ist ein Protokoll aufzunehmen; das Ergebnis staatsanwaltschaftlicher Untersuchungshandlungen ist aktenkundig zu machen. ${ }^{376}$

Bieten die Ermittlungen des Vorverfahrens ,genügenden Anlaß“ zur „Eröffnung einer gerichtlichen Untersuchung“, erhebt die StA als Anklagebehörde ${ }^{377}$ öffentliche Klage. ${ }^{378}$ Andernfalls stellt sie (aus prozessualen, materiell-rechtlichen oder tatsächlichen Gründen) das Verfahren ein. Auch bei einem bestehenden Tatverdacht gibt es gleichwohl diverse Möglichkeiten für die StA - ohne bzw. mit Zustimmung des Gerichts und eventuell des Beschuldigten und ohne bzw. durch Erteilung von Auflagen und Weisungen -, von der Strafverfolgung aufgrund von Opportunitätserwägungen abzusehen. Dies kann insbesondere in den leichteren Deliktsfällen, unter Wahrnehmung der Schuldschwere und des öffentlichen Interesses, sowie in bestimmten anderen Straffällen geschehen. ${ }^{379}$

Entscheidet sich die StA auf der Basis der Ermittlungsergebnisse für die Erhebung der Klage, reicht sie beim zuständigen Gericht die Anklageschrift ein, die den Antrag enthält, das Hauptverfahren zu eröffnen; mit der Anklageschrift werden auch die Akten dem Gericht vorgelegt. ${ }^{380}$ Von diesem Zeitpunkt an trägt das Gericht die Verantwortung für den weiteren Verfahrensablauf. ${ }^{381}$ Die folgenden gerichtlichen Untersuchungen und Entscheidungen erstrecken sich ausschließlich auf die in der Klage bezeichnete Tat und auf die durch die Klage beschuldigten Personen. „Innerhalb dieser Grenzen sind die Gerichte zu einer selbständigen Tätigkeit berechtigt und verpflichtet; insbesondere sind sie bei Anwendung des Strafgesetzes an die gestellten Anträge nicht gebunden. “382

Über die Eröffnung des Hauptverfahrens entscheidet in den meisten Fällen das für die Hauptverhandlung zuständige Gericht (ohne Laienrichter). ${ }^{383} \mathrm{Im}$ Rahmen

Vorschriften Roxin/Schünemann, Strafverfahrensrecht, § 9 Rn. 26-29. Siehe auch Schroeder/Verrel, Strafprozessrecht, Rn. 94-97.

376 § 168-168b StPO. Dazu Roxin/Schünemann, Strafverfahrensrecht, § 39 Rn. 28.

377 Zum geltenden Anklagegrundsatz/Akkusationsprinzip u.a. Roxin/Schünemann, Strafverfahrensrecht, §13 Rn. 4-9. Zur Privatklage siehe $\S \S 374-394$ StPO. Zum Klageerzwingungsverfahren siehe $\S \S 171-177$ StPO.

$378 \S \S 151,152(1)$ und 170 StPO. Siehe ferner Roxin/Schünemann, Strafverfahrensrecht, $\S 40$ Rn. $1-13$.

$379 \mathrm{Zu}$ den gesetzlichen Möglichkeiten der StA zum Absehen von der Klageerhebung bzw. zu entsprechenden Einstellungsmöglichkeiten durch das Gericht in späteren Verfahrensstadien siehe $\S \S 153-154 f$, 376-377 StPO. Details dazu bei Roxin/Schünemann, Strafverfahrensrecht, $\S 14$ Rn. 5-27. Siehe auch Schroeder/Verrel, Strafprozessrecht, Rn. 85-92.

$380 § 199(2)$ StPO. Zur Erhebung der Klage beim hier nicht weiter behandelten Strafbefehlsverfahren siehe $\S 407$ StPO.

381 Roxin/Schünemann, Strafverfahrensrecht, § 40 Rn. 11-13.

$382 \S 155$ StPO. Zur Nachtragsanklage $\S 266$ StPO. Siehe auch $\S 207$ StPO.

$383 \S 30(2), 76(1) \mathrm{GVG}$. 
des Zwischenverfahrens ${ }^{384}$ prüft es die Zulässigkeit und Notwendigkeit einer Fortsetzung der Strafverfolgung im Hauptverfahren. ${ }^{385}$ In dieser nichtöffentlichen Verfahrensphase wird dem Angeschuldigten die Anklageschrift mitgeteilt; auf Antrag des Angeschuldigten oder von Amts wegen (im Wege des Freibeweises) ${ }^{386}$ können gezielte (ergänzende) Beweiserhebungen stattfinden; Einwendungen gegen die Eröffnung des Hauptverfahrens können vorgebracht werden; und das Gericht kann den Verfahrensstand zur Förderung des Verfahrens (vor allem zur „Einfädelung einer Urteilsabsprache“ $)^{387}$ mit den Verfahrensbeteiligten erörtern. ${ }^{388}$ „Das Gericht beschließt die Eröffnung des Hauptverfahrens, wenn nach den Ergebnissen des vorbereitenden Verfahrens der Angeschuldigte einer Straftat hinreichend verdächtig erscheint. “389 Andernfalls muss das Gericht unter Bekanntgabe der entsprechenden tatsächlichen oder rechtlichen Gründe die Eröffnung des Hauptverfahrens ablehnen; möglich sind unter bestimmten Bedingungen auch die Einstellung aus Opportunitätsgründen sowie die vorläufige Einstellung des Verfahrens. ${ }^{390}$ Die StA kann ihrerseits bis zur Eröffnung des Hauptverfahrens die Klage zurücknehmen. ${ }^{391}$

\section{- Erkenntnisverfahren und Gerichtsbarkeit}

Endet das Zwischenverfahren mit einem Eröffnungsbeschluss, schließt sich das Hauptverfahren an. Dieses besteht aus der Phase der Vorbereitung der Hauptverhandlung und der (grundsätzlich öffentlichen) Hauptverhandlung selbst. ${ }^{392}$ Die Vorbereitungsphase erstreckt sich unter anderem auf die Festsetzung der notwendigen Termine, (Zeugen-)Ladungen, Anordnungen zur Herbeischaffung von Beweismitteln, Benennung der Zeugen und Mitteilung der Gerichtsbesetzung; es können auch kommissarische Beweisaufnahmen sowie die Erörterung des Verfahrensstandes mit den Verfahrensbeteiligten (etwa mit dem Ziel einer Verständigung) stattfinden. ${ }^{393}$ Stellt sich nach Eröffnung des Hauptverfahrens ein Verfahrenshindernis heraus oder fällt durch eine Gesetzesänderung die Strafbarkeit weg, kann

384 Zur sofortigen (ohne Zwischenverfahren) Durchführung einer Hauptverhandlung im Rahmen des beschleunigten Verfahrens siehe $\$ \S 417-420$ StPO.

385 Dazu und zusammengefasst zur Kritik hinsichtlich der Gefahr der Voreingenommenheit, die entstehen könnte, wenn das eröffnende und das erkennende Gericht identisch sind, Roxin/Schünemann, Strafverfahrensrecht, § 42 Rn. 2-3. Siehe auch die verschiedenen Gegenargumente bei Gössel, FS für Meyer-Gossner, S. 188-199, 202-206.

386 Roxin/Schünemann, Strafverfahrensrecht, § 24 Rn. 3, § 42 Rn. 6.

387 Roxin/Schünemann, Strafverfahrensrecht, § 42 Rn. 6. 365 .

388 Siehe ferner $\S \S 199-211$ StPO. Mehr dazu bei Beulke, Strafprozessrecht, Rn. 352-

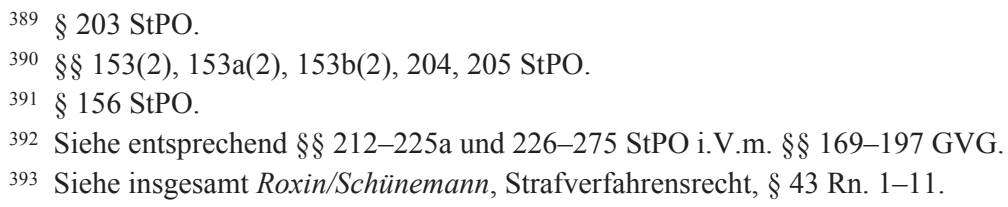


bzw. muss das Gericht außerhalb der Hauptverhandlung das Verfahren durch Beschluss einstellen; auch eine Verfahrenseinstellung aus Opportunitätsgründen ist vor dem Beginn der eigentlichen Hauptverhandlung möglich. ${ }^{394}$

Die Hauptverhandlung wird unter ständiger Anwesenheit der zur Urteilsfindung berufenen Personen und der StA geführt; Letztere vertritt hierbei (wie auch beim Zwischenverfahren) die Anklage. ${ }^{395}$ Der Angeklagte hat in der Regel eine Erscheinens- und Anwesenheitspflicht und kann sich des Beistandes eines Verteidigers bedienen. Gegen einen ausgebliebenen bzw. abwesenden Angeklagten darf grundsätzlich keine Hauptverhandlung stattfinden. ${ }^{396}$ Es gibt jedoch bestimmte gesetzlich geregelte Ausnahmefälle, in denen die Hauptverhandlung trotz Ausbleibens bzw. Entfernung des Angeklagten aus dem Sitzungszimmer durchgeführt werden kann; bei leichten Straffällen ist eine Entbindung des Angeklagten von der Pflicht zum Erscheinen möglich. Soweit die Hauptverhandlung ohne den Angeklagten stattfinden kann, ist dieser befugt, sich durch einen Verteidiger vertreten zu lassen. Das Gericht seinerseits kann das persönliche Erscheinen des Angeklagten jederzeit anordnen. Darüber hinaus existieren auch Regeln, die in bestimmten Fällen die obligatorische Mitwirkung eines Verteidigers verlangen; im Rahmen der notwendigen Verteidigung hat der Verteidiger nicht nur ein Recht zur ständigen Anwesenheit, sondern auch eine Anwesenheitspflicht. ${ }^{397}$

Die Leitung der Hauptverhandlung erfolgt grundsätzlich durch den Vorsitzenden des Gerichts; ihm obliegt ebenso die Aufrechterhaltung der Ordnung in der Sitzung. ${ }^{398}$ Das Gericht kann auch während der Hauptverhandlung den Verfahrensstand mit den Verfahrensbeteiligten erörtern; es kann sich in geeigneten Fällen in der Regel am Anfang der Beweisaufnahme - mit den Beteiligten auf der Basis eines Geständnisses über den weiteren Fortgang und das Ergebnis des Verfahrens verständigen. ${ }^{399}$ Die Anfangsstadien ${ }^{400}$ der Hauptverhandlung werden in $\S 243$ StPO konkreter bestimmt.

\footnotetext{
$394 \S 1$ 153(2), 153a(2), 153b(2), 206a, 206b StPO.
}

$395 \S \S 226(1), 243(3)$ StPO. Beulke, Strafprozessrecht, Rn. 79; Roxin/Schünemann, Strafverfahrensrecht, $\S 9$ Rn. 2.

$396 \S \S 137,230-231,285$ StPO.

397 Siehe zum relevanten Regelungskomplex insb. §§ 137-138b, 140-143, 145, 230236, 247 StPO; allgemein zur Wahl, Ausschließung, Bestellung und Stellung des Verteidigers im Strafprozess $\S \S 137-149$ StPO. Insgesamt dazu sowie zusammenfassend zur Stellung und zu den Rechten des Beschuldigten Roxin/Schünemann, Strafverfahrensrecht, $\S \S 18-19$ und $\S 44$ Rn. $40-58$.

$398 \S 238$ StPO und $\S 176$ GVG.

$399 \S \S 257 b-257 c, 273(1)$ i.V.m. $\S 243(4)$ StPO; dazu u.a. Meyer-Goßner, StPO, $\S \S 257 \mathrm{~b}, 257 \mathrm{c}$. Vgl. auch die Regelungen zum „Täter-Opfer-Ausgleich“ in $\S \S 155 \mathrm{a}-155 \mathrm{~b}$ i.V.m. $\S \S 136(1), 153 \mathrm{a}(1 \mathrm{Nr} .5,2), 153 \mathrm{~b}$ StPO und $\S 46 \mathrm{a}$ StGB.

400 Zum Ablauf der Hauptverhandlung siehe zusammenfassend Schroeder/Verrel, Strafprozessrecht, Rn. 193. 
An die Vernehmung des Angeklagten zur Sache schließt sich vor allem bei einem streitigen Sachverhalt eine umfassende Beweisaufnahme an, die unter anderem Zeugen- und Sachverständigenvernehmungen sowie Verlesungen von Urkunden und Protokollen umfasst. ${ }^{401}$ Nach Schluss der Beweisaufnahme werden üblicherweise die Schlussvorträge gehalten; dem Angeklagten gebührt das letzte Wort. ${ }^{402}$ Die erstinstanzliche Hauptverhandlung schließt mit der (im Kollegialgericht auf die richterliche Beratung und Abstimmung folgenden) Verkündung des Urteils, die aus Verlesung der Urteilsformel und Eröffnung der Urteilsgründe (d.h. Verlesung oder mündliche Mitteilung ihres wesentlichen Inhalts) besteht. ${ }^{403}$ Das vollständige Urteil mit den gesetzlich erforderlichen Entscheidungsgründen ist (innerhalb bestimmter Fristen) von den Richtern zu unterschreiben und schriftlich zu den Akten zu bringen. 404

Die sachliche Zuständigkeit der deutschen Gerichte wird grundsätzlich anhand bestehender gesetzlicher Regelungen und unabhängig vom Willen der konkreten Verfahrensbeteiligten entsprechend der Art und Schwere der Rechtssache bestimmt. Dabei werden abstrakte Kriterien (bestimmte Straftaten sind per Gesetz ausdrücklich bestimmten Spruchkörpern zugewiesen; im Gesetz angedrohte Höchststrafe) sowie konkrete Kriterien (insbesondere: die im Einzelfall voraussichtlich höchstens zu erwartende Strafe) angewandt. ${ }^{405}$ Die erstinstanzlichen Strafgerichte sind:

- das Amtsgericht (Strafrichter: ein Berufsrichter bzw. Schöffengericht: ein oder zwei Berufsrichter und zwei Schöffen),

- das Landgericht (allgemeine große Strafkammer und besondere große Strafkammern, namentlich das Schwurgericht, die Wirtschaftskammer und die Staatsschutzkammer: drei oder zwei Berufsrichter und zwei Schöffen); und

- das Oberlandesgericht (erstinstanzlicher Strafsenat: drei bzw. fünf Berufsrichter). ${ }^{406}$

Die Grundstadien des herkömmlichen erstinstanzlichen (Erkenntnis-)Verfahrens werden bei sämtlichen Gerichten und Spruchkörpern grundsätzlich in derselben, gerade beschriebenen Art und Weise und größtenteils nach einheitlichen Verfahrensregeln durchlaufen. Außer in Bezug auf Verfahrensleitungsangelegenheiten, die dem Berufsrichter vorbehalten sind, ist während der Hauptverhandlung wie

401 Siehe ferner $\S \S 244-275$ a StPO.

$402 \S 258$ StPO.

$403 \S \S 260,263,268$ StPO i.V.m. $\S 192-197$ GVG.

404 Weitere Details dazu und allgemein zur Begründungspflicht $\S \S 34,267,275,338$ Nr. 7 StPO. Meyer-Goßner, StPO, $\S \S 34,267,275$ und $\S 338$ Rn. 51-57.

405 Roxin/Schünemann, Strafverfahrensrecht, § 6 Rn. 2-5.

406 Siehe insb. $\S \S 24,25,28,29,74(1,2), 74 a, 74 c, 76,120,122$ GVG. Ausführlich, auch zu den Problemen der ,beweglichen Zuständigkeit“ und zu den Berufungs- und Revisionszuständigkeiten, siehe Beulke, Strafprozessrecht, Rn. 34-56; Roxin/Schünemann, Strafverfahrensrecht, § 6 Rn. 6-20. 
auch beim Treffen der Entscheidung keine substantielle Aufgabenverteilung zwischen Berufsrichtern und eventuell mitwirkenden Laienrichtern vorgesehen: Die Schöffen (ehrenamtliche Richter) ${ }^{407}$ wirken ,neben den Berufsrichtern im Spruchkollegium in derselben Funktion und (ausgenommen die Aktenkenntnis) mit denselben Rechten “408 zusammen. Für die Schöffen des Schöffengerichts (und entsprechend für die Schöffen der Strafkammern) wird konkreter im GVG bestimmt: ${ }^{409}$

(1) Insoweit das Gesetz nicht Ausnahmen bestimmt, üben die Schöffen während der Hauptverhandlung das Richteramt in vollem Umfang und mit gleichem Stimmrecht wie die Richter beim Amtsgericht aus und nehmen auch an den im Laufe einer Hauptverhandlung zu erlassenden Entscheidungen teil, die in keiner Beziehung zu der Urteilsfällung stehen und die auch ohne mündliche Verhandlung erlassen werden können.

(2) Die außerhalb der Hauptverhandlung erforderlichen Entscheidungen werden von dem Richter beim Amtsgericht erlassen.

\section{Die Grundsätze des Beweisrechts und -verfahrens}

Der deutsche Strafprozess befasst sich primär mit der Ermittlung des wahren Sachverhalts. ${ }^{410}$ Wahrheit wird weithin als (eine) Voraussetzung der Gerechtigkeit anerkannt, wobei ,ein gerechtes Urteil [...] ohne genaue Ermittlung der entscheidungsrelevanten Tatsachen nicht denkbar" ist. ${ }^{411}$ Diese Ermittlung erfolgt nach den Grundprinzipien und Regeln des strafprozessualen Beweises. ${ }^{412}$ Nach § 244(2) StPO hat das Gericht im Rahmen seiner Aufklärungspflicht ,zur Erforschung der Wahrheit die Beweisaufnahme von Amts wegen auf alle Tatsachen und Beweismittel zu erstrecken, die für die Entscheidung von Bedeutung sind." Nach § 155(2) StPO sind die Gerichte innerhalb der durch die Strafklage gezogenen Grenzen ,zu einer selbständigen Tätigkeit berechtigt und verpflichtet.““

$407 \mathrm{Zu}$ deren Auswahl usw. siehe $\S \S 31-58,76-77,192$ GVG. Hierzu zusammengefasst Haller/Conzen, Strafverfahren, Rn. 344-350.

408 Roxin/Schünemann, Strafverfahrensrecht, §6 Rn. 16. Zur These, dass es jedenfalls „eine pauschale Gleichheit auf der Richterbank“ nicht gibt, und zu entsprechenden Paradigmen aus der StPO und dem GVG Börner, ZStW 122 (2010), 157 (158-181).

$409 \S 30$ i.V.m. 76(1), 77, 195-197 GVG und $§ 263$ StPO.

410 U.a. BVerfGE 57, 250 (275); BVerfG, NStZ 1987, 419 (419); BVerfGE 122, 248 (270).

411 Neumann, ZStW 101 (1989), 52 (52). Siehe auch Theile, NStZ 2012, 666 (666).

412 Nach der Definition von Gössel, Strafverfahrensrecht, S. 178: „Die Feststellung des Untersuchungs- und Entscheidungsobjekts, eines bestimmten Sachverhalts also, geschieht im Wege des Beweises. Bezeichnet die Vorsilbe ,be-' eine ,Einwirkung auf eine Sache oder Person' und das Verbum ,weisen' den Vorgang des ,wissend machen(s) ' (Duden, Band 7, Etymologie, Stichwörter ,be' ... und ,weisen'), so bedeutet , beweisen' demnach: jemanden wissend machen, im Falle gerichtlicher Untersuchung also: das Gericht wissend machen. Weil aber nur der weiß, der die Wahrheit kennt - ,Kenntnis' der Unwahrheit ist Nichtwissen - folgt schon aus diesen philologischen Überlegungen: ,beweisen' heißt Erforschung des wahren Sachverhalts [...]."Vgl. auch Dedes, Beweisverfahren, S. 11, 56-57. 
Im Rahmen der Beweisaufnahme innerhalb der Hauptverhandlung wird in vollem Umfang das Vorliegen oder Nicht-Vorliegen aller (Haupt-, Neben-/Indizienund Hilfs-/Glaubwürdigkeits-)Tatsachen geprüft, die nach den Definitionen des materiellen Strafrechts von Bedeutung für die Entscheidung über Schuld und Strafe, also entscheidungserheblich sind. ${ }^{413}$ Bei den Beweiserhebungen und -sicherungen im Vorverfahren (das gleichermaßen durch den Untersuchungsgrundsatz geprägt ist $)^{414}$ und im gerichtlichen Zwischenverfahren geht es dagegen grundsätzlich nicht um einen vollen Nachweis der Schuld und schon gar nicht um die Entscheidung über das Strafmaß; vielmehr geht es zunächst um die Begründung des jeweils erforderlichen Verdachtsgrades zur Einleitung und Fortsetzung der Strafverfolgung bzw. zur Eröffnung des Hauptverfahrens. ${ }^{415}$ Nach $§ 261$ StPO entscheidet letztendlich das Gericht im Hauptverfahren über das Ergebnis der Beweisaufnahme ,nach seiner freien, aus dem Inbegriff der Verhandlung geschöpften Überzeugung. “416

Zur Klärung der Schuld- und Straffrage in der Hauptverhandlung - insbesondere zur Vorzeichnung der Wege, auf denen ,ein Beweisgegenstand zum Beweismittel und zum ,Inbegriff der Hauptverhandlung“ werden“ " ${ }^{417}$ kann - wird das sogenannte Strengbeweisverfahren angewandt. Hierbei dürfen nur die gesetzlichen Beweismittel (namentlich: Einlassung des Angeklagten als Beweismittel i.w.S., Zeugenbeweis, Sachverständigenbeweis, Augenscheinsbeweis und Urkundenbeweis) ${ }^{418}$ verwendet werden, wobei deren Einführung in den Prozess und deren Prüfung

413 Gleß, Beweisrechtsgrundsätze, S. 58; Neumann, ZStW 101 (1989), 52 (53); Roxin/ Schünemann, Strafverfahrensrecht, § 24 Rn. 1, 6-7. Ferner zur Unterscheidung zwischen äußeren und inneren Tatsachen, Rechtsfragen, Erfahrungssätzen und übrigen Beweisarten Kühne, Strafprozessrecht, Rn. 752-760.

${ }^{414}$ Siehe $§ 160(2)$ StPO. Beulke, Strafprozessrecht, Rn. 21; Gleß, Beweisrechtsgrundsätze, S. 58.

415 Ferner, auch zur Glaubhaftmachung im Sinne einer bloßen Wahrscheinlichmachung, die bei gewissen prozessualen Entscheidungen (z.B. für die Ablehnung von Richtern oder die Begründung eines Zeugnisverweigerungsrechts) erforderlich ist, Roxin/Schünemann, Strafverfahrensrecht, § 24 Rn. 1. Siehe auch Haller/Conzen, Strafverfahren, Rn. 118-125, 355-364.

416 In BGHSt 50, 40 (48-49), wird wie folgt zusammengefasst: „Ein zentrales Ziel des rechtsstaatlich geordneten Strafverfahrens ist die Ermittlung des wahren Sachverhalts als der notwendigen Grundlage eines gerechten Urteils. Die Ermittlung des Sachverhalts durch den Tatrichter untersteht dem aus $\S 244$ Abs. 2 StPO abzuleitenden und den verfassungsrechtlichen Anforderungen entsprechenden, Gebot bestmöglicher Sachaufklärung ' (vgl. BVerfGE 57, 250, 275; 63, 45, 61; BVerfG - Kammer - NJW 2003, 2444 und Beschl. vom 17. September 2004 - 2 BvR 2122/03). Dabei ist die Feststellung des Ergebnisses der Beweisaufnahme grundsätzlich der Urteilsberatung vorbehalten, denn die für das Urteil maßgeblichen Feststellungen muß der Tatrichter nach § 261 StPO aus dem Inbegriff der Hauptverhandlung gewinnen (BGHSt 43, 360)."Vgl. auch Paulus, FS für Fezer, S. 243-244.

417 Dallmeyer, Beweisführung, S. 134.

418 Siehe insb. $\S \S 48-71,72-85,86-93,243(5), 244,249-256$ StPO. Dazu u.a. Beulke, Strafprozessrecht, Rn. 179-204. 
grundsätzlich nach $\S \S 238-257$ StPO erfolgen müssen. ${ }^{419}$ Soweit es dagegen um die Klärung von Fragen im Vor- und Zwischenverfahren (etwa in Bezug auf den Erlass eines Haftbefehls oder auf die Eröffnung des Hauptverfahrens) und allgemein um die Klärung von lediglich prozessualen Angelegenheiten (z.B. das Vorliegen von Prozessvoraussetzungen oder die notwendigen Vereidigungsvoraussetzungen) geht, gilt der Freibeweis. ${ }^{420}$ Das Gericht kann sich daher ohne Rücksicht auf die Regeln des Strengbeweises, ,auf beliebige Weise Gewissheit über den Beweisgegenstand verschaffen. [...] Ist eine Tatsache sowohl für die Sachentscheidung als auch für die prozessualen Fragen relevant, gilt das Strengbeweisverfahren." ${ }^{621}$ Nach der (nicht völlig unumstrittenen) ${ }^{422}$ Ansicht der Rechtsprechung gilt auch für die Prüfung, ob die Voraussetzungen eines Beweisverwertungsverbots nach $\S 136 \mathrm{a}(3)$ StPO vorliegen, der Grundsatz des Freibeweises, denn hierbei handelt es sich ,nicht um den Inhalt des für die Schuldfrage bedeutsamen Geständnisses, sondern um die Art, wie es zustandegekommen ist, also um die Feststellung eines Verfahrensfehlers. “423

Die Vorschrift des $\S 136$ a StPO über die verbotenen Vernehmungsmethoden und das Verbot der Verwertung ihres Aussageergebnisses bei der Urteilsfindung stellt darüber hinaus ein klassisches gesetzliches Paradigma des Grundsatzes dar, dass der Untersuchungsgrundsatz und die Amtsaufklärungspflicht des Gerichts in Bezug auf die anzuwendenden Ermittlungsmethoden und die zu verwendenden (nach den Regeln des Strengbeweises zunächst zugelassenen) Beweismittel nicht uneingeschränkt gelten. ${ }^{424}$ Es geht hierbei hauptsächlich um die Problematik der Beweisverbote, genauer um die Beweiserhebungs- ${ }^{425}$ und Beweisverwertungsverbote; Letztere entstehen sehr oft aufgrund der Verletzung eines Beweiserhebungsverbots, manchmal aber auch selbstständig. ${ }^{426}$ Die Beweisverbote werden in Gesetz, Recht-

419 Kühne, Strafprozessrecht, Rn. 760; Roxin/Schünemann, Strafverfahrensrecht, § 24 Rn. 2. Ferner i.V.m. der Problematik der Beweisverbote Dallmeyer, Beweisführung, insb. S. 39-127.

420 Weitere Details und Beispiele bei Beulke, Strafprozessrecht, Rn. 180; Eisenberg, Beweisrecht, Rn. 35-41; Roxin/Schünemann, Strafverfahrensrecht, § 24 Rn. 3-5.

421 Kühne, Strafprozessrecht, Rn. 760 m.w.N.

422 Siehe u.a. die Gegenansicht von Eisenberg, Beweisrecht, Rn. 40, 707 und Kühne, Strafprozessrecht, Rn. 760.

423 BGHSt 16, 164 (166-167).

${ }^{424}$ Vgl. auch $\S \S 244(3)$ und 245 StPO; hierzu Dallmeyer, Beweisführung, S. 129-131.

425 Siehe zusammengefasst mit Rechtsprechungshinweisen zu den Unterkategorien, namentlich zu den Beweisthemaverboten (z.B. § 51(1) BZRG), den Beweismittelverboten (z.B. $\S \S 52-55,81$ c(3), 97, 160a StPO) und den Beweismethodenverboten (z.B. $\S 136 a(1-$ 2) StPO), Roxin/Schünemann, Strafverfahrensrecht, § 24 Rn. 15-20.

426 Siehe etwa die ausdrücklichen Regelungen in $\S \S 69(3), 81 \mathrm{c}(3), 100 \mathrm{a}(4), 100 \mathrm{c}(5)$, 100d(5), 101(8), 108(2-3), 136a(3), 160a, 161(2) StPO; Art. 13(5) GG. Detaillierter dazu, zu den nicht ausdrücklich geregelten Fällen und zu den diesbezüglichen Konstruktionen in Rechtsprechung und Literatur - insb. zu Rechtskreistheorie und Schutzzwecktheorie, Abwägungstheorie, Widerspruchslösung, Strafzumessungslösung/Vollstreckungslösung und 
sprechung und Lehre vielfach und vielfältig angesprochen. ${ }^{427}$ Der Wahrheitssuche werden hierbei Grenzen gesetzt durch die Grundrechte und die übergeordneten Interessen der Verfahrensbeteiligten, der Justiz und der Rechtsstaatlichkeit. ${ }^{428}$ Die Beurteilung der Beweisverbotsfragen kann für das Gericht - zumindest soweit eine ausdrückliche gesetzliche Regelung nicht vorhanden ist - eine komplexe Angelegenheit sein. Insbesondere in Bezug auf die Verwertungsverbote sind die nicht immer klaren bzw. einheitlichen Kriterien anzuwenden, die sich in Rechtsprechung und Lehre mit Blick auf den Ausschluss bzw. den Umfang der Verwendung zu Urteilsfindungszwecken von (menschen-)rechtswidrig/in unfairer Weise erlangten Beweisen entwickelt haben.

Darüber hinaus darf das Gericht nur dasjenige (zulässige) Beweismaterial für seine Entscheidung verwenden, das in der mündlichen Hauptverhandlung präsentiert und geprüft worden ist. ${ }^{429}$ Des Weiteren gilt zumindest im Grundsatz, dass die Entscheidung des Gerichts über die Schuldfrage auf eigenen Wahrnehmungen der entscheidenden Richter basieren muss, die in der Hauptverhandlung ununterbrochen anwesend sein müssen und die Durchführung der Beweisaufnahme grundsätzlich nicht anderen Personen überlassen dürfen (formelle Unmittelbarkeit). Ferner soll das Gericht in der Regel „die Tatsachen aus der Quelle selbst schöpfen““430 und keine Beweissurrogate benutzen, die Zeugen persönlich vernehmen und im Einklang mit der Aufklärungspflicht das bestmögliche Beweismittel verwenden (materielle Unmittelbarkeit). Einschränkungen und Ausnahmen von den diversen Aspekten des Unmittelbarkeitsgrundsatzes sind jedoch heute in Gesetz und Rechtsprechung - etwa in Bezug auf die erlaubte gerichtliche Vernehmung von Zeugen vom Hörensagen, deren geringer Beweiswert jedoch von den Obergerichten anerkannt wird, oder auf die Verlesung von vorgerichtlichen Vernehmungsprotokollen - häufig anzutreffen. ${ }^{431}$

Beweiswürdigungslösung sowie zur Problematik der Fernwirkung der Beweisverbote und des Spurenansatzes - Roxin/Schünemann, Strafverfahrensrecht, § 24 Rn. 21-67 m.w.N.

427 Siehe für weitere Details, Schematisierungen und Rechtsprechungshinweise u.a. Ambos, Beweisverwertungsverbote, S. 21-72; Beulke, Strafprozessrecht, Rn. 454-483; Dalakouras, Beweisverbote, S. 103-147; Eisenberg, Beweisrecht, Rn. 329-430; Fezer, Grundfragen, S. 4-39; Jäger, GA 2008, 473 (474-499); Rogall, in: Höpfel/Huber (Hrsg.), Beweisverbote, S. 124-146; Wolter, FG BGH, S. 963-1001.

428 Gle $\beta$, Beweisrechtsgrundsätze, S. 58.

429 Dazu Eisenberg, Beweisrecht, Rn. 64; Roxin/Schünemann, Strafverfahrensrecht, $\S 46$ Rn. 1-2.

430 Roxin/Schünemann, Strafverfahrensrecht, § 46 Rn. 4.

431 Siehe insgesamt zu diesem Regelungskomplex sowie zu Ausnahmen und Durchbrechungen u.a. Eisenberg, Beweisrecht, Rn. 65-87; Roxin/Schünemann, Strafverfahrensrecht, § 46 Rn. 3-39. Ferner zu den ,theoretischen und dogmatischen Grundlagen“ des Unmittelbarkeitsprinzips Geppert, Unmittelbarkeit, S. 121-302. Siehe auch Großkopf, Beweissurrogate, S. 16-61. Neuerdings zu möglichen Einwänden gegenüber dem Unmittelbarkeitsprinzip und zu entsprechendem Reformbedarf Weigend, FS für Eisenberg, S. 663-671. 
Die Ergebnisse der Durchführung des gerichtlichen Beweisverfahrens entsprechend den gerade beschriebenen ,strengen“ Grundsätzen und Regeln werden anschließend der freien Beweiswürdigung seitens der (Berufs- bzw. Berufs- und Laien-) Richter unterzogen, die Voraussetzung für die Entscheidung über die Schuldfrage ist. Das Prinzip der freien Beweiswürdigung steht zunächst den gesetzlichen Beweisregeln, die zur Bindung der richterlichen Schlussfolgerungen und Würdigungen an bestimmte formale Kriterien führen können (wie es vor allem im alten Inquisitionsprozess der Fall war), ${ }^{432}$ entgegen. ${ }^{433}$ Dieses Prinzip fordert jedenfalls eine subjektive zweifelsfreie Überzeugungsbildung seitens der Richter - konkreter: es verlangt in der geltenden Fassung des $\S 261$ StPO nach einer freien, aus dem Inbegriff der Hauptverhandlung geschöpften persönlichen Gewissheit. Bloße Vermutungen sowie mangelhafte, willkürliche, nicht genügend begründete und rational-objektiv nicht nachvollziehbare Würdigungen werden heute nicht mehr akzeptiert. ${ }^{434}$ Neben den umfangreichen und komplexen (nicht immer einheitlichen) Äußerungen der Rechtsprechung über die diversen Aspekte, Parameter und notwendigen Begründungen des richterlichen Würdigungsprozesses existieren auch (ausdrücklichere) Einschränkungen und Ausnahmen in Bezug auf den Grundsatz der freien Beweiswürdigung: Diese betreffen hauptsächlich Denkgesetze und Regeln der Logik, Erfahrungssätze und die Einführung von wissenschaftlich ${ }^{435}$ gesicherten Erkenntnissen in das Verfahren, die klare Durchbrechung des Grundsatzes aufgrund von Gesetzesvorschriften ${ }^{436}$ und eventuell auch die Beweisverbotskonstellationen. ${ }^{437}$

Schließlich muss das Gericht nach Abschluss der Beweiswürdigung im Fall eines eventuell vorhandenen Zweifels hinsichtlich der materiell-rechtlich relevanten Tatsachenlage - also ,wenn es nach abgeschlossener Beweiswürdigung nicht die volle Überzeugung vom Vorliegen einer für den Schuld- oder Rechtsfolgenausspruch unmittelbar entscheidungserheblichen Tatsache zu gewinnen vermag'“438 zugunsten des Angeklagten entscheiden. Der in dubio pro reo-Grundsatz lässt sich

\footnotetext{
432 Siehe unter Teil 1, I.B.3.c), Teil 1, I.B.4.

433 Siehe etwa Gleß, Beweisrechtsgrundsätze, S. 59-60. Ausführlich auch zu den historischen Entwicklungen Frisch, FS für Stürner, S. 850-856.

${ }^{434}$ Mehr dazu u.a. bei Eisenberg, Beweisrecht, Rn. 88-101; Roxin/Schünemann, Strafverfahrensrecht, $\S 45 \mathrm{Rn} .42-48$. Im theoretischen Kontext siehe zu dem „Beweismodell“, dem „Überzeugungsmodell“" und den „Mischmodellen“ der Sachverhaltsfeststellung Schulz, Sachverhaltsfeststellung, insb. S. 7-172. Siehe auch Androulakis, FS für Roxin 2011, S. 1369-1374.

435 Siehe BGH, NJW 1979, 2318 (2319): „Wo eine Tatsache aufgrund wissenschaftlicher Erkenntnis feststeht, ist für eine richterliche Würdigung und Überzeugungsbildung kein Raum mehr." Siehe auch BGHSt 10, 208 (211).

436 Siehe insb. § $190 \mathrm{StGB}$; 274 StPO.

437 Insgesamt dazu m.w.N. Eisenberg, Beweisrecht, Rn. 102-115b; Roxin/Schünemann, Strafverfahrensrecht, $\S 45$ Rn. 49-55.
}

438 U.a. BGH, NStZ 2001, 609 (609); BGH, NStZ-RR 2008, 350 (351). 
vor allem mit dem Rechtsstaatsprinzip, dem Schuldprinzip, dem $\S 261$ StPO und der Unschuldsvermutung nach Art. 6(2) EMRK korrelieren. ${ }^{439}$ Schuldvermutungen und Beweislastumkehrungen zulasten des Angeklagten sind prinzipiell ausgeschlossen. ${ }^{440}$

\section{B. Die vorbereitenden Beweisführungsvorgänge}

Die nachfolgende Auseinandersetzung mit den Besonderheiten des deutschen Beweisführungssystems konzentriert sich hauptsächlich, wie bereits angedeutet, auf die Vorbereitung und Durchführung einer durch die Strafklageerhebung eröffneten gerichtlichen Untersuchung und insbesondere auf die Verfahrensweisen, die zur Sachverhaltsaufklärung eingesetzt werden. ${ }^{441}$ Die Strukturen und weiteren Einzelheiten der polizeilichen und staatsanwaltlichen Ermittlungen und Beweissicherungen im Vorverfahren, die primär der Einleitung und Fortsetzung - nicht aber der endgültigen Aufklärung - (nur) von stichhaltigen Strafverfolgungen dienen, werden hier nicht näher betrachtet.

Ebenso wenig werden die auf Effektivitäts- und Opportunitätserwägungen basierenden prozessualen Möglichkeiten zur ,vorzeitigen“ Verfahrenseinstellung sowie zur abgesprochenen Verfahrenserledigung analysiert. Die relevanten rechtspolitischen Entwicklungen haben in den letzten Jahrzehnten allgemein nicht unerhebliche Veränderungen im deutschen Strafverfahrenssystem hervorgerufen. ${ }^{442}$ Insbesondere die erst seit 2009 gesetzlich geregelten „Verständigungen“ ( $\$ 257 \mathrm{c} \mathrm{StPO}$ ), aber auch die bereits in den letzten 30 Jahren tatsächlich ausgeübte weitverbreitete Absprachenpraxis wurden vielfach kritisiert, nicht zuletzt wegen ihrer Unvereinbarkeit mit bestimmten traditionellen Prozessprinzipien. ${ }^{443}$ Die bisherigen rechts-

439 Siehe u.a. Eisenberg, Beweisrecht, Rn. 116-118; Roxin/Schünemann, Strafverfahrensrecht, § 45 Rn. 56. Siehe auch Frisch, FS für Henkel, S. 273-274, 283-285.

440 Ausführlicher dazu und zu möglichen (scheinbaren) Ausnahmen i.V.m. der Problematik des genauen Anwendungsbereichs des Grundsatzes (etwa in Bezug auf die Klärung von Fragen zur Rechtswidrigkeit und Strafausschließung, von Alibibehauptungen und von zweifelhaften verfahrensrechtlichen Fragen), Eisenberg, Beweisrecht, Rn. 119-136; Roxin/ Schünemann, Strafverfahrensrecht, § 45 Rn. 57-64.

441 Siehe zum Untersuchungs- und Vergleichsrahmen entsprechend den vorhergehenden abstrakt-theoretischen (modellhaften) Bestimmungen insb. unter Teil 1, II.C.3.a); Teil 1, II.C.3.e); Teil 1, II.C.4.; Teil 2, I.; Teil 2, II.B.

442 Vgl. u.a. Wagner, GS für Eckert, S. 939-940, 945 m.w.N.; Weigend, FS für Maiwald, S. 829-831, 845-847.

443 Siehe u.a. m.w.N. Roxin/Schünemann, Strafverfahrensrecht, § 10 Rn. 4-5, § 17 Rn. 7-32; Schroeder/Verrel, Strafprozessrecht, Rn. 194; Wohlers, NJW 2010, 2470 (24732474). Siehe auch die allgemeineren Diskussionen in dieser Arbeit unter Teil 1, I.B.2.a)aa)-bb); Teil 1, I.B.3.b)bb); Teil 1, I.B.4.; Teil 1, II.C.2.d)bb); Teil 1, II.C.2.e)aa)bb); Teil 1, II.C.3.e) m.w.N. 
politischen Planungen scheinen nicht auf die bewusste Einführung eines neuen, selbstständigen Verfahrensrahmens zur raschen/konsensualen Erledigung der Strafkonflikte in das deutsche Strafprozesssystem ausgerichtet $\mathrm{zu}$ sein. Außerdem scheint allgemein eine Neudefinition der wesentlichen (Beweis-)Verfahrensprinzipien und der normativ geforderten Rolle der Verfahrensakteure nicht erwünscht zu sein; freilich lässt sich nicht leugnen, dass sich dann bei einer solchen ungeordneten Zusammenstellung ,neuer“ und ,alter“ Prozessformen mit faktisch unterschiedlichen Zielsetzungen Systemwidersprüche ergeben können. ${ }^{444}$ An dieser Stelle ist jedenfalls noch einmal zu betonen, dass es in den nachfolgenden Ausführungen im Einklang mit den modellhaften Bestimmungen grundsätzlich nur um die Untersuchung der Strukturen, der Prüfungsmethoden und der Rollenverteilung innerhalb des Beweisprozesses geht, der normalerweise zur umfassenden Aufklärung eines streitigen Sachverhalts stattfindet.

\section{Die „Aufbereitung“ des Beweismaterials}

\section{a) Allgemeine Grundsätze: Strukturen, Waffengleichheit und Objektivitätspflichten}

Die Beweisergebnisse des staatsanwaltlichen und polizeilichen Vorverfahrens, das mit Erhebung der Klage seitens der StA endet, werden dem Gericht in Form der Anklageschrift (die in der Regel das wesentliche Ergebnis der Ermittlungen darstellt) und der umfassenden Verfahrensakten mitgeteilt. ${ }^{445}$ Die vorzulegenden Akten müssen grundsätzlich sämtliche bisher gesammelten und dokumentierten entlastenden und belastenden Beweise, die von der Polizei übersendeten Vorgänge und die bei der StA entstandenen Vorgänge - ,einschließlich etwaiger Bild- und Tonaufnahmen nebst hiervon gefertigter Verschriftungen,“ nicht aber rein ,innerdienstlicher" Unterlagen und Handakten - enthalten. ${ }^{446}$

Mit der Anklageerhebung und Einreichung der Verfahrensakte bei Gericht setzt die gerichtliche Untersuchung des Sachverhaltes ein. ${ }^{447}$ In einer ersten Phase konzentriert sich diese Untersuchung (zumindest in normativer Hinsicht) zwar aus-

${ }_{444}$ Vgl. Meyer-Goßner, StPO, § 257c Rn. 3. Vgl. auch den Gehalt der erläuterten Grundsätze für die Absprachen in BVerfG, 2 BvR 2628/10 vom 19.3.2013, Absatz-Nr. 48, 53-72, http://www.bverfg.de/entscheidungen/rs20130319_2bvr262810.html; hierzu u.a. Globke, JR 2014, 9 (9-12). Siehe auch die Überlegungen von Fezer, NStZ 2010, 177 (179-184); Hassemer, FS für Volk, S. 221-222; Theile, NStZ 2012, 666 (667-669); Wagner, GS für Eckert, S. 958-959; Weigend, FS für Maiwald, S. 831-838; Weßlau, FS für Müller, S. 781-790.

445 Siehe $\S \S 152(1), 160(2), 163(2), 168-168 b, 169 a, 170(1), 199(2), 200$ StPO. Zum üblichen Inhalt der Anklageschrift Roxin/Schünemann, Strafverfahrensrecht, § 40 Rn. 16-19.

446 BGH, Urt. v. 18.6.2009 - 3 StR 89/09, HRRS 2009 Nr. 665, Rn. 24; ferner zum notwendigen Inhalt der Akten Meyer-Goßner, StPO, § 199 Rn. 2 m.w.N.

447 Siehe $\S \S 151,156,170(1), 199(2)$ StPO. 
schließlich auf die Frage der Stichhaltigkeit des Anklagevorbringens mit Blick auf die Fortsetzung der Strafverfolgung durch Eröffnung des Hauptverfahrens. Aber auch in diesem Zwischenverfahrensstadium können einzelne (ergänzende) Beweiserhebungen von dem für die Hauptverhandlung zuständigen Gericht von Amts wegen oder auf Antrag der Verteidigung zwecks besserer Aufklärung der Sache angeordnet werden; derartige Beweiserhebungen sollen hauptsächlich gezielt der Entscheidung über die Eröffnung des Hauptverfahrens, aber auch Beweissicherungszwecken dienen. ${ }^{448}$ Nach Eröffnung des Hauptverfahrens kann das Gericht bei der Vorbereitung und außerhalb der Hauptverhandlung die Vernehmung von Zeugen und Sachverständigen sowie die Einnahme von Augenschein durch einen beauftragten oder ersuchten Richter zur Beweissicherung anordnen. Die dabei aufgenommenen Protokolle sind der StA und dem Verteidiger vorzulegen. ${ }^{449}$ Während der Hauptverhandlung findet vor Gericht eine umfassende, grundsätzlich selbstständige und mündliche Beweisaufnahme statt. Die Berufsrichter haben hierfür Kenntnis von den vorgelegten Akten (was freilich auch den Inhalt und Umfang der weiteren Beweisaufnahme bestimmen kann), ${ }^{450}$ das Gericht muss aber am Ende über die Schuldfrage nur nach seiner aus dem Inbegriff der Verhandlung geschöpften Überzeugung entscheiden. ${ }^{451}$

Die StA als primäre Ermittlungsbehörde im Vorverfahren entscheidet über die diversen Aspekte der Fortsetzung der Strafverfolgung unabhängig von Polizei und Gericht, oft aber in praktischer Zusammenarbeit mit diesen Behörden. Sie ist, zumindest normativ, nicht als Partei i.e.S. zu betrachten; ${ }^{452}$ vielmehr muss sie schon im Vorverfahren bei der Beweissammlung und Ermittlung der Sachverhaltsumstände objektiv und unter Wahrnehmung der Verteidigungsanträge wirken. Nach der Anklageerhebung und Einreichung des gesammelten Beweismaterials bei Gericht, also nach Beginn der gerichtlichen Untersuchung, vertritt die StA die Anklage. Auch jetzt ist sie jedoch als unabhängige Justizbehörde zur Objektivität bei der Gesetzesanwendung verpflichtet. ${ }^{453}$ Ausnahmsweise darf die StA auch nach dem Beginn der gerichtlichen Untersuchung, soweit diese nicht gestört wird, weiterhin von sich aus Ermittlungen anstellen. ${ }^{454}$

${ }_{448}$ Siehe $\S \S 199-204,223-224$ StPO. Details m.w.N. bei Meyer-Goßner, StPO, $§ 202$ Rn. 1-6.

449 Siehe $\S \S 223-225$ StPO.

$450 \mathrm{Vgl}$. BGHSt 52, 175 (181).

$451 \S \S 243-245,261$ StPO. Zur Frage der Aktenkenntnis siehe unter Teil 2, III.C.1.

452 Vgl. u.a. BVerfGE 63, 45 (63).

453 Siehe insgesamt $\S \S 33,160(2), 161(1), 163 \mathrm{a}(2), 226(1), 243(3), 296(2), 301,365$ StPO; ferner unter Teil 2, III.A.2. Siehe auch m.w.N. Beulke, Strafprozessrecht, Rn. 79; Roxin/Schünemann, Strafverfahrensrecht, § 9 Rn. 1-2, 10-15, § 17 Rn. 5.

${ }^{454}$ Meyer-Goßner, StPO, § 202 Rn. 5; Roxin/Schünemann, Strafverfahrensrecht, § 9 Rn. 4 m.w.N. 
Der Verteidiger hat ein während des Vorverfahrens unter Umständen begrenzbares, nach Abschluss der Ermittlungen jedoch grundsätzlich uneingeschränktes Recht zur Einsicht in die von den Strafverfolgungsbehörden offiziell gesammelten Beweise und zusammengestellten Akten. Ein Beschuldigter, der keinen Verteidiger hat, hat kein umfassendes Akteneinsichtsrecht; ihm können unter bestimmten Voraussetzungen nur die zu einer angemessenen Verteidigung erforderlichen Auskünfte und Abschriften aus den Akten erteilt werden. ${ }^{455}$ Das Recht des Verteidigers zur Akteneinsicht und sein Recht zum grundsätzlich freien Verkehr mit dem Beschuldigten (§ 148 StPO) können, zusammen mit den übrigen Möglichkeiten der Verteidigung in Bezug auf Anwesenheit, Beteiligung und Antragstellung, eventuell eine bessere Vorbereitung der Verteidigungs- und Beweisthesen ermöglichen. Fraglich bleibt allerdings sowohl in der deutschen als auch in anderen westlichen Rechtsordnungen, inwieweit die bestehenden Verteidigungsgarantien „Waffengleichheit“ (im Sinne eher von „Chancengleichheit“ bei der Prozessmitwirkung) ${ }^{456}$ zwischen dem Beschuldigten und den mächtigen, bei den Beweiserhebungen in der Praxis möglicherweise nicht immer objektiv (unvoreingenommen) handelnden staatlichen Strafverfolgungsorganen gewährleisten können. ${ }^{457}$

In normativer Hinsicht sind jedenfalls die Strafverfolgungsbehörden (auch die StA), wie schon erläutert, auch während der Vorbereitung und Durchführung eines Beweisverfahrens ebenso der Objektivität, Gerechtigkeit und Wahrheit verpflichtet.

455 Siehe $\S 147$ StPO. Ferner unter Teil 2, III.C.2.

456 Vgl. BVerfGE 110, 226 (252, 253): „Unter der Geltung des Rechtsstaatsprinzips des Grundgesetzes müssen dem Bürger schon aus Gründen der Chancen- und Waffengleichheit Rechtskundige zur Seite stehen, denen er vertrauen und von denen er erwarten kann, dass sie seine Interessen unabhängig, frei und uneigennützig wahrnehmen. [...] Ein rechtsstaatliches und faires Verfahren fordert 'Waffengleichheit' zwischen den Strafverfolgungsbehörden einerseits und dem Beschuldigten andererseits. Der Beschuldigte hat deshalb ein Recht auf möglichst frühzeitigen und umfassenden Zugang zu Beweismitteln und Ermittlungsergebnissen und auf die Vermittlung der erforderlichen materiell- und prozessrechtlichen Informationen, ohne die er seine Rechte nicht wirkungsvoll wahrnehmen könnte. Die Mitwirkung eines Strafverteidigers, der dem Beschuldigten beratend zur Seite steht und für diesen die ihn entlastenden Umstände zu Gehör bringt, ist für die Herstellung von 'Waffengleichheit', abgesehen von einfach gelagerten Situationen, unentbehrlich." Nach BVerfGE 122, 248 (271-272, 275): „Als ein unverzichtbares Element der Rechtsstaatlichkeit des Strafverfahrens gewährleistet das Recht auf ein faires Verfahren dem Beschuldigten, prozessuale Rechte und Möglichkeiten mit der erforderlichen Sachkunde wahrnehmen und Übergriffe der staatlichen Stellen oder anderer Verfahrensbeteiligter angemessen abwehren zu können. [...] Der Gedanke der Waffengleichheit bezieht sich jedoch in erster Linie auf das Verhältnis der Verteidigung zur Staatsanwaltschaft und gebietet selbst in diesem Verhältnis keinen umfassenden Ausgleich verfahrensspezifischer Unterschiede in der Rollenverteilung (vgl. BVerfGE 63, 45 [67]; 63, 380 [392 f.]). Auf das Verhältnis des Gerichts zur Verteidigung kann der Gedanke der Waffengleichheit nicht übertragen werden."

457 Siehe zur Problematik der Waffengleichheit u.a. Beulke, Strafprozessrecht, Rn. 147149; Roxin/Schünemann, Strafverfahrensrecht, § 11 Rn. 7, § 19 Rn. 1-2; Rzepka, Fairness, S. 186-187; Safferling, NStZ 2004, 181 (183-186). Siehe auch etwa BVerfGE 38, 105 (111). 
Der Verteidiger ist seinerseits zunächst wie jeder Rechtsanwalt dem normativen Leitbild zufolge ein ,,unabhängiges Organ der Rechtspflege“458 und der unabhängige berufene Berater in Rechtsangelegenheiten. Im Strafprozess wird er jedoch konkreter als allseitig unabhängiger „Beistand“ des Beschuldigten, der gleichzeitig „auch den Belangen einer funktionstüchtigen Strafrechtspflege verpflichtet ist“" ${ }^{459}$ angesehen. ${ }^{460}$

Nach herrschender Ansicht und mit Blick auf die bestehenden strafprozessualen Gesetzesvorschriften wirkt also der Verteidiger grundsätzlich einseitig/parteilich (und in vielen Fällen völlig unabhängig) zum effektiven Schutz und zur Förderung der gesetzlich anerkannten Interessen des Beschuldigten; gleichzeitig nimmt er aber öffentliche Aufgaben und Interessen wahr. Ungeachtet des Zeugnisverweigerungsrechts ( $§ 53$ StPO) und der Verschwiegenheitspflicht ( $\$ 203$ StGB) des Verteidigers sind jedenfalls nicht nur strafrechtswidrige Handlungen, sondern auch der offensichtliche Missbrauch der Verteidigungsrechte verboten. Nicht akzeptabel ist es insbesondere, aktiv zu lügen, Beweisquellen zu trüben und Beweismittel zu verfälschen oder den Prozess $\mathrm{zu}$ verschleppen. ${ }^{461}$ Als faktische und rechtsstaatlich geforderte Hauptfunktion des Verteidigers wird die Gewährleistung einer ,möglichst intensiven Gegenwehr ${ }^{\text {*462 }}$ gegen den staatlichen Strafverfolgungsmechanismus anerkannt; der Verteidiger muss insbesondere alle zugunsten des Beschuldigten ,sprechenden Tatsachen und alle diesem gewährten Rechte in bestmöglicher Weise zur Geltung bringen. “463 Dabei stehen die Möglichkeiten des Verteidigers zur effektiven Ausübung der gesetzlichen Verteidigungs- und Mitwirkungsrechte, zur Durchführung eigener (privater) Ermittlungen und zum unmittelbaren Kontakt mit dem Beschuldigten (und eventuell mit anderen Beteiligten) im Vordergrund. Diese Möglichkeiten können letztendlich unter anderem der besseren Aufklärung des Geschehens und der vorbereitenden Beratung hinsichtlich der Verteidigungsstrategien dienen. ${ }^{464}$

${ }^{458}$ Zum Verteidiger als Organ der Rechtspflege auch in rechtshistorischer Hinsicht Beulke, Der Verteidiger, S. 164-182.

459 Roxin/Schünemann, Strafverfahrensrecht, § 19 Rn. 3.

460 Siehe $\S \S 1,3$ BRAO; 137 StPO; BGHSt 12, 367 (369); BGHSt 39, 310 (313). Siehe auch BVerfGE 110, 226 (252-254).

461 Ausführlich (auch zu den verschiedenen Theorien) mit Gesetzes- und Rechtsprechungsverweisen Beulke, Strafprozessrecht, Rn. 147-152a, 164, 175-176; Roxin/Schünemann, Strafverfahrensrecht, $\S 19$ Rn. 3-16, 61-62.

462 Beulke, Strafprozessrecht, Rn. 150.

463 Roxin/Schünemann, Strafverfahrensrecht, § 19 Rn. 9.

464 Siehe einen Überblick bei Beulke, Strafprozessrecht, Rn. 147-149, 153-162, 176; Roxin/Schünemann, Strafverfahrensrecht, § 18 Rn. 3-17, § 19 Rn. 60-79. Praxisorientierte Ausführungen und taktische Überlegungen bei Burhoff, Handbuch, Rn. 3424-3446. 


\section{b) Speziell zum aussagenbasierten Beweis}

aa) Die Beweismittel und der zeugenbasierte Beweis

\section{- Bedeutung des Zeugenbeweises}

Die im Strafprozessrecht geregelten und zur Sachverhaltsaufklärung im Rahmen des Strengbeweisverfahrens verwendbaren Beweismittel sind der Zeugenbeweis, der Sachverständigenbeweis, der Augenscheinsbeweis und der Urkundenbeweis. ${ }^{465}$ Die materiellen Elemente und Zulässigkeitsvoraussetzungen des Urkunden- und des Augenscheinsbeweises sind nicht besonders ausführlich geregelt. ${ }^{466}$ Auch in Bezug auf die Analyse der strukturellen Aspekte der Beweisführung, die hier von Interesse sind, haben diese beiden Arten von Beweismitteln keine besondere ,diagnostische“ Aussagekraft: Der Umfang des Urkundenbeweises, der immer zulässig ist, soweit ihn das Gesetz nicht ausdrücklich ausschließt, wird nach den allgemeinen Regeln der richterlichen Aufklärungspflicht und des Beweisantragsrechts (§ 244 StPO) bestimmt. ${ }^{467}$ Der eigentliche Urkundenbeweis findet regelmäßig durch die Verlesung von Schriftstücken in der Hauptverhandlung statt, auch wenn nach $\S 249(2)$ StPO unter Umständen von der Verlesung abgesehen werden kann, insbesondere wenn die Richter vom Wortlaut der Urkunde schon Kenntnis genommen haben. ${ }^{468}$ Die Einnahme des Augenscheins kann ebenso gemäß den Grundsätzen der Aufklärungspflicht nach Ermessen des Gerichts in jeder Verfahrenslage angeordnet werden; ${ }^{469}$ ein diesbezüglicher Beweisantrag kann nach $\S 244(5)$ StPO abgelehnt werden, ,wenn der Augenschein nach dem pflichtgemäßen Ermessen des Gerichts zur Erforschung der Wahrheit nicht erforderlich ist.“ Ein Augenschein kann im Vorverfahren, vor Gericht in der Hauptverhandlung sowie auch durch einen beauftragten oder ersuchten Richter zur Vorbereitung oder während der Hauptverhandlung eingenommen werden; die zentralen Verfahrensbeteiligten haben hierbei meistens ein Anwesenheitsrecht. ${ }^{470}$

465 Siehe insb. §§ 48-71, 72-85, 86-93, 239-257 StPO. Zur Unterscheidung zwischen Streng- und Freibeweisverfahren sowie zu den übrigen Beweisgrundsätzen siehe bereits unter Teil 2, III.A.3.

466 Siehe zum Urkundenbeweis insb. § 249 StPO; BGHSt 39, 305 (306). Zum Augenscheinsbeweis insb. $\S \S 81 \mathrm{a}, 81 \mathrm{c}, 86-91$ StPO; BGHSt 14, 339 (341); BGHSt 18, 51 (53). Zur Abgrenzung von Urkunden- und Augenscheinsbeweis etwa BayObLG, NStZ 2002, 388 (388-389).

467 Vgl. BGHSt 52, 175 (179-181).

468 Zusammengefasst zum Urkundenbeweis Beulke, Strafprozessrecht, Rn. 203. Ausführlich Eisenberg, Beweisrecht, Rn. 2003-2219. Zum „Selbstleseverfahren“ nach $\S 249$ (2) StPO als „Beweisaufnahme short to go" Meyer-Lohkamp, StV 2014, 121 (121123).

469 Beulke, Strafprozessrecht, Rn. 204; Eisenberg, Beweisrecht, Rn. 2220, 2227-2238.

470 Siehe $\S \S 86,162,168 d, 202,224,225,249(1)$ StPO; RGSt 47, 100 (104). Ausführlich zum Augenscheinsbeweis Eisenberg, Beweisrecht, Rn. 2220-2323. 
Darüber hinaus bleibt die Zeugenaussage, trotz ihres in vielfacher Hinsicht bezweifelten Beweiswerts, die meistdiskutierte Beweisform in Lehre und Rechtsprechung. ${ }^{471}$ Ein Zeuge im Sinne der StPO ist nach der Rechtsprechung, wer in einer Strafsache, die sich nicht gegen ihn richtet (,ohne Partei zu sein“), ,seine Wahrnehmungen über Tatsachen durch Aussage kundgeben soll.“472 Die StPO beinhaltet eine große Anzahl von Vorschriften zur materiellen Regulierung des Zeugenbeweises. Die relevanten Problemkreise betreffen insbesondere die Zeugeneigenschaft, die Auskunfts- und Zeugnisverweigerungsrechte, die übrigen Rechte und Pflichten der Zeugen, den Zeugenschutz i.V.m. den technologischen Entwicklungen im Bereich der Beweisaufnahme sowie die abschließende Würdigung der Zeugenaussagen. ${ }^{473}$ Die prozessuale Praxis zum Zeugenbeweis kann aber auch einen anschaulichen und nützlichen Anknüpfungspunkt für die Auseinandersetzung mit den Ausgestaltungsformen und der Rollenverteilung innerhalb der hauptgerichtlichen Beweisführung bieten.

\section{- Vernehmungen im Vor- und Hauptverfahren}

Zunächst ist jeder Mensch zeugnisfähig. ${ }^{474}$ Jedermann kann zum Erscheinen und zur (der Wahrheitspflicht unterworfenen) Aussage vor der StA, dem Ermittlungsrichter, dem beauftragten oder ersuchten Richter und dem Gericht nach den Grundsätzen der Amtsaufklärungspflicht und des Beweisantragssystems verbindlich geladen werden. ${ }^{475}$ Ausnahmen von der Aussagepflicht können sich nur aufgrund gesetzlich bestimmter Einschränkungen (etwa bei Richtern und Beamten) oder aus Zeugnisverweigerungsrechten ergeben. ${ }^{476}$

471 Siehe m.w.N. etwa Kühne, Strafprozessrecht, Rn. 756, 851-855; Roxin/Schünemann, Strafverfahrensrecht, § 26 Rn. 1. Ausführlicher Schünemann, FS für Meyer-Gossner, insb. S. 385-389. Siehe auch Pfordte, FS für Müller, S. 551-554.

472 RGSt 52, 289 (289); vgl. auch BGH, NJW 1969, 1219 (1220), Eisenberg, Beweisrecht, Rn. 1000. Nach Roxin/Schünemann, Strafverfahrensrecht, § 26 Rn. 1, ist jemand als Zeuge zu betrachten, nur soweit er nicht durch eine andersartige Verfahrensrolle von dieser Position ausgeschlossen ist. Zur Unterscheidung zwischen materiellem und formellem Zeugenbegriff siehe Zacharias, Der gefährdete Zeuge, S. 30: „Materiell ist eine Person Zeuge, wenn sie Tatsachen wahrgenommen hat und darüber berichten kann. Zeuge im formellen Sinne ist dagegen eine Person, deren Wahrnehmungen über Tatsachen nach den strafprozessualen Vorschriften über den Zeugenbeweis in das Verfahren eingeführt werden sollen."

473 Siehe insb. $\S \S 22$ Nr. 5, 48-71, 74(1), 161a, 163(3), 168e, 223, 241a, 247, 247a, 251, 255a, 397(1), 397a, 406f, 406g StPO. Für einen Überblick siehe auch Beulke, Strafprozessrecht, Rn. 181-196a. Ausführlicher Kühne, Strafprozessrecht, Rn. 795-855. Vertiefend Eisenberg, Beweisrecht, Rn. 1000-1488.

474 Siehe weitere Differenzierungen bei Kühne, Strafprozessrecht, Rn. 802-809.

475 Siehe $\S \S 48,51,57,64,70,160,161 \mathrm{a}, 162,163 \mathrm{a}(2), 166,201-202,214,219,220$, 223, 244-245 StPO. Zusammengefasst zu den Zeugenpflichten Beulke, Strafprozessrecht, Rn. 181, 187-189. Zur Problematik der Zeugenladungen siehe unter Teil 2, III.B.2.

476 Siehe Details und Verweise u.a. bei Beulke, Strafprozessrecht, Rn. 190-195. 
Die im Vorverfahren bzw. außerhalb der Hauptverhandlung (eventuell mit elektronischen Mitteln) aufgezeichneten Zeugenvernehmungen, die durch die Strafverfolgungsbehörden und die Richter erfolgen, werden Bestandteil der Verfahrensakten, von denen das Gericht und der Verteidiger im Voraus umfassende Kenntnis erhalten. $^{477}$ Das Gericht muss im Rahmen seiner Aufklärungspflicht und unter Wahrnehmung der Anträge der Verfahrensbeteiligten jede Tatsache, die nach den vorgelegten Akten und den darin beinhalteten Aussagen als entscheidungserheblich erscheint, im Hauptverfahren durch die (erneute) Vernehmung der betreffenden Zeugen prüfen. ${ }^{478}$ Somit müssen alle zentralen Zeugen grundsätzlich persönlich vor Gericht im Hauptverfahren Auskunft geben.

Ausnahmsweise können anstatt einer Vernehmung vor Gericht unter Umständen, insbesondere im Fall von schutzbedürftigen minderjährigen Zeugen und von Zeugen, die in der Hauptverhandlung faktisch nicht vernommen werden können, bestimmte frühere - auf Bild-Ton-Träger oder schriftlich aufgezeichnete - Vernehmungen vorgeführt bzw. verlesen werden. ${ }^{479}$ Zumindest im Fall der Vorführung der Bild-Ton-Aufzeichnung der richterlichen Vernehmung eines minderjährigen Zeugen ist jedoch eine ergänzende Vernehmung des Zeugen in der Hauptverhandlung zulässig; eine solche ergänzende Vernehmung kann auch unter Anwendung von Zeugenschutzmaßnahmen (etwa: Aufenthalt des Zeugen an einem anderen Ort und zeitgleiche elektronische Übertragung der Vernehmung nach § 247a StPO) erfolgen. ${ }^{480}$

\section{- Der Angeklagte als Beweisperson}

Der Angeklagte ist kein Zeuge im technischen Sinne. Er kann jedoch ungeachtet seiner Aussagefreiheit insbesondere im Rahmen seiner sachlichen Vernehmung im Hauptverfahren ein zentrales Beweismittel im weiteren (materiellen) Sinne darstellen. ${ }^{481}$

477 Siehe insb. $\S \S 58 \mathrm{a}, 147,163,168-168 \mathrm{~b}, 199(2), 202,223-224,245(1)$ und vgl. $\S \S 247 \mathrm{a}, 251 \mathrm{StPO}$. Siehe auch unter Teil 2, III.B.1.a) m.w.N.

$478 \S \S 244-245,250,261$ StPO. Vgl. BGHSt 52, 175 (181).

479 Siehe $\S \S 58 \mathrm{a}, 223,251,255 \mathrm{a}$ StPO.

$480 \mathrm{Zu}$ den vorgerichtlichen Bild-Ton-Aufzeichnungen Meyer-Goßner, StPO, § 58a Rn. 1-15, § 255a Rn. 1-13. Für einen allgemeinen Überblick der modernen Zeugenschutzregelungen siehe Beulke, Strafprozessrecht, Rn. 196a, 425-430m.

$481 \S \S 136(2), 243(5), 244(1), 261$ StPO. BGHSt 52, 175 (178). Beulke, Strafprozessrecht, Rn. 179. Ferner zum Beschuldigten als Beweismittel und auch zu den möglichen Schlussfolgerungen aus seinem Schweigen Roxin/Schünemann, Strafverfahrensrecht, § 25 Rn. 1-35. 
bb) Die „Zusammenstellung“ des zeugenbasierten Beweises

\section{- Subjekt und Objekt der Beweisführung}

Alle Personen, deren Aussage im Rahmen der Amtsaufklärungspflicht ${ }^{482}$ und nach den Beweisantragsregeln ${ }^{483}$ als fallrelevant und für die Schuldfrage als entscheidend zu betrachten ist, müssen grundsätzlich im Hauptverfahren öffentlich, persönlich und mündlich de novo (wenn auch eventuell unter Berücksichtigung früherer Vernehmungen) ${ }^{484}$ Auskunft geben. ${ }^{485}$ Die Vernehmung sämtlicher Zeugen in der Hauptverhandlung findet im Regelfall durch den Vorsitzenden Richter und unter Mitwirkung vor allem der Verteidigung und der Anklage statt; zumindest in normativer Hinsicht existiert dabei keine Unterscheidung zwischen Belastungsund Entlastungszeugen. ${ }^{486}$

Nach § 223 StPO kann jedoch das Gericht zur Vorbereitung der Hauptverhandlung die Vernehmung eines Zeugen (wie auch eines Sachverständigen) durch einen beauftragten oder ersuchten Richter anordnen, wenn dem Erscheinen des Zeugen in der Hauptverhandlung für eine längere oder ungewisse Zeit Krankheit oder Gebrechlichkeit oder andere nicht zu beseitigende Hindernisse entgegenstehen sowie wenn dem Zeugen das Erscheinen wegen großer Entfernung nicht zugemutet werden kann. ${ }^{487}$ Die StA, der Angeklagte und der Verteidiger haben dabei in der Regel ein Benachrichtigungs- und Anwesenheitsrecht; das aufgenommene Vernehmungsprotokoll ist in jedem Fall der StA und dem Verteidiger vorzulegen (§ 224 StPO). Der vernehmende Richter entscheidet über die Zulassung von Fragen seitens der Verfahrensbeteiligten; ein Verteidiger, der bei einer solchen außergerichtlichen Vernehmung nicht anwesend sein kann, darf seine Fragen in schriftlicher Form einreichen. ${ }^{488}$ Eine kommissarische Vernehmung kann darüber hinaus sowohl während des Zwischenverfahrens als auch im Rahmen einer schon laufenden Hauptverhandlung angeordnet werden. Die Anordnung kann von Amts wegen oder auf Antrag der StA, der Verteidigung oder der anderen Verfahrensbeteiligten oder sogar auf Antrag des geladenen Zeugen erfolgen. ${ }^{489}$

\footnotetext{
${ }^{482}$ Hierzu bereits unter Teil 2, III.A.3.

483 Siehe insb. unter Teil 2, III.B.2.

484 Siehe $\S 253$ StPO.

485 Vgl. etwa BGHSt 29, 99 (104).

486 Zur Beweisaufnahme im Hauptverfahren siehe unter Teil 2, III.D.2.

487 Details bei Meyer-Goßner, StPO, § 223 Rn. 1-9.

488 Meyer-Goßner, StPO, § 223 Rn. 18-22 m.w.N.

489 Meyer-Goßner, StPO, § 223 Rn. 10-11 m.w.N.
} 


\section{- Direkter und indirekter Beweis}

Grundsätzlich ist aber nach $\S 250$ StPO, soweit der Beweis einer Tatsache auf der Wahrnehmung einer Person beruht, diese Person in der Hauptverhandlung zu vernehmen. Auch der sogenannte Leumundszeuge wird hierbei wie ein normaler Zeuge behandelt. ${ }^{490}$ Ein Zeuge darf ferner nicht nur über die für das Geschehen unmittelbar relevanten Tatsachen berichten, von denen er persönliche Kenntnis hat; er darf auch über eine Wahrnehmung aussagen, welche die Auskunft einer anderen Person in Bezug auf das Geschehen betrifft. Auch die sogenannten Zeugen vom Hörensagen können somit im deutschen Strafverfahren zur Aussage geladen werden. ${ }^{491}$ Ein solcher (in diesem Sinne eigentlich indirekter) Beweis ist also nicht ausgeschlossen. Er stellt aber nach den Grundsätzen der materiellen Unmittelbarkeit und der richterlichen Aufklärungspflicht sicherlich nicht das bevorzugte Mittel für die Sachverhaltsaufklärung dar und ist meistens auch im Rahmen der Beweiswürdigung als geringwertig zu betrachten. ${ }^{492}$

An dieser Stelle können der materielle Gehalt des Unmittelbarkeitsgrundsatzes, seine Durchbrechungen sowie die entsprechenden Konstruktionen der Rechtsprechung hinsichtlich der Würdigung mittelbarer Beweise nicht tiefer gehend analysiert werden. ${ }^{493}$ Bestimmte Aspekte der Unmittelbarkeit der Beweisaufnahme, welche die Zusammenstellung des aussagenbasierten Beweises betreffen und große Bedeutung für die Verfahrenspraxis haben, sind in $\S \S 250-251$ StPO ausdrücklich geregelt: Zunächst gilt hierbei als Grundsatz, dass die persönliche Vernehmung eines Zeugen ,nicht durch Verlesung des über eine frühere Vernehmung aufgenommenen Protokolls oder einer schriftlichen Erklärung ersetzt werden“ darf (§ $250 \mathrm{StPO}$ ). Es ist jedoch ausnahmsweise im Interesse „der Wahrheitsfindung sowie der Erleichterung und Beschleunigung des Verfahrens "4944 vorgesehen, dass in konkreten Fällen die Vernehmung eines Zeugen (sowie eines Sachverständigen oder Mitbeschuldigten) vor Gericht ,durch die Verlesung einer Niederschrift über eine frühere Vernehmung oder einer Urkunde, die eine von ihm stammende schriftliche Erklärung enthält, ersetzt werden“" $\operatorname{kann}(\S 251 \mathrm{StPO}) .{ }^{495}$

\footnotetext{
490 Beulke, Strafprozessrecht, Rn. 181; Kühne, Strafprozessrecht, Rn. 797.

491 Dazu (und auch zur V-Mann-Problematik) Beulke, Strafprozessrecht, Rn. 181, 422429.

492 Siehe Beulke, Strafprozessrecht, Rn. 422, mit Rechtsprechungshinweisen; Kühne, Strafprozessrecht, Rn. 915.

${ }^{493} \mathrm{Zu}$ den Grundsätzen und diversen Aspekten der persönlichen Vernehmung, der Mündlichkeit und der Unmittelbarkeit u.a. Eisenberg, Beweisrecht, Rn. 63-87, 10271054b, 2076-2205. Siehe auch weitere Verweise unter Teil 2, III.A.3.

494 BGHSt 46, 73 (77); in BGHSt 10, 186 (189), wird bestimmt: „Die Vorschrift dient einmal der Verhütung des Beweisverlustes und ferner der Ermöglichung einer praktischen und zügigen Durchführung des Strafverfahrens.“

495 Für Einzelheiten mit weiteren Rechtsprechungsverweisen Meyer-Goßner, StPO, $\S 251 \mathrm{Rn} .1-37$.
} 
Eine solche Verlesung kann in Bezug auf sämtliche früheren Vernehmungen und auf schriftliche Erklärungen aber nur in den in $§ 251(1)$ StPO ausdrücklich bestimmten Fällen erfolgen: Dies kann erstens geschehen, wenn „der Angeklagte einen Verteidiger hat und der Staatsanwalt, der Verteidiger und der Angeklagte ${ }^{496}$ damit einverstanden sind“ - wenngleich dadurch die Aufklärungspflicht des Gerichts unangetastet bleibt, sodass auch im Fall einer solchen einvernehmlichen Verlesung die richterliche Anordnung einer persönlichen Zeugenvernehmung (etwa aus Klarstellungsgründen) möglich bzw. geboten sein kann. ${ }^{497}$ Die Verlesung von protokollierten Aussagen und schriftlichen Äußerungen ist zweitens möglich, wenn der Zeuge inzwischen ,,verstorben ist oder aus einem anderen Grunde in absehbarer Zeit gerichtlich nicht vernommen werden kann." Drittens kann § 251(1) StPO Anwendung finden, soweit ,die Niederschrift oder Urkunde das Vorliegen oder die Höhe eines Vermögensschadens betrifft.“

Des Weiteren ist nach $\S 251(2)$ StPO die Ersetzung der mündlichen Aussage vor Gericht durch Verlesung der Niederschrift über eine frühere richterliche (etwa ermittlungsrichterliche, zwischenverfahrensrichterliche oder kommissarische) $)^{498}$ Vernehmung zusätzlich in folgenden Fällen möglich: wenn dem Erscheinen des Zeugen in der Hauptverhandlung ,für eine längere oder ungewisse Zeit Krankheit, Gebrechlichkeit oder andere nicht zu beseitigende Hindernisse entgegenstehen“, wenn dem Zeugen ,das Erscheinen in der Hauptverhandlung wegen großer Entfernung unter Berücksichtigung der Bedeutung seiner Aussage nicht zugemutet werden kann“ oder wenn ,der Staatsanwalt, der Verteidiger und der Angeklagte mit der Verlesung einverstanden sind,“ wobei das Einverständnis auch vor dem Beginn der Hauptverhandlung erklärt werden kann. ${ }^{499}$ In allen diesen Fällen beschließt das Gericht, ob die Verlesung angeordnet wird, wobei der Grund der Verlesung bekanntzugeben ist (§ 251(4) StPO). ${ }^{500}$ Soweit die Verlesung lediglich zur Vorbereitung der Entscheidung darüber dienen soll, „ob die Ladung und Vernehmung einer Person erfolgen sollen, so dürfen Vernehmungsniederschriften, Urkunden und andere als Beweismittel dienende Schriftstücke auch sonst verlesen werden“" (§ 251(3) StPO); diese Verlesung im Freibeweis wird vom Vorsitzenden im Rahmen der Sachleitung angeordnet. ${ }^{501}$

\footnotetext{
496 Siehe auch $\S \S 234 \mathrm{a}, 247$ StPO.

497 BGHSt 10, 186 (188-192); BGH, NStZ 1988, 37 (38). Meyer-Goßner, StPO, § 251 Rn. 7-8, 24-28 m.w.N. Ferner LR-StPO-Sander/Cirener, § 251 Rn. 17-26.

498 Siehe Meyer-Goßner, StPO, § 251 Rn. 30 mit weiteren Beispielen und Nachweisen.

499 Meyer-Goßner, StPO, § 251 Rn. 25-28 m.w.N.

500 Dazu Meyer-Goßner, StPO, § 251 Rn. 40-41.

501 Meyer-Goßner, StPO, § 251 Rn. 37.
} 
cc) Die „Vorbereitung“ des zeugenbasierten Beweises

Hinsichtlich der Problematik der außergerichtlichen Vorbereitung bzw. Beeinflussung des Zeugen mit Blick auf die Ausformung seiner späteren Aussage vor Gericht ist an dieser Stelle nur auf die normative Lage hinzuweisen - wobei diese, wie es auch sonst in der Praxis häufig der Fall ist, nicht immer mit den eigentlichen Verhaltensweisen hinter verschlossener Tür übereinstimmt. Von Bedeutung ist hierbei vor allem die bereits angesprochene, gesetzlich geforderte Objektivität der staatlichen Ermittlungs- und Vernehmungsbehörden (einschließlich der StA) sowie die Nicht-Anerkennung der Existenz von Parteien im engeren Sinne und von ,,parteilichen“ Zeugen im deutschen Strafverfahrenssystem. ${ }^{502}$ Wie im Folgenden ausführlicher zu sehen ist, hat der Richter bei der Ladung von Zeugen und bei ihrer Vernehmung die wichtigste Rolle. Die StA und die Verteidigung können allerdings selbst Zeugen benennen und insbesondere ihre Ladung vom Gericht verlangen oder sie unmittelbar laden und ihre gerichtliche Vernehmung beantragen. ${ }^{503}$

In den Verfahrensstadien vor Beginn der Hauptverhandlung finden die Kontakte zwischen den Strafverfolgungs- bzw. Justizorganen und sämtlichen Personen, deren Aussage fallrelevant ist, grundsätzlich im Wege von offiziellen Vernehmungen statt, die anschließend protokolliert und Teil der Verfahrensakte werden. Diverse (wenn auch nicht immer umfassende) ${ }^{504}$ Anwesenheits- und Mitwirkungsmöglichkeiten der Verteidigung können eventuell zur möglichst objektiven Durchführung der Vernehmungen beitragen und die informelle einseitige Beeinflussung der Zeugen verhindern. ${ }^{505}$ Allerdings ist während des ganzen Strafverfolgungsvorgangs die Möglichkeit einseitiger Beeinflussungen keinesfalls ausgeschlossen: Dies ist insbesondere möglich im Rahmen von informellen außergerichtlichen Gesprächen bzw. internen Anweisungen zwischen Polizei-/Ermittlungsbeamten, die als Zeugen auftreten, und ihren Kollegen, die Kenntnis des Sachverhalts haben; oder etwa auch im Rahmen von Zeugenschutzprogrammen und den sich dabei entwickelnden Vertrauens- bzw. Austauschverhältnissen; sowie im Rahmen von vorgerichtlichen Kontakten zwischen verschiedenen Personen, die aus irgendwelchen (z.B. faktischen oder dienstlichen) Gründen bzw. aufgrund gemeinsamer Interessen in Verbindung zueinander stehen, was zur Ausformung inhaltlich einheitlicher Aussagen führen kann. ${ }^{506}$ Die sich daraus ergebenden Gefahren hinsichtlich der Glaubhaftigkeit der

502 Vgl. auch Ambos, FS für Volk, S. 8-9.

503 Siehe insb. $\S$ 200, 214, 219, 220, 222, 239, 245 StPO.

504 Hierzu Roxin/Schünemann, Strafverfahrensrecht, § 19 Rn. 64-65.

505 Siehe zum relevanten Regelungskomplex bezüglich der außergerichtlichen Vernehmungen insb. §§ 58-58a, 69, 147, 160, 161a-163, 168-168c, 168e, 223-224 StPO.

506 Mehr dazu m.w.N. Eisenberg, Beweisrecht, Rn. 1337-1337a, 1381-1381a, 1455$1456,1485-1486$ a. 
vorgebrachten Beweise müssen bei der gerichtlichen Prüfung sowie der letztendlichen Würdigung der Aussagen berücksichtigt werden.

Der Verteidiger kann/muss seinerseits im Rahmen der rechtmäßigen Ausübung seiner Aufgaben nach möglichen Entlastungszeugen suchen und kann außergerichtlich mit Zeugen Kontakt aufnehmen. Es gibt keine generellen kategorischen Regelungen darüber, was insbesondere mit Blick auf die Vorbereitung der späteren Zeugenaussage Inhalt eines solchen Gesprächs sein darf. ${ }^{507}$ Der Verteidiger ist sogar berechtigt, Zeugen auf ihr Zeugnisverweigerungsrecht hinzuweisen und in Bezug auf die Ausübung dieses Rechts zu beraten. ${ }^{508}$ Er darf aber nicht auf die freie Willensbildung der Zeugen einwirken, sie nicht zu falschen Aussagen veranlassen und allgemein nicht zur Verfälschung von Beweismitteln beitragen; der Verteidiger darf also ,keine Beweisquellen trüben. “509 Der Bundesgerichtshof hat die betreffende Abgrenzung zwischen erlaubtem und unerlaubtem Verhalten des Verteidigers wie folgt zusammengefasst: ${ }^{510}$

Die Stellung als Verteidiger in einem Strafprozeß und das damit verbundene Spannungsverhältnis zwischen Organstellung und Beistandsfunktion erfordert eine besondere Abgrenzung zwischen erlaubtem und unerlaubtem Verhalten [...]. [...] Der Verteidiger darf grundsätzlich alles tun, was in gesetzlich nicht zu beanstandender Weise seinem Mandanten nützt [...]. Er hat die Aufgabe, zum Finden einer sachgerechten Entscheidung beizutragen und dabei das Gericht vor Fehlentscheidungen zu Lasten seines Mandanten zu bewahren [...]. Zu seinen besonderen Aufgaben gehört es auch, auf die Einhaltung der Verfahrensgarantien zu achten [...]. Allerdings muß er sich bei seinem Vorgehen auf verfahrensrechtlich erlaubte Mittel beschränken, und er muß sich jeder bewußten Verdunkelung des Sachverhalts und jeder sachwidrigen Erschwerung der Strafverfolgung enthalten [...]. Ihm ist es insbesondere untersagt, durch aktive Verdunkelung und Verzerrung des Sachverhalts die Wahrheitserforschung zu erschweren, insbesondere Beweisquellen zu verfälschen [...]. [...] Soweit es [...] um Zeugenaussagen geht, darf der Verteidiger zwar nicht wissentlich falsche Tatsachen behaupten und hierfür Zeugen benennen [...]. In den von der Rechtsprechung aufgestellten Grenzen [...] ist er verpflichtet, darauf zu achten, daß er nicht Zeugen benennt, von denen er erkennt, daß sie eine Falschaussage machen werden. Auch darf er einen Zeugen nicht absichtlich in einer vorsätzlichen Falschaussage bestärken [...]. Er kann eigene Ermittlungen führen und insbesondere Zeugen auch außerhalb der Hauptverhandlung befragen [...]. Hat er lediglich Zweifel an der Richtigkeit einer Zeugenaussage, die seinen Mandanten entlasten könnte, so ist es ihm nicht verwehrt, den Zeugen zu benennen; er wird dazu regelmäßig sogar verpflichtet sein. Andernfalls würde er in Kauf nehmen, ein möglicherweise zuverlässiges, entlastendes Beweismittel zu unterdrücken [...].

507 Siehe ferner praxisorientiert Burhoff, Handbuch, Rn. 3424-3427.

508 BGH, NJW 1957, 1808 (1809).

509 Roxin/Schünemann, Strafverfahrensrecht, § 19 Rn. 63. Siehe auch Beulke, Strafprozessrecht, Rn. 174-176 m.w.N.

510 BGHSt 46, 53 (54-56) mit weiteren Verweisen, die an dieser Stelle ausgelassen wurden. Siehe auch BGHSt 29, 99 (insb. 106-107). 
dd) Zum Expertenbeweis

- Expertenbegriff

Als Zeuge wird im deutschen Strafverfahrensrecht, wie schon gesehen, eine Person betrachtet, die ihre Wahrnehmungen über Tatsachen durch Aussage kundgeben soll. Der Zeuge darf somit grundsätzlich keine eigenen Meinungen und Werturteile, die keine Tatsachen darstellen, zum Geschehen äußern. ${ }^{511}$ Aufgabe des Sachverständigen ist es dagegen, ,vorliegende Tatsachen auf Grund seiner besonderen Fachkenntnis zu bewerten. “512 Der Sachverständige wird aufgrund seiner besonderen Kenntnisse oder speziellen Fähigkeiten vor allem mit der Feststellung und/oder Beurteilung (Bewertung) von konkreten sachverhaltsrelevanten Tatsachen bzw. mit der Mitteilung von Erfahrungssätzen beauftragt; dies geschieht in solchen Fällen, in denen der Richter wegen mangelnder Fachkenntnisse/Fähigkeiten ohne Hilfe keine oder nur unvollständige Feststellungen machen bzw. Schlüsse ziehen kann. ${ }^{513}$ Nicht zuletzt wegen der enormen naturwissenschaftlichen und technologischen Entwicklungen der Moderne ist in den letzten Jahrzehnten ein zunehmender Einsatz von Sachverständigen im Strafverfahren zu beobachten. ${ }^{514}$ Darüber hinaus kann auch für die vorbereitenden Ermittlungstätigkeiten der Verteidigung die Anfertigung von privat bestellten Sachverständigengutachten von Wert sein. ${ }^{515}$

\section{- Einführung des Beweises}

Die Anordnung des Sachverständigenbeweises ist heute nach wie vor primär eine zentral-amtliche bzw. gerichtliche Angelegenheit. Konkreter: ein für das gerichtliche Verfahren hinzuzuziehender Sachverständiger muss vom Richter im

511 Ausgenommen davon sind die einfachen, selbstverständlichen Schlussfolgerungen (,urteilenden Tätigkeiten“), die eine Person mit normaler Lebenserfahrung gleichzeitig mit der sinnlichen Wahrnehmung der Tatsachen zieht und die notwendigerweise an der Entstehung des vollständigen Bildes, das sich die Person von dem Vorkommnis macht, mitwirken, wobei dann solche Bekundungen über Vorgänge, wie z.B. ,ob eine Person sinnlos betrunken gewesen, ob ein Fuhrmann schnell gefahren ist [...], unbedenklich dem Gebiete des Zeugenbeweises zuzurechnen" sind, so RGSt 37, 371 (371-372). Siehe auch Beulke, Strafprozessrecht, Rn. 181. Detaillierter zu den Schwierigkeiten einer klaren Trennung zwischen sinnlicher Wahrnehmung und Bewertung von Tatsachen Kühne, Strafprozessrecht, Rn. 795-798.

512 Kühne, Strafprozessrecht, Rn. 795. Siehe für die technischen Details zum Sachverständigenbeweis (zum Teil i.Z.m. relevanten Augenscheinsvorschriften) insb. $\S \S 72-93$ StPO. Zum „sachverständigen Zeugen“ siehe $\S 85$ StPO und dazu u.a. KK-StPO-Senge, $\S 85$ Rn. 1-4.

513 Siehe u.a. Beulke, Strafprozessrecht, Rn. 197; ferner Toepel, Grundstrukturen, S. 5761. Ausführlich zu den materiellen Definitionen und Voraussetzungen sowie zu allgemeinen und speziellen Gestaltungen des Sachverständigenbeweises u.a. Eisenberg, Beweisrecht, Rn. 1500-1999.

514 U.a. Zwiehoff, Recht, S. 1-2.

515 Roxin/Schünemann, Strafverfahrensrecht, § 19 Rn. 63. 
Rahmen seines Beurteilungsspielraums ${ }^{516}$ als sachkundig in Bezug auf den jeweiligen Fall eingestuft, ausgewählt und beauftragt werden (§ 73 StPO). Ein dergestalt ernannter Sachverständiger ist dem StA und dem Beschuldigten (als zur Ablehnung berechtigten Personen) namhaft zu machen, wenn nicht besondere Umstände entgegenstehen; der Sachverständige kann aus denselben Gründen, die zur Ablehnung eines Richters berechtigen, abgelehnt werden (§ 74 StPO) ${ }^{517}$ Der Sachverständige muss sein Gutachten im Vor- und Zwischenverfahren und vor dem Beginn der Hauptverhandlung schriftlich oder mündlich erstatten, in der maßgebenden Hauptverhandlung jedoch in der Regel in eigener Person mündlich vortragen. ${ }^{518}$

Das Gericht ist grundsätzlich nicht verpflichtet, einen Sachverständigen zu bestellen, sondern hat hierbei meistens einen Beurteilungsspielraum; dieser betrifft insbesondere die spezifischen Schwierigkeiten des Einzelfalles und die Einschätzung, ob die Richter selbst in Bezug auf die Feststellung und Beurteilung der konkreten Fallumstände ausreichend sachkundig sind. ${ }^{519}$ Gleichwohl kann vor allem hinsichtlich besonders streitiger Sachverhaltsumstände (wie z.B. bei Sexualdelikten oder bei der Beurteilung der Aussage kindlicher Zeugen) die Einsetzung eines Sachverständigen nach den Grundsätzen der Amtsaufklärungspflicht geboten sein. ${ }^{520}$ Die Verfahrensbeteiligten können ihrerseits Beweisanträge auf (Ladung und) Vernehmung eines Sachverständigen stellen. ${ }^{521}$ Derartige Anträge können allerdings, abgesehen von den in $§ 244(3)$ StPO allgemein vorgesehenen Gründen, auch abgelehnt werden, wenn das Gericht selbst die erforderliche Sachkunde besitzt; zusätzlich kann in der Regel der Antrag auf Anhörung eines weiteren Sachverständigen vom Gericht abgelehnt werden, wenn durch das frühere Gutachten das Gegenteil der behaupteten Tatsache bereits erwiesen ist. ${ }^{522}$

516 Beulke, Strafprozessrecht, Rn. 199 m.w.N.

517 Zur Ablehnung eines Sachverständigen u.a. Eisenberg, Beweisrecht, Rn. 1549-1565.

518 Siehe, auch zu den relevanten Durchbrechungen des Unmittelbarkeitsgrundsatzes, $\S \S 82,202,251,256$ StPO. Eisenberg, Beweisrecht, Rn. 1503-1505; Meyer-Goßner, StPO, § 82 Rn. 1-3 m.w.N.

519 Beulke, Strafprozessrecht, Rn. 199. Ferner mit Beispielen Eisenberg, Beweisrecht, Rn. 1518-1523. Zur obligatorischen Mitwirkung eines Sachverständigen in konkreten Fällen siehe insb. §§ 80a, 231a(3), 246a, 415(2, 5) StPO.

520 Beulke, Strafprozessrecht, Rn. 199 mit Rechtsprechungsverweisen.

$521 \S \S 214,219,244-245$ StPO.

522 Konkreter wird in $\S 244(4)$ StPO bestimmt: „Ein Beweisantrag auf Vernehmung eines Sachverständigen kann, soweit nichts anderes bestimmt ist, auch abgelehnt werden, wenn das Gericht selbst die erforderliche Sachkunde besitzt. Die Anhörung eines weiteren Sachverständigen kann auch dann abgelehnt werden, wenn durch das frühere Gutachten das Gegenteil der behaupteten Tatsache bereits erwiesen ist; dies gilt nicht, wenn die Sachkunde des früheren Gutachters zweifelhaft ist, wenn sein Gutachten von unzutreffenden tatsächlichen Voraussetzungen ausgeht, wenn das Gutachten Widersprüche enthält oder wenn der neue Sachverständige über Forschungsmittel verfügt, die denen eines früheren Gutachters überlegen erscheinen.“ 


\section{- Stellung und Pflichten des Experten und Gefahr der Befangenheit}

Der Sachverständige wird im förmlichen Strafverfahren des Öfteren als „Gehilfe des Gerichts ${ }^{\text {‘523 }}$ bezeichnet. Im Vorverfahren kann, zumindest nach der in der Praxis vertretenen Ansicht, auch die StA (sowie eventuell auch die Polizei und auf Antrag der Ermittlungsrichter) einen Sachverständigen ihrer Wahl bestellen. ${ }^{524}$ Fraglich ist, ob faktisch die Objektivität einer solchen Auswahl durch die StA als Auftragsbehörde im Voraus gewährleistet werden kann und ob eine gezielte Beauftragung der sachverständigen Person (mit Blick etwa auf die von ihr bekanntermaßen vertretenen wissenschaftlichen Thesen) ausgeschlossen werden kann. Das Gericht ist in jedem Fall berechtigt, aber nicht verpflichtet, anstatt eines im Vorverfahren bestellten Sachverständigen eine andere Person zu beauftragen, was aber in der Praxis eher selten passiert. ${ }^{55}$ Die StA wie auch das Gericht sind letztendlich bei der Auswahl eines Sachverständigen an Vorschläge der anderen Verfahrensbeteiligten nicht gebunden. ${ }^{526}$

Der Richter (bzw. im Vorverfahren der StA) hat mit Blick auf die Vorbereitung des Gutachtens, ,soweit ihm dies erforderlich erscheint, die Tätigkeit der Sachverständigen zu leiten" ( $\$ 78 \mathrm{StPO}$ ); im Vordergrund sollen dabei vor allem die klare Auftragsbeschreibung und die eindeutige Bestimmung der zu beantwortenden Beweisfragen stehen. ${ }^{527}$ Die fachliche Durchführung der beauftragten Untersuchung ist jedoch ,allein Sache des Sachverständigen; er hat hinsichtlich der Informationsbeschaffung und der Methodenwahl weitgehend freie Hand. Das Gericht darf ihm keine Weisungen darüber erteilen, auf welchem Weg er das Gutachten zu erarbeiten hat. “528 Der Sachverständige hat seinerseits eine Erscheinenspflicht und eine Wahrheitspflicht bei der Erstellung seines Gutachtens; er muss immer objektiv und allseitig neutral (unparteiisch und nach bestem Wissen und Gewissen) ${ }^{529}$ wirken. ${ }^{530}$

Schließlich können sowohl die Verteidigung als auch die StA einen bestimmten Sachverständigen unmittelbar laden und seine Vernehmung vor Gericht beantra-

\footnotetext{
523 U.a. BGH, NJW 1952, 899 (899).

524 Vgl. insb. § 161a(1), 162 StPO; Nr. 69-72 RiStBV. Beulke, Strafprozessrecht, Rn. 199; Eisenberg, Beweisrecht, Rn. 1526-1527a; Meyer-Goßner, StPO, § 73 Rn. 1. Siehe für die Gegenargumente, die gemäß dem Wortlaut der $\S \S 73,78,82$ StPO eine Auswahl des Sachverständigen durch den Richter bei sämtlichen Verfahrensstadien verlangen, Dippel, FS für Müller, S. 133-135.

525 Siehe auch Brüning, StV 2008, 100 (101-102); Dippel, FS für Müller, S. 136-138 (mit Reformvorschlägen). Weitere Details zur Auswahl der Sachverständigen bei MeyerGoßner, StPO, § 73 Rn. 1-19.

526 Eisenberg, Beweisrecht, Rn. 1527-1527a.

527 Meyer-Goßner, StPO, § 78 Rn. 2-5.

528 BGH, NStZ 2003, 101 (101).

529 Vgl. $\$ 79(2)$ StPO.

${ }_{530}$ U.a. Brüning, StV 2008, 100 (101-102); Eisenberg, Beweisrecht, Rn. 1506. Zu den Pflichten des Sachverständigen siehe insb. §§ 72, 75-77 StPO.
} 
gen. ${ }^{531}$ Wie Ulrich Eisenberg hierzu bemerkt: „In der Beweismittelqualität unterscheidet sich ein privat eingeholtes Gutachten prinzipiell nicht von einem vom Gericht in Auftrag gegebenen, und auch $\S 74$ sowie die Pflicht gemäß $§ 79$ Abs 2 gelten einheitlich, wenngleich von der Einführung in das Verfahren (möglicherweise) eher abgesehen würde, wenn das Ergebnis der Prozessstrategie zuwiderliefe. “532 Ferner soll die Vorbereitung des vom Angeklagten unmittelbar beauftragten Sachverständigen ohne sachlichen Grund richterlich nicht verhindert werden; vielmehr sind etwa die zur Erstattung des Gutachtens erforderliche Untersuchung des (inhaftierten) Angeklagten durch den Sachverständigen oder der Zugang zu nötigen Unterlagen grundsätzlich zu ermöglichen. ${ }^{533}$

\section{Die Bestimmung des Umfangs der Beweiserhebungen}

\section{a) Beweisführung und Offenkundigkeit}

Die Festlegung des Bundesgerichtshofs, dass ,die Strafprozeßordnung [...] am Leitbild der materiellen Wahrheit orientiert [ist], die vom Gericht in der Hauptverhandlung von Amts wegen zu ermitteln und der Disposition der Verfahrensbeteiligten weitgehend entzogen ist, "534 entspricht den bisherigen Ausführungen. Wie noch gezeigt wird, können die StA und die Verteidigung nach Anklageerhebung zur Unterstützung ihrer Beweisthesen die gerichtliche Erhebung bestimmter Beweise und zusätzlich zum bereits gesammelten und amtlich dokumentierten Material die Einführung von weiteren Beweismitteln in das Verfahren beantragen. Der Richter hat jedoch das erste und (meistens auch) das letzte Wort bei der Bestimmung des Umfangs der maßgebenden Beweiserhebungen und bei der Prüfung des Beweismaterials. Das Gericht muss nämlich nach § 244(2) StPO von Amts wegen die Beweisaufnahme auf alle entscheidungserheblichen Tatsachen und Beweismittel erstrecken.

Nur bei den vom Richter als offenkundig angesehenen Tatsachen ist eine förmliche Beweiserhebung überflüssig, was entsprechend nach $\S \S 244(3)$ und 245(2) StPO zur Ablehnung diesbezüglicher Beweisanträge der Verfahrensbeteiligten führen kann. ${ }^{535}$ Als offenkundig werden erstens solche Tatsachen angesehen, die ,allgemeinkundig sind, d.h. von denen verständige Menschen regelmäßig Kenntnis haben oder über die sie sich aus zuverlässiger Quelle ohne besondere Fachkunde

$531 \S \S 214(3), 220,245(2)$ StPO. U.a. KK-StPO-Senge, § 73 Rn. 3.

532 Eisenberg, Beweisrecht, Rn. 1527b (Fußnoten wurden ausgelassen).

533 Vgl. BGH, NStZ 1998, 93 (93-94); ferner Eisenberg, Beweisrecht, Rn. 1528-1528d, auch zur Problematik der gesetzlichen Entschädigung des vom Angeklagten beauftragten Sachverständigen aus der Staatskasse nach § 220(3) StPO.

534 BGHSt 50, 40 (63).

535 Siehe auch Keller, ZStW 101 (1989), 381 (381-383); BGHSt 6, 292 (292-297); OLG Düsseldorf, StV 1992, 314 (314). 
sicher unterrichten können [...]. ${ }^{\text {(536 }}$ Diese Allgemeinkundigkeit kann etwa naturwissenschaftliche Fakten oder historische Daten betreffen, ${ }^{537}$,,sie kann sich auch auf einen begrenzten Kreis von Personen oder eine bestimmte Ortschaft beschränken, wie zB hinsichtlich der besonderen Verkehrsverhältnisse in einer Gemeinde. “538 Zweitens sind solche Tatsachen offenkundig, die ,gerichtskundig sind, d.h. von denen die zur Entscheidung berufenen Richter durch ihre richterliche Tätigkeit vor allem aus anderen Verfahren Kenntnis erlangt haben [...]. ${ }^{6539}$ Offenkundige Tatsachen betreffen jedoch nicht das private Wissen des Richters; solches Wissen kann ein Richter nur durch seine Vernehmung als Zeuge (also nicht mehr als Richter des konkreten Falles) in das Verfahren einführen. ${ }^{540}$

Auch wenn die offenkundigen Tatsachen keiner Beweiserhebung bedürfen, müssen sie trotzdem - soweit sie nicht völlig selbstverständlich sind - förmlich zum Gegenstand der Hauptverhandlung gemacht werden, wobei das Gericht darauf hinweisen muss, dass es diese Tatsachen möglicherweise als offenkundig seiner Entscheidung zugrunde legen werde. ${ }^{541}$ Es ist nämlich grundsätzlich unzulässig, „solche Umstände bei der Entscheidung zu verwerten, wenn dem Angeklagten nicht die Möglichkeit gegeben worden ist, dazu Stellung zu nehmen. ${ }^{\text {"542 }}$ Um die Offenkundigkeit einer Tatsache zu erschüttern und folglich die Erhebung von Beweisen über diese Tatsache zu ermöglichen, muss der interessierte Verfahrensbeteiligte vortragen, dass es neue Tatsachen, neue Beweismittel oder bisher noch nicht berücksichtigte Umstände gibt, die geeignet sind, die erachtete Offenkundigkeit zu erschüttern. ${ }^{543}$

\section{b) Das Vorbringen von Beweisen: Zeugenladungen und Beweisanträge}

\section{- Verantwortlichkeit für die Bestimmung des Umfangs der Beweiserhebungen}

Bei der Aufklärung von nicht offenkundigen Tatsachenkomplexen kann die Rollenverteilung zwischen dem Richter und den zentralen Prozessbeteiligten bei der Bestimmung der Beweiserhebungen mit Blick auf die Beweisführungen in der Hauptverhandlung vor allem anhand der Regelungen zur Zeugenladung und zur

\footnotetext{
536 BGHSt 26, 56 (59).

537 Beulke, Strafprozessrecht, Rn. 404; Roxin/Schünemann, Strafverfahrensrecht, § 24 Rn. 9. Ferner Keller, ZStW 101 (1989), 381 (381-382).

538 BGHSt 6, 292 (293).

539 BGHSt 26, 56 (59). Ferner BGHSt 6, 292 (293-295); Roxin/Schünemann, Strafverfahrensrecht, § 24 Rn. 10.

540 Roxin/Schünemann, Strafverfahrensrecht, § 24 Rn. 10, § 46 Rn. 27 m.w.N.

541 BGH, NStZ 1995, 246 (247); Beulke, Strafprozessrecht, Rn. 407; Roxin/Schünemann, Strafverfahrensrecht, § 24 Rn. 11.

542 BGHSt 6, 292 (296). Siehe auch OLG Thüringen, StV 2007, 26 (26).

543 OLG Düsseldorf, StV 1992, 314 (314-315). Siehe auch Roxin/Schünemann, Strafverfahrensrecht, $\S 24$ Rn. 12.
} 
Stellung von Beweisanträgen sichtbar werden. Zunächst ist das Gericht primär verantwortlich für diese maßgebenden Beweisführungen. Es hat, wie bereits erwähnt, die Pflicht, die Beweisaufnahme auf alle erlaubten Beweismittel zu erstrecken, die für die Entscheidung von Bedeutung sind.

\section{- Zeugenladungen, Beweisanträge und die Rolle des Richters}

Das Gericht handelt im Rahmen seiner Amtsaufklärungspflicht, beispielsweise bei der Entscheidung über die Anhörung oder Nicht-Anhörung eines Zeugen, unabhängig von Anträgen und Anregungen sämtlicher Verfahrensbeteiligter. ${ }^{544}$ Sogar eine Verlesung früherer Vernehmungsniederschriften, die nach $\S 251$ StPO von den Verfahrensbeteiligten genehmigt worden ist, lässt, wie schon gesehen, die Aufklärungspflicht des Gerichts unangetastet; somit ist letztendlich die richterliche Anordnung einer persönlichen Zeugenvernehmung in der Hauptverhandlung immer möglich bzw. sie kann geboten sein. ${ }^{545}$

Der Umfang der Aufklärungspflicht richtet sich ,,nach den Umständen des Einzelfalls. Sie reicht so weit, wie die Umstände, die dem Gericht bekannt sind oder aus den Akten oder dem Verfahrensablauf bekannt sein müssen, zum Gebrauch eines oder eines weiteren Beweismittels drängen oder dies doch nahelegen. ${ }^{\text {"556 }}$ Die Aufklärungspflicht gebietet jedoch, ,nicht unterschiedslos aufwendige Ermittlungsmaßnahmen. ${ }^{\text {“547 }}$ Das Gericht muss in den meisten Fällen ,,nur allen erkennbaren und sinnvollen Möglichkeiten zur Aufklärung des Sachverhalts nachgehen. “548 Insbesondere gebietet es ,die Verpflichtung zur umfassenden Sachaufklärung dem Gericht nicht, voraussichtlich nutzlose Beweiserhebungen bzw. Ermittlungen anzustellen. “549

$544 \S \S 155(2), 244(2)$ StPO. Meyer-Goßner, StPO, § 244 Rn. 10 mit Rechtsprechungshinweisen.

545 Siehe die Nachweise unter Teil 2, III.B.1.b)bb).

${ }^{546}$ BGH, NJW 1978, 113 (114). Siehe auch BGHSt 3, 169 (175); BGH, NJW 1981, 2267 (2268).

547 BGH, NStZ 2005, 44 (45).

548 Meyer-Goßner, StPO, § 244 Rn. 12 m.w.N. und Differenzierungen.

549 BGH, Urt. v. 17.5.2001 - 4 StR 412/00, HRRS-Datenbank, Rn. 12. Siehe auch BGH, NStZ 1994, 247 (248): „Die Aufklärungspflicht, deren Rahmen durch die prozessuale Tat abgesteckt wird, erstreckt sich auf alle rechtlich erheblichen Tatsachen [...]. Das bedeutet nicht, daß versucht werden muß, jedes Detail der Vorgeschichte oder des Randgeschehens oder etwa Teile der Lebensgeschichte von Zeugen wegen deren Glaubwürdigkeit zu ermitteln. Der Tatrichter ist nicht zu ausufernder Aufklärung verpflichtet [...]. Kern und Ausgangspunkt des Aufklärungsgebotes ist es, die Wahrheit in Bezug auf die zu beurteilende Tat zu erforschen und deren tatbestandsverwirklichenden Unrechtsgehalt festzustellen. Nach Auffassung des Senats kommt es darauf an, ob bei verständiger Würdigung der Sachlage durch den abwägenden Richter die Verwendung einer Aufklärungsmöglichkeit den Schuldvorwurf [...] möglicherweise widerlegt, in Frage gestellt oder als begründet erwiesen hätte [...]. Im Rahmen des ihm von Recht und Gesetz eingeräumten Ermessens 
Die StA (als Anklagevertreterin und im Einklang mit ihrer Objektivitätspflicht) und die Verteidigung (unbeschadet der Selbstbelastungsfreiheitsnormen) können ihrerseits in die Bestimmung des Umfangs der Beweiserhebungen durch bloße Beweisanregungen und generelle formlose Ermittlungsanträge eingreifen, die dem gerichtlichen Ermessen überlassen werden. ${ }^{550}$ Vor allem können sie verlangen, in Form von im Gesetz ausdrücklich vorgesehenen Anträgen zur gerichtlichen Erhebung von Beweisen oder durch die unmittelbare Herbeischaffung von Beweismitteln mitwirken zu dürfen. ${ }^{551}$ Der Vorsitzende bzw. das Gericht besitzt aber zum Teil - im Rahmen insbesondere der Amtsaufklärungspflicht und bei Vorliegen von gesetzlich bestimmten Gründen - die Befugnis zur Beschränkung dieser Beweisführungsmöglichkeiten der Verfahrensbeteiligten. ${ }^{552}$

Zunächst ist der Vorsitzende Richter des erkennenden Gerichts für die Anordnung der zur Hauptverhandlung erforderlichen (verbindlichen) ${ }^{553}$ Ladung unter anderem des Angeklagten, der Zeugen und der Sachverständigen zuständig; er handelt dabei ohne Bindung an Anträge der Verfahrensbeteiligten. ${ }^{554}$ Die StA bewirkt die Herbeischaffung der als Beweismittel dienenden Gegenstände, wobei diese aber auch vom Gericht bewirkt werden kann. ${ }^{555}$ Der Vorsitzende kann von Amts wegen auch die Herbeischaffung von weiteren (in der Anklageschrift nicht aufgeführten) als Beweismittel dienenden Gegenständen anordnen. ${ }^{556}$ Der StA steht ferner (auch während der Hauptverhandlung) das Recht der unmittelbaren Ladung weiterer Personen zu, wenn sie entweder vom Vorsitzenden trotz ihrer Aufführung in der Anklageschrift nicht geladen wurden oder von der StA nachträglich als erforderliche Beweismittel angesehen wurden. ${ }^{557}$

Der Angeklagte (oder der Verteidiger) kann seinerseits nach Eröffnung des Hauptverfahrens schon zur Vorbereitung der Hauptverhandlung die richterliche Ladung von Zeugen oder Sachverständigen oder die Herbeischaffung anderer Beweismittel (Urkunden, Augenscheinsgegenstände) zur Hauptverhandlung nach $\S 219$ (1) StPO verlangen. Dazu muss er unter Angabe der Tatsachen, in Bezug auf die der Beweis erhoben werden soll, einen entsprechenden Antrag beim Vorsitzen-

darf der Richter [...] auch bedenken, wie bei gewissenhafter Verwirklichung des Aufklärungsgebotes die Wichtigkeit der Zeugenaussage oder einer sonstigen Beweiserhebung für die Wahrheitsfindung einerseits gegen das Interesse an einer reibungslosen und beschleunigten Durchführung des Verfahrens andererseits zu beurteilen ist."

550 Vgl. auch $\S 257$ a StPO.

551 Siehe zu den relevanten Differenzierungen u.a. Roxin/Schünemann, Strafverfahrensrecht, § 45 Rn. 5-11. BVerfGE 63, 45 (68).

552 Vgl. auch Alsberg-Dallmeyer, Der Beweisantrag, Rn. 76-77.

553 Siehe insb. $\S \S 48,51,72,77,133,145,216-218,220,230-236$ StPO.

$554 \S \S 214,216-217,222$ StPO. Details bei Meyer-Goßner, StPO, § 214 Rn. 2-14.

$555 \S 214(4)$ StPO.

$556 \S 221 \mathrm{StPO}$.

$557 \S \S 214(3), 222$ StPO. Meyer-Goßner, StPO, § 214 Rn. 13. 
den des Gerichts stellen. Derartige Beweisanträge des Angeklagten sind, soweit ihnen stattgegeben wird, der StA mitzuteilen. ${ }^{558}$ Abgelehnte Anträge können in der Hauptverhandlung wiederholt gestellt werden. ${ }^{559}$ Der Erfolg eines solchen Beweisantrags im Vorfeld der Hauptverhandlung macht zunächst die unmittelbare Ladung von Beweispersonen durch die Verteidigung unnötig; dadurch wird des Weiteren die erforderliche Zeit zur Vorbereitung des Sachverständigenbeweises gewährt. Außerdem ist das Gericht in der Hauptverhandlung nach § 245(1) StPO verpflichtet, die Beweisaufnahme auf alle vom Gericht vorgeladenen und auch erschienenen Zeugen und Sachverständigen - also einschließlich der auf Antrag nach § 219 StPO geladenen Personen - sowie auf die vom Gericht oder der Staatsanwaltschaft herbeigeschafften ${ }^{560}$ Beweismittel zu erstrecken, es sei denn, die Beweiserhebung ist unzulässig. ${ }^{561}$

Lehnt der Vorsitzende jedoch den Antrag auf Ladung einer Person nach § 219 StPO ab, so kann der Angeklagte diese Person nach $§ 220(1)$ StPO zur Hauptverhandlung unmittelbar laden lassen; hierzu ist der Angeklagte auch ohne vorgängigen Antrag befugt. ${ }^{562}$ Auch Urkunden und Augenscheinsgegenstände kann der Angeklagte zur Hauptverhandlung direkt mitbringen oder ihre Vorlegung durch den Verfügungsberechtigten veranlassen. ${ }^{563}$ Den Beweisantrag auf Vernehmung der von der Verteidigung (wie auch von der StA) unmittelbar vorgeladenen und erschienenen Personen sowie den Antrag auf die Erstreckung der Beweisaufnahme auf die sonstigen von den Prozessbeteiligten herbeigeschafften Beweismittel kann das Gericht nur unter den Voraussetzungen des § 245(2) StPO ablehnen: „Der Antrag ist abzulehnen, wenn die Beweiserhebung unzulässig ist. Im übrigen darf er nur abgelehnt werden, wenn die Tatsache, die bewiesen werden soll, schon erwiesen oder offenkundig ist, wenn zwischen ihr und dem Gegenstand der Urteilsfindung kein Zusammenhang besteht, wenn das Beweismittel völlig ungeeignet ist oder wenn der Antrag zum Zwecke der Prozeßverschleppung gestellt ist." ${ }^{\text {"564 }}$ Bei

$558 \S 219$ i.V.m. § 214 StPO. Ausführlich Alsberg-Tsambikakis, Der Beweisantrag, Rn. 635-674.

559 Meyer-Goßner, StPO, § 219 Rn. 3.

$560 \mathrm{Zu}$ den „herbeigeschafften“ Beweismitteln nach § 245(1) StPO (Augenscheinsobjekte und Urkunden; in den Akten vorhandene Gegenstände; Gegenstände, die das Gericht im Laufe der Hauptverhandlung beizieht; Gegenstände, welche die StA vor Beginn der Hauptverhandlung beizieht; in der Anklageschrift bezeichnete sachliche Beweismittel) i.G.z. zu den von den Prozessbeteiligten (auch von der StA erstmals in der Hauptverhandlung) „herbeigeschafften“ Beweismitteln nach § 245(2) StPO, siehe Alsberg-Tsambikakis, Der Beweisantrag, Rn. 1487-1492, 1532-1534 m.w.N.

561 Siehe Alsberg-Tsambikakis, Der Beweisantrag, Rn. 638; SK-StPO-Deiters, § 219 Rn. 2.

$562 \S \S 220,222$ i.V.m. $\S 38$ StPO. Details bei Graf-Ritscher, StPO Kommentar, § 220 Rn. 1-15; Meyer-Goßner, StPO, § 220 Rn. 1-15.

${ }_{563}$ Meyer-Goßner, StPO, § 220 Rn. 5.

564 Die selbstständige Möglichkeit der Verteidigung, „Beweise vorzuführen“, wurde einst von Köhler, Inquisitionsprinzip, S. 12, als ,ein ursprüngliches Stück Parteiprozeß in 
Personen, die der Angeklagte in der Hauptverhandlung nicht vorgeladen, sondern gestellt (d.h. zur Sitzung mitgebracht) hat, gilt jedoch nicht der § 245(2) StPO, sondern meistens der $\S 244(3-4)$ StPO mit weniger engen Ablehnungsvoraussetzungen. ${ }^{565}$

Schließlich können die Verfahrensbeteiligten zwecks Einflussnahme auf die Beweisführung während der Hauptverhandlung Beweisanträge ${ }^{566}$ auch in Bezug auf nicht präsente Beweise unter den Voraussetzungen des § 244(3-5) StPO stellen; auch diese maßgebenden Anträge müssen die Beweiserhebung hinsichtlich bestimmter Tatsachen mit bestimmten Beweismitteln verlangen. ${ }^{567}$ Die StA kann einen auf Belastung wie auch einen auf Entlastung oder neutral auf Sachverhaltsaufklärung abzielenden Beweisantrag stellen; der Angeklagte und sein Verteidiger können in den meisten Fällen selbstständig und auch unabhängig voneinander (sogar widersprüchlich zueinander) Beweisanträge stellen. ${ }^{568}$

Das Gericht muss die Beweisanträge der Verfahrensbeteiligten nach der allgemeinen Vorschrift des $§ 244(3)$ StPO ohnehin immer dann ablehnen, wenn die Beweiserhebung unzulässig ist; darüber hinaus kann es, wie bereits gesehen, einen solchen Antrag ablehnen, wenn die Tatsache offenkundig ist. Ein Beweisantrag kann ferner auch dann abgelehnt werden, ,wenn die Tatsache, die bewiesen werden soll, für die Entscheidung ohne Bedeutung oder schon erwiesen ist, wenn das Beweismittel völlig ungeeignet oder wenn es unerreichbar ist, wenn der Antrag zum Zweck der Prozeßverschleppung gestellt ist oder wenn eine erhebliche Behauptung, die zur Entlastung des Angeklagten bewiesen werden soll, so behandelt werden kann, als wäre die behauptete Tatsache wahr. ${ }^{\text {(569 }}$ Zur Unterstützung der Verfah-

unserem reformierten Inquisitionsprozeß“ bezeichnet. Ausführlich zu § 245 StPO AlsbergTsambikakis, Der Beweisantrag, Rn. 1465-1558.

565 Alsberg-Tsambikakis, Der Beweisantrag, Rn. 1527; Meyer-Goßner, StPO, § 220 Rn. $1, \S 245$ Rn. 16.

566 Meyer-Goßner, StPO, § 244 Rn. 18, fasst zum Begriff des klassischen Beweisantrags zusammen: „Der Beweisantrag ist das ernsthafte, unbedingte oder an eine Bedingung geknüpfte Verlangen eines Prozessbeteiligten, über eine die Schuld- oder Rechtsfolgenfrage betreffende Behauptung durch bestimmte, nach der StPO zulässige Beweismittel Beweis zu erheben.“ Ähnlich mit weiteren Rechtsprechungsverweisen und Literaturhinweisen Alsberg-Dallmeyer, Der Beweisantrag, Rn. 82. $\mathrm{Zu}$ den Vorschriften, die allgemein die Möglichkeiten der Prozessbeteiligten zur Stellung von Beweisanträgen bzw. zur Äußerung von Beweisanregungen in sämtlichen Verfahrensphasen betreffen, siehe insb. §§ 163a(12), 166(1), 168d, 201, 219, 225a(2), 244(3-6), 245, 246, 270(4) StPO. Zu den verfassungsrechtlichen Grundlagen des Beweisantragsrechts Jahn, FS für Hassemer, S. 1033-1040.

567 Vgl. § 219(1) i.V.m. § 244(3) StPO. Vertiefend Alsberg-Dallmeyer, Der Beweisantrag, Rn. 78, 83-159.

${ }_{568} \mathrm{Zu}$ den Antragsberechtigten siehe Alsberg-Güntge, Der Beweisantrag, Rn. 690-716; LR-StPO-Becker, § 244 Rn. 118-121.

$569 \mathrm{Zu}$ den Anträgen, die den Sachverständigen- und den Augenscheinsbeweis betreffen, siehe zusätzlich § 244(4-5) StPO; siehe auch unter Teil 2, III.B.1.b)aa), dd). Ausführlich zu den technischen Details und dem materiellen Gehalt der Ablehnungsgründe des 
rensbeteiligten bei sachdienlichen und förmlich korrekten Beweisanträgen ist das Gericht auch durch $\S 244(2)$ StPO verpflichtet (Fürsorgepflicht). Beweisanträge müssen grundsätzlich mündlich - optional: eventuell gleichzeitig auch schriftlich in der Hauptverhandlung bis zum Beginn der Urteilsverkündung gestellt werden. ${ }^{570}$ Nach § 246(1) StPO darf jedenfalls - möglicherweise vorbehaltlich eventueller Prozessverschleppungsfälle - eine Beweiserhebung nicht deshalb vom Gericht abgelehnt werden, weil das Beweismittel oder die zu beweisende Tatsache zu spät vorgebracht worden sei. ${ }^{571}$

\section{c) Einverständliche Bestimmung der Beweiserhebungen}

Obwohl der Richter zweifellos eine dominante Rolle bei der Bestimmung der Beweiserhebungen im Hauptverfahren innehat, stehen also auch den Verfahrensbeteiligten diverse Mitbestimmungsmöglichkeiten zur Verfügung. Gleichwohl behält das Gericht, auch in den Fällen, in denen das Gesetz den Prozessbeteiligten zunächst die Befugnis erteilt, spezifische inhaltliche Aspekte der Beweisaufnahme in gegenseitigem Einverständnis zu steuern, kraft seiner Amtsaufklärungspflicht das letzte Wort. Dies wurde bereits anhand der weiter oben ausgeführten Regelungen zur Verlesung früherer Vernehmungsniederschriften mit Einverständnis der StA und der Verteidigung nach $\S 251$ StPO deutlich: Dabei sind nämlich die richterliche Ablehnung der Verlesung und stattdessen die Anordnung der persönlichen Vernehmung der betreffenden Beweisperson in der Hauptverhandlung keinesfalls ausgeschlossen.

Beweiserhebungen mit Zustimmung der Prozessbeteiligten können des Weiteren im Rahmen einer in verfahrensökonomischer Hinsicht vorteilhaften Verständigung nach $\S 257$ c(2) StPO stattfinden. Dieser Paragraph bestimmt unter anderem, dass Gegenstand der Verständigung auch verfahrensbezogene Maßnahmen im Erkenntnisverfahren sowie das Prozessverhalten der Verfahrensbeteiligten sein können. Als Beispiele hierfür können das Absehen des Gerichts von bestimmten notwendigen Beweiserhebungen, der Verzicht auf notwendige Beweisanträge oder die Zustimmung der Verfahrensbeteiligten zur Verlesung von sonst nach dem Unmittelbarkeitsprinzip nicht verlesbaren Niederschriften dienen. ${ }^{572}$ Zumindest nach den normativen Vorstellungen muss gleichwohl auch in diesen Fällen die richterliche

§ 244(3-6) StPO siehe Alsberg-Güntge, Der Beweisantrag, Rn. 687-1464. Zusammenfassend u.a. Krell, JURA 2012, 355 (358-361).

570 Dazu m.w.N. und Rechtsprechungsverweisen Meyer-Goßner, StPO, § 244 Rn. 32-36.

571 Hierzu Meyer-Goßner, StPO, § 246 Rn. 1-7 i.V.m. § 244 Rn. 67-69c; SK-StPOFrister, § 246 Rn. 1-11 i.V.m. § 244 Rn. 176-180.

572 Mehr zu dieser in vielerlei Hinsicht problematischen Regelung bei Meyer-Goßner, StPO, § 257c Rn. 13-15. Siehe auch Graf-Eschelbach, StPO Kommentar, § 257c Rn. 1719; SK-StPO-Velten, § 257c Rn. 11. 
Amtsaufklärungspflicht nach $\S \S 257 c(1), 244(2)$ StPO unberührt bleiben; die Umsetzung dieses Gebotes in der Praxis ist freilich nicht unproblematisch.

Darüber hinaus können die StA und die Verteidigung im Rahmen der richterlichen Bestimmung des Umfangs der Beweiserhebungen durch allseitiges (grundsätzlich bedingungsfeindliches) Einverständnis nach § 245(1) StPO das Absehen des Gerichts von der Erhebung einzelner präsenter Beweise ermöglichen. ${ }^{573}$ Die Aufklärungspflicht des Gerichts nach § 244(2) StPO bleibt jedoch auch hierbei unberührt: Ein nach §245(1) StPO erklärtes Einverständnis „kann zwar für die Frage, ob dem Gericht ein weiteres Beharren auf diesem Beweismittel sich aufdrängen muß, von Bedeutung sein, bezieht sich aber doch zunächst nur auf den Beweiserhebungsanspruch nach $\S 245$ Abs. 1 Satz 1 StPO und ist ohne Einfluß auf die Aufklärungspflicht des Gerichts. “574

\section{d) Case Management}

\section{- Verfahrensökonomie}

Neben den genannten Vorgaben über die Grenzen der Amtsaufklärungspflicht muss das Gericht ,den gebotenen Umfang seiner Aufklärungsbemühungen auch an seiner Pflicht zur Beschleunigung und Konzentration der Hauptverhandlung mes-

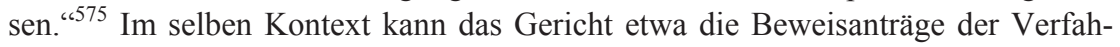
rensbeteiligten wegen Bedeutungslosigkeit der behaupteten Tatsache nach $\S 244(3)$ StPO ablehnen.

\section{- Gegenstand, Ziele und Rollenverteilung}

In organisatorischer Hinsicht ist darüber hinaus der Vorsitzende bzw. das Gericht zur zügigen Vorbereitung der Hauptverhandlung unter anderem für die Terminbestimmung, die ordnungs- und fristgemäße Anordnung der erforderlichen Ladungen und Benachrichtigungen, die Namhaftmachung der amtlich geladenen Beweispersonen und die Mitteilung der Gerichtsbesetzung verantwortlich. ${ }^{576}$ Der Vorsitzende muss auch, insbesondere für sich voraussichtlich über längere Zeit erstreckende Prozesse, einen sinnvollen Verhandlungsplan etwa bezüglich der Reihenfolge der Beweiserhebungen entwerfen; er soll hierzu, wenn nötig, einen Plan für die Ladung der Beweispersonen nach $\S 214(2)$ StPO aufstellen. ${ }^{577}$ Ferner kann das Gericht un-

573 Details bei LR-StPO-Becker, § 245 Rn. 30-40. Siehe auch Burhoff, Handbuch, Rn. 1067-1076; KK-StPO-Krehl, § 245 Rn. 17-22; Meyer-Goßner, StPO, § 245 Rn. 8-14.

574 BGH, StV 1983, 495 (496).

575 BGH, NStZ-RR 1996, 334 (335); Meyer-Goßner, StPO, § 244 Rn. 54.

576 Siehe $\S \S 212-225$ StPO. Zusammengefasst dazu Roxin/Schünemann, Strafverfahrensrecht, § $43 \mathrm{Rn} .1-10$.

577 Meyer-Goßner, StPO, § 214 Rn. 12; KK-StPO-Gmel, Vorbemerkungen $§ 213$ Rn. 4. Siehe auch praxisbezogen Schellenberg, Hauptverhandlung, S. 13-15. 
ter Umständen auf die Vorwegnahme von Teilen der hauptgerichtlichen Beweisaufnahme durch Anordnung von kommissarischen Beweisführungen nach $\S \S 223-$ 225 StPO entscheiden. ${ }^{578}$

Des Weiteren kann das Gericht nach der Anklageerhebung zunächst im Rahmen des Zwischenverfahrens, danach während der Vorbereitung der Hauptverhandlung und schließlich auch in der Hauptverhandlung den jeweiligen Stand des Verfahrens mit den Verfahrensbeteiligten erörtern, soweit dies geeignet erscheint, das Verfahren zu fördern; über den Inhalt einer solchen Erörterung besteht eine gewisse Dokumentierungspflicht. ${ }^{579}$ Als Hauptgegenstand derartiger Erörterungen ist an die Möglichkeit einer Verständigung nach $§ 257 \mathrm{c}$ StPO gedacht. ${ }^{580}$ Allgemein wird dadurch meistens frühzeitig eine schnelle oder abgekürzte Prozesserledigung angestrebt. Je nach Verfahrensphase können aber im Rahmen solcher Kommunikationen zwischen Gericht und Verfahrensbeteiligten auch etwa allgemeinere prozesstechnische Angelegenheiten, strittige Rechts- und Tatsachenpunkte hinsichtlich der Anklagevorwürfe, Einwände und Missverständnisse in Bezug auf die Beweisund Aktenlage sowie Fragen zur effizienten und transparenten Strukturierung des Hauptverfahrens oder zur Erforderlichkeit von (weiteren) Beweiserhebungen angesprochen werden. ${ }^{581}$

\section{Kenntnisnahme und Offenlegung von Beweisen}

\section{Die Kenntnis der Beweisergebnisse des Vorverfahrens seitens des Richters}

Wie bereits dargelegt, beginnt die gerichtliche Untersuchung eines Straffalles mit der Anklageerhebung durch die StA, also mit der Einreichung der Anklageschrift (in der Regel einschließlich des wesentlichen Ergebnisses der Ermittlungen) ${ }^{582}$ und

\footnotetext{
578 Dazu schon unter Teil 2, III.B.1.b)bb).

$579 \S \S 202 \mathrm{a}, 212,257 \mathrm{~b}, 273(1)$ StPO.

580 Vgl. § 243(4) StPO. Siehe auch Salditt, FS für Imme Roxin, S. 689-690. Ferner SKStPO-Paeffgen, § 202a Rn. 1-5.

581 Siehe Meyer-Goßner, StPO, § 202a Rn. 3, § 257b Rn. 1-2; SK-StPO-Deiters, § 212 Rn. 1-5; SK-StPO-Paeffgen, § 202a Rn. 27, 39; SK-StPO-Velten § 257b Rn. 1-4. Vgl. auch Salditt, FS für Imme Roxin, S. 688-689.

582 Konkreter bestimmt $\S 200$ StPO zum Inhalt der Anklageschrift: „(1) Die Anklageschrift hat den Angeschuldigten, die Tat, die ihm zur Last gelegt wird, Zeit und Ort ihrer Begehung, die gesetzlichen Merkmale der Straftat und die anzuwendenden Strafvorschriften zu bezeichnen (Anklagesatz). In ihr sind ferner die Beweismittel, das Gericht, vor dem die Hauptverhandlung stattfinden soll, und der Verteidiger anzugeben. Bei der Benennung von Zeugen ist deren Wohn- oder Aufenthaltsort anzugeben, wobei es jedoch der Angabe der vollständigen Anschrift nicht bedarf. In den Fällen des $\S 68$ Absatz 1 Satz 2, Absatz 2 Satz 1 genügt die Angabe des Namens des Zeugen. Wird ein Zeuge benannt, dessen Identität ganz oder teilweise nicht offenbart werden soll, so ist dies anzugeben; für die Geheim-
} 
der Verfahrensakten beim zuständigen Gericht; die Letzteren müssen im Normalfall alle bisher durch die Ermittlungsbehörden gesammelten und schriftlich oder elektronisch dokumentierten verfahrensbezogenen (entlastenden und belastenden) Beweise beinhalten. ${ }^{583}$ Die Berufsrichter des erkennenden Gerichts können somit schon im Zwischenverfahren umfassende Kenntnis vom Ergebnis der Ermittlungen sowie von dem nach dem Offizial- und Ermittlungsprinzip (in der Praxis jedoch möglicherweise nicht immer in objektiver oder lückenloser Weise ${ }^{584}$ gesammelten Beweismaterial erhalten. Ein besseres Verständnis der allgemeinen Beweislage und der möglichen Beweisstrategien kann das Gericht bzw. der Vorsitzende auch im Rahmen der (beantragten) Beweiserhebungen im Zwischenverfahren oder aufgrund der zur Vorbereitung der Hauptverhandlung gestellten Beweisanträge ${ }^{585}$ und der Namhaftmachung von unmittelbar geladenen Zeugen und Sachverständigen entwickeln. ${ }^{586}$ Im letzteren Fall stellt jedoch die Bekanntgabe des Beweisthemas, zu dem die durch die Verfahrensbeteiligten unmittelbar geladenen oder gestellten Beweispersonen vor Gericht vernommen werden sollen, keine gesetzliche Pflicht dar. ${ }^{587}$ Selbstverständlich werden darüber hinaus den Richtern auch die Unterlagen eventueller kommissarischer Beweisaufnahmen vorgelegt, die vom Gericht nach $\S \S 223-225$ StPO angeordnet wurden.

In der Hauptverhandlung verfügen nun die Berufsrichter - in der Regel aber nicht die eventuell mitwirkenden Schöffen ${ }^{588}$ über detaillierte Kenntnis des größtenteils im Vor- und Zwischenverfahren zusammengetragenen Beweismaterials (einschließlich Vernehmungsprotokollen, Beweisaufzeichnungen, Einlassungen, Schriftsätzen und Anträgen). ${ }^{589}$ Diese Kenntnis kann zur Bildung eines relativ konkreten Vorverständnisses ${ }^{590}$ hinsichtlich des gesamten Sachverhalts führen sowie nicht nur die Bestimmung des Umfangs, ${ }^{591}$ sondern auch die Art und Weise der maßgebenden Beweisaufnahme in der Hauptverhandlung beeinflussen. Nach HansHeiner Kühne: „Wenngleich in der Hauptverhandlung jeder einzelne Beweis neu

haltung des Wohn- oder Aufenthaltsortes des Zeugen gilt dies entsprechend. (2) In der Anklageschrift wird auch das wesentliche Ergebnis der Ermittlungen dargestellt. Davon kann abgesehen werden, wenn Anklage beim Strafrichter erhoben wird.“

583 Siehe ferner unter Teil 2, III.B.1.a) und Teil 2, III.C.2. m.w.N.

584 Roxin, in: Lüttger (Hrsg.), Probleme, S. 54.

585 Vgl. Perron, Beweisantragsrecht, S. 177-178.

586 Siehe insb. $\S \S 201,202,219,222,223-225$ StPO.

587 Meyer-Goßner, StPO, § 222 Rn. 9.

588 U.a. Beulke, Strafprozessrecht, Rn. 408 m.w.N.; Burhoff, Handbuch, Rn. 257-260; Eisenberg, Beweisrecht, Rn. 74-75; Kühne, Strafprozessrecht, Rn. 116-116.1. Vertiefend Börner, ZStW 122 (2010), 157 (insb. 157-158, 181-198).

589 Zur dienstlichen Sperrung der behördlichen Vorlegung von in amtlicher Verwahrung befindlichen Akten und Schriftstücken aufgrund bestimmter staatlicher Interessen siehe $\S 96 \mathrm{StPO}$.

590 Siehe auch Gleß, Beweisrechtsgrundsätze, S. 57-58.

591 Vgl. BGHSt 52, 175 (181). 
geführt und geprüft werden muss, geht jede Beweisaufnahme und damit jede Vernehmung grundsätzlich von Bekanntem aus und kann daher sowohl sehr viel gezielter wie auch effizienter eingesetzt werden. ${ }^{\text {"592 }}$ Wegen des Gebots aus $\S 238(1)$ StPO zur Verhandlungsleitung und Beweisführung durch den Richter (also nicht durch die Verfahrensbeteiligten) lässt sich freilich die Aktenkenntnis zumindest seitens des Vorsitzenden nur schwer vermeiden. ${ }^{593}$ Nicht zu überhören sind allerdings die vielen kritischen, auch auf empirische Ansätze gestützten Stimmen, die bei umfassender Aktenkenntnis schon mit Blick auf die Beweisführung vor der Gefahr einer erheblichen ,psychologischen Vorbelastung“ und Voreingenommenheit des Richters meistens zuungunsten des Angeklagten warnen. ${ }^{594}$

\section{Akteneinsicht und Offenlegung des Vorverfahrensmaterials}

\section{- Allgemeines}

Die Verfahrensakten, die größtenteils die Beweisergebnisse der staatsanwaltlichen und polizeilichen Ermittlungen dokumentieren, müssen dem Gericht mit der Anklageerhebung durch die StA (nicht die Polizei) vorgelegt werden ( $\S 170,199$ StPO) ${ }^{595}$ Die Verteidigung besitzt ein je nach Verfahrenslage eingeschränktes bzw. uneingeschränktes Recht auf Einsicht in die offiziell zusammengestellten Akten sowie zur Besichtigung von amtlich verwahrten Beweisstücken. ${ }^{596}$ Konkreter: grundsätzlich sind der Verteidiger und in begrenzterem Maße ein unverteidigter Beschuldigter zur Einsichtnahme berechtigt, nicht jedoch (zumindest nicht selbstständig/unmittelbar) ein Beschuldigter mit Verteidiger. ${ }^{597}$ Die Akteneinsicht kann

592 Kühne, Strafprozessrecht, Rn. 353.

593 Vgl. auch $\S \S 199,203,219,221$ StPO. Eisenberg, Beweisrecht, Rn. 73; Kühne, Strafprozessrecht, Rn. 116.1; Schünemann, FS für Pfeiffer, S. 478, versteht die Aktenkenntnis ,als notwendige Konsequenz unserer inquisitorischen Hauptverhandlung“; siehe auch Gössel, FS für Meyer-Gossner, S. 191.

594 Dazu m.w.N. u.a. Schünemann, in: Bierbrauer u.a. (Hrsg.), Verfahrensgerechtigkeit, insb. S. 216-217, 226-232, der experimentelle Ergebnisse zum „Perseveranz-“, „Redundanz-“, „Aufmerksamkeits-“ und ,Schulterschlußeffekt" präsentiert; auch Schünemann, FS für Kühne, S. 362-364; Weißmann, Stellung, insb. S. 16-22, der zusammengefasst u.a. die Probleme der einseitigen Beweisführung und Überführung des Angeklagten im Sinne der Anklage sowie der mangelnden Selbstreflexion und Flexibilität seitens des Richters anspricht. Vgl. auch zu den früheren Diskussionen Küper, Richteridee, S. 208-213, 258-266. Siehe auch weitere Verweise unter Teil 1, II.C.2.e)ee) und Teil 1, II.C.3.b)aa).

${ }_{595}$ Zur praktischen Vorbereitung des jeweiligen Sitzungsvertreters der StA auf der Basis der Verfahrensakten mit Blick auf die Beweisaufnahme in der Hauptverhandlung Schellenberg, Hauptverhandlung, S. 32-34.

596 Siehe bereits die Nachweise unter Teil 2, III.B.1.a). Zusammenfassend zum Akteneinsichtsrecht des Verteidigers mit verschiedenen Fallkonstellationen u.a. Kühne, Strafprozessrecht, Rn. 216-221.

$597 \mathrm{Zu}$ dieser nach wie vor strittigen Verfahrensangelegenheit m.w.N. Kühne, Strafprozessrecht, Rn. 220; Meyer-Goßner, StPO, § 147 Rn. 2-7, 20-23, 28-31. 
der effektiveren Vorbereitung der Beweisthesen der Verteidigung dienen; informatorisch wird sie in dieser Hinsicht insbesondere durch die Mitteilung des beweisbezogenen Inhalts der Anklageschrift ( $\S 200-201$ StPO), die Vorlage der Protokolle kommissarischer Beweisaufnahmen ( $\S 224-225$ StPO) und die Namhaftmachung der von Gericht und StA vorgeladenen Zeugen und Sachverständigen ( $\$ 222$ StPO) $)^{598}$ ergänzt.

\section{- Beweisoffenlegung seitens der Anklage}

Das Recht nach $\S 147(1)$ StPO auf Einsicht in alle entlastenden und belastenden Materialien bezieht sich aktuell nach einer jüngeren Entscheidung des BGH

auf die dem Gericht vorliegenden oder ihm im Falle der Anklage gemäß $§ 199$ Abs. 2 Satz 2 StPO vorzulegenden Akten. Das sind nach herrschender Meinung die von der Staatsanwaltschaft nach objektiven Kriterien (vgl. §160 Abs. 2 StPO) als entscheidungserheblich dem Gericht zu präsentierenden Unterlagen. Dazu gehören - verfassungsrechtlich unbedenklich [...] - zwar (nur) diejenigen, die durch die Identität der Tat und der des Täters konkretisiert werden [...]. Jedoch muss danach jedenfalls das gesamte vom ersten Zugriff der Polizei (§ 163 StPO) an gesammelte Beweismaterial, einschließlich etwaiger Bild- und Tonaufnahmen nebst hiervon gefertigter Verschriftungen, zugänglich gemacht werden, das gerade in dem gegen den Angeklagten gerichteten Ermittlungsverfahren angefallen ist [...]. Eine Ausnahme gilt nur für Unterlagen oder Daten, denen eine allein innerdienstliche Bedeutung zukommt. Dies können etwa polizeiliche Arbeitsvermerke im Fortgang der Ermittlungen unter Bewertung der bisherigen Ermittlungsergebnisse oder sonstige rein interne polizeilichen Hilfs- oder Arbeitsmittel nebst entsprechender Dateien sein [...]. Im Bereich der Justizbehörden sind vom Akteneinsichtsrecht ausgenommen etwa entsprechende Bestandteile der staatsanwaltschaftlichen Handakten, Notizen von Mitgliedern des Gerichts während der Hauptverhandlung oder so genannte Senatshefte [...]. ${ }^{599}$

Das Einsichtsrecht betrifft außerdem sowohl die nach der Anklageerhebung entstandenen Aktenteile als auch die vom Gericht herbeigezogenen oder von der StA nachgereichten Beiakten. ${ }^{600}$ Vor allem in Bezug auf die Ergebnisse von während der Hauptverhandlung durchgeführten außergerichtlichen Ermittlungen legt die Rechtsprechung besonderes Gewicht auf die Möglichkeit der Verteidigung zum kontinuierlichen Zugang zu sämtlichen verfahrensbezogenen - also nicht nur zu den amtlich für entscheidungserheblich erachteten - Akten. ${ }^{601}$ Insgesamt hat das

598 Zur Geheimhaltung bestimmter Identitäts- und Wohnortdaten aus Gründen des Zeugenschutzes siehe $\S 222(1)$ i.V.m. $\S \S 200(1)$ und 68 StPO. Siehe ferner Eisenberg, Beweisrecht, Rn. 1087-1095.

599 BGH, Urt. v. 18.6.2009 - 3 StR 89/09, HRRS 2009 Nr. 665, Rn. 24.

${ }^{600}$ Meyer-Goßner, StPO, $§ 147$ Rn. 15 mit Rechtsprechungsverweisen.

601 Siehe BGH, StV 2005, 652 (652-653): „Dem Tatgericht, dem in der Hauptverhandlung durch die StA neue verfahrensbezogene Ermittlungsergebnisse zugänglich gemacht werden, erwächst aus dem Gebot der Verfahrensfairness (Art. 6 MRK i.V.m. § 147 StPO) die Pflicht, dem Angekl. und seinem Verteidiger durch eine entsprechende Unterrichtung Gelegenheit zu geben, sich Kenntnis von den Ergebnissen dieser Ermittlungen zu verschaffen. Der Pflicht zur Erteilung eines solchen Hinweises ist das Tatgericht auch dann nicht 
BVerfG zur zentralen Bedeutung des Akteneinsichtsrechts u.a. mit Blick auf die Gewährleistung des Rechts auf rechtliches Gehör, des Fairnessgrundsatzes und der Waffengleichheit im Prozess, zum notwendigen Inhalt der amtlich in objektiver Weise zusammenzustellenden und offenzulegenden Akten sowie auch zur Möglichkeit der StA, bestimmte Kategorien von Akten zurückzuhalten, Folgendes dargelegt: ${ }^{602}$

[...] Art. 103 Abs. 1 GG gewährleistet, daß der Beschuldigte im Strafverfahren Gelegenheit erhält, sich zu dem einer Entscheidung zugrunde liegenden Sachverhalt grundsätzlich vor deren Erlaß zu äußern und damit das Gericht in seiner Willensbildung zu beeinflussen. Es dürfen einer gerichtlichen Entscheidung nur solche Tatsachen und Beweisergebnisse zugrunde gelegt werden, zu denen der Beschuldigte Stellung nehmen konnte [...]. Art. 103 Abs. 1 GG will verhindern, daß das Gericht ihm bekannte, dem Beschuldigten aber verschlossene Sachverhalte zu dessen Nachteil verwertet. [...] Auch wenn man unterstellt, daß der Anspruch des Beschuldigten auf rechtliches Gehör ihm [...] ein Recht auf Kenntnis von Akteninhalten einräumt, ist dieses Recht daher jedenfalls beschränkt auf die dem Gericht tatsächlich vorliegenden Akten. [...]

Die Zusammenstellung der mit der Anklageerhebung vorzulegenden Verfahrensakten durch die Staatsanwaltschaft dient der Vorbereitung der vom Gericht zu treffenden Entscheidung über die Eröffnung des Hauptverfahrens und der Vorbereitung der Hauptverhandlung. Sie ist selbst keine den Beschuldigten unmittelbar treffende Sachentscheidung [...], vor der ihm nach Art. 103 Abs. 1 GG - etwa durch Gewährung vollständiger Einsicht in sämtliche Ermittlungsvorgänge - rechtliches Gehör zustünde. [...]

Ein zentrales Anliegen eines rechtsstaatlich geordneten Strafverfahrens ist die Ermittlung des wahren Sachverhalts als der notwendigen Grundlage eines gerechten Urteils. Ausgestaltungen des Strafverfahrens, welche die Ermittlung der Wahrheit zu Lasten des Beschuldigten behindern, können daher seinen Anspruch auf ein faires Verfahren verletzen [...]. Ferner sichert dieser Anspruch dem Beschuldigten, der im Rechtsstaat des Grundgesetzes nicht bloßes Objekt des Verfahrens sein darf, den erforderlichen Bestand an aktiven verfahrensrechtlichen Befugnissen, damit er zur Wahrung seiner Rechte auf den Gang und das Ergebnis des Strafverfahrens Einfluß nehmen kann [...]. Dies verlangt eine gewisse verfahrensrechtliche "Waffengleichheit" von Staatsanwaltschaft und Beschuldigtem im Strafprozeß [...].

[...] $\S 147$ StPO konkretisiert aktive verfahrensrechtliche Befugnisse des Beschuldigten in einem rechtsstaatlich geordneten Strafverfahren. Die Vorschrift gebietet, die Akten und Beweisstücke dem Verteidiger des Beschuldigten so früh wie möglich, auf jeden Fall aber - und dann ohne Ausnahme - nach Abschluß der Ermittlungen offenzulegen, damit er vom Ergebnis der Ermittlungen rechtzeitig Kenntnis erlangt und Verteidigungsmittel beschaffen und vorbringen kann. Das Recht auf Akteneinsicht umschließt die vollständigen Akten, die dem Gericht vorliegen oder ihm im Falle der Erhebung der Anklage nach § 199 Abs. 2 Satz 2 StPO von der Staatsanwaltschaft vorzulegen wären $[\ldots]$.

enthoben, wenn es die Ergebnisse der Ermittlungen selbst nicht für entscheidungserheblich hält; denn es muß den übrigen Verfahrensbeteiligten überlassen bleiben, selbst zu beurteilen, ob es sich um relevante Umstände handelt [...]. Diese Hinweispflicht kann grundsätzlich auch schon für das Verfahren zwischen Eröffnungsbeschl. und Hauptverhandlung gelten." Siehe auch BGH, NJW 1990, 584 (585); BGH, NJW 2006, 3290 (3296). Zur strittigen Frage der Aktenvollständigkeit siehe ferner Beulke, Strafprozessrecht, Rn. 160; Kühne, Strafprozessrecht, Rn. 217; Meyer-Goßner, StPO, § 147 Rn. 12-18b, § 199 Rn. 2.

602 BVerfGE 63, 45 (59-67). 
Akten in diesem Sinne umfassen [...] sämtliche vom ersten Zugriff der Polizei ( $§ 163$ StPO) an gesammelten be- und entlastenden Vorgänge, die im Rahmen der Ermittlungen gegen den Beschuldigten entstanden sind, sowie herangezogene Beiakten. Spurenakten, in denen tatbezogene Untersuchungen gegen Dritte und deren Ergebnisse festgehalten wurden, gehören danach nicht notwendig zu den Hauptakten, weil sie außerhalb der Ermittlungen gegen den Beschuldigten entstanden sind; sie müssen dem Gericht nur dann vorgelegt und damit der Einsicht des Verteidigers zugänglich gemacht werden, wenn ihr Inhalt für die Feststellung der dem Beschuldigten vorgeworfenen Tat und für etwaige gegen ihn zu verhängende Rechtsfolgen von irgendeiner Bedeutung sein kann. [...]

Daran ändert es nichts, daß es zunächst Sache des Staatsanwalts ist, darüber zu befinden, welche Spurenakten für die anhängige Strafsache Bedeutung haben können und damit dem Gericht vorzulegen und der Akteneinsicht des Verteidigers zu öffnen sind.

[...] Dem Ziel, die materielle Wahrheit zu erforschen, um auf dieser Grundlage im Strafverfahren die Entscheidung über Schuld oder Nichtschuld und die daraus zu ziehenden rechtlichen Folgerungen zu treffen, ist nicht nur das Gericht, sondern gleichermaßen der Staatsanwalt verpflichtet. [...] Der Staatsanwalt hat nach $§ 160$ Abs. 2 StPO [...] auch die zur Entlastung des Verdächtigen dienenden Umstände zu ermitteln und für die Erhebung der entsprechenden Beweise Sorge zu tragen. Diese gesetzliche Pflicht ist sorgfältig zu beachten. Sie soll sicherstellen, daß alle erheblichen Gesichtspunkte aufgeklärt werden, und damit der Gefahr einseitiger Ermittlungstätigkeit begegnen [...].

Unter der Maxime der Wahrheitserforschungspflicht und der Verpflichtung zur Objektivität steht selbstverständlich auch die Aufgabe des Staatsanwalts, als Herr des Vorverfahrens die Strafakten vollständig zusammenzustellen, die er dem Gericht nach § 199 Abs. 2 Satz 2 StPO mit der Anklageschrift vorzulegen hat. Ihm werden dabei [...] mit Wertungen verbundene Entscheidungen abverlangt, die sich daran auszurichten haben, daß dem Gericht und dem Beschuldigten Aktenkenntnisse nicht vorenthalten bleiben dürfen, die für die gerechte Beurteilung der anhängigen Strafsache nützlich sein können. Bestehen daran hinsichtlich einzelner Ermittlungsvorgänge Zweifel, darf der Staatsanwalt sie nicht zurückhalten; er muß sie dem Gericht im Interesse rechtsstaatlicher Verfahrensgestaltung vorlegen. [...]

Die selbständige gerichtliche Überprüfung, ob die Erforschung der Wahrheit die Beiziehung weiterer Akten erfordert, stellt die StPO bereits im Zwischenverfahren ( $§ 202$ StPO), ferner vor Beginn der Hauptverhandlung durch den Vorsitzenden des Gerichts ( 221 StPO) und insbesondere während der Hauptverhandlung ( 244 Abs. 2 StPO) sicher [...]. Danach hat sich das Gericht in jeder Lage des Verfahrens zu vergewissern, ob begründeter Anlaß zu Zweifeln daran besteht, daß ihm alle zur Beurteilung des Falles bedeutsamen Akten vorliegen. Gegebenenfalls hat es dafür Sorge zu tragen, daß die Strafakten vervollständigt werden. Dabei kann es vom Staatsanwalt Auskünfte, insbesondere nähere Erläuterungen über die Kriterien bei der Zusammenstellung der Verfahrensakten und über Art und Inhalt nicht vorgelegter Ermittlungsvorgänge, verlangen.

Einer gerichtlichen Aktenanforderung hat der Staatsanwalt nachzukommen, sofern nicht ein gesetzlich geregelter Ausnahmefall vorliegt, etwa weil seine oberste Dienstbehörde ausnahmsweise die Herausgabe der Akten aufgrund überwiegender staatlicher Geheimhaltungsinteressen zu verweigern befugt ist ( $996 \mathrm{StPO}$ ).

[...] Bei alledem ist der Beschuldigte keineswegs zur Passivität verurteilt oder gar in die Rolle eines bloßen Objekts gedrängt, die es ihm prozessual verschlösse, auf die von ihm für sachdienlich gehaltene Beiziehung weiterer Akten Einfluß zu nehmen. Er kann, falls es an den prozessualen Voraussetzungen für die Stellung von Beweisanträgen fehlt, mit sogenannten Beweisermittlungsanträgen Anregungen für eine weitere Sachaufklärung an das Gericht herantragen. 
[...] Damit sind die Möglichkeiten des Beschuldigten, Kenntnis vom Inhalt auch solcher Spurenakten zu erhalten, die der Staatsanwalt dem Gericht nicht vorgelegt hat und zu deren Beiziehung auch das Gericht von sich aus keine Veranlassung sieht, nicht erschöpft. Er kann durch Vermittlung eines Rechtsanwalts [...] Einsicht in diese Vorgänge unmittelbar bei der für die Ermittlungen verantwortlichen Staatsanwaltschaft beantragen.

Darüber hinaus werden in $\S 147 \mathrm{StPO}^{603}$ die genauen Ausübungsvoraussetzungen und Grenzen des Akteneinsichtsrechts, die berechtigten Personen sowie die Organe, die (in Streitfällen) darüber zu befinden haben, bestimmt.Von zentraler Bedeutung ist hierbei das uneingeschränkte Einsichtsrecht der Verteidigung ab dem Zeitpunkt des Abschlusses der Ermittlungen. Überdies stellt nach $§ 96$ StPO die Sperrung der Vorlegung von amtlichen Schriftstücken zum Schutz bestimmter staatlicher Interessen eine wichtige allseitige Beschränkung des Informationsflusses und der Verfahrensvorbereitung auf der Basis der Prozessakten dar. Eine solche Sperrung erfolgt ausschließlich durch die jeweils zuständige oberste Dienstbehörde und wirkt erga omnes, sodass ,eine Überlassung der geheimhaltungsbedürftigen Akten nur an das auf Geheimhaltung verpflichtete Gericht, ohne dass der Betroffene Akteneinsicht erhalte (sogenannte in camera-Verfahren), [...] nicht [...] in einem strafprozessualen Verfahren möglich“ ist. ${ }^{604}$ Wenn die Sperrerklärung unbegründet bzw. offensichtlich fehlerhaft begründet ist, ist das Gericht zur Erhebung von Gegenvorstellungen verpflichtet. Allgemein ist aber das Gericht in der Regel letztendlich an die dienstlichen Sperrerklärungen gebunden, sodass es hier eigentlich meistens um unerreichbare Beweismittel (nicht jedoch um Beweisverbote) geht. Das Gericht darf aber die Konsequenzen der Sperrung für die Sachverhaltsaufklärung bei seiner kritischen Beweiswürdigung nicht übersehen. ${ }^{605}$

\section{- Beweisoffenlegung seitens der Verteidigung}

Die Verteidigung ist ihrerseits schließlich nicht verpflichtet, ihre Beweisthesen vorab weitgehend offenzulegen. Sie hat freilich gemäß dem Grundrecht auf rechtliches Gehör während des ganzen Prozesses Anhörungs- und Antragsrechte. ${ }^{606} \mathrm{Im}$ Rahmen der Erörterungen des Verfahrensstandes nach $\S \S 160 b, 202 a, 212,257 b$ StPO ist die Verteidigung berechtigt (aber nicht verpflichtet), sich zu diversen Verfahrens- und Beweisfragen $\mathrm{zu}$ äußern. ${ }^{607}$ Des Weiteren kann die Verteidigung

${ }^{603}$ Siehe auch $\S 138 \mathrm{c}(3)$ StPO; $\S 34(3$ Nr. 2) EGGVG.

604 BGH, NStZ 2000, 265 (266-267).

${ }^{605}$ Meyer-Goßner, StPO, § 96 Rn. 9-13 m.w.N. auch zur entsprechenden Anwendung des $\S 96$ StPO aus Gründen des Zeugenschutzes i.V.m. der Problematik der Geheimhaltung der Personalien von Verdeckten Ermittlern ( $\$ 110 \mathrm{~b}$ StPO) und V-Personen. Siehe auch hierzu KK-StPO-Greven, § 96 Rn. 10-14, 17-31.

606 Vgl. insb. §§ 33, 136, 163a(2), 166, 201, 243(5), 248, 257, 257a, 258, 265 StPO.

607 Siehe unter Teil 2, III.B.2.d). Zu den strategischen Schwierigkeiten der Verteidigung im Rahmen solcher Gespräche zwischen den Verfahrensbeteiligten vgl. Schellenberg, Hauptverhandlung, S. 35. 
neben allgemeinen (inhaltlich nicht unbedingt vollständigen) Beweisanregungen und -ermittlungsanträgen schon in der Phase der Vorbereitung der Hauptverhandlung inhaltlich klar definierte, unmittelbar entscheidungsrelevante Anträge stellen, um letztendlich die gerichtliche Erhebung von Beweisen zu verlangen. Entscheidet sie sich für einen solchen strengförmlichen Beweisantrag, muss sie konkrete Angaben über die verlangten Beweismittel und die behaupteten Beweistatsachen (sowie eventuell über ihre „Konnexität" ${ }^{608}$ machen, sonst ist der Antrag abzulehnen. ${ }^{609}$

Der Angeklagte hat ferner nach $§ 222(2)$ StPO ,die von ihm unmittelbar geladenen oder zur Hauptverhandlung zu stellenden Zeugen und Sachverständigen rechtzeitig dem Gericht und der Staatsanwaltschaft namhaft $\mathrm{zu}$ machen und ihren Wohn- oder Aufenthaltsort anzugeben." Es existiert aber zumindest in dieser Phase der Namhaftmachungen keine Verpflichtung zur Bekanntgabe des hiermit zu untersuchenden Beweisthemas. ${ }^{610}$ Darüber hinaus darf allein das verspätete Vorbringen von Beweismitteln und Beweistatsachen nicht zur Ablehnung der beantragten Beweiserhebung führen. ,Ist jedoch ein zu vernehmender Zeuge oder Sachverständiger dem Gegner des Antragstellers so spät namhaft gemacht oder eine zu beweisende Tatsache so spät vorgebracht worden, daß es dem Gegner an der zur Einziehung von Erkundigungen erforderlichen Zeit gefehlt hat, so kann er bis zum Schluß der Beweisaufnahme die Aussetzung der Hauptverhandlung zum Zweck der Erkundigung beantragen“ ( $§ 246(2)$ StPO); über die Aussetzung entscheidet dabei das Gericht nach freiem Ermessen (§ 246(4) StPO).

\section{Die Beweisführung im Hauptverfahren}

\section{Zulässigkeit und Ausschluss von Beweisen}

\section{- Beweisregeln und richterliches Ermessen}

Im deutschen Strafprozess ist das Gericht zur umfassenden Aufklärung eines angeklagten streitigen Sachverhalts durch vollständige Beweisführung innerhalb einer Hauptverhandlung verpflichtet. Außer vielleicht bei extremen Fairnessverletzungen kommen ein Verfahrenshindernis und die Möglichkeit der Verfahrenseinstellung ${ }^{611}$ im Interesse der Rechtsstaatlichkeit - etwa wegen erheblicher Verfahrensverzögerungen oder rechtswidriger Ermittlungsweisen der Strafverfolgungsbehörden grundsätzlich nicht in Betracht. Vielmehr wird ein eröffnetes Hauptverfahren meis-

608 Dazu u.a. Eisenberg, Beweisrecht, Rn. 146-147.

609 Siehe $\S 219$ i.V.m. $\S \S 244(3), 245(2)$ StPO. Ferner unter Teil 2, III.B.2.b).

610 Siehe RGSt 67, 180 (182): „Die Prozeßbeteiligten sind nicht verpflichtet, im voraus den Gegenstand der Vernehmung anzugeben, wenn sie unmittelbar einen Zeugen oder Sachverständigen zur Hauptverhandlung laden."

611 Vgl. insb. §§ 153(2), 153a(2), 156, 170(2), 204, 206a(1), 260(3) StPO. 
tens grundsätzlich in mündlicher und unmittelbarer Weise bis zum Ende fortgesetzt. Je nach Einzelfall (wenn auch nicht immer nach einheitlichen Kriterien) können sich Verletzungen von Rechtsstaatlichkeit und Fairness - die heute unter Berücksichtigung der relevanten Bestimmungen des EGMR, etwa in Bezug auf die Verfahrensdauer, die Lockspitzelfälle oder die Verwendung von Verdeckten Ermittlern, immer häufiger festgestellt werden - auf der Ebene der Beweisverwertung oder der Beweiswürdigung auswirken. Derartige Verletzungen können aber auch das Verfahrensergebnis erst auf der Basis solcher Konstruktionen der Rechtsprechung wie der sogenannten Strafzumessungs- und der Vollstreckungslösung beeinflussen. ${ }^{612}$

Aus dem Erkenntnisverfahren und aus der informatorischen Urteilsbasis auszuschließen sind, neben den im Strengbeweisverfahren und nach den Unmittelbarkeitsregeln unzulässigen Beweismitteln, darüber hinaus allgemein möglicherweise auch entscheidungserhebliche Beweise aufgrund von Beweisverbotsbestimmungen (z.B. in Zeugnisverweigerungsfällen oder nach § 136a StPO). Inhaltliche Ausführungen in Bezug auf die Zulässigkeit der Beweismittel und die Beweisverbote, die vor allem ,die Erhebung und Verwertung von Beweisen [hindern], also die Amtsaufklärungspflicht nach $\S 244$ II [einschränken], “613 finden sich bereits in anderen Teilen dieser Forschungsarbeit. ${ }^{614}$

An dieser Stelle ist besonders zu beachten, dass der Vorsitzende bzw. das Gericht nach $\S 244(2)$ i.V.m. $\S \S 245(1), 261$ StPO von Amts wegen für die Erhebung und Verwertung zunächst aller entscheidungsrelevanten Beweise nach den Regeln des Strengbeweises und der (nicht ausnahmslos geltenden) Verfahrensunmittelbarkeit sorgen muss. Die Amtsaufklärungspflicht ist gleichwohl, wie der Regelungskomplex der Beweisverbote zeigt, nicht um jeden Preis umzusetzen. ${ }^{615}$ Dies wird schon durch die Existenz von in der Hauptverhandlung direkt wirkenden Beweiserhebungsverboten sichtbar, die etwa die wirksame Ausübung der Zeugnisverweigerungsrechte betreffen. Insbesondere die Anwendung oder Nichtanwendung eines Beweisverwertungsverbots wird aber des Öfteren - mit Ausnahme bestimmter gesetzlich ausdrücklich geregelter Fälle, wie bei den auch unter Berücksichtigung der Menschenrechte verbotenen Vernehmungsmethoden nach $\S 136$ a StPO - von den Richtern durch Abwägung der im Einzelfall betroffenen Interessen entschieden werden; ${ }^{616}$ in ähnlicher Weise sind auch die Fragen zur Fernwirkung der Beweis-

$612 \mathrm{Zu}$ den einzelnen Unterkategorien, mit Rechtsprechungsverweisen und Beispielen zur Verletzung des Beschleunigungsgebots und anderer Aspekte des Fairnessprinzips, Beulke, Strafprozessrecht, Rn. 26-26a, 28, 171, 287-288, 289b-292, 295.

613 Meyer-Goßner, StPO, Einl. Rn. 50.

614 Siehe unter Teil 2, III.A.3. und Teil 2, III.B.1.b)bb) m.w.N.

615 Zusammenfassend LR-StPO-Gössel, Einl. Abschn. L Rn. 11-17.

616 Vgl. neuerdings BVerfG, NJW 2012, 907 (910). 
verwertungsverbote $\mathrm{zu}$ behandeln, wenngleich dabei meistens die Entscheidung zugunsten der Strafverfolgungsinteressen erfolgen wird. ${ }^{617}$

Darüber hinaus muss das Gericht nach $\S \S 244(3), 245(2)$ StPO die Beweisanträge der Verfahrensbeteiligten ablehnen, wenn die Beweiserhebungen „unzulässig“ sind. Unzulässig ist die beantragte Beweiserhebung insbesondere in Fällen von in der StPO nicht zugelassenen Beweismitteln, von Beweisthema- (z.B. bei getilgten Eintragungen über Vorverurteilungen nach $\S 51$ BZRG) und Beweismittelverboten (z.B. $§ 52$ StPO) sowie von Beweismethodenverboten (z.B. $\S 136 a$ StPO) und allgemein bei gesetzeswidriger Sammlung von Beweisen (z.B. bei Verstoß gegen die Belehrungspflicht nach $\S 52(3)$ StPO). ${ }^{618}$ Dieselben Bestimmungen zum Unzulässigkeitsbegriff gelten grundsätzlich auch für die selbstständige Beweiserhebungspflicht des Gerichts und ihre Grenzen nach $§ 245(1)$ StPO. ${ }^{619}$

\section{- Verfahren und Strukturprobleme}

In prozessstruktureller Hinsicht können freilich die diversen beweisrechtlichen Angelegenheiten bereits im Vorfeld der Hauptverhandlung, insbesondere im Rahmen des Zwischenverfahrens, der vorbereitenden richterlichen Verhandlungsplanungen, der ,privaten“ Vorbereitungstätigkeiten der Verfahrensbeteiligten oder eventueller formeller und informeller Erörterungen der Beweislage in den Vordergrund treten. Auch schon vor Beginn der Hauptverhandlung ist die Äußerung eines Widerspruchs seitens des Verteidigers gegen die Verwertbarkeit eines Beweismittels nicht ausgeschlossen; ${ }^{620}$ die bisherige Rechtsprechung will aber solchen Einwänden keine besondere Bedeutung für das weitere Verfahren beimessen. ${ }^{621}$ Es existieren jedenfalls keine eigenständigen Verfahren bzw. Rechtsbehelfe, die in vorwegnehmender Weise ausschließlich zur verbindlichen vorgerichtlichen Klärung der Rechts- und Beweisausschlussfragen eingesetzt werden können.

${ }^{617} \mathrm{Zu}$ den verschiedenen Theorien und Lösungsansätzen mit Beispielen aus Rechtsprechung und Lehre u.a. LR-StPO-Gössel, Einl. Abschn. L Rn. 18-187; Meyer-Goßner, StPO, Einl. Rn. 55-57e. Siehe auch Gleß, in: Thaman (Hrsg.), Exclusionary Rules, S. 115-138.

618 Meyer-Goßner, StPO, § 244 Rn. 49 mit weiteren Beispielen.

619 Meyer-Goßner, StPO, § 244 Rn. 49, § 245 Rn. 7.

620 U.a. Maul/Eschelbach, StraFo 1996, 66 (69). Nach der praxisorientierten Ansicht von Burhoff, Handbuch, Rn. 3504: „Das Gericht muss sich dann über die Verwertbarkeit des 'angegriffenen' Beweismittels klar werden und ggf. auf andere Beweiserhebungen einrichten. Der Verteidiger kann mit einem möglichst frühen Widerspruch zudem erreichen, dass das als unverwertbar angesehene Beweismittel gar nicht erst in die HV eingeführt wird, was besonders in Bezug auf die Laienrichter von erheblichem Vorteil ist." Siehe auch Neuhaus, NStZ 1997, 312 (315-316). Allgemein zur Bedeutung der Beweisverbote im Rahmen der Anklageerhebung bzw. des Zwischenverfahrens Schlothauer, FS für Lüderssen, S. 762-771.

621 Vgl. etwa OLG Hamm, NStZ-RR 2010, 148 (149) m.w.N. Siehe auch LR-StPOGössel, Einl. Abschn. L Rn. 31. 
In der Hauptverhandlung gilt nach herrschender Meinung für die Feststellung des Vorliegens der Voraussetzungen eines Beweisverwertungsverbots, vor allem bezüglich $\S 136$ a StPO oder etwa in Zusammenhang mit $§ 136(1)$ StPO, der Freibeweis. ${ }^{622}$ Darüber hinaus hat die Rechtsprechung hauptsächlich in Bezug auf die Verwertung von im Vorverfahren durch rechtswidrige Beweiserhebungen erlangten Beweisen bei der Urteilsfindung in mehreren Fällen eine Widerspruchslösung protegiert: Dabei ,macht der BGH ein Beweisverwertungsverbot davon abhängig, dass der Verwertung der betroffenen Information nach ihrer Einführung in die Hauptverhandlung widersprochen wird.“623 Der Widerspruch muss spätestens im Rahmen des Äußerungsrechts nach $\S 257$ StPO erfolgen. ${ }^{624}$ So hat der BGH im Hinblick auf den Fall einer unterbliebenen Belehrung des Beschuldigten nach $\S \S 136(1), 163 \mathrm{a}(4)$ StPO charakteristisch hierfür bestimmt:

Hat ein Verteidiger des Angeklagten in der Hauptverhandlung mitgewirkt und hat der verteidigte Angeklagte ausdrücklich der Verwertung des Inhalts einer ohne Belehrung ( 136 Abs. 1 Satz 2 StPO) zustandegekommenen Aussage zugestimmt, so besteht kein Verwertungsverbot. Dasselbe gilt, wenn der verteidigte Angeklagte einer solchen Verwertung nicht widersprochen hat. Der Widerspruch kann nur bis zu dem in $\S 257$ StPO genannten Zeitpunkt erklärt werden. Er muß also spätestens in der Erklärung enthalten sein, die der Angeklagte oder sein Verteidiger im Anschluß an diejenige Beweiserhebung abgibt, die sich auf den Inhalt der ohne Belehrung (§ 136 Abs. 1 Satz 2, § 163a Abs. 4 Satz 2 StPO) gemachten Aussage bezieht. Die Rechtsprechung hat schon bisher in vergleichbaren Fällen die Möglichkeit ins Auge gefaßt, daß das Recht, sich auf ein Verwertungsverbot zu berufen, verlorengeht, wenn der verteidigte Angeklagte in der tatrichterlichen Verhandlung der Verwertung und der ihr vorangehenden Beweiserhebung nicht widersprochen hat [...]. Diese Einschränkung des Verwertungsverbotes beschneidet die Rechte des Angeklagten nicht in unangemessener Weise. Sie entspricht der besonderen Verantwortung des Verteidigers und seiner Fähigkeit, Belehrungsmängel aufzudecken und zu erkennen, ob die Berufung auf das Verwertungsverbot einer sinnvollen Verteidigung dient. ${ }^{625}$

Für den Fall solcher Widersprüche ist allerdings während der tatrichterlichen Hauptverhandlung, ,ein Zwischenbescheid, in dem sich das Gericht zur Frage eines Beweisverwertungsverbots erklären müsste, nicht vorgesehen. Freilich ist es dem

622 Siehe Meyer-Goßner, StPO, § 136 Rn. 23, § 244 Rn. 7-9 m.w.N.

623 BVerfG, NJW 2012, 907 (911). Mehr zu dieser in vielerlei Hinsicht kritisierten Lösung u.a. bei Burhoff, Handbuch, Rn. 3493-3517; LR-StPO-Gössel, Einl. Abschn. L Rn. 28-33; Maul/Eschelbach, StraFo 1996, 66 (66-70); Meyer-Goßner, StPO, § 136 Rn. 24-26.

624 U.a. BGH, NJW 1996, 2239 (2241).

625 BGHSt 38, 214 (225-226). In BVerfG, NJW 2012, 907 (911), wird ferner bemerkt: „Es begegnet keinen Bedenken, dass ein Verwertungsverbot nach einem Rechtsverstoß bei der Informationserhebung oder -verwendung von einem Widerspruch in der Hauptverhandlung abhängig gemacht wird. Dies trägt einerseits dem Interesse des Angeklagten an einer möglichst weitreichenden Dispositionsbefugnis Rechnung und gewährleistet andererseits, dass eine Beanstandung sowie die sich daraus ergebenden Rechtsfolgen noch während der Hauptverhandlung geprüft werden können, damit rechtzeitig Klarheit für deren weiteren Verlauf geschaffen wird." 
Gericht auch keineswegs verboten, seine Rechtsauffassung hierzu mitzuteilen. “626 Durch diese Ausführungen wird nun unter anderem evident, dass das Gericht meistens Kenntnis von rechtswidrig erlangten Beweisinformationen (nicht zuletzt) ${ }^{627}$ aufgrund ihrer Einführung in die Hauptverhandlung durch Beweiserhebungen erlangen wird, bevor es dann eventuell entscheidet, solche Beweise bei der Urteilsfindung nicht zu verwerten. Es ist dabei nicht von der Hand zu weisen, dass eine solche Kenntnis ,verbotener“ Informationen einen tatsächlichen Einfluss nicht nur auf der Ebene der Urteilsfindung, sondern auch auf die Art und Weise der übrigen Beweisführungen haben kann. ${ }^{628}$ Einen faktischen (wenn auch weniger unmittelbaren und normativ ebenfalls unverwertbaren) Einblick in auszuschließende Beweise können die (Berufs-)Richter jedoch sehr oft auch dann erhalten, wenn eine Beweiserhebung in der Hauptverhandlung ausdrücklich (z.B. nach $\S \S 52,252$ StPO) verboten ist: Dies kann vor allem aufgrund der Kenntnis der Verfahrensakten geschehen, die möglicherweise den vorprozessualen Inhalt solcher Beweise etwa in Form von Vernehmungsprotokollen dokumentieren.

Jedenfalls erfolgt die Beweisaufnahme in der Hauptverhandlung nach der allgemeinen Vorschrift des $§ 238(1)$ StPO durch den Vorsitzenden. Seitens der von seinen Anordnungen betroffenen Verfahrensbeteiligten ist die Erhebung von Beanstandungen nach $§ 238(2)$ StPO erlaubt: Diese Beanstandungen können unter anderem die allgemeine Zulässigkeit einer richterlich angeordneten Beweisaufnahme, ${ }^{629}$ die Zulässigkeit einer richterlichen Anordnung über die Nicht-Benutzung oder die Benutzung eines Beweismittels entgegen einem Beweisverbot ${ }^{630}$ oder sogar die Sachgerechtigkeit der Vernehmung ${ }^{631}$ der Beweispersonen betreffen; das Gericht muss (nach Anhörung auch der übrigen Verfahrensbeteiligten) über die beanstandeten Punkte entscheiden. ${ }^{632}$ Somit sollte es nicht ausgeschlossen sein, dass ein Verfahrensbeteiligter schon gegen eine vom Vorsitzenden beabsichtigte Beweiserhebung einen Einwand nach § 238(2) StPO auf der Basis von Zulässigkeitserwägungen aller Art (einschließlich möglicher Beweisverwertungsverbote) vorbringen kann. ${ }^{633}$ Schließlich ist es der Rechtsprechung zufolge für die spätere

\footnotetext{
626 BGH, NStZ 2007, 719 (719).

627 Zum Problem der Kenntnisnahme von unverwertbaren Beweismitteln im Rahmen des Zwischenverfahrens Gössel, FS für Meyer-Gossner, S. 206.

628 Siehe auch Maul/Eschelbach, StraFo 1996, 66 (69); Neuhaus, NStZ 1997, 312 (316).

629 Vgl. BGH, NStZ 1982, 432 (432).

${ }^{630}$ Meyer-Goßner, StPO, § 245 Rn. 7; vgl. BGH, NStZ 2006, 178 (178).

631 Vgl. BGH, NJW 2004, 239 (240). Siehe auch § 242 StPO.

${ }^{632}$ Ferner KK-StPO-Schneider, § 238 Rn. 7-23; Meyer-Goßner, StPO, § 238 Rn. 5-19.

633 Siehe hierzu Mosbacher, NStZ 2011, 606 (610-611), der u.a. analytisch bemerkt: „Mein Vorschlag ist es, den Widerspruch bei Beweisverwertungsverboten als Unterfall des Zwischenrechtsbehelfs nach $\S 238$ Absatz II StPO anzusehen, der sich in erster Linie gegen die Erhebung unverwertbarer Beweise in der Hauptverhandlung und erst in zweiter Linie gegen deren Verwertung richtet. [...] Die Beweiserhebung ist gemäß § 238 Absatz I StPO Sache des Vorsitzenden. Der Vorsitzende ordnet in eigener Kompetenz die Beweis-
} 
Begründung einer nicht aussichtslosen Revision grundsätzlich erforderlich, dass eine unzulässige sachleitende Handlung des Vorsitzenden gemäß § 238(2) StPO in der Hauptverhandlung beanstandet wird. ${ }^{634}$

\title{
2. Erhebung, Präsentation und Prüfung der Stichhaltigkeit der Beweise
}

\author{
a) Grundlagen
}

\section{- Allgemeine Charakteristika der Beweisführung in der Hauptverhandlung}

Als Ausgangspunkt für die Darstellung der Besonderheiten der Beweisführung im Rahmen einer herkömmlichen erstinstanzlichen Hauptverhandlung kann folgende eindeutige Definition von Karl Heinz Gössel dienen:

Ziel der Hauptverhandlung im Strafverfahren ist nach $\S 260$ Abs. 1 StPO das Urteil, dessen Gegenstand die gerichtliche Feststellung der ,in der Anklage bezeichneten Tat“ (§ 264 Abs. 1 StPO) in ihrem Verhältnis zu den „,durch die Klage beschuldigten Personen“ (§ 155 Abs. 1 StPO), also eines von Menschen verwirklichten Sachverhalts, ist. Unter Beweis ist eben diese Feststellung zu verstehen: bedeutet doch beweisen sprachlich nichts anderes als ,wissend machen“, was im Strafverfahren nur auf den verfahrensgegenständlichen Sachverhalt bezogen werden kann. [...] Unter Beweis ist [...] der am Ziel der Ermittlung der objektiv-relativen Wahrheit orientierte Vorgang zu verstehen, in dem Tatsachen festgestellt werden. ${ }^{635}$

Das gerichtliche Tatsachenfeststellungsverfahren ist durch die Aufklärungspflicht der Richter nach $\S \S 155(2), 244(2)$ StPO gekennzeichnet: Die Richter müssen von Amts wegen und selbstständig auf der Basis der jeweils bekannten Umstände des Einzelfalls mit allen zulässigen Beweismitteln sämtliche materiell-rechtlich relevanten Tataspekte des Sachverhalts sinnvoll erforschen; es sind jedoch

erhebung an und führt sie durch. Im Rahmen der Beweiserhebung entscheidet der Vorsitzende in eigener Wertung auch darüber, ob ein Beweisverwertungsverbot greift. Will sich ein Verfahrensbeteiligter gegen die vom Vorsitzenden beabsichtigte Beweiserhebung wenden, kann er nach $\S 238$ Absatz II StPO das Gericht anrufen. Das Gericht muss, sofern der Vorsitzende der Beanstandung nicht abhilft, durch Beschluss entscheiden, ob die vom Vorsitzenden beabsichtigte Beweiserhebung zulässig ist oder nicht, ob also etwa eine Urkunde verlesen werden darf oder nicht. In diesem Rahmen muss sich das Gericht auch mit der Frage des Beweisverwertungsverbots begründet auseinandersetzen. [...] Der Verfahrensbeteiligte, der ein Beweisverwertungsverbot geltend machen will, hat nach meinem Ansatz regelmäßig schon der Erhebung des Beweises durch den Vorsitzenden zu widersprechen. Den Streit um ein Beweisverwertungsverbot vor die Beweiserhebung zu ziehen, ist auch schon deshalb sinnvoll, weil damit die Beeinflussung von Schöffen, Richtern und anderen Verfahrensbeteiligten durch eine letztlich eventuell unverwertbare Beweiserhebung vermieden wird. In einzelnen Fällen werden sich die Anknüpfungspunkte für ein Beweisverwertungsverbot allerdings erst aus der Beweiserhebung selbst ergeben. Ergibt etwa erst die nähere Befragung des Zeugen neue belastende Erkenntnisse, hat der Verteidiger erst jetzt Anlass, sich mit der Verwertbarkeit dieses Beweises näher zu beschäftigen und dies im zeitlichen Rahmen des $\S 257$ StPO zu beanstanden."

${ }^{634}$ Hierzu und zu den Ausnahmefällen KK-StPO-Schneider, § 238 Rn. 28-39.

${ }^{635}$ LR-StPO-Gössel, Einl. Abschn. L Rn. 1-2 (Fußnoten wurden ausgelassen). Hierzu Jäger, Beweisverwertung, S. 131-132. 
keine „überschießenden Aufklärungen“636 unterschiedslos geboten. ${ }^{637}$ „Kern und Ausgangspunkt des Aufklärungsgebotes ist es, die Wahrheit in Bezug auf die zu beurteilende Tat zu erforschen und deren tatbestandsverwirklichenden Unrechtsgehalt festzustellen. ${ }^{\text {"638 }}$

Die StA hat im Wege der vorverfahrensrechtlichen Beweiserhebungen, der Zusammenstellung der Verfahrensakte und der sonstigen Herbeischaffung von Beweismitteln ihre selbstständigen Beweisführungsmöglichkeiten schon vor dem eigentlichen Beginn der Hauptverhandlung weitestgehend ausgeschöpft. In der Hauptverhandlung vertritt die StA selbstverständlich ihr Anklagevorbringen; sie ist allerdings auch bei der Ausübung ihrer Mitwirkungsbefugnisse während der Beweisführungen zur Objektivität verpflichtet. ${ }^{639}$ Der (auch im Rahmen der anfänglichen gerichtlichen Sachvernehmung nicht zur Aussage verpflichtete) ${ }^{640}$ Angeklagte muss seinerseits grundsätzlich nicht aktiv die Sachaufklärung fördern oder an den Beweisführungen mitwirken. Der Angeklagte ,muss nicht seine Unschuld beweisen“641, auch wenn eine auf totale Weigerung und Passivität ausgerichtete „Verteidigungsstrategie“ sich in der Praxis nicht immer zu seinen Gunsten auswirken wird. ${ }^{642}$

Zusammengefasst heißt das, „eine Verurteilung setzt voraus, dass das Gericht (mit Hilfe der StA) nachweist, was zur Verurteilung erforderlich ist." ${ }^{\text {"643 }}$ Hierfür müssen die sich an die Beweisführung anschließenden richterlichen Würdigungen alle in der Hauptverhandlung erhobenen Beweise umfassen ( $\$ 261$ StPO). Eine sorgfältige Beweiswürdigung muss sich (sogar bei Geständnissen) im deutschen Strafprozesssystem auf die Ergebnisse einer selbstständigen sorgfältigen und allseitigen richterlichen Ermittlung der Beweise sowie der eventuell vorgebrachten Beweisthesen ${ }^{644}$ beziehen. Können durch die richterliche Beweisführung und Wür-

\footnotetext{
${ }^{636}$ Meyer-Goßner, StPO, § 244 Rn. 13.

637 Ferner m.w.N. insb. unter Teil 2, III.B.1.a), Teil 2, III.B.2.b).

638 BGH, NStZ 1994, 247 (248).

639 Vgl. schon insb. unter Teil 2, III.B.1.a), Teil 2, III.B.2. m.w.N.

640 § 243(5) StPO. Überlegungen zum „Für und Wider einer Sacheinlassung“ in strategischer Hinsicht siehe Burhoff, Handbuch, Rn. 3428-3442.

641 BGH, NStZ 2004, 392 (393).

642 Vgl. u.a. Walter, JZ 2006, 340 (340-341) m.w.N.

${ }^{643}$ Meyer-Goßner, StPO, $\S 155$ Rn. 3.

${ }^{644}$ Vgl. etwa am Beispiel einer „falschen“ Alibibehauptung BGH, NStZ 2004, 392 (394-395): „Nach ständiger Rechtsprechung des BGH kann ein objektiv widerlegtes, aber auch ein nachweislich erlogenes Alibi für sich allein und ohne Rücksicht auf Gründe und Begleitumstände seines Vorbringens nicht als Beweisanzeichen für die Überführung des Angekl. gewürdigt werden. Auch ein Unschuldiger kann meinen, seine Aussichten auf einen Freispruch seien besser, wenn er nicht nur auf die Wahrheit setze, sondern überdies versuche, auf ein unwahres, konstruiertes Alibi zu bauen, also mit dem Mittel der Lüge ein übriges tun zu sollen, um seinen Freispruch gleichsam abzusichern. Ebensowenig ist der lediglich gescheiterte Alibibeweis - bei dem die Lüge nicht erwiesen ist - für sich allein
} 
digung nicht alle Zweifel hinsichtlich des Vorliegens einer oder mehrerer in materiell-rechtlicher Hinsicht entscheidungserheblicher Tatsachen ausgeräumt werden, wirkt sich dies auf Urteilsebene zugunsten des Angeklagten aus. ${ }^{645}$ Der in dubio pro reo-Grundsatz, der unter anderem auch für Rechtswidrigkeits- und Strafausschließungsbehauptungen gilt, ${ }^{646}$ könnte gewissermaßen und in Zusammenhang mit der Unschuldsvermutung und dem Verbot der Beweislastumkehrung auch in prozessstruktureller Hinsicht und mit Blick auf das Ausmaß der richterlichen Aufklärungsbemühungen in der Praxis richtungweisend wirken.

Der Richter darf ohnehin seine eigenen unabhängigen Aufklärungstätigkeiten nicht ohne Weiteres aufgeben, etwa weil die StA im Rahmen der Hauptverhandlung kein aktives Interesse mehr am Nachweis der Schuld des Angeklagten zeigt oder sich aufgrund von Objektivitäts- bzw. anderen Interessenerwägungen und unter Neuevaluation der bisherigen Sachlage für einen Freispruch oder eine Verfahrenseinstellung einsetzt. Nach $\S 156$ StPO kann die Strafklage nach Eröffnung des Hauptverfahrens ohnehin nicht mehr zurückgenommen werden (Immutabilitätsprinzip); ${ }^{647}$ ein Abbruch der Strafverfolgung bzw. eine einseitige Verfahrenseinstellung durch die StA ist nach dem Eröffnungsbeschluss ${ }^{648}$ grundsätzlich nicht mehr möglich. ${ }^{649}$ Die Durchführung einer umfassenden richterlichen Beweisauf-

ein Beweisanzeichen für die Täterschaft. Der Angekl. ist nicht gehalten, sein Alibi zu beweisen. Dass er dies versucht hat, wenn auch im Ergebnis erfolglos, darf ihm nicht ohne weiteres zum Nachteil gereichen. Freilich muss ein widerlegtes Alibi deshalb bei der Beweisführung nicht stets außer Betracht bleiben. Treten besondere Umstände hinzu, so darf berücksichtigt werden, dass der Angekl. sich bewusst wahrheitswidrig auf ein Alibi berufen hat [...]. Die Gründe und Begleitumstände der Alibibehauptung sind dabei zu bewerten [...]. Will der Tatrichter eine erlogene Entlastungsbehauptung als zusätzliches Belastungsanzeichen werten, so muss er sich bewusst sein, dass eine wissentlich falsche Einlassung hierzu ihren Grund nicht darin haben muss, dass der Angekl. die Tat begangen hat, vielmehr auch eine andere Erklärung finden kann. Deshalb hat er in solchen Fällen darzutun, dass eine andere, nicht auf die Täterschaft hindeutende Erklärung im konkreten Fall nicht in Betracht kommt oder - obgleich denkbar - nach den Umständen jedenfalls so fern liegt, dass sie ausscheidet [...].“

${ }^{645}$ Siehe unter Teil 2, III.A.3. m.w.N.

646 U.a. Eisenberg, Beweisrecht, Rn. 120.

647 Dazu i.V.m. der Unterscheidung zwischen „kontradiktorischem“ und ,inquisitorischem“ Strafprozess Schroeder, GA 2011, 501 (501-503). Siehe auch Haas, Strafbegriff, S. 7-8.

648 Auch der Eröffnungsbeschluss kann vor dem Beginn der Hauptverhandlung vom Gericht nicht mehr nach Belieben zurückgezogen werden, vielmehr muss der Sachverhalt nun in der öffentlichen Hauptverhandlung geprüft werden; nur in den in $\S 206 \mathrm{a}, 206 \mathrm{~b}$ StPO vorgesehenen Fällen ist eine Verfahrenseinstellung durch das Gericht außerhalb der Hauptverhandlung möglich, siehe hierzu Beulke, Strafprozessrecht, Rn. 360; Roxin/ Schünemann, Strafverfahrensrecht, § 43 Rn. 11.

649 Siehe aber zur Möglichkeit der Verfahrenseinstellung durch die StA in jeder Verfahrenslage in bestimmten Fällen von besonderem öffentlichem Interesse $\S \S 153 \mathrm{c}(4), 153 \mathrm{~d}(2)$, $153 f(3)$ StPO. 
nahme zur Feststellung der Schuld ist in der StPO normiert als Regelfall für gerichtliche Untersuchungen.

Freilich bestehen, wie bereits dargelegt, nach Eröffnung des Hauptverfahrens neben den Vorschriften zur Prozesseinstellung durch das Gericht auf der Basis von Opportunitätserwägungen ${ }^{650}$ und zur zwischen Gericht und Verfahrensbeteiligten abgesprochenen Erledigung des (Beweis-)Verfahrens nach § 257c StPO aus Prozessökonomiegründen - teilweise auch Möglichkeiten zur vereinfachten Durchführung der Beweisaufnahme. Zu erwähnen sind hierbei insbesondere die Fälle der Tatsachenoffenkundigkeit sowie das Absehen ${ }^{651}$ von einzelnen Beweiserhebungen nach $\S 245(1)$ StPO bzw. der Gebrauch bestimmter (sonst unzulässiger) Beweismittel aufgrund des Einverständnisses der Verfahrensbeteiligten ( $§ 251$ StPO). ${ }^{652}$ Aber auch in faktischer Hinsicht ist bei Unterlassen des Vorbringens von Beweisthesen/-mitteln seitens aller zentralen Prozessbeteiligten (einschließlich der StA) nicht auszuschließen, dass die richterlichen Beweiserhebungen dadurch in einem gewissen Grad zur Wirkungslosigkeit verurteilt sein können. Dies kann in der verfahrensrechtlichen Realität (unter Berücksichtigung der Unschuldsvermutung und des in dubio pro reo-Grundsatzes) eventuell ,schneller“ zu einem Freispruch führen - es handelt sich hier quasi um das praktische Gegenstück eines Geständnisses, das sehr oft eine ,unkomplizierte“ Verurteilung ermöglichen wird.

Jedenfalls lässt sich nicht leugnen, dass auf normativer Ebene auch hinsichtlich des gerade beschriebenen Beweisführungskomplexes meistens ein richterliches Entscheidungsermessen besteht; die richterliche Amtsaufklärungspflicht kann letztendlich niemals wirklich aufgehoben werden. Die Durchführung einer vollständigen Beweisaufnahme unabhängig vom Willen der Verfahrensbeteiligten ist somit weitgehend möglich bzw. kann je nach Einzelfall geboten erscheinen.

\section{- Leitsätze zur Rollenverteilung}

Die Aufgabe des deutschen Hauptverfahrens besteht vor allem in der gerichtlichen Untersuchung des angeklagten Sachverhalts. Als Grundsatz dieser in der StPO geregelten Untersuchung hat einst das Reichsgericht bestimmt, dass „die Prozeßbeteiligten niemals Beweisführer sind, sondern stets das Gericht von Amts wegen Beweis erhebt, wenn auch nach bestimmten Regeln, die die Rechte der Prozeß-

${ }^{650}$ Siehe insb. $\S \S 153(2), 153 \mathrm{a}(2), 153 \mathrm{~b}(2), 154(2) 154 \mathrm{a}(2), 154 \mathrm{~b}(4)$. Praxisorientiert hierzu Schellenberg, Hauptverhandlung, S. 15-16. Zum Problem des (begrenzten) Umfangs der gerichtlichen Aufklärungen im Vorfeld solcher Einstellungsentscheidungen vgl. Deiters/Albrecht, ZIS 2013, 483 (484-487).

${ }^{651}$ Zur zulässigen Zurücknahme eines Beweisantrags und zum Verzicht auf eine bereits beschlossene Beweiserhebung in Bezug auf nicht präsente Beweismittel siehe MeyerGoßner, StPO, § 244 Rn. 37. Zur gerichtlichen Ablehnung eines Beweisantrags nach $\S 244(3)$ StPO, wenn die Beweiserhebung wegen Wahrunterstellung einer entlastenden Beweistatsache nun überflüssig ist, Meyer-Goßner, StPO, § 244 Rn. 70-71a.

${ }_{652}$ Insgesamt dazu schon unter Teil 2, III.B.1.b)bb) und Teil 2, III.B.2. 
beteiligten sichern, insbesondere den Angeklagten vor Beschränkung seiner Verteidigung schützen sollen. “653

Gegenwärtig obliegt in sämtlichen erstinstanzlichen Gerichtsverfahren weiterhin dem Vorsitzenden des erkennenden Gerichts nach § 238(1) StPO die ordnungsgemäße Verhandlungsleitung, die Vernehmung des Angeklagten und die Beweisaufnahme. ${ }^{654}$ Die Letztere schließt u.a. die Hauptbefragung von Beweispersonen, die ergänzende Befragung in den praktisch seltenen Fällen eines Kreuzverhörs nach $\S 239$ StPO, die Zurückweisung von unzulässigen Fragen nach § 241 StPO und die Anordnungen hinsichtlich der Verlesung von Schriftstücken nach § 249 StPO ein. ${ }^{65}$ Das ganze Gericht entscheidet gemeinsam unter anderem über die Anordnung von kommissarischen Beweiserhebungen nach $\S \S 223-225$ StPO und beschließt über Beanstandungen der Verfahrensbeteiligten gegen Leitungsanordnungen des Vorsitzenden nach § 238(2) StPO, über Zweifel über die Zulässigkeit gestellter Fragen nach $\S 242$ StPO, über die in der Hauptverhandlung gestellten Beweisanträge nach $\S \S 244(3-6), 245(2)$ StPO und über die Verlesung von Vernehmungsprotokollen nach $\S 251$ StPO; außerdem kann den beisitzenden (Berufsund eventuell Laien-)Richtern nach $\S 240(1)$ StPO gestattet werden, Fragen an die Beweispersonen zu stellen. Allgemein - außer in Bezug auf die Leitung der Verhandlung und die Beweisaufnahme, die zum Großteil durch den Vorsitzenden erfolgt - entscheidet das ganze Gericht (je nach Sachzuständigkeit der professionelle Strafrichter bzw. gemeinsam die Berufsrichter und Schöffen) über die Rechts- und Tatsachenfragen innerhalb der Hauptverhandlung, einschließlich der Schuldfrage am Verfahrensende. ${ }^{656}$

Das Gesetz sieht ferner in beträchtlichem Umfang Mitwirkungsrechte der zentralen Verfahrensbeteiligten (besonders des Angeklagten als vollständig anerkannten Prozesssubjekts) ${ }^{657}$ in Bezug auf Beweisangelegenheiten vor. Sowohl die StA als auch die Verteidigung sind aber grundsätzlich nicht selbstständig für die Durchführung der maßgebenden Beweisvorgänge in der Hauptverhandlung verantwortlich. Neben den schon angesprochenen Möglichkeiten zur Mitbestimmung des Umfangs der Beweiserhebungen ${ }^{658}$ regeln weitere, im Folgenden genauer erläuterte Vorschriften die Ausübung der Fragerechte, die Durchführung von Kreuzverhören in

653 RGSt 67, 180 (182).

${ }^{654}$ Zur Befugnis des Vorsitzenden, Zeugen und Sachverständige vorzuladen, weitere Beweise herbeizuschaffen und über vorbereitende Beweisanträge der Verteidigung zu entscheiden, siehe $\S \S 214,219,221,245(1)$ StPO. Hierzu bereits unter Teil 2, III.B.2.b).

655 Für eine generelle Auflistung der verhandlungsleitenden Tätigkeiten des Vorsitzenden sowie allgemein über $\S 238$ StPO siehe Burhoff, Handbuch, Rn. 2894-2910. Siehe auch Roxin/Schünemann, Strafverfahrensrecht, § 17 Rn. 5, § 44 Rn. 14-18.

656 Siehe ferner unter Teil 2, III.A.2.

657 Hierzu mit einer generellen Auflistung der aktiven und passiven Beteiligungsrechte des Beschuldigten Roxin/Schünemann, Strafverfahrensrecht, § 18 Rn. 1-19, § 44 Rn. 1.

${ }^{658}$ Siehe unter Teil 2, III.B.2. 
bestimmten Fällen, die Erhebung von Einwänden sowie auch die Stellung von Anträgen und die Äußerung von Anregungen während der Beweiserhebungen, die Abgabe von Erklärungen in Bezug auf bereits erhobene Beweise sowie die Gewährleistung des Rechts auf Schlussvortrag. ${ }^{659}$

\section{b) Der Ablauf der Beweisvorgänge im Gerichtsverfahren}

Vor allen sachlich zuständigen Strafgerichten beginnt die herkömmliche erstinstanzliche Hauptverhandlung, die unter kontinuierlicher Anwesenheit der StA und meistens in Gegenwart der Verteidigung (im Normalfall: Angeklagter $u n d$ Verteidiger) ${ }^{660}$ geführt wird, nach der in $\S 243$ StPO bestimmten Reihenfolge ${ }^{661}$ mit dem Aufruf der Sache. Darauf folgen die Präsenzfeststellung, ${ }^{662}$ die Zeugenbelehrung nach $\S 57$ StPO und das anschließende Entfernen der Zeugen, die Vernehmung des Angeklagten über seine persönlichen Verhältnisse (lediglich zum Zweck der Identitätsfeststellung sowie der Klärung von Prozessvoraussetzungen) ${ }^{663}$ und die Verlesung des Anklagesatzes durch den StA. ${ }^{664}$

Nach Ansicht des BGH geht ,der Zweck der Verlesung des Anklagesatzes [...] dahin, die Teilnehmer an der Hauptverhandlung mit dem Gegenstand der Verhandlung und mit den Grenzen, in denen sich diese und die Urteilsfindung zu bewegen hat, bekannt zu machen. Es sollen die mitwirkenden Richter darüber unterrichtet werden, auf welchen geschichtlichen Vorgang sich das Verfahren bezieht, und den Prozeßbeteiligten soll Gewißheit darüber vermittelt werden, auf welche Tat sie ihr Angriffs- und Verteidigungsvorbringen einzurichten haben. “665 Die Verlesung des in $§ 200(1)$ StPO vorgeschriebenen Inhalts des Anklagesatzes darf, zumindest nach

659 Siehe insb. $\S$ 230, 238-243, 257-257a, 258, 265 StPO.

$660 \mathrm{Zu}$ den anwesenheitsberechtigten und -pflichtigen Personen während der Hauptverhandlung sowie zur möglichen Abwesenheit oder Entfernung des Angeklagten bzw. zu seiner Vertretung durch Verteidiger siehe insb. §§ 137-146a, 149, 226-227, 230-236, 243, 247-248 StPO. Siehe auch unter Teil 2, III.A.2.

${ }^{661}$ Zur begrenzten Möglichkeit einer Abweichung siehe Meyer-Goßner, StPO, § 243 Rn. 1-3 mit Rechtsprechungsverweisen.

662 Die Präsenzfeststellung dient, wie Meyer-Goßner, StPO, § 243 Rn. 5, zusammenfasst, ,der Klärung, ob die Hauptverhandlung durchgeführt werden kann, ob noch Beweispersonen geladen und ob Zwangsmittel angewendet werden müssen. Die Präsenzfeststellung erstreckt sich ferner auf die herbeigeschafften sachlichen Beweismittel [...], für die $\S 245$ I gilt.“

${ }^{663}$ Mehr bei Meyer-Goßner, StPO, § 243 Rn. 10-12.

664 Detaillierter zum generellen Ablauf der Hauptverhandlung unter Teil 2, III.A.2.

665 BGH, NJW 1982, 1057 (1057). Nach BGH, NStZ 1995, 200 (201) besteht der Hauptzweck der Verlesung darin, ,diejenigen Richter, denen der Inhalt der Anklage noch nicht bekannt ist, darüber zu unterrichten, auf welchen geschichtlichen Vorgang sich das Verfahren bezieht, und ihnen zu ermöglichen, während der ganzen Verhandlung ihr Augenmerk auf die Umstände zu richten, auf die es in tatsächlicher und rechtlicher Hinsicht ankommt." 
einer Meinung, wegen der Gefahr unbewusster Beeinflussung der eventuell mitwirkenden Schöffen grundsätzlich nicht durch Bezüge auf den Inhalt der Beweisergebnisse des Vorverfahrens und durch Beweiswürdigungen ergänzt werden. ${ }^{666}$

Nach Verlesung des Anklagesatzes und vor der Vernehmung des Angeklagten zur Sache kann der Vorsitzende im Rahmen seiner Sachleitungsbefugnis nach seinem Ermessen dem Verteidiger Gelegenheit zu einer Eingangserklärung unter anderem hinsichtlich der Anklagepunkte, der Verteidigungsstrategie und der vorzubringenden Beweisthesen geben; der Verteidiger hat aber kein Recht darauf und eine solche Ansprache darf den Schlussvortrag nicht vorwegnehmen. ${ }^{667}$ Vorbehaltlich von in dieser Arbeit nicht näher diskutierten möglichen Abweichungen im Rahmen von Verständigungs-Erörterungen nach $\S \S 243(4), 257 b, 257 c$ StPO setzen anschließend die eigentlichen beweisrelevanten Vorgänge in der Hauptverhandlung mit der richterlichen Vernehmung des Angeklagten zur Sache ein. ${ }^{668}$ Nach § 243(5) StPO wird zunächst der Angeklagte darauf hingewiesen, „daß es ihm freistehe, sich zu der Anklage zu äußern oder nicht zur Sache auszusagen. Ist der Angeklagte zur Äußerung bereit, so wird er nach Maßgabe des $\S 136$ Abs. 2 zur Sache vernommen. Vorstrafen des Angeklagten sollen nur insoweit festgestellt werden, als sie für die Entscheidung von Bedeutung sind. Wann sie festgestellt werden, bestimmt der Vorsitzende. “669

Im Rahmen seiner sachlichen Einlassung kann der Angeklagte etwa ein Geständnis vor Gericht ablegen oder davon absehen, sich zur Sache zu äußern - für den BGH ist allerdings das Schweigen ,nicht ohne weiteres die zweckmäßigste Art der Verteidigung. “670 Der Richter wird gesetzlich nicht daran gehindert, den Angeklagten über eventuelle Nachteile einer Aussageverweigerung bzw. eines Verteidigungsverzichts zu informieren; dadurch darf jedoch die freie Willensbildung des Angeklagten nicht beeinträchtigt werden. ${ }^{671}$ Falls der Angeklagte sich nun dafür entscheidet, auszusagen, soll ihm die für die weiteren Beweisführungen und -würdigungen allgemein maßgebende Vernehmung nach $\S \S 243(5), 136(2)$ StPO Gelegenheit geben, „die gegen ihn vorliegenden Verdachtsgründe zu beseitigen

666 Roxin/Schünemann, Strafverfahrensrecht, § 44 Rn. 3, § 46 Rn. 6 mit teilweise abweichenden Rechtsprechungsverweisen. Siehe auch KK-StPO-Schneider, § 243 Rn. 21.

667 LR-StPO-Becker, § 243 Rn. 53. Siehe auch KK-StPO-Schneider, $§ 243$ Rn. 33; Meyer-Goßner, StPO, § 238 Rn. 5; SK-StPO-Frister, § 243 Rn. 41.

668 Vgl. auch LR-StPO-Gössel, Einl. Abschn. L Rn. 9; Roxin/Schünemann, Strafverfahrensrecht, $§ 4 \mathrm{Rn} .6$.

669 Zur Frage der zulässigen Erörterung der (entscheidungserheblichen und nicht getilgten) Vorstrafen des Angeklagten in der Hauptverhandlung siehe u.a. SK-StPO-Frister, $\S 243$ Rn. 80-85.

670 BGHSt 25, 325 (332). Zum unerlaubten und erlaubten (insb. bei Teilschweigen) Ziehen von nachteiligen Schlüssen auf der Ebene der Beweiswürdigung im Falle der Ausübung des Schweigerechts seitens des Angeklagten u.a. Roxin/Schünemann, Strafverfahrensrecht, § 25 Rn. 31-35.

671 Meyer-Goßner, StPO, § 136 Rn. 8; SK-StPO-Rogall, § 136 Rn. 44 m.w.N. 
und die zu seinen Gunsten sprechenden Tatsachen geltend zu machen."672 Einer Meinung zufolge kann die Einlassung übrigens auch im Wege eines vom Verteidiger gehaltenen (und vom Angeklagten inhaltlich bestätigten) Vortrags erfolgen. ${ }^{673}$

Die Beweisaufnahme im engeren Sinne beginnt nach § 244(1) StPO nach der Vernehmung des Angeklagten zur Sache. Dabei sind unter Berücksichtigung der Regeln der Amtsaufklärungspflicht, des Strengbeweises, der Beweiserhebungsverbote und der Verfahrensunmittelbarkeit unter anderem von Amts wegen die vom Gericht vorgeladenen und tatsächlich erschienenen Zeugen (grundsätzlich einzeln und in Abwesenheit der später zu hörenden Zeugen) ${ }^{674}$ zu vernehmen, die Sachverständigen zu vernehmen, die Urkunden zu verlesen und der Augenschein einzunehmen. ${ }^{675}$ Zulässige Beweiserhebungen finden auch auf Antrag der Verfahrensbeteiligten statt nach den bereits diskutierten Regeln der $\S \S 244(3-6), 245(2)$, 246(1) StPO, die sowohl nicht präsente als auch präsente (von der Verteidigung und StA vorgeladene, gestellte und herbeigeschaffte) Beweismittel betreffen. ${ }^{676}$ Eine Differenzierung zwischen Verteidigungs- und Anklagethesen im Sinne einer strengen formalen Trennung zwischen entlastenden und belastenden Beweismaterialien bzw. vorgebrachten Beweismitteln, die auch den Ablauf der Beweiserhebungen und -präsentationen beeinflussen könnte, wird im deutschen Strafprozess nicht vorgenommen. Die Beweisaufnahme wird in der Regel von Amts wegen zur Klärung der Schuldfrage so lange fortgesetzt, bis der Richter ihre Fortsetzung vor allem nach den Maßstäben der richterlichen Aufklärungspflicht und des Beweisantragssystems nicht mehr für erforderlich hält; eine klar erkennbar schwache Beweislage gegen den Angeklagten wird freilich in der Praxis oft zum schnellen Abschluss der Beweisaufnahme und (nach den Schlussvorträgen der Verfahrensbeteiligten) zum Freispruch führen.

Für die Benutzung der diversen Beweismittel bei der Erhebung und Prüfung der strittigen Beweise schreibt das Gesetz keine allgemeine Reihenfolge vor; diese wird vielmehr je nach Einzelfall aufgrund von Zweckmäßigkeitserwägungen vom Vorsitzenden (unter Wahrnehmung der Aufklärungs- und Fürsorgegebote) ${ }^{677}$ be-

672 Siehe auch Roxin/Schünemann, Strafverfahrensrecht, § 25 Rn. 8, § 44 Rn. 4 m.w.N.

673 Hierzu und auch zur Möglichkeit einer schriftlichen Einlassung u.a. LR-StPOBecker, § 243 Rn. 74-80; SK-StPO-Frister, § 243 Rn. 73-79 m.w.N. Siehe auch Roxin/ Schünemann, Strafverfahrensrecht, § 44 Rn. 4a, § 46 Rn. 18.

$674 \S 58(1)$ StPO. Zur Möglichkeit einer Gegenüberstellung mit anderen Zeugen oder dem Angeklagten im Vorverfahren und in der Hauptverhandlung siehe Meyer-Goßner, StPO, § 58 Rn. 7-14. Zur Entlassung der Zeugen und Sachverständigen nach ihrer Vernehmung siehe § 248 StPO. Allgemein zur Erscheinenspflicht sowie zur Möglichkeit einer zwangsweisen Vorführung der Zeugen siehe insb. §§ 48, 51, 70, 214, 220, 243(1), 245 StPO.

675 Siehe bereits unter Teil 2, III.B.1.b), Teil 2, III.B.2.a)-c).

676 Siehe ferner unter Teil 2, III.B.2.b).

677 Vgl. Meyer-Goßner, StPO, § 58 Rn. 4. Vgl. auch BGH, NJW 1962, 260 (261): „Es lag im pflichtgemäßen Ermessen des Vorsitzenden, in welcher Weise er die Ordnung in 
stimmt. ${ }^{678}$ Auch ein mehrfacher bzw. wiederholter Gebrauch desselben Beweismittels während und bis zum Schluss der Hauptverhandlung - vor allem eine erneute Befragung zum Beweis einer neuen (anfänglich nicht voraussehbaren) Behauptung oder eine wiederholte bzw. ergänzende Befragung einer Beweisperson - ist auf (Beweis-)Antrag grundsätzlich (je nach Einzelfall in Übereinstimmung mit den Beweisantragsprinzipien oder der Aufklärungspflicht) möglich. ${ }^{679}$

Darüber hinaus darf nach $\S 246(1)$ StPO eine Beweiserhebung nicht allein deshalb vom Gericht abgelehnt werden, weil das Beweismittel oder die zu beweisende Tatsache zu spät vorgebracht worden sind. ${ }^{680}$ Das verspätete Vorbringen von Beweismitteln und zu beweisenden Tatsachen kann aber auf Antrag oder von Amts wegen zur Aussetzung der Hauptverhandlung zwecks diesbezüglicher Erkundigungen seitens der Verfahrensbeteiligten führen. ${ }^{681}$ Die Stellung von Beweisanträgen ist in allen Fällen in der Hauptverhandlung bis zum Beginn der Urteilsverkündung möglich; danach und bis zum Schluss der mündlichen Bekanntgabe der Urteilsgründe entscheidet der Vorsitzende nach seinem Ermessen und nach Maßgabe der Aufklärungspflicht darüber, ob weitere Anträge entgegenzunehmen sind und ob auf einen Antrag hin wieder in die Verhandlung eingetreten werden soll. ${ }^{682}$ Allgemein ist das Gericht bis zum Abschluss der Bekanntgabe der Gründe und somit bis zur vollständigen Verkündung des Urteils ,noch nicht an die beschlossene Entscheidung gebunden, es kann vielmehr noch während der Eröffnung der Urteilsgründe mit der weiteren Verkündung innehalten und wieder in die Verhandlung und Beweisaufnahme eintreten [...] und sein Urteil ändern oder ergänzen [...]. “683

der Sitzung ( $§ 177 \mathrm{GVG}$ ) wahrte, die Verhandlungsleitung handhabte und die Beweisaufnahme (§ 238 Abs. 1 StPO) durchführte. [...] Es stand im pflichtmäßigen Ermessen des Vorsitzenden, in welcher Reihenfolge und welchen Abschnitten er die Zeugen vernahm oder erneut ergänzend hörte und ob dies in Gegenwart oder in Abwesenheit schon ganz oder teilweise vernommener Zeugen geschah. Der $\S 58$ Abs. 1 StPO ist nur eine Ordnungsvorschrift [...]." Nach Nr. 135(3) RiStBV sind Kinder und Jugendliche möglichst vor anderen Zeugen zu vernehmen.

678 Roxin/Schünemann, Strafverfahrensrecht, § 4 Rn. 7.

679 Siehe zu den relevanten Differenzierungen BGH, NStZ-RR 1996, 107 (107-108). Vgl. auch den in $\S 255 \mathrm{a}(2)$ geregelten Fall hinsichtlich der ergänzenden Vernehmung bei Vorführung der Bild-Ton-Aufzeichnung einer früheren richterlichen Vernehmung, hierzu BGH, NStZ 2003, 613 (614-615). Vgl. noch zur Funktion des 248 StPO Meyer-Goßner, StPO, § 58 Rn. 6, § 248 Rn. 3-4.

${ }^{680}$ Hierzu schon unter Teil 2, II.B.2.b) m.w.N. Zur viel kritisierten jüngeren Rechtsprechung, nach der es i.V.m. der Problematik der Ablehnung eines Beweisantrags wegen Prozessverschleppungsabsicht möglich ist, den Verfahrensbeteiligten eine Frist zur Stellung von Beweisanträgen zu setzen u.a. Meyer-Goßner, StPO, § 244 Rn. 69b-69c.

$681 \S 246(2-4)$ StPO. Meyer-Goßner, StPO, § 246 Rn. 2-6. Siehe auch unter Teil 2, III.C.2.

${ }^{682}$ BGH, NStZ 1986, 182 (182); Meyer-Goßner, StPO, § 244 Rn. 33 m.w.N. Vgl. $\S \S 246(1), 260(1), 261,268(2)$ StPO.

683 BGH, NJW 1974, 1518 (1518-1519) m.w.N. Nach BGH, NStZ 2004, 505 (507), liegt ein Wiedereintritt in die Beweisaufnahme insbesondere dann vor, „wenn der Wille 
Wie schon dargelegt erfolgen die Vernehmung des Angeklagten und die Beweisaufnahme - einschließlich der Vernehmung ${ }^{684}$ der Beweispersonen sowie der Anordnung und Durchführung der weiteren zulässigen Beweiserhebungen von Amts wegen oder etwa auf (nicht durch Beschluss abgelehnten) Beweisantrag - nach $\S 238$ (1) StPO grundsätzlich persönlich durch den Vorsitzenden des Gerichts. Der Vorsitzende erteilt und entzieht den Verfahrensbeteiligten auch das Wort und stellt den Abschluss der Beweisaufnahme fest. ${ }^{685}$ Besondere Vorschriften regeln gleichwohl unter anderem die Möglichkeit zur und die Art und Weise der Befragung der Beweispersonen sowohl durch die beisitzenden Richter als auch durch die Prozessbeteiligten, die Durchführung von Kreuzverhören sowie die Verlesung von Schriftstücken und Vernehmungsprotokollen. ${ }^{686}$

Die Verhandlungsbeteiligten sind berechtigt - falls sie eine künftige Revision anstreben: verpflichtet -, Beanstandungen gegen als unzulässig angesehene Anordnungen des Vorsitzenden gemäß $§ 238(2)$ StPO in der Hauptverhandlung zu erheben, die unter anderem auch die Zulässigkeit der Beweiserhebung betreffen können; über solche Beanstandungen entscheidet das Gericht im laufenden Verfahren nach Anhörung der Verfahrensbeteiligten. ${ }^{67}$ Derartige Einwände der Prozessbeteiligten können unter anderem auch die Art und Weise der Befragung der Beweispersonen betreffen, wobei auch die Äußerung von Zweifeln über die Zulässigkeit von allseitig gestellten Fragen nach $\S 242$ StPO möglich ist. Des Weiteren können die Verfahrensbeteiligten, wie weiter oben dargelegt, in der Hauptverhandlung ein Beweisverwertungsverbot geltend machen. Eine solche Beanstandung muss, zumindest für die Zwecke der Widerspruchslösung, spätestens im Rahmen des Äußerungsrechts nach $\S 257$ StPO, also spätestens unmittelbar nach dem Ende der entsprechenden Beweiserhebung in der Hauptverhandlung, vorgebracht werden wobei zu diesem Zeitpunkt im deutschen Strafprozess die ,verbotene“ Beweisinformation tatsächlich meistens schon in das Hauptverfahren eingeführt worden ist, auch wenn sie unter normativen Gesichtspunkten bei der Urteilsfindung eventuell nicht verwertet werden darf. Hierbei ist kein Zwischenbescheid zur verbindlichen gerichtlichen Klärung der Beweisverwertungsfrage im Rahmen der noch laufenden Beweisaufnahme und vor Beginn der Beweiswürdigungsphase vorgesehen. ${ }^{68}$

des Gerichts zum Ausdruck kommt, im Zusammenwirken mit den Prozessbeteiligten in der Beweisaufnahme fortzufahren oder wenn Anträge mit den Verfahrensbeteiligten erörtert werden [...]." Siehe auch etwa BGH, NStZ 2012, 587 (587). Weitere Beispiele eines Wiedereintritts bei Meyer-Goßner, StPO, § 258 Rn. 2, 28-30.

684 Vgl. BGHSt 40, 211 (213): „Zum Begriff der Vernehmung gehört, daß der Vernehmende dem Zeugen in amtlicher Funktion gegenübertritt (z.B. als Polizei- oder Zollbeamter, als Staatsanwalt oder Richter) und in dieser Eigenschaft von ihm Auskunft verlangt."

685 Siehe bereits unter Teil 2, III.D.2.a) und ferner unten unter Teil 2, III.D.2.c); zusammenfassend Meyer-Goßner, StPO, § 238 Rn. 5-8, § 258 Rn. 2.

686 Siehe an dieser Stelle insb. §§ 239-242, 247-256 StPO.

687 Siehe ferner bereits unter Teil 2, III.D.1.

688 Mehr dazu unter Teil 2, III.D.1. m.w.N. 
Darüber hinaus begründet $\S 257 \mathrm{StPO}$ allgemein für die zentralen Verfahrensbeteiligten die Möglichkeit, sich zu jeder einzelnen (unmittelbar vorangegangenen) Beweiserhebung etwa in Bezug auf ihren Beweiswert oder auf mögliche Unklarheiten und Widersprüche zu äußern; solche Äußerungen zu den einzelnen Beweiserhebungen, die aber keine Gesamtwürdigung aller bisherigen Beweiserhebungen beinhalten dürfen, sind bei der anschließenden Urteilsfindung zu berücksichtigen. ${ }^{689}$ Konkreter: nach $\S 257$ StPO soll zunächst der Angeklagte ,nach der Vernehmung eines jeden Mitangeklagten und nach jeder einzelnen Beweiserhebung“ vom Vorsitzenden ,befragt werden, ob er dazu etwas zu erklären habe“ (§ 257(1) StPO). Auf Verlangen ist nach § 257(2) StPO ,auch dem Staatsanwalt und dem Verteidiger nach der Vernehmung des Angeklagten und nach jeder einzelnen Beweiserhebung Gelegenheit zu geben, sich dazu zu erklären." Nach § 257(3) StPO dürfen die Erklärungen „den Schlußvortrag nicht vorwegnehmen.“

Die Schlussvorträge der Verfahrensbeteiligten folgen nach dem Schluss der Beweisaufnahme grundsätzlich in der in $\S 258$ StPO vorgeschriebenen Reihenfolge und nach Erteilung des Wortes von Amts wegen durch den Richter - wobei das letzte Wort immer, auch bei (mehrmaliger) Erwiderung des StA oder im Rahmen einer neuen Reihe von Vorträgen nach einem eventuellen Wiedereintritt ${ }^{690}$ in die Beweisaufnahme, dem Angeklagten zu erteilen ist. ${ }^{691}$ Genauer bestimmt $\S 258$ StPO:

(1) Nach dem Schluß der Beweisaufnahme erhalten der Staatsanwalt und sodann der Angeklagte zu ihren Ausführungen und Anträgen das Wort.

(2) Dem Staatsanwalt steht das Recht der Erwiderung zu; dem Angeklagten gebührt das letzte Wort.

(3) Der Angeklagte ist, auch wenn ein Verteidiger für ihn gesprochen hat, zu befragen, ob er selbst noch etwas zu seiner Verteidigung anzuführen habe.

Auch wenn der Verteidiger in der Vorschrift des § 258(1-2) StPO nicht ausdrücklich genannt wird, hat er selbstverständlich das Recht, wie es sich auch aus $\S 258(3)$ StPO ergibt, einen Schlussvortrag für den Angeklagten zu halten, um ,,vor der endgültigen Entscheidung des Gerichts zum gesamten Sachverhalt und zu allen Rechtsfragen des Verfahrens Stellung zu nehmen. " ${ }^{\text {"692 }}$ Im Zuge der Ausübung dieses Rechts kann er sogar eine Unterbrechung des Verfahrens zur Vorbereitung

689 Dazu und allgemein zu dieser Vorschrift u.a. Meyer-Goßner, StPO, § 257 Rn. 1-8 m.w.N.

690 Siehe auch BGH, NStZ 2004, 505 (507).

691 Siehe Details bei Meyer-Goßner, StPO, § 258 Rn. 4-8, 18-27.

692 BVerfGE 54, 140 (142), worin zur Vorschrift des $\S 258$ StPO auch bemerkt wird: „Sie dient damit unmittelbar der Gewährleistung des durch Art. 103 Abs. 1 GG garantierten Anspruchs auf rechtliches Gehör. Art. 103 Abs. 1 GG gibt dem Beteiligten eines gerichtlichen Verfahrens das Recht, sich zu dem einer gerichtlichen Entscheidung zugrunde liegenden Sachverhalt vor Erlaß der Entscheidung zu äußern, vor Gericht Anträge zu stellen und Ausführungen zu machen [...].“ 
seiner Ausführungen beantragen. ${ }^{693}$ Die Ausführungen im Rahmen der Plädoyers der StA und des Verteidigers sowie das letzte Wort des Angeklagten nach $§ 258(2)$ StPO gehören zum Inbegriff der Verhandlung, aus dem der Tatrichter seine Überzeugung zu schöpfen hat, und müssen somit bei der Urteilsfindung berücksichtigt werden. $^{694}$

Der StA muss einen objektiven und unvoreingenommenen Schlussvortrag in Bezug auf das Gesamtergebnis der Verhandlung halten und insbesondere alle belastenden und entlastenden Umstände und rechtlichen Fragen zusammenfassend ansprechen und würdigen sowie die Freisprechung oder Verurteilung oder auch die Durchführung von weiteren Beweiserhebungen beantragen. ${ }^{695}$ Der Verteidiger ist nicht verpflichtet, einen Schlussvortrag zu halten; gleichwohl wird die Ausübung seines Vortragsrechts in strategischer Hinsicht, insbesondere zur Erwiderung der Ausführungen und Anträge der StA, meistens von erheblicher Bedeutung sein. Der Verteidiger kann, grundsätzlich ${ }^{696}$ ohne zeitliche Beschränkung, in seiner Rede die zugunsten des Angeklagten sprechenden Umstände einseitig hervorheben; er ist nicht zu objektiven Würdigungen oder zur Stellung von Anträgen entsprechend seinem privaten Sachverhaltswissen verpflichtet. ${ }^{697}$ Allgemein dürfen die Schlussvorträge des StA und des Verteidigers nur die in der Hauptverhandlung schon mündlich angesprochenen Tatsachen sowie die Ergebnisse der Untersuchung der in die Hauptverhandlung eingeführten Beweismittel betreffen. ${ }^{698}$ Dagegen genießt der Angeklagte selbst viel mehr Freiheit in Bezug auf die inhaltliche Gestaltung seiner Schlussausführungen, die selbstverständlich sein Recht (keine Pflicht) darstellen und die sogar die erstmalige Ablegung eines Geständnisses beinhalten und somit zum Wiedereintritt in die Verhandlung führen können. ${ }^{699}$ Der BGH hat zum Fall eines vom Richter kontrollierbaren Missbrauchs ${ }^{700}$ des Schlussvortrags und zum zulässigen Inhalt des letzten Wortes des Angeklagten Folgendes bestimmt: ${ }^{701}$

\footnotetext{
${ }^{693} \mathrm{KG}, \mathrm{NStZ}$ 1984, 523 (523-524).

694 BGHSt 11, 74 (75). Siehe auch BGH, StV 1983, 402 (402).

${ }^{695}$ Meyer-Goßner, StPO, § 258 Rn. 10, 14 mit Rechtsprechungsverweisen. Konkrete Bestimmungen zum Inhalt des Schlussvortrags und der Anträge der StA siehe in Nr. 138139 RiStBV.

$696 \mathrm{Zu}$ möglichen Ausnahmen LR-StPO-Stuckenberg, § 258 Rn. 26.

697 LR-StPO-Stuckenberg, § 258 Rn. 33; Meyer-Goßner, StPO, § 258 Rn. 11, 15 m.w.N. Zu den allgemeinen Grenzen des erlaubten Handelns des Verteidigers siehe bereits unter Teil 2, III.B.1.a).

${ }^{698}$ Mehr dazu bei LR-StPO-Stuckenberg, § 258 Rn. 27 und Meyer-Goßner, StPO, § 258 Rn. 13, der auch die Beispiele des unzulässigen Vorbringens von privatem Wissen und der unzulässigen Verlesung von Schriftstücken, die nicht schon vorher in die Hauptverhandlung eingeführt worden sind, erwähnt.
}

699 LR-StPO-Stuckenberg, § 258 Rn. 32.

700 Siehe Beispiele bei Meyer-Goßner, StPO, § 258 Rn. 16, 26.

701 BGH, StV 1985, 355 (356). Siehe ferner Meyer-Goßner, StPO, § 258 Rn. 25-26. 
Zwar muß der Vorsitzende des Gerichts auch bei den Schlußausführungen und dem letzten Wort eines Angekl. darauf bedacht sein, daß dieser die ihm gewährte Redefreiheit nicht mißbraucht, indem er etwa vom Gegenstand des Strafverfahrens abschweift, sich fortwährend wiederholt oder gar seine Redebefugnis zu verfahrensfremden Zwecken ausnutzt [...]. Gerade beim letzten Wort ist dem Angekl. aber andererseits weitestgehende Verteidigungsfreiheit zu ermöglichen [...]; der Sinn der Schlußausführungen besteht gerade darin, daß der Angekl. das sagen kann, was er aus seiner Sicht für wichtig hält [...]. Das Gericht muß daher auch bereit sein, Ausführungen über solche Dinge anzuhören, auf die es die Beweisaufnahme gem. § 244 Abs. 2 StPO nicht zu erstrecken braucht. Vor allem muß einem Angekl. Gelegenheit gegeben werden, die Beweggründe seiner Tat darzulegen [...].

Auf die Schlussvorträge und das letzte Wort des Angeklagten folgt schließlich (im Kollegialgericht) die nichtöffentliche Beratung und Abstimmung durch die (Berufs- und Laien-)Richter in Bezug auf die Schuld- und die Rechtsfolgenfrage nach den Mehrheitsregeln der $\S \S 260(1), 263$ StPO i.V.m. $§ \S 192-197$ GVG; im Rahmen der Beratung dürfen keine neuen richterlichen Beweisermittlungen stattfinden. ${ }^{702}$ „Über das Ergebnis der Beweisaufnahme entscheidet das Gericht nach seiner freien, aus dem Inbegriff der Verhandlung geschöpften Überzeugung“ (§ 261 StPO). Die erstinstanzliche Hauptverhandlung schließt dann nach $\S \S 260$, 268(2) StPO mit der Verkündung des Urteils, also mit der Verlesung der Urteilsformel und der Eröffnung der Urteilsgründe. ${ }^{703}$

\section{c) Die Methoden der Beweisprüfung}

aa) Allgemeine Bemerkungen

Die Beweisaufnahme in der Hauptverhandlung liegt grundsätzlich in den Händen des Vorsitzenden (§ 238 StPO). Er und das Gericht entscheiden nicht nur über den Umfang der Beweiserhebungen in Übereinstimmung mit den weiter oben diskutierten Regeln der Amtsaufklärungspflicht, der Beweisoffenlegung, des Beweisantragssystems, der Unmittelbarkeit und des Komplexes der Beweisverbote. Die eigentliche Durchführung der hiernach erforderlichen und zugelassenen Beweiserhebungen wird ebenfalls richterlich gesteuert, ungeachtet der Mitwirkungsrechte der Verfahrensbeteiligten. Während dieser Beweiserhebungen vor Gericht wird die Stichhaltigkeit $^{704}$ der in die Hauptverhandlung eingeführten Beweise, die in der Folge als Basis für die Entscheidung über die Schuldfrage dienen werden, geprüft. Das charakteristischste und in prozessstruktureller Hinsicht umfassendste Beispiel hierfür, das im Folgenden ausführlicher dargestellt wird, betrifft die mündliche Erhebung und allseitige Prüfung des Zeugenbeweises.

\footnotetext{
702 Siehe Roxin/Schünemann, Strafverfahrensrecht, § 46 Rn. 28.

${ }_{703}$ Mehr zu den für das Urteil relevanten Fragen u.a. bei Roxin/Schünemann, Strafverfahrensrecht, $\S \S 48-50$. Siehe auch m.w.N. unter Teil 2, III.A.2., III. A.3.

704 Siehe auch unter Teil 2, III.A.3.
} 
Die technischen Details der gerichtlichen Benutzung der übrigen, an anderen Stellen dieser Arbeit teilweise schon angesprochenen Beweismittel - wie etwa die Art und Weise der zulässigen Verlesung von Urkunden und Verhörprotokollen, des Abspielens von Videoaufzeichnungen und allgemein der Augenscheinseinnahme können hier hingegen nicht eingehend betrachtet werden. ${ }^{705}$ In Bezug auf alle Beweismittel und Beweistatsachen haben jedenfalls die Verfahrensbeteiligten durch das Vorbringen von Einwänden, durch Kommentierungen und durch die Abgabe von Erklärungen diverse Möglichkeiten, in die einzelnen richterlichen Beweiserhebungen einzugreifen: In diesem Zusammenhang sind die Beanstandungsrechte nach $\S \S 238(2), 242$ StPO, das Äußerungsrecht nach $\S 257$ StPO und das Recht auf Schlussvortrag nach $\S 258$ StPO noch einmal zu erwähnen. ${ }^{706}$

\section{bb) Die Art und Weise der Vernehmungen}

Die Vernehmung der Beweispersonen findet in der Hauptverhandlung grundsätzlich zuerst durch den Vorsitzenden Richter in - zumindest nach den normativen Vorgaben - neutral-amtlicher Weise statt. ${ }^{707}$ Wie jede Beweiserhebung erfolgen die Vernehmungen in der vom Vorsitzenden nach den Umständen des Einzelfalls bestimmten Reihenfolge, wobei der Angeklagte grundsätzlich als Erster und vor Beginn der Beweisaufnahme zu vernehmen ist. ${ }^{708}$ Die beisitzenden Richter und Schöffen, die StA und die Verteidigung (der Angeklagte und sein Anwalt) haben im Rahmen der Vernehmung Befragungsmöglichkeiten; der Vorsitzende bestimmt den Zeitpunkt, zu dem die Fragerechte ausgeübt werden dürfen, wobei die Befragung jeder einzelnen Beweisperson durch die Prozessbeteiligten grundsätzlich erst nach dem Abschluss der richterlichen Befragung folgt. ${ }^{709}$

Wie weiter unten erläutert wird, kann der Vorsitzende einerseits in den Verlauf der Befragungen durch die Verfahrensbeteiligten insbesondere wegen möglicher Missbräuche und ungeeigneter Fragestellungen korrigierend eingreifen. Anderer-

705 Siehe teilweise unter Teil 2, III.A.3.; Teil 2, III.B.; Teil 2, III.D.2.a)-b). Ausführlich zu den sachlichen Beweismitteln Eisenberg, Beweisrecht, Rn. 2000-2323.

706 Siehe unter Teil 2, III.D.1., 2.a)-b).

707 Siehe insb. $\S 238(1), 239(2), 240-242,243(5), 244(2)$ StPO. Zur Gefahr, dass der Vorsitzende im Rahmen seiner Aufklärungspflicht und durch seine dominierenden Leitungs- und Vernehmungstätigkeiten (also rollenbedingt) zum tatsächlichen Gegner des Angeklagten werden könnte oder zumindest oft als solcher erscheinen wird, siehe Roxin, in: Lüttger (Hrsg.), Probleme, S. 53-56. Allgemein zur Gestaltung der Vernehmungen im ganzen Strafprozess in empirischer, kriminalistischer und kognitiver Hinsicht eingehend Eisenberg, Beweisrecht, insb. Rn. 580-624, 1188-1203, 1318-1354a, 1362-1469b.

708 Siehe etwa BGH, NStZ 1981, 111 (111). Siehe auch unter Teil 2, III.D.2.b). Ferner SK-StPO-Frister, § 243 Rn. 62-67.

709 BGH, NJW 1961, 1221 (1222); LR-StPO-Becker, § 238 Rn. 11, auch zur Bedeutung der Gewährleistung des Verteidigungsrechts auf konfrontative Befragung nach Art. 6(3d) EMRK. 
seits können die Verfahrensbeteiligten Einwände gegen die Zulässigkeit der richterlichen Vernehmungsvorgänge erheben; die Äußerung von Zweifeln über die Zulässigkeit von allseitig gestellten Fragen ist in allen Fällen möglich (§§ 238, 241, 242 StPO). Unter bestimmten Voraussetzungen ist ferner die Durchführung von Kreuzverhören von Zeugen und Sachverständigen durch die StA und die Verteidigung zuzulassen ( $\$ 239$ StPO); auch hierbei darf der Vorsitzende vor allem zur Gewährleistung von ordnungsgemäßen (nicht missbräuchlichen) Befragungen eingreifen und muss am Ende weitere ihm zur Sachverhaltsaufklärung erforderlich scheinende Fragen stellen.

\section{- Struktur und Umfang der Vernehmungen: Vernehmung des Angeklagten zur Sache}

Der Angeklagte ist, soweit er überhaupt zur Sache aussagen will, durch den Vorsitzenden in neutralem, ruhigem und sachlichem Ton $^{710}$ nach $\S 243(5)$ i.V.m. $\S 136(2)$ StPO zu vernehmen: Ihm ist hierdurch Gelegenheit zu geben, die gegen ihn vorliegenden Verdachtsgründe zu beseitigen und die zu seinen Gunsten sprechenden Tatsachen geltend zu machen. ${ }^{711}$ Die Vernehmung darf sich nicht nur auf die konkreten Umstände des Sachverhalts, sondern auch auf allgemeine (entscheidungsrelevante) persönliche Verhältnisse des Angeklagten, auf sein Verhältnis zu Mitangeklagten und (Belastungs-)Zeugen ${ }^{712}$ sowie unter den Voraussetzungen des $\S 243(5)$ StPO auf entscheidungserhebliche (und nicht getilgte) ${ }^{713}$ Vorstrafen beziehen. ${ }^{714}$ Der Angeklagte soll im Rahmen seiner grundsätzlich mündlichen ${ }^{715}$ Ein-

\footnotetext{
710 LR-StPO-Becker, § 243 Rn. 72 m.w.N.; SK-StPO-Frister, § 243 Rn. 69.

711 Zur Funktion der Vernehmung des Angeklagten siehe Roxin/Schünemann, Strafverfahrensrecht, § 25 Rn. 4: „Die Vernehmung des Beschuldigten hat nach heute h.M. eine 'Doppelfunktion', indem sie sowohl die Wahrheitsermittlung als auch das rechtliche Gehör für den Beschuldigten (Art. 103 I GG) bezweckt [...].“ In BGH, NStZ 1981, 111 (111) wurde zusammenfassend bestimmt: „Die $\S \S 243$ Absatz IV, 244 Absatz I StPO schreiben vor, daß die Vernehmung des Angekl. zur Sache der Beweisaufnahme voranzugehen habe. Die Vernehmung soll dem Angekl. Gelegenheit geben, die gegen ihn vorliegenden Verdachtsgründe zu beseitigen und die zu seinen Gunsten sprechenden Tatsachen geltend zu machen ( $\$ 136$ II StPO). Diese Vorschriften zielen darauf ab, dem Angekl. vorweg die Möglichkeit zu geben, zusammenhängend seine Verteidigung zu führen und das Gericht zu veranlassen, bei der folgenden Beweisaufnahme den von ihm vorgebrachten Gesichtspunkten Rechnung zu tragen. Die Gelegenheit zur zusammenhängenden Widerlegung der Verdachtsmomente und zur geschlossenen Darstellung der entlastenden Gesichtspunkte vor der Beweisaufnahme wird nicht dadurch ersetzt, daß der Angekl. nach der Vernehmung eines jeden Zeugen, Sachverständigen oder Mitangekl. sowie nach der Verlesung eines jeden Schriftstücks befragt wird, ob er dazu etwas zu erklären habe (§ $257 \mathrm{StPO})$, und daß er das letzte Wort erhält ( $\$ 258$ Absatz II StPO). Diese Rechte müssen ihm ohnedies eingeräumt werden $[\ldots]$. “

712 Vgl. BGH, NStZ 1981, 111 (111).

$713 \S 51$ BZRG.

${ }_{114}$ Siehe ferner Meyer-Goßner, StPO, § 243 Rn. 26, 29, 32-35. Siehe auch Roxin/ Schünemann, Strafverfahrensrecht, $§ 25$ Rn. 8.
} 
lassungen vor Gericht möglichst Gelegenheit haben, sich zunächst umfassend im Zusammenhang (eventuell mit Hilfe von Notizen) zu äußern. ${ }^{716}$ Nach der Rechtsprechung können allerdings

je nach den Umständen des Einzelfalls Abweichungen hiervon angezeigt sein, so etwa, wenn $[\ldots]$ es um einen besonders verwickelten oder umfangreichen Anklagevorwurf geht. Gleiches gilt, wenn der Angekl. zu einer auch nur einigermaßen geordneten Sachdarstellung nicht bereit oder in der Lage ist. Hiervon abgesehen soll der Vorsitzende in diesem Stadium der Hauptverhandlung nur eingreifen, um im Interesse der Verständlichkeit Zusammenhänge herzustellen oder erkennbar bedeutungslose Weitschweifigkeiten zu unterbinden. Gelegenheit zu einem „Frage- und Antwortspiel“ besteht, sobald der Angekl. zu erkennen gibt, dass er von sich aus im Zusammenhang nichts mehr sagen will. $^{717}$

Nach $\S 240$ StPO muss der Vorsitzende den beisitzenden Richtern und Schöffen, der StA und dem Verteidiger auf Verlangen gestatten, unmittelbar Fragen an den Angeklagten zu stellen; die unmittelbare persönliche Befragung eines Angeklagten durch einen Mitangeklagten ist jedoch nicht zulässig, wobei die gewünschten Fragen dem Angeklagten jedoch statt dessen durch den Vorsitzenden (oder den Verteidiger des Mitangeklagten) gestellt werden können. ${ }^{718}$ Nach $\S 241$ (2) StPO kann der Vorsitzende ungeeignete oder nicht zur Sache gehörende Fragen der Verfahrensbeteiligten zurückweisen. Die relevanten Anordnungen des Vorsitzenden können beanstandet werden, und es können allgemein Zweifel über die Zulässigkeit von allseitig gestellten Fragen geäußert werden; in beiden Fällen entscheidet das Gericht ( $\S 238,242$ StPO).

Darüber hinaus gibt es für den Vorsitzenden (wie auch für die Verfahrensbeteiligten) die Möglichkeit, dem Angeklagten im Rahmen seiner Vernehmung frühere dokumentierte Erklärungen vorzuhalten; dies kann etwa in Form einer einfachen Inhaltsangabe der früheren Aussage, der wörtlichen Verlesung der betreffenden Urkunde oder des Abspielens einer Tonbandaufnahme geschehen. ${ }^{719}$ Bei der Urteilsfindung ist in solchen Fällen als Beweisgrundlage nicht die Urkunde mit der früheren Aussage zu verwenden, sondern nur die bestätigende Erklärung, die vom

715 Nach BGH, NStZ 2008, 349 (350) m.w.N., kann die Verlesung eines vom Verteidiger übergebenen Schreibens durch das Gericht die Einlassung des Angeklagten nicht ersetzen. Nach BGH, NStZ 2013, 59 (60) ist das Gericht jedenfalls verpflichtet, eine schriftliche Stellungnahme des Angeklagten zur Kenntnis zu nehmen. Ferner zum Problem der Vorlegung oder Verlesung einer Verteidigungsschrift siehe LR-StPO-Becker, § 243 Rn. 76-80; Meyer-Goßner, StPO, § 243 Rn. 30.

716 LR-StPO-Becker, § 243 Rn. 70, 76; Meyer-Goßner, StPO, § 243 Rn. 31; SK-StPOFrister, § 243 Rn. 70-72 m.w.N. Nach Roxin/Schünemann, Strafverfahrensrecht, § 25 Rn. 8, muss hier jedenfalls eine analoge Anwendung des $\S 69$ StPO stattfinden.

717 BGH, NStZ 2000, 549 (549).

718 Hierzu Meyer-Goßner, StPO, § 240 Rn. 10.

719 Siehe etwa BGH, NJW 1967, 2020 (2020-2021); mehr bei LR-StPO-Becker, § 243 Rn. 71; Meyer-Goßner, StPO, § 249 Rn. 28. 
Angeklagten auf den Vorhalt hin abgegeben worden ist. ${ }^{720}$ Jedenfalls können auch etwa im Fall einer vorgehaltenen, aber vom Angeklagten in der Hauptverhandlung nicht bestätigten früheren Erklärung ${ }^{721}$ - im Wege nun des Urkundenbeweises nach $\S 254$ StPO Erklärungen des Angeklagten, die in einem richterlichen Protokoll enthalten sind, ,zum Zweck der Beweisaufnahme über ein Geständnis verlesen werden; [dasselbe] kann geschehen, wenn ein in der Vernehmung hervortretender Widerspruch mit der früheren Aussage nicht auf andere Weise ohne Unterbrechung der Hauptverhandlung festgestellt oder behoben werden kann. ${ }^{\text {“722 }}$

\section{- Struktur und Umfang der Vernehmungen: Vernehmung der Zeugen zur Sache}

In der Hauptverhandlung sind alle Zeugen grundsätzlich mündlich und unmittelbar zunächst durch den Vorsitzenden und anschließend durch die Prozessbeteiligten im Wege der Ausübung ihrer Fragerechte ${ }^{723}$ nach $\S \S 238,240-245$ StPO zu vernehmen. ${ }^{724}$ Wie weiter oben erläutert, ist jedoch unter bestimmten Voraussetzungen die komplette Ersetzung der Vernehmung vor Gericht durch die Verlesung bzw. Vorführung früherer schriftlich bzw. (für die Zwecke der Wahrheitserfor-

720 BGH, NJW 1958, 559 (559). Siehe auch BGH, NJW 1967, 2020 (2020-2021). Beulke, Strafprozessrecht, Rn. 421, bemerkt jedoch zu den Gefahren des Vorhalts: „Die Rspr zum Vorhalt erscheint problematisch, denn selbst für den Berufsjuristen - und erst recht für die Laienrichter - dürfte es zumeist unmöglich sein, das Verlesene (als prozessual nicht existent) von der Reaktion des Befragten (als einzig relevantes Beweismittel) zu unterscheiden. Wegen der Unmöglichkeit des Auseinanderhaltens von Vorhalt und Verlesung zum Urkundenbeweis wird deshalb im Schrifttum zu Recht gefordert, dass eine Verlesung auch zum Zwecke des Vorhalts nur in den Fällen der $\S \S 251$ ff StPO zulässig sei. Sollen weitergehende Vorhalte gemacht werden, muss der Richter dies durch formlose Mitteilungen aus dem Akteninhalt bewerkstelligen, ohne das Protokoll wörtlich zu verlesen [...]. In der Praxis ist aber der Vorhalt offensichtlich ein unverzichtbares Instrument." Eingehend Eisenberg, Beweisrecht, Rn. 868-879.

721 Vgl. BGH, NJW 1960, 1630 (1630-1631).

722 Hierzu u.a. Meyer-Goßner, StPO, § 254 Rn. 1-8. Siehe auch Beulke, Strafprozessrecht, Rn. 416.

723 Der Angeklagte hat jedenfalls das Recht aus Art. 6(3d) EMRK „Fragen an die Belastungszeugen zu stellen oder stellen zu lassen [...].“ Zur Bedeutung und Funktion des Fragerechts des Angeklagten Eisenberg, Beweisrecht, Rn. 792-794.

724 In BGH, NJW 2004, 239 (240), wird zur diesbezüglichen Rollenverteilung zusammengefasst: „Die Leitung der Verhandlung erfolgt durch den Vorsitzenden ( $\$ 238$ Absatz I StPO). Seine Leitungsbefugnis umfasst auch die Befugnis, die sachgerechte Vernehmung von Zeugen und Sachverständigen zu gewährleisten und insbesondere für die sachgerechte Ausübung des Fragerechts ( $\S 240$ Absatz II, 241a StPO) durch die Verfahrensbeteiligten Sorge zu tragen [...]. Er muss sicherstellen, dass der Zeuge zur Sache im Zusammenhang vortragen kann ( $\$ 69$ Absatz I StPO), Angriffe abwehren, die mit dem Anspruch des Zeugen auf angemessene Behandlung und Ehrenschutz unvereinbar sind und nicht erforderliche Fragen nach entehrenden Tatsachen ( $\$ 68 \mathrm{a}$ StPO) sowie unzulässige, ungeeignete und nicht zur Sache gehörende Fragen ( $§ 241$ Absatz II StPO) zurückweisen. Dies gebietet die Achtung vor der menschlichen Würde des Zeugen sowie das Rechtsstaatsprinzip [...].“ 
schung) $)^{725}$ elektronisch aufgezeichneter Vernehmungen zulässig, wie etwa in Fällen von faktisch unerreichbaren Zeugen. ${ }^{726}$ Nach $§ 255 a(2)$ StPO kann ferner die Vernehmung eines Zeugen unter 18 Jahren (sowie eines Verletzten, der zur Zeit der Tat unter 18 Jahre alt war) in Verfahren wegen der in dieser Vorschrift aufgelisteten Straftaten (z.B. bei Delikten gegen die sexuelle Selbstbestimmung) und unter Berücksichtigung u.a. der schutzwürdigen Interessen des Zeugen durch die Vorführung der Bild-Ton-Aufzeichnung einer früheren richterlichen Vernehmung ersetzt werden. Voraussetzung hierfür ist, dass der Angeklagte und sein Verteidiger Gelegenheit hatten, an der früheren Vernehmung mitzuwirken. Eine ergänzende Vernehmung des Zeugen vor Gericht ist hierbei allerdings zulässig und kann von Amts wegen nach Maßgabe der Aufklärungspflicht angeordnet werden. Eine solche ergänzende Vernehmung kann jedoch auch unter Anwendung von Zeugenschutzmaßnahmen, wie z.B. dem Aufenthalt des Zeugen an einem anderen Ort und der zeitgleichen Übertragung der Vernehmung in Bild und Ton in das Sitzungszimmer nach $\S 247$ a StPO, erfolgen. ${ }^{727}$ Neben der Vorschrift des $§ 247$ a StPO, ${ }^{728}$ welche die Durchbrechung der Prozessunmittelbarkeit im Wege der Videotechnik erlaubt, betreffen weitere im Rahmen der Hauptverhandlung selbstständig vorgesehene Vernehmungsmaßnahmen, die bei schutzbedürftigen Zeugen und/oder im Interesse der Wahrheitserforschung angewendet werden können/müssen, insbesondere: die Geheimhaltung der Identitäts- und Wohnortsdaten des Zeugen nach $§ 68$ StPO; die Entfernung des Angeklagten aus dem Sitzungszimmer während der Vernehmung nach $\S 247$ StPO; sowie die Vernehmung von minderjährigen Zeugen allein durch den Vorsitzenden nach $\S 241$ a StPO. ${ }^{729}$

Darüber hinaus sind generell sämtliche Zeugen zur Sache - ungeachtet dessen, wer sie erstmals vorgeladen bzw. gestellt hat und ob es sich bei ihnen faktisch um Entlastungs- oder Belastungszeugen oder um ,feindliche“ Zeugen handelt - mündlich in folgender Weise zu vernehmen: ${ }^{730}$ Anfangs ist der Zeuge in der Berichtsphase nach $\S 69$ (1) StPO, ,zu veranlassen, das, was ihm von dem Gegenstand seiner Vernehmung bekannt ist, im Zusammenhang anzugeben." Anschließend sind in der

\footnotetext{
725 Vgl. $\$ 58 \mathrm{a}(1-2)$ StPO.

726 Siehe insb. den Regelungskomplex der $\S \S 58 \mathrm{a}, 223$, 249-256 StPO. Ferner unter Teil 2, III.B.1.b).

727 Details bei Meyer-Goßner, StPO, § 255a Rn. 6-12.

728 Ausführlich hierzu u.a. Meyer-Goßner, StPO, § 247a Rn.1-13.

729 Nach §241a StPO gilt: ,(1) Die Vernehmung von Zeugen unter 18 Jahren wird allein von dem Vorsitzenden durchgeführt. (2) Die in $\S 240$ Abs. 1 und Abs. 2 Satz 1 bezeichneten Personen können verlangen, daß der Vorsitzende den Zeugen weitere Fragen stellt. Der Vorsitzende kann diesen Personen eine unmittelbare Befragung der Zeugen gestatten, wenn nach pflichtgemäßem Ermessen ein Nachteil für das Wohl der Zeugen nicht zu befürchten ist. (3) § 241 Abs. 2 gilt entsprechend." Siehe zusammenfassend zu diesen Vernehmungsmaßnahmen und den relevanten Rechtsprechungsansätzen Beulke, Strafprozessrecht, Rn. 196a, 425-430m.
}

730 Zum Gang der Zeugenvernehmung allgemein Beulke, Strafprozessrecht, Rn. 196. 
Verhörphase nach § 69(2) StPO ,zur Aufklärung und zur Vervollständigung der Aussage sowie zur Erforschung des Grundes, auf dem das Wissen des Zeugen beruht, $[\ldots]$ nötigenfalls weitere Fragen zu stellen. Zeugen, die durch die Straftat verletzt sind, ist insbesondere Gelegenheit zu geben, sich zu den Auswirkungen, die die Tat auf sie hatte, zu äußern." ${ }^{\text {(731 }}$

Nach § 68a(1) StPO sollen Fragen nach (entscheidungserheblichen) Tatsachen, die dem Zeugen oder einem Angehörigen ,zur Unehre gereichen können oder deren persönlichen Lebensbereich betreffen, [...] nur gestellt werden, wenn es unerläßlich ist" ${ }^{\text {" }}$ also wenn die Frage zur Erforschung der Wahrheit notwendig ist. ${ }^{732}$ Hinsichtlich der Prüfung der Glaubwürdigkeit des Zeugen wird ferner in $§ 68 \mathrm{a}(2)$ StPO bestimmt: „Fragen nach Umständen, die die Glaubwürdigkeit des Zeugen in der vorliegenden Sache betreffen, insbesondere nach seinen Beziehungen zu dem Beschuldigten oder der verletzten Person, sind zu stellen, soweit dies erforderlich ist. Der Zeuge soll nach Vorstrafen nur gefragt werden, wenn ihre Feststellung notwendig ist, [...] um seine Glaubwürdigkeit zu beurteilen. “733 Über die Zulässigkeit einer Glaubwürdigkeitsfrage nach $§ 68$ a StPO entscheidet der Vorsitzende und nach Bedarf das Gericht nach $§ 238(2)$ StPO. $^{734}$

Die Verwendung (z.B. durch Vorlegung) von schriftlichen Unterlagen, Protokollen und Lichtbildern als Vernehmungshilfen zur Gedächtnisauffrischung ist zulässig und gegebenenfalls auch geboten. ${ }^{735}$ Als Vernehmungsbehelf können dem Zeugen zur Unterstützung seines Gedächtnisses (und somit in der Praxis meistens zur Klärung von Lücken) Vorhalte etwa aus früheren protokollierten Vernehmungen und anderen Urkunden gemacht werden. Hier gelten die gerade diskutierten Vorhaltsmöglichkeiten im Rahmen der Vernehmung des Angeklagten entsprechend. ${ }^{736}$

731 Siehe ferner Meyer-Goßner, StPO, § 69 Rn. 1-11.

732 U.a. BGH, NStZ 1982, 170 (170).

733 Siehe dazu Meyer-Goßner, StPO, § 68a Rn. 6a-7. Zur Frage der Erörterung der Vorstrafen von Zeugen zum Zweck der Glaubwürdigkeitsprüfung Deutscher, NStZ 2012, 359 (359-362).

734 Meyer-Goßner, StPO, § 68a Rn. 8 m.w.N.

${ }_{735}$ Meyer-Goßner, StPO, $\S 69$ Rn. 8 mit weiteren Verweisen. Siehe auch Eisenberg, Beweisrecht, Rn. 1199-1202.

736 Nach BGH, NJW 1960, 1630 (1631): „Der Vorhalt ist ein bloßer Vernehmungsbehelf, der durch das Verbot des Urkundenbeweises nicht ohne weiteres unzulässig geworden ist. Die Grenzen zwischen dem Urkundenbeweis und dem Zeugenbeweis dürfen jedoch nicht verwischt werden. Der Vorhalt darf nicht dazu dienen, einen unzulässigen Urkundenbeweis zu ersetzen oder zu umgehen, sondern hat nur den Zweck, dem Zeugen, den das Gedächtnis im Stich gelassen hat, die Abgabe einer Erklärung zu ermöglichen. Beweismittel bleibt allein die Erklärung des Zeugen [...]. Nur was in dem Gedächtnis des Zeugen haften geblieben ist oder auf Vorhalt in die Erinnerung zurückkehrt und von ihm als Inhalt des Geständnisses bestätigt wird, ist als Beweisergebnis verwertbar." Siehe auch ergänzend BGH, NJW 2011, 3733 (3733): „Zwar kann der Inhalt einer Urkunde auch durch ihren Vorhalt an Zeugen zum Gegenstand der Hauptverhandlung gemacht werden [...]. Beweisgrundlage ist dann allerdings nicht der Vorhalt selbst, sondern die bestätigen- 
Durch Vorhalt einer früheren Vernehmungsniederschrift und die daraufhin abgegebene bestätigende Erklärung des Zeugen können nach einer Meinung zwecks Prüfung der Glaubwürdigkeit des Zeugen auch Erkenntnisse über die Konstanz seines Aussageverhaltens in die Hauptverhandlung eingeführt werden - diese Meinung ist aber, nicht zuletzt wegen des inhärenten Zirkelschlusses und somit des geminderten Beweiswertes, nicht unumstritten. ${ }^{737}$

Des Weiteren kann der Vorsitzende, insbesondere bei Misserfolg ${ }^{738}$ einer auf Vorhalten basierenden Vernehmungsweise und grundsätzlich nach der vollständigen Vernehmung des Zeugen, die Erhebung des Urkundenbeweises in Form der Verlesung eines früheren Vernehmungsprotokolls zum Zweck der Gedächtnisunterstützung und der Klärung von Widersprüchen anordnen; anschließend muss sich der Zeuge zum Protokollinhalt äußern. ${ }^{739}$ Konkreter gilt nach $§ 253$ StPO:

(1) Erklärt ein Zeuge oder Sachverständiger, daß er sich einer Tatsache nicht mehr erinnere, so kann der hierauf bezügliche Teil des Protokolls über seine frühere Vernehmung zur Unterstützung seines Gedächtnisses verlesen werden.

(2) Dasselbe kann geschehen, wenn ein in der Vernehmung hervortretender Widerspruch mit der früheren Aussage nicht auf andere Weise ohne Unterbrechung der Hauptverhandlung festgestellt oder behoben werden kann.

Darüber hinaus kann für die Sachaufklärung, insbesondere für die Klärung von Widersprüchen und allgemein für die vollständige Prüfung der Glaubwürdigkeit bzw. des Erinnerungsvermögens der Zeugen und der Glaubhaftigkeit ihrer Aussagen die Möglichkeit der Prozessbeteiligten (einschließlich des Angeklagten persönlich) zur unmittelbaren ${ }^{740}$ Befragung von ausschlaggebender Bedeutung sein. ${ }^{741}$

de Erklärung desjenigen, dem der Vorhalt gemacht wurde [...]. Der Einführung einer Urkunde mittels Vorhalt sind deshalb Grenzen gesetzt. Insbesondere wenn es sich um längere oder sehr komplexe Ausführungen handelt, besteht die Gefahr, dass die Auskunftsperson den Sinn der schriftlichen Erklärung auf den bloßen inhaltlichen Vorhalt hin nicht richtig oder nur unvollständig erfasst oder sich an den genauen Wortlaut eines Schriftstücks nicht zuverlässig erinnern kann [...].“ Dazu auch Meyer-Goßner, StPO, § 69 Rn. 7, § 249 Rn. 28, § 253 Rn. 3, 10.

737 BGH, StV 1993, 59 (60), mit ablehnender Anmerkung von Weider, StV 1993, 60 (60-61). Hierzu m.w.N. auch Meyer-Goßner, StPO, § 253 Rn. 10.

738 Siehe BGH, NStZ 2002, 46 (47): „Nach der Rechtsprechung des BGH kommt die Verlesung der früheren Aussage nur in Betracht, 'nachdem Vorhalte aus dem Protokoll weder eine Übereinstimmung der gegenwärtigen Aussage mit dem Inhalt des Protokolls bewirkt noch dazu geführt haben, dass der Zeuge bekundete, bei der Aufnahme des Protokolls abweichend von seiner gegenwärtigen Aussage tatsächlich das im Protokoll Festgehaltene ausgesagt zu haben' (vgl. BGHSt 20, 160, 162; BGH Urt. v. 2.3.1983 - 2 StR 744/82, teilw. wiedergegeben in NStZ 1984, 17).“

739 Siehe Meyer-Goßner, StPO, § 253 Rn. 1-10 mit weiteren Details und Verweisen.

740 Zur Unmittelbarkeit der Befragung durch die Prozessbeteiligten, bei der grundsätzlich keine Vermittlung des Vorsitzenden und keine vorherige Mitteilung der Fragen geboten ist, siehe Meyer-Goßner, StPO, $\S 240$ Rn. 9. Das Fragerecht des Angeklagten aus $\S 240(2)$ StPO betrifft ferner nur die in der Hauptverhandlung anwesenden Zeugen, siehe hierzu Eisenberg, Beweisrecht, Rn. 797b. Dagegen bezieht sich das Konfrontationsrecht aus Art. 6(3d) EMRK grundsätzlich auch auf die originäre belastende Beweisquelle; vgl. 
Nach $\S 240$ StPO hat der Vorsitzende ,den beisitzenden Richtern auf Verlangen zu gestatten, Fragen an [...] die Zeugen und die Sachverständigen zu stellen. Dasselbe hat der Vorsitzende der Staatsanwaltschaft, dem Angeklagten und dem Verteidiger sowie den Schöffen zu gestatten." Dies geschieht in der Regel nach dem Ende der richterlichen Vernehmung jedes einzelnen Zeugen; jedenfalls dürfen die Prozessbeteiligten die Befragung durch den Vorsitzenden oder durch die anderen Beteiligten nicht unterbrechen, um eigene Fragen zu stellen. Auf Verlangen wird der Vorsitzende das Wort oft zuerst den beisitzenden Richtern, dann dem StA und dem Verteidiger bzw. dem Beteiligten, der den Zeugen benannt hat, erteilen; der Vorsitzende ist jedenfalls dabei nur an die Zweckmäßigkeitsmaßstäbe der Aufklärungspflicht und nicht an eine bestimmte Reihenfolge gebunden. ${ }^{742}$ Die Befragung seitens der Verfahrensbeteiligten muss grundsätzlich durch Stellen von einzelnen und genau umrissenen Fragen stattfinden; sie kann jedoch auch in Form von kurzen Vorhalten, möglicherweise einschließlich kurzer Ausführungen zum besseren Verständnis der Frage, erfolgen. ${ }^{743}$ Das Fragerecht endet mit der Entlassung nach $\S 248$ StPO und der Entfernung des jeweiligen Zeugen. ${ }^{744}$

\section{- Kreuzverhör als prozessuale Möglichkeit}

Die Strafprozessordnung eröffnet dem Verteidiger und der StA unter bestimmten Voraussetzungen die Möglichkeit, die ganze Vernehmung der von ihnen benann$\operatorname{ten}^{745}$ Zeugen (und Sachverständigen) selbst in die Hand zu nehmen und hierzu ein förmliches Kreuzverhör durchzuführen. Der Vorsitzende ist jedoch auch hierbei verpflichtet, den Zeugen weitere zur Sachverhaltsaufklärung erforderliche Fragen selbst zu stellen. $\S 239$ StPO bestimmt:

(1) Die Vernehmung der von der Staatsanwaltschaft und dem Angeklagten benannten Zeugen und Sachverständigen ist der Staatsanwaltschaft und dem Verteidiger auf deren übereinstimmenden Antrag von dem Vorsitzenden zu überlassen. Bei den von der

jedoch zusammenfassend zur Beweiswürdigungslösung der Rechtsprechung bei nicht konfrontierten Zeugenaussagen Roxin/Schünemann, Strafverfahrensrecht, § 44 Rn. 20.

${ }^{741}$ Vgl. u.a. Eisenberg, Beweisrecht, Rn. 792-792b, zur Funktion des Fragerechts des Angeklagten.

742 LR-StPO-Becker, $§ 240$ Rn. 12; Meyer-Goßner, StPO, § 240 Rn. 6-7.

743 LR-StPO-Becker, § 240 Rn. 16; Meyer-Goßner, StPO, § 240 Rn. 5 mit weiteren Verweisen.

${ }^{744}$ U.a. Eisenberg, Beweisrecht, Rn. 796. In BGHSt 15, 161 (163), wurde bestimmt, dass mit der Entlassung der Beweisperson im allseitigen Einverständnis „das Fragerecht [endete]. Es setzt voraus, daß die Beweisaufnahme bezüglich der zu befragenden Beweisperson noch andauert und diese vor Gericht anwesend ist. In dem Verlangen, eine bereits vernommene und entlassene Beweisperson neuerlich über eine bestimmte Frage zu hören, kann aber ein Beweisantrag liegen [...].“

745 Siehe Meyer-Goßner, StPO, § 239 Rn. 4-5: „Benannt iS I S 1 sind auch Zeugen und Sachverständige, die das Gericht auf bloße Anregung von StA oder Angeklagten geladen hat oder die von ihnen selbst geladen oder in der Hauptverhandlung gestellt worden sind." 
Staatsanwaltschaft benannten Zeugen und Sachverständigen hat diese, bei den von dem Angeklagten benannten der Verteidiger in erster Reihe das Recht zur Vernehmung.

(2) Der Vorsitzende hat auch nach dieser Vernehmung die ihm zur weiteren Aufklärung der Sache erforderlich scheinenden Fragen an die Zeugen und Sachverständigen zu richten.

Der Vorsitzende kann ferner nach $\S 241$ StPO in das Kreuzverhör eingreifen, um einzelne ungeeignete oder nicht zur Sache gehörende Fragen zurückzuweisen oder um Prozessbeteiligten, welche die Vernehmungsbefugnis aus § 239(1) StPO missbrauchen, diese Befugnis völlig zu entziehen. Ein Missbrauch liegt insbesondere vor bei die Wahrheitsfindung behindernden, die schutzwürdigen Interessen des Zeugen verletzenden oder sich wiederholenden und sachfremde Zwecke verfolgenden Befragungen. ${ }^{746}$ Bei einer Entziehung der Kreuzverhörbefugnis setzt an Stelle des davon Betroffenen der Vorsitzende die Vernehmung fort. ${ }^{747}$

Im Allgemeinen findet in der Praxis ein förmliches Kreuzverhör nach § 239 StPO sehr selten statt. Das Kreuzverhör ist sogar als ein „Fremdkörper“ im deutschen Strafprozess charakterisiert worden: „[Das] Schwergewicht liegt in diesem Verfahren bei der Sachaufklärung durch den Vorsitzenden und das Gericht. StA und Verteidiger sind idR weder daran interessiert noch darauf vorbereitet, die Vernehmung der von ihnen benannten Zeugen vollständig zu übernehmen. “748 Darüber hinaus ist jedenfalls die Durchführung eines informellen Kreuzverhörs zulässig: Hierbei kann der Vorsitzende, ungeachtet der Voraussetzungen des $§ 239$ StPO, im Anschluss an die Berichtsphase (\$ 69(1) StPO) frühzeitig der StA und dem Verteidiger die eigentliche Befragung des Zeugen überlassen; erst am Ende des Verhörs kann der Vorsitzende selbst erforderlichenfalls weitere Fragen stellen. ${ }^{749}$

\section{- Richterliche Kontrolle der Befragungen}

Der Vorsitzende kann (von Amts wegen oder auf Antrag) ${ }^{750}$ grundsätzlich nur nach $\S 241(2)$ StPO im Fall einer missbräuchlichen Ausübung des Fragerechts seitens der StA, des Angeklagten, des Verteidigers oder der Schöffen zur Beschrän-

\footnotetext{
746 LR-StPO-Becker, § 241 Rn. 2; Meyer-Goßner, StPO, § 241 Rn. 1-2.

747 LR-StPO-Becker, $\S 241$ Rn. 4.

748 Meyer-Goßner, StPO, § 239 Rn. 1. Siehe auch Roxin/Schünemann, Strafverfahrensrecht, § 44 Rn. 24: „Das aus dem angloamerikanischen Rechtskreis übernommene Kreuzverhör (cross examination) [...] passt, weil es den Vorsitzenden aus der Verhandlungsleitung verdrängt, nicht in die Struktur des deutschen Strafprozesses. [...] In der Praxis hat es sich [...] nicht durchgesetzt, hauptsächlich deshalb, weil der Sitzungsvertreter der StA meistens über keine Aktenkenntnis verfügt und der Vorsitzende ohnehin auf der Marschroute der Ermittlungsakten vorgeht [...].“ Siehe auch Weigend, ZStW 100 (1988), 733 (734). Siehe aber auch Gaede, StV 2012, 51 (55-56).

${ }^{749}$ Dazu Meyer-Goßner, StPO, § 239 Rn. 2. Siehe ferner zur Problematik Dencker, FS für Kleinknecht, S. 81-89.

750 Meyer-Goßner, StPO, § 241 Rn. 16.
} 
kung ihrer Befragungsbefugnis eingreifen und einzelne, ungeeignete oder nicht zur Sache gehörende Fragen“ zurückweisen; eine völlige Entziehung des Fragerechts ist jedoch grundsätzlich unzulässig. ${ }^{751}$ Als ,nicht zur Sache gehörend“ ist eine Frage anzusehen, wenn sie ,,sich weder unmittelbar noch mittelbar auf den Gegenstand der Untersuchung ${ }^{6752}$ bezieht; Fragen, die ersichtlich ernsthaft auf die Prüfung der Glaubwürdigkeit oder des Erinnerungsvermögens des Zeugen abzielen, sind, weil sie zur Sache gehören, nicht zurückzuweisen. ${ }^{753}$ Als ,ungeeignet" ist eine Frage insbesondere dann anzusehen, wenn sie , in tatsächlicher Hinsicht nichts zur Wahrheitsfindung beitragen“754 kann oder „wenn sie nach den Bestimmungen der StPO nicht gestellt werden soll.“755 Die nach § 68a StPO unzulässigen Glaubwürdigkeitsfragen der Verfahrensbeteiligten können somit vom Vorsitzenden nach § 241(2) StPO als ,ungeeignet“ zurückgewiesen werden. ${ }^{756}$ Unter anderem sind auch Fragen, die Werturteile oder rechtliche Beurteilungen betreffen, sowie Suggestivfragen als ungeeignet $\mathrm{zu}$ betrachten. ${ }^{757}$

Beanstandungen der richterlichen Zurückweisung einer Frage und die entsprechende Anrufung des Gerichts sind, wie auch sonst bei sämtlichen Anordnungen des Vorsitzenden im Rahmen einer Zeugenvernehmung, nach § 238(2) StPO möglich. ${ }^{758}$ In allen Fällen - auch dort, wo $§ 238(2)$ StPO nicht anwendbar ist ${ }^{759}$ - ent-

751 Sonstige Unterbrechungen und Eingriffe des Richters während der Ausübung des Fragerechts sind grundsätzlich nicht erlaubt, siehe hierzu LR-StPO-Becker, § 240 Rn. 17, $\S 241$ Rn. 24 m.w.N. Siehe auch Roxin/Schünemann, Strafverfahrensrecht, § 44 Rn. 21-23. In BGH, NStZ 1995, 143 (143), wurde aber bestimmt: „Ein Recht des Verteidigers, eine einmal begonnene Zeugenbefragung fortzusetzen und zu Ende zu führen, gibt es nicht; den Zeitpunkt, zu dem eine solche Befragung begonnen, fortgesetzt oder zum Abschluß gebracht wird, bestimmt der Vorsitzende - kraft der ihm zustehenden Befugnis zur Verhandlungsleitung (§ 238 Absatz I StPO) - allein; die Verfahrensbeteiligten können hierzu zwar unverbindliche Anregungen geben, Mitspracherechte stehen ihnen aber insoweit nicht zu.“

752 BGHSt 2, 284 (287).

753 BGHSt 2, 284 (288-289); BGHSt 13, 252 (255); BGH, StraFo 2009, 333 (333); mehr Verweise bei Eisenberg, Beweisrecht, Rn. 798-798a.

754 Meyer-Goßner, StPO, § 241 Rn. 15.

755 BGH, NJW 1968, 710 (713).

756 BGH, NJW 1968, 710 (713).

757 LR-StPO-Becker, § 241 Rn. 13-16, worin auch Suggestivfragen als Fragen definiert werden, die in einer solchen Form gestellt werden, ,die darauf abzielt, dem Befragten eine bestimmte Antwort in den Mund zu legen oder ihn zu einer mehrdeutigen Antwort zu verleiten, um ihn festzulegen oder einen Einwand gegen seine Aussage zu gewinnen"; siehe auch Meyer-Goßner, StPO, § 241 Rn. 15 mit weiteren Beispielen.

758 Mehr dazu bei Meyer-Goßner, StPO, § 241 Rn. 16-23.

759 Siehe die Auflistung bei LR-StPO-Becker, § 242 Rn. 1: „Dies ist der Fall, wenn der Vorsitzende nicht befugt ist, die konkrete Frage zu beanstanden, etwa weil sie von einem der beisitzenden Berufsrichter gestellt wurde (§ 240 Abs. 1; § 241 Abs. 2), oder wenn er aus welchen Gründen auch immer - von einer Beanstandung der Frage absieht. § 242 gilt ferner für die Beanstandung der Fragen des Vorsitzenden selbst. [...] Im Übrigen darf dieser auch dort, wo er zunächst selbst entscheiden könnte, von sich aus eine Entscheidung des Gerichts über die Zulässigkeit einer Frage nach § 242 herbeiführen.“ 
scheidet letztendlich das gesamte Gericht nach $§ 242$ StPO über Zweifel der Richter und der sonstigen Prozessbeteiligten an der Zulässigkeit von allseitig gestellten Fragen.

\section{E. Zusammenfassung: Besonderheiten des Beweisführungssystems}

Im Hinblick auf den Schwerpunkt des Forschungsvorhabens sind insbesondere folgende Besonderheiten des gerade präsentierten herkömmlichen erstinstanzlichen deutschen Beweisführungssystems im Rahmen einer zusammenfassenden Kurzbetrachtung hervorzuheben: ${ }^{760}$

\section{Die vorbereitenden Beweisführungsvorgänge}

In Bezug auf die Problematik der „Aufbereitung“ des Beweismaterials und der Bestimmung des Umfangs der Beweiserhebungen ist vor allem Folgendes festzuhalten:

- Im deutschen Strafprozess werden die Ziele der materiellen und prozessualen Gerechtigkeit gleichzeitig verfolgt; als zentrales, die diversen Erscheinungen des Strafprozessrechts weitgehend umfassendes (End-)Ziel des Strafverfahrens wird heute die Rechtsfriedensschaffung anerkannt. Im Zentrum der Gerechtigkeitserwägungen steht die Ermittlung des wahren Sachverhalts nach den Grundprinzipien und Regeln des strafprozessualen Beweises. Das Gericht hat im Rahmen seiner Aufklärungspflicht zur Erforschung der materiellen Wahrheit die Beweisaufnahme von Amts wegen auf alle Tatsachen und Beweismittel zu erstrecken, die für die Entscheidung von Bedeutung sind.

- In der Hauptverhandlung wird das Vorliegen oder Nicht-Vorliegen der entscheidungserheblichen Tatsachen im Wege des Strengbeweisverfahrens durch Benutzung aller gesetzlichen Beweismittel unter Anwendung der Bestimmungen des Beweisverbotssystems und der Unmittelbarkeitsregeln geprüft. Das Gericht entscheidet im Hauptverfahren über das Ergebnis der Beweisaufnahme ,nach seiner freien, aus dem Inbegriff der Verhandlung geschöpften Überzeugung“ ( $\$ 261$ StPO). Das Prinzip der freien Beweiswürdigung fordert eine subjektive zweifelsfreie Überzeugungsbildung seitens der (Berufs- und Laien-)Richter. Das Gericht muss nach Abschluss der Beweiswürdigung im Fall eines eventuell vorhandenen Zweifels hinsichtlich der materiell-rechtlich relevanten Tatsachenlage zugunsten des Angeklagten entscheiden (in dubio pro reo). Schuldvermutungen und Beweislastumkehrungen zulasten des Angeklagten sind prinzipiell ausgeschlossen.

${ }^{760}$ Vgl. inbs. an dieser Stelle noch einmal die Zusammenfassung der definierten Modellelemente unter Teil 1, II.C.4. 
- Mit der Anklageerhebung und Einreichung der polizeilichen und staatsanwaltlichen Verfahrensakte und sämtlicher Beweisergebnisse des amtlichen Vorverfahrens bei Gericht setzt im deutschen Strafverfahren die gerichtliche Untersuchung des Sachverhaltes ein. Auch im Stadium des Zwischenverfahrens können ergänzende Beweiserhebungen vom Gericht zur besseren Aufklärung der Sache angeordnet werden; ausnahmsweise darf die StA auch nach dem Beginn der gerichtlichen Untersuchung, soweit diese nicht gestört wird, weiterhin von sich aus Ermittlungen anstellen. Nach Eröffnung des Hauptverfahrens kann das Gericht bei der Vorbereitung und außerhalb der Hauptverhandlung kommissarische Beweiserhebungen anordnen. In der Hauptverhandlung wird die Beweisaufnahme durch den Richter und unter Mitwirkung der Prozessbeteiligten durchgeführt. Der StA ist im ganzen Verfahren, auch in der Hauptverhandlung als Vertreter der Anklage, der Objektivität, Gerechtigkeit und Wahrheit verpflichtet. Die Akteneinsichts- und übrigen Verteidigungsrechte des Verteidigers dienen der besseren Vorbereitung und der Gewährleistung einer „Chancengleichheit“ im Prozess. Der Verteidiger wirkt grundsätzlich einseitig zum effektiven Schutz und zur Förderung der gesetzlich anerkannten Interessen des Beschuldigten; gleichzeitig nimmt er jedoch auch öffentliche Aufgaben und Interessen wahr. Strafrechtswidrige Handlungen sowie auch offensichtlicher Missbrauch der Verteidigungsrechte sind verboten.

- In Bezug auf den zeugenbasierten Beweis gilt allgemein, dass alle Personen, deren Aussage nach den Maßstäben der Amtsaufklärungspflicht bzw. den Beweisantragsregeln als fallrelevant und für die Schuldfrage als entscheidend anzusehen ist, grundsätzlich in der Hauptverhandlung öffentlich, persönlich und mündlich Auskunft geben müssen. Somit müssen alle zentralen Beweispersonen, unabhängig davon, ob es sich bei ihnen faktisch um Belastungs- oder Entlastungszeugen handelt, hinsichtlich ihrer Tatsachenwahrnehmungen zunächst vom Vorsitzenden Richter des erkennenden Gerichts vernommen werden; auch Zeugen vom Hörensagen sind in der deutschen Hauptverhandlung anzuhören (vgl. die Problematik des Unmittelbarkeitsprinzips und seiner Durchbrechungen). ${ }^{761}$ Vorgerichtlich sind die Anklage-, Ermittlungs- und Vernehmungsbehörden, die auf normativer Ebene keine selbstständigen Verfahrensparteien sind, bei etwaigen Kontakten mit Zeugen zur Objektivität verpflichtet, wobei faktische Beeinflussungen der Zeugen nicht immer einfach zu vermeiden sind. Der Verteidiger darf jedenfalls im Rahmen seiner außergerichtlichen Kontakte mit aufzurufenden Zeugen und mit Blick auf die Vorbereitung ihrer späteren Aussage keine Beweisquellen trüben.

• Erforderlichenfalls werden als Hilfsmittel für das Gericht Sachverständige aufgrund ihrer besonderen Kenntnisse oder speziellen Fähigkeiten mit der Feststellung und/oder Beurteilung von konkreten sachverhaltsrelevanten Tatsachen bzw. mit der Mitteilung von Erfahrungssätzen beauftragt. Die Anordnung des Sachverständigenbeweises, insbesondere die Auswahl eines im konkreten Fall sachkundigen

761 Unter Teil 2, III.B.1.b)bb). 
Sachverständigen und die Leitung seiner Tätigkeiten, sind primär eine zentralamtliche bzw. richterliche Angelegenheit. Der Sachverständige hat eine Erscheinenspflicht und eine Wahrheitspflicht bei der Erstellung seines Gutachtens. Sein Gutachten muss er in der maßgebenden Hauptverhandlung in der Regel in eigener Person mündlich erstatten. Die Verfahrensbeteiligten können Beweisanträge auf (Ladung und) Vernehmung eines Sachverständigen stellen. Schließlich können sowohl die Verteidigung als auch die StA einen bestimmten (in der Praxis gezielt ausgewählten) Sachverständigen selbst unmittelbar laden und seine Vernehmung vor Gericht beantragen.

- Nach der Anklageerhebung können die StA und die Verteidigung die gerichtliche Erhebung bestimmter Beweise und zusätzlich zum bereits gesammelten und amtlich dokumentierten Material die Einführung von weiteren Beweismitteln in das Verfahren beantragen. Der Richter hat jedoch das erste und (meistens auch) das letzte Wort bei der Bestimmung des Umfangs der maßgebenden Beweiserhebungen und bei der Prüfung des Beweismaterials. Auch für die Anordnung der Ladung der zur Hauptverhandlung erforderlichen Zeugen und Sachverständigen ist zunächst der Vorsitzende Richter des erkennenden Gerichts zuständig. Der Umfang der richterlichen Aufklärungspflicht richtet sich dabei nach den Umständen des Einzelfalls. Die Aufklärungspflicht gebietet jedoch keine sinnlosen und unterschiedslos aufwendigen Beweisermittlungen. Ihrerseits können die StA (als Anklagevertreterin im Einklang mit ihrer Objektivitätspflicht) und die Verteidigung (unbeschadet der Selbstbelastungsfreiheitsnormen) in die Bestimmung des Umfangs der Beweiserhebungen durch bloße Beweisanregungen und generelle formlose Ermittlungsanträge, durch förmliche Anträge auf gerichtliche Erhebung von Beweisen oder durch die unmittelbare Ladung von Beweispersonen bzw. Herbeischaffung von weiteren Beweismitteln eingreifen. Allerdings verfügt der Vorsitzende bzw. das Gericht zum Teil, im Rahmen insbesondere der Amtsaufklärungspflicht und bei Vorliegen von gesetzlich vorgesehenen Gründen, über die Befugnis zur Beschränkung dieser Beweisführungsmöglichkeiten der Verfahrensbeteiligten.

- In organisatorischer Hinsicht ist der Vorsitzende bzw. das Gericht zur zügigen Vorbereitung der Hauptverhandlung unter anderem für die Terminbestimmung, die ordnungs- und fristgemäße Anordnung der erforderlichen Ladungen und Benachrichtigungen und die Namhaftmachung der amtlich geladenen Beweispersonen verantwortlich. Der Vorsitzende hat auch, insbesondere mit Blick auf einen sich voraussichtlich über längere Zeit erstreckenden Prozess, einen Plan für die Ladung der Beweispersonen und eine sinnvolle Planung etwa bezüglich der Reihenfolge der Beweiserhebungen zu entwerfen. Ferner kann das Gericht unter Umständen auf die Vorwegnahme von Teilen der hauptgerichtlichen Beweisaufnahme durch Anordnung von kommissarischen Beweisführungen entscheiden. Des Weiteren kann das Gericht nach der Anklageerhebung zunächst im Zwischenverfahren, während der Vorbereitung der Hauptverhandlung und auch in der Hauptverhandlung den jeweiligen Stand des Verfahrens mit den Verfahrensbeteiligten erörtern, soweit dies 
geeignet erscheint, das Verfahren, etwa durch die Klärung diverser technischer Beweisfragen, zu fördern.

\section{Kenntnisnahme und Offenlegung von Beweisen}

In Bezug auf die Problematik der Kenntnis der Beweisergebnisse des Vorverfahrens seitens des Richters sowie der Akteneinsicht und Offenlegung des Vorverfahrensmaterials durch die Prozessbeteiligten ist vor allem Folgendes festzuhalten:

- Schon im Zwischenverfahren und bei der Vorbereitung der Hauptverhandlung können die Berufsrichter des erkennenden Gerichts umfassende Kenntnis vom Ergebnis der Ermittlungen, vom amtlich gesammelten Beweismaterial und von der allgemeinen Beweislage erhalten; dies kann nicht zuletzt aufgrund der Vorlegung der Anklageschrift und der bisherigen Verfahrensakten, aufgrund der eventuell gestellten vorbereitenden Beweisanträge oder der Namhaftmachung von durch die Verteidigung und StA unmittelbar geladenen Zeugen und Sachverständigen geschehen. Diese Kenntnis seitens der Berufsrichter (in der Regel nicht seitens der mitwirkenden Schöffen) kann nicht nur die Bestimmung des Umfangs, sondern auch die Art und Weise der maßgebenden Beweisaufnahme in der Hauptverhandlung beeinflussen. Wegen der Pflicht zur richterlichen Verhandlungsleitung und Beweisführung lässt sich freilich die Aktenkenntnis zumindest seitens des Vorsitzenden nur schwer vermeiden. Nicht von der Hand zu weisen ist jedoch hierbei schon mit Blick auf die Beweisführung die Gefahr der Voreingenommenheit des Richters.

- Die Verfahrensakten, die insbesondere die entscheidungsrelevanten Beweisergebnisse der staatsanwaltlichen und polizeilichen Ermittlungen in objektiver und vollständiger Weise dokumentieren müssen, sind mit der Anklageerhebung durch die StA dem Gericht vorzulegen. Die Verteidigung besitzt ein (zumindest nach Abschluss der Ermittlungen) uneingeschränktes Recht auf Einsicht in die offiziell zusammengestellten Akten sowie zur Besichtigung von amtlich verwahrten Beweisstücken, was sich grundsätzlich auf alle dem Gericht vorliegenden oder vorzulegenden entlastenden und belastenden Materialien bezieht. Die Akteneinsicht kann der effektiveren Vorbereitung der Beweisthesen der Verteidigung und der Gewährleistung des Rechts auf rechtliches Gehör, des Fairnessgrundsatzes und der Waffengleichheit im Prozess dienen. Die Verteidigung wird in informatorischer Hinsicht des Weiteren insbesondere durch die Mitteilung des beweisbezogenen Inhalts der Anklageschrift, durch die Vorlage der Protokolle kommissarischer Beweisaufnahmen und durch die Namhaftmachung der von Gericht und StA vorgeladenen Zeugen und Sachverständigen unterstützt. Das Einsichtsrecht erstreckt sich darüber hinaus kontinuierlich auch auf die nach der Anklageerhebung entstandenen Aktenteile und die vom Gericht herbeigezogenen oder von der StA nachgereichten Beiakten sowie auf die Ergebnisse von während der Hauptverhandlung durchgeführten außergerichtlichen Ermittlungen. In konkreten Fällen haben die StA (insbesondere 
bei nicht entscheidungserheblichen Spurenakten) und die obersten Dienstbehörden (aufgrund überwiegender staatlicher Geheimhaltungsinteressen) allerdings die Möglichkeit, bestimmte Kategorien von Beweisinformationen vom Gericht und vom Angeklagten zurückzuhalten. Schließlich ist die Verteidigung ihrerseits nicht verpflichtet, ihre Beweisthesen im Voraus weitgehend offenzulegen. Entscheidet sie sich aber für die Stellung eines strengförmlichen vorbereitenden Beweisantrags, muss sie darin konkrete Angaben über die verlangten Beweismittel und die behaupteten Beweistatsachen machen. Der Angeklagte hat ferner die von ihm unmittelbar geladenen oder zur Hauptverhandlung zu stellenden Zeugen und Sachverständigen rechtzeitig dem Gericht und der StA namhaft zu machen; es existiert jedoch keine Verpflichtung zur Bekanntgabe des hierbei zu untersuchenden Beweisthemas. Allein das verspätete Vorbringen von Beweismitteln und Beweistatsachen darf darüber hinaus nicht zur Ablehnung der beantragten Beweiserhebung führen.

\section{Die Beweisführung im Hauptverfahren}

In Bezug auf die Problematik des Beweisausschlusses sowie der Erhebung, Präsentation und Prüfung der Stichhaltigkeit der Beweise vor Gericht ist vor allem Folgendes festzuhalten:

- Im deutschen Strafprozess ist das Gericht zur umfassenden Aufklärung eines angeklagten streitigen Sachverhalts durch vollständige Beweisführung innerhalb einer Hauptverhandlung verpflichtet. Außer vielleicht bei extremen Fairnessverletzungen kommen ein Verfahrenshindernis und die Möglichkeit der Verfahrenseinstellung aufgrund von rechtsstaatlichen Prinzipien grundsätzlich nicht in Betracht. Vielmehr wird ein eröffnetes Hauptverfahren meistens bis zur Phase der Beweiswürdigung und Strafzumessung grundsätzlich in mündlicher und unmittelbarer Weise fortgesetzt.

- Der Vorsitzende bzw. das Gericht muss von Amts wegen für die Erhebung und Verwertung der entscheidungsrelevanten Beweise unter Anwendung der Regeln des Strengbeweises und der Verfahrensunmittelbarkeit sorgen. Überdies sind aus dem Erkenntnisverfahren und aus der Urteilsbasis möglicherweise sogar entscheidungserhebliche Beweise aufgrund von Beweisverbotsbestimmungen auszuschließen. Die Amtsaufklärungspflicht ist nicht um jeden Preis umzusetzen, wie insbesondere die im Rahmen der Beweisführung unmittelbar wirkenden Beweiserhebungsverbote sowie auch die bei ihrer richterlichen Anwendung oft abwägungsbedürftigen und meistens erst bei der Urteilsfindung (also nach der jeweiligen Beweiserhebung) wirkenden Beweisverwertungsverbote zeigen. Ferner muss das Gericht Beweisanträge der Verfahrensbeteiligten ablehnen, wenn die entsprechenden Beweiserhebungen, etwa aufgrund von Beweisverboten, unzulässig sind. Es existieren keine eigenständigen vorgerichtlichen Verfahren, die vorwegnehmend zur verbindlichen Klärung der Beweisausschlussfragen eingesetzt werden könnten. In der Hauptverhandlung kann/muss das Gericht von Amts wegen die relevanten Gesetzes- 
vorschriften anwenden und über das Vorliegen der Voraussetzungen eines Beweisverbots entscheiden. Die Rechtsprechung macht ein Beweisverwertungsverbot dennoch davon abhängig, ob der Verwertung der betroffenen Information bei der Urteilsfindung nach ihrer Einführung in die Hauptverhandlung (und spätestens unmittelbar im Anschluss an die jeweilige Beweiserhebung) widersprochen wird. Wird ein solcher Widerspruch erhoben, ist jedoch während der Hauptverhandlung kein Zwischenbescheid, in dem sich das Gericht zur Frage des Beweisverwertungsverbots erklären müsste, vorgesehen, auch wenn das Gericht seine Rechtsauffassung hierzu im laufenden Verfahren mitteilen darf. Jedenfalls ist während der Hauptverhandlung die Erhebung von Beanstandungen seitens der Verfahrensbeteiligten gegen unzulässige Leitungsanordnungen des Vorsitzenden erlaubt bzw. aus revisionsrechtlichen Gründen sogar geboten; solche Beanstandungen können auch die Zulässigkeit der Anordnung zur Nicht-Benutzung oder Benutzung eines Beweismittels betreffen.

- Der eigentliche Tatsachenfeststellungsvorgang im deutschen Gerichtsverfahren ist durch die richterliche Aufklärungspflicht gekennzeichnet. Die Richter müssen von Amts wegen und selbstständig auf der Basis der jeweils bekannten Umstände des Einzelfalls mit allen zulässigen Beweismitteln sämtliche materiell-rechtlich relevanten Tataspekte des Sachverhalts in sinnvoller, aber nicht überschießender Weise erforschen. Die StA vertritt in der Hauptverhandlung ihr Anklagevorbringen; auch sie ist bei der Ausübung ihrer Mitwirkungsbefugnisse während der Beweisführungen zur Objektivität verpflichtet. Der Angeklagte muss seinerseits grundsätzlich nicht aktiv die Sachaufklärung fördern oder an den Beweisführungen mitwirken. Im deutschen Hauptverfahren findet letztendlich vor allem eine gerichtliche Untersuchung des angeklagten Sachverhalts statt, bei der die zentralen Prozessbeteiligten Mitwirkungsrechte haben, jedoch nicht wirkliche Beweisführer sind. Die Durchführung einer vollständigen richterlichen Beweisaufnahme unabhängig vom Willen der Verfahrensbeteiligten ist somit weitgehend möglich bzw. kann je nach Einzelfall geboten erscheinen. Die Strafklage kann nach Eröffnung des Hauptverfahrens nicht zurückgenommen werden, und ein Strafverfolgungsabbruch bzw. eine einseitige Verfahrenseinstellung durch die StA ist nach dem Eröffnungsbeschluss grundsätzlich nicht mehr möglich. Darüber hinaus existieren (neben den Vorschriften zur Prozesseinstellung aufgrund von Opportunitätserwägungen und zur abgesprochenen Erledigung des Verfahrens aus Prozessökonomiegründen) teilweise auch Möglichkeiten zur vereinfachten Durchführung der Beweisaufnahme. $\mathrm{Zu}$ erwähnen sind insbesondere die Fälle der Tatsachenoffenkundigkeit sowie die Möglichkeiten des Absehens von der richterlichen Erhebung einzelner präsenter Beweise und der (sonst unzulässigen) Verlesung früherer Vernehmungsprotokolle aufgrund des Einverständnisses der Verfahrensbeteiligten. Gleichwohl besteht auch hierbei meistens ein richterliches Entscheidungsermessen, und die richterliche Amtsaufklärungspflicht wird niemals wirklich aufgehoben. 
- Die Verhandlungsleitung, die Vernehmung des Angeklagten und die Beweisaufnahme, einschließlich u.a. der Hauptbefragung der Beweispersonen, obliegen in sämtlichen erstinstanzlichen Gerichtsverfahren weiterhin dem Vorsitzenden des erkennenden Gerichts. Das ganze Gericht entscheidet gemeinsam u.a. über Beanstandungen der Verfahrensbeteiligten in Bezug auf Leitungsanordnungen des Vorsitzenden, über Zweifel über die Zulässigkeit der Zeugenbefragungen, über die in der Hauptverhandlung gestellten Beweisanträge und über die Verlesung von Vernehmungsprotokollen; außerdem kann es den beisitzenden (Berufs- und Laien-) Richtern auch gestattet werden, Fragen an die Beweispersonen zu stellen. Allgemein entscheidet das ganze Gericht, namentlich je nach Sachzuständigkeit der professionelle Strafrichter bzw. gemeinsam die Berufsrichter und Schöffen, über die Rechts- und Tatsachenfragen (mit Ausnahme der Leitungsangelegenheiten) innerhalb der Hauptverhandlung, einschließlich der Schuldfrage am Verfahrensende. Für die zentralen Verfahrensbeteiligten sind im Gesetz erhebliche Mitwirkungsrechte in Bezug auf Beweisangelegenheiten vorgesehen. Sowohl die StA als auch die Verteidigung sind aber grundsätzlich nicht selbstständig für die Durchführung der maßgebenden Beweisvorgänge verantwortlich.

• Vor sämtlichen sachzuständigen Strafgerichten beginnt die herkömmliche erstinstanzliche Hauptverhandlung mit dem Aufruf der Sache, an den sich die Präsenzfeststellung, die Zeugenbelehrung und das Entfernen der Zeugen, die Vernehmung des Angeklagten über seine persönlichen Verhältnisse und die Verlesung des Anklagesatzes durch den StA anschließen. Nach Verlesung des Anklagesatzes und vor der Sachvernehmung des Angeklagten kann der Vorsitzende im Rahmen seiner Sachleitungsbefugnis nach seinem Ermessen dem Verteidiger Gelegenheit zu einer Eingangserklärung hinsichtlich u.a. der Anklagepunkte, der Verteidigungsstrategie und der vorzubringenden Beweisthesen geben; es existiert allerdings kein diesbezügliches Recht des Verteidigers. Die eigentlichen beweisrelevanten Vorgänge setzen dann mit der richterlichen Vernehmung des Angeklagten zur Sache ein, wobei der Angeklagte etwa ein Geständnis vor Gericht ablegen oder sich einfach gar nicht zur Sache äußern kann. Falls der Angeklagte sich nun dafür entscheidet auszusagen, soll er Gelegenheit haben, die gegen ihn vorliegenden Verdachtsgründe zu beseitigen und die zu seinen Gunsten sprechenden Tatsachen geltend zu machen. Die Beweisaufnahme im engeren Sinne folgt nach der Sachvernehmung des Angeklagten. Dabei sind unter Berücksichtigung der Regeln der Amtsaufklärungspflicht, des Strengbeweises, der Beweiserhebungsverbote und der Verfahrensunmittelbarkeit unter anderem von Amts wegen die vom Gericht vorgeladenen und tatsächlich erschienenen Zeugen zu vernehmen, die Sachverständigen zu vernehmen, die Urkunden zu verlesen und der Augenschein einzunehmen. Zulässige Beweiserhebungen erfolgen auch auf Anträge der Verfahrensbeteiligten, die sowohl präsente als auch nicht präsente Beweismittel betreffen können. Die Beweisaufnahme wird in der Regel von Amts wegen zur Klärung der Schuldfrage so lange fortgesetzt, bis der Richter ihre Fortsetzung vor allem nach 
den Maßstäben der richterlichen Aufklärungspflicht und des Beweisantragssystems nicht mehr für erforderlich hält. Die allgemeine Reihenfolge der Benutzung der diversen Beweismittel bei der Erhebung und Prüfung der strittigen Beweise ist nicht gesetzlich vorgeschrieben; sie wird vielmehr je nach Einzelfall aufgrund von Zweckmäßigkeitserwägungen vom Vorsitzenden bestimmt. Ein mehrfacher bzw. wiederholter Gebrauch desselben Beweismittels während und bis zum Schluss der Hauptverhandlung ist auch auf (Beweis-)Antrag grundsätzlich möglich. Darüber hinaus darf eine Beweiserhebung nicht allein deshalb vom Gericht abgelehnt werden, weil das Beweismittel oder die zu beweisende Tatsache zu spät vorgebracht worden ist. Die Stellung von Beweisanträgen ist in allen Fällen in der Hauptverhandlung bis zum Beginn der Urteilsverkündung möglich. Allgemein kann das Gericht bis zur vollständigen Verkündung des Urteils wieder in die Verhandlung und Beweisaufnahme eintreten.

- Die Vernehmung des Angeklagten und die Beweisaufnahme, einschließlich der Vernehmung sämtlicher Beweispersonen, erfolgen grundsätzlich durch den Vorsitzenden persönlich; der Vorsitzende erteilt und entzieht den Verfahrensbeteiligten darüber hinaus das Wort vor allem zur Ausübung ihrer Fragerechte und stellt den Abschluss der Beweisaufnahme fest. Gegen eine als unzulässig angesehene Anordnung des Vorsitzenden in der Hauptverhandlung können Beanstandungen seitens der Verhandlungsbeteiligten erhoben werden. Im Anschluss an jede einzelne Beweiserhebung haben die zentralen Verfahrensbeteiligten ferner die Möglichkeit, sich etwa in Bezug auf deren Beweiswert oder auf mögliche Unklarheiten und Widersprüche zu äußern. Die Schlussvorträge der Verfahrensbeteiligten, namentlich zuerst des StA und dann des Verteidigers und/oder des Angeklagten, folgen nach Abschluss der kompletten Beweisaufnahme, wobei das letzte Wort immer dem Angeklagten zu erteilen ist. Der StA muss einen objektiven und unvoreingenommenen Schlussvortrag zur Darstellung des Gesamtergebnisses der Verhandlung halten. Der Verteidiger kann bei der Ausübung seines Vortragsrechts, das grundsätzlich ohne zeitliche Beschränkung gilt, die zugunsten des Angeklagten sprechenden Umstände in seiner Ansprache einseitig hervorheben; er ist nicht zu objektiven Würdigungen verpflichtet. Allgemein dürfen die Schlussvorträge des StA und des Verteidigers nur die in der Hauptverhandlung schon mündlich angesprochenen Tatsachen sowie die Ergebnisse der Untersuchung der in die Hauptverhandlung eingeführten Beweismittel betreffen. Dagegen genießt der Angeklagte selbst deutlich mehr Freiheit in Bezug auf die inhaltliche Gestaltung seiner Schlussausführungen.

- Die eigentliche Durchführung der erforderlichen und zulässigen Beweiserhebungen erfolgt zentral und wird richterlich gesteuert, ungeachtet der Mitwirkungsrechte der Verfahrensbeteiligten. Während dieser Beweiserhebungen vor Gericht wird die Stichhaltigkeit der in die Hauptverhandlung eingeführten Beweise geprüft. In Bezug auf sämtliche Beweismittel und Beweistatsachen haben die Verfahrensbeteiligten in jedem Fall Fragerechte bzw. diverse andere Möglichkeiten, in die einzelnen rich- 
terlichen Beweiserhebungen durch Vorbringen von Einwänden und durch Kommentare und Erklärungen einzugreifen.

- Insbesondere die Vernehmung des Angeklagten und der Beweispersonen muss durch den Vorsitzenden Richter in neutral-amtlicher Weise erfolgen. Wie jede Beweiserhebung finden die Vernehmungen in der vom Vorsitzenden nach den Einzelfallumständen bestimmten Reihenfolge statt, wobei jedoch der Angeklagte grundsätzlich als Erster zu vernehmen ist; außerdem gibt es keine förmliche Trennung zwischen Belastungs- und Entlastungszeugen. Dabei ist vor allem die Zeugenvernehmung nach gesetzlicher Vorschrift in eine Berichts- und eine Verhörphase gegliedert. Die beisitzenden Richter und Schöffen, die StA und die Verteidigung (der Angeklagte und sein Anwalt) verfügen im Rahmen sämtlicher Vernehmungen über Befragungsmöglichkeiten; der Vorsitzende bestimmt den Zeitpunkt, zu dem die Fragerechte ausgeübt werden dürfen, wobei die Befragung jeder einzelnen Beweisperson durch die Prozessbeteiligten grundsätzlich erst nach dem Abschluss der richterlichen Befragung folgt. Darüber hinaus kann der Vorsitzende in den Verlauf der Befragungen durch die Verfahrensbeteiligten besonders wegen möglicher Missbräuche und ungeeigneter Fragestellungen (z.B. im Fall von Suggestivfragen) korrigierend eingreifen; für die Wahrheitsfindung erforderliche (entscheidungserhebliche) Glaubwürdigkeitsfragen sind grundsätzlich erlaubt. Die Verfahrensbeteiligten können ihrerseits Einwände gegen die Zulässigkeit der richterlichen Vernehmungsvorgänge erheben; die Äußerung von Zweifeln über die Zulässigkeit von allseitig gestellten Fragen und die Anrufung hierzu des ganzen Gerichts ist in allen Fällen möglich. Im Allgemeinen können der Beweisperson als Vernehmungsbehelf schriftliche Unterlagen vorgelegt oder Vorhalte etwa aus früheren Protokollen gemacht werden; ferner existieren auch im Wege des Urkundenbeweises Regelungen zur Unterstützung des Gedächtnisses sowie zur Klärung von Geständnisfragen und von widersprüchlichen Aussagen. Unter bestimmten Voraussetzungen ist es schließlich der StA und der Verteidigung zu gestatten, die von ihnen benannten Zeugen und Sachverständigen ins Kreuzverhör zu nehmen. Auch hierbei darf der Vorsitzende vor allem zur Verhinderung von missbräuchlichen (d.h. insbesondere die Wahrheitsfindung hindernden, schutzwürdige Interessen des Zeugen verletzenden oder sich wiederholenden und sachfremde Zwecke verfolgenden) Befragungen eingreifen; er muss in jedem Fall am Ende des Kreuzverhörs weitere ihm zur Sachverhaltsaufklärung erforderlich scheinende Fragen stellen. 


\section{Vergleich und Klassifizierung}

\section{A. Überblick und Vorbemerkungen}

Die Vergleiche in diesem Abschnitt erfolgen nach dem Schema der vorhergehenden thematischen Darstellungen der nationalen Beweisführungssysteme. Gegenüberstellung und Vergleichung des englischen und des deutschen Strafverfahrens orientieren sich auch hier am zentralen Ausgangs- und Anknüpfungspunkt des gesamten Forschungsvorhabens: den für analytisch-vergleichende Zwecke eingesetzten Idealtypen des westlichen Beweisverfahrens (dem ,adversatorischen“ und dem ,inquisitorischen“ Modell) und ihren in Teil 1 der Forschungsarbeit definierten essenziellen Elementen. ${ }^{762}$ Die für die Untersuchung insgesamt maßgebliche Sachfrage und somit der Bezugspunkt für die drei Unterebenen des vorliegenden vergleichenden Teils betreffen konkret die strafprozessualen Strukturen und Rollenverteilungen innerhalb der gerichtlichen Beweisführungssysteme. Im Vordergrund stehen insbesondere die vorbereitenden Beweisführungsvorgänge und damit die vorgerichtliche „Aufbereitung“ des Beweismaterials und die Bestimmung des Umfangs der Beweiserhebungen (hier unter B.); die Kenntnisnahme und Offenlegung der Beweisergebnisse des Vorverfahrens (hier unter C.); sowie die streitige Beweisführung in der Hauptverhandlung (hier unter D.). ${ }^{763}$

Zur Vermeidung von unnötigen Wiederholungen und zur übersichtlicheren Präsentation der eigentlichen Vergleichsergebnisse beziehen sich die nachfolgenden Ausführungen nicht erneut auf alle technischen Einzelheiten und Sonderfälle der nationalen Beweisrechte und beschreiben nicht noch einmal konkret und extensiv die schon diskutierte Literatur, Gesetzeslage und Rechtsprechung. Hierfür und für alle sonst erforderlichen Informationen wird auf die einzelnen Landesberichte direkt verwiesen. ${ }^{764}$

${ }^{762}$ Vgl. zur Erstellung des komparativen Teils einer rechtsvergleichenden Forschungsarbeit Engelhart, Sanktionierung, S. 29: „Während sich die Landesberichte auf die umfassende Darstellung des jeweiligen nationalen Rechts konzentrieren, werden die Informationen im vergleichenden Teil aus den verschiedenen Rechtsordnungen thematisch zusammengeführt, gegenübergestellt und verglichen. [...] Dabei können die Gemeinsamkeiten und Unterschiede präzise herausgearbeitet werden. [...] Die Vornahme eines Vergleichs bedingt, dass Klarheit darüber herrscht, welcher Bezugspunkt (tertium comparationis) eingenommen wird. [...] Im Rahmen des funktionalen Ansatzes dienen die die Untersuchung leitenden Sachfragen als maßgeblicher inhaltlicher Bezugspunkt für den Vergleich. [...] Hieraus ergibt sich, welche Aspekte in Bezug zueinander gesetzt werden. Die darüber hinausgehende Einordnung als gleich oder verschieden orientiert sich im Grundsatz an einer graduellen Beurteilung von 'mehr' oder 'weniger' im Hinblick auf einen idealisierten Standard oder eine idealisierte Typisierung [...]."

${ }^{763}$ Siehe auch die Zusammenfassung der definierten Modellelemente unter Teil 1, II.C.4.

${ }^{764}$ Konkreter beziehen sich die Vergleichungen unter Teil 2, IV.B. auf die Darstellungen unter Teil 2, II.B. und Teil 2, III.B., diejenigen unter Teil 2, IV.C. auf Teil 2, II.C. und 
Eine vollständige Gegenüberstellung sämtlicher Stadien und Institutionen des herkömmlichen erstinstanzlichen englischen und deutschen Strafverfahrens, insbesondere der komplexen Ermittlungs- und Klageerhebungsvorgänge sowie der unterschiedlichen Funktionen aller Strafverfolgungs- und Justizorgane, ist daher hier ausgeschlossen. ${ }^{765}$ Soweit dies zur besseren Veranschaulichung dienen kann, wird auf den jeweils relevanten Überblick über Ablauf, Ziele und Grundprinzipien des Strafprozesses unter Teil 2, II.A. und Teil 2, III.A. verwiesen. Besonders in Bezug auf die Grundsätze des Straf- und Beweisverfahrens ist in vereinfachter Weise kurz an Folgendes zu erinnern: Im englischen wie auch im deutschen Justizsystem werden programmatisch die in der Praxis oft in einem Spannungsverhältnis stehenden Ziele der Wahrheitserforschung (im Sinne der möglichst zuverlässigen und materiell-rechtlich richtigen Aufklärung des angeklagten Sachverhalts) und der Verfahrensgerechtigkeit (hauptsächlich im Sinne der prozessualen Gewährleistung von Fairness, Rechtsstaatlichkeit und Menschenrechtsschutz) gleichzeitig verfolgt. ${ }^{766}$ Die Verankerung der in der westlichen Rechtswelt allgemein anerkannten grundlegenden Prozessprinzipien in beiden Rechtsordnungen ist heute nicht zu bezweifeln. Ihre genaue Anwendung in den einzelnen Staaten kann sich in rechtstechnischer Hinsicht unterscheiden, was jedoch nicht Gegenstand der nachfolgenden Vergleiche ist. Schließlich ist sowohl die englische als auch die deutsche Strafrechtsordnung an die Mindestrechte und Mitwirkungsvorschriften der EMRK und an die verfahrensrechtlichen Leitlinien der Rechtsprechung des EGMR gebunden, deren konkrete nationalrechtliche Umsetzung hier aber nicht angesprochen werden kann.

\title{
B. Die vorbereitenden Beweisführungsvorgänge
}

\section{Die „Aufbereitung“ des Beweismaterials}

\author{
a) Allgemeine Grundsätze: Strukturen, Waffengleichheit \\ und Objektivitätspflichten
}

Im englischen Strafverfahrenssystem schließt sich an die Anklageerhebung das Zusammentragen der bisher gesammelten Beweise und generell die beweisbezogene Vorbereitung der Hauptverhandlung in einer solchen Art und Weise an, dass die Anklage (CPS) und die Verteidigung - die zwei gesetzlich anerkannten Parteien und somit die zentralen Prozessbeteiligten - eigene cases zur Präsentation vor Gericht (vor dem magistrates' court im bench-Verfahren oder vor dem Crown Court

Teil 2, III.C. und diejenigen unter Teil 2, IV.D. auf Teil 2, II.D. und Teil 2, III.D., sowie auf die jeweils entsprechenden Untergliederungen.

765 Siehe ferner zum Darstellungs- und Vergleichsrahmen unter Teil 2, I.

766 Vgl. auch Gleß, Beweisrechtsgrundsätze, S. 94-106. 
im jury-Verfahren) selbstständig ,aufbauen“. Im deutschen Strafverfahrenssystem setzt dagegen mit der Anklageerhebung und der Einreichung der Verfahrensakte beim jeweils zuständigen Gericht eine zentral-amtliche gerichtliche Untersuchung des Sachverhaltes ein. In prozessstruktureller Hinsicht stellt dies einen erheblichen Unterschied zum englischen Verfahrenssystem dar. Zunächst ist in der deutschen Strafverfahrensordnung sogar die Verwendung des Begriffs „Parteien“ unerwünscht. Es obliegt hier nicht den zentralen Verfahrensbeteiligten, also der StA (nun als Anklagevertreterin) und der Verteidigung, vollständige selbstständige cases zu sämtlichen Tatsachen- und Rechtsfragen vorzubereiten, um in dieser Form anschließend alle diversen Aspekte des ganzen Sachverhalts vor Gericht zu präsentieren.

Die zur Vorbereitung des englischen Hauptverfahrens verwendeten Beweisinformationen und gegensätzlichen Beweismittel stammen zu einem Großteil aus den dokumentierten Ermittlungsergebnissen und gesammelten Beweisen des polizeilichen Vorverfahrens; diese werden nach der Klageerhebung der CPS und durch die Letztere größtenteils auch der Verteidigung vorgelegt. In normativer Hinsicht muss zwischen Verteidigung und Anklage allgemein und vor allem was den jeweiligen Informationsstand anbelangt Waffengleichheit herrschen; es ist jedoch in der Praxis und mit Blick auf die beträchtlichen staatlichen Verfolgungsressourcen, die der CPS zur Verfügung stehen, zweifelhaft, inwieweit das immer möglich ist. Alle Prozessbeteiligten sind generell verpflichtet, bei der Vorbereitung und Durchführung des Strafprozesses gemäß der overriding objective nach Part 1 CPR 2014 zu handeln und somit die gerechte Erledigung des jeweiligen Straffalles (insbesondere die Verurteilung nur der wirklich Schuldigen sowie die faire, menschenwürdige, effektive und proportionale Behandlung aller Beteiligten und Fallaspekte) zu fördern.

Einer extremen Parteilichkeit bei der Vorbereitung der gegensätzlichen cases wirkt das englische Recht jedenfalls entgegen. Der Anklageanwalt, der sich nicht als bloßer Vertreter einer Partei ansehen darf, ist gesetzlich bzw. nach soft lawVorschriften verpflichtet, seine Beweisthesen und alle entscheidungsrelevanten Beweise in fairer und objektiver (unvoreingenommener) Weise vor Gericht vorzubringen, seine gesetzlichen Offenlegungspflichten gegenüber der Verteidigung zu erfüllen, nicht unterschiedslos alle vorhandenen (etwa rechtswidrigen) Mittel zu verwenden, um eine Verurteilung zu erreichen, und dem Gericht bei sämtlichen Rechtsfragen Hilfe zu leisten. Der Verteidiger trägt auch ethisch-rechtliche Verantwortung gegenüber dem Gericht: Er muss insbesondere das Gericht bei der Justizhandhabung unterstützen; er darf keine rechtswidrigen Mittel zur Förderung und Sicherstellung der Interessen seines Mandanten verwenden, und er darf das Gericht nicht täuschen oder bewusst bzw. leichtsinnig verleiten. Die in den meisten westlichen Rechtssystemen in der Praxis eher einseitige Stellung des Verteidigers wird auch im englischen Strafverfahrensrecht anerkannt: Der Verteidiger ist u.a. verpflichtet, seinen Mandanten vor einer Verurteilung auf der Basis von rechtlich un- 
zulässigen Beweisen zu schützen, sich mit seinem Mandanten über die Fallaspekte zu beraten und erforderlichenfalls für die Durchführung weiterer privater Ermittlungen sowie für die Ladung von Entlastungszeugen und Experten zu sorgen.

Im deutschen Strafverfahren findet die Vorbereitung der grundsätzlich durch das Gericht geführten Untersuchung sowohl im Zwischen- als auch im Hauptverfahren größtenteils auf der Basis der mit der Anklageschrift und den Verfahrensakten vorgelegten Beweisergebnisse des staatsanwaltlichen und polizeilichen Vorverfahrens statt. In das amtlich gesammelte Beweismaterial kann auch der Verteidiger Einsicht nehmen, was der Vorbereitung der Verteidigungsthesen und der effektiven Mitwirkung in der maßgebenden Hauptverhandlung dient. Ob bei der Vorbereitung der vorzubringenden Beweisthesen und allgemein bei der Verfahrensmitwirkung die gesetzlich geforderte Waffen- oder Chancengleichheit zwischen Strafverfolgungs-/ Anklagebehörden und Angeklagtem tatsächlich immer gewährleistet werden kann, bleibt auch im Fall des deutschen Rechtssystems fraglich.

Während des gesamten deutschen gerichtlichen Strafverfahrens, auch bei der faktischen Vorbereitung und Präsentation ihres Beweisvorbringens, ist jedenfalls die StA als unabhängige Justizbehörde sowohl zur Objektivität bei der Gesetzesanwendung als auch der Gerechtigkeit und der Wahrheit verpflichtet. Der Verteidiger wirkt grundsätzlich, wie auch im englischen Strafverfahren, einseitig zum effektiven Schutz und zur Förderung der gesetzlich anerkannten Interessen des Angeklagten; gleichzeitig nimmt er aber auch öffentliche Aufgaben und Interessen wahr. Nicht nur strafrechtswidrige Handlungen, sondern auch der offensichtliche Missbrauch der Verteidigungsrechte ist verboten; nicht akzeptabel ist es insbesondere, aktiv zu lügen, Beweisquellen zu trüben und Beweismittel zu verfälschen sowie den Prozess zu verschleppen. Die Hauptfunktion des Verteidigers besteht auch in der deutschen Rechtsordnung darin, eine intensive Gegenwehr für den Angeklagten gegen den staatlichen Strafverfolgungsmechanismus zu erwirken und dabei alle zugunsten des Angeklagten sprechenden Tatsachen und alle diesem gewährten Rechte zur Geltung zu bringen. Im Vordergrund stehen die diversen Möglichkeiten des Verteidigers zur effektiven Ausübung der gesetzlich vorgesehenen Verteidigungs- und Mitwirkungsrechte, zur Durchführung eigener (privater) Ermittlungen und zum unmittelbaren Kontakt mit dem Angeklagten.

\section{b) Speziell zum aussagenbasierten Beweis}

aa) Die Beweismittel und der zeugenbasierte Beweis

\section{- Bedeutung des Zeugenbeweises}

Sowohl das englische als auch das deutsche Strafverfahrenssystem stellt von allen gesetzlichen Beweismitteln den aussagenbasierten und insbesondere den zeugenbasierten Beweis in den Mittelpunkt aller beweisverfahrensbezogenen Regelungen und Rechtsprechungserwägungen, Vorgänge, rechtspolitischen Reformen 
und wissenschaftlichen Forschungsarbeiten. Richtungweisend kann die verfahrensrechtliche Auseinandersetzung mit dem Zeugenbeweis - d.h., an dieser Stelle vereinfacht und möglichst systemneutral betrachtet: mit Personen, die über sachverhaltsrelevante Wahrnehmungen berichten können - unter anderem auch für die konkrete Vergleichung der klassischen Prozessstrukturen und Methoden zur Erhebung und Prüfung von Beweisen in beiden Rechtsordnungen wirken.

\section{- Vernehmungen im Vor- und Hauptverfahren}

In England finden, wie in den meisten westlichen Rechtsordnungen während der staatlichen Ermittlungen, Zeugenvernehmungen im Vorverfahren statt; diese werden von der Polizei bzw. anderen Ermittlungsbehörden aufgezeichnet und danach der CPS sowie eventuell auch der Verteidigung zur Vorbereitung ihrer Beweisthesen mitgeteilt. Umfassende vorgerichtliche Zeugenvernehmungen durch richterliche Behörden finden allgemein nicht statt. Die (zunächst nach Ansicht der Parteien) zentralen Zeugen müssen aber, soweit sie nach den relevanten Gesetzesvorschriften dazu ,fähig“ und aussagepflichtig sind, auch vor Gericht im maßgebenden Hauptverfahren grundsätzlich persönlich (mit Ausnahmen) aussagen.

In Deutschland kann zunächst jedermann (mit Ausnahmen) zum Erscheinen und zur Aussage vor der StA, dem Ermittlungsrichter, dem beauftragten oder ersuchten Richter und dem Gericht nach den Grundsätzen der Amtsaufklärungspflicht und des Beweisantragssystems verbindlich geladen werden. Die im Vorverfahren bzw. außerhalb der Hauptverhandlung von den Strafverfolgungsbehörden und den Richtern durchgeführten Zeugenvernehmungen werden aufgezeichnet und werden Bestandteil der Verfahrensakten, von denen das Gericht und auch der Verteidiger im Voraus umfassende Kenntnis erhalten. Das Gericht muss jede Tatsache, die nach den vorgelegten Akten und den darin beinhalteten Aussagen als entscheidungserheblich erscheint, im Hauptverfahren durch die (erneute) Vernehmung der betreffenden Zeugen prüfen. Somit müssen alle zentralen Zeugen grundsätzlich persönlich (auch hier mit Ausnahmen) vor Gericht im Hauptverfahren Auskunft geben.

\section{- Der Angeklagte als Beweisperson}

Der Angeklagte kann im englischen Hauptverfahren, falls er sich dafür entscheidet auszusagen, nur als Zeuge für die Verteidigung aufgerufen werden. Im deutschen Verfahren ist der Angeklagte kein Zeuge im technischen Sinne, er stellt jedoch, falls er sich dafür entscheidet auszusagen, insbesondere im Rahmen seiner sachlichen Vernehmung im Hauptverfahren ein zentrales Beweismittel im materiellen Sinne dar. 
bb) Die „Zusammenstellung“ des zeugenbasierten Beweises

\section{- Subjekt und Objekt der Beweisführung}

Im englischen Prozess bestimmen vor sämtlichen Strafgerichten die Anklage und die Verteidigung die Belastungs- und Entlastungszeugen zunächst selbst. Die geladenen Zeugen müssen anschließend im Hauptverfahren öffentlich, persönlich und mündlich de novo Auskunft geben. Dies geschieht traditionellerweise im Wege von examinations-in-chief (d.h. Verhör durch die Partei, die den jeweiligen Zeugen geladen hat) und direkt daran anschließenden cross-examinations (durch die Gegenpartei), wobei jeder Zeuge grundsätzlich nur über Tatsachen berichten darf, von denen er persönliche Kenntnis hat.

Im deutschen Strafverfahren müssen alle Personen, deren Aussage grundsätzlich vom Richter (nicht von den Prozessbeteiligten) im Rahmen der Amtsaufklärungspflicht und nach den Beweisantragsregeln als fallrelevant und für die Schuldfrage als entscheidend betrachtet wird, in der Regel im Hauptverfahren öffentlich, persönlich und mündlich de novo Auskunft geben. Die Vernehmung sämtlicher Zeugen in der Hauptverhandlung findet im Regelfall durch den Vorsitzenden und unter Mitwirkung vor allem der Verteidigung und der Anklage statt; zumindest in normativer Hinsicht existiert dabei im Gegensatz zum englischen Verfahren keine Unterscheidung zwischen Belastungs- und Entlastungszeugen. Als Grundsatz gilt, dass, soweit der Beweis einer Tatsache auf der Wahrnehmung einer Person beruht, diese Person in der Hauptverhandlung zu vernehmen ist.

\section{- Direkter und indirekter Beweis}

In England dürfen außergerichtliche Auskünfte und statements als indirekter Beweis in die Hauptverhandlung nicht eingeführt werden, soweit nicht eine der (gegenwärtig zahlreichen) Ausnahmen von den hochkomplexen hearsay-Ausschlussregeln anzuwenden ist. Das prozessuale Vorbringen von hearsay evidence seitens der Parteien ist gesetzlich reguliert und es setzt in vielen Fällen die Zustellung einer entsprechenden Benachrichtigung an das Gericht und die Gegenpartei voraus, wobei die Gegenpartei immer widersprechen kann, und das Gericht über die Zulässigkeit der hearsay statement als Beweis in Übereinstimmung mit dem materiellen Gehalt der hearsay-Regeln entscheiden muss; allerdings ist es für die Parteien möglich, hearsay evidence durch Einverständnis (bzw. Nicht-Widerlegung) in das Verfahren verbindlich einzuführen. Ähnliches gilt für die Einführung von vorgerichtlichen förmlichen written statements der Zeugen in die Hauptverhandlung. Vor allem kann der Angeklagte gegen die Einführung einer written statement als Ersatz für eine direkte mündliche Aussage Einspruch erheben, und das Gericht kann auch von Amts wegen die Einführung der schriftlichen Äußerung als Beweis ablehnen und stattdessen die persönliche Vernehmung des Zeugen vor Gericht anordnen. Darüber hinaus sind richterliche kommissarische 
Vernehmungen in England (im Gegensatz zum deutschen Verfahren) im Prinzip nicht vorgesehen.

In Deutschland darf ein Zeuge nicht nur über die für das Geschehen unmittelbar relevanten Tatsachen berichten, von denen er persönliche Kenntnis hat; Zeugen vom Hörensagen können im deutschen Strafverfahren viel einfacher als im englischen Verfahren zur Aussage geladen werden, auch wenn ihr meistens geminderter Beweiswert auch in Deutschland nicht bezweifelt wird. Eine wichtige Durchbrechung des Unmittelbarkeitsgrundsatzes im Sinne des Gebots zur persönlichen Vernehmung des Zeugen betrifft ferner die gerichtlich beschlossene Ersetzung der persönlichen Vernehmung durch Verlesung eines früheren Vernehmungsprotokolls oder einer schriftlichen Erklärung. Eine solche Ersetzung, die nur in den gesetzlich vorgesehenen Fällen erfolgen kann, ist auch dann möglich, wenn die zentralen Prozessbeteiligten mit ihr einverstanden sind - durch diese Regelung bleibt gleichwohl die allgemeine Aufklärungspflicht des deutschen Gerichts unangetastet, sodass letztendlich die richterliche Anordnung einer persönlichen Zeugenvernehmung (etwa aus Klarstellungsgründen) immer möglich ist bzw. geboten sein kann.

\section{cc) Die „Vorbereitung“ des zeugenbasierten Beweises}

Auch wenn angloamerikanische Filme oft einen anderen Eindruck vermitteln, erlaubt die englische Rechtsprechung es keiner der beiden Verfahrensparteien, Zeugen vorgerichtlich in umfassender Weise vorzubereiten, um strategisch günstige Beweisergebnisse im Hauptverfahren zu erzielen. Allgemein sind die parteiliche Vorbereitung der aufzurufenden Zeugen im Vorfeld eines gerichtlichen Verhörs durch intensives coaching, intensive rehearsals oder Mitteilung der Auskünfte anderer Zeugen sowie solche (eventuell strafbaren) Verhaltensweisen, welche die Zeugen ermuntern, unwahre bzw. unvollständige Aussagen zu machen, grundsätzlich nicht erlaubt. Zulässig sind nur allgemeine court familiarisation arrangements sowie einfache „ermittelnde“ Gespräche zwischen einer Partei und den „eigenen“ Zeugen. Die Durchführung von pre-trial interviews der von der Verteidigung benannten (und in vorherigen Prozessstadien nicht polizeilich vernommenen) Zeugen durch die Strafverfolgungsbehörden nach der Klageerhebung ist heute ebenfalls erlaubt, auch wenn solche Zeugen in diesem Fall nicht zur vorgerichtlichen Aussage gezwungen werden können.

Im deutschen Strafverfahrenssystem wird die Existenz von ,parteilichen“ Zeugen auf normativer Ebene zunächst nicht anerkannt. Auch die StA und die Verteidigung können allerdings, neben den unmittelbar vom Richter geladenen Beweispersonen, selbst Zeugen benennen und insbesondere ihre richterliche Ladung verlangen oder sie unmittelbar laden und ihre gerichtliche Vernehmung beantragen. Im Rahmen der außergerichtlichen Kontakte zwischen den Strafverfolgungs-/ Justizorganen und sämtlichen Personen, deren Aussage fallrelevant ist, sind die 
staatlichen Behörden (auch die StA) zur Objektivität verpflichtet. Gleichwohl sind einseitige vorgerichtliche Beeinflussungen der Zeugen in der Praxis aus verschiedenen Gründen immer möglich; die sich daraus ergebenden Gefahren für die Glaubhaftigkeit der vorgebrachten Beweise müssen bei der gerichtlichen Prüfung sowie bei der letztendlichen Würdigung der Aussagen berücksichtigt werden. Der Verteidiger kann/muss seinerseits im Rahmen der rechtmäßigen Ausübung seiner Aufgaben nach möglichen Entlastungszeugen suchen und darf sich mit Zeugen außergerichtlich in Kontakt setzen und Befragungen durchführen. Generelle kategorische Bestimmungen zum zulässigen Inhalt solcher Gespräche mit Blick insbesondere auf die Vorbereitung der späteren Zeugenaussage sind im deutschen Recht nicht enthalten. Ähnlich wie in England darf der Verteidiger jedoch weder auf die freie Willensbildung der Zeugen einwirken noch diese zu falschen Aussagen veranlassen oder allgemein zur Verfälschung von Beweismitteln beitragen.

\section{dd) Zum Expertenbeweis}

\section{- Expertenbegriff}

Sowohl im englischen als auch im deutschen Strafverfahren müssen die Zeugen i.e.S. grundsätzlich nur über ihre Tatsachenwahrnehmung aussagen und dürfen keine wertenden Beurteilungen zum Geschehen äußern. In beiden Verfahren ist jedoch die wertende Aussage von Experten (expert witnesses bzw. Sachverständige) zulässig. Schon in faktischer Hinsicht kann die Einsetzung von Experten für die Unterstützung sämtlicher (richterlicher und nicht richterlicher) Verfahrensbeteiligter und insbesondere für die Zwecke einer zuverlässigen Sachverhaltsaufklärung von erheblicher Bedeutung sein. Mit ihren speziellen beruflichen oder wissenschaftlichen Fähigkeiten und Fachkenntnissen können diese Beweispersonen nämlich vor allem die mangelnden Erfahrungen und Kenntnisse des Gerichts in spezifischen Fachgebieten ergänzen.

\section{- Einführung des Beweises}

Im englischen Verfahren kann jede Partei wie bei der Benennung normaler Zeugen zur Ermöglichung des Beweises konkreter Tatsachen ihre ,eigenen“ Expertenzeugen vorbringen. Die Entscheidung über die Zulassung der Aussage der Expertenzeugen, die vor allem nach Notwendigkeitskriterien erfolgt, obliegt letztendlich dem Richter. Die Expertenzeugen werden unmittelbar von der einen oder der anderen Partei ausgewählt und mit der vorgerichtlichen Anfertigung von Gutachten und/oder mit der grundsätzlich persönlichen Aussage vor Gericht beauftragt. Die Partei, die Expertenbeweise in das Verfahren einführen will, muss zuerst den relevanten Beweisinhalt den Gerichtsbeamten und jeder anderen Partei zustellen sowie auf Antrag der Gegenpartei Kopien von grundlegenden Untersuchungsprotokollen einreichen bzw. deren Inspektion erlauben. 
Als wichtigster Unterschied zur englischen Rechtslage gilt, dass die Anordnung des Sachverständigenbeweises in Deutschland hauptsächlich eine zentral-amtliche bzw. gerichtliche (nicht parteiliche) Angelegenheit ist. ${ }^{767}$ Konkreter: Ein für das gerichtliche Verfahren hinzuzuziehender Sachverständiger wird im Prinzip vom Richter im Rahmen seines Beurteilungsspielraums (unter Wahrnehmung der besonderen Schwierigkeiten des Einzelfalles und der hierfür erforderlichen Sachkunde) ausgewählt und beauftragt. Ein auf diese Weise ernannter Sachverständiger ist dem StA und dem Beschuldigten namhaft zu machen; der Sachverständige kann aus denselben Gründen, die zur Ablehnung eines Richters berechtigen, abgelehnt werden.

\section{- Stellung und Pflichten des Experten und Gefahr der Befangenheit}

In normativer Hinsicht hat der Experte in England nicht nur eine Pflicht gegenüber seinem Mandanten (d.h. gegenüber der ihn beauftragenden Partei), sondern primär eine übergeordnete „Hilfspflicht“ gegenüber dem Gericht für die Zwecke einer präzisen Tatsachenfeststellung. Dennoch sind die Parteien im englischen Strafverfahren für die (meist gezielte) Auswahl und die Instruktion der Expertenzeugen verantwortlich. Es ist dem englischen Strafgericht trotz häufiger Justizirrtümer aufgrund von befangenem expert evidence heutzutage weiterhin grundsätzlich nicht möglich, Sachverständige aus einer neutral erstellten Liste auszuwählen und selbstständig zu laden bzw. weitere forensische Expertenuntersuchungen anzuordnen. Die Rechtsprechung hat sich jedoch mit Blick auf die Gewährleistung der normativ geforderten Objektivität und die Vermeidung von Manipulationen des Expertenbeweises prinzipiell gegen eine parteiliche fallgezielte vorgerichtliche Vorbereitung (training) der Expertenzeugen geäußert.

Auch im deutschen Strafverfahrenssystem wird der Sachverständige grundsätzlich als Gehilfe des Gerichts angesehen. Die StA kann zwar im Vorverfahren einen Sachverständigen ihrer Wahl bestellen; eine gezielte (für die Beweisthesen der Anklage günstige) Auswahl kann dabei in der Praxis nicht ausgeschlossen werden. Das Gericht kann aber in jedem Fall an Stelle des im Vorverfahren von der StA bestellten Sachverständigen eine andere Person beauftragen, was jedoch in der Praxis eher selten passiert. Letztendlich ist das Gericht (bzw. der StA) bei der Auswahl eines Sachverständigen nicht an Vorschläge der anderen Verfahrensbeteiligten gebunden. Der Richter (bzw. im Vorverfahren der StA) ist für die klare Auftragsbeschreibung und die eindeutige Bestimmung der im Gutachten zu beantwortenden

767 Toepel, Grundstrukturen, S. 291, bemerkt zur diesbezüglichen Antithese zwischen deutschem und angloamerikanischem Recht, dass im deutschen Strafprozess „der Sachverständige in der Hauptverhandlung auch nicht als Ent- oder Belastungszeuge dem Beschuldigten oder der Staatsanwaltschaft zugeordnet [ist], sondern der neutralen Sphäre des Gerichts. Die übrigen Prozeßbeteiligten besitzen lediglich die Möglichkeit, die Beweiserhebung durch Antragsrechte zu beeinflussen.“ 
Beweisfragen verantwortlich. Der Sachverständige hat seinerseits eine Wahrheitspflicht bei der Erstellung seines Gutachtens, das er zumindest in der maßgebenden Hauptverhandlung in der Regel in eigener Person mündlich erstatten muss; er muss im Prinzip, ähnlich dem englischen Expertenzeugen, immer objektiv und allseitig neutral Auskunft geben. Letzteres gilt auch für den Sachverständigen, der nicht durch den Richter im Rahmen der Amtsaufklärungspflicht oder aufgrund des Beweisantrags eines Verfahrensbeteiligten zur richterlichen Vernehmung ausgewählt und geladen wurde, sondern etwa von der Verteidigung ,privat“" beauftragt wurde. Auch im deutschen Verfahren steht es den Verfahrensbeteiligten frei, einen bestimmten (wahrscheinlich im Hinblick auf ihre Beweisführungserfordernisse gezielt ausgewählten) Sachverständigen zum Verfahren unmittelbar zu laden und seine Vernehmung vor Gericht zu beantragen.

\section{Die Bestimmung des Umfangs der Beweiserhebungen}

\section{a) Beweisführung und Offenkundigkeit}

Im englischen Strafverfahren liegt die Beweisführung grundsätzlich in den Händen der Anklage und der Verteidigung; jede Partei bringt ihre „eigenen“ Beweismittel vor und kann die von der anderen Partei vorgebrachten Beweismittel prüfen. Beim deutschen Strafverfahren handelt es sich im Grunde um eine gerichtliche Untersuchung des Sachverhalts, wobei die Beweisvorgänge (einschließlich der Bestimmung der Beweiserhebungen) grundsätzlich vom Richter und unabhängig von der Disposition der Prozessbeteiligten durchgeführt werden, auch wenn die Letzteren weitgehende Mitwirkungsrechte haben. In beiden nationalen Gerichtsverfahren können jedoch von Zeit zu Zeit bestimmte Sachfragen vorliegen, die summarisch und durch den Richter/das Gericht allein geklärt werden können; in solchen Fällen wird richterlich entschieden, dass keine gesonderte Beweisvorbringung seitens der Parteien erforderlich ist bzw. dass die Mitwirkung der Verfahrensbeteiligten insbesondere durch Beweisanträge unnötig ist.

Im englischen Strafverfahren betrifft dies genauer die ,judicial notice“ von facts, wie in Fällen von matters of common knowledge oder von historical issues. Solche facts können so offensichtlich und unbestreitbar sein, dass das Gericht selbst sichere Kenntnis davon (eventuell nach gewissen begrenzten Ermittlungen) haben kann und dass deswegen keine formelle Beweisführung durch die Parteien diesbezüglich nötig ist. Auch die Möglichkeit der ,judicial notice“ von Tatsachen auf der Basis einer lediglich persönlichen Vorkenntnis des Richters, die keine common knowledge darstellt, wurde wenigstens in einem Fall von der Rechtsprechung nicht als unzulässig angesehen - besonders problematisch ist dabei eine eventuelle automatische Umwandlung des Richters in einen faktischen Anklagezeugen, denn die Verteidigung hat gegenwärtig im Rahmen des (sonst parteilich gesteuerten) Beweisführungssystems wegen der richterlich deklarierten , judicial notice“ keine Möglichkeit, den Richter zu vernehmen und Gegenbeweis zu erheben. 
Im deutschen System werden dagegen derartige Verfahrenspraktiken grundsätzlich als nicht akzeptabel betrachtet. Auch hier ist zwar bei den vom Richter als offenkundig (d.h. allgemeinkundig oder gerichtskundig) angesehenen Tatsachen eine umfassende förmliche Beweiserhebung überflüssig, was zur Ablehnung von diesbezüglichen Beweisanträgen der Verfahrensbeteiligten führen kann. Offenkundige offenkundige Tatsachen schließen jedoch nicht das private Wissen des Richters ein; solches Wissen kann nur durch eine herkömmliche Vernehmung des Richters als Zeuge (also nicht mehr als Richter des konkreten Falles) in das Verfahren eingeführt werden. Auch wenn die offenkundigen Tatsachen keiner Beweiserhebung bedürfen, müssen sie in der Regel trotzdem förmlich zum Gegenstand der Hauptverhandlung gemacht werden, sodass dem Angeklagten die Möglichkeit gegeben wird, dazu Stellung zu nehmen.

\section{b) Das Vorbringen von Beweisen: Zeugenladungen und Beweisanträge}

\section{- Verantwortlichkeit für die Bestimmung des Umfangs der Beweiserhebungen}

Im englischen Strafverfahren besitzen die Parteien weitgehende, aber nicht völlig unkontrollierbare Autonomie bei der Beweisführung und insbesondere bei der Bestimmung des Umfangs der Beweiserhebungen. Im deutschen Strafverfahren ist der Vorsitzende bzw. das Gericht primär verantwortlich für die maßgebenden Beweisführungen einschließlich der Bestimmung der Beweiserhebungen; die Richter haben die Pflicht, unabhängig von Anträgen und Anregungen sämtlicher Verfahrensbeteiligter, die Beweisaufnahme von Amts wegen auf alle entscheidungserheblichen Tatsachen und erlaubten Beweismittel zu erstrecken. Ein anschauliches Beispiel bietet hierfür in beiden Rechtsordnungen, neben den übrigen Vorgängen zum Vorbringen von Beweismitteln, der Regelungskomplex der Zeugenladungen.

\section{- Zeugenladungen, Beweisanträge und die Rolle des Richters}

Im englischen Verfahrenssystem können sowohl die Anklage als auch die Verteidigung zunächst selbst entscheiden, welche Zeugen zur Aussage vor Gericht zu laden bzw. aufzurufen sind. Im Gegensatz zum deutschen Prozessrecht müssen die Parteien keine strengförmlichen Beweisanträge bei Gericht stellen, um ein Zeugenverhör in der Hauptverhandlung zu erwirken. Ungeachtet eventueller faktischer Konsequenzen ist die Verteidigung in England in keinem Fall verpflichtet, Zeugen aufzurufen. Die Autonomie der Anklage mit Blick auf die (Nicht-)Ladung von Zeugen zur Verankerung des prosecution case kann aus Fairnessgründen eingeschränkt werden. Letztendlich muss die Anklage alle Personen, die unmittelbare Zeugen von zentralen Tatsachen und gleichzeitig (nach Meinung der Anklage) glaubwürdig sind, laden, auch wenn solche Zeugen in negativer bzw. widersprüchlicher Weise für das Anklagevorbringen wirken könnten. In allen Fällen ist die An- 
klage grundsätzlich zur vollständigen Beweisoffenlegung bezüglich der aufzurufenden und der nicht aufzurufenden Zeugen (und ihrer früheren statements) verpflichtet; der Verteidigung wird es dadurch ermöglicht, selbst die für sie ,,passenden" Zeugen zu laden oder die Vermeidung einer Zeugenladung seitens der Anklage vor Gericht zu bestreiten. Die Anklage muss also im Rahmen ihres Ermessens bei den Zeugenladungen und -vorführungen gerecht und in fairer Weise für den Angeklagten handeln. Der Richter kann sonst als ultima ratio die von der Anklage unterlassenen Zeugenladungen selbst übernehmen. Die Befugnis des Richters zur Zeugenladung wird allerdings in der englischen Gerichtspraxis nur selten ausgeübt - der ,neutrale“ Richter greift in die Bestimmung der Beweiserhebungen durch die Parteien grundsätzlich nicht ein, es sei denn, dies erscheint vor allem wegen unerwarteter Umstände im Interesse der Gerechtigkeit als notwendig.

Im herkömmlichen deutschen Strafprozess ist zunächst das Gericht verpflichtet, alle entscheidungserheblichen Zeugen von Amts wegen zu laden und zu vernehmen, unabhängig vom prozessualen Verhalten und den Wünschen der übrigen Prozessbeteiligten - im Vergleich zum englischen Strafprozess gehen die gerichtlichen Sachverhaltsaufklärungsvorgänge somit von einem unterschiedlichen Ausgangspunkt aus. Genauer: der Umfang der Aufklärungspflicht in Deutschland richtet sich nach den Umständen des Einzelfalls. Zumindest auf den ersten Blick reicht die Pflicht der deutschen Richter zur allseitig umfassenden Bestimmung der Beweiserhebungen weiter als die entsprechenden Verpflichtungen des englischen Richters bzw. der englischen Anklage. Auch im deutschen Verfahrenssystem gebietet die richterliche Aufklärungspflicht keine sinnlosen, voraussichtlich nutzlosen und unterschiedslos aufwendigen Beweisermittlungen, was letztendlich auch die Ladung von Zeugen betrifft. Die StA (als Anklagevertreterin im Einklang mit ihrer Objektivitätspflicht) und die Verteidigung (unbeschadet der Selbstbelastungsfreiheitsnormen) können ihrerseits wie folgt in die Bestimmung des Umfangs der Beweiserhebungen eingreifen: durch formlose Beweisermittlungsanträge; durch streng-förmliche (vorbereitende oder hauptgerichtliche) Anträge zur gerichtlichen Erhebung von Beweisen, wobei vor allem auch die richterliche Ladung und Vernehmung von Zeugen verlangt werden kann; oder durch die unmittelbare Ladung von Beweispersonen bzw. die direkte Herbeischaffung von weiteren Beweismitteln. Auch im Fall der unmittelbaren Ladung von Zeugen durch die Prozessbeteiligten müssen jedoch in der Hauptverhandlung relevante Beweisanträge zur Durchführung der eigentlichen Zeugenvernehmungen gestellt werden, auch wenn solche Anträge grundsätzlich nur unter engen Voraussetzungen vom Gericht abgelehnt werden können.

In den meisten Fällen kann also der Vorsitzende bzw. das deutsche Gericht, insbesondere im Rahmen der Amtsaufklärungspflicht und bei Vorliegen von gesetzlich vorgesehenen Gründen zur Ablehnung der Beweisanträge, die Beweisführungsmöglichkeiten der Verfahrensbeteiligten zumindest teilweise begrenzen. 
Nicht nur in Bezug auf die selbstständigen Verfahrensbefugnisse des Richters, sondern auch hinsichtlich der Autonomie der Verfahrensbeteiligten bei der Bestimmung des Umfangs der Beweiserhebungen sind also die Unterschiede zwischen dem deutschen und dem englischen Beweisführungssystem, wie insbesondere das Beispiel des aussagenbasierten Beweises zeigt, nicht unbeträchtlich.

\section{c) Einverständliche Bestimmung der Beweiserhebungen}

Ein weiteres Beispiel dafür, dass im englischen Beweisverfahren die Parteien (und nicht das Gericht) für die Bestimmung des Umfangs der Beweiserhebungen primär verantwortlich sind, betrifft die Möglichkeit der verbindlichen Einführung von (sonst eventuell unzulässigen) hearsay evidence durch Übereinstimmung der Anklage und der Verteidigung in das Verfahren. Ferner gibt es im Allgemeinen die Möglichkeit, dass eine Partei die von der jeweils anderen Partei eventuell zugegebenen Fakten als eindeutigen - nicht mehr bestreitbaren - Beweis einführen kann, bzw. die Möglichkeit für beide Parteien, die Existenz eines Faktes gemeinsam zuzugeben. Diese, für das Gericht meistens zwingende, Umgehung der normalen Beweisverfahrensstrukturen durch die Einführung von ,,agreed evidence“" wird hauptsächlich durch Erwägungen der Verfahrensökonomie begründet.

Auch in Deutschland steht es, ungeachtet der dominierenden Rolle des Richters bei der Bestimmung der Beweiserhebungen im Hauptverfahren, den Verfahrensbeteiligten in bestimmten Fällen frei, spezifische Aspekte der Beweisaufnahme in gegenseitigem Einverständnis zu steuern; auch hierbei behält aber das deutsche Gericht aufgrund seiner Aufklärungspflicht im Gegensatz zum englischen Gericht meistens das letzte Wort. Relevante Fälle betreffen - neben den auch aus Gründen der Verfahrensökonomie eingeführten Möglichkeiten zur Verständigung sogar mit Blick auf die Ausgestaltung des Beweisverfahrens, die angloamerikanischen Ursprungs sind - die Regelungen zur (sonst unzulässigen) Verlesung früherer Vernehmungsniederschriften mit Einverständnis der StA und der Verteidigung. Darüber hinaus ist auf der Basis eines Einverständnisses der zentralen Prozessbeteiligten auch das Absehen des Gerichts von der Erhebung einzelner präsenter Beweise in der Hauptverhandlung möglich. Die richterliche Aufklärungspflicht nach $\S 244(2)$ StPO bleibt in all diesen Fällen in Bezug auf das Ob und Wie der betreffenden Beweiserhebungen gleichwohl unberührt.

\section{d) Case Management}

\section{- Verfahrensökonomie}

Im englischen, größtenteils von den Parteien dominierten Strafverfahren bilden gegenwärtig die case management-Aktivitäten des Richters im Vorfeld sowie während der Hauptverhandlung vor dem magistrates' court und dem Crown Court eine zentrale, primär aus Gründen der Verfahrensökonomie gesetzlich regulierte Pro- 
zessangelegenheit - diese Entwicklung wird oft als ein wesentlicher Bruch mit der „adversarial tradition“ und insbesondere mit den Prinzipien der Parteienautonomie und der richterlichen Passivität betrachtet. ${ }^{768}$ Solche case management-Vorgänge können jedenfalls unter anderem auch die möglichst frühe Klärung diverser Beweisangelegenheiten betreffen. Auch in Deutschland hat das Gericht, neben seiner Aufklärungspflicht und der Pflicht zur effektiven Planung der Beweisvorgänge, eine allgemeine Pflicht zur Beschleunigung und Konzentration der Hauptverhandlung. Im Vorfeld wie auch während des richterzentrierten deutschen Hauptverfahrens kann heute die Ansicht der Verfahrensbeteiligten in Bezug auf Fragen, die eine möglichst frühe Verfahrenserledigung, prozesstechnische Probleme oder die vereinfachte Durchführung des Beweisverfahrens betreffen, eingehender gehört werden.

\section{- Gegenstand, Ziele und Rollenverteilung}

Im Rahmen des englischen case management kann, neben der Festlegung eines effektiven Verhandlungs- und Aufsichtsplans durch den Richter, die Art und Weise der Beweiserhebungen sowie (wenn auch eher indirekt) die Bestimmung ihres Umfangs eventuell durch richterliche Initiative beeinflusst werden; dies kann etwa den Umfang der Zeugenladungen, die Reihenfolge der Beweispräsentationen oder die Dauer der Beweisführungen betreffen. Im selben Rahmen kann außerdem richterlich verlangt werden, dass die beiden Parteien die streitigen (Sach- und Rechts-) Punkte des jeweiligen Strafkonflikts und die vorzubringenden Beweismittel so früh wie möglich eindeutig und öffentlich bekanntzugeben haben - dadurch sollen vor allem parteiliche Angriffe aus dem Hinterhalt verhindert werden, die einer fairen und präzisen Sachverhaltsaufklärung im Wege stehen. Im Allgemeinen wird in der englischen Lehre, Gesetzgebung und Rechtsprechung die Notwendigkeit einer weiteren Zurückdrängung früherer „kampfartiger“ Praktiken im Beweisprozess und gleichzeitig einer aktiveren Rolle des Richters im Strafverfahren immer deutlicher zum Ausdruck gebracht.

Im modernen deutschen Verfahrenssystem wird heute noch sowohl prinzipiell als auch auf der Basis mehrerer einzelner Gesetzesvorschriften und Rechtsprechungsbestimmungen den richterlichen Personen die aktive Vorbereitung, Leitung und kontinuierliche (sinnvolle und in prozessökonomischer Hinsicht effektive) Koordinierung sämtlicher Aspekte der gerichtlichen Untersuchung eines Straffalles anvertraut. Eine (wie in England) zusammenfassende, ausdrückliche und systematische Institutionalisierung der case management-Möglichkeiten und Kontrollfunktionen des Richters im Laufe des ganzen Strafverfahrens war somit auf Gesetzes-

768 Dennis, Evidence, Rn. 1.025; kritisch gegenüber dieser progressiven Umwandlung des ,,adversarialism“ in „,managerialism“ in der englischen Strafjustiz (auch in Bezug auf die Gefahr der Beeinträchtigung der Verteidigungsgarantien) McEwan, L.S. 31 (2011), 519 (insb. 527-546). 
ebene, außer im Hinblick auf die Vorschriften zur Hauptverhandlungsleitung, nicht notwendig. In einem in neutral-amtlicher Weise durchgeführten Verfahren haben die Richter und die übrigen mitwirkenden Staatsorgane freilich eine Objektivitätsund Transparenzpflicht. Die Verfahrensbeteiligten haben jedoch keine allgemeine Pflicht zur Förderung der richterlichen Ermittlungen durch pauschale frühzeitige Offenbarung ihrer sachlichen und rechtlichen Thesen und vorzubringenden Beweismittel. Gleichwohl hat der Richter nicht nur das letzte Wort mit Blick auf die Bestimmung der Beweiserhebungen, sondern auch aufgrund diverser Vorschriften die Befugnis, in Bezug auf einzelne Missbräuche aller Prozessbeteiligten, welche die Wahrheitserforschung, die Fairness und die Beschleunigung des Verfahrens beeinträchtigen können, aktiv und effektiv Abhilfe zu schaffen. Während und zur Förderung der gerichtlichen Untersuchung stehen dem deutschen Gericht bestimmte (inzwischen auch gesetzlich regulierte) Möglichkeiten zur Verfügung, um den jeweiligen Stand des Verfahrens mit den Verfahrensbeteiligten nicht nur für die Zwecke einer Verständigung zu erörtern. Je nach Verfahrensphase können in diesem Rahmen auch etwa generellere prozesstechnische Angelegenheiten, strittige Rechts- und Tatsachenpunkte hinsichtlich der Anklagevorwürfe, Einwände und Missverständnisse in Bezug auf die Beweis- und Aktenlage sowie Fragen zur effizienten und transparenten Ausgestaltung des Hauptverfahrens oder zur Erforderlichkeit von (weiteren) Beweiserhebungen angesprochen werden.

\section{Kenntnisnahme und Offenlegung von Beweisen}

\section{Die Kenntnis der Beweisergebnisse des Vorverfahrens seitens des Richters}

Im Gegensatz zum deutschen Strafverfahren kennt der englische Prozess keine amtliche Zusammenstellung von Verfahrensakten, die in zentralisierter Weise alle „Beweisprodukte“ der staatlichen Ermittlungen im Vorverfahren (sowie eventueller außergerichtlicher Beweiserhebungen nach der Klageerhebung) dokumentieren und anschließend dem Gericht zur Vorbereitung der Durchführung der Hauptverhandlung vorgelegt werden müssen. Die Anklage muss allerdings vor dem Beginn der englischen Hauptverhandlung die Grundzüge ihrer vorzubringenden Beweisthesen - grundsätzlich einschließlich polizeilicher Verhörprotokolle und anderer im Vorverfahren gesammelter beweiskräftiger Materialien - auch dem Gericht zustellen. Im Anschluss an die Beweisoffenlegungen und Zustellungen seitens der Anklage muss die Verteidigung bei einem bevorstehenden Crown Court-Verfahren bzw. kann sie bei einem bevorstehenden magistrates' court-Verfahren eine defence statement anfertigen; sie muss außerdem in sämtlichen Gerichtsverfahren eine defence witness notice aufsetzen. Diese Erklärungen sind auch dem Gericht zuzustellen.

Die englischen Richter können somit sehr oft bereits im Vorfeld einer Hauptverhandlung Kenntnis zumindest von einem Teil der gegensätzlichen Beweisthesen und der diesbezüglichen Beweise haben. Ergänzt wird diese Kenntnis der Richter 
eventuell durch Beweisinformationen, die sie im Rahmen der verschiedenen disclosure-Prozesse, in denen möglicherweise über Fragen zur (Nicht-)Offenlegung inter partes von bestimmten Beweisen richterlich entschieden werden muss, sowie im Rahmen der diversen case management-Aktivitäten und pre-trial hearings erlangen können. $\mathrm{Ob}$ eine solche eher fragmentarische Kenntnis zu einer frühen vollständigen Erfassung sämtlicher Aspekte des ganzen Falles führen kann, lässt sich auf theoretischer Ebene nicht mit Sicherheit sagen. Die Geschworenen des reinen jury-Verfahrens (jurors) dürfen jedenfalls keine konkrete Vorkenntnis des Straffalles haben; ihnen wird nämlich der ganze Sachverhalt durch die Parteien präsentiert.

Dieser letztere Grundsatz des englischen Strafverfahrens, nämlich dass der ausschließlich mit Geschworenen besetzte Spruchkörper des Crown Court keine Vorkenntnis des Beweismaterials des Vorverfahrens haben darf, wird oft als ein allgemein geltendes Prinzip angesehen. Die Frage, ob dieser Grundsatz auch hinsichtlich des verfahrensleitenden Berufsrichters des Crown Court-Verfahrens sowie der (Berufs- oder Laien-)Richter im bench-Verfahren vor dem magistrates' court anzuwenden ist, wird somit vor allem in der rechtsvergleichenden Literatur und in verallgemeinerten Deklarationen meistens gar nicht gesondert angesprochen. Schon auf Gesetzesebene ist aber, wie gerade gesehen, keinesfalls ausgeschlossen, dass sowohl der Vorsitzende Richter im jury-Verfahren als auch die ohne jury sitzenden Richter im bench-Verfahren wenigstens teilweise eine Vorkenntnis der Einzelheiten der gegensätzlichen cases haben können. Die Möglichkeit, dass die Richter hierdurch schon mit Blick auf die Art und Weise der Verhandlungsleitung während der parteilichen Beweisführungen faktisch beeinflusst werden, ist nicht von der Hand zu weisen. Insbesondere im bench-Verfahren, in dem die Richter selbst über alle Rechts- und Tatsachenfragen entscheiden müssen und somit erheblich mehr Verantwortung tragen, ist oft eine eingehendere Vorbereitung auf der Basis der vorhandenen Beweise (insbesondere: Vernehmungsprotokolle) zu beobachten.

Gleichwohl existiert auf prinzipieller Ebene ein wesentlicher Unterschied zum deutschen Prozessrecht. In Deutschland stellt nämlich die vorgerichtliche Kenntnisnahme des Beweismaterials seitens des Berufsrichters nicht lediglich eine Möglichkeit dar, sondern wird vielmehr als wesentlicher Faktor für die zweckmäßige Durchführung der Hauptverhandlung angesehen. Konkreter: die Berufsrichter können schon im Zwischenverfahren und bei der Vorbereitung der Hauptverhandlung eine umfassende Kenntnis grundsätzlich aller bisher durch die Ermittlungsbehörden gesammelten und dokumentierten verfahrensbezogenen (entlastenden und belastenden) Beweise erhalten. Dies erfolgt vor allem aufgrund der Vorlegung der Anklageschrift und der bisherigen Verfahrensakten durch die StA beim erkennenden Gericht; ergänzt wird diese frühe richterliche Wahrnehmung der konkreten Beweislage etwa durch die eventuelle Zustellung von vorbereitenden Beweisanträgen oder durch die Namhaftmachung von durch die Verteidigung und die StA unmittelbar geladenen Zeugen und Sachverständigen. Diese Vorkenntnis der Akten und des entsprechenden, nicht immer in mangelfreier Weise gesammelten Beweismaterials 
seitens der Berufsrichter (in der Regel nicht seitens der mitwirkenden Schöffen) kann nicht nur die Bestimmung des Umfangs, sondern auch die Art und Weise der maßgebenden Beweisaufnahme in der Hauptverhandlung beeinflussen. Wegen der Pflicht zur richterlichen Verhandlungsleitung und Beweisführung lässt sich die Aktenkenntnis zumindest seitens des Vorsitzenden im deutschen Strafprozess nur schwer vermeiden. Nicht zu übersehen ist aber in diesem (im Gegensatz zum englischen Prozess) traditionell auf den Verfahrensakten basierenden Beweisverfahrenssystem, dass schon mit Blick auf die Beweisführung die Gefahr der Vorbeeinflussung des Richters insbesondere zulasten des Angeklagten nach wie vor besteht.

\section{Akteneinsicht und Offenlegung des Vorverfahrensmaterials}

\section{- Allgemeines: Strukturelle Unterschiede und Umfang der Beweisinformationen}

Auch im Rahmen der vielschichtigen Problematik der Beweisoffenlegungen, die zwischen den zentralen Verfahrensbeteiligten nach der Klageerhebung und zur Vorbereitung der Hauptverhandlung stattfinden, gilt als Ausgangspunkt der prozessstrukturellen Vergleichungen die Gegenüberstellung von parteilich kontrollierten Beweisführungen und richterlicher Untersuchung des Straffalles. In Deutschland steht in dieser Hinsicht die Vorbereitung einer zentral-amtlichen Ermittlung des Sachverhalts auf der Basis von möglichst vollständigen (amtlich zusammengestellten) Informationen im Vordergrund, wobei aber gleichzeitig die Mitwirkungsund Informationsrechte der Verteidigung respektiert werden müssen. In England ist für beide Parteien zur Vorbereitung der Präsentation ihrer selbstständigen Beweisthesen vor Gericht die Kenntnis aller fallrelevanten Beweisinformationen von zentraler Bedeutung. Im Rahmen der gegensätzlich ausgerichteten Vorbereitungsvorgänge liegt es allerdings tendenziell im strategischen Interesse jeder Partei, der Gegenpartei wesentliche Beweisstücke vorzuenthalten. Immerhin erkennt auch das moderne englische Beweisoffenlegungsrecht die Benachteiligung der Verteidigung in Bezug auf den Zugang zu Informationen, die Notwendigkeit zur Gewährleistung der Waffengleichheit und die entsprechenden Objektivitätspflichten der Anklage sowie die allseitige Pflicht zur Förderung einer präzisen und fairen Sachverhaltsaufklärung durch die Abkehr von extremen spielstrategischen Praktiken an.

Es kann nicht mit Sicherheit festgestellt werden, wie unterschiedlich der Umfang der Beweisinformationen, die den Verfahrensbeteiligten zu Beginn der gerichtlichen Verhandlung zur Verfügung stehen sollen, in den beiden Rechtsordnungen ist. Sowohl im englischen als auch im deutschen Strafverfahren haben zunächst die Anklagevertreter einen weitgehenden (quasi automatischen) Zugang zu den Beweisergebnissen der staatlichen Ermittlungen des Vorverfahrens. In beiden Ländern gibt es ferner Vorschriften, die ein möglichst umfassendes Recht der Verteidigung zur Einsicht in alle entscheidungserheblichen - belastenden oder entlastenden sowie im Prozess in irgendeiner Weise zu verwendenden oder nicht zu verwendenden - Beweismaterialien gewährleisten sollen. In beiden Verfahrensordnungen 
existieren darüber hinaus Mechanismen, welche die Geheimhaltung bestimmter Informationen insbesondere zum Schutz staatlicher Interessen ermöglichen.

\section{- Beweisoffenlegung seitens der Anklage}

Im englischen Verfahrenssystem kann die Verteidigung teilweise gleichwohl auf große Schwierigkeiten hinsichtlich der Einsichtnahme in die vor Gericht nicht vorzubringenden Beweise stoßen. So können bestimmte „sensible“, für die Unterstützung der Verteidigungsthesen eventuell aber wichtige Informationen auf Antrag der Anklage durch Entscheidung des Gerichts, das gegenwärtig weite Befugnisse auch mit Blick auf Offenlegungsstreitigkeiten besitzt, zurückgehalten werden. Des Weiteren kann die vollständige Offenlegung der nicht vorzubringenden Beweisinformationen, welche die Anklage besitzt, von der frühzeitigen Gegenoffenlegung des fast gesamten Beweisvorbringens (einschließlich der Verteidigungsstrategien) seitens der Verteidigung abhängig gemacht werden. Dadurch wird allseitige Fairness gefordert und insbesondere versucht, die Möglichkeiten der Verteidigung zum „Überraschen“ der Anklage vor Gericht zu begrenzen, ohne gleichzeitig die parteienzentrierte Struktur des englischen Sachaufklärungsprozesses anzutasten. Ob hierbei die faktische Ressourcenungleichheit von Anklage und Verteidigung i.V.m. der Tatsache, dass eine vollständige Beweisführung im englischen Hauptverfahren die umfassende Vorbereitung und Präsentation von zwei gegensätzlichen cases benötigt, genügend wahrgenommen wird, bleibt jedoch fraglich.

Jedenfalls muss die Anklage im englischen Verfahren nach Erhebung der Strafklage der Verteidigung den Zugriff auf grundlegende Beweismaterialien des prosecution case ermöglichen. In umfassender Weise findet auch die Offenlegung derjenigen Beweise statt, deren Einführung in das Verfahren die Anklage als Teil ihres case nicht beabsichtigt, deren Gehalt jedoch für die Unterstützung des defence case bzw. für die Schwächung des prosecution case von Bedeutung sein könnte. Die Anklage ist grundsätzlich kontinuierlich verpflichtet, derartige nicht vorzubringende Beweismaterialien der Verteidigung so bald wie möglich zukommen zu lassen bzw. zur Einsichtnahme verfügbar zu machen.

Im deutschen Verfahrenssystem kann in der Regel vor allem der Verteidiger mindestens $\mathrm{zu}$ allen (belastenden und entlastenden) Beweisinformationen Zugang haben, die dem Gericht durch die Anklagebehörde als entscheidungserheblich bekannt gemacht werden müssen. Den umfassenden Offenlegungspflichten der Anklage in England entspricht in Deutschland die gesetzliche Verankerung des uneingeschränkten Akteneinsichtsrechts der Verteidigung nach dem Abschluss der Ermittlungen. Gleichwohl wird die Gewährleistung des deutschen Akteneinsichtsrechts nicht von der Erfüllung von Offenlegungspflichten seitens der Verteidigung (wie teilweise in England) abhängig gemacht. Unter Rücksichtnahme auf die Objektivitätspflicht der StA bei der Zusammenstellung der vorzulegenden Akten und auf die Möglichkeit des Gerichts, weitere für die Wahrheitserforschung erforder- 
liche Offenlegungen seitens der StA zu verlangen, handelt es sich in Deutschland, zumindest auf normativer Ebene, um ein sehr umfassendes Einsichtsrecht der Verteidigung. Die wichtigste allseitige Beschränkung des Informationsflusses und der Verfahrensvorbereitung auf der Basis der Prozessakten entsteht durch die behördliche Sperrung der Vorlegung von amtlichen Schriftstücken zum Schutz bestimmter Öffentlichkeitsinteressen. Eine solche dienstliche Sperrung wirkt im deutschen Strafverfahren erga omnes, also auch gegenüber dem Gericht.

In Deutschland beziehen sich übrigens die prozessstrukturellen Erwägungen mit Blick auf die Offenlegung der Verfahrensakten, die prinzipiell alle entscheidungsrelevanten Beweisergebnisse der staatsanwaltlichen und polizeilichen Ermittlungen in objektiver und vollständiger Weise dokumentieren müssen, grundsätzlich auf die effektive Vorbereitung der maßgebenden richterlichen Untersuchungen. Für den Angeklagten allerdings geht es zunächst um ein unverzichtbares Verteidigungsrecht, das im Prinzip unabhängig von Sachaufklärungsgedanken gewährleistet werden muss. Die vollständige und kontinuierliche Einsicht in die Akten und in andere entscheidungserhebliche Beweismaterialien und Informationen kann aber in der deutschen Prozesspraxis, ebenso wie in England, der effektiveren Vorbereitung der Beweisthesen der Verteidigung und der Gewährleistung des Rechts auf gerichtliches Gehör, des Fairnessgrundsatzes und der Waffengleichheit dienen.

\section{- Beweisoffenlegung seitens der Verteidigung}

Die Verteidigung muss im englischen Verfahren nicht vorzubringendes Beweismaterial grundsätzlich nicht offenbaren. Sie hat allerdings im Anschluss an die Offenlegung des Anklagevorbringens bestimmte disclosure-Pflichten hinsichtlich ihres eigentlichen Beweisvorbringens gegenüber dem Gericht und der Anklage. Diese Offenlegungen erfolgen hauptsächlich im Wege der Zustellung einer defence statement, die recht ausführliche Angaben bezüglich der Verteidigungsstrategien und der dadurch zu bestreitenden rechtlichen und tatsächlichen Fragen enthalten muss, sowie einer defence witness notice, in der die vorzubringenden Zeugen namhaft $\mathrm{zu}$ machen sind. Insbesondere die Abgabe einer vollständigen defence statement kann zu zusätzlichen Beweisoffenlegungen seitens der Anklage führen bzw. die entsprechende Antragstellung beim Gericht seitens der Verteidigung ermöglichen, aber auch viele ,strategische“ Schwierigkeiten für die Verteidigung verursachen. Die Nicht-Offenlegung bzw. eine mangelhafte disclosure kann jedenfalls negative prozessuale Folgen für die Verteidigung haben, vor allem darf der Spruchkörper Schlüsse hinsichtlich der Schuld des Angeklagten ziehen.

Im deutschen Verfahren ist die Verteidigung kaum verpflichtet, ihre Beweisthesen im Voraus weitgehend offenzulegen. Entscheidet sie sich jedoch dafür, einen strengförmlichen vorbereitenden Beweisantrag zu stellen, muss sie darin konkrete Angaben über die verlangten Beweismittel und die behaupteten Beweistatsachen (zunächst gegenüber dem Gericht) machen. Der Angeklagte hat ferner die von ihm 
unmittelbar geladenen oder zur Hauptverhandlung zu stellenden Zeugen und Sachverständigen rechtzeitig dem Gericht und der StA namhaft zu machen; hingegen existiert keine Verpflichtung zur Bekanntgabe des zu untersuchenden Beweisthemas. Darüber hinaus hat allein das verspätete Identifizieren bzw. Vorbringen von Beweismitteln und Beweistatsachen im deutschen Strafverfahren keine wesentlichen Konsequenzen und darf nicht zur Ablehnung der beantragten Beweiserhebungen führen.

\section{Die Beweisführung im Hauptverfahren}

\section{Zulässigkeit und Ausschluss von Beweisen}

Ein wesentlicher Teil des allgemeinen Beweisrechts und der darauf bezogenen Lehre und Rechtsprechung in beiden Rechtsordnungen befasst sich mit den hochkomplexen Problemen, welche die Einführung in das Verfahren und die Verwertung bei der Urteilsfindung von rechtlich (un-)zulässigen und (un-)zuverlässigen Beweisen betreffen. Die vielfältigen materiellen Aspekte des Strafbeweisrechts erlauben im Rahmen des vorliegenden Forschungsvorhabens keine erschöpfende Darstellung und Gegenüberstellung. Allgemein ist zu bemerken, dass je nach Einzelfrage sich der Ausgangspunkt der anzuwendenden Lösungen zwischen englischem und deutschem Rechtssystem zumindest teilweise erheblich unterscheiden kann. In prozessstruktureller Hinsicht ist jedenfalls zunächst festzuhalten, dass in beiden Verfahrensordnungen meistens das Gericht für die Gewährleistung einer fairen Sachaufklärung im Hauptverfahren auf der Basis eines rechtlich zulässigen und möglichst unmittelbaren Informationsflusses verantwortlich ist; hierfür greifen die Richter eventuell von Amts wegen, in der Praxis aber des Öfteren aufgrund des Antrags bzw. Einwands eines Verfahrensbeteiligten ein.

\section{- Beweisregeln und richterliches Ermessen}

Im englischen Verfahren muss der Richter zuweilen sehr strikte Beweisregeln in Bezug auf die durch die Parteien vorgebrachten förmlichen Beweismittel anwenden. Insbesondere die Einführung von mittelbaren Beweisen aller Art in das Verfahren ist im Grundsatz (mit vielen gesetzlichen Ausnahmen) nicht erlaubt. Auch bei Anwendung der ausdrücklichen Beweisausschlussregeln (wie im Fall von hearsay evidence) hat aber der Richter oft ein gewisses Ermessen mit Blick auf die letztendliche Beweiszulassung, das er auch von der Rechtmäßigkeit des relevanten Prozessverhaltens der Parteien abhängig machen kann. Das Ermessen des Richters erlaubt ihm ferner, aus seiner Sicht extrem einseitig beeinflussende und die Verfahrensfairness beeinträchtigende Beweisinformationen völlig aus den Beweisführungen auszuschließen, auch wenn diese Informationen fallrelevant sind. Bei extremen Fairnessverletzungen haben die Richter darüber hinaus eine strikt begrenzte Befug- 
nis, die Strafklage wegen abuse of process (Verfahrensmissbrauch) schon vor dem Beginn der eigentlichen Beweiserhebungen abzuweisen bzw. die Strafverfolgung einzustellen. Mit Ausnahme der obligatorischen Regeln zur Nicht-Zulassung von durch Folter erlangten Geständnissen scheint aber in den meisten Fällen einer unfairen bzw. rechtswidrigen Beweisgewinnung auch in England die effektive Wahrheitserforschung durch möglichst vollständige Beweisführungen Priorität zu genießen: Der Richter muss nämlich derartige Beweise, die letztendlich glaubwürdig sein können, meistens nicht automatisch ausschließen; im Rahmen seines allgemeinen Ermessensspielraums hat er jedoch die Möglichkeit, die relevanten Beweiseinführungen nach den jeweiligen Fallumständen zur Wahrung der Verfahrensfairness nicht zuzulassen.

Im deutschen Hauptverfahren muss der Vorsitzende bzw. das Gericht zunächst von Amts wegen für die Erhebung und Verwertung aller entscheidungsrelevanten Beweise in Übereinstimmung mit den Regeln des förmlichen Strengbeweises und der Verfahrensunmittelbarkeit sorgen. Die Verwendung mittelbarer Beweise lehnt jedoch das deutsche Recht (wie vor allem das Beispiel des Zeugen vom Hörensagen zeigt) sogar auf prinzipieller Ebene nicht ab; auch im Fall des gesetzlich geregelten Vorgangs des persönlichen Beweises gibt es zahlreiche Durchbrechungen des Unmittelbarkeitsgrundsatzes, die stattdessen den Urkundenbeweis erlauben. Ferner hat der deutsche Richter keinen allgemeinen (dem Ermessen des englischen Richters äquivalenten) Ermessensspielraum, der ihm ohne Weiteres erlauben würde, die nach seiner Sicht ,unfairen“ Beweise aus den Beweiserhebungen in der Hauptverhandlung völlig auszuschließen. Verfahrenshindernisse und die Möglichkeit der Verfahrenseinstellung aus Rechtsstaatlichkeitsgründen kommen ferner außer vielleicht bei extremen Fairnessverletzungen - grundsätzlich nicht in Betracht. Im deutschen Strafprozess ist das Gericht letztendlich an die Amtsaufklärungspflicht gebunden und somit zur umfassenden Aufklärung des streitigen Sachverhalts durch vollständige Beweisführung innerhalb der Hauptverhandlung verpflichtet.

Dessen ungeachtet gilt auch im deutschen Verfahrenssystem der Grundsatz, dass die Amtsaufklärungspflicht nicht um jeden Preis umzusetzen ist. Entscheidungserhebliche Beweise können somit aufgrund von Beweisverbotsbestimmungen aus dem Erkenntnisverfahren und aus der Urteilsbasis ausgeschlossen werden. Im Vordergrund stehen zum einen die bei der Beweisführung unmittelbar wirkenden Beweiserhebungsverbote; zum anderen sind die bei ihrer richterlichen Anwendung oft abwägungsbedürftigen und meistens erst bei der Urteilsfindung (also nach der jeweiligen Beweiserhebung) wirkenden Beweisverwertungsverbote von großer praktischer Bedeutung. Das Gericht muss ferner auch die Beweisanträge der Verfahrensbeteiligten ablehnen, wenn die relevanten Beweiserhebungen, etwa aufgrund von Beweisverboten, unzulässig sind. 


\section{- Verfahren und Strukturprobleme}

Insgesamt hat somit der Richter im englischen Hauptverfahren eine ganz entscheidende Funktion bei der Auseinandersetzung mit den komplexen Fragen zur Zulässigkeit und zum Ausschluss von Beweisen. In der Gegenwart können (müssen aber nicht) die meisten Beweisausschlussangelegenheiten aus prozessökonomischen Gründen im Rahmen von diversen Vorverhandlungen oder vorbereitenden Verhandlungen innerhalb des Hauptverfahrens verbindlich erledigt werden. Auch wenn die Hauptverhandlung i.e.S. angefangen hat, wird es allgemein für wünschenswert gehalten, dass die Beweisausschlussfragen so früh wie möglich - noch vor Beginn der eigentlichen Beweisführungen - angesprochen werden. Fragen zur Beweiszulässigkeit werden des Öfteren von dem das jury-Verfahren leitenden trial judge bzw. von den verfahrensleitenden magistrates des bench-Verfahrens persönlich entschieden; durch diese tatsächliche (wenn auch frühe) Kenntnisnahme von eventuell unzulässigen Beweisen kann eine gewisse Beeinflussung des Prozessverhaltens der Richter während der parteilichen Beweisführungen nicht ausgeschlossen werden. Als Leitprinzip des englischen Verfahrensrechts gilt ferner, dass der Spruchkörper möglichst keine Kenntnis von unzulässigen Beweisen haben darf; allerdings ist es im magistrates' court-Verfahren möglich, dass die Richter über den Ausschluss von Beweisen aus der weiteren Hauptverhandlung entscheiden und deren Existenz dann bei der Beurteilung der Schuldfrage ,vergessen“ müssen. Innerhalb einer bereits laufenden jury trial (insbesondere in der sogenannten voir dire-Phase) kann dagegen der verfahrensleitende Richter in Abwesenheit der Geschworenen über eventuelle admissibility-Fragen entscheiden.

Vorgerichtlich existieren im deutschen Strafverfahren, im Gegensatz zum englischen Strafprozess, keine eigenständigen Prozessstadien zur verbindlichen Klärung der Beweisausschlussfragen. In der deutschen Hauptverhandlung kann/muss das Gericht in der Regel auch von Amts wegen die relevanten gesetzlichen Vorschriften anwenden und über das Vorliegen der Voraussetzungen eines Beweisverbots entscheiden. Trotzdem macht die Rechtsprechung ein Beweisverwertungsverbot vor allem davon abhängig, ob der Verwertung der betreffenden Information bei der Urteilsfindung nach ihrer Einführung in die Hauptverhandlung durch die Prozessbeteiligten widersprochen wird. Auch wenn hierbei die englische und die deutsche Verfahrenspraxis nicht völlig vergleichbar sind, kann über solche Ansätze wie die deutsche Widerspruchslösung bemerkt werden, dass sie auf eine Tendenz zur Erweiterung der prozessualen Eigenverantwortung der Verfahrensbeteiligten hindeuten. Dagegen verlangt die englische Rechtsprechung im Rahmen des sonst parteienzentrierten Prozesses nicht unbedingt einen Einwand seitens der Prozessbeteiligten für die gerichtliche Auseinandersetzung mit etwaigen Fairnessproblemen und Rechtsfragen; in der Praxis bestimmt aber das Prozessverhalten der Anklage und der Verteidigung größtenteils den allgemeinen Verlauf der Beweisaufnahme.

Jedenfalls steht es dem englischen Richter heute in vielen Fällen frei, von Amts wegen einzugreifen und Beweise aus dem gesamten Verfahren (nicht nur aus der 
richterlichen Urteilsfindung) auszuschließen. Das deutsche Gericht erlangt ferner im Rahmen der Beweisverbotspraxis häufig eine (im Vergleich zum englischen Gericht meistens umfassendere) Kenntnis von rechtswidrig erlangten Beweisinformationen (nicht zuletzt) aufgrund ihrer Einführung in die Hauptverhandlung durch Beweiserhebungen, bevor es eventuell entscheidet, solche Beweise bei der Urteilsfindung nicht zu verwerten. Eine solche Kenntnis von „verbotenen“ Informationen kann freilich einen tatsächlichen Einfluss nicht nur auf der Ebene der Urteilsfindung, sondern auch auf die Art und Weise der übrigen Beweisführungen haben.

\section{Erhebung, Präsentation und Prüfung der Stichhaltigkeit der Beweise}

\section{a) Grundlagen}

\section{- Allgemeine Charakteristika der Beweisführung in der Hauptverhandlung}

Der Vergleich der Beweisvorgänge in der englischen und der deutschen Hauptverhandlung führt zu der zentralen Erkenntnis, dass in England die maßgebenden Beweisführungen grundsätzlich im Wege der Präsentation und Prüfung der Beweise durch die Parteien (mit begrenzten Eingriffsmöglichkeiten seitens des Richters), in Deutschland dagegen primär in Form von Beweiserhebungen durch den Richter (und unter Mitwirkung der Verfahrensbeteiligten) erfolgen. Auf Grundlagenebene sind zusammengefasst insbesondere folgende Punkte in Bezug auf die prozessstrukturellen Besonderheiten und Rollenverteilungen zu beachten:

- Gerichtsbarkeit: Zunächst ist im Voraus zu bemerken, dass es in England keine großen Unterschiede zwischen einem magistrates' court- und einem Crown CourtVerfahren gibt, was die Regeln und Teilstadien der herkömmlichen Beweisführung vor Gericht mit Blick auf die erstinstanzlichen streitigen Straffälle anbelangt. Die (Berufs- oder Laien-)Richter eines bench-Verfahrens vor dem magistrates' court sind insgesamt für die Verfahrensleitung und für die Beurteilung sowohl der Rechts- als auch der Tatsachenfragen zuständig. In einer jury trial vor dem Crown Court ist dagegen der Vorsitzende Berufsrichter hauptsächlich für die ordnungsgemäße und faire Verfahrensleitung und für die Entscheidung über die diversen Rechtsfragen verantwortlich, während die Beurteilung der präsentierten Tatsachen und die letztendliche Entscheidung über die Schuld den Laien der separaten Geschworenenbank obliegen. Vor sämtlichen deutschen Strafgerichten und Spruchkörpern laufen die grundlegenden Stadien des herkömmlichen erstinstanzlichen Hauptverfahrens grundsätzlich in derselben Art und Weise und größtenteils nach einheitlichen Verfahrensregeln ab. Im Gegensatz zum englischen Hauptverfahren ist innerhalb der deutschen Hauptverhandlung (ausgenommen die reine Verfahrensleitung) und im Rahmen der Entscheidungsfindung keine substantielle Aufgabenverteilung zwischen Berufsrichtern und den eventuell mitwirkenden Laienrichtern vorgesehen. 
- Aufklärungspflichten: Die Hauptaufgabe der Anklage in sämtlichen englischen Hauptverfahrensarten besteht darin, beyond reasonable doubt nachzuweisen, dass die angeklagten Tatbestände nach den Definitionen des materiellen Strafrechts erfüllt sind. Die Anklage kann jedoch im Rahmen eines schon laufenden Hauptverfahrens, z.B. aus Anlass einer Absprache oder aus sachlichen Gründen und public interest-Erwägungen, die Entscheidung treffen, keine Beweise vor Gericht zu präsentieren (offering no evidence). Nach herrschender Meinung hat das Gericht in der Folge, nicht zuletzt aufgrund seiner allgemein eng begrenzten Beweiserhebungsbefugnisse, in den meisten Fällen tatsächlich keine andere Wahl, als den Angeklagten entsprechend freizusprechen. Im Allgemeinen kann die Anklage eine Strafverfolgung ohne Zustimmung des Richters grundsätzlich nur vor dem Anfang, während und bis zum Abschluss der gerichtlichen Präsentation ihres case abbrechen. Der eigentliche Tatsachenfeststellungsvorgang im deutschen Gerichtsverfahren ist durch die richterliche Aufklärungspflicht (anstatt durch die Beweislast der Anklagebehörde wie in England) gekennzeichnet. Die deutschen Richter müssen von Amts wegen und selbstständig auf der Basis der jeweils bekannten Umstände des Einzelfalls mit allen zulässigen Beweismitteln sämtliche materiell-rechtlich relevanten Tataspekte des Sachverhalts in sinnvoller, aber nicht überschießender Weise erforschen. Der Angeklagte muss nicht seine Unschuld beweisen. Die StA vertritt in der Hauptverhandlung ihr Anklagevorbringen, ist aber auch bei der Ausübung ihrer Mitwirkungsbefugnisse während der Beweisführungen zur Objektivität verpflichtet. Die Strafklage kann jedenfalls nach Eröffnung des Hauptverfahrens nicht zurückgenommen werden, und ein Strafverfolgungsabbruch bzw. eine einseitige Verfahrenseinstellung durch die StA ist nach dem Eröffnungsbeschluss und während der Beweisführungen in der Hauptverhandlung grundsätzlich nicht möglich. Die Durchführung einer vollständigen richterlichen Beweisaufnahme unabhängig vom Willen und Vorbringen der Verfahrensbeteiligten ist letztendlich in der deutschen Rechtsordnung weitgehend möglich bzw. kann je nach Einzelfall als geboten erscheinen. Inwieweit das prozessuale Verhalten der Prozessbeteiligten in der überlasteten Gerichtspraxis auf die Erledigung der Strafkonflikte tatsächlich (informell) einwirkt, stellt freilich eine gesonderte Frage dar.

- Einverständliche Beweisführung: Mit Ausnahme der judicial notice-Fälle finden die eigentlichen Beweiserhebungen und die umfassenden mündlichen Präsentationen und Gegenpräsentationen der strittigen Tatsachen im herkömmlichen englischen Hauptverfahren größtenteils durch die Anklage und die Verteidigung nach dem Grundsatz der Parteienautonomie statt. In diesem Rahmen können die Parteien, wie gesehen, in bestimmten Fällen auch die Vermeidung zeitaufwendiger gegensätzlicher Beweiserhebungen und Tatsachenpräsentationen mit Blick auf unbestreitbare Aspekte des Sachverhaltes im Wege der Einführung von ,agreed evidence" verbindlich fordern. Jenseits der Fälle von Tatsachenoffenkundigkeit, die in beiden Systemen eine primär richterliche Angelegenheit sind, existieren im deutschen Verfahren darüber hinaus weitere Möglichkeiten zur vereinfachten Durch- 
führung bestimmter Teile der Beweisaufnahme auf der Basis eines Einverständnisses der StA und der Verteidigung. In diesem Zusammenhang zu erwähnen sind das einvernehmliche Absehen von der richterlichen Erhebung einzelner präsenter Beweise und die (sonst unzulässige) Verlesung von früheren Vernehmungsprotokollen. Auch in solchen Fällen besteht jedoch meistens ein richterliches Entscheidungsermessen und die richterliche Amtsaufklärungspflicht wird niemals wirklich verdrängt. Im Gegensatz zu Entsprechungen im englischen Strafprozess sind in Deutschland eventuelle beweisverfahrensbezogene Vereinbarungen zwischen den Verfahrensbeteiligten niemals wirklich verbindlich für das Gericht.

\section{- Leitsätze zur Rollenverteilung}

Der Vorsitzende Richter wird im englischen Strafverfahrenssystem, auch wenn er nicht selbstständig alle Aspekte des Sachverhalts ermittelt und die eigentliche Durchführung des Beweisverfahrens grundsätzlich nicht übernehmen darf, nicht als bloßer Schiedsrichter angesehen. Seine Hauptaufgabe ist vielmehr die Wahrheitsfindung und Gerechtigkeitsgewährleistung. Diese Ziele können aber nach dem englischen Prozessverständnis nur durch eine unmittelbare (im Grunde ununterbrochene) und faire (eventuell richterlich ausbalancierte) Gegenüberstellung der unterschiedlichen Parteivorbringen effektiv und vollständig erfüllt werden. Den allgemeinen Leitlinien des englischen case law zufolge wird dem neutralen Richter keinesfalls eine absolut passive Rolle zugewiesen. Im Prinzip darf der Richter begrenzt vor allem zur Sicherstellung von rechtlich zulässigen, fairen, zügigen, ordnungsgemäßen, klaren und widerspruchsfreien Beweispräsentationen eingreifen; die eigentliche Beschränkung des diesbezüglichen Ermessensspielraums des Richters durch die Hochgerichte bezieht sich aber fast ausschließlich auf Fälle, in denen durch das Eingreifen des Richters die Verfahrensfairness extrem beeinträchtigt werden könnte. Moderne empirische Beobachtungen deuten außerdem auf eine in der Gerichtspraxis sich ständig erweiternde, interventionistischere Rolle des Richters bzw. auf entsprechende Tendenzen hin; insbesondere scheinen die Richter oft bereit zu sein, sich etwa mit den Zeugenbefragungen aktiver zu befassen.

Beim deutschen Hauptverfahren handelt es sich letztendlich um eine gerichtliche Untersuchung des angeklagten Sachverhalts, bei der die zentralen Prozessbeteiligten (insbesondere die Verteidigung) beträchtliche Mitwirkungsrechte haben, jedoch nicht wirklich Beweisführer sind - vereinfacht betrachtet repräsentieren die deutsche und die englische Hauptverhandlung in diesem Zusammenhang quasi zwei Gegenbilder der Sachverhaltsaufklärung. Dem Vorsitzenden des deutschen Gerichts obliegen die ordnungsgemäße Verhandlungsleitung, die Vernehmung des Angeklagten und die Beweisaufnahme. Das ganze Gericht entscheidet gemeinsam unter anderem über die Anordnung von kommissarischen Beweiserhebungen und beschließt über Beanstandungen der Verfahrensbeteiligten gegen Leitungsanordnungen des Vorsitzenden, über Zweifel in Bezug auf die Zulässigkeit gestellter Fragen und über die in der Hauptverhandlung gestellten Beweisanträge. Sowohl die 
StA als auch die Verteidigung sind nicht selbstständig für die maßgebende Beweisaufnahme in der Hauptverhandlung verantwortlich. Die aktive Mitwirkung der Verfahrensbeteiligten an den richterlichen Beweisführungen ist allerdings in diversen Vorschriften verankert, die unter anderem die Gewährleistung des Fragerechts, die Erhebung von Einwänden sowie auch die Stellung von Anträgen betreffen.

\section{b) Der Ablauf der Beweisvorgänge im Gerichtsverfahren}

Das vergleichende Studium des Ablaufs der Beweisvorgänge im englischen und im deutschen Hauptverfahren wird am besten durch die unmittelbare Gegenüberstellung der entsprechenden Abschnitte der vorangehenden Landesberichte bedient. ${ }^{769}$ Diese Textabschnitte sollen einen kohärenten und konzisen Überblick über die gerichtlichen Beweisführungsstadien sowie über die kontextuale Funktion und Konnexität der einzelnen Sachaufklärungsmechanismen innerhalb der Hauptverhandlung liefern. Um extensive Wiederholungen zu vermeiden, wird an dieser Stelle nur auf bestimmte maßgebende Grundzüge, Gemeinsamkeiten und Unterschiede in Bezug auf die verschiedenen Beweisführungsstrukturen und Rollenverteilungen in der englischen und der deutschen Hauptverhandlung zusammenfassend eingegangen. Zum genauen Verständnis des gesamten Ablaufs der nationalen Hauptverfahren sind die im Folgenden präsentierten Erkenntnisse freilich zusammen mit den entsprechenden ausführlichen Textstellen in den einzelnen Landesberichten zu lesen.

\section{- Auswirkungen der unterschiedlichen Besetzung der Gerichte}

Zunächst ist noch einmal zu bemerken, dass in Deutschland die gerichtliche Untersuchung, die Beweisführungen und die Mitwirkung der zentralen Verfahrensbeteiligten im Rahmen der herkömmlichen erstinstanzlichen Hauptverhandlung meistens in einheitlicher Weise und nach denselben Regeln und Prinzipien vor sämtlichen Strafgerichten und Spruchkörpern erfolgen. Es ist bemerkenswert, dass auch in England keine großen Unterschiede zwischen einem jury-Verfahren und einem bench-Verfahren bezüglich der anzuwendenden Beweisregeln und Beweisvorgänge existieren. Allerdings ist festzuhalten, dass das Hauptverfahren vor dem Crown Court allgemein in förmlicherer Weise als vor dem magistrates' court abläuft. Aufgrund der strikten Aufgabenverteilung zwischen verfahrensleitendem Richter und jurors sowie der Tatsache, dass die jurors allein entscheidende Laienrichter sind, gibt es bestimmte (praktische oder sogar normative) Teilunterschiede in Bezug auf den Ablauf gewisser Verfahrensphasen. Diese Unterschiede zwischen jury- und bench-Verfahren betreffen aber im Grunde nicht den Kern der parteilichen Beweisauseinandersetzungen.

769 Siehe entsprechend unter Teil 2, II.D.2.b) und Teil 2, III.D.2.b). 
Insbesondere ist $\mathrm{zu}$ beachten, dass vor den Richtern des englischen benchVerfahrens nicht die Verteidigung, sondern nur die Anklage ein formales Recht auf opening speech hat, von dem sie aber nicht immer Gebrauch macht. Dagegen spielt im jury-Verfahren sowohl die Eingangsansprache der Anklage im Rahmen des prosecution case als auch die Eingangsansprache der Verteidigung im Rahmen des defence case für beide Parteien eine strategisch sehr wichtige Rolle besonders mit Blick auf die informatorische Vorstellung ihres gesamten Beweisvorbringens vor den jurors. Demgegenüber hat die Verteidigung in Deutschland nach der durch den StA zu informatorischen Zwecken (und möglichst ohne Bezug auf konkrete Beweisergebnisse des Vorverfahrens) erfolgenden Verlesung des Anklagesatzes kein Recht auf eine Eingangserklärung.

Des Weiteren gibt es in England bestimmte Unterschiede zwischen dem juryund dem bench-Verfahren in Bezug auf das Wann und Wie der richterlichen Auseinandersetzung mit Beweisausschlussfragen, die bereits oben (im Vergleich auch zum deutschen Verfahren) angesprochen wurden. ${ }^{770}$ Schließlich zeichnet sich das englische jury-Verfahren durch die inhaltlich weitgehende informatorische Unterstützung der jurors bei ihrer Tatsachenfeststellungsaufgabe durch den Richter im Rahmen der öffentlichen summing-up Abschlussphase aus - dabei kann der Richter nicht nur die Rechtsfragen und alle bereits präsentierten Beweismittel und Tatsachen zusammenfassend kommentieren, sondern in einer sehr aktiven Weise in die Beweiserwägungen eingreifen und ausnahmsweise sogar alternative defences zugunsten des Angeklagten vorbringen, welche die Verteidigung während der Beweisführungen nicht ins Feld geführt hat. Eine solche summing-up Verfahrensphase ist für das englische bench-Verfahren sowie in der öffentlichen deutschen Hauptverhandlung, da diese keine separate Geschworenenbank aufweisen, nicht vorgesehen. Die Laienrichter des englischen bench-Verfahrens werden aber in Bezug auf Rechtsfragen und prozesstechnische Angelegenheiten weitgehend von juristisch ausgebildeten clerks oder legal advisers unterstützt.

\section{- Beweisführungsphasen}

Hinsichtlich der Ausgestaltung der eigentlichen Beweiserhebungen ist darüber hinaus zunächst zu beachten, dass in der englischen Hauptverhandlung sowohl im jury- als auch im bench-Verfahren die grundsätzlich durch die Parteien gesteuerten Beweisführungen in zwei große Phasen gegliedert sind: die Präsentation des prosecution case und die anschließende Präsentation des defence case. Nach dem Ende der Beweisführungen im Rahmen des prosecution case und vor dem Beginn der Beweiserhebungen im Rahmen des defence case kann die Verteidigung einen Antrag auf sofortigen Prozessabbruch wegen bestimmter substantieller Beweismängel im prosecution case stellen (submission of no case to answer); die Richter des

770 Siehe unter Teil 2, IV.D.1. i.V.m. Teil 2, II.D.2.b) und Teil 2, III.D.2.b). 
magistrates' court bzw. der verfahrensleitende Richter oder sogar die jurors des Crown Court können unter Umständen auch von Amts wegen (immer nach Anhörung der Beteiligten) auf einen derartigen Freispruch des Angeklagten entscheiden.

Der deutsche Strafprozess kennt dagegen keine entsprechende streng formale Unterscheidung zwischen Beweisführungsphasen, zwischen Anklage- und Verteidigungsvorbringen und zwischen entlastenden und belastenden Beweismaterialien, die den Ablauf der Beweiserhebungen beeinflussen könnte. Das Beweisverfahren ist in Deutschland letztendlich richterlich gesteuert und muss durchgehend vor allem nach den Grundsätzen der Amtsaufklärungspflicht und des Beweisantragssystems durchgeführt werden. Das deutsche Hauptverfahren weist auch keine ausdrücklichen Prozessmechanismen auf, die ähnlich wie in den englischen no case to answer-Fällen die vereinfachte Beendigung des Verfahrens ungeachtet dieser Grundsätze ermöglichen würden; eine ersichtlich schwache Beweislage führt aber in der Praxis auch im deutschen Verfahren oft zum schnellen Abschluss der Beweisaufnahme und (nach den Schlussvorträgen und -anträgen der Verfahrensbeteiligten) zum Freispruch.

\section{- Reihenfolge der Beweiserhebungen}

Im englischen Hauptverfahren beginnen die Beweisführungen (sowohl vor dem magistrates' court als auch vor dem Crown Court), wie oben dargelegt, mit der Darstellung des prosecution case. Der Anklagevertreter muss (nach seiner opening speech) die Beweise, auf denen sein Vorbringen basiert, präsentieren. Insbesondere muss die Anklage die nach den allgemeinen Beweisregeln zulässigen belastendenden Beweismittel vorbringen und zu diesem Zweck vor allem die Anklagezeugen zur Aussage aufrufen sowie Expertengutachten, schriftlich aufgezeichnete Aussagen, written statements und andere zulässige hearsay-Beweise vorlesen und mögliche real evidence präsentieren. Die Anklagezeugen sind unter Anwendung der Beweisausschlussregeln zu vernehmen. Die Vernehmung der einzelnen Zeugen geschieht jeweils im Wege von examinations-in-chief (durch die Anklage), von direkt daran anschließenden cross-examinations (durch die Verteidigung), von möglichen re-examinations (durch die Anklage) sowie erforderlichenfalls (meistens am Ende der parteilichen Verhöre) von Befragungen durch den/die Richter und im jury-Verfahren gegebenenfalls auch von mittelbaren Befragungen durch die jurors. Entsprechendes gilt für die anschließende Darstellung des defence case (die, wie gesehen, nur im jury-Verfahren und nur unter bestimmten Voraussetzungen mit einer opening speech des Verteidigers eingeleitet werden kann). In dieser Phase ist die Verteidigung die primäre Beweisführerin. Ihr obliegt insbesondere zuerst die examination-in-chief des Angeklagten (falls er sich nach Kenntnisnahme der möglichen Konsequenzen seines Schweigens dafür entscheidet, als Verteidigungszeuge auszusagen) und danach der übrigen Verteidigungszeugen. Der Angeklagte oder sein Anwalt sind aber in normativer Hinsicht allgemein nicht verpflichtet, Entlastungsbeweise vorzubringen. Darüber hinaus haben die Richter selbst, wie gesehen, 
die ultima ratio-Befugnis, die von den Parteien nicht geladenen Zeugen zur Vernehmung aufzurufen; der/die Richter stellt/stellen dabei selbst Fragen an die betreffenden Zeugen und kann/können danach die Durchführung von Kreuzverhören durch die Parteien erlauben.

Die eigentlichen beweisrelevanten Vorgänge setzen dagegen in der deutschen Hauptverhandlung mit der Vernehmung des Angeklagten zur Sache ein, wobei der Angeklagte (ungeachtet eventueller faktischer Nachteile) nicht verpflichtet ist, sich zur Sache zu äußern. Der Angeklagte, der nicht als Zeuge betrachtet wird, wird zunächst durch den Vorsitzenden Richter vernommen, wobei auch alle beisitzenden Richter, die StA und der Verteidiger unmittelbare Fragerechte haben; im Gegensatz dazu wird der Angeklagte im englischen Verfahren als Verteidigungszeuge angesehen und somit erst im Rahmen des defence case vernommen. Die Beweisaufnahme i.e.S. folgt in der deutschen Hauptverhandlung nach der Sachvernehmung des Angeklagten. Dabei sind unter Berücksichtigung der Regeln der Amtsaufklärungspflicht, des Strengbeweises, der Beweiserhebungsverbote und der Verfahrensunmittelbarkeit unter anderem von Amts wegen die vom Gericht vorgeladenen und tatsächlich erschienenen Zeugen zu vernehmen, die Sachverständigen zu vernehmen, die Urkunden zu verlesen und der Augenschein einzunehmen. Zulässige Beweiserhebungen gründen sich auch auf Anträge der Verfahrensbeteiligten, die sowohl nicht präsente als auch präsente Beweismittel betreffen können. Analog zum englischen Verfahren ist die Verteidigung in Deutschland in keinem Fall verpflichtet, Beweisanträge zu stellen und allgemein Beweise vorzubringen. Die allgemeine Reihenfolge der Benutzung der diversen Beweismittel bei der Erhebung und Prüfung der strittigen Beweise ist darüber hinaus nicht im deutschen Gesetz festgelegt; sie wird vielmehr je nach Einzelfall aufgrund von Zweckmäßigkeitserwägungen vom Vorsitzenden bestimmt - und nicht von den Verfahrensbeteiligten im Rahmen der Präsentation ihres Vorbringens, wie es sehr oft im englischen Verfahren geschieht. Die Vernehmung sämtlicher Beweispersonen findet, wie grundsätzlich jede Beweiserhebung im deutschen Hauptverfahren, in der Regel zunächst durch den Vorsitzenden persönlich statt; es spielt dabei keine besondere Rolle (mit der seltenen Ausnahme des förmlichen Kreuzverhörs), ob der Richter selbst im Rahmen seiner Aufklärungspflicht den Zeugen geladen hat oder ob der Zeuge von einem Verfahrensbeteiligten im Wege eines Beweisantrags benannt wurde. Die beisitzenden Richter und die Prozessbeteiligten haben in jedem Fall das Recht, Fragen an die Beweispersonen unmittelbar (und meistens im Anschluss an die Befragungen seitens des Vorsitzenden) zu stellen.

\section{- Verspätete Beweisführungen}

Sowohl während der englischen als auch während der deutschen Hauptverhandlung ist eine mehrfache bzw. wiederholte Examinierung desselben Beweismittels insbesondere die Durchführung weiterer Vernehmungen der Beweispersonen (in England einschließlich des Angeklagten) - von Amts wegen oder auf Antrag 
der Verfahrensbeteiligten grundsätzlich nicht ausgeschlossen. Darüber hinaus gilt zunächst als Regel im englischen Hauptverfahren, dass eine Partei nach dem Abschluss der Darstellung ihres case keine weiteren Beweise in das Verfahren einführen darf. Jede Partei kann jedoch unter bestimmten Umständen zusätzliche zulässige Beweismittel vor allem zur Widerlegung von bereits eingeführten Beweisen vorbringen. Eine allgemeine „Neueröffnung“ des prosecution case kann insbesondere im jury-Verfahren nur in ganz bestimmten Fällen vom Richter erlaubt werden. Der Richter kann nach freiem Ermessen und im Hinblick auf die jeweiligen Fallumstände die „Neueröffnung“ des defence case sogar nach dem Ende der summingup Phase erlauben. Im Allgemeinen dürfen die Parteien (sowie auch der Richter) nach dem Beginn der nicht öffentlichen jury-Beratungen in keinem Fall mehr Beweise in den Prozess einführen; im bench-Verfahren sind nach Verkündung des Urteils keine Beweisaufnahmen mehr möglich.

In der deutschen Hauptverhandlung darf dagegen heute noch im Prinzip (ungeachtet der jüngeren, viel kritisierten Tendenz der Rechtsprechung zur Setzung von Beweisantragsfristen) eine Beweiserhebung nicht deshalb vom Gericht abgelehnt werden, weil das Beweismittel oder die zu beweisende Tatsache zu spät vorgebracht worden sei. Beweisanträge sind in allen Fällen in der Hauptverhandlung bis zum Beginn der Urteilsverkündung möglich. Allgemein kann das deutsche Strafgericht (auch im Rahmen seiner Aufklärungspflicht) bis zur vollständigen Verkündung des Urteils wieder in die Verhandlung und die Beweisaufnahme eintreten.

\section{- Schlussvorträge}

Im englischen bench-Verfahren und in der deutschen Hauptverhandlung bilden schließlich die Schlussvorträge der Parteien/Verfahrensbeteiligten den letzten substantiellen (entscheidungserheblichen) Teil der öffentlichen beweisrelevanten Vorgänge. Im englischen jury-Verfahren folgen zusätzlich nach den Schlussvorträgen, wie gesehen, die richterlichen summing-up Ausführungen, die auf die anschließende Beweiswürdigung durch die jurors einen erheblichen Einfluss haben können.

Sowohl im englischen bench- als auch im jury-Verfahren kann also nach der Präsentation und Prüfung der Verteidigungsbeweise zuerst die Anklage Abschlussdarstellungen zur Unterstützung ihres case geben. Die Möglichkeit zum Schlussvortrag hat die Anklage, soweit der Angeklagte sich durch einen Rechtsanwalt vertreten lässt oder soweit der Angeklagte (mit oder ohne Verteidiger) nicht lediglich selbst als Zeuge ausgesagt, sondern auch weitere Zeugen in den Prozess aufgerufen hat. Die Anklage muss ihre Abschlussdarstellungen möglichst objektiv, in Übereinstimmung mit den vorhandenen Beweisen und unemotional vortragen. Anschließend kann in allen Fällen die Verteidigung (der Angeklagte oder sein Anwalt) einen inhaltlich umfangreichen Schlussvortrag zur kritischen Zusammenfassung ihres Vorbringens und der übrigen Beweisführungen halten, wobei aber nur solche Tatsachenbehauptungen gemacht werden dürfen, bezüglich derer schon im Verfahren Beweise erhoben worden sind. 
In der deutschen Hauptverhandlung folgen die Schlussvorträge zuerst des StA und dann des Verteidigers und/oder des Angeklagten nach dem Schluss der Beweisaufnahme, und das letzte Wort ist in allen Fällen dem Angeklagten zu erteilen. Auch hier muss der StA einen objektiven und unvoreingenommenen Schlussvortrag in Bezug auf das Gesamtergebnis der Verhandlung halten. Der Verteidiger kann, wie auch in England, bei der Ausübung seines Vortragsrechts die zugunsten des Angeklagten sprechenden Umstände einseitig hervorheben. Ähnlich wie im englischen Strafverfahren dürfen die Schlussvorträge des StA und des Verteidigers nur die in der Hauptverhandlung bereits mündlich angesprochenen Tatsachen sowie die Ergebnisse der Untersuchung der in die Hauptverhandlung eingeführten Beweismittel betreffen. Dagegen genießt im deutschen Verfahrenssystem der Angeklagte selbst viel mehr Freiheit in Bezug auf die inhaltliche Gestaltung seiner Schlussausführungen.

\section{c) Die Methoden der Beweisprüfung}

aa) Allgemeine Bemerkungen

Sowohl im Verlauf des englischen als auch des deutschen Verfahrens können die Richter und die zentralen Prozessbeteiligten die rechtliche Zulässigkeit der Erhebung und die Stichhaltigkeit aller vorgebrachten Beweise auf diversen Wegen in Zweifel ziehen. Im englischen Strafverfahren findet die allseitige Prüfung des zeugenbasierten Beweises grundsätzlich im Rahmen der parteilichen examinations-inchief und der cross-examinations statt. Auch die Einführung anderer Beweisarten, wie des schriftlichen aussagenbasierten Beweises und des Urkundenbeweises, der real evidence und des Augenscheinsbeweises, ist zunächst nach den allgemeinen Beweisoffenlegungs- und Beweisausschlussregeln bzw. nach den Regeln zur Einführung von Beweisen durch Zustimmung der Parteien zu beurteilen. Soweit derartige Beweise im Verfahren aufgrund richterlicher Entscheidung verbindlich zugelassen worden sind bzw. soweit ihre Einführung nicht widerlegt worden ist, werden diese vor sämtlichen Verfahrensbeteiligten, dem Richter und (im Rahmen einer jury trial) den Geschworenen präsentiert. Während der englischen parteienzentrierten Beweisführungen besteht die Möglichkeit, dass eine Partei die von der Gegenpartei durchgeführten Beweiserhebungen in vielfacher (insbesondere prozesstechnischer) Hinsicht beanstandet. Umfassende substantielle Beweiskommentierungen und die Abgabe von Erklärungen zu den bezüglich sämtlicher Beweise sich ergebenden Rechts- und Stichhaltigkeitsfragen sind seitens der Parteien auch im Rahmen der anwaltlichen Anfangs- und Schlussvorträge bzw. seitens des Richters im jury-Verfahren während seiner Abschlusszusammenfassungen möglich.

Die Beweisaufnahme in der deutschen Hauptverhandlung liegt dagegen grundsätzlich in den Händen des Vorsitzenden. Er und das Gericht entscheiden unter Anwendung der Regeln der Amtsaufklärungspflicht, der Beweisoffenlegung, des 
Beweisantragssystems, der Unmittelbarkeit und des Beweisverbotskomplexes über den Umfang der Beweiserhebungen. Die eigentliche Durchführung der hiernach erforderlichen und zugelassenen Beweiserhebungen wird ebenso richterlich gesteuert. In Bezug auf den zeugenbasierten Beweis besitzen die anderen Verfahrensbeteiligten in jedem Fall Fragerechte. Mit Blick auf sämtliche Beweismittel und Beweistatsachen haben sie ferner diverse Möglichkeiten zu substantiellen Eingriffen während oder am Ende der einzelnen richterlichen Beweiserhebungen und -anordnungen oder am Ende der gesamten Beweisaufnahme. Eingreifen können die Verfahrensbeteiligten vor allem durch die Erhebung von (auch prozesstechnischen) Einwänden, durch Kommentierungen und durch Erklärungen etwa in Bezug auf den Wert oder auf mögliche Unklarheiten und Widersprüche der Beweiserhebungen sowie im Rahmen der Schlussvorträge. Auch in Deutschland kann darüber hinaus die Zulässigkeit der Zeugenbefragungen seitens eines Verfahrensbeteiligten durch einen anderen Beteiligten angezweifelt werden.

bb) Die Art und Weise der Vernehmungen

Im Rahmen der Gegenüberstellung der englischen und der deutschen gerichtlichen Beweisführungsmethoden dient der Vergleich der mündlichen Erhebung und allseitigen Prüfung des aussagenbasierten (insbesondere zeugenbasierten) Beweises als besonders anschauliches Beispiel. Die Vernehmung der Beweispersonen und somit die Prüfung ihrer entscheidungserheblichen Aussagen sind nämlich im englischen Hauptverfahren in einer ganz anderen Art und Weise geregelt als in der deutschen Hauptverhandlung. Im Vordergrund der englischen Beweismethoden in sämtlichen Gerichtsverfahren steht die erschöpfende gegenseitige Vernehmung durch die Anklage und die Verteidigung der meistens durch die Parteien selbst zur Aussage aufgerufenen Zeugen. Beim deutschen Hauptverfahren handelt es sich dagegen um einen neutral-amtlichen Beweisbestimmungs- und Sachaufklärungsvorgang; dieser verlangt unter anderem, dass die umfassenden Vernehmungen der Beweispersonen primär durch den Vorsitzenden Richter durchgeführt werden. ${ }^{771}$

Dessen ungeachtet bezwecken beide Hauptverfahrenssysteme mit ihren unterschiedlichen Beweismechanismen die möglichst präzise Aufklärung des angeklagten Sachverhalts; im Fall des Zeugenbeweises setzt das die ausführliche Wahrnehmung der entscheidungsrelevanten Aussagen und die umfassende Prüfung ihrer Zuverlässigkeit und Glaubwürdigkeit voraus. Beide Verfahrensordnungen lassen außerdem gegenwärtig in ähnlicher Weise für die Zwecke der Wahrheitserforschung durch verbesserte Beweisqualität sowie des effektiven Zeugenschutzes den Einsatz diverser technischer Hilfsmittel bei den Vernehmungen auf Antrag der Pro-

771 Allgemeine Ausführungen zu den diversen Vor- und Nachteilen der unterschiedlichen Beweisprüfungsmethoden mit Blick auf die Erfüllung des Wahrheitserforschungszwecks siehe schon unter Teil 1, II.C.2.e) m.w.N. 
zessbeteiligten oder von Amts wegen zu. So sind z.B. die Vorführung von BildTon-Aufzeichnungen früherer Vernehmungen von schutzbedürftigen Zeugen, live link-Verhöre sowie die Geheimhaltung der Identitätsdaten von Zeugen möglich.

\section{- Struktur und Umfang der Vernehmungen}

Im englischen Verfahrenssystem finden im Allgemeinen die Verhöre der Zeugen (einschließlich des Angeklagten), die mündlich im magistrates' court- oder Crown Court-Verfahren aussagen, während der Anklage- und Verteidigungspräsentationen statt und nicht zentralisiert im Wege von neutral-amtlichen, richterlich gesteuerten Vernehmungen wie in Deutschland. Die unmittelbaren kontinuierlichen und gegenseitigen Befragungen durch die Parteien ermöglichen ferner keine völlig freie, umfassende Wiedergabe der beobachteten Fakten seitens der Zeugen. Jeder einzelne Zeuge durchläuft üblicherweise in der englischen Hauptverhandlung zuerst die examination-in-chief durch die Partei, die ihn aufgerufen hat, dann die cross-examination durch die Gegenpartei(en) und am Ende eventuell noch eine re-examination durch die erstere Partei. Die Befragung sämtlicher Zeugen durch den/die Richter nach eigenem Ermessen ist gleichwohl in jedem Stadium des englischen Hauptverfahrens möglich. Der Richter muss jedoch bei seinen Eingriffen in die Beweiserhebungen und insbesondere bei der Unterbrechung der durch die Parteien stattfindenden (Kreuz-)Verhöre erhebliche Zurückhaltung im Einklang mit seiner unparteiischen Rolle üben; inhaltliche Unterbrechungen der anwaltlichen Beweisprüfungen sind grundsätzlich nur aus Klarstellungsgründen erlaubt, während selbstständige richterliche Befragungen idealerweise am Ende der parteilichen Verhöre folgen sollen. Die Durchführung sämtlicher Verhöre durch die Parteien erfolgt allerdings nicht auf unkontrollierte Weise; vielmehr kann bzw. muss der verfahrensleitende Richter unter bestimmten Voraussetzungen und oft aufgrund eines parteilichen Einspruchs eingreifen und die Einhaltung sowohl gewisser Prozess- und Fairnessregeln als auch eines hohen Qualitätsniveaus der wahrzunehmenden Beweise sowie die Förderung allgemein der Wahrheitsfindung sicherstellen.

So gilt zunächst bei den examinations-in-chief die Regel, dass den Zeugen nur Fragen gestellt werden dürfen, die sachrelevant und nicht unzulässig nach den Beweisausschlussregeln (vor allem nach den hearsay-Regeln) sind. Fragen, die ausschließlich die Glaubwürdigkeit des Zeugen betreffen, sind im Rahmen des englischen Hauptverhörs logischerweise (da irrelevant) nicht erlaubt. Grundsätzlich unzulässig ist auch die Einführung in das Verfahren von vorherigen inhaltsgleichen Aussagen des Zeugen, die seine Aussagen vor Gericht stimmig erscheinen lassen könnten; frühere widersprüchliche Aussagen des Zeugen, deren Existenz nachgewiesen wird oder deren Existenz der Zeuge während des Verhörs zugibt, sind hingegen nach den hearsay-Regeln auch als substantieller Tatsachenbeweis zulässig. Eine weitere wichtige Regel bei der Durchführung der Hauptverhöre besteht im Verbot von leading questions (mit möglichen Ausnahmen, nach richterlichem 
Ermessen, bei den sogenannten hostile witnesses und etwa auch bei Zeugen, die ein mangelhaftes Erinnerungsvermögen haben). Beweise, die aufgrund von Suggestivfragen bereits erbracht worden sind, sind nicht unbedingt per se völlig auszuschließen, können aber jedenfalls im Hinblick auf ihren Beweiswert negativ gewürdigt werden.

Im Anschluss daran kann eine cross-examination, die ebenfalls unter dem Vorbehalt der diversen Beweisausschlussregeln steht, sämtliche fallrelevanten Tatsachen betreffen. Hierbei können freilich Fragen hinsichtlich der Glaubwürdigkeit des Zeugen gestellt werden, und es kann Gegenbeweis zur Nachprüfung der Widersprüchlichkeit der Aussagen vorgebracht werden. Außerdem sind im Rahmen eines englischen Kreuzverhörs grundsätzlich leading questions (mit Ausnahme offensichtlich unfairer Fangfragen) erlaubt. Normative Beschränkungen der Möglichkeit zur cross-examination betreffen etwa das richterliche Verbot der persönlichen Vernehmung von Beschwerdeführern bei Sexualdelikten und von anderen schutzbedürftigen (insbesondere minderjährigen) Zeugen durch den Angeklagten. Außerdem darf im Kontext der Sexualdelikte ein Angeklagter oder sein Verteidiger ohne richterliche Erlaubnis während des Kreuzverhörs keine Fragen stellen, die das sexuelle Verhalten des Beschwerdeführers betreffen.

Demgegenüber muss in der deutschen Hauptverhandlung die sachliche Vernehmung des Angeklagten und sämtlicher Beweispersonen zunächst durch den Vorsitzenden des Gerichts in neutral-amtlicher Weise durchgeführt werden und kann in der Regel alle entscheidungsrelevanten Tatsachen und Verhältnisse betreffen. Die Vernehmungen erfolgen in der vom Vorsitzenden nach den Einzelfallumständen bestimmten Reihenfolge, wobei aber der Angeklagte grundsätzlich als Erster zu vernehmen ist. Für die Ausgestaltung der Vernehmungsvorgänge spielt es keine besondere Rolle, wer die Beweisperson zuerst vorgeladen bzw. gestellt hat und ob es sich bei ihr tatsächlich um einen Entlastungs- oder Belastungszeugen oder um einen ,feindlichen“ Zeugen handelt. Anders als die englischen parteilichen Befragungen ist die Zeugenvernehmung nach der deutschen StPO in eine Berichts- und eine Verhörphase gegliedert. Eine solche Phasentrennung ist dagegen für die Vernehmung des Angeklagten nicht ausdrücklich vorgesehen; dem Angeklagten ist im Rahmen seiner Vernehmung in jedem Fall die Gelegenheit zu geben, die gegen ihn vorliegenden Verdachtsgründe zu beseitigen und die zu seinen Gunsten sprechenden Tatsachen geltend zu machen, sodass praktisch die Möglichkeit des Angeklagten, zusammenhängende Angaben zu machen, zumindest zu Vernehmungsbeginn grundsätzlich nötig erscheint.

Die beisitzenden deutschen Richter und Schöffen, die StA und die Verteidigung (der Angeklagte und sein Anwalt) verfügen darüber hinaus im Rahmen sämtlicher Vernehmungen mit Blick auf die vollständige Prüfung der Glaubwürdigkeit bzw. des Erinnerungsvermögens der Beweispersonen und der Glaubhaftigkeit ihrer Aussagen über unmittelbare Befragungsmöglichkeiten. Relevante normative Beschränkungen betreffen hierbei insbesondere die Unzulässigkeit der unmittelbaren Ver- 
nehmung des Angeklagten durch einen Mitangeklagten (was dagegen in England in der Regel nicht verboten ist) sowie das Gebot der Vernehmung von minderjährigen Zeugen grundsätzlich allein durch den Vorsitzenden. Der Vorsitzende bestimmt ferner im Rahmen seiner Aufklärungspflicht den Zeitpunkt und die Reihenfolge, zu dem und in der die Fragerechte zweckmäßig auszuüben sind. Die Befragung jeder einzelnen Beweisperson durch die Prozessbeteiligten folgt aber grundsätzlich erst nach dem Abschluss der richterlichen Befragungen, und ein Prozessbeteiligter darf im Prinzip die Befragung durch den Vorsitzenden oder durch die anderen Beteiligten nicht unterbrechen, um eigene Fragen zu stellen. Vereinfacht ausgedrückt, stehen die Verfahrensabläufe in Deutschland und England quasi unter umgekehrten Vorzeichen.

Darüber hinaus kann in der englischen Hauptverhandlung im Rahmen der examinations-in-chief wie auch der cross-examinations auf Antrag des Anwalts oder auch aufgrund einer richterlichen Anweisung von Amts wegen den Zeugen die Möglichkeit gegeben werden, während des Verhörs ihre vorherigen schriftlich aufgezeichneten Aussagen zur „Auffrischung“ des Gedächtnisses einzusehen. Der Richter kann allerdings nach eigenem Ermessen eine derartige „Auffrischung“ des Zeugengedächtnisses immer ablehnen.

Im Allgemeinen können auch in der deutschen Hauptverhandlung einer Beweisperson während ihrer Vernehmung schriftliche Unterlagen zur Gedächtnisauffrischung vorgelegt oder Vorhalte etwa aus früheren Protokollen und elektronischen Aufzeichnungen gemacht werden. Die prozesstechnischen Einzelheiten und der Umfang der Verwendung solcher Vernehmungsbehelfe durch den Richter oder die Verfahrensbeteiligten sind in Deutschland und England auch in Anbetracht der jeweils geltenden Unmittelbarkeitsregelungen und hearsay-Regeln freilich nicht identisch. Unter anderem scheint in der deutschen (nicht aber in der englischen) Rechtsprechung die Möglichkeit anerkannt zu sein, durch Vorhalt einer früheren Vernehmungsniederschrift und die daraufhin abgegebene bestätigende Erklärung des Zeugen sogar Erkenntnisse über die Konstanz seines Aussageverhaltens (und somit über seine Glaubwürdigkeit) in die Hauptverhandlung einzuführen. Jedenfalls existieren im deutschen Verfahren Regelungen zur Unterstützung des Gedächtnisses der Beweispersonen sowie zur Klärung von Geständnisfragen und von widersprüchlichen Aussagen auch im Wege des Urkundenbeweises. Die entsprechenden Vorgänge können von Amts wegen oder auf Antrag/Anregung eines Prozessbeteiligten richterlich angeordnet werden.

\section{- Kreuzverhör: Verfahrensstruktur versus prozessuale Möglichkeit}

Im Gegensatz zur deutschen Verfahrensordnung entsprechen im englischen Strafverfahren die wechselseitigen Befragungen der Beweispersonen durch die Parteien und insbesondere das Kreuzverhör der Zeugen letztendlich nicht nur prozessualen Rechten, Mitwirkungsmöglichkeiten oder alternativen Prozessformen. 
Ihre selbstständige prozessstrukturelle Bedeutung im Rahmen der gerichtlichen Sachaufklärungsvorgänge ist auch auf normativer Ebene, nicht zuletzt kraft der Bestimmungen der overriding objective des englischen Strafprozesses, anerkannt. So ist es möglich, dass eine Partei einzelne Tatsachen- und Glaubwürdigkeitsfragen nicht im Wege des Kreuzverhörs und durch die Einführung von Gegenbeweisen widerlegt bzw. nicht infrage stellt. Ein solcher Verzicht auf cross-examination kann aber eventuell mit der stillschweigenden Anerkennung der Wahrheit des betreffenden in chief vorgebrachten Beweises gleichgesetzt werden. Einem Anwalt ist es grundsätzlich nicht erlaubt, solche unwiderlegten Fragen erst im Rahmen seines Schlussvortrags anzusprechen und entsprechende Vorwürfe zu erheben.

In der deutschen Hauptverhandlung ist auf übereinstimmenden Antrag der StA und der Verteidigung die Durchführung von Kreuzverhören der (nur) von ihnen benannten Zeugen und Sachverständigen zu gestatten. Solche förmlichen Kreuzverhöre sind gleichwohl in der deutschen richterzentrierten Sachaufklärungspraxis sehr selten und werden oft als systemfremd angesehen; ihre Durchführung bildet eigentlich keine unmittelbare Analogie zu dem das gesamte englische Strafverfahrensbild prägenden Haupt- und Kreuzverhörsystem. Im deutschen Verfahren ist zudem ein aktiveres Eingreifen des Vorsitzenden gesetzlich gefordert: Der deutsche Richter darf nicht nur (wie sein englisches Pendant) gegen ungeeignete und missbräuchliche Befragungen vorgehen, welche die Wahrheitsfindung behindern, die schutzwürdigen Interessen des Zeugen verletzen oder sachfremde Zwecke verfolgen, sondern er muss zusätzlich in allen Fällen am Ende des Kreuzverhörs weitere ihm zur Sachverhaltsaufklärung erforderlich scheinende Fragen stellen. Nicht ausgeschlossen ist im deutschen Verfahren die Durchführung von informellen Kreuzverhören: Hierbei kann der Vorsitzende, ungeachtet der gesetzlichen Voraussetzungen des förmlichen Kreuzverhörs, sofort nach der Berichtsphase einer Zeugenvernehmung der StA und dem Verteidiger die eigentliche Befragung des Zeugen überlassen und am Verhörsende erforderlichenfalls selbst weitere Fragen stellen.

\section{- Richterliche Kontrolle der Befragungen}

Die englischen Richter haben heute (anders als oft vermutet) die allgemeine Befugnis, insbesondere zur Gewährleistung einer allseitigen Verfahrensfairness und zur Optimierung der Beweisqualität, die Art und Weise der parteilichen Befragungen zu kontrollieren. Das Gericht kann den inhaltlichen Umfang der examination, cross-examination oder re-examination eines Zeugen sowie die Dauer sämtlicher Verhandlungen einschränken; dies kann etwa bei lang andauernden Kreuzverhören sowie weitschweifigen und sich wiederholenden Befragungen als notwendig erscheinen. Der Richter kann außerdem nach eigenem Ermessen überflüssige, prozessverschleppende, beleidigende oder provokatorische Fragen im Rahmen insbesondere eines Kreuzverhörs zurückweisen. Schließlich tragen auch die Anwälte während der parteilich gesteuerten Beweisführungen entsprechende ethisch-recht- 
liche Verantwortung gegenüber dem Gericht und sind zur Vermeidung solcher Verhaltensweisen verpflichtet; Missbräuche während der Kreuzverhöre sind aber im englischen Hauptverfahren weiterhin zu beobachten, wenn auch nicht im selben Maße wie in anderen common law-Ländern.

Der Vorsitzende des deutschen Gerichts kann (ähnlich wie der englische Richter) nicht nur auf Antrag, sondern auch von Amts wegen in die Befragungen durch die Verfahrensbeteiligten eingreifen, um mögliche Missbräuche und ungeeignete Fragestellungen zu unterbinden. Er kann insbesondere ungeeignete (z.B. gesetzlich verbotene oder auch offensichtlich suggestive) oder nicht zur Sache gehörende Fragen der Verfahrensbeteiligten zurückweisen. Für die Wahrheitsfindung erforderliche (entscheidungserhebliche) Glaubwürdigkeitsfragen sind in jedem Fall grundsätzlich erlaubt. Die Verfahrensbeteiligten können ihrerseits Einwände gegen die Zulässigkeit der richterlichen Vernehmungsvorgänge und Leitungsanordnungen erheben; die Äußerung von Zweifeln in Bezug auf die Zulässigkeit von allseitig gestellten Fragen und die Anrufung des ganzen Gerichts in diesem Zusammenhang ist in allen Fällen möglich.

\section{E. Zusammenfassung und Klassifizierung der nationalen Beweisführungssysteme anhand des ,adversatorischen“" und des ,inquisitorischen“" Idealtypus}

Der Versuch, die oben dargestellten und miteinander verglichenen englischen und deutschen gerichtlichen Beweisführungssysteme anhand der in Teil 1 der vorliegenden Forschungsarbeit definierten Beweisverfahrensmodelle zu klassifizieren, scheint auf den ersten Blick Elemente eines Zirkelschlusses zu beinhalten. Für die Konstruktion der betreffenden Modelle wurden in der Tat unter anderem reale Ausgestaltungsformen des modernen englischen und des deutschen Strafprozesses berücksichtigt. Die mögliche Erkenntnis, dass die englische Verfahrensordnung näher an dem idealen ,adversatorischen“ und die deutsche näher an dem idealen „,inquisitorischen“ Beweisführungstypus steht, ist aber nicht mit solchen kategorischen Bestimmungen gleichzusetzen, die etwa zwischen einem ,englischen, adversatorischen Modell“ und einem ,deutschen, inquisitorischen Modell“ differenzieren. Wie oben bereits ausführlich erläutert wurde, ${ }^{772}$ knüpft die prozedurale Idee hinter der Unterscheidung zwischen zwei grundlegenden Beweisverfahrensmodellen, namentlich die Gegenüberstellung von ,,amtlicher Ermittlung“ und „Parteienwettstreit", an die Wahrnehmung zentraler Prozessfiguren in der civil law- und der common law-Welt an. Durch die in Teil 1 vorgenommene Bearbeitung dieser Idee wurden allerdings abstrakte Verfahrenstypen in einer logisch-systematischen Weise so definiert, dass sie jenseits von konkreten nationalrechtlichen Prozesserschei-

772 Siehe insb. in Teil 1, II.B. und Teil 1, II.C.4. 
nungsformen, gemeinsamen Nennern und historischen Gegebenheiten eigenständig eingesetzt werden können.

Hauptsächlich wurde hierdurch die Bereitstellung neutraler abstrakt-theoretischer Vergleichungsinstrumente angestrebt, die sich quasi auf universaler Ebene auf eine unbestimmte Anzahl von gegenwärtigen Beweisverfahrenssystemen orientieren; derartige heuristische Instrumente sollen zur möglichst kompakten und konsistenten Identifizierung, Gegenüberstellung und Bewertung struktureller und funktionaler Besonderheiten der Beweisführung sowie relevanter Tendenzen einsetzbar sein. Innerhalb des sich aus dieser Auseinandersetzung mit dem ,adversatorischen“ und dem ,,inquisitorischen“ Modell ergebenden Analyserahmens wurden nun oben das englische und das deutsche Beweisführungssystem eingehend miteinander verglichen. Daneben soll die Zusammenstellung und Verwendung von Idealtypen des Beweisverfahrens im Sinne idealtypischer Schemata, wie sie auch sonst bei sämtlichen vergleichenden Untersuchungen ausdrücklich oder implizit wahrgenommen werden, taxonomischen Zwecken dienen. Unter Rücksichtnahme auf die jeweils konkrete Erfüllung der abstrakten Dichotomisierungskriterien lassen sich die Beweisverfahren einzelner Rechtsordnungen in dem Spektrum zwischen den zwei Extremmodellen verorten. Solche Klassifizierungen können dann eventuell als vereinfachter Ausgangspunkt oder grober Ablaufplan für die weitere Forschung bzw. rechtspolitische Reformarbeiten dienen. In der vorliegenden Arbeit folgt nun im Rahmen der Klassifizierungserwägungen zunächst eine Zusammenfassung der bereits gegenübergestellten Grundprinzipien und -mechanismen der nationalen Beweisführungssysteme. Dieser Überblick (unter 1.-3.) und die abschließenden Betrachtungen zur Klassifizierung (unter 4.) können jedoch auf Erkenntnisebene weder die ausführlichen Darstellungen in den vorhergehenden Landesberichten noch die daran anschließende Vergleichung der englischen und der deutschen Beweisführungsformen ersetzen.

\section{Die vorbereitenden Beweisführungsvorgänge}

Basierend auf der Definition der essenziellen Elemente ${ }^{773}$ des ,,adversatorischen“ und des ,inquisitorischen“ Analysemodells in Teil 1 der Arbeit wurden oben in Teil 2 die strafprozessualen Strukturen und Rollenverteilungen innerhalb des englischen und des deutschen Beweisführungssystems auf drei Unterebenen gesondert untersucht und anschließend verglichen. Diese Unterebenen sind: die vorbereitenden Beweisführungsvorgänge; die Kenntnisnahme und Offenlegung von Beweisen; und die Beweisführung im Hauptverfahren. An dieser Stelle sind nun, zunächst in Bezug auf die vorbereitenden Beweisführungsvorgänge, besonders folgende Erkenntnisse aus der vorhergehenden Betrachtung des englischen und des deutschen Strafverfahrenssystems zusammenfassend hervorzuheben und gegenüberzustellen:

773 Siehe ihre Zusammenfassung unter Teil 1, II.C.4. 


\section{a) Das englische Verfahrenssystem}

- Die Anklage (vertreten grundsätzlich durch die CPS-Anwälte) und die Verteidigung bilden zwei Parteien im Sinne von zentralen nicht richterlichen Prozessbeteiligten. Die Parteien (und nicht die Richter) sind nach der Klageerhebung für die tatsächliche Durchführung der Sachaufklärungsvorgänge primär verantwortlich.

- Nach der Anklageerhebung bauen die Anklage und die Verteidigung selbstständig eigene cases zur Präsentation vor Gericht auf.

- Die zur Vorbereitung des Hauptverfahrens allseitig verwendeten Beweisinformationen und Beweismittel stammen zu einem Großteil aus den dokumentierten Ermittlungsergebnissen und gesammelten Beweisen des polizeilichen Vorverfahrens; diese werden nach der Klageerhebung der CPS und durch die Letztere größtenteils auch der Verteidigung vorgelegt. Zwischen Verteidigung und Anklage muss vor allem was den Informationsstand anbelangt Waffengleichheit herrschen.

- Alle Prozessbeteiligten sind verpflichtet, bei der Vorbereitung und Durchführung des Strafprozesses die gerechte Erledigung des jeweiligen Straffalles (insbesondere die Verurteilung nur der wirklich Schuldigen sowie die faire, menschenwürdige, effektive und proportionale Behandlung aller Beteiligten und Fallaspekte) anzustreben. Extreme parteiische Verhaltensweisen bei der Vorbereitung der gegensätzlichen cases sind keinesfalls normativ gefördert. Der Anklageanwalt darf sich nicht als bloßen Vertreter einer Partei ansehen und muss seine Beweisthesen und alle entscheidungsrelevanten Beweise in fairer, rechtlich zulässiger und objektiver (unvoreingenommener) Weise vor Gericht vorbringen.

- Der Verteidiger muss das Gericht bei der Justizhandhabung und der Gesetzesanwendung unterstützen und darf es weder täuschen noch rechtswidrige Mittel zur Förderung der Interessen seines Mandanten einsetzen. Er ist primär verpflichtet, seinen Mandanten vor einer Verurteilung auf der Basis von rechtlich unzulässigen Beweisen zu schützen, und ist einseitig für die effektive Vorbereitung des Verteidigungsfalles (eventuell auch durch private außergerichtliche Ermittlungen und durch die Herbeischaffung des notwendigen Beweismaterials) zuständig.

- Vor sämtlichen Strafgerichten bestimmen die Anklage und die Verteidigung die Belastungs- und Entlastungszeugen zunächst selbst. Ungeachtet früherer (meistens polizeilicher) Vernehmungen, die für die Vorbereitung der parteilichen Beweisvorbringen freilich berücksichtigt werden, müssen die aufgerufenen Zeugen in der Regel im Hauptverfahren öffentlich, persönlich und mündlich de novo Auskunft geben. Der Angeklagte kann sich frei dafür entscheiden, als Entlastungszeuge vor Gericht auszusagen.

- Die parteiliche Vorbereitung der aufzurufenden Zeugen im Vorfeld eines gerichtlichen Verhörs durch intensives coaching, intensive rehearsals oder Mitteilung der Auskünfte anderer Zeugen sowie solche (eventuell strafbaren) Verhaltensweisen, welche die Zeugen ermuntern, unwahre bzw. unvollständige Aussagen zu 
machen, sind grundsätzlich nicht erlaubt. Zulässig sind nur allgemeine court familiarisation arrangements sowie einfache „ermittelnde“ Gespräche zwischen einer Partei und den „eigenen“ Zeugen.

- Jede Partei kann zur Ermöglichung des Beweises konkreter Tatsachen ihre „eigenen“ Expertenzeugen vorbringen; die Entscheidung über die Zulassung der Aussage der Expertenzeugen, die vor allem nach Notwendigkeitskriterien erfolgt, obliegt letztendlich dem Richter. In normativer Hinsicht hat der Experte nicht nur eine Pflicht gegenüber seinem Mandanten (d.h. der jeweiligen Partei), sondern in erster Linie eine übergeordnete „Hilfspflicht“ gegenüber dem Gericht für die Zwecke einer präzisen Tatsachenfeststellung. Dessen ungeachtet sind die Parteien für die Auswahl und die Instruktion der Expertenzeugen verantwortlich. Das Gericht hat grundsätzlich nicht die Möglichkeit, Sachverständige aus einer neutral erstellten Liste auszuwählen und selbstständig zu laden bzw. weitere forensische Expertenuntersuchungen anzuordnen. Die fallgezielte vorgerichtliche Vorbereitung (training) der Expertenzeugen durch die Parteien ist jedoch verboten.

- Die Beweisführung obliegt im Allgemeinen grundsätzlich der Anklage und der Verteidigung; jede Partei bringt ihre ,eigenen“ Beweismittel vor und kann die von der anderen Partei vorgebrachten Beweismittel prüfen. Insbesondere bei offensichtlichen matters of common knowledge oder historical issues steht es den Richtern aber frei, die Plausibilität der betreffenden Sachfragen allein und summarisch, ohne formelle Beweisführung durch die Parteien, zu erklären (,judicial notice" von facts). Problematisch gestaltet sich die Möglichkeit zur ,judicial notice“ von Tatsachen auf der Basis einer lediglich persönlichen Vorkenntnis des Richters, die keine common knowledge darstellt: Der Richter wird dadurch faktisch zu einem Anklagezeugen, wobei die Verteidigung nach den geltenden Regeln, die nur die kontradiktorische Beweisführung durch die Parteien betreffen, wegen der richterlich deklarierten ,judicial notice“ keine Möglichkeit mehr hat, den Richter zu vernehmen oder Gegenbeweis zu erheben.

- Die Parteien besitzen weitgehende, aber nicht völlig unkontrollierbare Autonomie bei der Bestimmung des Umfangs der Beweiserhebungen. Sowohl die Anklage als auch die Verteidigung können insbesondere zunächst selbst entscheiden, welche Zeugen zur Aussage vor Gericht zu laden bzw. aufzurufen sind. Sie müssen keine strengförmlichen Beweisanträge bei Gericht stellen, um ein Zeugenverhör in der Hauptverhandlung zu erwirken. Für die Verteidigung ist es überhaupt nicht obligatorisch, Zeugen aufzurufen. Die Autonomie der Anklage mit Blick auf die (Nicht-) Ladung von Zeugen zur Verankerung der prosecution case kann wegen Fairnesserwägungen eingeschränkt werden. Die Anklage muss alle Personen, die unmittelbare Zeugen von zentralen Tatsachen und gleichzeitig (nach Meinung der Anklage) glaubwürdig sind, laden oder für die Verteidigung verfügbar machen, auch wenn solche Zeugen in negativer bzw. widersprüchlicher Weise für das Anklagevorbringen wirken könnten. Der Richter hat die ultima ratio-Befugnis, die von der Anklage unterlassenen Zeugenladungen selbst zu übernehmen. In der Gerichtspraxis 
greift der Richter allgemein in die Bestimmung der Beweiserhebungen durch die Parteien grundsätzlich nicht ein, es sei denn, dies erscheint vor allem wegen unerwarteter Umstände im Interesse der Gerechtigkeit als notwendig.

- Weitere Beispiele dafür, dass die Parteien (und nicht das Gericht) für die Bestimmung des Umfangs der Beweiserhebungen primär verantwortlich sind, sind die Möglichkeit zur verbindlichen Einführung von hearsay evidence durch übereinstimmende Einwilligung der Anklage und der Verteidigung in das Verfahren sowie die allgemeine Möglichkeit der Parteien zur Einführung diverser Arten von, ,agreed evidence" als eindeutige, nicht mehr bestreitbare Beweise.

- Obwohl die Parteien die Beweisführung größtenteils steuern, stellen gegenwärtig die case management-Aktivitäten des Richters im Vorfeld sowie während der Hauptverhandlung eine zentrale, primär aus Gründen der Verfahrensökonomie gesetzlich geregelte Prozessangelegenheit dar. Im Rahmen der case management-Vorgänge kann der Richter, neben der Ausarbeitung eines effektiven Verhandlungs- und Aufsichtsplans, eventuell auch initiativ auf die Art und Weise der Beweiserhebungen sowie (wenn auch eher indirekt) auf die Bestimmung ihres Umfangs Einfluss nehmen. Im selben Rahmen kann richterlich verlangt werden, dass beide Parteien die streitigen (Sach- und Rechts-)Punkte des jeweiligen Strafkonflikts und die vorzubringenden Beweismittel so früh wie möglich eindeutig und öffentlich bekanntgeben. Im Allgemeinen kommt in Lehre, Gesetzgebung und Rechtsprechung das Streben nach einer weiteren Abkehr von früheren „kampfartigen“ Praktiken im Beweisprozess sowie gleichzeitig nach der allgemeinen Förderung einer aktiveren Rolle des Richters im Strafverfahren immer deutlicher zum Ausdruck.

\section{b) Das deutsche Verfahrenssystem}

- Mit der Anklageerhebung setzt eine zentral-amtliche, richterlich durchgeführte Untersuchung des Sachverhalts ein. Der Begriff „Parteien“ zur Bezeichnung der StA (als Anklagevertreterin) und der Verteidigung als zentralen Verfahrensbeteiligten mit Mitwirkungsrechten wird in diesem Rahmen grundsätzlich nicht verwendet.

- Es obliegt nicht den zentralen Verfahrensbeteiligten, vollständige selbstständige cases zu sämtlichen Tatsachen- und Rechtsfragen vorzubereiten und anschließend alle diversen Aspekte des ganzen Sachverhalts in dieser Form vor Gericht zu präsentieren.

- Die allseitigen (amtlichen und ,privaten“) vorbereitenden Beweisaktivitäten finden mit Blick auf die gerichtliche Untersuchung größtenteils auf der Basis der mit der Anklageschrift und den Verfahrensakten vorgelegten und offengelegten Beweisergebnisse des staatsanwaltlichen und polizeilichen Vorverfahrens statt. Hierbei muss zwischen den Strafverfolgungs-/Anklagebehörden und dem Angeklagten Waffen-/Chancengleichheit herrschen, was den Informationsstand anbelangt. 
- Die StA ist als unabhängige Justizbehörde auch im Rahmen der gerichtlichen Beweisvorgänge sowohl zur Objektivität bei der Gesetzesanwendung als auch der Gerechtigkeit und der Wahrheit verpflichtet.

- Der Verteidiger wirkt grundsätzlich einseitig zum effektiven Schutz und zur Förderung der gesetzlich anerkannten Interessen des Angeklagten, nimmt jedoch gleichzeitig auch öffentliche Aufgaben und Interessen wahr. Er muss rechtmäßig handeln und darf die Verteidigungsrechte weder missbrauchen noch Beweisquellen trüben oder Beweismittel verfälschen. Er muss vor allem für die effektive Ausübung der Verteidigungs- und Mitwirkungsrechte sorgen.

- Alle Personen, deren Aussage unter Rücksichtnahme auch auf frühere Vernehmungen vom Richter (nicht allein von den Prozessbeteiligten) im Rahmen der Amtsaufklärungspflicht und nach den Beweisantragsregeln als fallrelevant und für die Schuldfrage als entscheidend betrachtet wird, müssen in der Regel in der Hauptverhandlung öffentlich, persönlich und mündlich de novo Auskunft geben. Zumindest in normativer Hinsicht existiert keine Unterscheidung zwischen Belastungs- und Entlastungszeugen. Der Angeklagte ist kein Zeuge im technischen Sinne, stellt allerdings, falls er sich dafür entscheidet auszusagen, ein zentrales Beweismittel dar.

- Bei außergerichtlichen Kontakten zwischen den Strafverfolgungs-/Justizorganen und sämtlichen Personen, deren Aussage fallrelevant ist, sind die staatlichen Behörden (auch die StA) zur Objektivität verpflichtet. Es existieren keine generellen kategorischen Regelungen zum zulässigen Inhalt der außergerichtlichen Gespräche zwischen dem Verteidiger und möglichen (Entlastungs-)Zeugen mit Blick insbesondere auf die Vorbereitung der späteren Aussagen. Der Verteidiger darf jedenfalls auf die freie Willensbildung der Zeugen nicht einwirken, sie nicht zu falschen Aussagen veranlassen und allgemein nicht zur Verfälschung von Beweismitteln beitragen.

- Die Anordnung des Sachverständigenbeweises ist hauptsächlich eine zentralamtliche bzw. gerichtliche (nicht parteiliche) Angelegenheit. Ein für das gerichtliche Verfahren hinzuzuziehender Sachverständiger wird vom Richter im Rahmen seines Beurteilungsspielraums (unter Wahrnehmung der besonderen Schwierigkeiten des Einzelfalles und der hierbei erforderlichen Sachkunde) ausgewählt und beauftragt. Im Vorverfahren kann auch die StA einen Sachverständigen ihrer Wahl bestellen; das Gericht kann aber in jedem Fall an Stelle eines im Vorverfahren bestellten Sachverständigen eine andere Person beauftragen. Der Richter (bzw. im Vorverfahren der StA) ist für die klare Auftragsbeschreibung und die eindeutige Bestimmung der im Gutachten zu beantwortenden Beweisfragen verantwortlich. Der Sachverständige muss objektiv und allseitig neutral Auskunft geben. Es steht den Verfahrensbeteiligten frei, einen bestimmten (wahrscheinlich im Hinblick auf ihre Beweisführungserfordernisse gezielt ausgewählten) Sachverständigen zum Verfahren unmittelbar zu laden und dessen Vernehmung vor Gericht zu beantragen. 
- Im Rahmen der gerichtlichen Untersuchung des Sachverhalts ist die Mehrheit der Beweisvorgänge (einschließlich der Bestimmung der Beweiserhebungen) richterlich gesteuert und erfolgt unabhängig von der Disposition der Prozessbeteiligten, auch wenn die Letzteren weitgehende Mitwirkungsrechte haben. Bei den vom Richter als offenkundig angesehenen Tatsachen ist eine umfassende förmliche Beweiserhebung überflüssig, was auch zur Ablehnung von diesbezüglichen Beweisanträgen der Verfahrensbeteiligten führen kann. Offenkundige Tatsachen betreffen nicht das private Wissen des Richters. Auch wenn die offenkundigen Tatsachen keiner Beweiserhebung bedürfen, müssen sie trotzdem in der Regel förmlich zum Gegenstand der Hauptverhandlung gemacht werden, sodass dem Angeklagten die Möglichkeit gegeben wird, dazu Stellung zu nehmen.

- Die Richter haben die Pflicht, unabhängig von Anträgen und Anregungen sämtlicher Verfahrensbeteiligter, von Amts wegen die Beweisaufnahme auf alle entscheidungserheblichen Tatsachen und erlaubten Beweismittel zu erstrecken. Insbesondere ist das Gericht nach den Umständen des Einzelfalls verpflichtet, alle entscheidungserheblichen Zeugen von Amts wegen zu laden und zu vernehmen. Die richterliche Aufklärungspflicht gebietet allerdings keine sinnlosen, voraussichtlich nutzlosen und unterschiedslos anzuwendenden aufwendigen Beweisermittlungen. Die StA und die Verteidigung können ihrerseits in die Bestimmung des Umfangs der Beweiserhebungen etwa durch formlose Beweisermittlungsanträge, durch strengförmliche Beweisanträge zur richterlichen Ladung und Vernehmung von Zeugen oder durch die unmittelbare Ladung von Beweispersonen (und die Beantragung ihrer gerichtlichen Vernehmung) eingreifen. Der Vorsitzende bzw. das Gericht kann aber, insbesondere bei Vorliegen gesetzlich vorgesehener (wenn auch inhaltlich meistens eng definierter) Gründe zur Ablehnung der Beweisanträge, diese Beweisführungsmöglichkeiten der Verfahrensbeteiligten zumindest teilweise einschränken.

- Den Verfahrensbeteiligten steht es in bestimmten Fällen frei, spezifische Aspekte der Beweisaufnahme unmittelbar durch Übereinstimmung zu steuern; relevante Fälle betreffen die Verlesung früherer Vernehmungsniederschriften und das Absehen des Gerichts von der Erhebung einzelner präsenter Beweise. Auch hierbei behält aber das Gericht im Rahmen seiner Amtsaufklärungspflicht meistens das letzte Wort.

- Der Richter hat eine allgemeine Pflicht zur aktiven Vorbereitung, Leitung und kontinuierlichen (sinnvollen, konzentrierten und in prozessökonomischer Hinsicht effektiven) Koordinierung sämtlicher Aspekte der gerichtlichen Untersuchung eines Straffalles. Die Richter und die übrigen mitwirkenden Staatsorgane haben allgemein eine Objektivitäts- und Transparenzpflicht. Die Verfahrensbeteiligten (insbesondere die Verteidigung) haben jedoch keine allgemeine Pflicht zur Förderung der richterlichen Ermittlungen durch pauschale frühzeitige Offenbarung ihrer sachlichen und rechtlichen Thesen und vorzubringenden Beweismittel. Der Richter ist gleichwohl befugt, gegen einzelne Missbräuche aller Prozessbeteiligten, welche 
die Wahrheitserforschung, die Fairness und die Beschleunigung des Verfahrens beeinträchtigen können, in diversen Fällen aktiv und effektiv vorzugehen. Zur Förderung der gerichtlichen Untersuchung kann ferner das Gericht den jeweiligen Stand des Verfahrens mit den Verfahrensbeteiligten auch in Bezug auf generelle prozesstechnische Angelegenheiten, strittige Rechts- und Tatsachenpunkte, Einwände, Missverständnisse bezüglich der Beweislage sowie Fragen zur effizienten und transparenten Ausgestaltung des Hauptverfahrens oder zur Erforderlichkeit der Beweiserhebungen erörtern.

\section{Kenntnisnahme und Offenlegung von Beweisen}

In Bezug auf die Problematik der Kenntnisnahme und Offenlegung von Beweisen sind besonders folgende Erkenntnisse aus dem englischen und dem deutschen Beweisverfahrenssystem zusammenfassend hervorzuheben und einander gegenüberzustellen:

\section{a) Das englische Verfahrenssystem}

- Dem Gericht werden keine umfassenden, zentral-amtlich zusammengestellten Verfahrensakten zur Vorbereitung der Hauptverhandlung vorgelegt. Die Anklage muss aber vor dem Beginn der Hauptverhandlung der Verteidigung und dem Gericht die Grundzüge ihrer vorzubringenden Beweisthesen offenlegen und den Zugriff auf grundlegende Beweismaterialien der prosecution case, einschließlich polizeilicher Verhörprotokolle und anderer Beweismaterialien, ermöglichen. Die Anklage hat ferner die Pflicht, die von ihr nicht vorzubringenden Beweismaterialien, deren Gehalt jedoch für die Unterstützung der defence case bzw. für die Schwächung der prosecution case von Bedeutung sein könnte, der Verteidigung so bald wie möglich zukommen zu lassen. Bestimmte „sensible“, für die Unterstützung der Verteidigungsthesen eventuell aber wichtige Informationen können auf Antrag der Anklage durch Entscheidung des Gerichts zurückgehalten werden.

- Im Anschluss an die Beweisoffenlegungen seitens der Anklage muss die Verteidigung vor einem Crown Court-Verfahren bzw. kann sie vor einem magistrates' court-Verfahren eine ausführliche defence statement anfertigen; sie muss außerdem bei sämtlichen Gerichtsverfahren eine defence witness notice aufsetzen. Diese Erklärungen sind dem Gericht und der Anklage zuzustellen. Eine mangelhafte Erfüllung dieser Pflichten kann negative prozessuale Folgen für die Verteidigung haben, wie das Schlussfolgern hinsichtlich der Schuld des Angeklagten seitens des Spruchkörpers. Von der Abgabe einer vollständigen defence statement (einschließlich der Verteidigungsstrategien) kann ferner die zusätzliche Offenlegung von nicht vorzubringenden Beweisinformationen seitens der Anklage abhängig gemacht werden. Ziel dieser Regelungen ist idealerweise die Gewährleistung von allseitiger Fairness und die Vermeidung von gegenseitigen parteilichen „Überraschungen“, 
ohne dass gleichzeitig die parteienzentrierte Struktur des Sachaufklärungsprozesses angetastet wird.

- Die Richter können letztendlich sowohl im jury- als auch im bench-Verfahren aufgrund der diversen Beweiszustellungen, disclosure-Prozesse, case managementAktivitäten und pre-trial hearings sehr oft bereits im Vorfeld der Hauptverhandlung Kenntnis zumindest von einem Teil der gegensätzlichen Beweisthesen und der vorhandenen Beweise haben. Die Möglichkeit einer faktischen Beeinflussung der Richter schon mit Blick auf die Art und Weise der Verhandlungsleitung während der parteilichen Beweisführungen ist nicht von der Hand zu weisen. Nur die Geschworenen des reinen jury-Verfahrens haben keine Vorkenntnis des Beweismaterials.

• Für die Parteien ist im Allgemeinen die Kenntnisnahme aller fallrelevanten Beweisinformationen von zentraler Bedeutung für die Vorbereitung der Präsentation ihrer selbstständigen Beweisthesen vor Gericht. Das moderne Beweisoffenlegungsrecht erkennt die meistens schwache informatorische Stellung der Verteidigung, die Notwendigkeit der Gewährleistung von Waffengleichheit und die entsprechenden Objektivitätspflichten der Anklage sowie die allseitige Pflicht zur Förderung einer präzisen und fairen Sachverhaltsaufklärung durch die Abkehr von extremen spielstrategischen Praktiken an.

\section{b) Das deutsche Verfahrenssystem}

- Dem Gericht werden die umfassenden, zentral-amtlich zusammengestellten Verfahrensakten, einschließlich der Beweisergebnisse der staatlichen Ermittlungen des Vorverfahrens, zur Vorbereitung der Hauptverhandlung durch die StA vorgelegt. Der Verteidiger kann in der Regel zu allen belastenden und entlastenden Beweisinformationen Zugang haben, die dem Gericht durch die Anklagebehörde als entscheidungserheblich bekannt gemacht werden müssen. Das Gericht kann weitere für die Wahrheitserforschung erforderliche Offenlegungen seitens der StA verlangen. Die behördliche Sperrung der Vorlegung von amtlichen Schriftstücken zum Schutz bestimmter Öffentlichkeitsinteressen wirkt erga omnes, also auch gegenüber dem Gericht.

- Die Verteidigung ist nicht verpflichtet, ihre Beweisthesen im Voraus weitgehend offenzulegen. Entscheidet sie sich aber dafür, einen strengförmlichen vorbereitenden Beweisantrag zu stellen, muss sie darin konkrete Angaben über die verlangten Beweismittel und die behaupteten Beweistatsachen (zunächst gegenüber dem Gericht) machen. Der Angeklagte hat ferner die von ihm unmittelbar geladenen oder zur Hauptverhandlung zu stellenden Zeugen und Sachverständigen rechtzeitig dem Gericht und der StA namhaft zu machen. Allein das verspätete Identifizieren bzw. Vorbringen von Beweismitteln und Beweistatsachen hat (zumindest laut Gesetz) keine wesentlichen Konsequenzen auf der Ebene der Beweiserhebungen und der Urteilsfindung. 
- Die Berufsrichter können letztendlich bereits bei der Vorbereitung der Hauptverhandlung eine umfassende Kenntnis der bisherigen Beweislage, insbesondere der in den Verfahrensakten dokumentierten Beweise, erhalten. Die vorgerichtliche Kenntnisnahme des vorhandenen Beweismaterials seitens des Berufsrichters (in der Regel nicht seitens der mitwirkenden Schöffen) wird als essenzieller Faktor für die Leitung und zweckmäßige Durchführung der Hauptverhandlung betrachtet. In einem traditionell auf den Verfahrensakten basierenden Beweisverfahren ist allerdings die Gefahr nicht zu übersehen, dass aufgrund der Aktenkenntnis eine Voreingenommenheit des Richters schon mit Blick auf die Beweisführung nach wie vor möglich ist.

- Im Allgemeinen müssen im Rahmen der zentral-amtlichen Ermittlung des Sachverhalts, die auf der Basis möglichst vollständiger Informationen erfolgen muss, auch die Mitwirkungs- und Informationsrechte der Verteidigung respektiert werden. Die vollständige und kontinuierliche Einsicht in die Akten und in andere entscheidungserhebliche Beweismaterialien und Informationen kann der effektiven Vorbereitung der Beweisthesen der Verteidigung und der Gewährleistung des Rechts auf gerichtliches Gehör, des Fairnessgrundsatzes und der Waffengleichheit dienen.

\section{Die Beweisführung im Hauptverfahren}

In Bezug auf die Beweisführungen während des Hauptverfahrens sind folgende Erkenntnisse aus dem englischen und dem deutschen Beweisverfahrenssystem zusammenfassend hervorzuheben und gegenüberzustellen:

\section{a) Das englische Verfahrenssystem}

- Im Allgemeinen erfolgen die Beweisführungen in der Hauptverhandlung grundsätzlich im Wege der Präsentation und gegenseitigen Prüfung der Beweise durch die Parteien (mit begrenzten Eingriffsmöglichkeiten des Richters). Hierbei und allgemein hinsichtlich der Regeln und Teilstadien der herkömmlichen Beweisführung vor Gericht sind keine großen Unterschiede zwischen einem bench- und einem jury-Verfahren zu beobachten, trotz der Existenz einer separaten Geschworenenbank in der jury trial, die für die abschließende Beurteilung der Tatsachenfragen ausschließlich zuständig ist. Das Hauptverfahren vor dem Crown Court findet in förmlicherer Weise als das Verfahren vor dem magistrates' court statt. Im Gegensatz zum jury-Verfahren hat ferner vor den Richtern des bench-Verfahrens nicht die Verteidigung, sondern nur die Anklage ein formales Recht auf opening speech. Im jury-Verfahren werden die jurors darüber hinaus mit Blick auf ihre Tatsachenfeststellungsaufgabe vom Richter aktiv und umfassend im Rahmen der öffentlichen summing-up Abschlussphase unterstützt. Den Laienrichtern des englischen benchVerfahrens stehen im Verfahrensverlauf in Bezug auf Rechtsfragen und prozess- 
technische Angelegenheiten über weite Strecken juristisch ausgebildete legal advisers zur Seite.

- Der Berufsrichter im jury-Verfahren und der/die Berufs- oder Laienrichter im bench-Verfahren sind bei der Leitung des parteienzentrierten Sachaufklärungsprozesses für die Gewährleistung eines rechtlich zulässigen und möglichst unmittelbaren Informationsflusses verantwortlich; zu diesem Zweck können die Richter in vielen Fällen von Amts wegen, in der Praxis aber des Öfteren aufgrund des Antrags bzw. Einwands einer Partei eingreifen. Der Richter hat oft im Fall einer unfairen bzw. rechtswidrigen Beweisgewinnung (im Hinblick auch auf die Erforschung der Wahrheit als Prozessziel), im Fall von Beweisen, welche die Verfahrensfairness beeinträchtigen, sowie sogar bei Anwendung von ausdrücklichen Beweisausschlussregeln (wie bei hearsay evidence) ein gewisses Ermessen mit Blick auf die letztendliche Beweiszulassung. Bei extremen Fairnessverletzungen haben die Richter eine strikt begrenzte Befugnis, die Strafklage wegen abuse of process schon vor dem Beginn der eigentlichen Beweiserhebungen abzuweisen. Die meisten Beweisausschlussangelegenheiten sollen nach Möglichkeit im Vorfeld der Hauptverhandlung oder vor dem Beginn der eigentlichen Beweisführungen und im jury-Verfahren möglichst in Abwesenheit der jurors endgültig angesprochen werden. Fragen zur Beweiszulässigkeit werden des Öfteren von dem das jury-Verfahren leitenden Richter bzw. von den magistrates des bench-Verfahrens persönlich entschieden; hierbei ist aufgrund der faktischen Auseinandersetzung mit „verbotenen“ Beweisinformationen eine Beeinflussung der Richter mit Blick auf die Verfahrensleitung (im bench-Verfahren auch mit Blick auf die Urteilsfindung) nicht auszuschließen.

- Die Anklage muss beyond reasonable doubt nachweisen, dass die angeklagten Tatbestände nach den Definitionen des materiellen Strafrechts erfüllt sind. Sie kann aber auch im Rahmen eines schon laufenden Hauptverfahrens die Entscheidung treffen, keine Beweise vor Gericht zu präsentieren (offering no evidence). Nach herrschender Meinung hat das Gericht, nicht zuletzt aufgrund seiner allgemein eng begrenzten Beweiserhebungsbefugnisse, in den meisten derartigen Fällen tatsächlich keine andere Wahl, als den Angeklagten entsprechend freizusprechen. Im Allgemeinen kann die Anklage eine Strafverfolgung ohne Zustimmung des Richters grundsätzlich nur bis zum Abschluss der gerichtlichen Präsentation ihrer case abbrechen.

- Der Richter wird nicht als bloßer Schiedsrichter angesehen. Seine Hauptaufgabe ist vielmehr die Wahrheitsfindung und Gerechtigkeitsgewährleistung. Dieses Ziel kann aber nach dem englischen Prozessverständnis nur durch eine unmittelbare (im Grunde ununterbrochene) und faire (eventuell richterlich ausbalancierte) Gegenüberstellung der unterschiedlichen Parteivorbringen effektiv und vollständig erfüllt werden. Dem neutralen Richter wird keinesfalls eine absolut passive Rolle zugewiesen. Im Prinzip darf der Richter vor allem zur Sicherstellung von rechtlich zulässigen, fairen, zügigen, ordnungsgemäßen, klaren und widerspruchsfreien Be- 
weispräsentationen eingreifen. Moderne empirische Beobachtungen deuten auf eine in der Gerichtspraxis sich ständig erweiternde, interventionistischere Rolle des Richters bzw. auf entsprechende Tendenzen hin; die Richter scheinen insbesondere oft bereit zu sein, sich etwa mit den Zeugenbefragungen aktiver zu befassen.

- Die Beweisführungen sind in zwei große Phasen gegliedert: zunächst die Präsentation der prosecution case, bei der hauptsächlich die zulässigen belastenden Beweismittel durch die Anklage vorgebracht und durch die Verteidigung geprüft werden; und anschließend die entsprechende Präsentation der defence case durch die Verteidigung (einschließlich des Verhörs des Angeklagten, falls er sich entscheidet, auszusagen), bei der die Anklage die Stichhaltigkeit der eventuell vorgebrachten entlastenden Beweise prüft. Ein mehrfacher bzw. wiederholter Gebrauch desselben Beweismittels ist grundsätzlich nicht ausgeschlossen. Als Regel (mit Ausnahmen) gilt, dass eine Partei nach dem Abschluss der Darstellung ihrer case keine weiteren Beweise in das Verfahren einführen darf. Im Allgemeinen dürfen nach dem Beginn der nicht öffentlichen jury-Beratungen die Parteien (sowie auch der Richter) in keinem Fall mehr Beweise in den Prozess einführen; im bench-Verfahren sind nach Verkündung des Urteils keine Beweisaufnahmen mehr möglich. Während der Beweisführungen gibt es die Möglichkeit, dass eine Partei die von der Gegenpartei durchgeführten Beweiserhebungen in vielfacher (insbesondere prozesstechnischer) Hinsicht beanstandet. Umfassende substantielle Beweiskommentierungen sind seitens der Parteien auch im Rahmen der anwaltlichen Anfangs- und Schlussvorträge bzw. seitens des Richters im jury-Verfahren während seiner Abschlusszusammenfassungen möglich. Darüber hinaus kann die Verteidigung nach dem Ende der Beweisführungen im Rahmen der prosecution case und vor dem Beginn der Beweiserhebungen im Rahmen der defence case einen Antrag auf sofortigen Prozessabbruch wegen erheblicher substantieller Beweismängel in der prosecution case stellen (submission of no case to answer); die Richter und die jurors können unter Umständen auch von Amts wegen auf einen derartigen frühzeitigen Freispruch des Angeklagten entscheiden.

- Die allseitige Prüfung des zeugenbasierten Beweises findet grundsätzlich im Rahmen der für jeden einzelnen Zeugen (einschließlich des Angeklagten) unmittelbar durch die Parteien durchgeführten und direkt aufeinander folgenden examinations-in-chief, cross-examinations und re-examinations statt. Die zentrale Stellung dieses Prüfungsschemas in der englischen Sachaufklärungspraxis wird u.a. dadurch sichtbar, dass ein Verzicht auf cross-examination eventuell als stillschweigende Anerkennung der Wahrheit des betreffenden in chief vorgebrachten Beweises angesehen werden kann und dass der Anwalt die während der cross-examination nicht widerlegten Fragen nicht erst im Rahmen seines Schlussvortrags ansprechen darf. Erforderlichenfalls können meistens am Ende der parteilichen Verhöre Befragungen durch die Richter nach eigenem Ermessen und im jury-Verfahren gegebenenfalls auch (mittelbare) Befragungen durch die jurors stattfinden. Der Richter muss bei seinen Eingriffen in die Beweiserhebungen und insbesondere bei der Un- 
terbrechung der durch die Parteien vorgenommenen (Kreuz-)Verhöre im Einklang mit seiner unparteiischen Rolle erhebliche Zurückhaltung üben. Der Richter hat ferner die ultima ratio-Befugnis, die von den Parteien nicht geladenen Zeugen selbst zur Vernehmung aufzurufen; er stellt dabei Fragen an die betreffenden Zeugen und kann danach die Durchführung von Kreuzverhören durch die Parteien erlauben. Sämtliche Verhöre durch die Parteien laufen darüber hinaus nicht auf unkontrollierte Weise ab; vielmehr kann bzw. muss der verfahrensleitende Richter unter bestimmten Voraussetzungen und oft aufgrund eines parteilichen Einspruchs eingreifen, um die Einhaltung gewisser Prozess- und Fairnessregeln und eines hohen Qualitätsniveaus der wahrzunehmenden Beweise sowie allgemein die Förderung der Wahrheitsermittlung sicherzustellen. Die Einmischung des Richters kann bestehen in der Anwendung von bestimmten Zeugenschutzmaßnahmen und Vernehmungsbehelfen, der (Nicht-)Einführung von mittelbaren Beweisen in den Prozess, in der Zulassung von Glaubwürdigkeitsfragen und leading questions oder etwa in der Zurückweisung von überflüssigen, prozessverschleppenden und provokatorischen Fragen im Rahmen eines Kreuzverhörs.

- Nach der Präsentation und Prüfung der Verteidigungsbeweise können die Anklage (unter bestimmten Voraussetzungen) und anschließend die Verteidigung Abschlussdarstellungen zur Unterstützung ihrer gegensätzlichen cases vortragen. Die Anklage muss ihren Schlussvortrag möglichst objektiv, in Übereinstimmung mit den vorhandenen Beweisen und in unemotionaler Weise halten. Auch im Rahmen des umfangreichen Schlussvortrags der Verteidigung dürfen nur solche Tatsachenbehauptungen gemacht werden, bezüglich derer bereits im Verfahren Beweise erhoben worden sind. Im jury-Verfahren folgen zusätzlich nach den Schlussvorträgen die richterlichen summing-up Ausführungen und Beweiskommentierungen, die auf die anschließende Beweiswürdigung durch die jurors einen erheblichen Einfluss haben können.

\section{b) Das deutsche Verfahrenssystem}

- Die Beweiserhebungen in der Hauptverhandlung erfolgen primär durch den Richter (unter Mitwirkung der Verfahrensbeteiligten). Vor sämtlichen Strafgerichten und Spruchkörpern finden die Beweisführungen grundsätzlich in derselben Art und Weise und größtenteils nach einheitlichen Verfahrensregeln statt.

- Der Vorsitzende bzw. das Gericht muss bei den (grundsätzlich richterlich gesteuerten) Beweiserhebungen in der Hauptverhandlung zunächst von Amts wegen, in der Praxis aber oft aufgrund des Antrags bzw. Einwands eines Verfahrensbeteiligten, für die Einhaltung der Regeln des förmlichen Strengbeweises, der Verfahrensunmittelbarkeit und des Beweisverbotskomplexes sorgen. Der Richter hat keinen allgemeinen Ermessensspielraum, der es ihm ohne Weiteres erlauben würde, die aus seiner Sicht ,unfairen“ Beweise aus den Beweiserhebungen in der Hauptverhandlung völlig auszuschließen. Verfahrenshindernisse und die Möglichkeit der 
Verfahrenseinstellung aus Rechtsstaatlichkeitsgründen kommen grundsätzlich nicht in Betracht. Das Gericht ist letztendlich an die Amtsaufklärungspflicht gebunden und somit zur umfassenden Aufklärung des streitigen Sachverhalts durch vollständige Beweisführung innerhalb der Hauptverhandlung verpflichtet. Die Amtsaufklärungspflicht ist aber nicht um jeden Preis umzusetzen: Im Vordergrund stehen hierbei die bei der Beweisführung in der Hauptverhandlung unmittelbar wirkenden Beweiserhebungsverbote sowie die bei ihrer richterlichen Anwendung oft abwägungsbedürftigen und meistens erst bei der Urteilsfindung (also nach der jeweiligen Beweiserhebung und grundsätzlich nach der Erhebung eines relevanten Widerspruchs) wirkenden Beweisverwertungsverbote. Insbesondere im Rahmen der richterlichen Auseinandersetzung mit Beweisverwertungsfragen kann die Kenntnis „verbotener“ Informationen einen tatsächlichen Einfluss nicht nur auf der Ebene der Urteilsfindung, sondern auch auf die Art und Weise der weiteren richterlichen Beweisführungen haben. Das Gericht muss die Beweisanträge der Verfahrensbeteiligten ablehnen, wenn die relevanten Beweiserhebungen, etwa aufgrund von Beweisverboten, unzulässig sind.

- Der Tatsachenfeststellungsvorgang ist durch die richterliche Aufklärungspflicht und nicht durch die Beweislast der durchgehend zur Objektivität verpflichteten Anklagebehörde gekennzeichnet. Die Richter müssen von Amts wegen und selbstständig auf der Basis der jeweils bekannten Umstände des Einzelfalls mit allen zulässigen Beweismitteln sämtliche materiell-rechtlich relevanten Tataspekte des Sachverhalts in sinnvoller, aber nicht überschießender Weise erforschen. Der Angeklagte muss nicht seine Unschuld beweisen. Die Strafklage kann nach Eröffnung des Hauptverfahrens nicht zurückgenommen werden, und eine einseitige Verfahrenseinstellung durch die StA ist nach dem Eröffnungsbeschluss und während der Beweisführungen in der Hauptverhandlung grundsätzlich nicht möglich. Die Durchführung einer vollständigen richterlichen Beweisaufnahme unabhängig vom Willen und Vorbringen der Verfahrensbeteiligten ist letztendlich weitgehend möglich bzw. kann je nach Einzelfall geboten sein.

- Dem Vorsitzenden des Gerichts obliegen die ordnungsgemäße Verhandlungsleitung, die Vernehmung des Angeklagten und die Beweisaufnahme (in bestimmten Angelegenheiten unter Mitwirkung des ganzen Gerichts). Weder die StA noch die Verteidigung sind selbstständig für die Durchführung der maßgebenden Beweiserhebungen in der Hauptverhandlung verantwortlich. Die Mitwirkung der Verfahrensbeteiligten an den richterlichen Beweisführungen ist immerhin in diversen Vorschriften verankert, die insbesondere die Ermöglichung des Fragerechts, die Durchführung von Kreuzverhören in bestimmten Fällen, die Äußerung von Einwänden und außerdem Anträge und Anregungen, die Abgabe von Erklärungen in Bezug auf bereits erhobene Beweise sowie die Gewährleistung des Rechts auf Schlussvortrag betreffen.

- Eine formale Unterscheidung zwischen Beweisführungsphasen, zwischen Anklage- und Verteidigungsvorbringen und zwischen entlastenden und belastenden 
Beweismaterialien, die den Ablauf der Beweiserhebungen beeinflussen könnte, ist nicht vorgesehen. Auch die allgemeine Reihenfolge der Benutzung der diversen Beweismittel ist nicht gesetzlich vorgeschrieben; sie wird je nach Einzelfall aufgrund von Zweckmäßigkeitserwägungen vom Vorsitzenden bestimmt. Die eigentlichen beweisrelevanten Vorgänge setzen meistens mit der Vernehmung des Angeklagten zur Sache ein (falls er sich entscheidet, auszusagen). Anschließend folgt die Beweisaufnahme i.e.S., wobei alle rechtlich zulässigen Beweiserhebungen von Amts wegen oder auf eventuelle Beweisanträge der Verfahrensbeteiligten stattfinden. Eine mehrfache bzw. wiederholte Examinierung desselben Beweismittels ist grundsätzlich nicht ausgeschlossen. Im Prinzip darf eine Beweiserhebung vom Gericht nicht mit der Begründung abgelehnt werden, dass das Beweismittel oder die $\mathrm{zu}$ beweisende Tatsache zu spät vorgebracht worden sei. Beweisanträge sind in allen Fällen in der Hauptverhandlung bis zum Beginn der Urteilsverkündung möglich. Allgemein kann das Gericht bis zur vollständigen Verkündung des Urteils wieder in die Beweisaufnahme eintreten. Die Verfahrensbeteiligten haben ferner diverse substantielle Eingriffsmöglichkeiten sowie Gelegenheit zur Erhebung von (prozesstechnischen) Einwänden und Beweiskommentierung während oder am Ende der einzelnen richterlichen Beweiserhebungen und -anordnungen oder am Ende der gesamten Beweisaufnahme. Darüber hinaus sind keine Prozessmechanismen verfügbar, die eine frühzeitige/vereinfachte Beendigung des Beweisverfahrens ohne Beachtung der Grundsätze der richterlichen Aufklärungspflicht und des Beweisantragssystems ermöglichen würden; eine ersichtlich schwache Beweislage wird allerdings in der Praxis oft zum schnellen Abschluss der Beweisaufnahme und (nach den Schlussvorträgen und -anträgen der Verfahrensbeteiligten) zum Freispruch führen.

- Die Vernehmung des Angeklagten findet zunächst durch den vorsitzenden Richter statt, wobei auch alle beisitzenden Richter (einschließlich der Schöffen), die StA und der Verteidiger ein unmittelbares Fragerecht haben. Die Vernehmung sämtlicher Beweispersonen erfolgt in der Regel ebenso durch den Vorsitzenden persönlich in neutral-amtlicher Weise. Es spielt dabei keine besondere Rolle (mit der in der Praxis seltenen Ausnahme des förmlichen Kreuzverhörs der durch die Prozessbeteiligten benannten Beweispersonen), ob der Richter im Rahmen seiner Aufklärungspflicht den Zeugen geladen hat oder ob der Zeuge von einem Verfahrensbeteiligten im Wege eines Beweisantrags benannt wurde. Die beisitzenden Richter und die Prozessbeteiligten haben in jedem Fall das Recht, Fragen an die Beweispersonen unmittelbar zu stellen; dies geschieht meistens im Anschluss an die Befragungen seitens des Vorsitzenden. Diverse Vorschriften in der StPO, die der Vorsitzende bzw. das Gericht gegebenenfalls von Amts wegen oder auf Antrag/ Einwand anwenden muss, regeln die inhaltliche und prozesstechnische Ausgestaltung der Befragungen durch den/die Richter und die Verfahrensbeteiligten. Diese Vorschriften betreffen u.a.: die Verwendung von bestimmten Zeugenschutzmaßnahmen und Vernehmungsbehelfen; die Zulässigkeit von Glaubwürdigkeitsfragen; 
die Zurückweisung von ungeeigneten (z.B. suggestiven) und nicht zur Sache gehörenden Fragen der Verfahrensbeteiligten; oder auch die Erhebung von Einwänden seitens der Verfahrensbeteiligten gegen die Zulässigkeit der richterlichen Vernehmungsvorgänge und Leitungsanordnungen sowie die Äußerung von Zweifeln in Bezug auf die Zulässigkeit von allseitig gestellten Fragen.

- Nach dem Ende der Beweisaufnahme folgen die Schlussvorträge zuerst des StA und dann des Verteidigers und/oder des Angeklagten. Der StA muss einen objektiven und unvoreingenommenen Schlussvortrag in Bezug auf das Gesamtergebnis der Verhandlung halten. Allgemein dürfen die Schlussvorträge des StA und des Verteidigers nur die in der Hauptverhandlung bereits mündlich angesprochenen Tatsachen und die Ergebnisse der Aufklärungsvorgänge betreffen. Dagegen genießt der Angeklagte selbst deutlich mehr Freiheit in Bezug auf die inhaltliche Gestaltung seiner Schlussausführungen.

\section{Klassifizierung}

\section{a) Vorbemerkungen}

Aus dem analytischen Vergleich der herkömmlichen englischen und deutschen Beweisvorgänge und aus den oben dargestellten Zusammenfassungen ergibt sich eindeutig, dass diese zwei nationalen Beweisverfahrenssysteme heute noch in Bezug auf die Rollenverteilung zwischen den Prozessakteuren und was die Einrichtung der gerichtlichen Strukturen zur bestmöglichen Sachverhaltsaufklärung anbelangt, von unterschiedlichen Ansätzen ausgehen. Aus der Gegenüberstellung der Ergebnisse des vorliegenden vergleichenden Teils mit den in Teil 1 der Forschungsarbeit definierten essenziellen Elementen ${ }^{774}$ der Beweisführungsmodelle kann zum einen der Schluss gezogen werden, dass das englische parteienzentrierte Beweisverfahren näher an dem ,adversatorischen“ Modell (wie es konkreter und detaillierter in dieser Arbeit definiert wird) steht; in der Gegenwart sind in der englischen Gesetzgebung und Rechtsprechung immerhin bewusste intensive Versuche zur Vermeidung der wettkämpferischen Exzesse der Vergangenheit zu beobachten. Zum anderen steht die deutsche richterzentrierte Untersuchung des angeklagten Straffalles näher an den Grundstrukturen des ,inquisitorischen“ Modells (wie es ebenso in dieser Arbeit definiert wird). Nach wie vor werden auf prozessstruktureller Ebene die aktive Rolle des Richters und seine Aufklärungspflicht als Eckpfeiler der deutschen gerichtlichen Beweisführungen angesehen, auch wenn heute weitgehende Mitwirkungsrechte für die Verfahrensbeteiligten und insbesondere für die Verteidigung gesetzlich verankert sind.

Die tatsächlichen, in der heutigen globalen Rechtswelt mehr denn je zuvor, gemischten" Strafverfahrenssysteme in England und Deutschland orientieren sich

774 Siehe unter Teil 1, II.C. 
freilich nicht an den Extremen der zwei reinen, primär für analytisch-vergleichende Zwecke konzipierten Beweismodelle. Die strikte Klassifizierung der Verfahrensordnungen anhand dieser Idealtypen stellt ferner keinen Selbstzweck der betreffenden Modellkonstruktionen dar. Es ist in allen Fällen nicht einfach und - außer zum Zweck von einführenden und vereinfachten Schematisierungen - nicht wirklich von substantieller Bedeutung, mit „mathematischer Genauigkeit“ zu bestimmen, inwieweit das englische Beweisverfahrenssystem nahe an dem ,adversatorischen“ bzw. das deutsche Beweisverfahrenssystem nahe an dem ,inquisitorischen“ Idealtypus steht. Im Rahmen der Kategorisierungserwägungen und Gegenüberstellungen auch für die Zwecke weiterer theoretischer und empirischer Forschungen sollen vielmehr primär die hinter der unterschiedlichen Ausgestaltung der nationalen Beweisverfahren identifizierten prozeduralen Grundideen behandelt werden. Außerdem sind die in der jeweiligen Rechtsordnung angewandten bzw. geförderten Maßnahmen wahrzunehmen, die als Korrektiv gegen frühere prozessstrukturelle Mängel und Missstände wirken sollen; durch derartige Maßnahmen und Reformen ist es möglich, die (Lösungsansätze der) Verfahrenssysteme bei der Verfolgung des gemeinsamen Ziels der präzisen Sachaufklärung näher zueinander zu bringen.

\section{b) Das englische Verfahrenssystem}

Als zusammenfassende Schlussfolgerung der vorhergehenden Analysen und Vergleiche kann an dieser Stelle zunächst mit Blick auf das englische herkömmliche erstinstanzliche Strafverfahren nach Erhebung der Strafklage Folgendes bemerkt werden: Das englische Beweisverfahrenssystem steht sowohl hinsichtlich der Vorbereitung der gerichtlichen Beweisführungen als auch in Bezug auf die eigentliche Durchführung der Beweiserhebungen im Hauptverfahren näher an den Zentralelementen des ,adversatorischen“ Modells. Hierbei ist keine wesentliche innere Differenzierung der Beweisverfahrensgrundlagen zwischen dem jury-Verfahren und dem bench-Verfahren auf normativer Ebene zu beobachten; ${ }^{775}$ ebensowenig sind umfassende empirische Untersuchungen vorhanden, die mit Bestimmtheit darauf hindeuten würden, dass im bench-Verfahren - in dem der Richter selbst auch für die Urteilsfindung verantwortlich ist und die Parteien ihre cases nicht vor völlig uninformierten jurors präsentieren - eine tatsächliche Tendenz zum aktiveren Eingreifen des Richters in die Beweisführungen und zur weniger kontradiktorischen Ausgestaltung der Hauptverhandlung im Vergleich zum jury-Verfahren zu erkennen wäre. ${ }^{776}$ Die Autonomie, die Aktivität und bis zu einem gewissen Grad die gegensätzliche Positionierung der Parteien (Anklage/Verteidigung) einerseits

775 Vgl. dazu auch Auld Report 2001, S. 516-517.

776 Siehe allgemein zur diesbezüglichen Problematik mit Verweisen auf relevante Forschungen (jedoch nicht unmittelbar in Bezug auf das englische Verfahren) oben in Teil 1, II.C.3.d)bb). Siehe auch Jackson/Doran, MLR 60 (1997), 759 (772-775); Jackson/Doran, Is.L.R. 31 (1997), 645 (664-672, 687-689). 
sowie die nur begrenzten Eingriffsmöglichkeiten des neutralen Richters in die materiellen Beweisführungen andererseits werden heute noch als allgemeine Grundprinzipien des englischen Strafverfahrens in den relevanten wissenschaftlichen Erwägungen und rechtspolitischen Programmen angesehen.

Trotzdem können Betrachtungen, die weiterhin einen absolut passiven Richter und die Anwendung extremer spielstrategischer Praktiken seitens der Parteien zur Gewinnung der trial abbilden, angesichts der modernen englischen Rechtslage und Gerichtspraxis nicht verifiziert werden. Die Befugnis der Parteien - die ein primäres Interesse an der Aufklärung des Sachverhalts haben - zur selbstständigen Zusammenstellung, Präsentation und Gegenüberstellung ihrer cases darf freilich nach englischem Prozessverständnis nicht durch ein weitreichendes Eingreifen des Richters beeinträchtigt werden; nach allgemeiner Meinung bestünde hierbei vor allem die Gefahr der Destabilisierung der Balance zwischen den Parteien und der richterlichen Voreingenommenheit zulasten insbesondere des Angeklagten. Gleichwohl wird der Richter allseitig, und trotz des allgemeinen Gebots zur Zurückhaltung, letztendlich nicht als bloßer Schiedsrichter, sondern als Herr des Hauptverfahrens anerkannt, dessen Hauptziele die Wahrheitsfindung und Gerechtigkeitsgewährleistung sind. Ihm wird vom Justizsystem - unter bewusster Wahrnehmung des „menschlichen Faktors“ und insbesondere der jederzeitigen Möglichkeit zum Systemmissbrauch seitens sowohl des Richters als auch der Parteien - die Aufgabe anvertraut, auch von Amts wegen die notwendigen Initiativen zur Förderung einer rechtlich zulässigen, fairen, zügigen, ordnungsgemäßen, klaren und widerspruchsfreien Beweisführung zu ergreifen.

Zum einen ist der englische Richter - nicht wesentlich anders als der deutsche Richter, auch wenn das materielle Beweisrecht in den beiden Rechtsordnungen teilweise sehr unterschiedlich ist - für die Gewährleistung von Fairness und Waffengleichheit während der Beweisführungen, für die richtige bzw. ermessensmäßige Anwendung der komplexen Beweisausschlussregeln sowie für die Vermeidung von Missbräuchen und Exzessen während der kontradiktorischen Beweisprüfungen verantwortlich; hierfür kann er auf Antrag/Einwand einer Partei, in den meisten Fällen aber auch von Amts wegen eingreifen. ${ }^{777}$ Zum anderen kann der Richter auch hinsichtlich substantieller Beweisführungsangelegenheiten eine aktive Rolle einnehmen. Gleichzeitig wird in der englischen Verfahrensordnung den Parteien ein solcher Grad an Autonomie zugesprochen, dass zumindest in normativer Hinsicht kaum Spielraum für die Entwicklung einer extremen prozessualen Gegnerschaft, insbesondere durch „kampfartige“ Praktiken und gegenseitige Angriffe aus dem Hinterhalt, bleibt. Auf diese Merkmale des modernen englischen Beweisführungssystems deuten insbesondere folgende, oben ausführlich angesprochene Prozessangelegenheiten hin:

777 Siehe insb. unter Teil 2, II.D., Teil 2, II.E.3., Teil 2, IV.D. Zusammenfassend Jackson/ Doran, Judge, S. 63-65, 111. 
- die vorgesehenen ethisch-rechtlichen Verpflichtungen der Parteien zur Förderung der „overriding objective“ des Strafprozesses und insbesondere die Objektivitätspflichten (wenn auch nicht im gleichen Maße wie in Deutschland) der Anklage bei den Beweisoffenlegungen und Zeugenladungen; ${ }^{778}$

- das allseitige Verbot zur parteilichen vorgerichtlichen Vorbereitung der Zeugenaussagen und die ausdrückliche normative Missbilligung von beweisbezogenen Manipulations- und Verdunkelungsstrategien; 779

- die ,judicial notice“ von offensichtlichen Tatsachen und die weitreichenden richterlichen case management-Aktivitäten; ${ }^{780}$

- die diversen Möglichkeiten des Richters zur Kenntnisnahme des Vorverfahrensmaterials und ihr möglicher Einfluss auf sein weiteres Prozessverhalten; ${ }^{781}$

- der Regelungskomplex der Beweisoffenlegungen inter partes und seine moderne Reformierung; ${ }^{782}$

- die ultima ratio-Befugnis des Richters zur Zeugenladung sowie seine Befugnis zum Eingreifen in die parteilichen Beweiserhebungen aus Klarstellungsgründen und zur selbstständigen (wenn auch meistens ergänzenden) Befragung der Beweispersonen; ${ }^{783}$

- die Möglichkeit zur frühzeitigen richterlichen Prozessbeendigung im Rahmen der no case to answer-Fälle, ${ }^{784}$ sowie

- die umfassenden richterlichen summing-up Ausführungen (wenn auch nur im jury-Verfahren). ${ }^{785}$

Gleichwohl sind im englischen Strafverfahren im Allgemeinen nach wie vor die Parteien für die wichtigsten Aspekte der Beweisführung größtenteils allein zuständig. Dies ergibt sich vor allem aus der zentralen Stellung der unmittelbar kontradiktorischen Beweiserhebungs- und Prüfungsmethoden (insbesondere der examinations-in-chief und cross-examinations) im englischen Aufklärungssystem sowie aus der Dominanz der Parteien bei der Bestimmung des Umfangs der Beweiserhebungen (einschließlich solcher in der Lehre und den englischen Reformdiskussionen nicht unumstrittener Angelegenheiten, wie der parteilichen Bestimmung der Exper-

778 Siehe insb. unter Teil 2, II.B.1.a) und 2.b), Teil 2, II.E.1., Teil 2, IV.B.1.a) und 2.b).

779 Siehe insb. unter Teil 2, II.B.1.b)cc) und 2.b), Teil 2, II.E.1., Teil 2, IV.B.1.b)cc) und 2.b).

780 Siehe insb. unter Teil 2, II.B.2.a) und 2.d), Teil 2, IV.B.2.a) und 2.d).

781 Siehe insb. unter Teil 2, II.C.1., Teil 2, IV.C.1.

782 Siehe insb. unter Teil 2, II.C.2., Teil 2, IV.C.2.

783 Siehe insb. unter Teil 2, II.B.2.b), Teil 2, II.D.2., Teil 2, IV.B.2.b), Teil 2, IV.D.2.

784 Siehe insb. unter Teil 2, II.D.2.b), Teil 2, II.E.3., Teil 2, IV.D.2.b).

785 Siehe insb. unter Teil 2, II.D.2.b). 
tenzeugen, der verbindlichen Einführung in den Prozess von ,,agreed evidence“ und der prozesseinstellenden offering no evidence-Fälle). ${ }^{786}$

\section{c) Das deutsche Verfahrenssystem}

Demgegenüber ist die klare Beherrschung des deutschen Beweisverfahrens durch den Richter bzw. das Gericht nicht zu leugnen. Das deutsche richterzentrierte Beweisführungssystem steht ohne Zweifel sowohl hinsichtlich der beweisbezogenen Vorbereitung der gerichtlichen Untersuchung nach Erhebung der Strafklage als auch in Bezug auf die eigentlichen Beweiserhebungen in der Hauptverhandlung nahe an den theoretischen Grundzügen des ,,inquisitorischen“ Modells. In der modernen Zeit sind freilich die Mitwirkungs- und Gehörrechte der Prozessbeteiligten und insbesondere der Verteidigung in umfassender Weise im Gesetz verankert. Zugleich sind aber der Untersuchungsgrundsatz und die Forderung nach richterlicher Steuerung aller zentralen Aspekte der Sachaufklärung - sowie des Strafverfahrens allgemein, wie heute vor allem das Beispiel der Verständigungsvorschriften zeigt - auf rechtspolitischer Ebene niemals wirklich in Zweifel gezogen worden. ${ }^{787}$

Das deutsche Justizsystem hat dem Richter die Leitung der zur Aufklärung des Sachverhalts maßgebenden Beweisvorgänge anvertraut. Die hierbei vorgesehenen Mitwirkungsmöglichkeiten der Prozessbeteiligten können nicht nur der Gewährleistung der menschenrechtlichen Vorgaben und der Verfahrensfairness, sondern zumindest zum Teil auch den prozessstrukturellen Erfordernissen der Wahrheitserforschung dienen. Die durchweg zur Objektivität verpflichtete StA als Anklagevertreterin und die Verteidigung, welche umfassende Kenntnis der Vorverfahrensakten haben und sich (abgesehen von rechtswidrigen und missbräuchlichen Verhaltensweisen) grundsätzlich uneingeschränkt um die Vorbereitung ihrer Be-

786 Siehe insb. unter Teil 2, II.B.1.b)dd), Teil 2, II.B.2., Teil 2, II.D.2., Teil 2, II.E.1. und 3., Teil 2, IV.B.1.b)dd), Teil 2, IV.B.2., Teil 2, IV.D.2.

787 Vgl. auch Roxin/Schünemann, Strafverfahrensrecht, § 17 Rn. 5-6: „Der deutsche Strafprozess, dessen Grundstruktur auf dem europäischen Kontinent vorherrscht und im 19. Jh. durch das französische Recht vielfältig beeinflusst wurde, verbindet Prinzipien des Inquisitionsprozesses mit denen des reinen Anklageverfahrens. [...] Er bewahrt [...] Züge des Inquisitionsprozesses insofern, als nach Erhebung der öffentlichen Klage die Verfahrensherrschaft auf den Richter übergeht, der [...] nicht nur die Vernehmungen durchführt, sondern sämtliche zur Überführung oder Entlastung des Beschuldigten dienenden Beweise in eigener Verantwortung erhebt. Darin liegt auch der tiefere Grund, warum das Kreuzverhör, das theoretisch von der StPO zugelassen wird (§ 239), in der Praxis keinerlei Bedeutung erlangt hat. Es gilt also im deutschen Verfahrensrecht der [...] Ermittlungsgrundsatz, der es von vornherein ausschließt, dass StA und Verteidigung über den Prozessstoff verfügen. [...] Will man die derart skizzierte Strukturform unseres Strafprozesses, deren Auswirkungen sämtliche Stadien des Verfahrens prägen, zusammenfassend kennzeichnen, so kann man von einem 'Akkusationsprozess mit inquisitorischer Hauptverhandlung' sprechen, der als eigenständiger Prozesstyp vom gemeinrechtlichen Inquisitionsverfahren ebenso wie vom reinen Anklageverfahren zu unterscheiden ist.“” 
weisthesen kümmern kann, können sich insbesondere wie folgt an den Beweisführungen aktiv beteiligen: ${ }^{788}$

- durch die Stellung von Beweisermittlungsanträgen sowie vor allem von förmlichen vorbereitenden Beweisanträgen und während der Hauptverhandlung von Beweisanträgen hinsichtlich nicht präsenter Beweismittel, die das Gericht nur aus bestimmten, gesetzlich eng definierten Gründen ablehnen darf;

- durch die unmittelbare Herbeischaffung von Beweismitteln und vor allem durch die unmittelbare Ladung von Beweispersonen, die meistens auch - nach Stellung des entsprechenden Antrags, der nur aus ganz bestimmten Unzulässigkeits-, Ungeeignetheits- und Prozessverschleppungsgründen abzulehnen ist - in der Hauptverhandlung vernommen werden müssen;

- durch die unmittelbare Ausübung der Fragerechte;

- durch die Erhebung von Einwänden gegen die richterlichen Anordnungen während der Beweiserhebungen und durch die Äußerung von Zweifeln in Bezug auf die Zulässigkeit sämtlicher Zeugenbefragungen;

- durch die Abgabe von Erklärungen in Bezug auf bereits erhobene Beweise;

- durch die Durchführung von förmlichen Kreuzverhören unter bestimmten Voraussetzungen; sowie

- durch die Schlussvorträge, die bei der Urteilsfindung zu berücksichtigen sind.

Die Verfahrensbeteiligten haben allerdings in der deutschen Strafverfahrensordnung keine selbstständige Befugnis zur Disposition über den Gegenstand der Beweisaufnahme bzw. über die zu erhebenden Beweise; sie sind auch während der Hauptverhandlung nicht die eigentlichen Beweisführer. Vielmehr ist der Richter/das Gericht mit Hilfe der umfassenden Vorkenntnis der Verfahrensakten für die Vorbereitung des maßgebenden Beweisverfahrens und vor allem für die Bestimmung der Beweiserhebungen, ihre eigentliche Durchführung und die Prüfung des Beweismaterials zuständig. Der Richter bzw. das Gericht ist freilich primär für die Verfahrensleitung, für die allgemeine Einhaltung der strengförmlichen Beweiserhebungs- und der Beweisverbots- und Unmittelbarkeitsregeln sowie für die Vermeidung von allseitigen Missbräuchen während der Beweisaufnahme verantwortlich. Neben den diesbezüglichen richterlichen Amtspflichten und den von Amts wegen-Befugnissen sowie den relevanten Beanstandungs- und Antragsrechten der Verteidigung und der StA ist heute die Tendenz zur Erweiterung der prozessualen Eigenverantwortung der Prozessbeteiligten zu beobachten (insbesondere bei solchen Angelegenheiten wie der Widerspruchslösung zur Geltendmachung von Beweisverwertungsverboten). ${ }^{789}$

788 Siehe insb. unter Teil 2, III.B.1.a) und III.B.1.b)cc) und dd), Teil 2, III.B.2.b), Teil 2, III.C.2., Teil 2, III.D.2., Teil 2, IV.B.1.a) und IV.B.1.b)cc) und dd), Teil 2, IV.B.2.b), Teil 2, IV.C.2., Teil 2, IV.D.2.

789 Siehe insb. unter Teil 2, III.D., Teil 2, III.E.3., Teil 2, IV.D. 
In Bezug auf die substantiellen Aspekte der Beweisführung im deutschen Hauptverfahren haben die Richter auf normativer Ebene im Einklang mit ihrer Amtspflicht zur Aufklärung des Sachverhalts grundsätzlich ebenfalls das erste und das letzte Wort und sind hierbei an Anträge und Anregungen der Verfahrensbeteiligten meistens nicht gebunden. Insbesondere folgende, hierfür charakteristische Punkte wurden in den vorhergehenden Ausführungen und Vergleichungen ausführlich dargestellt: ${ }^{790}$

- die richterliche „Herrschaft“ über die Ladung und den Aufruf sämtlicher Beweispersonen zur Vernehmung, über die Bestimmung des Sachverständigenbeweises und über die Herbeischaffung des sonstigen Beweismaterials i.V.m. der gerichtlichen Befugnis zur Beurteilung der Beweisanträge (auch wenn diese Befugnis nur im eng begrenzten Rahmen der gesetzlichen Ablehnungsgründe besteht) und unter Rücksichtnahme auf solche jüngeren Tendenzen wie die richterliche Setzung von Beweisantragsfristen;

- die Pflicht des Gerichts zur Erstreckung der Beweisaufnahme auf alle entscheidungsrelevanten Tatsachen und Beweismittel, die sich sogar auf die wenigen Fälle bezieht, in denen die Verfahrensbeteiligten zunächst kraft ihrer Autonomie befugt sind, in gegenseitigem Einverständnis bestimmte Aspekte der Beweisaufnahme zu steuern und insbesondere zu vereinfachen bzw. zu beschleunigen;

- das Immutabilitätsprinzip mit Blick auf die Fortsetzung eines bereits eröffneten Beweisverfahrens;

- die effektive Planung der Beweisvorgänge seitens des Richters sowie das richterliche pflichtgemäße Ermessen und die Zweckmäßigkeitserwägungen bei solchen Angelegenheiten wie der Bestimmung der Reihenfolge der Beweiserhebungen und den Entscheidungen zum Abschluss und Wiedereintritt in die Beweisaufnahme;

- die Offenkundigkeitsfälle;

- die Durchführung der Vernehmungen und der übrigen Beweiserhebungen durch den Richter; sowie

- die in der deutschen richterzentrierten Prozesskultur nicht sehr beliebte Durchführung von förmlichen Kreuzverhören durch die Parteien, wobei auch in diesen in der Gerichtspraxis sehr seltenen Fällen der Richter über Eingriffsmöglichkeiten und selbstständige Beweisprüfungsbefugnisse kraft seiner Amtsaufklärungspflicht verfügt.

${ }_{790}$ Siehe insb. unter Teil 2, III.B.1.b)dd), Teil 2, III.B.2., Teil 2, III.D.2., Teil 2, IV.B.1.b)dd), Teil 2, IV.B.2., Teil 2, IV.D.2. 


\section{Bewertung und rechtspolitische Schlussfolgerungen}

\section{A. Zum Wert der Bewertung und zum Bewertungsmaßstab}

Im Anschluss an den rein komparativen Abschnitt einer rechtsvergleichenden Untersuchung und im Hinblick auf die definierten Forschungsziele kann die Bewertung der Vergleichsergebnisse erfolgen. Darauf aufbauend ist es auch in gewissem Maße möglich, relevante rechtspolitische Überlegungen - etwa in Form von Vorschlägen für zukünftige Reformen der betreffenden Rechtslage und -praxis anzustellen. Solche wertenden Betrachtungen können, im unmittelbaren Zusammenhang mit den ausführlichen nationalrechtlichen Analysen und etwaigen vorangehenden abstrakt-theoretischen Grundlagendefinitionen, auch für die Ausgestaltung weiterer theoretischer und empirischer Untersuchungen von Nutzen sein. ${ }^{791}$ Die wertenden Schlussfolgerungen, die größtenteils ,nur skizzenhaft und beispielhaft“ sein können, dienen jedenfalls ,als Denkanstöße und rechtsvergleichend orientierte Ableitungen für eine weitere rechtspolitische Entwicklung der den Untersuchungen zugrunde liegenden Sachfragen.“" 792

Die vorliegende Forschungsarbeit befasst sich auch in ihrem vergleichenden Teil mit Grundfragen des Strafverfahrens(-rechts). Die Untersuchung konzentriert sich freilich, ebenso wie der Bewertungsteil, auf ein bestimmtes Problemfeld. Es wäre nicht sinnvoll zu versuchen, anhand der Vergleichsergebnisse - auch wenn diese sich teilweise auf grundlegende systemübergreifende strafjustizielle Angelegenheiten beziehen - absolute Schlüsse hinsichtlich der Frage zu ziehen, welches Strafprozesssystem im Allgemeinen das „beste“, also etwa das „gerechteste“, das „fairste" oder das „effektivste“" ist. Dem spezifischen Analysegegenstand und Vergleichsrahmen entsprechend ist ein konkreter Bewertungsmaßstab bzw. -rahmen heranzuziehen. ${ }^{793}$ Den generellen Gegenstand der Analysen und Vergleiche stellt vorliegend das Beweisverfahren dar, konkreter: die zur Erreichung seines Zieles geschaffenen Strukturen und geltenden Rollenverteilungen. Logisches unmittelbares Ziel der (Existenz von) Beweisverfahren innerhalb der herkömmlichen streitigen erstinstanzlichen Strafprozesse - und somit ein wichtiges Element der Zielsetzung der Strafverfahrenssysteme allgemein - ist systemübergreifend die im Hinblick auf die Bestimmungen des materiellen Strafrechts möglichst präzise Aufklärung des jeweiligen angeklagten Sachverhalts. Es geht hierbei vor allem um die konkrete Wahrnehmung des allgemeinen gesellschaftlichen Interesses an

791 Siehe ferner unter Teil 1, II.C.2.f).

792 Engelhart, Sanktionierung, S. 599.

${ }^{793} \mathrm{Zu}$ Fragen über die wertende Rechtsvergleichung und den Bewertungsmaßstab siehe Eser, FS für Frisch, insb. S. 1447, 1453, 1461-1466. Siehe auch Jung, GA 2005, 2 (4-10). Vgl. auch Engelhart, Sanktionierung, S. 30-31, 599; Sieber, in: Sieber/Albrecht (Hrsg.), Strafrecht und Kriminologie, S. 119-123. 
einer Verurteilung nur des tatsächlich Schuldigen als ein leitendes (auch wenn heute nicht immer in vollem Umfang beachtetes) Prinzip der westlichen Strafjustizsysteme. Die hierfür relevanten Darstellungen und Analysen mit entsprechenden Nachweisen finden sich bereits auf abstrakt-theoretischer Ebene eingehend in Teil 1 und in concreto in Bezug auf die englische und die deutsche Rechtsordnung im oberen Abschnitt des Teils 2 der Forschungsarbeit. ${ }^{794}$

Eine sinnvolle wertende Betrachtung der Erkenntnisse aus dem Vergleich der Beweisverfahrensstrukturen kann sich daher an der Frage der Erreichung des gemeinsamen Ziels der nationalen Beweisverfahren, namentlich der bestmöglichen Sachverhaltsaufklärung, orientieren. Allgemeine Gerechtigkeitserwägungen, Fragen zur Wahrung der Verfahrensfairness und der Menschenrechte oder Effektivitätsgedanken, die sich auf die Abwägung zwischen den unterschiedlichen strafprozessualen Zielsetzungen beziehen, stehen somit hier nicht per se im Vordergrund. Selbstverständlich ist niemals außer Acht zu lassen, dass die Bewertung von strafprozessualen Konturen und die Erwägungen zur Optimierung der Sachaufklärungsstrukturen keinen substantiellen Wert haben können, wenn/falls die Beweisführungen in unfairer und menschenrechtswidriger Weise erfolgen. Immerhin ist, wie schon festgestellt, das Streben nach Verfahrensfairness und umfassendem strafprozessualem Schutz der Menschenwürde in den westlichen Rechtsordnungen, die meistens auch weitgehende internationale Menschenrechtsverpflichtungen garantieren, allgemein als gegeben zu betrachten. ${ }^{795}$ Menschenrechtsschutz und Fairness können außerdem in alle Rechtsordnungen gleichermaßen und unabhängig von der diagnostischen Verfahrenskonstellation eingefügt werden. Vorliegend beziehen sich jedenfalls die Bewertungen eher auf die gerichtlichen Methoden zur Aufklärung eines streitigen Straffalles; denn die Sachaufklärung stellt das unmittelbare Ziel der in dieser Arbeit zu untersuchenden Beweisverfahrenssysteme dar.

Aber auch in diesem engen beweisprozessualen Rahmen kann durch die Bewertungen nicht in absoluter Weise die Frage beantwortet werden, ob und inwieweit eine bestimmte Verfahrensordnung insgesamt präzisere Ergebnisse bei der Wahrheitserforschung erreicht, garantieren kann oder durch Reform ihres ganzen Prozesssystems garantieren könnte. Einerseits liegen hierfür zu wenig relevante empirische Daten vor; andererseits geht die Gesamterfassung der vielfältigen Faktoren, die in diesem Zusammenhang berücksichtigt werden sollten, über den vorliegenden rechtstheoretisch-vergleichenden Rahmen und seine realistischen Untersuchungsdynamiken hinaus.

In dieser Arbeit stehen - im Einklang mit den Erwägungen zu den Idealtypen die möglichen prozessrelevanten Besonderheiten des materiellen Strafrechts, die Verfahrenspraxis bei der anfänglichen Erhebung und eventuellen späteren Um-

794 Siehe insb. unter Teil 1, II.C.2., Teil 2, II.A.1., Teil 2, II.A.3., Teil 2, III.A.1., Teil 2, III.A.3.

795 Siehe unter Teil 1, II.C.2.d), Teil 2, II.A.1., Teil 2, III.A.1. 
wandlung der Strafklage sowie die moderne Ausbreitung der Prozessformen zur abgesprochenen (Beweis-)Verfahrensabkürzung, nicht eigenständig im Fokus. Zudem wurden folgende, für die strafprozessuale Wahrheitsfindung mehr oder weniger bzw. direkt oder indirekt bedeutsame Themen bei den Darstellungen und Vergleichungen der nationalen Strafverfahren nicht oder nicht in vollem Umfang ausgeführt:

- der materielle Gehalt der zahlreichen und vielfältigen „Beweisregeln“ (wie der Unmittelbarkeits-, Beweiszulassungs- und Beweisausschlussnormen per se oder eventueller Beweislastbestimmungen);

- die Prinzipien und die Art und Weise der Beweiswürdigung, die im Anschluss an die Beweisführungen folgt;

- die normativen Lösungen und die prozesstechnischen Auswirkungen des Spannungsverhältnisses zwischen den unterschiedlichen Interessen verschiedener Prozessakteure (etwa auch der Zeugen bzw. des Opfers i.V.m. solchen Problemen wie der Gewährleistung einer möglichst weitreichenden Unmittelbarkeit bei den Beweisführungen);

- die Ausbildung und praktische Erfahrung bzw. Qualifikation, soziale Stellung und Unabhängigkeit der Richter, der Anwälte und der übrigen in institutioneller Hinsicht an den maßgebenden Urteilsfindungsvorgängen beteiligten Personen; sowie

- allgemein die im Rahmen der eigentlichen Justizhandhabung jeweils erkennbaren sozial- und rechtspolitischen Tendenzen und „Leitlinien“.

Im Ergebnis beschränken sich auch die nachfolgenden wertenden Überlegungen auf die oben verglichenen Strukturen und Rollenverteilungen im streitigen Beweisverfahren nach Erhebung der Strafklage und auf die entsprechenden prozessstrukturellen Erfordernisse der Sachverhaltsaufklärung. Die folgenden Ausführungen konzentrieren sich, zugespitzt und in Anlehnung an die relevanten abstrakten Auswertungen in Teil 1, ${ }^{796}$ auf bestimmte ,positive“, „negative“ und ,verbesserungsbedürftige" Aspekte der englischen und der deutschen Beweisführungsstrukturen und Beweisprüfungsmethoden.

\section{B. Wertende Betrachtung der Vergleichserkenntnisse und Überlegungen zur Annäherung der Verfahrenssysteme}

Die in England und Deutschland bei der Beweisführung und Beweisprüfung angewandten Methoden sollen zur möglichst präzisen und zuverlässigen Sachverhaltsaufklärung beitragen und sind daher grundsätzlich unter diesem Gesichtspunkt zu bewerten. Solche Wertungen und entsprechende Überlegungen in Bezug auf

796 Siehe unter Teil 1, II.C.2.e)-f). 
„Verbesserungsmöglichkeiten“ der Rechtssysteme werden sinnvollerweise analog zu der vorangehenden schematischen - mit eigentlichen, voneinander klar getrennten Prozessphasen freilich nicht übereinstimmenden - Gliederung der Landesberichte und der anschließenden Vergleichungen angestellt. Hierbei wird eine wertende Betrachtung der herkömmlichen erstinstanzlichen Beweisverfahrensstrukturen und Rollenverteilungen nach Erhebung der Klage und bis zum Abschluss der eigentlichen streitigen Beweisführungen im Hauptverfahren vorgenommen, die konkret auf folgenden drei Ebenen stattfindet: nämlich unter besonderer Berücksichtigung der vorbereitenden Beweisführungsvorgänge einschließlich der Bestimmung des Umfangs der Beweiserhebungen (unter 1.), der Kenntnisnahme und Offenlegung von Beweisen (unter 2.) sowie der maßgebenden Beweisführungen in der Hauptverhandlung (unter 3.).

\section{Die vorbereitenden Beweisführungsvorgänge und die Bestimmung der Beweiserhebungen}

Aus der vorangehenden Gegenüberstellung der Beweisverfahrensordnungen geht eindeutig hervor, dass in England nach der Klageerhebung primär die Parteien für die tatsächliche Vorbereitung und Durchführung sämtlicher beweisrelevanter Vorgänge verantwortlich sind. Im deutschen richterzentrierten und vom Untersuchungsgrundsatz dominierten Beweisverfahrenssystem haben dagegen die Anklagebehörde und die Verteidigung grundsätzlich keine selbstständigen Dispositionsbefugnisse über die Beweisführungen; es wird sogar größtenteils auf die Verwendung des Begriffs „Parteien“ zur Bezeichnung der zentralen Verfahrensbeteiligten und insbesondere der StA, die als Justizbehörde durchweg in objektiver Weise handeln muss, verzichtet.

Es lässt sich jedoch nicht leugnen, dass auch im modernen englischen Strafverfahrenssystem die Anklage und die Verteidigung auf normativer Ebene zentrale Prozessbeteiligte sind, die schon mit Blick auf die Vorbereitung der Gerichtsverhandlung einerseits erhebliche Autonomie genießen, andererseits aber auch weitreichende Objektivitäts- und Gerechtigkeitsverpflichtungen haben. Gleichzeitig werden die richterliche Kontrolle und die detaillierte und transparente Vorplanung der englischen Beweisvorgänge gegenwärtig gesetzlich gefordert. Das Eingreifen des Richters in die Bestimmung des Umfangs der Beweiserhebungen während des Hauptverfahrens ist ebenfalls durchgehend möglich, auch wenn diese richterliche Möglichkeit weiterhin als ultima ratio-Befugnis angesehen wird. Die Beweisbestimmungen werden letztendlich grundsätzlich unmittelbar durch die Parteien vorgenommen; sie sind jedoch zum größten Teil insbesondere von der Objektivitätsund Fairnesspflicht der Anklage sowie von den Offenlegungspflichten beider Parteien geprägt. Charakteristisch hierfür sind insbesondere die Ausführungen zu den allgemeinen ethisch-rechtlichen Verpflichtungen der Parteianwälte, zu den Zeugenladungen, zum grundsätzlichen Verbot der parteilichen Vorbereitung der Zeugen- 
aussagen im Vorfeld der trial und $\mathrm{zu}$ den weitreichenden richterlichen case management-Aktivitäten, die nicht ausschließlich aus prozessökonomischen Gründen vorgesehen sind. ${ }^{797}$

Dadurch distanziert sich die englische Rechtsordnung sowohl von vorherigen Exzessen als auch von extrem parteiischen Verfahrenspraktiken und vom traditionellen Verständnis des kompetitiven Charakters des Straf- und Beweisverfahrens. Mittlerweile findet ohnehin die These, dass unkontrollierbare kampfartige Praktiken und völlig einseitige Beweisbestimmungsstrategien der Parteien der Wahrheitserforschung effektiver dienen können, keine Unterstützung mehr bzw. lässt sich zumindest nicht mit empirisch nachprüfbaren Argumenten belegen; auch in theoretischer Hinsicht würden solche Praktiken sogar unter der Voraussetzung der Waffengleichheit nur zu den extremen Eckpunkten eines reinen „adversatorischen“ Modells passen. ${ }^{798}$ Gleichwohl ist in bestimmten Angelegenheiten weiterhin ein starres Festhalten des englischen Verfahrenssystems an den Autonomieprinzipien des reinen Parteiverfahrens zu beobachten.

Insbesondere durch die einseitige Hinzuziehung von expert witnesses (Sachverständigen) seitens der Parteien ergibt sich folgende Problematik: Die bestehenden normativen und faktischen Schwierigkeiten für den englischen Richter, die objektive Auswahl und Anweisung der Experten sicherzustellen sowie neutrale Experten von Amts wegen (insbesondere in Fällen von gegensätzlichen Gutachten) zu beauftragen, können beweisbezogene Manipulationen ermöglichen und somit die Wahrheitserforschung behindern. ${ }^{799}$ Die relevante englische Rechtslage bleibt daher weiterhin reformbedürftig. ${ }^{800}$ Es müssen vor allem die erforderlichen Strukturen für eine objektivere Auswahl und Beauftragung der Experten zur Verfügung gestellt sowie dem Richter die entsprechenden Möglichkeiten zu ihrer Nutzung geboten werden. Hierbei können die Relativierung bzw. eine gewisse Kontrolle der Autonomiebefugnisse der Parteien, die umfassende Heranziehung neutraler justizieller Einrichtungen sowie eventuell die Orientierung an bestimmten kontinentaleuropäischen Vorbildern im Sinne vor allem der Verwendung von im Voraus amtlich zusammengestellten bzw. geprüften „Expertenlisten“ eine wichtige Rolle spielen.

Demgegenüber ist in Deutschland die Anordnung des Sachverständigenbeweises wie auch allgemein die Vorbereitung und Bestimmung des Umfangs sämtlicher

797 Siehe insb. unter Teil 2, II.B.1.a) und b)cc), Teil 2, II.B.2.b) und d), Teil 2, IV.B.1.a) und b)cc), Teil 2, IV.B.2.b) und d).

${ }_{798}$ Vgl. Jörg/Field/Brants, in: Fennell u.a. (Hrsg.), Criminal Justice, S. 43; McEwan, L.S. 31 (2011), 519 (524).

799 Siehe m.w.N. unter Teil 2, II.B.1.b)dd), Teil 2, IV.B.1.b)dd). Siehe auch die rechtspolitischen Erwägungen in Auld Report 2001, S. 16, 571-582. Kritisch zu den unterschiedlichen Prozesstypen des Sachverständigenbeweises Spencer, in: Delmas-Marty/Spencer (Hrsg.), European Criminal Procedures, S. 632-635.

800 In diese Richtung bewegen sich, zumindest mit Blick auf die umfassendere Überprüfung der Glaubwürdigkeit des Expertenzeugen, die neuen Rules in Part 33 CPR 2014. 
Beweiserhebungen in der Regel eine richterliche Angelegenheit. Der Richter ist mit Blick auf seine Aufklärungspflicht an Anträge und Anregungen der Verfahrensbeteiligten grundsätzlich nicht gebunden. In beweisprozessualer Hinsicht legt das deutsche Gesetz hauptsächlich Gewicht auf die Aufklärungsaktivitäten und Verpflichtungen des Richters. In der Praxis findet die richterliche Vorbereitung der maßgebenden Beweisaufnahmen meist auf der Basis der Verfahrensakten statt. Die Sammlung der Beweise im Vorverfahren erfolgt zum Großteil durch die Polizei und die offizielle Zusammenstellung der Akten durch die zur Objektivität und Wahrheit verpflichteten StA; die tatsächliche Vollständigkeit und Objektivität der durch den Strafverfolgungsmechanismus einseitig dokumentierten Beweislage darf aber, wie auch in England und anderen Rechtsstaaten, in der Praxis nicht ohne Weiteres als gegeben angenommen werden.

Auf normativer Ebene gilt in der deutschen Verfahrensordnung das Leitprinzip, dass Chancengleichheit, allseitige Transparenz und Rechtmäßigkeit im Strafprozess durchweg herrschen müssen; dies gilt auch hinsichtlich des außergerichtlichen Kontakts der Behörden und Prozessbeteiligten mit den Beweismitteln bzw. hinsichtlich der Sammlung und Herbeischaffung der Beweise. ${ }^{801}$ Die Schwierigkeiten bei der tatsächlichen Umsetzung dieses Grundsatzes sind jedoch nicht außer Acht zu lassen; in diesem Zusammenhang kann die institutionelle Erweiterung der selbstständigen Beweismöglichkeiten der Verteidigung als besonders effektives Gegengewicht gegen den mächtigen staatlichen Strafverfolgungsapparat wirken.

Gegenwärtig steht es den Verfahrensbeteiligten und insbesondere der Verteidigung im deutschen Hauptverfahren nicht nur in jedem Fall frei, ihre Beweisthesen aufgrund der Verfahrensakten vorzubereiten, sondern auch auf verschiedene Weise aktiv bei der Bestimmung der Beweiserhebungen mitzuwirken. Allerdings wirken mögliche vorgerichtliche Erörterungen hinsichtlich der Beweislage, Anregungen und Beweisermittlungsanträge nicht automatisch bindend für das Gericht. Auch die förmlichen vorbereitenden Beweisanträge oder die unmittelbaren Ladungen von Beweispersonen seitens der Verfahrensbeteiligten führen nicht direkt zu den entsprechenden Beweiserhebungen. Hierbei darf das deutsche Gericht aber nur aus ganz bestimmten gesetzlichen Gründen die Beweiserhebungen ablehnen, insbesondere wenn es diese wegen gewisser Umstände als nicht substantiell für die Wahrheitsfindung ansieht. Die Verteidigung kann daher etwa auch ihren ,eigenen“ Sachverständigen vorbringen und oft auch die Präsentation seines Gutachtens in der Hauptverhandlung erwirken. ${ }^{802}$

Trotzdem kann in der Praxis in solchen „mittelbaren“, d.h. nicht durch das Gericht initiierten Beweiserhebungssituationen eine gewisse richterliche Untergra-

${ }^{801}$ Siehe insb. unter Teil 2, III.B.1.a) und b)cc), Teil 2, III.E.1., Teil 2, IV.B.1.a) und b)cc).

${ }^{802}$ Siehe insb. unter Teil 2, III.B.1.b)dd), Teil 2, III.B.2.b) und d), Teil 2, IV.B.1.b)dd), Teil 2, IV.B.2.b) und d). 
bung bzw. Bezweifelung des eigentlichen Wertes des Sachverständigenbeweises bzw. der anderen durch die Prozessbeteiligten (also nicht amtlich-autoritativ) vorgebrachten Beweismittel und Gegenbeweise nicht immer vermieden werden. Darüber hinaus kann sich der Spruchkörper eventuell umfassender und objektiver informieren, wenn vor ihm alle verfügbaren Beweismittel durch mehrere Seiten möglichst direkt, ohne richterliche Zwischenentscheidungen und -wertungen, vorgebracht werden. In diesem Sinne wäre die ausdrücklichere Anerkennung und umfassendere Verankerung von selbstständigen und unmittelbaren Möglichkeiten der Prozessbeteiligten zur Mitwirkung bei der Vorbereitung und Bestimmung des Umfangs der Beweiserhebungen nicht sinnlos. ${ }^{803}$

Freilich ist hiermit nicht gemeint, dass in diesem Kontext die Aufklärungspflicht des deutschen Richters verdrängt werden muss. Die Verstärkung der unmittelbaren Interaktionsmöglichkeiten der Verfahrensbeteiligten bei den Beweiserhebungen kann vor allem der Deckung des allseitigen Informationsbedarfs, der Begrenzung einseitiger richterlicher Verfahrensweisen und somit gewissermaßen der Sachaufklärung dienen, vorausgesetzt, es existieren auch die nötigen Schutzmechanismen gegen Missbrauch. Die Ergänzung der Beweislage durch richterliche Ermittlungen ist aber gleichzeitig keinesfalls als negativ für die Wahrheitsfindung zu bewerten. Befugnisse gleich denen der Parteien im englischen Strafverfahren, die bestimmte Aspekte der Beweisführungen - aus welchen Gründen auch immer - durch Übereinstimmung und durch die Einführung von ,agreed evidence“ verbindlich steuern können, sind im deutschen Verfahrenssystem ohnehin nicht analog vorgesehen. ${ }^{804}$ Auch wenn die Prozessbeteiligten im Rahmen der gesetzlichen Möglichkeiten in Bezug auf die Vereinfachung und spezifische Begrenzung des Umfangs der Beweisführungen übereinstimmen, kann der deutsche Richter erforderlichenfalls zur Sicherstellung einer umfassenden Wahrheitserforschung eingreifen. ${ }^{805}$

Letztendlich kann aber eine dialektischere Ausgestaltung der beweisrelevanten Vorgänge für die Erzielung zuverlässigerer Sachaufklärungen von Wert sein. Zu diesem Zweck kann sich sogar die Anwendung von bereits bestehenden gesetzlichen Prozessinstrumenten als nützlich erweisen. So kann eine richterliche Erörterung des Verfahrensstandes mit den Verfahrensbeteiligten schon im Vorfeld der deutschen Hauptverhandlung nicht nur für die Zwecke einer Absprache, sondern auch zur interaktiven Klärung bzw. Vereinfachung komplizierter Beweisthemen im

803 Die gegenläufige rechtspolitische und gerichtliche Tendenz der Moderne wird, insb. in Bezug auf die Einschränkungen des Beweisantragsrechts, den Aufstieg des Richters zum „Hauptverhandlungsdespoten“ und die Konsequenzen für die Wahrheitserforschung, von Roxin/Schünemann, Strafverfahrensrecht, § 45 Rn. 41, kritisiert. Vgl. auch Fezer, NStZ 2010, 177 (178).

${ }^{804}$ Kritisch gegenüber der relevanten englischen Rechtslage und Praxis unter Rücksichtnahme auf die Probleme, die bei der Wahrheitserforschung aufgrund der diesbezüglichen Parteienautonomie entstehen können, Roberts/Zuckerman, Criminal Evidence, S. 121.

${ }_{805}$ Vgl. unter Teil 2, II.B.2.c), Teil 2, III.B.2.c), Teil 2, IV.B.2.c). 
Voraus stattfinden. ${ }^{806}$ Sicherlich müssen bei der Umsetzung solcher mehrseitig partizipatorischer Beweisverfahrenselemente auch mögliche Probleme der Prozessökonomie berücksichtigt werden. Solche Probleme treten gegenwärtig jedoch bei allen geltenden herkömmlichen und alternativen westlichen Strafprozessarten auf $;{ }^{807}$ vor allem die Optimierung der Beweisverfahrensstrukturen sollte sich eben nicht ausschließlich an diesem Maßstab messen lassen.

\section{Kenntnisnahme und Offenlegung von Beweisen}

Im vorliegenden Kontext ist die Frage besonders relevant, inwieweit eine umfassende Vorkenntnis der Verfahrensakten und der Beweisergebnisse des Vorverfahrens seitens des Richters sowie seitens der zentralen Prozessbeteiligten zweckmäßig ist bzw. welche Auswirkungen diese Kenntnis auf die maßgebenden Beweisführungen im Hauptverfahren haben kann. Weder in der englischen noch in der deutschen Rechtsordnung wird bestritten, dass eine möglichst vollständige und im Voraus stattfindende Offenlegung aller entscheidungsrelevanten Beweisinformationen von zentraler Bedeutung für die Parteien/Verfahrensbeteiligten und insbesondere für die Verteidigung ist.

Im englischen Strafverfahrenssystem, das durch die Beweislast der oft besser mit Informationen versorgten Anklage geprägt ist, steht hauptsächlich die Ausbalancierung der faktischen Ungleichheiten des Parteiprozesses im Vordergrund. Das deutsche Strafverfahrenssystem konzentriert sich eher auf die selbstständige Gewährleistung von subjektiven, im Rahmen der Fairness- und Menschenrechtserwägungen zentral anerkannten Verteidigungs- und Gehörrechten. In prozessstruktureller Hinsicht stehen letztendlich nicht die möglichen faktischen Auswirkungen der Ausübung der Verteidigungsrechte auf die Beweisführungen, sondern die zentral-amtliche Ermittlung des Sachverhalts als die beste Methode und oft auch als eine ausreichende Garantie für die Erzielung präziser und zuverlässiger Wahrheitsergebnisse im Vordergrund.

Darüber hinaus wird die Kenntnisnahme der Akten seitens des verfahrensleitenden Berufsrichters weitgehend als zentrales und unverzichtbares Element des deutschen Hauptverfahrens anerkannt. In England berufen sich Lehre und Rechtsprechung weiterhin auf die Nichtkenntnis der Vorverfahrensakten seitens der Geschworenen und auf die Bedeutung dieser Nichtkenntnis für die Urteilsfindung in der jury trial. Die Frage der Vorkenntnis des Beweismaterials seitens des Berufsrichters im jury-Verfahren bzw. seitens der Richter im bench-Verfahren ist dagegen bisher meistens außer Betracht geblieben. ${ }^{808}$

\footnotetext{
806 Vgl. unter Teil 2, III.B.2.d), Teil 2, IV.B.2.d).

807 Vgl. u.a. McEwan, L.S. 31 (2011), 519 (520-521).

808 Siehe eingehend zu den verschiedenen Aspekten der vorliegenden Problematik unter Teil 2, II.C., Teil 2, III.C., Teil 2, IV.C.
} 
In der englischen Rechtsordnung stehen seit jeher ohnehin eher die Reformen der Rechtslage und -praxis hinsichtlich der gegenseitigen Offenlegungspflichten der Parteien im Mittelpunkt des rechtspolitischen Interesses. Die modernen Tendenzen in Gesetzgebung und Rechtsprechung, die allgemein gegen die Anwendung von gegeneinander gerichteten kampfartigen Verfahrenspraktiken und gegen Überraschungsangriffe durch die Parteien sprechen, sind in diesem Rahmen besonders deutlich sichtbar. Anklage und Verteidigung haben deshalb gegenwärtig erhebliche Offenlegungspflichten, die Anklage auch in Bezug auf nicht vorzubringende Beweise. Die englische Verfahrensordnung hat sich für eine ziemlich ,weitgehende“ Lösung, nämlich die der grundsätzlich vollen, aber auch verbindlich gegenseitigen Offenlegung, entschieden. Insbesondere was die Durchsetzung von sehr weitreichenden Offenlegungspflichten der Verteidigung und vor allem die vorgesehenen Konsequenzen ihrer Vernachlässigung anbelangt, scheinen die in den meisten Fällen tatsächlich zwischen den Parteien existierenden Ungleichheiten nicht genügend wahrgenommen $\mathrm{zu}$ werden. Es ist $\mathrm{zu}$ bezweifeln, dass die vorgesehenen Folgen einer mangelhaften vorgerichtlichen Offenlegung der Beweisthesen der Verteidigung, wie etwa die Verweigerung weiterer Offenlegungen von nicht vorzubringenden Beweisen seitens der Anklage und vor allem das Ziehen negativer Schlussfolgerungen durch den Spruchkörper zulasten der Verteidigung bei der Urteilsfindung, zur Wahrheitsfeststellung wirklich beitragen können. Dagegen könnte die Vorbereitung von umfassenden Sachaufklärungsvorgängen eventuell durch die Gewährleistung von vorbehaltloser Objektivität und Transparenz bei den Offenlegungen seitens der Anklage besser bedient werden; freilich müssten hierbei, wie auch sonst in sämtlichen Rechtsordnungen, korrektive Maßnahmen gegen allseitige Verdunkelungsstrategien und zum Schutz höherwertiger Interessen weiterhin angewandt werden. Bei mangelhaften Beweisoffenlegungen auf beiden Seiten könnte die Förderung von innerprozessualen Mechanismen, wie z.B. der Vertagung der Verhandlung oder in Extremfällen des Ausschlusses der betreffenden Beweiserhebung, für die bessere Vorbereitung der übrigen Verfahrensschritte und für die Vermeidung von extrem-parteilichen (spielstrategischen) Verhaltensweisen sorgen.

Darüber hinaus ist bezüglich der richterlichen Kenntnisnahme der Beweise nicht zu leugnen, dass heute normative oder tatsächliche Möglichkeiten existieren, die es dem englischen Richter (nicht den jurors) erlauben, das Hauptverfahren unter Rücksichtnahme auf wichtige Ergebnisse des Vorverfahrens zu leiten. Dies soll für das englische Aufklärungsverfahren zunächst keine große Rolle spielen, soweit für die Präsentation und Prüfung der Beweise in der Hauptverhandlung primär die Parteien verantwortlich sind. Hierbei dürfen allerdings die moderne Tendenz zur Erweiterung der bench-Gerichtsbarkeit, die zunehmende prozessuale Bedeutung der richterlichen case management-Aktivitäten sowie die empirische Beobachtung immer aktiver vorgehender Richter nicht unberücksich- 
tigt bleiben. Angesichts solcher Entwicklungen kann nämlich die Vorkenntnis der Akten und Beweise, welche die Haltung des Richters zum jeweiligen Straffall in der Praxis beeinflussen kann, an Gewicht gewinnen und erheblichere faktische Auswirkungen auf die Art und Weise der Verfahrensleitung und vor allem der Beweisführung haben.

In diesem Problemkreis (wie auch bei den entsprechenden Erwägungen zum deutschen Verfahren) geht es eindeutig nicht um die Auswirkungen der Aktenkenntnis auf die Urteilsfindung, die durch den jeweiligen Spruchkörper erfolgt. Die Existenz eines engen Zusammenhangs zwischen aktiver(er) Verfahrensleitung und Urteilsfindungsfunktion ist jedoch, wie bereits gesehen, nicht auszuschließen; einen solchen Zusammenhang kann es im englischen bench-Verfahren eventuell aufgrund der Doppelfunktion des für die Urteilsfindung selbstverantwortlichen Vorsitzenden Richters geben. In diesem Rahmen kann es passieren, dass ein Richter, der aufgrund seiner urteilsfindenden Rolle möglicherweise bereit ist, aktiver in die Aufklärung des Sachverhalts einzugreifen, die bestehenden Möglichkeiten zum Studium der Verfahrensakten in höherem Maße nutzen wird. Diese Einsichtnahme in die Beweisergebnisse des Vorverfahrens kann ihrerseits das eigentliche Eingreifen des Richters in die parteilichen Beweisführungen im Hauptverfahren signifikant prägen. In Anbetracht der kontinuierlichen Zunahme der professionellen bzw. geschworenenfreien Gerichtsbarkeit stellt das aktenbasierte englische Beweisverfahren nicht unbedingt eine ferne Realität dar.

Im deutschen Verfahrenssystem ist die Einschränkung der richterlichen Befugnis zur umfassenden Aktenkenntnisnahme weiterhin keine realistische Option. Es handelt sich hierbei freilich um ein facettenreiches und insbesondere in Bezug auf die tatsächliche Beeinflussung der Urteilsfindung durch die vorherige richterliche Aktenkenntnis viel diskutiertes Problem. In einem Prozesssystem, in dem der Richter für die technische Verfahrensleitung, die Beweisaufnahme in der Hauptverhandlung und die Urteilsfindung verantwortlich ist und die Parteien keine selbstständigen Tatsachenpräsentationen durchführen, ist sicherlich die richterliche Aktenkenntnis für die zweckmäßige Planung der Wahrheitserforschungsvorgänge von großer Bedeutung. In der vorliegenden Arbeit wurden die möglichen faktischen Auswirkungen einer solchen Vorkenntnis der durch die StA zusammengestellten Ermittlungsakten auf die Art und Weise der richterlichen Beweisführung mehrmals angesprochen.

Insbesondere wurde auf die Gefahr des psychologischen Verhaftetseins in den in der Verfolgungspraxis oft einseitig gesammelten Ermittlungserkenntnissen, der daraus resultierenden benachteiligenden Behandlung des Angeklagten seitens des Richters und der intuitiven und routinierten Unterschätzung der vorzubringenden Verteidigungsthesen hingewiesen. Die relevanten Fragen sollen durch weitere empirische Forschungen besser beleuchtet werden. Die Herausbildung einer direkten Alternative zur richterlichen Aktenkenntnis ist jedenfalls keine simple Angelegenheit und auch keine Notwendigkeit - eher im Gegenteil, zumindest in hochkomple- 
xen Straffällen mit großem Informationsbedarf. ${ }^{809}$ Deswegen ist es zunächst wichtig, dass die vorgerichtlichen kontradiktorischen Kontrollmechanismen zur Sicherstellung einer möglichst akkuraten und vielseitigen Beweissammlung und Aktenzusammenstellung im Vorverfahren optimiert werden. ${ }^{810}$ Eventuell kann aber auch eine Verstärkung jener gerichtlichen Prozessformen, die sich auf die unmittelbare kontradiktorische Beteiligung der Sitzungsvertreter der StA und der Verteidigungsanwälte an den maßgebenden Beweiserhebungen im Hauptverfahren beziehen, zumindest indirekt ausbalancierend wirken: Im Ergebnis kann somit die gesamte Beweisaufnahme weniger durch den Richter und seine Aktenkenntnis und möglicherweise also weniger einseitig bestimmt werden. ${ }^{811}$

Eine substantielle Erweiterung der unmittelbaren Beweisführungsmöglichkeiten der Prozessbeteiligten und ihre effektive praktische Umsetzung setzen ihrerseits möglichst umfassende Zugangsmöglichkeiten zu den Akten voraus, um den Informationsfluss zu gewährleisten. Insbesondere das Akteneinsichtsrecht der Verteidigung ist im deutschen Recht bereits weitgehend verankert; der Sitzungsvertreter der StA soll ebenso in der Lage sein, rechtzeitig Einsicht in die behördlich zusammengestellten Akten zu nehmen. Einzelne mögliche technische Verbesserungen des relevanten Regelungskomplexes können an dieser Stelle nicht berücksichtigt werden. In allen Fällen kann eine eingehendere Berücksichtigung der selbstständigen Bedeutung, welche die frühestmögliche Akteneinsichtnahme seitens der Prozessbeteiligten für die Sachaufklärungsprozesse allgemein haben kann, sowie des tatsächlichen informatorischen Ungleichgewichts zwischen Strafverfolgungsmechanismus und Angeklagtem eventuell zu zweckmäßigeren Reformen führen.

\section{Die Beweisführung im Hauptverfahren}

\section{a) Allgemeine Erwägungen}

Sowohl im englischen als auch im deutschen Hauptverfahren obliegt die Kontrolle der Einhaltung der diversen Verhandlungsregeln und materiellen Beweisnormen dem Richter bzw. dem Gericht, unabhängig davon, wer der eigentliche Beweisführer ist. Nur der neutrale Richter kann und muss nach herrschendem systemübergreifendem Prozessverständnis letztendlich für die Gewährleistung von Rechtmäßigkeit und Fairness im Verfahren zuständig sein. Größere Schwierigkeiten ergeben sich dabei im Rahmen der Vorgänge, der Abwägungen und der Ausübung des richterlichen Ermessens in Bezug auf den Ausschluss von bestimmten, aus diversen Gründen mutmaßlich unzulässigen Beweisinformationen aus dem Verfahren und aus der Urteilsfindung.

809 Vgl. Roxin/Schünemann, Strafverfahrensrecht, § 44 Rn. 80.

810 Vgl. in ähnlichem Kontext Jackson, Cardozo L. Rev. 10 (1988), 475 (523-525).

811 Vgl. auch Roxin, in: Lüttger (Hrsg.), Probleme, S. 58-60; Weißmann, Stellung, S. 86. 
Neben der Notwendigkeit einer genaueren Bestimmung der Grenzen des richterlichen Ermessensspielraums und der Mitwirkungsbefugnisse der Prozessbeteiligten ist es in diesem Kontext für die zweckmäßige Ausgestaltung des maßgebenden Beweisverfahrens in beiden Verfahrensordnungen besonders wichtig, dass die Angelegenheiten der Beweisausschluss so früh wie möglich und ohne vorherige vollständige Erhebung der relevanten Beweise in der Hauptverhandlung beurteilt werden können. Ziel soll hierbei sein, dass die Richter nicht nur bei der Urteilsfindung, sondern schon bei der Verfahrensleitung und besonders in Deutschland auch bei den Beweiserhebungen möglichst unbeeinflusst von ,verbotenen“ Informationen wirken. Insbesondere im deutschen Verfahren erscheint eine Neubestimmung der Vorgänge und Voraussetzungen für die richterliche Auseinandersetzung mit den Beweisverwertungsverboten notwendig. ${ }^{812}$ Selbstverständlich ist die praktische Umsetzung solcher Gedanken nicht in allen Fällen und unter allen Umständen möglich.

Im englischen Verfahrenssystem sind darüber hinaus, wie festgestellt, für die eigentlichen Beweispräsentationen und -prüfungen in der Hauptverhandlung die Parteien verantwortlich. Dagegen ist im deutschen Verfahrenssystem der Richter primär für die Durchführung der Beweiserhebungen zuständig. ${ }^{813}$ Das starre Festhalten an diesen traditionellen Beweisführungsgrundsätzen erscheint mit Blick auf die Wahrheitserforschung nicht in allen Fällen sinnvoll. Beispielsweise ist es in England im Rahmen der Offenkundigkeitsangelegenheiten (judicial notice) möglich, dass der Richter wegen seiner persönlichen Vorkenntnis bestimmter entscheidungserheblicher Tatsachen faktisch zu einem Anklagezeugen wird. Dabei hat aber die Verteidigung de jure, insbesondere nach den geltenden Beweiserhebungsregeln, die nur die kontradiktorische Beweisführung durch die Parteien betreffen, keine Möglichkeit, den Richter zu ,vernehmen“ oder Gegenbeweis zu erheben. ${ }^{814}$ Ein noch wichtigeres Paradigma bildet die bestehende Möglichkeit des Anklageanwalts, innerhalb der bereits laufenden Hauptverhandlung vom Vorbringen von Beweisen abzusehen (offering no evidence). Das Gericht hat dabei, nicht zuletzt aufgrund seiner allgemein eng begrenzten Beweiserhebungsbefugnisse, meistens tatsächlich keine andere Wahl, als den Angeklagten entsprechend freizusprechen, auch wenn es eine andere Ansicht zum Tatgeschehen hat. ${ }^{815}$

In derartigen Fällen kann eine Lockerung der strikten Beweisführungsregeln eventuell bessere Wahrheitsergebnisse garantieren, ohne dass die parteienzentrierte Struktur des englischen Beweisverfahrens erheblich gestört wird. Bei den judicial notice-Fällen kann etwa (ähnlich wie in Deutschland) dem Richter die beweisprozessuale Verwendung der persönlichen Vorkenntnis des Tatgeschehens verweigert

812 Siehe m.w.N. unter Teil 2, II.D.1., Teil 2, III.D.1., Teil 2, IV.D.1.

813 Ausführlich unter Teil 2, II.D.2., Teil 2, III.D.2., Teil 2, IV.D.2.

814 Mehr in Teil 2, II.B.2.a).

815 Mehr in Teil 2, II.D.2.a). 
werden; oder es soll den Parteien die Möglichkeit gegeben werden, ihre Gegenargumente im Hinblick auf die vermeintlich offenkundigen Tatsachen frei und unabhängig von strukturellen Formalitäten zu äußern. Bei den offering no evidenceFällen handelt es sich dagegen um ein komplizierteres Problem.

Im englischen Verfahrenssystem gilt zwar heute der verfahrensleitende Richter teilweise im Gegensatz zu manchen anderen Rechtssystemen angloamerikanischer Prägung - nicht als bloßer Schiedsrichter. Der englische Richter muss vielmehr für Wahrheit und Gerechtigkeit sorgen. Trotzdem stellt die richterliche Aufklärungspflicht kein allgemein anerkanntes und die Beweisführungen prägendes Prinzip dar. Der Richter muss zunächst lediglich die Beweispräsentationen der Parteien distanziert verfolgen. In Fällen, in denen die Parteien auf die Beweisführung völlig verzichten und der Richter keine selbstständigen Beweisermittlungsmöglichkeiten hat, kann somit eine weniger zuverlässige Sachentscheidung erwartet werden. Der Richter kann, wie gesehen, unter bestimmten Umständen aktiv in die (Bestimmung der) Beweiserhebungen eingreifen und etwa zusätzliche Zeugen (jedoch nicht Sachverständige) zur Aussage aufrufen und diese Zeugen vernehmen oder die durch die Parteien geladenen Zeugen ergänzend befragen. Soweit aber die Anklage überhaupt keine Beweismittel vorbringt, kann der englische Richter de jure und de facto den ganzen Sachverhalt nicht selbst ermitteln und muss daher den Angeklagten freisprechen.

Aber auch in Verfahrenssystemen mit Amtsermittlungsgrundsatz ist eine umfassende gerichtliche Untersuchung des Geschehens ohne substantiellen Beitrag der Verfahrensbeteiligten und insbesondere der Anklagebehörde in der Praxis sehr schwierig. Selbst wenn die rechtliche Verankerung des Amtsaufklärungsgrundsatzes als ausreichende Garantie für eine präzise und zuverlässige Sachaufklärung angesehen werden könnte - was nicht zuletzt angesichts der gerade beschriebenen praktischen Schwierigkeiten sowie der heutzutage systemübergreifend verbreiteten Absprachemechanismen eher zweifelhaft ist -, würde die Einführung dieses Grundsatzes eine grundlegende (und bisher allseitig nicht erwünschte) strukturelle Reform des traditionellen englischen Verfahrenssystems voraussetzen. Neben der ausschließlich parteilichen Bestimmung des Expertenbeweises bilden die relativ häufigen offering no evidence-Angelegenheiten letztendlich einen weiteren charakteristischen immanenten Schwachpunkt des großteils auf der Parteienautonomie basierenden englischen Beweisführungssystems. Das Letztere deklariert einerseits ausdrücklich sein Wahrheitserforschungsziel; andererseits verhilft die Verfahrensordnung dem Richter sogar bei extremen Beweisschranken nicht mit selbstständigen Aufklärungsbefugnissen und staatlichen Ermittlungsmechanismen zur Sicherstellung dieses Ziels. Zukünftige englische Reformprogramme müssen sich dringend eingehender mit derlei Problemen und allgemein mit Fragen zur Erweiterung der richterlichen Beweiserhebungsmöglichkeiten auseinandersetzen.

Entsprechende Probleme sollten im deutschen Verfahrenssystem, das durch das allgemeine Leitprinzip der Amtsaufklärungspflicht und dazu noch durch die Mit- 
wirkungsrechte der Verfahrensbeteiligten geprägt wird, zumindest auf theoretischer Ebene nicht auftreten. Gleichwohl kann das starre Festhalten an sämtlichen vermeintlichen Konnotationen der richterlichen Aufklärungspflicht teilweise auch Schwierigkeiten für die gerichtliche Wahrheitserforschung verursachen. Dies kann vor allem geschehen, wenn der Richter nicht nur als der ultimative Garant für die erschöpfende Ermittlung der entscheidungsrelevanten Tatsachen und Beweismittel angesehen wird, sondern überdies die Position eines absoluten amtlichen Beweisverfahrensherrschers erlangt. ${ }^{816}$

Als solcher steuert der in normativer Hinsicht neutrale Richter aktiv sämtliche Aspekte der Beweiserhebungen, wobei er sich aber meistens auf die Informationen aus den Vorverfahrensakten stützt. Diese Akten werden ihrerseits grundsätzlich auf der Basis der in der Praxis sich oft einseitig auf die Überführung des Verdächtigen konzentrierenden Ermittlungsarbeit der Verfolgungsbehörden zusammengestellt. Im Übrigen muss der Richter für die Gewährleistung von bestimmten, jedoch eigentlich supplementären Mitwirkungsmöglichkeiten der Verfahrensbeteiligten und insbesondere der Verteidigung bei der Durchführung der maßgebenden Beweiserhebungen sorgen; aber auch dieser Pflicht zeigt sich der Richter oft abgeneigt. ${ }^{817}$ In diesem Kontext wird letztendlich weniger Gewicht auf die prozessstrukturelle Förderung einer interaktiven und ,polyfonen“ Wahrheitserforschung als auf die autoritative Amtsaufklärung des Sachverhalts gelegt. Die richterliche Sachaufklärung soll nach gegenwärtigem deutschem Prozessverständnis dergestalt vonstattengehen, dass gleichzeitig prozessökonomische Prioritäten wahrgenommen und übergeordnete Fairnessbestimmungen respektiert werden; die Relativierung

816 Roxin/Schünemann, Strafverfahrensrecht, § 44 Rn. 79, bemerken u.a. Folgendes zur richterzentrierten Ausgestaltung der deutschen Hauptverhandlung und ihren möglichen Konsequenzen: ,In der Tat wirft in unserer Hauptverhandlung die Stellung des Vorsitzenden, der allein die Verhandlung leitet, den Angeklagten vernimmt und die Beweisaufnahme durchführt, manche Probleme auf. Da er sein Vernehmungskonzept im Wesentlichen anhand der Ermittlungsakten, also des Anklagematerials, aufbauen muss, wird er kraft des inertia-Effekts [...] unbewusst in die Sichtweise der Anklagebehörde hineingedrängt und verliert meist die für die Urteilstätigkeit erforderliche kritische Distanz zu den Ermittlungen der StA. Auch ist es nicht glücklich, dass der inquirierende Richter durch die Pflicht, sich um die Überführung des schuldigen Angeklagten zu bemühen, mit psychologischer Notwendigkeit zum Widerpart des Angeklagten wird. Der Vorsitzende muss ihm unbequeme Fragen stellen, Widersprüche aufzudecken versuchen und sich einer möglichst erfolgreichen Vernehmungstaktik bedienen. Beim Angeklagten entsteht dadurch leicht der wegen des Urteilsperseveranzeffekts nicht grundlose Anschein, er habe es mit einem Gegner zu tun, und die Hauptverhandlung droht zu einem bloßen Aktennachvollzug zu degenerieren. Indem ein und derselbe Richter (bzw. Richterkollegium) alle Machtpositionen auf sich vereinigt, die in anderen Modellen auf verschiedene Rollen verteilt sind (Leitung der Verhandlung, Beweisaufnahme, Schuldspruch, Strafzumessung), entsteht eine an die Figur eines absoluten Herrschers erinnernde Gewaltenhäufung, die [...] zur rechtsstaatlichen Achillesferse des deutschen Strafprozessmodells gesteigert wird [...].“ Ausführlich Roxin, in: Lüttger (Hrsg.), Probleme, S. 53-61. Siehe auch zu früheren Ansichten zusammenfassend Weißmann, Stellung, S. 11-24. Vgl. zur Reformbedürftigkeit u.a. auch Schroeder/ Verrel, Strafprozessrecht, Rn. 195.

817 Vgl. Gaede, StV 2012, 51 (53-54, 58-59). 
der Letzteren, sobald dies erforderlich wird, entspricht allerdings einer modernen Tendenz in der Verfahrenspraxis.

Anstelle eines absoluten Verhaftetbleibens in den jeweiligen traditionellen Beweisverfahrensstrukturen kann sich eine wenigstens leichte „Durchmischung“ der Rollen insbesondere durch die Zunahme der kommunikativen und unmittelbar interaktiven Elemente bei den Beweisführungen nicht nur in Deutschland, sondern auch in England für die Optimierung der Sachaufklärungsvorgänge eventuell als effektiver erweisen. Eine solche Entwicklung kann sich, wie gesehen, schon auf die Bestimmung des Umfangs der Beweiserhebungen beziehen. Von ihr können darüber hinaus die Möglichkeiten und Behelfe zur gegenseitigen innerprozessualen „Kontrolle“ des beweisbezogenen Verhaltens der Prozessbeteiligten und Richter im Hauptverfahren betroffen sein.

Die Vorgänge zur kontinuierlichen partizipatorischen Erörterung der Beweislage bzw. der jeweils anzuwendenden Beweisnormen und ihrer möglichen Alternativen (z.B. mit Blick auf die Unmittelbarkeits- und Beweisverbotsbestimmungen und ihre Umgehung, die Voraussetzungen des Sachbeweises oder die Verwendung von technischen Vernehmungs- und Zeugenschutzmaßnahmen) sind unter diesem Blickwinkel ebenfalls neu zu prüfen. Die Abkehr von zuvor extrem förmlichen Rollenverteilungen und Funktionstrennungen und die Hinwendung zu einer gezielt freieren und mehrseitigeren beweisbezogenen Kommunikation bzw. Auseinandersetzung zwischen den zentralen (richterlichen und nicht richterlichen) Prozessakteuren sollen dabei weiter im Vordergrund stehen. Die Erwägungen zur „Rebalancierung“ der Exzesse der traditionellen Beweisführungssysteme sollen sich aber auch konkret auf die Methoden der maßgebenden Beweiserhebungen und -prüfungen in der Hauptverhandlung beziehen.

\section{b) Zu den Vernehmungsstrukturen}

Insbesondere erscheint es nach den vorangegangenen Ausführungen für beide Verfahrenssysteme sinnvoll, die Vernehmungen der Beweispersonen in der Hauptverhandlung allseitig in partizipatorischerer Weise, also unter stärkerer Mitwirkung gleichzeitig der Richter und der Prozessbeteiligten, auszugestalten. Zunächst ist für die wirksame Anwendung derartiger Verfahrensformen, wie im Vorangehenden beschrieben, die gute informatorische Vorbereitung aller aktiv wirkenden Prozessakteure notwendig. Eine Kombination der englischen und der deutschen Vernehmungsformen kann des Weiteren eventuell neue, effektivere Aufklärungswege eröffnen. So kann die Vernehmung einer Beweisperson allgemein damit beginnen, dass die Letztere über ihre Sachverhaltskenntnis zunächst im Zusammenhang berichtet. $^{818}$ Unnötige inhaltliche Fragmentierung, Verwirrung in Bezug auf die

818 Vgl. $\S 69,72$ StPO. Vgl. auch Roxin, in: Lüttger (Hrsg.), Probleme, S. 60. 
eigentliche Reichweite der gewollten Aussage und mögliche Manipulationen des Beweismittels seitens der Vernehmungsperson lassen sich somit bei der mündlichen „Erstaufführung“ der betreffenden Beweisinformation vor Gericht leichter vermeiden. ${ }^{819}$ Danach kann das Verhör der Beweisperson in Form ihrer unmittelbaren Befragung durch die zentralen Prozessbeteiligten, vor allem durch die Anklage(-behörde) und die Verteidigung, ${ }^{820}$ folgen. ${ }^{821}$

Um eine solide Basis für die weitere Prüfung der Aussagen bereitzustellen, ist es sinnvoll, dass der Verfahrensbeteiligte bzw. der für ihn handelnde Anwalt, der die Beweisperson in irgendeiner Weise erstmals benannt hat, mit den Befragungen beginnen kann. Anschließend ist die Beweisperson durch die übrigen Verfahrensbeteiligten zu vernehmen. Zusatz-, Ergänzungs- oder Klarstellungsfragen durch den/die (urteilsfindenden wie auch nicht-urteilsfindenden) Richter zur Förderung einer präziseren Sachaufklärung sollen jederzeit, am besten aber im Anschluss an die Befragungen durch die Prozessbeteiligten, möglich sein. Der Richter soll jedenfalls auch die Möglichkeit haben, in Fällen, in denen die Prozessbeteiligten auf die eingehende Beweisprüfung völlig oder teilweise verzichten, die Vernehmung der betreffenden Beweisperson zu übernehmen. Soweit es sich darüber hinaus um Beweispersonen handelt, die der Richter selbst zur Aussage aufgerufen hat, ist es entsprechend sinnvoll, dass diese zuerst vom Richter und anschließend von den übrigen Prozessbeteiligten vernommen werden. Jedem zentralen richterlichen oder nicht richterlichen Beteiligten muss in allen Fällen die Gelegenheit gegeben werden, in sinnvoller und prozessökonomischer Weise Ergänzungs- oder Widerlegungsfragen zu stellen und Beweiskommentare (sogar nach jeder einzelnen Beweiserhebung) abzugeben.

Die Einführung eines solchen ,gemischten“ Vernehmungstyps kann nun in beiden Ländern die mehrseitige Beleuchtung der jeweiligen Tatsachenfragen sowie gleichzeitig die aktive Präsenz eines richterlichen Garanten der allumfassenden Wahrheitserforschung gewährleisten und somit möglicherweise zu präziseren und

819 Vgl. Schünemann, FS für Meyer-Gossner, S. 389-390.

820 Genauere Prozesskonstruktionen, die auch die Möglichkeiten zur aktiven Beteiligung des Opfers bei den Beweiserhebungen einbeziehen sollen, werden an dieser Stelle, wie schon im Rahmen der Überlegungen zu den Idealtypen in der vorliegenden Arbeit bestimmt worden ist, nicht berücksichtigt.

$821 \mathrm{Zu}$ den Vorteilen des unmittelbaren (Kreuz-)Verhörs des Zeugen durch die Prozessbeteiligten siehe auch Gaede, StV 2012, $51(55,59)$. Siehe auch die früheren Ansichten dazu und zu den möglichen Nachteilen mit Blick auf das deutsche Strafverfahren sowie zu anderen deutschen Reformmodellen, insb. zum „Wechselverhörmodell“, und zu den nicht durchgesetzten Vorschlägen zur Einführung eines nicht urteilsfindenden, ausschließlich die Durchführung der Beweisaufnahme übernehmenden Verhandlungsleiters bei Weißmann, Stellung, S. 25-40, 50-53, 75-85. Eingehend zum „Wechselverhör“ und den zusammenstehenden Reformvorschlägen für das deutsche Hauptverfahren Roxin, FS für SchmidtLeichner, S. 146-157. 
zuverlässigeren Wahrheitsergebnissen führen. Technische Angelegenheiten, wie etwa die vorherige Bestimmung der genauen Reihenfolge der Beweiserhebungen und Vernehmungen, brauchen nicht im Zentrum der relevanten Erwägungen zu stehen. Die Differenzierung zwischen Belastungs- und Entlastungszeugen lässt sich dabei freilich de facto in allen Verfahrenssystemen nicht vermeiden; derlei Unterscheidungen sollen aber den förmlichen Ablauf und die Methode der Beweisprüfungen nicht beeinflussen.

Für die Zwecke der Sachaufklärung soll es letztendlich genügen, wenn der verfahrensleitende Richter bei der Bestimmung der Reihenfolge der Beweiserhebungen je nach Einzelfall nach Notwendigkeits- und Zweckmäßigkeitskriterien und, wenn nötig, nach Anhörung der Prozessbeteiligten entscheiden kann. Auf die technischen Besonderheiten, die sich im Fall der Vernehmung des Angeklagten ergeben können, ist aber im Rahmen der detaillierten Planung der Vernehmungsstrukturen mit Vorsicht zu achten; dabei ist besonderes Augenmerk auf die Tatsache zu legen, dass im geltenden englischen Verfahren der Angeklagte nach seiner anfänglichen Einlassung zur Schuldfrage nur als Verteidigungszeuge aufgerufen werden kann, während er im deutschen Verfahren zwar nicht als Zeuge i.e.S. gilt, seine Einlassung jedoch meist von zentraler beweisprozessualer Bedeutung ist.

Darüber hinaus kann sich, wie gesehen, bei der inhaltlichen Ausgestaltung der Vernehmungen, etwa in Bezug auf die zulässige Reichweite der Glaubwürdigkeitsfragen, das Verbot von Suggestivfragen und die Benutzung von Vorhalten als Vernehmungsbehelf, eine Reihe von Problemen ergeben. ${ }^{822}$ Eine eingehende Auseinandersetzung mit diesen hauptsächlich praktischen Problemen sowie mit den Grenzen des erlaubten Handelns sämtlicher Prozessakteure und des diesbezüglichen Entscheidungsspielraums des Richters ist an dieser Stelle nicht möglich. Die effektive rechtspolitische Beantwortung dieser Fragen erfordert in allen Fällen die Durchführung selbstständiger empirischer und prozess-psychologischer Forschungen.

Es lässt sich nicht leicht feststellen, in genau welcher Art und Weise die Befragungen seitens des Richters sowie seitens der Verfahrensbeteiligten erfolgen müssen, um bessere Aufklärungsergebnisse zu erzielen. Noch dazu darf bei den rechtspolitischen Diskussionen über die Vernehmungsformen und -methoden das (menschenrechtliche) Erfordernis, die Interessen der Beweispersonen zu schützen, nicht unberücksichtigt bleiben. Notwendig erscheint jedenfalls sowohl im englischen als auch im deutschen Verfahrenssystem die umfassende Verankerung des Verbots von Vernehmungspraktiken, die nicht nur entehrend gegenüber der Beweisperson wirken können, sondern auch reine Fang-, Verwirrungs- und Verdunkelungsfragen

822 Siehe unter Teil 2, II.D.2.c)bb), Teil 2, III.D.2.c)bb), Teil 2, IV.D.2.c)bb). 
zum Gegenstand haben und somit die Vollständigkeit und Zuverlässigkeit des Aussageergebnisses gefährden können. ${ }^{823}$

Solche „missbräuchlichen“ Vernehmungspraktiken können überall von allen an der Sachaufklärung mitwirkenden Akteuren, d.h. auch von den Richtern, bewusst oder weniger bewusst angewandt bzw. begünstigt werden. Auch deswegen ist es in prozessstruktureller Hinsicht sinnvoll, dass die Vernehmungen in der Hauptphase in den meisten Fällen zunächst durch die Verfahrensbeteiligten bzw. die Parteien durchgeführt werden sollen. Ein einseitiges Prozessverhalten seitens der Letzteren wird nämlich in der Praxis in gewisser Weise immer erwartet - sowohl was das Vorbringen der ethisch-rechtlich zur Objektivität verpflichteten, aber gleichzeitig die Beweislast tragenden Anklageanwälte in England, als auch was das Vorbringen der gesetzlich durchweg zur strikten Objektivität verpflichteten, gleichzeitig jedoch die staatliche Klage vertretenden und somit die Strafverfolgungsaufgaben eigentlich fortführenden Staatsanwaltschaft in Deutschland betrifft. Die unmittelbare Gegenüberstellung der Beweisthesen und -praktiken der nicht richterlichen, am Verhandlungsergebnis jedenfalls überaus interessierten Prozessbeteiligten kann zumindest schneller zur Feststellung bestehender Antithesen und darüber hinaus zur Entdeckung möglicher Verschleierungs- bzw. Missbrauchsversuche führen. Der Richter kann dabei seinerseits möglichst unbeeinflusst jederzeit intervenieren und die Einhaltung der Prozess- und Fairnessregeln sowie der materiellen Beweiszulassungsregeln sicherstellen. Das frühzeitige persönliche Eingreifen des Richters in die Beweiserhebungen kann dagegen diese grundlegenden richterlichen Aufgaben beeinträchtigen. Ein „routiniertes“, ${ }^{824}$ meistens durch die Kenntnis der Akten oder durch das Anklagevorbringen einseitig beeinflusstes richterliches Eingreifen kann allgemein negative Auswirkungen auf die ganze Sachaufklärung haben.

Dagegen kann ein sich aus den Vernehmungen zunächst zurückziehender Richter die Beweisinformationen, die vor ihm im Zusammenhang oder im Wege der kontradiktorischen Verhöre durch die Prozessbeteiligten präsentiert werden, ,aus sicherem Abstand" mit Blick auf mögliche Widersprüche und logische Lücken prüfen. Außerdem können die eventuell mitwirkenden Berufs- und Laienrichter bzw. die jurors die Beweiserhebungen zunächst unbeeinflusst von den erfahrungsgemäß meist autoritativ ${ }^{825}$ wirkenden Beweisprüfungen des Vorsitzenden verfolgen. In allen Fällen muss aber der Richter in der Lage sein, die zur Sachaufklärung erforderlichen Zusatz- oder Klarstellungsfragen zu stellen oder auch in Fällen von erheblich mangelhaften Vernehmungsergebnissen die weiteren Beweisführungen

823 Vgl. insb. am Beispiel des englischen Kreuzverhörs auch in empirischer Hinsicht Jackson, in: McConville/Wilson (Hrsg.), Handbook, S. 344-346; McEwan, Evidence, S. 13-16.

${ }^{824}$ Vgl. Doran, in: Doran/Jackson (Hrsg.), Judicial Role, S. 13. Siehe auch unter Teil 1, II.C.2.e)bb)-cc).

825 Vgl. Doran, in: Doran/Jackson (Hrsg.), Judicial Role, S. 12. 
selbst zu übernehmen; dies soll aber in den herkömmlichen Vernehmungssituationen idealerweise erst nach den Verhören durch die Prozessbeteiligten geschehen. ${ }^{826}$

\section{c) Zu den Schlussvorträgen und den richterlichen Schlussdarstellungen}

Zur Beweisführung i.e.S. gehören die Schlussvorträge der Verfahrensbeteiligten eigentlich nicht. Die Schlussvorträge und die darin enthaltenen Wertungen des Beweismaterials sind gleichwohl, insbesondere in komplexen Straffällen, systemübergreifend von erheblicher Bedeutung für die Urteilsfindung. ${ }^{827}$ Sie finden grundsätzlich mündlich am Hauptverhandlungsende statt und müssen sowohl im englischen als auch im deutschen Verfahrenssystem in ähnlicher Weise erfolgen. Beide Verfahrenssysteme legen darüber hinaus gleichartige inhaltliche Grenzen fest und verfügen über richterliche Kontrollmechanismen zur Sicherstellung einer beweiskonsistenten Beurteilung der Sachfragen und Antragstellung seitens der Anwälte.

Ausschließlich im englischen jury-Verfahren können zusätzlich die an die Schlussvorträge anschließenden öffentlichen und grundsätzlich mündlichen Zusammenfassungen (summing-up) der Rechts- und Tatsachenfragen seitens des Richters von zentralem Wert für die Wahrheitsfindung sein. Diese Zusammenfassungen sollen nämlich der Instruktion und Unterstützung der Geschworenen bei ihren Aufgaben dienen. Für ihre zweckmäßige und lückenlose Vorbereitung kann der Richter verlangen, dass die Anwälte beider Parteien an deren Ausformulierung mitwirken. ${ }^{828}$

Eine entsprechend modifizierte Anwendung dieser richterlichen summing-upPraxis kann eventuell auch bei anderen Gerichtsverfahrensarten in England wie auch in Deutschland, insbesondere in Verfahren mit Berufsrichtern oder mit gemischten Spruchkörpern, der eindeutigen Aufklärung des Sachverhalts effektiver dienen. Solche möglichst neutralen und deskriptiven Schlussausführungen seitens des verfahrensleitenden (in der Regel erfahrenen) Richters könnten nämlich in öffentlicher und transparenterer Weise den anderen Berufs- und vor allem Laienrichtern im Vorfeld der nicht-öffentlichen Beratungs- und Beweiswürdigungsphase schlüssige Zusammenfassungen wichtiger Rechts- und Beweisthemen liefern. Vor allem könnte aber hierdurch den übrigen zentralen Prozessbeteiligten die Gelegenheit gegeben werden, an einer letzten formalen Erörterung der Beweislage teilzunehmen. Konkreter: es sollte dem Vorsitzenden Richter zunächst erlaubt werden, im Anschluss an die (anwaltlichen) Schlussvorträge neutrale Hinweise zu den

826 Vgl. Doran, in: Doran/Jackson (Hrsg.), Judicial Role, S. 15.

827 In diesem Sinne hat z.B. Dreher, FS für Bockelmann, S. 51, Folgendes bemerkt: „Dennoch kann die dialektische Auseinandersetzung zwischen Staatsanwalt und Verteidiger, das in ihren resümierenden Plädoyers gezeichnete Bild des Falles eine beträchtliche Hilfe für den Richter bedeuten.“

828 Siehe unter Teil 2, II.D.2.b), Teil 2, III.D.2.b), Teil 2, IV.D.2.b). 
wichtigsten (entscheidungserheblichen) und komplexen (Beweis-)Fragen zu geben; hierbei muss darauf geachtet werden, dass der Richter faktisch keinen zweiten „Anklagevortrag“629 einseitig zulasten des Angeklagten hält. Auch deswegen sollte den Prozessbeteiligten danach unbedingt das Wort erteilt werden, sodass sie Bemerkungen $\mathrm{zu}$ den richterlichen Schlussausführungen machen und Erklärungen abgeben können.

Mögliche Missverständnisse, Widersprüche, Lücken und Beweismängel sollten dadurch zum letzten Mal innerhalb der Hauptverhandlung zum Ausdruck gebracht und diskutiert werden. Durch die Einführung eines solchen kommunikativen ${ }^{830}$ Abschlussvorgangs in sämtliche Beweisverfahren wird es den Anwälten ermöglicht, einen besseren Einblick in die Ansicht des Richters in Bezug auf die bereits dargestellten Beweisprobleme zu gewinnen und eventuelle Endargumente entsprechend daran auszurichten; die Richter werden ihrerseits in die Lage versetzt, ihre bisherige Ansicht falls nötig rechtzeitig zu vervollständigen. Die Beweiserhebungen im Hauptverfahren, die nach den vorliegenden Reformüberlegungen sowohl in England als auch in Deutschland kontinuierlich in allseitig partizipatorischer bzw. kommunikativerer Weise stattfinden müssen, können somit mit einer zusammenfassenden „dialektischen“ ${ }^{\text {“831 }}$ Erörterung der zentralen Tatsachen- und Beweisfragen unmittelbar vor Beginn der Urteilsberatungen abgeschlossen werden.

\section{Rechtspolitische Schlussbetrachtungen: Leitsätze zur „Rebalancierung“ der Beweisführungssysteme}

\section{Vorbemerkungen}

Die systematische Betrachtung der Ergebnisse der vorangehenden Bewertungen und Reformvorschläge kann in die zusammenfassende Formulierung von Leitsätzen münden, die inter alia von den Rechtssystemen als Ansatzpunkte für zukünf-

${ }^{829}$ Vgl. Doran, in: Doran/Jackson (Hrsg.), Judicial Role, S. 13, 16-17; Wolchover, [1989] Crim.L.R., 781 (791).

830 Vgl. in Bezug auf die Zunahme der kommunikativen Interaktion der Akteure schon im Laufe der Vernehmungen und der weiterhin vom Richter beherrschten deutschen Beweisaufnahme die früheren Reformforderungen von Schünemann, GA 1978, 161 (177183), die insb. die deutliche inhaltliche Protokollierung der Zeugenaussagen, die grundsätzlich darauf basierende Anfertigung von vorläufigen richterlichen „BeweiswürdigungsZwischenstatements" zum Verlesen innerhalb der Hauptverhandlung und die Möglichkeiten zur Stellungnahme und Kontrolle seitens der Prozessbeteiligten betrafen; kritisch dazu Roxin, FS für Schmidt-Leichner, S. 152, 155-157.

831 Vgl. zur Verwendung dieses Begriffs im epistemologischen Kontext und unter Rücksichtnahme auf die ,adversatorischen“ und die ,inquisitorischen“ Wahrheitserforschungsmethoden Jackson, Cardozo L. Rev. 10 (1988), 475 (522-527); Jackson, MLR 51 (1988), 549 (561-568). Vgl. auch im konkreten Bezug auf die Rollenverteilungen im juryVerfahren Jackson/Doran, MLR 60 (1997), 759 (775-778). 
tige rechtspolitische Programme im betreffenden Themenbereich berücksichtigt werden können. Hierbei geht es weder um die weitere Bestimmung der ,,adversatorischen“ und der ,inquisitorischen“ Idealtypen, die primär für die Zwecke der analytischen Rechtsvergleichung eingesetzt wurden, noch um den Versuch ihrer abstrakt-theoretischen Mischung. Auch die Konstruktion eines rechtstechnisch detaillierten „Modells“632 für die prozessstrukturelle (Neu-)Planung des englischen, des deutschen oder eines anderen Beweisführungssystems wird vorliegend nicht angestrebt. Genausowenig steht die komplette Ersetzung der einzelnen geltenden Beweisverfahrensstrukturen bzw. ihre Harmonisierung oder die Durchführung umfassender Rechtstransplantationen wie auch die Ausarbeitung von verbindlichen Mindestlösungen für sämtliche Verfahrensordnungen im Vordergrund dieser Schlussbetrachtungen. Der Rahmen der vorliegenden Untersuchung ließ es, wie schon erläutert, von Anfang an nicht zu, mit Sicherheit festzustellen, welcher Prozesstyp bzw. welches konkrete Beweisverfahrenssystem bessere Wahrheitsergebnisse im streitigen Hauptverfahren, also präzisere Sachaufklärungen (besonders im Sinne der Verurteilung der wirklich Schuldigen) garantieren kann. ${ }^{833}$ Deshalb befasst sich diese Arbeit, vereinfacht gesagt, eher mit der Darlegung von einheitlichen maßgebenden Ansätzen für die Planung weiterer systemübergreifender Optimierungsstrategien. ${ }^{834}$

Genauer: Vor dem Hintergrund der „Vorteile“ und „Nachteile“ der theoretischen und angewandten Wahrheitserforschungsstrukturen, die in den abstrakten Überlegungen in Teil 1 und in den wertenden Betrachtungen in Teil 2 festgestellt wurden, ist es möglich, neben den bereits dargelegten konkreten Reformvorschlägen, die gegebenenfalls das englische oder das deutsche Verfahrenssystem betrafen, auch einheitliche Leitsätze festzulegen. Diese sollen zur Ermöglichung der stichhaltigen Konstruktion von weiteren Reformmodellen bzw. zur eigentlichen Durchführung von erforderlichen Teilreformen der angewandten Wahrheitserforschungsmethoden beitragen. Die diesbezüglichen Erwägungen beziehen sich primär auf das englische und das deutsche Rechtssystem; sie können aber möglicherweise auch weitere, in prozessstruktureller Hinsicht ähnliche und sich innerhalb des theoretischen Spektrums zwischen dem ,adversatorischen“ und dem ,inquisitorischen“ Modell befindende Rechtsordnungen betreffen. Die Überlegungen orientieren sich allgemein an der zielgerichteten Entwicklung von allseitig interaktiveren und kommunikativeren Verfahrensformen zum Korrigieren oder zur „Rebalancierung“ der Exzesse sowohl des parteien- als auch des richterzentrierten Beweisführungssystems.

832 Zur Bildung von Modellen in der Strafverfahrenstheorie und zu den diversen Modellkategorien siehe unter Teil 1, II.B.1.a).

833 Siehe auch unter Teil 1, II.C.2.f), Teil 2, V.A.

834 Es wäre auch relativ naheliegend, diese Ansätze mit den Grundsätzen oder Grundelementen eines vereinfachten best practices-Richtlinienprogramms aus dem Wirtschaftsbereich zu vergleichen; vgl. zu einer einführenden Definition des technischen Begriffs ,best practice“ Kanzenbach, Implementierung, S. 145. 


\section{Leitsätze für Reformstrategien}

Im unmittelbaren Zusammenhang mit den vorherigen ausführlichen Analysen und Bewertungen können nun folgende einheitliche Leitsätze aufgestellt werden, die systemübergreifend für die Planung weiterer Optimierungsprogramme zu beachten sind:

- Unabhängig von der Bezeichnung der Anklage(-behörde) und der Verteidigung als Parteien oder Verfahrensbeteiligte und zunächst unabhängig davon, ob und inwieweit sie Dispositionsbefugnisse über die Beweisführungen haben, müssen die ethisch-rechtlichen Verpflichtungen auf beiden Seiten in umfassender Weise geregelt sein; dies soll besonders die Anklageanwälte, die auch im Hauptverfahren heute in der Praxis meistens die staatliche Strafverfolgung fortführen, und ihre Objektivitätspflicht betreffen.

- Wie die Rechtslage im englischen sowie auch im deutschen Justizsystem gezeigt hat, müssen die notwendigen Maßnahmen getroffen werden, um Rechtmäßigkeit, Transparenz, Objektivität und möglichst auch Waffengleichheit insbesondere bei der Vorbereitung der maßgebenden Beweisführungen zu gewährleisten. Besonderes Gewicht muss hierbei auf die außergerichtlichen Beweisaktivitäten, wie etwa den vorgerichtlichen Umgang der Hauptakteure mit den Beweispersonen und anderen Beweismitteln, gelegt werden.

- Zur umfassenden Bestimmung der Beweiserhebungen muss vor allem der Anklagevertreter in objektiver Weise beitragen; dies kann insbesondere durch die frühzeitige Offenlegung des ihm zur Verfügung stehenden Beweismaterials geschehen sowie dadurch, dass er die Beweismittel, die nach seiner Kenntnis entscheidungsrelevant sind, möglichst vollständig vorbringt bzw. allseitig zur Verfügung stellt.

- Gleichzeitig muss der Richter über alle notwendigen Prozessmittel verfügen, um die möglichst transparente Vorplanung, Kontrolle und Vervollständigung der Beweisbestimmungen sicherstellen zu können. In Verfahrensordnungen, welche die präzise Aufklärung der streitigen Sachverhalte als ein zentrales Anliegen ausdrücklich anerkennen, muss der neutrale Richter jedenfalls in der Lage sein, die Vollständigkeit und Ordnungsgemäßheit der maßgebenden Beweiserhebungen zu gewährleisten.

- Insbesondere mit Blick auf einfach zu manipulierende Beweismittel wie den Expertenbeweis, der von erheblicher diagnostischer Bedeutung für die Mehrheit der im Wege eines streitigen Hauptverfahrens aufzuklärenden Straffälle sein kann, darf die Bestimmung der Beweiserhebungen nicht zum „Opfer“ einer extremen Beweisautonomie der amtlichen und nicht-amtlichen Prozessbeteiligten werden; sie darf aber auch nicht eine ausschließlich richterliche Angelegenheit darstellen. Es müssen Prozessformen gefördert werden, welche die grundsätzlich gleichzeitige unmittelbare Mitwirkung von Richtern und Prozessbeteiligten bei der objektiven Auswahl und Instruktion eines oder mehrerer Sachverständiger als Leitbild haben. 
- Für die Erzielung zuverlässigerer Wahrheitsergebnisse ist es aber auch allgemein wichtig, dass schon im Vorfeld der Hauptverhandlung und darüber hinaus partizipatorische Erörterungen des Richters mit den Prozessbeteiligten hinsichtlich der allgemeinen Ausgestaltung der Beweislage sowie vor allem hinsichtlich streitiger Beweisoffenlegungs- und Beweiszulassungsfragen regelmäßig stattfinden können. Anträge und Anregungen der Verfahrensbeteiligten sind in diesem Rahmen gründlich zu berücksichtigen.

- Die faktischen Schwierigkeiten einer transparenten, objektiven, umfassenden bzw. unvoreingenommenen Bestimmung der in der Hauptverhandlung zu untersuchenden Beweislage sind u.a. dadurch zu kompensieren, dass sowohl dem Gericht als auch der Anklage und der Verteidigung die Möglichkeit gegeben wird, weitgehend selbstständig und unmittelbar - zunächst also ohne gerichtliche Zwischenentscheidung hinsichtlich des materiellen Werts der vorgebrachten Beweismittel Beweise in das Hauptverfahren einzuführen und somit den Umfang der maßgebenden Beweiserhebungen gleichwertig mitzubestimmen.

- Freilich müssen überall auch die notwendigen Prozessbehelfe vorgesehen sein, die es dem Richter bzw. dem Gericht aufgrund des Einwands eines Hauptakteurs oder von Amts wegen ermöglichen, die Einhaltung der Unmittelbarkeits-, Beweisausschluss- und Beweiserhebungsregeln während der Beweisbestimmungen bzw. Beweiserhebungen effektiv zu kontrollieren.

- Hinsichtlich des Ausschlusses von unzulässigen und „verbotenen“ Beweisinformationen aus dem Verfahren muss das Gericht zur Vermeidung der Beeinflussung des weiteren Beweisverfahrens die diesbezüglichen Entscheidungen so früh wie möglich und nach Anhörung der Prozessbeteiligten, jedoch ohne vorherige vollständige Erhebung der relevanten Beweise treffen.

- Die Möglichkeiten zur umfassenden und frühzeitigen Informierung aller richterlichen und nicht richterlichen Hauptakteure über die vorhandenen Beweismittel und die Vorverfahrensergebnisse müssen weiterhin im Vordergrund der Erwägungen zur Beweisoffenlegungsproblematik stehen. Die faktischen Ungleichheiten zwischen den Akteuren, die oft aufgrund ihrer unterschiedlichen institutionellen und prozessualen Stellung entstehen, müssen aber dabei besonders beachtet werden.

- Die beeinflussende Wirkung der Kenntnis der Vorverfahrensakten auf die Verfahrensleitung und Beweisaufnahme ist durch die weitere Entwicklung eines Prozessverständnisses und Rechtsumfelds zu kompensieren, das der umfangreichen sachlichen Verwendung der vorgerichtlichen Beweisinformationen durch den Richter im Hauptverfahren entgegenwirkt und statt dessen die Verstärkung der Prozessformen zur unmittelbaren kontradiktorischen Beteiligung der Anwälte an den maßgebenden Beweiserhebungen fördert.

- Auf die in der Praxis oft notwendigen Vorhalte alter Vernehmungsprotokolle braucht in diesem Zusammenhang nicht unbedingt verzichtet zu werden; die pro- 
zess-psychologischen Schwächen des Vorhalts als Vernehmungsmittel dürfen dabei allerdings nicht unberücksichtigt bleiben. ${ }^{835}$

- Neben der Verstärkung der Prozessgarantien und richterlichen Befugnisse zur Sicherstellung einer allumfassenden Sachaufklärung müssen einerseits interaktive und kontradiktorische „Diskursmechanismen“ im Hauptverfahren zum Zweck der vielseitigen diagnostischen Beleuchtung der diversen Sachverhaltsaspekte weitere Verbreitung finden. Andererseits sollte eine graduelle Abkehr von einem kurzsichtigen oder unkritischen starren Festhalten an den traditionellen Prinzipien der Beweisautonomie der Prozessbeteiligten bzw. der richterlichen Amtsaufklärung und insbesondere von ihren extremen Ausprägungen und Formalitäten vollzogen werden.

- Insbesondere in Bezug auf die Erhebung des Personalbeweises erweist sich ein „gemischter“ Vernehmungstyp als grundlegender Orientierungspunkt. Im Rahmen einer solchen Vernehmung muss die Beweisperson über ihre Sachverhaltskenntnis zunächst im Zusammenhang berichten. Danach müssen in der Regel die Verhöre durch die Prozessbeteiligten und insbesondere zuerst durch die Seite, welche die Beweisperson erstmals benannt hat, folgen; nur die ursprünglich durch den Richter geladenen Personen sind zuerst von ihm zu vernehmen. Grundsätzlich müssen sich also der verfahrensleitende Richter sowie die mitwirkenden Berufs- und Laienrichter bzw. die jurors zumindest am Anfang aus den Verhören zurückziehen, um unbeeinflusst die vor ihnen präsentierten Beweisinformationen mit Blick auf mögliche Widersprüche und logische Lücken prüfen zu können. Der Richter soll jedoch jederzeit, im Normalfall am besten aber direkt im Anschluss an die Befragungen durch die Prozessbeteiligten, in der Lage sein, Zusatz-, Ergänzungs- oder Klarstellungsfragen zu stellen bzw. in Extremfällen zur Sicherstellung einer vollständigen Beweisprüfung sogar die Vernehmung selbst zu übernehmen.

- „Missbräuchliche“ und ,feindliche“ Vernehmungspraktiken seitens der richterlichen und nicht richterlichen Prozessakteure, die nicht nur entehrend gegenüber der Beweisperson wirken können, sondern auch reine Fang-, Verwirrungs- und Verdunkelungsfragen zum Gegenstand haben und somit die Vollständigkeit und Zuverlässigkeit des Aussageergebnisses gefährden können, müssen wirksam bekämpft werden. Auch deswegen darf der Richter im Normalfall in die Anfangsstadien der jeweiligen Beweiserhebung nicht persönlich eingreifen, sondern soll in distanzierter Weise, unbeeinflusst von seiner Kenntnis des Vorverfahrensmaterials und ,unroutiniert“ zunächst für die Einhaltung der materiellen Regeln zur umfassenden und fairen Beweisführung sorgen.

- Schließlich muss zum Zweck einer möglichst präzisen, zuverlässigen, lückenund widerspruchsfreien Sachaufklärung und Urteilsfindung eine abschließende partizipatorische Erörterung der wichtigsten Beweisthemen vorgesehen sein. Eine

835 Dazu Schünemann, in: Schroeder/Kudratov (Hrsg.), Hauptverhandlung, S. 101. 
derartige Erörterung soll nach dem Ende der Beweisführungen i.e.S. und insbesondere im Anschluss an die Schlussvorträge der Prozessbeteiligten und vor Beginn der Urteilsberatungen nur unter Bezugnahme auf die während der Beweisaufnahme angesprochenen Tatsachenfragen und geprüften Beweismittel stattfinden. Zunächst soll der Vorsitzende Richter die Möglichkeit haben, mündlich maßvolle neutrale Schlusshinweise zu den wichtigsten Rechts- und Beweisfragen vor den anderen Richtern und Prozessbeteiligten zu geben. Den Prozessbeteiligten ist danach unbedingt das Wort zu erteilen, sodass sie Bemerkungen zu den richterlichen Schlussausführungen machen und Erklärungen hinsichtlich eventueller Missverständnisse abgeben können.

Durch die konkrete Umsetzung dieser Leitsätze soll im Allgemeinen vor allem die möglichst gleichwertige, umfassende und unmittelbare Mitwirkung bzw. die parallele Anhörung aller an der Sachaufklärung primär interessierten Prozessakteure im maßgebenden Beweisverfahren ermöglicht werden. Die dialektische Umgestaltung der gesamten Beweisführungsstrukturen muss letzten Endes im Vordergrund der Überlegungen zur Reform der nationalen Beweisverfahrenssysteme stehen. 



\section{Internationalrechtliche Dimensionen}

\section{Einleitende Bemerkungen zum Analyserahmen}

Die Diskussion der unterschiedlichen Beweisverfahrenstypen und insbesondere der diversen Beweisführungsmethoden und der Optimierungsstrategien zur Erzielung besserer Wahrheitsergebnisse kann sich freilich nicht nur auf die nationalrechtliche Ebene beschränken. Schon die Verwendung der Begriffe ,adversatorisch“ und „inquisitorisch“ sowie die relevante Unterscheidung zwischen beweisprozessualer Parteienautonomie und Richterherrschaft im Erkenntnisverfahren werden oft auch unter internationalrechtlichen Gesichtspunkten betrachtet. In diesem Kontext ist hauptsächlich zwischen zwei Problemkreisen zu unterscheiden: Die erste Problematik betrifft die auf internationaler Justizebene normativ geforderten Typen für das (grundsätzlich nationale) Beweisverfahren (insbesondere die Frage, ob bestimmte Rechtsordnungen bestimmte typisierte Verfahrensstandards einhalten müssen). Die zweite Problematik betrifft die in den internationalen Strafgerichtsbarkeiten konkret anwendbaren (eventuell gemischten oder hybriden) Beweisverfahrensstrukturen. Es handelt sich hierbei um zwei unterschiedliche Ansätze.

Zum einen sind die nationalen Rechtsordnungen durch ihre Strafverfolgungsund Justizorgane in internationalen Rechtshilfe-, Menschenrechts- und Justizorganisationen, wie dem Europarat und ,seinem“ EGMR oder den diversen EU-Institutionen, vertreten. In einem solchen internationalen Umfeld wird die Produktion von innerstaatlich verbindlichen Prinzipien und Regeln bzw. Leitlinien, Mindeststandards oder maßgebenden Gerichtsentscheidungen in gewissem Maße durch die verschiedenen nationalen Vertreter mitbestimmt. Dies kann im vorliegenden Kontext z.B. durch die Förderung von jeweils eigenen Vorstellungen, Werten und Modellen im Hinblick auf die Strafjustizverwaltung und Verfahrensorganisation und durch deren rechtsvergleichende Ausarbeitung geschehen. Die strafverfahrensbezogenen normativen Vorgaben, die im Ergebnis in autonomer Weise aus solchen internationalen „Rechtsordnungen“ wie dem EMRK-Rechtssystem hervorgehen, werden ihrerseits oft sogar als selbstständiges Leitlinienmodell für die weitere Gestaltung des nationalen (Beweis-)Verfahrens der jeweiligen Mitgliedsländer angesehen. ${ }^{1}$

1 So z.B. Jackson, MLR 68 (2005), 737 (747). 
Zum anderen wird in Rechtswissenschaft und juristischer Praxis nicht selten der Ruf nach einem selbstständigen Beweisverfahrensmodell bzw. nach der Entwicklung eines hybriden oder gemischten Verfahrenstypus für die internationalen Strafgerichtsbarkeiten laut. ${ }^{2}$ Nach Weigend lassen sich beispielsweise die relevanten Zusammenhänge folgendermaßen beschreiben:

Gestützt auf menschenrechtliche Grundlagen entwickelt sich im Übrigen ein ,gemeines Recht" des Strafverfahrens aus der Praxis der internationalen Straftribunale [...]. Deren Verfahrensregelungen wirken selbstverständlich nicht unmittelbar auf die Anwendung der deutschen Strafprozessordnung ein, aber sie können aufgrund ihrer internationalen Herkunft sowie der rechts-multikulturellen Zusammensetzung der Gerichtshöfe jedenfalls auf grundsätzliche Akzeptanz jenseits einer einzelnen Rechtsordnung hoffen. Durch die Schaffung und das Funktionieren der internationalen Verfahrensordnungen ist auch neue Bewegung in den alten Wettstreit der Verfahrenssysteme gekommen: Insbesondere die Verfahrensordnung des IStGH weist Elemente sowohl des adversary system auf, das in der englischsprachigen Welt dominiert, als auch des immer noch als, inquisitorisch' apostrophierten kontinentaleuropäischen Strafverfahrens, das durch die beherrschende Stellung des Gerichts im Hauptverfahren gekennzeichnet ist. Durch die Vermischung und gegenseitige Beeinflussung der Verfahrenssysteme eröffnen sich neue Perspektiven für einige strafprozessuale Grundsatzfragen. ${ }^{3}$

Eine erschöpfende Analyse sämtlicher Fragen zu diesen und weiteren relevanten internationalrechtlichen Problemkreisen kann vorliegend nicht stattfinden. In den folgenden Ausführungen werden nur bestimmte Grundaspekte relevanter internationaler Entwicklungen und Perspektiven anhand der EMRK-,,Rechtsordnung“" (unter II.) und des IStGH-Verfahrenssystems (unter III.) konkreter angesprochen.

Die Mindestgarantien und die Fairness- und Mitwirkungsrechte der EMRK sowie ihre Auslegung durch Urteile und Entscheidungen des EGMR spielen in der Mehrheit der europäischen Rechtssysteme (einschließlich, wie gesehen, des englischen und des deutschen), die durch die herrschenden westlichen Verfahrenstraditionen geprägt sind, eine wichtige Rolle auch auf strafprozessualer Ebene. ${ }^{4}$ Im Folgenden werden insbesondere die erga omnes verbindlichen EMRK-Prinzipien und Leitlinien der EGMR-Rechtsprechung, die eventuell Einfluss auf die Ausgestaltung der strafprozessualen Beweisführung in den einzelnen Mitgliedsländern des Europarats haben können, untersucht; dies erfolgt grundsätzlich ohne konkreten Bezug auf Fragen zu ihrer innerstaatlichen Umsetzung.

Darüber hinaus stellt das IStGH-System die Krönung der langjährigen rechtspolitischen Planungen und Entwicklungen im Bereich der internationalen Straf-

2 Dazu u.a. Ambos, Int'l Crim. L. Rev. 3 (2003), 1 (5-7) m.w.N.

3 Weigend, FS für Rissing-van Saan, S. 750-751 (Fußnoten wurden ausgelassen).

4 Siehe unter Teil 2, II.A.1., Teil 2, III.A.1. auch mit Literaturverweisen hinsichtlich der Entstehungsgeschichte und Entwicklung der Konvention, ihrer Stellung im Recht der Mitgliedsländer, der Rechtswirkung der EGMR-Urteile sowie der Prozessgarantien und fair trial-Rechte an sich. Allgemein zur Struktur, zu den Organen und zum Verfahrensrecht des EMRK-Systems u.a. Grabenwarter/Pabel, Menschenrechtskonvention, §§ 6-16. Siehe auch Esser, Europäisches Strafrecht, § 9 Rn. 8-124. 
gerichtsbarkeit dar. ${ }^{5}$ Es handelt sich bei ihm um die gegenwärtig einzige unabhängige, ständige und aktive internationale Einrichtung, die eine hohe Anzahl von Mitgliedsstaaten (einschließlich Deutschlands und des Vereinigten Königreichs) unterschiedlicher Rechtstraditionen aufweist und die unter bestimmten Voraussetzungen die unmittelbare und ressourcenaufwendige internationale Ermittlung von gravierenden Straffällen mit völkerrechtlichem Bezug durchführen kann. Auf der Grundlage der in Teil 1 der Arbeit dargelegten Definitionen der Idealtypen konzentrieren sich die nachfolgenden Erwägungen zum Verfahren vor dem IStGH überwiegend auf zentrale Angelegenheiten, die sich auf die Beweisführungsstrukturen und -methoden zur Aufklärung der in vielerlei Hinsicht komplexen internationalen Sachverhalte beziehen.

\section{EMRK: Verfahrensfairness und Prinzip der ,adversarial proceedings ${ }^{66}$}

\section{A. Eckpfeiler eines fairen Strafverfahrens: Waffengleichheit und kontradiktorische Beweiserhebung}

\section{Einführung: Die Auslegung der EMRK durch den EGMR}

Die Europäische Menschenrechtskonvention und ihre Reform-, Auslegungs- und Anwendungsmechanismen setzen einen internationalrechtlichen Komplex von Mindestgarantien und Rechten ${ }^{6}$ durch, dessen innerstaatliche Umsetzung die Mitgliedsländer des Europarats in Übereinstimmung mit ihren völkerrechtlichen Verpflichtungen zweckgemäß sicherstellen müssen; die Rechtsprechung des Europäischen Gerichtshofs für Menschenrechte steht dabei im Vordergrund. ${ }^{7}$ Die Entschei-

\footnotetext{
5 Siehe zur geschichtlichen Entwicklung der internationalen Strafgerichtsbarkeiten und des internationalen Strafprozessrechts Safferling, International, S. 7-63. Siehe auch Schabas, International, S. 1-27. Zur Zuständigkeit und Organisation des IStGH siehe u.a. Schabas, Introduction, insb. S. 62-205, 369-403. Einführend zum IStGH und zum Verfahrensablauf Esser, Europäisches Strafrecht, § 19; Satzger, Internationales Strafrecht, § 14. Allgemein über die historische Entwicklung und die Grundlagen des Völkerstrafrechts und -verfahrens sowie die internationalen Strafgerichtsbarkeiten Werle, Völkerstrafrecht, Rn. 1-361.

${ }^{6}$ Zur Differenzierung zwischen Abwehrrechten und Verfahrens- bzw. Justizgarantien siehe Grabenwarter/Pabel, Menschenrechtskonvention, § 18 Rn. 1; Satzger, Internationales Strafrecht, § 11, Rn. 26-28.

7 Siehe insb. Art. 1, 19, 32-35, 46-49, 52-55 EMRK. Die (Zulässigkeits-)Entscheidungen des Einzelrichters, der Ausschüsse oder der Kammern sowie die Urteile der Ausschüsse, der Kammern oder der Großen Kammer des EGMR (und ggf. der Europäischen Kommission für Menschenrechte - EKMR) sind in den Amtssprachen (Englisch und/oder Französisch nach Nr. 76 EGMR-Rules of Court) des Gerichtshofs abgefasst und nach Angabe des Namens des Beschwerdeführers, des Entscheidungsdatums, des betroffenen Staates und/oder des Aktenzeichens in der amtlichen HUDOC database http://hudoc.echr.
} 
dungen und Urteile des EGMR legen autonom und einheitlich die zum Teil unbestimmten Rechtsvorschriften und Generalklauseln der EMRK aus und entwickeln ihren Inhalt unter Respektierung der Unterschiede zwischen den Rechtssystemen und unter Berücksichtigung der jeweiligen sozialen Umstände fort. ${ }^{8}$ Sowohl die unmittelbare inter partes-Wirkung der Urteile des Gerichtshofs als auch die erga omnes-Verbindlichkeit der Auslegung der Konvention durch die EGMR-Rechtsprechung und ihre Orientierungswirkung auf die nationalen Rechtsordnungen wurden bereits zusammenfassend behandelt. ${ }^{9}$ Sämtliche Mitgliedsstaaten müssen in allen Fällen, schon nach Art. 1 EMRK, für die effektive und somit einheitliche innerstaatliche Wahrung der Konventionsgarantien sorgen; ${ }^{10}$ in pragmatischer Hinsicht sollen sie sich - nicht zuletzt um eine zukünftige Verurteilung durch den EGMR zu vermeiden - bei der Ausgestaltung ihrer strafrechtlichen Justizordnungen an die Kernbestimmungen der EMRK und die entsprechenden Leitsätze der EGMR-Rechtsprechung halten.

Der EGMR wirkt bei der Auslegung der menschen- und grundrechtlichen Mindestvorschriften der EMRK sowie bei der Vorbereitung und Darlegung der Urteilsgründe und der zugrunde liegenden (allgemeineren) Grundsätze als internationaler Menschenrechtsgerichtshof zunächst unter Berücksichtigung der besonderen Umstände des jeweiligen Einzelfalls; ${ }^{11}$ dabei werden oft rechtsvergleichende Erkenntnisse und Begründungsweisen verwendet. ${ }^{12}$ Die allmähliche Konkretisierung der teilweise unbestimmten Begriffe und (Verfahrens-)Garantien der Konvention erfolgt auf der Basis einer case law-Praxis, ${ }^{13}$ in diesem Rahmen können auch die kontinuierlichen sozialen und rechtspolitischen Veränderungen sowie die traditio-

coe.int/ [Stand: Oktober 2014] abrufbar. Für weitere Informationen zu den amtlichen Rechtsprechungssammlungen, den Datenbanken und den deutschen Fundstellen siehe Peters/Altwicker, Menschenrechtskonvention, S. XXVII-XXVIII. Vorliegend sind grundsätzlich die englischen Texte als unmittelbare Quelle für die wissenschaftliche Auslegungsarbeit herangezogen worden.

8 Vgl. u.a. EGMR Engel a.o. v. the Netherlands, Urt. v. 8.6.1976 (5100/71 a.o.), §§ 8182; EGMR König v. Germany, Urt. v. 28.6 .1978 (6232/73), §§ 88-89. Zur Konvention als „living instrument" siehe u.a. EGMR Tyrer v. the United Kingdom, Urt. v. 25.4.1978 (5856/72), §31; EGMR Soering v. the United Kingdom, Urt. v. 7.7 .1989 (14038/88), $\S 102$. Mehr zur Auslegung der EMRK durch den EGMR bei Esser, Strafverfahrensrecht, S. 848-856; Grabenwarter/Pabel, Menschenrechtskonvention, § 5; Peters/Altwicker, Menschenrechtskonvention, § 2 Rn. 40-45; Satzger, Internationales Strafrecht, § 11, Rn. 19.

9 Siehe unter Teil 2, II.A.1. und insb. Teil 2, III.A.1. m.w.N.

$10 \mathrm{Zu}$ den völkerrechtlichen Achtungs-, Schutz- und Leistungspflichten der Staaten siehe Peters/Altwicker, Menschenrechtskonvention, § 2 Rn. 31-39.

11 Vgl. Art. 19, 45, 46, 53 EMRK.

12 Siehe Grabenwarter/Pabel, Menschenrechtskonvention, §14. Siehe auch zu den rechtsvergleichenden Interpretationsmethoden des EGMR Esser, Strafverfahrensrecht, S. 848-850; ferner Grabenwarter, in: Gamper/Verschraegen (Hrsg.), Rechtsvergleichung, S. $96-114$.

13 Siehe Renzikowski, GS für Keller, S. 199-200. Vgl. beispielsweise die Erwägungen und Abwägungen in EGMR (GK) Gäfgen v. Germany, Urt. v. 1.6.2010 (22978/05), $\S \S 162-188$. 
nellen Unterschiede zwischen den Rechts- und Verfahrenssystemen der Europaratsmitglieder eventuell besser berücksichtigt werden. Durch die Einzelfallentscheidungen werden somit auch allgemeine Leitsätze und Kriterien entwickelt bzw. verfeinert, die allerdings jeweils von den besonderen Fallumständen und entsprechenden nationalen Rechtsproblemen ausgehen. Außerdem findet insbesondere in Bezug auf die Problematik der Verfahrensfairness die ex post-Kontrolle der nationalen Wahrung der Konventionsvorschriften durch den EGMR jeweils im Wege einer Gesamtbetrachtung statt: Diese muss sowohl die einzelnen möglichen (durch eine Beschwerde vorgebrachten) innerstaatlichen Verletzungen der EMRKGarantien und Rechte als auch zugleich die Fairness des jeweiligen Strafverfahrens in seiner Gesamtheit erfassen. ${ }^{14}$ Die einzelfallbezogene, für Relativierungen entsprechend empfängliche und letztendlich nicht immer vorhersehbare bzw. in ihren Grundzügen nicht immer eindeutige Rechtsprechung des EGMR verkompliziert somit den Versuch einer für die Praxis sinnvollen systematischen Betrachtung der Konventionsvorgaben bzw. einer dogmatischen Auseinandersetzung mit der „Rechtsordnung“" der EMRK.

Nichtsdestoweniger kann eine systematische Wahrnehmung der gefestigten ${ }^{15}$ Auslegungsbestimmungen des EGMR in Bezug auf die strafprozessbezogenen ${ }^{16}$ Kerngarantien und Mitwirkungsrechte des Art. 6 EMRK unabhängig von den jeweiligen Einzelfallumständen allgemeine Auswirkungen auf die nationalen Strafverfahrensrechte und eventuell auch auf die Ausgestaltung des Straf- und Beweisverfahrens haben. Teilweise wird behauptet, dass die EGMR-Rechtsprechung der Harmonisierung ${ }^{17}$ der europäischen Strafverfahrenssysteme dienen oder sogar ein neues systemneutrales Beweismodell ${ }^{18}$ durchsetzen kann. Derartige Dynamiken des EMRK-Systems sind im Folgenden anhand der Grundbestimmungen, die in der

14 Siehe paradigmatisch an dieser Stelle EGMR (GK) Gäfgen v. Germany, Urt. v. 1.6.2010 (22978/05), §§ 162-168. Kritisch u.a. Esser, Strafverfahrensrecht, S. 860-863; siehe auch Schuska, Rechtsfolgen, S. 45-52. Siehe ferner unter Teil 3, II.A.3.c).

15 Hierzu Bárd, in: Aromaa/Viljanen (Hrsg.), International Key Issues, S. 42 m.w.N.: „The maintenance of what has already been achieved is guaranteed by the Court's general practice to follow its earlier case-law and to depart normally from its precedents only if societal changes justify a higher level of protection of human rights. Thus by observing its precedents the Court may set limits to a downward evolution and the lowering of already achieved standards."

16 Zum hierbei relevanten Begriff der „strafrechtlichen Anklage“ (,criminal charge“) des Art. 6(1) EMRK in materieller sowie zeitlicher Hinsicht siehe mit Rechtsprechungshinweisen u.a. Grabenwarter/Pabel, Menschenrechtskonvention, § 24 Rn. 16-26; Meyer-Ladewig, EMRK, Art. 6 Rn. 21-30. Eingehend SK-StPO-Paeffgen, Art. 6 EMRK Rn. 30-49.

$17 \mathrm{Zu}$ den verschiedenen Faktoren, die auf die „Motorfunktion“ der Rechtsprechung des EGMR für die Harmonisierung der nationalen Strafverfahrensrechte hindeuten, siehe Esser, Strafverfahrensrecht, S. 833-868; vgl. auch Schuska, Rechtsfolgen, S. 16. Siehe auch Satzger, JA 2005, 656 (658), der bemerkt, dass Produkt des von der EGMR-Rechtsprechung stammenden Harmonisierungsdruckes ,nur ein Minimalstrafverfahrensrecht, niemals eine wirklich harmonisierte StPO sein kann."

18 Siehe z.B. Jackson/Summers, Internationalisation, S. 77-79. 
EGMR-Rechtsprechung zu den Verfahrensrechten und Fairnessgarantien der Konvention insbesondere im beweisprozessualen Kontext ständig angeführt werden (unter II.A.2.-3.), sowie zusammenfassend auch im Lichte der jüngeren rechtspolitischen Tendenzen in der EMRK-,,Rechtsordnung“ (unter II.B.) zu untersuchen.

\section{Allgemeine Grundsätze mit Bezug auf das Beweisverfahren}

Dem subsidiären ${ }^{19}$ Charakter des Rechtsschutzsystems der EMRK entsprechend hat der EGMR allgemein nicht die Befugnis, abstrakte Verfahrens- und Beweisregeln mit innerstaatlich unmittelbarem Wirkungsanspruch zu erlassen. ${ }^{20}$ Insbesondere fordert der Gerichtshof mit seiner die EMRK-Justizrechte auslegenden Rechtsprechung kein einheitliches Strafverfahrensrecht für sämtliche Länder des Europarats. Die diversen Leitsätze der EGMR-Rechtsprechung bezüglich der Verfahrensrechte des Art. 6 EMRK können als Mindeststandards in einem gewissen Grad das nationale Beweisverfahren und seine Ausgestaltung mitbeeinflussen; sie müssen hierfür das Ziel der materiellen und systemübergreifend einheitlichen Wahrung der Mindestgarantien der Konvention fördern und gleichzeitig die nationalstaatlichen Souveränitätsvorbehalte, die dem Konventionssystem immanent sind, respektieren. ${ }^{21}$

Dabei mag es freilich für den EGMR besonders schwierig sein, die bestehenden Divergenzen zwischen den in den europäischen Ländern angewandten Verfahrenstypen und zwischen den sich in vielerlei Hinsicht unterscheidenden Einzelrechts-

19 Siehe insb. Art. 13, 35(1), 41, 46-53 EMRK. Zur ,margin of appreciation“-Doktrin und allgemein zum subsidiären Charakter des Konventionssystems siehe Bárd, in: Aromaa/Viljanen (Hrsg.), International Key Issues, S. 39-42; Esser, Strafverfahrensrecht, S. 843-846; Peters/Altwicker, Menschenrechtskonvention, § 2 Rn. 1-13; Satzger, Internationales Strafrecht, § 11 Rn. 20-22.

20 Vgl. u.a. EGMR Schenk v. Switzerland, Urt. v. 12.7 .1988 (10862/84), §§ 45-46: „According to Article 19 of the Convention, the Court's duty is to ensure the observance of the engagements undertaken by the Contracting States in the Convention. In particular, it is not its function to deal with errors of fact or of law allegedly committed by a national court unless and in so far as they may have infringed rights and freedoms protected by the Convention. While Article 6 of the Convention guarantees the right to a fair trial, it does not lay down any rules on the admissibility of evidence as such, which is therefore primarily a matter for regulation under national law. The Court therefore cannot exclude as a matter of principle and in the abstract that unlawfully obtained evidence of the present kind may be admissible. It has only to ascertain whether Mr. Schenk's trial as a whole was fair." Siehe auch EGMR Delta v. France, Urt. v. 19.12.1990 (11444/85), § 35; EGMR Mirilashvili v. Russia, Urt. v. 11.12.2008 (6293/04), § 161; EGMR (GK) Bykov v. Russia, Urt. v. 10.3.2009 (4378/02), §§ 88-89; EGMR Sharkunov and Mezentsev v. Russia, Urt. v. 10.6.2010 (75330/01), §§ 94-95; EGMR Duško Ivanovski v. The Former Yugoslav Republic of Macedonia, Urt. v. 24.4.2014 (10718/05), § 42. Zusammenfassend LR-StPO-Esser, Art. 6 EMRK Rn. 268-271.

21 Vgl. Bárd, in: Aromaa/Viljanen (Hrsg.), International Key Issues, S. 40: ,[...] for the sake of state sovereignty and because of the Court's limited legitimacy, the drafters of the Convention envisaged a modest, self-restraining international judicial body." 
ordnungen bei der Inhaltskonkretisierung der Konventionsvorschriften in ausbalancierter Weise zu berücksichtigen. ${ }^{22}$ Insbesondere die in Art. 6 EMRK verwendeten Begriffe $^{23}$,fair trial“ und ,witnesses against him“ sowie das durch den EGMR aus dem gesamten fair trial-Konzept abgeleitete ,,principle of equality of arms“" und der Grundsatz, dass „criminal proceedings should be adversarial“" ${ }^{24}$ weisen auf den ersten Blick auf eine Orientierung der EMRK-,,Rechtsordnung“ an den Strukturen des Parteiprozesses hin; ${ }^{25}$ und dies obwohl die Mehrheit der Mitgliedsländer des Europarats in historischer Hinsicht der kontinentaleuropäischen Verfahrenstradition zuzuordnen sind. Die EGMR-Rechtsprechung will jedoch anscheinend keinen bestimmten (z.B. rein ,adversatorischen“) Verfahrenstyp als einheitliches Modell für alle Rechtsordnungen befürworten. ${ }^{26}$ Vielmehr bemüht sich der Gerichtshof meistens, Art. 6 EMRK dergestalt auszulegen, dass der Inhalt der Rechte und Konventionsbegriffe neutral dargelegt und mit solchen Verfahrensleitsätzen ergänzt wird, die möglichst systemübergreifend angewandt werden können. ${ }^{27}$

In diesem Kontext hat der Gerichtshof in seiner Rechtsprechung mehrmals Gewicht auf die Einhaltung der Waffengleichheit zwischen Ankläger und Verteidigung (,principle of equality of arms“") sowie auf den kontradiktorischen Charakter des Strafprozesses (,criminal proceedings should be adversarial“ - „doit revêtir un caractère contradictoire“) als grundlegende Aspekte des Anspruchs auf ein faires

22 Vgl. etwa die Erwägungen in EGMR (GK) Al-Khawaja and Tahery v. the United Kingdom, Urt. v. 15.12.2011 (26766/05, 22228/06), §§ 129-130.

${ }_{23}$ Renzikowski, FS für Mehle, S. 529-530, bemerkt Folgendes: „Kreuzverhör‘ und ,Belastungszeugen' sind indes ebenso wie ,fair trial' Begriffe aus einer anderen Rechtstradition. [...] Von diesem Parteiprozess ist der deutsche Inquisitionsprozess grundverschieden. Zeugen der Anklage und der Verteidigung kann es hier schon deshalb nicht geben, weil jedes Beweismittel der Erforschung der objektiven Wahrheit dient, die allein dem Gericht überantwortet ist." Siehe auch Beulke, FS für Riess, S. 6 (Fn. 12); IntKommKühne, Art. 6 Rn. 577 (11. Lieferung 2009); Simon, Beschuldigtenrechte, S. 103. Zum Begriff des Belastungszeugen auch LR-StPO-Esser, Art. 6 EMRK Rn. 760, 764-765; Walther, GA 2003, 204 (208 Fn. 19).

24 Siehe EGMR (GK) Öcalan v. Turkey, Urt. v. 12.5 .2005 (46221/99), §§ 140, 146.

25 Dazu Ambos, ZStW 115 (2003), 583 (593-594, 607); Jung, GA 2009, 235 (235-236); Renzikowski, FS für Mehle, S. 529-530. Siehe auch Swart/Young, in: Fennell u.a. (Hrsg.), Criminal Justice, S. 71-72, 83-86. Vgl. auch Nijboer, Am. J. Comp. L. 41 (1993), 299 (311).

26 Siehe etwa EGMR Brandstetter v. Austria, Urt. v. 28.8 .1991 (11170/84 a.o.), § 67; EGMR (GK) Öcalan v. Turkey, Urt. v. 12.5.2005 (46221/99), § 146; EGMR (GK) AlKhawaja and Tahery v. the United Kingdom, Urt. v. 15.12.2011 (26766/05, 22228/06), $\S$ 130. Vgl. auch Ambos, ZStW 115 (2003), 583 (594); Jörg/Field/Brants, in: Fennell u.a. (Hrsg.), Criminal Justice, S. 56; Renzikowski, FS für Mehle, S. 530; Swart/Young, in: Fennell u.a. (Hrsg.), Criminal Justice, S. 84-85 m.w.N.

27 Dazu auch Jackson, in: Jackson u.a. (Hrsg.), Crime, S. 228-229, 231, 233-235. Vgl. auch Delmas-Marty, in: dies. (Hrsg.), Criminal Process, S. 196-198; Gaede, JR 2009, 493 (494). 
Verfahren nach Art. 6(1) EMRK gelegt. ${ }^{28}$ Der fair trial-Grundsatz als allgemeines „oberstes Gebot eines menschenrechtskonformen Strafverfahrens“"29 wird dabei nicht ausschließlich unter dem Blickwinkel eines rein ,adversatorischen“ (Beweis-) Verfahrensmodells, wie dieses vorliegend definiert wurde, oder eines in der angloamerikanischen Rechtswelt meistens herrschenden parteienzentrierten Prozessverständnisses ausgedeutet. ${ }^{30}$ Vielmehr ist hier die Fairness (einschließlich des Anspruchs auf adversarial procedure) ,zuförderst als Chance“ zu verstehen, „effektiv auf das Verfahrensergebnis Einfluss nehmen zu können;“31 ob es sich nun in struktureller Hinsicht eher um einen Parteiprozess oder um ein von dem Untersuchungsgrundsatz und der Amtsaufklärungspflicht beherrschtes Verfahren handelt, soll hierbei im Prinzip keine besondere Rolle spielen.

Spezieller verlangt der EGMR mit dem equality of arms-Grundsatz, dass jede Verfahrensparte $^{32}$ eine angemessene Gelegenheit erhalten muss, ihr fallrelevantes Vorbringen unter solchen Bedingungen zu präsentieren, dass sie nicht substantiell in eine nachteilige Position gegenüber der „Gegenpartei“ gerät:

The Court recalls that under the principle of equality of arms, as one of the features of the wider concept of a fair trial, each party must be afforded a reasonable opportunity

28 Siehe u.a. EGMR (GK) Jasper v. the United Kingdom, Urt. v. 16.2.2000 (27052/95), $\S 51$; EGMR (GK) Öcalan v. Turkey, Urt. v. 12.5.2005 (46221/99), §§ 140, 146. Nach Ambos, ZStW 115 (2003), 583 (593-594, 596) m.w.N. will der EGMR mit dem Begriff „proceedings“ den Anspruch auf ein kontradiktorisches Verfahren ,nicht a limine auf das Hauptverfahren beschränken [...]“ und die „Anwendung der Waffengleichheit auf das Vorverfahren ergibt sich schließlich auch aus der Auslegung der Einzelgarantien des Art. 6 Abs. 3 EMRK [...]." Allgemein zum equality of arms-Grundsatz und zum Prinzip des adversarial process in der EMRK-,,Rechtsordnung“ Fedorova, Principle, S. 30-68; Jackson/Summers, Internationalisation, S. 79-95. Zusammenfassend u.a. Safferling, NStZ 2004, 181 (182-183).

29 Weigend, ZStW 113 (2001), 271 (276).

30 Vgl. etwa EGMR Mirilashvili v. Russia, Urt. v. 11.12.2008 (6293/04), §§ 224-227. Ferner Jackson, in: Jackson u.a. (Hrsg.), Crime, S. 229-232; vgl. auch Rzepka, Fairness, S. 85.

31 Renzikowski, FS für Mehle, S. 529. Vgl. EGMR Stanford v. the United Kingdom, Urt. v. 23.2.1994 (16757/90), § 26: „Nor is it in dispute that Article 6, read as a whole, guarantees the right of an accused to participate effectively in a criminal trial. In general this includes, inter alia, not only his right to be present, but also to hear and follow the proceedings. Such rights are implicit in the very notion of an adversarial procedure and can also be derived from the guarantees contained in sub-paragraphs (c), (d) and (e) of paragraph 3 of Article 6, - 'to defend himself in person', 'to examine or have examined witnesses', and 'to have the free assistance of an interpreter if he cannot understand or speak the language used in court' [...].“ Siehe auch EGMR Colozza v. Italy, Urt. v. 12.2.1985 (9024/80), § 27; EGMR Barberà, Messegué and Jabardo v. Spain, Urt. v. 6.12 .1988 (10590/83), § 78; EGMR Lagerblom v. Sweden, Urt. v. 14.1.2003 (26891/95), § 49. Vgl. auch EGMR Granger v. the United Kingdom, Urt. v. 28.3 .1990 (11932/86), § 47. Allgemein zum Fairnessanspruch gemäß Art. 6 EMRK als Recht auf Teilhabe Gaede, Fairness, insb. S. 369426. Vgl. noch BVerfG, NJW 2001, 2245 (2246); BVerfG, NJW 2007, 204 (205); BVerfG, NJW 2010, 925 (925).

${ }^{32}$ Zur eher formell-technischen Verwendung des Parteibegriffs siehe Rzepka, Fairness, S. 85 . 
to present his case under conditions that do not place him at a disadvantage vis-à-vis his opponent [...]. In this context, importance is attached to appearances as well as to the increased sensitivity to the fair administration of justice $[\ldots]$. ${ }^{33}$

Um gleichzeitig den kontradiktorischen Charakter des innerstaatlichen Strafverfahrens und insbesondere der Beweisaufnahme sicherzustellen, sind dem EGMR zufolge die Beweise in der Regel im Beisein des Angeklagten in öffentlicher Sitzung zum Zweck einer adversatorischen Erörterung zu erheben (,,all the evidence must in principle be produced in the presence of the accused at a public hearing with a view to adversarial argument" $).{ }^{34}$ Sämtlichen Parteien muss jedenfalls die Gelegenheit gegeben werden, die von der jeweiligen Gegenseite angebotenen Beweismittel und vorgebrachten Beweisthesen zur Kenntnis zu nehmen und zu ihnen Stellung zu beziehen. ${ }^{35}$ In diesem Kontext kann mit Blick auf die Ausgestaltung der Beweisführungen unter anderem Art. 6(3d) EMRK eine zentrale Rolle spielen, dem zufolge die Zeugenvernehmungen in der Regel in einer kontradiktorischen Weise erfolgen müssen. ${ }^{36}$

Der Anspruch der Verteidigung auf Beweiserhebung und Zeugenvernehmung in einer öffentlichen kontradiktorischen Hauptverhandlung oder der Anspruch auf vorgerichtliche Offenlegung aller Beweismittel sind gleichwohl keine absoluten Rechte; im Strafverfahren ist vielmehr oft eine justizielle Abwägung zwischen

${ }^{33}$ EGMR Bulut v. Austria, Urt. v. 22.2 .1996 (17358/90), § 47 m.w.N. Siehe auch EGMR Foucher v. France, Urt. v. 18.3 .1997 (22209/93), § 34; EGMR (GK) Öcalan v. Turkey, Urt. v. 12.5.2005 (46221/99), § 140. Vgl. noch EGMR Delcourt v. Belgium, Urt. v. 17.1.1970 (2689/65), § 28; EGMR Borgers v. Belgium, Urt. v. 30.10 .1991 (12005/86), $\S 24$; EKMR Kaufman v. Belgium, Ent. v. 9.12.1986 (10938/84), Decisions and Reports 50, 110 (115). Dazu u.a. Ambos, ZStW 115 (2003), 583 (592-596); Meyer-Ladewig, EMRK, Art. 6 Rn. 112-114; Rzepka, Fairness, S. 83-86.

${ }^{34}$ EGMR Barberà, Messegué and Jabardo v. Spain, Urt. v. 6.12 .1988 (10590/83), § 78; EGMR Kostovski v. the Netherlands, Urt. v. 20.11 .1989 (11454/85), § 41; EGMR Windisch v. Austria, Urt. v. 27.9.1990 (12489/86), § 26; EGMR Lüdi v. Switzerland, Urt. v. 15.6.1992 (12433/86), § 47; EGMR Van Mechelen a.o. v. the Netherlands, Urt. v. 23.4.1997 (21363/93 a.o.), § 51; EGMR Krasniki v. the Czech Republic, Urt. v. 28.2.2006 (51277/99), § 75 .

35 EGMR Brandstetter v. Austria, Urt. v. 28.8 .1991 (11170/84 a.o.), § 67: „The right to an adversarial trial means, in a criminal case, that both prosecution and defence must be given the opportunity to have knowledge of and comment on the observations filed and the evidence adduced by the other party. Various ways are conceivable in which national law may secure that this requirement is met. However, whatever method is chosen, it should ensure that the other party will be aware that observations have been filed and will get a real opportunity to comment thereon." Siehe auch EGMR (GK) Jasper v. the United Kingdom, Urt. v. 16.2.2000 (27052/95), § 51; EGMR (GK) Öcalan v. Turkey, Urt. v. 12.5.2005 (46221/99), § 146; neuerdings EGMR Matytsina v. Russia, Urt. v. 27.3.2014 (58428/10), $\S 151$. Auch von Beweisen, die eine zur Objektivität verpflichtete Justizbehörde vorlegt, muss die Verteidigung grundsätzlich Kenntnis haben und zu ihnen Stellung nehmen können, eingehend dazu Esser, Strafverfahrensrecht, S. 407-416 m.w.N.

36 So z.B. EGMR Barberà, Messegué and Jabardo v. Spain, Urt. v. 6.12 .1988 (10590/ 83), § 78. Siehe auch Ambos, ZStW 115 (2003), 583 (594); Jackson, in: Jackson u.a. (Hrsg.), Crime, S. 231-232. 
konkurrierenden Interessen erforderlich. Solche Abwägungen sollen insbesondere dann stattfinden, wenn die nationale Sicherheit und andere bedeutsame öffentliche Interessen, die Wahrung von fundamentalen Rechten Dritter (z.B. nach Art. 8 EMRK) oder die Notwendigkeit, Zeugen (und ihre Rechte auf Leben, Freiheit und Sicherheit) etwa vor Vergeltungsmaßnahmen zu schützen, in Betracht kommen. ${ }^{37}$ In diesen Fällen sind aber nach der EGMR-Rechtsprechung nur solche, die Rechte der Verteidigung einschränkenden Maßnahmen gemäß Art. 6(1) EMRK zulässig, die als unabdingbar (,strictly necessary“) angesehen werden. ${ }^{38}$ Zusätzlich ist es nach Maßgabe des Gerichtshofs zur Sicherstellung eines fairen Verfahrens notwendig, dass sämtliche der Verteidigung durch die Begrenzung ihrer Rechte entstandenen Schwierigkeiten ausreichend durch das nationale Justizverfahren ausgeglichen werden (,must be sufficiently counterbalanced by the procedures followed by the judicial authorities" $).{ }^{39}$

\section{Teilgarantien}

a) Anspruch auf wirksame Verteidigung, Beweisoffenlegung und Zeugenladung

Die Teile 1 und 2 der Arbeit haben sich thematisch mit den Strukturen des herkömmlichen nationalen Beweisverfahrens und insbesondere mit der Rollenverteilung zwischen Richtern und zentralen Prozessbeteiligten bei den maßgebenden Beweisführungen auseinandergesetzt. Die EMRK-,,Rechtsordnung“ befasst sich, wie gesehen, nicht unmittelbar mit Fragen zu den Strafverfahrenstypen und den auf nationalrechtlicher Ebene anzuwendenden „Beweisregeln“; insbesondere im Kontext der Verfahrens- und Justizgarantien der Konvention stehen vielmehr die sub-

37 Siehe relevante Erwägungen z.B. in EGMR Unterpertinger v. Austria, Urt. v. 24.11.1986 (9120/80), insb. §§ 29-31; EGMR Kostovski v. the Netherlands, Urt. v. 20.11.1989 (11454/85), §§ 41, 44. In EGMR Doorson v. the Netherlands, Urt. v. 26.3.1996 (20524/92), §70, wurde betont, dass: „It is true that Article 6 does not explicitly require the interests of witnesses in general, and those of victims called upon to testify in particular, to be taken into consideration. However, their life, liberty or security of person may be at stake, as may interests coming generally within the ambit of Article 8 (art. 8) of the Convention. Such interests of witnesses and victims are in principle protected by other, substantive provisions of the Convention, which imply that Contracting States should organise their criminal proceedings in such a way that those interests are not unjustifiably imperilled. Against this background, principles of fair trial also require that in appropriate cases the interests of the defence are balanced against those of witnesses or victims called upon to testify." Siehe auch EGMR (GK) Jasper v. the United Kingdom, Urt. v. 16.2.2000 (27052/95), §§ 51-52; EGMR (GK) Rowe and Davis v. the United Kingdom, Urt. v. 16.2.2000 (28901/95), $\S \S 60-62$.

38 U.a. EGMR Van Mechelen a.o. v. the Netherlands, Urt. v. 23.4 .1997 (21363/93 a.o.), $\S 58$; EGMR (GK) Jasper v. the United Kingdom, Urt. v. 16.2.2000 (27052/95), § 52.

39 EGMR (GK) Jasper v. the United Kingdom, Urt. v. 16.2.2000 (27052/95), § 52. Siehe auch u.a. EGMR Doorson v. the Netherlands, Urt. v. 26.3 .1996 (20524/92), § 72; EGMR Van Mechelen a.o. v. the Netherlands, Urt. v. 23.4.1997 (21363/93 a.o.), § 54. 
jektiven Verteidigungsrechte des Beschuldigten im Vordergrund. Neben den vorangehend dargestellten allgemeinen Fairnessprinzipien werden jedenfalls nach Art. 6(3a-d) EMRK dem Angeklagten folgende Mindestrechte als konkrete Teilaspekte $^{40}$ der Garantien des Art. 6(1) ausdrücklich zugebilligt, deren innerstaatliche Wahrung einen Einfluss auch auf die Gestaltung der Beweisverfahren in den Konventionsländern haben kann:

(a) to be informed promptly, in a language which he understands and in detail, of the nature and cause of the accusation against him;

(b) to have adequate time and facilities for the preparation of his defence;

(c) to defend himself in person or through legal assistance of his own choosing or, if he has not sufficient means to pay for legal assistance, to be given it free when the interests of justice so require;

(d) to examine or have examined witnesses against him and to obtain the attendance and examination of witnesses on his behalf under the same conditions as witnesses against him. ${ }^{41}$

Hierzu hat der EGMR in seiner Rechtsprechung konkrete „Leitlinien“ erlassen, die sich (wenn auch eher indirekt) auf beweisprozessuale Aspekte der Vorbereitung einer wirksamen Verteidigung beziehen und sich somit in gewissem Maße mit den die Idealtypen betreffenden Erwägungen und Vergleichungen in den vorangehenden Arbeitsteilen korrelieren lassen. Mit Blick zunächst auf den vorgerichtlichen Informationsbedarf des Beschuldigten hinsichtlich des Vorbringens der (die „Beweislast“" grundsätzlich tragenden) ${ }^{42}$ Anklage und hinsichtlich der Beweislage so-

40 U.a. EGMR Van Mechelen a.o. v. the Netherlands, Urt. v. 23.4 .1997 (21363/93 a.o.), $\S 49$.

41 Art. 6(3a-d) EMRK, deutsche Übersetzung: ,Jeder Angeklagte hat mindestens (englischer Text) insbesondere (französischer Text) die folgenden Rechte: (a) in möglichst kurzer Frist in einer für ihn verständlichen Sprache in allen Einzelheiten über die Art und den Grund der gegen ihn erhobenen Beschuldigung in Kenntnis gesetzt zu werden; (b) über ausreichende Zeit und Gelegenheit zur Vorbereitung seiner Verteidigung zu verfügen; (c) sich selbst zu verteidigen oder den Beistand eines Verteidigers seiner Wahl zu erhalten und, falls er nicht über die Mittel zur Bezahlung eines Verteidigers verfügt, unentgeltlich den Beistand eines Pflichtverteidigers zu erhalten, wenn dies im Interesse der Rechtspflege erforderlich ist; (d) Fragen an die Belastungszeugen zu stellen oder stellen zu lassen und die Ladung und Vernehmung der Entlastungszeugen unter denselben Bedingungen wie die der Belastungszeugen zu erwirken." Für einen allgemeinen Überblick über die EGMR-Rechtsprechung zu den Teilgarantien des Art. 6(3) EMRK siehe u.a. Grabenwarter, Commentary, Art. 6 Rn. 124-151; Grabenwarter/Pabel, Menschenrechtskonvention, § 24 Rn. 98-122. Eingehend LR-StPO-Esser, Art. 6 EMRK Rn. 534-878. Siehe auch die gründlichen Analysen zur Problematik der „defence participation“ bei Jackson/Summers, Internationalisation, S. 285-366.

42 So z.B. EGMR Barberà, Messegué and Jabardo v. Spain, Urt. v. 6.12 .1988 (10590/ 83), § 77: „Paragraph 2 (art. 6-2) embodies the principle of the presumption of innocence. It requires, inter alia, that when carrying out their duties, the members of a court should not start with the preconceived idea that the accused has committed the offence charged; the burden of proof is on the prosecution, and any doubt should benefit the accused. It also follows that it is for the prosecution to inform the accused of the case that will be made against him, so that he may prepare and present his defence accordingly, and to adduce evidence sufficient to convict him." Siehe auch EGMR (GK) Allen v. the United Kingdom, 
wie allgemein mit Blick auf die Vorbereitung und Verankerung einer effektiven und aktiven Verteidigung hat der EGMR unter anderem Folgendes bestimmt:

- Wesentlicher Bestandteil der Verfahrensfairness, insbesondere des Rechts auf Vorbereitung der Verteidigung, ist die Bereitstellung von detaillierten Informationen hinsichtlich der Anklagepunkte und -gründe:

The Court considers that in criminal matters the provision of full, detailed information concerning the charges against a defendant, and consequently the legal characterisation that the court might adopt in the matter, is an essential prerequisite for ensuring that the proceedings are fair. [...] The Court considers that sub-paragraphs (a) and (b) of Article $6 \S 3$ are connected and that the right to be informed of the nature and the cause of the accusation must be considered in the light of the accused's right to prepare his defence. $^{43}$

- Die Rechte des Angeklagten auf Anwesenheit im Gerichtsverfahren und auf eine angemessene Verteidigung sind ebenfalls von enormer Bedeutung mit Blick auf die Gewährleistung eines fairen und gerechten Strafverfahrens:

The Court reiterates that in the interests of a fair and just criminal process it is of capital importance that the accused should appear at his trial [...], and that the duty to guarantee the right of a criminal defendant to be present in the courtroom [...] ranks as one of the essential requirements of Article 6 [...]. It is also of crucial importance for the fairness of the criminal justice system that the accused be adequately defended $[\ldots]{ }^{44}$

- Das Recht des Angeklagten auf effektive Beteiligung an der Hauptverhandlung beinhaltet das Anwesenheitsrecht sowie die Möglichkeit, den Verhandlungen zu folgen und sie zu verstehen. Diese Rechte sind im Begriff der ,adversarial procedure" und in den Verteidigungsgarantien des Art. 6(3) EMRK enthalten:

The right of an accused under Article 6 to effective participation in his or her criminal trial generally includes, inter alia, not only the right to be present, but also to hear and follow the proceedings. Such rights are implicit in the very notion of an adversarial procedure and can also be derived from the guarantees contained, in particular, in subparagraph (c) of paragraph 3 of Article 6 - "to defend himself in person" [...]. "Effective participation" in this context presupposes that the accused has a broad understanding of the nature of the trial process and of what is at stake for him or her, including the significance of any penalty which may be imposed. The defendant should be able, inter alia, to explain to his own lawyer his version of events, point out any statements with which he disagrees and make them aware of any facts which should be put forward in his defence $[\ldots]$. The circumstances of a case may require the Contracting States to take positive measures in order to enable the applicant to participate effectively in the proceedings $[\ldots] .{ }^{45}$

- Die Verfahrensfairness setzt die Gewährleistung der umfassenden Hinzuziehung eines Rechtsbeistands voraus. Der Verteidiger muss in der Lage sein, die fundamentalen Aspekte der Verteidigung, insbesondere die Beratung über den Fall, die

Urt. v. 12.7.2013 (25424/09), § 93. Siehe dazu u.a. Jackson/Summers, Internationalisation, S. 217-228.

43 EGMR (GK) Pélissier and Sassi v. France, Urt. v. 25.3.1999 (25444/94), §§ 52, 54.

44 EGMR Sinichkin v. Russia, Urt. v. 8.4.2010 (20508/03), §§ 30, 34 m.w.N.

45 EGMR Liebreich v. Germany, Ent. v. 8.1.2008 (30443/03) m.w.N. 
Sammlung von entlastenden Beweisen und die Vorbereitung mit Blick auf die Vernehmungen, durchzuführen:

Indeed, the fairness of proceedings requires that an accused be able to obtain the whole range of services specifically associated with legal assistance. In this regard, counsel has to be able to secure without restriction the fundamental aspects of that person's defence: discussion of the case, organisation of the defence, collection of evidence favourable to the accused, preparation for questioning, support of an accused in distress and checking of the conditions of detention. ${ }^{46}$

- Fundamentale Aspekte des Rechts auf ein faires Verfahren sind der adversarial Charakter des Strafprozesses und die Waffengleichheit zwischen Anklage und Verteidigung. Das Recht auf adversarial trial bedeutet, dass der Anklage und der Verteidigung Gelegenheit gegeben werden muss, die von der jeweiligen Gegenseite angebotenen Beweismittel zur Kenntnis zu nehmen und zu ihnen Stellung zu beziehen. Die Anklage muss der Verteidigung alle in ihrem Besitz befindlichen belastenden und entlastenden substantiellen Beweise offenlegen. Der Anspruch auf Offenlegung aller Beweismittel ist aber, wegen der erforderlichen Abwägung der in einem Strafverfahren konkurrierenden Interessen (z.B. nationale Sicherheit, fundamentale Rechte Dritter, Geheimhaltung von Ermittlungen), kein absolutes Recht. Es sind aber nur diejenigen die Rechte der Verteidigung einschränkenden Maßnahmen zulässig, welche als unabdingbar angesehen werden. Zusätzlich ist es zur Sicherung eines fairen Verfahrens notwendig, dass sämtliche der Verteidigung durch die Begrenzung ihrer Rechte entstandenen Schwierigkeiten ausreichend durch das Justizverfahren ausgeglichen werden:

It is in any event a fundamental aspect of the right to a fair trial that criminal proceedings, including the elements of such proceedings which relate to procedure, should be adversarial and that there should be equality of arms between the prosecution and defence. The right to an adversarial trial means, in a criminal case, that both prosecution and defence must be given the opportunity to have knowledge of and comment on the observations filed and the evidence adduced by the other party [...]. In addition Article $6 \S 1$ requires that the prosecution authorities should disclose to the defence all material evidence in their possession for or against the accused [...]. The entitlement to disclosure of relevant evidence is not, however, an absolute right. In any criminal proceedings there may be competing interests, such as national security or the need to protect witnesses at risk of reprisals or keep secret police methods of investigation of crime, which must be weighed against the rights of the accused. In some cases it may be necessary to withhold certain evidence from the defence so as to preserve the fundamental rights of another individual or to safeguard an important public interest. Nonetheless, only such measures restricting the rights of the defence which are strictly necessary are permissible under Article $6 \S 1$. Furthermore, in order to ensure that the accused receives a fair trial, any difficulties caused to the defence by a limitation on its rights must be sufficiently counterbalanced by the procedures followed by the judicial authorities [...]. ${ }^{47}$

46 EGMR Dayanan v. Turkey, Urt. v. 13.10 .2009 (7377/03), § 32.

47 EGMR Edwards and Lewis v. the United Kingdom, Urt. v. 22.7 .2003 (39647/98, 40461/98), §§ 52-53. Siehe auch EGMR (GK) Jasper v. the United Kingdom, Urt. v. 16.2.2000 (27052/95), §§ 50-53; EGMR (GK) Rowe and Davis v. the United Kingdom, 
In Bezug schließlich auf die Mitwirkung der Verteidigung bei der Bestimmung des Umfangs der Beweiserhebungen im Hauptverfahren und insbesondere in Bezug auf die Ladung von Zeugen hat sich der EGMR prinzipiell durch seine Rechtsprechung zum Art. 6(1) i.V.m. Art. 6(3d) EMRK geäußert. Offensichtlich kann oft ein Zusammenhang zwischen der wirksamen Ausübung der Rechte des Angeklagten nach Art. 6(3d) EMRK und der Ausgestaltung des nationalen Beweisverfahrens bestehen. Zum einen ist hinsichtlich beweisrelevanter Fragen zum sogenannten Konfrontationsrecht (,to examine ... witnesses against him“), die im Folgenden selbstständig angesprochen werden, eine umfangreiche und teilweise komplexe Rechtsprechung seitens des EGMR vorhanden. Zum anderen hat der Gerichtshof zur inhaltlichen Reichweite des Verteidigungsrechts auf Ladung und Vernehmung von Entlastungszeugen (,to obtain the attendance and examination of witnesses on his behalf under the same conditions as witnesses against him") eindeutig, aber eher zurückhaltend Stellung genommen. Allgemein haben die nationalen Strafgerichte laut EGMR ein weites Ermessen bei der Beurteilung der Relevanz der von der Verteidigung vorgebrachten Beweise und somit bei der Entscheidung über ihre Zulassung und Einführung in die Hauptverhandlung. ${ }^{48}$ Insbesondere im Kontext der Ladung von Zeugen (und entsprechend von Experten) ${ }^{49}$ durch die Verteidigung

Urt. v. 16.2.2000 (28901/95), §§ 59-62 m.w.N. Neuerdings z.B. EGMR Cevat Soysal v. Turkey, Urt. v. 23.9.2014 (17362/03), §§ 64-65.

48 Siehe etwa EGMR Erdem v. Germany, Ent. v. 9.12.1999 (38321/97, partial): „As regards the applicant's complaint about the rejection by the Düsseldorf Higher Regional Court of his requests to include various documents and expert reports as evidence, the Court recalls that the national courts have a wide margin of discretion in assessing the relevance of proposed evidence." Siehe auch EGMR Cornelis v. the Netherlands, Ent. v. 25.5.2004 (994/03).

49 Siehe etwa EGMR Matytsina v. Russia, Urt. v. 27.3 .2014 (58428/10), §§ 167-169 m.w.N.: ,[The] Court will concentrate on "expert evidence" in the broad meaning of the term, that is, sources of information which do not describe the particular facts of a case but instead provide a scientific, technical, or other similar analysis of those facts (which can also be defined as "opinion testimony"). [...] The Court reiterates that witnesses and experts play a different role in proceedings and have a different status. The latter cannot be fully associated with "witnesses", at least not for all purposes [...]. In analysing whether the personal appearance of an expert at the trial was necessary, the Court will therefore be primarily guided by the principles enshrined in the concept of a "fair trial" under Article 6 $\S 1$ of the Convention, and in particular by the guarantees of "adversarial proceedings" and "equality of arms". That being said, some of the Court's approaches to the personal examination of "witnesses" under Article $6 \S 3$ (d) are no doubt relevant in the context of examination of expert evidence and may be applied mutatis mutandis, with due regard to the difference in their status and role [...]. It is primarily for the national courts to decide whether a particular piece of evidence is formally admissible [...]. Similarly, under Article 6 it is normally not the Court's role to determine whether a particular expert report available to the domestic judge was reliable or not [...]. Subject to some exceptions, the general rule is that the domestic judge has a wide discretion in choosing amongst conflicting expert opinions and picking one which he or she deems consistent and credible. However, the rules on admissibility of evidence may sometimes run counter to the principles of equality of arms and adversarial proceedings, or affect the fairness of the proceedings otherwise [...]. In the context of expert evidence, the rules on its admissibility must not deprive the 
hat der EGMR diesbezüglich und zur Waffengleichheit als dem übergeordneten Ziel des Art. 6(3d) i.V.m. 6(1) EMRK sowie zur Gesamtbetrachtung der Verfahrensfairness bestimmt, dass es im Prinzip den nationalen Gerichten obliegt, das ihnen vorliegende Beweismaterial sowie die Erheblichkeit der von der Verteidigung vorzubringenden Beweise zu würdigen. Die nationalen Gerichte entscheiden in der Regel frei, ob Zeugen aufgerufen werden müssen. Die EMRK verlangt nicht die Anwesenheit und Vernehmung jedes vom Angeklagten benannten Zeugen; ihr zentrales Anliegen ist die Gewährleistung von Waffengleichheit und allgemeiner Fairness:

The Court recalls that, as a general rule, it is for the national courts to assess the evidence before them as well as the relevance of the evidence which defendants seek to adduce. More specifically, Article $6 \S 3$ (d) leaves it to them, again as a general rule, to assess whether it is appropriate to call witnesses, in the "autonomous" sense given to that word in the Convention system; it "does not require the attendance and examination of every witness on the accused's behalf: its essential aim, as is indicated by the words 'under the same conditions', is a full 'equality of arms' in the matter". The concept of "equality of arms" does not, however, exhaust the content of paragraph 3 (d) of Article 6 , nor that of paragraph 1 of which this phrase represents one application among many others [...]. The Court's task under the Convention is not to give a ruling as to whether statements of witnesses were properly admitted as evidence, but rather to ascertain whether the proceedings as a whole, including the way in which evidence was taken, were fair $[\ldots] .{ }^{50}$

\section{b) Das Konfrontationsrecht}

In Bezug auf das Recht nach Art. 6(3d) EMRK, Fragen an die Belastungszeugen zu stellen oder stellen zu lassen (,,to examine or have examined witnesses against him“), ist zunächst zu bemerken, dass der Beschuldigte sein Recht selbst ausüben oder die Ausübung seinem Verteidiger überlassen kann; allgemein kann nach der EGMR-Rechtsprechung für die Zwecke des Art. 6(3d) EMRK der Beschuldigte mit seinem Verteidiger gleichgesetzt werden. ${ }^{51}$ Die einzelnen Garantien des Art. 6(3) EMRK sind systematisch den subjektiven Mindestrechten zur effektiven Verteidigung zugeordnet. Trotz der sprachlichen Ungenauigkeiten der Konvention (,or

defence of the opportunity to challenge it effectively, in particular by introducing or obtaining alternative opinions and reports. In certain circumstances the refusal to allow an alternative expert examination of material evidence may be regarded as a breach of Article $6 \S 1$ [...].“ Allgemein zum Sachverständigenbeweis in der EMRK-,,Rechtsordnung“ siehe Esser, Strafverfahrensrecht, S. 693-706. Neuerdings Decaigny, NJECL 2014, 149 (154166).

50 EGMR Solakov v. the Former Yugoslav Republic of Macedonia, Urt. v. 31.10.2001 (47023/99), §57. Siehe auch EGMR Engel a.o. v. the Netherlands, Urt. v. 8.6.1976 (5100/71 a.o.), § 91; EGMR Barberà, Messegué and Jabardo v. Spain, Urt. v. 6.12.1988 (10590/83), § 78; EGMR Bricmont v. Belgium, Urt. v. 7.7.1989 (10857/84), § 89; EGMR Vidal v. Belgium, Urt. v. 22.4.1992 (12351/86), § 33 m.w.N.

${ }^{51}$ Siehe u.a. EGMR Kamasinski v. Austria, Urt. v. 19.12.1989 (9783/82), § 91; EGMR Doorson v. the Netherlands, Urt. v. 26.3.1996 (20524/92), § 74. 
have examined“") ${ }^{52}$ kann daher eine Vernehmung des Zeugen, die lediglich durch das Gericht und ohne das gleichzeitige Vorliegen einer selbstständigen Möglichkeit zur direkten Befragung und Überprüfung des betreffenden Beweises durch die Verteidigung erfolgt, nicht als erschöpfend bzw. den Kern des Verteidigungsrechts wahrend angesehen werden.

Darüber hinaus wird vorliegend der Begriff „Konfrontationsrecht“, nicht zuletzt unter Rücksichtnahme auf die historischen und theoretischen Grundlagen ${ }^{53}$ sowie $^{2}$ auf den anschaulichen englischen (authentischen) Wortlaut des Art. 6(3d) EMRK (,to examine“ $)^{54}$, zur Bezeichnung des inhaltlich umfangreichen Konventionsrechts bevorzugt. ${ }^{55}$ Die autonome inhaltliche Reichweite des Konfrontationsrechts der Konvention ist mit dem Fragerecht nach $§ 240(2)$ der deutschen StPO keinesfalls deckungsgleich, nicht zuletzt weil sich das Letztere ausschließlich auf die in der Hauptverhandlung anwesenden Beweispersonen bezieht. ${ }^{56}$ Nach der EGMR-Rechtsprechung ist für die materielle Wahrung der Mindestrechte der Verteidigung nach Abs. 1 und Abs. 3(d) des Art. 6 EMRK Folgendes erforderlich: Die Verteidigung muss eine angemessene und ausreichende Gelegenheit erhalten, einen Belastungszeugen zu bestreiten und ihn zu befragen, dies entweder, wenn er seine Aussage macht, oder zu einem späteren Zeitpunkt des innerstaatlichen Strafverfahrens - ,,as a general rule, paragraphs 3 (d) and 1 of Article 6 require that the defendant be

52 Dazu Walther, GA 2003, 204 (212-213).

53 Siehe etwa die (rechtsvergleichenden) Ausführungen in EGMR (GK) Al-Khawaja and Tahery v. the United Kingdom, Urt. v. 15.12.2011 (26766/05, 22228/06), insb. §§ 56, 63-87, 114-115. Siehe auch Beulke, FS für Riess, S. 6; Geppert, Unmittelbarkeit, S. 245246; Renzikowski, FS für Mehle, S. 529; Walther, GA 2003, 204 (213) m.w.N. Eingehende historische Ausführungen bei Krausbeck, Konfrontative Zeugenbefragung, S. 7-23.

54 Walther, GA 2003, 204 (212), bemerkt zutreffend: „[Der] Begriff des Examinierens verweist nun, im Gegensatz zum bloßen Fragenstellen, auf eine bestimmte Qualität der Verfahrensrolle, die der Fragesteller wahrnimmt: Examinieren heißt ,prüfen'; wer aber eine Prüfung durchführt, muss [...] ein Konzept der Befragung entwickeln und die Gelegenheit erhalten, den Prüfling in entsprechend selbstständiger und zusammenhängender Weise - und von Angesicht zu Angesicht - auf die Grundlagen seines Wissens abzuklopfen.“

55 Über ein in der Konvention verankertes „Fragerecht“" sprechen z.B. EMRK-Kommentar-Peukert, Art. 6 Rn. 308-311; Gollwitzer, GS für Meyer, S. 151-152; SK-StPOPaeffgen, Art. 6 EMRK Rn. 154-155. Grundsätzlich über ein „Konfrontationsrecht“" sprechen u.a. Beulke, FS für Riess, S. 6-7; R. Friedman, in: Jackson u.a. (Hrsg.), Crime, S. 268; Renzikowski, FS für Mehle, S. 529-531; Schmitt, FS für Rissing-van Saan, S. 617; Wattenberg, StV 2000, 688 (691); Weigend, FS für Wolter, S. 1145, 1150. Siehe auch Schlothauer, StV 2001, 127 (128), der über ein Fragerecht schreibt, das in der Regel die unmittelbare Konfrontation mit dem Belastungszeugen garantiert. In BVerfG, NStZ 2007, 534 (534) wurde festgelegt: „Für das Konfrontationsrecht gem. Art. 6 Abs.3 lit.d EMRK bedeutet dies, dass dem Angekl. die effektive Möglichkeit verschafft werden muss, einen Zeugen zu befragen und seine Glaubwürdigkeit und Zuverlässigkeit in Frage zu stellen.“ Zur Differenzierung zwischen einer ,physischen“ und einer sachlich-inhaltlichen Gegenüberstellung mit dem Zeugen siehe Walther, GA 2003, 204 (206-207).

${ }^{56}$ Hierzu und zu Fragen der Unmittelbarkeit im deutschen Hauptverfahren siehe unter Teil 2, III.B.1.b)bb) und Teil 2, III.D.2.c)bb). 
given an adequate and proper opportunity to challenge and question a witness against him, either when he makes his statements or at a later stage. “57

Zur zentralen Bedeutung des Konfrontationsrechts für die Wahrung der allgemeinen Garantie der adversarial proceedings hat der EGMR neuerdings bemerkt, dass, auch wenn die Verteidigung in der Lage war, den Zeugen während der polizeilichen Ermittlungen zu befragen, dies die Befragung (,cross-examination“) des Zeugen vor dem erkennenden Gericht u.a. zum Zweck der unmittelbaren Prüfung seiner Glaubwürdigkeit nicht ersetzen kann.

The Court further reiterates that the right of the defence to examine witnesses and test other evidence introduced by the prosecution should be read in the light of the more general guarantee of adversarial proceedings enshrined in the concept of a fair trial under Article $6 \S 1[\ldots]$. Even where the defence was able to cross-examine a witness or an expert at the stage of the police investigation, it cannot replace cross-examination of that witness or expert at the trial before the judges. It is an important element of fair criminal proceedings that the accused is confronted with the witness "in the presence of the judge who ultimately decides the case" in order for that judge to hear the witness directly, to observe his demeanour and to form an opinion about his credibility $[\ldots] .{ }^{58}$

Bei dieser Auslegung des Art. 6(3d) EMRK geht es letztendlich nicht bloß um ein „schwächliches Fragerecht“, sondern um ,ein geharnischtes Recht auf Infragestellung ${ }^{659}$ und insbesondere um den Anspruch auf Überprüfung der Glaubhaftigkeit und Glaubwürdigkeit des Belastungszeugen im Wege der unmittelbaren Gegenüberstellung der Verteidigung mit ihm. ${ }^{60}$ Der Begriff „witness against him“ wird dabei vom EGMR autonom ausgelegt: Grundsätzlich ist damit jede Person gemeint, die, unabhängig vom Zeitpunkt der Auskunft und von der Art und Weise (z.B. durch Beweissurrogate) der Einführung der betreffenden Beweisinformation in das Hauptverfahren, belastende Aussagen gegen den Beschuldigten macht, die

${ }^{57}$ EGMR Lüdi v. Switzerland, Urt. v. 15.6.1992 (12433/86), § 47. U.a. m.w.N. auch EGMR Kostovski v. the Netherlands, Urt. v. 20.11 .1989 (11454/85), §41; EGMR Windisch v. Austria, Urt. v. 27.9 .1990 (12489/86), § 26; EGMR Saïdi v. France, Urt. v. 20.9.1993 (14647/89), § 43; EGMR Van Mechelen a.o. v. the Netherlands, Urt. v. 23.4.1997 (21363/93 a.o.), § 51; EGMR (GK) Al-Khawaja and Tahery v. the United Kingdom, Urt. v. 15.12.2011 (26766/05, 22228/06), § 118; EGMR Matytsina v. Russia, Urt. v. 27.3.2014 (58428/10), § 152 .

58 EGMR Matytsina v. Russia, Urt. v. 27.3.2014 (58428/10), § 153.

59 Walther, GA 2003, 204 (215).

60 Vgl. EGMR Windisch v. Austria, Urt. v. 27.9.1990 (12489/86), § 28: ,[...] the nature and scope of the questions that could be put $[\ldots]$ were $[\ldots]$ considerably restricted by reason of the decision to preserve the anonymity of these two persons [...]. Being unaware of their identity, the defence was confronted with an almost insurmountable handicap: it was deprived of the necessary information permitting it to test the witnesses' reliability or cast doubt on their credibility [...].“ Und EGMR Saïdi v. France, Urt. v. 20.9.1993 (14647/89), $\S 41:,[\ldots]$ the refusal of the judicial authorities to organise a confrontation between him and the persons in question had deprived him of a fair trial". Vgl. auch u.a. EGMR Delta $v$. France, Urt. v. 19.12.1990 (11444/85), § 37; EGMR Van Mechelen a.o. v. the Netherlands, Urt. v. 23.4 .1997 (21363/93 a.o.), §§ 59, 62. Siehe auch R. Friedman, in: Jackson u.a. (Hrsg.), Crime, S. 268; Wohlers, FS für Trechsel, S. 816. 
vom Gericht für die Urteilsfindung tatsächlich verwendet werden können. ${ }^{61}$ Daher ist als Belastungszeuge im Sinne des Art. 6(3d) EMRK sowohl der (mittelbare) „Zeuge vom Hörensagen“ als auch die originäre Auskunftsperson zu betrachten. Entsprechendes gilt im Fall der (per se nicht konventionswidrigen) Verlesung eines früheren Vernehmungsprotokolls einer in der Hauptverhandlung abwesenden Beweisperson: Die Einhaltung der Garantien des kontradiktorischen Verfahrens und des Konfrontationsrechts nach Art. 6(1) i.V.m. Art. 6(3d) EMRK bezieht sich immer auch auf die originäre Beweisquelle. ${ }^{62}$ Schließlich sind auch die Experten ${ }^{63}$ und die Mitbeschuldigten ${ }^{64}$ - trotz einer Vielfalt von hier nicht näher diskutierten

${ }^{61}$ Siehe etwa EKMR Unterpertinger v. Austria, Rep. v. 11.10.1984 (9120/80), § 73: „In view of the fact that the statements of these persons, which contained clear allegations against the applicant, were submitted and relied on by the prosecution, they must be considered as 'witnesses against' the applicant"; und EGMR Gossa v. Poland, Urt. v. 9.1.2007 (47986/99), §56:,,[...] the Court reiterates that the term 'witness' has an 'autonomous' meaning in the Convention system (see Vidal v. Belgium, judgment of 22 April 1992, Series A no. 235-B, pp. 32-33, §33). Thus, where a statement may serve to a material degree as the basis for a conviction, then, irrespective of whether it was made by a witness in the strict sense or by a co-accused, it constitutes evidence for the prosecution to which the guarantees provided by Article $6 \S \S 1$ and 3 (d) of the Convention apply." Siehe auch EGMR Kostovski v. the Netherlands, Urt. v. 20.11 .1989 (11454/85), § 40; EGMR Delta v. France, Urt. v. 19.12.1990 (11444/85), § 34; EGMR Isgrò v. Italy, Urt. v. 19.2.1991 (11339/85), § 33; EGMR Asch v. Austria, Urt. v. 26.4.1991 (12398/86), § 25; EGMR Artner v. Austria, Urt. v. 28.8 .1992 (13161/87), § 19; EGMR Pullar v. the United Kingdom, Urt. v. 10.6.1996 (22399/93), § 45; EGMR S.N. v. Sweden, Urt. v. 2.7.2002 (34209/96), $\S$ 45; EGMR Haas v. Germany, Ent. v. 17.11 .2005 (73047/01), NStZ 2007, 103 (104); EGMR Trofimov v. Russia, Urt. v. 4.12 .2008 (1111/02), § 34. Ferner EGMR Sharkunov and Mezentsev v. Russia, Urt. v. 10.6 .2010 (75330/01), § 111 (bezüglich: statement during the identity parade procedure); EGMR Mirilashvili v. Russia, Urt. v. 11.12.2008 (6293/ 04), $\S \S 158-160$ (bezüglich: "documentary evidence" und "computer files relevant to the criminal accusations against the applicant"). Zum Zeugenbegriff auch $K$. Krau $\beta$, V-Leute, S. 99-102; Mahler, Recht, S. 51-53.

${ }^{62}$ U.a. EGMR Unterpertinger v. Austria, Urt. v. 24.11 .1986 (9120/80), § 31; EGMR Kostovski v. the Netherlands, Urt. v. 20.11 .1989 (11454/85), $\S \S 40-44$; EGMR Windisch v. Austria, Urt. v. 27.9.1990 (12489/86), §§ 23-31.

${ }^{63}$ Siehe etwa EGMR Mirilashvili v. Russia, Urt. v. 11.12.2008 (6293/04), § 158: „As to paragraph 3 (d) of Article 6, it refers to 'witnesses', and, if interpreted strictly, should not be applied to other evidence. However, this term must be given an autonomous interpretation. It can also include victims (see A.H. v. Finland, no. 46602/99, § 41, 10 May 2007), expert witnesses (see Doorson v. the Netherlands, judgment of 26 March 1996, Reports of Judgments and Decisions 1996 II, $\S \S 81-82$ ), and other persons testifying before the court." Siehe auch EKMR Bönisch v. Austria, Rep. v. 12.3 .1984 (8658/79), §§ 85-91; vgl. EKMR Hardiman v. the United Kingdom, Ent. v. 28.2.1996 (25935/94), Complaints: The Law: § 2. Siehe auch LR-StPO-Esser, Art. 6 EMRK Rn. 771; IntKomm-Kühne, Art. 6 Rn. 579 (11. Lieferung 2009). Unklar: EGMR Bönisch v. Austria, Urt. v. 6.5.1985 (8658/ 79), §§ 28-35; EGMR Balsytè-Lideikienè v. Lithuania, Urt. v. 4.11 .2008 (72596/01), § 63-66; vgl. auch EGMR Brandstetter v. Austria, Urt. v. 28.8.1991 (11170/84 a.o.), $\S \S 41-47$. Dazu auch Esser, Strafverfahrensrecht, S. 700-702; Renzikowski, FS für Mehle, S. 532 .

${ }^{64}$ U.a. EGMR Lucà v. Italy, Urt. v. 27.2 .2001 (33354/96), §§ 22, 30, 40-44; EGMR Kaste and Mathisen v. Norway, Urt. v. 9.11.2006 (18885/04, 21166/04), §§ 50-55; EGMR Gossa v. Poland, Urt. v. 9.1.2007 (47986/99), §54-56. LR-StPO-Esser, Art. 6 EMRK 
theoretischen und praktischen Problemen - für die Zwecke des Art. 6(3d) EMRK vom EGMR mehrmals als Belastungszeugen angesehen worden.

Die wichtigsten Kategorien von Belastungszeugen, mit denen sich die Rechtsprechung des EGMR zum Art. 6(3d) EMRK am häufigsten auseinandergesetzt hat, sind: ${ }^{65}$ erstens die aus rechtlichen oder faktischen Gründen ${ }^{66}$ während der öffentlichen Hauptverhandlung abwesenden bzw. nicht persönlich/unmittelbar aussagenden Beweispersonen; ${ }^{67}$ und zweitens die anonymen (und oft zugleich abwesenden) Zeugen. ${ }^{68}$ Die Besonderheiten der relevanten Einzelfälle und Kategorien

Rn. 771; SK-StPO-Paeffgen, Art. 6 EMRK Rn. 162 m.w.N. Zum Konflikt zwischen dem Konfrontationsrecht des Beschuldigten und dem Schweigerecht des Mitbeschuldigten siehe auch Dehne-Niemann, HRRS 4/2010 (online), 189 (191-192).

65 Zusammenfassend m.w.N. EGMR Al-Khawaja and Tahery v. the United Kingdom, Urt. v. 20.1.2009 (26766/05, 22228/06), § 35 .

66 Zur Differenzierung zwischen rechtlichen und faktischen Gründen siehe Grabenwarter/ Pabel, Menschenrechtskonvention, § 24 Rn. 118; Renzikowski, FS für Mehle, S. 540.

${ }^{67} \mathrm{Zu}$ den Fällen von Zeugnisverweigerungsrechten siehe u.a. EGMR Unterpertinger $v$. Austria, Urt. v. 24.11.1986 (9120/80), insb. $\S \S 31-33$; EGMR Asch v. Austria, Urt. v. 26.4.1991 (12398/86), insb. §§ 26-31; EGMR Hümmer v. Germany, Urt. v. 19.7.2012 (26171/07), insb. §§ 37-53. Hinsichtlich der Konfrontation mit Opfern von Sexualstraftaten i.V.m. der Problematik der Opferschutzmaßnahmen siehe u.a. EGMR P.S. v. Germany, Urt. v. 20.12.2001 (33900/96), insb. §§ 22-26, 28-31; EGMR S.N. v. Sweden, Urt. v. 2.7.2002 (34209/96), insb. §§ 46-47, 52; EGMR $W$ v. Finland, Urt. v. 24.4.2007 (14151/ 02), insb. $\S$ 45-48; EGMR A.H. v. Finland, Urt. v. 10.5.2007 (46602/99), insb. § 42; EGMR W.S. v. Poland, Urt. v. 19.6.2007 (21508/02), insb. §§ 55-63; EGMR A.L. v. Finland, Urt. v. 27.1.2009 (23220/04), insb. §§ 36-45. Bezüglich Fällen von Tod und Krankheit des Zeugen siehe u.a. EGMR Ferrantelli and Santangelo v. Italy, Urt. v. 7.8.1996 (19874/92), insb. § 52; EGMR Ubach Mortes v. Andorra, Ent. v. 4.5.2000 (46253/99); vgl. EGMR Bonev v. Bulgaria, Urt. v. 8.6.2006 (60018/00), insb. §§ 43-45. Zur tatsächlichen Unerreichbarkeit und Unauffindbarkeit des Zeugen siehe u.a. EGMR Artner v. Austria, Urt. v. 28.8.1992 (13161/87), insb. §§ 21-24; EGMR Doorson v. the Netherlands, Urt. v. 26.3.1996 (20524/92), insb. §§ 9-10, 18-19, 31-34, 79-80; EGMR Verdam v. the Netherlands, Ent. v. 31.8.1999 (35253/97); EGMR Haas v. Germany, Ent. v. 17.11.2005 (73047/01), NStZ 2007, 103 (103-106); EGMR Gossa v. Poland, Urt. v. 9.1.2007 (47986/ 99), insb. $\S \S 54-65$. Für eine möglichst systematische Betrachtung der Prüfungsschritte, welche die EGMR-Rechtsprechung in derartigen Fällen zur Feststellung einer Konventionsverletzung unternimmt, siehe Demko, ZStrR 2004, 416 (418-434); Esser, JR 2005 , 248 (249-256); Gaede, JR 2006, 292 (293-297); Schleiminger, Konfrontation, S. 9-21. Vgl. auch Schuska, Rechtsfolgen, S. 151-158.

$68 \mathrm{Zu}$ den anonymen ,Zivilen“ Zeugen siehe u.a. EGMR Kostovski v. the Netherlands, Urt. v. 20.11.1989 (11454/85), insb. §§ 41-44; EGMR Windisch v. Austria, Urt. v. 27.9.1990 (12489/86), insb. §§ 26-31; EGMR Saïdi v. France, Urt. v. 20.9.1993 (14647/89), insb. § 44; EGMR Doorson v. the Netherlands, Urt. v. 26.3.1996 (20524/92), insb. §§ 66-76; EGMR Kok v. the Netherlands, Ent. v. 4.7.2000 (43149/98); EGMR Birutis a.o. v. Lithuania, Urt. v. 28.3.2002 (47698/99, 48115/99), insb. §§ 30-34; EGMR Krasniki v. the Czech Republic, Urt. v. 28.2.2006 (51277/99), insb. §§ 80-86. Zu den anonymen Verdeckten Ermittlern siehe u.a. EGMR Lüdi v. Switzerland, Urt. v. 15.6.1992 (12433/86), insb. §§ 43-50; EGMR Van Mechelen a.o. v. the Netherlands, Urt. v. 23.4.1997 (21363/93 a.o.), insb. §§ 49-63. Einen Überblick siehe auch bei K. Krau $\beta, \mathrm{V}-$ Leute, S. 66-78; Ott, Verdeckte Ermittlungen, S. 207-214. Eine Zusammenfassung der Ebenen bei der Prüfung von Konventionsverletzungen in Fällen von anonymen Verdeckten 
sowie die dazu nicht immer einheitliche Rechtsprechung des EGMR können hier nicht analysiert werden. Für alle Fallkonstellationen, die sich auf eine mögliche Verletzung des Konfrontationsrechts beziehen, benutzt der EGMR jedenfalls im Zusatz zu den oben genannten Grundsätzen den sogenannten Lucà-Test ${ }^{69}$ als Prüfungsmaßstab.

Nach der EGMR-Rechtsprechung muss konkreter der Beschuldigte zunächst, wie gesehen, grundsätzlich eine angemessene und ausreichende Gelegenheit während des nationalen Strafprozesses erhalten, den (originären) Belastungszeugen in kontradiktorischer Weise zu widerlegen und ihn bei dessen Vernehmung bzw. Aussage oder auch in einem späteren Verfahrensstadium zu befragen. Die Konventionsstaaten müssen insbesondere in aktiver Weise für die Gewährleistung der Möglichkeit zur effektiven Konfrontation sorgen. ${ }^{70}$ Bei der Abwägung der konkurrierenden Interessen im Strafverfahren sind nur diejenigen die Rechte der Verteidigung einschränkenden Maßnahmen zulässig, welche unabdingbar sind. Zur Sicherstellung eines fairen Verfahrens ist es jedenfalls notwendig, dass sämtliche der Verteidigung durch die Begrenzung ihres unmittelbaren Konfrontationsrechts und die Einschränkung der Garantie des kontradiktorischen Verfahrens entstandenen Schwierigkeiten ausreichend durch counterbalancing factors und strong procedural safeguards ausgeglichen werden. ${ }^{71}$ Die Verwendung von außergerichtlichen Aussagen im Hauptverfahren ist darüber hinaus per se nicht unzulässig. Nach dem Lucà-Test sind aber die Rechte der Verteidigung in einem mit den Garantien des Art. 6 EMRK unvereinbaren Umfang dann begrenzt, wenn eine Verurteilung allein oder in einem entscheidenden ${ }^{72}$ Ausma $\beta$ auf Aussagen beruht, die von einer Person

Ermittlern siehe in EGMR Sapunarescu v. Germany, Ent. v. 11.9.2006 (22007/03). Vgl. auch Jung, GA 2003, 191 (200).

69 Siehe EGMR Lucà v. Italy, Urt. v. 27.2.2001 (33354/96), § 40.

${ }^{70}$ Insbesondere für die Fälle der in der Hauptverhandlung unerreichbaren Zeugen siehe zusammenfassend EGMR Khametshin v. Russia, Urt. v. 4.3.2010 (18487/03), §§ 31-32 m.w.N.: ,[Paragraphs 1 and 3 (d) of Article 6], taken together, require the Contracting States to take positive steps to enable the accused to examine or have examined witnesses against him, such measures being part of the diligence the Contracting States must exercise in order to ensure that the rights guaranteed by Article 6 are enjoyed in an effective manner [...]. If there has been no negligence on the part of the authorities, the impossibility of securing the appearance of a witness at the trial does not in itself make it necessary to halt the prosecution $[\ldots]$...

71 U.a. EGMR (GK) Al-Khawaja and Tahery v. the United Kingdom, Urt. v. 15.12.2011 (26766/05, 22228/06), §§ 118, 141, 144, 147.

72 EGMR (GK) Al-Khawaja and Tahery v. the United Kingdom, Urt. v. 15.12.2011 (26766/05, 22228/06), § 131, hat den Begriff „decisive“ wie folgt definiert: „[The] word 'decisive' should be narrowly understood as indicating evidence of such significance or importance as is likely to be determinative of the outcome of the case. Where the untested evidence of a witness is supported by other corroborative evidence, the assessment of whether it is decisive will depend on the strength of the supportive evidence; the stronger the corroborative evidence, the less likely that the evidence of the absent witness will be treated as decisive.“ 
gemacht wurden, zu deren Vernehmung die Verteidigung weder während der Ermittlungen noch im Hauptverfahren Gelegenheit erhalten hat: ${ }^{73}$

The Court's task under the Convention is [...] to ascertain whether the proceedings as a whole, including the way in which evidence was taken, were fair [...]. The evidence must normally be produced at a public hearing, in the presence of the accused, with a view to adversarial argument. There are exceptions to this principle, but they must not infringe the rights of the defence. As a general rule, paragraphs 1 and 3 (d) of Article 6 require that the defendant be given an adequate and proper opportunity to challenge and question a witness against him, either when he makes his statement or at a later stage [...]. [It] may prove necessary in certain circumstances to refer to depositions made during the investigative stage [...]. If the defendant has been given an adequate and proper opportunity to challenge the depositions, either when made or at a later stage, their admission in evidence will not in itself contravene Article $6 \S \S 1$ and 3 (d). The corollary of that, however, is that where a conviction is based solely or to a decisive degree on depositions that have been made by a person whom the accused has had no opportunity to examine or to have examined, whether during the investigation or at the trial, the rights of the defence are restricted to an extent that is incompatible with the guarantees provided by Article $6[\ldots]$.

\section{c) Die Gesamtbetrachtung der Verfahrensfairness}

Der Lucà-Test und die übrigen Leitlinien zur kontradiktorischen Beweiserhebung und zum Konfrontationsrecht - als das ,spezielle Prüfungsmodell“74 der EGMR-Rechtsprechung - werden vom Gerichtshof nicht in allen Einzelfällen ${ }^{75}$ immer in einheitlicher bzw. systematisch klarer Weise angewendet. In den letzten Jahren wirkt auch hierbei als Katalysator für die weitere Relativierung des selbstständigen Wirkungsanspruchs der Einzelgarantien des Art. 6 EMRK die vom EGMR befürwortete Gesamtbetrachtung der Verfahrensfairness. ${ }^{76}$ Wie sich aus der

73 EGMR Lucà v. Italy, Urt. v. 27.2 .2001 (33354/96), §§ 38-40 m.w.N. Siehe u.a. auch EGMR Gossa v. Poland, Urt. v. 9.1.2007 (47986/99), §§ 54-55; EGMR Babkin v. Russia, Ent. v. 8.1.2009 (14899/04); EGMR Taxquet v. Belgium, Urt. v. 13.1.2009 (926/05), § 58; EGMR Al-Khawaja and Tahery v. the United Kingdom, Urt. v. 20.1.2009 (26766/05, 22228/06), §§ 36-37; EGMR Mika v. Sweden, Ent. v. 27.1.2009 (31243/06), § 35; EGMR Caka v. Albania, Urt. v. 8.12.2009 (44023/02), § 102; EGMR Sharkunov and Mezentsev v. Russia, Urt. v. 10.6.2010 (75330/01), §§ 113-114. Der EGMR hat neuerdings, allerdings nicht durchweg in konsistenter bzw. deutlicher Weise, versucht, den Inhalt des Lucà-Tests und der übrigen relevanten Leitsätze und Begriffe seiner Rechtsprechung, insb. der Voraussetzung ,that there be a good reason for admitting the evidence of an absent witness", der ,sole or decisive“-Regel und der „,counterbalancing factors“, genauer zu konkretisieren, siehe EGMR (GK) Al-Khawaja and Tahery v. the United Kingdom, Urt. v. 15.12.2011 (26766/05, 22228/06), insb. §§ 118-147.

74 Esser, in: Marauhn (Hrsg.), Bausteine, S. 59.

75 Dies wird schon durch die Gegenüberstellung der in dieser Arbeit zitierten Urteile und Entscheidungen zum Konfrontationsrecht sichtbar.

${ }^{76}$ Eingehend zur Gesamtbetrachtung in der EGMR-Rechtsprechung Gaede, Fairness, S. $427-460$. 
Gegenüberstellung der zwei EGMR-Urteile zum Al-Khawaja and Tahery-Fall ${ }^{77}$ ergibt, ist selbst das Verständnis des EGMR in Bezug auf die inhaltliche Reichweite und die Stellung der Gesamtbetrachtung der Verfahrensfairness innerhalb der Methoden zur Prüfung einer Konventionsverletzung nicht stabil geblieben.

In seiner Rechtsprechung zum Art. 6(1) EMRK und zu den besonderen Garantien des Art. 6(3) EMRK und insbesondere zum Konfrontationsrecht hat der EGMR, wie gesehen, immer Gewicht auf die Prüfung gelegt, ob das nationale Strafverfahren in seiner Gesamtheit fair war. So hat der EGMR mehrmals betont, dass die Aufgabe des Gerichtshofs der Konvention zufolge nicht darin besteht zu entscheiden, ob Aussagen von Zeugen ordnungsgemäß als Beweise zugelassen wurden, sondern vielmehr festzustellen, ob das Verfahren insgesamt, einschließlich der Art, in der die Beweise aufgenommen wurden, fair war. ${ }^{78}$ Auch das Recht auf umfassende kontradiktorische Beweiserhebung und unmittelbare Examinierung der Zeugen in einer öffentlichen Verhandlung wird vom EGMR nicht als absolut betrachtet und seine innerstaatliche Wahrung wird nicht ausschließlich selbstständig, sondern im Zusammenhang mit anderen Fairnessaspekten geprüft. Die Einschränkung dieser Teilgarantien und Verteidigungsrechte wegen anderer konkurrierender Interessen kann laut EGMR unter Berücksichtigung der konkreten Umstände des jeweiligen Einzelfalls eventuell durch eine allgemein faire Ausgestaltung des ganzen Verfahrens kompensiert werden. ${ }^{79}$ Der EGMR hat bisher die zur Gewährleistung der Gesamtfairness erforderlichen Kompensationsfaktoren - bei Einschränkungen des unmittelbaren Konfrontationsrechts z.B. das Vorliegen einer Möglichkeit zur Zeugenbefragung durch den Verteidiger in vorherigen Verfahrensstadien oder die Verwendung von Videoaufzeichnungen bei den Vernehmungen und ihr Verhältnis zueinander nicht vereinheitlicht und abschließend aufgelistet.

Im Rahmen seiner Prüfungskompetenz ist es dem EGMR als internationalem Gerichtshof für Menschenrechte wichtiger, in jedem Einzelfall ex post und in concreto zunächst die einzelnen Umstände festzustellen, die einen negativen Einfluss auf die Fairness des jeweiligen nationalen Verfahrens haben und die eine unmittelbare Beschränkung bzw. Verletzung einer der besonderen Garantien des Art. 6(1) oder 6(3) EMRK verursachen können. Anschließend geht der EGMR meistens zur

77 EGMR Al-Khawaja and Tahery v. the United Kingdom, Urt. v. 20.1.2009 (26766/05, 22228/06) und EGMR (GK) Al-Khawaja and Tahery v. the United Kingdom, Urt. v. 15.12.2011 (26766/05, 22228/06).

78 EGMR Doorson v. the Netherlands, Urt. v. 26.3 .1996 (20524/92), § 67. Siehe auch z.B. EGMR Kostovski v. the Netherlands, Urt. v. 20.11 .1989 (11454/85), § 39.

79 Siehe etwa die nicht durchweg einheitlich angewandten Kompensationskriterien für die Fälle von anonymen Informanten in EGMR Kostovski v. the Netherlands, Urt. v. 20.11.1989 (11454/85), insb. §§ 38-39, 41-45; EGMR Windisch v. Austria, Urt. v. 27.9.1990 (12489/86), insb. §§ 25-28, 30-32; EGMR Doorson v. the Netherlands, Urt. v. 26.3.1996 (20524/92), insb. $\S \S 68-69,72-80,83$. Vgl. noch EGMR Unterpertinger v. Austria, Urt. v. 24.11.1986 (9120/80), insb. §§ 29-31. Vgl. auch Beulke, FS für Riess, S. 7; Simon, Beschuldigtenrechte, S. 109. 
Prüfung der Gesamtfairness des Verfahrens über. ${ }^{80}$ Er betrachtet hierfür das nationale Strafverfahren als Ganzes, einschließlich der Existenz von prozeduralen Garantien und counterbalancing factors zur Sicherstellung der Verfahrensfairness.

Trotz dieser Prüfungsmethode des EGMR wurde jedoch im ersten Al-Khawaja and Tahery-Urteil zum Konfrontationsrecht ausdrücklich betont, dass die nationalen Verfahrenssysteme die Garantien des Art. 6 EMRK, auch die Teilgarantien des Art. 6(3), als explizite selbstständige Mindeststandards ${ }^{81}$ eines fairen Verfahrens wahrnehmen müssen - und nicht als bloße Paradigmen von Angelegenheiten, die im Rahmen der Erwägungen hinsichtlich der Frage, ob ein faires Verfahren stattgefunden hat, berücksichtigt werden müssen. Dem vorgenannten Urteil zufolge bedeutete dies gleichermaßen für die Prüfung möglicher Konventionsverletzungen durch den EGMR, dass auch dann, wenn die einzelnen Mindestrechte der Konvention im nationalen Verfahren respektiert worden sind, das allgemeine Recht auf fair trial nach Art. 6(1) verlangt, dass der Europäische Gerichtshof auch festzustellen hat, ob das Verfahren insgesamt fair durchgeführt worden ist:

Article $6 \S 3(\mathrm{~d})$ is an aspect of the right to fair trial guaranteed by Article $6 \S 1$, which, in principle, requires that all evidence must be produced in the presence of the accused in a public hearing with a view to adversarial argument [...]. As with the other elements of Article $6 \S 3$, it is one of the minimum rights which must be accorded to anyone who is charged with a criminal offence. As minimum rights, the provisions of Article $6 \S 3$ constitute express guarantees and cannot be read, as it was by the Court of Appeal in Sellick [...], as illustrations of matters to be taken into account when considering whether a fair trial has been held [...]. Equally, even where those minimum rights have been respected, the general right to a fair trial guaranteed by Article $6 \S 1$ requires that the Court ascertain whether the proceedings as a whole were fair. ${ }^{82}$

Gleichwohl verwendet das zweite - vom ersten sich auch hinsichtlich der abschließenden Feststellung der Konventionsverletzungen teilweise unterscheidende - Urteil der Großen Kammer des EGMR zum Al-Khawaja and Tahery-Fall nicht mehr diese Grundannahme als Anknüpfungspunkt. ${ }^{83}$ Im Prinzip hat zwar auch die Große Kammer die Bedeutung des Lucà-Tests für die Wahrung des Mindestkerns des völkerrechtlich vorgeschriebenen Konfrontationsrechts und somit die notwendige Schlussfolgerung anerkannt, dass eine Verurteilung in der Regel nicht allein oder maßgeblich (,sole or decisive“) auf Aussagen gestützt werden darf, welche

80 Vgl. EGMR Doorson v. the Netherlands, Urt. v. 26.3.1996 (20524/92), § 83; EGMR Mirilashvili v. Russia, Urt. v. 11.12.2008 (6293/04), §§ 164-166 (§ 166: „In sum, in order to determine whether there has been a breach of Article $6 \S \S 1$ and 3, the Court may have to examine separately each limb of the applicant's complaint and then make an overall assessment").

81 Vgl. auch Gaede, JR 2009, 493 (495); Jung, GA 2009, 235 (240). Vgl. noch Beulke, FS für Riess, S. 17-18.

82 EGMR Al-Khawaja and Tahery v. the United Kingdom, Urt. v. 20.1.2009 (26766/05, 22228/06), § 34 .

${ }^{83}$ Kritische Besprechungen des Urteils der Großen Kammer siehe u.a. bei Du BoisPedain, HRRS 3/2012 (online), 120 (120-138); Guirao, FS für Wolter, S. 840-844; Jung, FS für Kühl, S. 915-922; Meyer, HRRS 3/2012 (online), 117 (117-120). 
die Verteidigung in keinem Verfahrensstadium konfrontieren konnte. ${ }^{84}$ Praktisch im Gegensatz zum ersten Urteil der Kammer hat aber die Große Kammer bei der Auslegung der "sole or decisive rule" festgestellt, dass es sich hierbei nicht um eine absolute Regel handelt, deren Verletzung automatisch zur Bejahung einer Fairnessverletzung nach Art. 6(1) EMRK führen muss. ${ }^{85}$

Vielmehr hat der EGMR beim zweiten Al-Khawaja and Tahery-Urteil in absoluter Weise über den zentralen Wert der Gesamtbetrachtung der Verfahrensfairness für die letztendliche Feststellung einer Konventionsverletzung mit Blick auf die Garantien des Art. 6(1) und 6(3) EMRK gesprochen. Die Erweiterung dieser Prüfungspraxis ermöglicht eventuell, wie der EGMR selbst bemerkt, die effektivere Berücksichtigung der Besonderheiten des jeweiligen Rechts- und Beweissystems, z.B. im konkreten Fall des englischen Verfahrenssystems und seiner hearsay-Regel mit ihren modernen Ausnahmen. ${ }^{86}$ Gleichzeitig ist aber nicht zu leugnen, dass dadurch allgemein neue Wege zu weiteren Relativierungen bzw. zur völligen Verneinung der Selbstständigkeit der EMRK-Teilgarantien eröffnet werden können. Hierzu zählt auch die innerstaatliche Verbreitung der Gesamtbetrachtungsmethode und die Durchsetzung von Beweiswürdigungslösungen ${ }^{87}$ zum Ausgleich der Einschränkungen der einzelnen Konventionsrechte in den nationalen Strafverfahren (wie z.B. die Beweiswürdigungslösung der deutschen Rechtsprechung bei Angelegenheiten zum Konfrontationsrecht). ${ }^{8}$ Insbesondere können folgende Ausführungen der Großen Kammer des EGMR zur Gesamtbetrachtung der Verfahrensfairness die Basis für solche Entwicklungen darstellen, die einer Stärkung der subjektiven Mitwirkungsrechte der Verteidigung eher abträglich sind: ${ }^{89}$

${ }^{84}$ Siehe EGMR Al-Khawaja and Tahery v. the United Kingdom, Urt. v. 20.1.2009 (26766/05, 22228/06), §§ 34-36 und EGMR (GK) Al-Khawaja and Tahery v. the United Kingdom, Urt. v. 15.12.2011 (26766/05, 22228/06), §§ 89-90, 118-119, 127-128, 139$140,142$.

85 EGMR (GK) Al-Khawaja and Tahery v. the United Kingdom, Urt. v. 15.12.2011 (26766/05, 22228/06), §§ 146-147.

86 Siehe EGMR (GK) Al-Khawaja and Tahery v. the United Kingdom, Urt. v. 15.12.2011 (26766/05, 22228/06), § 146 .

87 Vgl. EGMR (GK) Al-Khawaja and Tahery v. the United Kingdom, Urt. v. 15.12.2011 (26766/05, 22228/06), §§ 141, 147, 155-158, 165. Vgl. auch EGMR Haas v. Germany, Ent. v. 17.11.2005 (73047/01) mit kritischen Anmerkungen von Esser, NStZ 2007, 106 (106-109); Gaede, JR 2006, 292 (292-297).

88 Siehe u.a. BVerfG, NJW 2010, 925 (insb. 925-926); BGHSt 46, 93 (insb. 95-97, 103-106); BGHSt 49, 112 (insb. 117-119); BGH, NJW 2005, 1132 (1132-1133); BGH, NStZ-RR 2005, 321 (321); BGH, JR 2007, 300 (insb. 302-303); BGH, NJW 2010, 2224 (2225). So hat z.B. Schroeder, GA 2003, 293 (295), schon früher festgestellt: „Schließlich wird der Hinweis auf die erforderliche Gesamtbetrachtung von den nationalen Gerichten nur allzu gern aufgegriffen, um Vorgaben des EGMR zu unterlaufen."

89 EGMR (GK) Al-Khawaja and Tahery v. the United Kingdom, Urt. v. 15.12.2011 (26766/05, 22228/06), §§ 143-144, 146-147. Neuerdings bestätigt u.a. durch EGMR Blokhin v. Russia, Urt. v. 14.11.2013 (47152/06), §§ 162-163; EGMR Rosin v. Estonia, Urt. v. 19.12.2013 (26540/08), §§ 50-53; EGMR Lučić v. Croatia, Urt. v. 27.2.2014 
143. [...] the Court has always interpreted Article $6 \S 3$ in the context of an overall examination of the fairness of the proceedings. [...]

144. Traditionally, when examining complaints under Article $6 \S 1$, the Court has carried out its examination of the overall fairness of the proceedings by having regard to such factors as the way in which statutory safeguards have been applied, the extent to which procedural opportunities were afforded to the defence to counter handicaps that it laboured under and the manner in which the proceedings as a whole have been conducted by the trial judge [...].

146. The Court is of the view that the sole or decisive rule should also be applied in a similar manner. It would not be correct, when reviewing questions of fairness, to apply this rule in an inflexible manner. Nor would it be correct for the Court to ignore entirely the specificities of the particular legal system concerned and, in particular its rules of evidence $[\ldots]$. To do so would transform the rule into a blunt and indiscriminate instrument that runs counter to the traditional way in which the Court approaches the issue of the overall fairness of the proceedings, namely to weigh in the balance the competing interests of the defence, the victim, and witnesses, and the public interest in the effective administration of justice.

147. The Court therefore concludes that, where a hearsay statement is the sole or decisive evidence against a defendant, its admission as evidence will not automatically result in a breach of Article $6 \S 1$. At the same time where a conviction is based solely or decisively on the evidence of absent witnesses, the Court must subject the proceedings to the most searching scrutiny. Because of the dangers of the admission of such evidence, it would constitute a very important factor to balance in the scales [...] and one which would require sufficient counterbalancing factors, including the existence of strong procedural safeguards. The question in each case is whether there are sufficient counterbalancing factors in place, including measures that permit a fair and proper assessment of the reliability of that evidence to take place. This would permit a conviction to be based on such evidence only if it is sufficiently reliable given its importance in the case.

\section{B. Schlussfolgerungen: EMRK und Beweisführungsmodelle}

Eine sorgfältige und systematische Berücksichtigung der Kernbestimmungen der Rechtsprechung des EGMR zu Art. 6 EMRK seitens der europäischen Länder kann eventuell die Harmonisierung einzelner Bereiche der nationalen Strafprozessrechte erleichtern. Es ist aber nicht zu leugnen, dass das EMRK-System und der EGMR selbst zumindest zum Teil der Harmonisierung Hindernisse in den Weg legen. Der EGMR kann freilich als internationaler Menschenrechtsgerichtshof mit sehr spezifischen Kompetenzen die Rechte und Garantien der Konvention nur auf eine bestimmte Art und Weise auslegen. Insbesondere seine einzelfallbezogene, oft fragmentarische und hinsichtlich der mehrmals auftretenden prozessualen Teilfragen nicht durchweg einheitliche bzw. deutliche Rechtsprechung dient aber nicht wirklich der Bereitstellung eines umfassenden, klaren und konsistenten systemübergrei-

(5699/11), §§ 71-73; EGMR Matytsina v. Russia, Urt. v. 27.3.2014 (58428/10), § 152; EGMR Schatschaschwili v. Germany, Urt. v. 17.4.2014 (9154/10), §§ 62-66 m.w.N.; EGMR Cevat Soysal v. Turkey, Urt. v. 23.9.2014 (17362/03), §§ 74-75. 
fenden Vorbilds für die Ausgestaltung des Strafprozesses in den Konventionsländern. ${ }^{90}$ Darüber hinaus ist die gegenwärtige Erweiterung von Prüfungspraktiken des EGMR wie etwa der Gesamtbetrachtung der Verfahrensfairness in Betracht zu ziehen; Letztere leistet den vorangegangenen Analysen zufolge einer willkürlichen Relativierung des Wirkungsanspruchs der einzelnen strafprozessualen Konventionsgarantien während ihrer innerstaatlichen Umsetzung eher Vorschub, als dass sie eine solche Einschränkung erschwert.

Vor allem erscheint es immer noch wenig aussichtsreich, anhand der EMRK„Rechtsordnung“ ein kohärentes Beweisverfahrensmodell zu entwickeln, das auf rechtspolitischer Ebene wenigstens der Ausbalancierung der strukturellen Eigenheiten und Exzesse der nationalen Beweisführungssysteme dienen bzw. auf analytisch-vergleichender Ebene ergänzend oder sogar ersetzend zur klassischen Dichotomie zwischen ,,adversatorischem“ und ,inquisitorischem“ Verfahrenstyp wirken könnte. Freilich hat der EGMR durch seine gefestigte Rechtsprechung zum Art. 6(1) i.V.m. Art. 6(3) EMRK auch neutrale „Leitlinien“ mit autonomem Wirkungsanspruch erlassen, die sich unter anderem auf beweisprozessuale Angelegenheiten beziehen. Von zentraler Bedeutung sind hierbei, wie gesehen, die Bestimmungen zu den zentralen Fairnessprinzipien der ,equality of arms“ und der ,adversarial proceedings“. Diese lassen sich anhand der Rechtsprechung des EGMR, insbesondere vor dem Hintergrund der autonomen und dynamischen Interpretation der Teilrechte des Angeklagten auf Vorbereitung einer effektiven Verteidigung und auf Beweisoffenlegung aller entlastenden und belastenden Beweise, auf Ladung von Entlastungszeugen und Sachverständigen unter gleichen Bedingungen wie die Gegenpartei sowie auf kontradiktorische Prüfung des Zeugenbeweises inhaltlich konkretisieren. Gemeinsamer Ansatz der abstrakten Ausführungen des EGMR zu diesen Grundlagen und Teilaspekten des Fairnesssystems der Konvention ist die Sicherstellung der Möglichkeit zur wirksamen, aktiven und waffengleichen Teilhabe des Angeklagten als Hauptsubjekt des Strafverfahrens an allen maßgebenden Strafjustiz- und Gerichtsvorgängen; gleichzeitig wirkt das EMRK-System der Missachtung anderer grundlegender (im Rahmen eines Strafverfahrens möglicherweise konkurrierender) Interessen ausdrücklich entgegen. ${ }^{91}$ Jedenfalls kann die Umsetzung der diesbezüglichen Leitlinien der EGMR-Rechtsprechung folgerichtig gewisse Auswirkungen auch auf die Ausgestaltung der nationalen Beweisverfahren - unabhängig von ihrem rechtstraditionellen Ursprung - haben.

Die eingehende Ausarbeitung eines optimalen, rechtspolitisch bzw. dogmatisch europaweit akzeptablen und in rechtstraditioneller Hinsicht möglichst neutralen Beweisführungsmodells auf der Basis der verbindlichen EMRK-Mindestgarantien

90 Vgl. ferner Esser, Strafverfahrensrecht, S. 859-868. Jung, GA 2009, 235 (235), bemerkt Folgendes: „Die Erwartungen wären jedoch zu hoch gesteckt, wenn sie darauf zielten, dass das Gericht eine Art Modell-Strafprozessordnung für Europa dekretieren könnte.“

91 Vgl. auch Jackson, in: McConville/Wilson (Hrsg.), Handbook, S. 350-351. 
und der entsprechenden EGMR-Bestimmungen ist gleichwohl mit beträchtlichen Schwierigkeiten verbunden. Insbesondere sind bei eventuellen Versuchen, die diversen Fairnessvorgaben der EMRK-,,Rechtsordnung“ als umfassenden und ausgewogenen Lösungsansatz für die grundlegenden strukturellen Probleme des herkömmlichen Straf- und Beweisverfahrens zu typisieren, folgende Hemmfaktoren zu beachten:

Erstens ist der EGMR als internationales Justizorgan jeweils in concreto für die Feststellung von Konventionsverletzungen in Bezug auf die vor ihm vorgebrachten Einzelfälle zuständig. Durch die Verwendung von rechtsvergleichenden Ansätzen bei der Interpretation der Konvention setzt sich zwar der Gerichtshof bei der Prüfung des jeweiligen Einzelfalls oft auf abstrakter Ebene mit den Eigenheiten und Grundprinzipien mehrerer nationaler Rechtsordnungen desselben oder unterschiedlicher Rechtskreise auseinander. Unter anderem berücksichtigt der EGMR dabei die allgemeine prozessstrukturelle Ausrichtung und die diesbezüglichen Entwicklungen und Reformen in den diversen europäischen Verfahrensordnungen. Der EGMR per se ist allerdings weder ein internationales Gesetzgebungsorgan für die abstrakte Schaffung von einheitlichen Prozessregeln und -strukturen mit transnationalem Wirkungsanspruch noch ein Institut oder Forum für die Förderung von rechtspolitischen Reformprogrammen und umfassenden rechtsvergleichenden Forschungen.

Zweitens ist gegenwärtig nicht nur in der EGMR-Rechtsprechung, sondern auch auf Ebene der rechtspolitischen Planungen des Europarats oft die Rede von der Notwendigkeit einer Aufrechterhaltung bzw. Stärkung des subsidiären Charakters des Konventionssystems, der für die begrenzten Prüfungsbefugnisse des EGMR verantwortlich zeichnet. So muss nach dem noch nicht in Kraft getretenen 15. EMRK-Protokoll die Präambel der Konvention um einen ausdrücklichen Hinweis auf das Subsidiaritätsprinzip und die ,margin of appreciation“-Doktrin wie folgt ergänzt werden: „Affirming that the High Contracting Parties, in accordance with the principle of subsidiarity, have the primary responsibility to secure the rights and freedoms defined in this Convention and the Protocols thereto, and that in doing so they enjoy a margin of appreciation, subject to the supervisory jurisdiction of the European Court of Human Rights established by this Convention." ${ }^{\text {(92 }}$

92 Art. 1 Protocol No. 15 amending the Convention on the Protection of Human Rights and Fundamental Freedoms (24.6.2013, CETS No. 213). Im Explanatory Report des 15. Protokolls ( $\S 7-9$, abrufbar unter http://www.echr.coe.int/) wird bestimmt: „7. A new recital has been added at the end of the Preamble of the Convention containing a reference to the principle of subsidiarity and the doctrine of the margin of appreciation. It is intended to enhance the transparency and accessibility of these characteristics of the Convention system and to be consistent with the doctrine of the margin of appreciation as developed by the Court in its case law. [...] 8. The States Parties to the Convention are obliged to secure to everyone within their jurisdiction the rights and freedoms defined in the Convention, and to provide an effective remedy before a national authority for everyone whose rights and freedoms are violated. The Court authoritatively interprets the Convention. It also acts 
Dementsprechend ist es nicht ausgeschlossen, dass eine zentralisierte Betrachtung der bewusst fragmentarischen Vorgaben des EMRK-Systems im Sinne eines selbstständigen supranationalen Modells für die umfassende Reform und Vereinheitlichung der nationalen Beweisverfahrenssysteme am rechtspolitischen Willen der Konventionsländer eventuell scheitern wird. Die Letzteren haben sich nämlich nicht nur die Verantwortung für die Ausgestaltung ihrer nationalen Beweisrechte und Verfahrensordnungen, sondern auch das erste Wort und ein gewisses Ermessen bezüglich der Art und Weise der innerstaatlichen Umsetzung und insbesondere der Auslegung und konkreten Anwendung der Konventionsgarantien vorbehalten.

Drittens beziehen sich die Vorschriften des Art. 6(1) und Art. 6(3) EMRK, wie vom EGMR interpretiert, primär auf den Anspruch des Angeklagten auf wirksame Verteidigung gegen die Strafklage. Auf die Ausübung dieser subjektiven Verfahrensrechte kann grundsätzlich verzichtet werden. ${ }^{93}$ Die Leitlinien der EGMRRechtsprechung hinsichtlich der Wahrung der Verteidigungsrechte dürfen offensichtlich - auch wenn sie gleichzeitig durch Bestimmungen zum strafprozessualen Schutz der Rechte Dritter bzw. der staatlichen Interessen ergänzt werden - nicht mit Vorgaben verwechselt werden, welche die strukturelle Ausgestaltung des Strafprozesses und die Rollenverteilungen innerhalb der nationalen Beweisverfahren unmittelbar prägen sollen. ${ }^{94}$

as a safeguard for individuals whose rights and freedoms are not secured at the national level. 9. The jurisprudence of the Court makes clear that the States Parties enjoy a margin of appreciation in how they apply and implement the Convention, depending on the circumstances of the case and the rights and freedoms engaged. This reflects that the Convention system is subsidiary to the safeguarding of human rights at national level and that national authorities are in principle better placed than an international court to evaluate local needs and conditions. The margin of appreciation goes hand in hand with supervision under the Convention system. In this respect, the role of the Court is to review whether decisions taken by national authorities are compatible with the Convention, having due regard to the State's margin of appreciation."

93 Dazu u.a. mit Rechtsprechungshinweisen Esser, in: Marauhn (Hrsg.), Bausteine, S. 48; Grabenwarter, Commentary, Art. 6 Rn. 135, 141.

94 Vgl. Esser, in: Marauhn (Hrsg.), Bausteine, S. 42: „Aber auch dieses Beschuldigtenrecht [das Frage- und Konfrontationsrecht] ist eine Garantie, die an die Person des Beschuldigten anknüpft und sich nur mittelbar als ein an das erkennende Gericht adressierter Verfahrensgrundsatz bezeichnen lässt. [...] Die EMRK ist eine Konvention von Menschenrechten, die an die Person und den Status ihres Trägers anknüpft, und keine Modellstrafprozessordnung. Soweit diese menschenrechtlichen Garantien einen strafprozessualen Bezug haben, schützen sie größtenteils den Beschuldigten, daneben aber auch die Rechte Dritter, die von strafprozessualen Zwangsmaßnahmen betroffen werden. [...] Die hierbei [vom EGMR] aufgestellten Grundsätze erfüllen im Gegensatz zu den Vorschriften einer Strafprozessordnung keinen allgemeinen Verfahrenszweck, sondern dienen einzig und allein dem Schutz des durch eine staatliche Maßnahme betroffenen Menschenrechts und seines Trägers." Vgl. auch Krausbeck, Konfrontative Zeugenbefragung, S. 28-29, der bemerkt, dass das Konfrontationsrecht ausschließlich als Verteidigungsrecht und nicht als Mittel zur Wahrheitsfindung verstanden werden muss. 
Viertens sollen die wenigen und grundsätzlich zurückhaltenden Äußerungen des EGMR zu beweisprozessualen Themen nicht als selbstständige Verfahrensgrundsätze getrennt von der Auslegung der subjektiven Verfahrensrechte des Art. 6(1, 3) EMRK betrachtet werden. Insbesondere sind die Ausführungen der EGMRRechtsprechung zum Prinzip der ,adversarial proceedings“ nicht als normativer Anknüpfungspunkt für die Konstruktion von objektiven Beweisführungsmodellen auf der Basis der EMRK-Vorgaben zu verstehen. Nicht einmal durch die Verwendung des Begriffs ,adversarial“ in der Rechtsprechung des Gerichtshofs wird, wie gesehen, eine Gleichsetzung der fair trial-Garantien mit den parteienzentrierten Strukturen mehrerer common law-Verfahrenssysteme, in denen diese Terminologie üblich ist, angestrebt. ${ }^{95}$ Der EGMR befürwortet allgemein kein bestimmtes Beweisführungssystem für die Konventionsländer - Fairnessgesichtspunkte müssen in jedes Rechtssystem unabhängig vom angewandten Prozessmodell eingebaut werden. Er hat sich vielmehr in systemneutraler Weise mehrmals um die Feststellung von Fairnessverletzungen sowohl in klassischen partei- als auch in richterzentrierten Verfahrenssystemen bzw. sowohl in Rechtsordnungen angloamerikanischer als auch kontinentaleuropäischer Prägung bemüht. ${ }^{96}$ Die Rechtsprechung des EGMR gilt letztendlich auf europäischer Ebene als Garant und Orientierungspunkt für die einheitliche und effektive innerstaatliche Wahrung von grundlegenden, völkerrechtlich vorgeschriebenen Mindestrechten und Verfahrensgarantien; daneben ist die Aufstellung von Beweisverfahrenstypen bisher für die EMRK-,,Rechtsordnung“ eine systemfremde, primär nationalstaatliche Angelegenheit geblieben.

\section{Die Beweisführung im IStGH-System}

Bei der Auseinandersetzung mit dem EMRK-System wurde der Schwerpunkt hauptsächlich auf die Frage gelegt, ob durch die Konventionsvorgaben ein bestimmter Verfahrenstyp für alle Mitgliedsstaaten gefordert wird bzw. ob die systematische Betrachtung der Rechtsprechung des EGMR zu Art. 6 EMRK die Konstruktion eines neuen, systemübergreifenden Beweisführungsmodells für theoretisch-analytische oder rechtspolitische Zwecke ermöglicht. Bei Verfahren vor dem (ständigen und auf der Basis eines sehr breiten internationalen Konsenses eingerichteten) Internationalen Strafgerichtshof geht es dagegen um die Untersuchung der Beweisverfahrensstrukturen und Rollenverteilungen, die bei der internationalen gerichtlichen Ermittlung von in vielerlei Hinsicht komplexen und aufwendigen

95 Siehe insb. unter Teil 3, II.A.2.

96 Vgl. auch Jackson, in: Jackson u.a. (Hrsg.), Crime, S. 233-234 m.w.N. 
Sachverhalten mit völkerstrafrechtlichem Bezug tatsächlich Anwendung finden. ${ }^{97}$ Mit Blick auf die vorliegenden zentralen Forschungsfragen ist hierbei unter anderem die Untersuchung der Dynamiken hinsichtlich der internationalen Entwicklung von Verfahrenssystemen bzw. Prozesstypen mit gemischten oder hybriden Charakteristika von besonderer Bedeutung.

Die vorliegende Arbeit kann sich freilich, wie schon erläutert wurde, weder mit allen Themen der internationalen Strafgerichtsbarkeiten ${ }^{98}$ noch in detaillierter Weise mit sämtlichen Aspekten des Strafverfahrensrechts des IStGH-Systems auseinandersetzen. Im Folgenden werden, nach einer Einführung in den Ablauf des IStGH-Verfahrens (unter A.) und in die Ziele und Besonderheiten des internationalen Strafjustizsystems und -verfahrens (unter B.1.), die vorbereitenden Beweisvorgänge im Vorfeld des IStGH-Hauptverfahrens (unter B.2.) und anschließend die Beweisführungen vor der Hauptverfahrenskammer des IStGH (unter B.3.) in prozessstruktureller Hinsicht diskutiert. Der abschließende Abschnitt (unter C.) betrachtet dann in zusammenfassender, klassifizierender und wertender Weise die angesprochenen beweisprozessualen Themen unter Berücksichtigung auch der definitorischen und vergleichenden Ergebnisse und der rechtspolitischen Schlussfolgerungen der vorangehenden Teile der Arbeit.

\section{A. Der Ablauf des Verfahrens vor dem IStGH}

Als Hauptquellen des Strafverfahrensrechts im IStGH-System gelten das IStGHStatut (insbesondere die Teile 2, 4-6, 8-9) und die Verfahrens- und Beweisordnung des Gerichtshofs (Rules of Procedure and Evidence, RPE) ${ }^{99}$ Verfahren vor dem IStGH in Bezug auf Verbrechen, für die der Gerichtshof ratione materiae, ratione personae und ratione loci sowie ratione temporis und nach den Regeln der Komplementarität zuständig ist, ${ }^{100}$ können wie folgt initiiert werden:

- wenn eine Situation, in der es den Anschein hat, dass ein oder mehrere der in Art. 5 IStGH-Statut bezeichneten gravierenden Verbrechen begangen wurden, von einem Vertragsstaat dem Ankläger des IStGH unterbreitet wird;

97 Siehe schon unter Teil 3, I. mit Literaturhinweisen zur geschichtlichen Entwicklung der internationalen Strafgerichtsbarkeiten, zur Zuständigkeit und Organisation des IStGH und zu den Grundlagen des Völkerstrafrechts und -verfahrens.

98 Siehe ferner unter Teil 3, I.

99 Siehe ferner Safferling, International, S. 49-51. Die Texte sind abrufbar u.a. auf Englisch und Französisch auf der amtlichen Webseite des Gerichtshofs unter http://www.icccpi.int [Stand: Oktober 2014]. Die Amtssprachen des Gerichtshofs sind Arabisch, Chinesisch, Englisch, Französisch, Russisch und Spanisch, siehe dazu, zum authentischen Wortlaut von IStGH-Statut und RPE und zu den Urteils- und Arbeitssprachen Art. 50, 128 IStGH-Statut und R. 2, 41-43 RPE. Allgemein zum vom Gerichtshof anwendbaren Recht siehe Art. 21 IStGH-Statut.

100 Siehe dazu Bassiouni, Introduction, S. 655-666. 
- wenn eine derartige Situation vom UN-Sicherheitsrat dem Ankläger unterbreitet wird; oder

- wenn der Ankläger proprio motu Ermittlungen in Bezug auf solche Verbrechen einleitet, wobei aber zur formellen Einleitung der Ermittlungen die Vorverfahrenskammer des IStGH auf Antrag des Anklägers ihre Genehmigung erteilen muss. $^{101}$

Nach Art. 42(1, 2) IStGH-Statut ist der Ankläger - dem stellvertretende Ankläger zur Seite stehen - der Leiter der Anklagebehörde des IStGH und übt sein Amt hauptamtlich aus. Die Anklagebehörde handelt unabhängig als selbstständiges Organ des Gerichtshofs; ihr obliegt es, Unterbreitungen und Informationen in Bezug auf der Gerichtsbarkeit des Gerichtshofs unterliegende Verbrechen entgegenzunehmen und zu prüfen sowie die Ermittlungen durchzuführen und vor dem Gerichtshof die Anklage zu vertreten. ${ }^{102}$ Das Statut bestimmt in Art. 53, welche Angelegenheiten der Ankläger allgemein bei seiner Entscheidung über die Einleitung von Ermittlungen und nach den Ermittlungen über die Fortsetzung der Strafverfolgung (,prosecution“) prüfen muss (insbesondere: das Vorliegen von hinreichenden Verdachtsgründen, die Zulässigkeit nach den Regeln der Komplementarität und das Interesse der Gerechtigkeit); vorgesehen ist u.a. auch die Möglichkeit der Vorverfahrenskammer, die Entscheidung des Anklägers, mit den Ermittlungen bzw. mit der Strafverfolgung nicht weiter fortzufahren, anzufechten. Nach Art. 53(4) IStGHStatut kann der Ankläger selbst seine Entscheidung über die Einleitung der Ermittlungen oder der Strafverfolgung auf der Grundlage neuer Tatsachen oder Informationen jederzeit überprüfen.

Darüber hinaus bestimmt Art. 54(1) IStGH-Statut, dass der Ankläger die Ermittlungen zum Zweck der Wahrheitsfindung auf alle erheblichen entlastenden und belastenden Tatsachen und Beweismittel ausdehnen muss. In Art. 54 IStGH-Statut sind auch weitere Pflichten und Ermittlungsbefugnisse (z.B. hinsichtlich der Beweissammlung, der Zeugenvernehmung und der internationalen Zusammenarbeit) des Anklägers festgelegt. Art. 55 und 60 IStGH-Statut beziehen sich auf die Rechte der Personen (insbesondere des Verdächtigen) und die Menschenrechts- und Fairnessgarantien während der Ermittlungen (u.a. die Selbstbelastungsfreiheit und das Schweigerecht, das Folterverbot, die Belehrungs- und Verteidigungsrechte und die Haftprüfungsrechte). Die gerichtliche Vorverfahrenskammer sorgt nach Art. 56-60 IStGH-Statut auf Antrag bzw. von Amts wegen unter anderem für die Gewährleistung der Wirksamkeit und Ordnungsmäßigkeit der Ermittlungen, für die rechtzeiti-

101 Siehe (auch zu den Ermittlungsmaßnahmen und zur Anklageerhebung) insb. Art. 520, 25-29, 53-61 IStGH-Statut i.V.m. R. 44-62, 104-130 RPE. Zusammenfassend u.a. Satzger, Internationales Strafrecht, § 14 Rn. 5-23, 29-32.

102 Nach Art. 42(3) IStGH-Statut: „The Prosecutor and the Deputy Prosecutors shall be persons of high moral character, be highly competent in and have extensive practical experience in the prosecution or trial of criminal cases. They shall have an excellent knowledge of and be fluent in at least one of the working languages of the Court." 
ge Sicherung von wesentlichen Beweismitteln sowie für den Schutz von Opfern, Zeugen, festgenommenen Personen und empfindlichen Informationen, für die Wahrung der Verteidigungsrechte und für die Anordnung der eingreifenden Zwangsmaßnahmen (insbesondere: Haftbefehl bzw. Ladung und selbstständige Ermittlungen des Anklägers in einem Vertragsstaat).

Die Vorverfahrenskammer ist ferner nach Art. 61 IStGH-Statut für die Bestätigung der Anklagepunkte vor dem Hauptverfahren (,,confirmation of the charges before trial“) zuständig. Genauer muss die Vorverfahrenskammer nach Art. 61(1, 2) innerhalb einer angemessenen Frist nach Überstellung der betreffenden Person oder ihrem freiwilligen Erscheinen vor dem Gerichtshof eine mündliche Verhandlung grundsätzlich in Anwesenheit des Anklägers, der Person und ihres Verteidigers abhalten, um die Anklagepunkte zu bestätigen, die der Ankläger zum Gegenstand des Hauptverfahrens zu machen beabsichtigt. Nach Art. 61(4) kann der Ankläger vor der mündlichen Verhandlung die Ermittlungen fortsetzen und Anklagepunkte ändern oder zurücknehmen. Nach Art. 61(5) muss der Ankläger bei der mündlichen Verhandlung jeden Anklagepunkt durch ausreichende Beweise belegen, um den dringenden Verdacht (,substantial grounds“) zu begründen, dass die betreffende Person das angeklagte Verbrechen begangen hat; der Ankläger kann sich dabei auf schriftliche oder ,summarische“ Beweise stützen und ist nicht verpflichtet, die Zeugen aufzurufen, deren Aussage im Verfahren erwartet wird. Die betreffende Person kann ihrerseits nach Art. 61(6) vor der Vorverfahrenskammer Einwendungen gegen die Anklagepunkte vorbringen, die vom Ankläger beigebrachten Beweismittel anfechten und Beweismittel beibringen. Die Vorverfahrenskammer muss dann nach Art. 61(7) auf der Grundlage der mündlichen Verhandlung feststellen, ob ausreichende Beweise für die Begründung des dringenden Verdachts vorliegen; die Vorverfahrenskammer muss diejenigen Anklagepunkte, bezüglich derer sie entschieden hat, dass ausreichende Beweise vorliegen, bestätigen und entsprechend die betreffende Person einer Hauptverfahrenskammer zuweisen. Nach Art. 61(9) kann der Ankläger nach Bestätigung der Anklagepunkte und vor Beginn der Hauptverhandlung mit Genehmigung der Vorverfahrenskammer und nach Benachrichtigung des Angeklagten die Anklagepunkte ändern; nach Beginn der Hauptverhandlung kann der Ankläger mit Genehmigung der Hauptverfahrenskammer die Anklagepunkte zurücknehmen. Nach Art.61(11) ist nach Bestätigung der Anklagepunkte durch die Vorverfahrenskammer nun die Hauptverfahrenskammer für die Durchführung des anschließenden Verfahrens (einschließlich der Hauptverhandlung) zuständig. ${ }^{103}$

Eine Hauptverfahrenskammer besteht jeweils aus drei Richtern (Art. 39 IStGHStatut), ${ }^{104}$ diese sind, wie alle Richter des IStGH, als ,full-time members“ des

103 Zum Hauptverfahren u.a. Ambos, Internationales Strafrecht, § 8 Rn. 37-53.

104 Nach Art. 39(1, 2) IStGH-Statut: „1. The Appeals Division shall be composed of the President and four other judges, the Trial Division of not less than six judges and the Pre- 
Gerichtshofs gewählt worden (Art. 35 IStGH-Statut). Sie sind Staatsangehörige eines Vertragsstaats und sind unter Personen von hohem sittlichem Ansehen ausgewählt worden, die sich durch Unparteilichkeit und Ehrenhaftigkeit auszeichnen und in ihrem Staat die für die höchsten richterlichen Ämter erforderlichen Voraussetzungen erfüllen (Art. 36 IStGH-Statut), und sie sind bei der Erfüllung ihrer Aufgaben unabhängig (Art. 40 IStGH-Statut). ${ }^{105}$ Die Hauptverhandlung vor der Hauptverfahrenskammer findet nach Art. 63, 64(7) IStGH-Statut grundsätzlich öffentlich und in Anwesenheit des Angeklagten statt. Nach Art. 64(2) IStGH-Statut muss die Hauptverfahrenskammer sicherstellen, dass das Hauptverfahren fair und zügig verläuft und unter voller Beachtung der Rechte des Angeklagten (insbesondere der Informations-, Verteidigungs-, Mitwirkungs- und Schweigerechte wie in Art. 67 aufgelistet) und gebührender Berücksichtigung des Schutzes der Opfer und Zeugen (vor allem i.V.m. Art. 68) geführt wird. Die Hauptverhandlung wird vom Vorsitzenden Richter geleitet; dieser kann insbesondere nach Art. 64(8b) IStGH-Statut prozessleitende Verfügungen mit Blick auch auf die Sicherstellung eines fairen und unparteiischen Verfahrens erlassen. Falls der Vorsitzende keine prozessleitenden Verfügungen erlässt, sollen sich der Ankläger und die Verteidigung nach R. 140(1) RPE auf die Reihenfolge und die Art und Weise der Einführung der Beweise in die Hauptverhandlung einigen; falls sie sich nicht einigen können, muss der Vorsitzende diesbezügliche Verfügungen erlassen.

$\mathrm{Zu}$ Beginn der Hauptverhandlung werden nach Art. 64(8a) IStGH-Statut die bestätigten Anklagepunkte vorgelesen; darauf gibt die Hauptverfahrenskammer dem Angeklagten die Gelegenheit, ein Geständnis abzulegen (,,admission of guilt" ${ }^{\text {") }}$ oder

Trial Division of not less than six judges. [...] 2. (a) The judicial functions of the Court shall be carried out in each division by Chambers. (b) (i) The Appeals Chamber shall be composed of all the judges of the Appeals Division; (ii) The functions of the Trial Chamber shall be carried out by three judges of the Trial Division; (iii) The functions of the PreTrial Chamber shall be carried out either by three judges of the Pre-Trial Division or by a single judge of that division in accordance with this Statute and the Rules of Procedure and Evidence; (c) Nothing in this paragraph shall preclude the simultaneous constitution of more than one Trial Chamber or Pre-Trial Chamber when the efficient management of the Court's workload so requires."

105 Siehe ferner Art. 36(3) IStGH-Statut: „[...] (b) Every candidate for election to the Court shall: (i) Have established competence in criminal law and procedure, and the necessary relevant experience, whether as judge, prosecutor, advocate or in other similar capacity, in criminal proceedings; or (ii) Have established competence in relevant areas of international law such as international humanitarian law and the law of human rights, and extensive experience in a professional legal capacity which is of relevance to the judicial work of the Court; (c) Every candidate for election to the Court shall have an excellent knowledge of and be fluent in at least one of the working languages of the Court." Nach Art. 36(8) IStGH-Statut: ,(a) The States Parties shall, in the selection of judges, take into account the need, within the membership of the Court, for: (i) The representation of the principal legal systems of the world; (ii) Equitable geographical representation; and (iii) A fair representation of female and male judges. (b) States Parties shall also take into account the need to include judges with legal expertise on specific issues, including, but not limited to, violence against women or children." 
sich für nicht schuldig zu erklären. In Art. 65 IStGH-Statut sind die Voraussetzungen für die wirksame Ablegung eines Geständnisses sowie dessen Folgen vorgesehen, die hier nicht näher diskutiert werden können. Verständigungserörterungen zwischen dem Ankläger und der Verteidigung sind im Statut nicht verboten; allerdings sind nach Art. 65(5) solche Erörterungen in Bezug auf eine Änderung der Anklagepunkte, das Geständnis oder die zu verhängende Strafe für den Gerichtshof nicht bindend. ${ }^{106}$ Darüber hinaus sind mit Blick auf das erstinstanzliche streitige Hauptverfahren, das vorliegend von Interesse ist und in dem nach Art. 66(2) i.V.m. Art. 67(1i) IStGH-Statut die Beweislast beim Ankläger liegt, die Angelegenheiten hinsichtlich des Vorbringens von Beweismitteln, der Durchführung des Beweisverfahrens und der Mitwirkung der Verteidigung und der Opfer an den Beweisvorgängen hauptsächlich in den Art. 64(3, 6, 8, 9), 67(1), 68(3), 69 IStGH-Statut und in den entsprechenden Vorschriften der RPE geregelt. Nach dem Ende der Beweisaufnahme können der Ankläger und sodann die Verteidigung nach R. 141 RPE ihre Schlussvorträge halten. Daran schließen sich die geheimen Beratungen der Hauptverfahrenskammer nach Art. 74(4) IStGH-Statut i.V.m. R. 142 RPE an, wobei die Richter sich bemühen müssen, ihr Urteil einstimmig zu fällen; gelingt dies nicht, so ergeht das Urteil nach Art. 74(3) durch die Mehrheit der Richter.

Das Urteil der Hauptverfahrenskammer muss sich nach Art. 74(2) IStGH-Statut auf die Würdigung der Beweise und das gesamte Verfahren gründen; das Urteil darf nicht über die in der Anklage dargestellten Tatsachen und Umstände und etwaige Änderungen der Anklage hinausgehen, und der Gerichtshof darf seinem Urteil lediglich die Beweismittel zugrunde legen, die während der Verhandlung beigebracht und vor ihm erörtert wurden. Für eine Verurteilung muss der Gerichtshof nach Art. 66(3) IStGH-Statut von der Schuld des Angeklagten so weit überzeugt sein, dass kein vernünftiger Zweifel besteht (,,beyond reasonable doubt" $\left.{ }^{\circ}\right){ }^{107} \mathrm{Nach}$ Art. 74(5) IStGH-Statut ergeht das Urteil schriftlich und enthält eine vollständige und begründete Darstellung der Ergebnisse der Beweiswürdigung und der Schlussfolgerungen der Hauptverfahrenskammer (,full and reasoned statement of the Trial Chamber's findings on the evidence and conclusions"); das Urteil oder eine Zusammenfassung des Urteils wird in öffentlicher Sitzung verkündet. ${ }^{108}$ Mit Blick auf den Strafspruch kann die Hauptverfahrenskammer von Amts wegen bzw. muss sie auf Antrag eine weitere Verhandlung nach Art. 76(2) IStGH-Statut i.V.m. R. 143 RPE abhalten, um diesbezüglich zusätzliche Beweismittel oder Anträge entgegen-

106 Zur Abspracheproblematik in der internationalen Strafjustiz siehe u.a. Combs, in: Luna/Wade (Hrsg.), Prosecutor, S. 332-347; Rauxloh, Plea Bargaining, S. 204-247; Turner/Weigend, in: Sluiter u.a. (Hrsg.), International, S. 1377-1413. Siehe auch Damaška, JICJ 2 (2004), 1018 (insb. 1030-1039); Eser, in: Swart u.a. (Hrsg.), Legacy, S. 129-131; Petrig, Chi-Kent J. Int'1 \& Comp. L. 8 (2008), 1 (7-31).

107 Zur Problematik des Beweisstandards und der Beweislast in den internationalen Strafgerichtsbarkeiten u.a. Jacobs, in: Sluiter u.a. (Hrsg.), International, S. 1129-1149.

108 Siehe auch R. 144 RPE. 
zunehmen; die Strafe muss nach Art. 76(4) in öffentlicher Sitzung und soweit möglich in Anwesenheit des Angeklagten verkündet werden. In Art. 81-85 IStGHStatut sind schließlich das Berufungs- (,Appeal") und das Wiederaufnahmeverfahren („Revision“) vor der Berufungskammer geregelt. ${ }^{109}$

\section{B. Grundaspekte des Beweisführungssystems}

\section{Einführung: Internationale Zielsetzung und Beweisschwierigkeiten}

Die klare Bestimmung der diversen Ziele der internationalen Strafjustiz, an denen sich ihre gesamte rechtspolitische Leistung messen lässt, stellt ein bisher nicht endgültig gelöstes Problem dar. ${ }^{110}$ In der Lehre werden, unter Rücksichtnahme unter anderem auf die völkerrechtlichen Rechtsvorschriften, Abkommen und Deklarationen sowie auf die Rechtsprechung insbesondere der internationalen ad hocTribunale, meistens folgende (teilweise zu optimistische) Ziele erwähnt: die effektive Beendigung der Straflosigkeit, die Wahrheitsfindung und das Erstellen einer historischen Aufzeichnung (historical record) im Hinblick auf Verbrechen, die so schwer sind, dass sie den Frieden, die Sicherheit und das Wohl der Welt bedrohen; ${ }^{11}$ die Wiedergutmachung für die Opfer; die Versöhnung (reconciliation) zwischen Tätern, Opfern und Gesellschaft; sowie die Wiederherstellung von Frieden, Stabilität und des rule of law in den Post-Konflikt-Gesellschaften. ${ }^{112}$

109 Zusammenfassend dazu u.a. Esser, Europäisches Strafrecht, § 19 Rn. 53-57.

110 Siehe Damaška, in: Cassese (Hrsg.), Oxford Companion, S. 175 (vgl. auch S. 186: „As the ancient mariners used to say, no winds are favourable to a ship without a clear destination").

111 Vgl. die Präambel des IStGH-Statuts: „The States Parties to this Statute, [...] Recognizing that such grave crimes threaten the peace, security and well-being of the world, Affirming that the most serious crimes of concern to the international community as a whole must not go unpunished and that their effective prosecution must be ensured by taking measures at the national level and by enhancing international cooperation, Determined to put an end to impunity for the perpetrators of these crimes and thus to contribute to the prevention of such crimes, [...], Determined to these ends and for the sake of present and future generations, to establish an independent permanent International Criminal Court in relationship with the United Nations system, with jurisdiction over the most serious crimes of concern to the international community as a whole, [...]." Vgl. auch Assembly of States Parties, Strategic Plan of the International Criminal Court (unter III.), ICC-ASP/5/6, Fifth session, 4 August 2006, abrufbar unter http://www.icc-cpi.int/en_menus/asp/sessions/ documentation $/ 5$ th $\% 20$ session/Pages/fifth $\% 20$ session $\% 20$ of $\% 20$ the $\% \overline{2} 0$ assembly $\% 20$ of $\%$ 20states\%20parties.aspx [Stand: Oktober 2014].

112 Siehe u.a. die kritischen Ausführungen und differenzierenden Betrachtungen von Cryer/Friman/Robinson/Wilmshurst, Introduction, S. 28-45; Damaška, Chi.-Kent L. Rev. 83 (2008), 329 (331-340) und Damaška, in: Cassese (Hrsg.), Oxford Companion, S. 177184; Eser, in: Swart u.a. (Hrsg.), Legacy, S. 109-117 m.w.N.; Fedorova, Principle, S. 131-140; Jackson/Summers, Internationalisation, S. 111-112; Knust, Strafrecht, S. 4097; Ohlin, in: Sluiter u.a. (Hrsg.), International, S. 55-68. Vgl. auch Jackson, JICJ 7 
An dieser Stelle können diese allgemeinen und übergeordneten Ziele und Aufgaben der internationalen Strafgerichtsbarkeiten, ihre Teildifferenzierungen und Hierarchisierungen sowie die entsprechenden Spannungsverhältnisse - die sich u.a. auf Verfahrensebene z.B. in guilty plea- und plea bargaining-Fällen zwischen Effektivitäts-, Wahrheits- und Versöhnungserwägungen ergeben können - nicht im Einzelnen angesprochen werden. In Einklang mit dem vorliegend definierten Analyserahmen ${ }^{113}$ sowie mit den vorangehenden abstrakt-theoretischen und vergleichenden Teilen der Arbeit betreffen die nachfolgenden Ausführungen grundsätzlich die Formen und Beweisstrukturen des Verfahrens vor dem IStGH, die zur Erfüllung des prozessualen Ziels der Wahrheitsfindung im Sinne der bestmöglichen Tatsachenfeststellung Anwendung finden. Das Wahrheitsziel ist ausdrücklich oder implizit in den Vorschriften des IStGH-Statuts verankert. ${ }^{114}$ Freilich nimmt das IStGH-System in Zusammenhang mit der Wahrheitserforschung ebenfalls die Wahrung der Opferinteressen und eventuell auch die Erstellung einer „,sozialdidaktischen " ${ }^{\text {115 }}$ Aufzeichnung hinsichtlich der angeklagten Situationen wahr; ${ }^{116}$ ungeachtet dessen, dass auch hierbei Zielkollisionen nicht immer vermieden werden können. Darüber hinaus werden in den einzelnen Völkerstrafprozessen selbstverständlich auch die Sicherstellung der Verfahrensfairness und der wirksame Schutz der Menschenrechte angestrebt. ${ }^{117}$

Bevor nun die gerichtlichen Sachaufklärungsvorgänge, die in fairer und menschenwürdiger Weise erfolgen müssen, und allgemein die Strukturen und Rollenverteilungen im IStGH-Beweisführungssystem näher betrachtet werden, muss an dieser Stelle Folgendes bemerkt werden: Die Aufklärung der Sachverhalte mit völkerstrafrechtlichem Bezug, die in einem möglichst neutralen internationalen Umfeld durch Richter und Verfolgungsorgane erfolgt, die oft aus unterschiedlichen Rechtstraditionen stammen, weist besondere Beweisschwierigkeiten auf. Diese begründen sich vor allem durch:

(2009), 17 (19-22); Rauxloh, Plea Bargaining, S. 204; Safferling, Towards, S. 58-60. Siehe auch die Auflistung bei Schrag, JICJ 2 (2004), 427 (428).

113 Siehe unter Teil 3, I.

114 Siehe insb. Präambel und Art. 54(1a), 64(6), 67(2), 69(1, 3) IStGH-Statut. Siehe auch Decision Regarding the Practices Used to Prepare and Familiarise Witnesses for Giving Testimony at Trial, Prosecutor v. Thomas Lubanga Dyilo (Trial Chamber I, ICC01/04-01/06, 30 November 2007), § 47.

115 Siehe Damaška, in: Cassese (Hrsg.), Oxford Companion, S. 184.

116 Vgl. z.B. Art. 65(4) IStGH-Statut für den Fall eines Geständnisses: „Where the Trial Chamber is of the opinion that a more complete presentation of the facts of the case is required in the interests of justice, in particular the interests of the victims, the Trial Chamber may: (a) Request the Prosecutor to present additional evidence, including the testimony of witnesses; or (b) Order that the trial be continued under the ordinary trial procedures provided by this Statute, in which case it shall consider the admission of guilt as not having been made and may remit the case to another Trial Chamber.“

117 Siehe insb. Art. 21(3), 54(1c), 55, 56(1b), 57, 64(2, 8b), 67, 68, 69(4, 7) IStGHStatut. 
- die besonders komplexe und in vielerlei Hinsicht „sensible“ Natur der zu ermittelnden Situationen;

- die hohe Anzahl von Verdächtigen, Opfern und Zeugen;

- die politischen Implikationen der internationalen Ermittlung von Verbrechen mit staatlichem Bezug bzw. der Verfolgung von obersten staatlichen Amtspersonen und die entsprechenden Probleme für die internationale Zusammenarbeit;

- die begrenzten Ermittlungsressourcen und faktischen Ermittlungsmöglichkeiten der völkerrechtlichen Einrichtungen und noch mehr der Verteidigungsanwälte sowie

- die erheblichen sprachlichen, zeitlichen, geografischen und kulturellen Hindernisse, welche die internationalen Verfolgungsorgane jeweils überwinden müssen. $^{118}$

Theoretische und empirische Untersuchungen sowie rechtspolitische Reformdiskussionen, die sich mit beweisprozessualen Aspekten der internationalen Strafgerichtsbarkeiten eingehend beschäftigen wollen, müssen dementsprechend die jeweils vorgesehenen diagnostischen Verfahrensformen und ihre praktische Anwendung auch unter dem Blickwinkel dieser Besonderheiten der internationalen Strafjustiz betrachten und bewerten.

\section{Die Vorbereitung des Hauptverfahrens}

\section{a) Die Beweissammlung}

Für die Einleitung einer internationalen Ermittlung und für ihre Durchführung ist, wie oben festgestellt, primär der Ankläger des IStGH zuständig. ${ }^{119}$ Der Ankläger, der vor dem Gerichtshof als Partei ${ }^{120}$ die Anklage vertritt, ${ }^{121}$ ist bei seinen vorgerichtlichen Ermittlungstätigkeiten nach der ausdrücklichen Regel des Art. 54(1a) IStGH-Statut zur Objektivität verpflichtet: „,The Prosecutor shall [in] order to establish the truth, extend the investigation to cover all facts and evidence relevant to an assessment of whether there is criminal responsibility under this Statute, and, in doing so, investigate incriminating and exonerating circumstances equally. "Unter

118 Siehe u.a. Damaška, in: Cassese (Hrsg.), Oxford Companion, S. 178; Rauxloh, Plea Bargaining, S. 204.

119 Siehe unter Teil 3, III.A. u.a. auch zu den diesbezüglichen Kontrollbefugnissen der Vorverfahrenskammer. Ausführlich zur Ermittlungsphase und zur Beweissammlung Alamuddin, in: Khan u.a. (Hrsg.), Principles, S. 232-305; DeGuzman/Schabas, in: Sluiter u.a. (Hrsg.), International, S. 131-133, 143-149, 152-169 und De Meester/Pitcher/Rastan/ Sluiter, in: Sluiter u.a. (Hrsg.), International, S. 171-172, 181-192, 203-212, 232-236, 242-255, 263-269, 275-282, 292-298, 302-312, 317-319, 329-335, 339-351, 353-354, 362-368, 371-379. Zusammenfassend Ambos, Int'l Crim. L. Rev. 3 (2003), 1 (7-10).

120 Vgl. etwa Art. 64(3a, 6d, 8b), 82(1) IStGH-Statut.

121 Siehe Art. 42(1) IStGH-Statut. 
anderem kann der Ankläger dabei nach Art. 54(3a, b) und 56(1, 2) IStGH-Statut Beweismittel sammeln und prüfen sowie die Anwesenheit von Verdächtigen, Zeugen und Opfern verlangen und diese vernehmen. Auch die Vorverfahrenskammer kann aber nach Art. 56(3) IStGH-Statut unter bestimmten Voraussetzungen und insbesondere aus Gründen der Beweissicherung von Amts wegen die zur Sammlung und Prüfung bestimmter Beweise erforderlichen Maßnahmen ergreifen; in diesem Rahmen kann sie u.a. für die Bestellung eines Sachverständigen und vor allem für die Gewährleistung der Teilnahme der Verteidigung an den Ermittlungen und Vernehmungen sorgen.

Der Verdächtige bzw. Beschuldigte hat in diesem internationalen Umfeld, trotz seiner in Art. 55(2) IStGH-Statut vorgesehenen Belehrungs- und Verteidigungsrechte, faktisch nur begrenzte Möglichkeiten zur, ,privaten“ Sammlung von Beweisen; die Verteidigung kann weder innerstaatliche Ermittlungen selbstständig durchführen noch einen Staat um internationale Zusammenarbeit ersuchen. Die Verteidigung kann allerdings zum Zweck ihrer Vorbereitung gemäß Art. 57(3b) IStGH-Statut die Hilfe der Vorverfahrenskammer und insbesondere das Erlassen von Anordnungen durch die Letztere beantragen, die u.a. die vorgerichtliche Erhebung von Beweisen sowie Angelegenheiten der internationalen Zusammenarbeit betreffen können. ${ }^{122}$ Nach einer Meinung können sowohl das Eingreifen der Vorverfahrenskammer in die Ermittlungen des Anklägers und in die Beweissammlungen als auch die daraus resultierende Ermöglichung einer effektiveren Beteiligung der Verteidigung an den vorgerichtlichen Beweisvorgängen sowie allgemein die systematische Ausübung der richterlichen Kontrollfunktionen den einseitigen „Aufbau“ des Anklagefalles verhindern; es wird sogar behauptet, dass dadurch künftig der Weg zur zentralen Zusammenstellung von umfassenden und objektiven Verfahrensakten eröffnet wird. ${ }^{123} \mathrm{Ob}$ eine solche Entwicklung tatsächlich möglich ist, hängt aber letztendlich von der Art und Weise ab, wie die Vorverfahrenskammern des IStGH ihre diesbezüglichen Aufgaben und Befugnisse in der Praxis wahrnehmen werden.

\section{b) Beweisoffenlegung und Aktenkenntnis}

Bisher muss sich jedenfalls die beweisbezogene Vorbereitung der Verteidigung (sowie die Vorbereitung der IStGH-Kammern) in informatorischer Hinsicht größtenteils auf die Beweisoffenlegungen seitens des Anklägers stützen. Die Offenlegungsvorgaben des IStGH-Systems, die alle konkurrierenden Verfahrensinteressen gleichzeitig wahrzunehmen versuchen, sind relativ komplex, und die bisherige Rechtsprechung des Gerichtshofs ist nicht einheitlich in Bezug insbesondere auf

\footnotetext{
122 Siehe auch R. 114, 116 RPE.

123 Jackson, JICJ 7 (2009), 17 (35).
} 
die Reichweite und die organisatorischen Einzelheiten der Offenlegungsvorgänge. ${ }^{124}$ Folgende Grundregeln sind jedenfalls zu beachten:

- Die Offenlegungspflichten des Anklägers betreffen nicht die Gesamtheit der zusammengestellten Ermittlungsakten. ${ }^{125}$ Nach der allgemeinen Regel des Art. 67(2) IStGH-Statut muss der Ankläger so bald wie möglich (,,as soon as practicable") der Verteidigung die in seinem Besitz oder seiner Verfügungsgewalt befindlichen Beweismittel offenlegen, die seiner Überzeugung nach die Unschuld des Angeklagten beweisen oder zu beweisen geeignet sind, dessen Schuld mildern oder die Glaubwürdigkeit der vom Ankläger vorgebrachten Beweismittel beeinträchtigen können; bei Zweifeln entscheidet der Gerichtshof. ${ }^{126}$ Darüber hinaus muss der Ankläger nach R. 76(1) RPE der Verteidigung zur Ermöglichung ihrer Vorbereitung rechtzeitig die Namen aller aufzurufenden Zeugen und eventuell auch frühere Vernehmungsprotokolle zur Verfügung stellen. In R. 77 RPE sind auch die Besichtigungsrechte der Verteidigung hinsichtlich der im Besitz oder in der Verfügungsgewalt des Anklägers befindlichen (entlastenden und belastenden) Beweisstücke geregelt: „The Prosecutor shall, subject to the restrictions on disclosure as provided for in the Statute and in rules 81 and 82, permit the defence to inspect any books, documents, photographs and other tangible objects in the possession or control of the Prosecutor, which are material to the preparation of the defence or are intended for use by the Prosecutor as evidence for the purposes of the confirmation hearing or at trial, as the case may be, or were obtained from or belonged to the person.“ Die Erfüllung der Offenlegungspflichten des Anklägers stellt eine kontinuierliche Angelegenheit dar. ${ }^{127}$ Kein Gegenstand von Offenlegungen sind nach R. 81(1) RPE die Berichte, die Memoranda und die übrigen internen Dokumente, die durch eine Partei im Rahmen der Ermittlungen oder bei der Vorbereitung ihres Vorbringens erstellt worden sind. Die R. 76(4), 81, 82, 87, 88 RPE i.V.m. Art. 54(3e, f), 57(3c), 64(2, 6c, 6e), 68(5), 72, 73, 93 IStGH-Statut beziehen sich ferner auf die möglichen Beschränkungen der Offenlegung von Beweisen und Informationen, insbesondere aus Gründen des Opfer- und Zeugenschutzes sowie des Schutzes sensibler und vertraulicher Informationen.

- Nach Art. 61(3a) IStGH-Statut erhält der Beschuldigte innerhalb einer angemessenen Frist vor der Verhandlung zur Bestätigung der Anklage (,hearing to confirm

124 Siehe eingehend dazu Friman/Brady/Costi/Guariglia/Stuckenberg, in: Sluiter u.a. (Hrsg.), International, S. 400-403 i.V.m. Tochilovsky, in: Sluiter u.a. (Hrsg.), International, S. 1089-1092 und Klamberg, in: Sluiter u.a. (Hrsg.), International, S. 1101-1103 mit Rechtsprechungshinweisen. Siehe auch Büngener, in: Safferling (Verf.), International, S. 344-375; Gibson/Lussiaà-Berdou, in: Khan u.a. (Hrsg.), Principles, S. 350-359.

$125 \mathrm{Vgl}$. Decision on the Final System of Disclosure and the Establishment of a Timetable, Prosecutor v. Thomas Lubanga Dyilo (Pre-Trial Chamber I, ICC-01/04-01/06, 15 May 2006), insb. Annex I §§ 5, 11, 12, 15, 29, 125, 132, 133.

126 Siehe auch R. 83 RPE.

127 Siehe u.a. Reg. 55(2) Regulations of the Office of the Prosecutor (ICC-BD/05-0109). 
the charges“"), ${ }^{128}$ die vor der Vorverfahrenskammer stattfindet, eine Abschrift des Schriftstücks, aus dem die Anklagepunkte hervorgehen, die der Ankläger zum Gegenstand des Hauptverfahrens zu machen beabsichtigt. Der Beschuldigte nach Art. 61(3b) IStGH-Statut und die Vorverfahrenskammer nach R. 121(2c) RPE werden über die (hauptsächlich belastenden) Beweismittel in Kenntnis gesetzt, auf die sich der Ankläger bei der Bestätigungsverhandlung zu stützen beabsichtigt; die Vorverfahrenskammer kann in diesem Rahmen die Offenlegung von Informationen für die Zwecke der Bestätigungsverhandlung anordnen. ${ }^{129}$

- Auch die Verteidigung muss nach R. 121(6) RPE im Rahmen des Bestätigungsverfahrens eine Liste mit den Beweismitteln, die sie in die Bestätigungsverhandlung vor der Vorverfahrenskammer einzuführen beabsichtigt, der Vorverfahrenskammer und dadurch dem Ankläger vorlegen. Darüber hinaus ist in R. 79-80 RPE die allgemeine Pflicht der Verteidigung zur Offenlegung von bestimmten Informationen in Bezug auf vorzubringende Alibibehauptungen und Gründe für den Ausschluss der strafrechtlichen Verantwortlichkeit geregelt. Ferner wird in R. 78 RPE bezüglich der Besichtigungsansprüche des Anklägers Folgendes bestimmt: „The defence shall permit the Prosecutor to inspect any books, documents, photographs and other tangible objects in the possession or control of the defence, which are intended for use by the defence as evidence for the purposes of the confirmation hearing or at trial." Im Übrigen gelten hinsichtlich der Offenlegungen seitens der Verteidigung die Selbstbelastungsfreiheit und das Schweigerecht nach Art. 55(1a, 2b), 67(1g) IStGH-Statut. ${ }^{130}$

- Nach Art. 64(3c) IStGH-Statut muss die Hauptverfahrenskammer rechtzeitig vor Beginn der Hauptverhandlung für die Offenlegung zuvor nicht offengelegter Schriftstücke oder Informationen sorgen, damit eine hinreichende Vorbereitung auf die Verhandlung möglich ist. ${ }^{131}$ Hinsichtlich der allgemeinen Kenntnis der Beweise und Akten des Vorverfahrens seitens der Richter der Hauptverfahrenskammer gibt es keine ausdrückliche Regel. Die bisherige Gerichtspraxis weist darauf hin, dass die Richter in der Praxis Zugang zu den Vorverfahrensaufzeichnungen und -akten haben können, die von der Kanzlei (Registry) des IStGH nach R. 121(10) RPE zusammengetragen und durch das Präsidium nach R. 130 RPE der Hauptverfahrenskammer übermittelt werden - auch wenn für die Richter, im Gegensatz zu den

128 Dazu unter Teil 3, III.A. Ausführlich zur Anklagephase Friman/Brady/Costi/ Guariglia/Stuckenberg, in: Sluiter u.a. (Hrsg.), International, S. 389-393, 399-411, 422423. Zusammenfassend Ambos, Int'l Crim. L. Rev. 3 (2003), 1 (10-18).

129 Siehe auch Art. 67(1a, b) IStGH-Statut i.V.m. R. 121 RPE.

130 U.a. Ambos, Int'1 Crim. L. Rev. 3 (2003), 1 (14).

131 Siehe auch R. 84 RPE: „In order to enable the parties to prepare for trial and to facilitate the fair and expeditious conduct of the proceedings, the Trial Chamber shall, in accordance with article 64, paragraphs 3 (c) and 6 (d), and article 67, paragraph (2), and subject to article 68, paragraph 5, make any necessary orders for the disclosure of documents or information not previously disclosed and for the production of additional evidence." 
Opfern ${ }^{132}$ und den Parteien, keine ausdrücklichen Einsichtsmöglichkeiten nach R. 121(10), 131 RPE vorgesehen sind; überdies haben die Kammern oft vom Ankläger die Erstellung von Listen und Analysediagrammen bezüglich der vorzubringenden belastenden Beweismittel verlangt. ${ }^{133}$

\section{c) Das Vorbringen von Beweisen}

\section{aa) Allgemeines}

Die umfassende vorgerichtliche Kenntnis der Beweise kann, wie auch in Art. 64(3c) IStGH-Statut ausgeführt, eine wichtige Rolle bei der Vorbereitung der maßgebenden internationalen Beweisführungen spielen. ${ }^{134}$ Die dadurch erlangten Beweisinformationen können sowohl von den Parteien (insbesondere von der Verteidigung) als auch von der Hauptverfahrenskammer zur Bestimmung des Umfangs der Beweiserhebungen in der Hauptverhandlung verwendet werden. Für die Beweiserhebungen sind, wie in den nationalen Verfahren, insbesondere der aussagenbasierte Beweis sowie der Urkundenbeweis und die real evidence von zentraler Bedeutung - in praktischer Hinsicht unterscheidet sich jedoch das internationale vom nationalen Strafverfahren wegen der hohen Anzahl und des Umfangs der vorgebrachten Beweismittel erheblich. ${ }^{135}$ Nichtdestotrotz gibt auch das IStGH-System zumindest im Prinzip - und ungeachtet der vorgesehenen Zeugenschutzmaßnahmen $^{136}$ - der unmittelbaren und mündlichen Erhebung des aussagenbasierten Beweises in der Hauptverhandlung gegenüber der ,ökonomischeren“ Lösung der Einführung von vorherigen, schriftlich oder elektronisch dokumentierten Aussagen der Beweispersonen den Vorzug. ${ }^{137}$ Konkreter bestimmt Art. 69(2) IStGH-Statut Folgendes:

$132 \mathrm{Zu}$ den Akteneinsichtsmöglichkeiten der Opfer siehe Büngener, in: Safferling (Verf.), International, S. 372-373.

133 Siehe zu dieser Praxis und Rechtsprechung Büngener, in: Safferling (Verf.), International, S. 371-372.

${ }^{134}$ Vgl. auch Decision on the status before the Trial Chamber of the evidence heard by the Pre-Trial Chamber and the decisions of the Pre-Trial Chamber in trial proceedings, and the manner in which evidence shall be submitted, Prosecutor v. Thomas Lubanga Dyilo (Trial Chamber I, ICC-01/04-01/06, 13 December 2007), $\S 8$ : „Therefore, the record of the pre-trial proceedings (and all the evidence admitted for that purpose) transmitted to the Trial Chamber by virtue of Rule 130 is available mainly to be used as a 'tool' to help with preparation and the progress of the case."

135 Zum aussagenbasierten Beweis und zum documentary evidence (einschließlich u.a. von Foto- und Videomaterialien) siehe Farthofer, in: Safferling (Verf.), International, S. 464-484. Siehe auch Gaynor, in: Sluiter u.a. (Hrsg.), International, S. 1045-1047, 1062-1067.

136 Dazu u.a. Farthofer, in: Safferling (Verf.), International, S. 515-521.

137 Siehe etwa: Judgment on the appeals of Mr Jean-Pierre Bemba Gombo and the Prosecutor against the decision of Trial Chamber III entitled "Decision on the admission into evidence of materials contained in the prosecution's list of evidence", Prosecutor v. Jean- 
The testimony of a witness at trial shall be given in person, except to the extent provided by the measures set forth in article 68 or in the Rules of Procedure and Evidence. The Court may also permit the giving of viva voce (oral) ${ }^{138}$ or recorded testimony of a witness by means of video or audio technology, as well as the introduction of documents or written transcripts, subject to this Statute and in accordance with the Rules of Procedure and Evidence. These measures shall not be prejudicial to or inconsistent with the rights of the accused.

Ferner setzt R. 68 RPE bezüglich der Einführung von vorher aufgezeichneten Aussagen in die Hauptverhandlung - grundsätzlich in Übereinstimmung mit den EGMR-Leitlinien zum Konfrontationsrecht - vor allem Folgendes voraus: Es wird einerseits verlangt, dass der Ankläger und die Verteidigung Gelegenheit hatten, den in der Hauptverhandlung abwesenden Zeugen während der ursprünglichen Aufzeichnung seiner Aussage zu befragen. Andererseits kann mit Bezug auf einen in der Hauptverhandlung anwesenden Zeugen eine vorher aufgezeichnete Aussage in die Hauptverhandlung eingeführt werden, soweit der Zeuge der Einführung nicht widerspricht und der Ankläger, die Verteidigung und das Gericht die Möglichkeit haben, den Zeugen während des Verfahrens zu befragen: ${ }^{139}$

When the Pre-Trial Chamber has not taken measures under article 56, the Trial Chamber may, in accordance with article 69, paragraph 2, allow the introduction of previously recorded audio or video testimony of a witness, or the transcript or other documented evidence of such testimony, provided that: (a) If the witness who gave the previously recorded testimony is not present before the Trial Chamber, both the Prosecutor and the defence had the opportunity to examine the witness during the recording; or (b) If the witness who gave the previously recorded testimony is present before the Trial Chamber, he or she does not object to the submission of the previously recorded testimony and the Prosecutor, the defence and the Chamber have the opportunity to examine the witness during the proceedings. ${ }^{140}$

Des Weiteren hat der IStGH bezüglich der vorgerichtlichen Vorbereitung der mündlichen Zeugenaussagen durch die Verfahrensbeteiligten größtenteils die be-

Pierre Bemba Gombo (Appeals Chamber, ICC-01/05-01/08 OA 5 OA 6, 3 May 2011), $\S 76$; siehe auch Decision on Defence Request to Admit into Evidence Entirety of Document DRC-OTP-1017-0572, Prosecutor v. Germain Katanga and Mathieu Ngudjolo Chui (Trial Chamber II, ICC-01/04-01/07, 25 May 2011), § 4.

138 Siehe dazu R. 67 RPE: „1. In accordance with article 69, paragraph 2, a Chamber may allow a witness to give viva voce (oral) testimony before the Chamber by means of audio or video technology, provided that such technology permits the witness to be examined by the Prosecutor, the defence, and by the Chamber itself, at the time that the witness so testifies. [...] 3. The Chamber, with the assistance of the Registry, shall ensure that the venue chosen for the conduct of the audio or video-link testimony is conducive to the giving of truthful and open testimony and to the safety, physical and psychological wellbeing, dignity and privacy of the witness."

139 Siehe auch Ambos, Int'l Crim. L. Rev. 3 (2003), 1 (31). Zum Konfrontationsrecht siehe vorliegend unter Teil 3, II.A.3.b).

140 Siehe ferner auch zur Rechtsprechung in Bezug auf Zeugen, die in der Hauptverhandlung faktisch unerreichbar sind, Farthofer, in: Safferling (Verf.), International, S. $477-479$. 
reits angesprochenen Grundsätze der englischen ${ }^{141}$ Rechtsprechung übernommen, die zwischen erlaubtem witness familiarisation und verbotenem witness training or coaching unterscheiden. ${ }^{142}$ Ebenfalls in ähnlicher Weise wie in der englischen ${ }^{143}$ Verfahrensordnung sind u.a. im IStGH-Code of Professional Conduct for Coun$\mathrm{sel}^{144}$ die allgemeinen ethisch-rechtlichen Verpflichtungen der Anwälte mit Blick auf den Umgang mit den Beweismitteln vorgeschrieben. ${ }^{145}$

bb) Die Bestimmung des Umfangs der Beweiserhebungen

Hinsichtlich der Bestimmung der in das Hauptverfahren ${ }^{146}$ einzuführenden Beweismittel und insbesondere in Bezug auf die Ladung von Beweispersonen wird vom IStGH-System das Vorbringen der zentralen Verfahrensbeteiligten (Anklage und Verteidigung) ${ }^{147}$ als Ausgangspunkt für die Beweisführungen verwendet. Die Stellung eines Beweisantrags seitens der Parteien ist zunächst nicht erforderlich; nach R. 63(2, 3) RPE: ,[...] A Chamber shall have the authority, in accordance with the discretion described in article 64, paragraph 9, to assess freely all evidence submitted in order to determine its relevance or admissibility in accordance with article 69. [...] A Chamber shall rule on an application of a party or on its own mo-

141 Siehe unter Teil 2, II.B.1.b)cc).

142 Siehe Decision on the Practices of Witness Familiarisation and Witness Proofing, Prosecutor v. Thomas Lubanga Dyilo (Pre-Trial Chamber I, ICC-01/04-01/06, 8 November 2006), $\S \S 18-42$; Decision Regarding the Practices Used to Prepare and Familiarise Witnesses for Giving Testimony at Trial, Prosecutor v. Thomas Lubanga Dyilo (Trial Chamber I, ICC-01/04-01/06, 30 November 2007), §§ 28-57. Mehr dazu bei Ambos, FS für Volk, S. 1-18; Eser, in: Swart u.a. (Hrsg.), Legacy, S. 126-129.

143 Siehe unter Teil 2, II.B.1.a) und entsprechend zum deutschen Verfahren unter Teil 2, III.B.1.a).

144 ICC-ASP/4/Res.1.

145 Siehe insb. Art. 23-29 Code of Professional Conduct for Counsel. Siehe auch Art. 70(1b, c) IStGH-Statut.

146 Hinsichtlich des Bestätigungsverfahrens vor der Vorverfahrenskammer siehe Art. 61(5, 6, 7c) IStGH-Statut.

147 Die Opfer haben grundsätzlich kein eigenständiges Recht auf Einführung von Beweisen; sie können jedoch nach Art. 68(3) IStGH-Statut i.V.m. R. 89-93 RPE auf Antrag und unter bestimmten Voraussetzungen ihre Auffassungen und Anliegen zum Ausdruck bringen, sich durch einen Anwalt vertreten lassen und durch ihn bei den Beweisvorgängen (etwa bei den Zeugenvernehmungen) aktiv mitwirken. Vgl. auch Directions for the conduct of the proceedings and testimony in accordance with rule 140, Prosecutor v. Germain Katanga and Mathieu Ngudjolo Chui (Trial Chamber II, ICC-01/04-01/07, 20 November 2009), Annex § 45: „As a matter of principle, Victims’ Legal Representatives will not be able to call witnesses other than the victims they represent. However, in case the Legal Representatives have identified persons other than participating victims, who may be able to give evidence to the Chamber about issues that concern the victims' interests, they may take the initiative to bring this to the attention of the Chamber." Siehe aber auch Judgment pursuant to Article 74 of the Statute, Prosecutor v. Thomas Lubanga Dyilo (Trial Chamber I, ICC-01/04-01/06, 14 March 2012), § 14(vii). 
tion, made under article 64, subparagraph 9 (a), concerning admissibility when it is based on the grounds set out in article 69, paragraph 7.“

Es steht außer Frage, dass auf internationaler Ebene die Anklagebehörde die meisten institutionellen und faktischen Möglichkeiten hat, Zeugen und andere Beweismittel zu ermitteln und zu laden bzw. beizubringen. ${ }^{148}$ Deswegen und auch angesichts der faktischen Ressourcenungleichheit zwischen Anklage und Verteidigung ist die ausdrückliche Verankerung der Objektivitätspflichten des Anklägers in Art. 54(1a) und 67(2) IStGH-Statut von besonderer Bedeutung für die Gestaltung des weiteren Beweisverfahrens. Auch diejenigen Bestimmungen der IStGHRechtsprechung, die alle und somit auch die durch die Parteien geladenen Zeugen letztendlich als Zeugen des Gerichts ansehen, können eine zentrale Rolle bei der progressiven Entwicklung des internationalen Beweisverfahrenssystems spielen. ${ }^{149}$ Dass der Ankläger, der im Hauptverfahren sein Anklagevorbringen vertritt, sich in der Praxis meistens auf die Einführung von belastenden Beweisen konzentrieren wird, ist gleichwohl nicht zu leugnen. ${ }^{150}$ Eine Vorschrift, die, wie im deutschen Strafprozessrecht, die richterliche Amtsaufklärungspflicht als Wegweiser und Garant für eine umfassende Wahrheitserforschung ausdrücklich anerkennt, ist im IStGH-Statut nicht zu finden. Allerdings eröffnet das IStGH-System der Hauptverfahrenskammer - neben ihrer judicial notice-Befugnis ${ }^{151}$ - die Möglichkeit, in die Bestimmung des Umfangs der Beweiserhebungen selbstständig und aktiv einzugreifen, soweit dies für die Zwecke der Sachverhaltsaufklärung erforderlich ist. ${ }^{152}$ Genauer bestimmt das IStGH-Statut Folgendes: ${ }^{153}$

Article 64: [... 6. In performing its functions prior to trial or during the course of a trial, the Trial Chamber may, as necessary: [...] (b) Require the attendance and testimony of witnesses and production of documents and other evidence by obtaining, if necessary, the assistance of States as provided in this Statute; [...] (d) Order the production of evidence in addition to that already collected prior to the trial or presented during the trial

148 Vgl. auch Ambos, Int'l Crim. L. Rev. 3 (2003), 1 (35-36); Jackson, JICJ 7 (2009), 17 (25-26).

149 Siehe Decision Regarding the Practices Used to Prepare and Familiarise Witnesses for Giving Testimony at Trial, Prosecutor v. Thomas Lubanga Dyilo (Trial Chamber I, ICC-01/04-01/06, 30 November 2007), § 34: „The Trial Chamber agrees with the conclusion that witnesses are not attributable to parties, but rather are witnesses of the Court."

150 Vgl. Ambos, ZIS 2012, 313 (320-321).

151 Nach Art. 69(6) IStGH-Statut: „The Court shall not require proof of facts of common knowledge but may take judicial notice of them." Siehe dazu Farthofer, in: Safferling (Verf.), International, S. 484-488; Gaynor, in: Sluiter u.a. (Hrsg.), International, S. 1121. Siehe auch Jørgensen, in: Khan u.a. (Hrsg.), Principles, S. 697-710, 719-722. Zum englischen Recht siehe diesbezüglich unter Teil 2, II.B.2.a) und zum deutschen Recht unter Teil 2, III.B.2.a).

152 Vgl. auch Decision Regarding the Practices Used to Prepare and Familiarise Witnesses for Giving Testimony at Trial, Prosecutor v. Thomas Lubanga Dyilo (Trial Chamber I, ICC-01/04-01/06, 30 November 2007), § 45.

153 Dazu u.a. Schabas, International, S. 767-768, 810-812, 842-843. 
by the parties; [...]. 8. [...] (b) [...] Subject to any directions of the presiding judge, the parties may submit evidence in accordance with the provisions of this Statute. [...]

Article 67: 1. In the determination of any charge, the accused shall be entitled to $[\ldots]$ the following minimum guarantees, in full equality: [...] (e) To examine, or have examined, the witnesses against him or her and to obtain the attendance and examination of witnesses on his or her behalf under the same conditions as witnesses against him or her. The accused shall also be entitled to raise defences and to present other evidence admissible under this Statute. [...]

Article 69: [...] 3. The parties may submit evidence relevant to the case, in accordance with article 64 . The Court shall have the authority to request the submission of all evidence that it considers necessary for the determination of the truth. ${ }^{154}$

Bezüglich der Einführung des Expertenbeweises sind keine gesonderten Regeln im IStGH-Statut oder in den RPE zu finden. Die Verfahrensbeteiligten können in der Regel ihre „eigenen“ Experten vorbringen, die etwa aus der durch die IStGHKanzlei zusammengestellten Liste mit bereits „,verifizierten“ Experten ausgewählt werden können und die in der Hauptverhandlung grundsätzlich als normale Zeugen zu behandeln sind. ${ }^{155}$ Der Gerichtshof begünstigt allerdings die gemeinsame Beauftragung eines einzigen Experten durch die Parteien. ${ }^{156}$ Reg. 44 Regulations of the Court ${ }^{157}$ bestimmt jedenfalls, dass die Kammer die gemeinsame Beauftragung eines Experten durch die Verfahrensbeteiligten anordnen kann; dass im Anschluss an die Erstattung des Berichts eines gemeinsamen Experten ein Verfahrensbeteiligter auf Antrag einen weiteren Experten beauftragen kann; dass die Kammer von Amts wegen einen Experten beauftragen kann; und dass die Kammer Anordnungen hinsichtlich aller relevanten Angelegenheiten, etwa in Bezug auf die Anzahl der Experten, die Art und Weise ihrer Instruktion, die Einführung und Präsentation des Expertenbeweises und die Fristen für die Vorbereitung und Offenlegung des Expertenberichts, geben kann.

154 Siehe auch R. 84 RPE i.V.m. Art. 64(3c) IStGH-Statut.

155 Ferner dazu mit Rechtsprechungshinweisen Farthofer, in: Safferling (Verf.), International, S. 473-475, 482-484. Ausführlich zum Expertenbeweis im internationalrechtlichen Kontext Singh, in: Khan u.a. (Hrsg.), Principles, S. 602-649.

156 Siehe Decision on the procedures to be adopted for instructing expert witnesses, Prosecutor v. Thomas Lubanga Dyilo (Trial Chamber I, ICC-01/04-01/06, 10 December 2007), insb. $\S \S 14-25$.

157 ICC-BD/01-03-11. Nach Reg. 44: „1. The Registrar shall create and maintain a list of experts accessible at all times to all organs of the Court and to all participants. Experts shall be included on such a list following an appropriate indication of expertise in the relevant field. A person may seek review by the Presidency of a negative decision of the Registrar. 2. The Chamber may direct the joint instruction of an expert by the participants. 3 . On receipt of the report prepared by an expert jointly instructed, a participant may apply to the Chamber for leave to instruct a further expert. 4. The Chamber may proprio motu instruct an expert. 5. The Chamber may issue any order as to the subject of an expert report, the number of experts to be instructed, the mode of their instruction, the manner in which their evidence is to be presented and the time limits for the preparation and notification of their report." 
In Reg. 51 Regulations of the Office of the Prosecutor ${ }^{158}$ wird bestimmt, dass zwischen Anklagebehörde und Verteidigung Erörterungen zum Zweck unter anderem der gemeinsamen Beauftragung von Experten stattfinden sollen. Die Erörterungen zwischen den Verfahrensbeteiligten können weiterhin Folgendes betreffen: die Bestimmung der Beweiserhebungen; die Identifizierung der streitigen (Beweis-) Fragen; und die Einführung von agreed evidence nach R. 69 RPE, ${ }^{159}$ die aber dann nicht verbindlich ist, wenn die Kammer unter Berücksichtigung der Gerechtigkeitsund Opferinteressen weitere Beweisführungen in Bezug auf die jeweils betreffenden (zwischen den Parteien unbestrittenen) Fakten für erforderlich hält. Nicht nur in Reg. 51 Regulations of the Office of the Prosecutor wird die Notwendigkeit angesprochen, Erörterungen mit Blick auf die effektive Gestaltung diverser Aspekte des Straf- und Beweisverfahrens in wirksamer Weise durchzuführen. Auch die Hauptverfahrenskammer soll sich nach Art. 64(3a) IStGH-Statut mit den Parteien beraten und die Verfahren beschließen, die erforderlich sind, um eine faire und zügige Durchführung des Hauptverfahrens zu gewährleisten. ${ }^{160}$ In diesem Rahmen

158 Nach Reg. 51: „The Office shall constructively engage with the defence, in order to promote the efficient conduct of proceedings. In particular, the Office shall: (a) endeavour to identify, in consultation with the defence, issues in dispute or not in dispute, and agreed facts pursuant to rule 69; (b) consult with the defence in order to facilitate the identification of potentially exonerating information pursuant to article 67, paragraph 2 ; (c) seek agreement with the defence regarding the conduct of proceedings and the submission of evidence, as appropriate, pursuant to rule 140; and (d) consider the joint instruction of experts by the Prosecution and defence, or an agreement relating to the instruction of expert witnesses by the Court under regulation 44 of the Regulations of the Court."

159 Nach R. 69 RPE: „The Prosecutor and the defence may agree that an alleged fact, which is contained in the charges, the contents of a document, the expected testimony of a witness or other evidence is not contested and, accordingly, a Chamber may consider such alleged fact as being proven, unless the Chamber is of the opinion that a more complete presentation of the alleged facts is required in the interests of justice, in particular the interests of the victims." Siehe dazu Farthofer, in: Safferling (Verf.), International, S. 488489; Gaynor, in: Sluiter u.a. (Hrsg.), International, S. 1121. Zu den Angelegenheiten der einverständlichen Bestimmung der Beweiserhebungen und des Case Management in England siehe unter Teil 2, II.B.2.c), d) und entsprechend in Deutschland unter Teil 2, III.B.2.c), d).

160 Dazu u.a. Schabas, International, S. 764. Siehe auch R. 132(2) RPE. Nach R. 132bis RPE: „1. In exercising its authority under article 64, paragraph 3 (a), a Trial Chamber may designate one or more of its members for the purposes of ensuring the preparation of the trial. 2. The judge shall take all necessary preparatory measures in order to facilitate the fair and expeditious conduct of the trial proceedings, in consultation with the Trial Chamber. 3. The judge may at any time, proprio motu or, if appropriate, at the request of a party, refer specific issues to the Trial Chamber for its decision. A majority of the Trial Chamber may also decide proprio motu or, if appropriate, at the request of a party, to deal with issues that could otherwise be dealt with by the judge. 4 . In order to fulfil his or her responsibilities for the preparation of the trial, the judge may hold status conferences and render orders and decisions. The judge may also establish a work plan indicating the obligations the parties are required to meet pursuant to this rule and the dates by which these obligations must be fulfilled. 5. The functions of the judge may be performed in relation to preparatory issues, whether or not they arise before or after the commencement of the trial. 
hat die Hauptverfahrenskammer nach Reg. 54 Regulations of the Court folgende weitgehenden case management-Befugnisse, die unter anderem den Erlass von Anweisungen im Hinblick auf den Inhalt und die Dauer der Schlussvorträge, die inhaltliche Zusammenfassung und den Umfang der vorzubringenden Beweise, die Offenlegung des zeugenbasierten Beweises, die Dauer der Zeugenbefragungen, die Durchführung des Expertenbeweises und die summarische Einführung von Beweisen betreffen können:

At a status conference, the Trial Chamber may, in accordance with the Statute and the Rules, issue any order in the interests of justice for the purposes of the proceedings on, inter alia, the following issues: (a) The length and content of legal arguments and the opening and closing statements; (b) A summary of the evidence the participants intend to rely on; (c) The length of the evidence to be relied on; (d) The length of questioning of the witnesses; (e) The number and identity (including any pseudonym) of the witnesses to be called; (f) The production and disclosure of the statements of the witnesses on which the participants propose to rely; $(\mathrm{g})$ The number of documents as referred to in article 69, paragraph 2, or exhibits to be introduced together with their length and size; (h) The issues the participants propose to raise during the trial; (i) The extent to which a participant can rely on recorded evidence, including the transcripts and the audio- and video-record of evidence previously given; (j) The presentation of evidence in summary form; (k) The extent to which evidence is to be given by an audio- or video-link; (1) The disclosure of evidence; $(\mathrm{m})$ The joint or separate instruction by the participants of expert witnesses; (n) Evidence to be introduced under rule 69 as regards agreed facts; (o) The conditions under which victims shall participate in the proceedings; (p) The defences, if any, to be advanced by the accused.

\section{Die Beweisführung im Hauptverfahren}

\section{a) Zulässigkeit und Ausschluss von Beweisen}

Für die Einführung von Beweisen in die Hauptverhandlung gilt zunächst die „free admission“161 von Beweismitteln und das Prinzip der Nichtanwendung von nationalrechtlichen Zulässigkeitskriterien und Beweisregeln. Allerdings impliziert

These issues may include: (a) Ensuring proper disclosure between the parties; (b) Ordering protective measures where necessary; (c) Dealing with applications by victims for participation in the trial, as referred to in article 68, paragraph 3; (d) Conferring with the parties regarding issues referred to in regulation 54 of the Regulations of the Court, decisions thereon being taken by the Trial Chamber; (e) Scheduling matters, with the exception of setting the date of the trial, as referred to in rule 132, sub-rule 1; (f) Dealing with the conditions of detention and related matters; and (g) Dealing with any other preparatory matters that must be resolved which do not otherwise fall within the exclusive competence of the Trial Chamber. 6 . The judge shall not render decisions which significantly affect the rights of the accused or which touch upon the central legal and factual issues in the case, nor shall he or she, subject to sub-rule 5, make decisions that affect the substantive rights of victims."

161 Jackson, JICJ 7 (2009), 17 (34). 
das keinesfalls eine völlig unkontrollierbare Zulassung von Beweisen. ${ }^{162}$ R. 63 RPE bestimmt konkreter, dass:

[...] 2. A Chamber shall have the authority, in accordance with the discretion described in article 64, paragraph 9, to assess freely all evidence submitted in order to determine its relevance or admissibility in accordance with article 69. 3. A Chamber shall rule on an application of a party or on its own motion, made under article 64, subparagraph 9 (a), concerning admissibility when it is based on the grounds set out in article 69, paragraph 7. [...] 5. The Chambers shall not apply national laws governing evidence, other than in accordance with article 21.

Die Hauptverfahrenskammer hat also nach Art. 64(9a) IStGH-Statut die Befugnis (,shall have, inter alia, the power"), auf Antrag einer Partei oder aus eigener Initiative über die Zulässigkeit (,admissibility“) oder die Erheblichkeit (,relevance“) der Beweismittel zu entscheiden. Genauer kann („may“) der Gerichtshof nach Art. 69(4) IStGH-Statut über die Erheblichkeit oder Zulässigkeit jedes (,,any“) Beweismittels entscheiden, wobei er unter anderem die Beweiskraft des Beweismittels (,probative value of the evidence“) und alle Nachteile in Betracht zieht, die sich daraus möglicherweise für ein faires Verfahren oder für eine faire Bewertung des Zeugnisses eines Zeugen ergeben (,,any prejudice that such evidence may cause to a fair trial or to a fair evaluation of the testimony of a witness" $).{ }^{163}$ Bei seiner Entscheidung über die Erheblichkeit oder Zulässigkeit der von einem Staat gesammelten Beweise darf der Gerichtshof nach Art. 69(8) IStGH-Statut nicht über die Anwendung des nationalen Rechts dieses Staates befinden (,when deciding on the relevance or admissibility of evidence collected by a State, the Court shall not rule on the application of the State's national law"). Als unzulässig sind nach Art. 69(7) IStGH-Statut die Beweise, die durch Verletzung des Statuts oder international anerkannter Menschenrechte erlangt wurden, dann zu betrachten (,,shall not be admissible if"), wenn die Verletzung erhebliche Zweifel an ihrer Glaubwürdigkeit entstehen lässt (,the violation casts substantial doubt on the reliability of the evidence") oder ihre Zulassung im Widerspruch zur Ordnungsmäßigkeit des Verfahrens stehen und dieser schweren Schaden zufügen würde (,the admission of the evidence would be antithetical to and would seriously damage the integrity of the proceedings."). ${ }^{164}$

162 Eingehend zu den komplexen Fragen der Zulassung von Beweisen in den internationalen Strafgerichtsbarkeiten Gosnell, in: Khan u.a. (Hrsg.), Principles, S. 375-442; Klamberg, in: Sluiter u.a. (Hrsg.), International, S. 1016-1043.

163 Dazu mit Rechtsprechungshinweisen Farthofer, in: Safferling (Verf.), International, S. 492-495.

164 Dazu und zur Problematik des hearsay-Beweises siehe Farthofer, in: Safferling (Verf.), International, S. 498-506 m.w.N. Hinsichtlich der Zulässigkeit der im Vorverfahren aus Beweissicherungsgründen gesammelten Beweise siehe Art. 56(4) IStGH-Statut. Zur Unzulässigkeit von Beweisen in Bezug auf das frühere oder das nachfolgende sexuelle Verhalten von Zeugen oder Opfern siehe R. 71 RPE. 
In prozesstechnischer Hinsicht muss nach R. 64 RPE eine Frage zur Erheblichkeit oder zur Zulässigkeit in der Regel zum Zeitpunkt der Vorlage des betreffenden Beweises bei der Kammer gestellt werden; die Frage, zu welchem genauen Zeitpunkt (insbesondere vor oder nach der Beweiserhebung) die Entscheidung der verfahrensleitenden und urteilsfindenden Berufsrichter hinsichtlich der Beweiszulassung erfolgen soll, ist vom IStGH noch nicht endgültig beantwortet worden. ${ }^{165}$ Beweise, die mit begründeter Entscheidung der Kammer als unerheblich oder unzulässig betrachtet wurden, dürfen jedenfalls von der Kammer nicht berücksichtigt werden. Konkreter bestimmt R. 64 RPE, dass:

1. An issue relating to relevance or admissibility must be raised at the time when the evidence is submitted to a Chamber. Exceptionally, when those issues were not known at the time when the evidence was submitted, it may be raised immediately after the issue has become known. The Chamber may request that the issue be raised in writing. The written motion shall be communicated by the Court to all those who participate in the proceedings, unless otherwise decided by the Court. 2. A Chamber shall give reasons for any rulings it makes on evidentiary matters. [...] 3. Evidence ruled irrelevant or inadmissible shall not be considered by the Chamber. ${ }^{166}$

165 Siehe Judgment on the appeals of Mr Jean-Pierre Bemba Gombo and the Prosecutor against the decision of Trial Chamber III entitled "Decision on the admission into evidence of materials contained in the prosecution's list of evidence", Prosecutor v. Jean-Pierre Bemba Gombo (Appeals Chamber, ICC-01/05-01/08 OA 5 OA 6, 3 May 2011), § 37: „The above provisions accord the Trial Chamber discretion when admitting evidence at trial. As borne out by the use of the word 'may' in article 69 (4), the Trial Chamber has the power to rule or not on relevance or admissibility when evidence is submitted to the Chamber. Consequently, the Trial Chamber may rule on the relevance and/or admissibility of each item of evidence when it is submitted, and then determine the weight to be attached to the evidence at the end of the trial. In that case, an item will be admitted into evidence only if the Chamber rules that it is relevant and/or admissible in terms of article 69 (4), taking into account 'the probative value of the evidence and any prejudice that such evidence may cause to a fair trial or to a fair evaluation of the testimony of a witness'. Alternatively, the Chamber may defer its consideration of these criteria until the end of the proceedings, making it part of its assessment of the evidence when it is evaluating the guilt or innocence of the accused person. Nevertheless, under article 64 (2) of the Statute, the Chamber must always ensure that the trial 'is fair and expeditious and conducted with full respect for the rights of the accused and due regard for the protection of victims and witnesses'. In particular, if a party raises an issue regarding the relevance or admissibility of evidence, the Trial Chamber must balance its discretion to defer consideration of this issue with its obligations under that provision. Moreover, it should be underlined that irrespective of the approach the Trial Chamber chooses, it will have to consider the relevance, probative value and the potential prejudice of each item of evidence at some point in the proceedings - when evidence is submitted, during the trial, or at the end of the trial." Ferner zu den Differenzierungen der (nicht einheitlichen) IStGH-Rechtsprechung hinsichtlich des Zeitpunkts und der Stufen der Prüfung der Erheblichkeit und Zulässigkeit der Beweise siehe Farthofer, in: Safferling (Verf.), International, S. 489-495.

$166 \mathrm{Zu}$ den Besonderheiten des Verfahrens zur Beurteilung der Erheblichkeit und Zulässigkeit von Beweisen, die bei einem angeklagten Delikt sexueller Gewalt für den Nachweis der Einwilligung des Opfers vorgebracht werden, siehe R. 72 RPE. 


\section{b) Die Erhebung und Prüfung der Beweise}

aa) Allgemeine Grundsätze

Zuständig für die Durchführung der Hauptverhandlung ist die Hauptverfahrenskammer. ${ }^{167}$ Der Vorsitzende Richter leitet nach Art. 64(8b) IStGH-Statut die Verhandlung; genauere Einzelheiten zum Ablauf einer streitigen Hauptverhandlung nach ihrem eigentlichen Beginn, d.h. insbesondere wenn der Angeklagte sich nach dem Vorlesen der Anklagepunkte nach Art. 64(8a) IStGH-Statut für nicht schuldig erklärt hat, regelt das Statut nicht. Wie bereits festgestellt, sollen/dürfen der Ankläger und die Verteidigung nach R. 140(1) $\operatorname{RPE}^{168}$ (nur dann) eine gemeinsame Entscheidung in Bezug auf die Reihenfolge und die Art und Weise der Vorlage der Beweise bei der Hauptverfahrenskammer treffen, wenn der Vorsitzende keine prozessleitenden Verfügungen nach Art. 64(8b) IStGH-Statut erlässt. ${ }^{169}$ Art. 64(8) IStGH-Statut und R. 140(1) RPE fördern eine eher freie, nicht an feste Regeln gebundene Gestaltung des Beweisverfahrens; jede Hauptverfahrenskammer kann daher von Fall zu Fall über die zur Wahrheitserforschung durchzuführenden Vorgänge und ihre organisatorischen Details unterschiedlich entscheiden. ${ }^{170}$

$\mathrm{Zu}$ Beginn der gerichtlichen Untersuchung des Sachverhalts können beispielsweise die Anklage und die Verteidigung oder nur die Anklage (soweit die Verteidigung erst nach der Präsentation des Anklagefalles angehört werden will) einen

167 Siehe Art. 61(11), 64(4, 6a, 6f) IStGH-Statut. Siehe auch R. 134 RPE: „1. Prior to the commencement of the trial, the Trial Chamber on its own motion, or at the request of the Prosecutor or the defence, may rule on any issue concerning the conduct of the proceedings. [...] 2. At the commencement of the trial, the Trial Chamber shall ask the Prosecutor and the defence whether they have any objections or observations concerning the conduct of the proceedings which have arisen since the confirmation hearings. Such objections or observations may not be raised or made again on a subsequent occasion in the trial proceedings, without leave of the Trial Chamber in this proceeding. 3. After the commencement of the trial, the Trial Chamber, on its own motion, or at the request of the Prosecutor or the defence, may rule on issues that arise during the course of the trial.“

168 Nach R. 140(1) RPE: „If the Presiding Judge does not give directions under article 64, paragraph 8, the Prosecutor and the defence shall agree on the order and manner in which the evidence shall be submitted to the Trial Chamber. If no agreement can be reached, the Presiding Judge shall issue directions."

169 Hierzu und für einen Überblick über den generellen Verfahrensablauf siehe unter Teil 3, III.A. Allgemein zum Ablauf der Hauptverhandlung u.a. Safferling, International, S. 443-462. Siehe auch Schabas, International, S. 769-771. Zum Ablauf der englischen und der deutschen Hauptverhandlung siehe entsprechend unter Teil 2, II.D.2. und unter Teil 2, III.D.2.

170 Vgl. auch Reg. 43 Regulations of the Court: „Subject to the Statute and the Rules, the Presiding Judge, in consultation with the other members of the Chamber, shall determine the mode and order of questioning witnesses and presenting evidence so as to: (a) Make the questioning of witnesses and the presentation of evidence fair and effective for the determination of the truth; (b) Avoid delays and ensure the effective use of time." 
Eröffnungsvortrag halten. ${ }^{171}$ Eine solche Möglichkeit ist allerdings, im Einklang mit dem „Prinzip“ der freien Gestaltung der Hauptverhandlung und im Gegensatz zum Verfahrenssystem der ad hoc-Tribunale, ${ }^{172}$ nicht ausdrücklich im IStGHStatut oder den RPE vorgeschrieben. Eine gesonderte Vernehmung des Angeklagten im Sinne etwa der anfänglichen Vernehmung zur Sache in der deutschen Strafprozessordnung ist im IStGH-System ebenfalls nicht ausdrücklich vorgesehen. Der Angeklagte kann jederzeit eine unbeeidigte mündliche oder schriftliche Erklärung zu seiner Verteidigung nach Art. 67(1h) IStGH-Statut abgeben. Weiterhin liegt es kraft der Selbstbelastungsfreiheit und gemäß dem Schweigerecht nach Art. 67(1g) IStGH-Statut im Ermessen des Angeklagten, ob er als Beweisperson aussagen will oder nicht; willigt er in eine Vernehmung ein, gelten dafür jedoch, ähnlich wie im englischen Strafprozess, das Verfahren und die Regeln, die bei allen Zeugen anzuwenden sind. ${ }^{173}$ Ausdrücklich vorgesehen ist darüber hinaus in R. 141 RPE die Möglichkeit des Anklägers und anschließend der Verteidigung, nach dem Ende ${ }^{174}$ der Beweisaufnahme, das vom Vorsitzenden festgestellt wird, Schlussvorträge zu halten; der Verteidigung gebührt dabei immer das letzte Wort. ${ }^{175}$

Hinsichtlich der Durchführung der Zeugenvernehmungen ${ }^{176}$ schlagen die RPE in R. 140(2) folgende Vorgehensweise vor, die aber nicht verbindlich (,may“) für die

171 Siehe z.B. Decision on opening and closing statements, Prosecutor v. Thomas Lubanga Dyilo (Trial Chamber I, ICC-01/04-01/06, 22 May 2008), § 16. Siehe auch Directions for the conduct of the proceedings and testimony in accordance with rule 140, Prosecutor v. Germain Katanga and Mathieu Ngudjolo Chui (Trial Chamber II, ICC-01/0401/07, 20 November 2009), Annex § 1. Vgl. auch Reg. 54(a) Regulations of the Court.

172 Siehe z.B. R. 84 IStGHJ-RPE (IT/32/Rev. 49): „Before presentation of evidence by the Prosecutor, each party may make an opening statement. The defence may, however, elect to make its statement after the conclusion of the Prosecutor's presentation of evidence and before the presentation of evidence for the defence."

173 Siehe Directions for the conduct of the proceedings and testimony in accordance with rule 140, Prosecutor v. Germain Katanga and Mathieu Ngudjolo Chui (Trial Chamber II, ICC-01/04-01/07, 20 November 2009), Annex $\S 51$ : „The accused have the right to make an unsworn oral statement in their defence, in accordance with article 67(1)(h) of the Statute, without this affecting their right to remain silent. They cannot therefore be compelled to testify under oath, even if they make an unsworn statement. However, if an accused consents to giving evidence, he or she becomes subject to the same rules [...] that are applicable to other witnesses." Siehe auch Schabas, International, S. 814-815.

174 Zur Schlussphase der richterlichen Beratung und Beweiswürdigung siehe kurz unter Teil 3, III.A.

175 Siehe auch Reg. 54(a) Regulations of the Court: „At a status conference, the Trial Chamber may, in accordance with the Statute and the Rules, issue any order in the interests of justice for the purposes of the proceedings on, inter alia, the following issues: (a) The length and content of legal arguments and the opening and closing statements; [...]. "Siehe ferner zu diesen Möglichkeiten der Parteien und zu diesbezüglichen Offenlegungsfragen Decision on opening and closing statements, Prosecutor v. Thomas Lubanga Dyilo (Trial Chamber I, ICC-01/04-01/06, 22 May 2008).

176 Ausführlich etwa Rohan, in: Khan u.a. (Hrsg.), Principles, S. 504-549. Siehe auch allgemein zum Zeugenbeweis Kreß, in: Fischer u.a. (Hrsg.), International, S. 315-382. 
Hauptverfahrenskammer ist: Zunächst hat die Partei, die den Zeugen vorbringt, das Recht, ihm Fragen zu stellen. Darauf haben der Ankläger und die Verteidigung das Recht, dem Zeugen die bezüglich seiner Aussage relevanten Fragen sowie Glaubhaftigkeits- und Glaubwürdigkeitsfragen zu stellen. Die Hauptverfahrenskammer hat das Recht, dem Zeugen vor oder nach jeder Befragung, die durch einen Verfahrensbeteiligten erfolgt, Fragen zu stellen. Die Verteidigung hat das Recht auf abschließende Vernehmung des Zeugen. Genauer bestimmt R. 140(2) RPE, dass:

In all cases, subject to article 64, paragraphs 8 (b) and 9 , article 69 , paragraph 4 , and rule 88 , sub-rule 5, a witness may be questioned as follows: (a) A party that submits evidence in accordance with article 69, paragraph 3, by way of a witness, has the right to question that witness; (b) The prosecution and the defence have the right to question that witness about relevant matters related to the witness's testimony and its reliability, the credibility of the witness and other relevant matters; (c) The Trial Chamber has the right to question a witness before or after a witness is questioned by a participant referred to in sub-rules 2 (a) or (b); (d) The defence shall have the right to be the last to examine a witness.

\section{bb) Praktische Anweisungen des IStGH}

Im Einklang mit diesen Leitlinien der RPE hat z.B. die Hauptverfahrenskammer II im Fall Prosecutor v. Germain Katanga and Mathieu Ngudjolo Chui ausführliche Anweisungen zur Gestaltung der Hauptverhandlung erlassen. Diese Leitlinien, die nicht zuletzt nach Art. 21(2) IStGH-Statut ${ }^{177}$ auch in anderen Fällen und von anderen Kammern des IStGH berücksichtigt werden können, werden im Folgenden zusammengefasst und vereinfacht dargestellt, insbesondere ohne Berücksichtigung der Punkte, welche die gleichzeitige Mitwirkung von zwei Angeklagten an den Beweiserhebungen betreffen: ${ }^{178}$

- Die Verhandlung ist in verschiedene Phasen aufzuteilen; die Hauptverfahrenskammer kann jederzeit in die Beweisaufnahme eingreifen und die Beibringung von Beweisen nach Art. 64(6d) und 69(3) IStGH-Statut anordnen, die sie für die Wahrheitsfindung für erforderlich hält.

- Die erste Verfahrensphase betrifft die Präsentation des „Prosecution case“; in dieser Phase (genauer: am Ende des „Prosecution case“) können auch die mitwirkenden Opfer eigenständig auf Antrag und unter bestimmten strikten Voraussetzungen und Bedingungen ${ }^{179}$ persönliche, mündliche beeidigte Aussagen machen und durch die Verfahrensbeteiligten in grundsätzlich neutraler Weise

177 Nach Art. 21(2) IStGH-Statut: „The Court may apply principles and rules of law as interpreted in its previous decisions."

178 Siehe ausführlich Directions for the conduct of the proceedings and testimony in accordance with rule 140, Prosecutor v. Germain Katanga and Mathieu Ngudjolo Chui (Trial Chamber II, ICC-01/04-01/07, 20 November 2009), Annex §§ 3-48, 59-111.

179 Siehe Directions for the conduct of the proceedings and testimony in accordance with rule 140, Prosecutor v. Germain Katanga and Mathieu Ngudjolo Chui (Trial Chamber II, ICC-01/04-01/07, 20 November 2009), Annex §§ 19-32. 
befragt werden. Die zweite Verfahrensphase bezieht sich auf die Präsentation des „Case for the Defence“, sofern die Verteidigung überhaupt Beweise vorbringt. Im Anschluss daran können die Richter der Hauptverfahrenskammer entscheiden, weitere Zeugen aufzurufen.

- Jede Partei, die Beweise präsentiert, muss den anderen Parteien und Verfahrensbeteiligten sowie der Kammer rechtzeitig einen Vernehmungsplan vorlegen. Die genauen zeitlichen Grenzen für die Präsentation jeder case und für jede Zeugenbefragung werden von der Kammer bestimmt und dürfen nur in Ausnahmefällen überschritten werden.

- Die Kammer kann jederzeit ihr Recht ausüben, den Zeugen Fragen zu stellen.

- Der Angeklagte kann jederzeit entscheiden, eine unbeeidigte mündliche oder schriftliche Erklärung nach Art. 67(1h) IStGH-Statut abzugeben; den dafür geeigneten Zeitpunkt bestimmt die Kammer.

- Im Rahmen der Präsentation des „Prosecution case“ wird ein Zeuge zuerst von der Anklage vernommen (,examination-in-chief"). Darauf hat die Verteidigung die Möglichkeit zur „cross-examination“. Im Anschluss daran hat die Anklage die Möglichkeit zur „re-examination“ bezüglich der Angelegenheiten, die zum ersten Mal im Rahmen der „cross-examination“ angesprochen wurden. Die Verteidigung hat das Recht auf abschließende Befragung des Zeugen nach R. 140(2) RPE. Die Anwälte der am Verfahren formell mitwirkenden Opfer, die weder Ankläger noch Parteien im engen Sinne sind, ${ }^{180}$ können nach dem Ende der ,examination-in-chief" bei der Kammer einen Antrag auf Befragung des Zeugen nach R. 91(3) RPE stellen.

- Im Rahmen der Präsentation des „Case for the Defence“ wird ein von der Verteidigung aufgerufener Zeuge zuerst durch die Verteidigung vernommen (,examination-in-chief"). Im Anschluss daran hat die Anklage die Möglichkeit zur „cross-examination“. Die Verteidigung hat das Recht auf abschließende Befragung des Zeugen nach R. 140(2) RPE. Die Anwälte der Opfer können nach dem Ende der „cross-examination“ einen Antrag auf Befragung des Zeugen nach R. 91(3) RPE bei der Kammer stellen; eine solche Befragung kann nur unter

180 Siehe Directions for the conduct of the proceedings and testimony in accordance with rule 140, Prosecutor v. Germain Katanga and Mathieu Ngudjolo Chui (Trial Chamber II, ICC-01/04-01/07, 20 November 2009), Annex § 82: „As a matter of general principle, questioning by the Legal Representatives on behalf of victims who participate in the proceedings must have as its main aim the ascertainment of the truth. The victims are not parties to the trial and certainly have no role to support the case of the Prosecution. Nevertheless, their participation may be an important factor in helping the Chamber to better understand the contentious issues of the case in light of their local knowledge and sociocultural background." $\mathrm{Zu}$ den immerhin weitgehenden Mitwirkungsmöglichkeiten der Opfer und ihrer Anwälte im Verfahren vor dem IStGH siehe Art. 68(3) IStGH-Statut i.V.m. R. 89-93 RPE und Reg. 86-87 Regulations of the Court. Dazu u.a. Ambos, Internationales Strafrecht, § 8 Rn. 52-53; Ambos, ZIS 2012, 313 (315-316); Cryer/Friman/Robinson/ Wilmshurst, Introduction, S. 488-494; Safferling, International, S. 528-530. Vgl. auch Damaška, in: Cassese (Hrsg.), Oxford Companion, S. 180-181. 
bestimmten Bedingungen ${ }^{181}$ erfolgen, wobei der genaue Zeitpunkt und die Durchführungsart von der Kammer von Fall zu Fall festzulegen sind.

- Wenn die Hauptverfahrenskammer entscheidet, einen Zeugen nach Art. 64(6b, 6d) und 69(3) IStGH-Statut aufzurufen, den die Parteien nicht aufgerufen haben, beginnt sie mit der Vernehmung des Zeugen. Nach der Befragung durch die Kammer haben die Anklage und anschließend die Verteidigung die Möglichkeit, den Zeugen zu vernehmen. Die Befragung eines solchen Zeugen muss im Prinzip in neutraler Weise erfolgen; ausnahmsweise kann mit Erlaubnis der Kammer die Befragung durch die Parteien nach Art einer „cross-examination“182 stattfinden.

- Alle Fragen müssen in prägnanter, genauer, verständlicher und unkomplizierter Weise gestellt werden.

- Im Rahmen einer „examination-in-chief“ sind im Prinzip nur klare und tatsachenrelevante Fragen erlaubt. Fragen, die den historischen Kontext und/oder die kontextualen Elemente des Falls betreffen, müssen sich, soweit möglich, auf die zwischen den Parteien umstrittenen Punkte konzentrieren. Weiterhin sind bei einer „,examination-in-chief“ in der Regel nur „neutrale“ Fragen erlaubt; leading questions, d.h. „question framed in such a way as to suggest the answer sought or to assume the existence of facts yet to be established," und closed questions, d.h. „question framed in such a way that the answer can only be binary (yes or no), “183 sind grundsätzlich nicht erlaubt. Gleichwohl kann ein Zeuge mit Erlaubnis der Kammer als ,gegnerischer Zeuge“ behandelt und unter bestimmten Bedingungen im Wege der „cross-examination“ durch die Partei, die ihn geladen hat, vernommen werden.

- Eine „cross-examination“ muss sich allgemein auf Angelegenheiten, die im Rahmen der „examination-in-chief“ angesprochen wurden, sowie auf Glaubwürdigkeitsfragen beschränken. Soweit aber der Zeuge in der Lage ist, Aussagen zu machen, die für die vernehmende Partei erheblich sind, kann die Vernehmung auch Angelegenheiten betreffen, die im Rahmen der „examination-in-chief“ nicht angesprochen wurden. Wenn die Aussagen des Zeugen im Rahmen der „examination-in-chief“ in gewissem Gegensatz zum „case“ der Partei, welche die „cross-examination“ durchführt, stehen, muss die Letztere dem Zeugen dies vor Beginn der relevanten Befragung ausdrücklich erklären. In allen Fällen muss

181 Siehe Directions for the conduct of the proceedings and testimony in accordance with rule 140, Prosecutor v. Germain Katanga and Mathieu Ngudjolo Chui (Trial Chamber II, ICC-01/04-01/07, 20 November 2009), Annex §§ 82-91.

182 Siehe Directions for the conduct of the proceedings and testimony in accordance with rule 140, Prosecutor v. Germain Katanga and Mathieu Ngudjolo Chui (Trial Chamber II, ICC-01/04-01/07, 20 November 2009), Annex §§ 68-76.

183 Directions for the conduct of the proceedings and testimony in accordance with rule 140, Prosecutor v. Germain Katanga and Mathieu Ngudjolo Chui (Trial Chamber II, ICC01/04-01/07, 20 November 2009), Annex § 66. 
die „cross-examination“ der Zeugen der Wahrheitsfindung dienen und darf nicht in verwirrender oder prozessverschleppender Weise durchgeführt werden. ${ }^{184}$ Die Fragen, die für den ,case“ der vernehmenden Partei und für die Wahrheitsfindung relevant sind, müssen während der ,cross-examination“ in erschöpfender Weise gestellt werden; die Kammer wird den Wiederaufruf („re-call“) eines Zeugen im Prinzip nicht erlauben, sofern die Partei die Möglichkeit zur „cross-examination“ schon hatte. Darüber hinaus sind leading questions und closed questions im Rahmen der „,cross-examination“ erlaubt. Nicht erlaubt sind provozierende Fragen und Fragen, die versteckte Vorträge darstellen. Im Allgemeinen sind die Zeugen im Rahmen der ,cross-examinations“ immer mit Höflichkeit und Respekt zu behandeln; beleidigendes und verletzendes Verhalten seitens der Parteien ist nicht akzeptabel. ${ }^{185}$

- Hinsichtlich der Einführung von documentary evidence muss schließlich jedes Beweisstück in der Regel im Rahmen einer Verhandlung durch eine Partei vorgebracht werden, und die Gegenpartei muss die Gelegenheit haben, Anmerkungen dazu zu machen. Besteht ein Zusammenhang zwischen dem Beweisstück und einem Zeugen, kann die Partei, die den Zeugen aufruft, während seiner Vernehmung das Beweisstück vorbringen; Schriftstücke können unter bestimmten

${ }^{184} \mathrm{Zu}$ diesem Zweck hat die Kammer in Directions for the conduct of the proceedings and testimony in accordance with rule 140, Prosecutor v. Germain Katanga and Mathieu Ngudjolo Chui (Trial Chamber II, ICC-01/04-01/07, 20 November 2009), Annex § 71, folgende Leitsätze erlassen: ,The Chamber stresses that cross-examination must also contribute to the ascertainment of the truth and is not to be used to obfuscate or delay the factfinding process. As a general measure of good practice and subject to further specific instructions by the Chamber, parties are encouraged to adhere to the following guidelines when cross-examining: a) Questions must pertain to matters of fact that could reasonably be expected to be known to the witness. Unless the witness is called as an expert, parties may not ask witnesses to speculate or explain their opinion about facts not known to them. b) Before putting questions about contextual elements and/or the historical context of the case, counsel must state the purpose behind the question and explain how the evidence sought is relevant to the confirmed charges. c) Questions probing the credibility of the witness and the accuracy of his or her testimony are allowed, but must be limited to factors that could objectively influence reliability. When the witness has fully answered the question, the party cross-examining the witness will not be allowed to put further questions aimed at impeaching that answer without permission of the Chamber. d) If a witness did not provide all his or her testimony orally during examination-in-chief because the testimony was introduced by way of prior recorded testimony under rule 68(b), the crossexamining party must limit questioning to: i. issues contained in the passages of the prior recorded testimony that were relied upon by the party calling the witness, or ii. matters that are relevant to its own case. The Chamber will not allow cross-examination on matters raised in the previously recorded testimony that have not been tendered into evidence by the party calling the witness."

${ }^{185}$ Siehe auch R. 88(5) RPE: „Taking into consideration that violations of the privacy of a witness or victim may create risk to his or her security, a Chamber shall be vigilant in controlling the manner of questioning a witness or victim so as to avoid any harassment or intimidation, paying particular attention to attacks on victims of crimes of sexual violence." Vgl. auch Art. 29 Code of Professional Conduct for Counsel; und Art. 8 Code of Judicial Ethics (ICC-BD/02-01-05). 
Voraussetzungen und Bedingungen auch als Vernehmungshilfen verwendet werden. $^{186}$

Obwohl nach diesen Anweisungen die Beweisaufnahme grundsätzlich in zwei aufeinanderfolgende Phasen, namentlich die Präsentation des prosecution case und des defence case, zu gliedern ist, wird die Möglichkeit einer frühzeitigen Unterbrechung der gerichtlichen Untersuchung nach dem Ende des prosecution case aufgrund eines no case to answer-Antrags, wie sie etwa in England vorgesehen ist, ${ }^{187}$ nicht angesprochen. Dies bedeutet aber keinesfalls, dass eine solche Möglichkeit in der internationalen Strafgerichtsbarkeit, etwa unter Berücksichtigung der Erörterungsmöglichkeiten nach Art. 64(3a) IStGH-Statut, ausgeschlossen ist. ${ }^{188}$

Letztendlich offenbaren die Anweisungen der Hauptverfahrenskammer II des IStGH im oben genannten Fall eindeutige Parallelen zu den Konturen des englischen Beweisverfahrens, auch wenn mit Blick auf das IStGH-Verfahren viele weitere Eingriffsmöglichkeiten und case management-Befugnisse für die Richter vorgesehen sind. Zu beachten ist gleichwohl, dass es sich hierbei größtenteils nicht um allgemein verbindliche Regeln handelt, sondern um die prozesstechnischen Verfügungen einer bestimmten Hauptverfahrenskammer des IStGH nach ihrem im Statut und den RPE verankerten Ermessen und im Rahmen einer bestimmten Situation, also nur in Bezug auf die in concreto ermittelten Straftaten. Die Hauptverfahrenskammer I hat in einer anderen Angelegenheit bemerkt:

It is to be noted that the expressions the 'prosecution case' and 'defence case' are not to be found in the relevant provisions. The Rome Statute framework does not apply fixed stages for the presentation of evidence during the trial, and in this the ICC differs from the position in some other courts or tribunals [...]. Article 64(8)(b) of the Statute and Rule 140(1) of the Rules of Procedure and Evidence essentially leave it to the Chamber to determine the model to be followed instead of applying a mechanistic formula. ${ }^{189}$

Künftige Hauptverfahren vor dem IStGH können daher etwa in Form einer zentralen und einheitlichen, ab initio richterlich gesteuerten Prüfung des Sachverhalts und aller Beweismittel unter Mitwirkung der Verfahrensbeteiligten anstatt einer strikt in zwei Phasen (Parteien-cases) eingeteilten Hauptverhandlung stattfinden. In der bisherigen Praxis des IStGH als ständigen Nachfolgers der ad hoc-Tribunale

186 Ferner zum Verfahren und zu den Voraussetzungen der Einführung von documentary evidence einerseits direkt ,from the bar table“ und andererseits während der Vernehmung eines Zeugen sowie zur Verwendung von Dokumenten als Vernehmungshilfen siehe Directions for the conduct of the proceedings and testimony in accordance with rule 140, Prosecutor v. Germain Katanga and Mathieu Ngudjolo Chui (Trial Chamber II, ICC01/04-01/07, 20 November 2009), Annex §§ 95-111.

187 Siehe unter Teil 2, II.D.2.b).

188 Dazu Friman/Brady/Costi/Guariglia/Stuckenberg, in: Sluiter u.a. (Hrsg.), International, S. 430-431; Safferling, International, S. 449-450.

189 Decision on the 'Requête de la Défense sollicitant l'autorisation d'interjeter appel de la décision orale du 4 mars 2010 autorisant l'utilisation et le dépôt en preuve de trois photographies', Prosecutor v. Thomas Lubanga Dyilo (Trial Chamber I, ICC-01/04-01/06, 29 April 2010), § 26. 
haben sich allerdings, trotz der weitgehend vorgesehenen richterlichen Eingriffsund Kontrollmechanismen, offensichtlich solche Verhandlungsstrukturen durchgesetzt, wie sie oben beschrieben wurden und wie sie am häufigsten in parteienzentrierten Beweisführungssystemen wie dem englischen anzutreffen sind. ${ }^{190}$

\section{Klassifizierende und wertende Schlussfolgerungen}

Das IStGH-Normensystem hat sich zumindest durch seine terminologischen Präferenzen ${ }^{191}$ sowie durch die umfassende, systemneutrale und verfahrensprägende Verankerung der Menschen-, Verfahrens- und Opferrechte bemüht, direkte Bezüge $\mathrm{zu}$ konkreten traditionellen Arten des streitigen Straf- und Beweisverfahrens zu vermeiden. Die Rechtsprechung des IStGH hat dagegen bisher, wie festgestellt, nicht nur auf begrifflicher Ebene - etwa durch die konstante Bezeichnung der Anklage und der Verteidigung als Parteien - bestimmte Verfahrenseigenarten und Beweisprüfungsmechanismen angloamerikanischer Prägung adoptiert. Folgende strukturellen Merkmale des IStGH-Verfahrenssystems, die oben analysiert wurden, weisen in allen Fällen signifikante Ähnlichkeiten etwa mit dem in Teil 2 der vorliegenden Arbeit dargestellten englischen Beweisführungssystem ${ }^{192}$ auf:

- das Nicht-Anlegen von zentral zusammengestellten Verfahrensakten und die komplexen Förmlichkeiten und Beschränkungen der inter partes-Durchführung der Beweisoffenlegungen;

- die Nicht-Verankerung der richterlichen Amtsaufklärungspflicht als Leitprinzip des Verfahrens;

- die Institution der witness familiarisation;

- die weitgehenden Möglichkeiten der Parteien zur unmittelbaren Bestimmung des Umfangs der Beweiserhebungen und zur Einführung von agreed evidence;

- die Möglichkeit der Parteien zur Beauftragung von „eigenen“ Experten;

- schließlich vor allem die bisherige Gerichtspraxis der Einführung von Beweisen in die Hauptverhandlung im Wege der Präsentation zweier eigenständiger Fallvorbringen mit der prosecution case und der defence case, i.V.m. der Durchset-

190 Neben dem vorgenannten Fall Prosecutor v. Germain Katanga and Mathieu Ngudjolo Chui siehe Decision on Directions for the Conduct of the Proceedings, Prosecutor v. Jean-Pierre Bemba Gombo (Trial Chamber III, ICC-01/05-01/08, 19 November 2010), insb. $\S \S 5-16$. Vgl. auch Judgment pursuant to Article 74 of the Statute, Prosecutor v. Thomas Lubanga Dyilo (Trial Chamber I, ICC-01/04-01/06, 14 March 2012), §§ 10-11 und Decision on judicial questioning, Prosecutor v. Thomas Lubanga Dyilo (Trial Chamber I, ICC-01/04-01/06, 18 March 2010), §§ 43-50. Zum Lubanga-Fall siehe Ambos, ZIS 2012, 313 (316-318) mit weiteren Literaturhinweisen.

191 Siehe Kress, JICJ 1 (2003), 603 (605, 613).

192 Siehe zusammenfassend zum englischen und zum deutschen Beweisführungssystem sowie zu ihrem Vergleich unter Teil 2, II.E., Teil 2, III.E., Teil 2, IV.E. 
zung der examination-in-chief und der cross-examination als primären Prüfinstrumenten des gesamten persönlichen sowie des größten Teils des sachlichen Beweises.

Gleichwohl sind im IStGH-Verfahrenssystem in großem Umfang Elemente und Merkmale anzutreffen, die in ihrer Grundform für solche nationalen Verfahrenssysteme wie das deutsche typisch sind. Dazu gehören, wie bereits dargestellt, insbesondere:

- die ausdrückliche Verankerung der Pflicht des Anklägers zur Objektivität und Wahrheitserforschung im IStGH-Statut;

- die Gewährleistung von möglichst umfassenden Beweisoffenlegungen seitens des Anklägers gegenüber der Verteidigung und der Vorverfahrenskammer, die ebenfalls beachtliche Beweissammlungs- und Prüfungskompetenzen hat;

- die Befugnis der Hauptverfahrenskammer zur Anordnung von weiteren Beweisoffenlegungen für die Zwecke der Wahrheitserforschung und ihre (tatsächliche und in der Praxis bisher unwidersprochene) ${ }^{193}$ Möglichkeit zur Einsichtnahme in die umfangreichen Akten des Vorverfahrens, die zur Anordnung weiterer Offenlegungen sowie bei der Bestimmung des Umfangs der maßgebenden Beweiserhebungen und der Leitung des Hauptverfahrens dienlich sein kann;

- der Leitsatz der IStGH-Rechtsprechung, dass die Auswahl der Experten aus der vom Gerichtshof amtlich zusammengestellten Liste erfolgen soll und dass jedenfalls die gemeinsame Beauftragung von Experten in vielfacher Hinsicht sinnvoller ist, die Möglichkeit der IStGH-Kammern sowohl zur Anordnung einer solchen gemeinsamen Beauftragung durch die Parteien als auch zum Erlass von weitgehenden Verfügungen hinsichtlich der Vorbereitung und Einführung des Expertenbeweises sowie die selbstständige Möglichkeit der Richter, Experten zur Vernehmung aufzurufen;

- die Befugnis der Kammern, die Einführung von agreed evidence seitens der Parteien aus Gründen der Gerechtigkeits- und Opferinteressen zugunsten einer vollständigen Beweispräsentation abzulehnen;

- die ausdrückliche Anerkennung durch die IStGH-Rechtsprechung, dass die von den Parteien geladenen Zeugen letztendlich „Zeugen des Gerichts“ darstellen und dass ihre cross-examination der Wahrheitsfindung dienen muss;

- die Befugnis der Kammern, jederzeit die Beibringung von zusätzlichen Beweismitteln zum Zweck der Wahrheitserforschung zu verlangen, die Befugnis der Richter, jederzeit während der Hauptverhandlung (auch zu Beginn einer Vernehmung) allen Zeugen Fragen zu stellen, sowie die vorgesehenen Möglichkeiten zur richterlichen Kontrolle der Art und Weise der parteilichen Befragungen zum Zweck der Sicherstellung einer zügigen Sachaufklärung.

193 Siehe Schuon, International, S. 295-299. 
Weiterhin darf die Tatsache nicht außer Acht gelassen werden, dass die eher parteienzentrierte Struktur der bisherigen Hauptverhandlungen, die sich gegenwärtig durchgesetzt hat, weder vom IStGH-Statut oder anderen Vorschriften in ausschließlicher Weise gefordert wurde noch von der Rechtsprechung als verbindliches Vorbild für alle internationalen Gerichtsverfahren angesehen wird. Daher kann beispielsweise auch unter Berücksichtigung der normativ bereits vorgesehenen richterlichen case management-Befugnisse nicht ausgeschlossen werden, dass künftige Beweisführungen vor dem IStGH eher richterzentriert sein werden; oder etwa dass die Verhandlungen - in Anbetracht der weitgehenden Erörterungsmöglichkeiten, die das IStGH-Normensystem den Verfahrensbeteiligten und dem Gericht schon eröffnet hat - in einer ,dialektischeren“194 Weise stattfinden werden. Eine zentrale Rolle bei der weiteren Entwicklung der relevanten Verfahrenspraxis in diesem internationalen und gestaltungsoffenen ${ }^{195}$ prozessualen Umfeld wird in allen Fällen nach wie vor die „rechtstraditionelle Herkunft“ der jeweiligen Richter und ihr Verständnis der Funktionen der internationalen Strafgerichtsbarkeit spielen. ${ }^{196}$

Dementsprechend lässt sich nicht mit Sicherheit und endgültig feststellen, ob das IStGH-Beweisführungssystem unter Berücksichtigung der in Teil 1 der Arbeit definierten Modellelemente ${ }^{197}$ eher ,,adversatorisch“ oder eher ,inquisitorisch“ ist allerdings hat die oben dargelegte Modelldichotomie auch vorliegend den geeigneten vereinfachenden Hypothesenerstellungs- und Analyserahmen zur systematischen und gezielten Identifizierung der teilweise einzigartigen ${ }^{198}$ Merkmale und Formmischungen des IStGH-Systems zur Verfügung gestellt. ${ }^{199}$ Letztendlich ist sowohl der theoretische als auch der praktische Wert einer strikten Klassifizierung - etwa im Sinne der Annahme, dass die bisherige Ausgestaltung des IStGH-

\footnotetext{
194 Siehe etwa die in dieser Arbeit mit Blick auf das nationale Strafverfahren vorgeschlagenen ausbalancierenden Leitsätze unter Teil 2, V.C.

195 Vgl. zum Zeugenbeweis Kreß, in: Fischer u.a. (Hrsg.), International, S. 382: „,[Delegations] have also shown a genuine spirit of compromise with respect to those points such as the form of the witness testimony at trial [...] where they have left the ultimate decision on the appropriate procedural model to the judges. This is so as the adoption of a partly 'open' procedural framework entails the possibility that, in the end, the law will be construed in another way than one would have preferred on the basis of one's national perspective. [...] In other areas where it will, essentially, be up to the ICC judges to shape 'their' procedure - for example, as regards the form of the witness testimony at trial 'mixed' solutions may, however, be recommendable. At the end we are likely to see the evolution of an international witness regime which is truly unique in its mix of existing and introduction of new [...] procedural solutions."

196 Siehe Ambos, Int'l Crim. L. Rev. 3 (2003), 1 (32, 37); Damaška, in: Cassese (Hrsg.), Oxford Companion, S. 176. Vgl. auch die empirischen Beobachtungen zum IStGHJVerfahren von Pakes, in: van Koppen/Penrod (Hrsg.), Adversarial, S. 313-319.

197 Siehe ihre Zusammenfassung unter Teil 1, II.C.4.

198 Siehe auch Kress, JICJ 1 (2003), 603 (605).

199 Vgl. auch Sluiter, in: Cassese (Hrsg.), Oxford Companion, S. 231.
} 
Beweisverfahrens den Grundzügen des ,,adversatorischen“ Modells nahe steht eher gering. Von größerer Bedeutung ist die Frage, ob die derzeitigen oder zukünftigen Strukturen des Beweisverfahrens für die Erfüllung seines immanenten Ziels, nämlich der präzisen gerichtlichen Aufklärung der auf internationaler Ebene ermittelten Sachverhalte, tauglich sind.

Es ist noch zu früh, um eine Aussage darüber zu treffen, ob die bisherige Beweisverfahrenspraxis, die durch die Richter des IStGH anhand der größtenteils „flexiblen“ Rechtsvorschriften und weiterhin unter dem Einfluss der Verfahrenstradition $^{200}$ der ad hoc-Tribunale gefördert wird, die bestmögliche für die ständige internationale Strafgerichtsbarkeit ist. Freilich gibt es positive (zweckdienliche) Charakteristika, wie vor allem:

- die prinzipielle Orientierung von Prozessregeln und Rechtsprechung auf Objektivität und Wahrheit;

- die Aufteilung der Befugnisse zur Bestimmung der Beweiserhebungen zwischen Parteien und Gericht;

- die richterliche Befugnis zur durchgehenden Kontrolle der Zweck- und Ordnungsmäßigkeit der Beweiserhebungen (und zum Teil der Beweissammlungen); sowie

- die umfassenden Erörterungs-, Anhörungs- und Mitwirkungsmöglichkeiten aller zentralen Verfahrensbeteiligten.

Gleichzeitig treten aber auch problematische Aspekte zu Tage. Diese betreffen zum Beispiel das komplexe und zeitaufwendige System der inter partes-Beweisoffenlegungen; in diesem Zusammenhang ist insbesondere auf die mangelnde Wahrnehmung der auf internationaler Ebene häufig zu beobachtenden Ungleichheit von Anklage und Verteidigung in Bezug auf die rechtlichen und faktischen Mittel hinzuweisen, die für die Beweissammlung und die Vorbereitung der Beweisführungen zur Verfügung stehen. ${ }^{201}$ Vor allem aber darf das starre Festhalten der

200 Siehe dazu Cassese, International, S. 340-346; Orie, in: Cassese u.a. (Hrsg.), The Rome Statute, S. 1456-1474, 1492-1495. Siehe auch Sluiter, in: Cassese (Hrsg.), Oxford Companion, S. 231; Zappalà, Human Rights, S. 22-24.

201 Vgl. Jackson, JICJ 7 (2009), 17 (28): „But even with better resources it is difficult to see how the defence can ever operate effectively in obtaining evidence in a context where a state refuses to cooperate with it and within the adversarial culture of the tribunals it is hard to see prosecutors ever sharing the fruits of their investigations evenhandedly with the defence. Ultimately, of course, the prosecution bears a heavy burden of proving the defendant's guilt beyond reasonable doubt and this is sometimes claimed in domestic adversarial settings to be adequate compensation for the inequality of resources between the prosecution and defence. But this burden is made easier in the international context where the defence are unable to make effective investigations to combat the prosecution case. [...] But the international setting makes it almost impossible for an adversarial system of fact-gathering to grant the defence the substantive equality necessary to make the most effective case against the prosecution. This suggests that there needs to be greater responsibility placed upon the court for the gathering of evidence." 
Hauptverfahrenskammern an der nicht selten weitschweifigen Praxis der zwei Beweisaufnahmephasen (prosecution case und defence case) und an den übrigen einschränkenden Förmlichkeiten der Beweisprüfungsmethoden angloamerikanischer Prägung nicht außer Acht gelassen werden. ${ }^{202}$ Dies kann nämlich bei einer sehr großen Anzahl von Beweismitteln und komplizierten Beweisfragen und in Verbindung mit der Tatsache, dass die Richter im IStGH-System keine eigenständige Pflicht zur Gewährleistung einer erschöpfenden Ermittlung der Sachverhalte haben, zu verwirrenden, schwer nachvollziehbaren oder fragmentarischen Beweisergebnissen führen. ${ }^{203}$

Nicht zuletzt weil solche Charakteristika des gegenwärtigen Beweisverfahrenssystems des IStGH reformbedürftig sind, sind das im Statut und den RPE teilweise verankerte „Prinzip“ der freien Gestaltung der Beweisführungen und das hierfür vorgesehene richterliche Ermessen von besonderem Wert. Den Richtern des IStGH steht es nämlich frei, von Fall zu Fall ihr jeweiliges nationales und rechtstraditionelles Prozessverständnis, ihre Erfahrungen aus der völkerrechtlichen Justizpraxis und ihre rechtsvergleichenden Kenntnisse zum Zweck der kontinuierlichen Optimierung der internationalen Beweisprüfungsmethoden in flexibler und effektiver Weise kumulativ einzusetzen ${ }^{204}$ - freilich ist bei der Durchführung diesbezüglicher „Experimente“ besondere Vorsicht geboten, damit auch im internationalen Strafverfahren Rechtssicherheit gewährleistet ist und nicht Verwirrung und Willkür herrschen.

Die progressive Entwicklung des prozessualen Rahmens der ständigen internationalen Strafgerichtsbarkeit kann darüber hinaus auch innerstaatlich einen Einfluss ausüben: Die nationalen Rechtsordnungen stehen nämlich nicht nur unter dem rechtspolitischen Druck, gemäß dem Grundsatz der Komplementarität die volle Funktionsfähigkeit und Effektivität ihrer Verfahrenssysteme im Hinblick auf die nationale Ermittlung von völkerrechtlichen Verbrechen aufrechtzuerhalten, d.h.

\footnotetext{
202 Siehe auch Eser, FS für Jung, S. 179-180.

203 Aufgrund derartiger Erwägungen haben auch angesehene Forscher der common lawVerfahrenstradition die Meinung geäußert, dass gewisse Ansätze der richterdominierten civil law-Systeme oder eine weniger starke Gewichtung der klassischen (unflexiblen) common law-Verhandlungselemente den verschiedenen (auch allgemeineren) Zielen und Aufgaben des internationalen Strafverfahrens dienlicher sein könnten. Siehe in diesem Zusammenhang insb. Damaška, in: Cassese (Hrsg.), Oxford Companion, S. 180-182, und Jackson, JICJ 7 (2009), 17 (22-24), die u.a. solche Ziele der internationalen Strafjustiz berücksichtigen wie die Versöhnung i.V.m. der Wahrung und prozessualen Förderung der Opferinteressen und der Menschenrechte sowie das Erstellen einer historischen Aufzeichnung der betreffenden Situationen (auch wenn die Aufgabe des Historikers mit den üblichen normativen Richterfunktionen und den faktisch begrenzten Möglichkeiten eines Gerichtshofs nicht ohne weiteres vereinbar ist).

204 Vgl. Damaška, Law, Probability and Risk 2 (2003), 117 (122): „A satisfying hybrid can someday emerge, most likely from experiences provided by the practice of those tribunals in which judges and lawyers from different legal traditions interact." Vgl. auch Grande, in: Bussani/Mattei (Hrsg.), Comparative, S. 193.
} 
unter anderem in Übereinstimmung mit den vom IStGH-System gesetzten beweisprozessualen Maßstäben. ${ }^{205}$ Die Nationalstaaten können darüber hinaus auch die Erfahrungswerte und die Ergebnisse der internationalen Formmischungen bei der Suche nach besseren Lösungen und Paradigmen für die Optimierung und die (gegenwärtig in vielerlei Hinsicht geförderte) Annäherung ihrer innerstaatlichen Verfahrensordnungen berücksichtigen. Die Besonderheiten der internationalen Verbrechensverfolgung, die einen direkten Vergleich zwischen nationalen und internationalen Justizsystemen nicht immer erlauben, dürfen dabei jedoch nicht außer Acht gelassen werden.

Schließlich können auch die theoretischen, empirischen und rechtsvergleichenden Forschungen, welche die Untersuchung der beweisprozessualen Dimensionen des internationalen Strafjustizsystems zum Gegenstand haben, innerhalb dieses gestaltungsoffenen und noch in einem frühen Entwicklungsstadium befindlichen Strafverfahrensumfelds befreit von rechtstraditionellen Vorurteilen und sterilen Widerständen und in anspruchsvoller (,experimenteller“) Weise durchgeführt werden. Solche Forschungen sollten auch zur Förderung der entsprechenden rechtspolitischen Reformplanungen beitragen können. Die völkerrechtlichen Reformprogramme müssen ihrerseits auch die relevanten Entwicklungen und Tendenzen in der nationalen und der internationalen Gerichtspraxis sorgfältig und kontinuierlich wahrnehmen, um den Richtern und der internationalen Strafjustiz zeitgemäße, funktionale und mit breitem Konsens institutionell verankerte Prozessmechanismen zur Verfügung stellen zu können. Orientieren müssen sich solche Bemühungen, gleich den Optimierungsstrategien für die nationalen Strafverfahren, jedenfalls auf die Stärkung der Strukturen, Rollenverteilungen und Prozessgarantien, die das Streben nach Wahrheit, Fairness, umfassender dialektischer Teilhabe der Hauptakteure und Wahrung der Menschenrechte im Strafverfahren sowie nach einer möglichst friedlichen Koexistenz dieser Werte als vorrangig anerkennen und wahrnehmen. Letztendlich handelt es sich dabei um zentrale Verfahrensmaßstäbe, die auch langfristig systemübergreifend anerkannt und sozial legitimiert sein werden.

205 Vgl. Delmas-Marty, in: Cassese (Hrsg.), Oxford Companion, S. 97; Satzger, Internationales Strafrecht, § 14 Rn. 22. 


\section{Schlusswort}

Die Gegenüberstellung des „adversatorischen“ und des ,inquisitorischen“ Strafverfahrens weist sowohl national- als auch internationalrechtliche Dimensionen auf. Die Auseinandersetzung mit den Rechtssystemen der EMRK und des IStGH hat gezeigt, dass auch auf internationalrechtlicher Ebene die Identifizierung von „puren“ Strafverfahrensarten sowie die dichotomisierende Verwendung von absoluten Begriffen zur klassifizierenden Bezeichnung der diversen realen Prozesssysteme kaum möglich sind bzw. praktisch einen eher geringen Wert haben. Die Rechtsprechung des EGMR fordert keinesfalls die einheitliche Durchsetzung eines bestimmten Verfahrenstypus in den europäischen Staaten, auch wenn der Gerichtshof im menschenrechtlichen Kontext Begriffe aus der angloamerikanischen Rechtstradition, wie das Prinzip der „adversarial proceedings“, verwendet. Das Prozesssystem des IStGH kombiniert seinerseits Elemente von Rechtsordnungen beider großer Traditionen der westlichen Rechtswelt. Es erlaubt aber gleichzeitig der Gerichtspraxis, die von mehreren Richtern und Anwälten unterschiedlicher prozesskultureller Herkunft beherrscht wird, die in gewissem Maße gestaltungsoffenen Strukturen des internationalen Erkenntnisverfahrens von Fall zu Fall und in progressiver Weise mitzubestimmen; dadurch besteht die Möglichkeit, erstmals ein wirklich hybrides Verfahrenssystem zu entwickeln. Aber auch auf innerstaatlicher Ebene sind die Abkehr von bisherigen rechtstraditionellen Exzessen und zu diesem Zweck der transnationale Austausch von Lösungsansätzen von vorrangiger Bedeutung für die modernen westlichen Verfahrensordnungen. Freilich gibt es vor dem Hintergrund der in der vorliegenden Arbeit ausgearbeiteten Grundzüge für eine dialektischere Ausgestaltung der nationalen Beweisverfahren immer noch Raum für praktische Verbesserungen und rechtspolitische Reformen.

In diesem Kontext weist die abstrakte Konstruktion von reinen Modellen oder Idealtypen des Straf- und Beweisverfahrens, die sich auf die Beobachtung von charakteristischen strukturellen Merkmalen, Organisationsideen und Zielsetzungen eigentlicher Rechtssysteme gründet, einen hohen analytischen Wert sowohl auf nationalrechtlicher als auch auf internationalrechtlicher Ebene auf. Die konzeptionelle (dichotomisierende) Gegenüberstellung solcher Idealtypen soll vor allem die funktionale vergleichende Untersuchung von realen Verfahrenssystemen fördern und diese insbesondere durch die Bereitstellung eines kohärenten Analyserahmens vereinfachen. Hierfür ist es aber nötig, die Bestandteile der anzuwendenden Modelle in logischer, deutlicher, thematisch klar begrenzter und nicht widersprüchlicher Weise im Voraus zu bestimmen; gleiches gilt, wenn die Modellkonstruktionen von 
weitverbreiteten (aber nicht durchweg einheitlich definierten) Prozessbegriffen ausgehen, wie es z.B. bei der Gegenüberstellung des ,,adversatorischen“ und des „,inquisitorischen“ Beweisverfahrens der Fall ist. Die Idealtypen müssen nämlich geeignet sein, eine stabile „Infrastruktur“ für die konstruktive Durchführung von entsprechenden theoretischen, empirischen oder konkret-rechtsvergleichenden Forschungen zur Verfügung zu stellen. Solche Forschungen - insbesondere diejenigen, die sich mit einflussreichen Strafrechtssystemen, wie dem englischen, dem deutschen und dem internationalen, auseinandersetzen - und ihre theoretischen Hintergründe sollen ihrerseits als Grundlage für weitere (umfassendere) Untersuchungen und für rechtspolitische Optimierungsstrategien im jeweiligen Bereich dienen.

Die Bestimmung von analytisch nützlichen Idealtypen des Straf- und Beweisverfahrens zum Zweck der Rechtsvergleichung und der rechtspolitischen Planung setzt in allen Fällen die sinnvolle Beschäftigung mit der Theorie der Rechtskreise und Rechtstraditionen voraus. Simplifizierte Betrachtungen hinsichtlich der universellen Bedeutung und der Aussagekraft der diversen Einteilungen der Rechtsordnungen in Rechtskreise sowie polarisierende, folkloristische oder veraltete Klassifizierungen der modernen Verfahrenssysteme auf der Basis von historischen Ereignissen müssen dabei vermieden werden. Von Bedeutung ist vielmehr die Anwendung des rechtsvergleichenden Instrumentariums zur Identifizierung der aktuell jeweils vorherrschenden sozialpolitischen und rechtstechnischen Ideen hinter der strukturellen und institutionellen Organisation des betreffenden Bereichs der Justizsysteme. Gleichwohl darf auch in der heutigen globalen Welt die Kontinuität des rechtstraditionellen Denkens und insbesondere der Einfluss, den eine etablierte Verfahrenstradition als dynamische Gesamtheit von Grundvorstellungen zum Strafverfahren auf die Entwicklung der nationalen und der internationalen Strafjustiz ausüben kann, nicht unterschätzt werden.

Schließlich darf die Rolle nicht unterbewertet werden, die auch thematisch begrenzte abstrakt-theoretische und rechtsvergleichende Grundlagenuntersuchungen von Prozesstraditionen und Beweisverfahrenstypen bei der Forschung und Reformplanung hinsichtlich anderer Themenbereiche des Strafverfahrensrechts spielen können. Gegenwärtig steht überall die Suche nach wirksamen alternativen Prozessformen im Vordergrund; diese beziehen sich vor allem auf die effektive Durchsetzung von Absprachemechanismen oder auf die normative Verlagerung des beweisprozessualen Gewichts von der Hauptverhandlung hin zum Vorverfahren. Für die Ermöglichung einer solchen Suche ist zunächst die systematische Identifizierung der theoretischen und historischen Hintergründe des herkömmlichen Strafverfahrens, seiner Ziele und seiner Grundstrukturen erforderlich. Die Entwicklung und Optimierung der neuen Prozessformen erfordert weiterhin die Zusammenstellung selbstständiger analytischer Idealtypen und rechtspolitischer Reformmodelle; auch hierfür ist die theoretische, empirische und rechtsvergleichende Auseinandersetzung mit den klassischen Strafprozesstypen und den bisher zur Lösung von 
strafrechtlichen Konflikten angewandten Mechanismen Voraussetzung. Im Ergebnis stellen die Bildung und die Anwendung von Idealtypen im Verein mit der funktionalen Rechtsvergleichung vorzügliche Forschungsmethoden dar, die auch im strafprozessualen Kontext dem wissenschaftlichen Fortschritt und den rechtspolitischen Entwicklungen in der nationalen und in der internationalen Strafjustiz dienen bzw. diese prägen können. 



\section{Literaturverzeichnis}

Abou El Fadl, Khaled, The Islamic legal tradition. In: Mauro Bussani/Ugo Mattei (Hrsg.), The Cambridge Companion to Comparative Law. Cambridge u.a. 2012, S. 295-312 [zit. Abou El Fadl, in: Bussani/Mattei (Hrsg.), Comparative].

Afchar, Hassan, The Muslim Conception of Law. In: René David (Hrsg.), International Encyclopedia of Comparative Law, Volume II: The Legal Systems of the World: Their Comparison and Unification, Chapter 1: The Different Conceptions of the Law. Tübingen u.a. 1975, S. 84-106 [zit. Afchar, in: David (Hrsg.), International Encyclopedia].

Alamuddin, Amal, Collection of Evidence. In: Karim A. A. Khan u.a. (Hrsg.), Principles of Evidence in International Criminal Justice. Oxford u.a. 2010, S. 231-305 [zit. Alamuddin, in: Khan u.a. (Hrsg.), Principles].

Allen, Claud, Im englischen Strafprozeß. ZStW 72 (1960), 650-673 [zit. C. Allen, ZStW 72 (1960)].

Allen, Francis, The Comparative Study of Legal Institutions: The Case of American Criminal Justice. In: The Institute of Comparative Law in Japan (Hrsg.), Toward Comparative Law in the 21 st Century. The 50th anniversary of The Institute of Comparative Law in Japan Chuo University. Tokyo 1998, S. 767-780 [zit. F. Allen, in: The Institute of Comparative Law in Japan (Hrsg.), Toward].

Alsberg, Max (Begr.), Der Beweisantrag im Strafprozess. Fortgeführt von Karl-Heinz Nüse und Karlheinz Meyer. Bearbeitet von Jens Dallmeyer, Georg-Friedrich Güntge, Michael Tsambikakis. 6. Aufl. Köln 2013 [zit. Alsberg-Bearbeiter, Der Beweisantrag, Rn.].

Altenhain, Karsten/Haimerl, Michael, Die gesetzliche Regelung der Verständigung im Strafverfahren - eine verweigerte Reform. JZ 2010, 327-337 [zit. Altenhain/Haimerl, JZ 2010].

Ambos, Kai, Der Europäische Gerichtshof für Menschenrechte und die Verfahrensrechte. Waffengleichheit, partizipatorisches Vorverfahren und Art. 6 EMRK. ZStW 115 (2003), 583-637 [zit. Ambos, ZStW 115 (2003)].

- International criminal procedure: 'adversarial', 'inquisitorial', or mixed? Int'l Crim. L. Rev. 3 (2003), 1-37 [zit. Ambos, Int'l Crim. L. Rev. 3 (2003)].

- Zum heutigen Verständnis von Akkusationsprinzip und -verfahren aus historischer Sicht. JURA 2008, 586-594 [zit. Ambos, JURA 2008].

- Die Präparierung von Zeugen aus völkerstrafprozessualer und rechtsvergleichender Sicht. In: Winfried Hassemer u.a. (Hrsg.), In dubio pro libertate. Festschrift für Klaus Volk zum 65. Geburtstag. München 2009, S. 1-18 [zit. Ambos, FS für Volk].

- Beweisverwertungsverbote. Grundlagen und Kasuistik - internationale Bezüge - ausgewählte Probleme. Berlin 2010 [zit. Ambos, Beweisverwertungsverbote].

- Das erste Urteil des Internationalen Strafgerichtshofs (Prosecutor v. Lubanga). Eine kritische Analyse der Rechtsfragen. ZIS 2012, 313-337 [zit. Ambos, ZIS 2012]. 
- Internationales Strafrecht. Strafanwendungsrecht - Völkerstrafrecht - Europäisches Strafrecht - Rechtshilfe. 4. Aufl. München 2014 [zit. Ambos, Internationales Strafrecht, $\S \mathrm{Rn}$.$] .$

Androulakis, Nikolaos, Das Wesen des strafrechtlichen Beweises und seine Bestandteile, unter Einschluss seiner revisionsrechtlichen Kontrolle. Die Falsifizierung durch den vernünftigen Zweifel. In: Manfred Heinrich u.a. (Hrsg.), Strafrecht als Scientia Universalis. Festschrift für Claus Roxin zum 80. Geburtstag am 15. Mai 2011. Band 2. Berlin/ New York 2011, S. 1369-1384 [zit. Androulakis, FS für Roxin 2011].

Arenella, Peter, Rethinking the Functions of Criminal Procedure: The Warren and Burger Courts' Competing Ideologies. Geo. L. J. 72 (1983), 185-248 [zit. Arenella, Geo. L. J. $72(1983)]$.

Arminjon, Pierre/Nolde, Baron Boris/Wolff, Martin, Traité de droit comparé. Tome I. Paris 1950 [zit. Arminjon/Nolde/Wolff, Traité de droit comparé].

Arzt, Gunther, Einführung in die Rechtswissenschaft. Grundfragen mit Beispielen aus dem deutschen Recht. Neuwied u.a. 1996 [zit. Arzt, Einführung].

Ashworth, Andrew/Redmayne, Mike, The Criminal Process. 4. Aufl. Oxford 2010 [zit. Ashworth/Redmayne, Criminal Process].

Auld, Robin, Review of the Criminal Courts of England and Wales. Report October 2001. London 2001 [zit. Auld Report 2001].

Bachmaier, Lorena/Moral García, Antonio del, Criminal Law in Spain. Austin u.a. 2010 [zit. Bachmaier/Moral García, Spain].

Baker, John, An Introduction to English Legal History. 4. Aufl. (repr.) Oxford u.a. 2007 [zit. Baker, Introduction].

Bárd, Károly, The Role of the ECHR in Shaping the European Model of the Criminal Process. In: Kauko Aromaa/Terhi Viljanen (Hrsg.), International Key Issues in Crime Prevention and Criminal Justice. Papers in celebration of 25 years of HEUNI. Helsinki 2006, S. 34-52 [zit. Bárd, in: Aromaa/Viljanen (Hrsg.), International Key Issues].

Barton, Thomas, The Structure of Legal Systems. Am. J. Juris. 37 (1992), 291-317 [zit. Barton, Am. J. Juris. 37 (1992)].

Bassiouni, Cherif, Human Rights in the Context of Criminal Justice: Identifying International Procedural Protections and Equivalent Protections in National Constitutions. Duke J. Comp. \& Int'l L. 3 (1993), 235-297 [zit. Bassiouni, Duke J. Comp. \& Int'l L. 3 (1993)].

- Introduction to International Criminal Law: Second Revised Edition. 2. Aufl. Leiden/ Boston 2013 [zit. Bassiouni, Introduction].

Beijer, Annemarieke/Cobley, Cathy/Klip, André, Witness Evidence, Article 6 of the European Convention on Human Rights and the Principle of Open Justice. In: Phil Fennell u.a. (Hrsg.), Criminal Justice in Europe: A Comparative Study. Oxford 1995, S. $283-$ 300 [zit. Beijer/Cobley/Klip, in: Fennell u.a. (Hrsg.), Criminal Justice].

Bell, John, English Law and French Law - Not So Different? CLP 48 (1995, Part 2.), 63101 [zit. Bell, CLP 48 (1995)].

Bellomo, Manlio, Europäische Rechtseinheit. Grundlagen und System des Ius Commune. Übersetzt von Ellen Dilcher. München 2005 [zit. Bellomo, Europäische Rechtseinheit]. 
Berman, Harold, The Historical Background of American Law. In: Harold J. Berman (Hrsg.), Talks on American Law. 2. Aufl. New York 1971, S. 3-17 [zit. Berman, in: ders. (Hrsg.), Talks].

- Recht und Revolution. Die Bildung der westlichen Rechtstradition (Übersetzt von Hermann Vetter). Frankfurt a.M. 1991 [zit. Berman, Recht und Revolution].

Bernstorff, Christoph Graf von, Einführung in das englische Recht. 4. Aufl. München 2011 [zit. Bernstorff, Einführung].

Bertel, Christian/Venier, Andreas, Strafprozessrecht. 7. Aufl. Wien 2014 [zit. Bertel/ Venier, Strafprozessrecht, Rn.].

Beulke, Werner, Der Verteidiger im Strafverfahren. Funktionen und Rechtsstellung. Frankfurt a.M. 1980 [zit. Beulke, Der Verteidiger].

- Konfrontation und Strafprozessreform. Art. 6 Abs. 3 lit. d EMRK und ein ,partizipatorisches" Vorverfahren anstelle einer Hauptverhandlung in ihrer bisherigen kontradiktorischen Struktur. In: Ernst-Walter Hanack u.a. (Hrsg.), Festschrift für Peter Riess zum 70. Geburtstag am 4. Juni 2002. Berlin/New York 2002, S. 3-29 [zit. Beulke, FS für Riess].

- Strafprozessrecht, 12. Aufl. Heidelberg u.a. 2012 [zit. Beulke, Strafprozessrecht, Rn.].

Bielefeldt, Heiner, „Westliche“ versus ,islamische“ Menschenrechtskonzeptionen? In: Hatem Elliesie (Hrsg.), Beiträge zum Islamischen Recht VII: Islam und Menschenrechte. Frankfurt a.M. u.a. 2010, S. 99-119 [zit. Bielefeldt, in: Elliesie (Hrsg.), Islam und Menschenrechte].

Billis, Emmanouil, National characteristics, fundamental principles, and history of criminal law in Greece. In: Ulrich Sieber u.a. (Hrsg.), National Criminal Law in a Comparative Legal Context. Volume 1.2. Introduction to National Systems. National characteristics, fundamental principles, and history of criminal law. Australia, Côte d'Ivoire, Greece, South Korea. Berlin 2013, S. 187-290 [zit. Billis, in: Sieber u.a. (Hrsg.), National Criminal Law].

Blake, Nicholas, The Case for the Jury. In: Mark Findlay/Peter Duff (Hrsg.), The Jury Under Attack. London/Sydney 1988, S. 140-160 [zit. Blake, in: Findlay/Duff (Hrsg.), Jury].

Bleckmann, Albert, Verfassungsrang der Europäischen Menschenrechtskonvention? EuGRZ 1994, 149-155 [zit. Bleckmann, EuGRZ 1994].

Blondel, Erin, Victims' Rights in an Adversary System. Duke L.J. 58 (2008), 237-274 [zit. Blondel, Duke L.J. 58 (2008)].

Börner, René, Die Ungleichheit von Schöffen und Berufsrichtern - Schöffen als Garanten der Unmittelbarkeit. ZStW 122 (2010), 157-198 [zit. Börner, ZStW 122 (2010)].

Bohigian, Haig, What is a Model? In: Stuart S. Nagel (Hrsg.), Modeling the Criminal Justice System. Beverly Hills/London 1977, S. 15-27 [zit. Bohigian, in: Nagel (Hrsg.), Modeling].

Bohlander, Michael, Radbruch Redux: The Need for Revisiting the Conversation between Common and Civil Law at Root Level at the Example of International Criminal Justice. LJIL 24 (2011), 393-410 [zit. Bohlander, LJIL 24 (2011)]. 
- Language, Culture, Legal Traditions, and International Criminal Justice. JICJ 12 (2014), 491-513 [zit. Bohlander, JICJ 12 (2014)].

- Laienbeteiligung und adversarisches Verfahrensmodell - A match made in Heaven? In: Friedrich-Christian Schroeder/Manuchehr Kudratov (Hrsg.), Die strafprozessuale Hauptverhandlung zwischen inquisitorischem und adversatorischem Modell. Eine rechtsvergleichende Analyse am Beispiel des deutschen und des zentralasiatischen Strafprozessrechts. Frankfurt a.M. 2014, S. 167-177 [zit. Bohlander, in: Schroeder/ Kudratov (Hrsg.), Hauptverhandlung].

Boll, Matthias, Plea Bargaining and Agreement in the Criminal Process. A Comparison between Australia, England and Germany. Hamburg 2009 [zit. Boll, Plea Bargaining].

Bradley, Craig, The Convergence of the Continental and the Common Law Model of Criminal Procedure. CLF 7 (1996), 471-484 [zit. Bradley, CLF 7 (1996)].

- Overview. In: Craig M. Bradley (Hrsg.), Criminal Procedure. A Worldwide Study. 2. Aufl. Durham, North Carolina 2007, S. xvii-xxvii [zit. Bradley, in: ders. (Hrsg.), Criminal Procedure].

- United States. In: Craig M. Bradley (Hrsg.), Criminal Procedure. A Worldwide Study. 2. Aufl. Durham, North Carolina 2007, S. 519-548 [zit. Bradley, in: ders. (Hrsg.), Criminal Procedure].

- The Prosecutor's Role: Plea Bargaining and Evidentiary Exclusion. In: Erik Luna/ Marianne L. Wade (Hrsg.), The Prosecutor in Transnational Perspective. Oxford u.a. 2012, S. 91-101 [zit. Bradley, in: Luna/Wade (Hrsg.), Prosecutor].

Bradley, Craig/Hoffmann, Joseph, Public Perception, Justice, and the 'Search For Truth' in Criminal Cases. S. Cal. L. Rev. 69 (1996), 1267-1302 [zit. Bradley/Hoffmann, S. Cal. L. Rev. 69 (1996)].

Brants, Chrisje, Comparing Criminal Process as Part of Legal Culture. In: David Nelken (Hrsg.), Comparative Criminal Justice and Globalization. Farnham/Burlington 2011, S. 49-66 [zit. Brants, in: Nelken (Hrsg.), Comparative].

Brants, Chrisje/Ringnalda, Allard, Issues of Convergence: Inquisitorial Prosecution in England and Wales? Nijmegen 2011 [zit. Brants/Ringnalda, Issues].

Brennan, William, The Criminal Prosecution: Sporting Event or Quest for Truth? A Progress Report. Wash. U. L. Q. 68 (1990), 1-18 [zit. Brennan, Wash. U. L. Q. 68 (1990)].

Brouwer, G.E.P., Inquisitorial and Adversary Procedures - a Comparative Analysis. ALJ 55 (1981), 207-223 [zit. Brouwer, ALJ 55 (1981)].

Brüning, Janique, Privatisierungstendenzen im Strafprozeß - Chancen und Risiken der Mitwirkung sachverständiger Privatpersonen im strafrechtlichen Ermittlungsverfahren. StV 2008, 100-104 [zit. Brüning, StV 2008].

Büngener, Lars, Disclosure of Evidence. In: Christoph J. M. Safferling (Verf.), International Criminal Procedure. In cooperation with Lars Büngener, Hilde Farthofer, Alena Hartwig, Yvonne Koberg. Oxford 2012, S. 344-375 [zit. Büngener, in: Safferling (Verf.), International].

Burhoff, Detlef, Handbuch für die strafrechtliche Hauptverhandlung. 7. Aufl. Köln 2013 [zit. Burhoff, Handbuch, Rn.]. 
Cameron, Neil/Potter, Susan/Young, Warren, The New Zealand Jury. Towards Reform. In: Neil Vidmar (Hrsg.), World Jury Systems. Oxford u.a. 2000, S. 167-210 [zit. Cameron/ Potter/Young, in: Vidmar (Hrsg.), Jury].

Cassese, Antonio, Cassese's International Criminal Law. Revised by Antonio Cassese, Paola Gaeta, Laurel Baig, Mary Fan, Christopher Gosnell and Alex Whiting. 3. Aufl. Oxford 2013 [zit. Cassese, International].

Chase, Oscar/Walker, Janet, Common Law, Civil Law and the Future of Categories: An Introduction. In: Janet Walker/Oscar G. Chase (Hrsg.), Common Law, Civil Law and the Future of Categories. Markham 2010, S. li-lxviii [zit. Chase/Walker, in: Walker/ Chase (Hrsg.), Categories].

Chesterman, Michael, Criminal Trial Juries in Australia. From Penal Colonies to a Federal Democracy. In: Neil Vidmar (Hrsg.), World Jury Systems. Oxford u.a. 2000, S. 125165 [zit. Chesterman, in: Vidmar (Hrsg.), Jury].

Chloros, A.G., Common Law, Civil Law and Socialist Law. Three Leading Systems of the World, Three Kinds of Legal Thought. Cambrian L. Rev. 9 (1978), 11-26 [zit. Chloros, Cambrian L. Rev. 9 (1978)].

Choo, Andrew, England and Wales: Fair Trial Analysis and the Presumed Admissibility of Physical Evidence. In: Stephen C. Thaman (Hrsg.), Exclusionary Rules in Comparative Law. Dordrecht u.a. 2013, S. 331-354 [zit. Choo, in: Thaman (Hrsg.), Exclusionary Rules].

Chorus, Jeroen/Coppens, Chris, Chapter 1 - History. In: Jeroen Chorus u.a. (Hrsg.), Introduction to Dutch Law. 4. Aufl. Alphen aan den Rijn 2006, S. 3-11 [zit. Chorus/ Coppens, in: Chorus u.a. (Hrsg.), Introduction].

Clark, David, The Idea of the Civil Law Tradition. In: David S. Clark (Hrsg.), Comparative and Private International Law. Essays in Honor of John Henry Merryman on his Seventieth Birthday. Berlin 1990, S. 11-23 [zit. Clark, in: ders. (Hrsg.), Comparative].

Coing, Helmut, European Common Law: Historical Foundations. In: Mauro Cappelletti (Hrsg.), New Perspectives for a Common Law of Europe. Leyden u.a. 1978, S. 31-44 [zit. Coing, in: Cappelletti (Hrsg.), New Perspectives].

Cole, George/Frankowski, Stanislaw/Gertz, Marc, Comparative Criminal Justice: An Introduction. In: George F. Cole u.a. (Hrsg.), Major Criminal Justice Systems. A Comparative Survey. 2. Aufl. Newbury Park u.a. 1987, S. 15-26 [zit. Cole/Frankowski/Gertz, in: dies. (Hrsg.), Criminal Justice Systems].

Combs, Nancy Amoury, Obtaining Guilty Pleas for International Crimes: Prosecutorial Difficulties. In: Erik Luna/Marianne L. Wade (Hrsg.), The Prosecutor in Transnational Perspective. Oxford u.a. 2012, S. 331-348 [zit. Combs, in: Luna/Wade (Hrsg.), Prosecutor].

Constantinesco, Léontin-Jean, Ideologie als determinierendes Element zur Bildung der Rechtskreise. ZfRV 19 (1978), 161-172 [zit. Constantinesco, ZfRV 19 (1978)].

- Rechtsvergleichung. Band III Die rechtsvergleichende Wissenschaft: Die theoretischen Grundlagen. Köln u.a. 1983 [zit. Constantinesco, Rechtsvergleichung III].

Coriden, James, An Introduction to Canon Law (Revised). New York/Mahwah, N.J. 2004 [zit. Coriden, Canon Law]. 
Cotterrell, Roger, The Concept of Legal Culture. In: David Nelken (Hrsg.), Comparing Legal Cultures. Aldershot u.a. 1997, S. 13-31 [zit. Cotterrell, in: Nelken (Hrsg.), Comparing Legal Cultures].

Coughlan, Stephen, Criminal Procedure. Toronto 2008 [zit. Coughlan, Criminal Procedure].

Courakis, Nestor-Constantin, Struktur- und Auslegungsaspekte des angelsächsischen Strafrechts. GA 1981, 533-557 [zit. Courakis, GA 1981].

Coutts, John, Introduction. The Public Interest and the Interests of the Accused in the Criminal Process. In: John A. Coutts (Hrsg.), The Accused. A Comparative Study. London 1966, S. 1-20 [zit. Coutts, in: ders. (Hrsg.), The Accused].

Crombag, Hans, Adversarial or Inquisitorial. Do We Have a Choice? In: Peter J. van Koppen/Steven D. Penrod (Hrsg.), Adversarial versus Inquisitorial Justice. Psychological Perspectives on Criminal Justice Systems. New York u.a. 2003, S. 21-25 [zit. Crombag, in: van Koppen/Penrod (Hrsg.), Adversarial].

Cryer, Robert/Friman, Hakan/Robinson, Darryl/Wilmshurst, Elizabeth, An Introduction to International Criminal Law and Procedure. 3. Aufl. Cambridge 2014 [zit. Cryer/Friman/ Robinson/Wilmshurst, Introduction].

Dalakouras, Theoharis, Beweisverbote bezüglich der Achtung der Intimsphäre unter besonderer Berücksichtigung der Grundrechtsproblematik sowie des griechischen Rechts. Berlin 1988 [zit. Dalakouras, Beweisverbote].

Dallmeyer, Jens, Beweisführung im Strengbeweisverfahren. Die Beweisbefugnisse als Voraussetzungen der Wahrheitserforschung im Strafprozess. Frankfurt a.M. 2002 [zit. Dallmeyer, Beweisführung].

Damaška, Mirjan, Evidentiary Barriers to Conviction and Two Models of Criminal Procedure: A Comparative Study. U. Pa. L. Rev. 121 (1973), 506-589 [zit. Damaška, U. Pa. L. Rev. 121 (1973)].

- Presentation of Evidence and Factfinding Precision. U. Pa. L. Rev. 123 (1975), 10831106 [zit. Damaška, U. Pa. L. Rev. 123 (1975)].

- Structures of Authority and Comparative Criminal Procedure. Yale L.J. 84 (1975), 480544 [zit. Damaška, Yale L.J. 84 (1975)].

- Strukturmodelle der Staatsgewalt und ihre Bedeutung für das Strafverfahren - Eine vergleichende Untersuchung (Übersetzt von Thomas Weigend). ZStW 87 (1975), 713-741 [zit. Damaška, ZStW 87 (1975)].

- Die Stellung des Verteidigers im amerikanischen Strafprozeß. ZStW 90 (1978), 829864 [zit. Damaška, ZStW 90 (1978)].

- Adversary System. In: Sanford H. Kadish (Hrsg.), Encyclopedia of Crime and Justice, Volume I. New York 1983, S. 24-30 [zit. Damaška, in: Kadish (Hrsg.), Encyclopedia].

- The Faces of Justice and State Authority. A Comparative Approach to the Legal Process. New Haven/London 1986 [zit. Damaška, Faces].

- Der Austausch von Vorteilen im Strafverfahren: Plea-Bargaining und Absprachen. StV 1988, 398-402 [zit. Damaška, StV 1988].

- Of Hearsay and Its Analogues. Minn. L. Rev. 76 (1992), 425-458 [zit. Damaška, Minn. L. Rev. 76 (1992)]. 
- Evidence Law Adrift. New Haven/London 1997 [zit. Damaška, Evidence].

- Truth in Adjudication. Hastings L.J. 49 (1998), 289-308 [zit. Damaška, Hastings L.J. 49 (1998)].

- Models of Criminal Procedure. Zbornik PFZ 51 (2001), 477-516 [zit. Damaška, Zbornik PFZ 51 (2001)].

- Epistemology and legal regulation of proof. Law, Probability and Risk 2 (2003), 117130 [zit. Damaška, Law, Probability and Risk 2 (2003)].

- Negotiated Justice in International Criminal Courts. JICJ 2 (2004), 1018-1039 [zit. Damaška, JICJ 2 (2004)].

- The jury and the law of evidence: real and imagined interconnections. Law, Probability and Risk 5 (2006), 255-265 [zit. Damaška, Law, Probability and Risk 5 (2006)].

- What is the Point of International Criminal Justice? Chi.-Kent L. Rev. 83 (2008), 329365 [zit. Damaška, Chi.-Kent L. Rev. 83 (2008)].

- The International Criminal Court Between Aspiration and Achievement. UCLA J. INT'L L. \& FOREIGN AFF. 14 (2009), 19-35 [zit. Damaška, UCLA J. INT'L L. \& FOREIGN AFF. 14 (2009)].

- Problematic Features of International Criminal Procedure. In: Antonio Cassese (Hrsg.), The Oxford Companion to International Criminal Justice. Oxford u.a. 2009, S. 175-186 [zit. Damaška, in: Cassese (Hrsg.), Oxford Companion].

Dammer, Harry/Albanese, Jay, Comparative Criminal Justice Systems. International Edition. 5. Aufl. Belmont u.a. 2014, 2011 [zit. Dammer/Albanese, Comparative].

Dannecker, Gerhard, Die strafprozessualen Grundsätze der Mündlichkeit, Unmittelbarkeit und Öffentlichkeit in den Rechtsordnungen der Europäischen Union. Zur Notwendigkeit einer Absicherung der Mindestanforderungen an einen fairen und gerechten Strafprozeß als Menschenrechte. ZVglRWiss 97 (1998), 407-439 [zit. Dannecker, ZVglRWiss 97 (1998)].

Darbyshire, Penny, The Lamp That Shows That Freedom Lives - Is it Worth the Candle? Crim.L.R. 1991, 740-752 [zit. Darbyshire, [1991] Crim.L.R.].

- An Essay on the Importance and Neglect of the Magistracy. Crim.L.R. 1997, 627-643 [zit. Darbyshire, [1997] Crim.L.R.].

- The Mischief of Plea Bargaining and Sentencing Rewards. Crim.L.R. 2000, 895-910 [zit. Darbyshire, [2000] Crim.L.R.].

- Criminal Procedure in England and Wales. In: Richard Vogler/Barbara Huber (Hrsg.), Criminal Procedure in Europe. Berlin 2008, S. 39-169 [zit. Darbyshire, in: Vogler/ Huber (Hrsg.), Criminal Procedure].

- Darbyshire on the English Legal System. 10. Aufl. London 2011 [zit. Darbyshire, Legal System].

David, René, Introduction. In: René David (Hrsg.), International Encyclopedia of Comparative Law, Volume II: The Legal Systems of the World: Their Comparison and Unification, Chapter 1: The Different Conceptions of the Law. Tübingen u.a. 1975, S. 3-13 [zit. David, in: ders. (Hrsg.), International Encyclopedia]. 
David, René/Brierley, John, Major Legal Systems in the World Today. An Introduction to the Comparative Study of Law. 3. englische Aufl. London 1985 [zit. David/Brierley, Major Legal Systems].

David, René/Grasmann, Günther, Einführung in die großen Rechtssysteme der Gegenwart: auf der Grundlage „les grands systèmes de droit contemporains“, von René David und Camille Jauffret Spinosi / bearbeitet von Günther Grasmann u.a. 2. deutsche Aufl. München 1989 [zit. David/Grasmann, Einführung].

Davis, Kenneth Culp, An Approach to Rules of Evidence for Nonjury Cases. A.B.A.J. 50 (1964), 723-727 [zit. Davis, A.B.A.J. 50 (1964)].

Dawson, John, The Functions of the Judge. In: Harold J. Berman (Hrsg.), Talks on American Law. 2. Aufl. New York 1971, S. 19-33 [zit. Dawson, in: Berman (Hrsg.), Talks].

De Cruz, Peter, Comparative Law in a Changing World. 3. Aufl. London/New York 2007 [zit. de Cruz, Comparative Law].

Decaigny, Tom, Inquisitorial and Adversarial Expert Examinations in the Case Law of the European Court of Human Rights. NJECL 2014, 149-166 [zit. Decaigny, NJECL 2014].

Dedes, Christos, Beweisverfahren und Beweisrecht. Berlin 1992 [zit. Dedes, Beweisverfahren].

Deflem, Mathieu/Swygart, Amanda, Comparative Criminal Justice. In: M.A. DuPontMorales u.a. (Hrsg.), Handbook of Criminal Justice Administration. New York/Basel 2001, S. 51-68 [zit. Deflem/Swygart, in: DuPont-Morales u.a. (Hrsg.), Handbook].

DeGuzman, Margaret/Schabas, William, Initiation of Investigations and Selection of Cases. In: Göran Sluiter u.a. (Hrsg.), International Criminal Procedure. Principles and Rules. Oxford 2013, S. 131-169 [zit. deGuzman/Schabas, in: Sluiter u.a. (Hrsg.), International].

Dehne-Niemann, Jan, „Nie sollst du mich befragen“ - Zur Behandlung des Rechts zur Konfrontation mitbeschuldigter Belastungszeugen (Art. 6 Abs. 3 lit. d EMRK) durch den BGH. Zugleich Besprechung von BGH 4 StR 461/08 - Beschluss vom 9. Juni 2009, HRRS 2009 Nr. 803 und EGMR HRRS 2009 Nr. 459. HRRS 4/2010, 189-207 [zit. Dehne-Niemann, HRRS 4/2010 (online)].

Deiters, Mark/Albrecht, Anna Helena, § 153a Abs. 2 StPO bei weiter aufklärbarem Verdacht eines Verbrechens? Überlegungen aus Anlass der vorläufigen Einstellung des Bremer Brechmittelverfahrens. ZIS 2013, 483-487 [zit. Deiters/Albrecht, ZIS 2013].

Delmas-Marty, Mireille, Toward a European Model of the Criminal Trial. In: Mireille Delmas-Marty (Hrsg.), The Criminal Process and Human Rights. Toward a European Consciousness. Dordrecht u.a. 1995, S. 191-198 [zit. Delmas-Marty, in: dies. (Hrsg.), Criminal Process].

- Comparative Criminal Law as a Necessary Tool for the Application of International Criminal Law. In: Antonio Cassese (Hrsg.), The Oxford Companion to International Criminal Justice. Oxford u.a. 2009, S. 97-103 [zit. Delmas-Marty, in: Cassese (Hrsg.), Oxford Companion].

De Meester, Karel/Pitcher, Kelly/Rastan, Rod/Sluiter, Göran, Investigation, Coercive Measures, Arrest, and Surrender. In: Göran Sluiter u.a. (Hrsg.), International Criminal Procedure. Principles and Rules. Oxford 2013, S. 171-379 [zit. De Meester/Pitcher/ Rastan/Sluiter, in: Sluiter u.a. (Hrsg.), International]. 
Demko, Daniela, Das Fragerecht des Angeklagten nach Art. 6 Abs. 3 lit. d EMRK aus Sicht des Europäischen Gerichtshofs für Menschenrechte, der schweizerischen sowie der deutschen Rechtsprechung. ZStrR 2004, 416-435 [zit. Demko, ZStrR 2004].

Dencker, Friedrich, Informelles Kreuzverhör. In: Karl Heinz Gössel/Hans Kauffmann (Hrsg.), Strafverfahren im Rechtsstaat. Festschrift für Theodor Kleinknecht zum 75. Geburtstag am 18. August 1985. München 1985, S. 79-89 [zit. Dencker, FS für Kleinknecht].

Dennis, Ian, The Law of Evidence. 5. Aufl. London 2013 [zit. Dennis, Evidence, Rn.].

Dervieux, Valérie, The French system. In: Mireille Delmas-Marty/J.R. Spencer (Hrsg.), European Criminal Procedures, englische Aufl. Cambridge 2002, S. 218-291 [zit. Dervieux, in: Delmas-Marty/Spencer (Hrsg.), European Criminal Procedures].

Deu, Teresa Armenta, Die Beteiligung des Strafrichters im Ermittlungs- und Hauptverfahren. Die Modelle des Common Law und des Civil Law, des Corpus Juris, des Grünbuchs und des Internationalen Strafgerichtshofs. In: Albin Eser/Christiane Rabenstein (Hrsg.), Strafjustiz im Spannungsfeld von Effizienz und Fairness. Konvergente und divergente Entwicklungen im Strafprozessrecht (Criminal Justice between Crime Control and Due Process. Convergence and Divergence in Criminal Procedure Systems) - Internationales Kolloquium 8.-11. Mai 2002 auf Schloss Ringberg. Berlin 2004, S. 315-330 [zit. Deu, in: Eser/Rabenstein (Hrsg.), Strafjustiz].

Deutscher, Axel, Die Erörterung der Vorstrafen von Zeugen. NStZ 2012, 359-362 [zit. Deutscher, NStZ 2012].

Devlin, Patrick, The Judge. Oxford u.a. 1979 [zit. Devlin, The Judge].

Dieckmann, Johann, Einführung in die Systemtheorie. München 2005 [zit. Dieckmann, Einführung].

Dielmann, Heinz, ,Guilty Plea' und ,Plea Bargaining' im amerikanischen Strafverfahren Möglichkeiten für den deutschen Strafprozeß? GA 1981, 558-571 [zit. Dielmann, GA 1981].

Dippel, Karlhans, Urteilsabsprachen im Strafverfahren und das Prozessziel der Wiederherstellung des Rechtsfriedens. In: Heinz Schöch u.a. (Hrsg.), Strafverteidigung, Revision und die gesamten Strafrechtswissenschaften. Festschrift für Gunter Widmaier zum 70. Geburtstag. Köln/München 2008, S. 105-126 [zit. Dippel, FS für Widmaier].

- Ausgewählte Themen des Beweises durch Sachverständige im Strafverfahren. In: Heike Jung u.a. (Hrsg.), Festschrift für Egon Müller. Baden-Baden 2008, S. 125-145 [zit. Dippel, FS für Müller].

Dölling, Dieter, Zur Beteiligung von Laienrichtern an der Strafrechtspflege. In: Heinz Schöch u.a. (Hrsg.), Recht gestalten - dem Recht dienen. Festschrift für Reinhard Böttcher zum 70. Geburtstag am 29. Juli 2007. Berlin 2007, S. 41-52 [zit. Dölling, FS für Böttcher].

Doran, Sean, Alternative Defences: the 'invisible burden' on the trial judge. Crim.L.R. 1991, 878-891 [zit. Doran, [1991] Crim.L.R.].

- The Necessarily Expanding Role of the Criminal Trial Judge. In: Sean Doran/John D. Jackson (Hrsg.), The Judicial Role in Criminal Proceedings. Oxford/Portland 2000, S. 3-18 [zit. Doran, in: Doran/Jackson (Hrsg.), Judicial Role]. 
Dreher, Eduard, Das schlechte Gewissen des Strafrichters. In: Arthur Kaufmann u.a. (Hrsg.), Festschrift für Paul Bockelmann zum 70. Geburtstag am 7. Dezember 1978. München 1979, S. 45-65 [zit. Dreher, FS für Bockelmann].

Du Bois-Pedain, Antje, Artikel 6 Abs. 3 lit. d EMRK und der nicht verfügbare Zeuge: Weist der modifizierte Lucà-Test den Weg aus der Sackgasse? Zugleich eine Besprechung von EGMR Nr. 26766/05 und 22228/06 (Große Kammer), Urteil vom 15. Dezember 2011 (Al-Khawaja und Tahery v. Großbritannien). HRRS 3/2012, 120-138 [zit. Du Bois-Pedain, HRRS 3/2012 (online)].

Dubber, Markus, Einführung in das US-amerikanische Strafrecht. München 2005 [zit. Dubber, Einführung].

Dudenredaktion (Hrsg.), Duden Das große Fremdwörterbuch. Herkunft und Bedeutung der Fremdwörter. 2. Aufl. Mannheim u.a. 2000 [zit. Duden Fremdwörterbuch].

- Duden Das Herkunftswörterbuch. Etymologie der deutschen Sprache. 4. Aufl. Mannheim u.a. 2007 [zit. Duden Herkunftswörterbuch].

- Duden Deutsches Universalwörterbuch. 6. Aufl. Mannheim u.a. 2007 [zit. Duden Universalwörterbuch].

Duff, Antony, Trials and punishments. Cambridge u.a. 1986 [zit. A. Duff, Trials].

Duff, Antony/Farmer, Lindsay/Marshall, Sandra/Tadros, Victor, Introduction: Towards a Normative Theory of the Criminal Trial. In: Antony Duff u.a. (Hrsg.), The Trial on Trial. Volume 1: Truth and Due Process. Oxford/Portland 2004, S. 1-28 [zit. A. Duff/ Farmer/Marshall/Tadros, in: A. Duff u.a. (Hrsg.), Trial on Trial 1].

- The Trial on Trial: Volume 3. Towards a Normative Theory of the Criminal Trial. Oxford/Portland 2007 [zit. A. Duff/Farmer/Marshall/Tadros, Trial on Trial 3].

Duff, Peter, Changing Conceptions of the Scottish Criminal Trial: The Duty to Agree Uncontroversial Evidence. In: Antony Duff u.a. (Hrsg.), The Trial on Trial. Volume 1: Truth and Due Process. Oxford/Portland 2004, S. 29-50 [zit. P. Duff, in: A. Duff u.a. (Hrsg.), Trial on Trial 1].

Ehrmann, Henry, Comparative Legal Cultures. Englewood Cliffs, NJ 1976 [zit. Ehrmann, Comparative Legal Cultures].

Eicker, Andreas, Die Prinzipien der ,materiellen Wahrheit‘ und der ,freien Beweiswürdigung' im Strafprozeß. Eine Untersuchung unter besonderer Berücksichtigung des Sachverständigenbeweises und der Sachgebundenheit richterlicher Überzeugungsbildung bei der Schuldfähigkeitsfeststellung und der Feststellung subjektiver Deliktsmerkmale. Herbolzheim 2001 [zit. Eicker, Prinzipien].

Eisenberg, Ulrich, Beweisrecht der StPO. Spezialkommentar. 9. Aufl. München 2015 [zit. Eisenberg, Beweisrecht, Rn.].

Elliott, Catherine/Quinn, Frances, English Legal System. 13. Aufl. Harlow u.a. 2012 [zit. Elliott/Quinn, English Legal System].

Ellison, Louise, The Adversarial Process and the Vulnerable Witness. Oxford u.a. 2001 [zit. Ellison, Adversarial].

Elser, Julia Constanze, Die Rolle der Verfahrensbeteiligten im deutschen und amerikanischen Strafprozess im Rechtsvergleich. Examensarbeit. München 2011 [zit. Elser, Rolle]. 
EMRK-Kommentar = Europäische Menschenrechtskonvention $\rightarrow$ Frowein, Jochen/ Peukert, Wolfgang.

Engelhart, Marc, Sanktionierung von Unternehmen und Compliance. Eine rechtsvergleichende Analyse des Straf- und Ordnungswidrigkeitenrechts in Deutschland und den USA. 2. Aufl. Berlin 2012 [zit. Engelhart, Sanktionierung].

Erb, Volker, Legalität und Opportunität. Gegensätzliche Prinzipien der Anwendung von Strafrechtsnormen im Spiegel rechtstheoretischer, rechtsstaatlicher und rechtspolitischer Überlegungen. Berlin 1999 [zit. Erb, Legalität].

Erb, Volker u.a. (Hrsg.), Löwe-Rosenberg. Die Strafprozeßordnung und das Gerichtsverfassungsgesetz. Großkommentar. 1. Band 26. Aufl. Berlin 2006 [zit. LR-StPO-Bearbeiter, Einl./§ Rn.].

- Löwe-Rosenberg. Die Strafprozeßordnung und das Gerichtsverfassungsgesetz. Großkommentar. 6. Band 1. Teilband. 26. Aufl. Berlin 2010 [zit. LR-StPO-Bearbeiter, $\S \mathrm{Rn}$.$] .$

- Löwe-Rosenberg. Die Strafprozeßordnung und das Gerichtsverfassungsgesetz. Großkommentar. 6. Band 2. Teilband. 26. Aufl. Berlin 2013 [zit. LR-StPO-Bearbeiter, $\S \mathrm{Rn}$.$] .$

- Löwe-Rosenberg. Die Strafprozeßordnung und das Gerichtsverfassungsgesetz. Großkommentar. 11. Band EMRK; IPBPR. 26. Aufl. Berlin 2012 [zit. LR-StPO-Bearbeiter, Art. EMRK Rn.].

Eser, Albin, Beweisermittlung und Beweiswürdigung in vergleichender Perspektive. Einige überbrückende Beobachtungen zwischen ,adversatorischem' und ,inquisitorischem System. In: Hans-Heiner Kühne (Hrsg.), Festschrift für Koichi Miyazawa. Dem Wegbereiter des japanisch-deutschen Strafrechtsdiskurses. Baden-Baden 1995, S. 561-569 [zit. Eser, FS für Miyazawa].

- Funktionen, Methoden und Grenzen der Strafrechtsvergleichung. In: Hans-Jörg Albrecht u.a. (Hrsg.), Internationale Perspektiven in Kriminologie und Strafrecht. Festschrift für Günther Kaiser zum 70. Geburtstag. 2. Bd. Berlin 1998, S. 1499-1528 [zit. Eser, FS für Kaiser].

- Vorzugswürdigkeit des adversatorischen Prozesssystems in der internationalen Strafjustiz? Reflektionen eines Richters. In: Heinz Müller-Dietz u.a. (Hrsg.), Festschrift für Heike Jung zum 65. Geburtstag am 23. April 2007. Baden-Baden 2007, S. 167-187 [zit. Eser, FS für Jung].

- Reflexionen zum Prozesssystem und Verfahrensrecht internationaler Strafgerichtsbarkeit. In: Ulrich Sieber u.a. (Hrsg.), Strafrecht und Wirtschaftsstrafrecht - Dogmatik, Rechtsvergleich, Rechtstatsachen - Festschrift für Klaus Tiedemann zum 70. Geburtstag. Köln/München 2008, S. 1453-1472 [zit. Eser, FS für Tiedemann].

- Procedural Structure and Features of International Criminal Justice: Lessons from the ICTY. In: Bert Swart u.a. (Hrsg.), The Legacy of the International Criminal Tribunal for the Former Yugoslavia. Oxford 2011, S. 108-148 [zit. Eser, in: Swart u.a. (Hrsg.), Legacy].

- Evaluativ-kompetitive Strafrechtsvergleichung. Zu „,wertenden“ Funktionen und Methoden der Rechtsvergleichung. In: Georg Freund u.a. (Hrsg.), Grundlagen und Dogmatik des gesamten Strafrechtssystems. Festschrift für Wolfgang Frisch zum 70. Geburtstag. Berlin 2013, S. 1441-1466 [zit. Eser, FS für Frisch]. 
- Adversatorische und inquisitorische Verfahrensmodelle: Ein kritischer Vergleich mit Strukturalternativen. In: Friedrich-Christian Schroeder/Manuchehr Kudratov (Hrsg.), Die strafprozessuale Hauptverhandlung zwischen inquisitorischem und adversatorischem Modell. Eine rechtsvergleichende Analyse am Beispiel des deutschen und des zentralasiatischen Strafprozessrechts. Frankfurt a.M. 2014, S. 11-29 [zit. Eser, in: Schroeder/Kudratov (Hrsg.), Hauptverhandlung].

Esmein, Adhémar, A History of Continental Criminal Procedure. With Special Reference to France (Translated by John Simpson). South Hackensack u.a. 1968 (repr.) [zit. Esmein, History].

Esser, Robert, Auf dem Weg zu einem europäischen Strafverfahrensrecht. Die Grundlagen im Spiegel der Rechtsprechung des Europäischen Gerichtshofs für Menschenrechte (EGMR) in Straßburg. Berlin 2002 [zit. Esser, Strafverfahrensrecht].

- Anmerkung zu BGH, JR 2005, 247. JR 2005, 248-256 [zit. Esser, JR 2005].

- Anmerkung zu EGMR, NStZ 2007, 103. NStZ 2007, 106-109 [zit. Esser, NStZ 2007].

- Mindestanforderungen der Europäischen Menschenrechtskonvention (EMRK) an den strafprozessualen Beweis. In: Thilo Marauhn (Hrsg.), Bausteine eines europäischen Beweisrechts. Tübingen 2007, S. 39-63 [zit. Esser, in: Marauhn (Hrsg.), Bausteine].

- Europäisches und Internationales Strafrecht. München 2014 [zit. Esser, Europäisches Strafrecht, § Rn.].

Fabricius, Dirk, Aufklärung - ein erodierendes Ziel? In: Wilhelm Degener/Michael Heghmanns (Hrsg.), Festschrift für Friedrich Dencker zum 70. Geburtstag. Tübingen 2012, S. 71-93 [zit. Fabricius, FS für Dencker].

Fairlie, Megan, The Marriage of Common and Continental Law at the ICTY and its Progeny, Due Process Deficit. Int'l Crim. L. Rev. 4 (2004), 243-319 [zit. Fairlie, Int'l Crim. L. Rev. 4 (2004)].

Farthofer, Hilde, Evidence. In: Christoph J. M. Safferling (Verf.), International Criminal Procedure. In cooperation with Lars Büngener, Hilde Farthofer, Alena Hartwig, Yvonne Koberg. Oxford 2012, S. 463-515 [zit. Farthofer, in: Safferling (Verf.), International].

Fedorova, Masha, The Principle of Equality of Arms in International Criminal Proceedings. Cambridge u.a. 2012 [zit. Fedorova, Principle].

Feeley, Malcolm, Legal Complexity and the Transformation of the Criminal Process. The Origins of Plea Bargaining. Is.L.R. 31 (1997), 183-222 [zit. Feeley, Is.L.R. 31 (1997)].

Feldman, David, England and Wales. In: Craig M. Bradley (Hrsg.), Criminal Procedure. A Worldwide Study. 2. Aufl. Durham, North Carolina 2007, S. 149-200 [zit. Feldman, in: Bradley (Hrsg.), Criminal Procedure].

Fezer, Gerhard, Grundfragen der Beweisverwertungsverbote. Heidelberg 1995 [zit. Fezer, Grundfragen].

- Inquisitionsprozess ohne Ende? Zur Struktur des neuen Verständigungsgesetzes. NStZ 2010, 177-185 [zit. Fezer, NStZ 2010].

Fischer, Thomas, Strafgesetzbuch mit Nebengesetzen. 61. Aufl. München 2014 [zit. Fischer, StGB, Einl./§ Rn.]. 
Fletcher, George/Sheppard, Steve, American Law in a Global Context. The Basics. Oxford u.a. 2005 [zit. Fletcher/Sheppard, American Law].

Forster, Susanne, National characteristics, fundamental principles, and history of criminal law in England and Wales. In: Ulrich Sieber u.a. (Hrsg.), National Criminal Law in a Comparative Legal Context. Volume 1.1. Introduction to National Systems. National characteristics, fundamental principles, and history of criminal law. England and Wales, Scotland, Sweden, Switzerland. Berlin 2013, S. 1-71 [zit. Forster, in: Sieber u.a. (Hrsg.), National Criminal Law].

Foster, Don, Evaluating the Truth and Reconciliation Commission of South Africa. Social Justice Research 19 (2006), 527-540 [zit. Foster, Social Justice Research 19 (2006)].

Frankel, Marvin, The Search for Truth: An Umpireal View. U. Pa. L. Rev. 123 (1975), 1031-1059 [zit. Frankel, U. Pa. L. Rev. 123 (1975)].

Frankenberg, Günter, Critical Comparisons: Re-thinking Comparative Law. Harv. Int'l. L. J. 26 (1985), 411-455 [zit. Frankenberg, Harv. Int'l. L. J. 26 (1985)].

Frase, Richard, France. In: Craig M. Bradley (Hrsg.), Criminal Procedure. A Worldwide Study. 2. Aufl. Durham, North Carolina 2007, S. 201-242 [zit. Frase, in: Bradley (Hrsg.), Criminal Procedure].

Friedman, Lawrence, Legal Culture and Social Development. Law \& Soc'y Rev. 4 (1969), 29-44 [zit. L. Friedman, Law \& Soc'y Rev. 4 (1969)].

- The Republic of Choice. Law, Authority, and Culture. Cambridge/London 1990 [zit. L. Friedman, Republic of Choice].

- Some Thoughts on Comparative Legal Culture. In: David S. Clark (Hrsg.), Comparative and Private International Law. Essays in Honor of John Henry Merryman on his Seventieth Birthday. Berlin 1990, S. 49-57 [zit. L. Friedman, in: Clark (Hrsg.), Comparative].

- The Concept of Legal Culture. A Reply. In: David Nelken (Hrsg.), Comparing Legal Cultures. Aldershot u.a. 1997, S. 33-39 [zit. L. Friedman, in: Nelken (Hrsg.), Comparing Legal Cultures].

Friedman, Richard, The Confrontation Right Across the Systemic Divide. In: John Jackson u.a. (Hrsg.), Crime, Procedure and Evidence in a Comparative and International Context. Essays in Honour of Professor Mirjan Damaška. Oxford/Portland 2008, S. 261-271 [zit. R. Friedman, in: Jackson u.a. (Hrsg.), Crime].

Frigg, Roman/Hartmann, Stephan, Models in Science. In: Edward N. Zalta (Hrsg.), The Stanford Encyclopedia of Philosophy. http://plato.stanford.edu/archives/fall2012/entries/ models-science/ [Stand: Oktober 2014] [zit. Frigg/Hartmann, Models in Science].

Friman, Hakan/Brady, Helen/Costi, Matteo/Guariglia, Fabricio/Stuckenberg, Carl-Friedrich, Charges. In: Göran Sluiter u.a. (Hrsg.), International Criminal Procedure. Principles and Rules. Oxford 2013, S. 381-488 [zit. Friman/Brady/Costi/Guariglia/Stuckenberg, in: Sluiter u.a. (Hrsg.), International].

Frisch, Wolfgang, Zum Wesen des Grundsatzes „in dubio pro reo“. In: Claus Roxin (Hrsg.), Grundfragen der gesamten Strafrechtswissenschaft. Festschrift für Heinrich Henkel zum 70. Geburtstag am 12. September 1973. Berlin/New York 1974, S. 273-286 [zit. Frisch, FS für Henkel]. 
- Freie Beweiswürdigung und Beweismaß. Historische und erkenntnistheoretische Grundlagen. In: Alexander Bruns u.a. (Hrsg.), Festschrift für Rolf Stürner zum 70. Geburtstag. 1. Teilband. Tübingen, 2013, S. 849-874 [zit. Frisch, FS für Stürner].

Frowein, Jochen/Peukert, Wolfgang, Europäische Menschenrechtskonvention. EMRKKommentar. 3. Aufl. Kehl a.R. 2009 [zit. EMRK-Kommentar-Bearbeiter, Art. Rn.].

Fuller, Lon, The Adversary System. In: Harold J. Berman (Hrsg.), Talks on American Law. 2. Aufl. New York 1971, S. 34-47 [zit. Fuller, in: Berman (Hrsg.), Talks].

Gaede, Karsten, Anmerkung zu EGMR, JR 2006, 289. JR 2006, 292-297 [zit. Gaede, JR 2006].

- Fairness als Teilhabe - Das Recht auf konkrete und wirksame Teilhabe durch Verteidigung gemäß Art. 6 EMRK. Ein Beitrag zur Dogmatik des fairen Verfahrens in europäischen Strafverfahren und zur wirksamkeitsverpflichteten Konventionsauslegung unter besonderer Berücksichtigung des Rechts auf Verteidigerbeistand. Berlin 2007 [zit. Gaede, Fairness].

- Beweisverbote zur Wahrung des fairen Strafverfahrens in der Rechtsprechung des EGMR insbesondere bei verdeckten Ermittlungen - Meinungsstand und Perspektiven nach dem neuen leading case Bykov vs. Russland unter Berücksichtigung des §136a StPO. JR 2009, 493-502 [zit. Gaede, JR 2009].

- Parteirechte der Verteidigung im deutschen Inquisitionsprozess - das Beispiel des Vernehmungs- und Fragerechts - Zur gebotenen Aufwertung des Fragerechts der Verteidigung insbesondere in der Hauptverhandlung eines nicht nur pro forma reformierten Inquisitionsprozesses. StV 2012, 51-59 [zit. Gaede, StV 2012].

Gallanis, Thomas, The Rise of Modern Evidence Law. Iowa L. Rev. 84 (1999), 499-560 [zit. Gallanis, Iowa L. Rev. 84 (1999)].

Garner, Bryan (Hrsg.), Black’s Law Dictionary. 10. Aufl. St. Paul 2014 [zit. Black's Law Dictionary].

Garraud, François, The Different Types of Criminal Procedure. In: Adhémar Esmein (Verf.), A History of Continental Criminal Procedure. With Special Reference to France (Translated by John Simpson). South Hackensack u.a. 1968 (repr.), S. 3-12 [zit. Garraud, in: Esmein (Verf.), History].

- Introductory; General Features of the Evolution. In: Adhémar Esmein (Verf.), A History of Continental Criminal Procedure. With Special Reference to France (Translated by John Simpson). South Hackensack u.a. 1968 (repr.), S. 39-46 [zit. Garraud, in: Esmein (Verf.), History].

- Criminal Procedure Since 1800 in Other Countries. In: Adhémar Esmein (Verf.), A History of Continental Criminal Procedure. With Special Reference to France (Translated by John Simpson). South Hackensack u.a. 1968 (repr.), S. 570-606 [zit. Garraud, in: Esmein (Verf.), History].

- History of the Continental System of Evidence. In: Adhémar Esmein (Verf.), A History of Continental Criminal Procedure. With Special Reference to France (Translated by John Simpson). South Hackensack u.a. 1968 (repr.), S. 617-630 [zit. Garraud, in: Esmein (Verf.), History]. 
Gaynor, Fergal, Admissibility of Documentary Evidence. In: Göran Sluiter u.a. (Hrsg.), International Criminal Procedure. Principles and Rules. Oxford 2013, S. 1044-1083 [zit. Gaynor, in: Sluiter u.a. (Hrsg.), International].

- Judicial Notice and Agreed Facts. In: Göran Sluiter u.a. (Hrsg.), International Criminal Procedure. Principles and Rules. Oxford 2013, S. 1107-1128 [zit. Gaynor, in: Sluiter u.a. (Hrsg.), International].

Geppert, Klaus, Der Grundsatz der Unmittelbarkeit im deutschen Strafverfahren. Berlin/ New York 1979 [zit. Geppert, Unmittelbarkeit].

Gerding, Marc, Trial by Jury. Die Bewährung des englischen und des US-amerikanischen Jury-Systems. Eine Idee im verfassungsrechtlichen und gesellschaftlichen Wandel. Osnabrück 2007 [zit. Gerding, Trial].

Gibson, Kate/Lussiaà-Berdou, Cainnech, Disclosure of Evidence. In: Karim A. A. Khan u.a. (Hrsg.), Principles of Evidence in International Criminal Justice. Oxford u.a. 2010, S. 306-372 [zit. Gibson/Lussiaà-Berdou, in: Khan u.a. (Hrsg.), Principles].

Glendon, Mary Ann/Carozza, Paolo/Picker, Colin, Comparative Legal Traditions in a Nutshell. 3. Aufl. St. Paul 2008 [zit. Glendon/Carozza/Picker, Comparative Legal Traditions].

Glenn, Patrick, A Concept of Legal Tradition. Queen's L.J. 34 (2008-2009), 427-445 [zit. Glenn, Queen's L.J. 34 (2008-2009)].

- A Western Legal Tradition? S.C.L.R. 49 (2010), 601-619 [zit. Glenn, S.C.L.R. 49 (2010)].

- Legal Traditions of the World. Sustainable Diversity in Law. 5. Aufl. Oxford 2014 [zit. Glenn, Legal Traditions].

Gleß, Sabine, Beweisrechtsgrundsätze einer grenzüberschreitenden Strafverfolgung. Baden-Baden 2006 [zit. Gleß, Beweisrechtsgrundsätze].

- Germany: Balancing Truth Against Protected Constitutional Interests. In: Stephen C. Thaman (Hrsg.), Exclusionary Rules in Comparative Law. Dordrecht u.a. 2013, S. 113142 [zit. Gleß, in: Thaman (Hrsg.), Exclusionary Rules].

Globke, Christina, Die Verständigung im Strafprozess nach der Entscheidung des Bundesverfassungsgerichts oder „Da stelle mer uns mal janz dumm ...“. JR 2014, 9-25 [zit. Globke, JR 2014].

Göppinger, Hans (Begr.)/Bock, Michael (Hrsg.), Kriminologie. Bearbeitet von Michael Bock u.a. 6. Aufl. München 2008 [zit. Göppinger (Begr.), Kriminologie, § Rn.].

Gössel, Karl Heinz, Strafverfahrensrecht. Stuttgart u.a. 1977 [zit. Gössel, Strafverfahrensrecht].

- Ermittlung oder Herstellung von Wahrheit im Strafprozeß? Vortrag gehalten vor der Juristischen Gesellschaft zu Berlin am 2. Juni 1999. Berlin/New York 2000 [zit. Gössel, Ermittlung].

- Über die Pflicht zur Ermittlung der materiell-objektiven Wahrheit und die Zuständigkeiten zur Eröffnung eines Strafverfahrens und zu dessen Durchführung. In: Albin Eser u.a. (Hrsg.), Strafverfahrensrecht in Theorie und Praxis. Festschrift für Lutz Meyer-Gossner zum 65. Geburtstag. München 2001, S. 187-206 [zit. Gössel, FS für Meyer-Gossner]. 
- Quo vadis, Strafverfahren? Zweckmäßigkeit versus Gerechtigkeit: Vom rechtsstaatlichen Strafprozess zum geheimen Willkürverfahren in der babylonischen Gefangenschaft der Justiz. In: Edda Weßlau/Wolfgang Wohlers (Hrsg.), Festschrift für Gerhard Fezer zum 70. Geburtstag am 29. Oktober 2008. Berlin 2008, S. 495-530 [zit. Gössel, FS für Fezer].

Goldstein, Abraham, The State and the Accused: Balance of Advantage in Criminal Procedure. Yale L.J. 69 (1960), 1149-1199 [zit. Goldstein, Yale L.J. 69 (1960)].

- Reflections on Two Models: Inquisitorial Themes in American Criminal Procedure. Stan. L. Rev. 26 (1974), 1009-1025 [zit. Goldstein, Stan. L. Rev. 26 (1974)].

Goldstein, Abraham/Marcus, Martin, The Myth of Judicial Supervision in Three "Inquisitorial” Systems: France, Italy, and Germany. Yale L.J. 87 (1977), 240-283 [zit. Goldstein/Marcus, Yale L.J. 87 (1977)].

Gollwitzer, Walter, Das Fragerecht des Angeklagten. In: Klaus Geppert/Diether Dehnicke (Hrsg.), Gedächtnisschrift für Karlheinz Meyer. Berlin/New York 1990, S. 147-170 [zit. Gollwitzer, GS für Meyer].

Goodpaster, Gary, On the Theory of American Adversary Criminal Trial. J. Crim. L. \& Criminology 78 (1987), 118-154 [zit. Goodpaster, J. Crim. L. \& Criminology 78 (1987)].

Gosnell, Christopher, Admissibility of Evidence. In: Karim A. A. Khan u.a. (Hrsg.), Principles of Evidence in International Criminal Justice. Oxford u.a. 2010, S. 375-442 [zit. Gosnell, in: Khan u.a. (Hrsg.), Principles].

Grabenwarter, Christoph, Deutschland und die Menschenrechtskonvention - eine Außensicht. In: Sabine Leutheusser-Schnarrenberger (Hrsg.), Vom Recht auf Menschenwürde. 60 Jahre Europäische Menschenrechtskonvention. Tübingen 2013, S. 109-121 [zit. Grabenwarter, in: Leutheusser-Schnarrenberger (Hrsg.), Recht].

- Funktionalität und Bedeutung der Rechtsvergleichung in der Judikatur des EGMR. In: Anna Gamper/Bea Verschraegen (Hrsg.), Rechtsvergleichung als juristische Auslegungsmethode. Wien 2013, S. 95-114 [zit. Grabenwarter, in: Gamper/Verschraegen (Hrsg.), Rechtsvergleichung].

- European Convention on Human Rights - Commentary. München u.a. 2014 [zit. Grabenwarter, Commentary, Art. Rn.].

Grabenwarter, Christoph/Pabel, Katharina, Europäische Menschenrechtskonvention. Ein Studienbuch. 5. Aufl. München u.a. 2012 [zit. Grabenwarter/Pabel, Menschenrechtskonvention, § Rn.].

Graf, Jürgen Peter (Hrsg.), Strafprozessordnung. Mit Gerichtsverfassungsgesetz und Nebengesetzen. Kommentar. 2. Aufl. München 2012 [zit. Graf-Bearbeiter, StPO Kommentar, § Rn.].

Grande, Elisabetta, Dances of Criminal Justice: Thoughts on Systemic Differences and the Search for the Truth. In: John Jackson u.a. (Hrsg.), Crime, Procedure and Evidence in a Comparative and International Context. Essays in Honour of Professor Mirjan Damaška. Oxford/Portland 2008, S. 145-164 [zit. Grande, in: Jackson u.a. (Hrsg.), Crime].

- Comparative criminal justice. In: Mauro Bussani/Ugo Mattei (Hrsg.), The Cambridge Companion to Comparative Law. Cambridge u.a. 2012, S. 191-209 [zit. Grande, in: Bussani/Mattei (Hrsg.), Comparative]. 
Grasnick, Walter, Wahres über die Wahrheit - auch im Strafprozeß. In: Jürgen Wolter (Hrsg.), 140 Jahre Goltdammer's Archiv für Strafrecht. Eine Würdigung zum 70. Geburtstag von Paul-Günter Pötz. Heidelberg 1993, S. 55-75 [zit. Grasnick, in: Wolter (Hrsg.), 140 Jahre].

Griffiths, John, Ideology in Criminal Procedure or A Third "Model" of the Criminal Process. Yale L.J. 79 (1970), 359-417 [zit. Griffiths, Yale L.J. 79 (1970)].

Grigulevič, Iosif, Ketzer - Hexen - Inquisitoren. Geschichte der Inquisition (13.-20. Jahrhundert), Teil 1. Westberlin 1985 [zit. Grigulevič, Ketzer].

Groenhuijsen, Marc/Simmelink, Joep, Criminal Procedure in the Netherlands. In: Richard Vogler/Barbara Huber (Hrsg.), Criminal Procedure in Europe. Berlin 2008, S. 373-481 [zit. Groenhuijsen/Simmelink, in: Vogler/Huber (Hrsg.), Criminal Procedure].

Großkopf, Philipp, Beweissurrogate und Unmittelbarkeit der Hauptverhandlung. Zulässigkeit des Transfers von Vernehmungsergebnissen aus dem Ermittlungsverfahren in die Hauptverhandlung. Baden-Baden 2007 [zit. Großkopf, Beweissurrogate].

Grube, Friederike Charlotte, Richter ohne Robe. Laienrichter in Strafsachen im deutschen und anglo-amerikanischen Rechtskreis: Eine rechtsgeschichtliche und rechtsvergleichende Untersuchung unter besonderer Berücksichtigung verfassungsrechtlicher Aspekte. Frankfurt a.M. 2005 [zit. Grube, Richter].

Grünhut, Max, Das englische Strafrecht. In: Edmund Mezger u.a. (Hrsg.), Das ausländische Strafrecht der Gegenwart. 3. Bd. Berlin 1959, S. 133-253 [zit. Grünhut, in: Mezger u.a. (Hrsg.), Strafrecht].

Guirao, Rafael Alcácer, Die Abwertung des Rechts auf konfrontative Zeugenbefragung. In: Mark A. Zöller u.a. (Hrsg.), Gesamte Strafrechtswissenschaft in internationaler Dimension. Festschrift für Jürgen Wolter zum 70. Geburtstag am 7. September 2013. Berlin 2013, S. 833-844 [zit. Guirao, FS für Wolter].

Gusy, Christoph, Verfassungsfragen des Strafprozeßrechts. StV 2002, 153-160 [zit. Gusy, StV 2002].

- Wirkungen der Rechtsprechung des Europäischen Gerichtshofs für Menschenrechte in Deutschland. JA 2009, 406-410 [zit. Gusy, JA 2009].

Haas, Volker, Strafbegriff, Staatsverständnis und Prozessstruktur. Zur Ausübung hoheitlicher Gewalt durch Staatsanwaltschaft und erkennendes Gericht im deutschen Strafverfahren. Tübingen 2008 [zit. Haas, Strafbegriff].

- Überblick über die Typen des Strafprozesses. In: Friedrich-Christian Schroeder/Manuchehr Kudratov (Hrsg.), Das strafprozessuale Vorverfahren in Zentralasien zwischen inquisitorischem und adversatorischem Modell. Frankfurt a.M. 2012, S. 23-29 [zit. Haas, in: Schroeder/Kudratov (Hrsg.), Vorverfahren].

Haase, Richard/ Keller, Rolf, Grundlagen und Grundformen des Rechts. Eine Einführung. 10. Aufl. Stuttgart u.a. 1995 [zit. Haase/Keller, Grundlagen].

Hage, Jaap, Comparative Law as Method and the Method of Comparative Law. In: Maurice Adams/Dirk Heirbaut (Hrsg.), The Method and Culture of Comparative Law. Essays in Honour of Mark Van Hoecke. Oxford/Portland 2014, S. 37-52 [zit. Hage, in: Adams/ Heirbaut (Hrsg.), Method]. 
Haisch, Jochen, Urteilsperseveranz in simulierten Strafverfahren. MschrKrim 62 (1979), 157-162 [zit. Haisch, MschrKrim 62 (1979)].

- Psychologische Theorie des Strafverfahrens. In: Willi Seitz (Hrsg.), Kriminal- und Rechtspsychologie. Ein Handbuch in Schlüsselbegriffen. München u.a. 1983, S. 169171 [zit. Haisch, in: Seitz (Hrsg.), Rechtspsychologie].

Haller, Klaus/Conzen, Klaus, Das Strafverfahren. Eine systematische Darstellung mit Originalakte und Fallbeispielen. 7. Aufl. Heidelberg u.a. 2014 [zit. Haller/Conzen, Strafverfahren, Rn.].

Hamm, Rainer, Urteil oder Vergleich? § 257c StPO und die Wahrheitssuche. In: Wilhelm Degener/Michael Heghmanns (Hrsg.), Festschrift für Friedrich Dencker zum 70. Geburtstag. Tübingen 2012, S. 147-154 [zit. Hamm, FS für Dencker].

Hammelmann, H. A., Hearsay Evidence, A Comparison. L.Q.Rev. 67 (1951), 67-80 [zit. Hammelmann, L.Q.Rev. 67 (1951)].

Hannich, Rolf (Hrsg.), Karlsruher Kommentar zur Strafprozessordnung mit GVG, EGGVG und EMRK. 7. Aufl. München 2013 [zit. KK-StPO-Bearbeiter, § Rn.].

Hans, Valerie/Germain, Claire, The French Jury at a Crossroads. Chi.-Kent L. Rev. 86 (2011), 737-768 [zit. Hans/Germain, Chi.-Kent L. Rev. 86 (2011)].

Harding, Andrew, Global Doctrine and Local Knowledge. Law in South East Asia. ICLQ 51 (2002), 35-53 [zit. A. Harding, ICLQ 51 (2002)].

Harding, Christopher, Überblick über verschiedene Formen des Strafverfahrens. In: Albin Eser/Christiane Rabenstein (Hrsg.), Strafjustiz im Spannungsfeld von Effizienz und Fairness. Konvergente und divergente Entwicklungen im Strafprozessrecht (Criminal Justice between Crime Control and Due Process. Convergence and Divergence in Criminal Procedure Systems) - Internationales Kolloquium 8.-11. Mai 2002 auf Schloss Ringberg. Berlin 2004, S. 10-17 [zit. C. Harding, in: Eser/Rabenstein (Hrsg.), Strafjustiz].

Hassemer, Winfried, Förmlichkeiten im Strafprozess. In: Winfried Hassemer u.a. (Hrsg.), In dubio pro libertate. Festschrift für Klaus Volk zum 65. Geburtstag. München 2009, S. 207-222 [zit. Hassemer, FS für Volk].

Hassemer, Winfried/Matussek, Karin, Das Opfer als Verfolger. Ermittlungen des Verletzten im Strafverfahren. Frankfurt a.M. u.a. 1996 [zit. Hassemer/Matussek, Opfer].

Hattenhauer, Hans, Europäische Rechtsgeschichte. 4. Aufl. Heidelberg 2004 [zit. Hattenhauer, Europäische Rechtsgeschichte].

Heaton-Armstrong, Anthony/Corker, David/Wolchover, David, Disclosure of Unused Material by Prosecution Authorities and Third Parties. In: Anthony Heaton-Armstrong u.a. (Hrsg.), Witness Testimony. Psychological, Investigative and Evidential Perspectives. Oxford u.a. 2006, S. 381-399 [zit. Heaton-Armstrong/Corker/Wolchover, in: HeatonArmstrong u.a. (Hrsg.), Witness].

Henkel, Heinrich, Strafverfahrensrecht. Ein Lehrbuch. 2. Aufl. Stuttgart u.a. 1968 [zit. Henkel, Strafverfahrensrecht].

Herrmann, Joachim, Beweisaufnahme durch die Parteien und Kreuzverhör im angloamerikanischen Strafverfahren. ZStW 80 (1968), 775-814 [zit. Herrmann, ZStW 80 (1968)]. 
- Die Reform der deutschen Hauptverhandlung nach dem Vorbild des anglo-amerikanischen Strafverfahrens. Bonn 1971 [zit. Herrmann, Reform].

- Various Models of Criminal Proceedings. SACC 2 (1978), 3-19 [zit. Herrmann, SACC 2 (1978)].

- The Philosophy of Criminal Justice and the Administration of Criminal Justice. RIDP 53 (1982), 841-862 [zit. Herrmann, RIDP 53 (1982)].

- Der amerikanische Strafprozeß. In: Heike Jung (Hrsg.), Der Strafprozeß im Spiegel ausländischer Verfahrensordnungen. Frankreich, Österreich, Schweiz, UdSSR, USA. Berlin/New York 1990, S. 133-160 [zit. Herrmann, in: Jung (Hrsg.), Der Strafprozeß].

- Bargaining Justice - A Bargain for German Criminal Justice? U. Pitt. L. Rev. 53 (1992), 755-776 [zit. Herrmann, U. Pitt. L. Rev. 53 (1992)].

- Models for the Reform of Criminal Procedure in Eastern Europe: Comparative Remarks on Changes in Trial Structure and European Alternatives to Plea Bargaining. In: Edward M. Wise (Hrsg.), Criminal Science in a Global Society: Essays in Honor of Gerhard O. W. Mueller. Littleton 1994, S. 61-83 [zit. Herrmann, in: Wise (Hrsg.), Criminal Science].

- Die Entwicklung des Opferschutzes im deutschen Strafrecht und Strafprozessrecht Eine unendliche Geschichte. In: Henning Rosenau/Sangyun Kim (Hrsg.), Straftheorie und Strafgerechtigkeit. Deutsch-Japanischer Strafrechtsdialog. Frankfurt a.M. 2010, S. 89-107 [zit. Herrmann, in: Rosenau/Kim (Hrsg.), Straftheorie].

Hettinger, Michael, Die Absprache im Strafverfahren als rechtsstaatliches Problem. JZ 2011, 292-301 [zit. Hettinger, JZ 2011].

Hetzer, Wolfgang, Wahrheitsfindung im Strafprozeß unter Mitwirkung psychiatrisch / psychologischer Sachverständiger. Berlin 1982 [zit. Hetzer, Wahrheitsfindung].

Hilgendorf, Eric, Der Wahrheitsbegriff im Strafrecht am Beispiel der strafrechtlichen Aussagetheorien ( $\S 153$ ff. StGB). GA 1993, 547-559 [zit. Hilgendorf, GA 1993].

Hirschberg, Max, Das amerikanische und deutsche Strafverfahren. Neuwied am Rhein/ Berlin 1963 [zit. Hirschberg, Strafverfahren].

Ho, Hock Lai, A Philosophy of Evidence Law. Justice in the Search for Truth. Oxford u.a. 2008 [zit. Ho, Philosophy].

Hodgson, Jacqueline, French Criminal Justice. A Comparative Account of the Investigation and Prosecution of Crime in France. Oxford/Portland 2005 [zit. Hodgson, French Criminal Justice].

- Conceptions of the Trial in Inquisitorial and Adversarial Procedure. In: Antony Duff u.a. (Hrsg.), The Trial on Trial. Volume 2: Judgment and Calling to Account. Oxford/Portland 2006, S. 223-242 [zit. Hodgson, in: Duff u.a. (Hrsg.), Trial on Trial 2].

- The Role of the Criminal Defence Lawyer in Adversarial and Inquisitorial Procedure. In: Thomas Weigend u.a. (Hrsg.), Strafverteidigung vor neuen Herausforderungen. Denkanstöße aus sieben Rechtsordnungen. Berlin 2008, S. 45-59 [zit. Hodgson, in: Weigend u.a. (Hrsg.), Strafverteidigung].

Höffe, Otfried, Europäisches versus angloamerikanisches Recht. Standortkonkurrenz in Zeiten der Globalisierung. In: Felix Herzog/Ulfrid Neumann (Hrsg.), Festschrift für Winfried Hassemer. Heidelberg 2010, S. 57-68 [zit. Höffe, FS für Hassemer]. 
Hörnle, Tatjana, „Justice as Fairness“ - Ein Modell auch für das Strafverfahren? Rechtstheorie 35 (2004), 175-194 [zit. Hörnle, Rechtstheorie 35 (2004)].

- Unterschiede zwischen Strafverfahrensordnungen und ihre kulturellen Hintergründe. ZStW 117 (2005), 801-838 [zit. Hörnle, ZStW 117 (2005)].

- Democratic Accountability and Lay Participation in Criminal Trials. In: Antony Duff u.a. (Hrsg.), The Trial on Trial. Volume 2: Judgment and Calling to Account. Oxford/ Portland 2006, S. 135-153 [zit. Hörnle, in: Duff u.a. (Hrsg.), Trial on Trial 2].

Honert, Alessandro, Der italienische Strafprozeß: die Fortentwicklung einer Reform. ZStW 106 (1994), 427-447 [zit. Honert, ZStW 106 (1994)].

Hooper, Anthony/Ormerod, David (Hrsg.), Blackstone's Criminal Practice 2014. 24. Aufl. Oxford 2013 [zit. Blackstone's Criminal Practice, §].

Horovitz, Sigall, The role of victims. In: Linda Carter/Fausto Pocar (Hrsg.), International Criminal Procedure. The Interface of Civil Law and Common Law Legal Systems. Cheltenham/Northampton 2013, S. 166-191 [zit. Horovitz, in: Carter/Pocar (Hrsg.), International].

Hostettler, John, The Criminal Jury Old and New. Jury Power from Early Times to the Present Day. Winchester 2005 [zit. Hostettler, Criminal Jury].

- A History of Criminal Justice in England and Wales. Hook 2009 [zit. Hostettler, History].

Howard, Pendleton, Criminal Justice in England. A Study in Law Administration. New York 1931 [zit. Howard, Criminal Justice].

Huber, Barbara, England und Wales. In: Walter Perron (Hrsg.), Die Beweisaufnahme im Strafverfahrensrecht des Auslands. Rechtsvergleichendes Gutachten im Auftrag des Bundesministeriums der Justiz. Freiburg im Breisgau 1995, S. 11-87 [zit. Huber, in: Perron (Hrsg.), Beweisaufnahme].

- Die wichtigsten Strafverfahrensprinzipien der Europäischen Konvention für Menschenrechte im Lichte der englischen Rechtsprechung. In: Janina Czapska u.a. (Hrsg.), Zasady procesu karnego wobec wyzwań współczesności. Księga ku czci profesora Stanisława Waltosia. Warszawa 2000, S. 211-223 [zit. Huber, FS für Waltoś].

- Criminal Procedure in Germany. In: Richard Vogler/Barbara Huber (Hrsg.), Criminal Procedure in Europe. Berlin 2008, S. 269-371 [zit. Huber, in: Vogler/Huber (Hrsg.), Criminal Procedure].

Hübner, Ulrich/Constantinesco, Vlad, Einführung in das französische Recht. 3. Aufl. München 1994 [zit. Hübner/Constantinesco, Einführung].

Hunter, Jill/Cameron, Camille/Henning, Terese, Evidence and Criminal Process. 7. Aufl. Chatswood, NSW u.a. 2005 [zit. Hunter/Cameron/Henning, Evidence].

Husa, Jaakko, Legal families. In: Jan M. Smits (Hrsg.), Elgar Encyclopedia of Comparative Law. 2. Aufl. Cheltenham/Northampton 2012, S. 491-504 [zit. Husa, in: Smits (Hrsg.), Elgar Encyclopedia].

- Research Designs of Comparative Law - Methodology or Heuristics? In: Maurice Adams/Dirk Heirbaut (Hrsg.), The Method and Culture of Comparative Law. Essays in Honour of Mark Van Hoecke. Oxford/Portland 2014, S. 53-68 [zit. Husa, in: Adams/ Heirbaut (Hrsg.), Method]. 
Ignor, Alexander, Geschichte des Strafprozesses in Deutschland 1532-1846. Von der Carolin Karls V. bis zu den Reformen des Vormärz. Paderborn u.a. 2002 [zit. Ignor, Geschichte].

Ingraham, Barton, The Structure of Criminal Procedure. Laws and Practice of France, the Soviet Union, China, and the United States. New York u.a. 1987 [zit. Ingraham, Structure].

IntKomm = Internationaler Kommentar $\rightarrow$ Pabel, Katharina/Schmahl, Stefanie (Hrsg.).

Jackson, John, Theories of Truth Finding in Criminal Procedure: An Evolutionary Approach. Cardozo L. Rev. 10 (1988), 475-527 [zit. Jackson, Cardozo L. Rev. 10 (1988)].

- Two Methods of Proof in Criminal Procedure. MLR 51 (1988), 549-568 [zit. Jackson, MLR 51 (1988)].

- The Impact of Human Rights on Judicial Decision Making in Criminal Cases. In: Sean Doran/John D. Jackson (Hrsg.), The Judicial Role in Criminal Proceedings. Oxford/ Portland 2000, S. 109-125 [zit. Jackson, in: Doran/Jackson (Hrsg.), Judicial Role].

- The Adversary Trial and Trial By Judge Alone. In: Mike McConville/Geoffrey Wilson (Hrsg.), The Handbook of the Criminal Justice Process. Oxford u.a. 2002, S. 335-351 [zit. Jackson, in: McConville/Wilson (Hrsg.), Handbook].

- Managing Uncertainty and Finality: The Function of the Criminal Trial in Legal Inquiry. In: Antony Duff u.a. (Hrsg.), The Trial on Trial. Volume 1: Truth and Due Process. Oxford/Portland 2004, S. 121-145 [zit. Jackson, in: A. Duff u.a. (Hrsg.), Trial on Trial 1].

- The Effect of Human Rights on Criminal Evidentiary Processes: Towards Convergence, Divergence or Realignment? MLR 68 (2005), 737-764 [zit. Jackson, MLR 68 (2005)].

- Transnational Faces of Justice: Two Attempts to Build Common Standards Beyond National Boundaries. In: John Jackson u.a. (Hrsg.), Crime, Procedure and Evidence in a Comparative and International Context. Essays in Honour of Professor Mirjan Damaška. Oxford/Portland 2008, S. 221-249 [zit. Jackson, in: Jackson u.a. (Hrsg.), Crime].

- Finding the Best Epistemic Fit for International Criminal Tribunals. Beyond the Adversarial-Inquisitorial Dichotomy. JICJ 7 (2009), 17-39 [zit. Jackson, JICJ 7 (2009)].

Jackson, John/Doran, Sean, Judge Without Jury. Diplock Trials in the Adversary System. Oxford 1995 [zit. Jackson/Doran, Judge].

- Judge and Jury: Towards a New Division of Labour in Criminal Trials. MLR 60 (1997), 759-778 [zit. Jackson/Doran, MLR 60 (1997)].

- Addressing the Adversarial Deficit in Non-Jury Criminal Trials. Is.L.R. 31 (1997), 645689 [zit. Jackson/Doran, Is.L.R. 31 (1997)].

Jackson, John/Summers, Sarah, The Internationalisation of Criminal Evidence. Beyond the Common Law and Civil Law Traditions. Cambridge 2012 [zit. Jackson/Summers, Internationalisation].

Jacobs, Dov, Standard of Proof and Burden of Proof. In: Göran Sluiter u.a. (Hrsg.), International Criminal Procedure. Principles and Rules. Oxford 2013, S. 1128-1149 [zit. Jacobs, in: Sluiter u.a. (Hrsg.), International].

Jäger, Christian, Beweisverwertung und Beweisverwertungsverbote im Strafprozess. München 2003 [zit. Jäger, Beweisverwertung]. 
- Beweiserhebungs- und Beweisverwertungsverbote als prozessuale Regelungsinstrumente im strafverfolgenden Rechtsstaat. Zugleich ein Beitrag zum 67. Deutschen Juristentag. GA 2008, 473-499 [zit. Jäger, GA 2008].

Jaeger, Renate/Schmaltz, Christiane, Die deutsche Rechtsprechung und der EGMR. Kooperation oder Konfrontation? In: Sabine Leutheusser-Schnarrenberger (Hrsg.), Vom Recht auf Menschenwürde. 60 Jahre Europäische Menschenrechtskonvention. Tübingen 2013, S. 97-108 [zit. Jaeger/Schmaltz, in: Leutheusser-Schnarrenberger (Hrsg.), Recht].

Jahn, Matthias, Verfassungsrechtliche Grundlagen des Beweisantragsrechts der Verteidigung im deutschen Strafprozess. In: Felix Herzog/Ulfrid Neumann (Hrsg.), Festschrift für Winfried Hassemer. Heidelberg 2010, S. 1029-1040 [zit. Jahn, FS für Hassemer].

Jarvers, Konstanze, Rahmenbedingungen, Vorgaben, Grundlagen und Entwicklung des Strafrechts in Italien. In: Ulrich Sieber/Karin Cornils (Hrsg.), Nationales Strafrecht in rechtsvergleichender Darstellung. Allgemeiner Teil. Teilband 1: Grundlagen. Berlin 2009, S. 277-339 [zit. Jarvers, in: Sieber/Cornils (Hrsg.), Nationales Strafrecht].

Jescheck, Hans-Heinrich, Entwicklung, Aufgaben und Methoden der Strafrechtsvergleichung. Antrittsrede. Tübingen 1955 (Recht und Staat in Geschichte und Gegenwart. Eine Sammlung von Vorträgen und Schriften aus dem Gebiet der gesamten Staatswissenschaften 181/182) [zit. Jescheck, Strafrechtsvergleichung].

- Der Strafprozeß - Aktuelles und Zeitloses. JZ 1970, 201-207 [zit. Jescheck, JZ 1970].

- Principles of German Criminal Procedure in Comparison with American Law. Va. L. Rev. 56 (1970), 239-253 [zit. Jescheck, Va. L. Rev. 56 (1970)].

- Rechtsvergleichung als Grundlage der Strafprozeßreform. ZStW 86 (1974), 761-782 [zit. Jescheck, ZStW 86 (1974)].

Jescheck, Hans-Heinrich/Weigend, Thomas, Lehrbuch des Strafrechts. Allgemeiner Teil. 5. Aufl. Berlin 1996 [zit. Jescheck/Weigend, AT].

Jörg, Nico, Pitfalls of the Convergence of Criminal Procedure Systems. In: Albin Eser/ Christiane Rabenstein (Hrsg.), Strafjustiz im Spannungsfeld von Effizienz und Fairness. Konvergente und divergente Entwicklungen im Strafprozessrecht (Criminal Justice between Crime Control and Due Process. Convergence and Divergence in Criminal Procedure Systems) - Internationales Kolloquium 8.-11. Mai 2002 auf Schloss Ringberg. Berlin 2004, S. 221-229 [zit. Jörg, in: Eser/Rabenstein (Hrsg.), Strafjustiz].

Jörg, Nico/Field, Stewart/ Brants, Chrisje, Are Inquisitorial and Adversarial Systems Converging? In: Phil Fennell u.a. (Hrsg.), Criminal Justice in Europe: A Comparative Study. Oxford 1995, S. 41-56 [zit. Jörg/Field/Brants, in: Fennell u.a. (Hrsg.), Criminal Justice].

Jørgensen, Nina, Judicial Notice. In: Karim A. A. Khan u.a. (Hrsg.), Principles of Evidence in International Criminal Justice. Oxford u.a. 2010, S. 695-722 [zit. Jørgensen, in: Khan u.a. (Hrsg.), Principles].

Jung, Heike, Einführung. In: Heike Jung (Hrsg.), Der Strafprozeß im Spiegel ausländischer Verfahrensordnungen. Frankreich, Österreich, Schweiz, UdSSR, USA. Berlin/New York 1990, S. 1-6 [zit. Jung, in: ders. (Hrsg.), Der Strafprozeß].

- Plea Bargaining and its Repercussions on the Theory of Criminal Procedure. EJCCC 1997, 112-122 [zit. Jung, EJCCC 1997]. 
- Grundfragen der Strafrechtsvergleichung. JuS 1998, 1-7 [zit. Jung, JuS 1998].

- Der Strafprozeß: Konzepte, Modelle und Grundannahmen. In: Janina Czapska u.a. (Hrsg.), Zasady procesu karnego wobec wyzwań współczesności. Księga ku czci profesora Stanisława Waltosia. Warszawa 2000, S. 27-36 [zit. Jung, FS für Waltoś].

- Zu Theorie und Methoden der Strafrechtsvergleichung. In: Raffaele De Giorgi (Hrsg.), Il Diritto e La Differenza. Scritti in onore di Alessandro Baratta. Volume I. Lecce 2002, S. 361-384 [zit. Jung, FS für Baratta].

- ,Funktionstüchtigkeit der Strafrechtspflege‘ contra ,schützende Formen ‘ - ein prozessualer ,Klassiker' im Lichte der Rechtsprechung des Europäischen Gerichtshofes für Menschenrechte. GA 2003, 191-203 [zit. Jung, GA 2003].

- Wertende (Straf-)Rechtsvergleichung. Betrachtungen über einen elastischen Begriff. GA 2005, 2-10 [zit. Jung, GA 2005].

- Recht und kulturelle Identität - Anmerkungen zur Rezeption, Transplantation und Diffusion von Recht. ZStW 121 (2009), 467-500 [zit. Jung, ZStW 121 (2009)].

- Neues zum Konfrontationsrecht? Zugleich Besprechung von EGMR, Urteil vom 20.1.2009. GA 2009, 235-240 [zit. Jung, GA 2009].

- Über die Wahrheit und ihre institutionellen Garanten. JZ 2009, 1129-1135 [zit. Jung, JZ 2009].

- Die ganze Wahrheit? In: Michaela Wittinger u.a. (Hrsg.), Verfassung - Völkerrecht Kulturgüterschutz. Festschrift für Wilfried Fiedler zum 70. Geburtstag. Berlin 2011, S. 903-913 [zit. Jung, FS für Fiedler].

- Der Strafprozess aus rollentheoretischer Sicht. In: Manfred Heinrich u.a. (Hrsg.), Strafrecht als Scientia Universalis. Festschrift für Claus Roxin zum 80. Geburtstag am 15. Mai 2011. Band 2. Berlin/New York 2011, S. 1233-1243 [zit. Jung, FS für Roxin 2011].

- Rechtsvergleich oder Kulturvergleich? In: Georg Freund u.a. (Hrsg.), Grundlagen und Dogmatik des gesamten Strafrechtssystems. Festschrift für Wolfgang Frisch zum 70. Geburtstag. Berlin 2013, S. 1467-1481 [zit. Jung, FS für Frisch].

- „Overall Fairness“ - Anmerkungen zu einer verfehlten Begriffsbildung. In: Martin Heger u.a. (Hrsg.), Festschrift für Kristian Kühl zum 70. Geburtstag. München 2014, S. 915-922 [zit. Jung, FS für Kühl].

Jung, Heike/Nitschmann, Kathrin, Das Bekenntnis zum Schuldbekenntnis - zur Einführung des plaider coupable im französischen Strafprozess. ZStW 116 (2004), 785-796 [zit. Jung/Nitschmann, ZStW 116 (2004)].

Jung, Heike/Weigend, Thomas, Einführung. In: Heike Jung u.a. (Hrsg.), 200 Jahre Code d'instruction criminelle - Le Bicentenaire du Code d'instruction criminelle. BadenBaden 2010, S. 17-22 [zit. Jung/Weigend, in: Jung u.a. (Hrsg.), 200 Jahre].

Kahn-Freund, Otto, Common Law and Civil Law - Imaginary and Real Obstacles to Assimilation. In: Mauro Cappelletti (Hrsg.), New Perspectives for a Common Law of Europe. Leyden u.a. 1978, S. 137-168 [zit. Kahn-Freund, in: Cappelletti (Hrsg.), New Perspectives]. 
Kalisch, Muhammad, Islam und Menschenrechte. Betrachtungen zum Verhältnis von Religion und Recht. In: Hatem Elliesie (Hrsg.), Beiträge zum Islamischen Recht VII: Islam und Menschenrechte. Frankfurt a.M. u.a. 2010, S. 49-72 [zit. Kalisch, in: Elliesie (Hrsg.), Islam und Menschenrechte].

Kanzenbach, Katrin, Die Implementierung und Ausgestaltung eines „BEST-PRACTICE“ Hinweisgeber- bzw. Whistleblower-Systems unter arbeitsrechtlichen Gesichtspunkten Eine Handlungsempfehlung für Unternehmen. Aachen 2013 [zit. Kanzenbach, Implementierung].

Keller, Rainer, Offenkundigkeit und Beweisbedürftigkeit im Strafprozeß. ZStW 101 (1989), 381-418 [zit. Keller, ZStW 101 (1989)].

Kelly, Henry Ansgar, Inquisition and the Prosecution of Heresy: Misconceptions and Abuses. Church History 58 (1989), 439-451 [zit. Kelly, Church History 58 (1989)].

Kindhäuser, Urs, Strafprozessrecht. 3. Aufl. Baden-Baden 2013 [zit. Kindhäuser, Strafprozessrecht, § Rn.].

Killias, Martin, Errors Occur Everywhere - But Not At the Same Frequency. The Role of Procedural Systems in Wrongful Convictions. In: C. Ronald Huff/Martin Killias (Hrsg.), Wrongful Convictions and Miscarriages of Justice: Causes and Remedies in North American and European Criminal Justice Systems. New York/London 2013, S. 61-76 [zit. Killias, in: Huff/Killias (Hrsg.), Wrongful Convictions].

King, Matthew, Security, Scale, Form, and Function: The Search for Truth and the Exclusion of Evidence in Adversarial and Inquisitorial Justice Systems. Int'l Legal Persp. 12 (2001-2002), 185-236 [zit. M. King, Int'l Legal Persp. 12 (2001-2002)].

King, Nancy Jean, The American Criminal Jury. In: Neil Vidmar (Hrsg.), World Jury Systems. Oxford u.a. 2000, S. 93-124 [zit. N. King, in: Vidmar (Hrsg.), Jury].

Kirchengast, Tyrone, The Criminal Trial in Law and Discourse. Basingstoke 2010 [zit. Kirchengast, Criminal Trial].

Kirsch, Stefan, Verteidigung in Verfahren vor dem Internationalen Strafgerichtshof für das ehemalige Jugoslawien (JStGH). StV 2003, 636-640 [zit. Kirsch, StV 2003].

KK-StPO $=$ Karlsruher Kommentar $\rightarrow$ Hannich, Rolf (Hrsg.).

Klamberg, Mark, General Requirements for the Admission of Evidence. In: Göran Sluiter u.a. (Hrsg.), International Criminal Procedure. Principles and Rules. Oxford 2013, S. 1016-1043 [zit. Klamberg, in: Sluiter u.a. (Hrsg.), International].

- Prosecution Access to the Defence Material. In: Göran Sluiter u.a. (Hrsg.), International Criminal Procedure. Principles and Rules. Oxford 2013, S. 1099-1107 [zit. Klamberg, in: Sluiter u.a. (Hrsg.), International].

Knust, Nandor, Strafrecht und Gacaca. Entwicklung eines pluralistischen Rechtsmodells am Beispiel des ruandischen Völkermordes. Berlin 2013 [zit. Knust, Strafrecht].

Koch, Arnd, Strafrechtsgeschichte und Strafrechtsvergleichung. In: Georg Freund u.a. (Hrsg.), Grundlagen und Dogmatik des gesamten Strafrechtssystems. Festschrift für Wolfgang Frisch zum 70. Geburtstag. Berlin 2013, S. 1483-1499 [zit. Koch, FS für Frisch].

Köhler, Michael, Inquisitionsprinzip und autonome Beweisvorführung (§ 245 StPO). Heidelberg/Hamburg 1979 [zit. Köhler, Inquisitionsprinzip]. 
Kouassi, Adome Blaise, National characteristics, fundamental principles, and history of criminal law in Côte d'Ivoire. In: Ulrich Sieber u.a. (Hrsg.), National Criminal Law in a Comparative Legal Context. Volume 1.2. Introduction to National Systems. National characteristics, fundamental principles, and history of criminal law. Australia, Côte d'Ivoire, Greece, South Korea. Berlin 2013, S. 119-186 [zit. Kouassi, in: Sieber u.a. (Hrsg.), National Criminal Law].

Krausbeck, Matthias, Konfrontative Zeugenbefragung. Vorgaben des Art. 6 Abs. 3 lit. d EMRK für das deutsche Strafverfahren. Tübingen 2010 [zit. Krausbeck, Konfrontative Zeugenbefragung].

Krauß, Detlef, Das Prinzip der materiellen Wahrheit im Strafprozeß. In: Gerald Grünwald u.a. (Hrsg.), Festschrift für Friedrich Schaffstein zum 70. Geburtstag am 28. Juli 1975. Göttingen 1975, S. 411-431 [zit. D. Krau $\beta$, FS für Schaffstein].

Krauß, Katharina, V-Leute im Strafprozeß und die Europäische Menschenrechtskonvention. Freiburg im Breisgau 1999 [zit. K. Krauß, V-Leute].

Krawietz, Birgit, Hierarchie der Rechtsquellen im tradierten sunnitischen Islam. Berlin 2002 [zit. Krawietz, Rechtsquellen].

Krell, Paul, Der Beweisantrag und seine Ablehnung im Strafprozess. JURA 2012, 355361 [zit. Krell, JURA 2012].

Kress, Claus, The Procedural Law of the International Criminal Court in Outline: Anatomy of a Unique Compromise. JICJ 1 (2003), 603-617 [zit. Kress, JICJ 1 (2003)].

- Witnesses in Proceedings Before the International Criminal Court: An Analysis in the Light of Comparative Criminal Procedure. In: Horst Fischer u.a. (Hrsg.), International and National Prosecution of Crimes Under International Law. Current Developments. Berlin 2004, S. 309-383 [zit. Kreß, in: Fischer u.a. (Hrsg.), International].

Krey, Volker, Zur strafprozessualen Folter - Rechtshistorische Betrachtungen. In: Robert Esser u.a. (Hrsg.), Festschrift für Hans-Heiner Kühne zum 70. Geburtstag am 21. August 2013. Heidelberg u.a. 2013, S. 769-792 [zit. Krey, FS für Kühne].

Krimphove, Dieter, Was ist Wahrheit? Die ökonomische Seite des Phänomens. Rechtstheorie 39 (2008), 105-138 [zit. Krimphove, Rechtstheorie 39 (2008)].

Kröpil, Karl, Das strafprozessuale Verfahrensziel als Argumentationstopos in der Rechtsprechung. JR 2013, 14-19 [zit. Kröpil, JR 2013].

- Gerechtigkeit im Strafverfahren - Zusammenspiel von materiellem und formellem Strafrecht. JR 2013, 553-558 [zit. Kröpil, JR 2013].

Krygier, Martin, Law as Tradition. Law and Philosophy 5 (1986), 237-262 [zit. Krygier, Law and Philosophy 5 (1986)].

Kühne, Hans-Heiner, Die Instrumentalisierung der Wahrheitsfindung im Strafverfahren. GA 2008, 361-374 [zit. Kühne, GA 2008].

- Strafprozessrecht. Eine systematische Darstellung des deutschen und europäischen Strafverfahrensrechts. 8. Aufl. Heidelberg u.a. 2010 [zit. Kühne, Strafprozessrecht, Rn.].

Küper, Wilfried, Die Richteridee der Strafprozessordnung und ihre geschichtlichen Grundlagen. Berlin 1967 [zit. Küper, Richteridee]. 
Kunert, Karl, Some Observations on the Origin and Structure of Evidence Rules under the Common Law System and the Civil Law System of 'Free Proof' in the German Code of Criminal Procedure. Buff. L. Rev. 16 (1966-1967), 122 - 164 [zit. Kunert, Buff. L. Rev. 16 (1966-1967)].

LaFave, Wayne/Israel, Jerold/King, Nancy/Kerr, Orin, Criminal Procedure. 5. Aufl. St. Paul 2009 [zit. LaFave/Israel/King/Kerr, Criminal Procedure].

Lagodny, Otto, Die Ungeeignetheit von reinen Geschworenengerichten im kontinentalen Strafverfahren. In: Heinz Müller-Dietz u.a. (Hrsg.), Festschrift für Heike Jung zum 65. Geburtstag am 23. April 2007. Baden-Baden 2007, S. 499-510 [zit. Lagodny, FS für Jung].

Landau, Peter, Schwurgerichte und Schöffengerichte in Deutschland im 19. Jahrhundert bis 1870. In: Antonio Padoa Schioppa (Hrsg.), The Trial Jury in England, France, Germany 1700-1900. Berlin 1987, S. 241-304 [zit. Landau, in: Schioppa (Hrsg.), Trial Jury].

Landsman, Stephan, Readings on Adversarial Justice: The American Approach to Adjudication. St. Paul 1988 [zit. Landsman, Readings].

Langbein, John, The Origins of Public Prosecution at Common Law. AJLH 1973, 313-335 [zit. Langbein, AJLH 1973].

- Torture and the Law of Proof. Europe and England in the Ancien Régime. Chicago/ London 1977 [zit. Langbein, Torture].

- The Criminal Trial before the Lawyers. U. Chi. L. Rev. 45 (1978), 263-316 [zit. Langbein, U. Chi. L. Rev. 45 (1978)].

- Torture and Plea Bargaining. U. Chi. L. Rev. 46 (1978), 3-22 [zit. Langbein, U. Chi. L. Rev. 46 (1978)].

- Land Without Plea Bargaining: How the Germans Do It. Mich. L. Rev. 78 (1979), 204225 [zit. Langbein, Mich. L. Rev. 78 (1979)].

- Shaping the Eighteenth-Century Criminal Trial: A View from the Ryder Sources. U. Chi. L. Rev. 50 (1983), 1-136 [zit. Langbein, U. Chi. L. Rev. 50 (1983)].

- The English Criminal Trial Jury on the Eve of the French Revolution. In: Antonio Padoa Schioppa (Hrsg.), The Trial Jury in England, France, Germany 1700-1900. Berlin 1987, S. 13-39 [zit. Langbein, in: Schioppa (Hrsg.), Trial Jury].

- On the Myth of Written Constitutions: The Disappearance of Criminal Jury Trial. Harvard JLPP 15 (1992), 119-127 [zit. Langbein, Harvard JLPP 15 (1992)].

- Historical Foundations of the Law of Evidence: A View from the Ryder Sources. Colum. L. Rev. 96 (1996), 1168-1202 [zit. Langbein, Colum. L. Rev. 96 (1996)].

- The Origins of Adversary Criminal Trial. Oxford u.a. 2003 [zit. Langbein, Origins].

Langbein, John /Lerner, Renée Lettow/Smith, Bruce P., History of the Common Law. The Development of Anglo-American Legal Institutions. Austin u.a. 2009 [zit. Langbein/ Lerner/Smith, History].

Langbein, John/Weinreb, Lloyd, Continental Criminal Procedure: "Myth" and Reality. Yale L.J. 87 (1978), 1549-1569 [zit. Langbein/Weinreb, Yale L.J. 87 (1978)]. 
Langer, Máximo, From Legal Transplants to Legal Translations: The Globalization of Plea Bargaining and the Americanization Thesis in Criminal Procedure. Harv. Int'l L. J. 45 (2004), 1-64 [zit. Langer, Harv. Int'1 L. J. 45 (2004)].

Lave, Charles/March, James, An Introduction to Models in the Social Sciences. New York u.a. 1975 [zit. Lave/March, Introduction].

Legrand, Pierre, Comparative Legal Studies and Commitment to Theory. MLR 58 (1995), 262-273 [zit. Legrand, MLR 58 (1995)].

Leigh, Leonard, Liberty and Efficiency in the Criminal Process - The Significance of Models. Int'l \& Comp. L.Q. 26 (1977), 516-530 [zit. Leigh, Int'l \& Comp. L.Q. 26 (1977)].

Lelieur, Juliette, Diskussionsbericht über die I. Arbeitssitzung. In: Albin Eser/Christiane Rabenstein (Hrsg.), Strafjustiz im Spannungsfeld von Effizienz und Fairness. Konvergente und divergente Entwicklungen im Strafprozessrecht (Criminal Justice between Crime Control and Due Process. Convergence and Divergence in Criminal Procedure Systems) - Internationales Kolloquium 8.-11. Mai 2002 auf Schloss Ringberg. Berlin 2004, S. 63-73 [zit. Lelieur, in: Eser/Rabenstein (Hrsg.), Strafjustiz].

Lieber, Norman, Schöffengericht und Trial by Jury. Eine rechtsvergleichende Untersuchung zur Entstehung, gegenwärtigen Praxis und möglichen Zukunft zweier Modelle der Laienbeteiligung an Strafverfahren in Europa. Berlin 2010 [zit. Lieber, Schöffengericht].

Lilie, Hans, Der adversatorische und inquisitorische Strafprozess - der deutsche Strafprozess zwischen den Modellen. In: Friedrich-Christian Schroeder/Manuchehr Kudratov (Hrsg.), Das strafprozessuale Vorverfahren in Zentralasien zwischen inquisitorischem und adversatorischem Modell. Frankfurt a.M. 2012, S. 105-114 [zit. Lilie, in: Schroeder/ Kudratov (Hrsg.), Vorverfahren].

Lind, Allan/Thibaut, John/Walker, Laurens, Discovery and Presentation of Evidence in Adversary and Nonadversary Proceedings. Mich. L. Rev. 71 (1973), 1129-1144 [zit. Lind/Thibaut/Walker, Mich. L. Rev. 71 (1973)].

Linkenheil, Beate, Laienbeteiligung an der Strafjustiz. Relikt des bürgerlichen Emanzipationsprozesses oder Legitimation einer Rechtsprechung ,Im Namen des Volkes“? Berlin 2003 [zit. Linkenheil, Laienbeteiligung].

Llewellyn, Karl, Jurisprudence. Realism in Theory and Practice. Chicago 1962 [zit. Llewellyn, Jurisprudence].

Lloyd-Bostock, Sally/Thomas, Cheryl, The Continuing Decline of the English Jury. In: Neil Vidmar (Hrsg.), World Jury Systems. Oxford u.a. 2000, S. 53-91 [zit. Lloyd-Bostock/ Thomas, in: Vidmar (Hrsg.), Jury].

Löffelmann, Markus, Die normativen Grenzen der Wahrheitserforschung im Strafverfahren. Ideen zu einer Kritik der Funktionsfähigkeit der Strafrechtspflege. Berlin 2008 [zit. Löffelmann, Wahrheitserforschung].

LR-StPO = Löwe-Rosenberg $\rightarrow$ Erb, Volker u.a. (Hrsg.).

Luhmann, Niklas, Legitimation durch Verfahren. Neuwied am Rhein/Berlin 1969 [zit. Luhmann, Legitimation].

- Law as a Social System (Das Recht der Gesellschaft, Translated by Klaus A. Ziegert). Oxford u.a. 2004 (repr. 2007) [zit. Luhmann, Law]. 
Luna, Erik/Wade, Marianne, Plea Bargaining and Other 'Consensual Procedures'. Introduction. In: Erik Luna/Marianne L. Wade (Hrsg.), The Prosecutor in Transnational Perspective. Oxford u.a. 2012, S. 83-90 [zit. Luna/Wade, in: dies. (Hrsg.), Prosecutor].

Ma, Yue, Lay Participation in Criminal Trials: A Comparative Perspective. ICJR 8 (1998), 74-94 [zit. Ma, ICJR 8 (1998)].

Macchiarola, Frank, Finding the Truth in an American Criminal Trial: Some Observations. In: Johannes F. Nijboer/Jan M. Reijntjes (Hrsg.), Proceedings of The First World Conference on New Trends in Criminal Investigation and Evidence. The Hague, The Netherlands, December 1-5, 1995. Lelystad 1997, S. 85-93 [zit. Macchiarola, in: Nijboer/Reijntjes (Hrsg.), Proceedings].

MacCormick, Neil, Der Rechtsstaat und die rule of law. JZ 1984, 65-70 [zit. MacCormick, JZ 1984].

- Reconstruction after Deconstruction: A Response to CLS. O.J.L.S. 10 (1990), 539-558 [zit. MacCormick, O.J.L.S. 10 (1990)].

Mack, Raneta Lawson, Comparative Criminal Procedure: History, Processes and Case Studies. Buffalo 2008 [zit. Mack, Comparative].

Madsen, Mikael Rask, From Cold War Instrument to Supreme European Court: The European Court of Human Rights at the Crossroads of International and National Law and Politics. Law \& Social Inquiry 32 (2007), 137-159 [zit. Madsen, Law \& Social Inquiry 32 (2007)].

Maffei, Stefano, The Right to Confrontation in Europe. Absent, Anonymous and Vulnerable Witnesses. 2. Aufl. Groningen 2012 [zit. Maffei, Right to Confrontation].

Mahler, Franziska, Das Recht des Beschuldigten auf konfrontative Befragung der Belastungszeugen. Eine vergleichende Analyse der normativen und justiziellen Vorgaben für das Konfrontationsrecht im US-amerikanischen, europäischen und deutschen Strafverfahrensrecht. Frankfurt a.M. 2011 [zit. Mahler, Recht].

Maier, Julio, Inquisition oder Komposition? In: Bernd Schünemann u.a. (Hrsg.), Festschrift für Claus Roxin zum 70. Geburtstag am 15. Mai 2001. Berlin/New York 2001, S. 1215-1227 [zit. Maier, FS für Roxin 2001].

Maiwald, Manfred, Einführung in das italienische Strafrecht und Strafprozeßrecht. Frankfurt a.M. u.a. 2009 [zit. Maiwald, Einführung].

Manso Porto, Teresa, Rahmenbedingungen, Vorgaben, Grundlagen und Entwicklung des Strafrechts in Spanien. In: Ulrich Sieber/Karin Cornils (Hrsg.), Nationales Strafrecht in rechtsvergleichender Darstellung. Allgemeiner Teil. Teilband 1: Grundlagen. Berlin 2009, S. 663-730 [zit. Manso Porto, in: Sieber/Cornils (Hrsg.), Nationales Strafrecht].

Marafioti, Luca, Italian Criminal Procedure: A System Caught Between Two Traditions. In: John Jackson u.a. (Hrsg.), Crime, Procedure and Evidence in a Comparative and International Context. Essays in Honour of Professor Mirjan Damaška. Oxford/Portland 2008, S. 81-98 [zit. Marafioti, in: Jackson u.a. (Hrsg.), Crime].

Marshall, James/Marquis, Kent/Oskamp, Stuart, Effects of Kind of Question and Atmosphere of Interrogation on Accuracy and Completeness of Testimony. Harv. L. Rev. 84 (1971), 1620-1643 [zit. Marshall/Marquis/Oskamp, Harv. L. Rev. 84 (1971)].

Martinez-Torrón, Javier, Anglo-American Law and Canon Law. Canonical Roots of the Common Law Tradition. Berlin 1998 [zit. Martínez-Torrón, Anglo-American Law]. 
Mattei, Ugo, Three Patterns of Law: Taxonomy and Change in the World's Legal Systems. Am. J. Comp. L. 45 (1997), 5-44 [zit. Mattei, Am. J. Comp. L. 45 (1997)].

Maul, Heinrich/Eschelbach, Ralf, Zur „Widerspruchslösung“ von Beweisverbotsproblemen in der Rechtsprechung. StraFo 1996, 66-70 [zit. Maul/Eschelbach, StraFo 1996].

M'Baye, Kéba, The African Conception of Law. In: René David (Hrsg.), International Encyclopedia of Comparative Law. Volume II: The Legal Systems of the World: Their Comparison and Unification, Chapter 1: The Different Conceptions of the Law. Tübingen u.a. 1975, S. 138-158 [zit. M'Baye, in: David (Hrsg.), International Encyclopedia].

McEwan, Jenny, Evidence and the Adversarial Process - The Modern Law. 2. Aufl. Oxford 1998 [zit. McEwan, Evidence].

- Ritual, Fairness and Truth: The Adversarial and Inquisitorial Models of Criminal Trial. In: Antony Duff u.a. (Hrsg.), The Trial on Trial. Volume 1: Truth and Due Process. Oxford/Portland 2004, S. 51-69 [zit. McEwan, in: A. Duff u.a. (Hrsg.), Trial on Trial 1].

- From adversarialism to managerialism: criminal justice in transition. L.S. 31 (2011), 519-546 [zit. McEwan, L.S. 31 (2011)].

Merino-Blanco, Elena, Spanish Law and Legal System. 2. Aufl. London 2006 [zit. MerinoBlanco, Spanish Law].

Merryman, John Henry, On the Convergence (and Divergence) of the Civil Law and the Common Law. In: Mauro Cappelletti (Hrsg.), New Perspectives for a Common Law of Europe. Leyden u.a. 1978, S. 195-233 [zit. Merryman, in: Cappelletti (Hrsg.), New Perspectives].

Merryman, John Henry/Pérez-Perdomo, Rogelio, The Civil Law Tradition. An Introduction to the Legal Systems of Europe and Latin America. 3. Aufl. Stanford 2007 [zit. Merryman/Pérez-Perdomo, Civil Law Tradition].

Meyer, Frank, Die ,sole or decisive“-Regel zur Würdigung nicht konfrontierter Zeugenaussagen - not so decisive anymore. Besprechung zum Urteil EGMR HRRS 2012 Nr. 1 (Al-Khawaja and Tahery vs. UK). HRRS 3/2012, 117-120 [zit. Meyer, HRRS 3/2012 (online)].

Meyer-Goßner, Lutz, Rechtsprechung durch Staatsanwaltschaft und Angeklagten? - Urteilsabsprachen im Rechtsstaat des Grundgesetzes. NStZ 2007, 425-432 [zit. MeyerGoßner, NStZ 2007].

- Strafprozessordnung. Gerichtsverfassungsgesetz, Nebengesetze und ergänzende Bestimmungen. Erläutert von Lutz Meyer-Goßner und Bertram Schmitt. 56. Aufl. München 2013 [zit. Meyer-Goßner, StPO, Einl./§ Rn.].

Meyer-Ladewig, Jens, EMRK. Europäische Menschenrechtskonvention. Handkommentar. 3. Aufl. Baden-Baden 2011 [zit. Meyer-Ladewig, EMRK, Art. Rn.].

Meyer-Lohkamp, Jes, Beweisaufnahme short to go - Überlegungen zum Selbstleseverfahren. StV 2014, 121-123 [zit. Meyer-Lohkamp, StV 2014].

Milsom, Stroud, Historical Foundations of the Common Law. 2. Aufl. London 1981 [zit. Milsom, Foundations].

Mincke, Wolfgang, Einführung in das niederländische Recht. München 2002 [zit. Mincke, Einführung]. 
Mittermaier, Carl Joseph Anton, Die Lehre vom Beweise im deutschen Strafprozesse nach der Fortbildung durch Gerichtsgebrauch und deutsche Gesetzbücher in Vergleichung mit den Ansichten des englischen und französischen Strafverfahrens. Darmstadt 1834 [zit. Mittermaier, Lehre].

- Die Mündlichkeit, das Anklageprinzip, die Öffentlichkeit und das Geschwornengericht in ihrer Durchführung in den verschiedenen Gesetzgebungen. Stuttgart/Tübingen 1845 [zit. Mittermaier, Mündlichkeit].

- Roman Criminal Procedure. In: Adhémar Esmein (Verf.), A History of Continental Criminal Procedure. With Special Reference to France (Translated by John Simpson). South Hackensack u.a. 1968 (repr.), S. 13-29 [zit. Mittermaier, in: Esmein (Verf.), History].

- Primitive Germanic Criminal Procedure. In: Adhémar Esmein (Verf.), A History of Continental Criminal Procedure. With Special Reference to France (Translated by John Simpson). South Hackensack u.a. 1968 (repr.), S. 30-36 [zit. Mittermaier, in: Esmein (Verf.), History].

Monateri, Pier Giuseppe, Black Gaius: A Quest for the Multicultural Origins of the 'Western Legal Tradition'. Hastings L.J. 51 (1999-2000), 479-555 [zit. Monateri, Hastings L.J. 51 (1999-2000)].

Mosbacher, Andreas, Zur aktuellen Debatte um die Rügepräklusion - Zugleich ein Beitrag zur Zukunft der Widerspruchslösung. NStZ 2011, 606-611 [zit. Mosbacher, NStZ 2011].

Mülfarth, Christian, Grundlagen und Grenzen von Beweiserhebung und Beweisverwertung im spanischen Strafverfahren. Eine rechtsvergleichende Untersuchung. Frankfurt a.M. u.a. 2009 [zit. Mülfarth, Grundlagen].

Müller, Martin, Probleme um eine gesetzliche Regelung der Absprachen im Strafverfahren. Köln u.a. 2008 [zit. Müller, Probleme].

Murmann, Uwe, Über den Zweck des Strafprozesses. GA 2004, 65-86 [zit. Murmann, GA 2004].

- Reform ohne Wiederkehr? - Die gesetzliche Regelung der Absprachen im Strafverfahren. ZIS 2009, 526-538 [zit. Murmann, ZIS 2009].

- Probleme der gesetzlichen Regelung der Absprachen im Strafverfahren. In: Manfred Heinrich u.a. (Hrsg.), Strafrecht als Scientia Universalis. Festschrift für Claus Roxin zum 80. Geburtstag am 15. Mai 2011. Band 2. Berlin/New York 2011, S. 1385-1401 [zit. Murmann, FS für Roxin 2011].

Mylonopoulos, Christos, Zur Möglichkeit einer theoretischen Begründung des plea bargaining. In: Robert Esser u.a. (Hrsg.), Festschrift für Hans-Heiner Kühne zum 70. Geburtstag am 21. August 2013. Heidelberg u.a. 2013, S. 259-277 [zit. Mylonopoulos, FS für Kühne].

Naeem, Naseef, The Influence of Religious Clauses on Constitutional Law in Countries with an Islamic Character. In: Birgit Krawietz/ Helmut Reifeld (Hrsg.), Islam and the Rule of Law. Between Sharia and Secularization. Sankt Augustin/Berlin 2008 [zit. Naeem, in: Krawietz/Reifeld (Hrsg.), Islam]. 
Nagorcka, Felicity/Stanton, Michael/Wilson, Michael, Stranded Between Partisanship and the Truth? A Comparative Analysis of Legal Ethics in the Adversarial and Inquisitorial Systems of Justice. Melb. U. L. Rev. 29 (2005), 448-477 [zit. Nagorcka/Stanton/Wilson, Melb. U. L. Rev. 29 (2005)].

Navarro, Alicia González, Absprachen im spanischen Strafverfahren - mit besonderer Berücksichtigung des beschleunigten Verfahrens. ZStW 123 (2011), 163-178 [zit. Navarro, ZStW 123 (2011)].

Nelken, David, Defining and Using the Concept of Legal Culture. In: Esin Örücü/David Nelken (Hrsg.), Comparative Law. A Handbook. Oxford/Portland 2007, S. 109-132 [zit. Nelken, in: Örücü/Nelken (Hrsg.), Comparative Law].

Neuhaus, Ralf, Zur Notwendigkeit der qualifizierten Beschuldigtenbelehrung - Zugleich Anmerkung zu LG Dortmund NStZ 1997, 356. NStZ 1997, 312-316 [zit. Neuhaus, NStZ 1997].

Neumann, Ulfrid, Materiale und prozedurale Gerechtigkeit im Strafverfahren. ZStW 101 (1989), 52-74 [zit. Neumann, ZStW 101 (1989)].

Newman, Karl, Das englisch-amerikanische Beweisrecht. Mit einem Vorwort über die Behandlung des Beweisproblems im deutschen Strafverfahren von Walter Sachs. Heidelberg 1949 [zit. Newman, Beweisrecht].

Nijboer, Johannes, Common Law Tradition in Evidence Scholarship Observed from a Continental Perspective. Am. J. Comp. L. 41 (1993), 299-338 [zit. Nijboer, Am. J. Comp. L. 41 (1993)].

- The American Adversarial System in Criminal Cases: Between Ideology and Reality. Cardozo J. of Int'l \& Comp. L. 5 (1997), 79-96 [zit. Nijboer, Cardozo J. of Int'l \& Comp. L. 5 (1997)].

- Beweisprobleme und Strafrechtssysteme. Proof and Criminal Justice Systems. 2. Aufl. Frankfurt a.M. u.a. 1997 [zit. Nijboer, Beweisprobleme].

- Comparative Perspectives on the Judicial Role. In: Sean Doran/John D. Jackson (Hrsg.), The Judicial Role in Criminal Proceedings. Oxford/Portland 2000, S. 19-30 [zit. Nijboer, in: Doran/Jackson (Hrsg.), Judicial Role].

- Development of the Systems of the Law of Evidence in Europe. Diverging and Converging Tendencies. In: J.F. Nijboer/W.J.J.M. Sprangers (Hrsg.), Harmonisation in Forensic Expertise. An inquiry into the desirability of and opportunities for international standards. Amsterdam 2000, S. 7-11 [zit. Nijboer, in: Nijboer/Sprangers (Hrsg.), Harmonisation].

- The Significance of Comparative Legal Studies. In: J.F. Nijboer/W.J.J.M. Sprangers (Hrsg.), Harmonisation in Forensic Expertise. An inquiry into the desirability of and opportunities for international standards. Amsterdam 2000, S. 399-410 [zit. Nijboer, in: Nijboer/Sprangers (Hrsg.), Harmonisation].

- Comparative Criminal Law \& Procedure. An Introduction. Deventer 2005 [zit. Nijboer, Comparative Criminal Law].

- Chapter 19 - The Criminal Justice System. In: Jeroen Chorus u.a. (Hrsg.), Introduction to Dutch Law. 4. Aufl. Alphen aan den Rijn 2006, S. 399-444 [zit. Nijboer, in: Chorus u.a. (Hrsg.), Introduction]. 
Örücü, Esin, A General View of 'Legal Families' and of 'Mixing Systems'. In: Esin Örücü/David Nelken (Hrsg.), Comparative Law. A Handbook. Oxford/Portland 2007, S. 169-187 [zit. Örücü, in: Örücü/Nelken (Hrsg.), Comparative Law].

Ohlin, Jens, Goals of International Criminal Justice and International Criminal Procedure. In: Göran Sluiter u.a. (Hrsg.), International Criminal Procedure. Principles and Rules. Oxford 2013, S. 55-68 [zit. Ohlin, in: Sluiter u.a. (Hrsg.), International].

Orie, Alphons, Accusatorial v. Inquisitorial Approach in International Criminal Proceedings Prior to the Establishment of the ICC and in the Proceedings Before the ICC. In: Antonio Cassese u.a. (Hrsg.), The Rome Statute of the International Criminal Court: A Commentary. Volume II. Oxford u.a. 2002, S. 1439-1495 [zit. Orie, in: Cassese u.a. (Hrsg.), The Rome Statute].

Ott, Katharina, Verdeckte Ermittlungen im Strafverfahren. Die deutsche Rechtsordnung und die Rechtslage nach der EMRK in einer rechtsvergleichenden Betrachtung. Frankfurt a.M. 2008 [zit. Ott, Verdeckte Ermittlungen].

Otton, Philip, The Role of the Judge in Criminal Cases. In: Mike McConville/Geoffrey Wilson (Hrsg.), The Handbook of the Criminal Justice Process. Oxford u.a. 2002, S. 323-333 [zit. Otton, in: McConville/Wilson (Hrsg.), Handbook].

Pabel, Katharina/Schmahl, Stefanie (Hrsg.), Internationaler Kommentar zur Europäischen Menschenrechtskonvention mit einschlägigen Texten und Dokumenten. Köln u.a. 2013 [zit. IntKomm-Bearbeiter, Art. Rn. (Lieferung)].

Packer, Herbert, Two Models of the Criminal Process. U. Pa. L. Rev. 113 (1964), 1-68 [zit. Packer, U. Pa. L. Rev. 113 (1964)].

- The Limits of the Criminal Sanction. Stanford 1968 [zit. Packer, Limits].

Paeffgen, Hans-Ullrich, Vorüberlegungen zu einer Dogmatik des UntersuchungshaftRechts. Köln u.a. 1986 [zit. Paeffgen, Vorüberlegungen].

Pakes, Francis, Styles of Trial Procedure at the International Criminal Tribunal for the Former Yugoslavia. In: Peter J. van Koppen/Steven D. Penrod (Hrsg.), Adversarial versus Inquisitorial Justice. Psychological Perspectives on Criminal Justice Systems. New York u.a. 2003, S. 309-319 [zit. Pakes, in: van Koppen/Penrod (Hrsg.), Adversarial].

- Comparative Criminal Justice. 2. Aufl. Cullompton 2010 [zit. Pakes, Comparative].

Palmer, Vernon Valentine, Introduction to the Mixed Jurisdictions. In: Vernon Valentine Palmer (Hrsg.), Mixed Jurisdictions Worldwide. The Third Legal Family. Cambridge 2001, S. 3-16 [zit. Palmer, in: ders. (Hrsg.), Mixed Jurisdictions].

- Mixed legal systems. In: Mauro Bussani/Ugo Mattei (Hrsg.), The Cambridge Companion to Comparative Law. Cambridge u.a. 2012, S. 368-383 [zit. Palmer, in: Bussani/ Mattei (Hrsg.), Comparative].

Park, Roger, Adversarial Influences on the Interrogation of Trial Witnesses. In: Peter J. van Koppen/Steven D. Penrod (Hrsg.), Adversarial versus Inquisitorial Justice. Psychological Perspectives on Criminal Justice Systems. New York u.a. 2003, S. 131-166 [zit. Park, in: van Koppen/Penrod (Hrsg.), Adversarial].

Parlato, Lucia, Ein Blick auf den italienischen Strafprozess: Vorbild oder abschreckendes Beispiel? Die aktuelle Situation und Gedanken zur Reform. ZIS 2012, 513-520 [zit. Parlato, ZIS 2012]. 
Partington, Martin, An Introduction to the English Legal System. 4. Aufl. Oxford u.a. 2008 [zit. Partington, Introduction].

Pattenden, Rosemary, Judicial Discretion and Criminal Litigation. Oxford 1990 [zit. Pattenden, Judicial Discretion].

- Pre-verdict Judicial Fact-finding in Criminal Trials with Juries. O.J.L.S. 29 (2009), 1-24 [zit. Pattenden, O.J.L.S. 29 (2009)].

Paulsen, Monrad, Grundzüge des amerikanischen Strafprozesses. ZStW 77 (1965), 637668 [zit. Paulsen, ZStW 77 (1965)].

Paulus, Rainer, Strafprozessuale Beweisstrukturen. In: Edda Weßlau/Wolfgang Wohlers (Hrsg.), Festschrift für Gerhard Fezer zum 70. Geburtstag am 29. Oktober 2008. Berlin 2008, S. 243-265 [zit. Paulus, FS für Fezer].

Perrodet, Antoinette, The public prosecutor. In: Mireille Delmas-Marty/J.R. Spencer (Hrsg.), European Criminal Procedures, englische Aufl. Cambridge 2002, S. 415-458 [zit. Perrodet, in: Delmas-Marty/Spencer (Hrsg.), European Criminal Procedures].

Perron, Walter, Das Beweisantragsrecht des Beschuldigten im deutschen Strafprozeß. Eine Untersuchung der verfassungsrechtlichen und verfahrensstrukturellen Grundlagen, gesetzlichen Regelungen und rechtstatsächlichen Auswirkungen sowie eine Erörterung der Reformperspektiven unter rechtsvergleichender Berücksichtigung des adversatorischen Prozeßmodells. Berlin 1995 [zit. Perron, Beweisantragsrecht].

- Erläuterung der Vorgehensweise. In: Walter Perron (Hrsg.), Die Beweisaufnahme im Strafverfahrensrecht des Auslands. Rechtsvergleichendes Gutachten im Auftrag des Bundesministeriums der Justiz. Freiburg im Breisgau 1995, S. 1-7 [zit. Perron, in: ders. (Hrsg.), Beweisaufnahme].

- Rechtsvergleichender Querschnitt und rechtspolitische Bewertung. In: Walter Perron (Hrsg.), Die Beweisaufnahme im Strafverfahrensrecht des Auslands. Rechtsvergleichendes Gutachten im Auftrag des Bundesministeriums der Justiz. Freiburg im Breisgau 1995, S. 549-608 [zit. Perron, in: ders. (Hrsg.), Beweisaufnahme].

- Sind die nationalen Grenzen des Strafrechts überwindbar? Überlegungen zu den strukturellen Voraussetzungen der Angleichung und Vereinheitlichung unterschiedlicher Strafrechtssysteme. ZStW 109 (1997), 281-301 [zit. Perron, ZStW 109 (1997)].

- Funktion und Zusammensetzung des Gerichts im Ermittlungs- und Hauptverfahren. In: Albin Eser/Christiane Rabenstein (Hrsg.), Strafjustiz im Spannungsfeld von Effizienz und Fairness. Konvergente und divergente Entwicklungen im Strafprozessrecht (Criminal Justice between Crime Control and Due Process. Convergence and Divergence in Criminal Procedure Systems) - Internationales Kolloquium 8.-11. Mai 2002 auf Schloss Ringberg. Berlin 2004, S. 291-302 [zit. Perron, in: Eser/Rabenstein (Hrsg.), Strafjustiz].

- Adversatorisches Parteienverfahren oder Amtsermittlungsprinzip im Strafprozess? Beobachtungen zum US-amerikanischen Strafverfahren anhand des aktuellen Streits zur Verurteilung von Kindern nach Erwachsenenstrafrecht. In: Alexander Bruns u.a. (Hrsg.), Festschrift für Rolf Stürner zum 70. Geburtstag. 1. Teilband. Tübingen, 2013, S. 875-889 [zit. Perron, FS für Stürner].

Peters, Anne/Altwicker, Tilmann, Europäische Menschenrechtskonvention. Mit rechtsvergleichenden Bezügen zum deutschen Grundgesetz. 2. Aufl. München 2012 [zit. Peters/ Altwicker, Menschenrechtskonvention, § Rn.]. 
Peters, Julia, Urteilsabsprachen im Strafprozess. Die deutsche Regelung im Vergleich mit Entwicklungen in England \& Wales, Frankreich und Polen. Göttingen 2011 [zit. J. Peters, Urteilsabsprachen].

Peters, Karl, Strafprozeß. Ein Lehrbuch. 4. Aufl. Heidelberg 1985 [zit. K. Peters, Strafprozeß].

Petrig, Anna, Negotiated Justice and the Goals of International Criminal Tribunals. With a Focus on the Plea-Bargaining Practice of the ICTY and the Legal Framework of the ICC. Chi-Kent J. Int'l \& Comp. L. 8 (2008), 1-31 [zit. Petrig, Chi-Kent J. Int'l \& Comp. L. 8 (2008)].

Pfordte, Thilo, Der informierte Zeuge im Strafverfahren - einige Gedanken über das wichtigste Beweismittel der StPO. In: Heike Jung u.a. (Hrsg.), Festschrift für Egon Müller. Baden-Baden 2008, S. 551-568 [zit. Pfordte, FS für Müller].

Pfützner, Peggy/Adams, Sabine/Neumann, Leveke, Rahmenbedingungen, Vorgaben, Grundlagen und Entwicklung des Strafrechts in Frankreich. In: Ulrich Sieber/Karin Cornils (Hrsg.), Nationales Strafrecht in rechtsvergleichender Darstellung. Allgemeiner Teil. Teilband 1: Grundlagen. Berlin 2009, S. 191-276 [zit. Pfützner/Adams/Neumann, in: Sieber/Cornils (Hrsg.), Nationales Strafrecht].

Pizzi, William, Trials Without Truth. Why Our System of Criminal Trials Has Become an Expensive Failure and What We Need to Do to Rebuild It. New York/London 1999 [zit. Pizzi, Trials].

Pizzi, William/Montagna, Mariangela, The Battle to Establish an Adversarial Trial System in Italy. Mich. J. Int'l L. 25 (2004), 429-466 [zit. Pizzi/Montagna, Mich. J. Int'l L. 25 (2004)].

Ploscowe, Morris, The Development of Present-Day Criminal Procedures in Europe and America. Harv. L. Rev. 48 (1934-1935), 433-473 [zit. Ploscowe, Harv. L. Rev. 48 (1935)].

Pocar, Fausto, Common Law and Civil Law Traditions in the ICTY Criminal Procedure. Does Oil Blend with Water? In: Janet Walker/Oscar G. Chase (Hrsg.), Common Law, Civil Law and the Future of Categories. Markham 2010, S. 437-460 [zit. Pocar, in: Walker/Chase (Hrsg.), Categories].

Posner, Richard, An Economic Approach to the Law of Evidence. Stan. L. Rev. 51 (19981999), 1477-1546 [zit. Posner, Stan. L. Rev. 51 (1998-1999)].

Pradel, Jean, Rapport Général. RIDP 63 (1992), 13-31 [zit. Pradel, RIDP 63 (1992)].

- Inquisitoire - Accusatoire: Une Redoutable Complexité. RIDP 68 (1997), 213-229 [zit. Pradel, RIDP 68 (1997)].

Putzke, Holm/Scheinfeld, Jörg, Strafprozessrecht. 5. Aufl. München 2013 [zit. Putzke/ Scheinfeld, Strafprozessrecht, Rn.].

Radtke, Henning, Das Strafverfahren als Diskurs? In: Knut Amelung u.a. (Hrsg.), Strafrecht, Biorecht, Rechtsphilosophie. Festschrift für Hans-Ludwig Schreiber zum 70. Geburtstag am 10. Mai 2003. Heidelberg 2003, S. 375-385 [zit. Radtke, FS für Schreiber].

- Wahrheitsermittlung im Strafverfahren. Leitprinzipien, Methoden und Grenzen. GA 2012, 187-201 [zit. Radtke, GA 2012]. 
Ransiek, Andreas, Zur Urteilsabsprache im Strafprozess: ein amerikanischer Fall. ZIS 2008, 116-122 [zit. Ransiek, ZIS 2008].

Rauxloh, Regina, Plea Bargaining in National and International Law. London/New York 2012 [zit. Rauxloh, Plea Bargaining].

Raz, Joseph, The Concept of a Legal System. An Introduction to the Theory of Legal System. 2. Aufl. Oxford 1980 [zit. Raz, The Concept].

Redmayne, Mike, Theorising Jury Reform. In: Antony Duff u.a. (Hrsg.), The Trial on Trial. Volume 2: Judgment and Calling to Account. Oxford/Portland 2006, S. 99-116 [zit. Redmayne, in: Duff u.a. (Hrsg.), Trial on Trial 2].

Rees, Wilhelm, Die Strafgewalt der Kirche. Das geltende kirchliche Strafrecht - dargestellt auf der Grundlage seiner Entwicklungsgeschichte. Berlin 1993 [zit. Rees, Strafgewalt].

Reichard, Hans, Über die Hauptverhandlung. Ein Beitrag zur Reform des Strafprozeßrechts. In: Vorstand der Rechtsanwaltskammer Düsseldorf (Hrsg.), Anwälte zur Reform des Strafrechts und Standesrechts. Eine Gedenkschrift für Dr. Josef Cüppers. Essen 1955, S. 103-121 [zit. Reichard, GS für Cüppers].

Reichel, Philip, Comparative Criminal Justice Systems. A Topical Approach. 6. Aufl. Boston u.a. 2013 [zit. Reichel, Comparative Criminal Justice].

Reinbacher, Tobias, Das Strafrechtssystem der USA. Eine Untersuchung zur Strafgewalt im föderativen Staat. Berlin 2010 [zit. Reinbacher, Strafrechtssystem der USA].

Rennig, Christoph, Die Entscheidungsfindung durch Schöffen und Berufsrichter in rechtlicher und psychologischer Sicht. Empirische, rechtsdogmatische und psychologischtheoretische Untersuchungen zur Laienbeteiligung an der Strafgerichtsbarkeit. Marburg 1993 [zit. Rennig, Entscheidungsfindung].

Renzikowski, Joachim, „Fair trial“ im Strafprozeß. In: Dieter Dölling (Hrsg.), Jus humanum. Grundlagen des Rechts und Strafrecht. Festschrift für Ernst-Joachim Lampe zum 70. Geburtstag. Berlin 2003, S. 791-804 [zit. Renzikowski, FS für Lampe].

- Faires Verfahren bei rechtswidriger Tatprovokation? Zum Einfluß der MRK auf das deutsche Recht. In: Gedächtnisschrift für Rolf Keller. Herausgegeben von den Strafrechtsprofessoren der Tübinger Juristenfakultät und dem Justizministerium BadenWürttemberg. Tübingen 2003, S. 197-211 [zit. Renzikowski, GS für Keller].

- Das Konfrontationsrecht im Fokus des Anspruchs auf ein faires Verfahren. In: Stefan Hiebl u.a. (Hrsg.), Festschrift für Volkmar Mehle zum 65. Geburtstag am 11.11.2009. Baden-Baden 2009, S. 529-548 [zit. Renzikowski, FS für Mehle].

Rheinstein, Max, Einführung in die Rechtsvergleichung. 2. Aufl. München 1987 [zit. Rheinstein, Einführung].

Richardson, Paul (Hrsg.), Archbold. Criminal Pleading, Evidence and Practice 2013. 61. Aufl. London 2013 [zit. Archbold, §].

Rieß, Peter, Prolegomena zu einer Gesamtreform des Strafverfahrensrechts. In: Helwig Hassenpflug (Hrsg.), Festschrift für Karl Schäfer zum 80. Geburtstag am 11. Dezember 1979. Berlin/New York 1980, S. 155-221 [zit. Rieß, FS für Schäfer].

- Über die Aufgaben des Strafverfahrens. JR 2006, 269-277 [zit. Rieß, JR 2006].

- Beiträge zur Entwicklung der deutschen Strafprozessordnung. Berlin 2012 [zit. Rieß, Beiträge]. 
Roach, Kent, Canada. In: Craig M. Bradley (Hrsg.), Criminal Procedure. A Worldwide Study. 2. Aufl. Durham, North Carolina 2007, S. 57-90 [zit. Roach, in: Bradley (Hrsg.), Criminal Procedure].

Roberson, Cliff/Das, Dilip, An Introduction to Comparative Legal Models of Criminal Justice. Boca Raton u.a. 2008 [zit. Roberson/Das, Comparative Legal Models].

Roberts, Paul/Zuckerman, Adrian, Criminal Evidence. 2. Aufl. Oxford u.a. 2010 [zit. Roberts/ Zuckerman, Criminal Evidence].

Rogall, Klaus, Grundsatzfragen der Beweisverbote. In: Frank Höpfel/Barbara Huber (Hrsg.), Beweisverbote in Ländern der EU und vergleichbaren Rechtsordnungen. Europäisches Kolloquium Wien, 18.-20. September 1997. Freiburg im Breisgau 1999, S. 119-148 [zit. Rogall, in: Höpfel/Huber (Hrsg.), Beweisverbote].

Rohan, Colleen, Rules Governing the Presentation of Testimonial Evidence. In: Karim A. A. Khan u.a. (Hrsg.), Principles of Evidence in International Criminal Justice. Oxford u.a. 2010, S. 499-550 [zit. Rohan, in: Khan u.a. (Hrsg.), Principles].

Rosenau, Henning, Plea bargaining in deutschen Strafgerichtssälen. Die Rechtsvergleichung als Auslegungshilfe am Beispiel der Absprachen im Strafverfahren betrachtet. In: Hans-Ullrich Paeffgen u.a. (Hrsg.), Strafrechtswissenschaft als Analyse und Konstruktion. Festschrift für Ingeborg Puppe zum 70. Geburtstag. Berlin 2011, S. 15971628 [zit. Rosenau, FS für Puppe].

Roxin, Claus, Die Reform der Hauptverhandlung im deutschen Strafprozeß. In: Hans Lüttger (Hrsg.), Probleme der Strafprozeßreform. Berliner Gastvorträge von Hans-Heinrich Jescheck, Hanns Dünnebier, Claus Roxin, Herbert Tröndle, Karl Peters. Berlin/New York 1975, S. 52-72 [zit. Roxin, in: Lüttger (Hrsg.), Probleme].

- Fragen der Hauptverhandlungsreform im Strafprozess. In: Rainer Hamm/Walter Matzke (Hrsg.), Festschrift für Erich Schmidt-Leichner zum 65. Geburtstag. München 1977, S. 145-158 [zit. Roxin, FS für Schmidt-Leichner].

Roxin, Claus/Schünemann, Bernd, Strafverfahrensrecht. Ein Studienbuch. 28. Aufl. München 2014 [zit. Roxin/Schünemann, Strafverfahrensrecht, § Rn.].

Rüping, Hinrich/Jerouschek, Günter, Grundriss der Strafrechtsgeschichte. 6. Aufl. München 2011 [zit. Rüping/Jerouschek, Strafrechtsgeschichte].

Rzepka, Dorothea, Zur Fairness im deutschen Strafverfahren. Frankfurt a.M. 2000 [zit. Rzepka, Fairness].

Sacco, Rodolfo, Einführung in die Rechtsvergleichung. Aus dem Italienischen übersetzt von Dr. Jacob Joussen. 2. Aufl. Baden-Baden 2011 [zit. Sacco, Einführung].

- The sub-Saharan legal tradition. In: Mauro Bussani/Ugo Mattei (Hrsg.), The Cambridge Companion to Comparative Law. Cambridge u.a. 2012, S. 313-343 [zit. Sacco, in: Bussani/Mattei (Hrsg.), Comparative].

Sachs, Albie, The Task for Civil Society. In: Alex Boraine/Janet Levy (Hrsg.), Healing of a Nation? Cape Town 1995, S. 103-109 [zit. Sachs, in: Boraine/Levy (Hrsg.), Healing].

Sadoghi, Alice, Thesen zur Geschworenengerichtsbarkeit - historische Aufarbeitung und Perspektiven. Linz 2007 [zit. Sadoghi, Thesen].

Safferling, Christoph, Towards an International Criminal Procedure. Oxford u.a. 2001 (2003 paperback) [zit. Safferling, Towards]. 
- Audiatur et altera pars - die prozessuale Waffengleichheit als Prozessprinzip? - Qui statuit alliquid parte inaudita altera, Aequm liquet statuerit haud aequs fuit. NStZ 2004, 181-188 [zit. Safferling, NStZ 2004].

- Die Rolle des Opfers im Strafverfahren - Paradigmenwechsel im nationalen und internationalen Recht? ZStW 122 (2010), 87-116 [zit. Safferling, ZStW 122 (2010)].

- International Criminal Procedure. In cooperation with Lars Büngener, Hilde Farthofer, Alena Hartwig, Yvonne Koberg. Oxford 2012 [zit. Safferling, International].

- Strafrechtsentwicklung in der EU - Konglomerat oder Synthese? In: Franz Streng/ Gabriele Kett-Straub (Hrsg.), Strafrechtsvergleichung als Kulturvergleich. Beiträge zur Evaluation deutschen „Strafrechtsexports“ als „Strafrechtsimport“. Tübingen 2012, S. 187-211 [zit. Safferling, in: Streng/Kett-Straub (Hrsg.), Strafrechtsvergleichung].

Salas, Denis, The role of the judge (revised by Alejandro Alvarez). In: Mireille DelmasMarty/J.R. Spencer (Hrsg.), European Criminal Procedures, englische Aufl. Cambridge 2002, S. 488-540 [zit. Salas, in: Delmas-Marty/Spencer (Hrsg.), European Criminal Procedures].

Salditt, Franz, Das neue Zwischenverfahren und die Unparteilichkeit des Richters. In: Lorenz Schulz u.a. (Hrsg.), Festschrift für Imme Roxin. Heidelberg u.a. 2012, S. 687696 [zit. Salditt, FS für Imme Roxin].

Samuel, Geoffrey, Common law. In: Jan M. Smits (Hrsg.), Elgar Encyclopedia of Comparative Law. 2. Aufl. Cheltenham/Northampton 2012, S. 169-190 [zit. Samuel, in: Smits (Hrsg.), Elgar Encyclopedia].

Sanders, Andrew/Young, Richard/Burton, Mandy, Criminal Justice. 4. Aufl. Oxford u.a. 2010 [zit. Sanders/Young/Burton, Criminal Justice].

Satzger, Helmut, Die Rspr des EGMR als Motor der europäischen Strafprozessrechtsharmonisierung - zugleich eine Rezension von Esser, Auf dem Weg zu einem europäischen Strafverfahrensrecht. JA 2005, 656-658 [zit. Satzger, JA 2005].

- Internationales und Europäisches Strafrecht. Strafanwendungsrecht, Europäisches Strafund Strafverfahrensrecht, Völkerstrafrecht. 6. Aufl. Baden-Baden 2013 [zit. Satzger, Internationales Strafrecht, $\S$ Rn.].

Sawer, Geoffrey, The Western Conception of Law. In: René David (Hrsg.), International Encyclopedia of Comparative Law, Volume II: The Legal Systems of the World: Their Comparison and Unification, Chapter 1: The Different Conceptions of the Law. Tübingen u.a. 1975, S. 14-48 [zit. Sawer, in: David (Hrsg.), International Encyclopedia].

Schabas, William, The International Criminal Court: A Commentary on the Rome Statute. Oxford u.a. 2010 [zit. Schabas, International].

- An Introduction to the International Criminal Court. 4. Aufl. Cambridge u.a. 2011 [zit. Schabas, Introduction].

Schacht, Joseph, An Introduction to Islamic Law. Oxford 1964 [zit. Schacht, Introduction].

Schellenberg, Frank, Die Hauptverhandlung im Strafverfahren. 2. Aufl. Köln u.a. 2000 [zit. Schellenberg, Hauptverhandlung].

Schleiminger, Dorrit, Konfrontation im Strafprozess. Art. 6 Ziff. 3 lit. d EMRK mit besonderer Berücksichtigung des Verhältnisses zum Opferschutz im Bereich von Sexualdelikten gegen Minderjährige. Basel u.a. 2001 [zit. Schleiminger, Konfrontation]. 
Schlesinger, Rudolf, Comparative Criminal Procedure: A Plea for Utilizing Foreign Experience. Buff. L. Rev. 26 (1976-1977), 361-385 [zit. Schlesinger, Buff. L. Rev. 26 (1976-1977)].

Schlesinger, Rudolf/Baade, Hans/Herzog, Peter/Wise, Edward, Comparative Law. Cases Text - Materials. 6. Aufl. New York 1998 [zit. Schlesinger/Baade/Herzog/Wise, Comparative Law].

Schlothauer, Reinhold, Die Flucht aus der Justizförmigkeit durch die europäische Hintertür. Zum Urteil des BGH v. 25.7.2000 - 1 StR 169/00. StV 2001, 127-131 [zit. Schlothauer, StV 2001].

- Zur Bedeutung der Beweisverwertungsverbote im Ermittlungs- und Zwischenverfahren. In: Cornelius Prittwitz u.a. (Hrsg.), Festschrift für Klaus Lüderssen. Zum 70. Geburtstag am 2. Mai 2002. Baden-Baden 2002, S. 761-772 [zit. Schlothauer, FS für Lüderssen].

Schlüchter, Ellen, Wert der Form im Strafprozeß. In: Jürgen Wolter (Hrsg.), Zur Theorie und Systematik des Strafprozeßrechts. Symposium zu Ehren von Hans-Joachim Rudolphi. Neuwied u.a. 1995, S. 205-231 [zit. Schlüchter, in: Wolter (Hrsg.), Theorie].

Schmid, Niklaus, Strafverfahren und Strafrecht in den Vereinigten Staaten. Eine Einführung. 2. Aufl. Heidelberg 1993 [zit. Schmid, Strafverfahren].

Schmidhäuser, Eberhard, Zur Frage nach dem Ziel des Strafprozesses. In: Paul Bockelmann/Wilhelm Gallas (Hrsg.), Festschrift für Eberhard Schmidt zum 70. Geburtstag. Göttingen 1961, S. 511-524 [zit. Schmidhäuser, FS für E. Schmidt].

Schmidt, Eberhard, Inquisitionsprozess und Rezeption. Studien zur Geschichte des Strafverfahrens in Deutschland vom 13. bis 16. Jahrhundert. Sonderausgabe aus der Festschrift der Leipziger Juristenfakultät für Heinrich Siber. Leipzig 1940 [zit. E. Schmidt, Inquisitionsprozess].

- Einführung in die Geschichte der deutschen Strafrechtspflege. 3. Aufl. Göttingen 1965 [zit. E. Schmidt, Einführung].

- Introduction. In: Gerhard O.W. Mueller (Hrsg.), The German Code of Criminal Procedure. With an Introduction by Dr. Eberhard Schmidt. Translated by Dr. Horst Niebler. Introduction translated by Dr. Manfred A. Pfeiffer. South Hackensack/London 1965, S. 1-23 [zit. E. Schmidt, in: Mueller (Hrsg.), German Code].

- Strafprozeß und Rechtsstaat. Strafprozeßrechtliche Aufsätze und Vorträge (1952 bis 1969). Göttingen 1970 [zit. E. Schmidt, Strafprozeß].

Schmidt, Jürgen, Noch einmal: Wahrheitsbegriff und Rechtswissenschaft. JuS 1973, 204207 [zit. J. Schmidt, JuS 1973].

Schmitt, Bertram, Zum Konfrontationsrecht nach Art. 6 Abs. 3d) EMRK. In: Klaus Bernsmann/Thomas Fischer (Hrsg.), Festschrift für Ruth Rissing-van Saan zum 65. Geburtstag am 25. Januar 2011. Berlin/New York 2011, S. 617-637 [zit. Schmitt, FS für Rissing-van Saan].

Schmitz, Bianca, Schwur- und Schöffengerichte im 19. Jahrhundert. In: Günter Jerouschek/Hinrich Rüping (Hrsg.), „Auss liebe der gerechtigkeit vnd umb gemeines nutz willenn“. Historische Beiträge zur Strafverfolgung. Tübingen 2000, S. 165-190 [zit. Schmitz, in: Jerouschek/Rüping (Hrsg.), Auss liebe].

Schnitzer, Adolf, Vergleichende Rechtslehre. Bd. I. 2. Aufl. Basel 1961 [zit. Schnitzer, Vergleichende Rechtslehre]. 
Schrag, Minna, Lessons Learned from ICTY Experience. JICJ 2 (2004), 427-434 [zit. Schrag, JICJ 2 (2004)].

Schreiber, Hans-Ludwig, Verfahrensrecht und Verfahrenswirklichkeit. ZStW 88 (1976), 117-161 [zit. Schreiber, ZStW 88 (1976)].

Schroeder, Friedrich-Christian, Literaturbericht: Rechtsvergleichung. ZStW 86 (1974), 783-827 [zit. Schroeder, ZStW 86 (1974)].

- Die Gesamtprüfung der Verfahrensfairness durch den EGMR. GA 2003, 293-298 [zit. Schroeder, GA 2003].

- Das Immutabilitätsprinzip als Merkmal des inquisitorischen Strafprozesses. GA 2011, 501-503 [zit. Schroeder, GA 2011].

Schroeder, Friedrich-Christian/Verrel, Torsten, Strafprozessrecht. 6. Aufl. München 2014 [zit. Schroeder/Verrel, Strafprozessrecht, Rn.].

Schünemann, Bernd, Zur Reform der Hauptverhandlung im Strafprozeß. GA 1978, 161185 [zit. Schünemann, GA 1978].

- Experimentelle Untersuchungen zur Reform der Hauptverhandlung in Strafsachen. In: Hans-Jürgen Kerner u.a. (Hrsg.), Deutsche Forschungen zur Kriminalitätsentstehung und Kriminalitätskontrolle. Band 6/2. Teilband. Köln u.a. 1983, S. 1109-1151 [zit. Schünemann, in: Kerner u.a. (Hrsg.), Deutsche Forschungen].

- Reflexionen über die Zukunft des deutschen Strafverfahrens. In: Otto Friedrich Freiherr von Gamm u.a. (Hrsg.), Strafrecht, Unternehmensrecht, Anwaltsrecht. Festschrift für Gerd Pfeiffer zum Abschied aus dem Amt als Präsident des Bundesgerichtshofes. Köln u.a. 1988, S. 461-484 [zit. Schünemann, FS für Pfeiffer].

- Der Richter im Strafverfahren als manipulierter Dritter? Zur empirischen Bestätigung von Perseveranz- und Schulterschlußeffekt. In: Günter Bierbrauer u.a. (Hrsg.), Verfahrensgerechtigkeit. Rechtspsychologische Forschungsbeiträge für die Justizpraxis. Köln 1995, S. 215-232 [zit. Schünemann, in: Bierbrauer u.a. (Hrsg.), Verfahrensgerechtigkeit].

- Die Stellung des Opfers im System der Strafrechtspflege: Ein Drei-Säulen-Modell. In: Bernd Schünemann/Markus Dirk Dubber (Hrsg.), Die Stellung des Opfers im Strafrechtssystem. Neue Entwicklungen in Deutschland und in den USA. Köln u.a. 2000, S. 1-13 [zit. Schünemann, in: Schünemann/Dubber (Hrsg.), Stellung].

- Zeugenbeweis auf dünnem Eis - Von seinen tatsächlichen Schwächen, seinen rechtlichen Gebrechen und seiner notwendigen Reform. In: Albin Eser u.a. (Hrsg.), Strafverfahrensrecht in Theorie und Praxis. Festschrift für Lutz Meyer-Gossner zum 65. Geburtstag. München 2001, S. 385-407 [zit. Schünemann, FS für Meyer-Gossner].

- Zur Reform des strafprozessualen Ermittlungsverfahrens in Europa: Kontradiktorische Ausbalancierung statt Partizipation. In: Otto Triffterer (Hrsg.), Gedächtnisschrift für Theo Vogler. Heidelberg 2004, S. 81-92 [zit. Schünemann, GS für Vogler].

- Zur Kritik des amerikanischen Strafprozessmodells. In: Edda Weßlau/Wolfgang Wohlers (Hrsg.), Festschrift für Gerhard Fezer zum 70. Geburtstag am 29. Oktober 2008. Berlin 2008, S. 555-575 [zit. Schünemann, FS für Fezer].

- Die Hauptverhandlung im Strafverfahren. Was sie leistet, wo sie versagt und in welcher Form sie bewahrt werden muss. StraFo 2010, 90-96 [zit. Schünemann, StraFo 2010]. 
- Die Allmacht des Tatrichters und die Einseitigkeit der Wahrheitsfindung - Erläutert am Beispiel eines Verbrechens am Seelenleben der Menschheit. In: Robert Esser u.a. (Hrsg.), Festschrift für Hans-Heiner Kühne zum 70. Geburtstag am 21. August 2013. Heidelberg u.a. 2013, S. 361-377 [zit. Schünemann, FS für Kühne].

- Information über das Vorverfahren und die Befugnisse des Richters in der Hauptverhandlung aus deutscher Sicht. In: Friedrich-Christian Schroeder/Manuchehr Kudratov (Hrsg.), Die strafprozessuale Hauptverhandlung zwischen inquisitorischem und adversatorischem Modell. Eine rechtsvergleichende Analyse am Beispiel des deutschen und des zentralasiatischen Strafprozessrechts. Frankfurt a.M. 2014, S. 91-107 [zit. Schünemann, in: Schroeder/Kudratov (Hrsg.), Hauptverhandlung].

Schünemann, Bernd/Bandilla, Wolfgang, Perseverance in Courtroom Decisions. In: Hermann Wegener u.a. (Hrsg.), Criminal Behavior and the Justice System. Psychological Perspectives. New York u.a. 1989, S. 181-192 [zit. Schünemann/Bandilla, in: Wegener u.a. (Hrsg.), Criminal Behavior].

Schulte-Nover, Sandra, Strafrichter in Deutschland und England. Ein systematischer Rechtsvergleich im Hinblick auf die richterlichen Kompetenzen im Strafverfahren. Frankfurt a.M. 2003 [zit. Schulte-Nover, Strafrichter].

Schultz, Hans, Strafrechtsvergleichung als Grundlagenforschung. In: Hans-Heinrich Jescheck/Günther Kaiser (Hrsg.), Die Vergleichung als Methode der Strafrechtswissenschaft und der Kriminologie. Internationales Kolloquium des Max-Planck-Instituts für ausländisches und internationales Strafrecht in Freiburg im Breisgau vom 23. bis 25. Oktober 1978 aus Anlaß der Einweihung des Institutsneubaus. Berlin 1980, S. 7-25 [zit. Schultz, in: Jescheck/Kaiser (Hrsg.), Vergleichung als Methode].

Schulz, Joachim, Sachverhaltsfeststellung und Beweistheorie. Elemente einer Theorie strafprozessualer Sachverhaltsfeststellung. Köln u.a. 1992 [zit. Schulz, Sachverhaltsfeststellung].

Schuon, Christine, International Criminal Procedure. A Clash of Legal Cultures. The Hague 2010 [zit. Schuon, International].

Schuska, Frederek, Die Rechtsfolgen von Verstößen gegen Art. 6 EMRK und ihre revisionsrechtliche Geltendmachung. Frankfurt a.M. 2006 [zit. Schuska, Rechtsfolgen].

Schwabenbauer, Peter, Der Zweifelssatz im Strafprozessrecht. Tübingen 2012 [zit. Schwabenbauer, Zweifelssatz].

Schwarzer, William, Dealing With Incompetent Counsel - The Trial Judge's Role. Harv. L. Rev. 93 (1980), 633-669 [zit. Schwarzer, Harv. L. Rev. 93 (1980)].

Scott, Robert/Stuntz, William, Plea Bargaining as Contract. Yale L.J. 101 (1992), 1909_ 1968 [zit. Scott/Stuntz, Yale L.J. 101 (1992)].

Sebba, Leslie, The Victim's Role in the Penal Process: A Theoretical Orientation. Am. J. Comp. L. 30 (1982), 217-240 [zit. Sebba, Am. J. Comp. L. 30 (1982)].

Sellert, Wolfgang, Die Bedeutung und Bewertung des Inquisitionsprinzips aus rechtshistorischer Sicht. In: Norbert Achterberg u.a. (Hrsg.), Recht und Staat im sozialen Wandel. Festschrift für Hans Ulrich Scupin zum 80. Geburtstag. Berlin 1983, S. 161-182 [zit. Sellert, FS für Scupin].

Servidio-Delabre, Eileen, Common Law. Introduction to the English and American legal systems. Paris 2004 [zit. Servidio-Delabre, Common Law]. 
Sickor, Jens Andreas, Das Geständnis. Tübingen 2014 [zit. Sickor, Geständnis].

Sieber, Ulrich, Zivilrechtliche Beweisinteressen im Strafprozeß. In: Manfred Seebode (Hrsg.), Festschrift für Günter Spendel zum 70. Geburtstag am 11. Juli 1992. Berlin/ New York 1992, S. 757-776 [zit. Sieber, FS für Spendel].

- Die Kollision von materiellem und prozessualem Strafrecht - Ein Grundlagenproblem des Strafrechtssystems. In: Schünemann u.a. (Hrsg.), Festschrift für Claus Roxin zum 70. Geburtstag am 15. Mai 2001. Berlin/New York 2001, S. 1113-1139 [zit. Sieber, FS für Roxin 2001].

- Strafrechtsvergleichung im Wandel. Aufgaben, Methoden und Theorieansätze der vergleichenden Strafrechtswissenschaft. In: Ulrich Sieber/Hans-Jörg Albrecht (Hrsg.), Strafrecht und Kriminologie unter einem Dach, Kolloquium zum 90. Geburtstag von Professor Dr. Dr. h.c. mult. Hans-Heinrich Jescheck. Berlin 2006, S. 78-130 [zit. Sieber, in: Sieber/Albrecht (Hrsg.), Strafrecht und Kriminologie].

- Grenzen des Strafrechts - Grundlagen und Herausforderungen des neuen strafrechtlichen Forschungsprogramms am Max-Planck-Institut für ausländisches und internationales Strafrecht -. ZStW 119 (2007), 1-68 [zit. Sieber, ZStW 119 (2007)].

- Rechtliche Ordnung in einer globalen Welt. Die Entwicklung zu einem fragmentierten System von nationalen, internationalen und privaten Normen. Rechtstheorie 41 (2010), 151-198 [zit. Sieber, Rechtstheorie 41 (2010)].

- Einführung: Entwicklung, Ziele und Probleme des Europäischen Strafrechts. In: Ulrich Sieber u.a. (Hrsg.), Europäisches Strafrecht. 2. Aufl. Baden-Baden 2014, S. 29-101 [zit. Sieber, in: EuropStrafRecht, Einf. Rn.].

Sieber, Ulrich/Engelhart, Marc, Strafrechtskodifikation - Eine Analyse des Kodifikationskonzepts und seiner Umsetzung im deutschen Strafrecht. RW 2012, 364-405 [zit. Sieber/Engelhart, RW 2012].

Simon, Oliver, Die Beschuldigtenrechte nach Art. 6 Abs. 3 EMRK. Ein Vergleich zur StPO im Hinblick auf die Auswirkungen der Konventionsrechte auf die deutsche Strafrechtsprechung. Diss. Tübingen 1998 [zit. Simon, Beschuldigtenrechte].

Singh, Avi, Expert Evidence. In: Karim A. A. Khan u.a. (Hrsg.), Principles of Evidence in International Criminal Justice. Oxford u.a. 2010, S. 599-649 [zit. Singh, in: Khan u.a. (Hrsg.), Principles].

SK-StPO = Systematischer Kommentar $\rightarrow$ Wolter, Jürgen (Hrsg.).

Sklansky, David Alan, Anti-Inquisitorialism. Harv. L. Rev. 122 (2009), 1634-1704 [zit. Sklansky, Harv. L. Rev. 122 (2009)].

Slapper, Gary/Kelly, David, The English Legal System. 13. Aufl. London/New York 2012 [zit. Slapper/Kelly, English Legal System].

Sluiter, Göran, Adversarial v. Inquisitorial Model. In: Antonio Cassese (Hrsg.), The Oxford Companion to International Criminal Justice. Oxford u.a. 2009, S. 230-234 [zit. Sluiter, in: Cassese (Hrsg.), Oxford Companion].

Smith, John, Evidence in Criminal Trials. In: Mike McConville/Geoffrey Wilson (Hrsg.), The Handbook of the Criminal Justice Process. Oxford u.a. 2002, S. 183-203 [zit. Smith, in: McConville/Wilson (Hrsg.), Handbook]. 
Snyman, $C R$, The accusatorial and inquisitorial approaches to criminal procedure: some points of comparison between the South African and continental systems. CILSA 1975, 100-111 [zit. Snyman, CILSA 1975].

Spencer, John, Introduction. In: Mireille Delmas-Marty/J.R. Spencer (Hrsg.), European Criminal Procedures, englische Aufl. Cambridge 2002, S. 1-75 [zit. Spencer, in: Delmas-Marty/Spencer (Hrsg.), European Criminal Procedures].

- The English system. In: Mireille Delmas-Marty/J.R. Spencer (Hrsg.), European Criminal Procedures, englische Aufl. Cambridge 2002, S. 142-217 [zit. Spencer, in: DelmasMarty/Spencer (Hrsg.), European Criminal Procedures].

- Evidence. In: Mireille Delmas-Marty/J.R. Spencer (Hrsg.), European Criminal Procedures, englische Aufl. Cambridge 2002, S. 594-640 [zit. Spencer, in: Delmas-Marty/ Spencer (Hrsg.), European Criminal Procedures].

Spendel, Günter, Wahrheitsfindung im Strafprozeß. JuS 1964, 465-473 [zit. Spendel, JuS 1964].

Spinellis, Dionysios, Victims of Crime and the Criminal Process. Is.L.R. 31 (1997), 337378 [zit. Spinellis, Is.L.R. 31 (1997)].

Sprack, John, Disclosure in the Criminal Trial. In: Caroline Breur u.a. (Hrsg.), New Trends in Criminal Investigation and Evidence. Volume II. Antwerpen u.a. 2000, S. 579-587 [zit. Sprack, in: Breur u.a. (Hrsg.), New Trends].

- A Practical Approach to Criminal Procedure. 14. Aufl. Oxford 2012 [zit. Sprack, Criminal Procedure, Rn.].

Stachowiak, Herbert, Allgemeine Modelltheorie. Wien/New York 1973 [zit. Stachowiak, Allgemeine Modelltheorie].

Stamp, Frauke, Die Wahrheit im Strafverfahren. Eine Untersuchung zur prozessualen Wahrheit unter besonderer Berücksichtigung der Perspektive des erkennenden Gerichts in der Hauptverhandlung. Baden-Baden 1998 [zit. Stamp, Wahrheit].

Stein, Alex, Foundations of Evidence Law. Oxford u.a. 2005 [zit. Stein, Foundations].

Stevenson, Angus (Hrsg.), Oxford Dictionary of English. 3. Aufl. Oxford u.a. 2010 [zit. Oxford Dictionary].

Stock, Ulrich, Zur Frage der Übernahme anglo-amerikanischer Strafprozeßgrundsätze in das deutsche Strafprozeßrecht. In: Siegfried Hohenleitner u.a. (Hrsg.), Festschrift für Theodor Rittler. Zu seinem achtzigsten Geburtstag. Aalen 1957, S. 305-325 [zit. Stock, FS für Rittler].

Strafverteidigervereinigungen, Organisationsbüro (Hrsg.), Abschied von der Wahrheitssuche. Texte und Ergebnisse des 35. Strafverteidigertages Berlin, 25.-27.3.2011. Berlin 2012 [zit. Strafverteidigervereinigungen (Hrsg.), Abschied].

Stuckenberg, Carl-Friedrich, Untersuchungen zur Unschuldsvermutung. Berlin/New York 1998 [zit. Stuckenberg, Untersuchungen].

- In dubio pro reo. JA 2000, 568-573 [zit. Stuckenberg, JA 2000].

- Die Erforschung der materiellen Wahrheit im Strafprozess. In: Friedrich-Christian Schroeder/Manuchehr Kudratov (Hrsg.), Die strafprozessuale Hauptverhandlung zwischen inquisitorischem und adversatorischem Modell. Eine rechtsvergleichende Analyse 
am Beispiel des deutschen und des zentralasiatischen Strafprozessrechts. Frankfurt a.M. 2014, S. 39-52 [zit. Stuckenberg, in: Schroeder/Kudratov (Hrsg.), Hauptverhandlung].

Stübinger, Stephan, Das ,idealisierte“ Strafrecht. Über Freiheit und Wahrheit in der Straftheorie und Strafprozessrechtslehre. Frankfurt a.M. 2008 [zit. Stübinger, Strafrecht].

Summers, Sarah, Fair Trials. The European Criminal Procedural Tradition and the European Court of Human Rights. Oxford/Portland 2007 [zit. Summers, Fair Trials].

Swanson, Guy, Frameworks for Comparative Research: Structural Anthropology and the Theory of Action. In: Ivan Vallier (Hrsg.), Comparative Methods in Sociology. Essays on Trends and Applications. Berkeley u.a. 1971, S. 141-202 [zit. Guy Swanson, in: Vallier (Hrsg.), Comparative Methods].

Sward, Ellen, Values, Ideology, and the Evolution of the Adversary System. Ind. L.J. 64 (1989), 301-355 [zit. Sward, Ind. L.J. 64 (1989)].

Swart, Bert/Young, James, The European Convention on Human Rights and Criminal Justice in the Netherlands and the United Kingdom. In: Phil Fennell u.a. (Hrsg.), Criminal Justice in Europe: A Comparative Study. Oxford 1995, S. 57-86 [zit. Swart/Young, in: Fennell u.a. (Hrsg.), Criminal Justice].

Tapper, Colin, Cross and Tapper on Evidence. 12. Aufl. Oxford u.a. 2010 [zit. Tapper, Evidence].

Teubner, Werner, Kodifikation und Rechtsreform in England. Ein Beitrag zur Untersuchung des Einflusses von Naturrecht und Utilitarismus auf die Idee einer Kodifikation des englischen Rechts. Berlin 1974 [zit. Teubner, Kodifikation].

Thaman, Stephen, Europe's New Jury Systems: The Cases of Spain and Russia. In: Neil Vidmar (Hrsg.), World Jury Systems. Oxford u.a. 2000, S. 319-351 [zit. Thaman, in: Vidmar (Hrsg.), Jury].

- A Typology of Consensual Criminal Procedures: An Historical and Comparative Perspective on the Theory and Practice of Avoiding the Full Criminal Trial. In: Stephen C. Thaman (Hrsg.), World Plea Bargaining. Consensual Procedures and the Avoidance of the Full Criminal Trial. Durham 2010, S. 297-396 [zit. Thaman, in: ders. (Hrsg.), World].

- Should Criminal Juries Give Reasons for their Verdicts? The Spanish Experience and the Implications of the European Court of Human Rights Decision in Taxquet v. Belgium. Chi.-Kent L. Rev. 86 (2011), 613-668 [zit. Thaman, Chi.-Kent L. Rev. 86 (2011)].

- The Penal Order: Prosecutorial Sentencing as a Model for Criminal Justice Reform? In: Erik Luna/Marianne L. Wade (Hrsg.), The Prosecutor in Transnational Perspective. Oxford u.a. 2012, S. 156-175 [zit. Thaman, in: Luna/Wade (Hrsg.), Prosecutor].

- Balancing Truth Against Human Rights: A Theory of Modern Exclusionary Rules. In: Stephen C. Thaman (Hrsg.), Exclusionary Rules in Comparative Law. Dordrecht u.a. 2013, S. 403-446 [zit. Thaman, in: ders. (Hrsg.), Exclusionary Rules].

The Royal Commission on Criminal Justice. Chairman: Sir Viscount Runciman. Report. Cm 2263 London 1993 [zit. Royal Commission on Criminal Justice Report 1993]. 
The Royal Commission on Criminal Procedure. Chairman: Sir Cyril Philips. Report Presented to Parliament by Command of Her Majesty January 1981. Cmnd 8092 London 1981 [zit. Royal Commission on Criminal Procedure Report 1981, §].

Theile, Hans, Wahrheit, Konsens und § 257c StPO. NStZ 2012, 666-671 [zit. Theile, NStZ 2012].

Thibaut, John/Walker, Laurens, Procedural Justice. A Psychological Analysis. New York u.a. 1975 [zit. Thibaut/Walker, Procedural Justice].

- A Theory of Procedure. Cal. L. Rev. 66 (1978), 541-566 [zit. Thibaut/Walker, Cal. L. Rev. 66 (1978)].

Thibaut, John/Walker, Laurens/Lind, Allan, Adversary Presentation and Bias in Legal Decisionmaking. Harv. L. Rev. 86 (1972), 386-401 [zit. Thibaut/Walker/Lind, Harv. L. Rev. 86 (1972)].

Tiedemann, Klaus, 13 Thesen zu einem modernen menschenrechtsorientierten Strafprozeß. ZRP 1992, 107-109 [zit. Tiedemann, ZRP 1992].

Tochilovsky, Vladimir, Defence Access to the Prosecution Material. In: Göran Sluiter u.a. (Hrsg.), International Criminal Procedure. Principles and Rules. Oxford 2013, S. 10831098 [zit. Tochilovsky, in: Sluiter u.a. (Hrsg.), International].

Toepel, Friedrich, Grundstrukturen des Sachverständigenbeweises im Strafprozeßrecht. Tübingen 2002 [zit. Toepel, Grundstrukturen].

Tomlinson, Edward, Nonadversarial Justice: The French Experience. Md. L. Rev. 42 (1983), 131-195 [zit. Tomlinson, Md. L. Rev. 42 (1983)].

Trüg, Gerson, Lösungskonvergenzen trotz Systemdivergenzen im deutschen und USamerikanischen Strafverfahren. Ein strukturanalytischer Vergleich am Beispiel der Wahrheitserforschung. Tübingen 2003 [zit. Trüg, Lösungskonvergenzen].

- Erkenntnisse aus der Untersuchung des US-amerikanischen plea bargaining-Systems für den deutschen Absprachendiskurs. ZStW 120 (2008), 331-374 [zit. Trüg, ZStW 120 (2008)].

- Quo curris, Strafverfahren? - Zum Verhältnis der objektiven Dimension der Beschleunigungsmaxime zur Wahrheitsfindung. StV 2010, 528-538 [zit. Trüg, StV 2010].

Trüg, Gerson/Kerner, Hans-Jürgen, Formalisierung der Wahrheitsfindung im (reformiert-) inquisitorischen Strafverfahren? Betrachtungen unter rechtsvergleichender Perspektive. In: Heinz Schöch u.a. (Hrsg.), Recht gestalten - dem Recht dienen. Festschrift für Reinhard Böttcher zum 70. Geburtstag am 29. Juli 2007. Berlin 2007, S. 191-212 [zit. Trüg/ Kerner, FS für Böttcher].

Trusen, Winfried, Der Inquisitionsprozeß. Seine historischen Grundlagen und frühen Formen. ZRG KA 74 (1988), 168-230 [zit. Trusen, ZRG KA 74 (1988)].

Tulkens, Françoise, Criminal Procedure: Main Comparable Features of the National Systems. In: Mireille Delmas-Marty (Hrsg.), The Criminal Process and Human Rights. Toward a European Consciousness. Dordrecht u.a. 1995, S. 5-13 [zit. Tulkens, in: Delmas-Marty (Hrsg.), Criminal Process].

Turner, Jenia, Plea Bargaining Across Borders. Criminal Procedure. Austin u.a. 2009 [zit. Turner, Plea Bargaining]. 
- Plea bargaining. In: Linda Carter/Fausto Pocar (Hrsg.), International Criminal Procedure. The Interface of Civil Law and Common Law Legal Systems. Cheltenham/ Northampton 2013, S. 34-65 [zit. Turner, in: Carter/Pocar (Hrsg.), International].

Turner, Jenia/Weigend, Thomas, Negotiated Justice. In: Göran Sluiter u.a. (Hrsg.), International Criminal Procedure. Principles and Rules. Oxford 2013, S. 1375-1413 [zit. Turner/Weigend, in: Sluiter u.a. (Hrsg.), International].

Uglow, Steve, Evidence: Text and Materials. 2. Aufl. London 2006 [zit. Uglow, Evidence].

Van Caenegem, Raoul Charles, Judges, Legislators and Professors. Chapters in European Legal History. Cambridge u.a. 1987 [zit. van Caenegem, Judges].

- The Birth of the English Common Law. 2. Aufl. Cambridge u.a. 1988 [zit. van Caenegem, Birth].

Van Cleave, Rachel, Italy. In: Craig M. Bradley (Hrsg.), Criminal Procedure. A Worldwide Study. 2. Aufl. Durham, North Carolina 2007, S. 303-349 [zit. Van Cleave, in: Bradley (Hrsg.), Criminal Procedure].

Van Hoecke, Mark/Warrington, Mark, Legal Cultures, Legal Paradigms and Legal Doctrine. Towards a New Model for Comparative Law. ICLQ 47 (1998), 495-536 [zit. van Hoecke/Warrington, ICLQ 47 (1998)].

Van Kessel, Gordon, Adversary Excesses in the American Criminal Trial. Notre Dame L. Rev. 67 (1992), 403-551 [zit. van Kessel, Notre Dame L. Rev. 67 (1992)].

Van Koppen, Peter/Penrod, Steven, Adversarial or Inquisitorial. Comparing Systems. In: Peter J. van Koppen/Steven D. Penrod (Hrsg.), Adversarial versus Inquisitorial Justice. Psychological Perspectives on Criminal Justice Systems. New York u.a. 2003, S. 1-19 [zit. van Koppen/Penrod, in: dies. (Hrsg.), Adversarial].

Vidmar, Neil, The Canadian Criminal Jury: Searching for a Middle Ground. In: Neil Vidmar (Hrsg.), World Jury Systems. Oxford u.a. 2000, S. 211-248 [zit. Vidmar, in: ders. (Hrsg.), Jury].

- The Jury Elsewhere in the World. In: Neil Vidmar (Hrsg.), World Jury Systems. Oxford u.a. 2000, S. 421-447 [zit. Vidmar, in: ders. (Hrsg.), Jury].

Vogel, Joachim, Transkulturelles Strafrecht. GA 2010, 1-14 [zit. Vogel, GA 2010].

Vogler, Richard, Konsensuale Elemente im Strafprozess in England und Wales sowie in den USA. ZStW 116 (2004), 129-149 [zit. Vogler, ZStW 116 (2004)].

- A World View of Criminal Justice. Hants/Burlington 2005 [zit. Vogler, A World View].

- Introduction. In: Richard Vogler/Barbara Huber (Hrsg.), Criminal Procedure in Europe. Berlin 2008, S. 1-38 [zit. Vogler, in: Vogler/Huber (Hrsg.), Criminal Procedure].

- Criminal Procedure in France. In: Richard Vogler/Barbara Huber (Hrsg.), Criminal Procedure in Europe. Berlin 2008, S. 171-268 [zit. Vogler, in: Vogler/Huber (Hrsg.), Criminal Procedure].

Volk, Klaus, Wahrheit und materielles Recht im Strafprozess. Konstanz 1980 [zit. Volk, Wahrheit].

- Diverse Wahrheiten. In: Albin Eser u.a. (Hrsg.), Straf- und Strafverfahrensrecht, Recht und Verkehr, Recht und Medizin. Festschrift für Hannskarl Salger zum Abschied aus 
dem Amt als Vizepräsident des Bundesgerichtshofes. Köln u.a. 1995, S. 411-419 [zit. Volk, FS für Salger].

Volk, Klaus/Engländer, Armin, Grundkurs StPO. 8. Aufl. München 2013 [zit. Volk/Engländer, Grundkurs].

Volkmann-Schluck, Thomas, Der spanische Strafprozeß zwischen Inquisitions- und Parteiverfahren. Baden-Baden 1979 [zit. Volkmann-Schluck, Der spanische Strafprozeß].

- Continental European Criminal Procedures: True or Illusive Model? Am. J. Crim. Law 9 (1981), 1-32 [zit. Volkmann-Schluck, Am. J. Crim. Law 9 (1981)].

Vormbaum, Thomas, Einführung in die moderne Strafrechtsgeschichte. Berlin/Heidelberg 2009 [zit. Vormbaum, Einführung].

Wagner, Heinz, Ziele des Strafprozesses? In: Andreas Hoyer u.a. (Hrsg.), Gedächtnisschrift für Jörn Eckert. 15. Mai. 1954 bis 21. März 2006. Baden-Baden 2008, S. 939 960 [zit. Wagner, GS für Eckert].

Wahrig-Burfeind, Renate (Hrsg.), Wahrig Deutsches Wörterbuch. 8. Aufl. Gütersloh/ München 2010 [zit. Wahrig Wörterbuch].

Walpin, Gerald, America's Adversarial and Jury Systems: More Likely to Do Justice. Harvard JLPP 26 (2003), 175-186 [zit. Walpin, Harvard JLPP 26 (2003)].

Walter, Tonio, Die Beweislast im Strafprozeß. JZ 2006, 340-349 [zit. Walter, JZ 2006].

Walther, Susanne, Zur Frage eines Rechts des Beschuldigten auf „Konfrontation von Belastungszeugen“. GA 2003, 204-225 [zit. Walther, GA 2003].

Wattenberg, Andreas, Die Rechtsprechung des Europäischen Gerichtshofs zum mittelbaren Zeugenbeweis - zugleich eine Anm. zum Urt. des BGH vom 11.2.2000 - 3 StR 377/99. StV 2000, 688-696 [zit. Wattenberg, StV 2000].

Weber, Max, Gesammelte Aufsätze zur Wissenschaftslehre. 3. Aufl. Tübingen 1968 [zit. Weber, Wissenschaftslehre].

- Die Wirtschaftsethik der Weltreligionen. Konfuzianismus und Taoismus. Schriften 1915-1920. Studienausgabe. Tübingen 1991 [zit. Weber, Wirtschaftsethik].

Weider, Hans-Joachim, Anmerkung zu BGH, StV 1993, 59. StV 1993, 60-61 [zit. Weider, StV 1993].

Weigend, Thomas, Wechselverhör in der Hauptverhandlung? ZStW 100 (1988), 733-757 [zit. Weigend, ZStW 100 (1988)].

- Deliktsopfer und Strafverfahren. Berlin 1989 [zit. Weigend, Deliktsopfer].

- Die Reform des Strafverfahrens. Europäische und deutsche Tendenzen und Probleme. ZStW 104 (1992), 486-512 [zit. Weigend, ZStW 104 (1992)].

- Die Europäische Menschenrechtskonvention als deutsches Recht - Kollisionen und ihre Lösung. StV 2000, 384-390 [zit. Weigend, StV 2000].

- Unverzichtbares im Strafverfahrensrecht. ZStW 113 (2001), 271-304 [zit. Weigend, ZStW 113 (2001)].

- Criminal Procedure: Comparative Aspects. In: Joshua Dressler (Hrsg.), Encyclopedia of Crime \& Justice. Volume I: Abortion-Cruel \& Unusual Punishment. 2. Aufl. New York u.a. 2002, S. 444-457 [zit. Weigend, in: Dressler (Hrsg.), Encyclopedia]. 
- Is the Criminal Process about Truth?: A German Perspective. Harvard JLPP 26 (2003), 157-173 [zit. Weigend, Harvard JLPP 26 (2003)].

- The Decay of the Inquisitorial Ideal: Plea Bargaining Invades German Criminal Procedure. In: John Jackson u.a. (Hrsg.), Crime, Procedure and Evidence in a Comparative and International Context. Essays in Honour of Professor Mirjan Damaška. Oxford/ Portland 2008, S. 39-64 [zit. Weigend, in: Jackson u.a. (Hrsg.), Crime].

- Unmittelbare Beweisaufnahme - ein Konzept für das Strafverfahren des 21. Jahrhunderts? In: Henning Ernst Müller u.a. (Hrsg.), Festschrift für Ulrich Eisenberg zum 70. Geburtstag. München 2009, S. 657-671 [zit. Weigend, FS für Eisenberg].

- Verständigung in der Strafprozessordnung - auf dem Weg zu einem neuen Verfahrensmodell? In: René Bloy u.a. (Hrsg.), Gerechte Strafe und legitimes Strafrecht. Festschrift für Manfred Maiwald zum 75. Geburtstag. Berlin 2010, S. 829-848 [zit. Weigend, FS für Maiwald].

- Rechtsvergleichende Bemerkungen zur Wahrheitssuche im Strafverfahren. In: Klaus Bernsmann/Thomas Fischer (Hrsg.), Festschrift für Ruth Rissing-van Saan zum 65. Geburtstag am 25. Januar 2011. Berlin/New York 2011, S. 749-766 [zit. Weigend, FS für Rissing-van Saan].

- Criminal law and criminal procedure. In: Jan M. Smits (Hrsg.), Elgar Encyclopedia of Comparative Law. 2. Aufl. Cheltenham/Northampton 2012, S. 261-278 [zit. Weigend, in: Smits (Hrsg.), Elgar Encyclopedia].

- A Judge by Another Name? Comparative Perspectives on the Role of the Public Prosecutor. In: Erik Luna/Marianne L. Wade (Hrsg.), The Prosecutor in Transnational Perspective. Oxford u.a. 2012, S. 377-391 [zit. Weigend, in: Luna/Wade (Hrsg.), Prosecutor].

- Das Konfrontationsrecht des Angeklagten - wesentliches Element eines fairen Verfahrens oder Fremdkörper im deutschen Strafprozess? In: Mark A. Zöller u.a. (Hrsg.), Gesamte Strafrechtswissenschaft in internationaler Dimension. Festschrift für Jürgen Wolter zum 70. Geburtstag am 7. September 2013. Berlin 2013, S. 1145-1165 [zit. Weigend, FS für Wolter].

Weinreb, Lloyd, Denial of Justice. Criminal Process in the United States. New York/ London 1977 [zit. Weinreb, Denial].

Weißmann, Ulrich, Die Stellung des Vorsitzenden in der Hauptverhandlung. Die Entwicklung einer Verfahrensordnung zum Wechselverhör mit einer empirischen Studie über den „Passivrichter“. Göttingen 1982 [zit. Weißmann, Stellung].

Werle, Gerhard, Völkerstrafrecht. 3. Aufl. Tübingen 2012 [zit. Werle, Völkerstrafrecht].

Werwie-Haas, Martina, Die Umsetzung der strafrechtlichen Entscheidungen des Europäischen Gerichtshofs für Menschenrechte in Deutschland, Österreich, der Schweiz und im Vereinigten Königreich. Frankfurt a.M. u.a. 2008 [zit. Werwie-Haas, Umsetzung].

Wesel, Uwe, Geschichte des Rechts in Europa. Von den Griechen bis zum Vertrag von Lissabon. München 2010 [zit. Wesel, Geschichte].

Weßlau, Edda, Strategische Planspiele oder konzeptionelle Neuausrichtung? Zur aktuellen Kontroverse um eine gesetzliche Regelung der Absprache im Strafverfahren. In: Heike 
Jung u.a. (Hrsg.), Festschrift für Egon Müller. Baden-Baden 2008, S. 779-795 [zit. Weßlau, FS für Müller].

White, Robin, The Structure and Organization of Criminal Justice in England and Wales. An Overview. In: Mike McConville/Geoffrey Wilson (Hrsg.), The Handbook of the Criminal Justice Process. Oxford u.a. 2002, S. 5-20 [zit. White, in: McConville/Wilson (Hrsg.), Handbook].

Wigmore, John, Evidence in Trials at Common Law. In Ten Volumes, Volume 1 (Revised by Peter Tillers). Boston/Toronto 1983 [zit. Wigmore, Evidence 1].

- Evidence in Trials at Common Law. In Ten Volumes, Volume 1A (Revised by Peter Tillers). Boston/Toronto 1983 [zit. Wigmore, Evidence 1A].

- Evidence in Trials at Common Law. In Ten Volumes, Volume 5 (Revised by James H. Chadbourn). Boston/Toronto 1974 [zit. Wigmore, Evidence 5].

Wijffels, Alain, 'Ius commune', Comparative Law and Public Governance. In: Maurice Adams/Dirk Heirbaut (Hrsg.), The Method and Culture of Comparative Law. Essays in Honour of Mark Van Hoecke. Oxford/Portland 2014, S. 147-160 [zit. Wijffels, in: Adams/Heirbaut (Hrsg.), Method].

Williams, Glanville, The Proof of Guilt. A Study of the English Criminal Trial. 3. Aufl. London 1963 [zit. Williams, Proof].

Wohlers, Wolfgang, Art.6 Abs.3 lit. d) EMRK als Grenze der Einführung des Wissens anonym bleibender Zeugen. In: Andreas Donatsch u.a. (Hrsg.), Strafrecht, Strafprozessrecht und Menschenrechte. Festschrift für Stefan Trechsel zum 65. Geburtstag. Zürich u.a. 2002, S. 813-831 [zit. Wohlers, FS für Trechsel].

- Das Strafverfahren in den Zeiten der „Eilkrankheit”. NJW 2010, 2470-2475 [zit. Wohlers, NJW 2010].

Wolchover, David, Should Judges Sum up on the Facts? Crim.L.R. 1989, 781-792 [zit. Wolchover, [1989] Crim.L.R.].

Wolter, Jürgen, Beweisverbote und Umgehungsverbote zwischen Wahrheitserforschung und Ausforschung. In: Claus Roxin/Gunter Widmaier (Hrsg.), 50 Jahre Bundesgerichtshof. Festgabe aus der Wissenschaft. Band IV. Strafrecht, Strafprozeßrecht. München 2000, S. 963-1009 [zit. Wolter, FG BGH].

Wolter, Jürgen (Hrsg.), SK-StPO. Systematischer Kommentar zur Strafprozessordnung. Mit GVG und EMRK. Band II - §§ 94-136a StPO. 4. Aufl. Köln 2010 [zit. SK-StPOBearbeiter, § Rn.].

- SK-StPO. Systematischer Kommentar zur Strafprozessordnung. Mit GVG und EMRK. Band IV - §§ 198-246 StPO. 4. Aufl. Köln 2011 [zit. SK-StPO-Bearbeiter, § Rn.].

- SK-StPO. Systematischer Kommentar zur Strafprozessordnung. Mit GVG und EMRK. Band V - §§ 246a-295 StPO. 4. Aufl. Köln 2012 [zit. SK-StPO-Bearbeiter, § Rn.].

- SK-StPO. Systematischer Kommentar zur Strafprozessordnung. Mit GVG und EMRK. Band X - EMRK. 4. Aufl. Köln 2012 [zit. SK-StPO-Bearbeiter, Einl./Art. EMRK Rn.].

Zachariä, Heinrich Albert, Die Gebrechen und die Reform des deutschen Strafverfahrens, dargestellt auf der Basis einer consequenten Entwickelung des inquisitorischen und des accusatorischen Prinzips. Göttingen 1846 [zit. Zachariä, Gebrechen]. 
Zacharias, Klaus, Der gefährdete Zeuge im Strafverfahren. Berlin 1997 [zit. Zacharias, Der gefährdete Zeuge].

Zappalà, Salvatore, Human Rights in International Criminal Proceedings. Oxford u.a. 2003 [zit. Zappalà, Human Rights].

- Comparative Models and the Enduring Relevance of the Accusatorial-Inquisitorial Dichotomy. In: Göran Sluiter u.a. (Hrsg.), International Criminal Procedure. Principles and Rules. Oxford 2013, S. 44-54 [zit. Zappalà, in: Sluiter u.a. (Hrsg.), International].

Zeidler, Wolfgang, Evaluation of the Adversary System: As Comparison, Some Remarks on the Investigatory System of Procedure. ALJ 55 (1981), 390-400 [zit. Zeidler, ALJ 55 (1981)].

Zerbes, Ingeborg, Rahmenbedingungen, Vorgaben, Grundlagen und Entwicklung des Strafrechts in Österreich. In: Ulrich Sieber/Karin Cornils (Hrsg.), Nationales Strafrecht in rechtsvergleichender Darstellung. Allgemeiner Teil. Teilband 1: Grundlagen. Berlin 2009, S. 415-480 [zit. Zerbes, in: Sieber/Cornils (Hrsg.), Nationales Strafrecht].

Ziegler, Benno, Bestehen Möglichkeiten zur Beseitigung der inquisitorischen Stellung des erkennenden Gerichts de lege ferenda? Diss. München 1961 [zit. Ziegler, Möglichkeiten].

Zopfs, Jan, Der Grundsatz „in dubio pro reo“. Baden-Baden 1999 [zit. Zopfs, Grundsatz].

Zweigert, Konrad/Kötz, Hein, Einführung in die Rechtsvergleichung auf dem Gebiete des Privatrechts. 3. Aufl. Tübingen 1996 [zit. Zweigert/Kötz, Einführung].

Zwiehoff, Gabriele, Das Recht auf den Sachverständigen. Baden-Baden 2000 [zit. Zwiehoff, Recht]. 



\section{Schriftenreihe des Max-Planck-Instituts für ausländisches und internationales Strafrecht}

Die zentralen Veröffentlichungen des Max-Planck-Instituts für ausländisches und internationales Strafrecht werden in Zusammenarbeit mit dem Verlag Duncker \& Humblot in den folgenden vier Unterreihen der „Schriftenreihe des Max-Planck-Instituts für ausländisches und internationales Strafrecht" vertrieben:

- „Strafrechtliche Forschungsberichte“,

- „Kriminologische Forschungsberichte“,

- „Interdisziplinäre Forschungen aus Strafrecht und Kriminologie“ sowie

- „Sammlung ausländischer Strafgesetzbücher in deutscher Übersetzung“.

Diese Publikationen können direkt über das Max-Planck-Institut unter <www.mpicc.de> oder über den Verlag Duncker \& Humblot unter $<$ www.duncker-humblot.de $>$ erworben werden.

Darüber hinaus erscheinen im Hausverlag des Max-Planck-Instituts in der Unterreihe „research in brief" zusammenfassende Kurzbeschreibungen von Forschungsergebnissen und in der Unterreihe „Arbeitsberichte“ Veröffentlichungen vorläufiger Forschungsergebnisse. Diese Veröffentlichungen können über das Max-Planck-Institut bezogen werden.

Detaillierte Informationen zu den einzelnen Publikationen des Max-Planck-Instituts für ausländisches und internationales Strafrecht sind unter $<$ www.mpicc.de $>$ abrufbar.

The main research activities of the Max Planck Institute for Foreign and International Criminal Law are published in the following four subseries of the "Schriftenreihe des MaxPlanck-Instituts für ausländisches und internationales Strafrecht" (Research Series of the Max Planck Institute for Foreign and International Criminal Law), which are distributed in cooperation with the publisher Duncker \& Humblot:

- "Strafrechtliche Forschungsberichte" (Reports on Research in Criminal Law),

- "Kriminologische Forschungsberichte" (Reports on Research in Criminology),

- "Interdisziplinäre Forschungen aus Strafrecht und Kriminologie" (Reports on Interdisciplinary Research in Criminal Law and Criminology), and

- "Sammlung ausländischer Strafgesetzbücher in deutscher Übersetzung" (Collection of Foreign Criminal Laws in German Translation).

These publications can be ordered from the Max Planck Institute at <www.mpicc.de> or from Duncker \& Humblot at $<$ www.duncker-humblot.de $>$.

Two additional subseries are published directly by the Max Planck Institute for Foreign and International Criminal Law: "research in brief" contains short reports on results of research activities, and "Arbeitsberichte" (working materials) present preliminary results of research projects. These publications are available at the Max Planck Institute.

Detailed information on all publications of the Max Planck Institute for Foreign and International Criminal Law can be found at $<$ www.mpicc.de $>$. 
Auswahl aus dem strafrechtlichen Veröffentlichungsprogramm:

S $150 \quad$ Ulrich Sieber / Benjamin Vogel

Terrorismusfinanzierung

Prävention im Spannungsfeld von internationalen

Vorgaben und nationalem Tatstrafrecht

2015 • 237 Seiten • ISBN 978-3-86113-805-1

S 145 Xenia Lang

Geheimdienstinformationen

im deutschen und amerikanischen Strafprozess

2014 • 400 Seiten • ISBN 978-3-86113-811-2

S 144 Michael Albrecht

Die Kriminalisierung von Dual-Use-Software

$2014 \cdot 297$ Seiten • ISBN 978-3-86113-812-9

S 143 Zunyou Zhou

Balancing Security and Liberty

Counter-Terrorism Legislation in Germany and China

2014 • 352 Seiten • ISBN 978-3-86113-813-6

S $142 \quad$ Nadine Dombrowski

Extraterritoriale Rechtsanwendung im Internet

2014 • 206 Seiten • ISBN 978-3-86113-814-3

S 141 Gang Wang

Die strafrechtliche Rechtfertigung von Rettungsfolter

Ein Rechtsvergleich zwischen Deutschland und den USA

2014 • 428 Seiten • ISBN 978-3-86113-815-0

S $140 \quad$ Ulrich Sieber / Marc Engelhart

Compliance Programs for the Prevention of Economic Crimes

An Empirical Survey of German Companies

2014 • 312 Seiten • ISBN 978-3-86113-816-7

S 139 Susanne Rheinbay

Die Errichtung einer Europäischen Staatsanwaltschaft

2014 • 347 Seiten • ISBN 978-3-86113-819-8

S 138 Sarah Herbert

Grenzen des Strafrechts bei der Terrorismusgesetzgebung

Ein Rechtsvergleich zwischen Deutschland und England

2014 • 300 Seiten • ISBN 978-3-86113-820-4

S 137 Nadine Zurkinden

Joint Investigation Teams

Chancen und Grenzen von gemeinsamen Ermittlungsgruppen

in der Schweiz, Europa und den USA

2013 • 396 Seiten • ISBN 978-3-86113-821-1 
Auswahl aus dem strafrechtlichen Veröffentlichungsprogramm:

S 128.1.1 Ulrich Sieber / Konstanze Jarvers / Emily Silverman (eds.) National Criminal Law in a Comparative Legal Context Volume 1.1: Introduction to National Systems $2013 \cdot 314$ Seiten • ISBN 978-3-86113-822-8

S 128.1.2 Volume 1.2: Introduction to National Systems 2013 • 363 Seiten • ISBN 978-3-86113-826-6

S 128.1.3 Volume 1.3: Introduction to National Systems $2014 \cdot 297$ Seiten $•$ ISBN 978-3-86113-818-1

S 128.1.4 Volume 1.4: Introduction to National Systems $2014 \cdot 391$ Seiten ISBN 978-3-86113-810-5

S 128.2.1 Ulrich Sieber / Susanne Forster / Konstanze Jarvers (eds.) National Criminal Law in a Comparative Legal Context Volume 2.1: General limitations on the application of criminal law $2011 \cdot 399$ Seiten $•$ ISBN 978-3-86113-834-1

S 128.3.1 Ulrich Sieber / Susanne Forster / Konstanze Jarvers (eds.) National Criminal Law in a Comparative Legal Context Volume 3.1: Defining criminal conduct 2011 519 Seiten • ISBN 978-3-86113-833-4

S 114.1 Ulrich Sieber/Karin Cornils (Hrsg.)

Nationales Strafrecht in rechtsvergleichender Darstellung - Allgemeiner Teil Band 1: Grundlagen $2009 \cdot 790$ Seiten • ISBN 978-3-86113-849-5

S 114.2 Band 2: Gesetzlichkeitsprinzip - Internationaler Geltungsbereich - Begriff und Systematisierung der Straftat 2008 • 470 Seiten $・$ ISBN 978-3-86113-860-0

S 114.3 Band 3: Objektive Tatseite - Subjektive Tatseite Strafbares Verhalten vor der Tatvollendung 2008 • 490 Seiten • ISBN 978-3-86113-859-4

S 114.4 Band 4: Tatbeteiligung - Straftaten in Unternehmen, Verbänden und anderen Kollektiven 2010 • 527 Seiten • ISBN 978-3-86113-842-6

S 114.5 Band 5: Gründe für den Ausschluss der Strafbarkeit Aufhebung der Strafbarkeit - Verjährung 2010 718 Seiten • ISBN 978-3-86113-841-9 
Auswahl aktueller Publikationen aus dem kriminologischen Veröffentlichungsprogramm:

K 167 Christopher Murphy

"Come in Spinner" - Money Laundering

in the Australian Casino Industry

Berlin 2014 • 152 Seiten • ISBN 978-3-86113-250-9

K 166 Ramin Tehrani

Die „Smart Sanctions“ im Kampf gegen den Terrorismus

und als Vorbild einer präventiven Vermögensabschöpfung

Berlin 2014 • 256 Seiten • ISBN 978-3-86113-247-9

K 165 Daniela Cernko

Die Umsetzung der CPT-Empfehlungen im deutschen Strafvollzug

Eine Untersuchung über den Einfluss des Europäischen Komitees

zur Verhütung von Folter und unmenschlicher oder erniedrigender

Behandlung oder Strafe auf die deutsche Strafvollzugsverwaltung

Berlin 2014 • 455 Seiten • ISBN 978-3-86113-246-2

K 164 Franziska Kunz

Kriminalität älterer Menschen

Beschreibung und Erklärung auf der Basis von Selbstberichtsdaten

Berlin 2014 • 387 Seiten • ISBN 978-3-86113-244-8

K 163 David Jensen

\section{Maras}

A study of their origin, international impact, and the measures taken to fight them

Berlin 2013 • 245 Seiten • ISBN 978-3-86113-243-1

K 161 Gunda Wößner, Roland Hefendehl, Hans-Jörg Albrecht (Hrsg.)

Sexuelle Gewalt und Sozialtherapie

Bisherige Daten und Analysen zur Längsschnittstudie ,Sexual-

straftäter in den sozialtherapeutischen Abteilungen des

Freistaates Sachsen“

Berlin 2013 • 274 Seiten • ISBN 978-3-86113-241-7

K 159 Andreas Armborst

Jihadi Violence

A study of al-Qaeda's media

Berlin 2013 • 266 Seiten • ISBN 978-3-86113-119-9

K 158 Martin Brandenstein

Auswirkungen von Hafterfahrungen auf Selbstbild

und Identität rechtsextremer jugendlicher Gewalttäter

Berlin 2012 • 335 Seiten • ISBN 978-3-86113-118-2

K 157 Ghassem Ghassemi

Criminal Policy in Iran Following the Revolution of 1979

A Comparative Analysis of Criminal Punishment and Sentencing in Iran and Germany

Berlin 2013 • 265 Seiten • ISBN 978-3-86113-116-8 